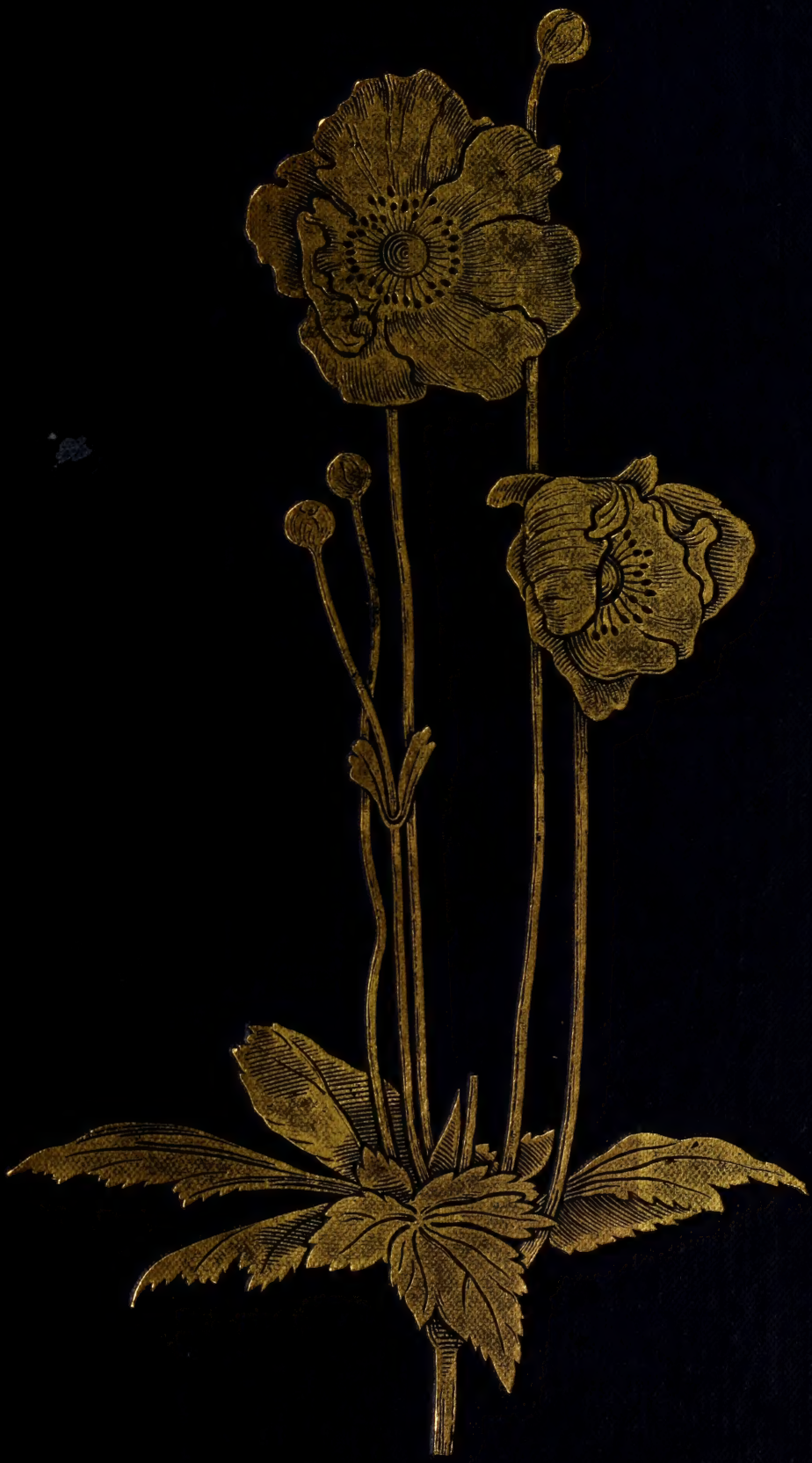




$$
\frac{n 7 i}{159}
$$



Digitized by the Internet Archive in 2015 


\section{THE ENGLISH FLOWER GARDEN}




\section{BY THE SAME.}

ALPINE FLOWERS for English Gardens. Second Edition.

THE SUB-TROPICAL GARDEN; or, Beauty of Form in the Flower Garden. Second Edition.

HARDY FLOWERS. Description of upwards of $\mathrm{I} 300$ of the most ornamental species, with Directions for their Arrangement, Culture, etc. Fourth and Cheaper Edition.

THE WILD GARDEN ; or, Our Graves and Gardens made beautiful by the Naturalisation of Hardy Exotic Plants. Illustrated by ALFRED Parsons. Second Edition.

GOD'S ACRE BEAUTIFUL; or, The Cemeteries of the Future. Third Edition. With Illustrations. London: John Murray. New York: Scribner and Welford. Published in a cheaper form and with additions under the name-

CREMATION AND URN-BURIAL. Cassell and Co., Limited.

THE PARKS AND GARDENS OF PARIS. Considered in Relation to the Wants of other Cities, and of Public and Private Gardens. Being notes made in Paris Gardens. Illustrated. London: John Murray.

GARDEN DESIGN AND ARCHITECTS' GARDENS. Illustrated, to show, by actual examples from British Gardens, that clipping and aligning trees to make them "harmonise" with architecture is barbarous, needless, and inartistic. 1892. John Murray.

\section{JOURNALS, ETC.}

THE GARDEN. An Illustrated Weekly Journal of Gardening in all its branches. Vol. XL.

GARDENING ILLUSTRATED. For Town and Country. A Weekly Journal for Amateurs and Gardeners, Vol. XIII.

FARM AND HOME. A Weekly Illustrated Journal of Agriculture in all its branches. Stock, Dairy, Tillage, Stable, Pasture, Orchard, MarketGarden, Poultry, House. Vol. X.'

WOODS AND FORESTS. A Weekly Illustrated Tournal of Forestry, Ornamental Planting, and Estate Management. Vols. I. and II. 1885 .

COTTAGE GARDENING. Poultry, Bees, Allotments, Food, House, Window and Town Gardens. 1892. 
TH E

\section{ENGLISH FLOWER GARDEN}

\section{STYLE, POSITION, \& ARRANGEMENT}

FOLLOWED BY

A DESCRIPTION OF ALL THE BEST PLANTS FOR IT THEIR CULTURE AND ARRANGEMENT

BY

W. ROBINSON, F.L.S.

ILLUSTRATED WITH MANY ENGRAVINGS

THIRD EDITIOUN

LONDON

JOHN MURRAY, ALBEMARLE STREET 
3844.79

Replacement

Given in the name of

Dr George E. Richards April 7, 1980

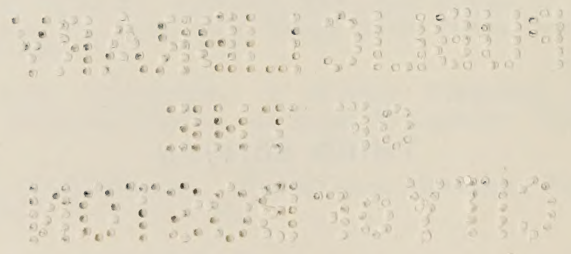




\section{PREFACE TO FIRST EDITION}

Hitherto I have mostly dealt with the flower garden in relation to rock-gardens, plants of fine form, those we may grow without care in the "wild garden," and the many beautiful things included among the hardy flowers of Northern countries. A book on the convenient plan of a Dictionary, embracing all the plants, hardy and half-hardy, in our British flower gardens, seemed likely to best meet the wants of the time. It is illustrated, with a view to show the beauty of many of the plants, and in the first part to help design. The aim of the book is to make the flower garden a reflex, so to say, of the world of beautiful plant-life, instead of the formal thing it has long been.

Few know the many flowers worth a place in our open-air gardens, and without such knowledge, progress is not easy. It is useless to discuss arrangement if the beauty of the flowers is sealed to us. No stereotyped garden of half-a-dozen kinds of plants will satisfy any one who knows that not "six," but hundreds of beautiful aspects of vegetation are possible in a garden in spring, summer, and autumn. At present the rule is no artistic arrangement, no bold good grouping, no garden pictures, no variety, repetitions of ugly patterns. The choke-muddle shrubbery, in which the shrubs kill each other, shows betimes a few ill-grown plants and has wide patches of bare earth in summer, over which pretty green things might crowd. Yet the smallest garden may be a picture, and a pretty one. Not only may we easily have much more variety in any one garden - and that of the highest quality, but if men would give up mere imitation, we should be charmed with the contrasts between gardens. Every district should have flower gardens characteristic of itself, and adapted to its soil, climate, and position. 
Even small suburban gardens might refresh us with their variety. In the larger gardens opportunities are great-and yet they are stereotyped at the season when they ought to be full of delightful change.

In the compilation of this book the storehouse of information in The Garden has been taken advantage of, but articles have been specially written where it was thought necessary. In preparation of the second part of the work valuable aid has been given by Mr. Goldring, late superintendent of the hardy-plant department of the Royal Gardens at Kew. Mr. H. Hyde gave useful aid in the selection of the illustrations, and engraved many of them. The following are the names of the other writers whose contributions are embodied in the book, and frequently marked by their initials :-

J. Allen
J. Atkins
P. Barr
J. Birkenhead
T. C. Boston
J. Britten
W. Brockbank
F. W. Burbidge
Latimer Clarke
E. T. Cook
J. Cornhill
Rev. Harpur Crewe
A. Dean
R. Dean
D. Dewar
Rev. C. Wolley Dod
Rev. H. H. Dombrain
J. Douglas
J. Dundas
Rev. Canon Ellacombe
H. J. Elwes
H. Ewbank
W. Falconer
D. T. Fish
Dr. M. Foster

P. Neill Fraser

O. Froebel

W. Goldring

P. Grieve

J. Groom

W. E. Gumbleton

T. Hatfield

W. B. Hemsley

I. Anderson-Henry

T. H. Archer-Hind

E. Hobday

Rev. F. D. Horner

Miss F. Hope

C. M. Hovey

E. Jackson

Miss G. Jekyll

Miss R. Kingsley
A. Kingsmill
Max Leichtlin
E. G. Loder
R. I. Lynch
J. M'Nab
R. Marnock
G. Maw
J. G. Nelson

G. Nicholson

J. C. Niven

Miss C. M. Owen

A. Perry
J. T. Pö̈

R. Potter

A. Rawson

The Very Rev. The Dean of Rochester
A. Salter
C. W. Shaw
J. Sheppard
J. Simpson
J. Smith
T. Spanswick
J. Stevens

Rev. Canon Swayne

W. Thompson

W. P. Thomson

Rev. F. Tymons

W. Wildsmith

T. Williams

G. F. Wilson

J. Wood

E. H. Woodall

The book consists of two parts: First, an introduction, dealing with the question of design - the aim being to make each place at various seasons and in every available situation an epitome of the great flower garden of the world itself. The usual plan is to repeat in the garden the lifeless formality of wall-paper or carpet. How to 
destroy this conventionality is shown, and that, too, not by diminishing the number of flowers, but, on the contrary, by much increasing them. The second part shows the many beautiful families of plants which grow in the open air in Britain, with their culture and the positions suited for each-a point hitherto little attended to in books.

The illustrations may well suggest the number of beautiful types of plant-life shut out from our gardens by the few plants used to perpetrate the crudities of "bedding out." During the past dozen years, some gardens have been much enriched; and even new aspects of garden vegetation have appeared, as, for instance, the fine Japanese and North American lilies. But gardens are still often poor in variety of flower. There is much more in flower-gardening than is usually shown. It is an art that in all stages of life might afford us infinite pleasure. But we can only know a few of its charms without a complete change in the narrow way in which it is generally practised.

W. R.

30 th Nov. 1883 .

\section{SECOND EDITION}

IN this Second Edition many changes have been made. It would be better if any one who wrote a book with a useful aim were compelled by law to keep to it and mend it all his life, but in that case I should want five years to see many beautiful things in their own homes in many parts of the Northern and temperate world, from California to Siberia. Under present circumstances, I do my best, and hope I may be able, some day, to make the "English Flower Garden" more worthy of the theme.

W. R.

Gravetye Manor, 25th Feb. 1889 . 


\section{THIRD EDITION}

In this Edition we have broken up the old plates and taken the opportunity of bringing into the book many of the flowering shrubs and flowering trees omitted in the First Edition, also many of the trees which, like the Evergreen Oak and Holly, have often a very important place near the flower garden or in its surroundings. The need of keeping the book to the handbook form precludes any considerable enlargiement. I shall, however, never give up the hope of making it better, and shall be thankful to any reader who lets me know of omissions, defects, or may suggest an improvement. I regret the book has been long out of print, and hope to prevent this in future.

W. R.

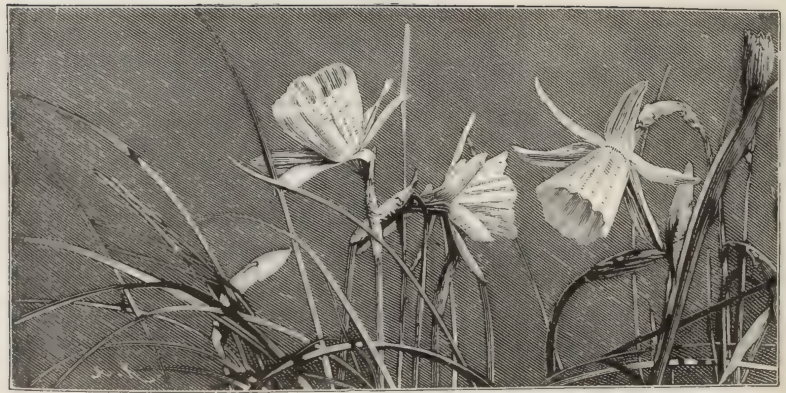




\section{CONTENTS}

\section{CHAPTER I}

Design AND Position

PAGE

Terraced Gardens .

A few Words with an Architect

Some English Flower Gardens

Bare Flower Gardens

English Cottage Gardens .

Greenlands

Goodwood

Pendell Court

Rhianva

Garden at Weybridge

Sheen Cottage

Drummond Castle .

Steps and Terrace in the Old Park, Axminster

Vegetable Sculpture

CHAPTER II

The Wild Garden, or the Naturalisation of Hardy Exotic Flowers

Wild Gardening in Meadow Grass

40

Principal Families of Plants for the Wild Garden .

\section{CHAPTER III}

Borders, Beds, and Groups of Hardy Flowers .

Labour and Care .

The True Way

Flower Borders

The Flower Border against a Wall

The Flower Border in the Fruit or Kitchen Garden

The Mixed Border

Mr. Frank Miles on the Flower Border .

Evergreen Borders 


\section{CHAPTER IV}

PAGE

The special Culture of Hardy Flowers-the Reserve and Cut-Flower.

GARDENS

What to grow in the Reserve Garden $\quad$. $\quad$. $\quad$. $\quad$. 79

Flowers for the Breakfast Table . . . . . . . . $\quad 82$

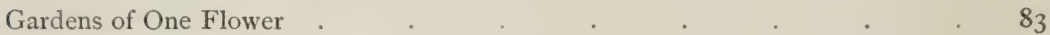

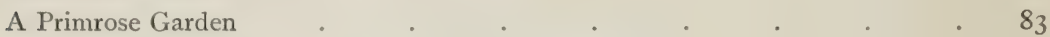

Hardy Plants for Reserve Garden and for Cutting Flowers _ . . . 85

\section{CHAPTER V}

Hardy Bulbs . $\quad$. $\quad$. $\quad$. . . 87

Bulbs in Large Beds $\quad$. $\quad$. $\quad$. $\quad$. $\quad$. $\quad$. $\quad$. 89

Bulbs in the Shrubbery . . . . . . . . . 90

Some Bulbous and like Plants for British Flower Gardens . . . 9I

\section{CHAPTER VI}

Alpine ANd Rock Gardens . . . . . . . . . . 92

Position for the Rock-Garden . . . . . . . . . . 95

Soil

Alpine Plants in Groups .

Plants for Rock-Gardens .

\section{CHAPTER VII}

Flowering Shrubs and Trees

Principal Families of Flowering Trees and Shrubs hardy in English ${ }_{6}$ Gardens

106

\section{CHAPTER VIII}

Annual and Biennial Plants for the Flower Garden • . . II3

Half-hardy Plants treated as Annuals . . . . . . . II5

Some of the more important Families of Annual and Biennial Flowers, including half-hardy Bedding Plants, for the Flower Garden

\section{CHAPTER IX}

Waterside, Streamlet, Bog-Garden, and Hardy Ferns . . . 120

The Bog-Garden . $\quad$. . . . . . . . 125

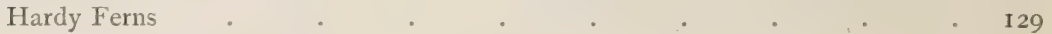




\section{CHAPTER X}

PAGE

Beauty of Form in the Flower Garden .

Yuccas in Groups .

I4I

Principal Families of Plants with fine Foliage or Form, for use in British Gardens

\section{CHAPTER XI}

Climber.

A Pergola .

Climbing Roses on Trees .

Some Families of Hardy Climbing Plants, including also Wall-Plants

147

I 50

I53

\section{CHAPTER XII}

SPRING FlowerS . . . . . . . . ${ }^{56}$

Some Spring and early Summer Flowers hardy in English Gardens . . $\quad{ }_{5} 8$

\section{CHAPTER XIII}

\section{Autumn Flowers}

Some of the Families of hardy and half-hardy Plants blooming in London

District in September and October

Starworts .

New Aspect of Beauty for the Autumnal Garden .

I6I

The Lilac Starwort

162

164

The Italian Starwort

I64

The Blue Starwort

The New England Starwort

The New York Starwort .

The Pink Starwort

I64

164

165

The Spreading Starwort

The Daisy Starwort

\section{CHAPTER XIV}

\section{Summer-Bedding Gardening}

Soil and Cultivation

Coloured Foliage .

Bedding and fine-leaved Plants

Vases

Sub-tropical Bedding

Summer and Winter Bedding

Shrubs for Winter Bedding

Principal Families of Plants used for Bedding-out 


\section{CHAPTER XV}

Roseries, Past and Present

Places for Roses

Thick Planting

Pruning and large Bushes of Roses

Roses on Lawns

A'spects for Roses .

Soil for Roses

Roses on Palings

Wall Roses

List of some of the best Garden Roses

\section{CHAPTER XVI}

Colour in the Flower Garden

Harmony rather than Contrast

Breadth of Mass and Intergrouping

Warm Colours

Purple and Lilac .

White Flowers

Blue Flowers

A Progression of Colour

Silvery-leaved Plants

In Sunny Places

A Shady Border

Bedded-out Plants

Contrasts-How to be used

Grass

Walks

Glass

Watering

For all Half-hardy Bedding Plants 


\section{LIST OF ILLUSTRATIONS}

Example of the Natural Style. Thrumpington Hall, Derby . . . . 3

The Two Styles: the Formal. Terraces to Sussex House . . . . 5

Old Place, Lindfield. 'A simple Lawn Garden for Hardy Flowers . . . . 7

Arundel. Example of Ground requiring Terracing . . . . . 10

Watermouth Castle, Devon. On Ground where Terracing is essential . I2

Gardens at Berkeley Castle, with old Terrace Walls . . . . . I4

Wakehurst. Elizabethan House on level Ground without Terraces . . . I5

Sussex House on gently-sloping Ground. Terracing not necessary . . . 18

A Cottage Garden at Maltingley, near Winchfield, Hants . . . . 2 I

A Thames-side Garden (Greenlands), with wide sloping Lawn and Flower Beds to right and left. Visible from the Lawn seen through the Trees . . . 23

Goodwood Park front, with Cedars and Oaks. Example of Grassy Foreground to House. From a Sketch by Alfred Parsons, 6th May 1880 . . . 24

View of Lawn Garden at Pendell Court : Elizabethan. Flowers in simple Beds near

House . . . . . . . .

Cottage Garden and Lawn, with Flowers mostly on the outer Fringes of Lawn, in Borders, and around Beds of Peat Shrubs. Gilbert White's Garden at Selborne, sketched by A. Parsons in I880 . . . . . . . 26

A Terraced Garden with Picturesque Planting. Rhianva, Anglesey . • . 29

View of Flower Garden at Madresfield Court . . . . . . . 30

View in Picturesque Heath. Garden at Weybridge . . . . . $\quad$. 32

Upper Terrace at Drummond Castle, Crieff, Perthshire. Ground being steep, Terraces

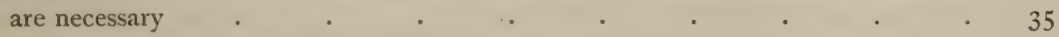

Steps and Terrace, "The Old Park," Axminster. Example of Terrace Garden not stiffly planted. From a Photograph by Miss Dryden, Canons Ashby, Northamptonshire . . . . . . . . . 37

Star of Bethlehem in Grass . . . . . . . . 40

Group of Mullein, near Scotch Firs, in Surrey Heath . • . . . 4 I

A Beautiful Accident. A Colony of Sweet Cicely in Shrubbery, with White Harebells 42

Columbines and Geraniums in Meadow Grass . . . . . . . 46

Poet's Narcissus and large Rockfoils in open Shrubbery . . . . 48

Giant Cow Parsnip. Type of Great Siberian Herbaceous Vegetation. Chiefly fitted for the Wild Garden . . . . . . . . . 49

Night Effect of Evening Primrose in the Wild Garden _ . . . . 50

View in Moat Mead, Gravetye Manor, with Poet's Narcissus in Bloom in early Summer 1891, planted five years. From a sketch by W. E. Norton . . 53 
Tailpiece

Headpiece

Japanese Windflower

A Mixed Border of Hardy Flowers

Group of Meadow Sweets

A well-covered Border of Hardy Flowers. Campden, Glos. .

Hardy Border Flowers against House, with Climbers behind .

Portion of Group of pink Japan Anemone in the Garden at Mirehouse, Keswick

A Fern Border with Flowers here and there .

Flowers at the Window without intervening Walk

Evergreen Hardy Flowers in Waste Corner .

Tailpiece

Headpiece

Portion of Bed of White Trumpet Lily (Lilium longiflorum) .

Mass of Giant Indian Lily in a Surrey Garden ․ . . . . . 8 I

A Primrose Garden in small Clearing in Wood in Surrey . . . . . . 84

Tailpiece . $\quad . \quad$. $\quad . \quad$. . . . 86

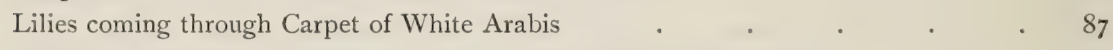

Colony of Summer Snowflake, on Margin of Shrubbery (Longleat) . 88

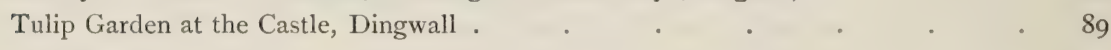

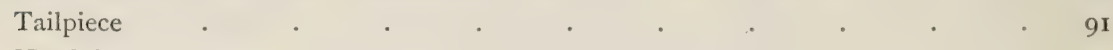

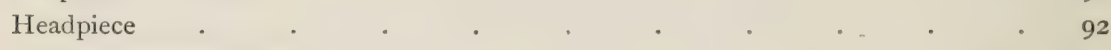

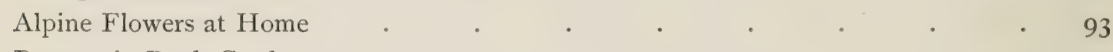

Passage in Rock-Garden $\quad$. $\quad$. $\quad$. $\quad . \quad$. 95

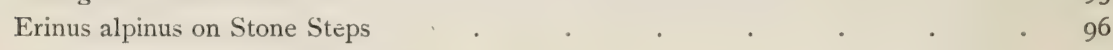

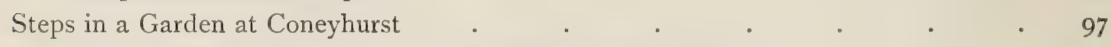

Shady Side of Wall of Terrace covered with Rockfoil and Ferns . . . . $\quad 98$

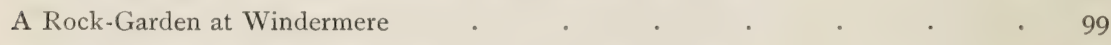

Cheddar Pink, Saxifrage, and Ferns, on Cottage Wall at Mells . . . . roo

Houseleeks, etc., at Lamport Hall . . . . . . . . IOI

Alpine Garden on level Ground with Gentianella in large Group (figure to give scale) IO2

Tailpiece .- . . . . . . . . . . 105

Bed of the Plumed Hydrangea at Shoreham, Kent . . . . . 107

Rhododendron Garden at Bidston, Cheshire . . . . . . . 109

The White Indian Azalea (A. indica), in a Wood at Coolhurst, Sussex . . II

Tailpiece . . . . . . . . . 112

Bed of "China Asters": showing Effect of well-grown annual Plants in Garden.

Engraved from a Photograph . . . . . . $\quad$ II3

Double Hollyhock . . . . . . . . . . 114

White Foxglove. Engraved from a Photograph by H. Hyde of a Self-sown Plant in

Shrubbery at Gravetye Manor . . . . . . . . $\quad$ II6

Sweet Sultan . . . . . . . . . . . 118

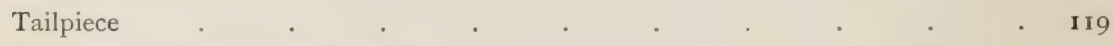

Streamlet in a Devonshire Garden . . . . . . . . . 120

Solomon's Seal and Herb Paris, in Copse by Streamlet . . . . . I2I

Hardy Water-Lilies . . . . . . . . . . 122

Colony of Iris, by Brook-side . . . . . . . . . . . . 123 
Cyperus longus

PAGE

Mocassin-flower in Rocky Bog .

A Bog-Garden .

Royal Fern (Osmunda regalis)

Rock Fernery at Danesbury

Tailpiece

Sheltered Dell, with Tree Ferns and Stove Plants placed out for the Summer (Battersea)

Hardy Palm in the open air in England

Pampas Grass in a Sussex Garden (Chichester)

The New Zealand Reed (Arundo conspicua)

Musa Ensete in the open Garden at Park Place, Henley-on-Thames

Bed of Fine-leaved Plants in Hyde Park. From a sketch by H. G. Moon • $\quad$ I39

Yucca gloriosa, Salisbury . . . . . . . . . . 140

Group of House Plants placed out for Summer. Harrow Lodge, Dorking . I4I

American Aloe. Example of Greenhouse Plants set in open air in Summer. Engraved from a Photograph taken in Knightwick Rectory Garden, Worcestershire

Fine-leaved Sub-tropical Plants, with Ivy and Climbers, in the Gardens of the Princess

Kotschoubey, at Nice . . . . . . . . . . . . $\quad$ I44

Group of Solomon's Seal at foot of wall . . . . . . . . $\quad$ I46

Clematis over Porch . $\quad$. $\quad$. . . . . . . . . $\quad$ I47

Climbers on the Vicarage, Odiham, Hants . . . . . . . . $\quad$ I49

Pergola, with White Lilies, in Mrs. Eden's Garden at Venice . . . . 5I

Newly-formed Pergola at Munstead, with brick pillars and oak timbers . $\quad$ I52 $^{2}$

Mexican Orange-flower (Choisya) . . . . . . . . . $\quad$ I54

Wistaria on Cottage in Surrey . . . . . . . . . . $\quad$ I55

Creeping Forget-me-not . . . . . . . . . . . $\quad$ I56

The Spring Snowflake . . . . . . . . . . . $\quad$ I59

Autumn Crocus in the Flower Garden . . . . . . . . . 160

A Border of Michaelmas Daisies in a Surrey Garden . . . . . 162

Bed of Hardy and Half-hardy Plants . . . . . . . . . $\quad$ I67

"Carpet" Bed . . . . . . . . . . . . . . . 168

Do. do. . . . . . . . . . . . . . . 169

Summer Bedding, with occasional use of Fine-foliaged Plants . . . I70

Bed of Succulents and Coloured-leaved Plants . . . . . . I7I

Stone Basket of Flowers and Fine-Leaved Plants in the Garden at Heckfield Place . $\quad \mathbf{I}_{72}$

Part of Bed of "Begonias" at Canons Ashly . . . . . . . 174

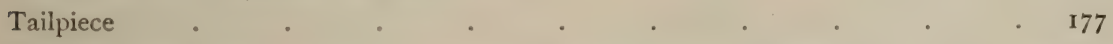

Climbing Rose (Rosa alba) on Cottage Porch, Surrey _ . . $\quad$ I79

White Climbing Rose on old Catalpa Tree . _ . _ . . . . . $\quad$ I 82

Tea Rose, Marie van Houtte . . . . . . . . . $\quad$ I 85

Roses on Palings . . . . . . . . . . . . . . $\quad$. 187

Tea Rose, "Rubens," in the Garden of Malwood, Hampshire * . . $\quad$ I89

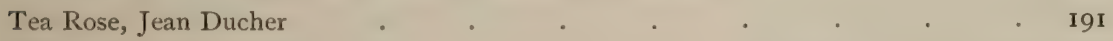

Tailpiece . . . . . . . . . . . . . 196

Cast-iron Labels; the simplest, neatest, and best Form for Shrubs, bold Herbaceous

Plants, and for all Cases where the Label has to be fixed in the Ground . 200

The simplest and best Label for Trees . . . . . . 20 I

Position for Tree Label . . . . . . . . . . . 201 
Tailpiece

Aciena microphylla

Acanthus

Achillea Eupatorium (Caspian Milfoil)

Aconitum Napellus (Monkshood)

Adiantum pedatum (The Bird's-foot Maiden-hair)

Adonis vernalis

White Agapanthus (African Lily)

Ailantus with Cannas .

Akebia quinata

Allium Moly (Yellow Allium).

Alströmeria (Peruvian Lily)

Althæa rosea (Double-flowered Hollyhock)

Single Hollyhock

Amarantus (Prince's Feather) .

Flowers of Amygdalus nana

Androsace foliosa

Anemone fulgens fl.-pl. (Scarlet Windflower) .

White Japan Anemone in Shrubbery .

Anomatheca cruenta*

Antirrhinum (Snapdragon, White Swan)

Cape Pond-flower

ica (Californian Columbine)

Flower of Rocky Mountain Columbine.

Siberian Columbine

White Columbine

Aralia spinosa (Angelica Tree)

,, Sieboldi .

Flowers of Arbutus Unedo (Strawberry Tree) .

Arctotis arborescens

Arenaria balearica (Balearic Sandwort)

Flower of Argemone mexicana

Aristolochia Sipho (Dutchman's Pipe) .

Asperula odorata (Woodruff) . 
Astilbe rivularis (Goat's-beard)

Astrantia major

Athyrium Filix-foemina (Lady Fern)

Flowers of Azalea mollis

Bæria chrysostoma

Spray of Bambusa Mazelli and B. Metake

The Metake Bamboo .

Bartonia aurea .

Tuberous Begonia

Double Daisy

Benthamia fragifera, Elm House, Guernsey

Evergreen Barberry

Blumenbachia coronata

The Plume Poppy (Bocconia cordata) .

Swan River Daisy

Brevoortia (Satin-flower)

Brugmansia Knighti in the Flower Garden

Datura suaveolens, Cosham, Hants

Bulbocodium .

Calandrinia oppositifolia

Arum Lily (Calla æthiopica)

Dwarf Crown China Aster

Calochortus flavus

Calopogon pulchellus

Allspice Tree (Calycanthus)

Campanula persicifolia alba (Peach-leaved Bell-flower)

Campanula pyramidalis

Campanula rotundifolia

Indian Shot (Canna indica), flowers and leaves

Cannabis sativa (Hemp Plant)

Carpenteria californica in a Sussex Garden

Celsia cretica (Cretan Mullein) .

Centaurea babylonica .

Red Valerian (Centranthus ruber)

Cephalaria procera

Cherry Flowers (Cerasus Watereri)

Chamærops Fortunei in a Surrey Garden

Snow Glory (Chionodoxa)

Choisya ternata (Mexican Orange-flower) in Devon Garden

Chrysanthemum tricolor

,

Rock Rose (Cistus florentinus). 


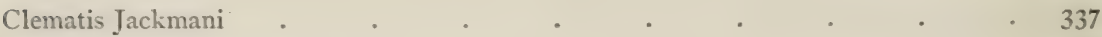

Flowers of Clematis erecta $\quad . \quad$. . . . . . . 338

Clematis, Lady Caroline Nevill . . . . . . 340

Colchicum Parkinsoni . . . . . . . . . 342

Convallaria majalis (Lily of the Valley) _ . . . . . . 345

Convolvulus sylvaticus . $\quad . \quad$. . . . . . 346

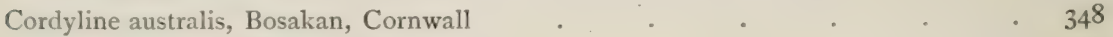

Coreopsis tinctoria (Tickseed) . . . . . . . 349

Yellow Fumitory (Corydalis lutea) on wall $\quad . \quad . \quad . \quad . \quad . \quad$. $\quad . \quad 35$ I

May, Hawthorn . . . . . . . . . 353

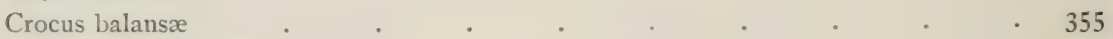

", biflorus pusillus. . . . . . . . . 355

" etruscus. . . . . . . . 355

, leucorhynchus. . . . . . . . . 355

, reticulatus . . . . . . . 355

, Imperati . . . . . . . . 357

" nudiflorus . . . . . . . . . $35^{8}$

Gourds in a Surrey Garden . . . . . . . . . . 360

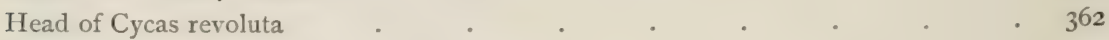

European Cyclamen, Sowbread (C. europæum) . . . . . . . $\quad 364$

Mocassin-flower (Cypripedium spectabile) . . . . . . 366

Dahlia imperialis . . . . . . . . . . 370

Garland-flower (Daphne Cneorum) _ _ . . . . . . 37 I

Dasylirion acrotrichum . $\quad$. $\quad$. . . . 373

Delphinium . . . . . . . 375

Deutzia . . . . . . 378

Dianthus alpinus (Alpine Pink) . . . . . . . 379

Carnation . . . . . . . 380

Redbraes Picotee . . . . . . . . 382

Dianthus deltoides (Maiden Pink) . . . . . . . . . 385

Dianthus nelgectus (Glacier Pink) . . . . . . . . 386

Dictamnus fraxinella . . . . . . . . 388

Dimorphanthus mandschuricus . $\quad$. $\quad . \quad . \quad 389$

Foliage of Teasel . . . . . . . . . . 390

Doronicum (Leopard's Bane) . . . . . . . . . 392

Drosera filiformis . . . . . . . . . . . . 393

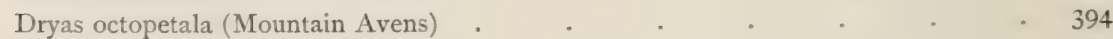

Echinops ruthenicus (Globe Thistle) . . . . . . . 396

Edraianthus Pumilio . . . . . . . . . 397

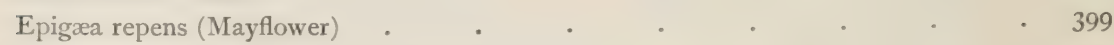

Equisetum Telmateia (Giant Horse-tail) . . . . . . 400

Erodium petræum . . . . . . . . . . 405

Erpetion reniforme (New Holland Violet) . . . . . . . . . 406

Eryngium alpinum (Sea Holly) _ . . . . . . . . 407

Eulalia japonica . . . . . . 4 4I2

Euonymus latifolius (fruiting branch) . . . . . . . . 4I3

Eupatorium purpureum (Thorough-wort) . . . . . . . 4I4

Francoa ramosa (Maiden's Wreath) . . . . . . . . 4I9 
White Fritillary

PAGE

Fuchsia pumila

Plantain Lily (Funkia Sieboldi)

Gaillardia

Snowdrop

Garrya elliptica

426

Genista tinctoria

Gentiana verna

Gladiolus The Bride

Hybrid Gladiolus (Lemoine's)

Gunnera scabra

Large-leaved Ivy, one of many fine forms . . . . . . . . . 444

Ivy in Wreaths and Sheets on Railings of Suburban Gardens . . 445

- Pyramid of Large-leaved Ivy, $7 \mathrm{ft}$. high . . . . . . . . . 446

Sun Rose on Rocks (Cheddar)

Double Perennial Sunflower .

Heliotrope

Christmas Rose

Helleborus viridis

Hemerocallis fulva (Day Lily) .

Houstonia cœrulea

Hyacinth

The Plumed Hydrangea

Iberis gibraltarica

Holly Hedge at Bagshot

Inula glandulosa

Ionopsidium acaule 470

Iris fotidissima (Gladwin)

, Kæmpferi (Japanese Iris)

,, pallida

,, persica

, reticulata

„, susiana

Spanish Iris (I. Xiphium)

Jasminum nudiflorum .

Juniperus recurva at Castlewellan

Jew's Mallow (Kerria japonica)

Kniphofia grandis

Libertia formosa

Lilium auratum 
Lilium longiflorum var. (White Trumpet Lily)

,, tigrinum (Tiger Lilies amongst Grass) .

Lobelia fulgens (Cardinal Flower)

Lonicera Periclymenum (Honeysuckle)

Lupinus arboreus (Tree Lupine)

The Yulan (Magnolia conspicua) at Gunnersbury House

Menziesia polifolia alba

Mertensia virginica (Virginian Cowslip)

Michauxia campanuloides

Molopospermum cicutarium

Mulgedium Plumieri (Blue Thistle)

Musa Ensete

Myosotis alpestris

Myrrhis odorato (Sweet Cicely)

Myrtle.

Narcissus Horsfieldi

, Bulbocodium (Hoop Petticoat Narcissus)

, jonquilla

, poeticus

Group of Daffodils

Nicotiana affinis

Nigella damascena

Enothera riparia

Olearia Haasti .

Omphalodes Luciliæ

Onosma tauricum (Golden Drop)

Orchis foliosa (Madeira Orchis)

Arabian Star of Bethlehem (Ornithogalum arabicum)

Ozothamnus rosmarinifolius

Double Pronies in Grass

Pæonia Moutan (Tree Pæony) .

White Poppies .

Parnassia palustris (Grass of Parnassus)

Passiflora Constance Elliot

Pelargonium grown under a Verandah .

Periploca græca

Philadelphus grandiflorus 
Polygonum sachalinense

PAGE

, vaccinifolium

593

Primula capitata

594

, farinosa (Bird's-eye Primrose)

,, rosea .

,$\quad$ Sieboldi

" vulgaris

Primrose Munstead early white

"Bunch" Primroses

Prunus sinensis flo-pl.

Pterocephalus Parnassi

Puschkinia scilloides

Pyrethrum uliginosum .

Pear Blossom .

Shoot and Acorns of Evergreen Oak

Ramondia pyrenaica

Ranunculus aconitifolius fl.-pl. (Fair Maids of France)

Rheum officinale

Early Rhododendron in Bloom

599

600

603

604

606

607

608

610

6 II

612

613

$6 \mathrm{I} 4$

$6 \mathrm{I} 6$

618

619

621

623

Rhododendron nobleanum

624

Tree Rhododendron at Castlewellan, County Down

625

629

Rhus Cotinus (Venetian Sumach)

632

Rodgersia podophylla

Romneya Coulteri

Triomphe de Rennes

633

635

637

Rose, Celeste

638

641

642

643

645

647

648

650

654

66 I

665

667

669

670

$67 \mathrm{I}$

672

673

674

677

678

$68 \mathrm{I}$
684

The Japanese Stonecrop (Sedum spectabile)

Cobweb Houseleek 
Senecio balbisianus

PAGE

Sibthorpia europæa variegata (Moneywort) . . . . . . . 688

Skimmia fragrans

Smilacina bifolia

Smilax aspera (Prickly Ivy)

Spiræa Aruncus

, ariæfolia

,, Filipendula (Dropwort)

Syringa Bretschneideri .

The Irish Yew. One of the forms of the Common Yew

Thalictrum aquilegifolium

Tigridia Pavonia

Trillium grandiflorum (Wood Lily)

Tropæolum polyphyllum

Tropæolum speciosum (Flame Nasturtium)

Late Dutch Tulips

Tunica Saxifraga

Tussilago Farfara variegata (Variegated Coltsfoot) . . . . . 723

Vallota purpurea (Scarborough Lily) . . . . . . . 725

Verbascum nigrum var, album . . . . . . . . 726

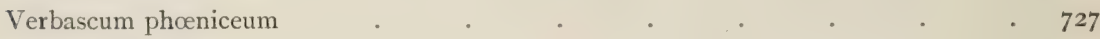

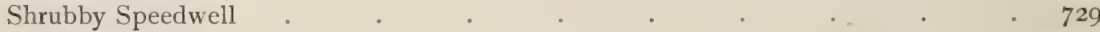

Viola pedata (Bird's-foot Violet) _ . . . . . . . . 736

Tufted Pansy, Mrs. Gray . . . . . . . . 739

Weigela grandiflora . . . . . . . . . 742

Wistaria (Glycine) sinensis _ . . . . . . . . 744

Woodwardia radicans . $\quad . \quad$. . . . . 745

Yucca gloriosa (Adam's Needle) . . . . . . . . 747

Zea caragua . . . . . . . . . . 749

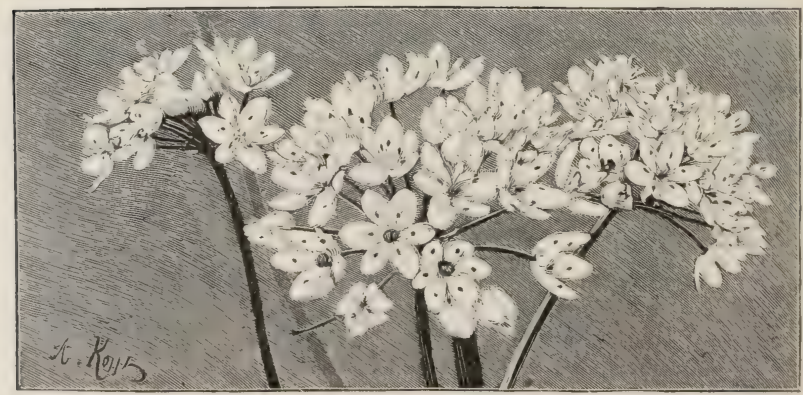




\title{
THE ENGLISH FLOWER GARDEN
}

\author{
CHAPTER I
}

\section{DESIGN AND POSITION}

ONE aim of this book is to uproot the idea that a flower garden is necessarily of set pattern-usually geometrical-placed on one side of the house. The wants of flowers can be best met, and their varied loveliness fully shown, only in a variety of positions, and the first thing to do is to consider the error of arraying all our flowers in one spot under exactly the same conditions! Such arrangements can never give us a tithe of the beauty of which our gardens are capable. That a flower garden should occupy one spot, and all the flowers be therein shown, is the old and general rule. We must take no notice of it if our gardens are to be varied and beautiful with the flowers of all seasons. The settled way has been to regard one spot with the same soil and aspect-with every condition alike, in fact - as the only home for open-air flowers. Yet in the same place, or near, there may be many different positions, each favourable to a different type of flower life.

Things said to be "matters of taste," like flower gardening, are really matters of law. The shades are so fine, the swift changes so beautiful, the creatures of wood, grass, and air so many and so fair, as they pass, that we may well forget for a moment that life is law. For all that concerns our lives there are laws which will guide us if we seek for them. The laws here meant are Nature's laws-not merely landmarks set out by man for his convenience. Only they are not laws that bind with weary fetters, but as infinite in delightful change as the restless clouds on the hills. No one need fear their tyranny, for in them is perfect liberty and all the sweet wanderings the earth mother has for her children. We shall never settle the most trifling question by the stupid saying that it is " a matter of taste." If the reader will come with me through these early chapters 
I may convince him that flower gardening is " a matter of reason." I do not want him to think as I do without considering the matter for himself. The laws of all true art can only be based on the eternal laws of Nature.

There are many dissertations on the several styles of laying out gardens: the authors go even to China and to Mexico for illustrations. The first thing every writer on this subject does is to puzzle himself and his readers with words about "styles." But when all is read, what is the result to anybody who looks from words to things? That there are two styles: the one straitlaced, mechanical, with much wall and stone, with water-squirts, plaster-work, and sculpture of the poorest sort; the other naturalin most cases accepting the ground lines of the earth herself as the best, and getting plant beauty from its true source-with the flowers and trees arranged in picturesque ways. Mr. Ruskin tells us that

We are forced, for the sake of accumulating our power and knowledge, to live in cities; but such advantage as we have in association with each other is in great part counterbalanced by our loss of fellowship with Nature. We cannot all have gardens now, nor our pleasant fields to meditate in at eventide. Then the function of our architecture is, as far as may be, to replace these ; to tell us about Nature; to possess us with memories of her quietness; to be solemn and full of tenderness like her, and rich in portraitures of her; full of delicate imagery of the flowers we can no more gather, and of the living creatures now far away from us in their own solitude.

What, then, are we to think of those who carry the dead lines of the builder into the garden, which, above every other artificial creation, should give us the sweetest "fellowship with Nature"? A flower garden should not be a stone yard. There are positions, it is true, where stonework may be necessary. The most beautiful terrace gardens are those built where the nature of the ground requires them, but the natural disposition of even monotonous ground is preferable to the most elaborate geometrical arrangement. Let us, then, use as few carpet patterns and as little stonework as possible, and have our gardens full of life and change, and of such beauty as is nowhere to be found in deadly formalism.

We have an example of formal gardening in the great fountain basins of the Crystal Palace. There is nothing more melancholy than the walls, fountain basins, clipped trees, and long canals of places like these, not only because they fail to satisfy the desire for beauty, but because they suggest wasted effort and riches worse than lost. There are, from Versailles to Caserta, a great many ugly gardens in Europe, but at Sydenham we have the greatest modern example of the waste of enormous means in making hideous a fine piece of ground. This has been called a work of genius, but 


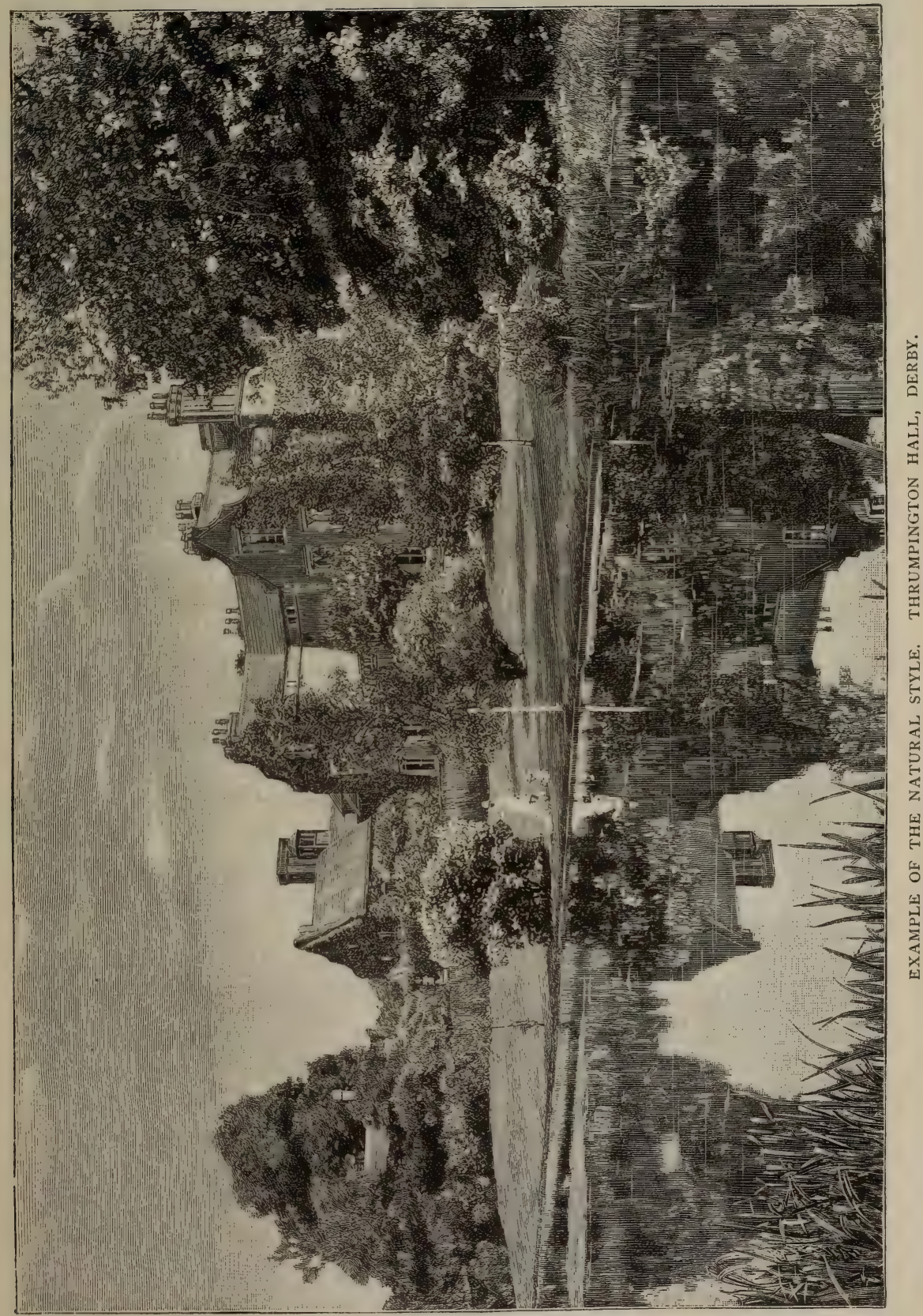


it is the fruit of a vulgar ambition to outdo another sad monument of great means put to base uses-Versailles. But Versailles is a relic of a past epoch, and was the expression of such knowledge of the gardening art as men possessed at the date of its creation. Our means for garden adornment have increased a hundredfold since Versailles was designed, and our modern illustration of a barbarous style has none of the excuses which might be urged for Versailles. As Versailles had numerous tall water-squirts, the best way of glorifying ourselves was to make some taller ones at Sydenham! Instead of confining the geometrical gardening to the upper terrace, by far the greater portion of the ground was devoted to the baser features of a stony style of garden design, and nearly in the centre were placed the vast fountain basins with their ugly pipes. These water basins are more hideous than the crater of a volcano. The contrivances to enable the water to go downstairs, the temples, the statues, the dead walls, all add to the distracting elements of the central region. This costly rubbish was praised by the gardening papers as the marvellous work of a genius-Paxton!

When a private individual indulges in expensive fancies, he may not injure many but himself and his family; but in this public garden - set up as an example of all that is admirable - we have, in addition to wasteful outlay, an object absolutely hurtful to the public taste. It sows the seeds of its ugliness all over the country. Many whose lawns were, or might readily have been made, the most beautiful of gardens have spoiled them for sham terraced gardens. There is a modern castle in Scotland where the embankments are piled one above another, till the whole looks as if Uncle Toby with an army of corporals had been carrying out his grandest scheme in fortification. The style is in doubtful taste in climates and positions more suited to it than our own, but he who adopts it at the present day, and in the presence of the many trees and plants we now have, is an enemy to every true interest of the garden. The rude stone wall of the hill husbandman, supporting a narrow slip of soil for olive trees or vines, became indeed, in the ornamental garden of the wealthy Roman, an architectural feature, varied by vases, statues, etc. ; but it must be remembered that the beauty of an Italian garden, or a geometrical garden of any kind, depends on the predominance of vegetation over the merely artificial. This is true of all gardens, but applies chiefly to the terraced style, inasmuch as it is in that style that artificial things are most seen.

TERRACED GARDENS, allowing of an endless variety of architectural work, apart from the house, have naturally been much in favour with architects, and with artists who have taken up the profession of landscape gardening. The landscape gardener proper, so to say, 
impressed by custom, falls in with the popular notion that every house, no matter what its position, should be fortified by terraces.

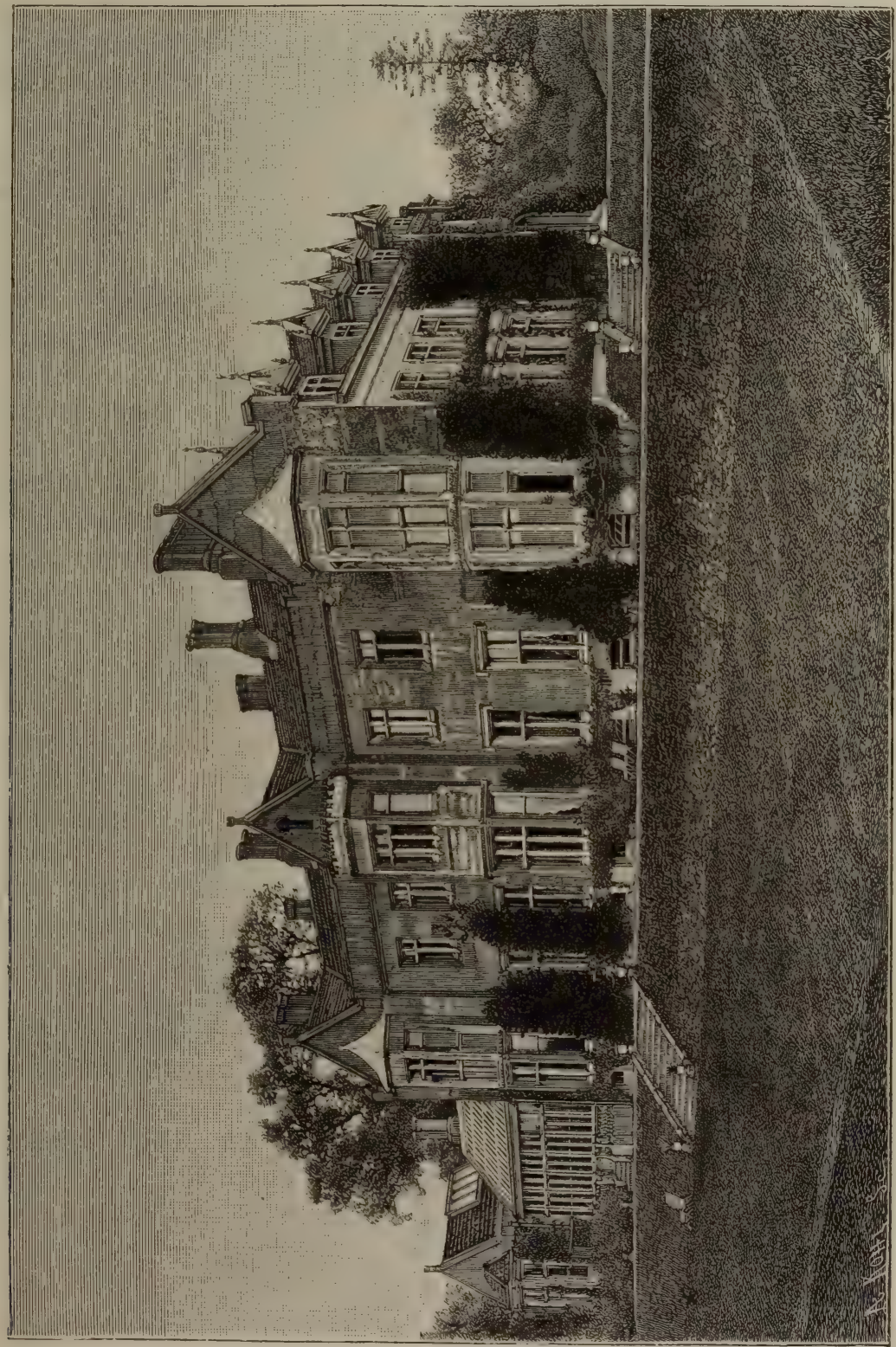

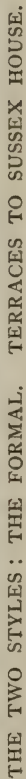

Accordingly he busies himself in forming them, usually on level ground. Thus vast sums, ostensibly devoted to the garden, are spent on waterworks, fountains, vases, statues, balustrades, walls, and 
stucco work. By the extensive use of such materials many a noble lawn is cut up; and sometimes, as at Witley Court, the architectural gardening is pushed so far into the park as to absolutely curtail and injure the prospect. Indeed, if the cost of the stone and stucco ornament lavished on the garden were spent on its legitimate object - the house-it would be all the better for architecture as well as for gardening.

Where the ground is level a finer effect results from turf allowed to sweep up to the walk in front, or on some side, of the house than from an elaborate terrace, as may be seen on the north side of Holland House, and in many other English gardens. In many cases there is need for a straight walk, it may be for a small terrace -but this entirely depends on the position. But where the ground is level, as in most English gardens, there is no occasion for more than a grassy foreground, which leaves us free to adopt natural gardening everywhere. In level town gardens, where the excuse of formal surroundings is used to justify a stony style, it is often a mistake. The best effect is to be obtained, not by carrying architectural features into the usually small town garden, but by securing an absolute contrast between the garden vegetation and its unavoidable formal surroundings. This contrast should be got, not by the sham picturesque, with rocks, cascades, and undulations of the ground, but mainly by the simple dignity of trees and the charm of level turf. It was said that none but an Italian garden would suit South Kensington. Well, we had an elaborate garden designed there, and skilfully designed: the design was carried out with the greatest care, yet the result, as everybody knows, was poor indeed. There are many private gardens in European cities, of a more limited extent and with more formal surroundings than that of South Kensington, which are as beautiful and as devoid of artificial aspects as if in some happy valley far away from the city.

We may often see the effect of the terrace wall approaching the house from some pleasant part of the park. If the wall be raised, as in places it must be, on the level or nearly level ground, so as to cut the foreground of the house off from the park, a bad effect results. A beautiful house should not be cut off by any ugly wall. In many places laid out at great cost within the past thirty years or so the effect from the park is as cheerful as a piece of the wall of Millbank Prison.

Another matter of some importance is that these geometrical gardens prevent the formation of wide and beautiful lawns. A simple lawn is the happiest thing in a garden. For many years past there has been so much cutting up, geometry, and stonework, that it is extremely rare to find a good lawn left. Many a site cut 


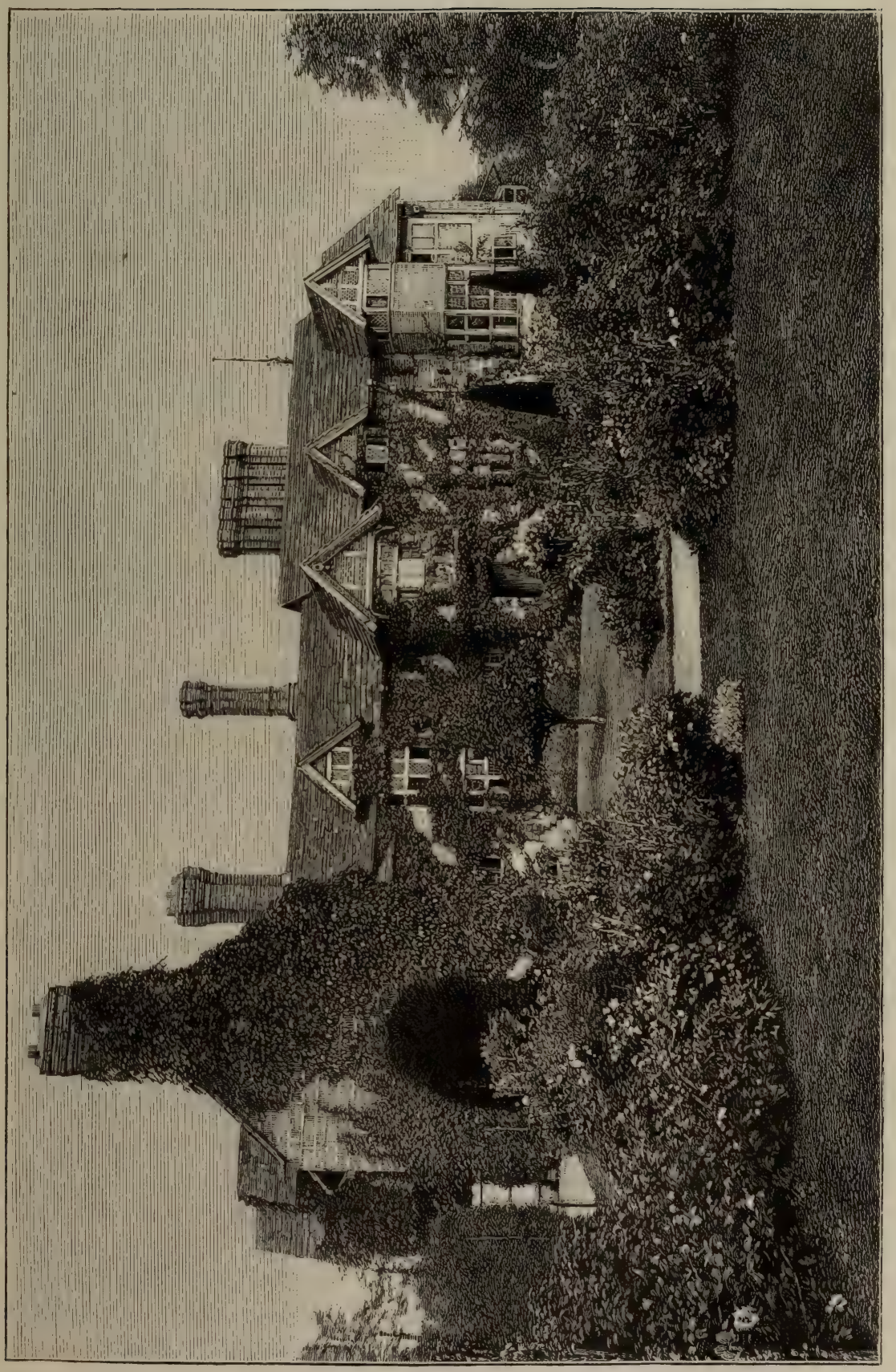

告 
up by terrace gardens and other formalities would be vastly improved by the substitution of a large nobly-fringed lawn. Imagine a fine, well-built old house, seen across a wide lawn, with plenty of trees and shrubs on its outer parts, and nothing to impede the view; and then consider the wisdom of facing it with a wide terrace. A very common, poorly-built house with a fine lawn has often a better effect than a fine one with a rectilineal garden and terraces in front of it. If men would watch the effect of such lawns as remain to us, and compare them with what has been done by certain landscape gardeners, there would shortly be, at many a country seat, a rapid carting away of the terrace and all its adjuncts. The Italian made his terrace because he could not make a lawn on the steep hillside. In imitating him we do away with the most precious feature of the English garden-the lawn. Some of the finest lawns in England have been destroyed to make costly, lifeless terraces.

I would, of course, except cases in which the terrace was really called for by the nature of the ground, and have no desire to limit the flower garden in any way. The few complicated and paltry beds that are on these terraces, to serve the place of the flower garden, are not half big enough for raising all the beautiful flowers we ought to grow. In removing, in a large place, a useless terrace, and in forming a sweet lawn instead, I should make three times the amount of flower space in different parts of the garden or the pleasure ground-on the outer fringes of the lawn, by the sides of the pleasant walks, anywhere, in fact, that favourite plants can be grown best and would look best. Abolish all complex beds and adopt simple, large forms, using an irregular outline in the case of picturesque lawns. I have formed such beds on the great terrace at Shrubland Park, Suffolk, where the formal plan required all the beds to be alike in shape; so that one may be as bold and simple in such a garden as on the margins of a beautiful sweep of turf.

A striking example of a style of garden design that for a long time has had an injurious effect on country seats, and especially on the garden and the park, is the "railway embankment" phase of landscape gardening madness - one in which we see a series of sharply-graded slopes, exactly like well-smoothed railway embankments, more or less relieved by fountains, balustrades, etc. It is extraordinary that anybody supposed to have any taste should imagine that such an arrangement, marring the whole landscape, should give pleasure to any human being, or do anything but make the home landscape formal and wearisome to the last degree. 


\section{A FEW WORDS WITH AN ARCHITECT}

A beautiful house in a fair landscape is the most delightful scene of the cultivated earth, all the more so if there be an artistic garden-the rarest thing to find! The union between the house beautiful and the ground near it - a happy marriage it should beis worthy of more thought than it has had in the past, and the best ways of effecting that union artistically should interest men more and more as our cities grow larger and our lovely English landscape shrinks back. We have never yet got from the garden and the home landscape half the beauty which we might get by abolishing the needless formality and geometry which disfigure so many gardens, both in plan and in flower planting. Formality is often essential to the plan of a garden-never in the arrangement of its flowers or shrubs. To array these in rigid lines, circles, or patterns, can only be ugly wherever done!

That men have never yet generally enjoyed the beauty of good garden design is clear from the fact that the painter is driven from the garden! The artist dislikes the usual class of garden with its formality and bedding; he hates it, and cannot help hating it. $\mathrm{He}$ will seek anything but the garden, but may, perhaps, be found near a wild Rose tossing over the pig-stye. This dislike is natural and right, since from most flower gardens the possibility of any beautiful result is shut out! Yet the beautiful garden exists, and there are numbers of cottage gardens in Surrey or Kent that are as "paintable" as any bit of pure landscape! Why is the cottage garden often a picture, and the gentleman's garden near wholly shut out of the realm of art-a thing which an artist cannot long look at? It is the absence of pretentious "plan" in the cottage garden which lets the flowers tell their own tale; the simple walks going where they are wanted; flowers not set in patterns; the walls and porch alive with flowers. Can the gentleman's garden, too, be a picture? Certainly; and the greater the breadth and means the better the picture should be. But never if our formal "decorative" style of design is kept to. Reform must come by letting Nature take her just place in the garden.

After we have settled the essential approaches and levels around a house, the natural form or lines of the earth herself are in nearly all cases the best to follow, and in my work I face any labour to get the ground back into its natural grade where it is disfigured by ugly or needless banks, lines, or angles.

But in the true Italian garden on the hills we have to alter the natural line of the earth or "terrace" it, because we cannot otherwise 


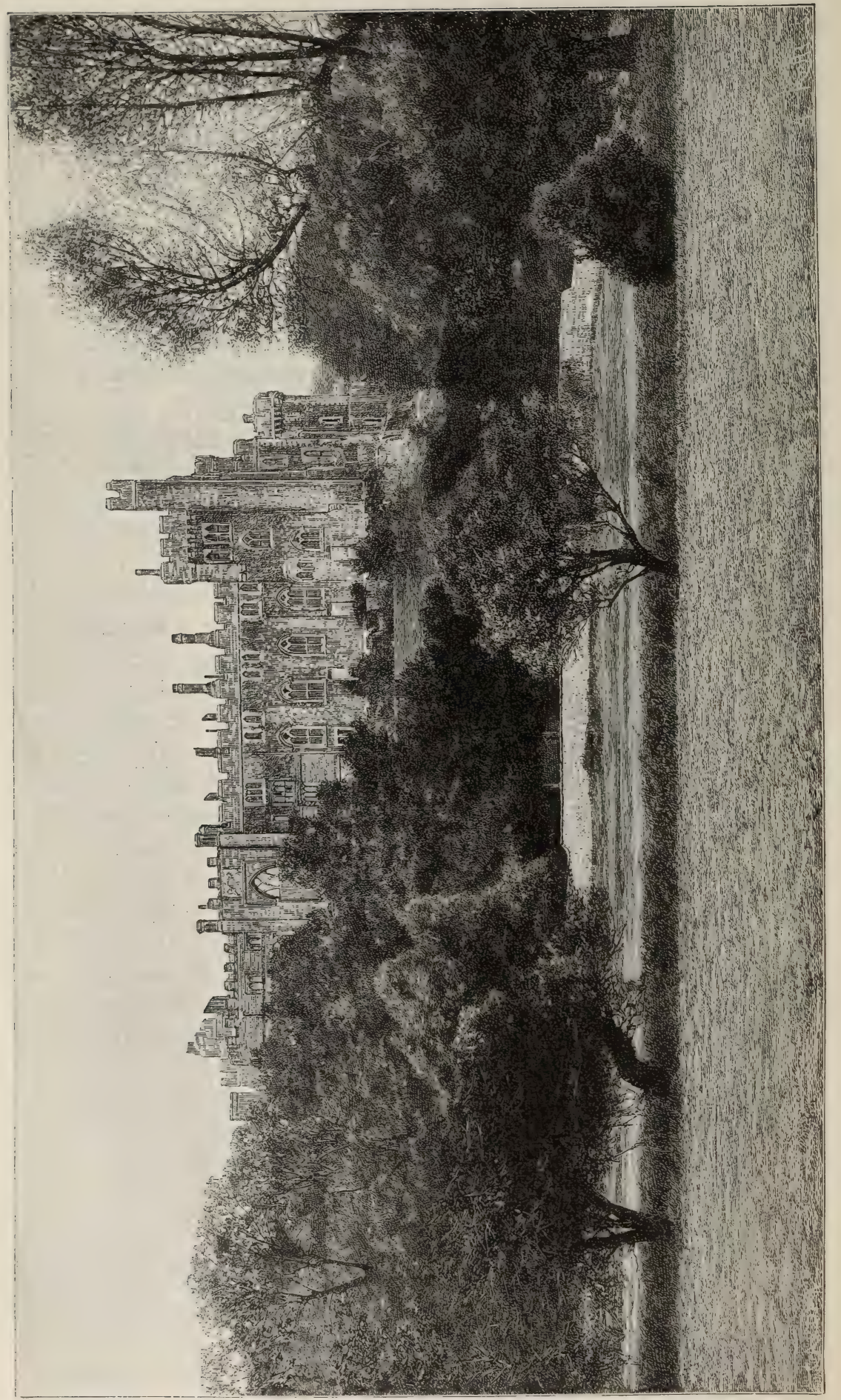


cultivate the ground or stand at ease upon it. In such ground the strictly formal is as right as the lawn in a garden in the Thames valley. But the lawn is the heart of the true English garden, and as essential to it as the terrace to the gardens on the steep hills. English lawns have been too often destroyed for "geometrical" gardens not only needless, but absolutely ruinous both to the garden and the home landscape. Sometimes on level ground the terrace walls cut off the landscape from the house, and, on the other hand, the house from the landscape!

I hold that it is possible to get every charm of a garden and every use of a country place without sacrificing the picturesque or beautiful; that there is no reason, either in the working or design of gardens, why there should be a single false line in them; and that every charm of the flower garden may be secured by wholly avoiding the knots and scrolls which subordinate all the plants and flowers of a garden, all its joy and life, to a wretched conventional design. The true way is the opposite. With only the simplest plans to ensure good working, we should see the flowers and feel the beauty of plant forms, and secure every scrap of turf wanted for play or lawn, and for every enjoyment of a garden.

It is natural that these views should meet with opposition, and the consideration of an article by $\mathrm{Mr}$. R. T. Blomfield in the Portfolio (December I 889) gives us the opportunity of examining the objections. He says :-

The question briefly stated is this: Are we, in laying out our gardens, to ignore the house, and to reproduce uncultivated Nature to the best of our ability in the garden? Or are we to treat the house and garden as inseparable factors in one homogeneous whole, which are to co-operate for one premeditated result?

No sane person has ever proposed to ignore the house. Where there is a beautiful house it tells me what to do! Unhappily, the house is often so bad that nothing can prevent its evil effect on the garden. Reproducing uncultivated Nature is no part of any gardener's business, as the whole reason of a flower garden is that it is a home for cultivated Nature. A wretched flowerless pinched bedding plant and a great buff climbing Tea Rose are both cultivated things, but what a vast difference in their beauty! There are many kinds of "cultivated Nature," and many kinds of ugliness among them.

Sir C. Barry's idea was that the garden was gradually to become less and less formal till it melted away into the park. Compromises such as these, however, will be rejected by thorough-going adherents of the formal gardens, who hold that the garden should be avowedly separated from the adjacent country by a clean boundary line, a good high wall for choice. 
Would Mr. Blomfield put this high wall in front of Gilbert White's house at Selborne, of Golder's Hill at Hampstead, or of many English houses where a high wall would cut off the landscape? Not a word about the vast variety of situations, each requiring to be treated quite differently. There are many gardens in every county that would be robbed of their best charms if separated from the adjacent country by a "good high wall."

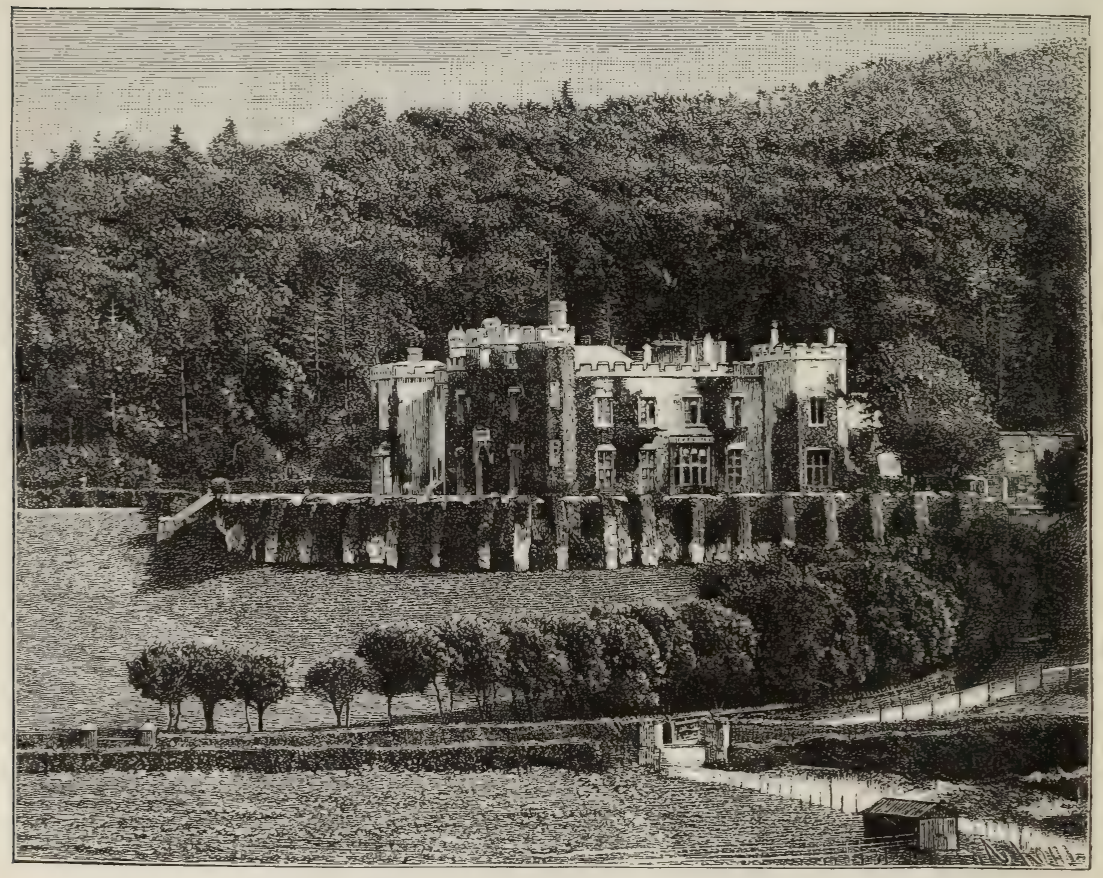

WATERMOUTH CASTLE, DEVON. ON GROUND WHERE TERRACING IS ESSENTIAL.

\section{The True Landscape}

Mr. Blomfield attributes this to me:-

That is to say, we go to Claude, and having saturated our minds with his rocks and trees, we return to Nature and try to worry her into a resemblance to Claude.

I am never concerned with Claude, but seek the best expression I can secure of our beautiful English real landscapes, which are far finer than Claude's. At least I never saw any painted landscape like these-that from the Chestnut Walk at Shrubland, for instance, looking over the lovely Suffolk country. That is the precious heritage we have to keep. And that is where simple and picturesque 
gardening will help us-making the garden a beautiful foreground for the true landscape, instead of cutting it off with a "high wall" or anything else that is ugly and needless.

The lawns are not to be left in broad expanse, but to have Pampas Grasses, foreign shrubs, etc., dotted about on the surface.

I have fought for years for the lawn destroyed by the terrace builders and the bedding-out gardeners! But how are we to have our lawns in "broad expanse" if we build a "good high wall" and cut off even the possibility of a lawn? In too many cases this has been done to the ruin of all good effect, often shutting out landscapes as good and simple as ever were painted! There are flagrant instances in the suburbs of London.

\section{Buildings in Relation to the Garden}

The use of formal gardening is clear for ever. The architect can help us much by building a beautiful house! That is his work. The true architect seeks to go no farther. The better the real work of the architect is done, the better for the garden and the landscape. If there are any difficulties of level about the house beautiful he should deal with them; and the better his work and the necessary terracing, if any, the pleasanter the work of the gardener who has to follow him.

If a garden has any use, it is to treasure beautiful flowers, shrubs, and trees. In these days - when to a great extent our ways of building are the laughing-stock of all who care for the beautifulthere is plenty for the architect to do without spoiling our gardens. Most of the houses built in our time are so bad that even the best gardens could hardly save them from contempt. But I am very glad to see that we are beginning to build beautifully again-for example, at Clouds, by Mr. Philip Webb, and Batsford, by Messrs. George and Peto. Such work, however, is quite enough to absorb all the architect's energies without his dealing with the vast number of things which gardening is now concerned with. It should be remembered, moreover, that our garden flora is now so large that it requires almost a life's work to know it. How is a man to make gardens wisely if he does not know what has to be grown in them? Consider the great number of trees from North America alone ; how men can presume to design landscapes without these trees, which they know nothing of and care nothing for, is beyond belief. It is only fifth-rate architects who scatter stony rubbish about a landscape and call it gardening! I do not mean that we are to exclude everybody but the landscape gardener proper from the 
garden. We want all the help we can get from those whose tastes and training enable them to help us-the landscape painter best of

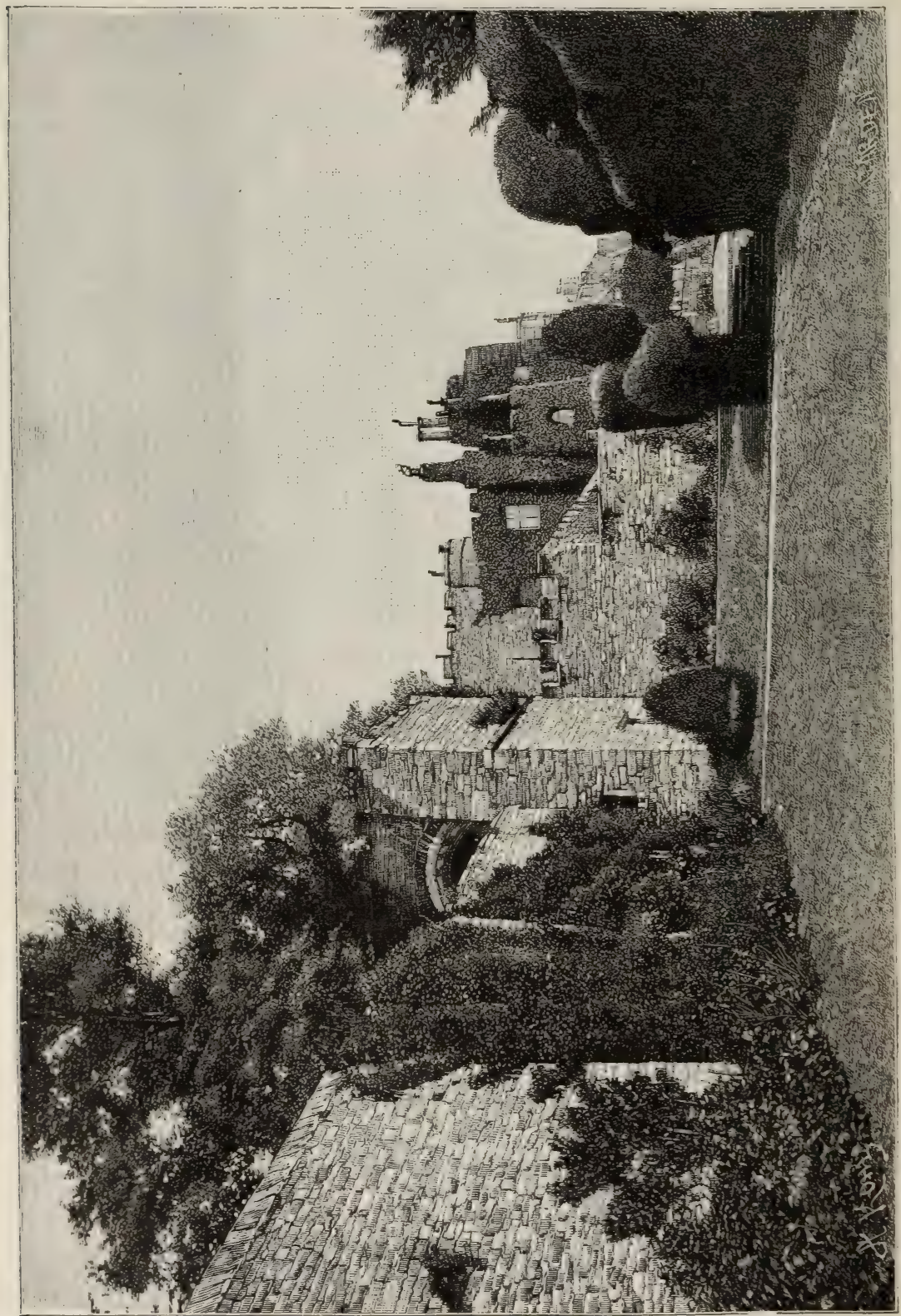

all, if he cares for gardens and trees, the country gentleman, or any lover of Nature. We do not want the landscape gardener of the present day whose work often looks like an engineer's. His garden- 
ing near the house is usually a repetition of the decorative work in the house, which I hope many are already tired of. And as I think people will some day see the evil and wastefulness of this "decora-

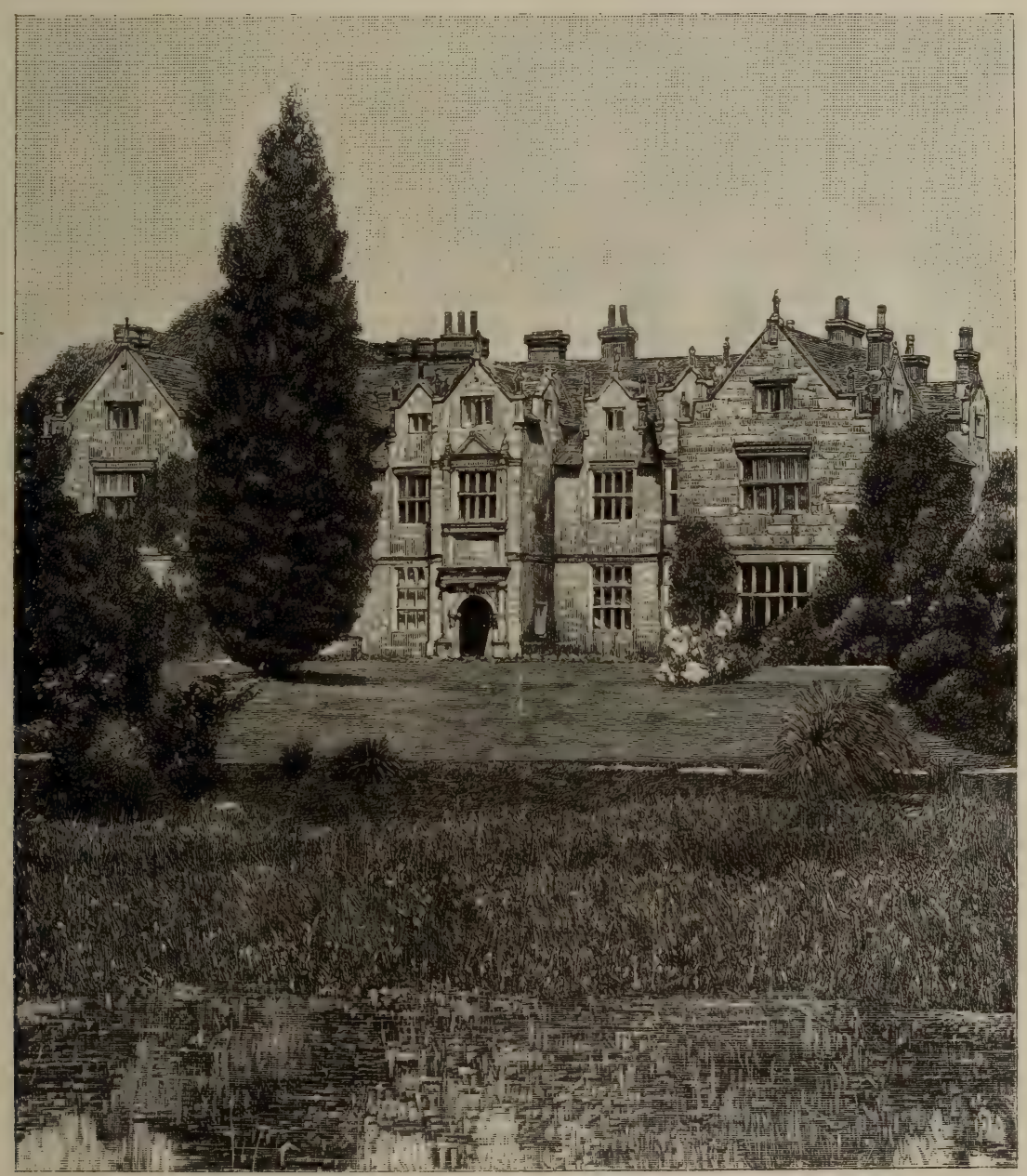

WAKEHURST. ELIZABETHAN HOUSE ON LEVEL GROUND WITHOUT TERRACES.

tive" stuff, and spend their money on really beautiful things, so I think the same oft-repeated knots and patterns must leave the garden.

\section{Time and Gardens}

Not one word of the great changer, Time. His effect on gardens is one of the first considerations. Fortress-town, castle, and moat, all without further use! In old days gardens had to be set within 
the walls; hence they were formal in outline, though often charming inside. To keep all that remains of them should be our first carenever to imitate them now! Many are far more beautiful than the modern formal gardens, which by a wicked perversity have been kept bare of plants or flower life! At one time it was rash to make a garden away from protecting walls; but when safety came from civil war, then arose the often beautiful Elizabethan house, free from all moat or trace of war.

Again, in the fighting days there was less art away from the house. Rugged wastes and hills; vast woodland districts near London; even small houses moated to keep the cattle safe from wolves - fear of the rough hills and deep woods. In those days the extension of the decorative work of the house into the garden had some novelty to carry it off, while the kinds of cultivated plants were very much fewer than now. Hence if the old gardeners wanted an evergreen hedge, or bush of a certain height, they clipped a yew tree to the form and size they wanted. Notwithstanding this we have no evidence that anything like the geometrical monotony often seen in our own time existed then. To-day the ever-growing city, pushing its hard face over our once beautiful land, should make us wish more and more to keep such beauty of the earth as may be still possible to us. The horrible railway embankments, where once were the beautiful suburbs of London, cry to us to save all we can save of the natural beauty of the earth.

\section{True Use of a Garden}

\section{Mr. Blomfield says :-}

To suppose that love of Nature is shown by trying to reproduce the effects of wild Nature on a small scale in a garden is clearly absurd; any one who loves natural scenery will want the real thing; he will hardly be content to sit in his rockery and suppose himself to be among the mountains. And, again, some loyalty to her methods might have been expected of these enthusiasts for Nature. It is surely flying in the face of Nature to fill our gardens with tropical plants, as we are urged to do by the writers on landscape gardening, ignoring the entire difference of climate and the fact that a colour which may look superb in the midst of other strong colours will look gaudy and vulgar amongst our sober tints, and that a leaf like that of the Yucca, which may be all very well in its own country, is out of scale and character amidst the modest foliage of our English trees.

A passage full of nonsense! There are many men of good taste who do try to "reproduce" and who succeed in "reproducing the effects of wild Nature on a small scale in a garden." No one loved the hills of Northern England better than the late James Backhouse. But he could not be always there to do his work, and so he was right in making his beautiful rock garden. The true use 
of a garden is to keep and grow for us plants not in our woods but mostly from other countries. The Yucca, says Mr. Blomfield, is a "plant out of scale and character amidst the modest foliage of our English trees"! The Yuccas of our gardens are natives of the often cold plains of Eastern America, hardy in, and in every way fitted for, English gardens, but not "amidst English trees." Is the aim of a garden to show the "modest foliage" of English trees when almost every country house is surrounded by native woods? According to such childish views, the noble Cedars in Goodwood Park, and on the lawn at Pain's Hill, are out of place.

What Mr. Blomfield declares to be absurd is the soul of true gardening-to show, if only on a small scale, some of the precious and inexhaustible loveliness of vegetation of plain, wood, or mountain. This is the necessary and only true, just, and fair use of a garden.

\section{Formal Gardening}

But those who attack the old English formal garden do not take the trouble to understand its very considerable differences from the Continental gardens of the same period.

No one has "attacked the old English formal garden." Part of my work has been to preserve much record of their beauty. The necessary terraces round houses like Haddon may be as beautiful as any garden ever made by man. Can two things be more unlike than the delicate veil of beautiful climbers and flowers over the gray walls of the courtyard at Ightham Mote and the hard, bare walls of some gardens of our own day? The great, dark, rock-like, feudal Berkeley is clad with Fig and Vine and Rose as far as they can reach. In these old gardens there is no trace of the modern "landscape architect," who says, "My walls are not made for plants, and for my beds I prefer coloured brick"!

What, then, is the

\section{Kind of Formal Gardening}

that is bad? It is the purely formal or stone garden made for its own sake, often without a shadow of excuse. The garden of the Crystal Palace in part; the stone "garden" at the head of the Serpentine; Versailles; the Grand Trianon; Caserta, Schonbrunn, are among the public gardens of Europe where this kind of work is seen. Great harm has come to many a fair English lawn through this system. Let us learn by one instance, easily seen, the harm done in formal gardening, even where the ground calls for an amount of terracing not usual in the plains and, for the most 
part, gentle lawns of England-I mean the flower garden at Shrubland Park, laid out by Sir Charles Barry, which I have recently planted with graceful life where I found bare walls.

As the place stands on a bluff we will assume that the main terrace lines were needed, and speak of a secondary evil, which arose, I think, about the time Barry laid out Shrubland. That is, that the walls of the house or garden are not to be graced by plants, and that, to secure the keeping of the design, coloured gravels take the place of flowers. This rule, as is well known, has been carried out

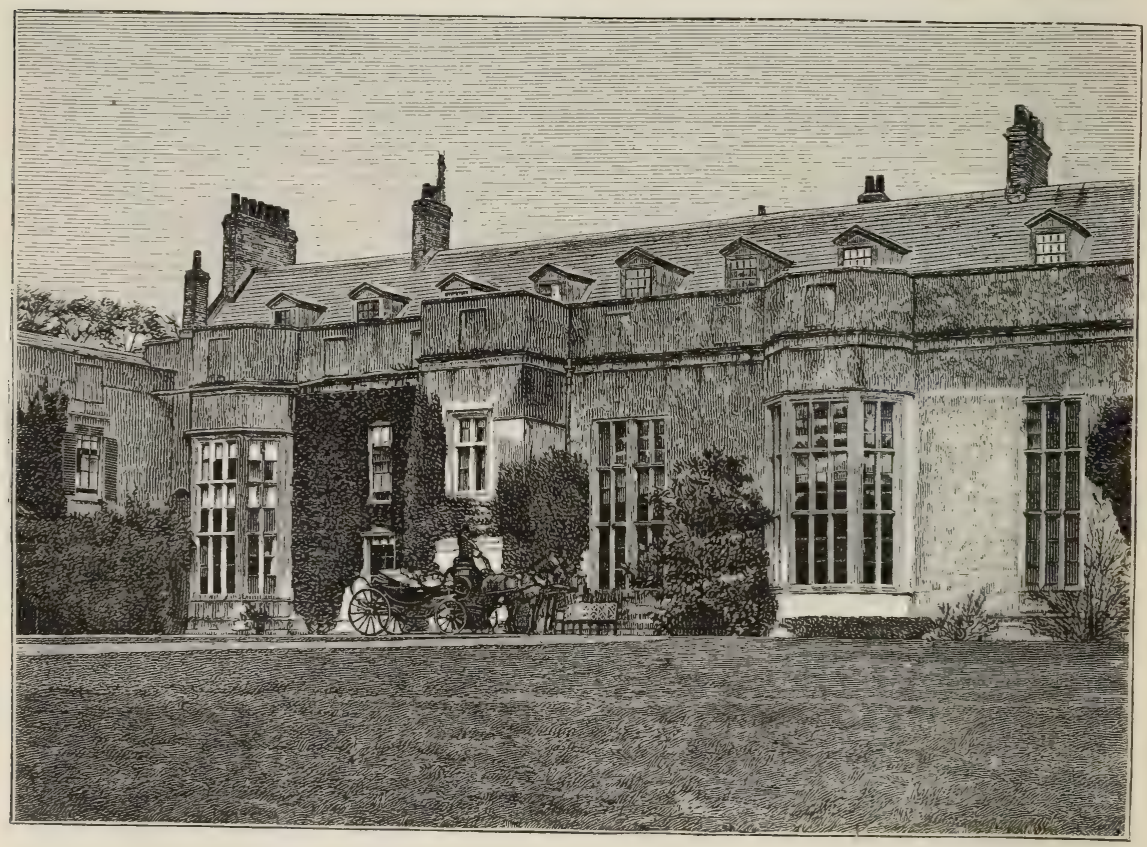

SUSSEX HOUSE ON GENTLY-SLOPING GROUND. TERRACING NOT NECESSARY.

in many gardens - it was rigid here. I see it in some of the new gardens, and in asking why a long terra-cotta wall at Worth Park had not climbers on it, was told the designer would not allow it! Yet Nature clothes the rock walls with beautiful life; even at the snow line the gems of the flower world stain the rocks with loveliest flowers. The crag walls of every Alpine valley are her gardens; the Harebells toss their azure bells from the seams of the stones in the bridges across the mountain streams; and the ruins of the temples of the great peoples of old, who could build nobly, grow many a wild flower. Even when we take the stone and build with it, tender colours of lowly plants soon come and clothe it. 
But the maker of these miserable modern garden walls, without use or need, says in effect, Nature shall not come to hide my cleverness. I have built bare walls, and bare they must be!

Well, with this bareness of the wall there were the usual frivolous pattern beds, many filled with sand and broken stone, and only very low and formal beds of flowers pinched into carpets, with much Box often edging beds a foot across. When I first went one spring day with Lord Saumarez we saw a large and showy bed, but, going near, found it made up of bits of broken brick, painted yellow, blue, and red!

So that, apart from needless formality of design and bare walls where no walls were wanted, there was often an ugly formality of detail, a senseless attempt to leave Nature out of the garden, an outrage against all that ever can make a garden delightful throughout the year-by ruling that even the walls of the house should not shelter a Rose! And that is only part of what we get by letting "builders and decorators" waste in stone precious means that should be devoted to the living treasures of garden or woodland.

\section{Some Englisi Flower Gardens}

Everywhere the most stupid things are seen, especially in the larger and more pretentious class of gardens. But here and there one sees gardens that are beautiful, and those to be described here are spoken of mainly for that reason. No plan will help us so well to a clear view of what is best in the way of design as a visit to a few gardens. For, though we must look to the coming men, starting without prejudice or ill-training, for the artistic flower garden of the future, we may learn something by considering a few gardens where true art is not completely set aside. But first let us visit Barebones, who has a fine garden with nothing in it.

BARE FLOWER GARDENS.-During the summer of I89I I visited several of the most beautiful country houses in England, without a flower of any kind near the windows! Surely this can arise only from the idea that there is no beautiful flower-gardening possible.

The ugliness of what is generally called flower-gardening has indeed led many people to have no flower garden at or near the house. Those who notice the gardens round country seats need not be surprised to find now and then a house without any flower garden, or with the turf running hard into the walls. A world without trees, a ship on the high seas without sails or 
men, is not worse than a flower garden without flowers. The fashion of having no flowers near the house crept in about Sir C. Barry's time, when, not satisfied with building commonplace houses, he laid out pastrycooks' gardens, and as anything the planter or gardener might introduce into the pattern garden could only call attention from the "art" displayed, he thought it well to forbid planting at all, occasionally using instead of flowers broken and painted bricks, gravels, and white sand. This unnatural and foolish idea has often made a desert of what should be a happy home for flowers.

It is a mistake to suppose that the only alternatives to such rubbish are coarse and weedy perennials and annuals, that flower a short time and are weedy the rest of their days. Many delightful things may grow near a house ; everywhere may be fragrant plants, beautiful not only throughout the summer, but beautiful in colour even in winter. The ceaseless digging about of the beds also may prejudice people against flowers in the garden. This arose from a miserable phase of the bedding-out system, called spring gardening. The bedding things planted in June were taken away in autumn, and immediately replaced by spring-flowering things. These had a short period of bloom in spring and were, in their turn, pulled up, presenting bare beds again until the summer flowers were planted, which sometimes happened very late; so that in June, when we ought to have beautiful flowers and buds, or, at all events, pleasant colour over the ground, there was nothing but bare, grave-like earth. The spring flowers round a country house should be grown in quite a different way. They may be naturalised in multitudes (Narcissus, Snowdrop, Crocus, Snake's-head, Grape Hyacinth). They may be grown in borders, in special little gardens for bulbs, and in various other ways, without in the least disturbing the beds near the house. In short, the true way of flower-gardening is to plant the chief beds permanently, so that the greatest amount of beauty may be had throughout the fine months, without disfiguring the beds during those months.

The permanent flowers must be hardy, and of the highest order of beauty, and such as require more than a few weeks or months for development; though here and there blanks might be filled with really fine summer things, such as Heliotrope. Many of the hardy flowers, too, should be sweet-scented as well-Tea Roses, Carnations, tufted Pansies; all those, grown with others in large groups, give off a grateful odour round a house. For their odour alone they are worth growing. What is the soil in these gardens for? Why do people make them? Surely it is not to have them laid down to grass like cricket grounds! 


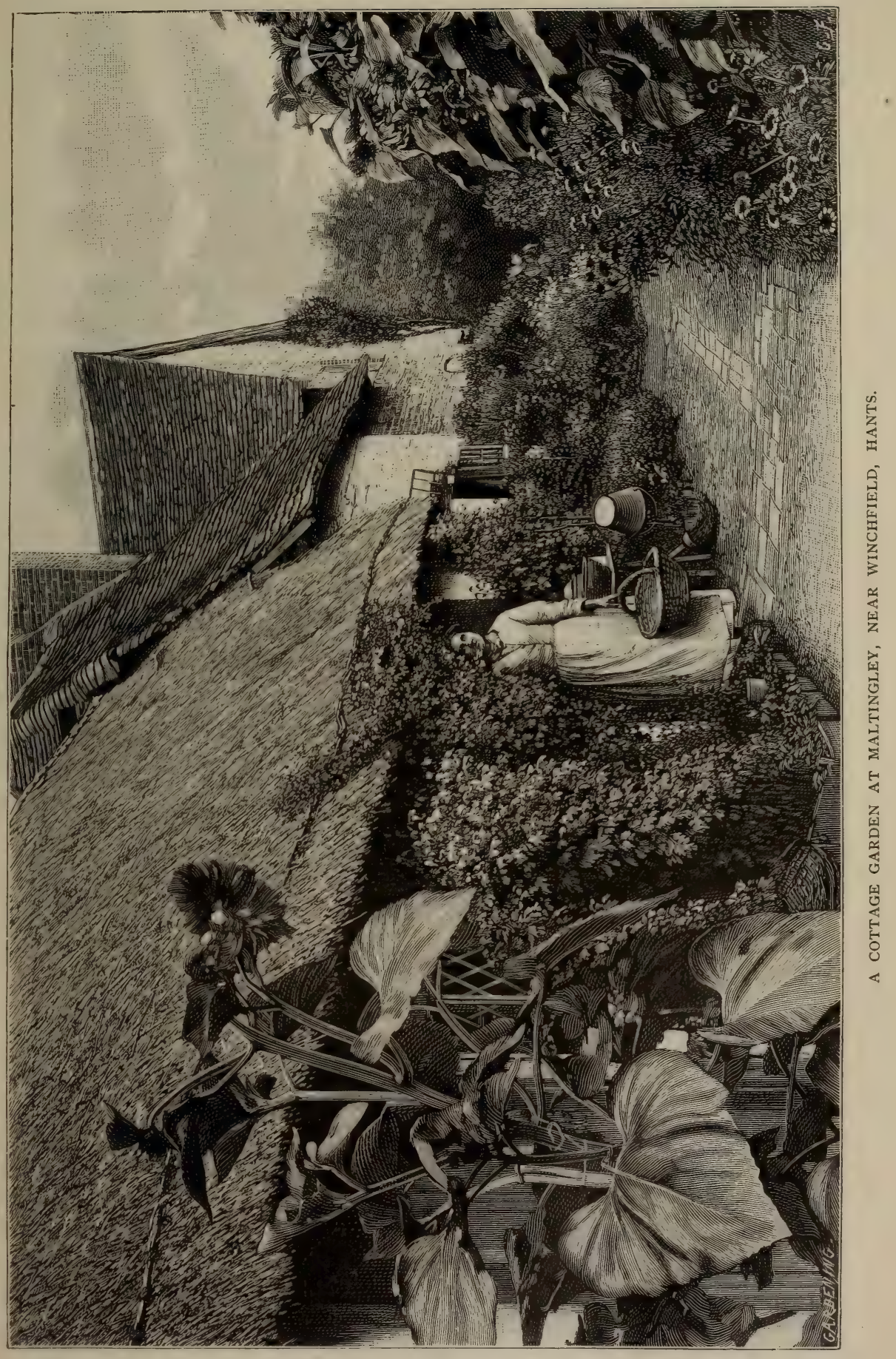


The objection to the bare surface of beds in such gardens is a just one ; the endless mess they cause is easily got rid of by adopting a permanent system ; and if the ground in the early state of the bed, or from any other cause, is bare below the flowers, it is quite easy to surface the beds with small plants, so that they are a beautiful colour always.

English Cottage Gardens. - We will next consider the gardens that are never bare and seldom ugly. Those who look at sea or sky or wood see beauty that no art can show ; but among the things made by man nothing is prettier than an English cottage garden. We do not see the same thing in other lands. The bare cottages of Belgium and North France are shocking in their ugliness. Even in Ireland and Scotland we do not see the same simple and charming little gardens. And these are not so good in some parts of England. In Surrey, Kent, and the Southern counties we find the prettiest. I often pass a cottage garden by a road in the Weald of Sussex never without a flower for nine months in the year. It is only a square patch of earth, but the beauty of it is far more delightful than that of the large gardens near. It is often pretty when they are bare.

What is the secret of the cottage garden's charms? Cottage gardeners are good to their plots, and in the course of years they make them fertile. The shelter, too, of the little house and hedge favours the flowers. But there is something more. It is the absence of any pretentious pattern which lets the flowers tell their story to the heart. The walks are only what are needed, and so we see only the earth and its blossoms. Wherever the cottage garden threw off its good old ways and went in for the new style, the result was sad to see, and all the old year-round charm of flowers was lost. The cottage garden being often beautiful as a spring garden, to make it into a "bedding-out" garden was to rob it of all life. The very pretty cottage garden of which Mr. Mason Good has sent me a view is in that charming country south of London where good cottage gardens abound. May their charms never grow less! They often teach lessons that "great gardeners" should learn. I never pass one by without looking at it. One asks how, with so few plants, they are pretty from Violet and Snowdrop till the Fuchsia bushes bloom nearly into winter.

GREENLANDS is an example of a garden in which the principal and river front of the house is a simple sloping lawn. It is not to the country seats of great families that one must look for good design in gardens, and Greenlands is one of the places that show the truth of the remark. Originally laid out by Mr. Marnock for Mr. Majoribanks, it has long been a garden showing good taste. 
The situation of the house by the river is well shown in the engraving. As will be seen, there are no terrace gardens, no walls for stucco or terra-cotta vases. One passes easily from the house to a pleasant lawn, which slopes gently till it touches the river. From this lawn one approaches the wide and well-planted grounds around, studded with many fine trees, among which are beautiful groups of Cedars. It may be noticed that the common fashion of a garden in front of the house is here avoided altogether; but at a little distance there are various flower gardens which, without being exactly under the windows, are within easy reach of them. It need

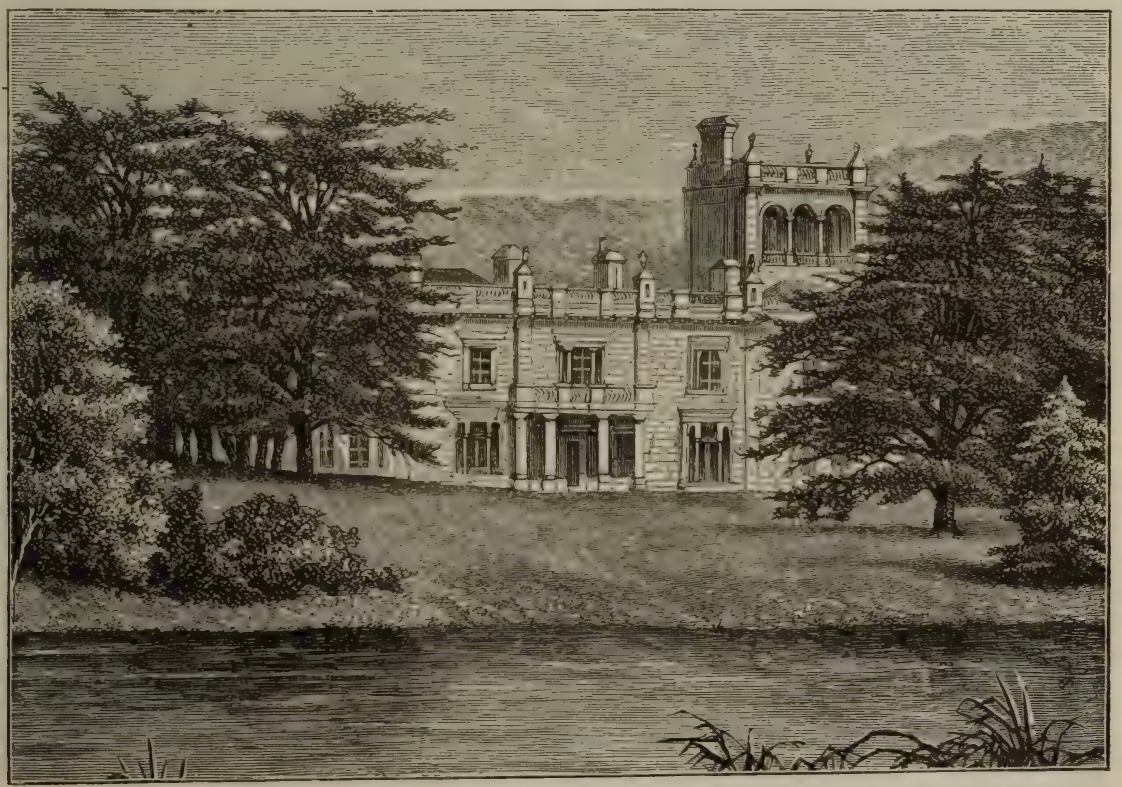

A THAMES-SIDE GARDEN (GREENLANDS), WITH WIDE SLOPING LAWN AND FLOWER BEDS TO RIGHT AND LEFT. VISIBLE FROM THE LAWN SEEN THROUGH THE TREES.

scarcely be pointed out that this plan keeps the lawn immediately in front of the house unbroken and quiet, instead of what it too often is-patched with brown earth or, not always happy, masses of flowers. It would not be the best plan to follow in every case, and the more variety the greater the charm. But there are ways of delightful flower-gardening in which no bare earth need be. There are many cases where the sunny side and the secluded side of the house afford the best of sites for a true flower garden.

GOODWOOD.-As shown in the engraving, no terrace wall stands up to cut off the house from the park with its wide lawns and noble groups of trees, both deciduous and evergreen. Its greatest charms are perhaps the noble groups of evergreen Oaks and the great 
Cedars of Lebanon standing, as our native trees might do, in a wide, open park, with little of an artificial or pleasure-ground aspect. The delightful contrasts between British Oak in noble groups, and evergreen Oak in groups equally fine, and Cedars of Lebanon, change completely the character of the landscape from what is usually met with in English parks. This is the only place, perhaps, where one may see the majesty and noble variety of the Cedar of Lebanon, whether scattered in groves and groups or in

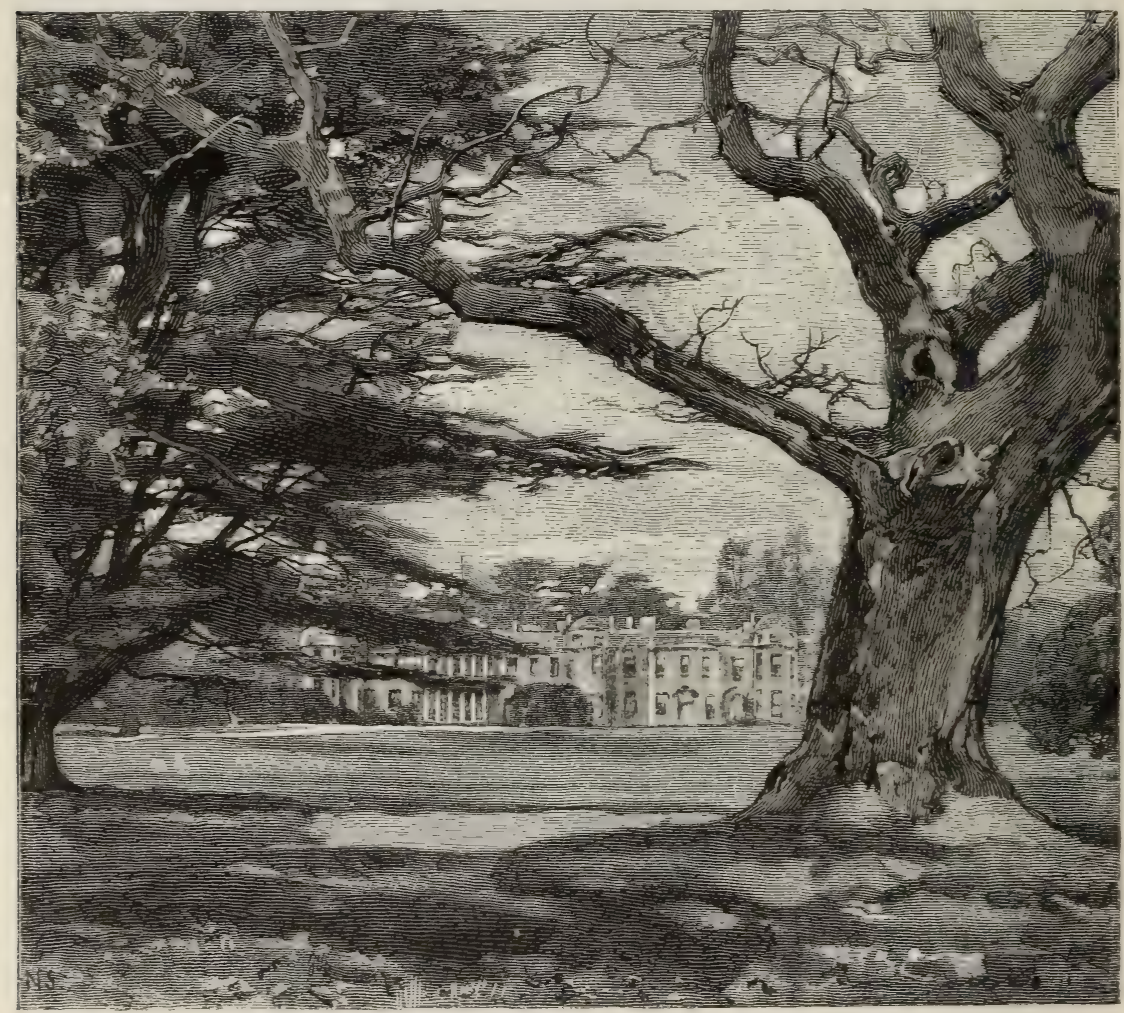

GOODWOOD PARK FRONT, WITH CEDARS AND OAKS. EXAMPLE OF GRASSY FOREGROUND TO HOUSE. FROM A SKETCH BY ALFRED PARSONS, MAY 6, I880.

single specimens over a large and varied landscape. No pleasureground preparation of deep, well-selected, and gathered soil for these giants of the hills which here compete with the sturdiness of the finest British Oak! Scant soil over chalk and perfect exposure to the hill and sea winds is their fare. One tree is well up the hillside, fully exposed on every side, and, beyond a picturesque leaning of the plumes in one direction, shows as little sign of suffering as the group of the common Yew near it. Somewhat larger and more stately, in the lower level part of the park, the great Cedars contrast superbly 
with the great Oaks and Chestnuts. Some wise planter must have been here years ago to give us all this stateliness of tree life without torturing the sward with dots, or obscuring the view of sea and hill. Oak and Chestnut and Lime, fine in stature, are grouped like herds of great animals. Away on the hills is grove after grove of Fir and Beech, with here and there the dark plumes of the Yew, or the pale green of Box bushes showing themselves prettily outside

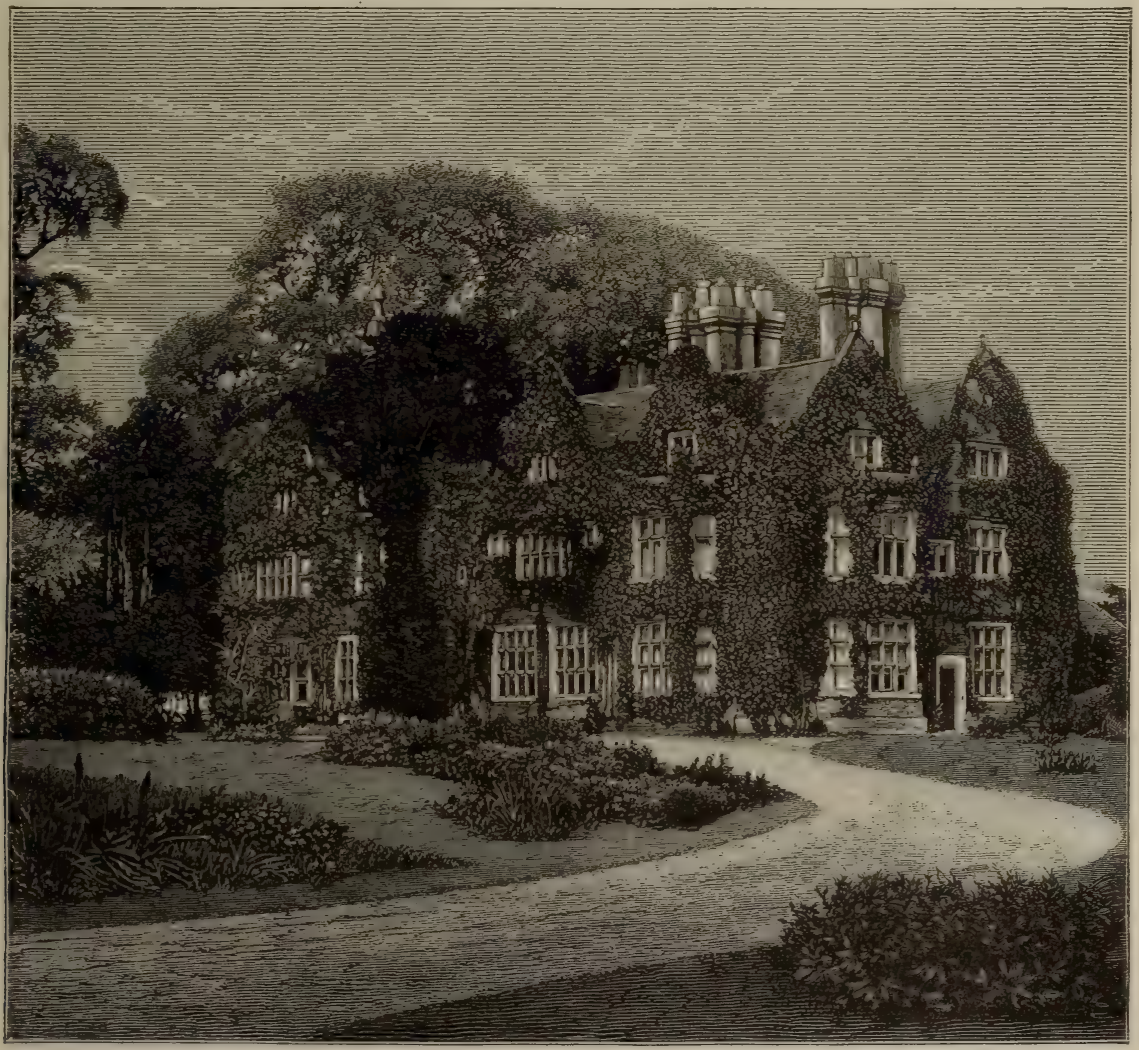

VIEW OF LAWN GARDEN AT PENDELL COURT : ELIZABETHAN. FLOWERS IN SIMPLE BEDS NEAR HOUSE.

the masses; while, standing clear out of the nearest downs, are the round tufts of trees of the down country. What would be lost by any contrivance to cut off the view of such a lawn and such noble trees from the windows of the principal rooms in the house! In many places such views of the house have been quite shut out by heavy terrace walls for which there was no reason whatever.

PENDEll COURT.-It will be seen here that even where it is desired to have the garden, or a portion of it, against the 
house, it is by no means necessary that the ground should be made "architectural." It is a great pleasure to see a beautiful old house, made to live in, with no impediment to keep one away from the door. There are three good views of it. First, that of the lawn in front of the house, which was a flowery meadow yet uncut, with no beds or other obstructions to the view of the house, and with a fine group of trees on either hand. It was a poem in building and in lawn. Quite on the other side a border of flowers

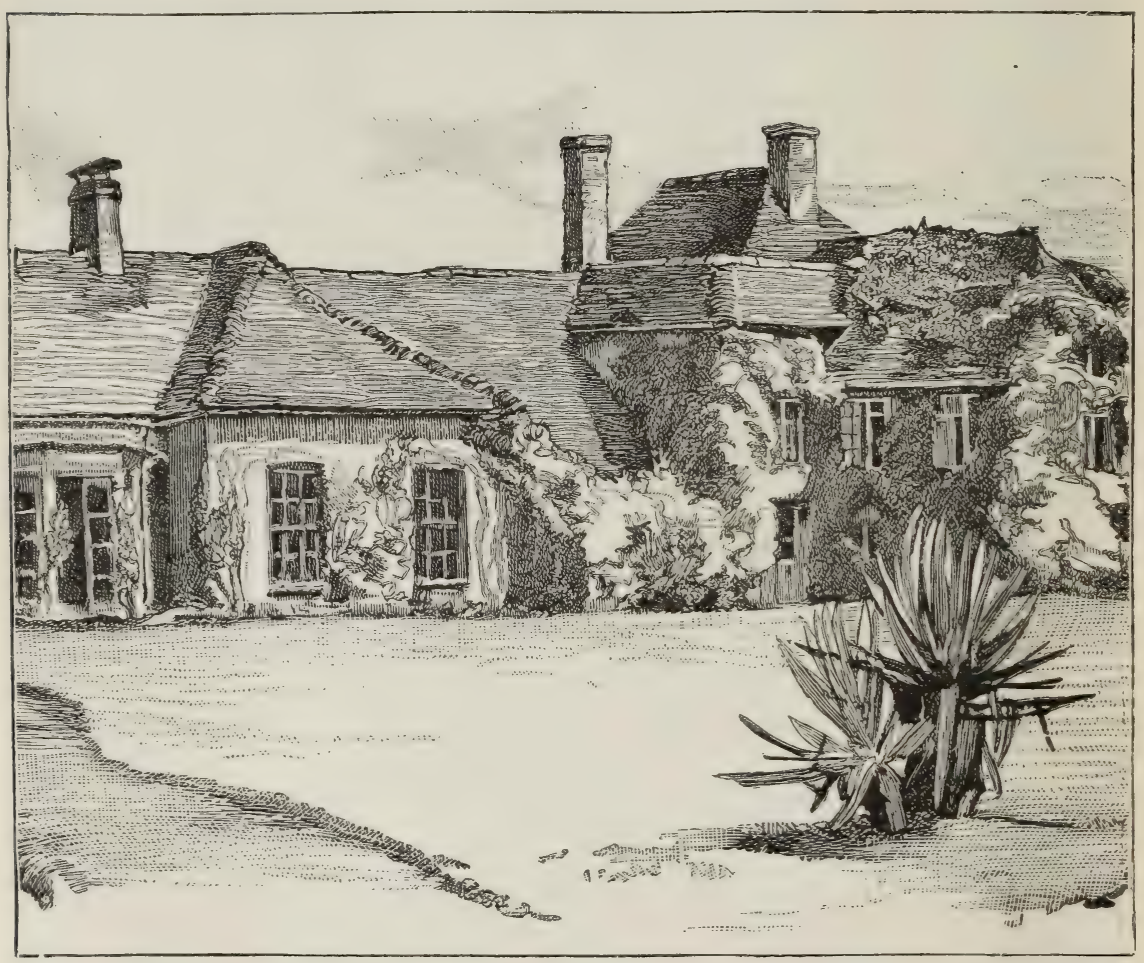

COTTAGE GARDEN AND LAWN, WITH FLOWERS MOSTLY ON THE OUTER FRINGES OF LAWN, IN BORDERS, AND AROUND BEDS OF PEAT SHRUBS. GILBERT WHITE'S GARDEN AT SELBORNE, SKETCHED BY A. PARSONS IN I88O.

and a wall of climbers ran from the house. Looking along this border to the house, a shower of white climbing Roses were seen falling from the wall, and a quaint gable and a few windows and glistening rich Ivy behind formed a lovely picture. Another view of the house from across the water, showing its west end, is also very beautiful. There is a Wild Rose bush on the right and a tuft of Flag leaves on the left; before you the water and its Lilies; then a smooth, gently-rising lawn creeping up to the windows, which on this side are all wreathed with white climbing Roses. All these 
views of the same house, although distinct, have none of the impediments which a false art frequently places so very near our houses - that is to say, formal patterns in beds, fountains, statues, and such objects, which destroy all repose. Frivolous patterns of beds, in the very place where the garden should be green and quiet, are a mistake in all cases. The view from the house to the left is also free and charming-a wide meadow climbing up the hill through groups of trees, and in the woody region reminding one a little of Alpine pastures.

RhIANVA.-We have not only to deal with ugly gardens, made in the wrong places, but with a false idea that all in formal gardens must be as "hard" as tin plate, and that they are not suited for our most beautiful and stately flowers. They are accordingly "bedded out" with dwarf plants, often clipped to make them dwarfer. But despite this almost invariable clipping one may here and there see a little of the. better way, and at Rhianva, in Anglesey, there is such an example, where the free growth of evergreens and climbers, and the delightful interlacements of hardy flowers, ferns, and creepers, make a garden bcautiful. Again, I remember the beautiful old garden at Ockham Park in Dr. Lushington's time, which was formal and yet beautiful, through the beauty of the vegetation. So again in Italy, where from the nature of the ground formal gardening is often a necessity, the stiffness of the stone is soon softened by the graceful forms of trees, shrubs, and trailers. Forty years ago the site of Rhianva, on the banks of the Menai Straits, was a steep field, with the large lumps of gray rock so characteristic of Anglesey, and was crossed by a small stream which lost itself in marshy ground by the shore. A couple of old Apple and Thorn trees and a little whitewashed cottage made up its features.

The garden at Rhianva was laid out by Sir J. H. Williams in I 850 and $\mathrm{I} 85 \mathrm{I}$. The quantity of rock and the extreme steepness of the ground made it difficult to deal with, and a number of supporting walls were built to form terraces; and, by the help of a protecting sea-wall, the flowers were carried down to the very edge of the water. Facing a little to the south-east, the garden was protected from the violence of the westerly gales, while the more tender plants were sheltered from the nipping east winds of spring by the larger shrubs and trees. The climate is mild in winter, and the garden being on a southern slope the trees and shrubs grew with great rapidity; hedges of red Fuchsias and of blue and pink Hydrangeas soon hid the stone walls. Myrtles and Camellias, and some Acacias, were found to do admirably out of doors; and at the present time the only difficulty is to prevent the shrubs from injuring each other, through their rapid growth in the 
limited space. In summer the luxuriant abundance of the Roses, climbing from bush to bush, the Cypresses, the Tamarisk and the Vines, and the water, and the purple mountains in the background, seem to belong rather to the Lake of Como than to the wilds of Wales. All the borders are mossed over with small green plants; large, hardy exotic Ferns are spread into groups; lacework of Ivy, Vine, and creepers is in many parts. A mixed order of planting is pursued, but in many cases the shrubs and plants are allowed to spread as they will, and the climbers take picturesque shapes. This is an example of the vast absurdity of the common notion that a terraced garden can only be properly dealt with as a stiff " beddedout" garden. We have here a terraced garden in a position that called for it-a rocky slope, in which the only way of making a garden was by terracing the ground. It is a precious example of a terraced garden that shelters every treasure of our garden flora, from the Cyclamen to the Tea Rose.

It has been said that, however valuable the more beautiful hardy flowers, their place is not the parterre, but some out-of-the-way spot. Not only may any terrace garden be embellished with hardy flowers, but it is the best place for them. The odd notion that our fairest flowers must not show themselves in the flower garden might lead one to suppose that there was nothing in the flower garden before bedding-out was invented. The ugliest formal garden may be planted in the most beautiful way with hardy flowers alone. Is it well to devote the flower beds to one type of vegetation onlyhardy or tender? What should we say of the gardener who filled his winter garden with low soft-wooded plants only, and omitted from his collection Camellia, Palm, and Heath? We have been so long accustomed to forming flat surfaces of colour in flower beds that no one ever thinks of the higher and better way of filling them. But it is worth considering whether it would not be right to fill the beds permanently rather than leave them naked in the usual way. In Nature vegetation in its most beautiful aspects is rarely a thing of one effect, but a union or mixing of different types of life-often succeeding each other in bloom. So it should be in the garden. The most beautiful effects must be obtained by combining different forms so as to aid each other, and give us a succession of pictures instead of monotony. If any place asks for permanent planting it is the precious spot of ground near the house; for no one can wish to see large, grave-like masses of soil frequently dug near the windows. It is easy to form beds that would look well in all seasons by the use of choice shrubs of many kinds-Spiræa, Rhododendron, Azalea, Dwarf Cypress, Japan Quince, Heath, Coronilla, Clematis, Aralia, Honeysuckle, Weigela, Sweet Brier, Vine, Hydrangea, Azara, 
Skimmia, Rock Rose, Tamarix, Daphne, Yucca, Tree Pæony, bushy St. John's Worts. Why should we not use a beautiful Andromeda, or a Kalmia, or a rare evergreen Barberry in the flower garden in the same way as a Camellia, an Acacia, or a Tree Fern in the winter garden?

There would be better culture in the shrubbery for, and more beauty from, our many choice hardy shrubs now so often neglected. The shrubs should be arranged in an open way, the opposite to the crowding common in our beds of American shrubs. In these all

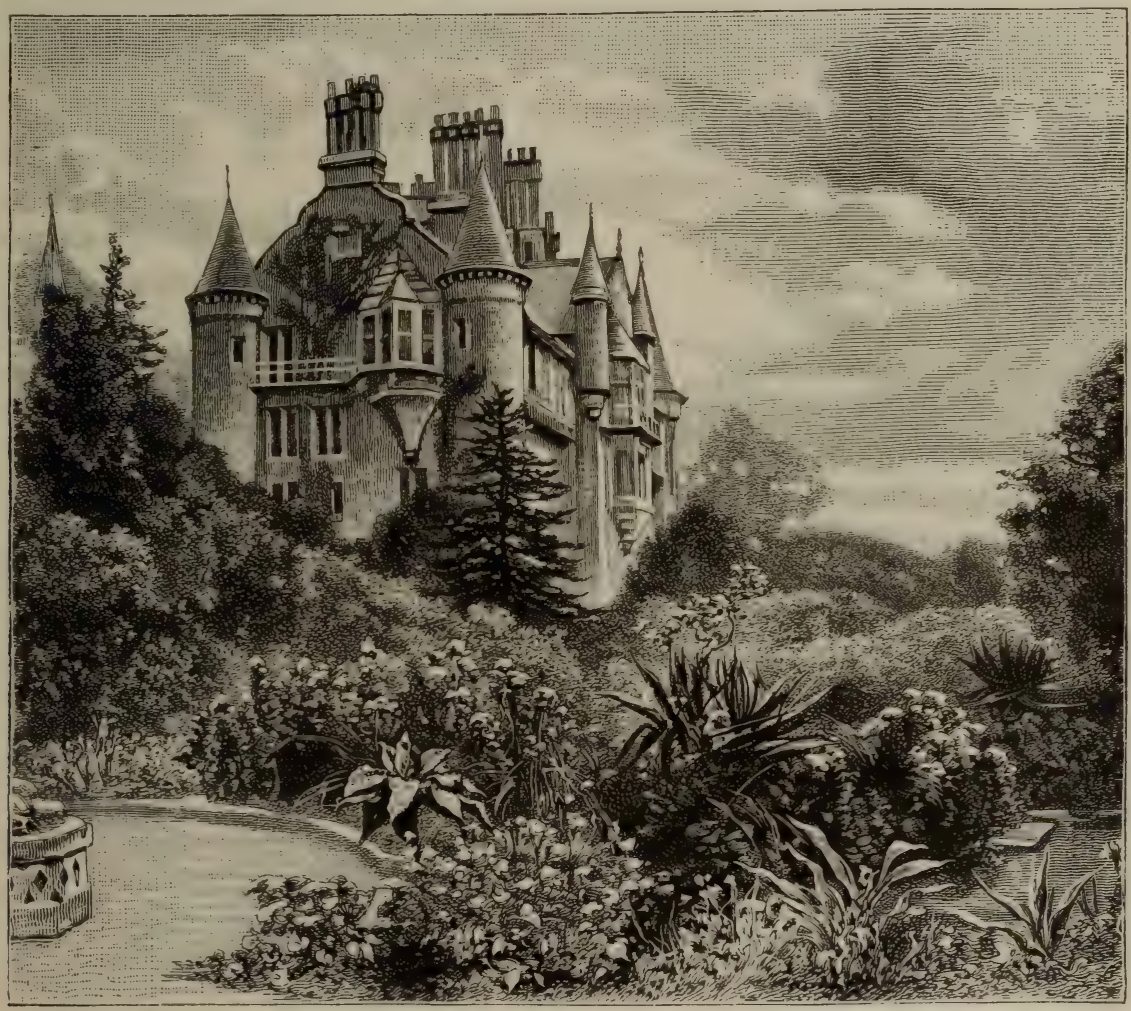

A TERRACED GARDEN With PICTURESQUe PLANTING. RHIANVA, ANGlesey.

individual character and form are crushed away in the crowd; yet there is scarcely a shrub that has not a charm of form it will show if allowed room. The plan is to allow no crowding, and to place the finest hardy flowers in groups between the free untortured shrubs. Thoroughly prepare the beds; put in the choicest shrubs, which, without obscuring the view, adorn the earth all the winter as well as all the summer, and give us a broken surface as well as a beautiful one. Between them allow for the planting of a variety of the choicer hardy flowers, which would come up and give us pictures 
following the seasons. So far from leading to monotony, this would lead to an infinite and varied succession of beauty.

We should not then have any set pattern to weary the eye, but quiet grace, and verdure, and little pictures, month by month. The beds, filled with shrubs, and garlanded with Ivy and other evergreens and creepers, would everywhere afford nooks and spaces among the shrubs where we could grow some of the many fine hardy Lilies

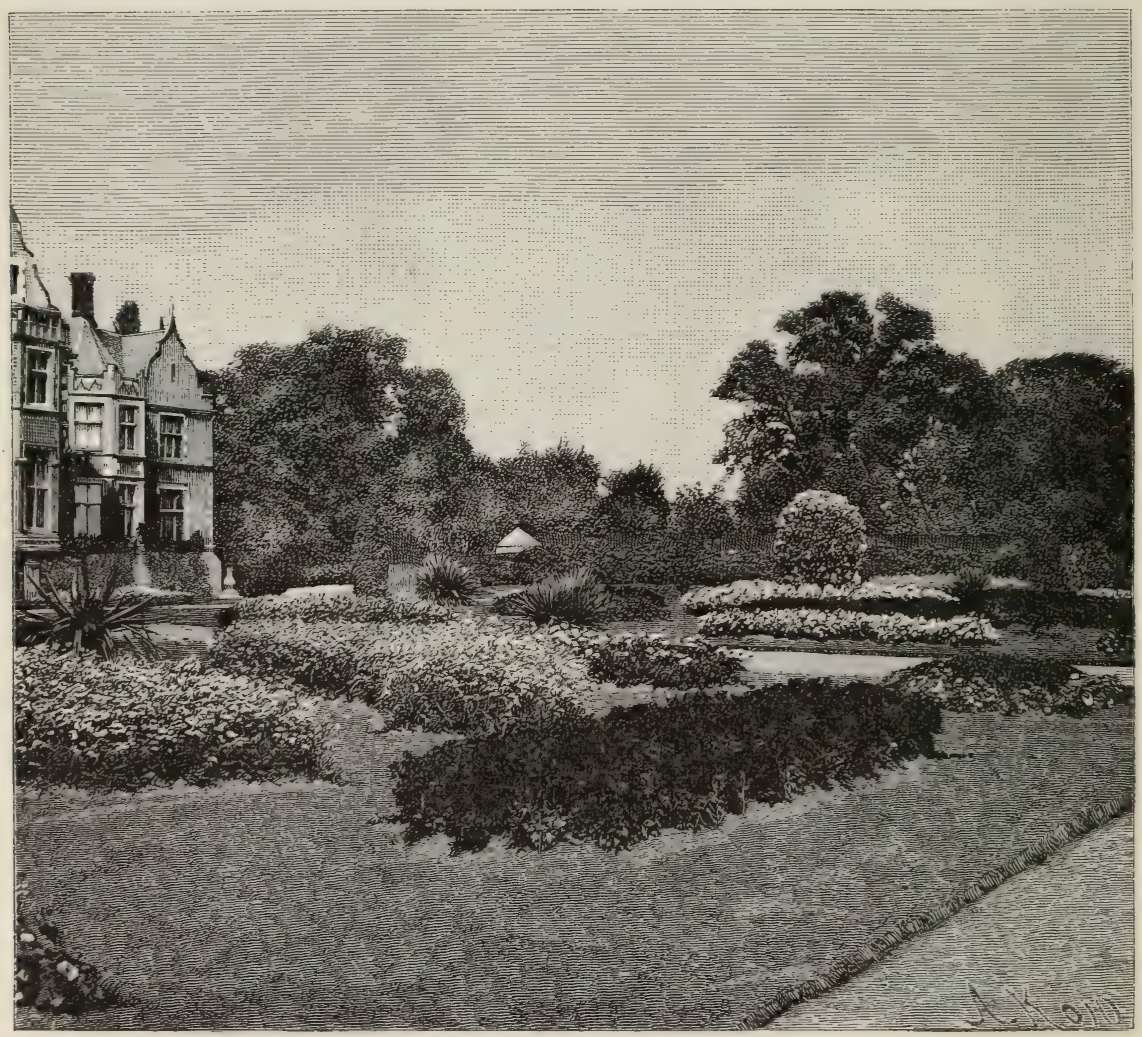

VIEW OF FLOWER GARDEN AT MADRESFIELD COURT.

with the Gladioli, Phlox, Pentstemon, Iris, tall Anemone, Pæony, and Delphinium. The choice shrubs suited for such beds are not gross feeders, like trees, but even encourage the finer hardy bulbs and flowers. They also relieve the plants by their bloom or foliage, and when a Lily or Cardinal Flower fades after blooming it is not noticed as it might be in a stiff border. Another important point is that we should not need the wretched plan of growing a number of low evergreens in pots, or otherwise, to "decorate" (!) the flower garden in winter. This is only one of various ways of adorning the flower 
garden in artistic and enduring ways, which I hope to show more of as we go on. It is spoken of here in connection with Rhianva, a precious example which shows us that the almost universal idea that a geometrical garden must be geometrically set with flowers is as false as it is usual.

To get artistic effects in such a flower garden we must not by any means adopt the close pattern beds usual, because no system allows of a good effect from beds crowded on each other like tarts on a pastrycook's tray. Repose and verdure are essential. Before making the change from the dwarf plants only, be they hardy or tender, it would be well to see that there is ample repose-room for the full expression of the beauty of each bed or groupno complication or crowding, no fanciful or angular beds. The contents of the beds and not the outlines are what we should see. In this way of planting with beautiful flowering summer or evergreen shrubs, with abundant space for flowers to grow between, we could have a permanent beauty in our terrace garden beds on the dullest day in winter. Between the bushes or evergreens we could have evergreen carpets of Alpine plants and tiny hill shrubs. Through these the autumn, winter, and spring flowering bulbs could peep to bloom, untarnished by the soil splashing of the ordinary border. Shelter, as well as the best culture, could be thus secured for many a fair flower, which, once well planted, would there come up year after year. Among the flowering shrubs we have many lovely Roses to help us with our plans. No one can refuse a place to the Rose in our formal garden. The Rose in its many forms is perhaps the greatest treasure of all, and, so disposed, its effect would be better than in any "Rosary"! We must get rid of the old collection of ugly sticks formally arranged as a Rose garden. The Rose should be planted in a natural manner, without formality, in simple, large, well-prepared beds, the plants trained as bushes or pegged down, so as to let their foliage and shoots spring from the ground. No Rose beds can be made in this way without offering positions for beautiful hardy plants. We may have many flowers beneath the Roses, or, like fair Lilies, to stand among them or above them.

GARDEN AT WEyBRIDGE.-We will now glance at another type of garden which will serve to show how much we lose by having only one ideal. No amount of money, no rich collections, good cultivation, large gardens, or expenditure of glass, will make up for the want of artistic taste such as we here see many signs of. A few acres of garden showing a real love of the beautiful are very rare, and are often the result of accident rather than design.

The garden of which I here give an engraving contains some 
most delightful bits of good gardening. Below the house, on the slope by the water of Oatlands Park, and below the lawn beds and trees, is a piece of heathy ground, a portion of which is shown. The ground is partially clad with common Heaths, through which run little irregular green paths. Abundantly naturalised in the warm

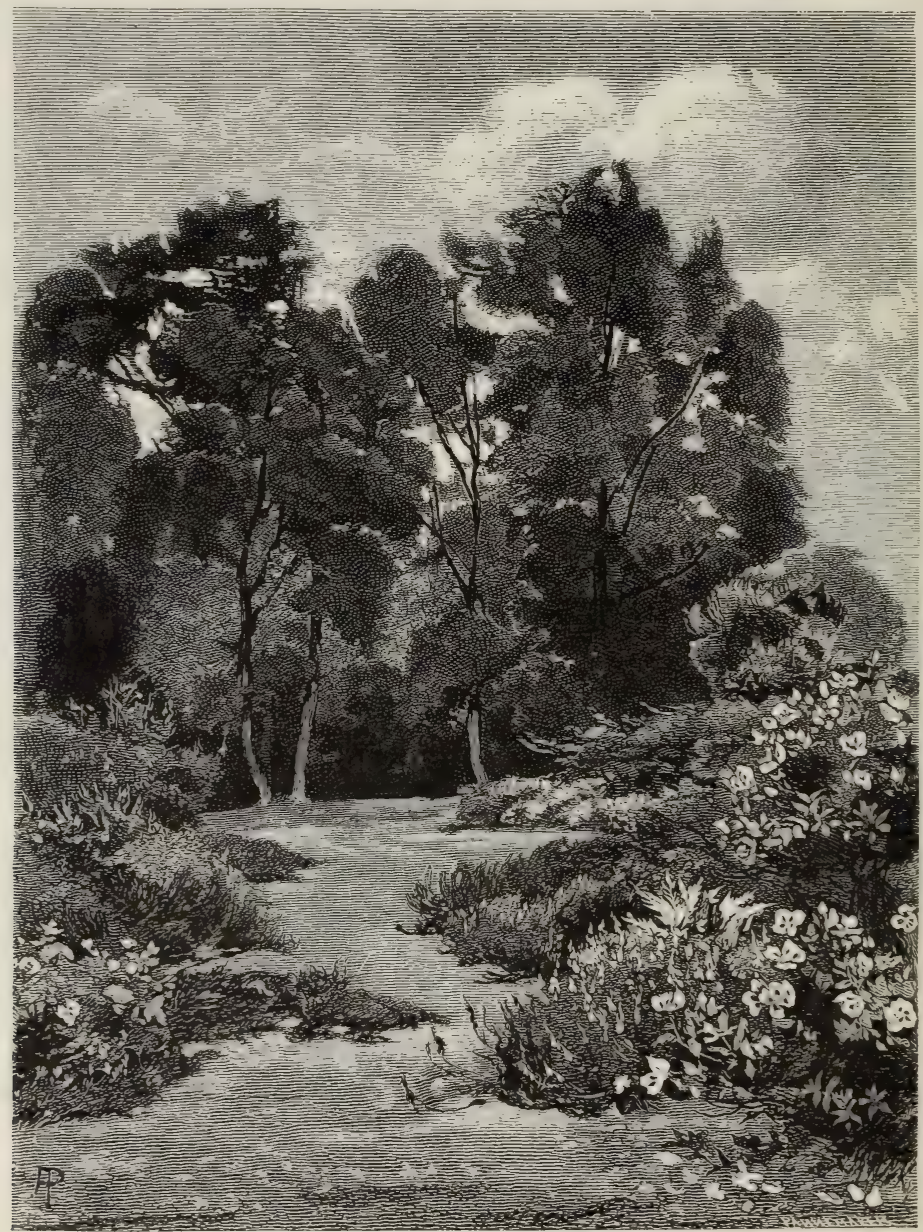

VIEW IN PICTURESQUE HEATH-GARDEN AT WEYBRIDGE.

sandy soil are the Sun Roses, shown in the foreground of the sketch. Here and there among the Heaths, creeping about in a perfectly natural fashion, too, is the Gentian-blue Gromwell, with other hardy plants suited to the soil. Among these naturalised groups are the large Evening Primroses and the yellow Peruvian Lily, the whole being well relieved by bold bushes of flowering shrubs, so well grouped as not to have the slightest trace of formality. Such plants 
as these are not set out singly and without preparation, but carefully planted in beds of such naturally irregular outline that, when the plants become established, they seem native children of the soil as much as the Bracken and Heath around. It is remarkable that all this is done without in the least taking from the most perfect order. Turf walks wind about among the Heaths and Sun Roses, while all trees that require care show by their health and size that they find all they require. This garden is freer from needless or offensive geometrical twirlings, barren expanse of gravelled surface, and all kinds of puerilities-old-fashioned and new-fangled-than any I have seen for years.

Sheen CotTAGE.-Sir Richard Owen's garden is one of the most charming and simple in the neighbourhood of London. Many a visitor to Richmond Park enjoys the look of his cottage, as it nestles on the margin of the sweep of undulating ground near the Sheen gate, but it is from the other or the garden side that the picture is best. A lawn, quite unbroken, stretches from near the windows to the boundary, and is fringed with numerous hardy trees. Here and there are masses of flowering shrubs and an odd bed of Lilies, while numerous hardy flowers are seen among the Roses and Rhododendrons. Quite near the house stands a noble specimen of the Honey Locust, graceful in foliage, and stately in the highest degree. Its long lower arms stretch far out on the turf, and are laden with fernlike leaves, and the whole tree is broken up in the boldest and most picturesque manner. No tree, except, perhaps, old specimens of the Weeping Beech, displays such variety of picturesque branching. There is in the main part of the garden only one walk, which takes one round the whole, and does not obtrude itself, as it glides behind the outside of the groups which fringe the sweet little open lawn. Instead of coming quite close to the house it is cut off from it by a deep border of evergreen shrubs, intermingled with Lilies and hardy flowers. These flowers look into the windows. Instead of looking out of the window, as usual, on a bare gravel walk, the eye is caught by Rhododendrons or Spiræas, with here and there a Lily, a Foxglove, or a tall Evening Primrose. From the other side of the garden the effect of the border is quite charming, and the creepercovered cottage seems to spring out of a bank of flowers. The placing of a wide border with Evergreens against the house is a pleasant change from the ordinary mode of laying out little gardens. Another agreeable feature of this garden is the grass walks, which ramble through a thick and shady plantation. Even in our coolest summers there is many a day on which such shady walks, carpeted with grass, are the most enjoyable retreats one can find. And their margins form capital situations for naturalising many beautiful 
hardy plants which are seen to great advantage in such positions, as, for example, Daffodils, hardy Ferns, Scillas, the Forget-me-not tribe, the Harebells, Snowdrops, and Snowflakes.

DRUMMOND CASTLE.-A house on a rock, graced with many Ferns and Ivy, and wild flowers natural to the spot. It would not be easy to find a more graceful example of " natural" rock gardening. It is only, however, on going to the south side of the house, where the ground falls rapidly and is supported by stately terrace walls, that all gloom is dispelled by the brightest array of blossoming climbers that ever clad gray stones with beauty. To fancy oneself in some fairyland of sun-bathed flowers a thousand miles south in a lap of the mountains would be easy. No Italian gardens could probably show the same high beauty at the same period of the year, whatever they might do earlier. The very coolness encourages and prolongs the bloom. The shelter of the terrace, with the house behind, helps many things; but, beyond training, there is little artificial help.

It is our privilege of growing so many plants from other countries that makes our open-air gardens so beautiful in the fall of the year: here, when the leaves begin to colour, and when even the Harebell is past its best on the banks, we have a very paradise of flowers. The fact that this fine plant beauty may be enjoyed by all who have a patch of ground and a wall is what makes it so precious a gift. The plants that here give most flowers are nearly all as easily grown as our common Honeysuckle.

Loveliest of all the climbers here is the Flame Nasturtium (Tropæolum speciosum), which drapes these stately walls, as it does those of many a cottage in Scotland. Admirable for walls as is this fragile and brilliant plant, it is seen to even greater advantage when a delicate shoot runs over a Yew-hedge, with its arrows of colour. Near it on the walls are many flowers of the older and once betterknown $\mathrm{T}$. pentaphyllum, which has a graceful habit and curious flowers, but lacks the brilliancy of colour of $T$. speciosum. It is, however, easily grown anywhere, while speciosum is established with some difficulty in our southern gardens. At least one other hardy Tropæolum should be added where the object is to have the climbing kinds, and that is the long-neglected $\mathrm{T}$. tuberosum, which is handsome in flower. The common, showy, climbing Nasturtiums of gardens grow high on the walls here, and add to the rich glow of colours. The whole of the Tropæolums are precious plants for our gardens, from the old and lovely Canary Creeper to the snake-like, sea-green T. polyphyllum, with its yellow blossoms, so admirable for banks or warm borders. Nothing could surpass the rich purple of the Clematis here-waves of colour, the flowers of enormous size. 
The cool hill air suits them admirably; but, as a rule, they are good throughout Britain. Still, we have never seen them show the largest flowers with profusion of bloom to such an extent elsewhere. One huge white variety (C. Anderson-Henryi) was a wonder to see, with its creamy white flowers a span across, crowding each other in the struggle for room and light, and forming a fine contrast with the purple kinds.

In the warm or temperate south, in Madeira or the Riviera, the

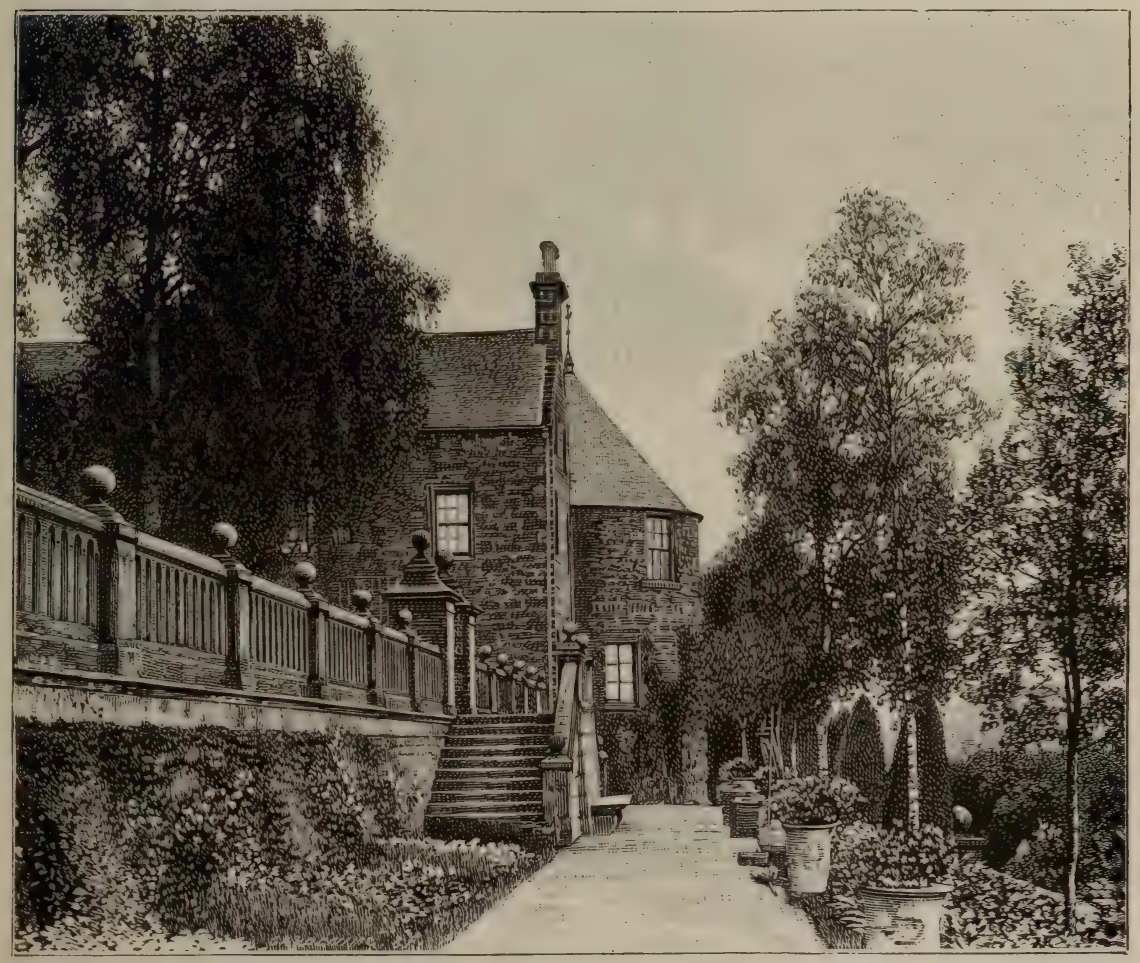

UPPER TERRACE AT DRUMMOND CASTLE, CRIEFF, PERTHSHIRE. GROUND BEING STEEP, TERRACES ARE NECESSARY.

garden lover sometimes makes himself a pretty hedge of Oak-leaved Geraniums ; but, as one does not see them in the South of England, it is a great surprise to see them happy on the walls here in Scotland, growing from four feet to seven feet high, with ample fresh foliage and many flowers. Their spicy fragrance and distinctly pretty foliage make them worth the trouble of storing in the winter, and placing in the open air in early summer. All the winter they are kept in the house in the grown or tall form on trellises, and being carefully trained against the warm wall, soon make fresh growth and 
flower freely; and are in good bloom late in September. Along with the Oak-leaved, the Iry-leaved Pelargoniums, both in the double and single forms, are here tall and in free bloom on the walls, and attain a height of four feet or so.

Large borders of the common river Forget-me-not remind us of its superiority to the wood and Alpine Forget-me-nots usually grown in gardens. It is charming in a peat or moist border, flowering long through summer and autumn. The charm of the place almost ceases with the terraces, for below them is one of those wonderful displays of "bedding out" in its cruder forms, which attains its greatest "glory" near large Scottish houses. Plants in squares, repeated by hundreds and thousands; walks from which all interest is taken by the planting on each side being of exactly the same pattern; and plants grouped as if for an oil-cloth pattern.

Steps and Terrace in the Old Park, Axminster.-This engraving is very instructive as regards the state of the English geometrical gardens. For many years past the rule in some of the most pretentious gardens of this sort has been to allow no regetation on the walls or balustrades. The older, the true and graceful way is to garland all such surfaces with beautiful life, and not to obliterate or make them less useful. Dividing lines and walls may do their work without being as bare as if in a stonemason's yard.

It cannot be too clearly known that the original idea of the terrace garden came from the sunny steep slopes of Italy and Greece. The rough terrace wall of the common cultivator, which kept the earth up and prevented it from being washed away, and gave a little depth on the stony hillside, became, in the garden of the wealthy man, the ornamental terrace. It was structurally right; it was necessary whether men gardened for pleasure or for profit. Well, these people having got their bits of ground level through terracing, it was the rule to have the terrace planted with beautiful thingsOlive-trees for profit and Cypress for shade. People in perfectly flat countries, however, got the dreadful idea that it is wrong to put flowers on the walls; and so we see terrace gardens where they are not wanted, and terrace walls perfectly bare of vegetation. If anybody will compare this picture with the common style of debased English planting of the terrace garden, where everything is clipped as close as a carpet and nothing is allowed on the walls, he will at once see a great difference.

The views in this chapter may give some idea of the many different sources of beauty in gardens, and help to show the error of making them all conform to one formal scheme. They will also show something of the great variety of positions in which beautiful flower gardens may be made. There is no one way! The garden 
should grow out of the spot and be characteristic of it, as the Alpine jewel flower is of the rock that bears it. Any way may be right that suits the place. All who care for flower gardens should see as

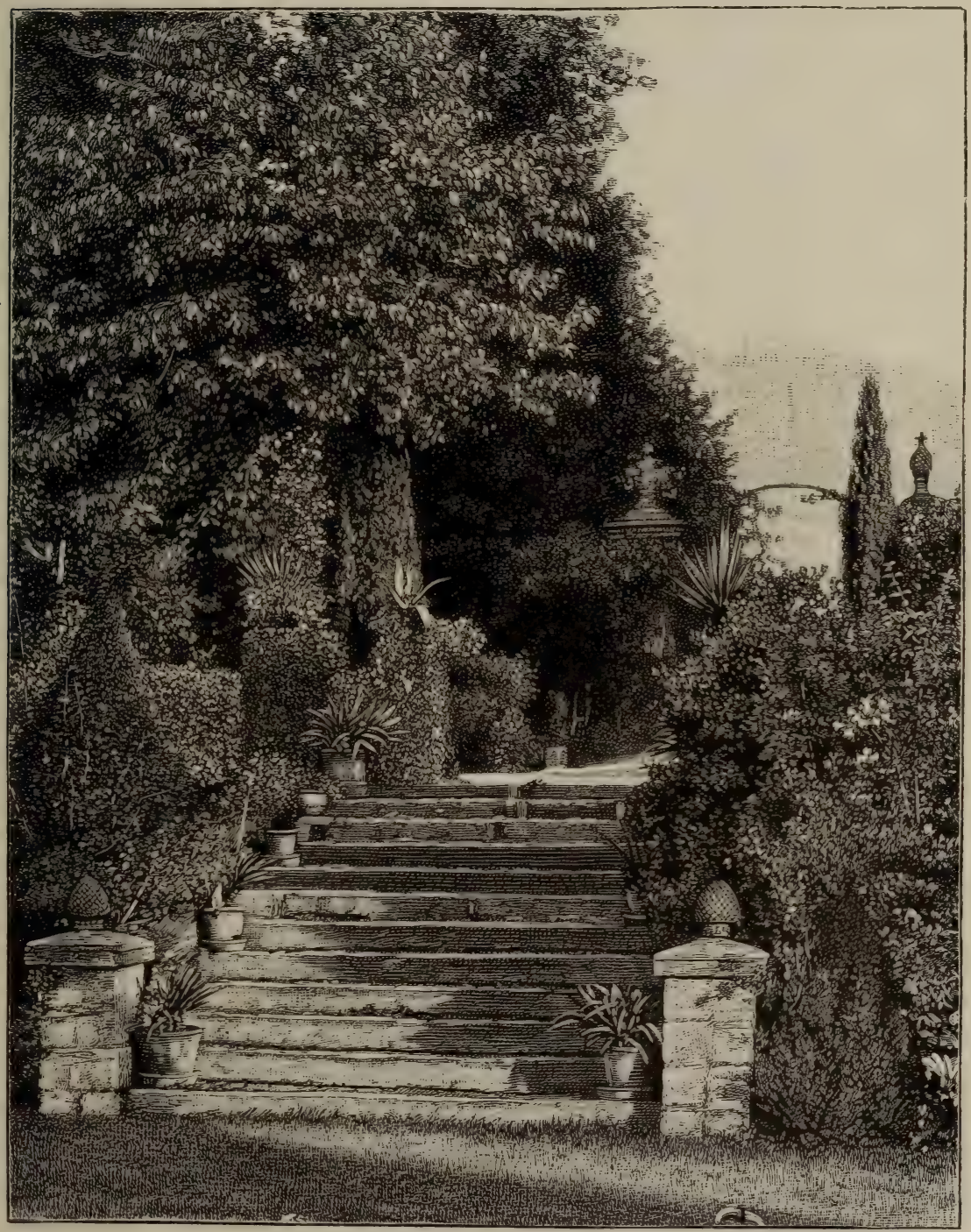

STEPS AND TERRACE, “THE OLD PARK," AXMINSTER. EXAMPLE OF TERRACE GARDEN NOT STIFFLY PLANTED, FROM A PHOTOGRAPH BY MISS DRYDEN, CANONS ASHBY, NORTHAMPTONSHIRE.

many diverse types of them as possible, and consider their sources of beauty and ugliness. Beware of old books on garden designmostly dreary quotations, or written by men who knew more of 
books than gardens. Beware also of public gardens, as they are often a long way behind the time, and in design often ugly-partly from the need of main walks and railings, etc. Many cottage gardens are charming and should always be looked at.

The aim should be never to rest till the garden is a reflex of Nature in her fairest moods. The great charm of the art of gardening over all other arts perhaps is that it gives us beautiful living things and not only representations of them. The Cedars on the lawn at Painshill and in the park at Goodwood are as precious and as real, happily, as those on Lebanon. The abounding life of things is one reason why it always seemed to me worth while rescuing the garden from its subjection to the mere decorator, who knows little or nothing of the life of a garden.

\section{VEgetable SCUlpture ${ }^{1}$}

A gentleman, unfortunately without knowledge of plants, trees, or landscape beauty, lately launched forth on a little raft of bladders into a dreary sea of quotations from old gardening books, and knew so little of where he was going that he was put out of his course by every little drift of wind. His aim is to decry, so far as he may, the natural and artistic revival in gardening : an architect, he is not satisfied with his own sphere, but wishes to teach us how to lay out our gardens.

$\mathrm{He}$ assumes that landscape gardeners all follow artistic and picturesque ways, and that only architects make terraces; whereas the greatest sinners in this respect have been landscape gardenersNesfield, Paxton, and many others. He has paid so little attention to the subject that he says that the landscape gardener's only notion is to put grass all around the house! It does not even occur to him that there may be grass on one side of a house and gardens of various sorts on the others, as at Goodwood, Shrubland, Knole, and that a house may have at each side a different kind of landscape.

He takes The English Flower Garden as the authority on landscape gardening practice; whereas the book, in all the parts that treat of design, is a protest against the formation by landscape gardeners and others of costly things which have nothing to do with gardening and nothing to do with true architecture.

Here is a specimen of Mr. Sedding's knowledge of the state of the subject:-

For the "landscape style" does not countenance a straight line, or terrace, or architectural form, or symmetrical beds about the house, for to allow these

${ }^{1}$ Garden Craft, Old and New. By John D. Sedding. London: Kegan Paul, Trench, Trübner, and Co. 
would not be to photograph Nature. As carried into practice, the style demands that the house shall rise abruptly from the Grass, and the general surface of the ground shall be characterised by smoothness and bareness (like Nature!).

If he had even taken the trouble to see a good garden laid out by Mr. Marnock, or anybody worthy of the name of landscape gardener, he would find that they knew the use of the terrace well. In my own gardens he would find beds quite as formal, but not so frivolous, as those described in the older books, and lines simple and straight as they can be. Where Barry left room for a dozen flowers at Shrubland I put one hundred: so much for the "bareness"! He has been carelessly reading about the matter and not really looking into it-too busy at his own work, no doubt.

On page I 80 the author says :-

I have no more scruple in using the scissors upon tree or shrub, where trimness is desirable, than $I$ have in mowing the turf of the lawn that once represented a virgin world. . . . And I would even introduce Bizarreries on the principle of not leaving all that is wild and odd to Nature outside of the garden paling; and in the formal part of the garden my Yews should take the shape of pyramids, or peacocks, or cocked hats, or ramping lions in Lincoln Green, or any other conceit I had a mind to, which vegetable sculpture can take.

After reading this I had a vision of true "vegetable sculpture"; of Reed and Lily, a "model" for ever in stem, leaf, and bloom; of the gray Willows of Britain, sometimes lovelier than Olives against our skies; of many-columned Oak groves set in seas of Primroses, Cuckoo flowers, and Violets; of the Silver Birch woods of Northern Europe beyond all grace possible in stone; of the eternal garland of beauty that one kind of Palm waves for hundreds of miles between the desert and the Nile; of the noble Pine woods of California and Oregon, like fleets of colossal masts on mountain waves, - of these and many other lovely forms in garden and woodland, and then wondered that any one could be so blind to the beauty of plant and tree as to write as this author does here.

From the days of the Greeks to our own time, the delight of all great artists has been to get as near this divine beauty of living things as the material they work in permits. But this deplorable "vegetable sculptor's" pleasure is in distorting beautiful natural forms; and this in the garden in which we have the rare privilege of enjoying the living things themselves, and not merely representations of them as in other arts. 


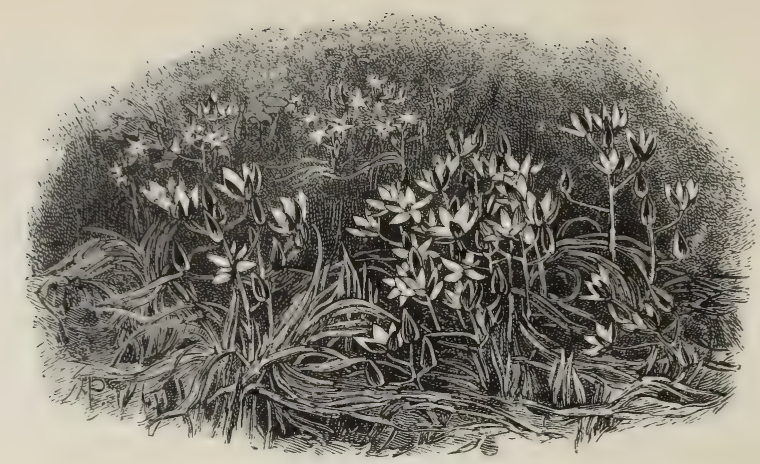

STAR OF BETHLEHEM IN GRASS.

\section{CHAPTER II}

\section{THE WILD GARDEN, OR THE NATURALISATION OF HARDY} EXOTIC FLOWERS

O universal Mother, who dost keep

From everlasting thy foundations deep,

Eldest of things, Great Earth, I sing of thee.

IN a rational system of flower-gardening the first thing to do is to get a clear idea of the aim and scope of the "Wild Garden." When I began, some years ago, to plead the cause of the innumerable hardy flowers against the few tender ones, put out in a formal way, the answer frequently was, "We cannot go back to the mixed border" - that is to say, to the old way of arranging flowers in borders. Knowing, then, a little of the vast world of plant beauty quite shut out of our gardens by the "system" then in vogue, I was led to consider the ways in which it might be introduced into them; and, among various ideas that then occurred to me, was that of the "Wild Garden." I was led to think of the numbers of beautiful hardy plants from other countries which might be naturalised, with very little trouble, in many situations in our gardens, fields, and woods - a world of delightful plant beauty that we might make happy around us, in places now bare or useless. I saw that we could grow thus not only flowers a thousandfold more lovely than those commonly seen in what is called the flower garden, but also many which, by any other plan, we should have no chance whatever of seeing around us.

There has been some misunderstanding as to the term "Wild Garden." It is applied to the placing of perfectly hardy exotic plants in places where they will take care of themselves. It has 
nothing to do with the "wilderness," though it may be carried out in connection with that. It does not necessarily mean the picturesque garden, for a garden may be picturesque, and yet in every part the result of ceaseless care. What it does mean is best explained by the winter Aconite flowering under a grove of naked trees in February; by the Snowflake growing abundantly in meadows by the Thames sides; and by the Apennine Anemone staining an English

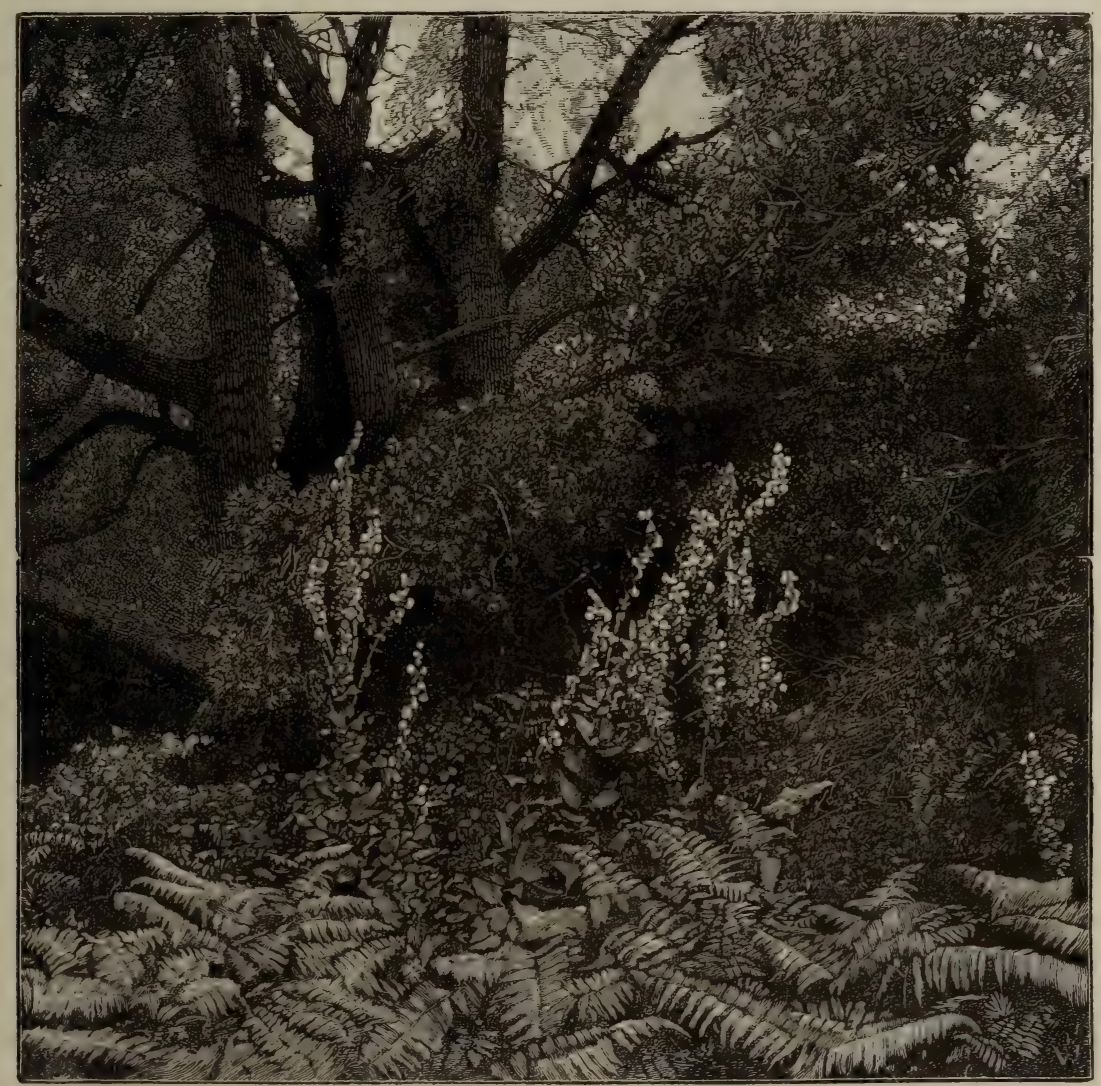

GROUP OF MULLEIN, NEAR SCOTCH FIRS, IN SURREY HEATH.

wood blue. Multiply these instances a thousandfold, add many different types of plants and hardy climbers from countries as cold as our own, or colder, and one may get a just idea of the wild garden. Some have thought of it as a garden allowed to run wild, or with annuals sown promiscuously, whereas it does not meddle with the garden proper at all, except in attempting the adornment of bare shrubbery borders in the London parks and elsewhere-waste spaces, not gardens. 
I wish the idea to be kept distinct from the various important phases of hardy plant growth in groups, beds, and borders, in which good culture may produce many happy effects; from the rock garden or borders reserved for choice hardy flowers; from the best phase of the sub-tropical garden-that of growing hardy plants of fine form ; from the ordinary type of spring garden ; and from the gardens of our own beautiful native flowers in our woods and wilds. How far in the smaller class of gardens the wild garden may be carried out as an aid to, or in connection with, any of these can be best decided on the spot. In the larger gardens, where there is often ample room on the outer fringes of the lawn, in grove, park,

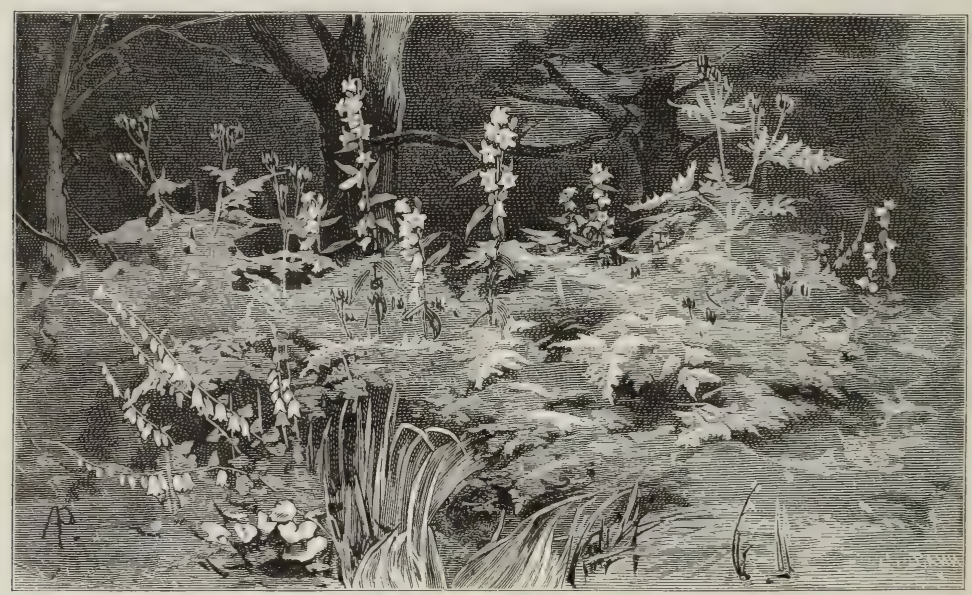

A Beautiful accident. A COlONy OF SWEet-Cicely in SHRUbBery, WITH WHITE HAREBELLS.

copse, or by woodland walks or drives, fair gardens and new and beautiful effects may be created by its means.

About a generation ago there began to be manifested a taste for placing a number of tender plants in the open air in summer, with a view to the production of showy masses of decided colour. The subjects selected were mostly from sub-tropical climates, placed annually in the open air, and in fresh rich earth; they grew rapidly and flowered during the summer and the early autumn months, and until cut down by the first frosts. This plan was called the "bedding" system. Its showy colour was attractive, and since its introduction there has been a gradual rooting out of all the old favourites. It was carried to such an extreme that it was common to find large gardens without a single hardy flower, all expense being devoted to a few exotics for summer decoration. It should be borne in mind that the expense of this system is an annual one; that no matter 
how much money may be spent, nor how many years devoted to perfecting it, the first sharp frost of November announces further expense and labour, usually heavier than the preceding.

Its highest results need hardly be described-they are seen in all our great public gardens; our London and many other city parks show them in the shape of showy beds filled with vast numbers of flowers covering the ground, while nearly every private garden is taken possession of in the same way. As to the merits of the system it is enough to state that even on its votaries it is beginning to pall. Some are looking back with regret to the old mixed border gardens; others are endeavouring to soften the harshness of the "system" by the introduction of fine-leaved plants; but while all are agreed that it was a great mistake to destroy all our old flowers, few have any idea of the numbers of beautiful subjects which, under a more artistic system, we might gather from every northern and temperate clime to adorn our gardens.

We might have more of the varied beauty of hardy flowers than the most ardent admirer of the old style ever dreamt of, by naturalising beautiful plants of many regions of the earth in our woods and copses, in the rough parts of pleasure-grounds and in the meadows.

I allude not to the hardy flowers of any one country, but to those which have their home in the vast fields of the whole northern world, and to those of the hill-ground that falls in furrowed folds from the great mountains, whether they rise from hot Indian plains or green European pastures. The Palm and sacred Fig, as well as the Wheat and the Vine, are separated from the stemless plants that cushion under the snow for half the year by a zone of hardier and not less beautiful life, varied as the breezes that whisper on the mountain sides, and as the rills that seam them. They are the Lilies, Bluebells, Foxgloves, Irises, Windflowers, Columbines, Rockroses, Violets, Cranesbills, countless Peaflowers, mountain Avens, Brambles, Cinquefoils, Evening Primroses, Clematis, Honeysuckles, Michaelmas Daisies, Wood Hyacinths, Daffodils, Bindweeds, Forgetme-nots, blue-eyed Omphalodes, Primroses, Day Lilies, Asphodels, St. Bruno's Lilies, and the innumerable plants which form the flora of the northern and temperate portions of Europe, Asia, and America. It is beyond the power of pen or pencil to picture the beauty of these plants. In the wilder parts of all northern and temperate regions, innumerable pictures made up of these plants occur at different elevations; the essential thing to bear in mind is that the plants that go to form them are hardy, and will thrive in our climate as well as native plants.

Such beauty may be realised in every wood, copse, or shrubbery that screens our "trim gardens." Our woods and wilds have naturally 
no little loveliness in spring; we have here and there the Lily-ofthe-valley and the Snowdrop, and everywhere the Primrose and Corslip; while the Bluebell and the Foxglove sometimes take nearly complete possession of whole woods; but, with all our treasures, we have no such attractions in or near our gardens as it is within our power to create. Many countries with winters as cold as our own, or colder, possess a rich flora; and by taking the best hardy exotics, and establishing them in wild or half-wild spots, we may produce beautiful pictures.

Among reasons for advocating this system are the following:I. Because hundreds of the finest hardy flowers will thrive much better in rough and wild places than ever they did in the oldfashioned border. Even comparatively small ones, like the beautiful Ivy-leaved Cyclamen, are perfectly naturalised and spread all over the mossy surface of woods. 2. Because, in consequence of plant, fern and flower and climber, grass and trailing shrub, relieving each other in delightful ways, they will look infinitely better than in gardens. 3. Because no ugly effects will result from decay and the swift passage of the seasons. After the first flush of spring and early summer bloom had passed, the raggedness of the old mixed border with its bundles of decayed stems tied to sticks was intolerable. When Lilies are sparsely dotted through masses of shrubs their flowers are far prettier than if they were in isolated showy masses; and when they pass out of bloom they are not eyesores, like rigid unrelieved tufts in borders. In a semi-wild state the beauty of individual species will proclaim itself when at its height; and when out of bloom they will be succeeded by other kinds, or lost among the numerous objects around. 4. Because it will enable us to grow many plants that have never yet obtained a place in our "trim gardens"-multitudes that are not showy enough to be considered worthy of a place in a garden. An isolated tuft may indeed be unsuitable to a formal border, but when the plants are grouped naturally in some glade, or wood, or little colony, the effect may be charming. Among the plants usually considered unfit for garden cultivation are a goodly number that, grown in gardens, are no addition to them-like the coarser American Asters, Golden Rods, and such plants, which overrun the choicer border-flowers when planted among them. Such plants would be quite at home in copses and woody places, where their blossoms might be seen in due season, and their vigorous vegetation form a covert welcome to the game preserver. To these might be added plants like the winter Heliotrope, and many others, which, while interesting in the garden, are apt to spread so rapidly as to become a nuisance. 5. Because in this way we may settle the question of spring flowers, 
and the spring garden, as well as that of hardy flowers generally; and many parts of the garden may be made alive with spring flowers, without in the least interfering with the geometrical beds that have been the stock-in-trade of the so-called landscape gardener for centuries. The blue stars of the Apennine Anemone will be seen to greater advantage when "wild" in shady or half-shady bare places, under trees, or in the meadow grass, than in any conceivable formal arrangement, and this is but one of hundreds of sweet spring flowers that will succeed perfectly in like ways. 6. Because there can be few more agreeable phases of communion with Nature than naturalising the native plants of countries in which we are more interested than in those from whence come our hothouse plants. From the Roman ruin-home of many flowers; from the prairies of the New World; from the woods and meadows of all the great mountains of Europe; from Greece and Italy; from the sunny hills of Asia Minor; from the Alpine regions of the great continents-in a word, from almost every interesting region in the world the traveller may bring seeds or plants, and establish near his home the pleasantest souvenirs of the various scenes he has visited.

Moreover, the merit of permanence belongs to this delightful phase of gardening. Select a rough slope, and embellish it with the hardiest climbing plants-say the mountain Clematis from Nepal, the sweet C. Flammula from Southern Europe, "Virginian creepers" in variety, the Nootka Bramble (Rubus nutkanus and R. odoratus), and various species of hardy Vines, Jasmines, Honeysuckles, and Wild Roses. Arranged with judgment, such a colony might be left to take care of itself; time would but add to its attractions.

To see what may be done in the wild garden with one class of flowers, let us consider hardy bulbs and other plants like the Winter Aconite and the Bloodroot (Sanguinaria), which die down after flowering early. How few get beyond the miserable conventionalities of the flower garden, with its edgings and patchings - get beyond taking up and drying our beautiful Spring Bulbs! The little we do leads to such a very poor result that numbers of people, alive to the real charms of a garden, scarcely notice Spring Bulbs at all, regarding them as things requiring endless trouble, and interfering with the "bedding-out." This is likely to be the case as long as they do not use the most simple of all modes of arranging them - the placing of them in wild and semi-wild parts of woods and shrubberies, and in the rougher parts of a garden, no matter where it may be situated or how it may be arranged.

Look, for instance, at the wide and bare belts of grass that wind in and around the shrubberies in nearly every country place; they are merely places to be roughly mown now and then. But if planted 
here and there with the Snowdrop, the blue Anemone, the Crocus, with Scillas, and other early flowers, they would in spring surpass the gayest of spring gardens. Cushioned among the grass, the flowers would have a more congenial medium in which to unfold than the beaten earth of a border; in the grass of spring, their natural bed, they would look far better than if "arranged" on the prim border.

Their leaves die down so early in spring that they would scarcely interfere with the mowing of the grass, if that were desired, but I should not attempt to mow such places till the season of spring flowers had quite passed by. Surely it is enough to have one portion of lawn as smooth as a carpet at all times, without

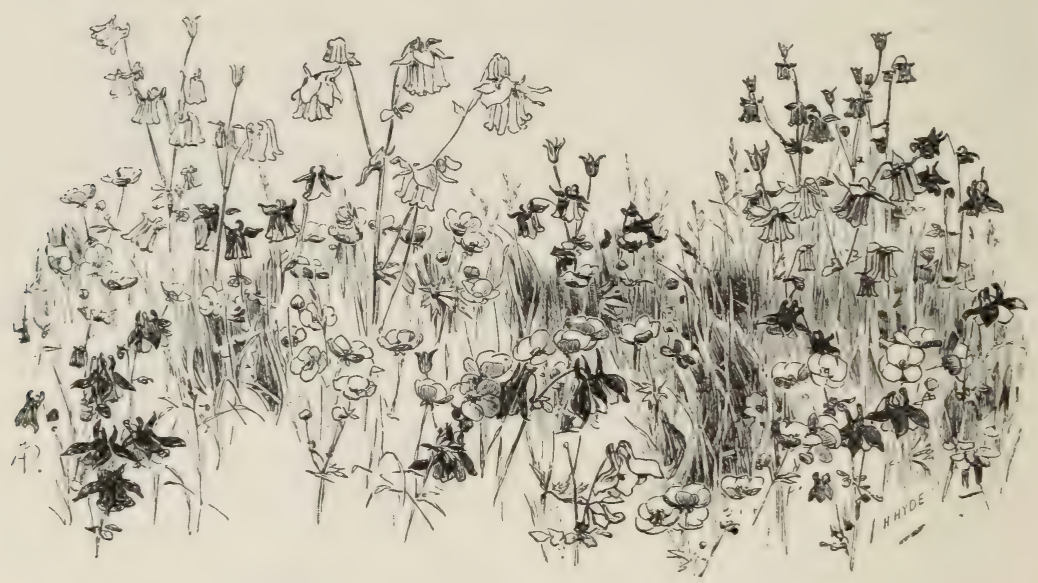

COLUMBINES AND GERANIUMS IN MEADOW GRASS.

sending the mower to shave the "long and pleasant grass" of the other parts of the grounds. It would indeed be worth while to leave many parts unmown for the sake of growing many beautiful plants. If some spot be selected where a wide fringe of grass spreads out in the bay of a shrubbery or plantation, and upon this carpet of rising and unshaven verdure there be dotted, in addition to the few pretty wild flowers that happen to take possession of it, the blue Apennine Anemone, the Snowflake, Crocuses in variety, Scillas, Grape-Hyacinths, earlier and smaller Narcissi, the Wood Anemone, and any other pretty spring flowers that are suitable to the soil and position, we shall have a glimpse of the vernal beauty of temperate and northern climes; every flower relieved by grass blades and green leaves, everything varied, indefinite, and changeful, and wholly devoid of any trace of man, and of his exceeding weakness for tracing wall-paper patterns. In such a garden it would be 
evident that the artist had caught the true meaning of Nature in her arrangement of vegetation, not sacrificing one jot of anything of value, but giving beauty to spots previously devoid of interest. Mowing the grass in pleasure-grounds once a fortnight, as now practised, is a great and costly mistake. There are indeed gardens where they boast of mowing forty acres! Who would not rather see the waving grass with countless flowers than a close-shaven surface without a blossom? Imagine the labour wasted in this ridiculous plan of cutting the heads off flowers and grass. Let the grass grow till fit to cut for hay, and we may enjoy in it a world of lovely flowers that will blossom and perfect their growth before the grass has to be mown. Several persons who have carried out the ideas here expressed have waving lawns of feathery grass where they used to shave the grass every ten days, a prairie of flowers where a daisy was not allowed to peep, and some addition to their hay crop, as they allow the grass to grow till hay time.

It is not only to shrubberies, and plantations, and belts of grass in the rougher parts of the pleasure-ground, and shady mossbordered wood walks, that these remarks apply. The suburban garden, with its single fringe of planting, may show like beauty. It may have the Solomon's Seal arching forth from a shady recess, behind tufts of the sweet-scented Narcissus; and wild fringes of strong and hardy flowers in the spring sun, flowers which cannot be cut off by harsh winds as when exposed in the open garden. Rough banks in or near the pleasure-ground or flower garden, at present perhaps containing nothing but weeds, and any rough or unused spot about the garden-such are the places for them. Even where all the lawn must be mown, the Snowdrop may be enjoyed in early spring, for its leaves die down, or, at all events, ripen sufficiently, before there is any occasion to mow the grass.

But the prettiest results are attainable only where the grass need not be cut till the meadows are mown. Then we may have gardens of Narcissi, such as no one ever thought possible in Britain. In grass not mown at all we may even enjoy many of the Lilies, and many of the lovelier and more stately bulbous flowers of the meadows and mountain lawns of Europe, Asia, and America. Copses and woods offer still better situations, as in these there is no destruction of the foliage by harrow, roller, or mower.

On a stretch of good grass which need not be mown, and on fairly good soil in any part of our country, we may enjoy such beauty as has hitherto only gladdened the heart of the wanderer on the high mountain lawns and copses in early summer, when the hill flowers bloom in multitudes in the Alpine grass.

All planting in the grass should be in natural groups or prettily- 
fringed colonies, growing to and fro as they like after planting. Lessons in this grouping are to be had in the woods, copses, heaths,

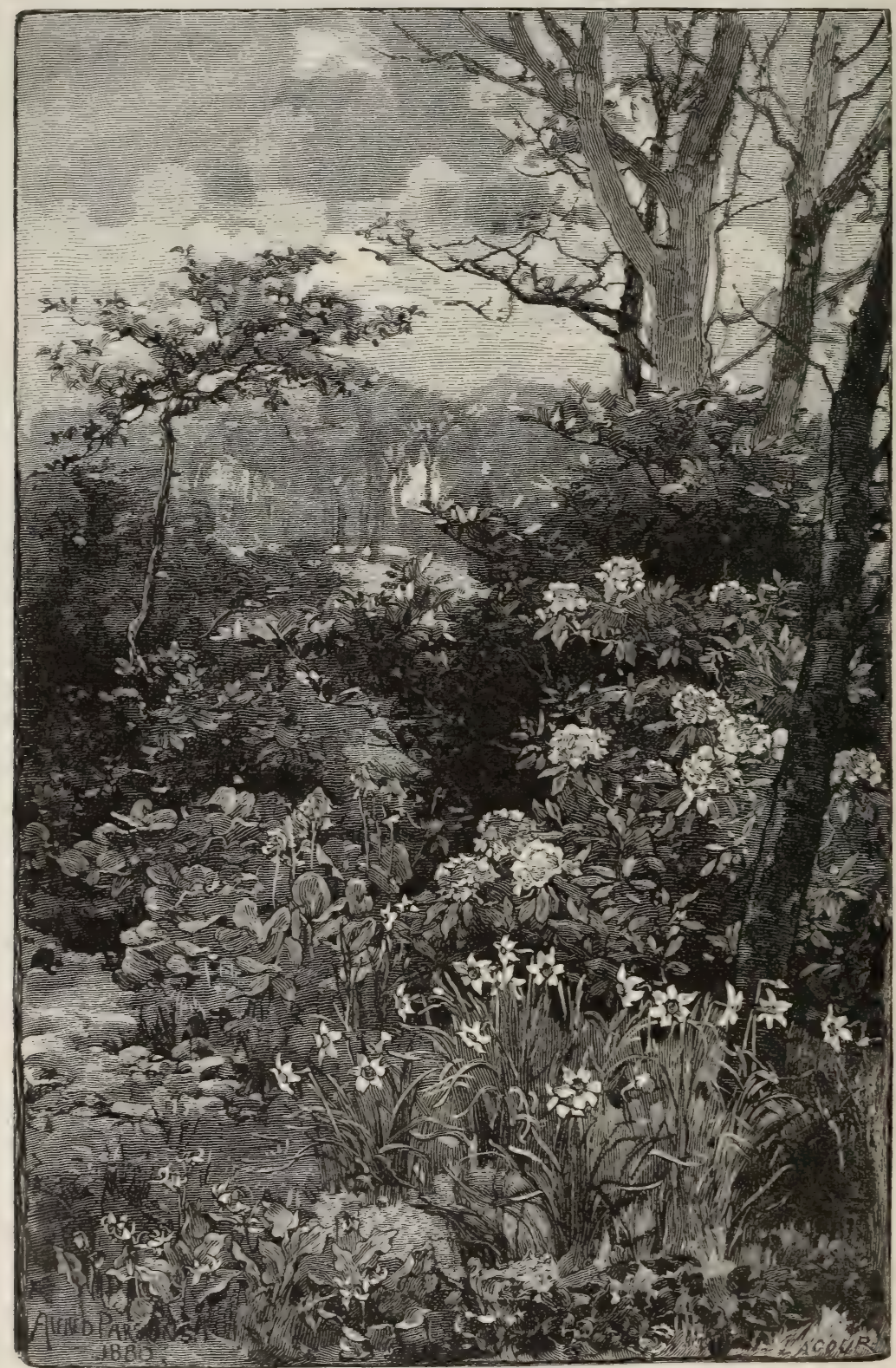

POET S NARCISSLS AND LARGE ROCKFOILS IN OPEN SHRLBBERY.

and meadows, by those who look about them as they go. At first many will find it difficult to get out of formal masses, but they may 
be got over by studying natural groupings of wild flowers. Once established, the plants soon begin to group themselves in pretty ways.

What first suggested to me the idea of the wild garden, and even

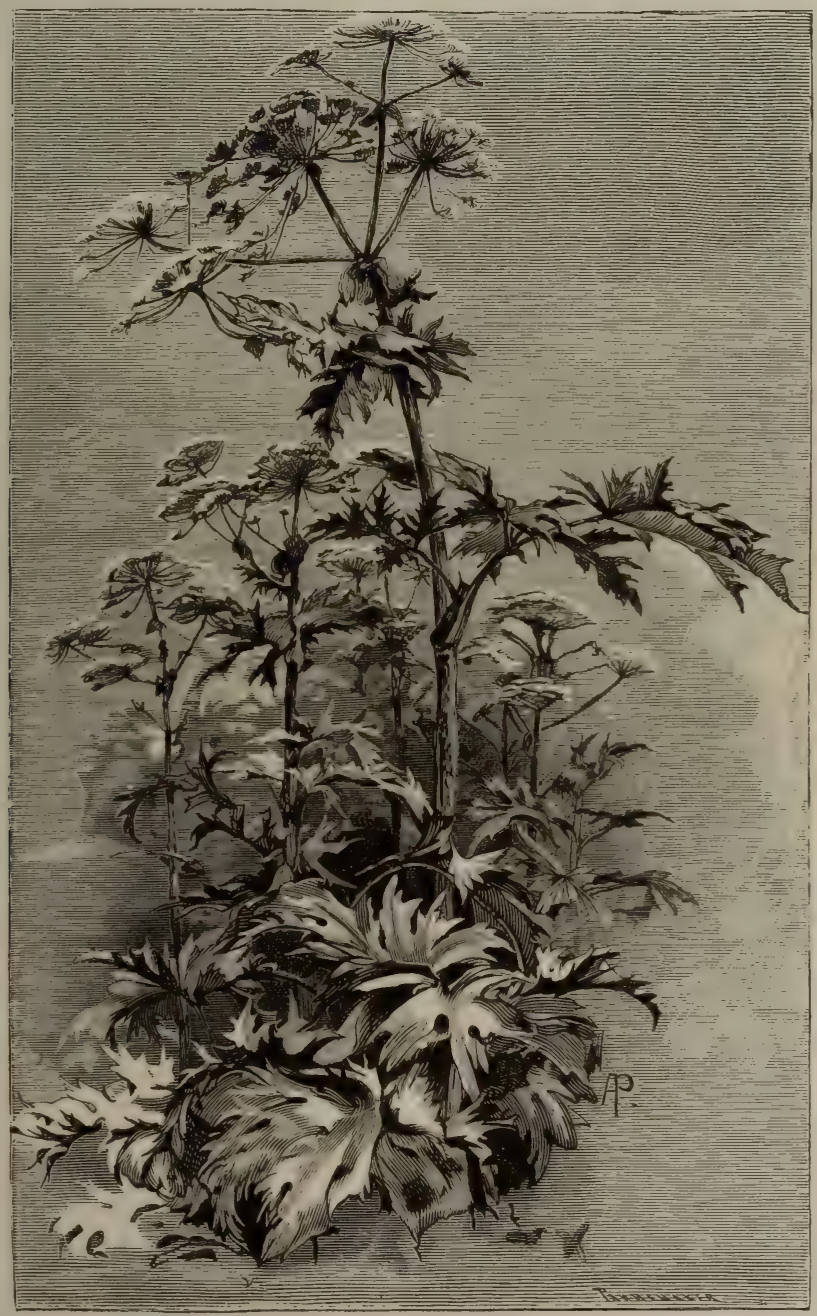

GIANT COW PARSNIP. TYPE OF GREAT SIBERIAN HERBACEOUS VEGETATION. CHIEFLY FITTED FOR THE WILD GARDEN.

the name of it, was the desire to provide a home for a great number of exotic plants that are unfitted for garden culture in the old sense. Many of these plants have great beauty when in flower, and perhaps at other seasons, but are frequently so free and vigorous in growth that they overrun and destroy all their more delicate neighbours. 
Many, too, are so coarse that they are ugly in choice borders, and after flowering they leave a blank or a mass of unsightly stems. These plants are often a cause of the neglect of hardy flowers; yet

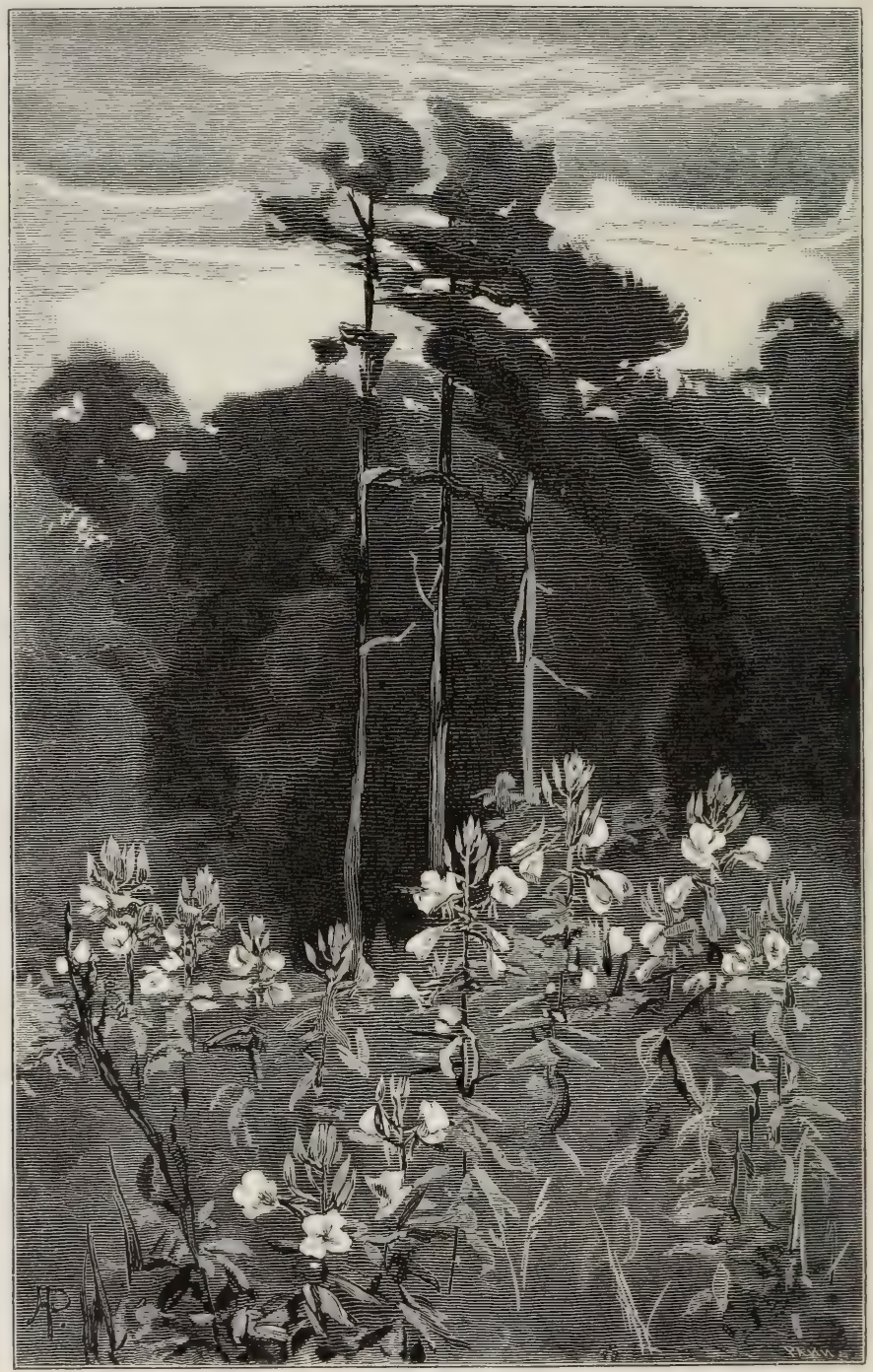

NIGHT EFFECT OF EVENING PRIMROSE IN THE WILD GARDEN.

many are beautiful at certain stages. A tall Harebell stiffly tied up in a garden border is not pretty, but the same plant growing among the long grass in a thin wood is lovely; the Golden Rods and Michaelmas Daisies used to overrun and ruin the old mixed border, but even the poorest of these seen together in a New England wood 
in autumn form a picture. When I first wrote on the "Wild Garden " not one of these plants was in cultivation outside botanic gardens ; and even the best friends of hardy flowers considered it a mistake to recommend one of them, for they knew that the predominance of these weedy vigorous subjects had made people give up hardy flowers for the sake of the glare of bedding plants. In the wild garden every plant vigorous enough to do without the cultivator, or without a choice place in the mixed border, will find a home. In every northern and mountainous country there are numbers of such plants, which travellers may gather and afterwards grow in their own gardens.

Where the branches of trees, both evergreen and summer-leafing, sweep the turf-and this, as a rule, they should be allowed to do when they are planted in ornamental grounds - a great number of pretty spring-flowering bulbs may be naturalised beneath the branches, and will thrive without attention. It is chiefly in the case of deciduous trees that this can be done; but even in the case of Conifers and Evergreens some graceful objects may be dotted beneath the outermost points of their lower branches. We know that a great number of our spring flowers and hardy bulbs mature their foliage and go to rest early in the year. In spring they require light and sun, which they obtain abundantly under the summerleafing tree; they have time to flower and grow under it before the foliage of the tree appears; then, as the summer heats approach, they are gradually overshadowed, and go to rest; but the leaves of the tree once fallen, they soon begin to reappear and cover the ground with beauty.

By extensive experiments in naturalising bulbous flowers in meadow grass, I learned that certain flowers with broad leaves do not thrive where the harrow and roller are used as they are in pastures and meadow land. The Wood Tulip suffers in this way in meadow grass, while in copses or woody places it is quite free. The Narcissi of the hardy sorts generally thrive in meadow grass, but owing to the injury to the leaves, and the struggle for life, they are not so vigorous as in the woods and copses. I am sure I should have had a better and more interesting result if I had put in our woods the same large numbers of bulbs that I put in pastures. On the other hand, certain very important flowers - such as the Apennine Anemone, Snowdrop, Scillas, Winter Aconite, Dog's-tooth Violet, and Snake's-head-thrive perfectly in meadow grass. Even the Narcissi are not less pretty in the grass, though they do not grow so large.

At most country seats there is so much pleasure-ground that delightful things of this kind are quite easy. In my own garden 
in Sussex cultivated fields come quite close to the house, and I made a delightful spring garden by planting in the grass early bulbs, which had quite disappeared, leaf and all, before the grass was mown in the usual way. The following paper on the subject was read before the Royal Horticultural Society in I 89 I :-

\section{Wild Gardening in MEAdow Grass}

Having during the past five years planted in meadow grass several hundred thousand bulbs and roots, the results may, perhaps, be suggestive to others. One advantage of this way is the delightfully artistic arrangements which it permits. It is also a deliverance of flower-beds from the poor thing known as spring bedding. This system of "bedding" - which began in France, and is still seen there in all its bareness, and which spread to many of our gardens-consisted of putting out in formal masses a few biennial plants such as the Wood Forget-menot and Silene. It necessitated a complete change in the contents of the beds once, or, rather, twice a year, and, therefore, prevented the beds being given to the nobler kinds of flower-gardening. The finest garden plants will not bear this ceaseless moving of the ground.

By the adoption of this system of wild-gardening it is possible to have all the flower-beds proper devoted to noble and permanent things, such as Tea Roses, Carnations, and the various plants that require time for development.

Perhaps the result will be more clearly seen if we take a flower and see what is done with it. We begin with the Blue Apennine Anemone. Of this I planted several thousand roots in grass. Not having any beds or borders near the house where.I wanted it, I put it in meadows immediately around the house in light broken groups and masses. It flowers and increases every year without the slightest attention; and, being earlier in growth than grass, ripens and disappears before the meadow grass has to be cut. This is a most important point, and shows what may be done with many beautiful spring flowers. One has the pleasure of seeing them year by year flowering in their seasons, and giving delightful effects both in groups in the open sunny fields and also clustering thickly round the base of old Elm trees on their margin. Among the Blue Anemone stood here and there groups of Narcissus, and when the Anemones and Daffodils flowered together the effect was often very beautiful. This Anemone is perfectly hardy, always grows freely in grass, and never deteriorates. In Greece this year I saw on the mountains many acres of the Blue Greek Anemone, and I think it quite as hardy and free as the Italian one, and as good for naturalisation in the grass. The simplicity of the culture of plants like this, which thrive in meadow grass, and whose foliage withers before the grass need be mown, makes them a most important group, as there is so much meadow grass near most country houses. A very great number of the spring flowers of the northern world may be treated in this manner, and will give us beautiful spring gardens!

The most important group of all these early flowers is the Narcissus. Five years ago I planted many thousands in the grass, the most important group being the Star Narcissus in large variety. I never doubted that I should succeed with them, but did not know I should succeed so well. They throve admirably, and flowered well; the flowers are large and handsome, and to my surprise have not diminished in size. In open, rich, heavy bottoms, along hedgerows, in quite open, loamy fields, in every position I have tried them. They are delightful when seen near at hand, and also effective at a distance. The leaves ripen, disappear before mowing time, and do not in any way interfere with farming. The harrowing 


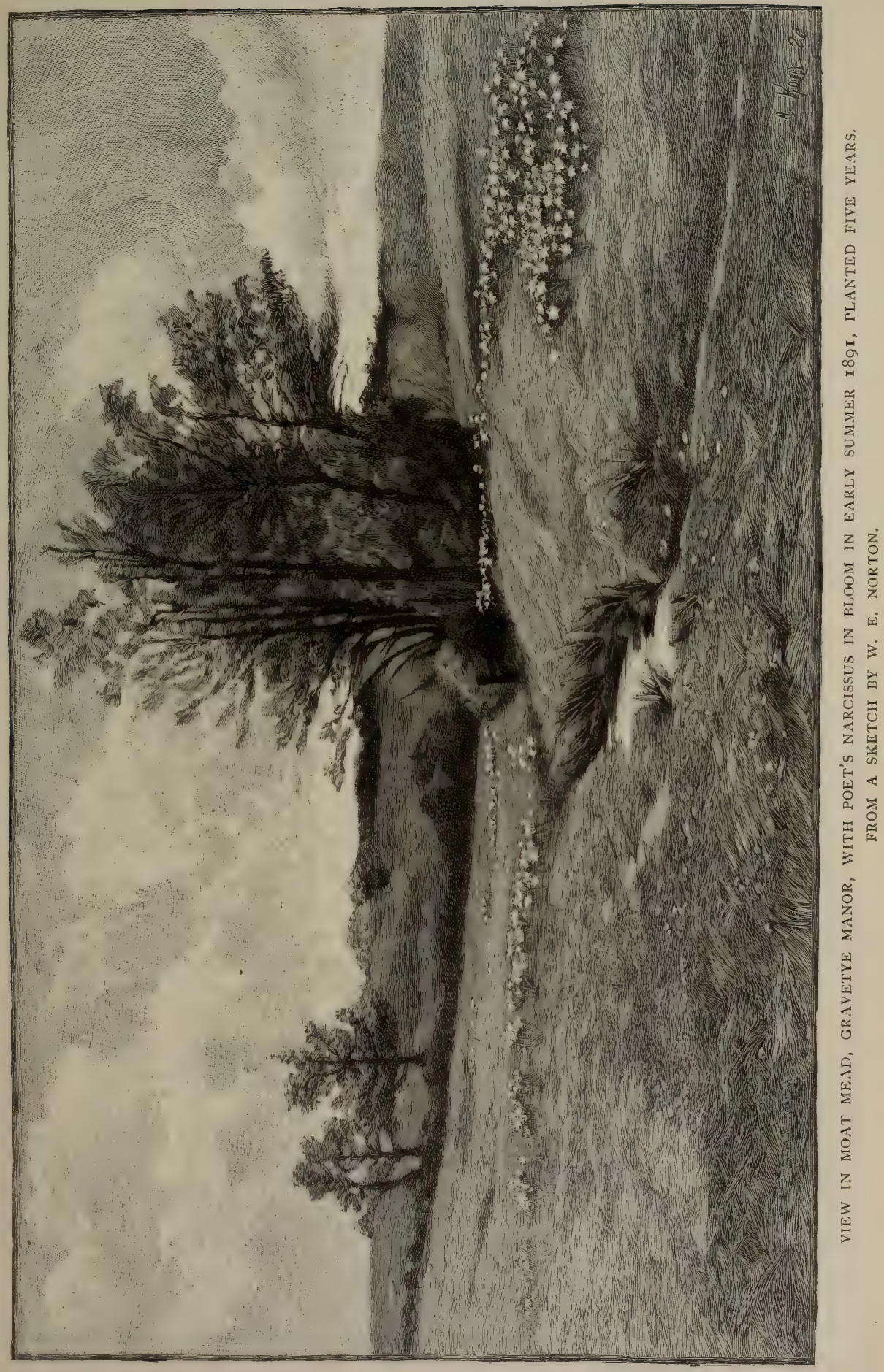


and rolling of the fields in spring, however, are a little against the foliage, and probably with the finer Narcissus a better result could be obtained by wood walks and open copses, which abound in so many English country places.

I have had good results with the great group of forms of the common English, Irish, and Scotch Daffodils, which thrive better and are more handsome than the wild plant-not uncommon in Sussex. The little Tenby Daffodil is very sturdy and pretty, and never fails us. The only one that has failed is the Bayonne Daffodil.

A very delightful feature of Narcissus meadow gardening is the way great groups follow each other in the fields. When the Star Narcissi begin to fade in their beauty the Poets follow, and, as I write this paper, we have the most beautiful picture. Five years ago I cleared a little valley of various fences, and opened up a pretty view. Through the fields runs a streamlet. I grouped the Poet's Narcissus near it; in a little orchard, and through a grove of Oaks on one side of the field. We have since had some beauty every year, but this year, the plants having become established, or being very happy from some other reason, the whole was a picture such as one might see in an Alpine valley! The flowers were large and beautiful when seen near at hand, and the effect in the distance was delightful. Mr. Norton, at this time, made a picture of it, which may perhaps serve to show that this kind of gardening will bring gardening into a line with art, and that the artist need not in future be divorced from the garden, as he has hitherto been, by geometrical patterns which cannot interest men accustomed to draw beautiful forms. I need say no more of the qualities of this magnificent group of plants for wild gardening, and many places have much greater advantages than mine for showing their beauty in rich stretches of grass by pleasure-ground walks. Various kinds of places may be thus adorned by Narcissi-meadows, woods, copses, wood walks, and drives through ornamental woodland and pleasure-grounds, where the grass need not be mown until late in summer.

DoG'S-ToоTH VIOLE'S. - These beautiful and delicate-looking plants surprise me by their free growth in grass in several places where I have planted them. They vary a good deal in size, according to soil, but never fail to charm by beautiful leaves and flowers. This plant withers early, and is a perfect plant for meadow culture !

GRAPE HYACINTH.-Last autumn I made a trial of the Grape Hyacinth (Muscari), and was delighted with the result this spring, with the pretty clouds of blue, quite distinct and new in the grass.

SNOWDROPS in various forms are indispensable, and do fairly well, though they vary very much on different soils. They look much better in the grass than on bare earth.

SNAKE'S-HEAD.-Among the flowers in meadow grass there is nothing more beautiful than the Snake's-head (Fritillaria) varieties. It is the very type of plant for this work, and the white and pretty purple flowers in the early grass are admired by all who see them.

THE CROCUS, from its early brilliancy, is valuable, and the hardier forms are well able to take care of themselves. If we could get the wild types of plant it would be all the better, because such beauty as they possess is never the result of cultivation. When we buy bulbs highly cultivated, we may expect some reduction in the size of the flower on its assuming a semi-wild state ; but nobody who cares for the form and beauty of the flowers will mind the reduction. Flowers from bulbs planted several years are somewhat smaller than the newlyplanted kinds, but certainly no less beautiful. While we have proof enough that Crocuses grow well on a large scale in meadow grass, they seem particularly suitable for growing under groves of trees, the vegetation coming before the trees 
put forth their leaves. In many country places without the garden proper many spaces under trees, often possessed by the Goatweed and other not-well-loved plants, should be given to the Crocus and like early flowers.

TULIPS. - I have tried, to the extent of a thousand roots, the Wood Tulip (T. sylvestris), sent me from Touraine, and I do not think we have lost any; they bloom gracefully every year. The shortness of bloom which Tulips show should lead one to try them in grass. Their broad, fragile leaves are apt to be injured by the harrow. They are better in copses or drives through woods, where they are free from this injury.

StARs of Bethlehem (Ornithogalum).-The starry trusses of the common old border kind are quite different in effect from our other early flowers, and very pretty. In this genus there is much difference in habit, the greenish, droopingflowered kind, like nutans, giving quite a different effect from the common white border kind. There is no trouble in growing these in the grass.

SNOWFLAKES do admirably, the early one being a more precious flower than even the Snowdrop; they are useful to gather, and all are brightly effective very early. The later ones are also graceful things, free and handsome in rich grass.

ScILLAS. - Gardening as I do in a world of Wood Hyacinths, there was less need to try the Scillas than the strictly non-British flowers, which give us new aspects of flower life; but so far we have had good results with the Spanish Scilla and the new Scilla-like plants (Chionodoxa), which disappear early.

As to this sort of flower-gardening, which so much extends the interest in flower life, the garden "trade" would do much good by offering such bulbs and roots by the thousand at the lowest possible rates. It would pay cultivators well to grow such roots in quantity for the public, as it now pays Lincolnshire farmers to grow the Snowdrop. The success of wild-gardening depends on arranging bold, natural groups with a free and artistic hand, and cannot be attained without quantity. It means an enormous addition to the bulb trade, a healthy, and what ought to be a British, industry, and the growth in quantity of the hardier bulbs, for which many parts of our country are perfectly suited.

The scope of this paper, it will be seen, leaves out several very important phases of wild-gardening, in which the plants do not die early, but long after those mentioned have perished, adorn the garden, if not with bloom, at least with foliage-such as the tall Polygonums, too free for the flower garden (but which do admirably with me in rough places outside the garden, the stems being handsome even in winter), Solomon's Seal, Lily-of-the-valley, Evening Primrose, Globe Flower, Japan Anemone, and many other flowers of later bloom and growth. Indeed, it mainly concerns that beautiful, early, hardy flower life which blossoms before the grass of our fields begins to grow freely.

\section{Principal Families of Plants for the Wild Garden}

The following are the chief families of plants that may be used in the wild garden. Where families are named which are British as well as natives of the Continent of Europe, as in the case of, say, Scilla, the foreign kinds are meant. In considering what may be done in naturalising plants in a given position, it may be well to cast the eye over the families available. Success will depend on how the plants are chosen to go in any one position. And in grounds of our country seats, soils and situations are so varied that it is not easy to generalise. The degree of moisture must be thought 
of. I failed with the American Wood Lily in a delightful shady lane in my Sussex place owing to want of moisture.

\begin{tabular}{|c|c|c|c|}
\hline Acanthus & Crocus & Leopard's-bane & St. Bruno's Lily \\
\hline Aconite & Cyclamen & Lily & St. John's Wort \\
\hline Aconite, Winter & Daffodil & Lily-of-the-Valley & Sandwort \\
\hline Alkanet & Day Lily & Lungwort & Scabious \\
\hline Arabis & \multicolumn{2}{|c|}{ Dog's-tooth Violet Lupine } & Scilla \\
\hline Asphodel & Ferns, Hardy & Lychnis & Snapdragon \\
\hline Aubrietia & Flag & Lythrum & Snake's-head \\
\hline Bamboo & Flax & Mallow & Snowdrop \\
\hline Barrenwort & Forget-me-not & May-apple & Snowflake \\
\hline Bee Balm & Foxglove & Mayflower & Soapwort \\
\hline Bellflower & French Willow & Meadow Rue & Solomon's Seal \\
\hline Bindweed & Fumitory & Meadow Saffron & Starwort \\
\hline Bitter Vetch & Gentian & Meadow Sweet & Star of Bethlehem \\
\hline Blood Root & Giant Fennel & Mim & Stock \\
\hline Borage & Giant Scabious & hood & Stonecrop \\
\hline Broom & Gladioli (hardy Eu- & ain Avens & Sun Rose \\
\hline Bugle & ropean kinds) & Mullein & Sunflower, Peren- \\
\hline Candytuft, Ever- & Globe Flower & Narc & \multirow[t]{2}{*}{ nial } \\
\hline green & Globe This & Daisy & \\
\hline Cape Pond-flower & Goat's-rue & Рæo & Thrift \\
\hline Catchfly & Golden Rod & Peri & Thyme \\
\hline Christmas Rose & Grape Hyacinth & Pea, Everlasting & Tulip \\
\hline Clematis & Heath & Peruvian Lily & \\
\hline Columbine & Heliotrope, Winter & Phlox & $\begin{array}{l}\text { Valerian } \\
\text { Viola }\end{array}$ \\
\hline Comfrey & Hemp Agrimony & Pink & Virginian Creeper \\
\hline Compass Plant & Hepatica & Plantain Lily & Virginian Poke \\
\hline Coralwort & Holly, Sea & Poppy & Wallflower \\
\hline Cornflower & Honesty & Primrose, Evenin & Water Lily \\
\hline Coronilla & suckle & Rest Harrow & Windflower \\
\hline Cotton Thistle & Houseleek & Rocket & Winter-green \\
\hline Cow Parsnip & Jasmine & Rockfoil & Wistaria \\
\hline Crane's-bill & Jerusalem Sage & Rock Rose & Wood Lily \\
\hline Creeping Forget & Knotweed & Rose & Wood-sorrel \\
\hline me-not & Lavender & Rosemary & Yarrow \\
\hline
\end{tabular}

Persons interested in this subject may refer to the Wild Garden (John Murray).

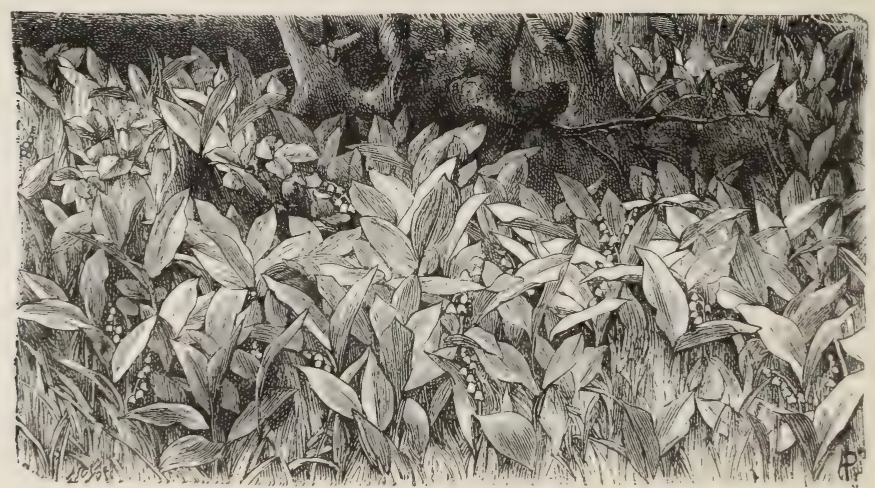




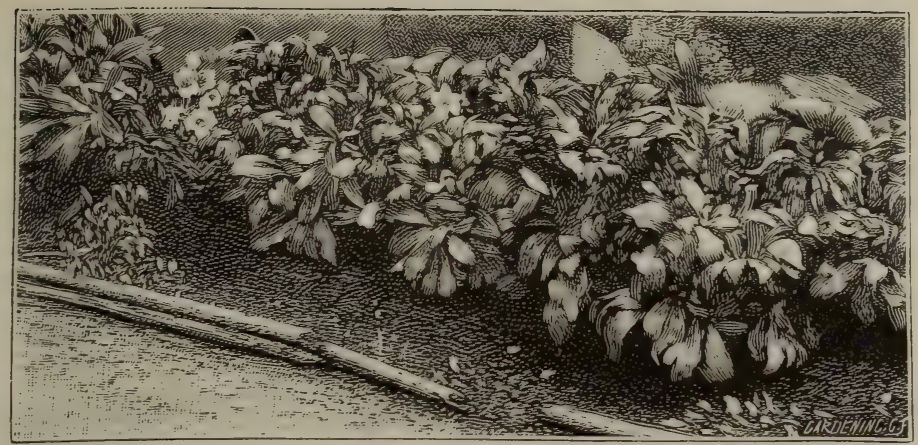

CHAPTER III

BORDERS, BEDS, AND GROUPS OF HARDY FLOWERS

WE next come to the various important classes of hardy flowers which should be cultivated apart from the many that, as shown in the preceding chapter, may be allowed to take care of themselves. We have to consider the various ways of arranging the flowers. Their immense number is shown in the alphabetical part of this book: it is inexhaustible. The question, then, is how the garden designer is to enjoy as much of this treasure as his circumstances allow. As in this country the true flower garden should be formed of the vegetation that will endure our climate, so precedence is given to hardy plants.

The difference between the expense of growing hardy flowers and tender ones is important. The sacrifice of flower gardens to plants that perish every year has left them poor of all the nobler plants. We must take into account the hothouses, the propagation of plants by thousands at certain seasons, the planting out at the busiest and fairest time of the year-in June, the digging up and storing in autumn, the care in the winter.

Mr. D. Thomson says :-

The idea, too, that once these hardy plants are planted they will go on satisfactorily for many years without any further cultivation, is one of the greatest delusions possible ; for, unless the soil in which they grow is kept in good order, the whole thing is a complete failure, and the vigour and display of bloom ceases to be at its best.

That the idea in question is no "delusion" any one can see for himself. Perhaps the most beautiful effects from individual plants ever seen in England were Lilies (auratum) grown by Mr. M'Intosh among his Rhododendrons at Weybridge Heath. Frequent disturb- 
ance would be ruinous to them. And not only Lilies; but many noble flowers may be grown in the same simple way. A few years ago we saw nothing but dense masses of Rhododendrons; now the idea of growing this shrub with the nobler hardy plants has spread. It means more room for the greater beauty of form, and, in consequence, more light, and shade, and grace; mutual relief of shrub and plant; no dotting, but colonies and groups of lovely plants among

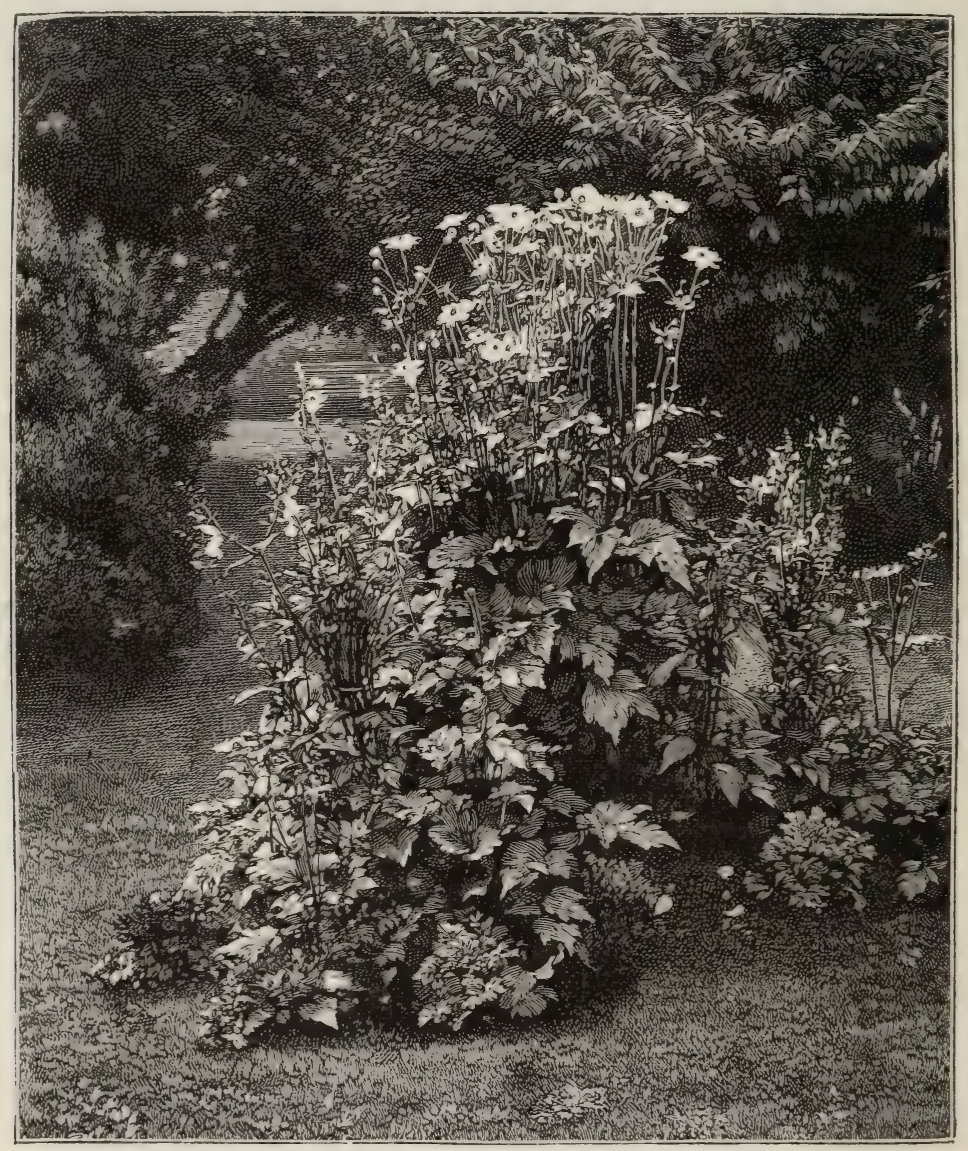

the shrubs. Good preparation and some knowledge are needed, but no necessity whatever for any system that may not be called permanent. Overgrowth will in time need attention, but that would be slight, and could be given autumn, winter, or spring. Properly done, such arrangements could be left for at least five years without any alteration. There are opportunities of growing in this way all the nobler hardy plants in many large or medium-sized pleasure gardens ; but to show the full security of the position, it may be well to name 
a few other modes of arranging flowers which do not require annual planting and digging up.

Coming to special arrangements, there are quite a number which, given thorough preparation at first, it would in every sense be wise to leave alone for some years at a time-as, for example, groups or beds of the various Tritomas, Irises, Globe Flowers, Pæonies, Aconites, the free flowering Yuccas ( $Y$. filamentosa and Y. flaccida), Narcissi - these and many more, either grouped with others or in families. When all these exhaust the ground or become too crowded, by all means move them and replant. But this is very different from the two radical operations, as in the common bedding garden, which are performed each year on the same spot of ground. I know a group of Pæonies that has been in good condition for ten years; and many arrangements can be made to last for half this time without anything but the routine attention which all gardens require. Then we have the mixed border, which is usually an eyesore, but which when well done is beautiful and lasting.

It would be an improvement in every way if, so far as the flower garden is concerned, gardeners were to see what could be done unaided by the hothouse; but meanwhile the wise man will reduce the expense of glass, labour, fire, repairs, paint, pipes, and boilers, to something like reasonable proportions. In the face of the splendid wealth of our hardy garden flora, the promise of which is now such as men never expected a few years ago, no one need doubt of making a fair flower garden from hardy plants alone.

TIIE LABOUR AND CARE required where beauty or variety is sought are so great that it is desirable to dispense with any frequently recurring work not essential for the full enjoyment of a garden. Where a kitchen garden and a good fruit garden exist, the annual labour is so great that any reduction of the work in the flower garden, especially in the busy season of spring and early summer, is an aid to good gardening in all ways, and may bring a little needed repose after the labours of autumn and winter work.

THE TRUE WAY to make gardens yield a return of beauty for the labour and skill given them is the permanent one. Choose some beautiful class of plants and select a place that will suit them, even as to their effect in the garden landscape. Let the beds be planted as permanently and as well as possible, so that there will remain little to do for years. All plants may not lend themselves to this permanent plan, but such as do not may be grouped together-for instance, the beautiful Anemones, Turban and Persian Ranunculuses, the Clove Carnation, Stocks, Asters, and the finer annuals. These, which no good garden should be without, do not lend themselves to such treatment, but to a great extent preparation for them can be 
made in the autumn, winter, or spring season, and no gardener will grudge the attention necessary for such fine things, unless he has the care of many thousand bedding plants. But a great many delightful plants can be planted permanently, and be either allowed to arrange themselves, to group with others, or to grow among peat-loring shrubs which, in hundreds of places, stand unrelieved.

One of the best reforms will be to aroid the "rug pattern," and adopt large and simple beds, placed singly or in groups, in positions suited to the plants they are to contain. These can easily be filled

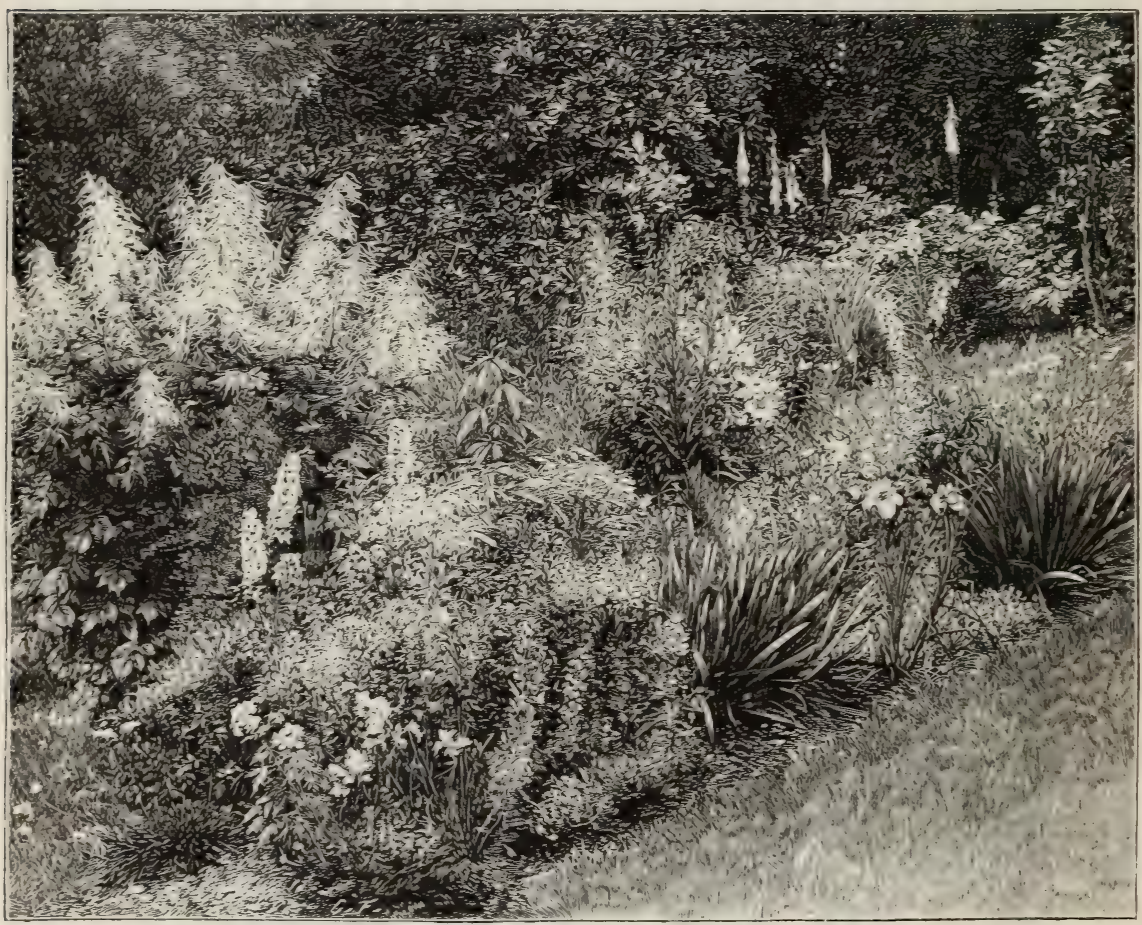

A MIXED BORDER OF HARDY FLUWERS.

permanently, or partially so, because the planter is free to deal with them in a bolder and more artistic way, and need not make them correspond with other beds. In this way, also, the delight of flowers is much more keenly felt. One sees them relieved, sees them at different times, and has to make a little journey to see them when they are not all stereotyped under the window. Roses-farourites with everybody-grouped in their different classes, and not trained as standards, would lend themselves admirably to culture with other things. For instance, we might have Moss Roses growing out of a carpet of double Primroses, Tea Roses with Carnations or Hybrid 
Perpetuals, and the varied kinds of beautiful Irises. Then there are many groups which could be made by the aid of the finer perennials themselves, such as the Delphiniums and white Phloxes, by choosing things that would go well together, where the plants permitted it, and finishing with fringes of dwarf plants to cover bare spaces by carpets of beautiful flowers. Other plants, such as Yuccas, of which there are now a good many beautiful kinds, are, perhaps, best by themselves; and noble groups they form, whether in flower or not. The kinds of Yucca that flower very freely, such as Y. recurva and $Y$. flaccida, lend themselves to grouping with Flame Flowers (Tritoma) and the bolder autumn plants. The gardener who is not overworked with excessive planting in the beginning of summer, year by year may, by thinking over the matter and visiting extensive collections, devise some beautiful new features, and soon make his garden rich in lasting beauty.

No plan which involves an expensive yearly effort on the same piece of ground can ever be satisfactory. All garden plants require attention, but not annual attention. The true way is quite different-the devotion of the skill and effort to fresh beds each year. It does not exclude summer "bedding," but includes numerous possibilities of lovely and varied aspects of vegetation far beyond that attainable in summer "bedding." It attempts to make the garden artistically beautiful. It also helps to make the skill of the gardener effective for lasting good, and prevents its being thrown away in annual fireworks. There can be no gardening without care ; but is there not a vast difference between some of the beds and groups just mentioned and those which disappear with the frosts of October, and leave us nothing but bare earth?

The main charm of bedding plants - that of lasting in bloom so long-is really their most serious fault. It is the stereotyped kind of garden which we all have to fight against; we want beautiful and varying gardens, and should, therefore, have the flowers of each season, and they should tell the season. Too short a bloom is a misfortune; but so is too long a bloom. Numbers of hardy plants bloom quite as long as can be desired.

There is nothing whatever used in bedding out to be compared in colour, scent, size, or bloom, or in any way, with flowers belonging to many families of hardy plants. The patronising admissions of "interesting," "pretty," which we sometimes hear are ridiculously misplaced. There is no beauty among bedding plants at all comparable with that of Irises, Lilies, Delphiniums, Evening Primroses, Pæonies, Carnations, Narcissi, and a host of others. Are we to put aside or into the background all this glorious beauty for the sake of a few things that merely give us flat colour? Let those who like 
bedding flowers enjoy them; but no one who knows what the plants of the northern and temperate world are can admit that this poor sort of gardening should have the first place. There is nothing among "bedding" plants equal to Windflowers-Anemones, in many kinds, flowering in spring, summer, and autumn; Flame Flowers (Tritoma), superb in autumn ; Columbines ; Harebells ; Delphiniums —no blue or purple flowers equal to these ; Day Lilies ; Everlasting

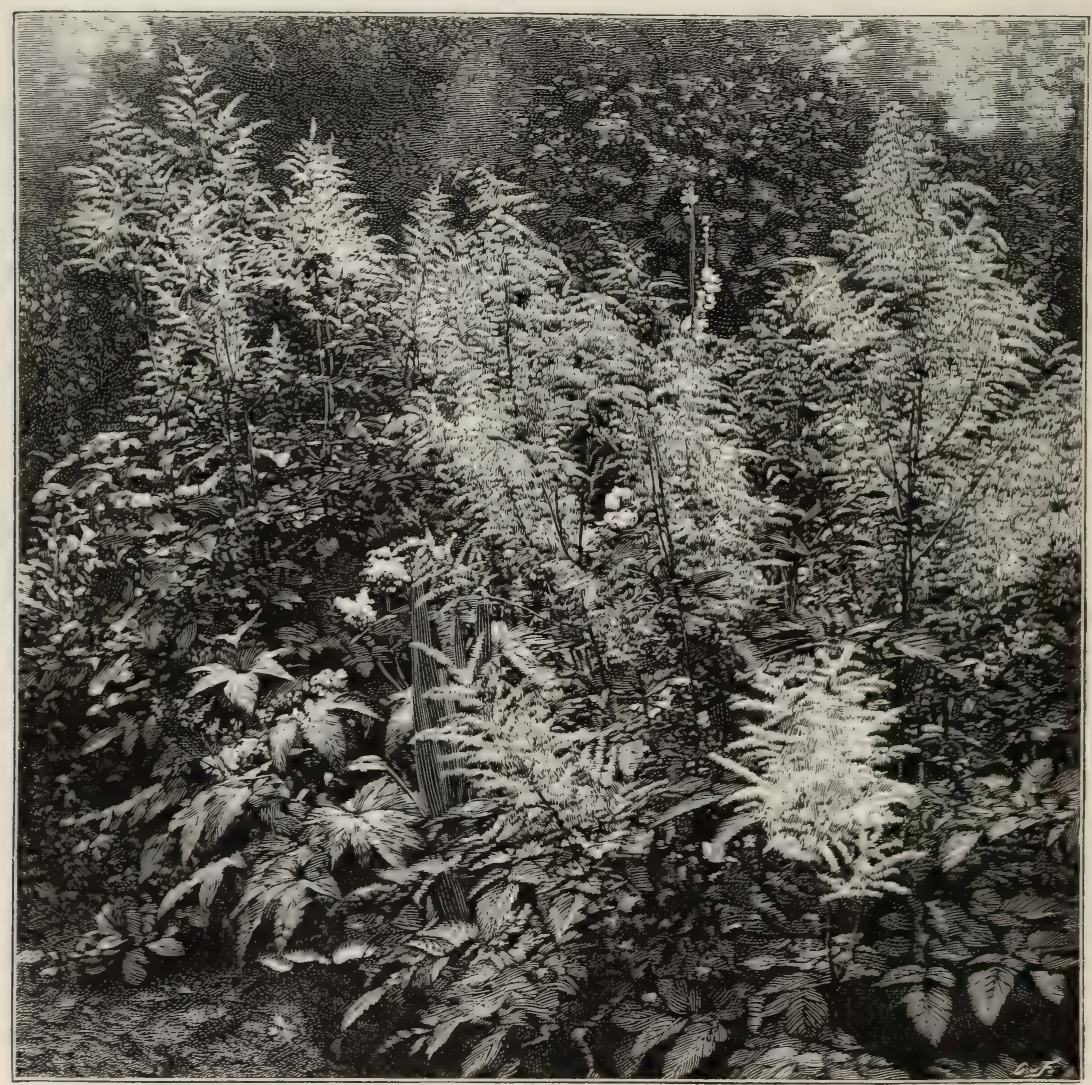

GROUP OF MEADOW SWEETS.

Peas; Evening Primroses, many bold kinds; Pæonies, both showy and delicate colours, some fragrant; Phloxes, in many kinds; Ranunculuses, double and single, and the many fine species; all the noble autumn-blooming, Daisy-like flowers; the large blue Scabious and the smaller kinds ; the Larkspurs, charming in colour; plumy Spiræas; Globe Flowers, fine in form; Lilies, in noble variety; Polyanthus; Primroses; Auriculas; Wallflowers; Meadow Saffrons; Crocuses, many kinds, both of the spring and autumn; 
Scillas ; Gladioli ; Snowflakes ; Grape Hyacinths ; Narcissi, in lovely variety ; Tulips, the old florists' kinds, and many wild species; Yucca, free-flowering kinds; Thrifts; Carnations and Pinks; Dielytras; Veronicas; Cornflowers ; Foxgloves ; Rhodanthes ; Stocks ; Asters ; the Great Scarlet and other Poppies; Christmas Roses, both of the winter and spring; Forget-me-nots; Pansies; and the pretty mountain Wallflowers, and yellow and purple and white Rock Cresses of the mountains of Europe-from the Alps to the hills of Greece, cushioned with Aubrietia and sky-blue Windflowers. All these are hardy as the Docks by the frozen brooks.

FLOWER BORDERS. - The usual way in which people attempt to cultivate hardy flowers is in what is called the "mixed border." This may be made in a variety of ways, and its success will depend equally upon how it is made and upon the position in which it is placed. It is frequently made on the edge of a plantation of trees, the roots of which leave little for the flowers. And now as to the various plans by which hardy flowers may be best brought near us. The bounteous store at hand for this, and the way to use it, will be found by means of the alphabetical arrangement of this book. The number of plants is so large that it is hopeless to give even an outline of the numerous ways in which they may be grown. Still, I may help many who, up to the present, have had the idea that a flower garden is a thing to be spread out in one spot, the plants of the same height all growing under the same conditions, their duty being to flower together and for a long time, and give us effects as like tile patterns as flowers can be made to give by torturing and pinching them into shapes and sizes they were never given by their mother Nature. In fact, the tendency has been to go farther than this on the part of certain stupid garden designers, who, knowing nothing about plants, thought they would be more certain of their effects by having a flower garden in broken slate or marble, as at Kensington, Crewe Hall, and many other gardens made even in our own day.

The face of a shrubbery should be broken; the shrubs should not form a hard line, but the hardy plants should begin at the line, and here and there the shrubs should come out to the edge and finish it, breaking the border agreeably. The variety of positions and places afforded by the front of a shrubbery is delightful. Here and there, even in a large open space, one might have groups or masses of plants requiring good cultivation, but it would generally be best to avoid this, and use plants which do not depend for their beauty on high culture-which, in fact, fight their way among shrubs - and there are a great many of them, such as the evergreen Candy- 
tuft, the large-leaved Saxifrage, the Acanthus, the Day Lily, the Everlasting Pea, and Solomon's Seal.

A scattered, dotty mixed border along the face of a shrubbery gives a miserable effect, but a good effect may be secured by grouping the plants in the open spaces between the shrubs, making a careful selection of plants, each occupying a bold space. Nothing can be more delightful than a border made thus; but it demands a knowledge of plants, and that desire to consider plants in relation to their surroundings which is never shown by those who make a "dotty" mixed border, which is the same all the way along and in no place looks pretty. The presence of tree and shrub life is a great advantage to those who know how to use it. Here is a group of shrubs over which we can throw a delicate veil of some pretty creeper that would look stiff and wretched against a wall. Here is a shady recess beneath a flowering tree: instead of planting it up with shrubs in the ordinary gardening way, cover the ground, if more important plants will not grow in it, with Woodruff, which will form a pretty carpet, and flower very early in the year, and through the Woodruff dot a few common British Ferns; in front of this use only low plants, and we shall thus get a pretty little vista, with shade and a pleasant relief. Next we come to a bare patch on the margin. Cover it with a strong evergreen Candytuft, and let this form the edge. Then allow a group of Japan Quince to come right into the grass edge and break the margin; then a carpet of broad-leaved Saxifrage, receding under the near bushes and trees; and so proceed artistically, making groups and colonies, considering every point, and never using a plant of which you do not know and enjoy the effect.

This border plan is capable of considerable variety, according to whether we are dealing with an established and grown shrubbery, a medium one of flowering trees and shrubs, or a choice plantation of flowering Evergreens. In the last case, owing to the soil and the neat habit of the bushes, we have excellent conditions in which good culture and effective arrangement are possible. One can have the finest things among them-if the bushes are not jammed together. The ordinary way of planting shrubs is such that they grow together, and then it is not possible to have flowers between them, nor to see the true form of the bushes, which are lost in one solid leafy mass. In growing fine things-Lilies or Cardinal Flowers, or tall Evening Primroses-among open bushes we form a delightful garden, we secure sufficient space for the bushes to show their form and habit, and we get light and shade among them. In such plantations one might have in the back parts "secret" colonies of lovely things which it might not be desirable to show in the front of the border, or which required shade and shelter that the front did not afford. 
The Flower Border AgAinst a WALL.-In many situations near houses, and especially large old houses, there are delightful opportunities for a very beautiful kind of flower border. The stone forms an excellent background, and cuts off any exhausting vegetation. Here we have conditions exactly opposite to those in the shrubbery; there are no hungry trees behind our plants to steal their food. Here we can have the best soil, and keep it for our favourites; we can have Delphiniums, Lilies, Pæonies, Irises, and all choice plants well grown. If the wall happens to be near the

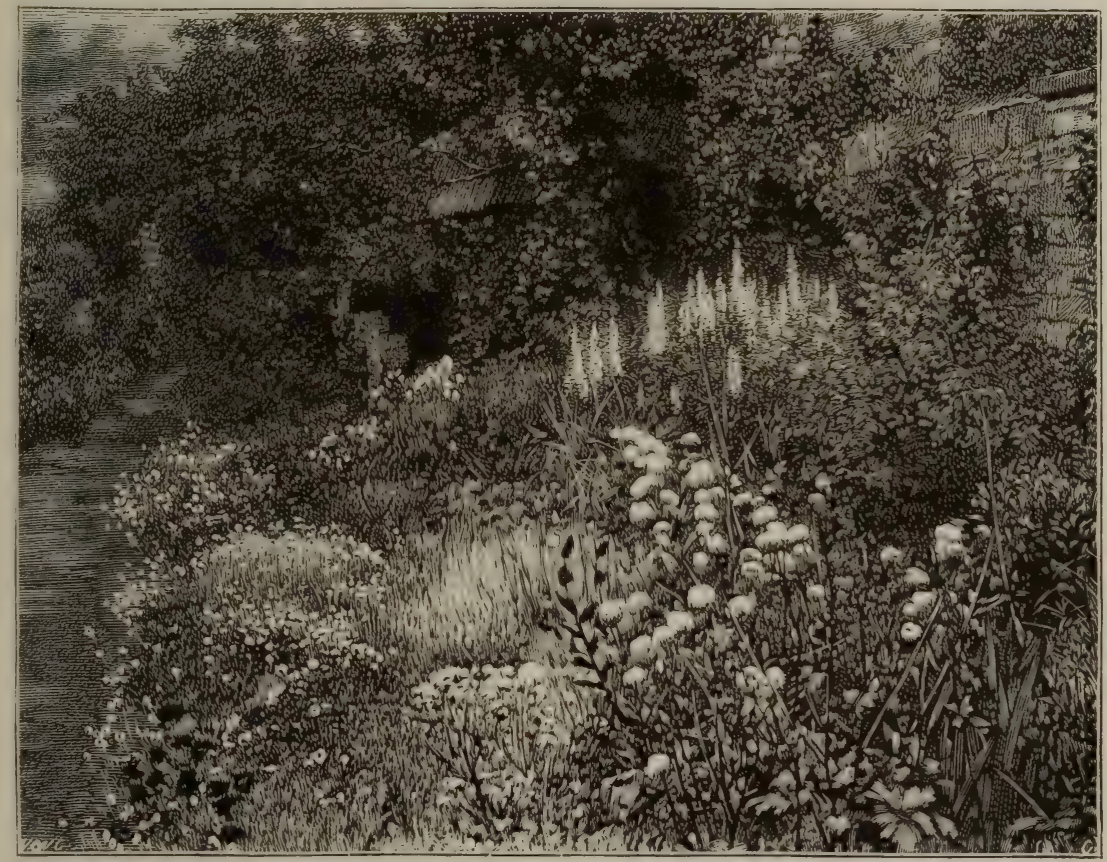

A WELL-COVERED BORDER OF HARDY FLOWERS. CAMPDEN, GLOS.

house, and we do not wish to have climbers on it, it is none the less valuable, especially if it be a good stone wall. It may be adorned with climbers of delicate growth, climbing Rose, Wistaria, Vine, or Clematis, which will help out our beautiful mixed border. Those trees must to some extent be trained, although they may be allowed a certain degree of abandoned grace even on a wall. In this kind of border we have, as a rule, no contrasts from shrubs, and therefore we must get the choicest variety of plant life into the border itself. We must try to secure a constant succession of interest, and this is very easy. There is scarcely a month of the year in which we may not have delightful things in bloom. In 
winter this kind of border may have a bare look when seen from the windows. The variety of plants is, however, so great, that we can make it evergreen by evergreen herbaceous plants. In large places also there are frequently positions not seen from the windows-fine massive walls that would form an admirable background to a mixed border composed wholly of hardy flowers, carefully chosen. On these walls a choice selection of well-grown climbers and evergreens forms an excellent addition to the hardy plants in the foreground. Where the wall is broken with pillars, a still better effect may be obtained by training Vines and Wistaria along the top and over the pillars or the buttresses.

The Flower Border in the Fruit or Kitchen Garden.IVe have here the original and perhaps the commonest form of mixed garden. This kind of border is often badly made, but may be a delightful one. The plan is to secure from about 8 to ro feet of rich soil on each side of the walk, and cut the borders off from the main garden by a trellis of some kind from 6 feet to 9 feet high. This trellis may be of strong iron or galvanised wire, or, better still, of simple rough wooden branches - uprights topped by other branches of the same kind. Any kind of rough permanent trellis will do. On this rough trellis we may grow Climbing Roses and Clematis, and all the choicer but not too rampant climbers. Moreover, we can grow them in their natural grace along the wires or rough branches, or up and across a rustic wooden trellis-Rose and Jasmine showing their grace uncontrolled. We fix the main branches to the supports, and leave the rest to the winds. We have the finest type of mixed border in this way, because we have all the graceful climbing plant life we desire in contrast with the flowers in the border.

Mixed borders may be made in various ways; but you will do well always to bear in mind the following points: Select only good plants; throw away weedy kinds; there is no scarcity of the very best. See good collections. Put, at first, the good kinds selected in lines across 4-feet nursery beds, so that a stock of young and strong plants may be at hand, and you may be able to exchange with others as well as form groups. Make bold borders which cannot be robbed by the roots of trees; see that the ground is thoroughly prepared, and rich, and that there is the best friable soil at least $2 \frac{1}{2}$ feet deep. The soil should be so deep that, in a dry season, the roots can seek their supplies far below the surface. On the making of the border depends whether the vegetation will be bold or stunted. If you are limited to one border only, some variety in the soil will be necessary to meet the various wants of peat-loving and moisture-loving plants. In planting, plant in groups, and not 
in the old dotting way. Never repeat the same plant along the border at intervals, as is so often done with favourites. Plant a bold, natural group of it, or two or three groups if you must have so many.

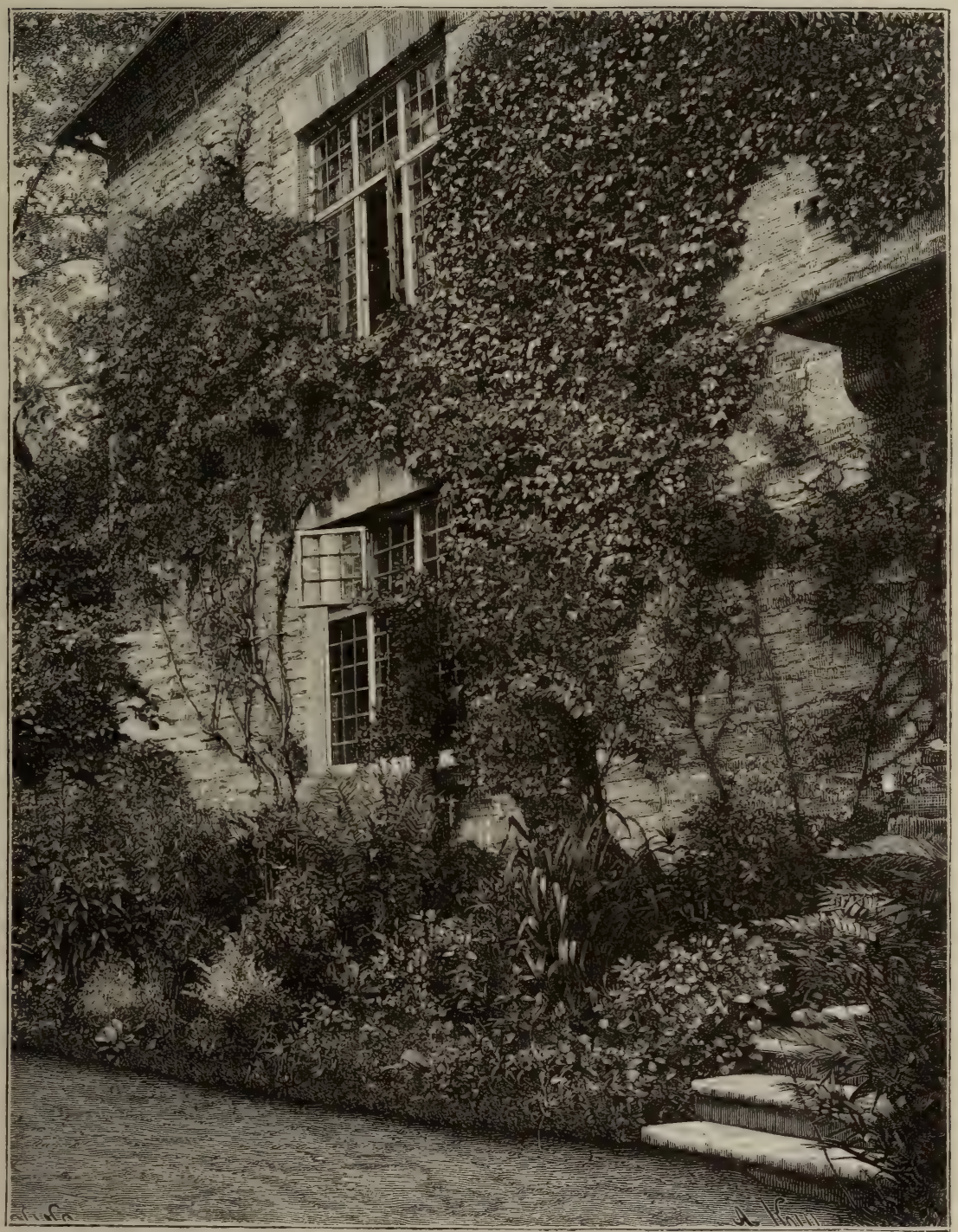

HARDY BORDER FLOWERS AGAINST HOUSE, WITH CLIMBERS BEHIND.

Do not graduate the plants always from the front to the back, as is generally done, but sometimes let a bold and sturdy plant come towards the edge; and, on the other hand, let a little carpet of a dwarf plant pass in here and there to the back, so as to give a 
broken and beautiful instead of a monotonous surface. Have no patience with bare ground. Cover the border with dwarf plants; do not put them along the front of the border only. Let Hepaticas and double and other Primroses, and Saxifrages, and Golden Moneywort and Stonecrops, and Forget-me-nots, and dwarf Phloxes, and many similar plants cover the ground among the tall plants everywhere-at the back as well as the front. Let the little ground plants form broad patches and colonies by themselves occasionally, and let them pass into and under other plants. A white Lily will be all the better for having a colony of creeping Forget-me-nots over it in the winter. The variety that may be thus obtained is infinite.

Thoroughly prepared at first, the border should remain for years without any digging in the usual sense. If the border is in the kitchen garden, or in any other position where it is desired to cut it off from its surroundings, erect a trellis at its back and cover this with climbing plants-Clematises, Roses, Sweet Briers, Honeysuckles, or any beautiful hardy climbing plants, not twined too stiffly but allowed to grow into free wreaths. To avoid loss in severe winters employ Roses of the hardiest kinds only; the old single Clematis, the mountain and the sweet autumn Clematis (C. Flammula), as well as other single kinds, should have a place here as much as the larger forms. If the soil is not very deep or well prepared, and the surface is not covered with small plants, it will be well in many cases to mulch the ground in summer by placing an inch of some light dressing on it. When a plant is old and rather too thick, never hesitate to replant it on a wet day in the middle of August or July any more than in the middle of winter. Take it up and put a fresh bold group in fresh ground; the young plants will have plenty of roots by the winter, and in the following spring will flower much stronger than if they had been transplanted in spring or in winter. Do not pay much attention to labelling; if a plant is not worth knowing, it is not worth growing; let each good thing be so bold and so well grown as to make its presence felt.

The Mixed BORDER, in which the plants are placed in rows, a single specimen of each, the tall growing ones having their flowerstems tied to stakes rigidly upright, is among the very worst arrangements for hardy flowers; but not the mixed border, in which spreading plants are allowed to form great patches yards across. All hardy plants will be found to have the best effect when planted in an informal manner. This does not mean that the plants are to be planted higgledy-piggledy; this is the very reverse of Nature's arrangements. When plants seed, the seedlings come up all round them and form clumps and masses; occasional seeds get blown 
away or carried away by birds, so that the approach to the colony of any particular plant is generally indicated by the appearance of stragglers detached from the principal groups. Let one thing be a

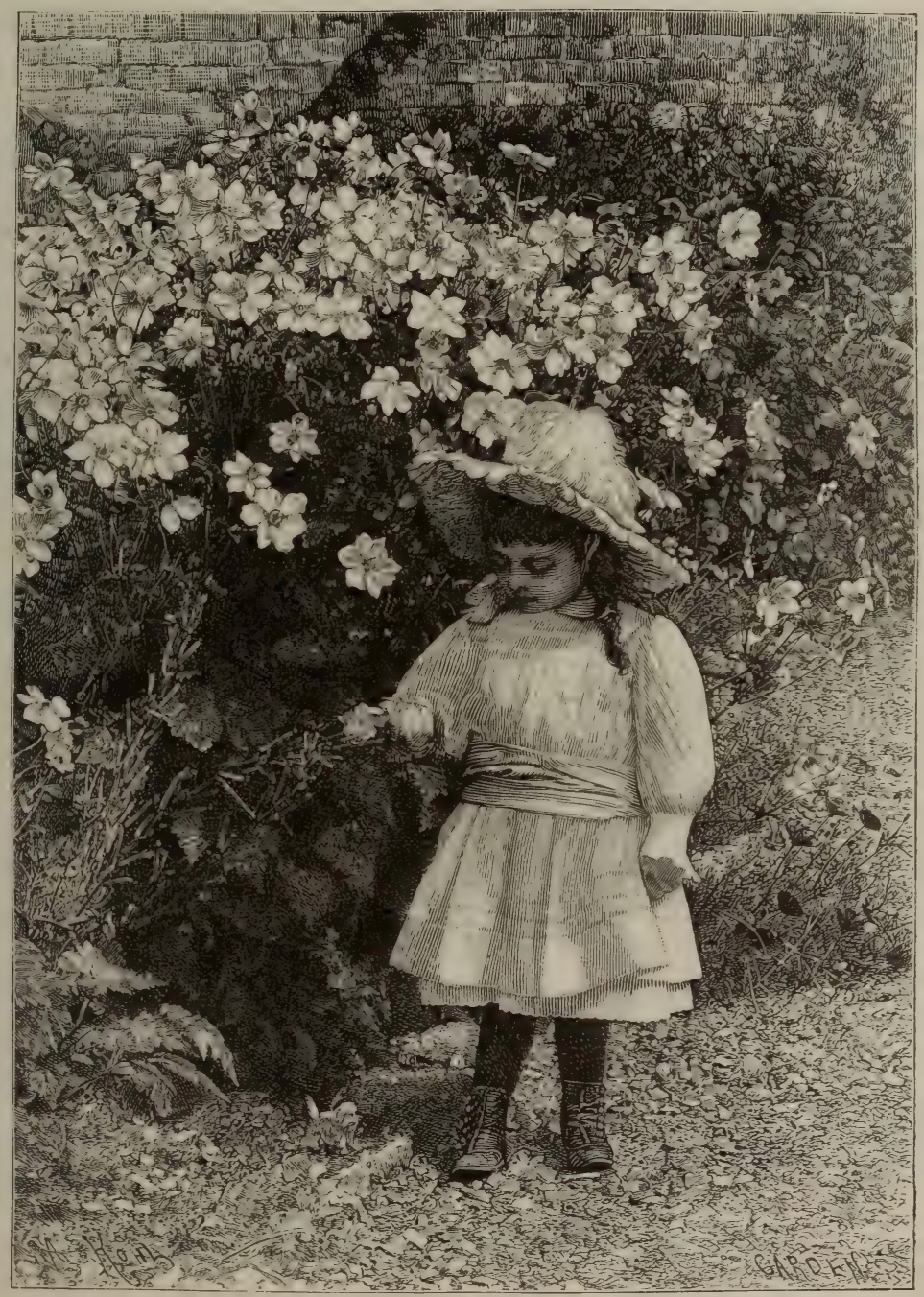

PORTION OF GROUP OF PINK JAPAN ANEMONE IN THE GARDEN AT MIREHOUSE, KESWICK.

feature in the several parts of the garden at one season, and all the rest be subordinate. At a particular time, for instance, a corner might be conspicuous for its Phloxes, at another time for its Roses, for its Dahlias, at another for its Gladioli, for its Japanese Anemones, and so on, always choosing for the conspicuous plants 
those which remain in bloom for a considerable time, and keeping subordinate those whose blooming period is short.

Mr. Frank Miles on the Flower Border. - Among the first to see the merits of naturally carpeting beds, and who made the border suggested in my "Hardy Flowers," was the late Mr. Frank Miles, an excellent gardener. His own account of his work I give here.

If we are to have, mixed borders of herbaceous plants, one thing is quite certain-we can never go back to the borders of our ancestors, in which every plant had a bare space of ground round it. In the spot where once a plant had bloomed there was an end for the year of any flowers. Now a yard of ground should have bloom on it at least eight months in the year, and this applies to every yard of ground in a really good mixed border. I am certain that, once a border is well made, it need not be dug up at all. But the question is-what is a well-made border? I think a border is not well made, or suitable for growing the most beautiful plants to perfection, unless it is as well made as a Vine border in a vinery. Why we should not take as much trouble with the garden border as the border of a conservatory I cannot imagine, seeing that Lilies will grow I I feet high in the open air, not less than $10 \frac{1}{2}$ inches across the flower, and Irises little less than that. The more I garden, the deeper I get my drainage, and the fuller of sand and fibre my soil. I consider, first, that a border must have a bed of broken bricks or other drainage, with ashes over that, to prevent the drainage from filing up; secondly, that that bed of drainage must have 2 feet of light soil over it; thirdly, that that soil must have equal parts of sand; soil, and vegetable matter. A soil of these constituents and depth is never wet in winter and never dry in summer. During the dry weather I found soil like this, in which quantities of auratum Lilies were growing, to be quite moist an inch below the surface, and I know in winter it always appears dry compared with the natural garden soil.

But, for all practical intents and purposes, every 6 inches of ground could contain its plant, so that no 6 inches of bare ground need obtrude on the eye. Almost any kind of bare rock has a certain beauty, but I cannot say bare ground is ever beautiful. Nature covers bulbs with greenery, and we can do it in our gardens. Well, supposing the back of the border filled with Delphiniums, Phloxes, and Roses, pegged down, and other summer and auturnn-blooming plants, and supposing the border to be made as I have described it, I should carpet the ground at the back with winter-blooming flowers, so that when the Roses are bare and the Delphiniums and Phloxes have not pushed above ground, the border should even then be a blaze of beauty. Crocuses, Snowdrops, Aconites, and Primroses are quite enough for that purpose. The whole space under the Roses I should cover with the Common Wood Anemone, and the golden Wood Anemone, and early Cyclamens, and the earliest Dwarf Daffodils. And among the Roses and Pæonies and other medium tall shrubs I would put all the taller Lilies, such as require continual shade on their roots; and such as pardalinum and the Californian section generally, all the forms of auratum (though the scarlet form does not grow quite so high, and wants to be more in front of the border); Lilies, like excelsum, tigrinum splendens, monadelphum, Martagon album, longiflorum Wilsoni, dalmaticum, Hansoni, and giganteum. Now we come more to the front of the border, and here I would have combinations, such as the great St. Bruno's Lily (Anthericum Liliastrum majus) and the delicate hybrid Columbines, Primroses planted over hardy autumn Gladioli, so that when the Primroses are at rest the Gladioli should catch the eye : Carnations and Daffodils, planted so that 
the Carnations form a maze of blue-green for the delicate creams and oranges of the Daffodils. When the Daffodils are gone there are the Carnations in the autumn. A mass of Iberis correæfolia happens to have been the very best thing possible for some Lilium Browni to grow through, for the Iberis flowered early and then made a protection for the young growth of the Browni, and then a lovely dark green setting for the infinite beauty of the Lily flowers. As for saying that this cannot be done, I say that it is nonsense, for the Iberis flowered beautifully under such circumstances, and the Lilies too. If once you get it into

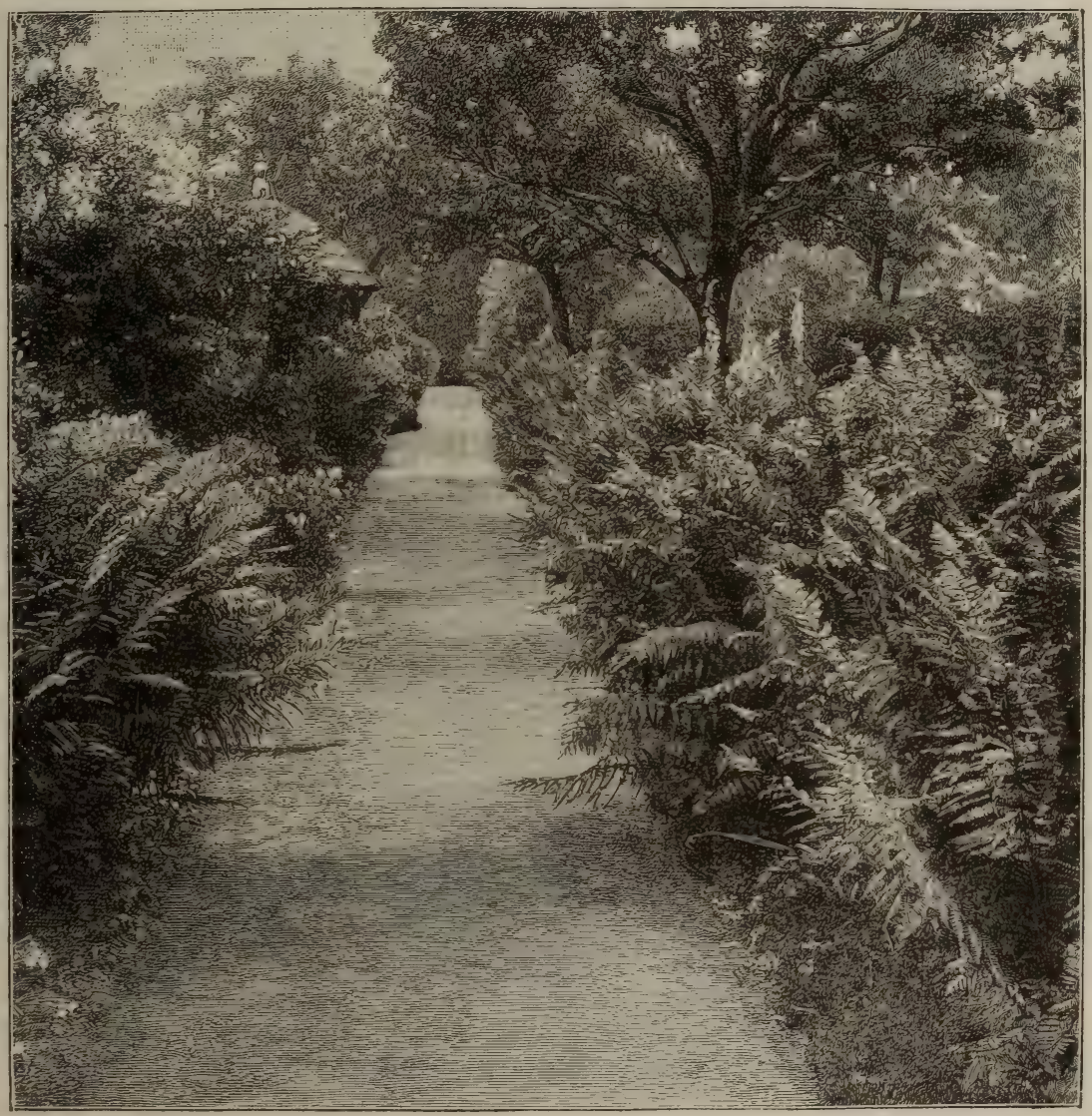

A FERN BORDER WITH FLOWERS HERE AND THERE.

your head that no bit of ground ought ever to be seen without flowers or immediate prospect of flowers, heaps of combinations will immediately occur to those conversant with plants and the deep-rooting habits of most bulbs and the surface rooting of most herbaceous plants-for instance, Colchicums and Daffodils, with a surface of Campanula pusilla alba. The big leaves of the Colchicum grow in spring, and there would be nothing but leaves were it not for the masses of Daffodils. By and by the leaves of the Colchicums and Daffodils are dry enough to pull away, and then the Campanula, be it pusilla, pusilla alba, or turbinata alba, comes into a sheet of bloom. Before the bloom has passed away the Colchicum blooms begin to push up, and as some of my Colchicums are 5 inches 
across, of the richest rose colour, I do not exactly feel that this is a colourless kind of gardening, and as 1 have a hundred different kinds of Daffodils, this little arrangement will not be without interest in spring.

ThE DAFFoDils and Colchicums root deeply and grow mostly in winter, requiring water then, and not in summer, when the Campanula carpet is taking it all. There are some, however, which one must be careful about - the common white Lily, for instance, which wants exposing to the sun in the autumn. I do not mind the exquisite French Poppies among these candidum Lilies, because the Poppies die about August, and then the Lilies get their baking and refuse to show the bare earth, soon covering it all with their leaves. For the extreme front of the border hundreds of combinations will occur-Pansies over Daffodils, Portulacas over Central Asian bulbs, Christmas Roses and Hellebores over the taller Daffodils, with Gladioli, Tritomas, and giant Daffodils, Hepaticas, and autumnblooming and spring-blooming Cyclamens, with Scillas and Snowdrops. When Anemone japonica is low, up come the taller Tulips, sylvestris for instance, and higher still out of the dark green leaves come the bejewelled Crown Imperials.

As for the cultural advantages, I can imagine this system in the hands of a skilful gardener to be the best of all. In the first place, the plants suffer much less from drought, because there is so much less surface exposed to sun and wind. Examine, not right under the root, but under the spreading part of a Mignonette, and see if, on a broiling hot day, the ground is not much cooler and moister than on the bare ground. Irises are almost the only plants I know of that do require the soil bare about their rootstocks, but then Irises are a carpet of green always, and a few clumps of Tiger Lilies or Tiger Irises will not seriously injure their flowering prospects. And what cannot be done with an herbaceous border edge when that edge is the green Grass? Crocuses and Crocuses all the autumn and winter and spring in the Grass. The tiniest Scillas, and Hyacinths, and Daffodils, and Snowdrops are leading into the border without any break. So I believe, and I think many others will believe by and by, that every bulbous plant ought to be grown in combination with something else, as Amaryllis Belladonna, for instance, which I plant with Arum italicum pictum. In spring the Arum comes up extremely early, and its leaves protect the far more delicate leaves of the Amaryllis till they are growing freely and the Arum dies down. The ground is surfaced with Violets, so that the Belladonnas are now coming into bloom, not with the bare ground but with a setting of Violet leaves in beautiful contrast with their pink blossoms. Christmas Roses of all kinds would probably be a more beautiful setting still, but the Belladonnas want a good deal of summer drying up, which the Hellebores could not stand so well.

WE CAN NEVER GO BACK to the mixed border of our ancestors; we have been spoilt for such blank, flowerless spaces as they had by the gorgeousness of bedding out. But we have now a wealth of hardy plants, especially bulbs, which they never had, and this combination of bulbous plants and herbaceous plants will certainly lead to a preparation of the borders which has been hardly dreamt of by people who do not care what they spend on tropical flowers; for it seems to be forgotten that we have Irises as big as a plate and Lilies as tall as a tree, all hardy and requiring little attention when once they have been properly planted. The time that used to be spent year after year in digging acres of borders might now be spent in properly making or re-making a few yards of border, till the whole outdoor borders are as exactly suited for the growth of plants to the uttermost perfection - as many as possible being put in the given space-as the borders of a large conservatory. It is in such a border as this that we attain the utmost variety, unceasingly beautiful, every yard different, every week varying, holding on its surface at least three times the value of plant life and successional plant beauty of any ordinary garden. The chief enemy to the system is the slug; 
but while the Belladonna Delphinium, which is usually half eaten by slugs in most gardens, grows 6 feet high with me, I am not going to give up my system.

What could be more delightful in a formal garden, even right against the house, than a good mixed border?-not a stiff collection of staked plants, but a well-stored and well-formed border, filled in autumn with Carnations and Picotees, as well as Stocks, white Lilies, and Christmas Roses, and in Spring with Daffodils and all the rest of the flowers that in olden times used to adorn these gardens, as well as those we have now. In the garden at Penshurst Place, for example, there is a raised walk on a terrace above the

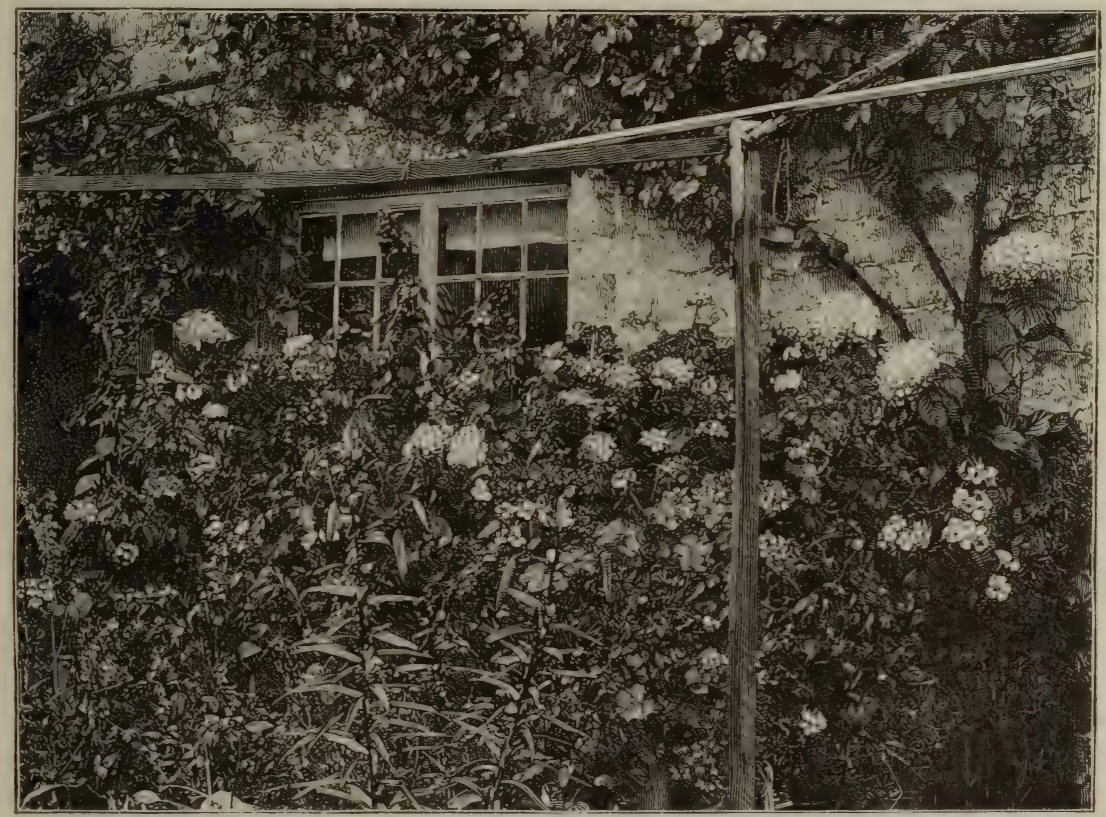

FLOWERS AT THE WINDOW WITHOUT INTERVENING WALK

main garden - a walk alongside of and sheltered by a high wall. Here is the very place for a mixed border, and, accordingly, one has been made there. A noble border of the finer shrubs, with flowers between them, would grace the fairest house or garden yet made.

One of the prettiest garden borders I know is against a small house. Instead of the walk coming near the windows, a bed of choice shrubs, varying from 9 feet to I 5 feet in width, is against the house. Nothing in this border grows high enough to intercept the view, but it is just high enough to hide the walk beyond it. Looking out of the windows on the ground floor, you see the foliage and bloom of the border, but not the walk, and the eye reaches a green 
lawn beyond. Among the shrubs are tall Evening Primroses, and Lilies, and Meadow Sweets, and tall blue Larkspurs, which after the early shrubs have flowered peer above their leaves. This is an example of the mixed border of choice shrubs which we talked of in connection with beds. The ground is always furnished, and the effect is good, even in winter. Let no one imagine, however, that this system can be carried out without thought, and taste, and labour. Any one can change into work that will last for years much of the profitless labour spent over a large area for a temporary aim; but any economy possible with tender plants is even more practicable with hardy ones, for we can dispense with the whole of the pot-and-kettle business, glass, coal, etc--even smoke!

Digging, in this system, is to be abolished entirely. The beds or borders should be thoroughly prepared, and the things wanted carefully planted. We have afterwards simply to keep the soil wholly free from weeds, and all cultivation must be in the form of surface dressing in autumn or spring. Only when the ground gets worn out, or some portion of it, owing to the excessive growth of a vigorous plant, wants to be replanted and re-enriched, should we take up the whole again. To prevent the effect of bare earth the whole surface should be covered with "ground plants," delicate things like Stonecrops or Saxifrages, and many others from the hills or rocks, which spread all over the surface, and frequently give bloom in spring. From these rise the groups of taller plants. Part of the common system in mixed arrangements is to repeat a favourite flower at intervals everywhere. The true way, as already said, is to group enough of any one plant in one or two places, so as to fully enjoy its character, and then be done with it. Besides other advantages this would give us different aspects of vegetation as we passed along the border: Primroses, Cowslips, Bluebells come in tangible, visible masses which we can see and enjoy. Occasionally they are mixed, as our groups in the border might be mixed, but they are not mixed in the common way of dotting fifty different things in a few yards' space. We may have artistic and succeeding mixtures without adopting a muddle mixture, which spoils the whole border. By grouping things we can see better what each subject is doing, and there is less fear of ignorant workmen destroying the plants than when a great number of kinds are dotted about promiscuously, with or without labels.

This artistic system need not prevent us from growing single specimens in a special border, or a collection for increase in nursery beds. I might pass on from this to beautiful plants like Yucca and Acanthus, which are so full of character that they might stand by 
themselves without any aid or arrangement, but enough has been said to explode the notion that all our fair garden flowers must be grown in obscure borders, where they may be robbed by tree roots and be ill-treated and forgotten, and to show how in one way at least we may fully enjoy them in positions said to be unsuitable.

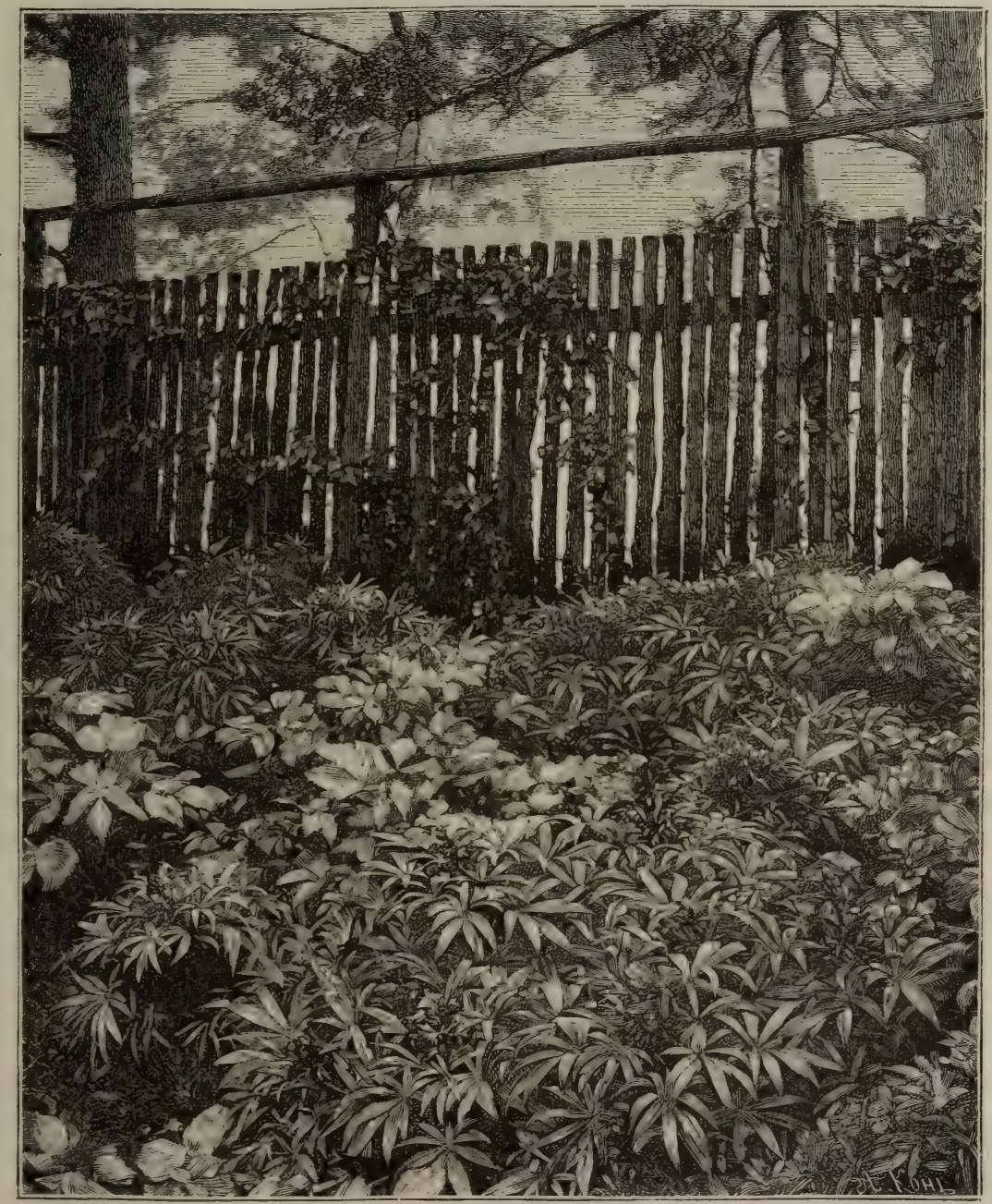

EVERGREEN HARDY FLOWERS IN WASTE CORNER.

Besides beautiful borders and groups and the square or plot garden, we have the possibilities of beds varying in beauty and interest, from the evergreen bed of Yuccas and Hellebores, so fine in winter, to the many bright combinations of bulbs in early summer. Here, however, we have to deal with a definite mass or 
group, which demands a different plan. The combinations of graceful form, beautiful flowers, and fine colour are endless. We can only suggest a few plans which will not disappoint beginners; those who know the plants can work out new combinations for themselves.

EvergReen Borders.- - It may be noted that the old garden favourites, Rosemary and Lavender, are charming when grouped in borders near or against a house. In summer, Cherry Pie, or Heliotrope, may be planted freely with them. A border so formed contrasts to advantage with more richly-stored and well-arranged borders of brilliant flowers, and there are a great many evergreens among the numbers of flowers now in our gardens. Those who wish for evergreen borders may easily have them from the following hardy plants_Christmas Roses, many; Heuchera, various ; Rockfoils (Saxifraga), many; Barrenworts (Epimediums), several very pretty evergreens; evergreen Candytufts (Iberis), several kinds; Stonecrop, (Sedum), many kinds; Galax, one plant; Periwinkle; Adam's Needle, several; Purple Rock-cress (Aubrietia), several; Wallflowers (common Alpine); Irises, many ; Indian Strawberry; Carnations and Pinks; creeping Forget-me-nots (Omphalodes), Alpine Phlox; White Rock-cress (Arabis); Sandworts; Mountain Avens; Gentianella; Houseleeks; Thymes; Forget-me-nots; and Lavender cotton. A great aid to these are hardy ferns - which help one to make the most delightful evergreen borders,- such as the common Polypody and its varieties; the Hart's tongue and its forms; Lastreas, forms of the filix-mas, and also dilatata, and spinulosa; the common Ceterach ; the native Maiden-hairs; Spleenworts. A very important aid can also be had from quite hardy rustic ferns such as the following :-Cyrtomium falcatum; Lastrea intermedia, L. goldicana, L. marginales, L. Sieboldi ; Lomaria chilensis, L. alpina or its var. major; Polystichum acrostichoides, P. angulare Brauni, P. vestitum proliferum, $\mathrm{P}$. setosum, and $\mathrm{P}$. munitum.

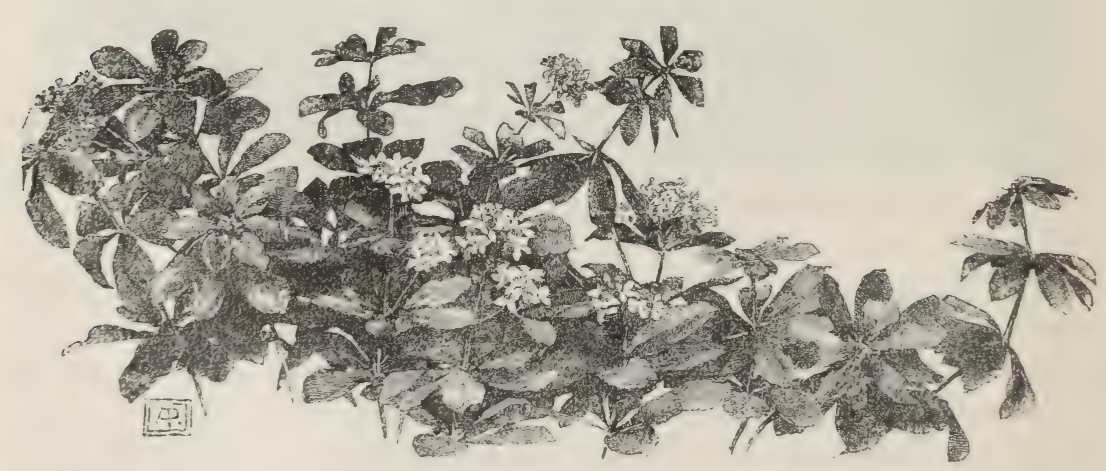




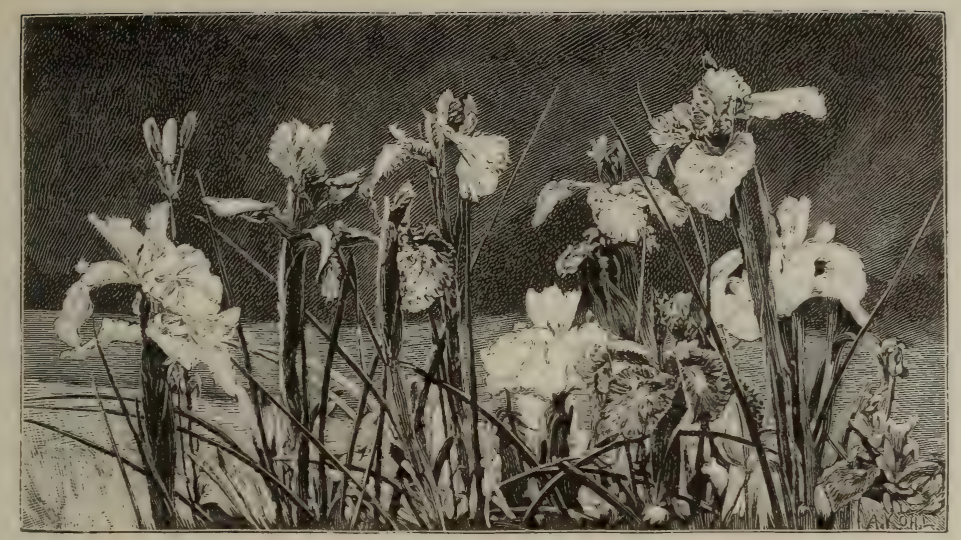

\section{CHAPTER IV}

THE SPECIAL CULTURE OF HARDY FLOWERS-THE RESERVE

\section{AND CUT-FLOIVER GARDENS}

Nothing is more unfortunate in gardens than the way in which plants of all kinds are huddled together without any fitness for association in stature, in time of blooming, or in needs of culture. The common scene of confusion is the shrubbery border, into which Carnations, annuals, alpine flowers, and rampant herbs are often thrown, to dwindle and perish. There is no shrubbery border that could not be made beautiful by carpeting it with wood and copse plants of the northern world in broad masses and groups. But many of our favourite flowers are not wood plants, and many-for example, Carnations-cannot maintain the struggle against the bushes and trees.

Another series of vigorous perennials require isolation if we want their fullest beauty, say the Lilies, Irises, and Pæonies. The Lilies and Irises will certainly do among bushes, the best of which are those called American, which thrive best in peat soil. Their chances in the common shrubbery with its coarse rooting plants and bushes are very different. Of all causes which tend to make the garden unsatisfactory, this inconsiderate placing of many things along the fringes of the garden-grove or shrubbery is the chief. Hardy plants should be divided into two broad series at least-those which thrive in and near woody growth, and those which must perish there. The Solomon's Seal and the blue Apennine Anemone are types of plants that one may grow in any shady place: Carnation, Pink, Auricula represent the flowers which must have good soil away from tree roots. Among hardy flowers there are, in fact, two sets-one set which require care and good culture, full sun and air; another which will almost take care of themselves in any soil. 
One good plan that all can follow is the growing of various lovely plants for their own sakes, without heed to their place in any design, but not in any kind of "mixed border" or in other mixed arrangements. The common way is to put almost every choice plant in the mixed border, but this very often means losing it. Nany important families of hardy flowers are worthy of special culture, and no good result can be obtained without it. Whether we grow Carnations, Pinks, Pansies, Phloxes, Lilies, Stocks, double Wallflowers, Cloves, or tall scarlet Lobelias, in every case they ought to have separate attention. Even an annual, such as the Rhodanthe,

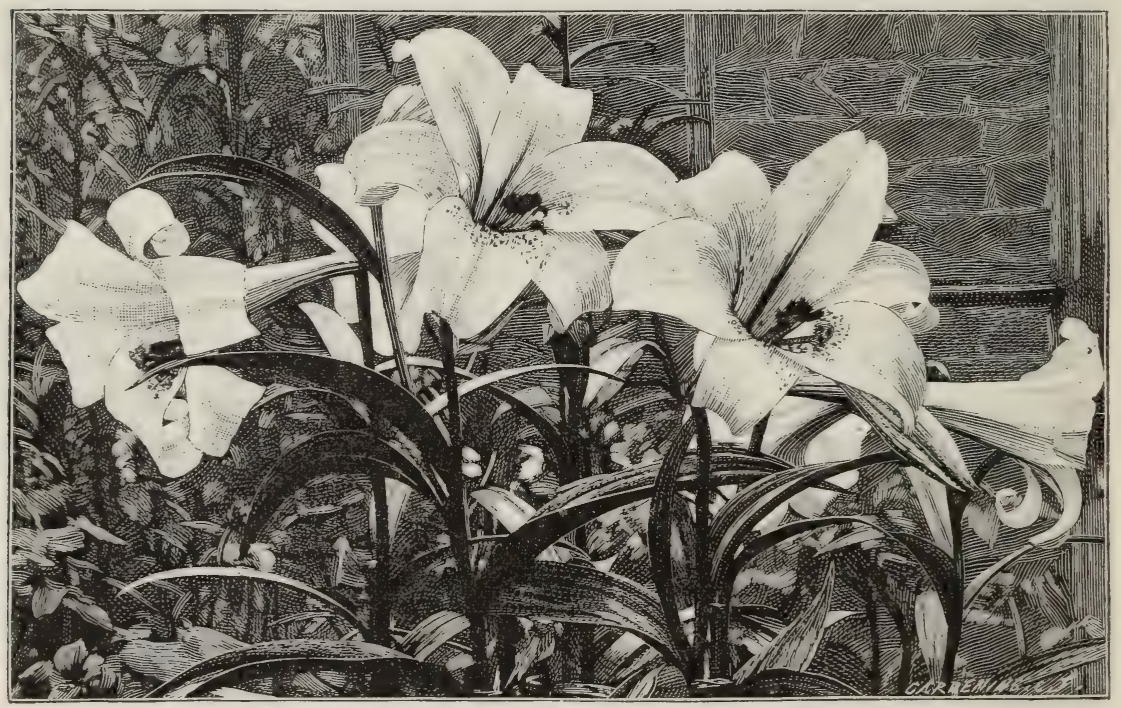

PORTION OF BED OF WHITE TRUMPET LILY (LILIUM LONGIFLORUM).

or a beautiful Grass, it is not easy to succeed with unless it has a fair chance, away from the confusion of the ordinary flower border.

This special culture of favourite flowers is possible either in the beds of the flower garden or in a plot of ground set aside for square beds of the choicer flowers.

A good way is to have a piece of ground in or near the kitchen garden or any other open position, sheltered, but not shaded. Such ground should be treated as a market gardener would treat it-well enriched, and open. It can be thrown into four-foot beds, but in this case the little pathways need not be gravelled or edged: they may simply be marked out with the feet. With the aid of such a division of the garden, the cultivation of many fine hardy plants becomes a pleasure. Well furnished, such a garden is a delight. When the things get tired of the soil, or require a change, it is easy 
to have a rotation, making the Carnation bed of past years the bulb one for the next year, and so on. It would be easy to change one's favourites from year to year, so that richly-feeding plants should follow those of a surface-rooting kind, and thus the freshness of the garden would be kept up. It is better to see ground covered with flowering plants than devoted to edgings and gravel. If any edging is used, it should be of thin stone sunk in the earth, as natural stone edgings are not offensive, troublesome, or costly. The abolition of all edgings, beyond one or two main lines through the plot, would tend to more careful culture, as the whole spot could be so readily attended to. Such a plot would be excellent for all who wish to cut flowers in quantity, and also a great aid as a nursery. It would also be a help to exchanges with friends or neighbours, in the generous way of all true gardeners. The space occupied by such an arrangement depends upon the size and wants of the place; but, wherever the room can be spared, an eighth of an acre might be devoted to the culture in simple beds of favourite flowers, and even the smallest garden should have a small plot of this kind.

What to GROW In THE RESERVE GARDEN.-Among the fair flowers which in this way may be cultivated, each separately and well, are the delightful old Clove Carnations-white, crimson, and scarlet, as well as the various mixed and named races of the same family; the tall and graceful Phloxes, so fair in country gardens in the autumn ; the scarlet Lobelias, splendid in colour ; Pinks of many kinds, white and coloured, and hybrid; pretty Persian and Turban Ranunculus; bright old garden Anemones, and the finer species of Anemone, like the scarlet A. fulgens; Lilies, commencing with the beautiful old white Lily, and as many as possible of the splendid species introduced into our gardens within the past dozen years from California and Japan; the tall perennial Delphiniums or perennial Larkspurs, with their spikes of lovely blue ; the old double Rockets ; beautiful Irises, English, Spanish, Japanese, and German; Pansies in great variety, the old Tiger Flowers ; the beautiful races of Columbine, including the lovely A. cœrulea of the Rocky Mountains and the golden Columbine of the same region; the blue African Lily in various forms, and with it the Belladonna Lily; Pyrethrums, showy and varied; Verbenas, which may be raised from seed during the current year; Chinese Pinks, rich in colour, large, and finely fringed; the old garden Scabious; the blue Cornflower, one of our most precious things; Sweet Williams; Stocks of many kinds; Wallflowers, double and single; the annual Phlox, which has now broken into a fine series of different colours; Zinnias, which, if grown as grown abroad - that is to say, well and singly grown-are very fine in colour and sometimes as large as Dahlias; China Asters, quilled 
and others ; the Sweet Sultan, in two or three forms; showy tricolour Chrysanthemums; Grasses of the more useful kinds, suitable for cutting in winter; Grape Hyacinths; Narcissus in choice variety; Meadow Saffrons, pretty in the autumn; Lilies of the Valley, of which a variety of kinds are now coming into cultivation, differing in length and size of raceme; Crocuses, the autumnal as well as the vernal kinds; the hardy Cyclamens, which are at home on the mountains of Europe and hardy in our own gardens; Dahlias, double and single ; Evening Primroses; Pæonies, in splendid variety; Primroses, double and single, of many kinds; Pentstemon, graceful autumn flowers; Polyanthus, richly-coloured vigorous kinds, for

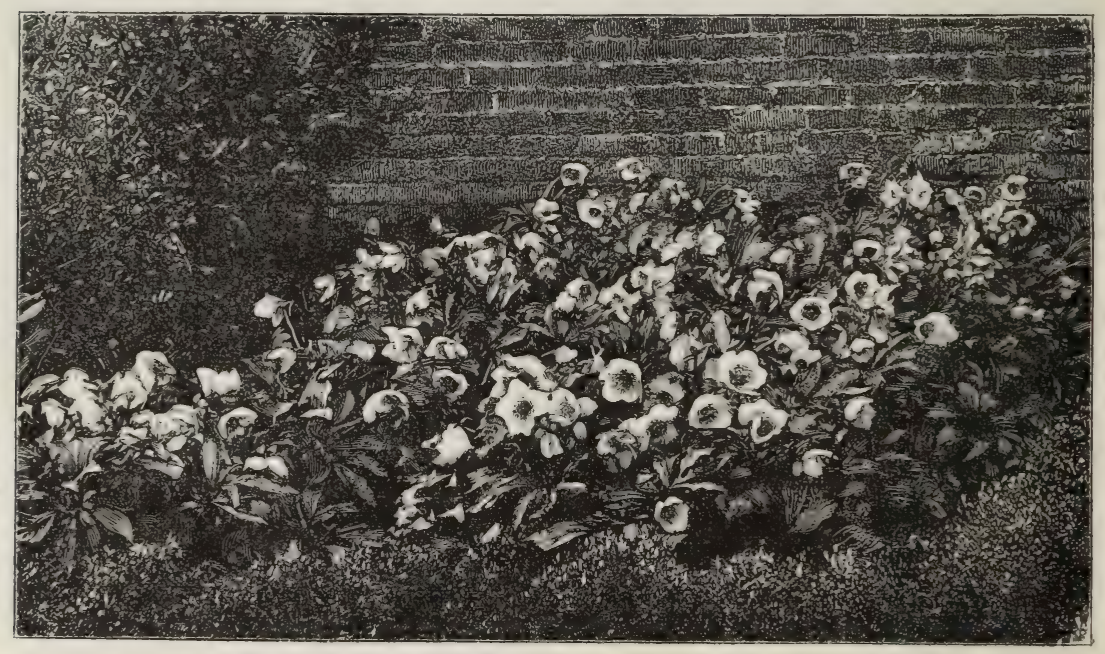

CHRISTMAS ROSES IN BED IN RESERVE GARDEN.

borders; Oxlips ; Tulips, many early and late kinds ; Sweet Violets ; American Cowslips; Gladioli, stately flowers of autumn; Christmas Roses; and lastly, Everlasting Flowers, which may be grown with the Grasses, and, like them, be gathered for the house in winter. All these fair flowers deserve special care in the smallest garden, and should not be trusted to the too often ill-tended and ill-cultivated slips called " mixed borders."

IVe have an example at Munstead of what is meant in the preceding passages by a reserve garden. As may be seen from the plan, it consists of an oblong piece of ground having the walls of the kitchen garden for two of its boundaries, and a Yew hedge sheltering it from the east winds, while the other is screened by trees and shrubs, with which are intermingled hardy plants of tall growth. The plants are set in beds without reference to the general effect, and all the 


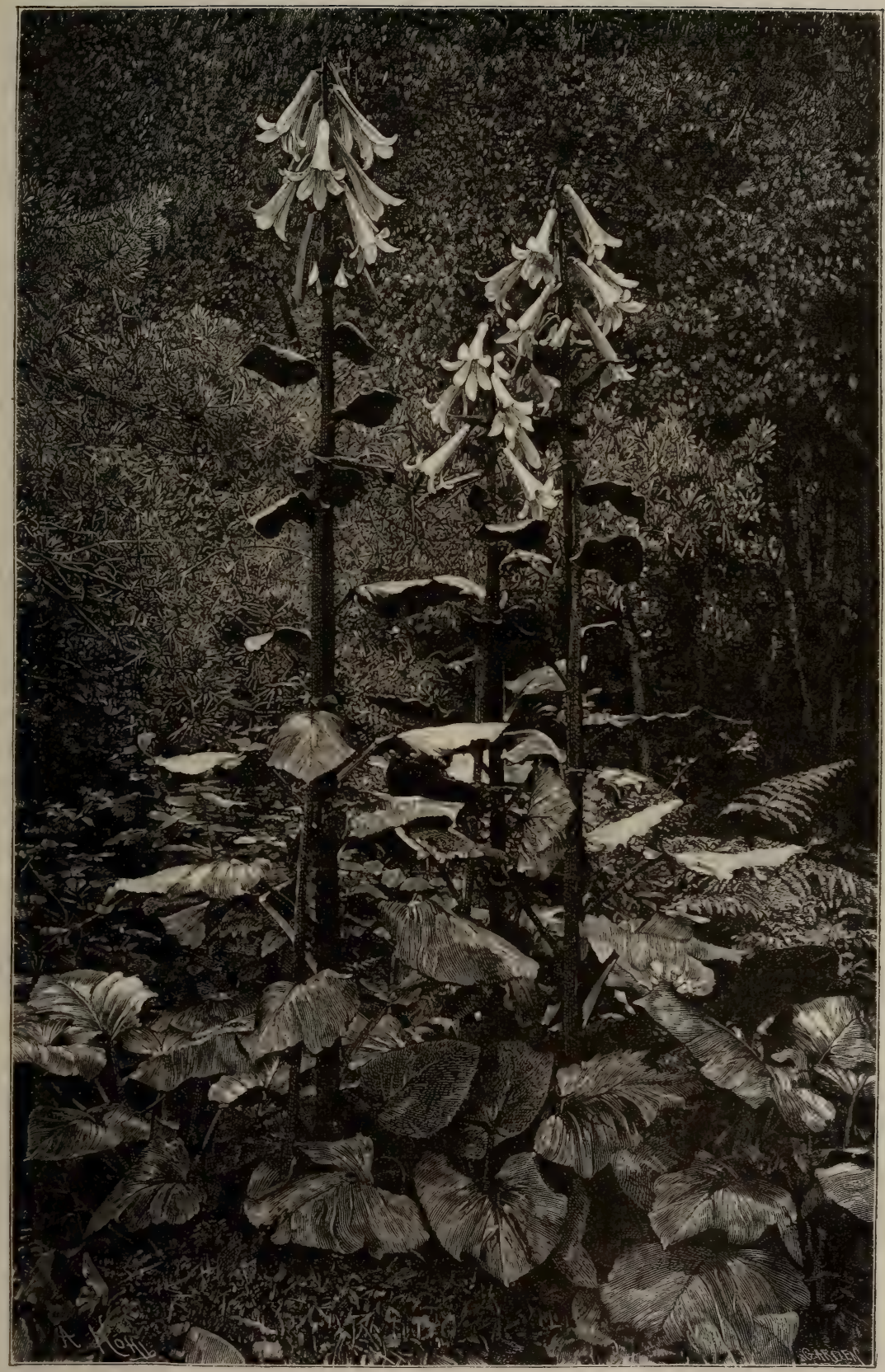

MASS OF GIANT INDIAN LILY IN A SURREY GARDEN. 
borders being edged with stone dug on the place, give no trouble after the stones are properly set; when old and moss-grown the stones look better than anything else that could be used-the dwarfer plants being allowed to run over them and break the lines. Every year the plan of such a garden may be varied as our tastes vary and as the flowers want change. A similar garden ought to be in every place where there are borders to be stocked and maintained in good condition, and particularly where there is a demand for cut flowers.

In these special gardens for hardy flowers are included the various hardy flowers of florists. The term "florists' flowers" was once applied to flowers supposed to be popular with amateurs and florists, but it had never any clear meaning. A Rose is above all a florist's flower; but it is more-it is everybody's flower, and we call it a Rose, and have no use for any other term. Flowers are for all who see as well as for specialists. In connection with the reserve garden, this is the best place to speak of growing

Flowers FOR THE BREAKFAST TABLE.-We hear a good deal of dinner-table decoration, but some attention should be given to the breakfast-table! Things that look well by night are all very well, but give us things that bear the light of the morning on a tablecloth. Some are not interested in flowers till they come near, especially the man so long accustomed to his few yellows, reds, and blues in lines and circles. People who love flowers will have them on their tables, even in London; but, considering the opportunities for the growth of hardy and beautiful flowers and for collecting them in the hedgerows which the dwellers in the country have, it is surprising that they do not more frequently use them in the house. Bringing the fair forms of many beautiful flowers near is the best way to make converts. The enemy in the way of plenty of cut flowers has hitherto, no doubt, been the gardener. But the poor fellow was confined in his cutting operations to glass houses, which he naturally wished to have gay. A supply equal to that of twenty plant houses can be got from an open square in the kitchen garden, or any piece of good ground. For eight months there is a continual progress of open-air flowers, which can easily be grown in sufficient quantity to allow the cutting of plenty for every want. A bed or a few lines of each favourite in a patch of good soil would give a great number of flowers, and these, aided by the Roses and other bush and tree flowers about the garden, would yield all the flowers that the largest house would require, and many besides for hospitals and for those who have no garden. Flowers grown for cutting should be carefully selected as regards odour, form, and colour. The gardener should do all he can to carry out an idea tending so much to enhance the resources of his art, and to give people pleasure 
at home. The smallest country place can afford a spot of ground to grow flowers for cutting. In large gardens this should be made a feature, and it would be enjoyed for its beauty as much as is the flower garden. From this and the general open garden collections - the woods, hedgerows, and copses - every charm of flower life might be culled in abundance for the adornment of the house. Here flowers, the most choice and elegant in form, should be brought near the eye, not in coarse, unconsidered jumbles, but each bunch placed where it would look best, and in such a quantity as best to show its form.

\section{GARDENS OF ONE FLOWER}

Branching away naturally, so to say, from the reserve garden, with flowers in formal and close masses, we may have for a variety of reasons gardens of one hardy flower and its forms, for the purpose of studying a family or adding to it by collecting or crossbreeding. Such gardens may now and then arise from the difficulty of cultivating a flower, as was the case of this most charming garden of the lovely forms of our native Primrose formed by a friend of mine, who thus describes it.

\section{A Primrose Garden}

"No flower better deserves a garden to itself than the Primrose. It is so old a favourite, and has been cultivated into so many forms, that any one determined to have a Primrose garden may choose the kind he likes best, and set to work accordingly. There are the single-stalked Primroses, the earliest of all, flowering from the middle of March onwards, while some may be had in bloom as soon as the end of February. They range in colour from pure white to deep primrose, and from palest pinky-lilac through strong red-purples to a colour nearly approaching blue, and there are also rich reds of many shades. There is not as yet any Primrose of a true pink colour, nor, though the type colour is yellow, are there as yet any strong yellows of the orange class. There are also double Primroses in nearly all the same colourings. The florist's Polyanthus, with its neat trusses of small flowers, though beautiful in the hand and indispensable in the good garden of hardy flowers, is not a plant for the Primrose garden, as it makes no show in the mass. The grand Primroses for garden effect are the large bunch-flowered kinds, white, yellow, and orange-coloured, red, crimson, and rich brown ; of infinite variety in form, texture, habit, and colouring, easy to raise to any amount by seed, as also by division of the older plants. A Primrose 


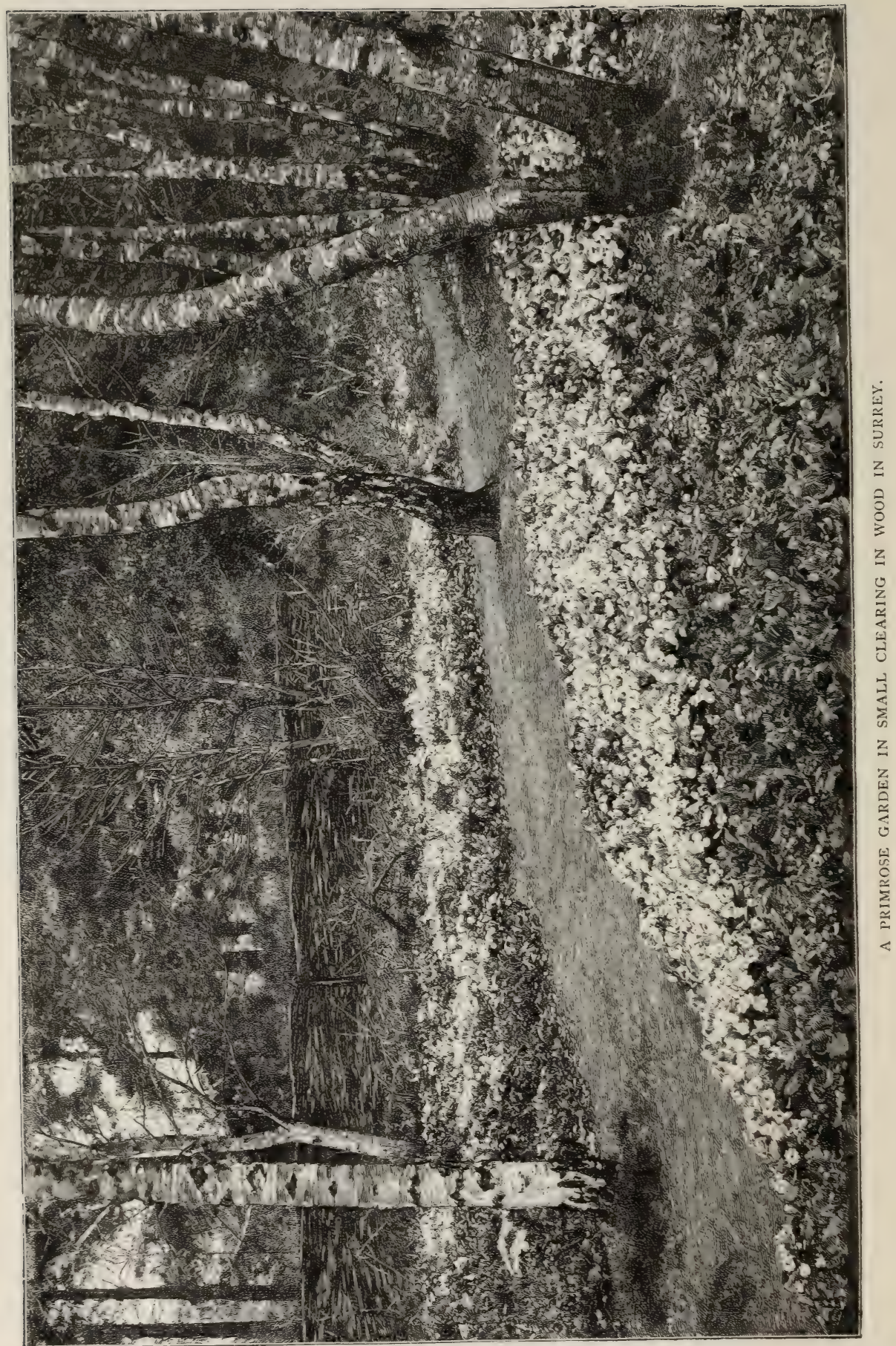


garden (part of which is here illustrated), that for some years has been an ever-increasing source of pleasure and interest to its owners, was formed a few years ago by making a cutting about 70 yards long, and varying from Io yards to I 5 yards wide, through a wild copse of young Birch trees. The natural soil was very poor and sandy, so it was prepared by a thorough trenching and a liberal addition of loam and manure, which has to be renewed every year. No formal walks are made, but one main track is trodden down about 2 feet wide near the middle of the space, dividing into two here and there, where a broader clearing makes it desirable to have two paths in the width. The older divided plants are put into groups of a colour together, from twenty to fifty of a sort. The groups of seedlings are of necessity more various, though they are more or less true to the parent colour, so that a patch of a hundred seedlings-from yellows, for instance-will give a general effect of yellow throughout the group. The whites and yellows are kept at one end of the garden, and the reds at the other; the deepest yellows next to the reds. Seen from a little distance, the yellow and white part of the Primrose garden looks like a river of silver and gold flowing through the copse. The white stems of the Birches and the tender green of their young leaves help to form a pretty picture, which is at its best when the whole is illuminated by the evening sunlight."

The question has been much discussed whether it is best to sow Primrose seed as soon as it is ripe, or to keep it over till March in the next year. Such strong opinions have been expressed on both sides, and by such trustworthy writers, that one can only conclude that each way is the best in its own place. Both have been tried in connection with the Primrose garden above described, where the seed sown the next March answers much the best. It may therefore be assumed that this is the way that suits seedlings for a light soil; whereas the sowing as soon as ripe is right on heavier ground, where the plants may also stand two years without division.

\section{Hardy Plants for Reserve Garden and for Cutting Flowers}

For convenience, a list of the plants suited for such a garden is here supplied. The amateur will bear in mind the distinction between plants which repay, and require special culture, and those which thrive anywhere.

Carnations, white, crimson and scarlet Phloxes Selfs, and mixed and named sorts

Lobelia cardinalis (Scarlet Lobelia)

Clove Pinks, and named sorts
Ranunculus (Persian and Turban)

Anemone, garden varieties and the finer Lilies species

Delphiniums (Larkspurs) 
Double Rockets

Iris, finer kinds

Pansies

Alstrœmeria (Herb Lily)

Tigridia (Tiger-flower)

Columbines, fine varieties and species

Agapanthus, the various kinds (African Lily)

Amaryllis (hardy), Belladonna and Ackermanni

Pyrethrum

Schizostylis coccinea (Caffre Lily)

Vallota purpurea (Scarboro' Lily)

Verbenas

Chinese Pinks

Scabious

Blue Cornflower

Sweet Williams

Stocks

Double Wallflowers

Tricolor Chrysanthemums

Grape Hyacinth, finer and rarer kinds

Grasses, the more graceful kinds, such as the Brizas, Bromus brizæformis, Panicum capillare, Agrostis nebulosa, and others

Phlox Drummondi

Zinnias

Sweet Sultan in var.
Narcissus, finer and rare kinds, till plentiful enough to spare for scattering in Grass or borders

China Asters in various classes

Campanula, finer kinds for cutting

Chrysanthemums (to flower in open garden)

Meadow Saffrons (Colchicum)

Lilies

Crinum capense in vars. (Cape Lily)

Crocus, newer and rare species

Cyclamen, hardy species

Hardy Orchids, the finer kinds

Dahlia, double, single, bouquet, and fancy

Pæonies, in great variety

Pentstemon

Primroses

Polyanthus

Oxlips

Tulips, vars. and species

Violets

American Cowslips

Dog's-tooth Violets

Gaillardia

Gladiolus (Sword Lily)

Everlasting flowers for gathering-Rhodanthe, Helichrysum, Acroclinium, Gnaphalium orientale

Helleborus, finer species and varieties

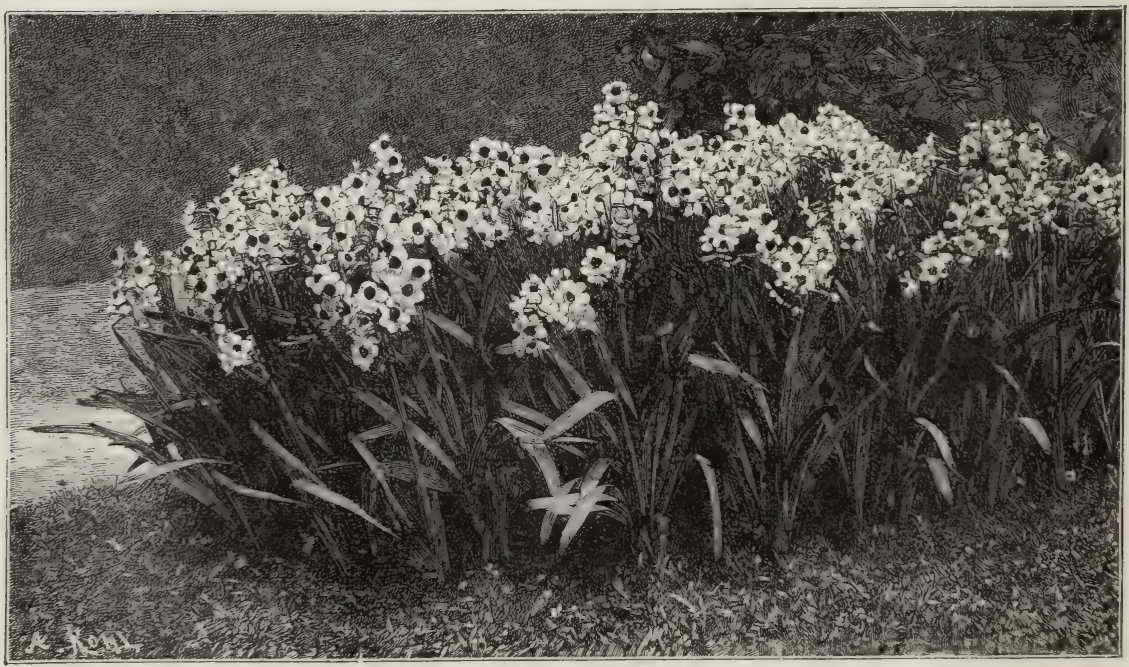




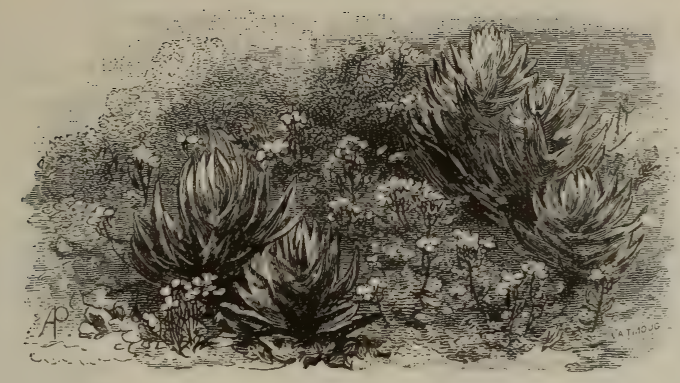

LILIES COMING THROUGH CARPET OF WHITE ARABIS.

\section{CHAPTER V}

\section{HARDY BULBS}

THE special or reserve garden includes beds for hardy bulbs-a very good way of growing them. They are, however, so much used in almost every kind of gardening with hardy plants, that we can treat of them separately to a limited extent only. It will be remembered that each family and kind is dealt with in the body of the book, and its culture there given.

Hardy bulbs are among the best plants for affording supplies of flowers for the house. A curious habit of the flowers of bulbs is that when cut from the plants early they get larger than they would out of doors. This peculiarity is one that may lead us to make more of the many lovely flowers among hardy bulbs. Hitherto the horror of the gardener has been cutting flowers for the house; but if cutting prolongs his bloom, strengthens his plants, and gives all who care for his flowers a fuller enjoyment of them, we may secure his powerful aid. Consider what one may escape in storms, frosts, and other dangers if a flower, cut just on arriving at maturity, lasts longer indoors than out, and actually, as in the case of the Narcissi, gets larger! Narcissi, through their hardiness and drooping heads, endure our climate better than any other flowers, and yet severe storms will beat them about and destroy flowers that might have been happy for days afterivards in the house. When we come to large showy flowers like Tulips and other bulbs exposed to the sky, then we have flowers that must suffer with every heavy shower. Anything which makes the presence of flowers in the house more easy is a real gain. Their exquisite forms are best seen, and tell their story best when brought near to the eye. A flower of our 
yellow wood Tulip opening and closing, and showing its exquisite form and texture in a room, gives an idea of its grace and beauty which cannot be gleaned by glancing at a bed of bulbs. A variety of hardy bulbs should therefore be grown for their value as cut flowers, apart from their great value in the open garden. The use of bulbs in the wild garden is discussed under that heading. In grassy or bushy half-wild places the hardier forms-and there are many-are much more at home than on bare borders; and, moreover, do not need care after planting.

One of the most marked improvements is the planting of handsome bulbs in heavy close masses of Rhododendrons and similar

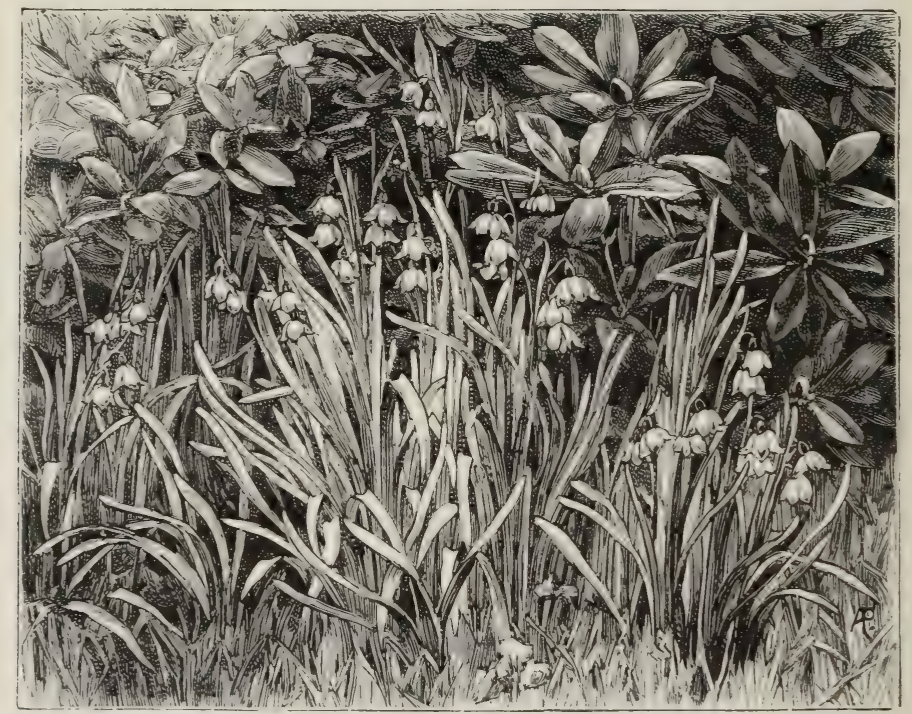

COLONY OF SUMMER SNOWFLAKE, ON MARGIN OF SHRUBBERY (LONGLEAT).

bushes. These beds look interesting only when in flower, and not always then, owing to the flat and monotonous surface into which the shrubs are pressed. I have frequently suggested that Lilies and the finer bulbs should be placed among the shrubs. In many cases where this view has been extensively adopted it has almost changed the entire aspect of gardens, and given various beautiful types of life instead of only one. Many fine rare bulbs find a home in such beds, which are, as a rule, unhurt by the spade. In placing choice, peat-loving shrubs, give the bushes room to fully attain their natural forms, and plant the interspaces with finer bulbs. Light and shade, relief and grace, are among the merits of this mode of planting. Beds of the smaller shrubs will suit admirably for the smaller and more delicate bulbs. Rose beds serve in the same 
way, the shelter of these and of low shrubs being an advantage to many bulbs whose leaves suffer from cold winds.

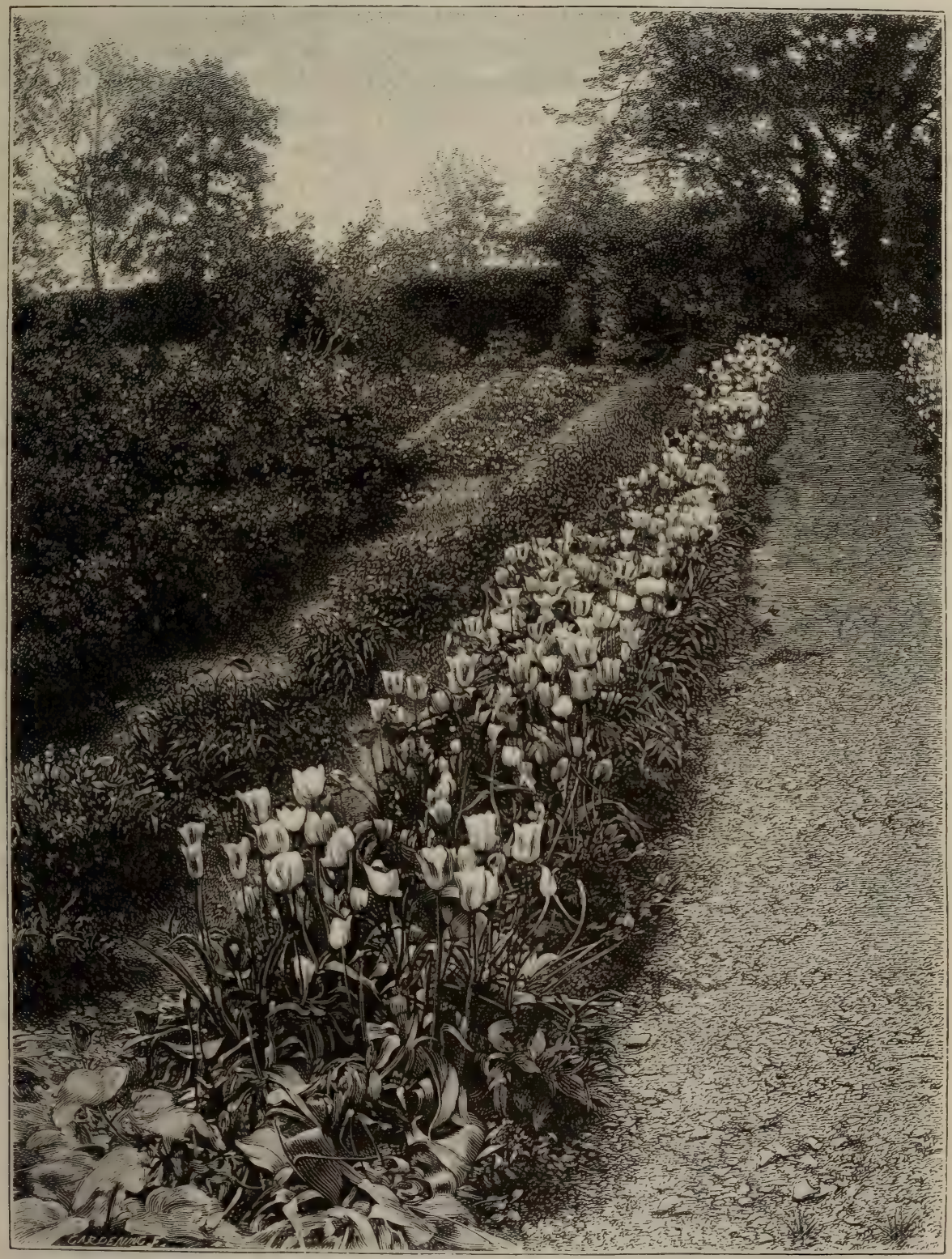

TULIP GARDEN AT THE CASTLE, DINGWALL.

BULBS IN LARGE BEDS.-Not only in beds in the reserve garden may bulbs produce a fine effect. They are admirable for 
the lawn, and for quiet corners of the pleasure-ground. The showy beds of bulbs which are to be seen in public and other gardens, and which come so largely into spring gardens, are familiar to all. The beds suggested here are of a higher and more permanent nature, and are to be placed where they will be let alone. In visiting Moulton Grange some years ago I saw on a piece of quiet Grass a bed of Tiger Lilies with no other flowers near to mar its beauty. It was a large oval bed, and the colour of the finely-grown Lilies was brilliant and effective when seen through the trees and glades. In point of colour alone, nothing could be better; the mass of bloom was profuse, and the plants, about 6 feet high, told well in the garden landscape. The plants had a great advantage in habit, form, and colour over the usual dwarf type, which is claimed to be the strong bedding plant. Many hardy flowers of the highest beauty would have as good colour if we took equal pains with them. Colour on a 6 -foot plant must usually be more effective than colour on a plant 6 inches or 12 inches high. But this is putting the thing in the lowest way, perhaps, for, after all, flowers will be judged of for other reasons, and however rigid our selection, the stronger and finer varieties of the Tiger Lily must find a place with us. The bed, it may be remarked, was on one of those little bits of turf which occur by most shrubberies, and within a few yards of a walk, so that it could be easily examined near at hand. It was perhaps better so placed, because other plants of varying height and character were not near to confuse or weary the eye. The plant could get exactly the proper culture, and should it tire of the spot, it would be easy to remore it to another home and to replace it with some wholly different plant. Among the most lovely beds are those of the nobler Lilies, in quiet, sheltered spots. The proposed plan also admits of fine variety,- -in the great hardy kinds, in the varieties of one species, like the Panther Lily, grouped together, or in the finer species mixed. Then, other good combinations may arise from intermingling Lilies with the finer Irises, and surfacing and edging the beds with spring flowers. Among Irises, I. reticulata is one of the loveliest of spring flowers, with its Violetscented blossoms of gold and purple as brave as Snowdrops.

BLLBS IN THE SHRUBbERI.--Here are large opportunities for using the hardier and handsomer bulbs. The present mode of forming a shrubbery should be given up by all. Our many fine hardy shrubs and our suitable climate should make us care more about them. Let each form a specimen, or a group, not mutilated, but well grown and furnished to the ground, the plants not touching each other, because to enjoy the beauty of their form and allow each to assume its natural shape it is necessary to leave spaces, 
such as do not occur in the "choke-muddle shrubbery." Those spaces may be alive with bulbous flowers, hardy, and beautiful. Any wide belt of shrubbery might be the most delightful garden, varied, broken, not dug on the edge; not stiff in any part; full of flowering things and beautiful Evergreens; and many kinds of bulbs happy among them, and all the better for the common occupation of the soil.

Some Bulbous and like Plants for British Flower Gardens

$\begin{array}{llll}\text { Acis } & \text { Convallaria } & \text { Leucojum } & \text { Schizostylis } \\ \text { Agapanthus } & \text { Crocus } & \text { Lilium } & \text { Scilla } \\ \text { Allium } & \text { Cyclamen } & \text { Montbretia } & \text { Sparaxis } \\ \text { Alstrœmeria } & \text { Dahlia } & \text { Muscari } & \text { Sternbergia } \\ \text { Amaryllis } & \text { Erythronium } & \text { Narcissus } & \text { Tigridia } \\ \text { Anemone } & \text { Fritillaria } & \text { Nerine } & \text { Trillium } \\ \text { Anthericum } & \text { Galanthus } & \text { Orchis } & \text { Triteleia } \\ \text { Arum } & \text { Gladiolus } & \text { Ornithogalum } & \text { Tritonia } \\ \text { Begonia } & \text { Galtonia } & \text { Oxalis } & \text { Tropæolum } \\ \text { Calla } & \text { Hyacinthus } & \text { Pæonia } & \text { Tulipa } \\ \text { Calochortus } & \text { Iris } & \text { Pancratium } & \text { Valotta } \\ \text { Chionodoxa } & \text { Ixia } & \text { Puschkinia } & \text { Zephyranthes } \\ \text { Colchicum } & \text { Ixiolirion } & \text { Ranunculus } & \text { Zygadenus }\end{array}$

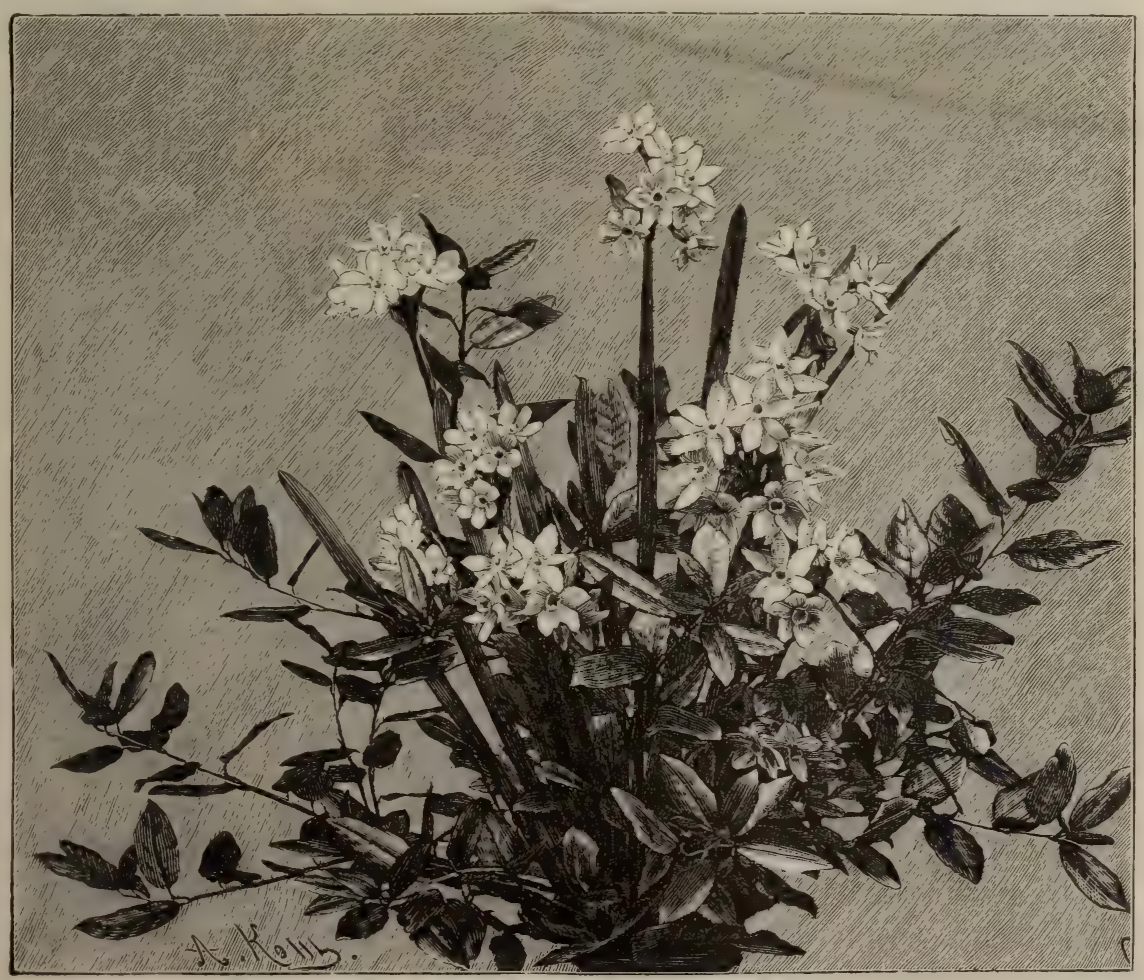




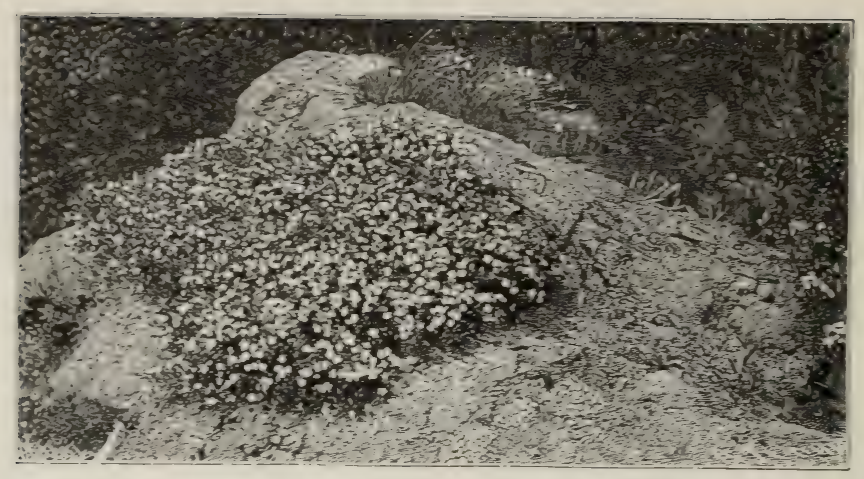

CHAPTER VI

\section{ALPINE AND ROCK GARDENS}

Is the culture of alpine plants, the first consideration is that much difference exists among them as regards size and vigour. We have, on the one hand, a number of plants that merely require to be sown or planted in the roughest way to flourish-the common Arabis and Aubrietia, for example; but, on the other, there are many kinds, like Gentiana verna, and the Primulas of the high Alps, which we rarely see in good health in gardens. It is as to the less vigorous species that adrice is chiefly required. Nearly all the misfortunes which these little plants have met with in our gardens are due to a false conception of what a rock-garden ought to be, and of what the alpine plant requires. It is too often thought they will do best in our gardens if merely elevated on tiny heaps of stones and brick rubbish, such as we frequently see piled together and dignified by the name of "rockwork." Mountains are often "bare," and cliffs are usually deroid of soil; but we must not conclude that the choice jewellery of plant life scattered orer the ribs of the mountain lives upon little more than the air and the melting snow! Where else can we find such a depth of stony soil as on the ridges of dibris flanking some great glacier, stained with tufts of crimson Rockfoil? Can we gauge the depth of that chink from which peep tufts of the beautiful little Androsace helretica? No; for ages it has gathered the crumbling grit, into which the roots enter so far that nothing we carry can dig them out. And if we find plants growing apparently from mere cracks without soil, eren then the roots simply search farther into the heart of the flaky rock, so that they are safer from want of moisture than in the best soil. 
I met on the Alps with plants not more than an inch high firmly rooted in crevices of slaty rock. By knocking away the sides

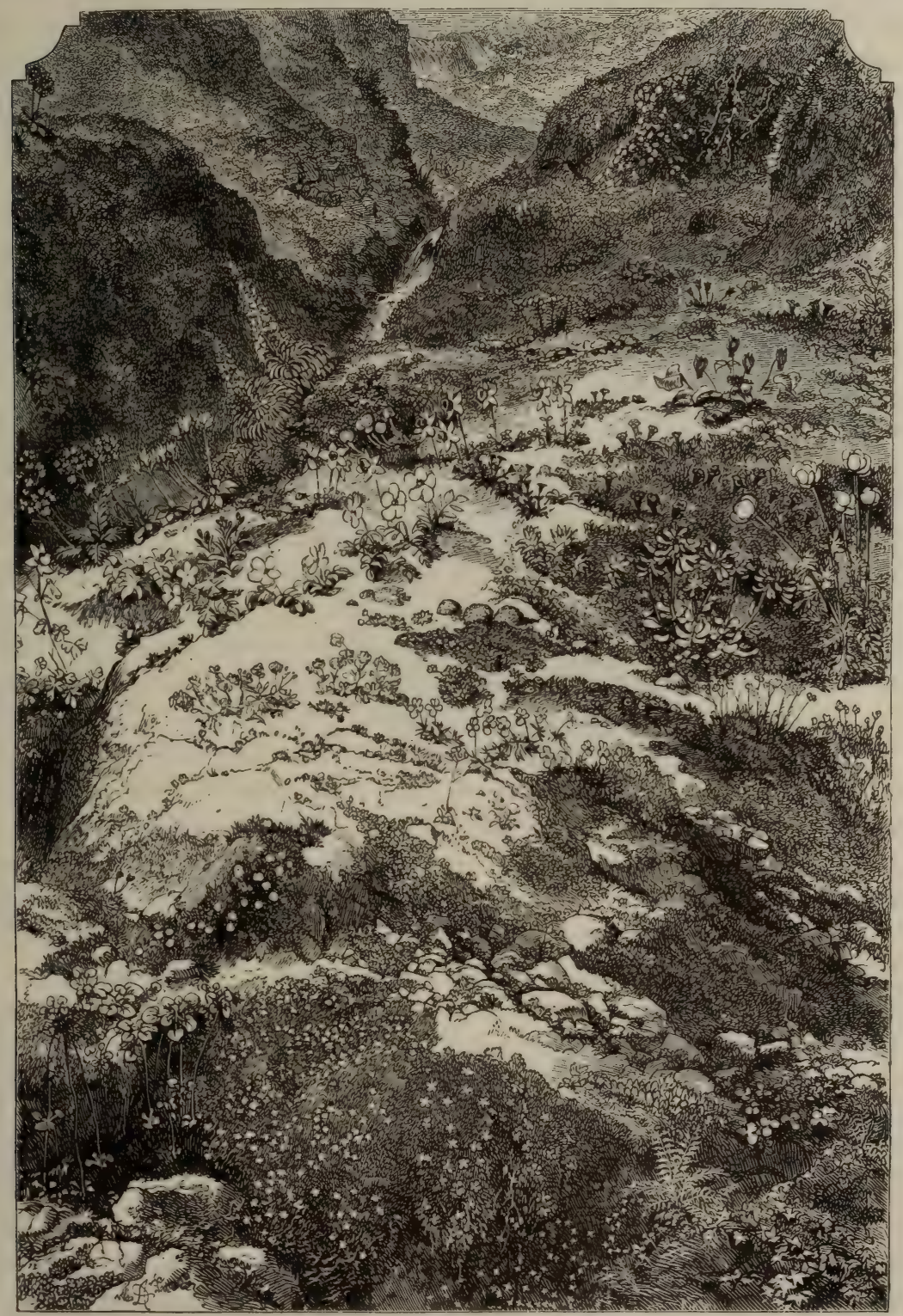

ALPINE FLOWERS AT HOME.

from bits of projecting rock, I laid the roots quite bare, and found them radiating in all directions against a flat rock, some of the largest being more than a yard long. Even smaller plants descend 
quite as deep or even deeper, though it is rare to find the texture and position of the rock such as will admit of tracing them. It is true we occasionally find in fields of flat hard rock hollows in which moss and leaves have gathered, and where, in a depression of the surface, without an outlet of any kind, plants grow freely enough ; but in droughts they are just as liable to suffer from want of water as they would be in our plains. On level or sloping spots of ground in the Alps the earth is of great depth, and if it is not all earth in the common sense of the word, it is more suitable to the plants than what we commonly understand by that term. Stones of all sizes broken up with the soil, sand, and grit, prevent evaporation; the roots lap round them and follow them deep down. In such positions they never suffer from want of moisture. It must be remembered that the continual degradation of the rocks effected by frost, snow, and heavy rains in summer serves to "earth up," so to speak, many alpine plants.

In numbers of gardens an attempt at "rockwork" has been made; but the result is often ridiculous, not because it is puny when compared with Nature's work, but because it is generally so arranged that rock-plants cannot exist upon it. The idea of rockwork first arose from a desire to imitate those natural croppingsout of rocks which are often half covered with dwarf mountain plants. The conditions which surround these are rarely taken into account by those who make rock-gardens.

In moist districts, where rains keep porous stone in a humid state, this straight-sided rockwork may support a few plants; but in the larger portion of the British Isles it is useless and ugly. It is not alone because they love the mountain air that the Gentians and such plants prefer it, but because the great elevation is unsuitable to coarser vegetation, and the alpine plants have it all to themselves. Take a patch of Silene acaulis, by which the summits of some of our highest mountains are sheeted over with rosy crimson, and plant it 2000 feet lower down in suitable soil, keeping it moist and free from weeds, and it will grow well; but leave it to Nature, and the strong herbs will soon cover it, excluding the light and killing it.

Although hundreds of alpine flowers may be grown without a particle of rock near them, yet the slight elevation given by stone is congenial to numbers of the rarest kinds. The effect of a wellmade rock-garden is pretty in garden scenery. It furnishes a home for many native and other plants which may not safely be put in among tall flowers in borders; and it is important that the most essential principles to be borne in mind when making it should be stated. The usual mistake is that of not providing a feeding-place for the roots of the plants. On ordinary rockwork even the coarsest British weeds cannot find a resting-place because there is no body 
of soil for the roots to penetrate and find nourishment sufficient to keep the plant fresh in all weathers.

POSITION FOR THE ROCK-GARDEN. - The rock-garden should never be near walls; never very near a house; never, if possible, within view of formal surroundings of any kind. It should be in an open situation. No efforts should be spared to make all the surroundings, and every point visible from the rockwork, as graceful and natural as they can be made. The part of the gardens around the rockwork should be picturesque, if possible, and, in any case, be a quiet open spot with as few jarring points as may be. No tree should be in the rock-garden; hence a site should not be selected where it would be necessary to remove favourite trees. The roots of trees would find their way into the masses of good soil for the alpine flowers and soon exhaust them.

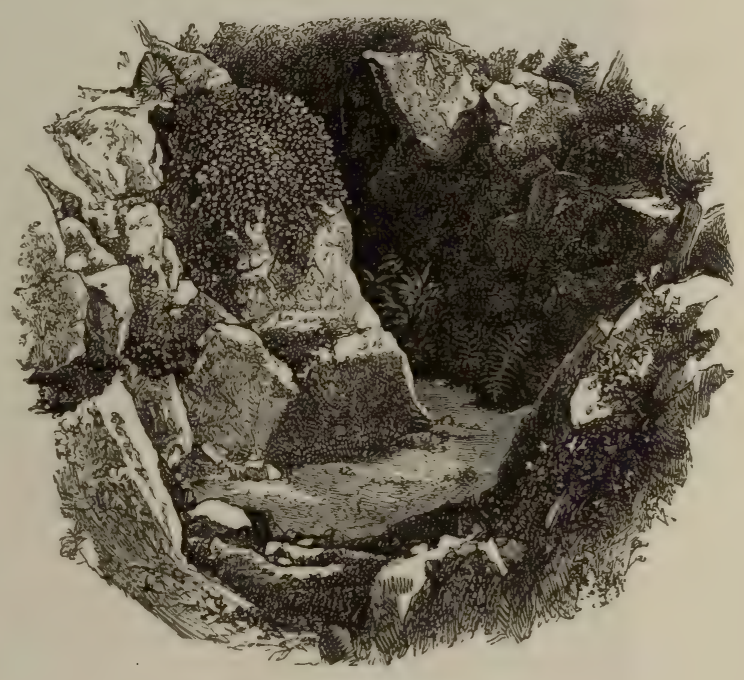

PASSAGE IN ROCK-GARDEN.

Besides, as these

flowers are usually found on treeless wastes, it is best not to place them in shaded places.

As regards the stone to be used, sandstone or millstone grit would perhaps be the best; but it is seldom that a choice can be made, and almost any kind of stone will do, from Kentish rag to limestone: soft and slaty kinds and others liable to crumble away should be avoided, as also should magnesian limestone. The stone of the neighbourhood should be adopted for economy's sake, if for no other reason. Wherever the natural rock crops out, it is sheer waste to create artificial rockwork instead of embellishing that which naturally occurs. In many cases nothing would be necessary but to clear the ground, and add here and there a few loads of good soil, with broken stones to prevent evaporation, the natural crevices and crests being planted where possible. Cliffs or banks of chalk, as well as all kinds of rock, should be taken advantage of in this way: many plants, like the dwarf Harebells and Rock Roses, thrive in such places. No burrs, clinkers, vitrified matter, portions of old arches 
and pillars, broken-nosed statues, etc., should ever be seen in a garden of alpine flowers. Never let any part of the rock-garden appear as if it had been shot out of a cart. The rocks should all have their bases buried in the ground, and the seams should not be visible; wherever a vertical or oblique seam occurs, it should be crammed with earth, and the plants put in with the earth will quickly hide the seam. Horizontal fissures should

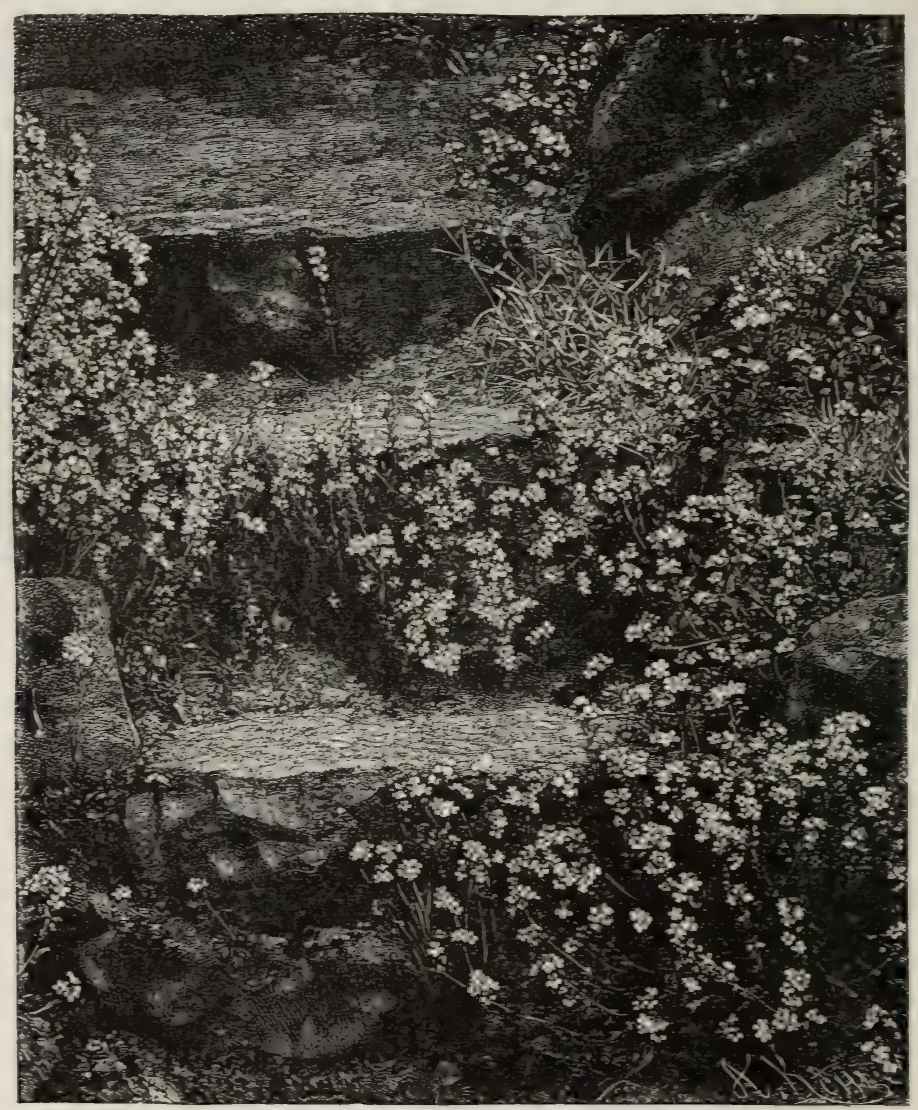

ERINTS ALPINUS ON STONE STEPS.

be aroided as much as possible. No racuum should exist beneath the surface of the soil or surface-stones. The broken stone and grit should be so disposed that there are no hollows. Myriads of alpine plants have been destroyed from the want of observing this precaution, the open crevices and loose soil allowing the dry air to destroy the alpine plants in a very short time, and so one often sees what was meant for a "rockery" covered with" weeds and brambles, and forgotten! 
In all cases where elevations of any kind are desired, the true way is to obtain them by a mass of soil suitable to the plants, putting a "rock" in here and there as the work proceeds; frequently it would be desirable to make these mounds of earth without any strata. The wrong and usual way is to get the elevation by piling up ugly masses of rock.

No very formal walk-that is to say, no walk with regularlytrimmed edges-should come near the rock-garden. This need not prevent the presence of good walks through or near it, as, by allowing the edges of the walk to be a little irregular and stony, and by encouraging Stonecrops, Rockfoils, and other little plants to crawl into the walk at will, a pretty margin will result. There is no surface of this kind that may not be thus adorned. Violets, Ferns,

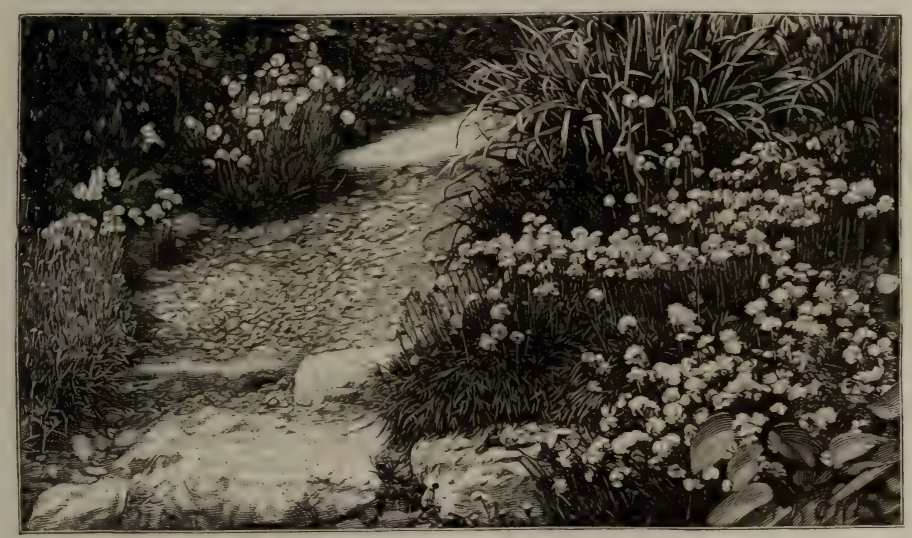

STEPS IN A GARDEN AT CONEYHURST.

Forget-me-nots, will do in the shadier parts, and the Stonecrops and many others will thrive in the full sun. The whole of the surface of the alpine garden should be covered with plants, except a few projecting points, as far as possible. In moist districts, Erinus and the Balearic Sandwort will grow on the face of the rocks ; and quite upright faces of rock will grow a variety of plants. Regular steps should never be in or near the rock-garden. Steps may be made quite irregular, and even beautiful, with violets and other small plants jutting from every crevice. No cement should be used.

In cases where the simplest type of rock-garden only is attempted, and where there are no steps or rude walks in the rock-garden, the very fringes of the gravel walks may be gracefully enlivened by allowing such plants as the dwarfer Stonecrops to become established in them. The alpine Toadflax is never more beautiful than when 
self-sown in a gravel walk. A rock-garden so made that its miniature cliffs orcrhang is useless for alpine vegetation; and all but such wall-loving plants as Corydalis lutea soon die on it. The tendency to make it with overhanging "peaks" is often seen in the cement rock-gardens now common.

SoIL.-The great majority of alpine plants thrive best in deep

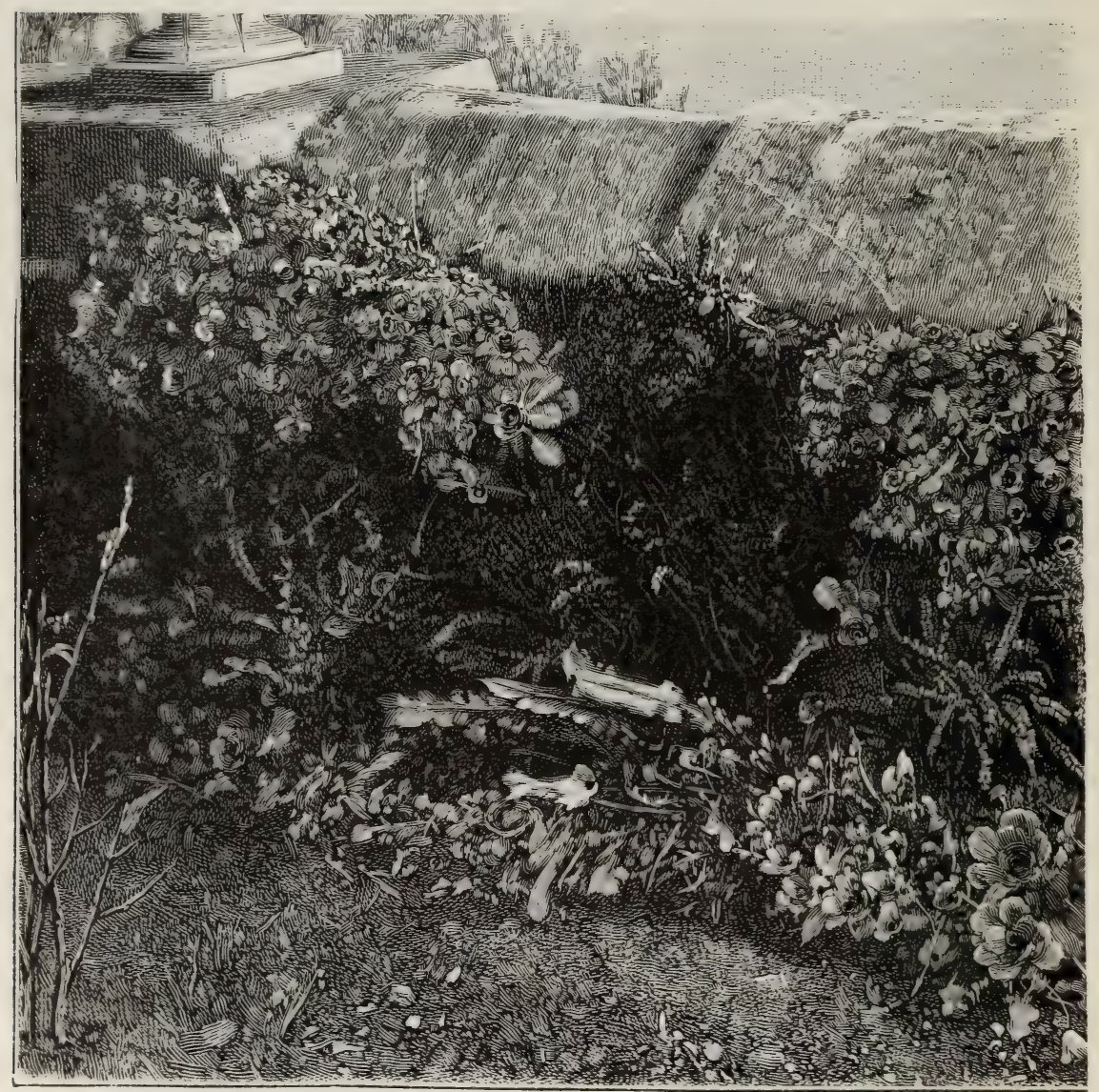

SHADY SIDE OF WALL OF TERRACE COVERED WITH ROCKFOIL AND FERNS.

soil. In it they can root deeply, and when once rooted they will not suffer from drought, from which they would quickly perish if planted in the usual way. Three feet deep is not too much for most species, and in nearly all cases it is a good plan to have plenty of broken sandstone or grit mixed with the soil. Any free loam, with plenty of sand, broken grit, etc., will suit most alpine plants. But peat is required by some, as, for example, various small and brilliant rock-plants like the Menziesia, Trillium, Cypripedium, Spigelia, and a 
number of other mountain and bog plants. Hence, though the general soil may be of the material above described, it will be desirable to have a few masses of peat here and there. This is better than forming all the ground of good loam, and then digging holes for the reception of small masses of peat. The soil of some portions might also be chalky or calcareous, for the sake of plants that are known to thrive best on such formations, like the Milkworts, the Bee Orchis, and Rhododendron Chamæcistus. Any other varieties of soil required by particular kinds can be given as they are planted.

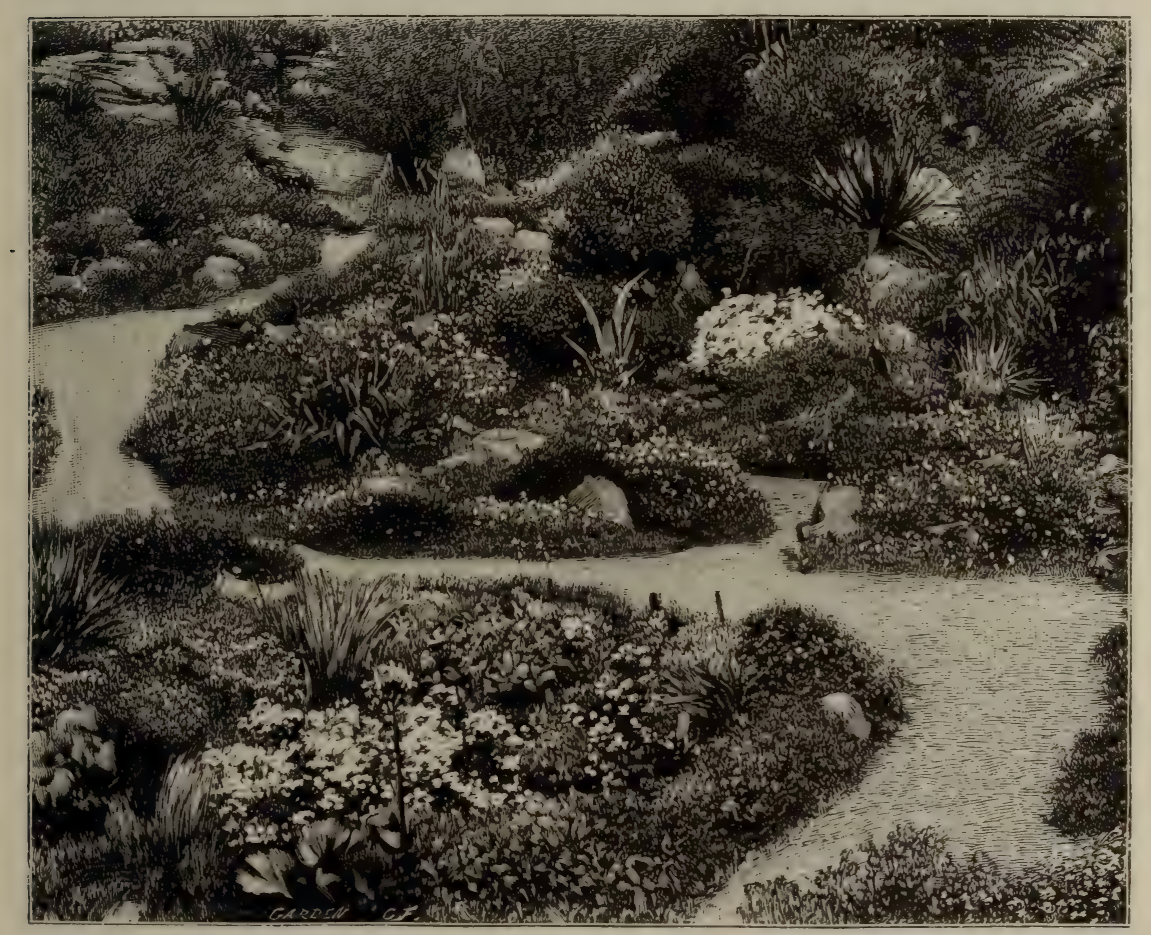

A ROCK-GARDEN AT WINDERMERE.

It is not well to associate a small lakelet or pond with the rockgarden, as is frequently done. If a picturesque piece of water can be seen from the rock-garden, well and good; but water should not, as a rule, be closely associated with it. Hence, in places of limited extent it should not be thought of at all. If a pretty streamlet comes near the rock-garden, so much the better.

In the planting of every kind of rock-garden, it should be remembered that all the surface should be planted. Not alone on slopes, or favourable ledges, or chinks, or miniature valleys, should we see this exquisite plant-life. Numbers of rare mountain species 
will thrive on the less-trodden parts of footways; others, like the two-flowered Violet, seem to thrive best in the fissures between steps; many divarf succulents delight in gravel and the hardest soil.

In cultivating the very rarest and most minute alpine plants, the stony, or partially stony, surface is to be preferred. Full exposure is necessary for very minute plants, and stones are useful in preventing evaporation from their roots.

Few have much idea of the number of alpine plants that may be grown on fully-exposed ordinary ground. But some kinds require care, and there are usually new kinds coming in, which, even if vigorous, should be kept apart for a time. Therefore, where the culture of alpine plants is entered into with zest, there ought to be a sort of nursery spot on which to grow the most delicate and rare

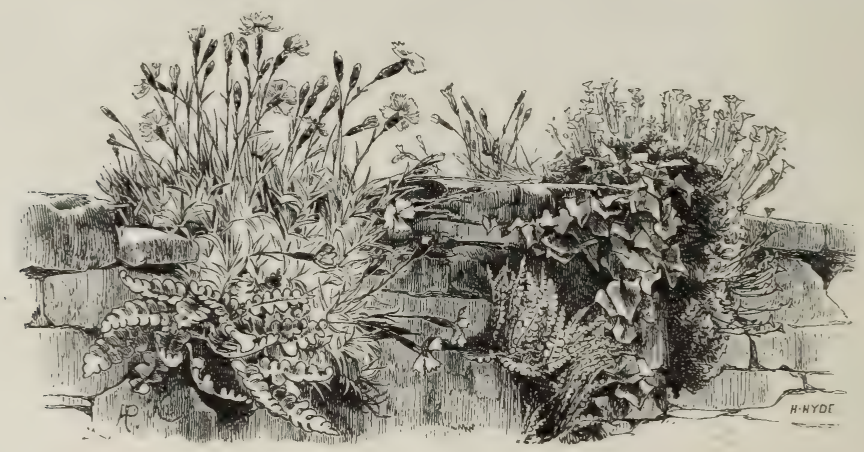

CHEDDAR PINK, SAXIFRAGE, AND FERNS, ON COTTAGE WALl AT MELLS.

kinds. It should be fully exposed, and sufficiently elevated to secure perfect drainage.

A mossy wall, or an old ruin, would give a place for many rockplants which no specially-prepared situation could rival. Those who have observed how alpine plants grow on stony ground must have noticed in what arid places many flourish-fine plants springing from a chink in a boulder. They are often stunted and small in such places, but are always more free-flowering and long-lived than when growing upon the ground. Now, numbers of alpine plants perish if planted in the ordinary soil of our gardens. This results from overmoisture in winter, the plants being more susceptible of injury when growth is induced in our winters. But if many of these delicate plants are placed where their roots dry in winter, they may be kept in perfect health. Many plants from countries a little farther south than our own, and from alpine regions, may find on walls, rocks, and ruins that dwarf, sturdy growth and dryness in winter which go to form the conditions that make them at home in our climate. There 
are many alpine plants now cultivated with difficulty in frames that may be grown on walls with ease!

The best way to establish plants on walls is by seed. The

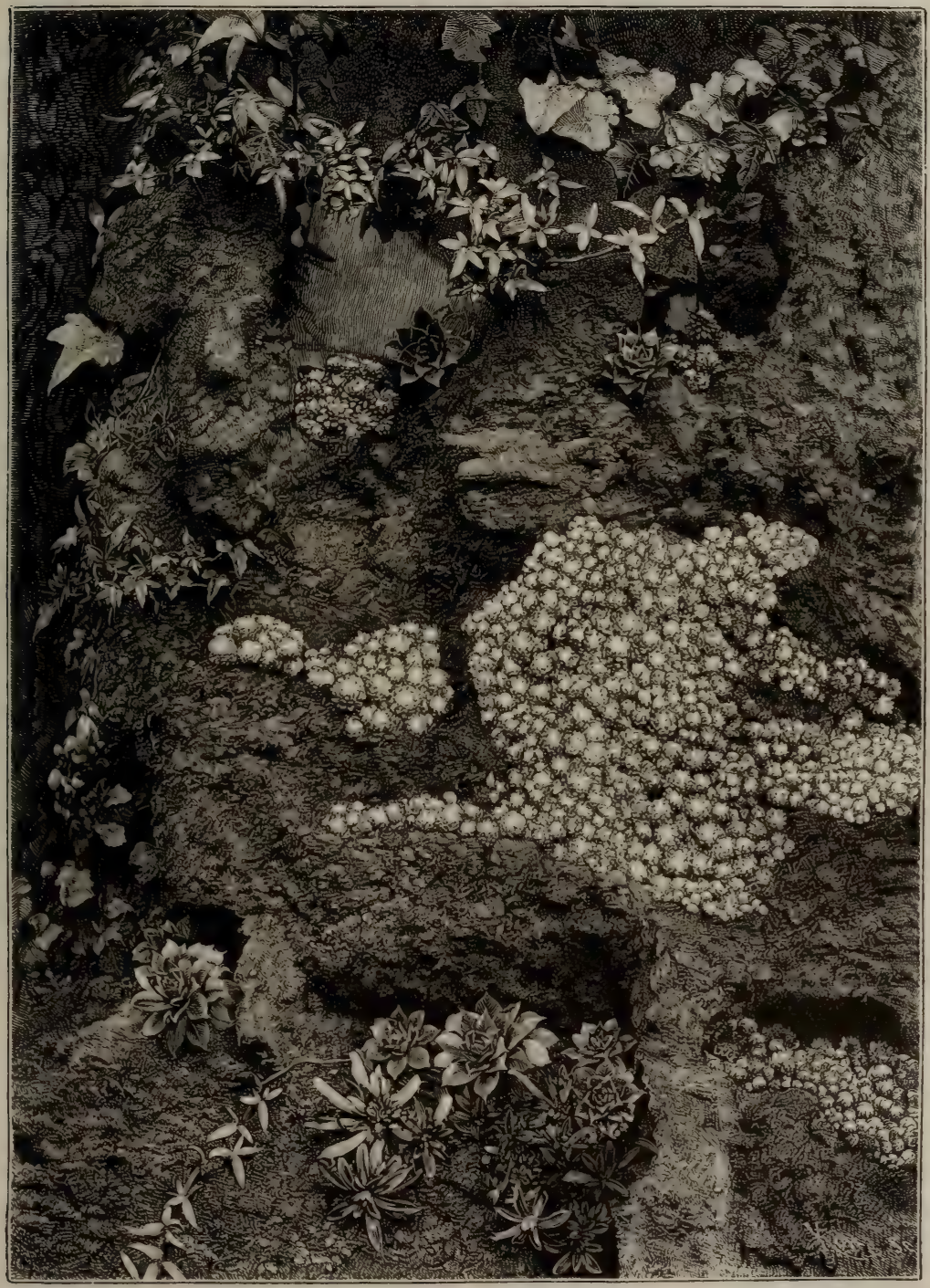

HOUSELEEKS, ETC., AT LAMPORT HALI.

Cheddar Pink, for example, grows on walls at Oxford much better than I have ever known it do on rockwork or on level ground. A few seeds of this plant, sown in an earthy chink, and covered with a dust of fine soil, would soon take root, living for years in fine sturdy tufts. 
Where no old walls exist, by building a rough stone wall, and packing the intervals as firmly as possible with loam, a host of rockplants may be grown. The wall affords the kind of nutriment they require. To many species the wall would prove a more congenial home than any but the best-constructed rock-garden.

AlPINE PLANTS In GROUPS.-A great number of alpine flowers will do perfectly well on level ground in our cool climate, if they are not overrun by coarser plants. Where there are natural rocks or good artificial ones it is best to plant them properly; but people

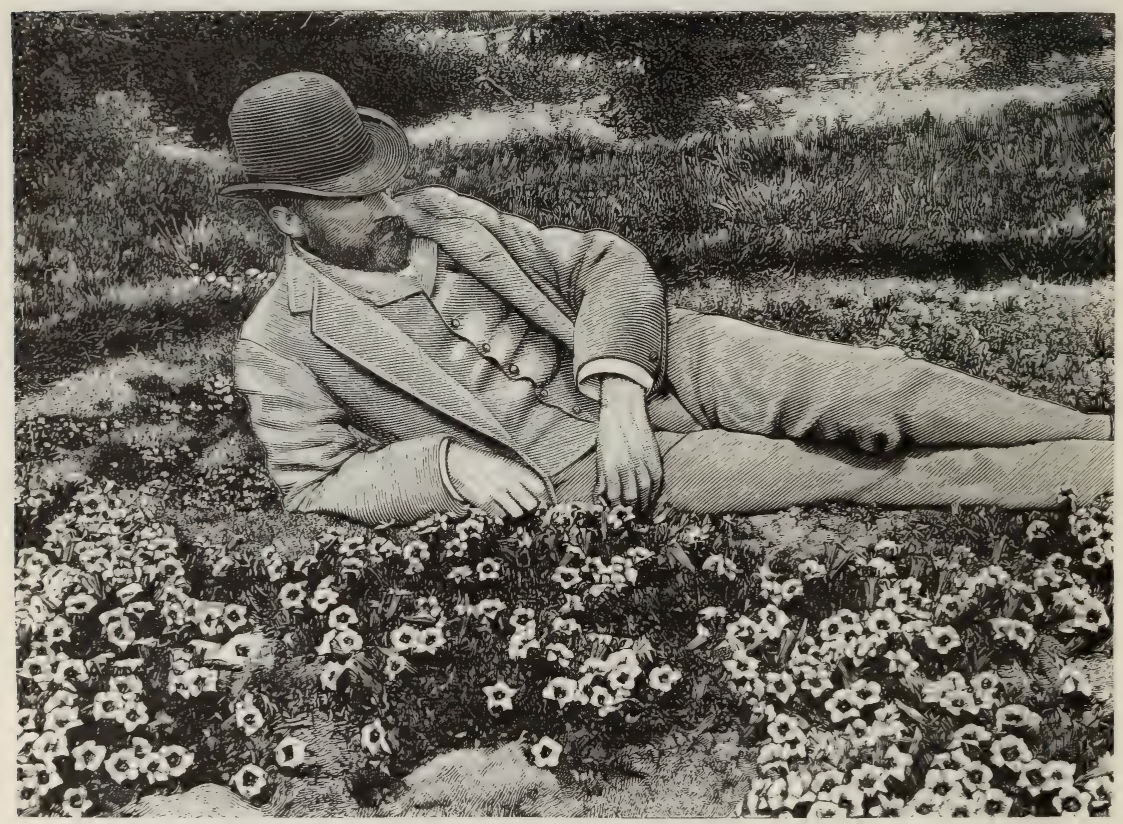

ALPINE GARDEN ON LEVEL GROUND WITH GENTIANELLA IN LARGE GROUP

(FIGURE TO GIVE SCALE).

who are particular would often be better without artificial rockwork if they wished to grow these plants in simpler ways. There is not the slightest occasion to have what is called "rockwork" for these flowers. I do not speak only of things like the beautiful Gentianella, which for many years has been grown in our gardens, but of the Rockfoils, the Stonecrops, and the true alpine plants in great numbers. Then, for the sake of securing the benefits of the refreshing rains, it would often be advisable, in the south of England at least, to avoid the dusty pockets hitherto built for rock flowers. The illustration of Gentians is that of a little alpine garden, made in quite a level place in the worst possible soil for growing the plant, the hot 
Bagshot sand, where the soil is always fit for working after heavy rain, but in hot summer is almost like ashes. By making the soil rather deep and by burying a few stones among the plants to prevent evaporation, this flower, which loves a clay or a rich loamy soil, grew well, as the picture, which is engraved from a photograph, shows.

The next point which I have long insisted on is the great superiority of the natural grouping over the botanical or labelled style of little single specimens of a great number of plants. In this stretch of bed, in the ordinary way, there would be fifty or more plants-but nothing pretty for those who have ever seen the beautiful mountain gardens. Many rightly contend that, in a sense, Nature includes all, and that therefore the term "natural" may be misapplied. But the term "natural" is a perfectly just one when used in the sense of Nature's own way of arranging flowers as opposed to the lines, circles, and other set patterns so commonly hitherto followed by man. By adopting a bold and natural grouping we could get all the colour of "bedding" without a trace of formality. But most gardeners find it difficult to group in this natural way-we have all been so used to setting things out in formal lines. This is a difficulty felt by the most artistic, but a little attention to natural objects will help us to get away from set patterns, and let things intermingle here and there and run into each other to form groups such as we may see among the rocks by alpine paths. After a little time the plants themselves begin to help us by growing irregularly. An excellent way is, if a number of plants are set out too formally -as in most cases they are-to pull up a number here and there after the whole are set.

\section{Plants for Rock-Gardens}

These are as follows. Where the name of a large and varied family is given, as in Phlox, Iris, Rhododendron, Pentstemon, Salix, Antirrhinum, it is the alpine, or dwarf mountain kinds, that are meant.

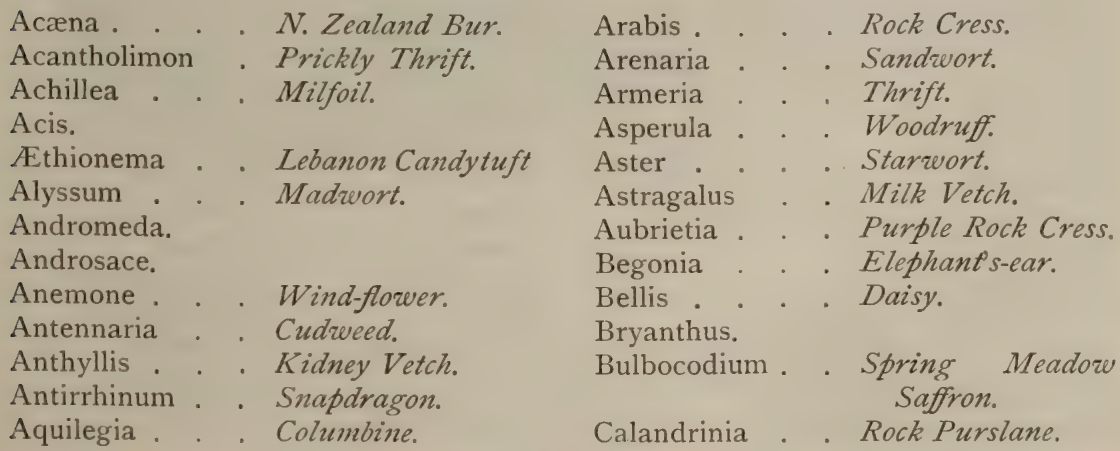


Plants for Rock-Gardens-Continued

\begin{tabular}{|c|c|c|c|c|}
\hline Campanula & & Bell-flower & Isopyrum. & \\
\hline Cardamine & & . Bitter Cress. & Jasione & . Sheep's-bitScabious. \\
\hline Centaurea . & . & . Centaury. & Jeffersonia & Twin-leaf. \\
\hline Cerastium . & . & $\begin{array}{l}\text { Mouse-ear, Chick- } \\
\text { weed. }\end{array}$ & $\begin{array}{l}\text { Leiophyllum } \\
\text { Leontopodium }\end{array}$ & $\begin{array}{l}\text { Sand Myrtle. } \\
\text { - Lion's-foot. }\end{array}$ \\
\hline Cheiranthus . & . & Wallflower. & Leucanthemum & - Ox-eye Daisy. \\
\hline Chimaphila . & . & Wintergreen. & Leucojum . . & - Snowflake. \\
\hline Colchicum & . & - Meadow Saffron. & Linaria & - Toadflax. \\
\hline Convolvulus . & . & . Bindweed. & Linnæa & - Twin-flower. \\
\hline Cornus. . . & . & - Cornel. & Linum . . & - Flax. \\
\hline Coronilla . . & & - Crown Vetch. & Lithospermum & . Gromzuell. \\
\hline Corydalis . . & & . Fumewort. & Loiseleuria & . Trailing Azalea. \\
\hline Crocus. & & & Lotus . & . Bird's-foot Trefoil. \\
\hline Cyclamen. & & & Lychnis . & . Campion. \\
\hline Cypripedium . & & . Lady's Slipper. & Lycopodium . & . Club Moss. \\
\hline Daphne. & & & Lysimachia . & - Loosestrife. \\
\hline Dianthus . & . & - Pink. & Mazus. & \\
\hline Diapensia. & & & Meconopsis . & - Poppyzurt. \\
\hline Dielytra . & 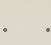 & . Lyre-flower. & Menziesia. & . Heath. \\
\hline Diotis . . & - & - Sea Cottonweed. & Mertensia . & . Smooth Lungwort. \\
\hline Dodecatheon . & & - American Cowslip. & Muscari. & - Grape Hyacinth. \\
\hline Draba . . & & Whitlow Grass. & Myosotis & Mouse-ear. \\
\hline Dracocephalun & & . Dragon's-head. & Narcissus. & . Daffodil. \\
\hline Dryas . . & . & . Mountain Avens. & Nierembergia & . Cup-flower. \\
\hline Epigæa & & . Mayflower. & Nertera . & . Fruiting Duck- \\
\hline Erica . & & Heath. & & weed. \\
\hline Erigeron . & & Flea-bane. & Enothera. . & . Evening Primrose. \\
\hline Erinus. & & & Omphalodes . & - Creeper. \\
\hline Erodium . & & - Heron's-bill. & Ononis. . & . Rest Harrow. \\
\hline Erpetion . & $\cdot$ & - Spurless Violet. & Onosma & Goldendrop. \\
\hline Erysimum. & & & Ophrys & Orchid \\
\hline Erythronium . & & . Dog's-tooth Violet. & Orchis. & \\
\hline Ficaria. & & . Pilewort. & Orobus & . Bitter Vetch. \\
\hline thus. & & Snowdrop. & Oxalis . & - Wood Sorrel. \\
\hline neria & & - Partridge Berry. & Oxytropis. & \\
\hline Genista & & Broom. & Papaver & Poppy. \\
\hline Gentiana . & . & - Gentian. & Paradisia. & . St. Bruno's Lily. \\
\hline Geranium . & . & - Crane's-bill. & Parnassia. & Grass of Parnassus. \\
\hline Globularia & 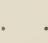 & - Globe Daisy. & Pentstemon. & \\
\hline Gypsophila. & & & Petrocallis & Rock Beauty. \\
\hline Hedysarum . & - & . Bush Clover. & Phlox. & \\
\hline Helianthemum & & . Sun Rose. & Polemonium & . Jacob's-ladder. \\
\hline Helichrysum . & . & . Everlasting. & Polygala & . Milkwort. \\
\hline Helleborus. & & - Christmas Rose. & Polygonum & . Knotweed. \\
\hline Hippocrepis . & & - Horseshoe Vetch. & Potentilla. & - Cinquefoil. \\
\hline Hottonia. & & Water Violet. & Primula . & - Primrose. \\
\hline Houstonia. & & & Prunella . & . Selfheal. \\
\hline Hutchinsia. & & & Puschkinia & . Striped Squill. \\
\hline Hyacinthus & " & Hyacinth. & Pyrola. . & Wintergreen. \\
\hline Iberis & & Candytuft. & Pyxidanthera. & - Pine-barren \\
\hline Ionopsidium . & • & Violet Cres & & Beauty. \\
\hline Iris. . & & Flag. & Ranunculus & Crowfoot. \\
\hline
\end{tabular}


Rhexia . . . Deer Grass.

Rhododendron.

Sagina . . . Pearlwort.

Salix . . . Willow.

Sanguinaria . Bloodroot.

Santolina . . Lavender Cotton.

Saponaria . . Soapwort.

Saxifraga . . Rockfoil.

Scilla . . . Squill.

Scutellaria . Skullcap.

Sedum. . . Stonecrop.

Sempervivum Houseleek.

Senecio . . Groundsel.

Silene. . . Catchfly.

Smilacina.

Soldanella . . Blue Moonwort.

Spigelia . . Worm Grass.

Statice. . . Sea Lavender.
Thalictrum . Meadow Rue.

Thlaspi . . Bastard Cress.

Thymus . . Thyme.

Trientalis . . Chickweed Winter.

Trillium . . Wood Lily.

Triteleia . . Triplet Lily.

Tropæolum . . Garden Nasturtium.

Tulipa . . . Tulip.

Tunica.

Vaccinium . Bilberry.

Veronica . . Speedruell.

Vesicaria . . Bladder-pod.

Vicia . . . Vetch.

Viola . . . Violet.

Waldsteinia.

Zephyranthes. . Zephyr-fower.

References to above will be found in the alphabetical part of the work.

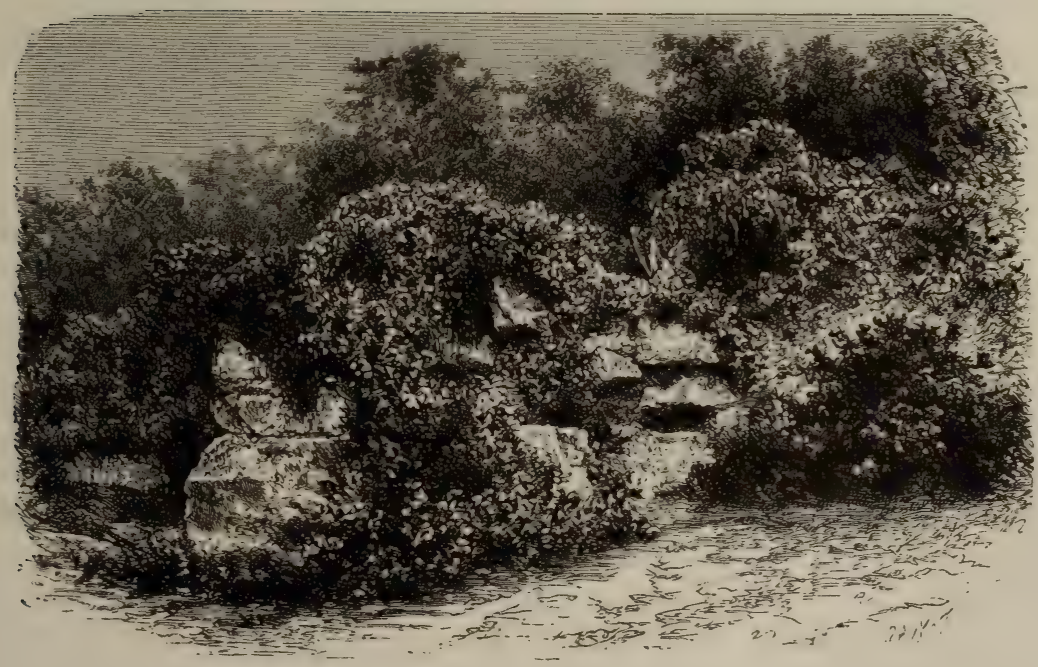




\section{CHAPTER VII}

FLOWERING SHRUBS AND TREES

IF one-tenth the trouble wasted on "carpet-bedding" plants and other fleeting and costly rubbish had been spent on flowering shrubs, our gardens would be all the better for it. There are no plants so much neglected as flowering shrubs. Even when planted they are rarely well treated, owing to the "traditions" of what is called the shrubbery.

The common way is to dig the shrubbery every winter. This is often carried out without giving the soil any manure, and much harm is done by mutilating the roots of the shrubs. The labour and time wasted in this way, if devoted to the proper culture of a portion of the ground each year, would make our gardens delightful indeed. Many shrubs, as fair as any flower requiring the shelter of glass, have been introduced into this country; but for the most part they have been destroyed by the muddle and bad cultivation of the shrubbery. The system is too "scratchy" to permit a beautiful group of hardy shrubs-say evergreen Barberries-to receive as much care as is given to plants in pots.

The idea of the common shrubbery as the home for beautiful shrubs is so rooted in the popular mind that it is almost hopeless to expect much change for the better. The true way is to depart wholly from the idea of the shubbery as a mass of mixed shrubs. Beautiful families like Spiræa may be grouped by themselves. Each family or plant should have a separate place free from the alldevouring Privet and Laurel. Each part of the shrubbery should have a character of its own. This may easily be given to it by grouping instead of the usual mixture, which ends in the starvation of the choice kinds. We do not allow stove and greenhouse plants to be choked in this way. No plants are more worthy of a distinct place and of fair care than many enumerated at the end of this chapter. Low flowering trees, like Hawthorns, group admirably on the turf; the finer kinds of flowering shrub should be planted in 
beds. The shrubbery itself need no longer be a dark mass, but light and shade may play in it, its varied life be well shown, and the habit and form of each kind may be seen. The bushes themselves will do what is needful, if they have a chance, and if coarse things like Laurels and Privet are kept out of the shrubbery. Plants of high quality like the finer varieties of Lilac deserve to be well grown. Any one who thinks how much less trouble is given by hardy plants, with their roots in the soil, than by pot plants, will not grudge a little attention to the outdoor things, but will consider a garden of beautiful

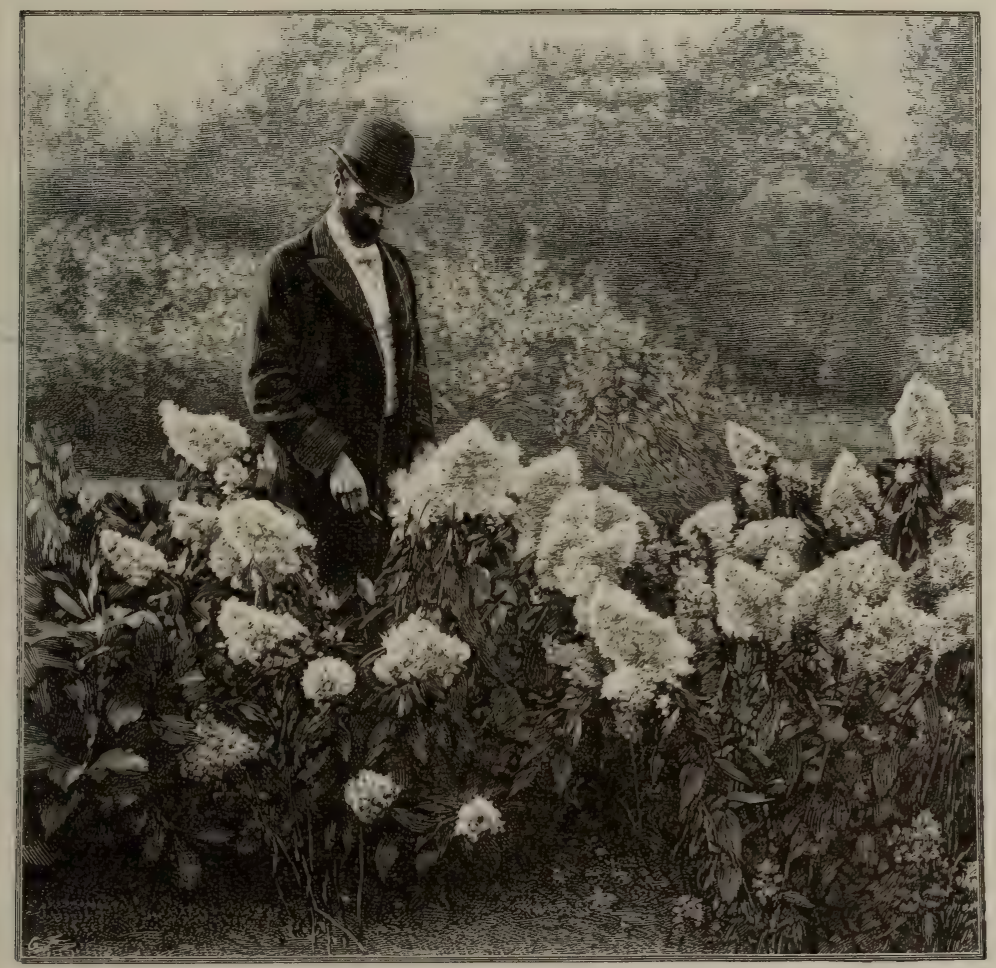

shrubs as a conservatory in the open air. No kind of flower gardening is more delightful or enduring. We have often to rearrange vigorous herbaceous plants, and constantly to work with the lovable Carnation, but Snowdrop Trees and Tree Pæonies give us no trouble. I am so convinced of the supreme value of the whole race of flowering trees, including our hardy fruit trees, that in my garden at Gravetye I planted an orchard close to the house, associating with the fruit trees other flowering shrubs of the same natural order. I did this against the advice of the wisest landscapegardener I ever knew, Robert Marnock, for I was sure that nothing 
else I could put there would in the end be so beautiful. But when he saw the planting done he admitted it was the best way-for posterity. All planting is for posterity!

It is not only flowers that suffer from being stuck in lines and patterns; our beautiful flowering shrubs are injured in the same way. The Rhododendron and the Azalea, and what are commonly called American plants, are often put in such close masses that their forms cannot be seen. We may get the flowers, to some extent, but they are not so enjoyable as when the plants, placed in picturesque and open ways, are allowed to show their individual forms.

There is not the slightest reason why we should not have all the force of colour, too, because it is quite possible to have a number of beautiful Rhododendrons and other flowering shrubs together, without putting them in the serried formal mass in which they are usually seen.

"There is one feature in our parks and gardens which requires thorough reform, and that is the shrubberies with their miserable fringe of earth in which nothing but poor bedding plants will grow, and these badly. Parks and gardens are too often designed to look pretty on paper, the shrubberies and the beds forming harmonious combinations of flowing curves in the plan. The ground plan of a garden has no business to look pretty, and flowing curves on paper are almost certain to be tame and ugly curves when carried out in walks and beds. Gardens should be designed and staked out on the ground they are to occupy-not drawn on paper and then transferred to the ground. The main difference between real mediæval building and modern imitations of it is, that the old work was staked out on the ground from a rough sketch and the details filled in as the work proceeded; whereas the modern work always fails in picturesque effect because it always looks like a built drawing. Our gardens have exactly the same fault-the shrubberies never look right; there is about them an utter absence of change, of variety, and of surprises. There are opportunities now for persons laying out new gardens to boldly go in for a new style of shrubbery, and to do away with the great belts of shrubs which wind along the walks. They might likewise abolish all evergreens of the beehive-shaped type, and plant instead groups and masses. Leave alleys and glades running in amongst the trees-here giving a glimpse of distance ; there narrowing and passing out of sight.

"All that is required is that people shall avoid doing as their neighbours do, and strike out new paths for themselves. In things involving such a multitude of details and varieties as gardening there is not one right way, but a great many right ways, and a great many wrong ones; one of the worst ways is that of making all gardens consist of the same features and every hundred yards of a garden like every other hundred yards. The shrubbery may itself be made a fair garden instead of the museum of crowded half-dead trees and shrubs it usually is."-J. D.

"The hardy Azaleas of the American races are very popular, but few know the value of the white Indian Azalea for the open garden over a large area in the south of England. Few plants give so little trouble when once established, and even though the late frosts may now and again spoil the beauty of the flowers, yet in the intervening years it is something to be grateful for. I have before this called attention to its habit of growth when planted out and left alone, not much more than three feet or four feet in height, dense-growing and spreading. The engraving shows a bush over ten feet across, with a shadow thrown over the upper part by a tree of Magnolia which grows at the side. 
"This, perhaps, may give some idea of the position it occupies and apparently is satisfied with, namely, shelter from cold winds and from too fierce a sun on the flowers or on the roots. Any one who intends to plant this Azalea should remember that it flowers naturally at a time when there may still be late frosts and cold winds hovering about, and that it would be a mistaken kindness to choose

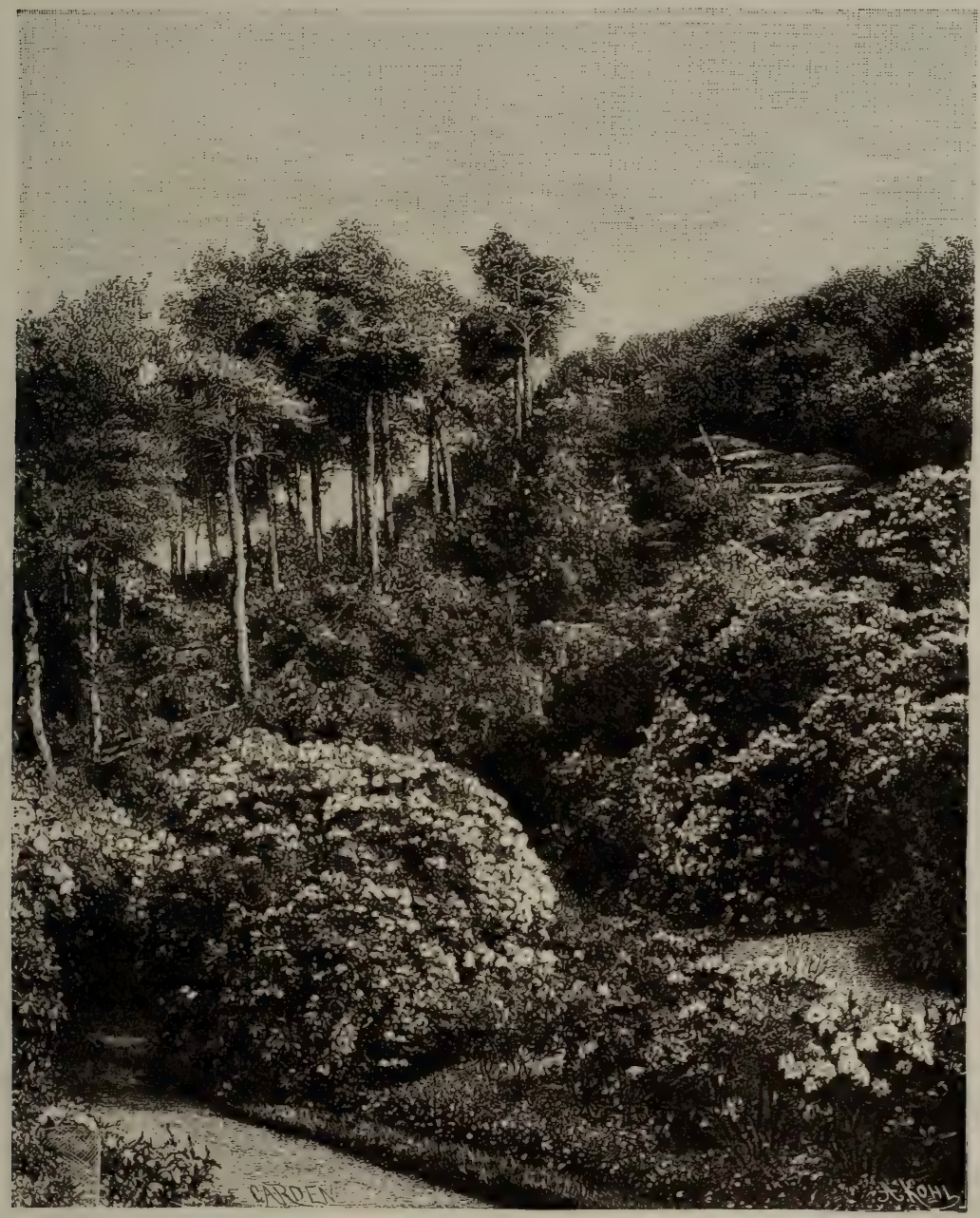

RHODODENDRON GARDEN AT BIDSTON, CHESHIRE.

any place, such as under a south wall, which would tend to make the blossoms open earlier in the season. We have some plants under a north wall which do admirably, but they seem to like association with other things and not to be spotted out by themselves in the open. The variety which does best here is the old typical white. Overgrown plants of other colours from the greenhouse have been turned out sometimes, but they do not seem so happy or produce so good an effect."-C. R. SCRASE-DiCKENS. 


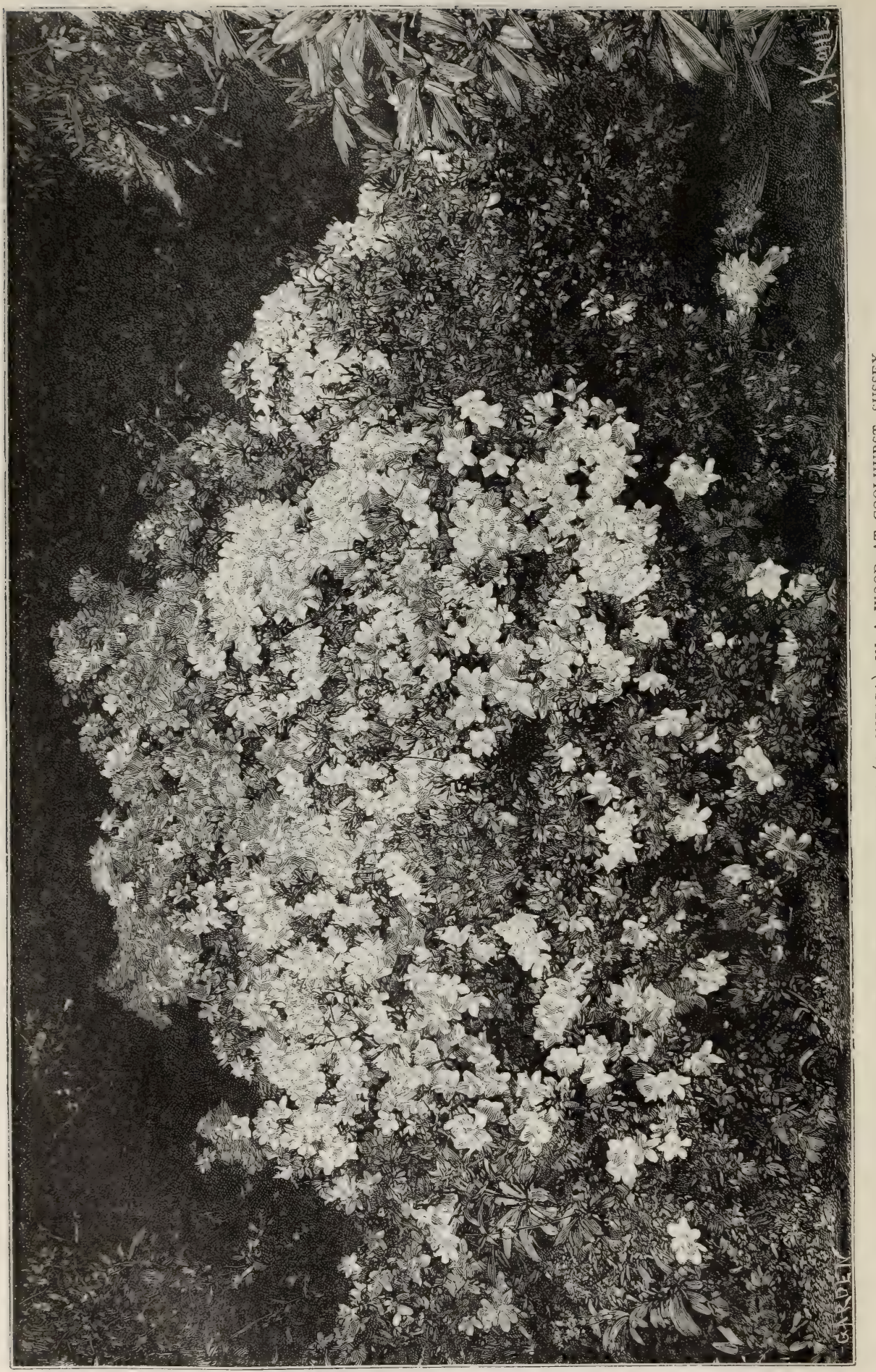


Principal Families of Flowering Trees and Shrubs Hardy in English Gardens

Abelia.

Asculus

Akebia.

Aloysia

Amygelalus . . Almond.

Andromeda.

Aralia . . . Angelica Tree.

Arbutus . . Strawberry Tree.

Arctostaphylos . Bearberry.

Asimina . . Virginian Papaw.

Azalea.

Azara.

Bambusa . . Bamboo.

Berberis . . Barberry.

Berberidopsis. . Coral Barberry.

Bignonia . . Trumpet-flower.

Buddleia . . Orange Ball.

Calycanthus . Carolina Allspice.

Camellia (in Southern Counties).

Caragana . . Siberia Pea Tree.

Catalpa.

Ceanothus. . Blue Bush.

Cerasus . . Cherry Tree.

Cercis . . . Judas Tree.

Chimonanthus. Japan Allspice.

Chionanthus . Fringe Tree.

Cladrastis . . Yellow Wood.

Clematis.

Clethra . . Pepper Bush.

Colletia . . Anchor Bush.

Colutea . . Bladder Senna.

Comptonia . . Sweet Fern Bush.

Cornus. . . Dog Wood.

Corylopsis. . . Japanese Hazel.

Cotoneaster . . Berry Box.

Cratægus . . May.

Cydonia . . Quince.

Cytisus. . . Broom.

Daphne.

Desfontainea.

Desmodium . . Tick Trefoil.

Deutzia . . Snow-flower.

Dimorphanthus.

Drimys . . . Winter's Bark.

Edwardsia . New Zealand

Laburnum.

Embothrium . Fire Bush.

Erica . . . Heath.

Escallonia. . Chilian Gum Box.

Eucryphia. . Brush-flower.

Euonymus . . Spindle Tree.
Exochorda . Pearl Bush.

Fabiana . . False Heath.

Forsythia . . Golden Bells.

Fothergilla.

Garrya.

Gaultheria. . American Bilberry.

Genista . . Broom.

Gleditschia . . Honey Locust.

Gordonia . . Loblolly Bay.

Helesia . . Snowdrop Tree.

Hamamelis . . Witch Hazel.

Hibiscus . . Shrubby Mallow.

Hypericum . . St. John's Wort.

Hydrangea.

Illicium . . Star Aniseed.

Indigofera . . Indigo Plant.

Itea. . . . . Virginian Willow.

Jamesia.

Jasminum . . Jasmine.

Kalmia . . Mountain Laurel.

Kerria . . . Jew's Mallow.

Kœlreulteria.

Laburnum.

Golden Rain.

Lardizabala.

Laurus. . . Laurel.

Ledum . . . Labrador Tea Plant.

Leiophyllum . . Sand Myrtle.

Lespedeza. . Bush Clover.

Leycesteria . : Himalayan Honeysuckle.

Ligustrum . . . Privet.

Liriodendron . Tulip Tree.

Lonicera . . Honeysuckle.

Lupinus . . Tree Lupine.

Magnolia . . Lily Tree.

Mahonia . . Evergreen Barberry.

Malus . . . Apple.

Mespilus . . Medlar.

Myrica. . . Sweet Gale.

Myrtus. . . Myrtle.

Nuttalia . . Osoberry Tree.

Olearia . . Australian Star Bush.

Ononis. . . Rest Harrow.

Ornus . . . Flowering Ash.

Ozothamnus.

Paulownia.

Pavia . . . Buckeye.

Periploca . . Syrian Silk Vine.

Pernettya . . Prickly Heath. 
Principal Families of Flowering Trees and Shrubs Hardy in English GardensContinued

\begin{tabular}{|c|c|c|c|c|c|}
\hline hiladelphus & . & Mock Orange. & Sophora & $\cdot$ & - Pagoda Tree. \\
\hline hlomis . & . & Jerusalem Sage. & Spartium & . & . Rush Broom. \\
\hline iptanthus & . & Nepaul Laburnum. & Spiræa . & . & - Shrubby Meadowe \\
\hline otentilla . & . & Shrubby Cinquefoil. & & & Sweet. \\
\hline runus. & & $\begin{array}{l}\text { Plum, Sloe, Dam- } \\
\text { son, Bullace. }\end{array}$ & $\begin{array}{l}\text { Staphylea . } \\
\text { Stauntonia. }\end{array}$ & . & - Bladder Nut. \\
\hline $\begin{array}{l}\text { Pterostyrax. } \\
\text { Punica. . }\end{array}$ & & & Stuartia. & & \\
\hline a. & & $\begin{array}{l}\text { Pomegranate. } \\
\text { Pear. }\end{array}$ & $\begin{array}{l}\text { Styrax } \\
\text { Syringa }\end{array}$ & & $\begin{array}{l}\text { Storax-shrub. } \\
\text { Lilac. }\end{array}$ \\
\hline Raphiolepis & . & Chinese Hawthorn. & Tamarix & . & Tamarisk. \\
\hline Rhododendro & & & Tecoma & . & . Trumpet-flower. \\
\hline Rhodora . & 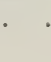 & $\begin{array}{l}\text { Canadian Rhodo- } \\
\text { dendron. }\end{array}$ & $\begin{array}{l}\text { Tilia } \\
\text { Ulex }\end{array}$ & . & . Lime. \\
\hline Rhodotypos & . & $\begin{array}{l}\text { White Jew's } \\
\text { Mallow. }\end{array}$ & $\begin{array}{l}\text { Veronica } \\
\text { Viburnum }\end{array}$ & . & $\begin{array}{l}\text { - Shrubby Speedwell } \\
\text { - Gueldre Rose. }\end{array}$ \\
\hline Ribes & . & Flowering Currant. & Virgilia & & . Yellow Wood. \\
\hline Robinia & . & Locust Tree. & Vitex & - & - Chaste Tree. \\
\hline Rosa & • & Rose. & Vitis & • & Vine. \\
\hline Rubus. & • & Bramble. & Weigela & . & . Bush Honeysuckle. \\
\hline Sambucus . & · & Elder. & Wistaria & . & - Grape-flower. \\
\hline jolanum & & Potato Tree. & Xanthoceras & & \\
\hline
\end{tabular}

Some of the evergreens in this list are killed or greatly injured in severe winters, and should be planted but little in cold inland districts or in heavy soils.

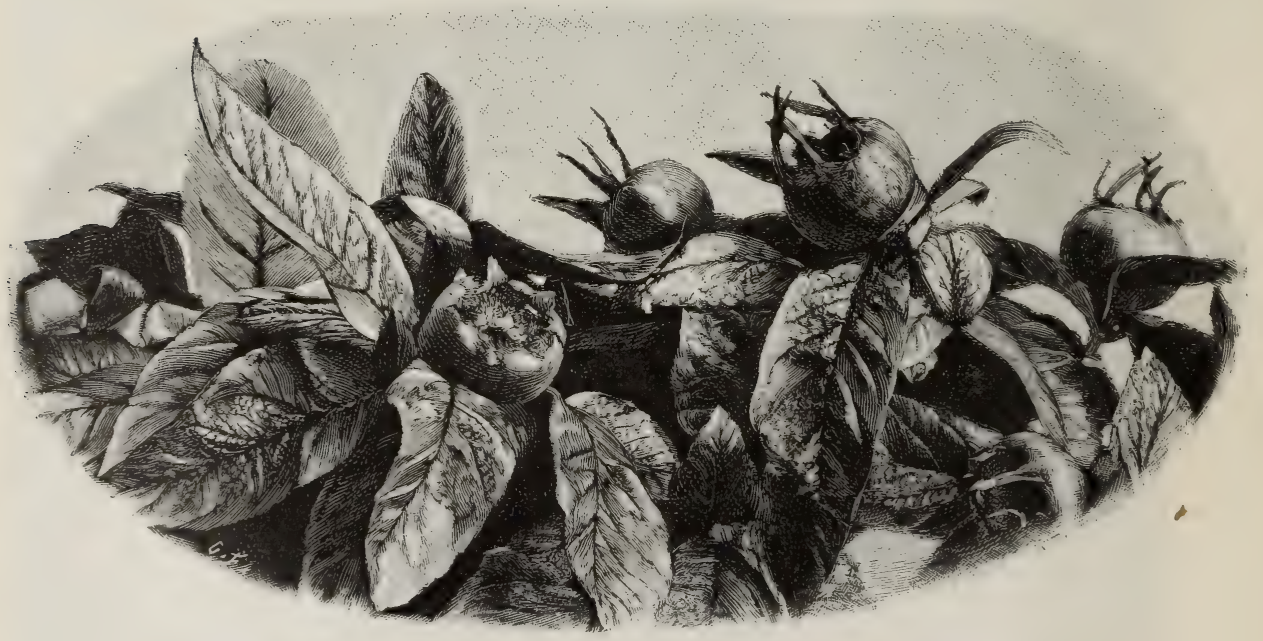




\section{CHAPTER VIII}

ANNUAL AND BIENNIAL PLANTS FOR THE FLOWER GARDEN

AMONG the beautiful things which "carpet-bedding" destroyed were the good annuals and like plants which once formed such pretty

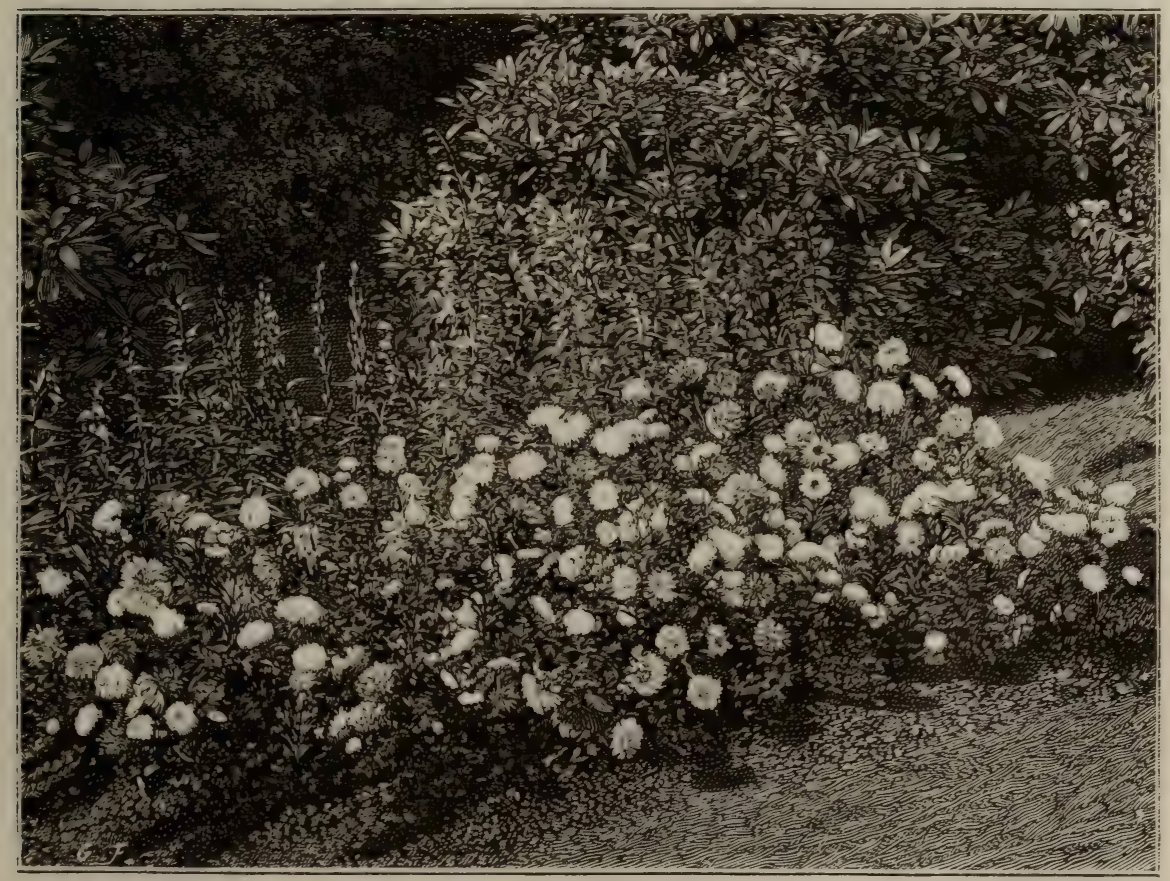

BED OF "CHINA ASTERS": SHOWING EFFECT OF WELL-GROWN ANNUAL PLANTS IN GARDEN, ENGRAVED FROM A PHOTOGRAPH.

beds in the flower garden. While it is not well to depend too much on annuals or biennials, not a few are indispensable, like Stocks, where they can be grown. Some are neglected, like the Rhodanthe, grown as an open-air flower, while many are badly grown, like the 
Zinnia. Some, like the Corn-flower, Sweet Sultan, Sweet Pea, Scabious, are charming for cutting ; others are good for trellis-work;

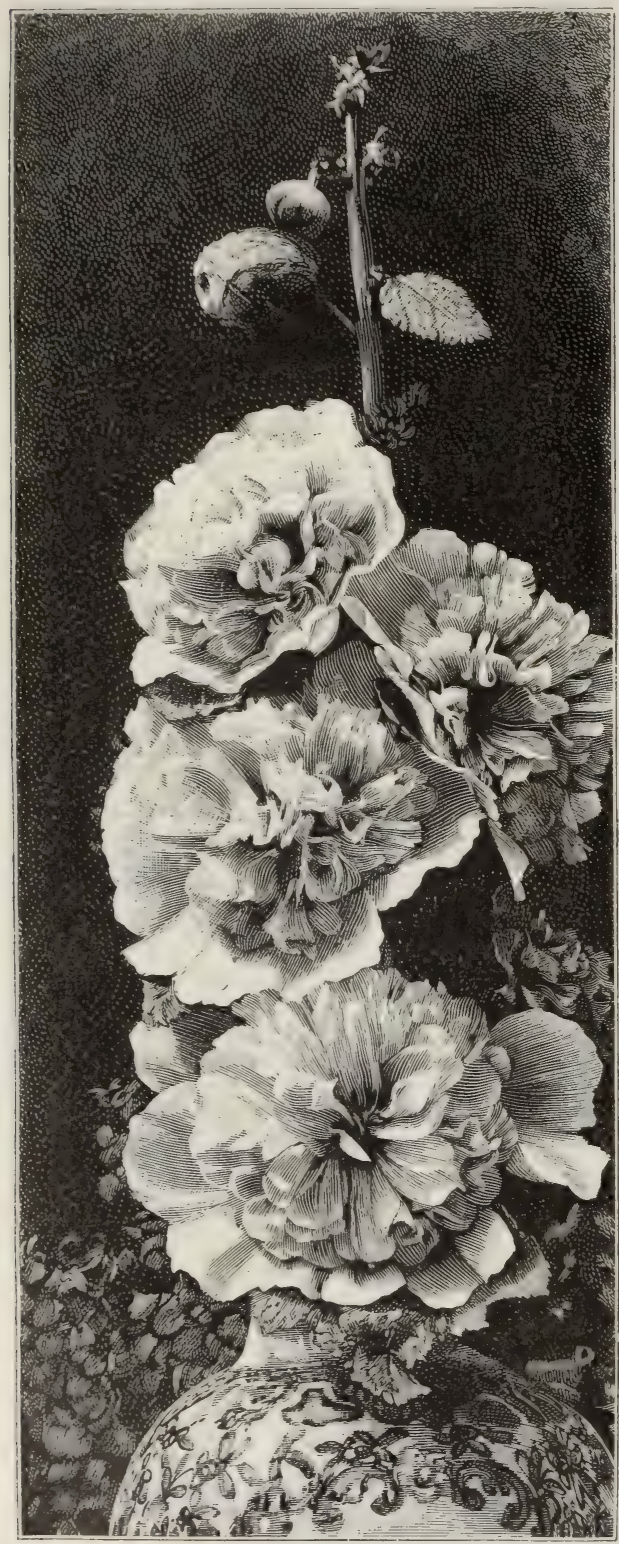

DOUBLE HOLLYHOCK. and others for surfaces we wish to adorn with pretty climbers, such as Canary Creeper, Maurandya, Adlumia, Gourds, Convolvulus; some are even plants of good foliage and habit, such as the Castor-oil-plant, the Hemp, the crisp Mallow, the annual Wormwood, Indian Corn, Cotton Thistle, Blessed Thistle, Olympian Mullein.

In wet seasons and in wet northern districts annuals surprise us by their vigour and beauty. In warmer counties, the effect of the heat may in the case of the hardy kinds be met by autumn-sowing in good rich ground. The autumn sowings are the best. The plants not only flower much sooner, but, where the soil and climate suit them, they are stronger and more beautiful. The reason why they are so often seen in poor condition is that they are sown on hungry soil and are crowded.

Concerning these, "Salmoniceps" writes - "I have just measured a plant to-day (October 4) of Nemophila insignis, sown more than a year ago. It has been in flower since May, and measures now 4 feet by 3 feet $\mathrm{IO}$ inches. It would take a long time to count the blossoms, although they are not so large as the carlier ones. The plant grows in a new and rich border. Accord- 
ing to the ordinary way of sowing annuals, this single plant occupies the space. which is usually allotted to a whole packet of seed." All the grown kinds are mentioned in the alphabetical part of this work, and their cultivation is given. It would be interesting to see what a good gardener could do with annuals, considering the requirements of each kind and sowing it at the season likely to get the best and longest bloom.

In nature, annuals are usually autumn sown and gather strength in the winter, no matter how small the growth. In growing a number of annuals from various countries we must remember that our winters can be faced by the hardy ones only, such as the Sweet Pea, Corn-flower, Silene, Nemophila, Viscaria, Limnanthes, Larkspur, Poppy, and Scabious. Annuals are best in masses or groups. They are never perhaps so full of colour and beauty as on an old rich vine border. In the course of alterations the soil has often to remain unplanted for a time; and this should be taken advantage of for annuals. While some annuals may show colour for only a short season, others are among our most fragrant and beautiful plants.

Half-hardy Plants treated as Annuals.-It is not every one who has the space or means to provide and winter a large number of tender bedding plants. No matter how favourable the situation, the keeping of a large stock involves a good deal of trouble, and takes up space that might be better occupied. But a garden may be made very gay in summer and autumn with seedlings alone, and without kceping or purchasing a single plant. In seedlings there may be differences in habit and colour, but to many people this will be no objection; and there are a few plants which come from seed true to the type through many generations, like Verbena venosa, one of the best and most pleasing of hardy bedding or border plants. We have raised many thousands from seed, and never saw any variation. Another is Salvia patens. Like the Verbena it should be sown on a hotbed early in spring, in order to get it into early flower. Lobelias of the speciosa race come fairly true from seed. Can anything, again, as a mixed bed be more effective than a mass of seedling Petunias? The colours are not harsh, but soft and pleasing. Seedling Verbenas make a handsome bed; and for a large bed, where the soil is good, few things are superior to the double Zinnias, which can be had in various colours, and separately if desired. Balsams, again, are not half so much used for open-air decoration as they deserve to be. Those who have only seen them starving in small pots cannot form an idea of their beauty when planted out in good open soil, away from trees. Among yellow-flowering plants, the small single form of 


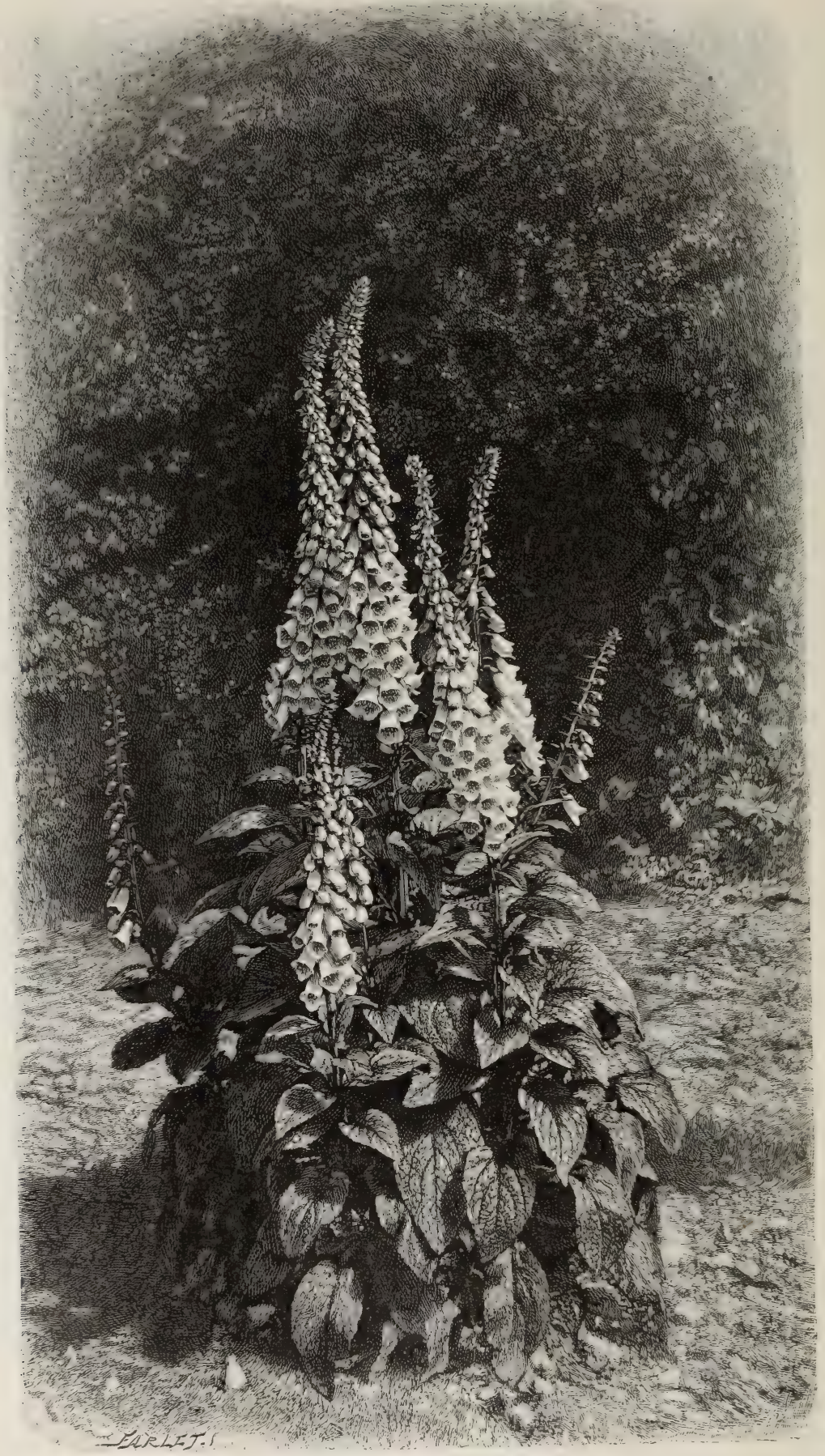

WHITE FOXGLOVE. ENGRAVED FROM A PHOTOGRAPH BY H. HYDE OF A SELF-SOWN PLANT IN SHRUBBERY AT GRAVETYE MANOR. 
Tagetes signata pumila is useful, but it is not equal to the double variety, which makes a handsome bed. For large beds or back positions in borders, the lemon and orange varieties of the African Marigold are very lasting and showy. The dwarf kinds of Ageratum, if selected and saved with care, may be raised in a gentle heat, and, with a little management, very effective masses may be easily had in summer. The tuberous Begonias form a good feature in sheltered positions; they will display all the colours of the Pelargonium without liability to be washed out by rain, and they require no expensive preparation to keep them through the winter. Take the large family of Violas, in almost all shades of purple, yellow, and white. Now that selection and fertilisation have so much improved them, varieties may be raised in the early spring for bedding out the same summer. This applies especially to such plants as the Verbena and Pansy, Pelargonium, Pyrethrum, Salvia patens, S. argentea, Heliotrope, and Antirrhinum, which should be sown in heat in January, much as the Verbena already described; to the Petunia, Phlox Drummondi, Dianthus, Indian Pink, Ageratum, and Lobelia, which in February should be sown in pans in heat, and, if kept growing, will be ready for planting out in May. Begonias, for bedding, may be grown from seed in the same year, but are much more effective if raised during the preceding year, selected according to colour, and stored in winter ready for bedding out early in summer. Fuchsias sown in January flower well in August. Of fine-foliaged plants adapted for bedding and which can be raised from seed, there are the useful Amaranthus, Celosia, Centaurea, Cineraria maritima, and Humea. There are many other fine-leaved plants, such as Canna, Chamæe uce, Nicotiana, Ricinus, Solanum, and Wigandia. If we were not so accustomed to depend on cuttings stored over the winter, we could make a display with seedling plants alone. If seedling Fuchsias may be grown to the flowering stage during the current year, there can be scarcely any difficulty in getting a large stock of other seedling plants for the open garden. The cleanliness of this plan would be a great gain. Old plants harbour through the winter the eggs of vermin always ready to eat up the collection if it is neglected for a week. But, starting with thoroughly clean houses and frames, and with seeds in early spring, the gardener could make a better fight against his many insect enemies. As regards the plants one would like to raise in this way, a point to desire is that seedsmen should select and fix distinct colours of different races of plants. It would not be difficult to select a bluish or purple Verbena which one might count on as coming pretty true from seed. We have so much relied upon cuttings and old plants, that the raising of seedlings in robust health has never had fair 
attention. We know that ererybody raises some seeds, but few give the early thinning, the perfect exposure to light, the sturdy growth, and the unchecked culture that seedlings require. They usually get little space and less care.

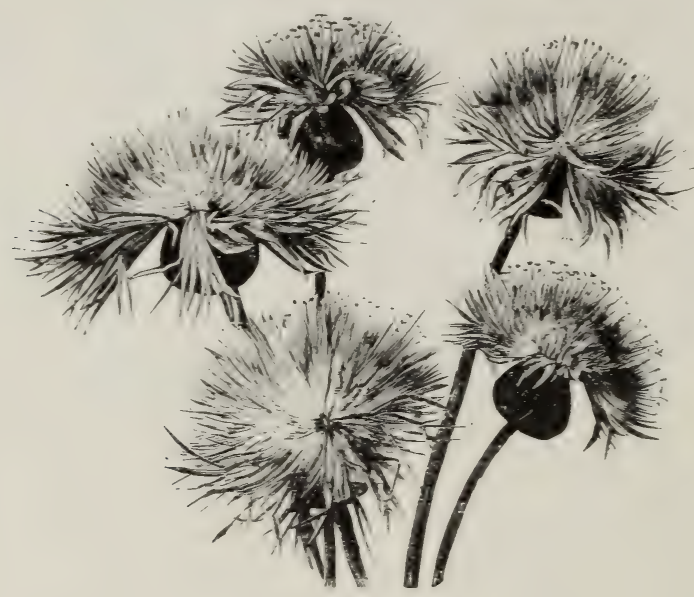

SWEET SULTAY.

Some of the more important Families of Annual and Biennial Flowers, including half-hardy Bedding Plants, for the Flower Garden

$\begin{array}{llll}\text { Acroclinium } & \text { Cannabis } & \text { Erysimum } & \text { Isotoma } \\ \text { Adlumia } & \text { Cape Marigold } & \text { Erythrea } & \text { Kaulfussia } \\ \text { Ageratum } & \text { Catananche } & \text { Eschscholtzia } & \text { Lasthenia } \\ \text { Agrostemma } & \text { Celosia } & \text { Eucharidium } & \text { Lavatera } \\ \text { Alonsoa } & \text { Celsia } & \text { Eutoca } & \text { Leptosiphon } \\ \text { Alyssum } & \text { Centranthus } & \text { Fuchsia } & \text { Leptosyne } \\ \text { Amaranthus (in } & \text { Cheiranthus } & \text { Gaillardia } & \text { Limnanthes } \\ \text { var.) } & \text { China Aster } & \text { Gilia } & \text { Linaria } \\ \text { Amberboa } & \text { Chrysanthemum } & \text { Glaucium } & \text { Linum } \\ \text { Ammobium } & \text { Clarkia } & \text { Godetia } & \text { Loasa } \\ \text { Anagallis } & \text { Clintonia } & \text { Gourds } & \text { Lobelia } \\ \text { Antirrhinum } & \text { Cnicus } & \text { Grasses } & \text { Lophospermum } \\ \text { Arctotis } & \text { Convolvulus } & \text { Gypsophila } & \text { Lupin } \\ \text { Argemone } & \text { Coreopsis } & \text { Hedysarum } & \text { Maize (in var.) } \\ \text { Artemisia } & \text { Cosmidium } & \text { Helichrysum } & \text { Malope } \\ \text { Bartonia } & \text { Cosmos } & \text { Heliophila } & \text { Malva } \\ \text { Begonia } & \text { Crepis } & \text { Hesperis } & \text { Martynia } \\ \text { Boerkhausia } & \text { Cuphea } & \text { Hibiscus } & \text { Maurandya } \\ \text { Brachycome } & \text { Datura } & \text { Hollyhock } & \text { Mesembryan- } \\ \text { Calandrinia } & \text { Delphinium } & \text { Iberis } & \text { themum } \\ \text { Calceolaria } & \text { Dianthus } & \text { Impatiens } & \text { Mignonette } \\ \text { Calendula } & \text { Didiscus } & \text { Ionopsidium } & \text { Mimulus } \\ \text { Calliopsis } & \text { Digitalis } & \text { Ipomaa } & \text { Mirabilis } \\ \text { Campanula } & \text { Eritrichium } & \text { Ipomopsis } & \text { Myosotis } \\ & & & \end{array}$




$\begin{array}{llll}\text { Nemesia } & \text { Pharbitis } & \text { Schizanthus } & \text { Thunbergia } \\ \text { Nemophila } & \text { Phlox } & \text { Schizopetalon } & \text { Tropæolum } \\ \text { Nicotiana } & \text { Platystemon } & \text { Senecio } & \text { Verbascum } \\ \text { Nigella } & \text { Podolepis } & \text { Silene } & \text { Verbena } \\ \text { Nolana } & \text { Polygonum } & \text { Solanum } & \text { Viola } \\ \text { Nycterinia } & \text { Portulaca } & \text { Sorghum } & \text { Virginia Stock } \\ \text { Enothera } & \text { Pyrethrum } & \text { Specularia } & \text { Viscaria } \\ \text { Onopordon } & \text { Rhodanthe } & \text { Sphenogyne } & \text { Waitzia } \\ \text { Oxalis rosea } & \text { Ricinus } & \text { Stenactis } & \text { Whitlavia } \\ \text { Oxyura } & \text { Salpiglossis } & \text { Stocks } & \text { Wigandia } \\ \text { Papaver } & \text { Salvia } & \text { Sweet Peas } & \text { Zea } \\ \text { Petunia } & \text { Saponaria } & \text { Sweet William } & \text { Zeranthemum } \\ \text { Phacelia } & \text { Scabious } & \text { Tagetes } & \text { Zinnia }\end{array}$

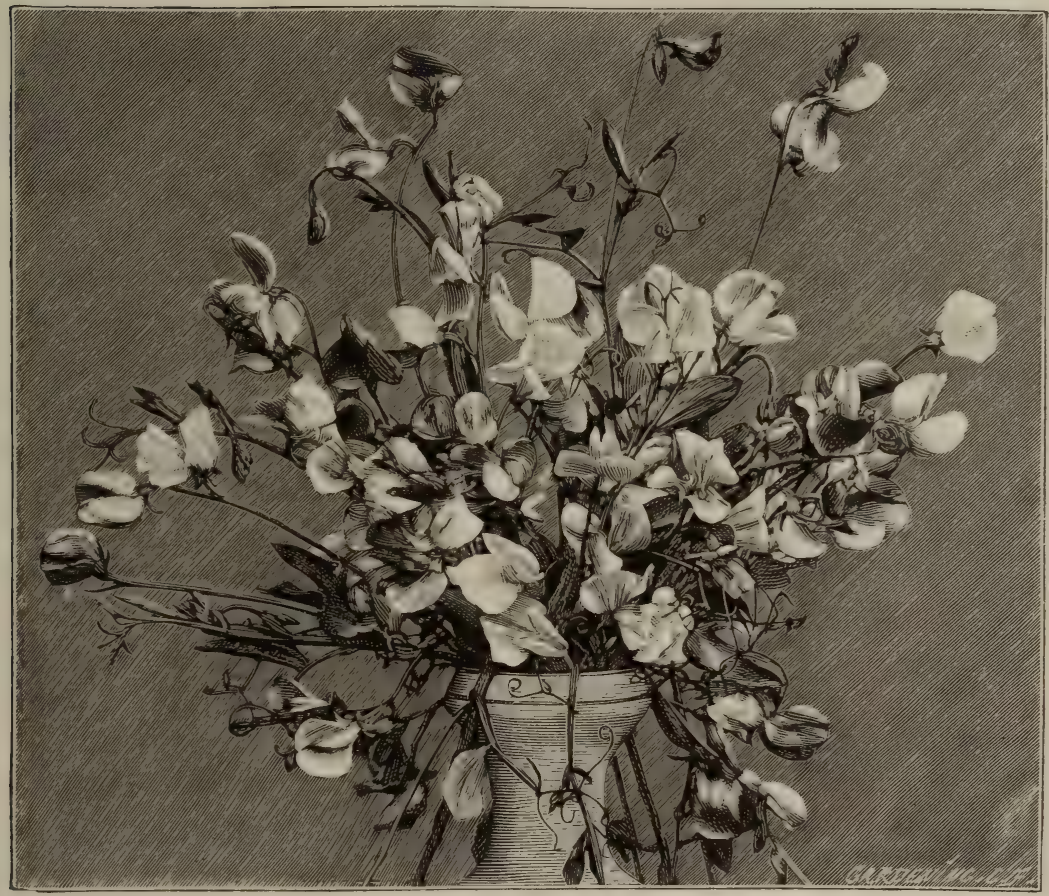




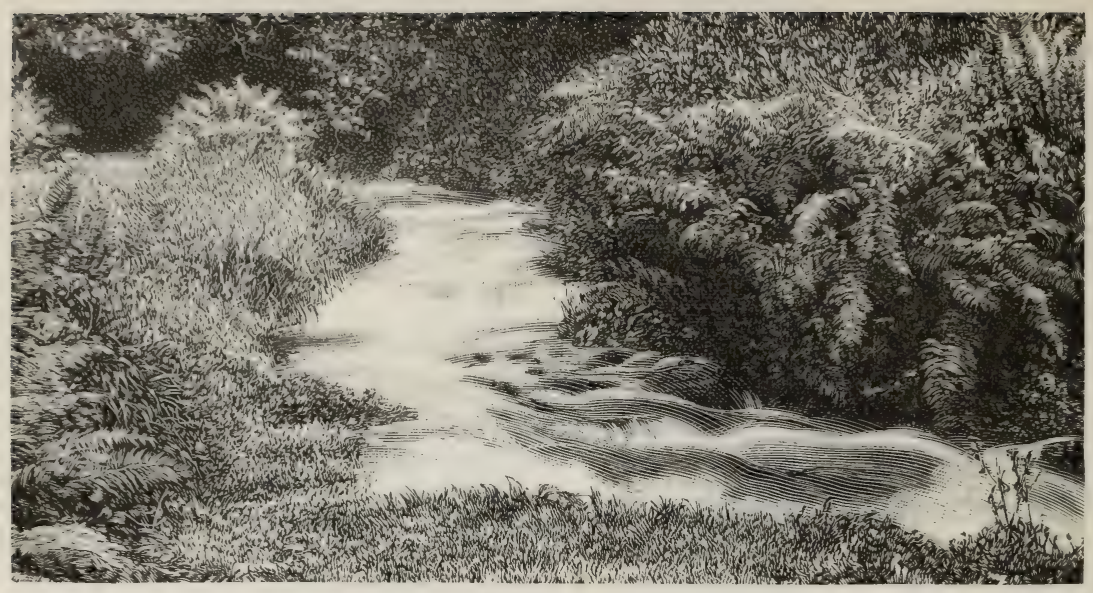

STREAMLET IN A DEVONSHIRE GARDEN.

\section{CHAPTER IX}

WATERSIDE, STREAMLET, BOG-GARDEN, AND HARDY FERNS

WHAT a number of unclean "duck ponds" deface our gardens! People have a mania for water. The effect of water under its best conditions pleases them so well, that they bring it near their houses, where they cannot have any of its good effects. But they have instead the filth that accumulates in stagnant water, and feel its deadly smell over what ought to be a pleasant lawn. Water is rarely tolerable, except in such sheets as to reflect light on the landscape. In our cold, wet climate, too, it is desirable that the vapour and more immediate effects of water-even beautiful and clean water-should be kept a little away; and since this is impossible in very small places, "artificial" water is better entirely excluded from them. In one form, however, it is always innocuous, and that is as a streamlet or rill. This can do no harm, and may, in a garden or near it, be kept always alive with beauty by bordering it with flowers and trailing shrubs, broken by little bits of smooth Grass. A hundred yards of a limpid chalk stream alive with fish, such as one may see among the Wiltshire Downs (clear as a diamond on the coldest day), is better than many pretentious and costly pieces of "artificial water." A very bad quality of the duck ponds - and, indeed, of all kinds of artificial water in gardens - is the way they fill up with mud. The cost of cleaning them is great. Where in a large park the effect of water in the distance is good, and the views picturesque, "mudding" may be worth doing, but in 
places where the scum and the smell are the main results, and the best part of the lawn is cut up for the sake of an ugly pond, the best way is to cut a drain from it, and make it into a little garden for Rhododendrons, hardy Ferns, and Lilies. Then, at all events, we should have something into which, if a child fell, it could be picked out unhurt. Ponds and fountain basins in gardens are often a danger to young children.

The brook-margin offers opportunities to lovers of hardy flowers which few situations equal. Hitherto we have used in and near such places aquatic or bog-plants only, and of these usually a very meagre selection; but the improvement of the brook-side will be most readily effected by planting the banks with hardy flowers. A great number of our finest herbaceous plants, from Irises to Globe-flowers, thrive best in moist soil. Land-plants have this advantage over water ones, that we can fix their position, whereas water-plants are apt to spread, and one kind often exterminates the rest, therefore it might

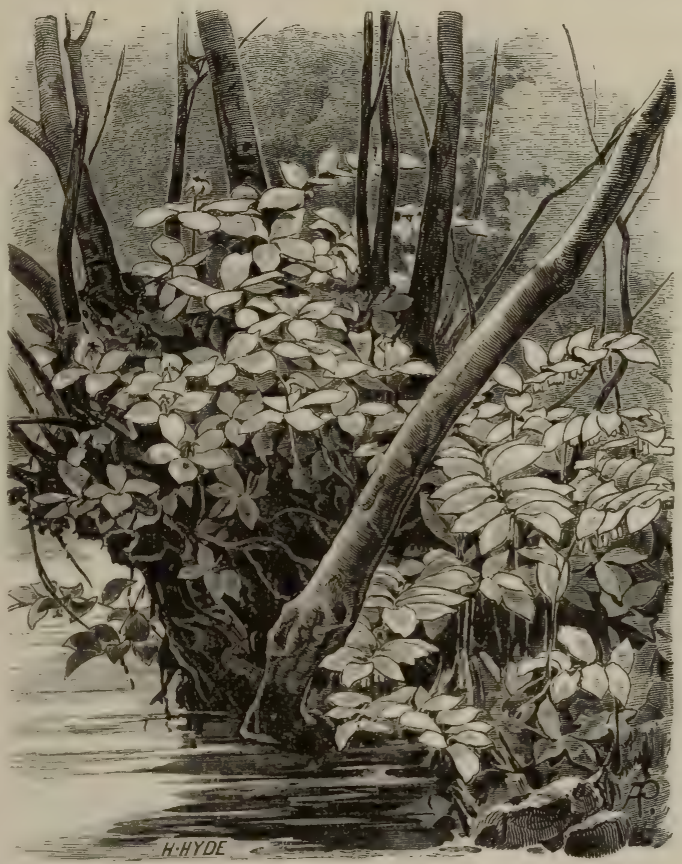

SOLOMON'S SEAL AND HERB PARIS, IN COPSE BY STREAMLET.

sometimes be better not to encourage the water vegetation, but to form little colonies of hardy flowers along the banks. The repeating of a favourite plant at intervals would spoil everything; groups of free hardy things, different in each place as one passed, would be best: Day Lilies; Phloxes, which love moisture ; Irises, mainly the beardless kinds, which love wet places, and all the German Irises; Gunnera; Aster; American swamp Lilies in peaty or boggy soil ; the deep rose Loosestrife; Golden Rods; the Spider Wort; the Compass-plants; Everlasting Peas; Monkshood; the Goat Rues; the hardiest Flame-flowers (Tritoma); the stouter kinds of Yarrow (Achillea); the common Lupin - these are some of many types of hardy flowers which would grow freely near the waterside 
apart from the plants that naturally frequent the place or are usually placed there. With these hardy plants, too, a variety of the nobler hardy ferns such as the Struthiopteris, and the finer types of the Umbellate order (Ferula and others) would also come well.

We will now consider the plants that belong naturally to such situations. Water-plants of northern and temperate regions, associated with native plants, add much beauty to a garden if they are well selected and well grown. If the soil be rich, we usually see the same monotonous vegetation all round the margin of the water, and where the bottom is of gravel, there is little vegetation, but an unbroken, ugly line of washed earth. Elsewhere water-plants

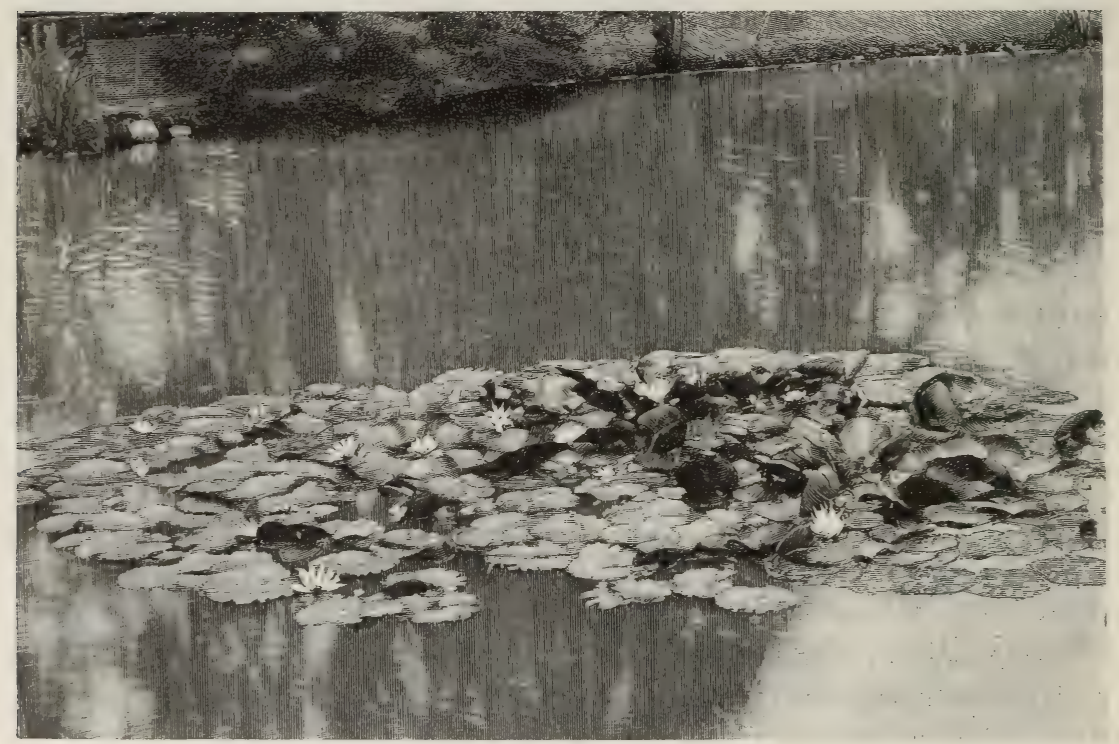

HARDY WATER LILIES.

accumulate till they are an eyesore. A group of Water Lily is beautiful; but Water Lilies lose their charm when they spread orer the whole of a piece of water-thickening and weakening-and water-fowl cannot make their way through them. No garden water, however, should be without the Water Lily. The Yellow Water Lily (Nuphar lutea), though less beautiful, is well worthy of a place; and so is the fine and large $\mathrm{N}$. adrena (a native of America), which pushes its leaves boldly above the water. The American White Water Lily (Nymphæa odorata) is a noble species, and would prove quite hardy. Other kinds have been recently introduced.

One of the prettiest effects I ever observed was afforded by a sheet of Villarsia nymphæoides near a woody recess, belting round 
the margin of a lake with a group of Water Lilies before it, nearer the deep water.

Not rare-growing, in fact, in nearly all districts of Britainbut beautiful and singular, is the Buckbean, with flowers fringed inside with white filaments, and with round unopened buds blushing on the top with a rosy red like an Apple-blossom. It will grow in any moist place, in a bog, or by the margin of any water.

For a bold and picturesque plant there is the great Water Dock;

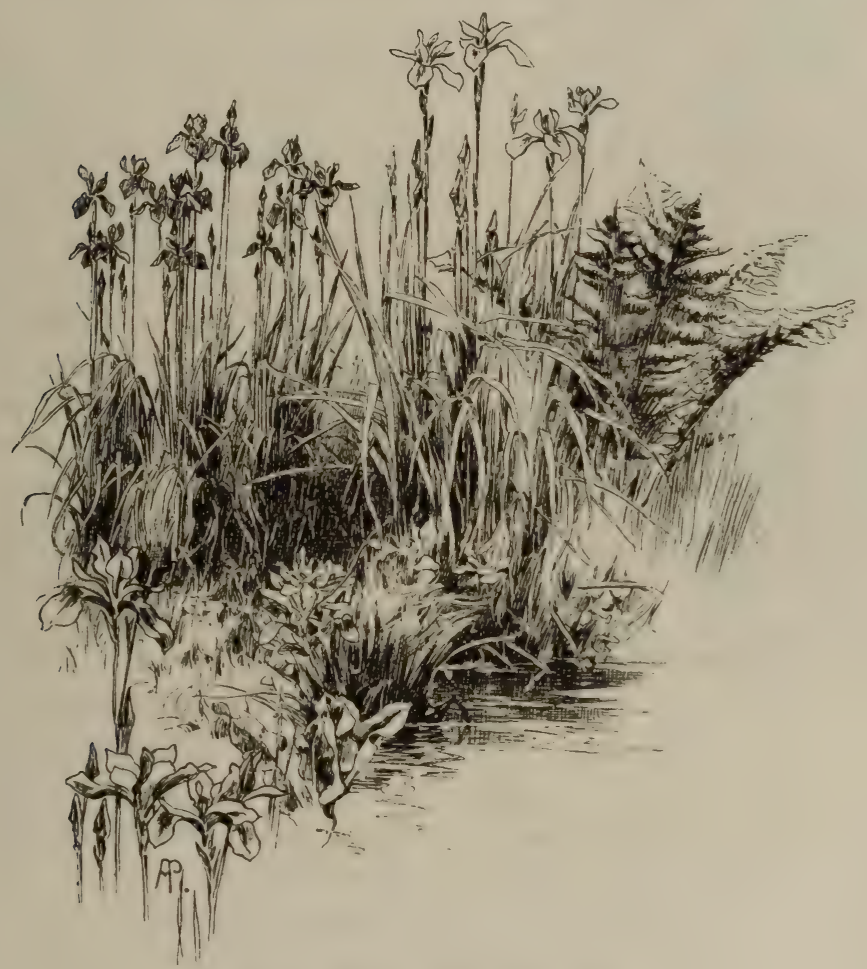

COLONY OF IRIS, BY BROOK-SIDE.

its leaves-quite sub-tropical in size-become a fine red in autumn. It forms a grand mass of foliage on rich muddy banks, and, unlike many water-plants, does not spread too much. The Reed-mace (Typha) must not be omitted. It should not be allowed too much liberty. The narrow-leaved one is more graceful than the common one ( $T$. latifolia). Carex pendula is excellent for the margins of water, its elegant drooping spikes being quite distinct in their way. Carex paniculata forms a strong and thick stem, sometimes 3 feet or 4 feet high, somewhat like a tree Fern, and it has luxuriant masses of drooping leaves: on that account it is some- 
times transferred to moist places in gardens, though these large specimens are generally difficult to remove and soon perish. The Bulrush is too distinct to be omitted, its stems sometimes attaining a height of more than 7 feet and even 8 feet; and Cyperus longus is also desirable and recalls Papyrus in flower. Poa aquatica might

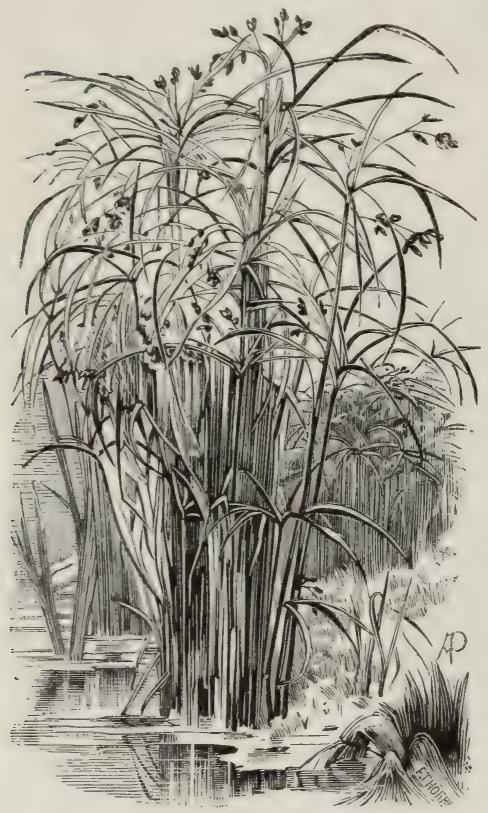

CYPERUS LONGUS. also be used. Cladium Mariscus is another distinct British aquatic which is worth a place.

A very long list might be made of the plants that grow in British and European water, but those which possess no distinct character or beauty of flower are useless, for it is only a selection of the best kinds that can give satisfaction.

Those who have seen the flowering Rush (Butomus umbellatus) in blossom are not likely to omit it from a collection of water-plants. Place it not far from the margin, for it likes rich muddy soil. The common Arrow Head (Sagittaria), very frequent in England and Ireland, might be associated with this; but there is a much finer double exotic kind, which is really handsome, with white flowers resembling those of the old white Double Rocket, but larger. The Bog Arum is a beautiful plant, and I know of nothing prettier on rich, soft, boggy ground. It will also grow by the side of water. The wellknown Lily of the Nile is hardy in some places if planted rather deep, and in nearly all may be placed out for summer; but in the south of England and Ireland it will not thrive except in quiet waters. The Sweet-flag will be associated with the Water Iris (I. pseudacorus), and in wet ground a number of exotic Irises will thrive, e.g. I. sibirica, ochroleuca, graminea, and many others. The Pond-flower is a native of the Cape of Good Hope, and is a singularly pretty plant, hardy enough for our climate, sweet and quaintly beautiful. It frequently succeeds where there are springs that keep the water a little warmer than usual. The Water Violet occurs in eastern and central districts. The best example of it that I have seen was on an expanse of soft mud near Lea Bridge, in Essex, where it covered the surface with a sheet of dark fresh green, and looked better than when in water, though doubtless the place 
was occasionally flooded. A suitable companion for the Marsh Marigold and its varieties is the very large and showy Ranunculus Lingua, which in rich ground grows to a height of 3 feet or more.

Fortunately in winter the margins of lakes and streams are not upturned by the spade, and just away from the water-line almost any vigorous and hardy flower will take care of itself. The Globeflowers alone would form beautiful effects and endure as long as the Grass. Near the various Irises that love the waterside might be planted those that thrive in moist ground, including the most beautiful kinds. It would require a long list to enumerate all the plants, apart from the aquatics proper, that would grow near the margin of water; but enough has been said to prove that on a strip of ground beside a stream or lake, a charming garden may be formed. The juxtaposition of plants naturally inhabiting different situations-water-plants, waterside plants, and land-plants thriving in moist ground-would prevent a general admixture of the whole. Distinct effects could be obtained from the beauty of the flowers close at hand; and from that of the more conspicuous kinds at a distance, or from the other side of a stream or lakelet.

THE BOG-GARDEN is a home for the numerous children of the wild that will not thrive on our harsh, bare, and dry garden borders, but must be cushioned on moss, and associated with their own relatives in moist peat soil. Many beautiful plants, like the Wild Gentian and Creeping Harebell, grow on our own bogs and marshes, much as these are now encroached upon. But even those acquainted with the beauty of the plants of our own bogs have, as a rule, but a feeble notion of the multitude of charming plants, natives of northern and temperate countries, whose home is the open marsh or boggy wood. In our own country, we have been so long encroaching upon the bogs and wastes that some of us come to regard bogs and wastes as exceptional tracts all over the world. But when one travels in new countries in northern climes, one soon learns what a vast extent of the world's surface was once covered with bogs. In North America, even by the margins of the railways, one sees, day after day, the vivid blooms of the Cardinal-flower springing erect from the wet peaty hollows; and far under the shady woods stretch the black bog pools, the ground between being so shaky that you move a few steps with difficulty. One wonders how the trees exist with their roots in such a bath. And where the forest vegetation disappears, the Pitcher-plant (Sarracenia), Golden Club (Orontium), Water Arum (Calla palustris), and a host of other handsome and interesting bogplants cover the ground for hundreds of acres, with perhaps an occasional slender bush of Laurel Magnolia (Magnolia glauca) 
among them. In some parts of Canada, where the painfully long and straight roads are often made through woody swamps, and where the few scattered and poor habitations offer little to cheer the traveller, a lover of plants will find beside the road conservatories of beauty in the ditches and pools of black water fringed with a profusion of stately ferns, and bog and water-bushes.

Southwards and seawards, the bog-flowers, like the splendid kinds of herbaceous Hibiscus, become tropical in size and brilliancy, while far north and west and south along the mountains grows the queen of the peat bog-the beautiful and showy Mocassin-flower

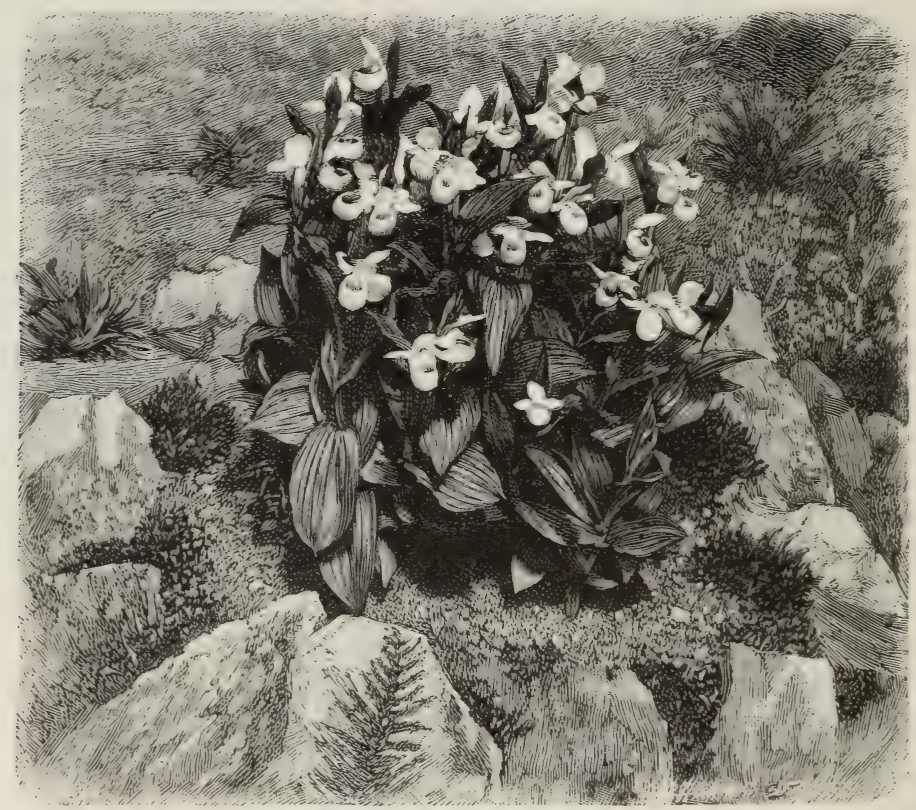

MOCASSIN-FLOWER IN ROCKY BOG.

(Cypripedium spectabile). Then in California, all along the Sierras, a number of delicate little annual plants continue to grow in small mountain bogs long after the plains are quite parched, and annual vegetation has quite disappeared from them. But who shall record the beauty and interest of the flowers of the wide-spreading marshlands of this globe of ours, from those of the vast wet woods of America, dark and brown, and hidden from the sunbeams, to those of the breezy uplands of the high Alps, far abore the woods, where the little bogs teem with Nature's most brilliant flowers, joyous in the sun? No one worthily; for many mountain-swamp regions are as yet little known to us. One thing, however, we may gather from 
our small experience-that many plants commonly termed "alpine," and found on high mountains, are true bog-plants. This must be clear to any one who has seen our pretty Bird's-eye Primrose in the wet mountain-side bogs of Westmoreland, or the Bavarian Gentian in the spongy soil by alpine rivulets.

In many country seats there are spots that with a little care can be made into pretty bog-gardens. Where there are no natural sites, a bog-garden may be made by forming a basin of brickwork and Portland cement, about one foot in depth ; the bottom may be either concreted or paved with tiles laid in cement, and the whole must be made water-tight; an orifice should be made in the side, at the height of 6 inches, to carry off the surplus water, and another in the bottom at the lowest point, with a cork, or, better still, with a brass plug valve to close it. Five or six inches of stones and bricks are to be first laid in, and the whole must be filled with good peat soil, the surface being raised into uneven banks and hillocks, with large pieces of clinker or stone imbedded in it, so as to afford drier and wetter spots. The size and form of this garden may be varied at discretion; it should be in an exposed situation; the back may be raised with a rockwork of stones imbedded in peat, and the moisture, ascending by capillary action, will make the position a charming one for Ferns and numberless other peat-loving plants. It is in every way desirable that a small trickle of water should constantly flow through the bog; ten or twelve gallons daily will be sufficient, but if this cannot be arranged it may be kept filled by hand. Such a bog may be bordered by a very low wall of flints or stones, built with mortar, diluted with half its bulk of road-sand and leaf-mould, and having a little earth on the top; the moisture will soon cause this to be covered with moss, and Ferns and all kinds of wall-plants will thrive on it.

Where space will permit, a much larger area may be converted into bog and rockwork intermingled, the surface being raised or depressed at various parts, so as to afford stations for more or less moisture-loving plants. Large stones should be freely used on the surface, so as to form mossy stepping-stones; and many plants will thrive better in the chinks between the stones than on the surface of the peat. It is not necessary to render water-tight the whole of such a large area. A channel of water about 6 inches deep, with drainpipes and bricks at the bottom, may be led to and fro or branched over the surface, the bends or branches being about 3 feet apart. The whole, when covered with peat, will form an admirable bog, the spaces between the channels forming drier portions, in which various plants will thrive vigorously.

Perhaps the best place for an artificial bog is on sloping ground. 
The water flows in at the top, and the surface must be rendered water-tight with Portland cement or concrete. Contour or level lines should then be traced on the whole surface at distances of about 3 feet apart, and a ridge, two bricks in height, should be cemented along each of the horizontal lines. These ridges, which must be perfectly level, serve to hold the water, and the surplus escapes over the top to the next lower level. Two-inch drain tiles, covered with coarse stones, should be laid along each ridge to keep the channel open, and a foot of peat should be thrown over the whole. Before adding the peat, ridges may be built on the surface,

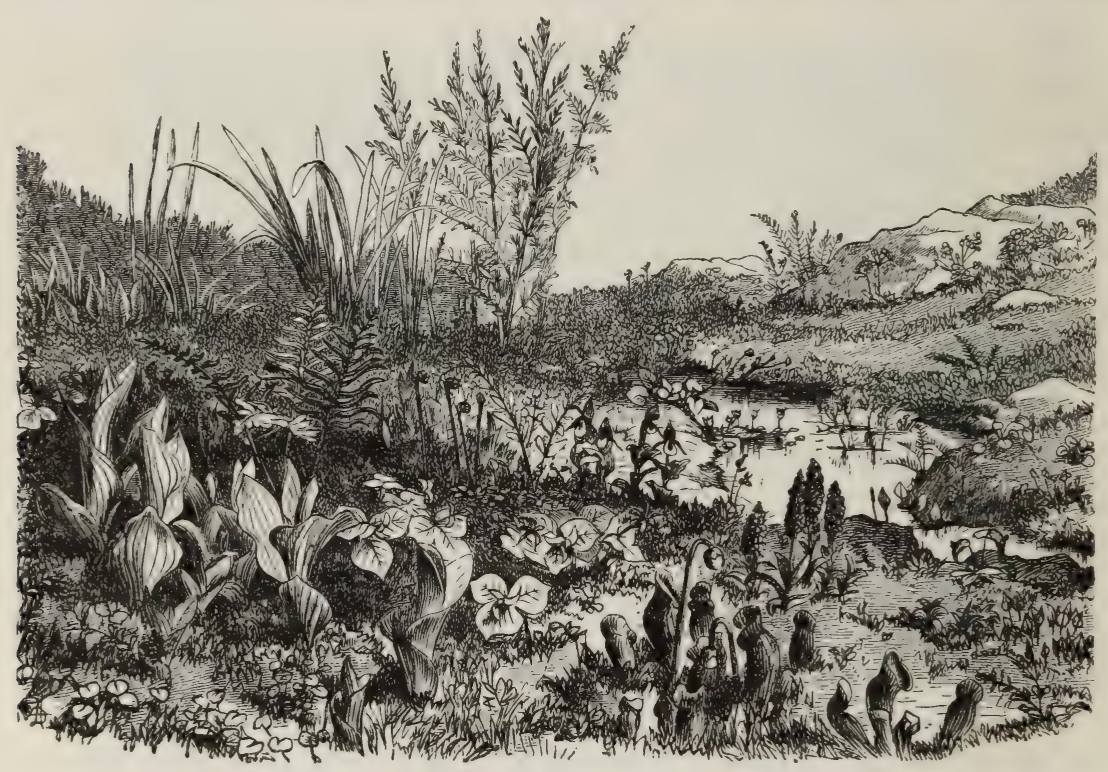

Cypripedium. Trillium.

Sarracenia.

Helonias.

Pinguicula.

A BOG-GARDEN.

the stones being built together with peat in the interstices. These ridges need not follow the horizontal lines. The positions thus formed are adapted both to grow and to display Ferns and alpine bog-plants to advantage.

In addition to regular bog-plants, almost all the choice alpines will thrive better in the drier and more elevated parts than in pots or an ordinary border. Perhaps the most charming plants to commence with are our own native bog-plants-Pinguicula, Drosera, Parnassia, Menyanthes, Viola palustris, Anagallis tenella, Narthecium, Osmunda, Lastrea Oreopteris, Thelypteris spinulosa, and other Ferns; Sibthorpia europæa, Linnæa borealis, Primula farinosa, Campanula hederacea, Chrysosplenium alternifolium and oppositifolium; Saxifraga 
Hirculus, aizoides, stellaris, Caltha, and Marsh Orchises. These, and a host of plants from our marshes and the summits of our higher mountains, will flourish as freely as in their native habitats, and may all be grown in a few square feet of bog; while Rhododendrons, Kalmias, dwarf Ferns, and Sedges will serve for the bolder features.

I have not space to enumerate the many beautiful foreign bogplants which abound, and which may be obtained from our nurseries, although some of the best are not yet introduced into this country. One of the great charms of the bog-garden is that everything thrives

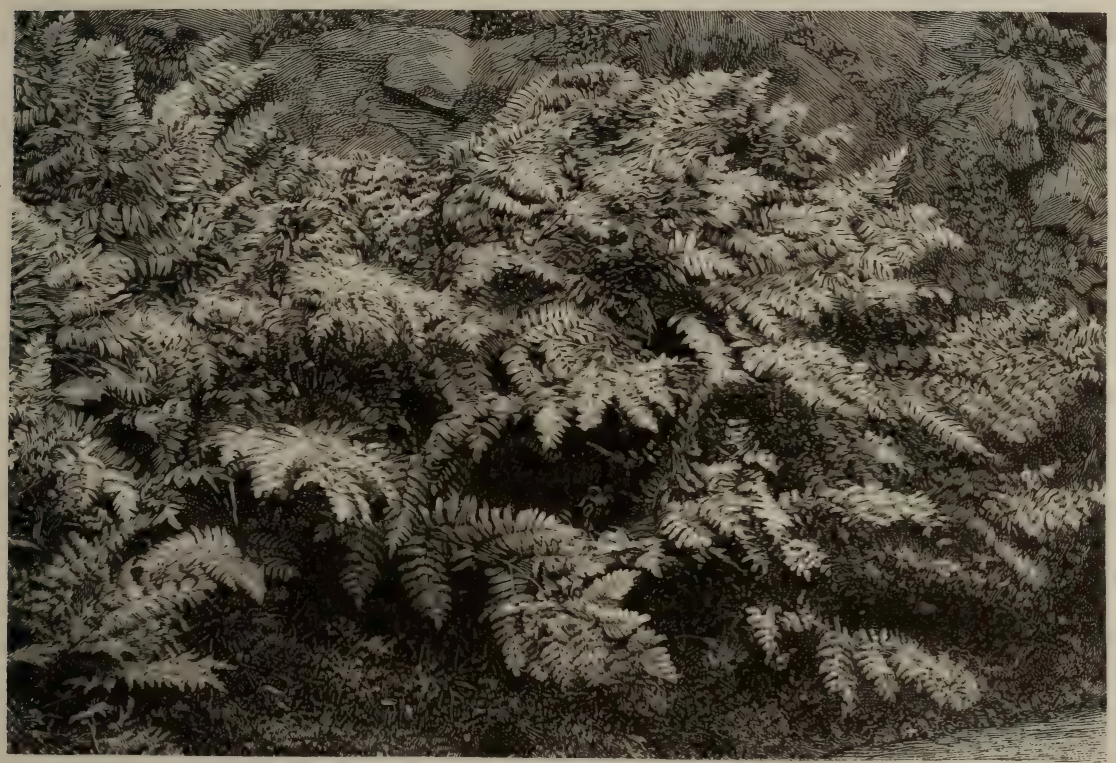

ROYAL FERN (OSMUNDA REGALIS).

and multiplies in it and nothing droops or dies, but the real difficulty is to prevent the stronger plants from overgrowing, and eventually destroying, the weaker. A small pool of water filled with water-plants forms a charming adjunct to the bog-garden. The only caution necessary is to destroy the strong weeds before they gain strength - a single plant of Sheep Rot (Hydrocotyle), for example, would smother and ruin the entire bog in a season.LATIMER ClARK.

HARDY FERNS. - In countries where hardy Ferns abound, they are often seen near water and in hollow and ditch-like places, and it is perhaps best to group them here with the waterside and bog plants. Many of the boldest and best may well be thus grouped. 
This is a way of treating them more artistically than arranging them in the prim and very special "hardy fernery."

The marriage of the fernery and the flower garden, too, is very desirable, our many hardy evergreen Ferns being excellent for association with hardy flowers. There are many varieties of our native Polystichums, Hart's-tongues, Blechnums, which would be excellent companions to evergreen herbaceous plants suited for sheltered, half-shady nooks. There are also many exotic kinds hardy and rigorous. Graceful effects may be developed in foregrounds, in drives through glades, and in many other positions, by the bold use of the larger hardy Ferns. The Bracken is everywhere; but others are more graceful in form, delighting in the partial shade of open woods and drives, and succeeding even in the sun. Up to the present time Ferns have, as a rule, been stowed away in obscure corners, and have never come into the garden landscape at all. But they can give us new and beautiful aspects of vegetation not only in the garden landscape, but even in parks and woods.

In the home counties there is probably not a better specimen than the fernery at Danesbury, of which I give an illustration. It is on a sloping bank in a rather deep dell, overhung with trees and Iry, in the shade of which the Ferns delight. The spot has been improved by artistic rockwork. As regards the planting, the various families are arranged in distinct groups, and each group has a position and a soil adapted to its requirements. The best way of growing Ferns, however, is with flowers, as in Nature, and a hardy fernery may be very beautiful. As a rule, Ferns have in their natural state both soil and locality exactly suited to their requirements; and the soil is yearly enriched by the decaying foliage of surrounding trees, which protects them in winter. In arranging a fernery, study the habits and requirements of the species, and allot to each the position most likely to produce the best results. At Danesbury the most sheltered, moist spot is given to the erergreen Blechnums, which delight in a damp atmosphere, and to the delicate forms of Asplenium. Osmunda, which thrives amazingly, is allotted a low swamp, which is, howerer, free from stagnant moisture. The soil used for these Royal Ferns is a mixture of good loam and fibrous peat. The better deciduous kinds of Polypodium, such as P. Phegopteris and P. Dryopteris, have sheltered positions; and in quiet nooks may be found charming groups of the Parsley Fern, and Cystopteris fragilis, a most delicate and graceful Fern. Lastrea Filix-mas and its varieties occupy the more exposed positions in company with fine colonies of the evergreen kinds, comprising some unique varieties of the Polystichums, Scolopendriums, Polypodiums, etc. A plentiful supply of water is available. 
The beauty of a fernery is much enhanced if the larger kinds of Ferns grow out of some plant of dwarfer habit. The Ferns them-

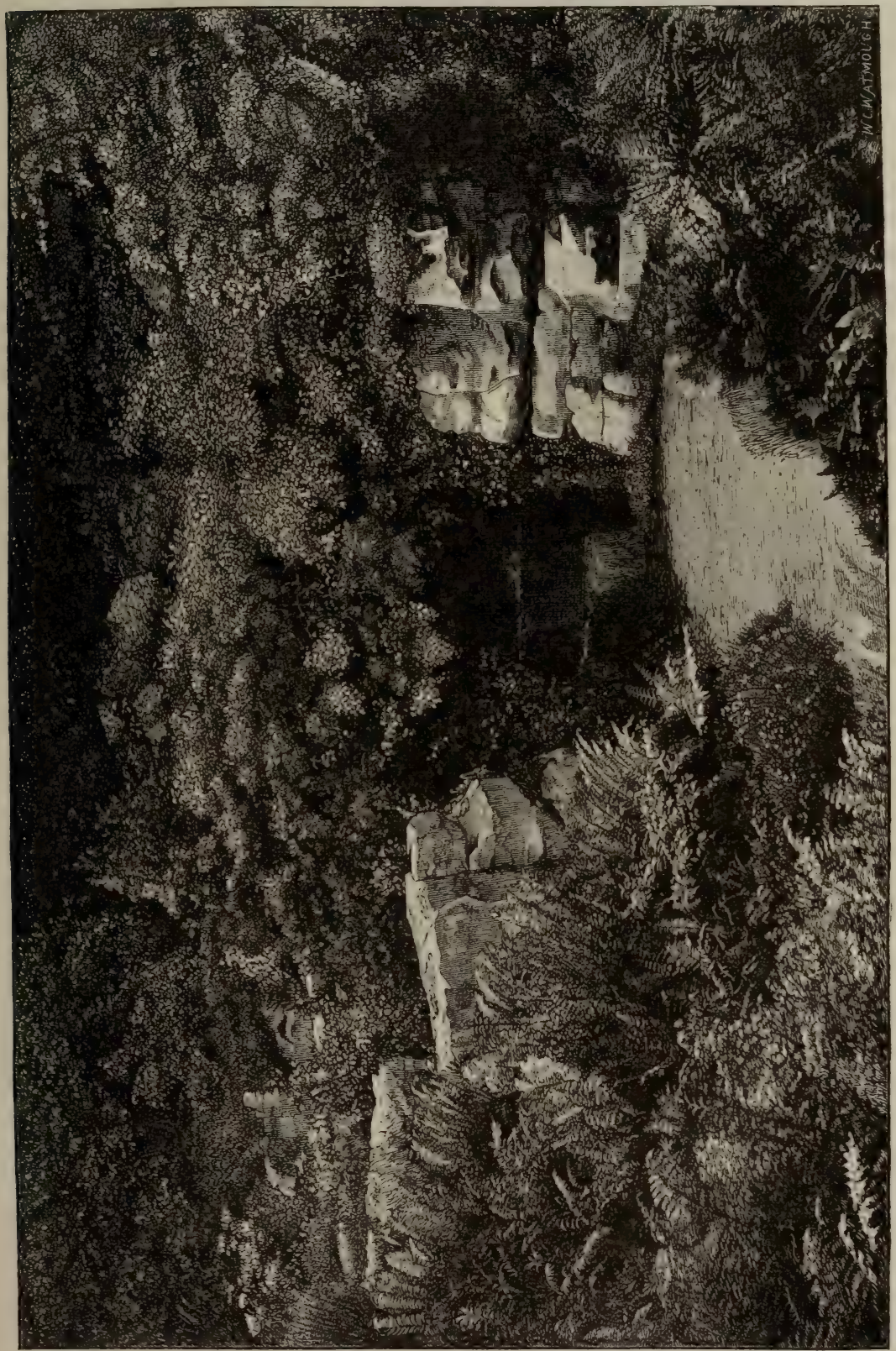

selves are much benefited by this, because there is not excessive evaporation during dry and hot weather. The small Ferns are best 
without any carpet. They are the choicest, rarest, and most difficult to grow, and as they require a little extra attention, it would be better not to risk their being smothered. The Fern-lover will remember that it is not only our own beautiful native Ferns that we possess for adorning our gardens, but that we have also the hardy Ferns of America, Asia, and the continent of Europe.

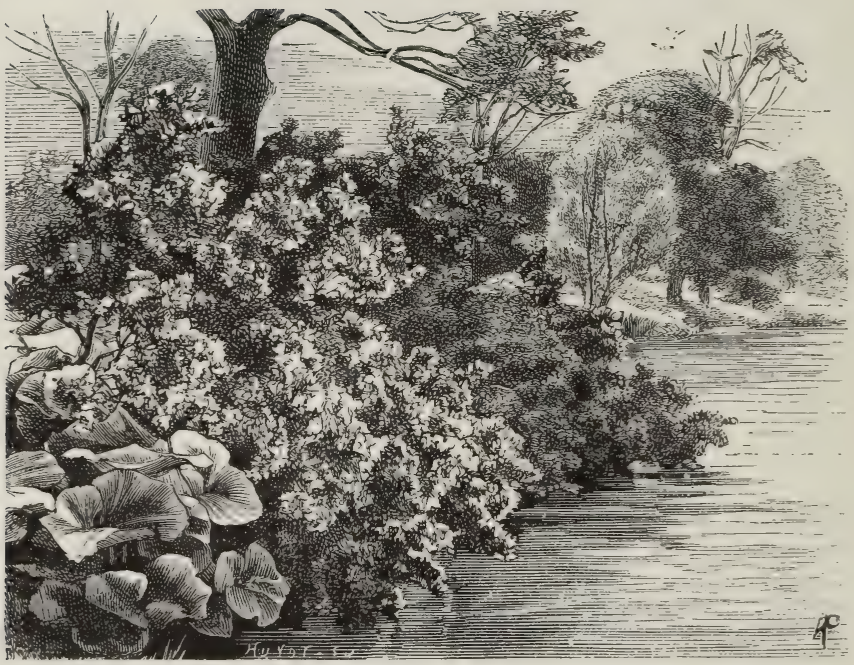




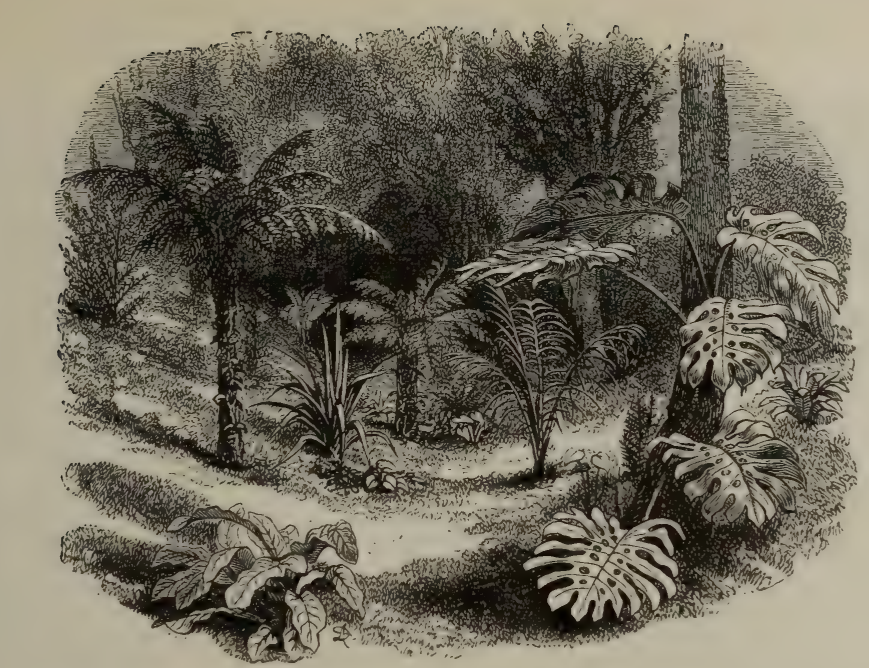

SHELTERED DELL, WITH TREE FERNS AND STOVE PLANTS PLACED OUT FOR THE SUMMER (BATTERSEA).

\section{CHAPTER X}

\section{BEAUTY OF FORM IN THE FLOWER GARDEN}

SUB-TROPICAL gardening is one way of avoiding the eternal round of Geraniums, Calceolarias, and a few other common bedding plants, which, however worthy of culture, can hardly be said to convey a full idea of the beauty of the plant world. For some years, however, the very name was sufficient to deter many from giving the system a trial, from the idea that only sub-tropical vegetation was admissible. This arose through Musas, Caladiums, and similar tender plants being tried, involving costly preparations for bottom heat, special soils, all considered necessary. Now, with the rich store of fine-foliaged plants from temperate climes it is quite possible to have a beautiful garden of hardy fine-leaved plants, for trees like the Ailantus and Paulownia make fine growth if cut down close to the ground every year. We have also the hardy palm (Chamærops), the Yuccas, and graceful Bamboos, and Siebold's Plantain Lily (Funkia), Acanthuses, and plants of a similar character. Amongst those annually raised from seeds, and requiring only the protection of glass to start them, we have much variety from the stately Castor-oil-plant to the divarf Centaurea. One advantage of using permanent plants in pots for central objects in groups or as isolated specimens on the turf is that, while they add variety to the arrangement during summer, they can be taken indoors when the 


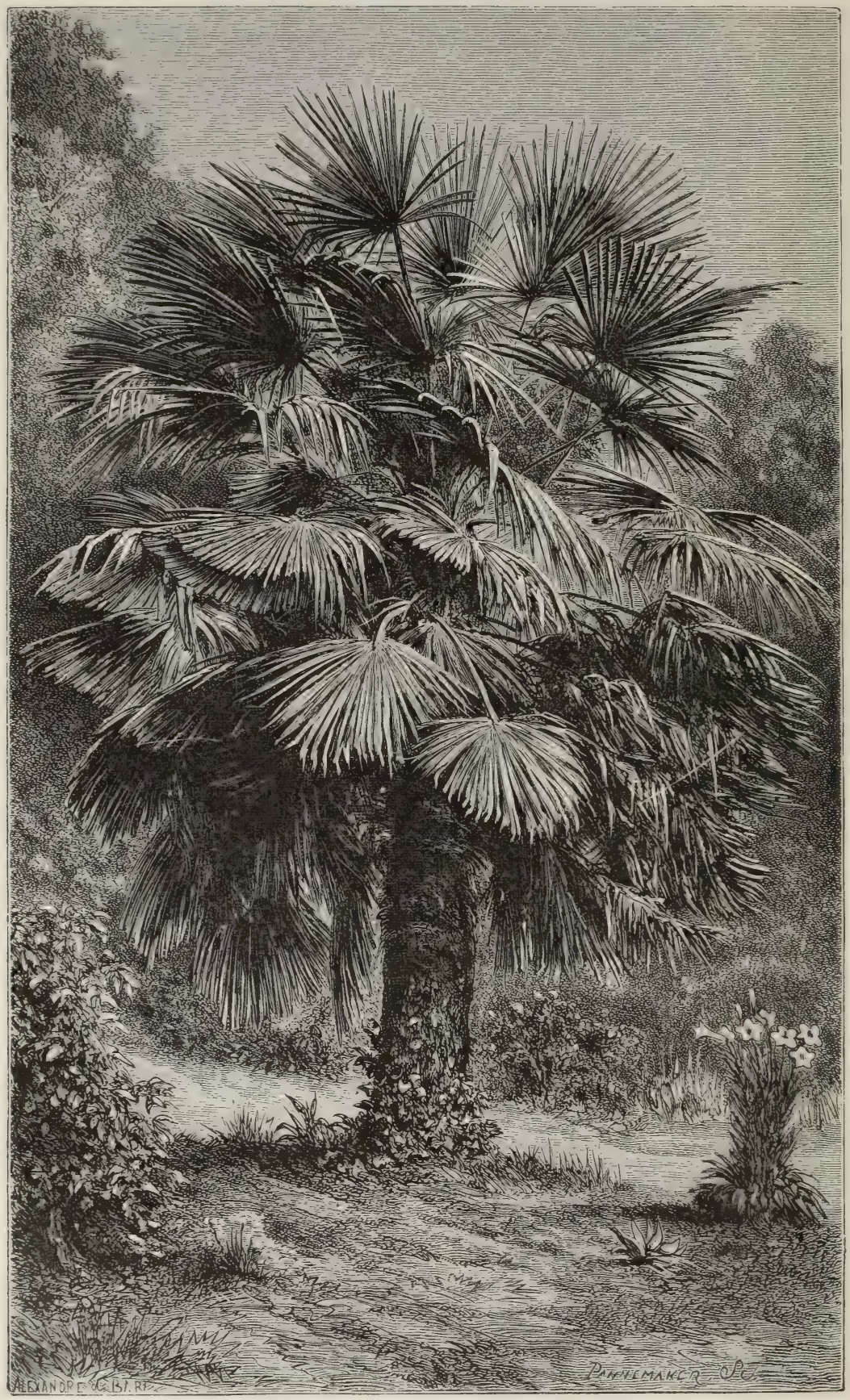

HARDY PALM IN THE OPEN AIR IN ENGLAND. 
beauty of the outdoor garden begins to fade. Although tender plants in pots are effective in summer in special positions, plants that cannot stand out-of-doors from the beginning of June until the end of September can hardly be called fit for summer gardening. Among the most suitable are several kinds of Palm, such as Seaforthia elegans, Chamærops excelsa, and C. humilis; Aralias, various; Dracænas, do.; Phormium tenax and its variegated form; Yucca aloifolia variegata, Ficus elastica, and Eucalyptus globulus, the bluish-gray tint of which is pretty. Erythrinas make fine autumn beds; they are brilliant in colour, and useful for lighting up masses of foliage. Bamboos have such beautiful foliage, that where the winter is severe they should be used as large pot plants for plunging out-of-doors in summer.

The hardiest Tree Fern, Dicksonia antarctica, looks well when plunged in shady dells where a canopy of overhanging foliage gives - shelter and shade; and several varieties of dwarf Ferns, such as the Bird's-nest Fern, are admirably adapted as undergrowth to this Fern. Plants raised from seed will, however, usually form the majority, owing to the lack of room under glass for many large plants. Of plants raised from seed the most useful are Cannas. If sown in February in strong heat, they make handsome plants for bedding ; their foliage is graceful and their flowers are rich in colour. The roots increase yearly in size and strength. They may be taken up and wintered under glass, or securely protected in the soil by means of external coverings. The Cannas in London public gardens are protected in winter.

Most of the tall light green-foliaged varieties flower freely and make excellent centres for groups, while the dwarf bronze-foliaged sorts are good for edging. Solanums are also effective. The spinyleaved S. robustum, the elegant cut-leaved S. laciniatum, and S. Warscewiczi make good single specimens, or edgings to groups of taller plants. Wigandias, Ferdinanda eminens, and Melianthus major are all good if treated as annuals; and among dwarf things that can be raised with them I may mention Brazilian Beet, with its richlytinted leaves and mid-ribs; Acacia lophantha, Amaranthus, Cineraria maritima, and Centaureas, with their silvery cut leaves. Bocconias, with their tall spikes of graceful flowers and noble foliage, make effective and permanent plants for isolated groups. The beautiful Pampas Grass and Arundo ought also to find a place. Several varieties of Rhus or Sumach have good foliage, Rhus glabra laciniata being elegant. Aralia japonica is also useful, and so are the Tritomas, with their Rush-like foliage and flame-like spikes of flower, and the Plantain Lilies.

As to arrangement, the best beds or sets of beds are those of 


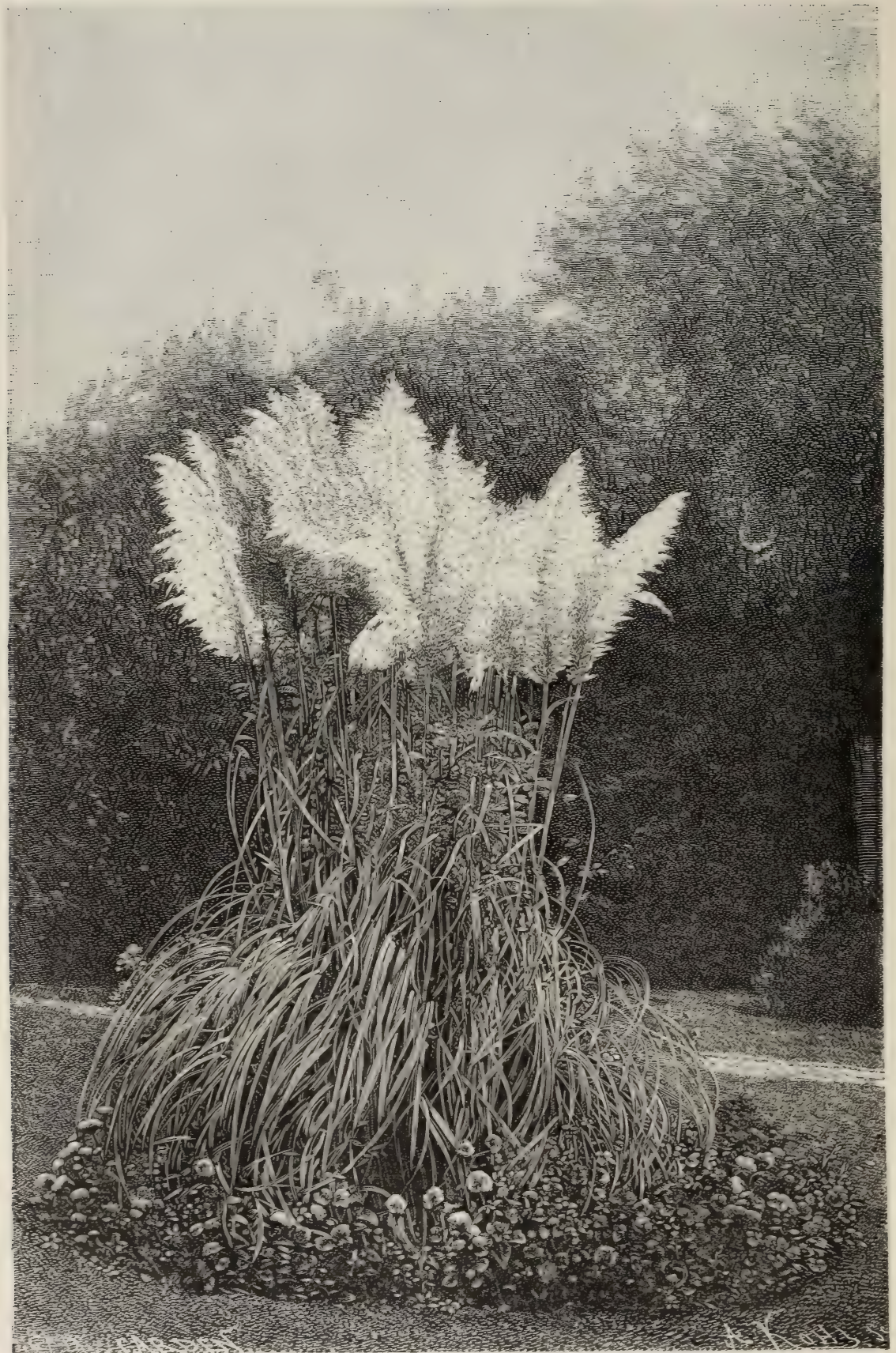

PAMPAS GRASS IN A SUSSEX GARDEN (CHICHESTER). 
the simplest design. Shelter is of importance, recesses in shrubberies or in banks clothed with foliage form the most fitting background for beds or groups to nestle in. Avoid Musas or Caladiums, the leaves of which tear to shreds if winds cannot be shut out, and also plants that look unhappy after a cold night or two. Make the most of plants that grow under nearly all conditions. If there is a dell or garden overhung by trees where flowering plants run to leaf

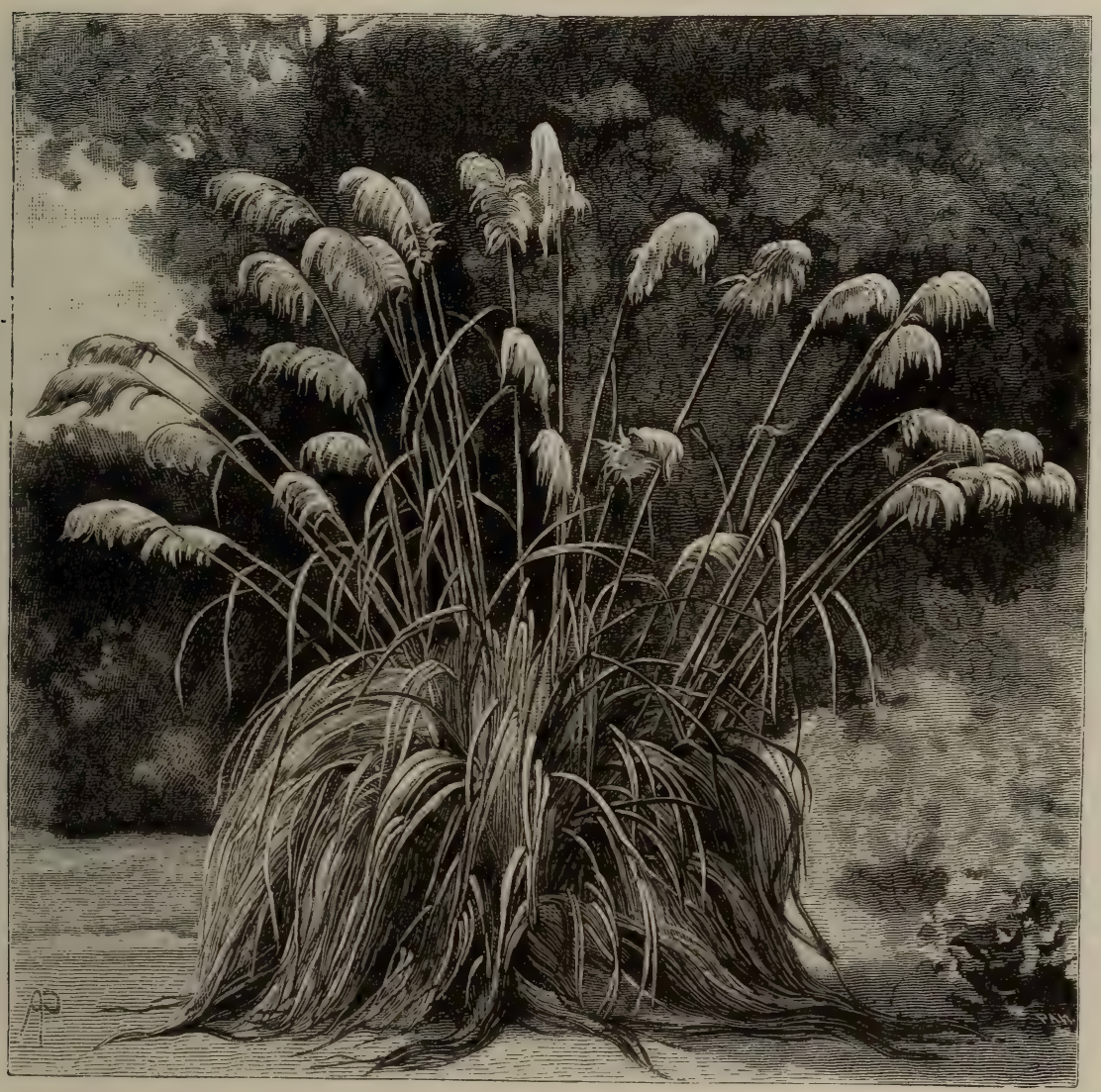

THE NEW ZEALAND REED (ARUNDO CONSPICUA).

and refuse to flower, use it for fine-leaved plants. A garden where each plant spreads forth its delicate foliage will form a pleasant change from brilliant bedding plants, or severely geometric carpet beds.-J. G.

But are we to adopt this system in its entirety like Mr. Gibson when superintendent of Battersea Park? Certainly not. To carry it out fully in private gardens would entail enormous expense. We can, however, introduce most of its better features into our gardens. 
By its aid, we can vary their contents, and render them more interesting. A better effect may be obtained from hardy plants only than from tender ones. There is the Pampas Grass, unsurpassed by anything requiring protection; there are the Yuccas, thoroughly hardy, and unsurpassed by anything of like habit grown in a hothouse; the Arundos, conspicua and donax; fine hardy plants like Crambe cordifolia, Rheum Emodi, Ferulas, and umbelliferous plants,

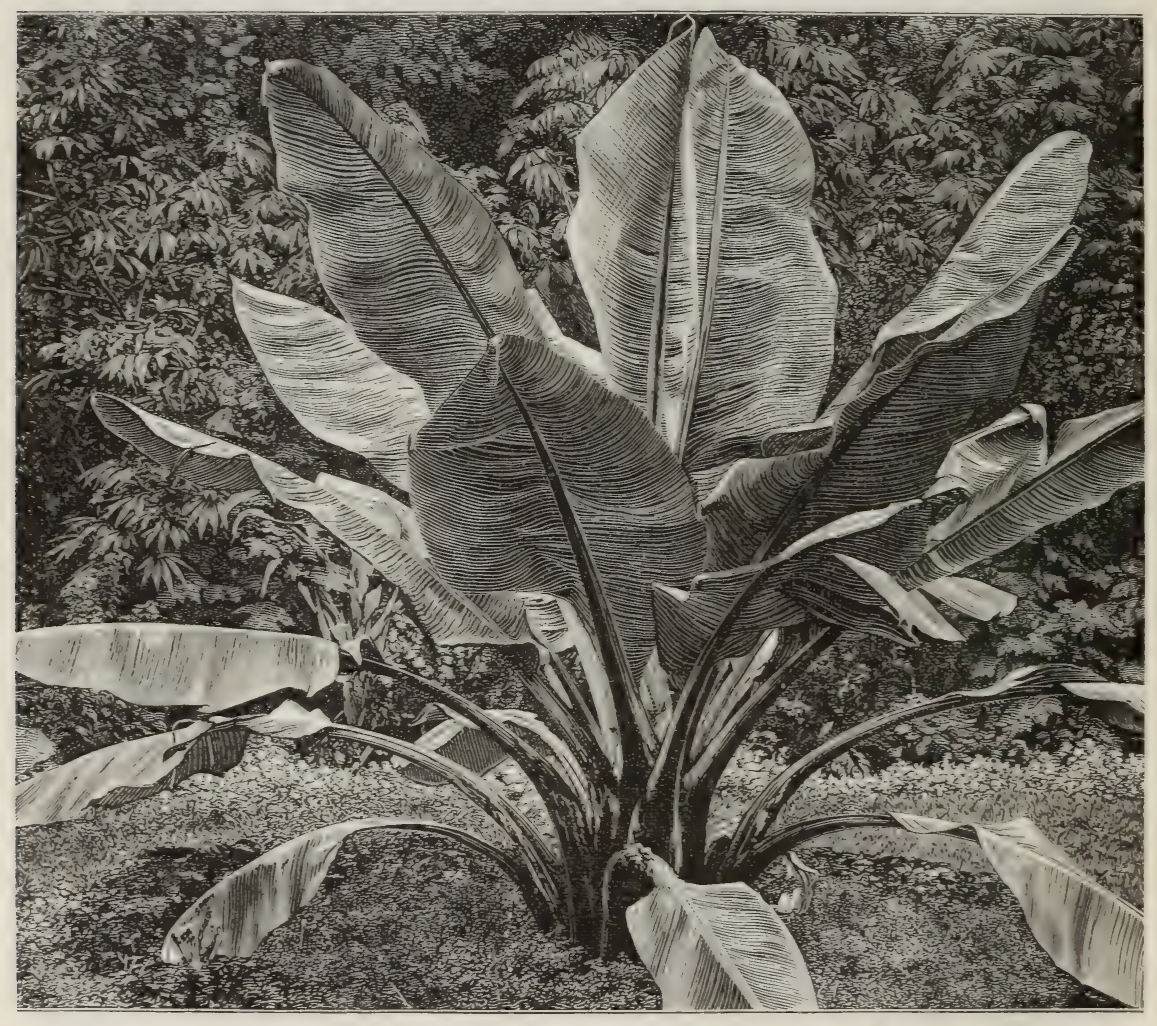

MUSA ENSETE IN THE OPEN GARDEN AT PARK PLACE, HENLEY-ON-THAMES.

as graceful as tenderest exotics. Acanthuses, too, when well grown are very suitable. Then we have a hardy Palm that through all our recent hard winters has preserved its health and greenness whereever its leaves could not be torn to shreds by storms.

As an example of fine form from hardy plants, I cannot do better than give the New Zealand Reed (Arundo conspicua). This handsome Grass produces its blossom-spikes earlier than the Pampas, and is more elegant in habit, the silky white tufts bending like ostrich plumes at the end of slender stalks. It is best adapted to 
a sheltered corner, where it is protected from rough winds, and relieved by a background of darker foliage.

As to tender plants in the open air, it would be difficult to give a better illustration than the stately Musa Ensete in Berkshire. In sheltered nooks in the southern counties it makes a very fair growth in the summer. In I877 I was struck with its health and vigour at Park Place, Henley-on-Thames. Mr. Stanton, the gardener, raised a batch from seed, and it was surprising what fine plants they became in fifteen months. They were sown in April, and planted out early in June. Placed indoors early in October, they remained throughout the winter in a warm greenhouse, and were

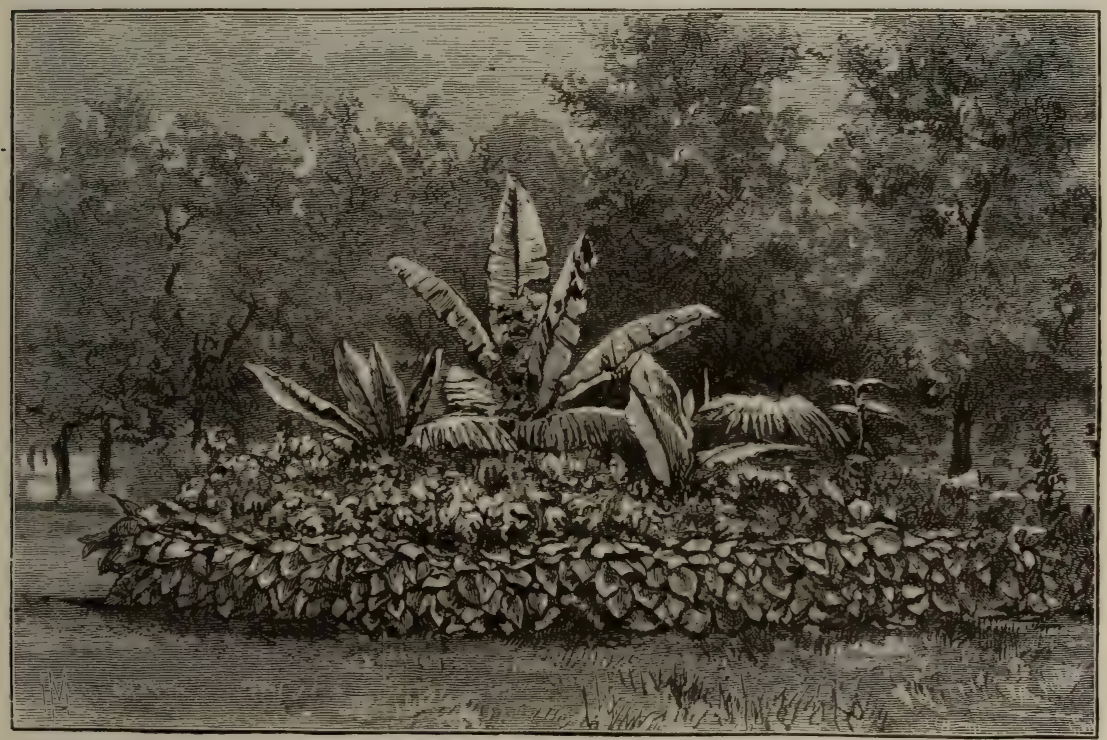

BED OF FINE-LEAVED PLANTS IN HYDE PARK. FROM A SKETCH BY H. G. MOON.

again planted out in the following June, when they formed fine young leaves. The plant is quite as effective in a conservatory in winter as when put out-of-doors during summer.

Here is an illustration of a bold mass formerly near Hyde Park Corner, which seemed to illustrate the best features of recent fineleaved gardening. It had a great Abyssinian Plantain in the middle, and was fringed by a few sub-tropical plants, and edged by an extraordinary fringe of the fine hardy Siebold's Plantain Lily, long-enduring in beauty. The reason of the success of this bed is clear. The bed was not a finicking angle or a wormy scrawl, but a bold circle, and presented no confusion to the observer, who simply saw the plants rising in a well-defined group from the roomy turf. 


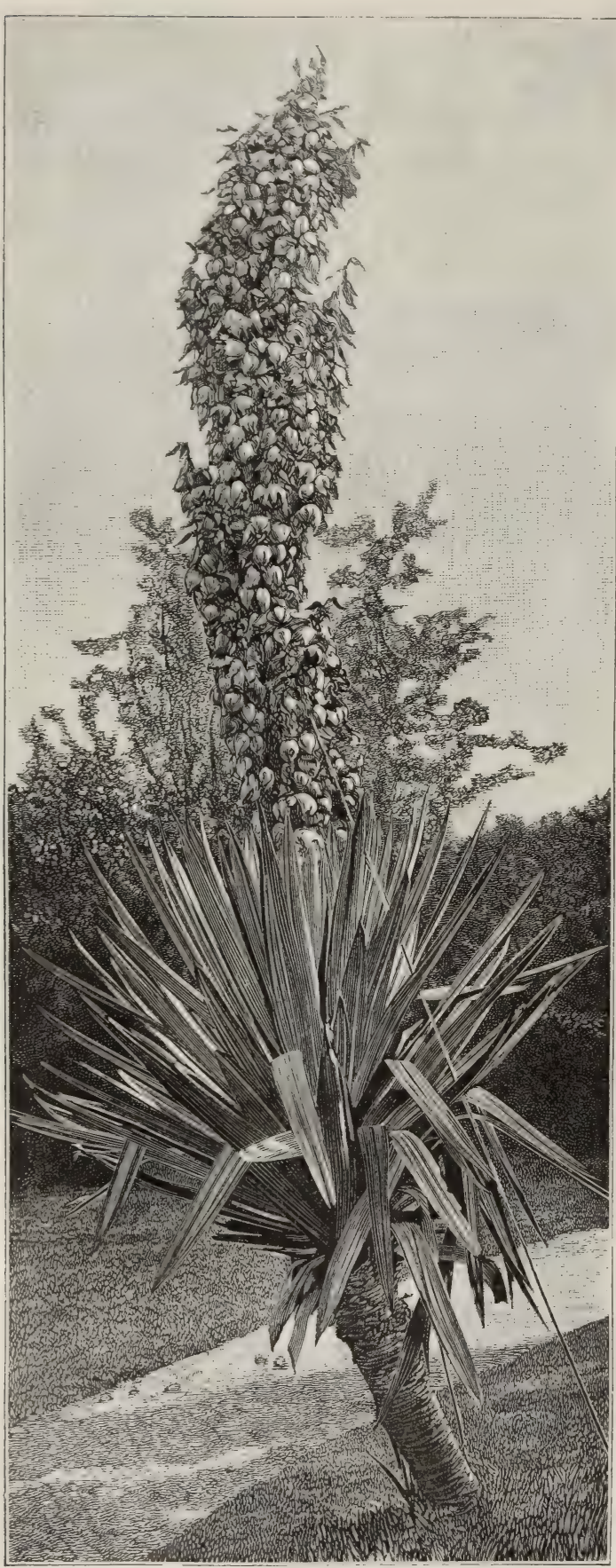

YUCCA GLORIOSA, SALISBURY.
It was by itself, could be seen unopposed, and was not muddled up with a lot of other beds near it. It may be noted that the eye does not, as a rule, care for more than one thing at a time, and if invited to look at a picture made up of many things, rests with pleasure on some one spot. Lastly, the plant forms were strong and well selected, and contrasted well with the ordinary tree vegetation near, as there was plenty of Grass about the bed to allow of contrasts withoutconfusion with rival subjects. The way in which the Plantain Lilies began early in the year to adorn the spot, and continued to do so throughout the whole summer and autumn, was a pleasure to see. The drawing was made about the end of September, shortly after some heavy storms which tore the Musa a little, but the effect remained excellent till October. Some of the Plantain Lily leaves had begun to fade, but they still produced a very fine effect. 
YUCCAS IN GROUPS.-Wherever space can be afforded, and suitable situations found, hardy Yuccas should be grown. Few hardy subjects are so distinct in foliage and manner of growth; but they appear to the best advantage if arranged in bold groups, and in the immediate vicinity of trees and shrubs, forming a harmonious contrast to them. Perhaps the best situation is a sloping ground fully exposed to the mid-day sun, and backed by evergreens. If allowed space for development, they will every year add beauty to the place.

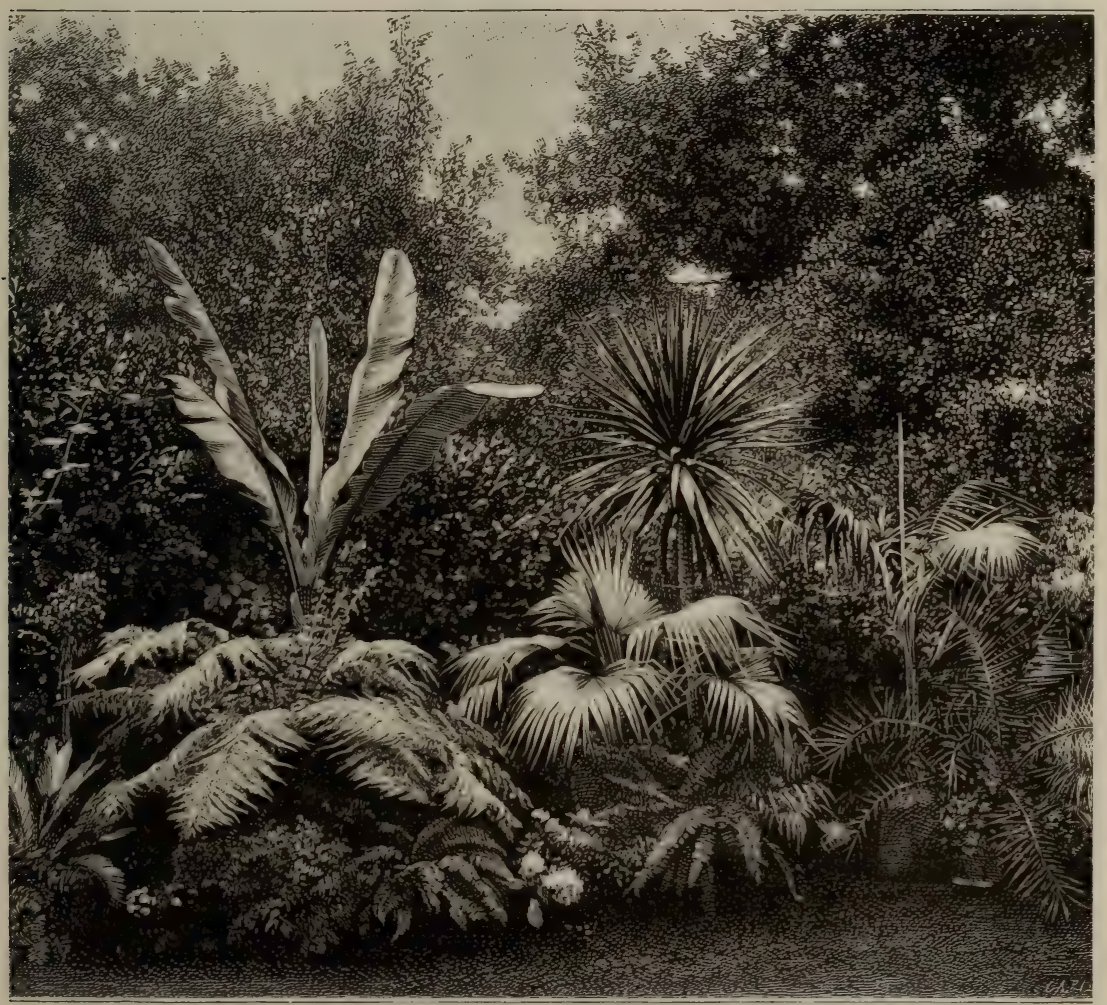

GROUP OF HOUSE PLANTS PLACED OUT FOR SUMMER. HARROW LODGE, DORKING.

The handsome spikes of their large cream-coloured flowers are extremely effective, especially when relieved by a background of verdure. Yuccas like a well-drained soil, and thrive on a subsoil of pure chalk. They delight in full exposure to the sun, and enjoy shelter from rough winds. Hence the advisability of planting them near trees or shrubs. The Yucca is hardy, but the foliage of several of the best species, such as filamentosa, is apt to get torn when much exposed.

In grouping Yuccas, a more natural effect is obtained where 
some of the specimens have the head of their foliage from 3 feet to 6 feet above the soil. These tall plants should not, however, be placed in a regular manner in a back line, but some should

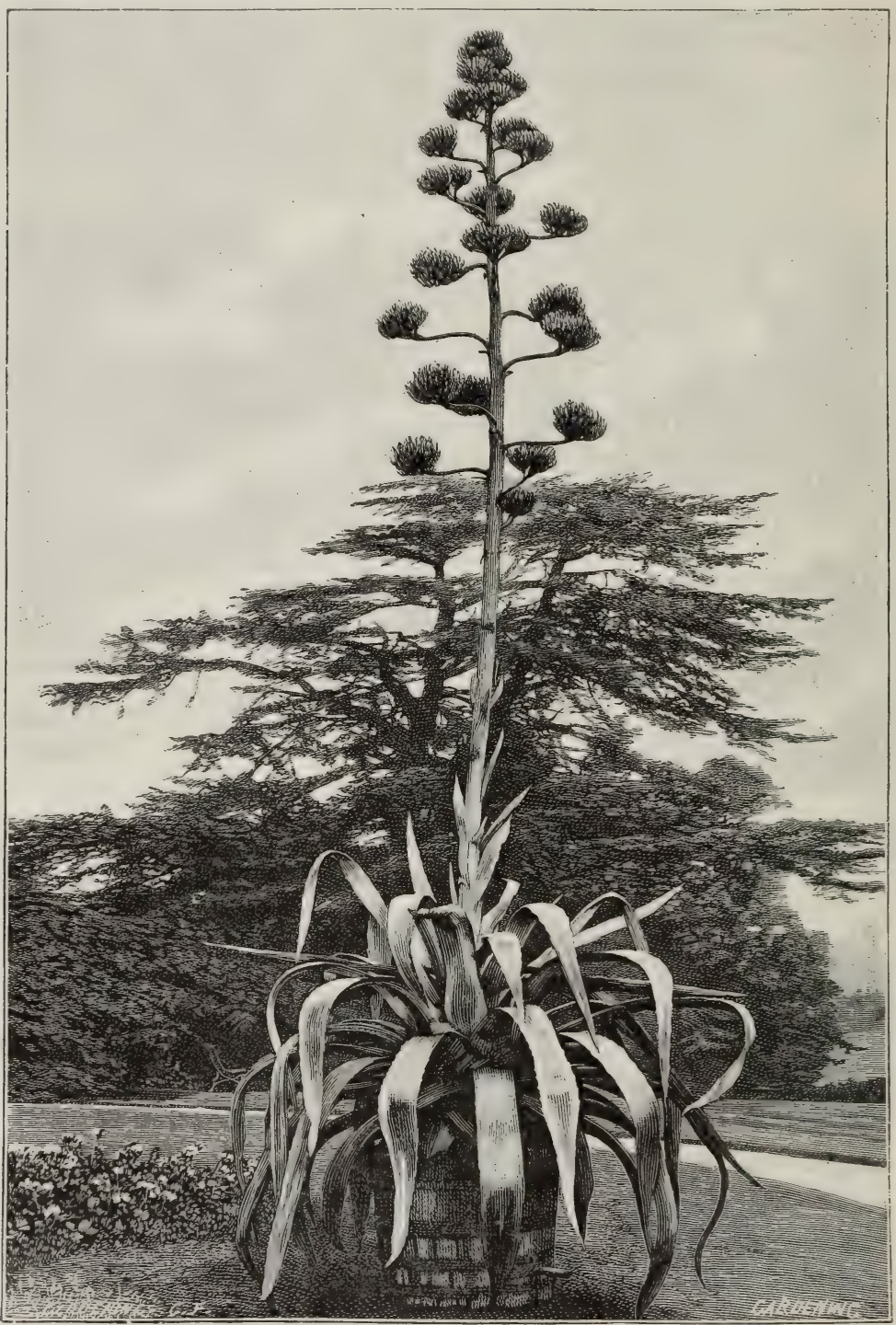

AMERICAN ALOE. EXAMPLE OF GREENHOUSE PLANTS SET IN OPEN AIR IN SUMMER. ENGRAVED FROM A PHOTOGRAPH TAKEN IN KNIGHTWICK RECTORY GARDEN, WORCESTERSHIRE.

be allowed here and there to advance into the foreground, some of the smaller specimens nestling at their feet. The effect of a group thus arranged charms by its irregularity and quaint beauty. 
The use in gardens of plants having handsome leaves and fine form has taught us the value of grace and verdure amid masses of flowers, and has reminded us how far we have diverged from artistic ways. In a wild state brilliant blossoms are usually relieved by a setting of abundant green. Where mountain and meadow plants of one kind produce a sea of colour at one season, there is intermingled a spray of pointed grass and leaves, which tone down the colour masses.

We may be pleased by the wide spread of purple on a heath or mountain, but when we go near we find that its most exquisite aspect is seen in places where the long moss cushions itself beside the ling, and the fronds of the Polypody come up around little masses of heather.

We cannot attempt to reproduce this exactly, but it will be found the chief source of the beauty and interest of our garden; and the more we keep this fact before our eyes, the nearer shall we be to success.

Nature's laws should not be violated; and few human beings have violated them more than flower-gardeners. We should compose from Nature, as landscape artists do. We may have in our gardens-without making wildernesses of them either-all the shade, the relief, the grace, and the beauty of Nature.

By selecting from the vast number of hardy plants in the country, and by associating them, where convenient, with house plants placed out for the summer, we may have as much variety and beauty of form as can be desired for the flower garden or pleasure-ground.

Among the more tender plants, we must choose such as grow healthily in sheltered places in the warmer parts of England. The kinds with permanent foliage, such as the New Zealand flax and the hardier Dracænas, will be as effective everywhere as they are around London and Paris, and to them the northern gardener should direct his careful attention. Even if it were possible in all parts to cultivate the softer-growing kinds to the same perfection as in the south of England, it would by no means be always desirable, as they cannot be used indoors in winter. The best are the many evergreen plants that stand out in summer without injury, and may be transferred to the conservatory in autumn, to produce through the cold months as fine an effect as in the flower garden in summer.

But the hardy plants are of far greater importance; for while few can afford the tender plants, many may enjoy hardy ones, and that too with far less trouble than tender ones.

The one illustration from the South of France exhibits very graceful vegetation; but the other engravings in the chapter show that effects quite as good may be had in English gardens. 
One kind of arrangement in particular must be guarded against - the geometro-picturesque one, seen in some parts of the London parks devoted to sub-tropical gardening. The plants are often of

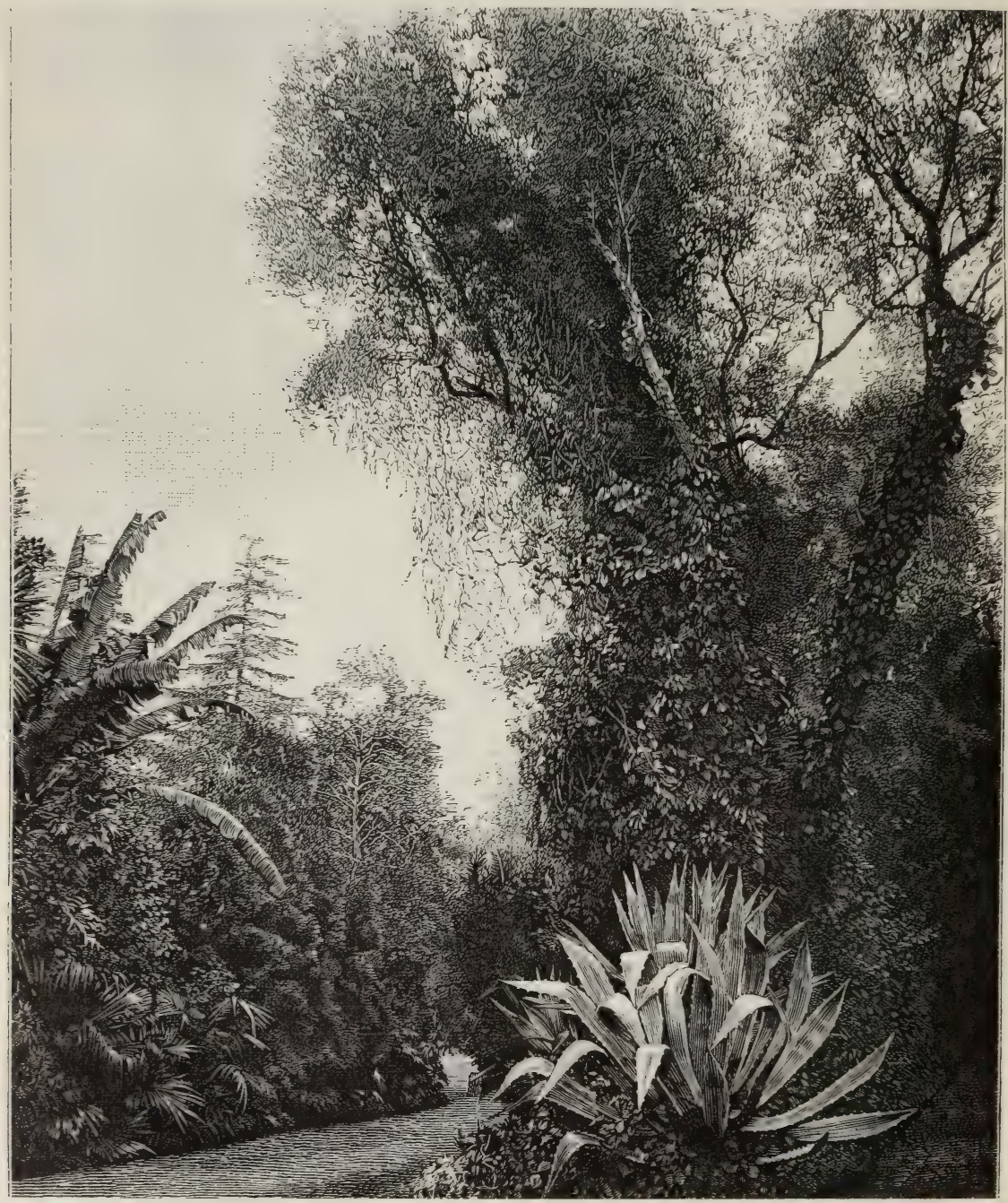

FINE-LEAVED SUB-TROPICAL PLANTS, WITH IVY AND CLIMBERS, IN THE GARDENS OF THE PRINCESS KOTSCHOUBEY, AT NICE.

the finest kinds and in the most robust health, and all the materials for the best results are abundant; yet the scene fails to satisfy, from the needless formality of the beds, from the heaping together of many specimens of one kind in long masses, straight or twisting, with high raised edges of hard-beaten soil. 
Principal Families of Plants with fine Foliage or Form, for use in British Gardens

Acacia.

Acanthus

Agave .

Ailanthus

Alsophila

Amaranthus

Andropogon

Aralia.

Aristolochia

Artemisia .

Arum

Arundo

Asparagus.

Asplenium

Astilbe .

-Bambusa

Berberis

Bocconia

Bupthalmum

Caladium .

Calla

Canna .

Cannabis

Carduus

Carex .

Carlina

Carludovica

Caryota

Centaurea.

Chamædorea.

Chamæpeuce .

Chamærops

Cineraria.

Cordyline .

Corypha

Crambe

Cucurbita

Cyathea

Cycas .

Cynara

Cyperus.

Datisca

Dicksonia .

Dicentra

Dimorphanthus.

Dipsacus

Dracæna

Echinops

Elymus

Epimedium

Tree Fern.

\section{Cretan Hemp.}

Bear's-breech. American Aloe.

Tree of Heaven.

Tree Fern.

Amaranth.

Beard Grass.

Birthwort.

Wormwood.

Wake Robin.

Reed.

Spleenwort.

False Goat's-beard.

Bamboo.

Barberry.

Tree Celandine.

Ox-eye.

Indian Kale.

Arum Lily.

Indian Shot.

Hemp.

Thistle.

- Sedge.

Carline Thistle.

- Small Palmetto

$$
\text { Palm. }
$$

Toddy Palm.

Centaury.

Fish-bone Thistle.

Fan Palm.

Palm Lily.

Palm.

Kale.

Gourd.

Fern Palm.

Cardoon.

Tree Fern.

Lyre-flower.

Teasel.

Dragon-plant.

Globe Thistle.

Lyme Grass.

Barrenwort.
Equisetum

Erianthus .

Grass.

Eryngium . . Sea Holly.

Erythrina . . Coral Tree.

Eucalyptus . Austratian Gum

$$
\text { Tree. }
$$

Farfugium

Ferdinanda.

Ferula .

Giant Fennel.

Ficus . . . Fig Tree.

Funkia . . Plantain Lily.

Gourds.

Gynerium .

Pampas Grass.

Gunnera.

Gymnocladus . Kentucky Coffee Tree.

Hedychium.

Helianthus . Sunflower.

Hemerocallis . . Day Lily.

Heracleum . . Cow Parsnip.

Humea . . Amaranth

Inula . . Elecampane.

Jubæa . . . Palm.

Kochia . . Summer Cypress.

Kœlreuteria.

Latania . . Palm.

Lavatera . . Tree Mallow.

Ligulariạ.

Malva . . Mallow.

Megasea . . Saxifraga.

Melanoselinum . Black Parsley.

Melia . . Indian Lilac.

Melianthus . Cape Honey-flower.

Meum . . . Spignel.

Molospermum.

Montagnæa.

Morina

Whorl-flower.

Mulgedium . Blue Sow Thistle.

Musa . . . Banana.

Nicotiana . . Tobacco-plant.

Nuphar . . Water Lily.

Onopordon . Cotton Thistle.

Osmunda . . Flowering Fern.

Panicum . . Panic Grass.

Paulownia.

Petasites . . Batter Dock.

Phœnix . . Palm.

Phormium . N. Zealand Flax.

Phytolacca . Poke-plant. 
Principal Families of Plants with fine Foliage or Form, for use in British Gardens-Continued

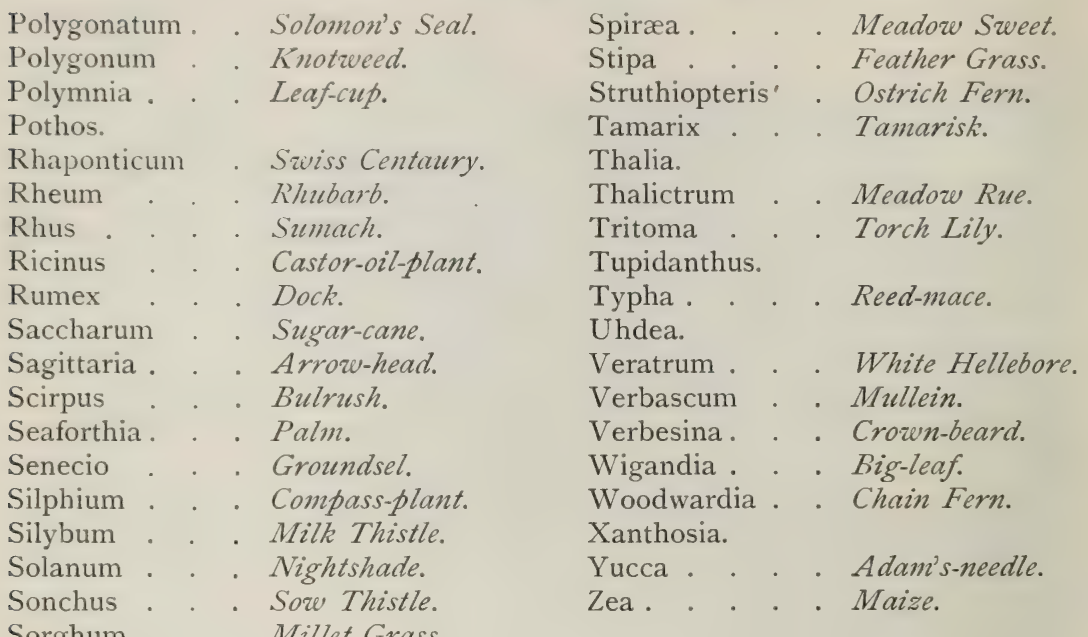

Sorghum . . Millet Grass.

Particulars of culture and position will be found in the alphabetical part.

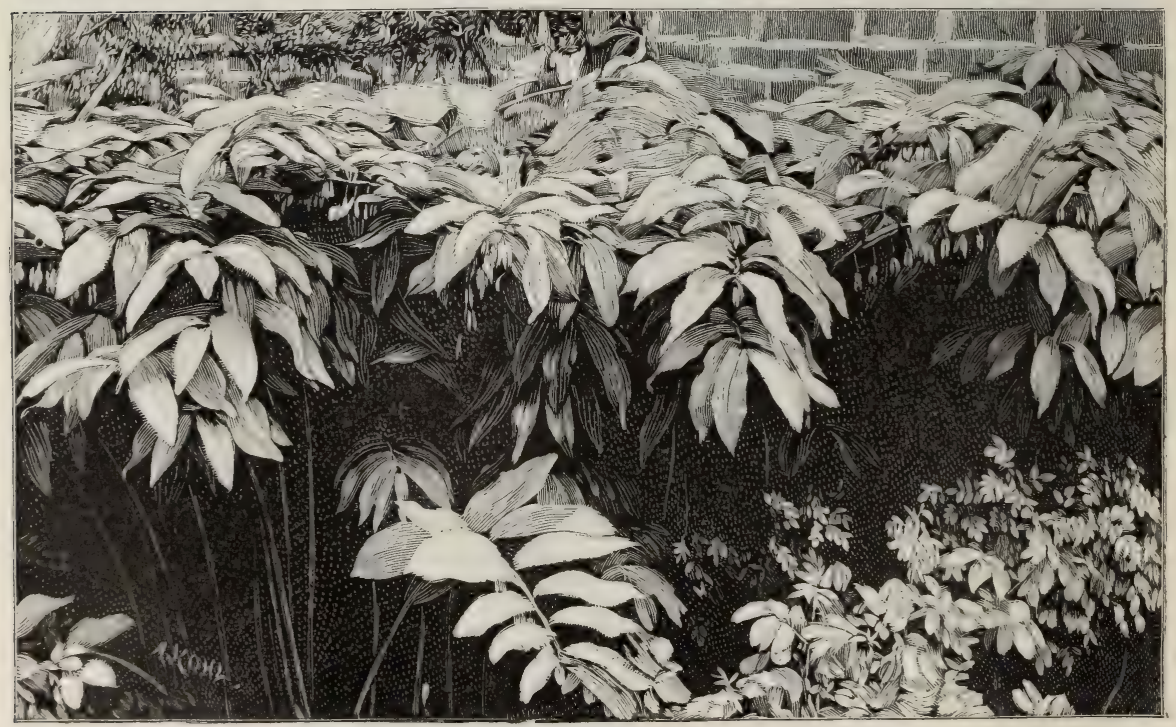

GROUP OF SOLOMON'S SEAL AT FOOT OF WALL. 


\section{CHAPTER XI}

CLIMBERS

OUR numerous hardy climbers are rarely seen to advantage, for they are too often stiffly trained against walls. Indeed, many have gone

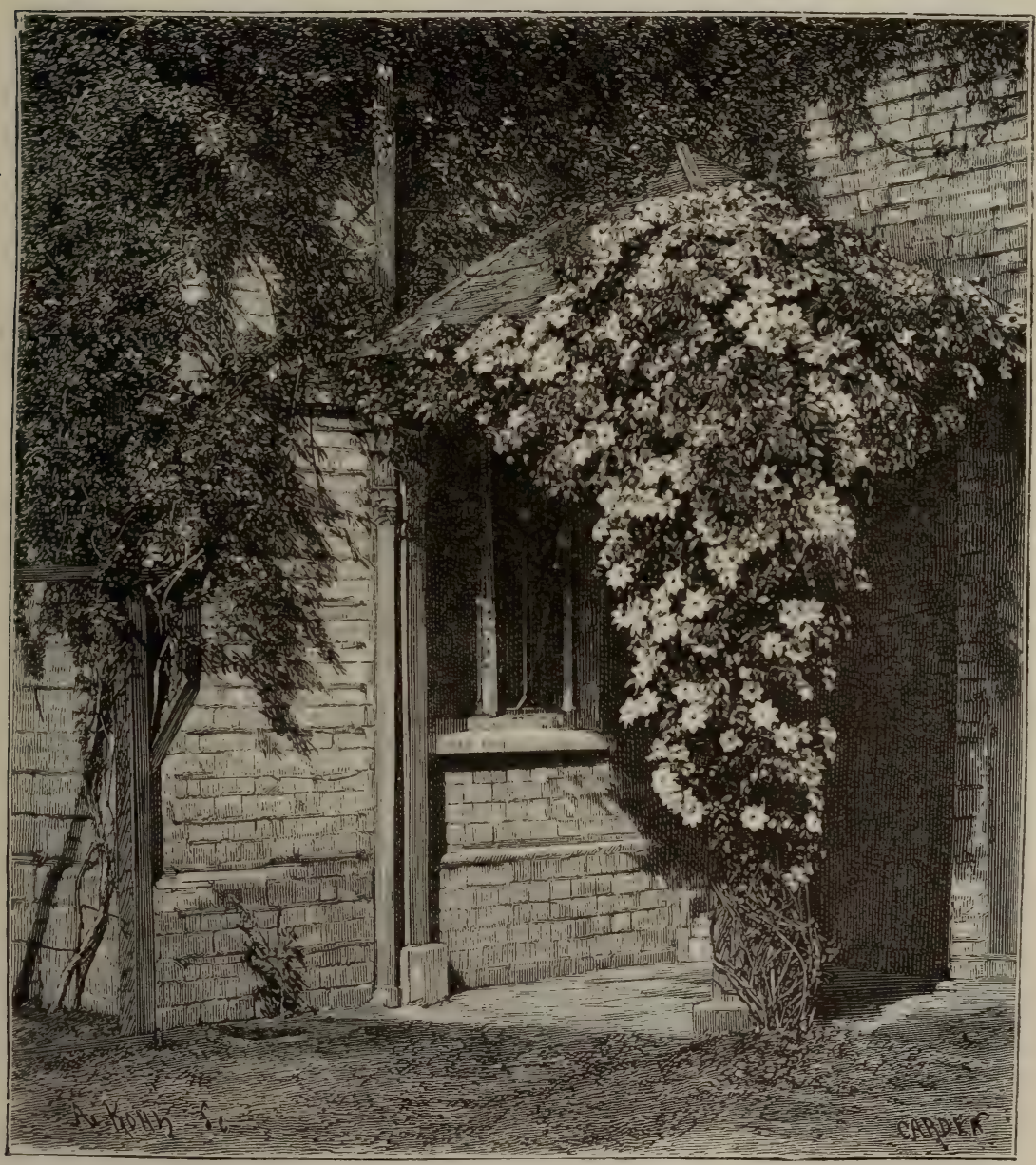

CLEMATIS OVER PORCH.

out of cultivation because there were no just ideas of their proper use. One of the happiest of all ways of using them is to train them 
freely against trees; and many good effects may be thus secured. The trees must not, of course, be crowded like those in shrubberies, but standing on the turf. The graceful companion may garland the heads of some low trees; in tall ones the stems only may at first be adorned. But some vigorous climbers could in time ascend the tallest trees, and I know of nothing more beautiful than a veil of Clematis montana suspended from the branch of a tall tree. Besides the well-known and popular climbers, there are various handsome plants which may be seen to great advantage in this way: for example, many species of Clematis, which have never come into general cultivation, but which are as beautiful as climbers can be. The same may be said of the Honeysuckles, wild Vines, and various other families of which the names may be found in catalogues. The nurseries are by no means rich in them; but much of the northern tree and shrub world is garlanded with creepers which may be grown in similar ways, for example, on banks and in hedgerows. The naked stems of the trees in our pleasure-grounds have, however, the first claim on our attention in planting garlands; for there would seldom be any fear of injury to well-grown trees.

A garden of creepers! Yes, why not? If any one likes to carry out the idea, a most interesting garden can be made of creepers, twiners, and climbers. Not indeed a garden of trim formal beds, as the growth of such plants could not-in fact, should not-be kept within set bounds, but what groups and clusters of climbing Roses, Honeysuckles, Jasmines, Clematis, and Ivies, might one possess in such a garden!

Those who have not made a study of creepers and their uses may be aided in the consideration of their merits by grouping them according to the season in which they are most effective. During the winter, Cotoneaster microphylla and C. Simonsi are good plants for walls, as well as for training up a pole or planting on the top of a mound of rockwork. Escallonia macrantha, Berberis Darwini, and B. stenophylla are useful to clothe walls to a height of I 2 or I 4 feet. Chimonanthus fragrans should be planted for the sake of the delicious spicy scent of its flowers in winter. In sheltered places in the south of England, Magnolias are handsome plants in winter, with their fine large leaves, but in many places they require protection in severe weather, and should therefore not be used for winter effect.

For the spring we have also a long list. Clematis montana grandiflora, Wistaria sinensis, and alba, the white form, are good for covering high walls, or for training over anywhere where quickgrowing creepers are required. Forsythia viridissima and Cydonia japonica are plants of lower growth, but are very desirable for 
making out the outlines of panels, or for covering the face of a buttress or a pier. The yellow-flowering Jasmines flower early;

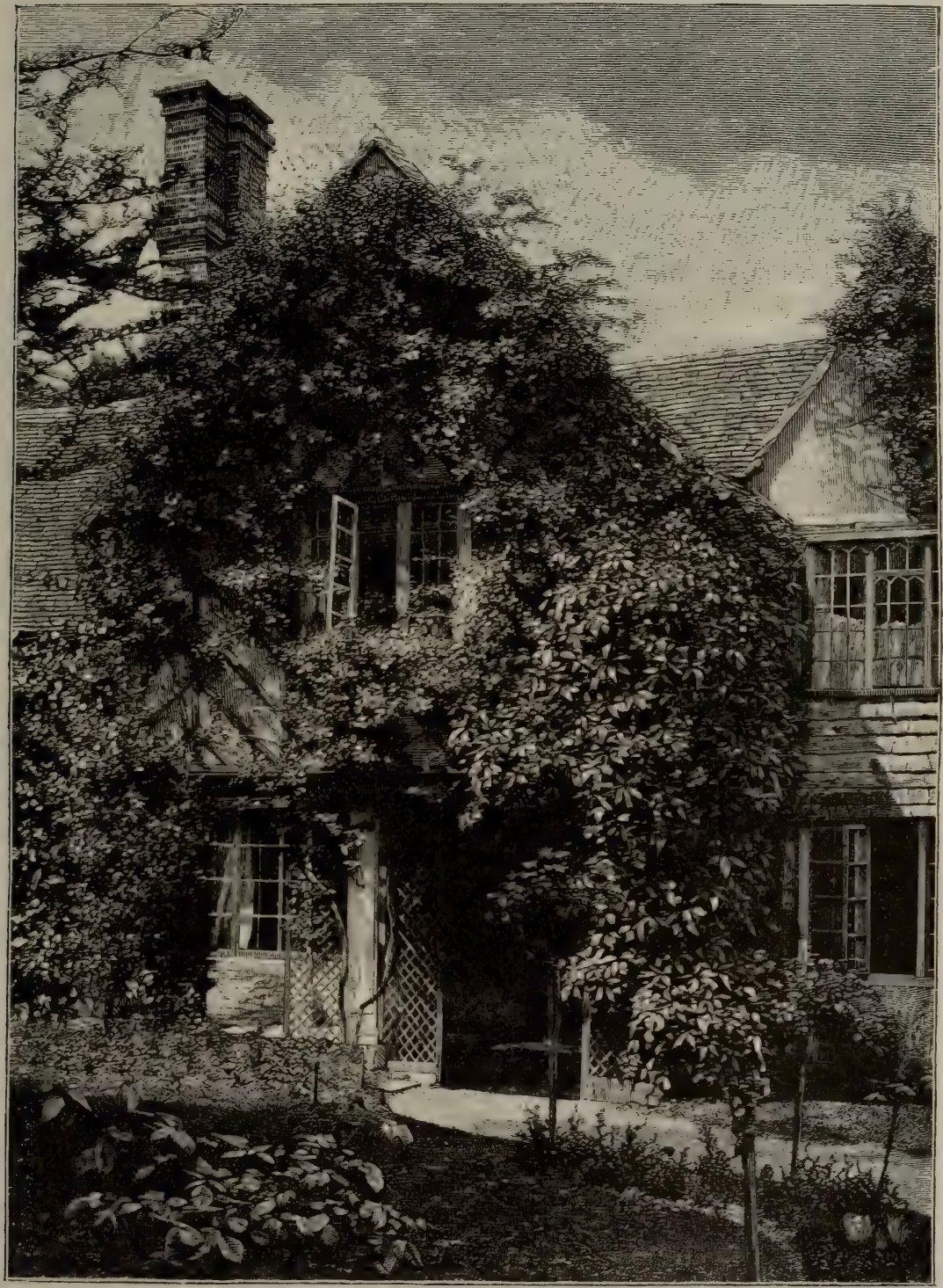

CLIMBERS ON THE VICARAGE, ODIHAM, HANTS.

and the spring offers us a few Roses, for the old pink China or Monthly is the earliest as well as the latest to flower, and Gloire de Dijon generally opens its first flowers early in May.

But it is in the summer that the creepers are at their best, for 
then the Rose, the Clematis, the Honeysuckle, the Magnolias, and the Jasmine are in season ; and what visions of beauty are conjured up by the mere mention of their names. Roses alone are capable of adorning the most commonplace buildings. Besides these plants there is the Passion-flower (Passiflora cœrulea), but it is only fit for sheltered places, as it is not quite hardy in our coldest seasons ; still, if its base be sheltered with some dry Fern, it will spring again from the base. The Stauntonia latifolia is a very rapid-growing creeper in the south of England. The Birthworts-Aristolochia Sipho and A. tomentosa-are good climbing plants, the last-named having silvery leaves. Then for warm sheltered places the Ceanothuses are very beautiful, freely producing blue flowers of various shades. And, besides the hardy creepers, there are a great many summer or annual creepers, bright and effective, such as the Tropæolum, Lophospermum, Maurandya, Convolvulus, and Ipomæa, in many varieties. In the autumn there is also much beauty of leaf and fruit or berry, if less of blossom. The Virginian Creepers are then in all the splendour of crimson and bronze; the Japanese Honeysuckle is resplendent in its network of gold, and we have the bright berries of the Pyracantha and the Cotoneaster-most fitting and appropriate autumn decoration.

Hardy climbers in gardens should, for the most part, be what they are in their native places: trailing over trees, or shrubs, or stumps, or banks, or over such artificial supports as railings, rustic work, etc. No plant bears repression and continual pruning so badly as a vigorous climber. In that way, moreover, its beauty can rarely be well seen. The shrub that does not climb is often fit to train on walls: for example, the evergreen Euonymus, the Pyracantha, and certain evergreen Barberries. The value of wild Vines for covering wall-surfaces must also not be forgotten. I have seen them clambering up forest trees, spreading into huge masses of fine foliage on the ground, and sending out long arms to find the nearest trees.

A Pergola.-Adaptations of the Italian pergola are much to be recommended for English gardens, since though our summer is short, there are a good three months when a bowery shaded walk would be most enjoyable, and the numbers of free-growing climbing plants at our disposal, besides Vines, give an abundant choice of material. Aristolochia, Wistaria, Virginian Creeper, rambling Roses, Honeysuckles, Jasmines, and the free Clematises are all suitable, and look well and do well in such a position. In Italy and other parts of the sunny south one often sees in gardens the pergola, as the creeper-clad arbour or walk is called, which generally serves the twofold purpose of supporting the Grape Vine and affording pleasant coolness during the summer heat. As a rule, these pergolas are 


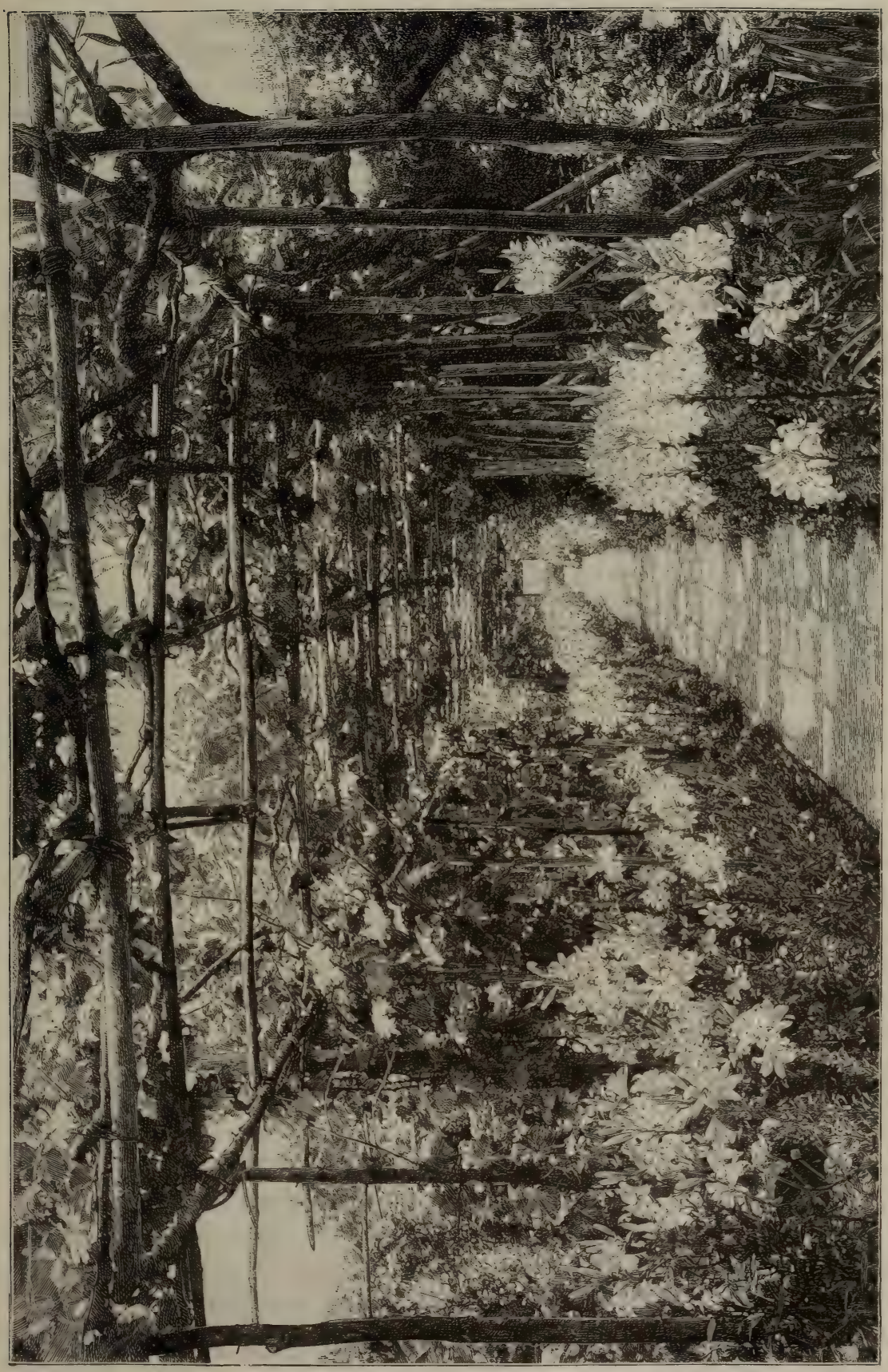


rude trellis-work structures of wood, sometimes supported by stone where this is at hand. In the gardens in the neighbourhood of Rome, Naples, and Florence I have seen some beautiful examples of the pergola-stately structures, the supports of which were massive columns of stone covered and festooned in a beautiful way

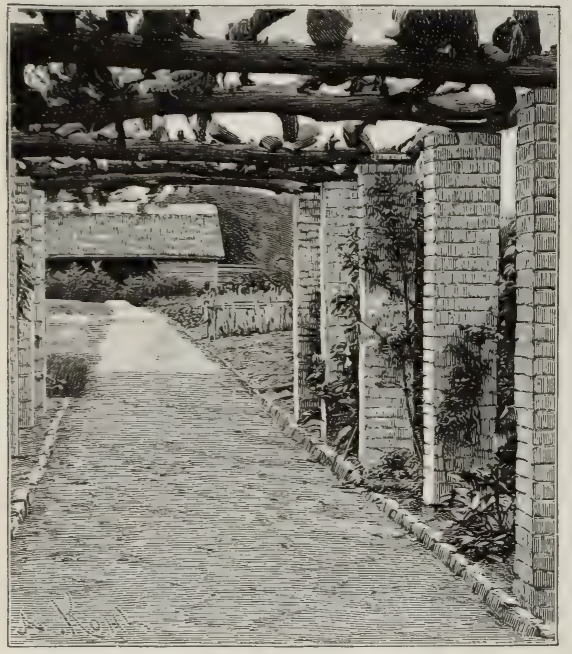

NEWLY-FORMED PERGOLA AT MUNSTEAD, WITH BRICK PILLARS AND OAK TIMBERS. with Banksian Roses, Wistaria, Pergularia odoratissima, Periploca græca, Clematises, Honeysuckles, blue Passion-flowers, scarlet Trumpet-flowers, and other beautiful climbers, structures which formed the most delightful retreats in flowertime, and were cool in the hot days. But such pergolas seldom occur outside the rich gardens of the great villas, and near humbler dwellings the pergola is usually a simple structure made for the purpose of supporting the Grape Vine.

The pergolas, like the stately fountains, are in Italy quite appropriate to the country and the climate. They are rarely necessities in our English climate ; but simple adaptations would add to the delights of many an English garden. A creeper-clad trellis spanning a frequented walk is a good feature in a garden, as it gives a contrast to the open breezy parts, and serves for growing many beautiful hardy climbers which can only be seen at their best when rambling over trees, trellises, or along the tops of walls. It should lead to somewhere and be over a frequented walk, and should not interrupt any line of view. The breadth, height, and length are points for individual taste to dispose of, but if flowering creepers are desired to cover it, it must not be placed under or near the shade of big trees, especially such as the Elm, whose hungry roots would travel a long way to feed upon the good soil that the creepers must be planted in.

The form of the structure must also be governed by circumstances and individual taste. A simple structure is the best; the supports should be Oak tree stems, about 9 inches in diameter with the bark on, let into the ground about 2 feet; if on a bed of concrete the better. The posts must be connected and firmly secured to each other by long pieces of similar width and running along the sides, while the top may be formed of small pieces fixed transversely 
across the top. This will make a more firm and massive structure, and the simpler it is kept the better it will look. On no account let the "rustic" carpenter begin to adorn it with his fantastic branches, which he is so fond of doing.

Climbing ROSES ON TREes.-Occasionally in England one sees a beautiful climbing Rose rambling over a tree, and perhaps among our garden pictures nothing is more lovely than such a Rose when in flower. By a selection of the hardiest of climbing Roses, very beautiful pictures might be formed in our pleasure-grounds, and even in our woods; and we might often see as the result of design what is now mainly an accident. There is a great deal too much pruning of Roses. A certain number of kinds lend themselves admirably to growing "free" among trees; and other kinds would succeed with a little pruning every few years after their growth became matured. There are, however, countries more favourably situated than ours for such Rose beauty. In Europe, perhaps the country that pleases one most by its fitness for Rose culture is that along the shores of the Mediterranean, about Nice, Genoa, and Cannes, where the Banksian and many other Roses may be seen literally "abandoning themselves"-up trees, forming hedges, and arranging themselves in other delightful ways.

I remember being very much struck, during the short time I spent in that country, with the beauty of the single Banksian Rose in such positions, and often wondered why it was not secured for our own gardens, even though it might not grow so freely as there. It is a little yellow single Rose, and is most free and graceful.

An arch or series of arches, when well furnished with beautiful climbing plants suitable for such a purpose, forms a charming feature in the garden. When a quiet and sequestered walk leads from one especially interesting part of the garden to another, and that walk is spanned at intervals with bold wire arches clothed with such beautiful climbers as Honeysuckles, Clematis, climbing Roses, Jasmine, and similar subjects, a great charm is imparted to what might be a dull and uninteresting walk, for the beauty of the flowers is in the case of many of these climbers supplemented by their fragrance. In immediate proximity to doorways or gateways in a garden such an arch will veil the hard outlines of the entrance. A pretty series of floral arches recently came under my observation. A tennis-ground was separated from the rest of the garden by a thick belt of shrubs, and over each of the openings giving admission to the ground a number of arches clothed principally with Clematis produced a striking effect. 
Some Families of Hardy Climbing Plants, including also Wall-Plants ${ }^{1}$

$\begin{array}{llll}\text { Abelia. } & \text { Calystegia. } & \text { Hablitzia. } & \text { Periploca. } \\ \text { Abutilon. } & \text { Camellia. } & \text { Hedera. } & \text { Piptanthus. } \\ \text { Adlumia. } & \text { Ceanothus. } & \text { Indigofera. } & \text { Punica. } \\ \text { Akebia. } & \text { Chimonanthus. } & \text { Jasminum. } & \text { Pyrus. } \\ \text { Aloysia. } & \text { Choisya. } & \text { Kerria. } & \text { Rosa. } \\ \text { Ampelopsis. } & \text { Clematis. } & \text { Lonicera. } & \text { Rubus. } \\ \text { Apios. } & \text { Cissus. } & \text { Lophospermum. } & \text { Smilax. } \\ \text { Aristolochia. } & \text { Convolvulus. } & \text { Maurandya. } & \text { Solanum. } \\ \text { Atragene. } & \text { Cotoneaster. } & \text { Magnolia. } & \text { Stauntonia. } \\ \text { Azara. } & \text { Eccremocarpus. } & \text { Menispermum. } & \text { Thunbergia. } \\ \text { Berberidopsis. } & \text { Echinocystis. } & \text { Mikania. } & \text { Viburnum. } \\ \text { Berberis. } & \text { Edwardsia. } & \text { Olearia. } & \text { Vitis. } \\ \text { Bignonia. } & \text { Escallonia. } & \text { Osmanthus. } & \text { Weigela. } \\ \text { Bomarea. } & \text { Fuchsia. } & \text { Passiflora. } & \text { Wistaria. }\end{array}$

1 In this country we are often led to plant against walls things which are naturally shrubs, Abelia, Pyrus Japonica, Sweet Verbena-but which thrive best on walls in Britain, and are often among our most beautiful things for them.

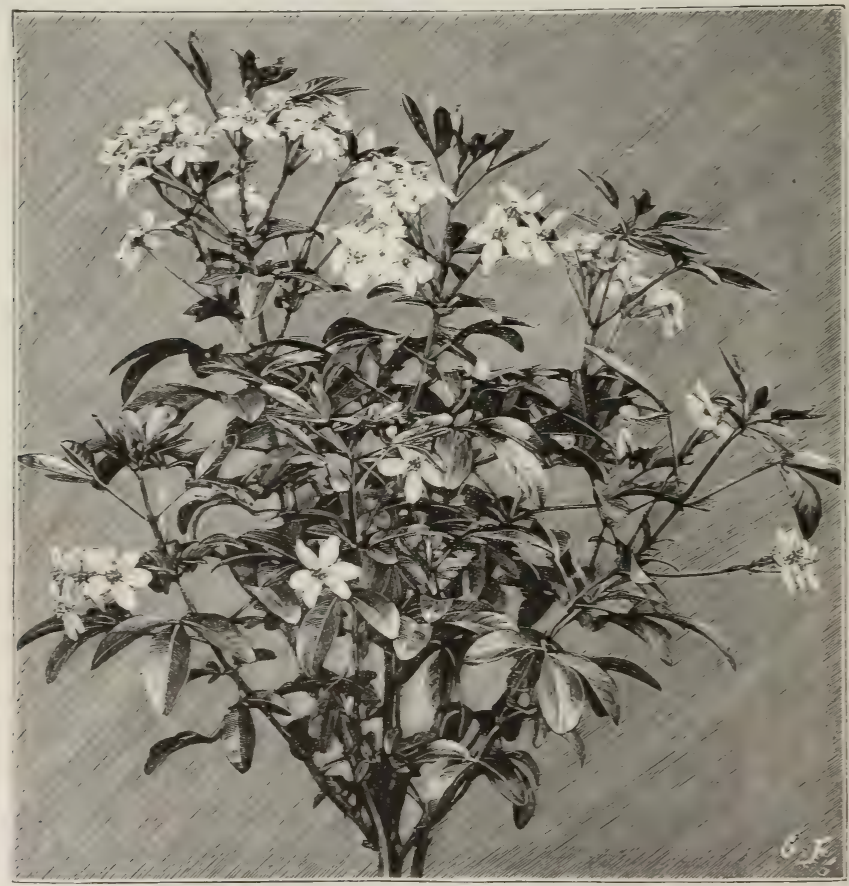

MEXICAN ORANGE-FLOWER (CHOISYA). 


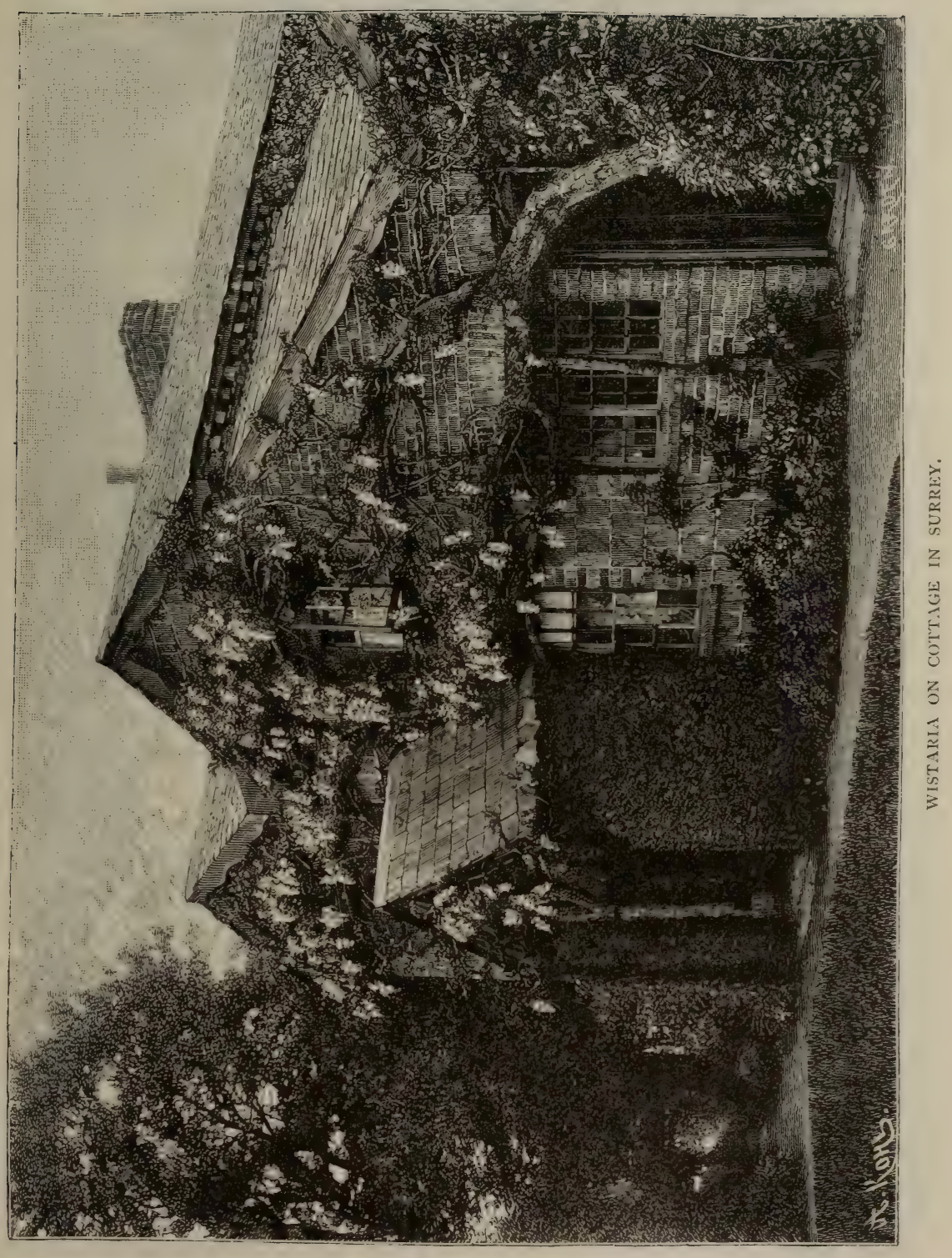




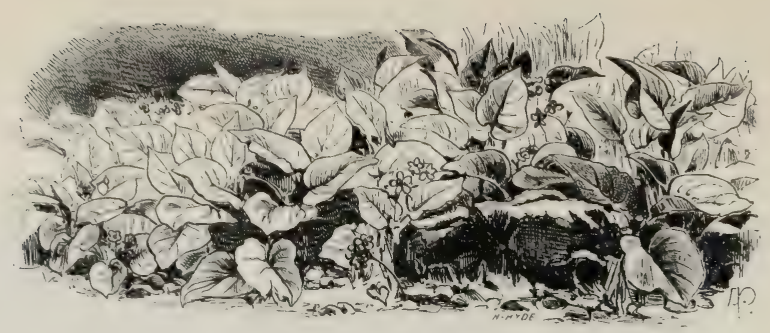

CREEPING FORGET-ME-NOT.

\section{CHAPTER XII}

\section{SPRING FLOWERS}

A GARDEN with many hardy flowers has at least three months' clear gain in flowers over one which depends entirely on "bedding-out." This "bedding-out" is usually done the first week in June. The plants being tender, the cold rains and storms after that date frequently injure them, and their period of beauty is often much later. The bedding system reduces the beauty of the garden by one half.

The first move towards spring gardening was a kind of beddingout-an arrangement of Forget-me-nots, Pansies, Daisies, Catchflies, Violets, and Hyacinths in beds and in ribbons ; but this way of cultivating spring flowers is not the best. The easiest and most artistic is to scatter about the flowers wherever they will grow - in mixed beds, hedgerows, or plantations. Many country gardens, like the London parks, are as bare and ugly in their dug borders as a London cemetery. It was uncommon some years ago to see a beautiful flower in the open air before the time of bedding-out. Now that we have doubled the length of our flower season, the best ways of enjoying spring flowers is an important question. Every place where there is a pleasure-ground, or any open space for grass with trees on it, may be made delightful with the winter Aconite and Snowdrop, the spring Snowflakes, the blue Apennine Anemone, and various other flowers dotted in the grass, and under the branches of summer-leafing trees. Some little plants that flower and ripen their leaves early find a happy home under Beech or Oak or other deciduous trees; they complete their season's work before the leaves come on the trees, and in spring are seen happy under the branches. Then again, wherever wild flowers grow well, numerous additions from other countries may be made to them. For instance, if we have a grove where the wood Anemone grows naturally (a common occurrence enough), nothing is easier than to introduce the blue Apennine Anemone with it. If the soil be chalky, the yellow Anemone (A. ranunculoides) would be a delightful addition. Or 
does the Bluebell or wood Hyacinth grow with us? Then certainly in the same place, or near it, will also grow the bell-flowered Scilla and S. bifolia-not native plants, but perfectly hardy in our country. Various kinds of Daffodils or Narcissi, as, for example, the different forms of Poet's or Pheasant-eye Narcissus, will grow in any place where the common Daffodil will. The beautiful wood Forget-me-not may be sown in any wood, copse, or shrubbery, and will give an ample return. Thus it will be seen that, apart from the garden proper, much may be done in adding the glory of spring flowers to any place where there are trees and grass. The corners in an old orchard are delightful for experiments of this kind.

Coming into the garden proper, we may look at the many positions in which spring flowers may be grown before we come to the geometrical bedding, which is the most troublesome of all. The fashion of leaving beds of Roses, choice shrubs, etc., bare of all but what -might be called their proper contents must be given up. In many places the half-bare Rose beds alone would furnish a happy home for numerous beautiful spring flowers - Pansies, Violets, choice Daffodils, Scillas; in fact, for many pretty dwarf plants established in colonies between the Roses. Double Primroses are particularly happy in such positions, and flower profusely. The slight shade such plants receive in summer from the other tenants of the bed assists them; they do better than in bare borders. Where the Rhododendron beds are planted in an "open" way as they often are (and the precious bushes never ought to be jammed together), a garden of another delightful kind is at our disposal. The peatloving plants (and there are many fair ones among them) will be quite at home there-much more so than in any bare borders. The white wood Lily of the American woods, the Virginian Lungwort, the Canadian Bloodroot, and the various Dog's-tooth Violets enjoy peat beds. Next we come to borders and beds of favourite spring flowers, such as Polyanthus, Primroses in their coloured forms, Cowslips, Auriculas, which in the self-coloured and border kinds are delightful. One can "cut and come again" for the flowers; they are also convenient for division and exchange. Then along favourite walks in quiet places, a rich border for those glorious Polyanthuses and coloured Primroses and any other favourite free spring flowers may be made. Thus it will be seen that before we come to the formal massing of spring flowers there is a variety of ways of enjoying them more artistic and more easily managed than "beddingout" pure and simple. That may follow the fashion of the hour, and be arranged according to taste, with a considerable variety of material-Forget-me-nots, Daisies (both variegated and green), Silene, Pansy, Violet, Hyacinth, Anemone, Tulip, and so on. If we 
have a group of beds, and, say, a parterre under a window or in any other conspicuous position, a bright and pretty effect may be formed ; but without any such thing as either parterre or formal beds under the windows, fair gardens of spring flowers may be made in every place. If they are, the eternal problem of the design for the few formal beds of the parterre will not be so terrible as at present.

Of late a number of beautiful forms of well-known flowers have been collected from various countries or raised from seed. For example, it is believed that there now exist over a dozen different forms of the Lily of the Valley, differing in size of bloom, in size of plant, and even in time of flowering. So, again, the Hepaticas, which we know in two or three bright forms, have broken into a much greater number. It needs only a small effort of the imagination to see what we can do with such treasures when they are sufficiently increased to be valuable for general garden decoration. Apart from these new forms of old friends, many wholly new species are being introduced yearly, thus adding to the store from which we may draw to make our spring gardens rich in form, colour, and fragrance.

Let all who love the early flowers (the joy of our climate) look at the following list, remembering that it is not a list of the kinds of spring flowers (which are innumerable), but of the families. Some of these names, such as Narcissus and Rockfoil, stand for very large groups of lovely flowers. Then perhaps persons may judge if these beautiful children of the mountains and plains of the northern world are fairly shown by what is called "spring bedding"- $-\mathrm{a}$ few bits of wood Forget-me-not and Silene in a pattern, like those horrid tiles with which æsthetic architects "decorate" our houses in their awakened sense of beauty. This system prevents any noble use of the beds, and we have to root all up when summer comes.

\section{Some Spring and Early Summer Flowers Hardy in English Gardens 1}

Adonis.

Alyssum.

Andromeda.

Androsace.

Anemone.

Aquilegia.

Arabis.

Armeria.

Arenaria.

Asperula.

Asphodelus.
Aubretia.

Bellis.

Caltha.

Centaurea.

Cerastium.

Clematis.

Crocus.

Convallaria.

Cyclamen.

Daphne.

Dentaria.
Dianthus.

Dicentra.

Dodecatheon.

Doronicum.

Draba.

Eranthis.

Epimedium.

Erica.

Erinus.

Erodium.

Erythronium.
Ficaria.

Fritillaria.

Fumaria.

Genista.

Geranium.

Galanthus.

Geum.

Gypsophila.

Helleborus.

Hepatica.

Hesperis.

1 Shrubs are excluded; they will be found in the chapter on "Flowering Trees and Shrubs." 
Houstonia.

Hyacinthus.

Iberis.

Iris.

Leucojum.

Linaria.

Linum.

Lithospermum.

Lupinus.

Lychnis.

Meconopsis.

Menyanthes.
Muscari.

Myosotis.

Narcissus.

Nemophila.

Omphalodes.

Ornithogalum.

Orobus.

Pæonia.

Papaver.

Phlox.

Polemonium.

Potentilla.
Primula.

Pulmonaria.

Pyrethrum.

Ramondia.

Ranunculus.

Sanguinaria.

Saponaria.

Saxifraga.

Scilla.

Sedum.

Sempervivum.

Silene.
Solomon's Seal.

Soldanella.

Trillium.

Triteleia.

Trollius.

Tulipa.

Uvularia.

Veronica.

Vinca.

Viola.

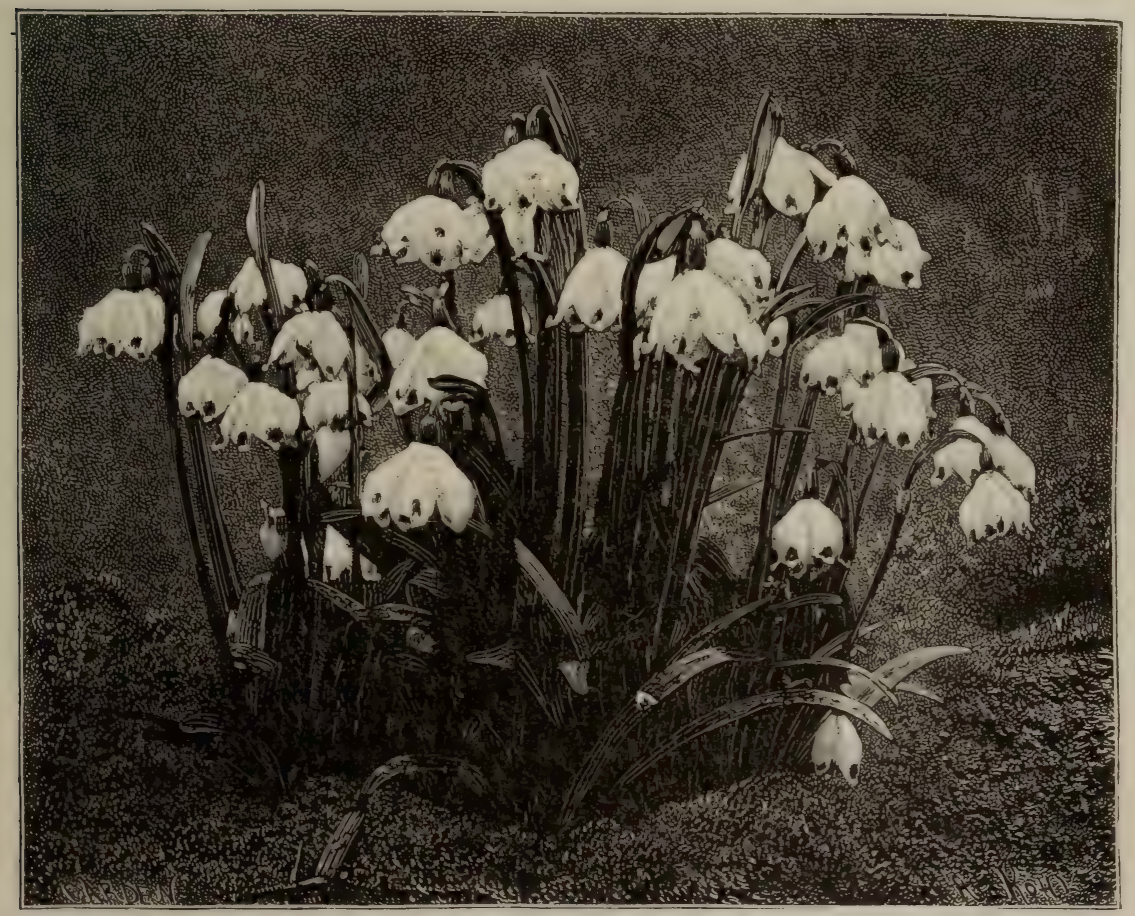

THE SPRING SNOWFLAKE. 


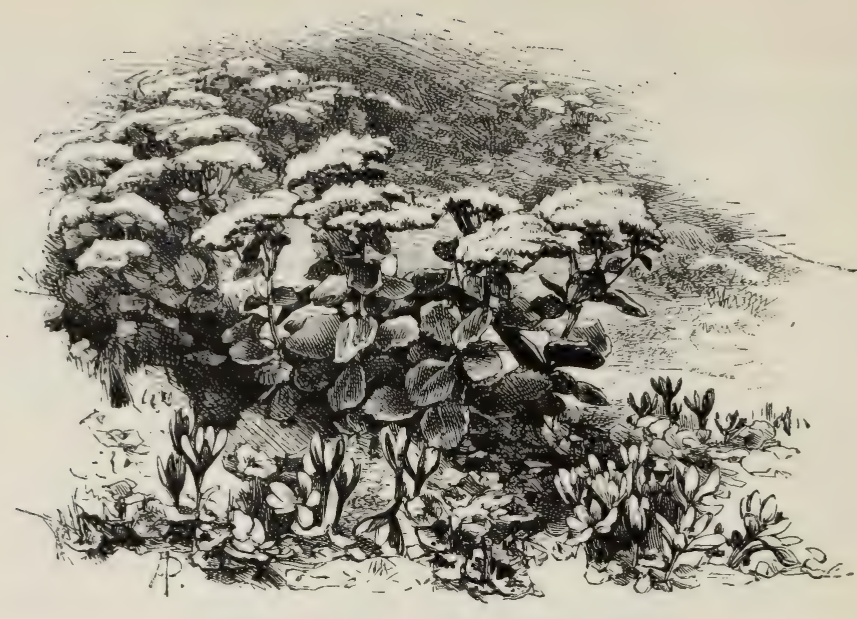

AUTUMN CROCUS IN THE FLOWER GARDEN.

\section{CHAPTER XIII}

\section{AUTUMN FLOWERS}

THE day will come when the beauty of the spring garden will have a reflex in the beauty of the autumn garden. Think of the many autumn-blooming plants similar to those which are the glory of the spring. Thus, for example, the autumn-flowering species of the Crocus (excluding hybrids) are probably more numerous than the spring-flowering kinds. Taken individually, the flowers of the autumn Crocuses are bold and strong, as, for example, Crocus nudiflorus and Crocus speciosus. Up to the present these have been very little cultivated, and have not yet broken into garden varieties. Their beauty in the golden days that often come in autumn is as delightful as any spring garden. At present, with the exception, perhaps, of two or three kinds, all the autumn Crocuses are scarce. Even the common kinds are only cultivated as border or nursery plants in the ordinary way, and a very proper way too. To secure, however, little pictures from such plants, we must have them happy in the Grass, or Moss, or with other dwarf plants which will keep their flowers from being splashed, and in carpets where they may be seen on sunny knolls or banks or in Grassy corners of the lawn or pleasure garden. Not less important are the Colchicums, sometimes called the autumn Crocuses, which flower at the same time as some of the Crocuses, or earlier. The remarks as to the arrangement of Crocuses are almost applicable to the Colchicums. As the meadows of much of Central Europe are bright in autumn with the flowers of the common Colchicum, so should our garden turf be with the 
precious garden kinds. Thus, from these two races alone, we could add new and distinct charms to our gardens-and that without troublesome culture-by securing some stock of the plants, and putting them out in well-considered positions. I give a list of

\section{Some of the Families of Hardy and Half-hardy Plants blooming in London District in September-October.}

\begin{tabular}{|c|c|c|c|}
\hline Abutilon. & Dahlia. & Lobelia. & Rudbeckia. \\
\hline Aconitum. & Delphinium. & Lonicera. & Salpiglossis. \\
\hline Agapanthus. & Desmodium. & Lupin. & Salvia. \\
\hline Ageratum. & Dianthus. & Lychnis. & Scabious. \\
\hline Amaryllis. & Diplacus. & Lythrum. & Sedum. \\
\hline Anagallis. & Diplopappus. & Magnolia. & Senecio. \\
\hline Anemone. & Eccremocarpus. & Marigold. & Silene. \\
\hline Arbutus. & Erica. & Matthiola. & Silphium. \\
\hline Arnebia. & Escallonia. & Mignonette. & Snapdragon. \\
\hline Aster. & Fuchsia. & Mimulus. & Solanum. \\
\hline Berberidopsis. & Gaillardia. & Montbretia. & Solidago. \\
\hline Bignonia. & Geum. & Nicotiana. & Statice. \\
\hline Boltonia. & Gladioli. & Nigella. & Strawberry. \\
\hline Borago. & Godetia. & Enothera. & Sweet William. \\
\hline Brugmansia. & Gypsophilia. & Pampas Grass. & Telekia. \\
\hline Calceolaria. & Helenium. & Pansy. & Thunbergia. \\
\hline Campanula. & Helianthus. & Papaver. & Trachelium. \\
\hline Candytuft. & Heliotrope. & Peas (Sweet and & Tradescantia. \\
\hline Canna. & Hieracium. & Everlasting). & Tritoma. \\
\hline Cassia. & Hollyhock. & Pentstemon. & Tritonia. \\
\hline Ceanothus. & Honeysuckle. & Petunia. & Tropæolum. \\
\hline Celsia. & Hyacinthus. & Phlox. & Tuberose. \\
\hline Centaurea. & Hypericum. & Phygelius. & Valerian. \\
\hline Chrysanthemum. & Iberis. & Physalis. & Venidium. \\
\hline Clematis. & Impatiens. & Physostegia. & Verbascum. \\
\hline Colchicum (Mea- & Lantana. & Plumbago. & Verbena. \\
\hline dow Saffron) & Lauristinus. & Polygonum. & Veronica. \\
\hline Convolvulus. & Lavender. & Prince's-feather. & Viola. \\
\hline Coreopsis. & Leycesteria. & Primula. & Yucca. \\
\hline Cornus. & Liatris. & Pyrethrum. & Zephyranthes. \\
\hline Crocus. & Lilium. & Pyrus. & Zinnia. \\
\hline Cuphea. & Linaria. & Rocket. & \\
\hline Cyclamen. & Linum. & Rose. & \\
\hline
\end{tabular}

STARWORTS.-There is a quiet beauty about the more select Starworts, or Michaelmas Daisies, which is charming in the autumn days. The variety of colour, of form, and of bud and blossom is delightful. For the most part Starworts are regardless of cold or rain. Less showy than the Chrysanthemum, they are more refined in colour and form, and when examined will be found full of exquisite grace. Where not introduced into the flower garden, they should always be grown for cutting, and some kinds would thrive admirably in a copse or hedgerow. The essential point is to get the distinct kinds, of which the following are among the best that 
flower in early October: Aster amellus, acris, bessarabicus, cassubicus, turbinellus, Chapmani, versicolor, pulchellus, cordifolius, Reevesi, discolor, discolor majus, purpuratus, laxus, horizontalis, ericoides, Shorti, multiflorus, dumosus, Curtisi, lævis, longifolius coccineus, longifolius var. Madame Soynuce, sericeus, and fragilis.

Every year adds to our autumn-blooming hardy plants, and a

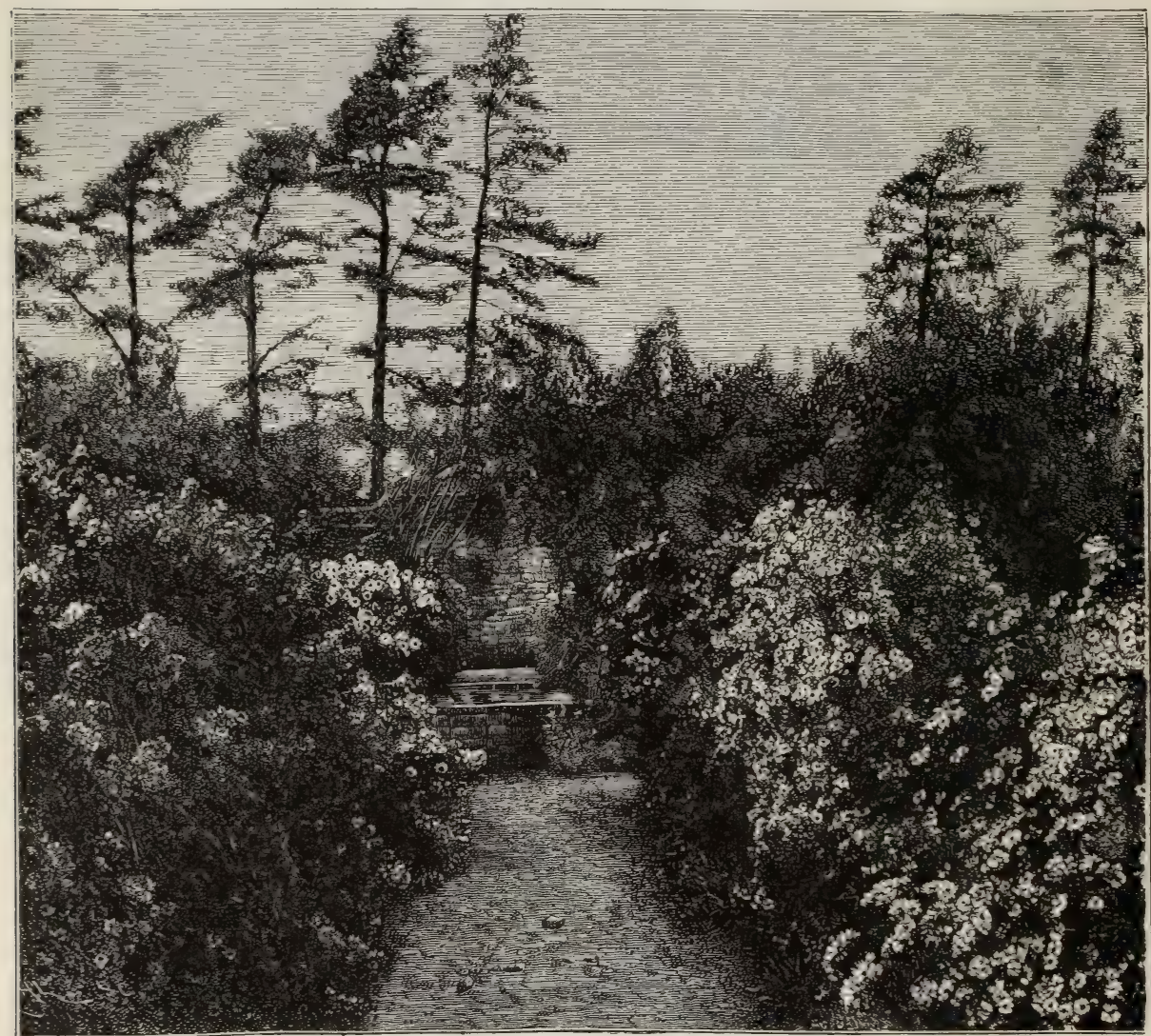

A BORDER OF MICHAELMAS DAISIES IN A SURREY GARDEN.

choice may best be made by autumn visits to gardens containing collections. The results of my own experiments with Starworts will be seen by the following :-

New Aspect of Beauty for the Autumnal Garden ${ }^{1}$

As yet gardeners seldom look at general effects-at the whole of things. The flowers are so dear to them that the garden, as a

${ }^{1}$ Extract from the Tree and Garden Book of Gravetye Manor, for the year I889. 
picture, is left to chance, and hence there is so much ugliness and formality in gardens, to those at least who regard the robe as more than the buttons.

Some years ago Starworts were rarely seen except in bunches in botanic gardens. Since the hardy flower revival, they have become more frequent in collections, but as yet they have no important place in gardens generally. As soon as the heavy groundwork near the house allowed the planting of belts and groups of flowering shrubs, I dotted a few of the best Starworts through them, to furnish the bare ground between them, and to flower in due season. The result was charming. In I 887 and I 888 there was a long bloom of Rhododendrons in the spring; but it was not so pretty as the wreaths of Starwort waving in the October winds. The bad effect of staking and bundling was wholly got rid of, the plants were supported and relieved by the bushes, and their flowers were massed above them here and there. Those that were dwarfer than the shrubs were not lessened in value, but their value was rather increased, as the variety helped to give light and shade, and destroyed the common way of setting plants to a face as if they were so many bricks. When the American plants close together it will be easy to move the Starworts into fresh beds, and to show their beauty in other ways. This is not the only way of growing these hardiest of northern flowers, but it is a charming one, and it lights up the garden with a new loveliness of refined colour.

Being so well pleased with the results in a few small plantings, I obtained from different sources in the early days of this year (1889) specimens of probably all the Starworts in the British Isles, so as to make trial of their merits. I asked for all, and many were kindly sent me by Mr. G. F. Wilson, by Mr. Woolley Dod, by Mr. Grant, and by various other friends from Kew, from Glasnevin, from Cambridge, from the Dublin College Gardens, from Munstead, and from the Hall Farm Nurseries. They came with and without names, tall and short, good and bad. Like many other flowers, they vary a great deal, and they have many names; so that it was well to find out the best, and to give them good and simple English names. The effect of the greater number of plants put out in the spring of the present year (I 889) was very pretty. We had lovely colours showing well through large masses of shrubs and visible in the distance, while the colours were held well together, i.e. naturally massed flowers of one kind. The colour was telling and refined; absolutely different, it need scarcely be said, from the pattern stuff of the ordinary flower garden.

And now for a few words as regards the elements of the picture, for such it was. There are many kinds of Starworts with little 
character or value, and much will depend on getting only beautiful kinds.

THE LilaC STARIORT (A. cordifolius elcgans).-Dense plumes of delicately-tinted little stars, that droop and toss gracefully in the wild autumn days. It comes late, regardless of the most pitiless rains of the fall, and stays long. The rains of the past October were the most severe we had for years, and it was very interesting to note how charming this Starwort looked in them and after them. It was in groups, naturally fringing through American shrubs, which are not jammed close, as such shrubs usually are, but have open spaces here and there for light and shade, and to give a home to flowers like this, which relieve the shrubs and add a new grace to the beds and a new charm to autumn's glorious colour.

The Italian Starwort ( $A$. amellus).-Earlier than most Starworts, this handsome purple kind deserves a place in many gardens for its own sake, without even the added charm of natural grouping. Being sturdy and dwarf, and with a pretty grayish leaf, it may be grouped with flowers rather than with shrubs, or with such things as Lavender. It is a very old plant in our gardens, though, like many others, long forgotten, till the recent revival of interest in such things. It is like the rest, as hardy as the rush or dock, forming sturdy tufts, bearing, as Gerard says, "faire blewish purple flowers, yellow in their middle, and shaped like marigolds, and almost of the same bignesse, whence some people have called them blew marigolds."

The Blue Starwort (A. acris).- - Soft clouds of lovely blue, charming when seen near at hand, and very effective at long distances. Many people love good blue flowers, always far from common in gardens. I think this Starwort is the prettiest flower of the colour among the flowery host. It is more precious than a Gentian, even if we could grow Gentian as it grows on the Alpine fields. A cloud of soft blue, I 8 inches to 2 feet high, and when well placed, a very poem of flowers.

The New England Stariwort (A. Nove Anglice).-Tall and vigorous as a Northern American should be, this is a very old flower of English gardens, but, owing to the staking in borders, seldom seen to advantage. There are two forms-a purple one and a soft red one-both pretty in bold groups among shrubs, say about the height of a man. The shoots of this have a curious and pleasant piny smell. It was charming last October (I 888) among Rhododendrons and in colonies near them. They, like most of the kinds, are so hardy and free that we can move them at any time without fear of losing them. Many of this kind were scattered about the garden, as they came from various places; I wished to group them 
in a more artistic way, and they were moved when in full bloom, without loss of any kind.

The New York Starwort (A. Nove Belgic).-Quite different from the England Starwort, and of very high value. Tall, sturdy, with myriads of delicate soft blue purple stars, varying into deeper or lighter colours, some white. A superb autumnal flower, that any one can grow, and which, like many others of the family, is admirable for cutting for the house. In rooms, the Starworts last long and are charmingly decorative, as the phrase is. The "florist" has not as yet made them double, and does not attempt to improve them with his "tweezers"! The New York Starwort was a cloud of delicate colour in various parts of the garden in I889. Vistas of its lovely hue appeared along a Holly grove and also in wider masses among the shrubs. It is easy to increase. We should enjoy plenty of it everywhere.

The Pink Starwort (A.longifolius roseus).-A - Apart from other Starworts in colour, this is a good autumn flower; but it is dwarf, and rather dumpy in habit of growth, so here the scattering and intergrouping through other things relieves its formal habit, and shows well its distinct colour. This year (I 889) it was planted all over a bed of dwarf trees in the orchard, and was very effective for many weeks.

The Spreading Starwort (A. diffusus horizontalis).-Red and white blossoms in myriads, and very bushy. This has a peculiar way of branching, all the side shoots coming level from the stem, so that it is always easily recognised. It is a dwarf kind and pretty almost anywhere. It was in scattered colonies among the evergreen Barberry, and also semi-wild among long Grass and Weeds on the edge of a wood. My first idea was that the best place for it was in the wild garden - in this case in the woods-where it would produce effects like those seen in American woods in autumn. But our shrubberies are often so monotonous or ugly that it is better to begin with them, and, as the Starworts increase, transfer them to the woods for trial.

The Daisy StaRwort (A. versicolor).-This I call the Daisy Starwort from its pretty variation in colour, white and pink flowers being borne at the same time. One form is tall and stately, about 5 feet high, and charmingly effective as it is tossed by the winds, rain and storm having little power to dim its beauty. There is a dwarfer form of the same plant growing about $I \frac{1}{2}$ foot high.

These kinds represent well the beauty of the Starworts as at present known. There are many more names, and many more kinds may come, but they will hardly surpass the above-named in beauty and vigour. 


\section{CHAPTER XIV ${ }^{1}$}

\section{SUMMER-BEDDING GARDENING}

WHEN the bedding system first came into vogue, it was no doubt its extreme brightness, or what we should now call its "gaudiness," that caused it to hold the position it did; but it was soon done to death. Only scarlet Geraniums, yellow Calceolarias, blue Lobelias, or purple Verbenas were used; and the following year by way of a change, there were Verbenas, Calceolarias, and Geraniums,- the constant repetition of this scarlet, yellow, and blue nauseating even those with little taste in gardening matters, whilst those with finer perceptions began to inquire for the Parsley bed, by way of relief. Such a state of things could not continue; but yet the system could not be given up for several reasons - a very good one being that the great bulk of hardy flowers had been ruthlessly swept out of the garden to make room for bedding plants, and so-gardeners being, as it were, in desperate straits - the development of the bedding system began, and foliage plants of various colours were mixed with the flowers. Then followed standard graceful foliage plants and hardy carpeting plants; and now dwarf-growing shrubs are freely associated with the commoner types of bedding plants. Indeed, the system improved so rapidly that its most relentless opponents admitted that it had some redeeming qualities. I think, however, that the strongest reason of all for its retention is its suitability to formal or geometrical parterres.

Most people have their own notions as to what constitutes perfection of colour in bedding arrangements. This perfection I have not attained to, nor have I, perhaps, any decided preference for one colour over another; but I have very decided notions that the various colours should be so completely commingled that one would be puzzled to determine what tint predominates in the entire arrange-

${ }_{1}$ As the aim of this book is to show in how many ways we can make a garden beautiful without resorting to the bedding system, that system is described by one who carries it out with great success. 
ment. This rule I have followed for years, and have had a fair amount of success in working it out. I am even still learning, my latest lesson being that, if any colour at all may predominate, it is "glaucous," that is, a light gray or whitish green. Of this colour the eye never tires, perhaps because it is in harmony with the tints of the landscape, and particularly of the lawn. To carry out my rule as to colour successfully, there are other rules which must be studied. The first is that high colours, such as scarlet and yellow, must be used in much less proportion than colours of a softer tint, for high colours overweigh all others; the second is that there must be no

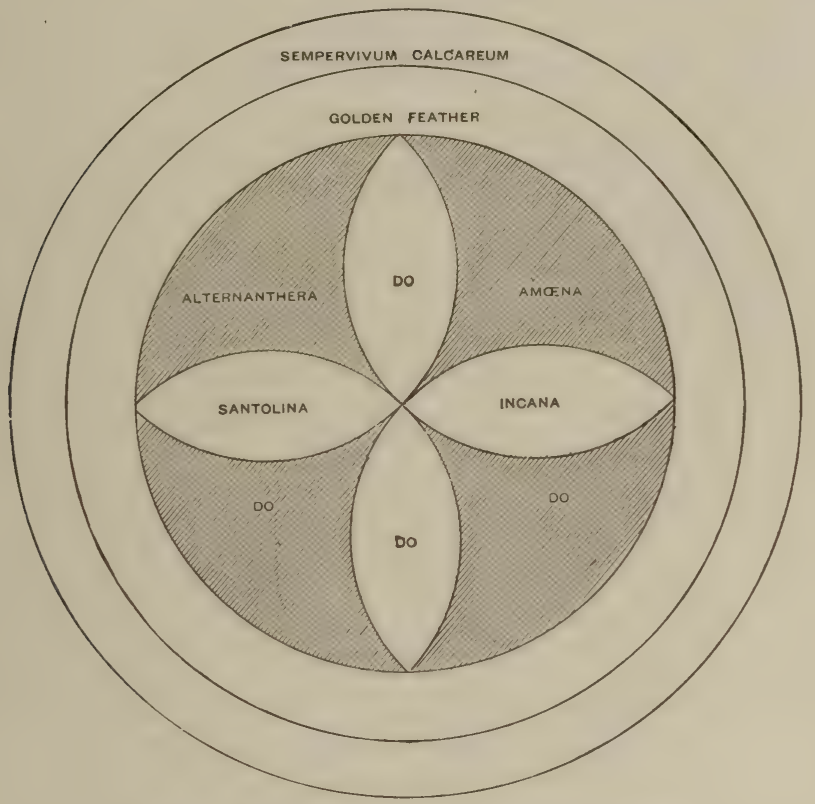

BED OF HARDY AND HALF-HARDY PLANTS.

violent transition from one colour to another-the contrast of colours must as far as possible be avoided in favour of their gradual intermingling or harmonising; the third, that the most decided or high colours, being the heaviest, ought to occupy the most central part of the beds, or be distributed in due proportion over the entire garden, so as to ensure an even balance throughout. Further, when dealing with such colours, use them in necessary proportion, and no more, and, if you err at all, err on the side of niggardliness. By close adherence to these rules, I have for years had no difficulty in producing a harmony of colour that has worn so well as to be as welcome at the end of the season as at the beginning; for the quieter the colouring the more lasting is the enjoyment of it. And it is pleasant 
to observe the great advance yearly made in favour of the quieter tints-gaudiness, in bedding-out, having become the exception rather than the rule. To fully carry out the ideal of colour here advocated, a great variety of plants is needed, though not more than is generally grown where bedding-out is practised to any extent. But there is colour and colour; and those who cannot have elaborate designs and variety in colour, may have an equivalent in graceful foliage and beautiful tinted shrubs of hues varying from deep green to bright yellow, and in habit tapering, weeping, or feathery. Cypresses, Yews, Yuccas, and many others, not only associate well with all kinds of bedding plants, but with the various kinds of hardy Sedums, Saxifrages, and Veronicas. These are all within the means of most owners of small gardens, and may be arranged in bedding-out form, the

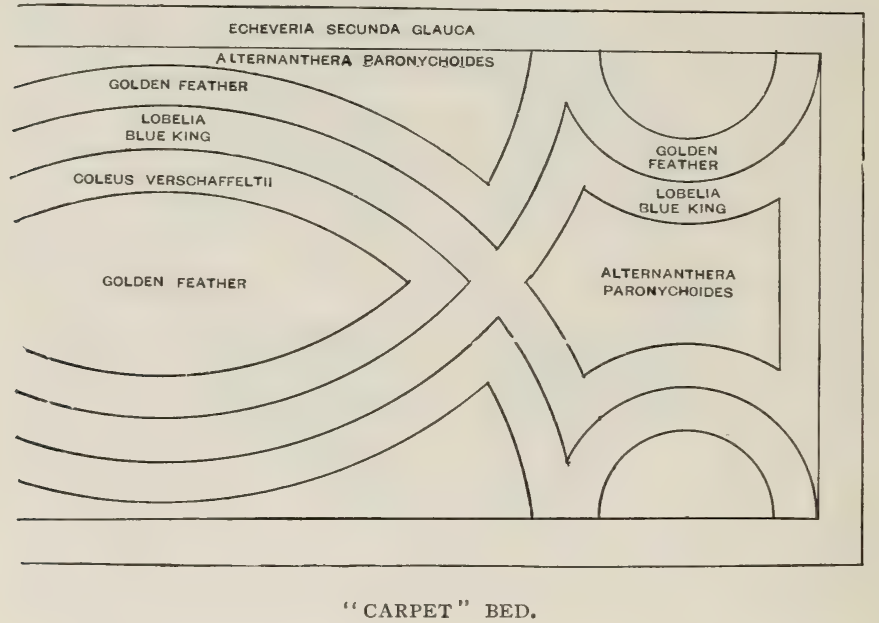

shrubs for centres and panels, and the dwarf hardy plants for massing and carpeting.

Soll and Cultivation.-Next to position, soil is the most important element in the formation of a garden. In selecting a soil, two things should be kept in view-first, that an open or welldrained soil assists climate (that is, the more porous a soil is, the warmer is the ground, and the better able to withstand extreme cold are the plants); and secondly, that the soil should be deep. Unless there is depth, permanent things will not flourish satisfactorily. And for less permanent things, depth of soil is just as important, as it renders unnecessary frequent dressings of fresh soil to maintain fertility. Wherever these conditions of soil exist, flower-gardening is easy; but in many cases opposite conditions have to be dealt with, and though it is hopeless to attempt to rival a naturally suitable 
soil, a very near approach can be made to doing so. The best soil is good loam, that is, soil of a clayey nature, but sufficiently sandy not to be sticky. Of the two states, light and heavy, the light is the better, because it is the warmer, and the more easily cultivated. In dealing with heavy soil, we must have drainage, deep tilth, and the working-in of material rendering it more porous, such as halfdecayed leaves, mortar or brick rubble, charcoal, and ashes. If manure be needed, it should be used in the long straw state as it comes from the stables. One mistake frequently made with regard to soil is, that sufficient attention is not paid to the kind of plants

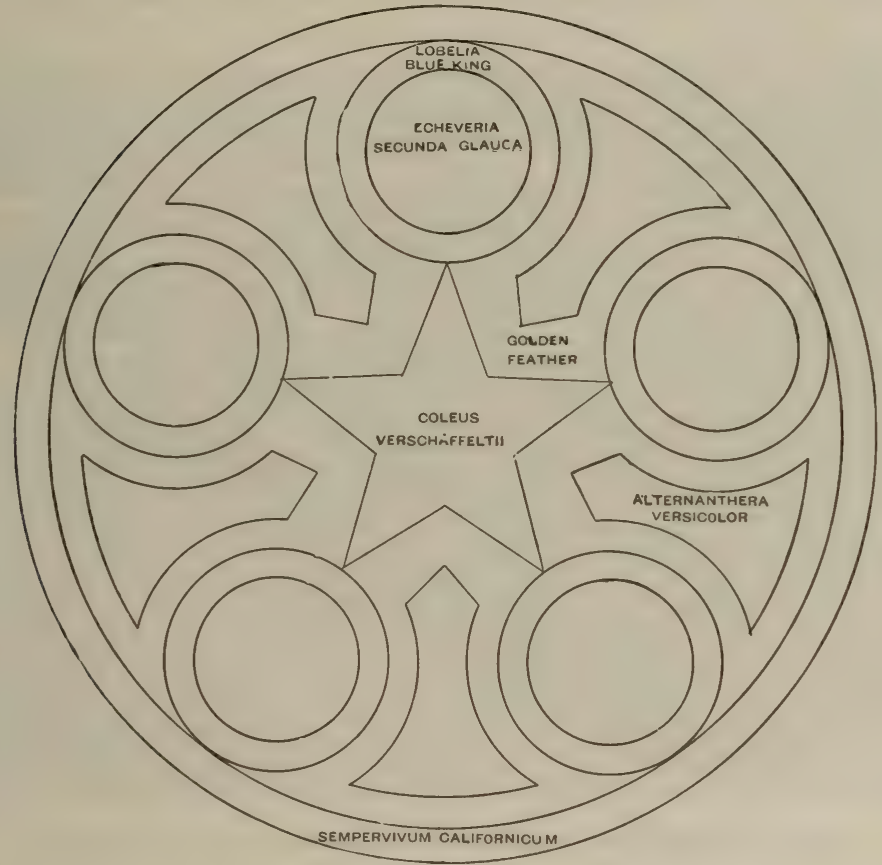

that the soil of a given district is best suited for. Were this always remembered, we should see fewer garden failures, and the gardening in different districts would possess an interest from variety. If each possessor of a garden were to strike out a line for himself, the question of suitability of soil would soon be settled, for a man would be too observant to plant a Rhododendron in chalky soil because he had admired a friend's Rhododendrons in peaty or vegetable soil. A healthy Yew or Box is infinitely preferable to a sickly Rhododendron. The annual dressing of flower-beds is needed to get the best effects; and by all means continue it, but not to the entire neglect of hardy flowers and shrubs. These, though they will do a long time without fresh food, enjoy rich top-dressings of good soil or 
manure; it is only by so treating them that their best effects are developed.

Flower-beds occasionally require to be deeply dug. Trenching is perhaps the proper term, but it scarcely expresses what I mean. The time to do it is when the beds are empty. I trench up my flower-beds once in two years - in autumn, after the summer bedders are removed, and before the spring-flowering plants are put in. Stirring flower-beds creates a wider field of action for the roots, and gives them an opportunity of getting out of the reach of drought in a dry season.

Coloured Foliage.-The use of coloured and fine-leaved

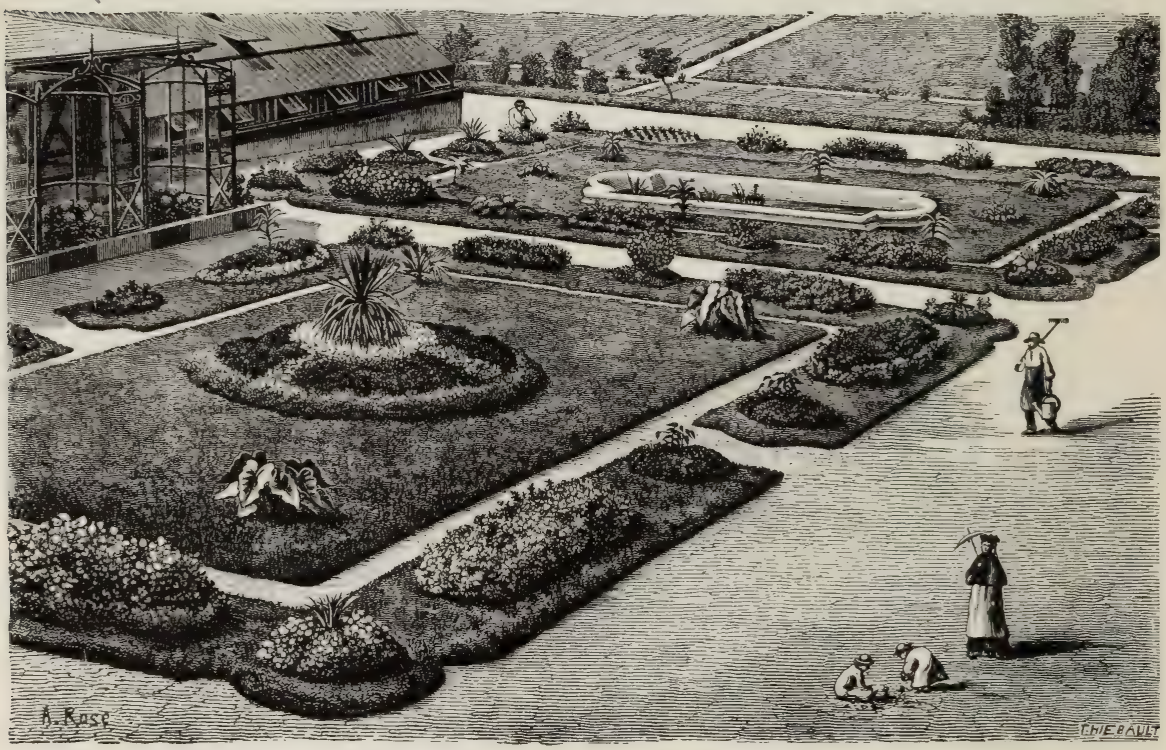

SUMMER BEDDING, WITH OCCASIONAL USE OF FINE-FOLIAGED PLANTS.

plants in the flower garden has increased, the causes being, the introduction of a number of suitable plants; and the weather, which has often been so wet that, no sooner have ordinary bedding plants got into full flower, than they have been dashed to pieces by the rain. Hence the desire for plants that would withstand such washings, and yet give bright effects. As regards coloured-foliaged bedding plants in particular, I do not think that if half of the bedding plants used were what are termed foliage plants, it would be out of proportion; in such coloured foliage I would include the variegated Pelargoniums, together with hardy variegated plants, such as Japanese Honeysuckles, variegated Periwinkles, Ivies, and the hardy Sedums and Saxifrages. The effects to be had from this class of plants combined 
with variegated and coloured-leaved plants of the tender section, and with graceful-leaved plants, are better than any to be had from flowering plants alone, as they stand all weathers without injury. One of the brightest coloured beds I have ever seen planted in geometrical form for summer effect was composed of the following plants, viz. Sedum acre elegans, creamy white ; Sedum glaucum, gray ; Herniaria glabra, green; Mesembryanthemum cordifolium variegatum, light yellow ; and the bright orange and scarlet Alternantheras, all dwarf plants; the standard or central plants being Grevillea robusta and variegated Abutilons.

Bedding AND Fine-Leaved Plants.-There can be no doubt that the use of the freer-growing green and graceful fine-leaved plants has done a great deal of good. In the south of England

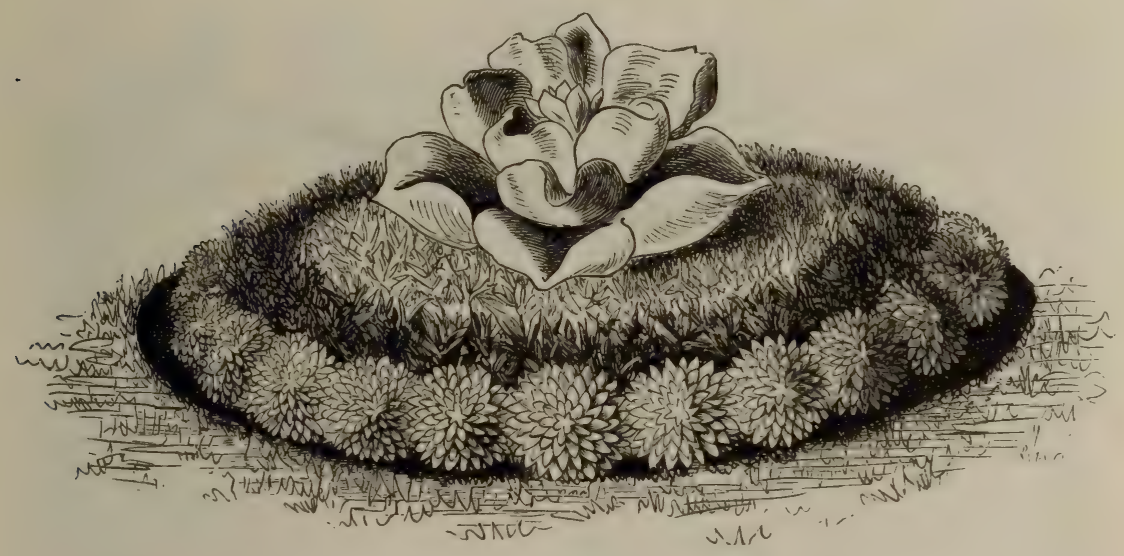

BED OF SUCCULENTS AND COLOURED-LEAVED PLANTS.

one may grow a great variety of plants of this kind. A number of greenhouse and even of stove plants may be placed in the open air without injury, and even with benefit to themselves. But some plants put out look sickly all the summer and make no good growth. Others always look well, even in the face of damaging storms. Where the climate is against the tenderer plants, a very good selection may be made from hardy subjects-from shrubs, plants like the Yucca, or young trees cut down and kept in a single-stemmed state. The illustration on p. I 70 (from André's L'Art des Jardins) shows a smaller and neater type of foliage. But there are errors in the system from which these things cannot save us. A geometrical bed is none the less geometrical because we place green-leaved or graceful plants in the middle of it. A more radical alteration is required, and that is the abolition of geometry itself, of formalism and straight lines, and of all the hateful gyrations which place the art of gardening 
on a level so much lower than it deserves to occupy. We can have all the variety, all the grace, all the beauty of form, all the glory of colour of the world of flowers and plants, without any of the pattern business which is now the rule. But we cannot make much progress in this direction except by suppressing the bed as much as possible, and by letting the vegetation tell its own story. The plants we must feed and the soil we must enrich; but finicking beds, reminding one of the art on fire-shovels and such productions, are not necessary. Let us then begin by adopting a bold, large, and simple type of bed, from which the flowers will spring and make us

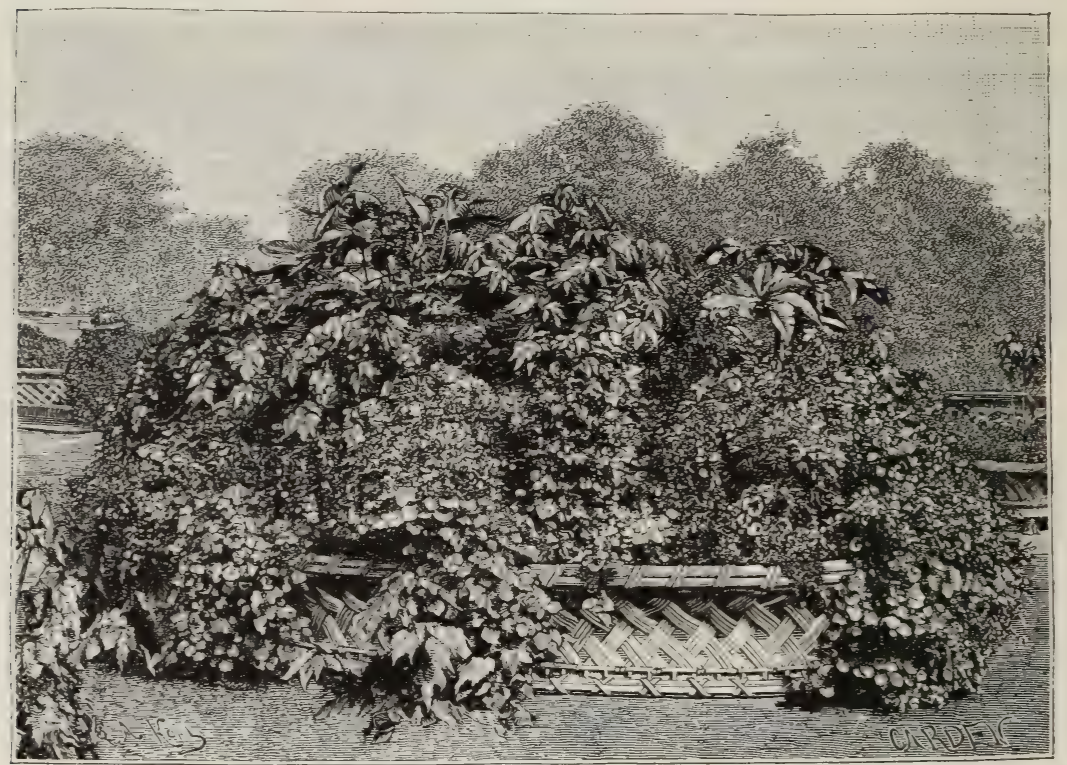

STONE BASKET OF FLOWERS AND FINE-LEAVED PLANTS IN THE GARDEN AT HECKFIELD PLACE.

think more of them than of the pattern. By way of variety, succulents are desirable plants for dry positions and under the shade of trees, where other bedding plants do not flourish satisfactorily. From their power of withstanding storms of wind and rain, and even drought and cold, they are always in good form ; and they should have a place in summer flower-garden arrangements of any extent. They harmonise well with many hardy plants that may serve as cushions for them to display their quaintness on. The term "succulent" includes all plants of a fleshy character, the more common types being the Echeverias, Cotyledons, and Kleinias. Agaves and Aloes are more rare, but are none the less valuable for bedding.

VASES. - In their proper place, and in due proportion, vases and 
baskets are useful in flower gardens, but they are frequently to a great extent out of all harmony with the style of the garden and its surroundings. Perhaps the tendency to over-decorate in this way is due to the geometrical plan of many gardens, when vases are placed on every pedestal and at every corner to square with many meaningless angles. Happily, this style of gardening is giving place to a less formal one in which vases and baskets can be used or not, according to the taste of the owner. When vases are used in large numbers, much may be done by planting plants of a drooping character in them; indeed, vases look most natural when trailers or climbers droop over the sides. Basket-formed beds are well suited to almost any position in pleasure-grounds ; but the best of all spots is in an isolated recess on the turf, and next, in the central bed of a flower garden, where the surrounding beds are circles or ovals. I have one, the extreme length of which is 16 feet; it is 8 feet wide in the middle, stands 2 feet 6 inches above the turf, and is made of Portland cement. The principal plants in it are Marguerites, Pelargoniums, Heliotropes, Fuchsias, Marvel of Peru, Abutilons, Castoroils, Cannas, Japanese Honeysuckles, and Tropæolums. More rusticlooking baskets would be better suited for isolation on the turf and for distant parts of the pleasure-grounds; and very good ones can be formed of wirework, lined inside with zinc, or made of barked Oak boughs instead of wirework. In baskets and vases of this kind permanent plants should be used, such as the variegated Ivies, Periwinkles, Japanese Honeysuckles, Clematises, and climbing Roses-space being reserved for flowering plants in summer and for small shrubs in winter.

SUB-TROPICAL BEDDING.-There are four types of summer flower-gardening: I, the massing (the oldest); 2, the carpet; 3, the neutral-quiet and low in colour, mainly through use of succulents; and 4, the sub-tropical, in which plants of noble growth and graceful foliage play the chief part. To my mind, a mixture of the four classes is the very ideal of flower-gardening. It is possible to plant a formal garden in such a manner that the severest critic could not complain of excessive formality; for, after all, it is the abuse of carpet bedding that has brought it into disrepute. And justly so, for when one sees bed after bed and arrangement after arrangement repeated without end, with no plants to relieve the monotony of flat surfaces, one has good reason to protest. I have charge of a terrace garden which has to be planted with a view to obtaining the best display from June to November, and I am therefore compelled to adopt the carpet-bedding system; but I supplement it by dotting over the surface, of necessarily formal arrangements, plants of noble or graceful aspect, such as Acacia, Dracæna, and Yucca. In such arrangements a judicious blending 
of beds of flowering plants, principally Pelargoniums, adds brightness to the whole; but, save under exceptional circumstances, flowers, and even fine-foliaged and flowering plants, should never be put in the same bed as succulents. The colour-massing or grouping style of summer-gardening is best adapted to a terrace or parterre that is well backed up or surrounded by evergreens, as these afford relief from the glare of brilliant colours, and at the same time set them off to advantage. A few plants of fine form distributed apart over the garden, and especially in beds of glaring colours, will be found to enhance the beauty of the whole. My view of sub-tropical gardening is, that it is only suitable for positions where it can be

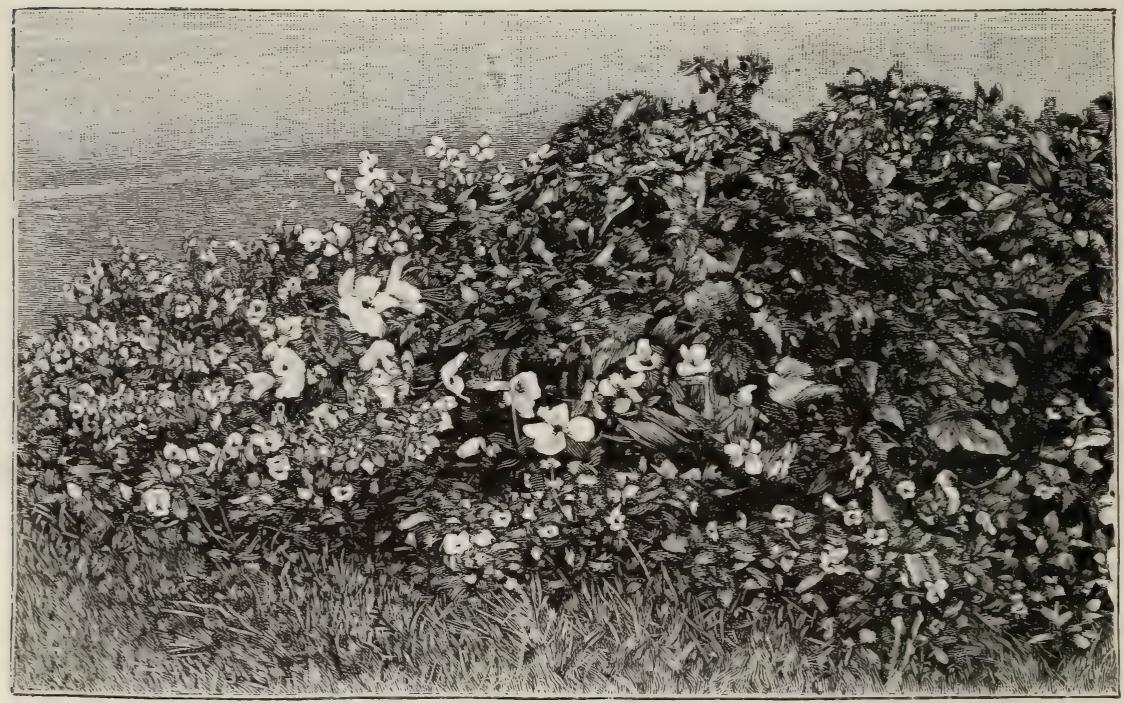

PART OF BED OF "BEGONIAS" AT CANONS ASHLY.

associated with water, or for sheltered nooks and dells, where the force of the wind is broken before it comes in contact with the plants. Where such positions are not at command, it is best to choose the hardier class of noble or handsome foliaged plants, many of which may be permanently planted, such as Ailantus, Rhus, Arundo, Salisburia, Yuccas, and the hardy Palm (Chamærops humilis). Of half-hardy plants that will withstand wind there are numbers, such as Araucaria, Acacia, Ficus, Cycas, Dracæna, Aralia. In planting sub-tropical plants, care should be taken that the beds when fully furnished do not have a "bunchy" appearance. To avoid this, plant thinly, and use as undergrowth divarfer plants, of which there are many suitable kinds.

Sumier And Winter Bedding.-Now that there is such a 
wealth of plants suited for furnishing the flower-beds in winter, there can be no excuse for their remaining empty after the summerbedding plants are cleared away. Much labour is required to carry out both summer and winter bedding; but I strongly recommend this kind of decoration. There are reasons why winter bedding should be encouraged. First, winter is the season when all around us is bleak, dull, and bare-leaden skies, leafless trees, flowerless meadows, and silent woods, all of which have a depressing effect on most temperaments. It therefore behoves us to endeavour to neutralise this prevailing dulness by making our gardens as cheerful as possible. Another reason - which to those fond of summer bedding should be the great reason for adopting winter beddingis the short period during which summer bedding continues in perfection. The thought is continually haunting one that it will fade all too soon. The adoption of winter bedding, however, in my own case obliterates such thoughts, and one looks forward to real pleasure from both systems. Nor has this been the only result. It being necessary that summer and winter bedding should meet, ingenuity had to devise means to this end. This led to my using as summer bedders many hardy plants which otherwise I should not have thought of using, but which are just as effective as tender exotics; nay, in some cases, more so; and which, when planted in the spring, serve till the following spring, when they are taken up, divided, and replanted for another year.

SHRUBS FOR WINTER BEDDING.-Isolated beds or a series of beds in parts of pleasure-grounds not much frequented in winter may not repay the labour and expense of thus planting them; but for gardens immediately under the windows of a mansion-as most bedded-out gardens are-the winter filling of the beds is of the utmost importance if permanent enjoyment is desired. There can certainly be no enjoyment in looking out upon bare beds, and that at a time usually gloomy enough without having a daily spectre of barrenness directly under our eyes. The naked beds in winter, no doubt, constitute the strongest objection to the bedding-out system, and, whilst acknowledging the justice of the objection, it is well to bear in mind that, to a great extent, the same objection is applicable to hardy herbaceous plants, as few of these do real furnishing service during the winter months. Indeed, for a garden overlooked from the windows, I should certainly prefer the bedding-out plan, supplemented by shrub-planting for the winter-and not necessarily the planting of shrubs alone, but of other hardy evergreen plants, particularly the dense-growing Sedums and Saxifrages, and similar plants, many of which are now used with excellent effect in combination with ordinary bedding plants in summer arrangements. 
The more plants of this type that it is possible to work in with the summer bedders, the less the labour when the time arrives for the winter planting; for, to furnish the parterre in winter, we do not require to move more than half the plants that have done duty in summer. It now only remains to give a list of the best kinds of shrubs for the purpose, the list being strictly composed of kinds that bear removal well, do not grow fast, or change colour after planting. It is as follows :-

$\begin{array}{ll}\text { Aucuba. } & \text { Euonymus. } \\ \text { Berberis. } & \text { Hollies. } \\ \text { Cotoneaster. } & \text { Juniper. } \\ \text { Cupressus. } & \text { Laurustinus. } \\ \text { Erica. } & \text { Osmanthus. }\end{array}$

Pernettya. Vinca.

Portugal Laurels. Yews (green and Retinospora. variegated).

Rhododendron. Yucca.

Thujopsis.

W. W.

\section{Principal Families of Plants used for Bedding-out.}

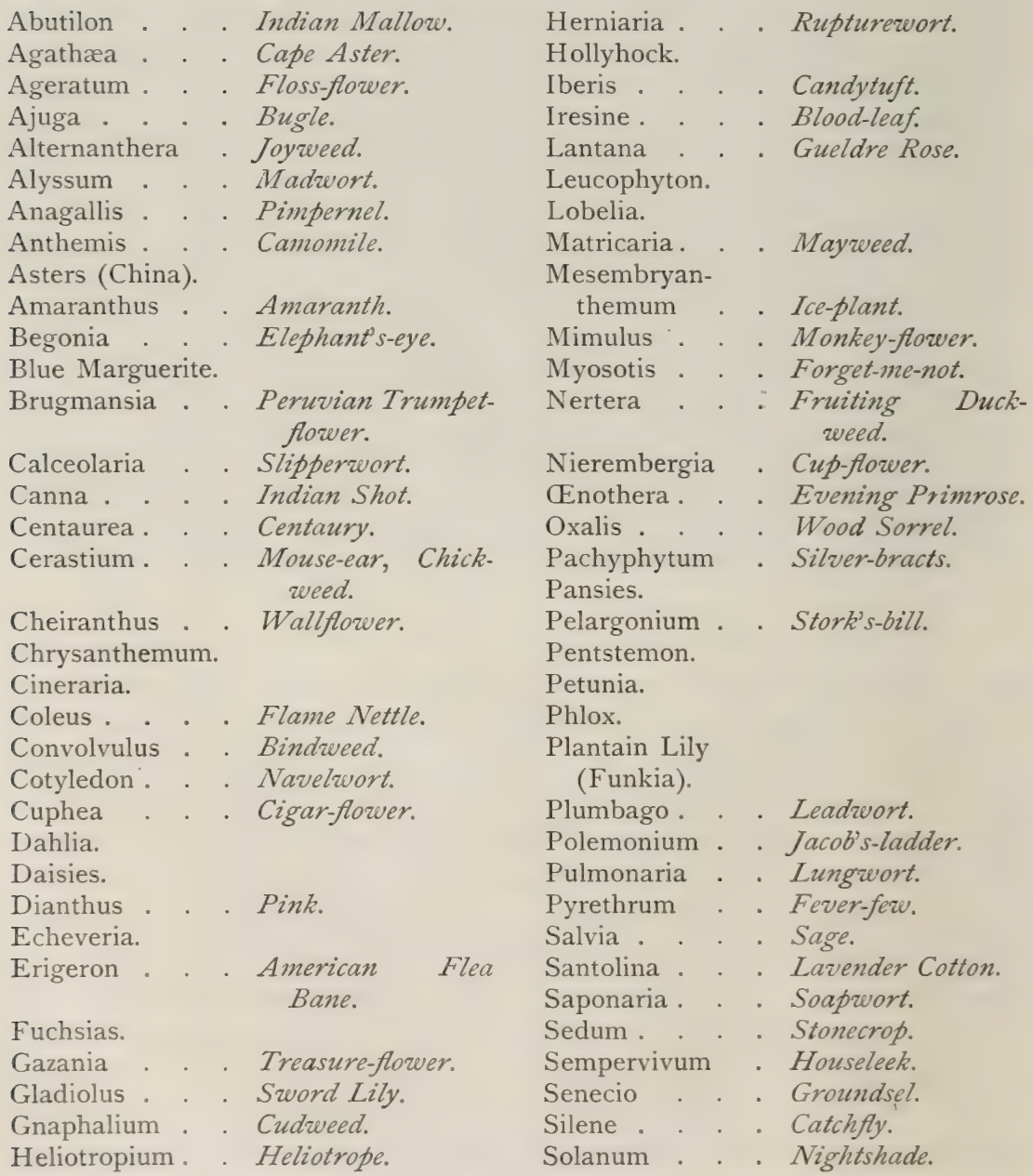




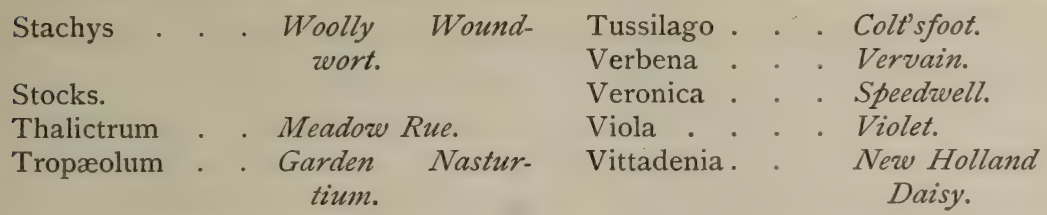

Reference to their culture and position will be found in the alphabetical part of the work.

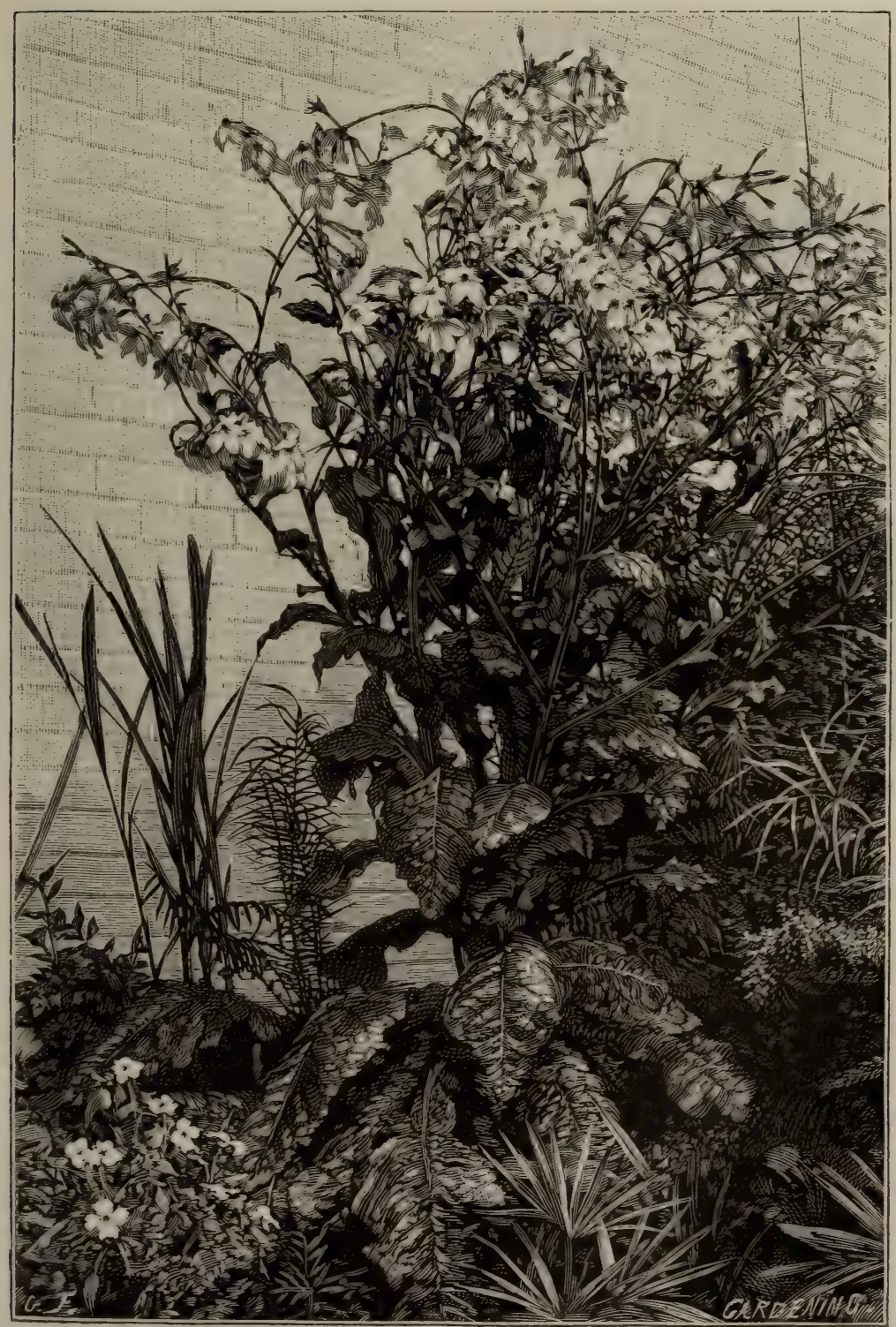




\section{CHAPTER XV}

\section{ROSERIES, PAST AND PRESENT}

UP to the present time the Rose has been almost confined to the "rosery," and has been sparingly used in connection with other plants for furnishing borders and shrubberies - the curious idea prevailing that Roses do not associate well with other forms of vegetation. In the Gardener's Assistant, published only a few years ago, the writer on Roses states that Roses should be confined to a rosery, because "the stems of standards, etc., contrast unfavourably with shrubs, and, indeed, all other vegetation which is not of a dwarf character" - a strange assertion when one remembers the unnatural appearance that standards present when arranged in the objectionable dotting system, as they generally are in roseries. When varieties of the Rose were few and poor, there was less objection to the rosery; but the rosery was not always planned in quite the same way as modern roseries, many of which are of the most formal pattern it is possible to conceive. For example, I was acquainted with one that consisted of a parallelogram, nearly half an acre in extent, intersected at right angles by walks, the plots being filled up on the general mixture principle-rows of standards, half standards, and dwarfs alternating with the walks in parallel lines. There was nothing beautiful or artistic in such an arrangement. Another example designed by a modern landscape gardener consisted of concentric circles laid out on Grass, with iron pillars round the outside, on which climbing Roses were trained as festoons. This looked better than the straight bed, but still had an inartistic look, as all such designs must have. Rose-planting and arrangement, indeed, is conducted on much the same lines as it was sixty or eighty years ago; but Loudon did anticipate modern taste so far that he recommended some of the more distinct species or varieties to be massed by themselves, which was a step in the right direction,- - not, however, generally adhered to. Formal roseries are as objectionable as formal "bedded-out" gardens in their barest and poorest aspect, if not more 
so; and it is no excuse that they enable the cultivator to give the bushes a special culture, for this can be given equally well in prettier situations. I am not speaking of growing Roses for exhibition, but of their culture for the general decoration of the garden. Hitherto the Rose decoration of the garden has been almost entirely neglected, because the "rosery" has absorbed the main supply of plants; and one of the saddest facts connected with our Roses is the annual mortality among them. Whether this is due to severe pruning, or the poor constitution of the plants, is not necessary to determine ; but it is certain that the mortality has become greater since varieties have so much increased and since severer methods of pruning have been adopted.

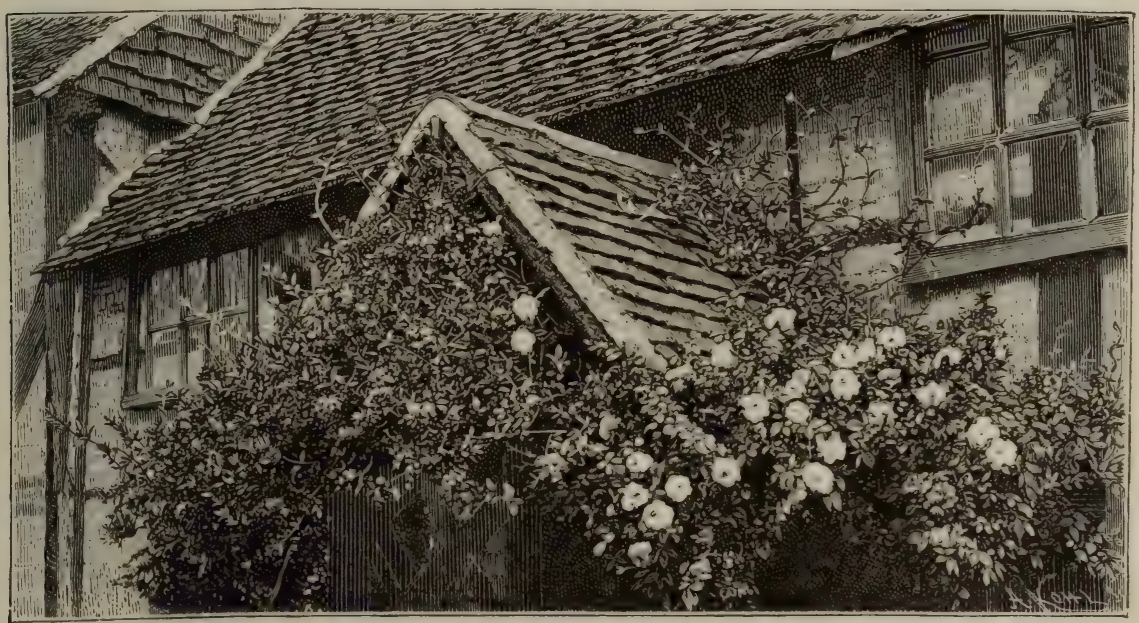

CLIMBING ROSE (ROSA ALBA) ON COTTAGE PORCH, SURREY

PLACES FOR ROSES.-They should be wherever they will grow. We cannot have too many Roses, or Roses in too many places, any more than we can have too many other popular flowers which we are now trying to extend so much. But in order to extend Rose plantations, especially where the cost of procuring and keeping up a stock is a consideration, we must abolish the "rosery," and send its contents to places where they are more wanted. I never saw a garden yet where it was necessary to invent places or positions for Roses. The walls, fences, and shrubberies, etc., will always absorb as many of the climbing or trailing varieties as can be spared and cultivated to good purposes, and numberless aspects and positions can always be found for bushes. Rose bushes may be in beds, borders, or shrubberies; and if it be true that the most pleasing effects with garden flowers are produced by planting them in good, 
visible, and striking groups or masses, then assuredly that is the way to use the Rose, and no plant is likely to be more accommodating and useful for this purpose. At present we mix indiscriminately summer and autumn flowering sorts and their varieties; but, on the grouping principle, we should have to divide these, or, as occasion required, mix them with a view to a succession of bloom, keeping the colours as far as possible to themselves. If this system were generally adopted, it would tend to shorten our Rose lists sooner than any other plan, for gardeners would soon discern what varieties suited their purpose best, and they are strongly conservative as to making changes. Thus we should have bold masses of the vivid Général Jacqueminot and its race, Gloire de Dijon, John Hopper, La France, Souvenir de la Malmaison, Victor Verdier, Moss Roses, and all the best and most striking kinds, which are comparatively few in number. For the ramblers, many suitable positions could be found, where, Brier-like, they could grow at their own sweet will, and produce masses of bloom to be estimated by square yards, such as we not unfrequently see on older varieties that, aided by a good soil and favourable position, have by chance established themselves and made headway. It would be as easy to cultivate Roses in this way as in a formal rosery, and it would enable us to choose the most favourable positions for the more tender and select kinds. The plants could be manured, pruned, and tended just as readily as under any other system, they would look in their natural and proper place, and would afford more pleasure than they could possibly do in a formal and perhaps inconveniently-situated "rosery." This system of planting might restrict the number of varieties in a collection, if only one sort were planted in each place-a most desirable object under certain circumstances; but, by planting several varieties of the best reds in one place, and of the best yellows in another, and so on, the number could be extended as much as might be desired : the plan would soon show which were the best in the different classes, and weeding out would follow as a natural consequence.

Certain varieties of Roses could also be mixed with other suitable flowering subjects in the same way that we now plant Gloire de Dijon among the purple Clematis. Roses would do well among Rhododendrons and Azaleas, would be benefited by the shelter, and would flower when the bloom of the sheltering plants was over; they would also succeed with many other things that will suggest themselves to the reader. The Rose patches, wherever they happened to be, could also be carpeted over to better purposes than beds of most other things. They might be literally crammed with spring and summer flowers of dwarf, low habit, including many kinds of bulbs, Saxifrages, and the like, which would just suit the Roses, and afford protection 
to their roots in winter-an important matter, for no cultivator doubts that one of the principal causes of mortality among Roses is the absence of a covering to the soil. Even the Brier dies in bare ground, while in the hedgerow and the copse it braves our hardest winters ; and many good old Roses do the same as the Brier.

THICK Planting.-Another fault is thin planting. The desire to cover much ground has been the cause of this, and Roses are generally planted as far apart as Gooseberry bushes-a great mistake in the case of plants that, like Roses, are pruned to stumps every winter. Both for effect and for shelter, Roses should be planted thickly according to their vigour, and "standards" should be used only to fill up backgrounds of clumps of Roses. Standards have been condemned as in bad taste, and certainly a mere addition of bare stem cannot under any circumstances add to the beauty of such a stiffly-habited plant as the Rose. But when standards are planted in the formal manner which has been so long the fashion, either as single objects on lawns or in regular rows in the rosery - their heads all on the same level,- - their objectionable appearance is forced prominently upon the sight. Nevertheless, in clumps placed against shrubs and other objects, and planted according to their size, so as to form a background to dwarf plants, standards may be useful. They are not, however, a necessity in any way, and they are both dear and troublesome to grow.

PRUNing and LARge Bushes OF Roses.-It is a pertinent question to ask whether Rose-pruning is not carried a trifle too far in general culture. There is no bush in the garden annually cut so close as the Rose, and it is to be feared that the advantages of the practice are more apparent than real. Close pruning is said to induce vigorous growth, and hence the weaker varieties are pruned most severely. Under good management and protection this system answers well enough, and it is the best plan for the nurseryman, who for commercial reasons has to keep his plants within bounds; but in private gardens, where a show of Roses is desired, and desired soon, severe pruning is best avoided. It may be different in the case of Roses for exhibition. It is pretty well ascertained that the most severely pruned plants suffer most in severe winters, and are shorter-lived than plants grown as unpruned bushes. It is quite an error to suppose that Hybrid Perpetuals, Bourbons, or Teas, etc., grow weakly and poorly by being left to develop their tops as large as they will. All the ordinarily vigorous kinds will make quite large bushes if allowed, and will continue to grow and do well for many years. Climbers excepted, the plants never grow above a certain height, but they spread out and annually throw up strong shoots which produce vast numbers of flowers every season. The 
cottager's Roses are never pruned, and they are sometimes of remarkable age and size. Thirteen years ago, I split up and planted as a hedge a large number of Hybrid Perpetuals, Teas, and other Roses, and ceased pruning them; they are now all fine large bushes 4 feet and 5 feet high. The vigour and length of their annual shoots is surprising. They are often over 5 feet long and an inch in diameter

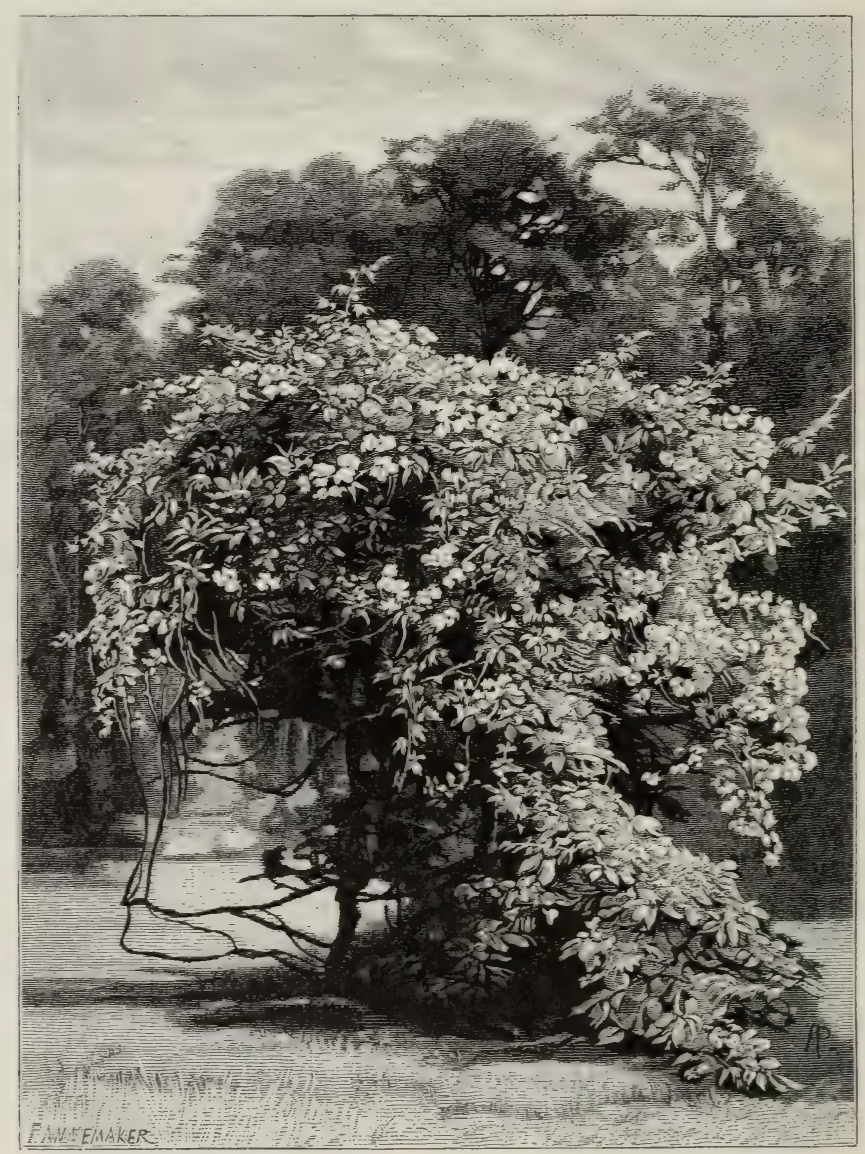

WHITE CLIMBING ROSE ON OLD CATALPA TREE.

near the base-just like Brier shoots, in fact. None of them have died, and the plants must now be twenty years of age-some of them probably a good deal older,- - while in the borders, among the pruned and select Roses, my losses have been great. During the severe winters of recent years these old bushes have stood unscathed, and are at present as vigorous as ever. The number of Roses they produce is surprising, and the productions of the highly-cultivated, 
much-pruned plants are quite put into the shade. From them in the course of an hour a man has frequently filled several large vegetable baskets with Rose petals for drying, and that without making much difference to the show of flowers. The way the unpruned Rose behaves is this: the plant, as soon as fairly established in a good soil, throws up plenty of strong shoots, and the following year these shoots break their buds freely along the stem, and each branch produces a mass of bloom, which, after a shower, weighs the branch almost down to the ground. The older branches flower equally well, but what pruning such bushes need consists principally in thinning out the oldest branches, and leaving the younger ones. What takes place in the case of dwarf bush Roses happens in climbers, only the mass of blooms is ten times greater. It is the climbing or scrambling Roses that show what the Rose is capable of when cultivated in this free and natural manner. One of my most attractive specimens is an old double white Ayrshire Rose growing in the shrubberies among a group of common Laurel. I cannot tell how old the plant is, but it has probably been in its present situation for more than thirty years, struggling to keep its place among the tall-growing Laurels-sending out a shoot of white flowers sometimes on this side, and sometimes on that side of the clump of bushes, and sometimes scrambling up to the tops of the tallest branches, and draping them with blossoms throughout June and July. Nearly six years ago I headed the Laurels down to within 6 feet of the ground, leaving the straggling branches of the Rose which were found among them, and since then this Rose has grown and thriven amazingly, and now fairly threatens to gain the mastery. Some time ago I measured the ground covered by the plant and found it rather over 70 feet in circumference. Within this space the bush forms an irregular undulating mound so densely covered with Roses that not a hand's-breadth is vacant, and the Laurel branches are quite hidden, and in fact are now dying smothered by the Rose. A finer example of luxurious development I never saw. The plant was a perfect sheet of bloom for a month or more, and hundreds of buds were cut just at the opening stage. The tree never received the least attention, with the exception of the removal of the Laurel tops to let in the light. It is growing in a tolerably deep and strong dry loam, and this, together with head room, seems to be all it requires. There are far too few examples of this kind, for our efforts have not been in the direction of showing what could be done with the Rose as a tree or bush. The common Brier teaches us a good lesson in Rose-pruning. No one has ever ventured to say the wild Rose was out of place in the hedgerow; and how does it behave there? It forms a mighty mound of 
branches, the older stems dying down as the young ones accumulate, till a large bush is formed, covered with flowers. On the roads and lanes I have seen wild Roses which old people said had been there ever since they remembered, and I have taken note of Briers in the woods that, to all appearance, have been more than fifty years of age; and yet our strongest-growing Roses on Brier stocks in gardens are short-lived. From these facts the Rose-grower may learn that to have Rose bushes and plenty of Roses he should plant good kinds of known repute for hardiness and vigour, and should mainly confine the use of his knife to thinning out the shoots.

Roses ON LAwns.-Climbing and strong-growing Roses make very ornamental objects in a few years. Climbers want something to support them at first; and for this purpose nothing is better or more convenient than four or five thin flat iron rods bent over each other at right angles, with their ends in the ground, so as to form a circular frame about 4 feet high and 6 feet through. The Rose tree is planted in the centre, and as it grows a shoot is trained each way to form the foundation of the future plant; but after the first or second year it is left entirely to itself. The supports are soon covered, and a large natural-looking mound of Roses is the result. I have seen specimens of this kind twenty years old in which the wood had accumulated about 2 feet or more deep all over the trellis, and yet nowhere was any dead wood to be seen, owing to the plants throwing out annually fresh shoots which covered the old ones. The plants, in fact, grow exactly in the same manner as the wild Brier, which keeps sending up from its centre long shoots, increasing its size every year. Those who desire very large mounds may have them just as easily as small ones, and in about as little time, by increasing the size of the iron framework and planting the Roses-as many as they choose-round the sides. This would leave the space inside vacant, and, by keeping the internal surface clipped with a pair of shears, they would have a veritable bower of Roses. Except against walls and in similar situations, there is no occasion to prune climbing Roses. They make by far the grandest display when left to themselves, and it is only necessary to provide them with a good, deep, strong soil at the beginning, and to let them have a fair amount of light on all sides. Whether planting be carried out with the object above described, or for the purpose of covering naked tree-stumps or branches, or for draping any unsightly object whatever, liberal treatment in the first instance is the main thing. A good soil makes all the difference in quickness of growth, and in the permanent vigour of the tree; and were I desirous of having a great Rose tree (whether a common Ayrshire, or a Gloire de Dijon which I 
expected to produce thousands of blooms in a few years), I should, if the soil were not naturally strong and deep, provide a welldrained pit, and fill it with two or three cartloads of sound loam and manure; and the result would be certain, provided an unrestricted growth were permitted. Among the best plants for such purposes are the Ayrshire Roses. These are all double, or semi-

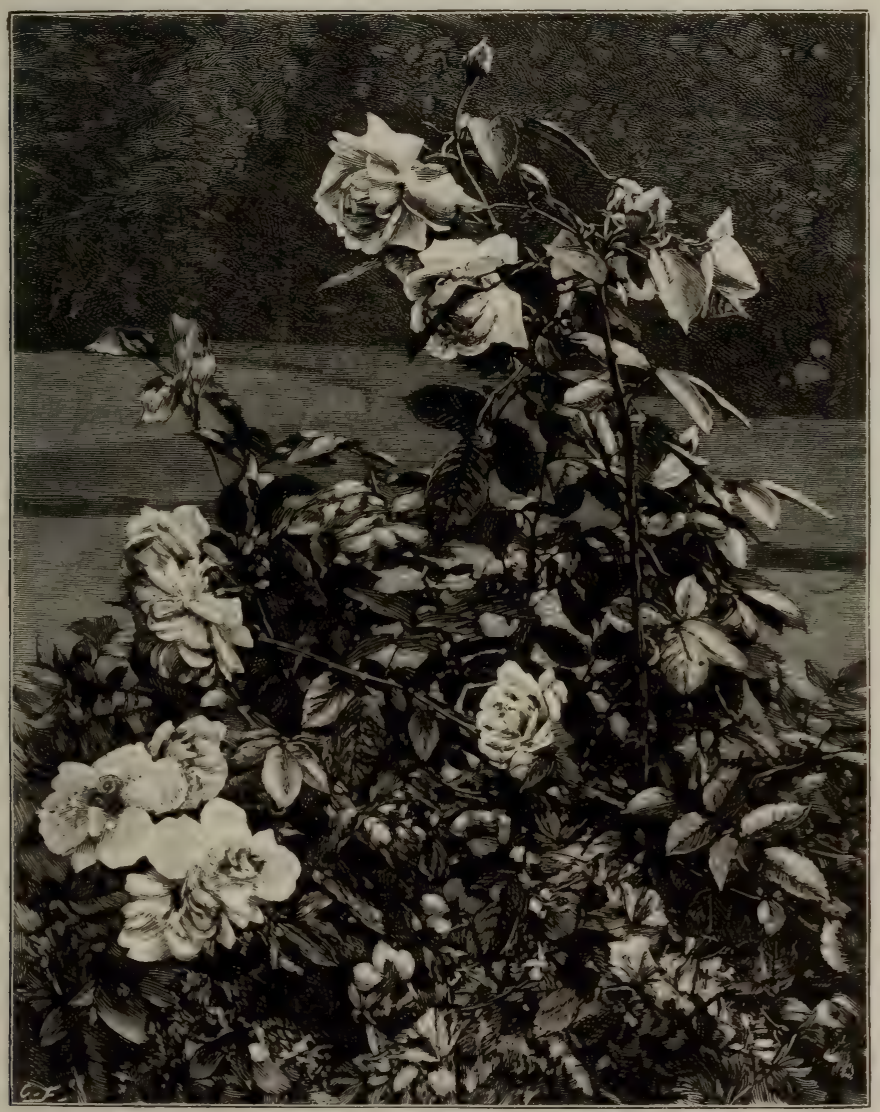

TEA ROSE. MARIE VAN HOUTTE.

double, and the best of them are white or of a pinkish colour. There are hardly a dozen varieties, and most of them are worth growing for the sake of variety. Almost equally hardy and useful is the evergreen Rose, so called on account of the length of time it retains its leaves in winter. There are several good varieties, and they are vigorous and rapid growers, and need little or no attention, except thinning when they are trained to pillars or walls. To these may be added the Boursault varieties, a few of the Bourbon kinds, and among the Tea-scented class, Gloire de Dijon and Maréchal 
Niel. The last two are worthy of all the attention that can be bestowed upon them. Gloire de Dijon comes in early and goes out late, the second growth often producing flowers in abundance late in the season, and in the south Naréchal Niel does well either on a wall or as a rambler in the open ground. As far north as the Tweed also it occasionally grows and flowers freely on a roof or against a wall in a favourable exposure. Both are hardier than some people imagine, and unpruned plants stand severe winters best. Both, too, are great ramblers, and, where the situation suits them, there is nothing to prevent any one from having single plants of either quite as large as the Rose described above.

AsPECTS FOR ROSES.-Aspects for Roses should be warm. The Rose's powers of enduring an English climate depend, next to protection, upon the thorough maturation of its growth each year; this in its turn depends upon the amount of heat received during the summer, and this again to some extent depends upon the position the plants occupy. Roses grow best and live longest on sunny sites, and the farther north we go the more apparent becomes this fact. The best Roses, like the best Peach trees, are grown in the south, and this is better known to the trade than to private growers. All nurserymen supply Roses, but all do not grow them equally well, and many northern nurserymen have to make up their stock annually from the south, or to supply their customers on commission-a very common plan. Roses love shelter and warmth, and the choice of a situation should always be regulated by these considerations. At the same time, they will endure severe exposure, and no one need hesitate to plant even if the site is less favourable than could be desired. In some of the northern and midland nurseries acres of Roses are grown in the open, and are quite exposed in every direction; but then the losses in such nurseries are enormous, and both stocks and buds are at a premium. For the private grower such facts are sufficiently instructive, and point to the importance of shelter, both for roots and tops, in all cold and exposed situations.

SoIL FOR ROSES.- Any good garden soil will do for Roses, but the nearer it approaches to a good fresh loam the better. Roses do not object to a rather tenacious loam, approaching a clayey texture, provided the drainage is good; and, in some nurseries, where Roses are successfully propagated by thousands and well grown, it would surprise fastidious growers to see what the soil is like-a stiff, clayey loam, which in summer lies in lumps, like baked bricks, upon the surface. I'et in this soil the plants make fine growth and flowerson the Brier stock especially. But the best soil for a general plantation of Roses is one neither too light nor too heavy; for Roses greatly differ in rooting power, more particularly when grown on 


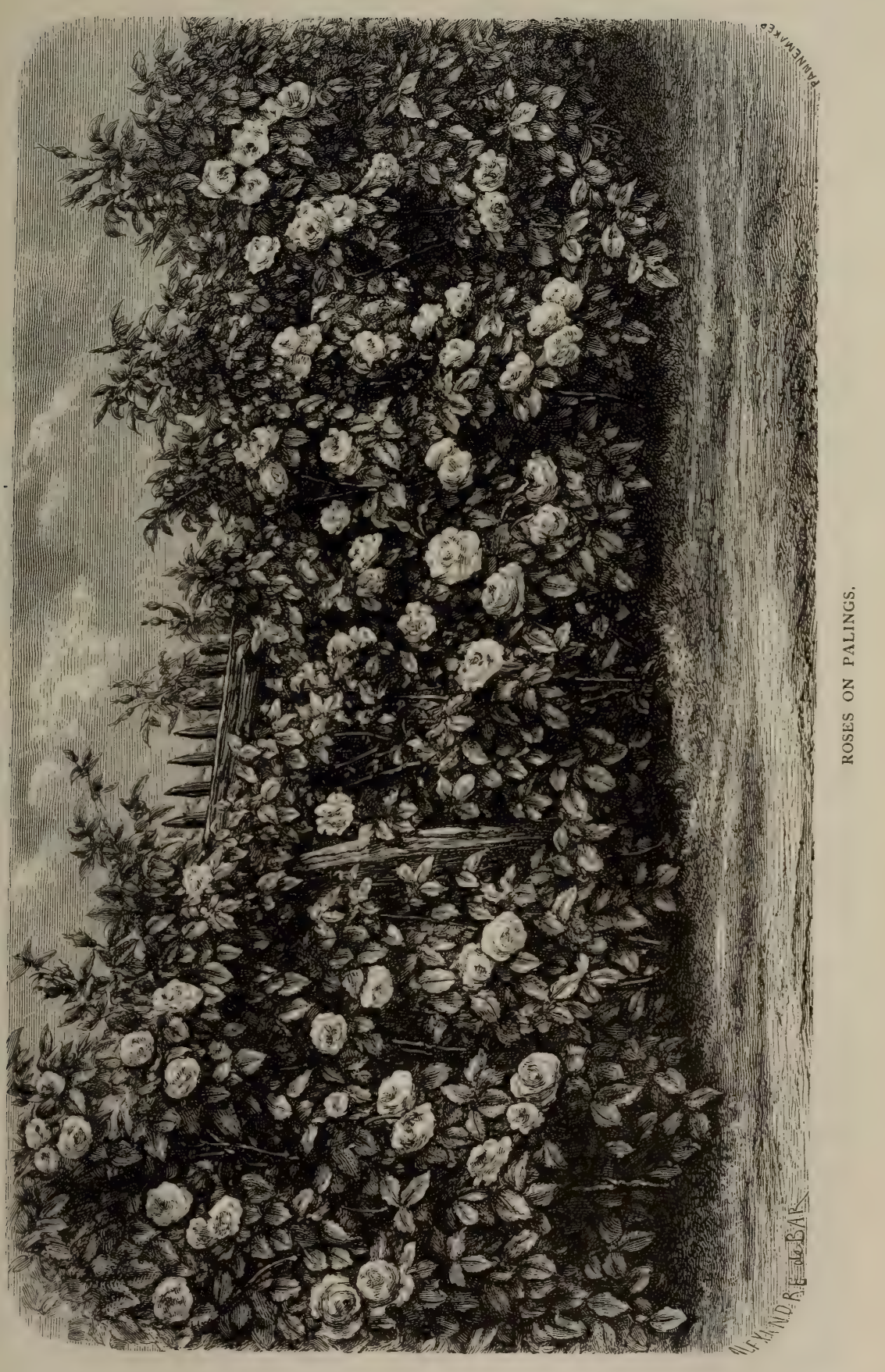


their own roots, the more tender Teas and the like doing best in moderately light and rich composts, and the strong briery climbers doing best in deep, strong loams. The habit of the variety itself indicates the nature of the compost likely to suit it. Strong growers are most likely to succeed in strong soils, and weak growers in light and open soils; and, in planting, it is not difficult to give each kind the soil it likes best, at least in starting at the beginning.-S.

Roses on Palings.-One of the prettiest and most useful purposes to which the Rose can be turned as a climbing plant is to cover palings, or fences. The preceding illustration represents a portion of a long fence in the Waltham Cross Nurseries, formed of common deal laths, which, otherwise bare and cheerless, is made attractive and beautiful by a covering of Roses, which, when well grown and encouraged by careful pruning, gracefully entwine themselves in and out the pales. The varieties best adapted for this purpose are Noisettes, Hybrid Chinas, and Tea-scented classes, together with some few of the Bourbons. If the exposure be northerly or the fence high, many of the Boursault, Ayrshire, and evergreen Roses will be found very suitable. When pruned the plants should not be much cut back, but the weak shoots should rather be removed altogether, as it is masses of flower, in preference to individual fine specimens, that are to be sought after.

WALL ROSES.- Roses are seldom more effective than when grown against walls and well managed. The protection afforded to the Tea-scented varieties is peculiarly favourable to growth. Nevertheless, judging from the condition in which they are often seen, Roses are frequently the least inviting of all wall plants. This arises, first, from the selection of unsuitable kinds ; secondly, from the exhaustion of the soil a few years after planting, through omission to take sufficient means to enrich it; thirdly, from unskilful training, which, in the case of strong-growing sorts, permits the lower portion of a high wall to become bare of young flower-producing shoots. The main reason, however, of such an unsatisfactory condition of walltrained Roses is the difficulty of keeping insects in check. When trained to a wall, Roses, more than other plants, are susceptible to the attacks of insects, particularly aphides, red spider, and Rose maggot. The difficulty in freeing the plants from the worst of these is all the greater on account of the walls offering an obstacle to the application of most kinds of liquid, excepting clean water. Most liquid insecticides leave ugly stains on the walls, unless washed off before they become dry. But in this case the material is also washed off before it has destroyed the insects. Since, however, paraffin in a very diluted state is an effectual insecticide which does not injure the plants, or leave traces on the walls, it answers the purpose well, 


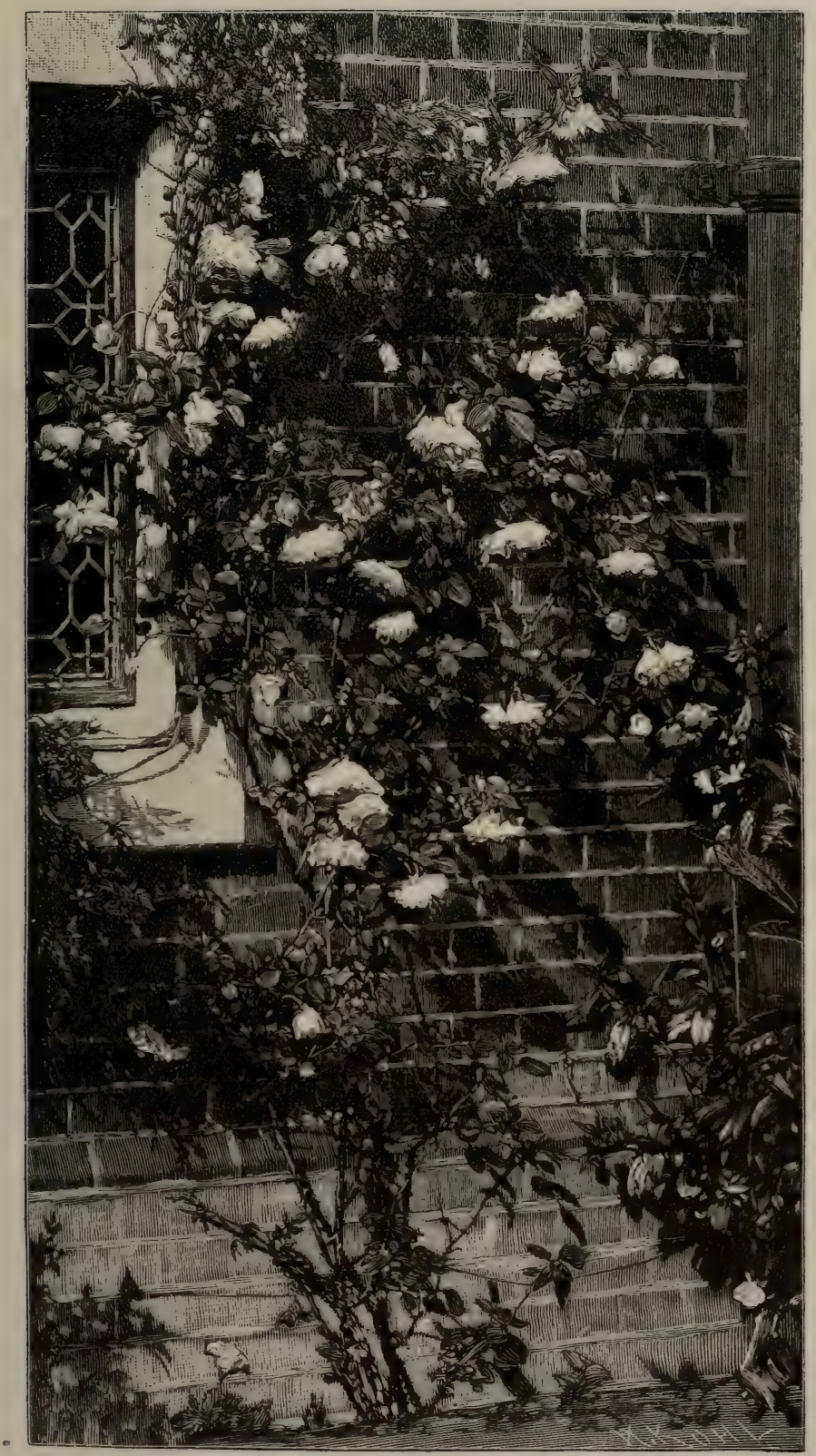

TEA ROSE, "RUBENS," IN THE GARDEN OF MALWOOD, HAMPSHIRE. 
and the worst drawback connected with the culture of wall-trained Roses is overcome. I have regularly applied it against a lightcoloured wall, where I could not use anything that left a mark. Prevention is always better than cure, and as soon as the Roses are pruned and nailed or tied to the trellises, they should have a good washing with paraffin water, by a syringe or a garden engine, for although it may be supposed that severe frosts destroy the eggs of aphides, such is not the case. One recommendation of Roses against walls is that, except in the colder parts of the country, they thrive better on east, or even northern, aspects than on the southern, which is no small advantage; for on a northern aspect few plants will flower successfully. As to the sorts suitable for walls, much depends upon the height and space to be covered. Any of the strongest and free-growing Hybrid Perpetual varieties may be grown, as well as the more commonly planted Tea-scented kinds; but the Teas have a more continuous habit of flowering, and handsomer and better foliage.

Lastly there are few ways in which our flower gardens may be more improved than by freeing the Rose from the stupid plans of the Rose books. Good Roses of all sorts should be grown as bushes in groups in any beds or borders we care for. The notion that Roses are only for the formal rosery has done vast harm to our flower gardens and to the Rose. It should be dropped for ever.

\section{List of some of the best Garden Roses.}

Owing to the great and, as I think, undue place given to show Roses as compared with those that bloom well in the garden, I give a list of good garden Roses.

Provence.-Cabbage, White Provence, Burgundy, Little Gem, Blanche Moreau, Common Moss, Muscosa, japonica.

Chinese, Bourbon, AND Noisette Hybrids.-Coupe d'Hébé, Madame Plantier, Souvenir de Pierre Dupuy, Alice Gray, Splendens, Simplex, Grandiflora, Félicité-Perpétué.

Hybrid Climbing.-Fortune's Yellow, Laura Davoust, The Garland.

AUstrian BRIERs.-Single Yellow (R. lutea), Single Copper (R. punicea), Persian Yellow, Harrison's Yellow.

Hybrid Perpetuals.-Alphonse Soupert, A. K. Williams, Anna Alexieff, Baroness Rothschild, Boule de Neige, Camille Bernardin, Charles Lamb, Charles Lefebrre, Dr. Andry, Duke of Edinburgh, Dupuy Jamain, Ella Gordon, Etienne Levet, Eugène Appert, Florence Paul, Garden Favourite, Général Jacqueminot, Gloire Lyonnaise, Glory of Cheshunt, Henri Ledechaux, Heinrich Schultheis, John Hopper, Jules Margottin, La France, Madame Gabriel Luizet, Madame Nachury, Marquise de Castellane, Merveille de Lyon, Pride of Waltham, Princess Louise Victoria, Suzanne Marie Rodocanachi, Thomas Mills, Ulrich Brunner, Violette Bouyer.

JAPANESE.-Rugosa alba, Coruscans.

Rosa Polyantha VARs.-Anne-Marie de Montravel, Ma Paquerette, Max Singer, Mignonette, Perle d'Or, Stanwell Perpetual.

Bourbon.-Armosa, Madame Isaac Pereire, Marie Paré, Queen, Souvenir de la Malmaison.

Noisette.-Aimée Vibert, Céline Forestier, Lamarque, Maréchal Niel, Narcisse, Ophirie, Rêve d'Or, Wm. Allen Richardson. 
Chinese OR Bengal.-Cramoisie Supérieure, Mrs. Bosanquet, White Pet, Red Pet.

Hybrid TEA-SCEnTED.-Camoens, Cannes la Coquette, Longworth Rambler, Madame Alfred Carrière, Marie Lavallée, Reine Marie Henriette, Reine Olga de Wurtemburg, Viscountess Folkestone.

\section{Berard.}

Climbing TeA.-Bouquet d'Or, Emilie Dupuy, Gloire de Dijon, Madame

TEA-SCENTED.-Anna Ollivier, Caroline Kuster, Ethel Brownlow, Francisca Kruger, Grace Darling, Hon. Edith Gifford, Innocente Pirola, Jean Ducher, Jean Pernet, Jules Finger, Madame Charles, Madame Chedane Guinoisseau, Madame Falcot, Madame Lambard, Marie van Houtte, Perle des Jardins, Souvenir d'un Ami.

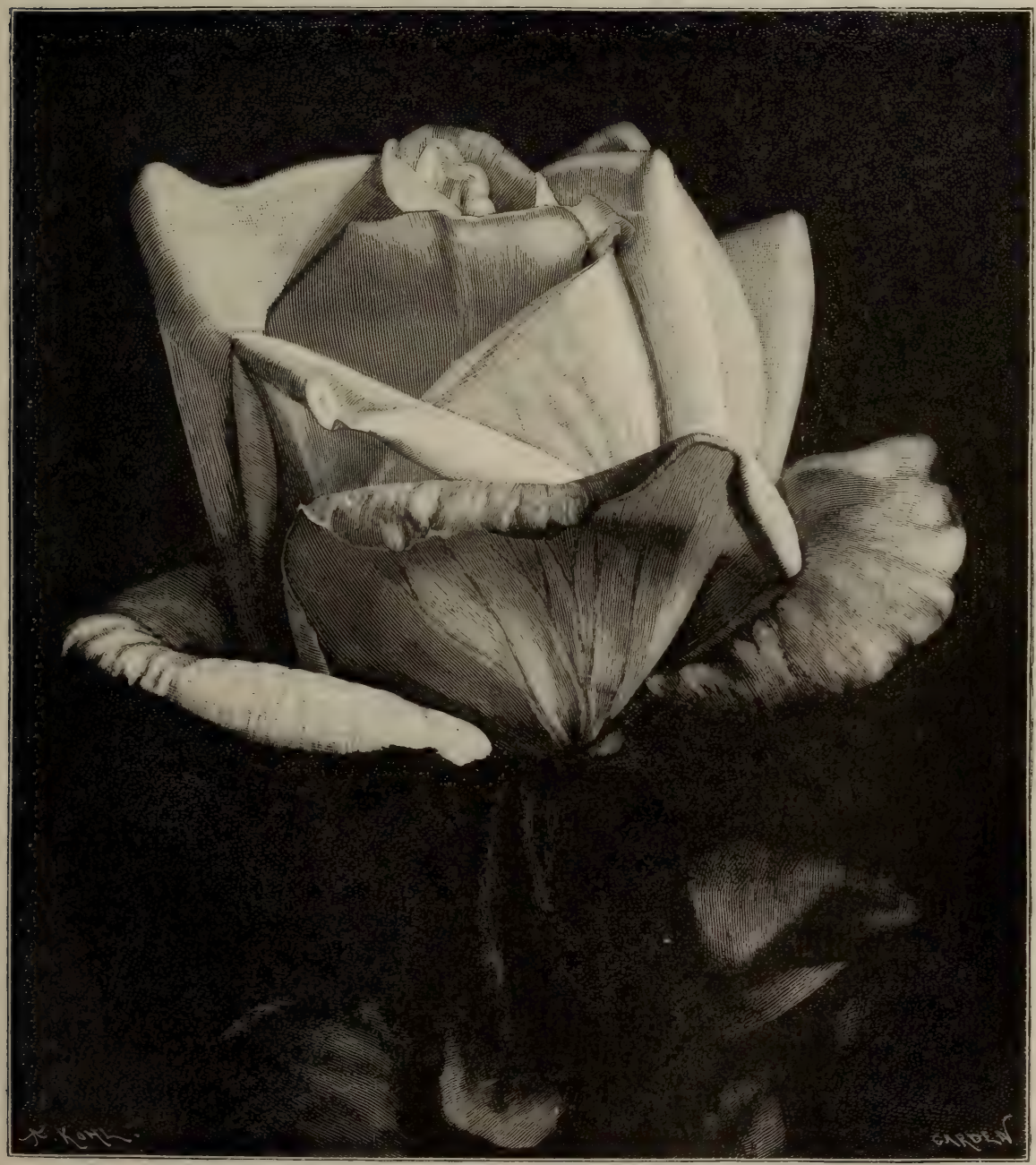

TEA ROSE. JEAN DUCHER. 


\section{CHAPTER XVI}

\section{COLOUR IN THE FLOWER GARDEN}

NATURE is a good colourist, and if we trust to her guidance, it is possible to be very good flower gardeners without considering laws of colour. We never find colour wrong in the wood, in the meadow, or on the mountain. "Laws" have been laid down about colours which the better kind of artists ignore. If people have to make pocket-handkerchiefs, or to spread about coloured gravels, then it is necessary to consider what ugly things will shock us the least; but dealing with living plants in their infinite and beautiful tints of green, and with their nearly always beautiful flowers, is a different thing. To consider the "laws" of colour laid down by writers on decoration is a waste of time. If we grow plants of good colour properly, all will be right in the end. The complicated pattern beds universal throughout the flower-gardening world should be given up in favour of simpler, larger beds, of whatever shape best suits the ground. A very important reason for this is the colour. When people have little pincushion-beds where the whole "pattern" is seen at once, and where they use dwarf plants, the desire comes to bring in colour in a geometric, unnatural, and inartistic way. For this purpose the wretched Alternanthera and other pinched plant rubbish were grown. Such plants are not worth growing at all. Plants naturally dwarf, like the beautiful alpine plants, should be grown in rocky beds, where their forms and flowers will be beautiful without any relation to patterns of colour.

When brilliant flowers are associated with plants like Roses, a little taller than themselves, and with plants like Carnations and tall Irises, having pointed and graceful foliage, the colours are relieved against the delicate and varied foliage of the plants. By having the beds large enough we have the chance of relieving the plants with taller plants behind. In a shrubbery, too, groups of flowers are nearly always right, and we can follow our desire in flowers without much thought of colour. But the roots of the shrubs rob 
the flowers; and the best way is to put in near and around shrubberies free-running plants that do not want fine gardening, like Solomon's Seal and Woodruff, and the numerous plants that grow naturally among shrubs. When we come to deal with flowers like Pansies, Carnations, and Roses, and other flowers that depend for their beauty to some extent on good cultivation, the best way is to keep them in the open, and free from contention with hungry tree-roots.

By having large simple beds, such as I use myself, we get the flowers relieved, and enjoy beauty of colour in the flowers and the forms of the plants without colour "pattern" of any kind. Instead of dotting the plants, there is nothing to do but to group them naturally without any definite plan, letting the groups run into each other, and varying them here and there with taller plants. A garden of any size could be planted in this way, without the geometry of the ordinary flower garden, and the poor effect of the "botanical" dotty mixed border. As, however, many may not be ready to follow my plan, the following notes on colour, by an excellent flower-gardener who has given much thought to the subject, will, I hope, be useful to them :-

One of the most important points in the arrangement of a garden is the placing of the flowers with regard to their colour-effect, and it is one which has been greatly neglected. Too often a garden is an assemblage of plants placed together haphazard, or if any intention be perceptible, as is commonly the case in the bedding system, it is to obtain as great a number as possible of the most violent contrasts; and the result is a hard, garish vulgarity. Then, in mixed borders, one usually sees lines or evenly-distributed spots of colour, wearying and annoying to the eye, and proving how poor an effect can be got by the misuse of the best materials. Should it not be remembered that in setting a garden we are painting a picture - a picture of hundreds of feet or yards instead of so many inches, painted with living flowers and seen by open daylight,-- so that to paint it rightly is a debt we owe to the beauty of the flowers and to the light of the sun ; that the colours should be placed with careful forethought and deliberation, as a painter employs them on his picture, and not dropped down in lifeless dabs, as he has them on the palette?

HARMONY RATHER THAN CONTRAST.-Splendid harmonies of rich and brilliant colour, and proper sequences of such harmonies, should be the main rule ; there should be large effects, each well studied and well placed, varying in different portions of the garden scheme. One of the commonest faults is a want of simplicity of intention, or an obvious absence of any definite plan of colouring. Many people have not given any attention to colour-harmony, or have not by nature the gift of perceiving it. Let them learn it by observing some natural examples of happily-related colouring, taking separate families of plants whose members are variously coloured. Some of the best to study would be American Azaleas, Wallflowers, German and Spanish Iris, Alpine Auriculas, Polyanthus, and Alstrœmerias.

BREADTH OF MASS AND INTERgROUPING.-It is important to notice that the mass of each colour should be large enough to have a certain dignity, but never so large as to be wearisome; a certain breadth in the masses is also 
wanted to counteract the effect of foreshortening when the border is seen from end to end. When a definite plan of colouring is decided on, it will save trouble if the plants whose flowers are approximately the same in colour are grouped together to follow each other in season of blooming. Thus, in a part of the border assigned to red, Oriental Poppies might be planted among or next to Tritomas, with scarlet Gladioli between both, so that there should be a succession of scarlet flowers, the places occupied by the Gladioli being filled previously with red Wallflowers.

WARM COLOURS are not difficult to place: scarlet, crimson, pink, orange, yellow, and warm white are easily arranged so as to pass agreeably from one to the other.

PURPLE and LILAC group well together, but are best kept well away from red and pink; they do well with the colder whites, and are seen at their best when surrounded and carpeted with gray-white foliage, like that of Cerastium tomentosum or Cineraria maritima ; but if it be desired to pass from a group of warm colour to purple and lilac, a good breadth of pale yellow or warm white may be interposed.

WHITE FLOWERS. - Care must be taken in placing very cold white flowers such as Iberis correæfolia, which are best used as quite a high light, led up to by whites of a softer character. Frequent repetitions of white patches catch the eye unpleasantly; it will generally be found that one mass or group of white will be enough in any piece of border or garden arrangement that can be seen from any one point of view.

BLUE requires rather special treatment, and is best approached by delicate contrasts of warm whites and pale yellows, such as the colours of double Meadow Sweet, and Enothera Lamarckiana, but rather avoiding the direct opposition of strong blue and full yellow. Blue flowers are also very beautiful when completely isolated and seen alone among rich dark foliage.

A PROGRESSION OF COLOUR in a mixed border might begin with strong blues, light and dark, grouped with white and pale yellow, passing on to pink; then to rose colour, crimson, and the strongest scarlet, leading to orange and bright yellow. A paler yellow followed by white would distantly connect the warm colours with the lilacs and purples, and a colder white would combine them pleasantly with low-growing plants with cool-coloured leaves.

Silvery-LEAVED PLANTS are valuable as edgings and carpets to purple flowers, and bear the same kind of relation to them as the warm-coloured foliage of some plants does to their strong red flowers, as in the case of the Cardinal Flower and double crimson Sweet William. The bright clear blue of Forget-menot goes best with fresh pale green, and pink flowers are beautiful with pale foliage striped with creamy white, such as the variegated forms of Jacob's-ladder or Iris pseudacorus. A useful carpeting plant, Acæna pulchella, assumes in spring a rich bronze between brown and green which is valuable with Wallflowers of the brown and orange colours. These few examples, out of many that will come under the notice of any careful observer, are enough to indicate what should be looked for in the way of accompanying foliage-such foliage, if well chosen and well placed, may have the same value to the flowering plant that a worthy and appropriate setting has to a jewel.

In SUnNy PLACES warm colours should preponderate; the yellow colour of sunlight brings them together and adds to their glowing effect.

A SHADY BORDER, on the other hand, seems best suited for the cooler and more delicate colours. A beautiful scheme of cool colouring might be arranged for a retired spot, out of sight of other brightly-coloured flowers, such as a border near the shady side of any shrubbery or wood that would afford a good background of dark foliage. Here would be the best opportunity for using blue, cool white, palest yellow, and fresh green. A few typical plants are the great Lark- 
spurs, Monkshoods, and Columbines, Anemones (such as japonica, sylvestris, apennina, Hepatica, and the single and double forms of nemorosa), white Lilies, Trilliums, Pyrolas, Habenarias, Primroses, white and yellow, double and single, Daffodils, white Cyclamen, Ferns and mossy Saxifrages, Lily of the Valley, and Woodruff. The most appropriate background to such flowers would be shrubs and trees, giving an effect of rich sombre masses of dusky shadow rather than a positive green colour, such as Bay Phillyrea, Box, Yew, and Evergreen Oak. Such a harmony of cool colouring, in a quiet shady place, would present a delightful piece of gardening.

BEDDED-OUT PLANTS, in such parts of a garden as may require them, may be arranged on the same general principle of related, rather than of violently opposed, masses of colour. As an example, a fine effect was obtained with halfhardy annuals, mostly kinds of Marigold, Chrysanthemum, and Nasturtium, of all shades of yellow, orange, and brown. This was in a finely-designed formal garden before the principal front of one of the stateliest of the great houses of England. It was a fine lesson in temperance, this employment of a simple scheme of restricted colouring, yet it left nothing to be desired in the way of richness and brilliancy, and well served its purpose as a dignified ornament, and worthy accompaniment to the fine old palace.

CONTRASTS-HOW TO BE USED.-The greater effects being secured, some carefully-arranged contrasts may be used to strike the eye when passing; for opposite colours in close companionship are not telling at a distance, and are still less so if interspersed, their tendency then being to neutralise each other. Here and there a charming effect may be produced by a bold contrast, such as a mass of orange Lilies against Delphiniums or Gentians against alpine Wallflowers; but these violent contrasts should be used sparingly and as brilliant accessories rather than trustworthy principals,

Climbers on WALLS.-There is often a question about the suitability of variously-coloured creepers on house or garden walls. The same principle of harmonious colouring is the best guide. A warm-coloured wall, one of Bath stone or buff bricks, for instance, is easily dealt with. On this all the redflowered, leaved, or berried plants look well-Japan Quince, red and pink Roses, Virginian Creeper, Cratægus Pyracantha, and the more delicate harmonies of Honeysuckle, Banksian Roses, and Clematis montana, and Flammula, while C. Jackmanni and other purple and lilac kinds are suitable as occasional contrasts. The large purple and white Clematises harmonise perfectly with the cool gray of Portland stone ; and so do dark-leaved climbers, such as White Jasmine, Passion Flower, and green Ivy. Red brickwork, especially when new, is not a happy ground colour; perhaps it is best treated with large-leaved climbers-Magnolias, Vines, Aristolochia - to counteract the fidgety look of the bricks and white joints. When brickwork is old and overgrown with gray Lichens, there can be no more beautiful ground for all colours of flowers from the brightest to the tenderestnone seems to come amiss.

Colour in BedDing-OUt. - We must here put out of mind nearly all the higher sense of the enjoyment of flowers: the delight in their beauty individually or in natural masses; the pleasure derived from a personal knowledge of their varied characters, appearances, and ways, which gives them so much of human interest and lovableness; and must regard them merely as so much colouring matter, to fill such and such spaces for a few months. We are restricted to a kind of gardening not far removed from that in which the spaces of the design are filled in with pounded brick, slate, or shells. The best rule in the arrangement of a bedded garden is to keep the scheme of colouring as simple as possible. The truth of this is easily perceived by an ordinary observer when shown a good example, and is obvious without any showing to one who has studied colour effects; and yet the very opposite intention is most commonly seen, to wit, a 
garish display of the greatest number of crudely-contrasting colours. How often do we see combinations of scarlet Geranium, Calceolaria, and blue Lobeliathree subjects that have excellent qualities as bedding plants if used in separate colour schemes, but which in combination can hardly fail to look bad? In this kind of gardening, as in any other, let us by all means have our colours in a brilliant blaze, but never in a discordant glare. One or two colours, used temperately and with careful judgment, will produce nobler and richer results than many colours purposely contrasted, or wantonly jumbled. The formal garden that is an architectural adjunct to an imposing building demands a dignified unity of colouring instead of the petty and frivolous effects so commonly obtained by the misuse of many colours. As practical examples of simple harmonies, let us take a scheme of red for summer bedding. It may range from palest pink to nearly black, the flowers being Pelargoniums in many shades of pink, rose, salmon, and scarlet; Verbenas, red and pink; and judicious mixtures of Iresine, Alternanthera, Amaranthus, the dark Ajuga, and red-foliaged Oxalis. Still finer is a colour scheme of yellow and orange, worked out with some eight varieties of Marigold, Zinnias, Calceolarias, and Nasturtiums - a long range of bright rich colour, from the palest buff and primrose to the deepest mahogany. Such examples of strong warm colouring are admirably suited for large spaces of bedded garden. Where a small space has to be dealt with it is better to have arrangements of blue, with white and the palest yellow, or of purple and lilac, with gray foliage. A satisfactory example of the latter could be worked out with beds of purple and lilac Clematis, trained over a carpet of Cineraria maritima, or one of the white-foliaged Centaureas, and Heliotropes and purple Verbenas, with silvery foliage of Cerastium, Antennaria, or Stachys lanata. These are some simple examples easily carried out. The principle once seen and understood (and the operator having a perception of colour), modifications will suggest themselves, and a correct working with two or more colours will be practicable; but the simpler ways are the best, and will always give the noblest results. There is a peculiar form of harmony to be got even in varied colours by putting together those of nearly the same strength or depth. As an example in spring bedding, Myosotis dissitiflora, Silene pendula (not the deepest shade), and double yellow Primrose or yellow Polyanthus, though distinctly red, blue, and yellow, yet are of such tender and equal depth of colouring, that they work together charmingly, especially if they are further connected with the gray-white foliage of Cerastium.-G. J.

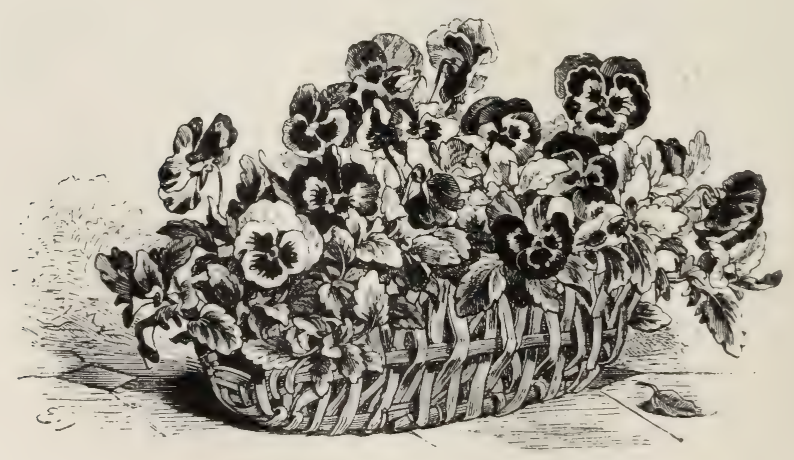




\section{CHAPTER XVII}

\section{SOME SOURCES OF WASTE}

To a great extent our gardens are laid out in a bad and oldfashioned way. There are so many needless walks, edgings, etc., that men cannot get to work in a simple way. Half the time is lost in "niggling," cleaning the feet, seeing that the edges are not injured, or repairing them when they are.

This effort thus wasted should be turned to good account in the growth of flowers. In many costly places there is no flower-gardening at all; a few wretched plants are stuck out in the parterre every year, and a few stunted hardy flowers are scratched in round the poor shrubbery, but little labour or love is bestowed on the growth of flowers. In many places there are miles of walks bordered by long bare stretches of earth, as cheerful as Woking Cemetery in its early years. The gardener is impotent to turn such a vast waste into a paradise; his time and his thoughts are eaten up by barber's work-shaving Grass and weeding walks. I went, not long ago, into one of the finest places in England for site and extent, the property of a wealthy peer. I saw six masses of lugubrious Perilla, and as many of yellow Calceolaria,-saw this at one saddened glance, and then turned for relief to the trees around. The gardeners say that, in consequence of the trouble of this vulgar daubing, and of their other work, they have no time for true gardening. But to form a garden of Roses, or groups of choice shrubs, or beds of Lilies, or of other noble hardy plants, so that the beds may fairly nourish their tenants for a dozen years, are the ends to which all good gardeners' labour should be directed. Instead of the never-ending scratchings of autumn and spring, we ought to have a thorough preparation of one portion of the flower garden every year, so that it would yield us quiet beauty for many years. We should then escape the massing of tender plants, with its great annual cost, its suite of hothouses, and its accompaniment of complete loss of the flowers every autumn. 
GRASS.- Then we have the endless shaving of big lawns. The soft turf is the glory of our gardens, but who can say that it is wise to mow forty acres of kept lawn, as some people boast of doing? Soft lawns we want near our houses, and we cannot take too much care of them, but the wide acres of Grass mown in many large country seats would be better if cut as hay. A flowering meadow is one of the most beautiful things in Nature, and our park or garden lawns might be lovely with the Grass growing long and with many flowers in it. The Grass itself should be a beautiful garden. We should see in it, as we often see in an alpine meadow, fair flowers which grow in English as well as in alpine turf. By allowing the Grass to grow in spring and till maturity, this phase of the wild garden will be enjoyed, and plants will come up year after year to reward us. ${ }^{1}$

Lawns for play, and smooth turf among the flower-beds we must have, but in most large gardens something may be gained if the Grass to be frequently mown be restricted to what is essential. A good deal of Grass in pleasure-grounds and among trees is quite as pretty if cut at hay-time. Grass so mown is that which best suits hardy bulbs and other flowers naturalised in the Grass. The leaves of the early bulbs are generally ripe or withered down before mowing.

WALKS. - After the Grass come the needless walks. Our own landscape gardeners are a little more sparing with these hideous things than are the French; but we very often have four times too many walks, which torment the poor gardener by needless and stupid labour. He is always hoeing, and weeding, and salting. The planning of these walks in various elaborate ways has been supposed to have some relation to landscape gardening; but one needless walk often destroys all possibility of good gardening in its vicinity. Walks are essential, but they should be designed simply to go wherever it is necessary they should go; they should be in keeping with the garden near them and with their own use. Flower-beds are often best set in Grass, and those who care to see them will approach them quite as readily on Grass as if hard walks are brought near them. For the three or four months of our dullest season there is little need of frequent resort to flower-beds, but for the rest of the year the turf is better than any walk. I do not mean that there should be no walk to the flower garden, but that every walk not necessary for frequent use should be suppressed. Few have any idea how much they would gain, not merely in labour, but in the beauty of their gardens, by doing away with needless walks. 
GLASS.-Among the evils of the bedding system is the need of extensive, costly glass-houses in which to keep the plants all the winter, not one in ten of these plants being as pretty as flowers that are as hardy as the Grass in the field,--like Roses, Carnations, and Pansies. It is absurd to grow Alternantheras in heat, and not to give a place to flowers that require no more heat than the Lilies of the Valley. Glass-houses are useful and charming helps for many purposes, but we may have noble flower gardens without them. To bloom Roses in winter, to ripen fruits that will not mature in our climate, to enable us to see many fair flowers of the tropics-for these purposes glass-houses are a precious gain; but for a beautiful flower garden they are needless. Therefore one great source of expense may be saved, and the numerous glass-houses in our gardens may be turned to better use. It would not be true to say that good hardy flower-gardening is cheaper than growing the masses of tender plants that often disgrace our gardens. The splendid variety of beautiful hardy things tempts one to buy, and it is therefore all the more necessary not to waste money in stupid ways.

WATERING.-In warmer countries much watering and irrigation are essential. In England, nine seasons out of ten, this fussy and heavy labour is unnecessary, particularly if we grow hardy flowers, and plant in autumn, winter, and early spring, so that the plants may be rooted before the hot days. When watering is necessary, it should be well done; that is, sufficient water should be given to moisten the soil to the full depth it is dug or trenched. The borders and beds should be 3 feet deep; and should be of good soil, so as to be free from drought.

From an economical point of view, nothing is more important than the due preparation of the soil by deep trenching. If this be well done in the first instance, and due after-attention be given to mulching, little artificial watering will be required. If mulching be applied as soon as the plants are put out in May, it saves much labour. The advantages of mulching are great. Cocoa-fibre refuse is the neatest mulch; it is clean to use, and is very cheap. The next best material is decayed leaf-soil. This, sifted, also looks very neat, but under bright sunshine it soon shrinks to nothing, and requires renewing. Well-rotted stable manure is another good mulch, particularly for plants you wish to feed liberally, like Dahlias. The mowings of lawn Grass is a good mulch for beds, and should not be wasted, especially if you have many recently transplanted shrubs. I myself use with very good results flat pieces of thin sandstone among Carnations and other choice hardy plants. These pieces of stone keep the ground between the plants clean, 
keep the soil cool and moist, and in winter keep the plants from being thrown up by frost, while, being of a good colour, they are not unpleasant in the beds at any time.

I find that a light carpet of alpine flowers under Roses tends to keep the beds moist; and for years my men have not had to use a watering-pot except when planting. Thorough preparation and deep soil do away with the need of any unpleasant mulch. The tufted Pansies, Rockfoils, gray and green Stonecrops which I use among the Roses and Carnations are a living and beautiful "mulch."

FANCY LABELS are a frequent source of waste, especially if stamped so as to suit only one plant. It would in many cases be
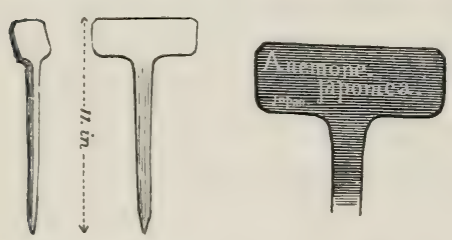

CAST-IRON LABELS; THE SIMPLEST, NEATEST, AND BEST FORM FOR SHRUBS, BOLD HERBACEOUS PLANTS, AND FOR ALL CASES WHERE THE LABEL HAS TO BE FIXED IN THE GROUND.

to replant. Fashion changes the garden vegetation too, and then the permanent labels, cast and burnt into hardware and cemented in cast-iron, are thrown aside. I prefer a label which can be used again, such as a cast-iron label of " $T$ shape" or, in other words, a slip of cast-iron with an oblong head slightly thrown back. These are cast very cheaply in the iron districts. You have to paint them and write the names of the trees on them when they come to hand; but that can be readily done by a handy painter, who will probably be glad of such a job in the winter. In a large garden, where much naming is required, the best way is to train a youth who is likely to remain in the place; and I have done that in a few weeks by placing a copy of the desired kind of letters before him. I find it an advantage to give the label a coat of copal varnish when the letters are dry, and generally use white letters on a black ground and give three coats of black over one of red lead. These are the best labels for the shrub and choice young tree vegetation of a pleasure-ground or flower garden. They will last for twenty years, and if you cease to cultivate the plants to which they belong, the labels may be repainted. You can get one hundred of them for the price of two or three of the costly permanent labels often used in pleasure gardens. 
With big trees it is always a mistake to use a ground label. The best labels for large trees are made of pieces of tin about $4 \frac{1}{2}$ inches by $3 \frac{1}{2}$ inches. About half an inch of the upper edge should be bent at a right angle so as to form a little coping for the label, two holes should be made just beneath the little angle, through which a strong copper wire should be put and firmly nailed to the tree. Place it so as to be easily read, and about $5 \frac{1}{2}$ feet or 6 feet from the ground. Paint it dark brown or black with white letters. It will last for many years. All labels inserted in the grass in pleasure-grounds are liable to be pulled up by mowers or others, and in this way to get lost. The labels on the bole are safe from such mishaps.

For Roses, and any tall or open shrub, perhaps the best label is a common wooden one about 3 inches long, with a hole at one end, through which a copper wire may be passed; the name should be written on while the paint is moist, and the copper wire bound round the branch rather loosely so as to allow for expansion.

For all Half-hardy Bedding Plants ordinary wooden labels are at once the most convenient and the simplest. If they are re-

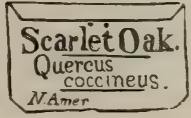

THE SIMPLEST AND BES'T LABEL FOR TREES.

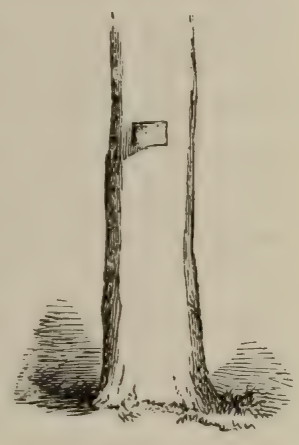

POSITION FOR TREE LABEL. quired to last, dip the ends in tar or pitch. In most gardens it is the practice to write the name at the part that goes in the ground, and to go on from thence to the top-a bad way, for the label always begins to decay at the base, and thus the beginning of the name is lost, while the end of it may be quite legible. Always begin to write it at the top. This may seem a small matter, but it is important where many wooden labels are used. After a little practice it becomes as easy to write from the top as from the other end. In writing the names always begin as near the top as possible.

FANCY EDGINGS of cast stone or tile ware to beds and walks are costly, ugly, needless, and a great source of waste. The most common of living edgings is Box, though it is far less used now than formerly. Where exactness has to be adhered to, there is nothing equal to Box, provided the blanks are made up and it is kept in good order by the shears. A neglected Box edging mars the appearance of a garden, and those who cannot afford to keep it properly should dispense with it. A beautiful evergreen edging is formed by the Irish Ivy, where carefully grown as in the public 
gardens of Paris. A broad, well-kept edging of Irish Ivy has a fine effect in various situations, but neglect soon mars any Ivy edging.

Some hardy plants make good edgings. Among the best are double Daisies, Thrift, Arabis, Auriculas, Primroses, Violets, and Gentianella. All these are easily increased. Enough is hardly made of these plants as edgings. Crimson and white double Daisies, for example, are charming for a long while in early summer; they increase fast and are easily grown.

Burnt tiles with a bead on the top are often used, because they are easy to procure and cheap; but they are useless, for the frost breaks them up in a couple of years unless they are very well burnt. They are always hard and ugly, and should never be used. A thin tile, made of fireclay and glazed, is also used, but, as a rule, all the burnt clay edgings are bad. Terra-cotta tiles stand fairly well, but they are expensive. Stout blue slate, with sawn edges, is enduring; it is expensive at first, but its great lasting properties are a compensation; it can be had in long lengths and is easily laid, but it is ugly.

Where hard stone is abundant it is excellent for edgings. In all quarries there is generally a quantity of refuse which might be used for edgings. If they are nearly the same thickness, pieces of various shapes and sizes may be used. The charm of rough stone edgings is due to their colour when clothed with small Mosses. They require no hard rigid setting, as they look much better set simply. Unlike the cast tiles they are none the worse if they fall out of line, and are easily removed and easily re-set. They are the cheapest of all edgings and give by far the best effect.

Edgings are best made of the natural stone which abounds in various counties, or of a line of flints. An edging in a garden may be beautiful by reason of dwarf rock plants being associated with it. If you have an ugly stiff tile edging, you would hardly think of putting an alpine flower near it ; but if, on the other hand, you have any good natural stone edging, it forms the most delightful place for rock-plants. If the stones are irregular in size, sink them partly in the ground, as in the case of a flint edging. You can have a whole flora of pretty plants running in and out among these stones, and spreading into gravel walk or soil. There is no difficulty in growing numbers of alpine flowers in this way. In all borders of hardy and alpine plants, a good plan is to let tufts of vigorous dwarf plants grow a little into the walk. Make the edging so that it will welcome such out-growths.

Stucco And Stone WASTE.-It is a costly folly to make a flower garden like a cemetery, with costly terracing work-where terraces are not required, and where the natural form of the earth is 
far fitter than any other form for a beautiful flower garden,- - vases, fountain basins, sculpture of the poorer sort, and lastly, pounded stones and gravel, set out instead of flowers,- - these are among the sources of great waste. The cost of all this rubbish should be laid out in good plants and good ways of growing them. The money spent on it in a single county (now and then, indeed, in a single place) would form many lovely gardens. If we ruin ourselves through extravagance in gardening, let it be for living and beautiful things.

PATENTED ARTICLES.-In this age of mechanism there are inventors who try to worry us out of our simplest, pleasantest little tasks by inventing many things that nobody wants. Stop them at the garden gate! Among the ugliest things in gardens are the remains of various too clever contrivances, rusty, useless, forgotten. At a show in London lately there was a teapot which saved the trouble of pouring out a cup of tea! Some garden inventions are as much called for as this, though it would not be fair to condemn those that really save labour, like a mowing machine. It is the invention of contrivances that instead of helping really add to our confusion that we should guard against. No contrivance should be admitted unless we know it is essential to our work. If it be ugly or showy in use, it should never be used.

RABBITS. - The most extravagant of all waste is the preservation of the rabbit. The injury rabbits do to young trees alone is incalculable; indeed, where they prevail there is no chance of getting up cover except at an enormous cost. Rabbits eat down the evergreen cover so necessary to the existence of pheasants in the way of shelter in winter. Pheasants will not remain in a wood where there is not shelter of this kind; and to nothing are they more partial than to Holly, which ought to abound in every wood, but which rabbits destroy first. Hares and pheasants many people can never have enough of, and the existence of both is directly interfered with by the rabbit, while expense is incurred year after year in making up losses in plantations, and for wire-netting and labour, etc., in protecting the trees. Hares should be encouraged at the expense of rabbits, and the extermination of the latter is not a difficult matter. Few, even among those who suffer most by their ravages, seem to know how much rabbits injure woodland, pasture, meadow, and arable land, as well as gardens.

Hungry rabbits will eat almost any green thing. As a rule they prefer to nibble over a pasture that contains short sweet grass, and a proportion of clover, dandelion, and daisies ; but in and about a wood where they are numerous the grass, from being closely and constantly eaten off, gradually disappears, and at the approach of winter is succeeded by moss, a very cold, watery, and innutritious 
substitute; then rabbits are driven to seek food from sources other than grass, and the bark of small trees, the leaves, stalks, and bark of shrubs, and the protruding roots of forest trees are eaten almost indiscriminately. Among evergreen shrubs, Rhododendrons and Box are generally avoided, but I have known newly-planted Rhododendrons to be partly eaten by rabbits. The Elder is distasteful, and so are American Azaleas. I have frequently seen Yew trees barked; Mahonias are devoured as soon as planted; and in severe weather Periwinkle, which is named amongst rabbit-proof plants, is generally eaten to the ground. Some of the bulbs and flowering plants may well escape in winter, because they are not seen above ground, but their immunity consists in their inaccessibility at a hungry time.-J. S.

All who really care for the beauty of woodland or garden should spare no effort to get rid of this pest. Those who suffer most are people in and near small estates, where "preserving" is so badly done that rabbits alone remain. Estates surrounded by farmers do not suffer so much, as the farmer must keep down the rabbits to secure his crops. Winged game of all kinds is helpful to the landowner and farmer, by reason of the insects and grubs they destroy, so that all who care for the true game should encourage them, and keep down the rabbit at all seasons.

In my Wild Garden a Scotch correspondent gives a list of rabbit-proof plants, and among these, to my surprise, I now see "Hollies." I have seen hundreds of Hollies destroyed in woods by being barked by rabbits. The one thing worth saying about rabbits is "destroy them utterly, or confine them to some waste where they can do little harm."

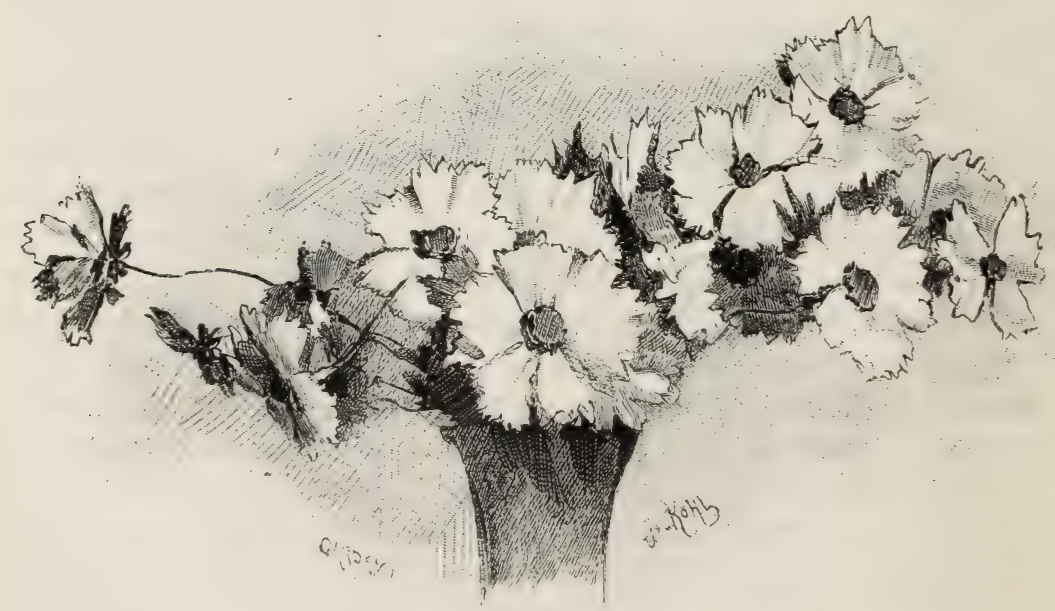




\section{ENGLISH FLOWER GARDEN}

\section{FLOWERS, FLOWERING SHRUBS, AND TREES OF THE OPEN AIR}

Abelia.-Beaụtiful shrubs, little grown in our country, and requiring either walls or favourable districts. The best known is the Rock Abelia (A. rupestris), a Chinese shrub, blooming in early autumn, the flowers borne in pairs, and of a delicate pale pink. It is always best to plant it in a raised place and in light soils, as it is then less liable to injury during winter. A. uniflora is of like habit, and also comes from China. The Three-flowered Abelia (A. triflora) comes from N. India, and is less hardy than the Chinese kinds, but it may be grown against a wall, which it will clothe in a few years. It bears fragrant pink flowers in clusters at the end of summer. A. floribunda is rather too tender for the open air, except in the mildest parts of the country. It is evergreen, and bears clusters of rose-purple flowers. Where it can be grown, it makes a good wall shrub. In mild districts in the southern parts of England and Ireland these shrubs sometimes do well on the open lawn; but, about London, do better on a wall.

Abobra viridiflora, a fragile South American twiner, belonging to the Cucumber family, of little garden value, easily raised from seed. It is graceful in habit, but does not seem to succeed in our climate generally.

Abronia (Sand Verbena).-A small genus of Californian annuals or perennials of a dwarf trailing habit, and bearing showy blossoms in dense Verbena-like clusters. Four kinds are known in gardens, viz. A. arenaria, known also as A. latifolia, a perennial having trailing stems and dense clusters of lemon-yellow flowers, with a honey-like fragrance; A. umbellata, an annual also with succulent trailing stems and clusters of rosy-purple, slightly fragrant flowers; A. fragrans, a perennial more erect in growth, forming large branching tufts from $1 \frac{1}{4} \mathrm{ft}$. to $2 \mathrm{ft}$. in height, and bearing umbels of white flowers which expand late in the afternoon, and then emit a delicate vanilla-like perfume; $\mathrm{A}$. Crux Maltæ, a pretty species with white scented flowers. A. arenaria and A. umbellata succeed best in rather poor, light, and dry soil ; in richer ground they grow too rank. The position best suited to them is one fully exposed-an open, well-drained border or rockwork. A. fragrans succeeds best in friable soil, and is larger than the others. The propagation of the species can only be effected by seed, which in favourable seasons may be obtained from A. arenaria and A. umbellata, but A. fragrans does not ripen seed in this country. The seeds often remain dormant some time before vegetating ; those of $A$. umbellata germinate more readily. The plants flower in summer and autumn, and being pretty in bloom, may be used with good effect in the varied flower garden, somewhat like dwarf Verbenas.

Abutilon.-Plants mostly requiring greenhouse temperature in winter, but growing freely out-of-doors in summer,a graceful aid in the flower garden. A. Darwini and its forms, as well as the varieties related to $A$. striata, under favourable conditions, grow from $4 \mathrm{ft}$. to $8 \mathrm{ft}$. in height. They can be made bushy by stopping, and they flower better than they do in pots. They are useful among the taller and more graceful plants for the flower garden, and are easily raised from seed and cuttings. A. vitifolia is a very handsome wall-plant in mild districts. A. Sellowianum marmoratum is a fine variety. Among the best in cultivation are the following, and new varieties are often raised: Admiration, Anna Crozy, Buisson d'Or, Darwini robustum, Darwini majus, Elegantissima, Grandiflorum, Lemoinei, Lady of the Lake, Leo, Orange Perfection, Boule de Neige, Delicata, Pactole, Darwini tesselatum, Thomsoni variegata, and vexillarium variegatum.

Acacia, False (Robinia Rose).

A. Julibrissin (Silk Rose)-with large 
and elegant leaves. By confining it to or protecting plant for choice hardy a single stem and using young plants, or Orchids and Trilliums, or such plants plants cut down every year, we get an erect stem covered with leaves as graceful as a Fern, and pretty amidst low-growing flowers. The leaves are slightly sensitive : on fine sunny days they spread out fully and afford a pleasant shade; on dull ones the leaflets fall down. Seed of A. Julibrissin - or the Silk Rose, as it is called by the Persians, in consequence of its silky stamens-is easily obtained, and it is much better raised from seed, as we get vigorous young plants which are to the flower garden what an elegant Fern is to the greenhouse. Persia.

\section{A. lophantha. - This elegant} plant, though not hardy, grows freely in the open air in summer. The beauty of its leaves and its quick growth in the open air give some graceful verdure among flowers. By confining it to a single stem and using it young, we get the fullest size and grace of which the leaves are capable. It may easily be raised from seed. By sowing it early in the year, it may be made fit for planting out in early summer; but plants a year old or so, strong and well hardened off for planting out at the end of May, are best. It would be well to raise an annual stock, as it is useful for room decoration. Australia.

\section{A. Rose (Robinia hispidia).}

Acæna.-Though not pretty in their flowers, if we except the crimson spines that give a charm to the little New Zealand A. microphylla, these plants have a neat habit of growth that renders them deserving of culture. For very dwarf carpets in the rock-garden and, now and then, to cover dry parts of borders and tufts on the margins of borders, they are very useful.

A. argentea, with glaucous leaves, is well worth a place among rock-plants.

A. microphylla (Rosy-spined Acana). - This spreads into dense tufts no taller than Moss, and in summer and autumn becomes thickly strewn with showy and singular globes of spines. It is easily increased by division, is perfectly hardy, grows in ordinary soil, but thrives much the best in soil of a fine sandy and somewhat moist character. Its home is on bare level parts of the rockwork, and it is also good as a border plant or even as an edging plant in soils where it thrives. Occasionally it may be used with a singularly good effect to form a carpet beneath larger plants not thickly placed. It would form a good ground

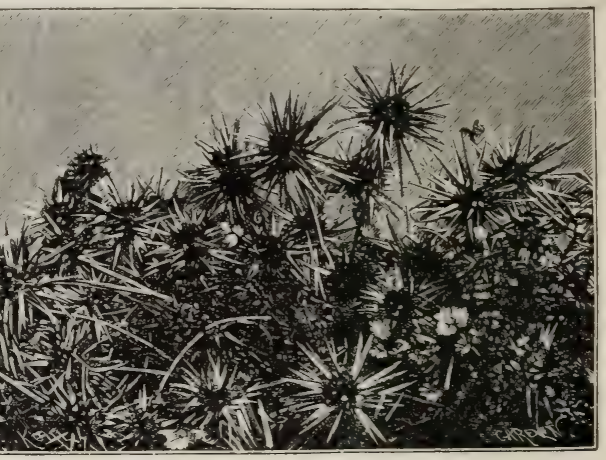

ACÆNA MICROPHYLLA.

in the bog bed. Syn.-A. Novæ-Zealandiæ.

A. millefolia is very unlike either of the preceding. It has finely-divided pale-green foliage, and is graceful for hanging down a bank. Its defect is its unsightly fruiting spikes (not heads, as in the others). Its points will adhere to anything they touch, and the result is that seedlings come up in the most unexpected spots. There are many other kinds in cultivation, such as A. ovalifolia and A. sarmentosa, but those mentioned are distinct enough and sufficiently represent the genus.

A. pulchella, though never showy in floral and fruiting characters, is worthy a place. Any soil or situation will suit it, but the best position we ever saw it in was when growing from interstices of stone by the steep side of a sunken rocky path. Its branches, rooting as they went, were covered throughout their entire length with pretty bronzy leaves, and suspended in graceful festoons over the face of the stone, even to the rocky path beneath, in wild profusion, often measuring as much as $7 \mathrm{ft}$. or $8 \mathrm{ft}$. in length, the result of little more than one year's growth. Its flowers are inconspicuous.

\section{Acantholimon (Prickly Thrift).-} Eastern plants extending from the east of Greece to Western Thibet, and having their headquarters in Persia. The flowers resemble those of the Statice and Armeria, but the habit of the Acantholimon at once distinguishes it from either of these. Acantholimons do, indeed, form branching, cushion-like tufts, somewhat after the style of Thrift; but the leaves, instead of being soft and Grass-like, are rigid and spiny. 
Culture and Position.-As known to us, they are dwarf evergreen rockgarden and choice border plants. We have had the following species for years, but have not been very successful in propagating any except $\mathrm{A}$. glumaceum, which is the freest-growing of the set ; the others are very slow-growing. Cuttings taken off in late summer and kept in a cold frame during winter make nice little plants in two years, but by layering one gets larger plants sooner. All are hardy and prefer warm, sunny situations in sandy loam. Few seem to have any idea of how much is lost by having many of our herbaceous and alpine plants in pots. There are three species in cultivation-A. glumaceum, venustum, and androsaceum, but the introduction of others is much to be desired. A. Kotschyi is a handsome species, with long spikes rising well above the leaves and numerous white flowers; A. -melananthum has short, very dense, capitate spikes, the limb of the calyx being bordered with dark violet or black; A. Phrygium is a variety of $A$. venustum, but is more robust, with longer spikes.

Acanthus (Bear's-breech). - A longneglected group of hardy plants, with singularly fine foliage and a stately habit when well grown. It comes to us mostly from the countries round the Mediterranean, and is hardy. Though the foliage may suffer now and then, the roots do not seem to perish.

Culture and Position.-The plants are not so showy for the mixed border as other perennials, but when they flower they possess a peculiar grace which more than compensates for this; and they are worth growing for their foliage alone. Their fine habit and foliage make them valuable for planting on the turf, either singly or in groups, but best in groups. The grouping should be graceful, the plants not dotted about in a geometrical manner, but irregularly, and not too close together. On rocky banks, about ruins, or on terrace gardens of the less formal kind, they look very well. They will live in shade; to flower well they should have full sun. The fine form of the leaves, and their leathery texture, have made the Acanthus much admired as a house-plant, as it is easily grown in a window, in which position we have seen it flower. These plants only require to be planted in any kind of soil in order to grow freely, but attain fair stature and their best bloom on warm, deep soil-a free sandy loam, or any deep and open soil. Clay they do poorly on, not flowering freely or at allwe mean bad clay like that in the northern suburbs of London. When placed on the lawn singly or in groups, the greatest care should be taken to give them deep, good soil. They are not difficult to increase by careful division of the roots in autumn or winter, and may be raised from seed in a gentle hot-bed, or out-of-doors with other perennials.

THE HARDY SPECIES introduced are not numerous: A. hirsutus (S. Europe); A. syriacus (Syria); A. mollis (S. Europe); A. spinosus (Turkey); A. longifolius

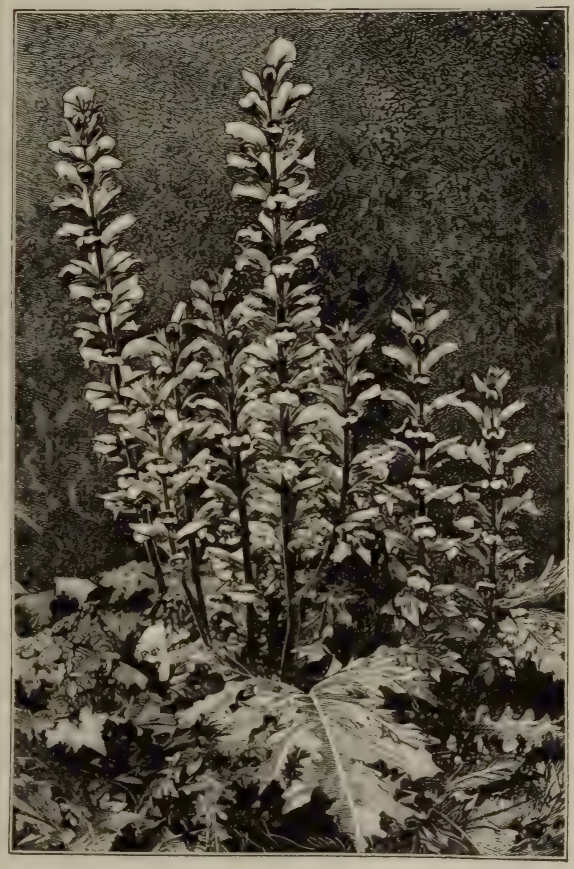

ACANTHUS.

(Dalmatia); A. spinosissimus (S.E. Europe). The fine bold kind known as A. latifolius (syn.-lusitanicus) is thought to be a variety of the oldest cultivated species, A. mollis, but as a garden plant is wholly distinct from it in size and appearance, and is more valuable. The plants vary from $I \frac{1}{2} \mathrm{ft}$. to $4 \mathrm{ft}$. in height according to the richness of the soil. When in flower in warm districts and on good soils, they may attain nearly $6 \mathrm{ft}$. in height, and in this state a good specimen is one of the handsomest of plants.

Aceranthus diphyllus.-Synonymous with Epimedium diphyllum, a Japanese species.

Aceras (Man Orchis).-A small genus of terrestrial Orchids of no garden value. Achillea (Milfoil, Yarrow)._-A numer- 
ous family of hardy plants spread through Northern Asia, Italy, Greece, Turkey, Hungary, etc., but more in Southern than in Central or Northern Europe. In the Alps and Pyrenees numerous species are found. A careful selection is very useful for garden culture. The plants vary in height from $2 \mathrm{in}$. to $4 \mathrm{ft}$. Their flowers are pale lemon, yellow, and white, but rarely pink or rose. A. Millefolium rubra is a fine plant when grown in poor soil; A. tomentosa is charming on dry gravelly soil. A. Ptarmica fl.-pl. (a double variety of the Sneezewort) is a handsome plant with snow-white flowers, but hard to keep within bounds. It should be lifted every year and replanted in clumps. Perhaps twenty varieties of this large family are available as border plants. A. Eupatorium is a noble plant, bearing very large corymbs of yellow flowers. A. ægyptiaca is, perhaps, the most graceful variety. A. pectinata is a pretty snow-white flowered plant, which should be treated as an alpine, and grown almost in gravel ; it is a native of Hungary. A. Clavennæ, a silvery Austrian species, is one of the most striking of the family. Its leaves are divided into club-shaped divisions. When planted with Trifolium rubrum or Ajuga purpurea it has a charming effect.

Culture and Position.-It is of the easiest possible culture, growing freely, and, with the exception of the dwarfer mountain species, increases even too freely in any soil. Some of the large kinds are fine plants for the choicest borders or groups, as A. Eupatorium. The alpine species, such as A. tomentosa and A. Aizoon, are well suited for the rockgarden, while the coarser, very prettygrowing white kinds, though unfit for garden culture, are strikingly effective in flower when naturalised in rough shrubberies and such places.

A. ægyptiaca may be, as the name indicates, an Egyptian plant, but is probably a native of Crete. It has beautifuily cut, white silvery leaves, and is of compact growth; the flowers are bright yellow, raised on stems about 15 in. high, and it would be a desirable plant if only for its foliage. It is hardy, and a good plant in the warm border.

A. ageratoides.-Originally introduced into the country under the name of Anthemis Aizoon. It is a dwarf, compactgrowing, silvery plant, with narrow leaves arranged in dense rosettes, with margins exquisitely crimped. The flowers are produced singly on stalks about 6 in. or 8 in. high, and are pure white, and of large size. In many respects the gem of the genus. A rock-garden plant. Greece.

A. aurea, a native of the Levant, is frequently confused with the foregoing species, but is quite distinct. Its habit of growth is tufted, not creeping. Its leaves are larger, and its flower-stems attain a height of at least $I_{5}$ in. The flowers are a golden yellow, and are produced in the autumn as well as the early summer. It is somewhat tender, and is now rarely met with.

A. Clavennæ.-A fine old plant with hoary leaves, deeply jagged at the margin. Of dwarf tufty habit of growth. Flowers white, in corymbs about 9 in. to 12 in. high. It is a native of Carinthia and the Austrian Alps. Under cultivation it loves dry sandy soil. In strong loam it rarely survives a winter without protection. A rock-garden or edging plant, and also suited for beds.

A. Eupatorium (sometimes called $A$. Filipendula) is a tall-growing, vigorous, herbaceous plant, somewhat woody in its lower growth. Its flowering corymbs are flat, bright yellow in colour, and elevated on stout stems to a height of $3 \mathrm{ft}$. to $4 \mathrm{ft}$. ; they retain their beauty and freshness for at least two months. This is admirably adapted for a shrubbery border, where its brilliant yellow flowers and its erect habit

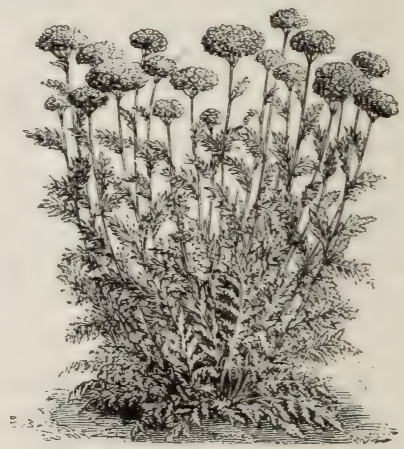

ACHILlea EUPATORIUM (CASPian MLFoIL).

of growth show to wonderful advantage amongst the evergreen foliage. It is a native of the shores of the Caspian Sea, and is one of the finest of perennials. It is very easily increased by division, and is worthy of good culture and position. It would go well with groups of the nobler hardy plants, whether deserving the name for their foliage or flowers.

A. Millefolium rosea (Rosy Yarrow) is a lovely plant with rose-coloured flowers of so deep a tint as to come near crimson. It is a strong grower, height 
$2 \mathrm{ft}$., and blooms freely. It deserves a place in every herbaceous border. There are such a number of species so closely related to the Milfoil, that it is needless to specify them. They may have a distinctive specific character, but for cultural purposes they may be taken as one.

A. Ptarmica (Sneezewort) is fairly distributed through Britain as an upland woodland plant, somewhat meagre and scattered in its native habitat, but when introduced into garden culture becoming a very showy and vigorous border plant, of some $2 \mathrm{ft}$. in height, with pure white flowers in corymbs. The double variety (A. Ptarmica fl.-pl.) is one of the loveliest white flowers we possess, and as a border plant of free growth and perfect hardiness has few rivals; it is worth a place among plants grown for cutting.

A. rupestris (Rock Yarrowe).-Among the dwarfer species this is one of the best, forming low tufts covered with pretty pure white flowers. Capital for the rock-garden or borders, growing well in poor sandy soil.

A. serrata.-A distinct species of dwarfish habit; height about 15 in.; leaves white, with adpressed hairs; flowers in corymbs, a good clear white. Alps of Central Europe. There is a double form, but it is not so good as the double Sneezewort.

A. tomentosa stands first amongst those with yellow flowers. Of creeping habit, its flower-stems scarcely exceed a height of 9 in., and its flowers are a bright yellow, produced in numbers in the month of June. Its foliage is much divided, and forms a dense carpet of bright green. Rock-garden and borders; not in wet places.

A. umbellata is a divarf compact grower of a tufty habit, scarcely exceeding 8 in. in height, the whole surface of leaf and stem being densely covered by short hairs of silvery whiteness. This peculiarity has given it an introduction into the flower garden. A neat and attractive border or rock-plant. The flowers are white, but, owing to the silvery character of the plant, they are inconspicuous. Greece.

Achlys (Oregon May Apple).-Only one species, A. triphylla, is in cultivation. It is a North American plant, belonging to the Barberry family, and of doubtful value.

Achyrachæna mollis.-An annual Composite from California; of little value for the garden.

Achyrocline-The only species, A. Saundersoni, is a small shrubby plant of the Composite family, having small leaves covered with a cottony material ; of doubtful hardiness and merit.

Acis. - A small genus of bulbous natives of South Europe, of which some three or four species are in cultivation. The best known and prettiest is A. autumnalis, a very slender-leaved little bulb, with stems rising 3 in. or 4 in. high, and bearing a couple of flowers that may be described as delicate pink Snowdrops, drooping elegantly on short reddish footstalks. They are of a deep red colour round the seed-vessel, and bloom in autumn before the leaves appear. It is a gem for the rock-garden, where it should be planted in a warm soil and a sunny position, and sheltered with a few stones, on which it would look very well springing from a carpet of delicate feeblerooting Sedum or other dwarf plant. The other kinds are A. trichophylla, rosea, and hyemalis, all of which will thrive in a fine sandy soil, but are as yet so rare as to be worthy of the best position and care. Mr. Elwes doubts if any of these plants will thrive in the open air in England. In the nurseries at Edinburgh, Acis autumnalis used to thrive in the open air in fine sandy soil.

\section{Aconite (Aconitum). \\ Aconite, Winter (Eranthis hyemalis). Aconitum (Monkshood). -An im-}

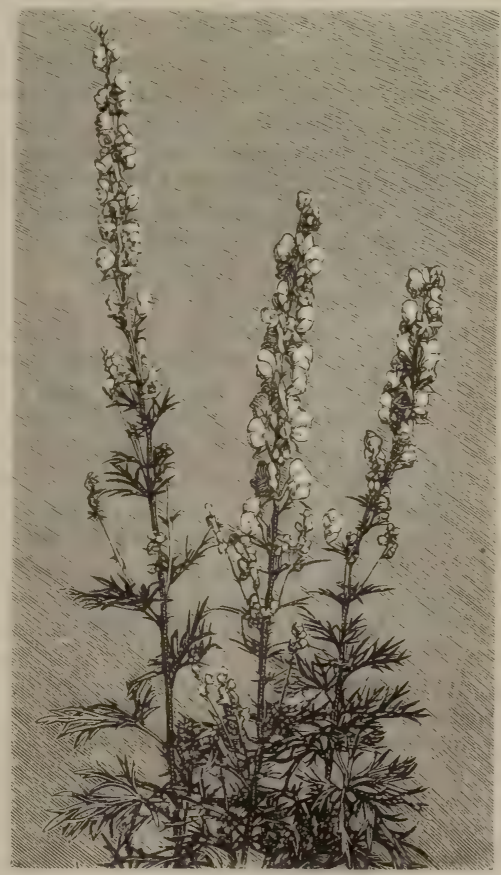

ACONITUM NAPELLUS (MONKSHOOD). 
portant family, though dangerous from its poisonous roots. There are too many names - not so many species, - and, judiciously placed, the best are of much value for our gardens.

Culture and Position.-Position is important, and few would risk their being planted where the roots could be by any chance dug up by mistake for edible roots, as they are so poisonous. Nevertheless, some of the kinds are so handsome and stately when in bloom, that they are worthy of a place beside the finest hardy plants; as, for example, the blue and white A. versicolor, which is a beautiful object in the good soil and partial shade of many a cottage garden. Almost all the kinds may be easily naturalised in copses or shrubberies away from the garden proper, or beside streamlets or in openings in rich bottoms.

The best kinds are A. Napellus and its forms, versicolor, and others ; A. chinense, A. autumnale, A. japonicum, and A. tauricum; A. Lycoctonum is a yellowflowered and vigorous species. All are tall plants, from $3 \mathrm{ft}$. to $5 \mathrm{ft}$. high; flowering from July to September. A. Fortuneî, the old chinense of gardens, is the best for late blooming.

Acorus (Sweet Flag).-A small family of waterside or marsh plants, occasionally cultivated, and of wide distribution. The Sweet Flag is fond of rather stiff moist soil, and may be planted either on the margin of water or in the water itself. Easily multiplied, like the Iris, by division. Acorus Calamus (Sweet Flag) is a marsh or waterside plant, now naturalised in most parts of Europe. A variety has gold-striped leaves, and has been called A. japonicus folis aureo-striatis. A. gramineus (Grass-leaved Acorus) is a species with a slender creeping rhizome covered with numerous Grass-like leaves, from 4 in. to $6 \mathrm{in}$. in length, a native of China and Japan. There is a variety with white-streaked leaves. This plant is often seen in the little bronze trays of water-plants in Japanese gardens and houses. The plants look pretty on the margins of fountain-basins.

Acroclinium.-A. roseum, the only species, is a pretty half-hardy annual from Western Australia. It grows over I foot high and bears pretty rosy-pink flowers, which, owing to their chaffiness, are used as "everlasting" flowers. Seeds should be sown in frames in March, and the seedlings planted at the end of April or early in May in a warm border; or the seeds may be sown in the open ground in fine rich soil at the end of April. If the flowers are desired for preservation as everlastings, it will be well to gather them when fresh and young,--some when scarcely out of the bud state. It does best in a warm sunny border, in good open and well-enriched soil. This annual might be made graceful use of in mixed beds. There is a white variety, and the two look well when mixed.

Actæa (Baneberry, Herb Christopher). -A small genus and not very important. Plants rather tall, $3 \mathrm{ft}$. to $6 \mathrm{ft}$., thriving in free soil; spikes, white and long, with showy berries which fruit freely. The white Baneberry has white berries with red footstalks. The var. rubra of $\mathrm{A}$. spicata has showy fruit; the plants are best suited for rich bottoms in the wild garden, as the foliage and habit are good. The flower is somewhat short-lived in the ordinary border, and they are somewhat coarse in habit. A. spicata (common Baneberry), A. racemosa (Black Snakeroot), A. alba (white Baneberry), having white berries with red stalks, and one or two American forms of the common Baneberry are the kinds in cultivation.

Actinella.-A small genus of North American Composite plants of which there are three kinds in gardens. They are all dwarf-growing plants with yellow flowers. The finest is A. grandiflora, a native of Colorado, a dwarf alpine plant with flower-heads $3 \mathrm{in}$. in diameter. It is more or less branched, and grows from 6 in. to 9 in. high. The other species, A. Brandiger and A. scaposa, are somewhat similar. They are all perennial, and thrive in an open warm border of light soil.

Actinidia--Climbing summer-leafing shrubs from Japan and China, little known in gardens. They do best in warm rich soil. Three species are grown now, A. Kolomikta, polygama, and volubilis. They all have climbing or twining stems and bear waxy white flowers. A. Kolomikta grows in a garden at Southampton, and the flowering specimens sent to The Garden were beautiful and distinct. This species should be grown against a wall or against a buttress or tree trunk placed against the wall, on which the stems support themselves. The leaves of A. Kolomikta are brightly tinted in autumn, and the flowers of A. polygama are fragrant. A. volubilis is free-growing and has small white flowers.

Actinomeris.-Coarse-growing North American plants of the Composite family. A. squarrosa and A. helianthoides are the kinds known in gardens.

Adam's Needle (Yucca). 


\section{Adamsia (Puschkinia).}

Adder's Tongue (Ophioglossum).

Adder's Tongue, Yellow (Erythronium anericanum).

Adenophora (Gland Bellflower).Elegant plants of the Campanula Order, not many of which are in cultivation.
Mostly from Siberia and Dahuria, and generally blue in colour. Some of the most distinct species are A. communis, A. coronata, A. liliifolia, A. Lamarcki, A. stylosa, and A. pereskiæfolia. In these occur slight variations in colour and size of flower, and in the form of the radical

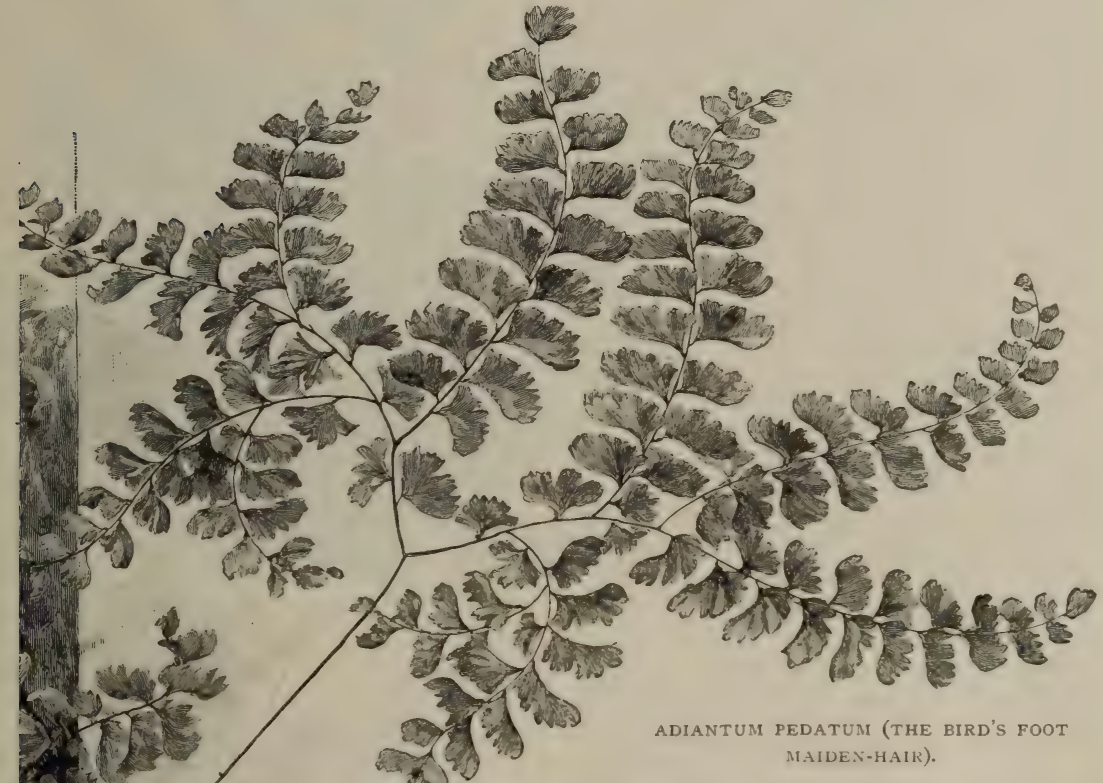

rather liberally mixed with sand and lumps of broken stone or brick. A. leaves. The thick fleshy roots of the Adenophora revel in a strong rich loam, and like a moderately damp subsoil ; they are impatient of removal, and should not be increased by division. Unlike the Platycodons, they produce their seeds freely, and the seedlings reproduce very constantly the characteristics of the parent. They vary in height from 18 pedatum, the fine American kind, might be usefully employed for forming a carpet for other shade-loving plants. It is also excellent for association in the wild garden with the more beautiful wood-flowers, such as Trillium, Hepatica, blue Anemone, and the like. The fronds rise from a creeping rhizome, and care must be taken to plant it where it is not likely to be disturbed. Like all Adiantums, it is fond of moisture while growing, but care must always be taken to provide plenty of drainage, as stagnant moisture around its roots would speedily prove fatal. A. Capillus-veneris, the British Maiden-hair Fern, succeeds best in a very sheltered, warm position; for instance, in a little nook at the foot of a shady wall, associated with some hardy plants equally moisture-loving. In such a position it ought to thrive well, and it would be easy and advisable to protect it with some portable covering during severe winters. Its native habitat is among the sheltered rocks of Cornwall, Devon, and Wales,

and in various parts of Ireland; there-

Adenostylis site plants of little garden interest. Kind in cultivation-A. Petasites, pyrenaica, and alpina, all natives of Europe.

Adiantum (Maiden-hair Fern).--Some of the species of this lovely genus of Fern are quite hardy. The soil best adapted to their growth is a rough fibry peat, 
fore some idea may be formed of the sort of climate in which it luxuriates. It has a great liking for damp, warm walls, which it speedily covers with verdure.

There are several varieties or forms of this Maiden-hair, among which Adiantum Capillus-veneris incisum is a distinct kind, found in Ireland. The pinnules of this are much more divided than those of the type. A. Capillus-veneris rotundatum, found in the Isle of Man, is also a beautiful though variable variety. The fronds are narrower and rounder than those of the type. A. Capillus-veneris Footi, a large form, which sometimes grows to I foot in height, has fronds beautifully cut and divided. The Cornwall variety (cornubiense) is a fine plant and very distinct from the others, but is as yet somewhat rare. A. C.-v. Luddemannianum is a crested variety. A. C.-v. magnificum is a fine form with an A. farleyense-like port.

Adlumia (Climbing Fumitory).-One species only (A. cirrhosa) is known. It is a rapid grower, and soon covers the object against which it is placed. Its Maiden-hair Fern-like leaves are borne in profusion on the slender twining stems, and the blossoms, which are white and about $\frac{1}{2}$ in. long, are also borne very freely. There is a variety with purple flowers (A. cirrhosa purpurea), which if grown with the type forms a pleasing contrast. It is strictly a biennial ; that is, it makes growth one year, flowers the next, and then dies, but it bears seed so profusely - the seed coming up year after year without being sown-that it may well claim to be a perennial. It is a native of North America, and was formerly known under the name of Corydalis fungosa. It requires a warm and good soil to make it worth having, and its place is trailing over a shrub or twiggy branch, placed either against a wall or in the open.

Adonis.-Plants belonging to the Ranunculus or Buttercup family. They are chiefly natives of corn-fields in Southern Europe and Western Asia, are dwarf in stature, with finely-divided leaves, and red, yellow, or straw-coloured flowers. There are about fifteen or sixteen species, most of which are annuals, and not very striking or ornamental in appearance; consequently, with the ex-

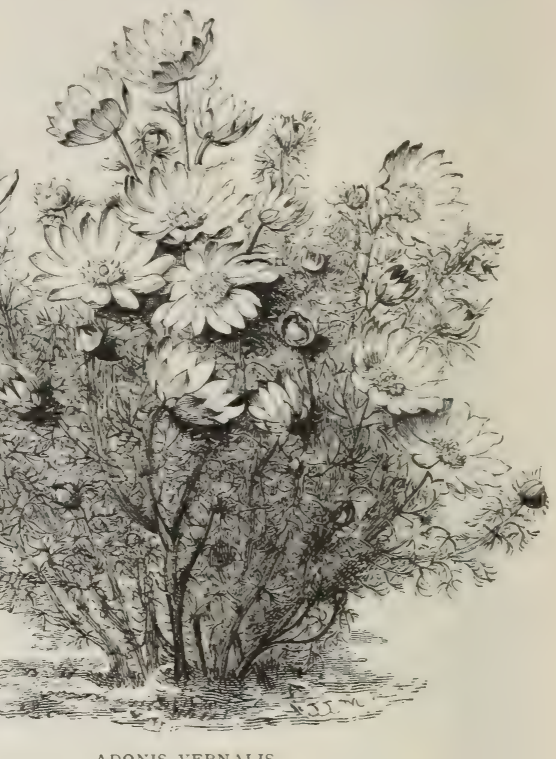

ception of two or three fine kinds, they are seldom seen in gardens.

A. autumnalis (Pheasant's-cye).-A British annual which grows I ft. or more in height and blooms at the end of summer or early in autumn. The flowers are of bright scarlet. By themselves the plants are not very effective, as they are rather straggling, but when grown in masses in borders or flower-beds with other autumn-flowering annuals, they are pretty, though the plant is not popular in gardens. May be sown in the open ground in autumn or spring.

A. vernalis forms dense tufts $8 \mathrm{in}$. to I 5 in. high of finely-divided leaves in whorls along the stems. It flowers in spring, when the tufts are covered with numerous large, brilliant yellow, Anemone-like flowers 3 in. in diameter, a single flower being at the end of each stem. Of $\mathrm{A}$. vernalis there are several varieties, the chief being A. v. sibirica, which differs from the type only in having larger flowers. A. apennina is a later-blooming form. A. pyrenaica is a fine and closely allied kind from the Eastern Pyrenees, with large deep yellow flowers resembling those of A. vernalis, but with broader petals. It flowers in April and May, and may be grown on the rock-garden and choice borders in sandy moist loam, if not often dis- 
turbed, robbed, or shaded by coarser plants. The rock-garden or a choice border of rock-plants suits the handsome perennial kinds well, and if the soil is poor it may be enriched with leaf-mould or any other decayed manure. Increased by careful division, or by seed sown as soon as gathered.

Agilops.-A small genus of Grasses allied to Triticum (the Wheat Grasses); of little garden value.

Ægopodium Podagraria (Gout Weed). -A troublesome, indigenous weed common in many gardens. It is very difficult to destroy, and the best way is by constantly digging out the roots. There is a rather pretty variegatedleaved variety which, however, soon turns green again in gardens, which partly accounts for the species being so widely spread in cultivation. No pains should be spared to root it out.

- Essculus (Horse Chestmit, Buckeve.)Mostly medium-sized trees, hardy, thriving in nearly every soil, and becoming trees as suitable for the park as for the garden. The Horse Chestnut is an exception as to size, and when well grown is a noble tree, and one of the most beautiful of flowering trees. There is at least one extremely handsome variety of it with very long spikes. The red Buckeye (A. pavia) is a very handsome small tree, with dense and large foliage, together with bright red flowers in large loose clusters in early summer. Sometimes it rises from 15 to $20 \mathrm{ft}$. high, but often not above shrub height, and some of its varieties are only low-spreading or trailing shrubs. A. humilis, pendula, arguta, and laciniata are forms of A. pavia, and the plants being of low growth are useful for grouping with taller trees. A. flava (the yellow Buckeye) is common, and sometimes $40 \mathrm{ft}$. high. It has something of the habit of the red Horse Chestnut (A. rubicunda), but has smoother leaves. It makes a dense, round-headed tree, and in good soil is of rapid growth. The loose, erect clusters of dull yellow flowers, produced in early summer, are not very attractive. A variety called purpurascens (sometimes A. discolor) has much showier flowers. They are larger, are produced more freely, and are of a reddish tint. The Esculi, named in gardens and nurseries as A. neglecta, hybrida, pubescens, Lyoni, rosea, and pallida, may be included in one of the foregoing species, and some differ but slightly from them. They are all low trees or large shrubs, coming into leaf early and losing their foliage in early autumn, especially in light or dry soils. A distinct species is the Californian Buckeye (A. californica), which in this country does not usually rise above shrub height. It has slender-stalked leaves, broad leaflets, and in early summer produces dense erect clusters of white or pinkish flowers, very fragrant. It is little known yet, but as it has proved a valuable hardy tree it will become more common. Quite different from the rest is the very beautiful A. parvifolia (dwarf Horse Chestnut), a native of North America. It is a handsome shrub, from $6 \mathrm{ft}$. to Io $\mathrm{ft}$. high, and invaluable as one of the few that flower in late summer. Fully grown, it makes a wide-spreading mass of slender stems which proceed from the suckers. Its foliage is very much like that of other Esculi, and its fragrant flowers are small and white, produced in long, erect, plume-like spikes, terminating the shoots. Its elegant growth and its attractiveness when in bloom render it one of the best of hardy flowering shrubs, and its indifference with respect to soil enchances its value. = Pavia.

Athionema.-A beautiful genus of the Arabis family, differing from the greater number of the Crucifers in light elegant habit and wiry stems, and usually glaucous leaves. It is mostly found on the sunny mountains near the Mediterranean, particularly eastward, and is especially valuable for gardens, forming stronger and more free-flowering tufts in them than in a wild state. These little plants will grow freely enough in borders of well-drained sandy loam, but their true home is the rock-garden. The tall $Æ$. grandiflorum forms a spreading bush about I foot high, from which spring numerous racemes of pink and lilac flowers. It grows well too in borders in ordinary soil ; seems to be a true perennial, and, when in flower in summer, is among the loveliest of alpine half-shrubby plants. It succeeds perfectly well on the front margin of the mixed border; and rockwork, though not required, will be a gain where the highest health of the plants is sought. In consequence of the prostrate habit of the stems, a good effect will come from planting them where the roots may descend into deep earth, and the stems fall over the face of rocks at about the level of the eye. Easily raised from seed, and thrive in sandy loam. There are many species, but few are in gardens. All the cultivated kinds are dwarf, and may be grouped with alpine plants. The best known are $\mathrm{A}$. coridifolium, pulchellum, and grandiflorum. 
Agapanthus (African Lily).-Beautiful plants from the Cape, with blue or white flowers in umbels on stems $18 \mathrm{in}$. to $4 \mathrm{ft}$. high. A. umbellatus, the old kind, is hardy in some mild seashore districts, and a fine plant in rich warm soil, but the better for protection of leaves or Cocoa fibre round the root in winter. Well
Lily. Of the best-known kind, A. umbellatus, there are several varieties; major and maximus are both larger than the type, and of maximus there is a whiteflowered variety. There is also another with white flowers, but smaller, and one with double flowers (flore-pleno). The variegated-leaved kinds, fol. albo vittatus

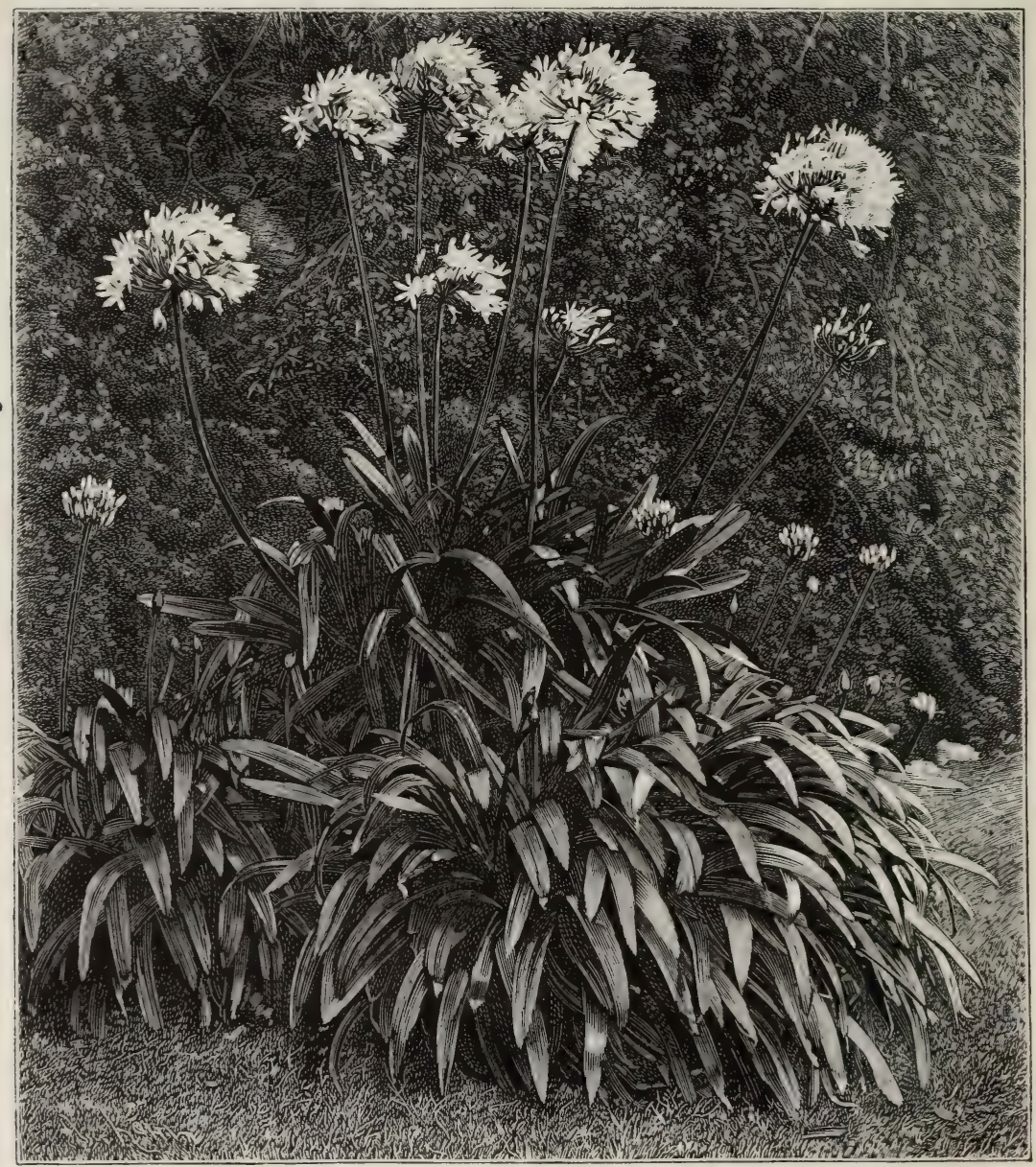

WHITE AGAPANTHUS (AFRICAN LILY).

worth growing everywhere for the flower garden and vases in summer, but should be protected in winter by storing under stages, in sheds or cellars. The fleshy roots may be so stored without potting. Enjoys plenty of water during out-of-door growth, and is easily increased by division. Various new kinds have been introduced, but their out-of-door value has not been so well tested as the favourite old African and fol. aureo vittatus, are likewise desirable for the sake of variety. These are variegated forms of A. umbellatus pallidus. Saundersonianus is a distinct variety with deeper-coloured flowers than the type.

The largest of all is the new A. umbellatus giganteus, the flower-spikes of which attain a height of from $3 \mathrm{ft}$. to $4 \mathrm{ft}$., with the umbels of flowers proportionately: large, bearing from I5O to 200 flowers. 
The colour is a gentian blue, while the buds are of a deeper hue. A. u. pallidus is a pale porcelain blue, a short-leaved variety. A. u. minor is a dwarf variety. Of A. umbellatus there is a double-flowered variety, a distinct plant. There is, moreover, A. u. atrocœruleus, a dark violet variety. A. u. maximus is a form with flower-stalks $4 \mathrm{ft}$. long, and full heads of flowers, one set opening while a second is rising to fill up the truss as the first crop fades. A. u. Mooreanus is a deciduous and hardy form; it grows from I 2 in. to I 8 in. high, has narrow leaves, and comes true from seed. A. u. albiflorus, a pure white kind, also is deciduous, the leaves turning yellow in autumn and dying off. It forms a stout root-crown.

Agathæa cœlestis (Blue Duisy).-A tender Daisy-like plant, with blue flowers, used for the margins of beds. There is also a pretty golden variegated form. Single plants or carpets of this are pretty. Cuttings or seed. It is among the prettiest of the half-hardy bedding plants, but is not effective on moist soils, or in moist districts.

Agave americana.-This and its variegated varieties are useful for placing outof-doors in summer in vases, or pots plunged in the ground, and also for the conservatory in winter. When the plant flowers, which it does only once, and after several years' growth, it sends up a flowering stem, from $26 \mathrm{ft}$. to nearly $40 \mathrm{ft}$. high. The flowers are a yellowish-green, and are very numerous on the ends of the chandelier-like branches. It will grow in winter in any moderately dry greenhouse or conservatory, or even in a large hall ; it may be placed out of doors at the end of May, and should be brought in in October. Large plants in tubs have a fine effect out-of-doors in summer. This old plant was thus used long before sub-tropical gardening was known in the land. All the varieties are easily increased from suckers.

A. Deserti, utahensis, cœrulescens, and Shawi have lately come into cultivation, and are supposed to be hardy, in which case they will be interesting for the rockgarden. North America.

Ageratum.-Tender plants, much used for the flower garden, varying in height from 6 in. to 24 in., with pale blue, lavender, or white blossoms. The dwarf Ageratums are among the best summer flower-garden plants, but the tall old kinds are as well deserving of culture as the dwarfs raised from them.

They are among the most lasting of summer bedding plants, a point in their favour being that they will withstand a few degrees of frost, and may be planted out earlier than most of the bedding plants. The flowers of all the varieties are not readily injured by rain, and do not fade in colour, but continue the same throughout the long flowering season. There are numerous varieties of varying merit, both as to flowering properties and habit, some in good soil attaining a height of $2 \mathrm{ft}$., and others not more than 6 in. The mean between the two heights will be found the best for bedding, and the variety named Cupid has not yet been excelled. Its average height is $9 \mathrm{in}$. ; it has bluish flowers of great size, well set off with bright green foliage, and flowers till severe frost clears off all bedding plants. Countess of Stair is nearly equally good, but of taller habit, and paler blue colour. Queen is also excellent, distinct in colour-a gray-blue; it grows about I foot in height, and is fine for massing, or for boundary lines to scarlet Pelargoniums. Swanley Blue is a dwarf kind, about 8 in. high; the flowers are a dark lavenderblue, and very pleasing when arranged as a belt to variegated Pelargoniums. The very dwarf kinds are disappointing ; they flower so freely, and the growth of the plants is so sparse, that they always appear stunted. For back lines in borders, or for grouping in mixed flower borders, there is no variety equal to the oldest of all, viz. mexicanum. All the kinds are easily increased from cuttings at any season. They strike best when placed on a gentle bottom-heat, and will winter in any position where there is plenty of light, and the temperature does not go below $40^{\circ}$.-W. W.

Agrimonia (Agrimony).-Plants of the Rose order, most of which are of no garden value.

A. coronaria (Rose Campion.) - A beautiful old flower, hardy and free, most at home in chalky and dry soils. It is a woolly plant, $2 \mathrm{ft}$. to $3 \mathrm{ft}$. high, with many rosy-crimson flowers, flowering in summer and autumn, and easily raised from seed. Excellent for borders, beds, and naturalisation on dry banks. It is biennial or often perishes on some soils. There is a white variety and a double red one ; the last is a good plant. The name is sometimes given to the annual Viscarias. A. Githago is a large annual, occasionally grown in botanic gardens.

\section{Agrostemma cœli rosea (Queen of} Heaven).

Agrostis (Cloud Grass).-A large family of Grasses, few of which are important in the garden. The best are the annual kinds so useful when dried and for preservation with "everlasting" flowers. 
There are some half-a-dozen annual species grown, but the best is A. nebulosa, which forms delicate tufts about I 5 in. high. Valuable for bouquets, vases, baskets, and for room decoration. If cut shortly before the seed ripens, and dried in the shade, it will keep for a long time. It may be sown either in September or in April or May. The seed, being very fine, should be lightly covered. A. Steveni, multiflora, plumosa, and pulchella require the same treatment. A. Spicaventi is very graceful, especially if it is grown as it is in the corn-fields, i.e. from self-sown seeds.

Ailantus (Tree of Heaven).-A well- rooms. Its delicate panicles give a charm to the finest bouquets. May be sown either in September or in April. South Europe. The British A. cæspitosa is a handsome plant, but too common to need culture. Aira cæspitosa vivipara, with its innumerable panicles of graceful viviparous awns, resembles a miniature Pampas Grass.

Ajuga (Bugle).-A small family of dwarf plants, flowering in spring and early summer, and having blue flowers. They are inhabitants of mountain or lowland pastures, are easily cultivated, and are readily increased by division. A. genevensis is distinguished from the Common Bugle (A. reptans) by the absence of creeping shoots. The flowerstems are erect, from 6 in. to 9 in. high; the flowers deep blue, arranged in dense whorls along fully half the stem, and forming a close spike. It is suitable for the front of mixed borders or for the margin of shrubberies, and also for naturalising. A. reptans is a native plant, flowering in early summer. The flowers are blue; there is a white variety of it, and there is also a form with variegated leaves and another with purplish ones. A. Brockbanki is a good kind; a mass of blue flowers in May. A. alpina is handsome, flowering in shady places all the summer.

Akebia. - A twining evergreen shrub from known hardy tree, young plants of which cut down every year give a good effect. The Ailantus should be kept in a young state, with a single stem clothed with its fine leaves; this can readily be done by cutting down annually, taking care to prevent it from breaking into an irregular head. Vigorous young plants and suckers in good soil will produce handsome arching leaves, $5 \mathrm{ft}$. or more long, not surpassed by those of any stove plant. Cuttings of the roots. China.

Aira pulchella.-One of the prettiest Grasses, with many hair-like stems, growing in light tufts 6 in. high. It is useful for forming graceful edgings, amongst plants in borders, or for growing in pots for
China, often grown in greenhouses, but hardy. It is a good plant for a trellis, pergola, wall, or any such place in cold districts. In southern localities it does not need this, but rambles like a Clematis. It is best to let it run over an Evergreen, as it is better protected against cold winds, which may injure its flowers. It has long slender shoots, foliage with five leaflets, and flowers of two kinds - large and small, which are produced in drooping spikes. They are claret-purple and fragrant. It grows on walls to the height of $12 \mathrm{ft}$. or more.

Alecost $=$ Costmary (Balsamita vulgaris). 
Alehoof, an English name for the Ground Ivy (Nepeta Glechoma).

Aletris (Star Grass). - The only hardy kind, A. farinosa, is an interesting dwarf perennial, forming numerous tufts, from the centre of which spring the

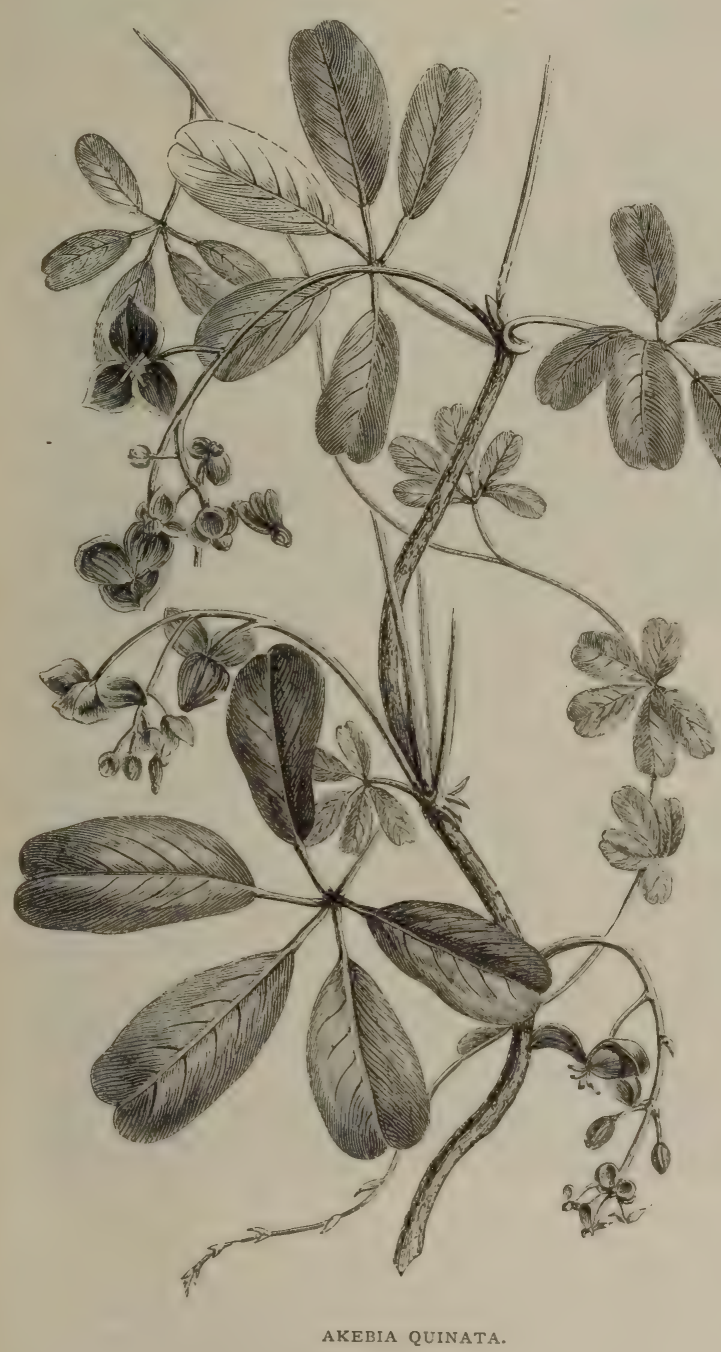

Alfredia.-A. cernua is the best-known kind. It is a Thistle-like perennial herb $4 \mathrm{ft}$. to $7 \mathrm{ft}$. high, but only suitable for planting among groups of rampant perennials of a Thistle-like and giant character or otherwise in the picturesque garden. In large places a bed or group of such plants fittingly placed in a quiet nook would have a certain charm for those who admire bold form in plants. Division or seeds. Siberia. $=$ Carduus.

Alisma (Water Plantain). -Water plants, of which two are fitted for growing with hardy aquatic plants. A. Plantago, a common waterside plant, is rather stately in habit, having broad foliage and tall panicles of pretty pink flowers. When once planted it sows itself freely. As the leaves are poisonous to animals, care should be taken as to where it is planted. The other kind is A. ranunculoides, which grows a few inches high and bears in summer an abundance of rosy blossoms. Both are adapted for wet ditches, margins of pools and lakes. A. natans is a small floating species, a pretty British plant. There are one or two Chinese kinds, single and double.

Alkanet (Anchusa tinctoria).

Alkekengi (Physalis Alkekengi).-The winter Cherry.

Allium.-Not an important garden family, and often with an unpleasant odour when crushed; but to growers of collections there are some interesting kinds, of which a few like neapolitanum, ciliatum, pedemontanum, and the American rose-coloured kinds, have some claims for their flower-stems. These are from $\mathrm{I}_{5}$ in. to 18 in. high, and on them are densely arranged pure white, bell-shaped flowers about $\frac{1}{2}$ in. in length. The outside of the blossom is much wrinkled, which gives it a mealy look. A cool and deep peaty soil, with partial shade, suits it.

Alexandrian Laurel (Ruscus racemoslis). beauty. One or two of these are worth growing for their white starry flowers. The others are mostly for the curious bulb garden, and are of easy culture in ordinary soil, the bulbs increasing rapidly. Some kinds give off little bulblets, which in certain situations make them too numerous! The following are among the kinds worthy of culture : A. 
neapolitanum, paradoxum, ciliatum, subhirsutum, Clusianum, triquetrum (all with white flowers), azureum and cœruleum (both blue), pedemontanum (mauve), Moly and flavum (yellow), fragrans (sweet-

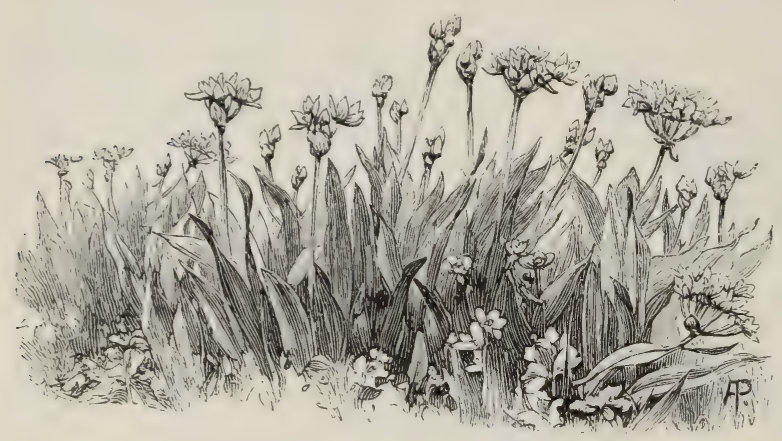

ALLIUM MOLY (YELLOW ALLIUM). height. A. incisifolia, likewise a very pretty kind; similar to this A. myrtifolia (Roezl), from $2 \mathrm{ft}$. to $2 \frac{1}{2} \mathrm{ft}$. high and of very vigorous growth, with individual flowers far larger than any other species of this genus, and of a more intense scarlet than those of A. linearifolia; A. patagonica, a pretty species from Patagonia, a free-flowering annual. It grows about 15 in. in height, and forms denselybranched, compact bushes with flowers vermilionscarlet, of fine form, and disposed in densely-set spikes. All the species are easily grown, and are susceptible of both pot and open ground culture. The seeds should be sown in March, and will flower early in July. The plants scented), oreophyllum (crimson), descendens (deep crimson), narcissiflorum (purplish), Murrayanum, acuminatum, and Macnabianum, (deep rose). These mostly grow from I ft. to 18 in. high. Some attain $2 \mathrm{ft}$. or $3 \mathrm{ft}$.

Allosorus crispus (Parsley Fern).A beautiful little Fern found in mountainous districts, its green being a pleasant shade ; the fronds grow in dense masses, and from their resemblance to Parsley have obtained for it the name of Parsley Fern. This pretty little Fern requires abundance of air and light, but should be shaded from the hot sun. When planted permanently out-of-doors some care should be shown to it in the matter of soil, drainage, and light. In the rockgarden it does well between large stones, with broken stones about its roots and its fronds just peeping out of the crevice. Growing this way it looks very well, and seems quite at home. Britain.

\section{Allspice (Calycanthus).}

Aloe.-Not of much value in English gardens out-of-doors, but very pretty and effective in temperate countries, where, in addition to their singular, and often fine forms, they have the charm of most graceful and pretty blossoms. Not to be confused with Agave.

Alonsoa (Mask-flower). - Plants mostly of annual duration. The best species are A. Warscewiczi, which grows over I foot high, and has small bright orange-red flowers; A. linearifolia, which grows from $\mathrm{I} \mathrm{ft}$. to $\mathrm{I} \frac{1}{2} \mathrm{ft}$. in height, and is bushy and compact; A. acutifolia-a slender-growing herb, I ft. to $2 \mathrm{ft}$. in may also be propagated by cuttings in the spring. A. Warscewiczi is more perennial than the rest, and more shrubby in growth, but resembles the others in flowers and foliage. As a pot plant it will flower freely from early spring until late autumn without intermission, if the roots are kept well nourished. It is rather dwarf in growth, and can be propagated at any time from February to September. The treatment given to the general stock of bedding plants during the winter season will suit this plant. The Alonsoas may be used as "ground plants" among taller plants.

Alopecurus pratensis fol. var. is a graceful golden variegated Grass, somewhat ornamental as an edging, but not so much as other variegated forms of native Grasses.

Aloysia (Sweet Verbena). - The favourite old Lemon plant. Every garden should have a bush of this fragrant plant. Its pale green foliage goes well with any flower. It is as hardy as most plants from Chili, and may be grown against a sunny wall, where, if protected by a heap of ashes over its roots and a warm straw mat over its branches, it will pass through the winter safely. When uncovered in spring, care must be taken that the young growths are not nipped by late frosts. It is increased from cuttings. It is a hardy wall plant in mild seashore districts, but not so common, owing to the cold, in inland districts. = Lippia.

Alsophila excelsa.-A tree Fern with a crest of fine fronds, a native of Norfolk Island, where it attains a height of $40 \mathrm{ft}$. 
It stands well in the open air in this country in shady, moist, and thoroughly sheltered places. It should be put out at the end of May, and taken indoors at the end of September or early in October, and receive warm greenhouse or temperate house treatment in winter. The same remarks apply to $\mathrm{A}$. australis ; and probably others of the family will be found to do in the open air, for which, however, we do not recommend them, as our flower gardens should for the most part be adorned with plants that will brave our climate. experience goes, A. Pelegrina comes nearest to it in freedom, enduring for years in favourable soils.

As regards the culture of the hybrid kinds, and the planting of all the hardy or half-hardy sorts in beds, it is useless attempting their cultivation unless the border is drained, so as to add to the warmth of the soil, and to prevent the tuberous roots from suffering from an excess of moisture. The best place is a south border, or along the front of a wall having a warm aspect, where, if the soil

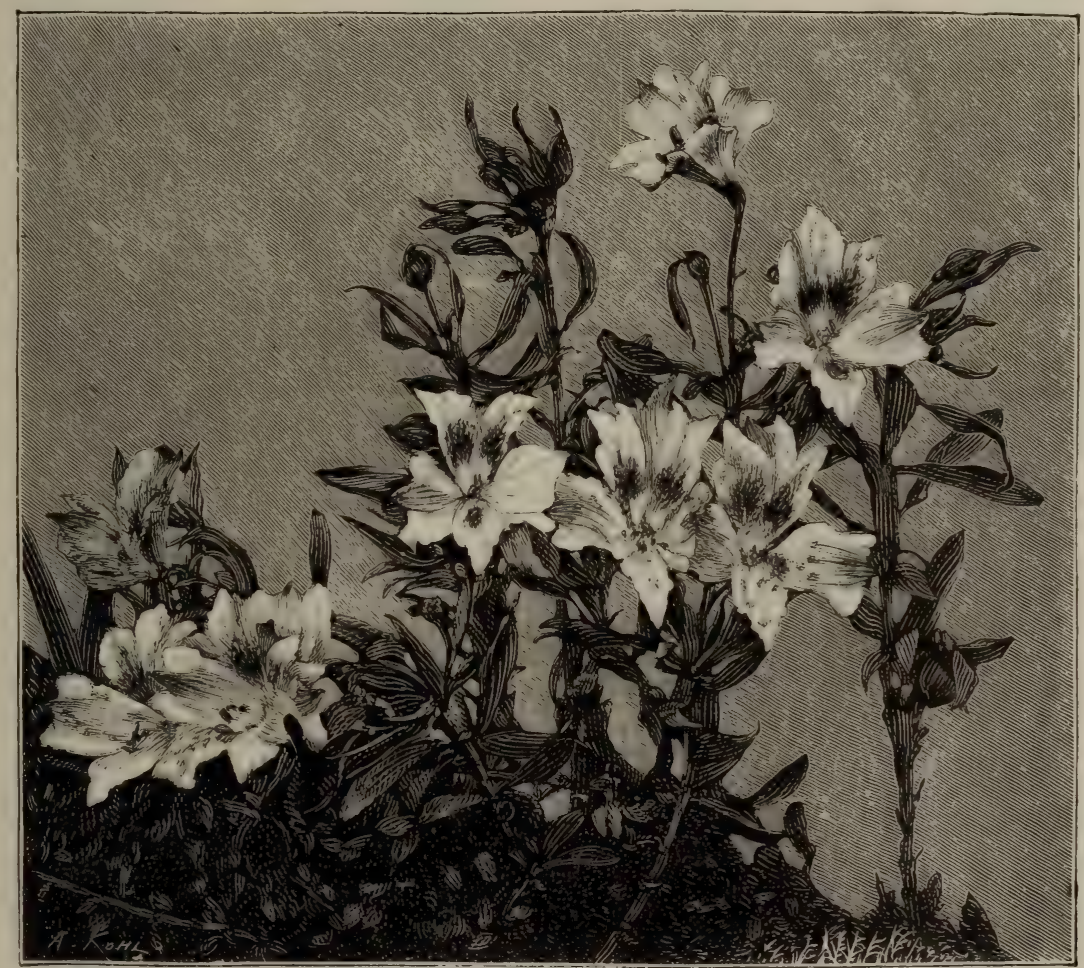

ALSTRÖMERIA (PERUVIAN LILY).

Alströmeria (Peruvian Lily).-A distinct and fine genus which has not found a home in our gardens to the extent that might be expected. Probably this arose from trying kinds not really hardy. One or two kinds, however, are as hardy and charming as any flowers on warm soil. A. aurantiaca, a handsome plant, is so free that it is easily naturalised in loose sandy soils, or even in those of a heavier nature which have been thrown up into banks. Few things are prettier than a colony of it thus grown. So far as our is not light and dry, it should be made so. Thoroughly prepare a spot at the outset. Dig out the soil to the depth of $3 \mathrm{ft}$., and spread 6 in. or so of brick rubbish over the bottom of the border. Shake over the drainage a coating of half-rotten leaves or short littery manure, so as to prevent the soil from running through the interstices of the bricks, and stopping up the drainage. If the natural soil is stiff, a portion should be exchanged for an equal quantity of leaf soil, or other light vegetable mould; with this a barrow- 
load of sand should be well mixed. The plants should be procured in pots, as they rarely succeed from divisions; and, once planted, they should never be interfered with. They should be placed in rows about $\mathrm{I} 8$ in. apart, and with $\mathrm{I} \mathrm{ft}$. from plant to plant. If planted during the winter, they should be placed from 6 in. to 9 in. deep, so as to keep them from frost; and a few inches of half-rotten leaves should be shaken over the soil. Should there be any difficulty in obtaining established plants in pots to start with, seed may be had; and this should be sown in pots or in beds where the plants are to remain.

The seeds being as large as Peas, they may be sown 2 or 3 inches deep; and, in order to ensure a regular plant, three or four seeds should be placed in a patch. If well treated, they will begin to bloom at a year old, and if not disturbed they will increase in strength and beauty every season. When grown in masses in this way they are strikingly beautiful, as every stem furnishes a large number of flowers; and as they vary much in their colour markings they make a gorgeous display. While growing and blooming they should have occasional watering, as, on account of the liberal drainage required to keep their roots healthy in winter, they would otherwise become too dry, and ripen off prematurely. A good mulching of old Mushroom dung or of leaf soil is a great assistance to them while in bloom. When going out of flower the seed-heads should be carefully removed, otherwise the plants are apt to become exhausted, as almost every flower sets; and such a load of seed should not be permitted to ripen. In removing the pods, care should be taken not to shorten the stems or reduce the leaves in any way, as all are needed to ripen the tubers and form fresh crowns for the following year. The stems should therefore not be cut down, but should die away naturally. Any one having deep light sandy soil resting on a dry bottom may grow these beautiful flowering plants without any preparation; all that is necessary being to pick out a wellsheltered spot, and to give the surface a slight mulching on the approach of severe weather. No trouble is involved in staking and tying, for the stems are strong enough to support themselves, unless in very exposed situations. They are quite worth cultivating for cut flowers, and they last long when cut.

The species in cultivation are

A. aurantiaca (A. aurea), a vigorousgrowing kind, from $2 \mathrm{ft}$. to $4 \mathrm{ft}$. high, flowering in summer and autumn. The blossoms are large, orange yellow, streaked with red, in umbels of from Io to I 5 blooms terminating the stems. Chili.

A. Pelegrina.-Not so tall or robust as the last; the flowers are larger, whitish, and are beautifully streaked and veined with purple. There are several varieties, including a white one.

A. psittacina (A.braziliensis).-Grows about $\mathrm{I} \frac{1}{2} \mathrm{ft}$. high, each stem being terminated by an umbel of from seven to nine flowers, smaller than either of the preceding, and green and deep red in colour.

"A. pulchra, Sims ; A. tricolor, Hook. ; A. Flos Martini, Kev.-These three names were also given to the same plant in the same year, but Herbert says that pulchra has priority. It is one of the most beautiful species, and though now very scarce is said to be fairly hardy. South Chili."

Alternanthera.-These plants are natives of Brazil, and tender, and can be used only in the more favoured parts of the country. Few plants produce the degree of colour and general effectiveness that these possess where they thrive. The varieties range in colour of foliage from deep purple to bright yellow, and all are most effective when used in masses, surrounded with plants of contrasting colours and similar habit of growth. The best varieties are A. paronychioides, of deep brown tipped with scarlet ; paronychioides major, of the same colour, but of more robust and broader foliage; paronychioides major aurea, with the same habit of plant as the last, but of deep yellow and red foliage, and very fine; A. amabilis latifolia has very broad foliage, of deep orange and scarlet; magnifica is much the same as the firstnamed, but has wider and deeper scarlet foliage; A. versicolor has dark purple and rose-coloured foliage, is a strong grower; A. amœna and amœna spectabilis are the brightest-coloured of all, but are most tender, and are therefore suited for only the most favoured southern districts. There are other varieties, but those named are among the best. They are all easy of propagation; in a couple of days the smallest particle will strike root in a bottom-heat of $75^{\circ}$. The quickest way to get up a large stock is to make up a hotbed of leaves and stable litter; on this place frames, and insert the cuttings firmly in about $4 \mathrm{in}$. of soil ; any kind of a light sandy nature will do. Well water them in, and keep the frame shaded and close for the first week, and afterwards give air as for other soft- 
wooded bedding plants. This plan is only intended for the spring season, as the plants should in due time be transferred from their cutting beds direct to their summer quarters. For stock plants to stand the winter, the cuttings are best inserted in 6-in. pots, plunged in bottomheat, and, as soon as well rooted, transferred to shelves in warm houses, there to remain till March, when they may be planted out on hotbeds, and will quickly produce abundance of cuttings. -W. W.

Althæa (Hollyhock).-A genus of the Mallow family consisting chiefly of coarsegrowing plants, though some, such as A. rosea, from which the Hollyhock has sprung, are showy garden flowers. There is another species, called A. Irolowiana, a tall plant with large orange and red flowers, which are very showy. The other species are generally characterised by great vigour of growth, and hence are not very suitable for the garden. They grow vigorously in almost any situation or soil. Among them A. armenaica, officinalis, narbonnensis, cannabina, and ficifolia are the best - mostly natives of South Europe ; flowering in summer and autumn.

A. rosea (Holly. hock). - One of the noblest of hardy plants, and there are many positions in almost all gardens where it would add finely to the general effect. For breaking up ugly lines of shrubs or walls, and for forming backgrounds, its tall column-like growth is well fitted. So, too, it is valuable for bold and stately effects among or near flower-beds. Cottage bee-keepers would do well to grow a few Hollyhocks, for bees are fond of their flowers.

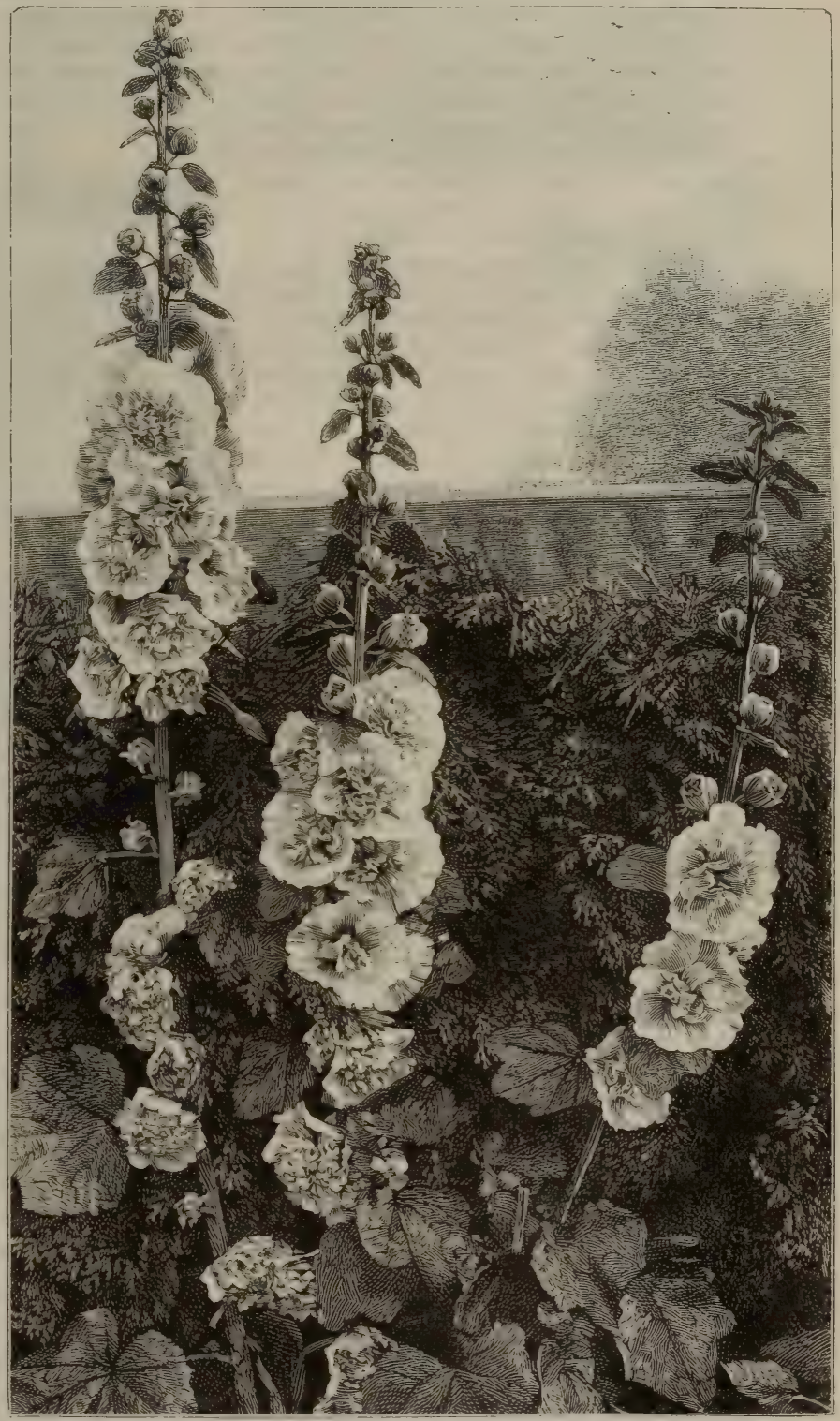

ALTHEA ROSEA (DOUBLE-FLOWERED HOLLYHOCK).
CULTURE.-Deep cultivation, much manure, frequent waterings in dry weather, with occasional soakings of liquid manure, will secure fine spikes and flowers. Hollyhocks require good garden soil, trenched to the depth of 2 
ft. A wet soil is good in summer, but in winter is injurious, and to prevent surface wet from injuring old plants left in the open ground, remove the mould round their necks and fill up with about 6 in. of white sand. This will preserve the crowns of the plants. It is best, however, if fine flowers are desired, to plant young plants every year, as one would Dahlias. Plant them $3 \mathrm{ft}$. apart in rows at least $4 \mathrm{ft}$. apart ; or if grouped in beds, not less than $3 \mathrm{ft}$. apart. In May or June, when the spikes have grown I ft. high, thin them out according to the strength of the plant; if well established and very strong, leave four spikes; if weak, two or three. When they are required for exhibition, leave only one spike. If fine blooms are required, cut off the side shoots, thin the flower buds if crowded together, and remove the top of the spike, according to the height desired, taking into consideration the usual height and habit of the plant. By topping you increase the size of the flower, but at the same time shorten its duration, and perhaps disfigure its appearance. Stake them before they get too high, tying them securely, so as to induce them to grow erect. The most robust will not require a stake higher than $4 \mathrm{ft}$. If the weather is dry, they may be watered with a solution of guano or any other liquid manure poured carefully round the roots, but not too near the stem.

The best way of showing Hollyhocks is in the form of spikes. In judging, the first point should be the individual flowers, the perfection of which consists in the petals being of good substance, the edges smooth and even, and the florets in the centre full and compact, closely arranged, high in the middle, and of a globular form, with a stiff guard petal projecting about $\frac{3}{4}$ in., or in proportion to the size of the centre ball, so that the different parts of the flower may be uniform. The next point should be the arrangement of the flowers on the spike. They should be regular, not crowded together in a confused mass, nor hanging loosely with open spaces between them, but so disposed that the shape of each, when fully blown, may be distinctly seen, the uppermost covering the top of the spike. A few small green leaves between the flowers also give an improved appearance. The third point is colour; the brightest, strongest, and most distinct should stand first, but as it is desirable to obtain shades of all kinds, anything new or distinct should be encouraged.
PYRAMID Hollyhocks,- - I am a great admirer of Hollyhocks, but I dislike their coarse and unsightly appearance a short time after the first flowers have faded, or have been reduced to a pulp by rain or strong sunshine, and also the inferiority of the terminal flowers of the spike. To obviate the last defect, I have been in the habit of cutting out the top while the

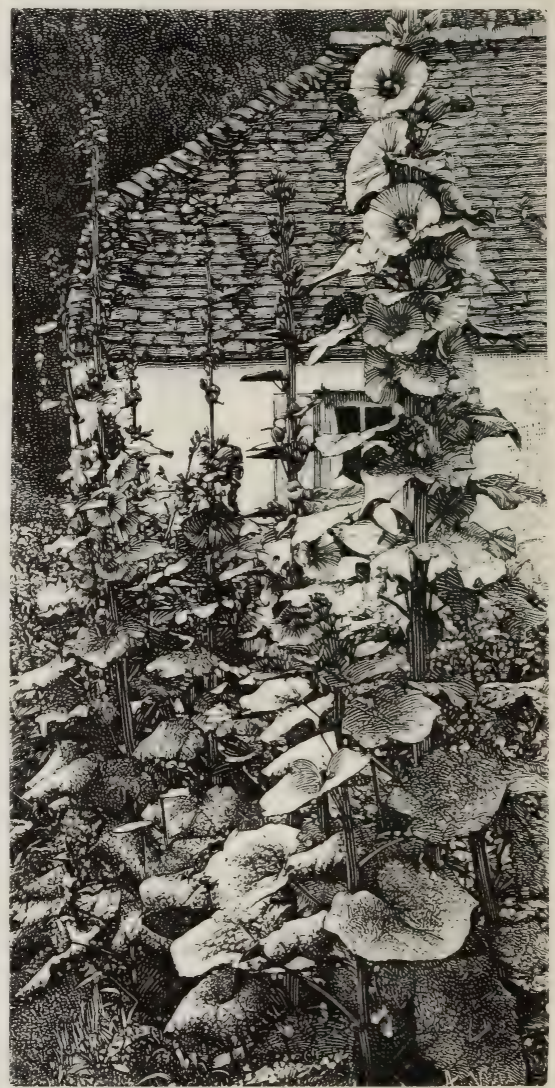

SINGLE HOLLYHOCK.

lower blooms were in perfection. Once the tops were removed before the flowers appeared, and the result was to spoil the main spike, which grew up stunted and closely packed; but to make up for the disappointment, there sprang out of every axil on the main stalk a number of shoots forming elegant and graceful branches, to the number of more than twenty on some of the plants. These were covered with perfect flowers, nicely spaced and distinct, alternating with very small leaves, and looked as if they would long continue in perfection. As these shoots grow uni- 
formly round the stem, the general outline was that of a pyramidal tree with about roo flowers expanded at once, and one may conceive the fine effect of the various beautiful shades of colour. would recommend leaving on the stool only one stalk, which can be staked and secured more easily than a great number, and will form a more elegant object than a number crowded together as usual. One of my plants is $7 \mathrm{ft}$. high, $-4 \mathrm{ft}$. across at the lower part and tapering to the top. The side shoots do not exceed $\frac{1}{2}$ in. in diameter.-W.

PROPAGATION.-Effected from eyes, cuttings, seeds, or careful division. Hollyhocks may be propagated by single eyes, put in in July and August, and also by cuttings put in in spring, on a slight hotbed. Plants raised in summer are best preserved by putting them in October into 4 -in. or 5 -in. pots in light, rich, sandy earth, and then placing them in a cold frame or greenhouse, giving them plenty of air on all favourable occasions. Thus treated they will grow a little in winter. In March or April turn them out into the open ground, and they will bloom as finely and as early as if planted in autumn. Plants put out even in May will flower the same year. If seeds are sown in autumn in a box or pan in heat, as soon as they are ripe, potted off and grown on in a pot through the winter, and planted out the following April, they will flower in the same summer and autumn. If allowed to remain in the beds or borders where they have flowered, choice Hollyhocks often perish from damp, or from snow settling round their collars, or penetrating the cavity left by the too close removal of the flowerstems. At the approach of winter, say in October, it is a good plan to carefully lift all it is desired to save, and lay them close together in a slanting direction, at an angle of about $45^{\circ}$, in a warm mellow soil at the foot of a wall or hedge, where in hard weather shelter can easily be given. But in wet, heavy soils, snow and damp have the most destructive effect. Lifting them thus not only makes them safe, but gives an opportunity of having the ground that is to receive them thoroughly worked in winter, and then, if a little rotten turf is worked in with them when re-planted in March or April, good spikes and large flowers may be expected. Choice and scarce varieties may be either potted up or planted out in a frame. Potting them is the better way, because they can be placed in a green-house or vinery, on shelves near the glass. Some of the stools will have numerous growths starting from them, and unless the plants have a little heat early in the year, many of the cuttings cannot be propagated soon enough to flower the same season. Growers in the south of England have an advantage with these spring-struck cuttings over the northern florists. There is quite three weeks' difference between the time of flowering in the south and in the northern districts of England and in Scotland. Root-grafting gives the propagator a little advantage, and early in the year the plants are propagated more readily in a light frame fixed in a heated propagating house. A hotbed is uncertain, as there is sometimes too much heat and then not enough. Although the young side shoots of old stocks will root in a gentle bottom-heat in spring, they may also be increased in July, just before the plants come into flower. The side shoots from the flower-spikes, or the smaller flower-spikes, if they can be spared, should be cut up into single joints, and dibbled in thickly in a prepared bed in a frame or pit, where they can be kept close and cared for by shading from bright sunshine, and sprinkling occasionally with water that has been warmed by standing in the sun. Nearly every cutting will then develop a bud from the axil of the leaf, rapidly strike root, and make a good strong plant by the following spring; as a rule, young plants propagated at this season give the best spikes. When cutting down the flowering stems of Hollyhocks after blooming, they should be left a good length, as they are impatient of damp about their crowns; in spring the old stems may be removed altogether.

INSECT PESTS AND DISEASES.-Red spider and thrips are both very troublesome, but the first does most injury. It appears on the under sides of the leaves as soon as the hot weather sets in, and is very difficult to dislodge. If there is any trace of red spider before planting out, the whole plant, except the roots, should be dipped in a pail of soft soapy water, to which a pint or so of Tobacco liquid has been added. It will be well to syringe the under sides of the leaves with the mixture if the plants have been planted out before the pest is perceived. Thrips may be destroyed in the same way. It is well to syringe the plants every day in hot weather.

The Hollyhock fungus (Puccinia malvacearum) is very destructive to the Hollyhock. When once it seizes a collection, probably the best way is to destroy all the plants affected. Those that do not seem to be attacked should 
be washed with soapy water, in which flowers of sulphur has been dissolved. The sulphur will settle at the bottom of the vessel, and must be frequently stirred up when the mixture is being used. Sulphur seems to destroy almost any fungus; and may destroy this in its very earliest stages; but will not move it when established.-D.

Alum Root Helucherer).

Alyssum (Madwort). - Rock and alpine plants, numerous in rocky and alpine districts, but the species resemble each other too much to make the culture of many kinds desirable. Alyssum saxatile (the Rock Madwort) is one of the most valuable of yellow spring flowers, hardy in all parts of these islands. The colour of its masses of bloom and its vigour have made it one of the bestknown plants. It is often grown in halfshady places; but like most rock-plants it should be fully exposed. It is the best of the genus, and is well fitted for the spring garden, and the mixed border, and for association with evergreen Candytufts and Aubrietias. In winter it perishes in heavy rich clays when on the level ground. A native of Southern Russia, it flowers with us in April or May. There is a dwarfer variety, distinguished by the name of $\mathrm{A}$. saxatile compactum, but it differs very little from the old plant. Alyssum montanum is a dwarf plant, spreading into compact tufts, 3 in. high, on the rock-garden in good sandy soil. Increased by division, or seeds, though it does not often seed with us. A. spinosum is a silvery little bush with white flowers. Small plants quickly become Liliputian bushes, 3 in. to 6 in. high; and when fully exposed, are almost as compact as Moss.

Among other kinds sometimes grown are A. Wiersbecki and A. olympicum, neither of which equals in habit, bloom, or endurance A. saxatile, which from its showy bloom in spring has been called Golden Tuft. The alpine and rock kinds are of easy culture in light or dry soil, as indeed are all the species. A. maritimum is the Sweet Alyssum, a small annual with white flowers useful as a carpet plant. It grows on the tops of walls in the west country, and in sandy places. In these situations it is perennial. England. Seed in spring or autumn, sowing itself freely. There is a variegated form.

Amarantus (Prince's Feather, Lovelies-bleeding).- Theold Love-lies-bleeding (A. caudatus), with its dark red pendent racemes, is a fine plant when well grown, but $A$. speciosus and some other varieties are finer. The more vigorous species grow from 2 to $5 \mathrm{ft}$. high. It is best to give them room to spread, otherwise much of their picturesque effect will be lost; and to use them in positions where their peculiar habit may be seen to advantage, as, for example, in large vases, and edges of large beds. Easily raised as any annual, they deserve to be well thinned out and put in rich ground, so that they may attain full size. The foliage of some varieties is very rich in its hues. Planted with Canna, Wigandia, Ricinus, Solanum, their effect is good. The varieties of $\mathrm{A}$. tricolor are a little more tender than the others, and require a light soil and a warmer place. They do well in gardens by the seaside. They should be sown in April in a hotbed, pricked out in a hotbed, and planted out about the end of May. The cultivated kinds embrace bicolor, tricolor, atro-purpureus. A. melancholicus ruber, a useful bedding plant with bright crimson leaves, A. Henderi, A. Princess of Wales, and A. salicifolius may be used in the summer garden with good effect. South America ; flowering in summer and autumn.

Amaryllis.-None of the species are quite hardy, but the beautiful Belladonna Lily (A. Belladona) may be grown well in the open air. It is a noble bulbous plant from the Cape of Good Hope, from $I_{2} \frac{1}{2} \mathrm{ft}$. to $3 \mathrm{ft}$. high, blooming late in summer, the flowers as large as the white Lily, and of delicate silvery rose in clusters on stout leafless stems, arising from the large pearshaped bulbs. Choose a place on the south side of a house or wall, take out the whole of the soil to the depth of $3 \mathrm{ft}$. or so, and place about 6 in. of broken brick in the bottom. Over this put some halfrotten manure to keep the drainage open, and feed the plant. If the natural soil is not good, some sandy mellow loam should be added. Should the soil be stiff, a few barrow-loads of decomposed leaf soil and one or two of sharp sand should be mixed with it. Having trod this firm, plant the bulbs singly, or in small groups if plentiful and it is desired to furnish the border quickly. Each clump should be about I foot apart, and if the border is of such a width as to take a double row, the plants in the second should be alternate with those in the first. In planting, a handful or so of sharp sand should be placed round the bulbs to keep them from rotting. If planted in autumn, or at any time during the winter, it will be well to protect the bulbs from severe weather by half-rotten leaves, Cocoa-nut fibre, or fern. The plants begin to push 
forth their new leaves, early in spring, and upon the freedom with which they send forth these during summer the bloom in the autumn depends. Once fairly in growth they should have during dry weather an occasional soaking of water, and with liquid manure once or twice. As soon as the foliage ripens off it should be removed, and the border cleaned before the blooms begin to come through the soil. A. B. blanda is a variety with larger bulbs, bearing noble umbels of
Berry). - There are two kinds of June Berry, the American (A. canadensis), and European (A. vulgaris), while the varieties one sees in gardens may be classed under either of these two. They are small trees, associating well with the Almond, Laburnum, the Cherry, Plum, and other low-growing trees. The American kinds-later in flowering-do not bear so much bloom. Of A. canadensis there are several varieties,-Botryapium, florida, ovalis, alnifolia, and sanguinea.

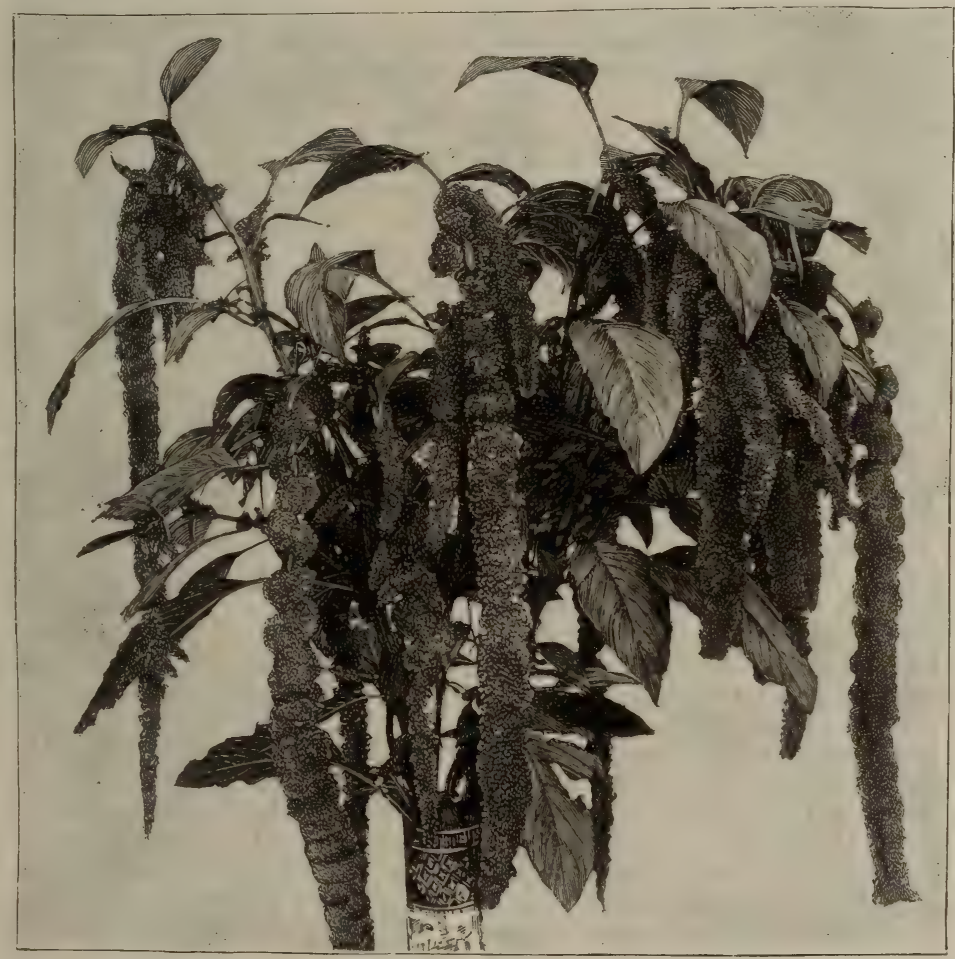

AMARANTUS (PRINCE'S FEATHER).

white blossoms, turning to pale rose, not scented, blooming in summer. There are other varieties worthy of cultivation.

A. AcRermanni is found to be hardy in various districts, and to flower well in the open ground. This suggests that other kinds grown in a high temperature are worth trial in the open air on warm borders.

Amberboa (Centaurea).

Amblyolepis setigera.-A dwarf halfhardy annual, with small heads of orangeyellow flowers sweetly scented. Compositæ. Texas.

Amelanchier (Snowy Mespilus, June
They grow freely in almost any soil, the bloom being best in sheltered places, as they bloom very early.

\section{Amellus annuus (Kaulfussia amel-} loides).

American Cowslip (Dodecatheon).

Amianthium muscætoxicum (Fly Poison).-A North American Liliaceous plant I to $2 \mathrm{ft}$. high, with a dense raceme of white flowers, which turn green with age, thriving in a moist sandy soil. Not a showy plant.

Amicia zygomeris.-A quaint greenhouse plant occasionally used in the sheltered flower garden. Mr. E. H. 
Woodall says of it: "I put it on a par (in England) with Melianthus majorgood for those who like a bold and distinct plant in a warm situation in summer, and have means to protect or take it up and pot it in winter. With me it has stood the cold, rain, and gales far better than the variegated Maize and big Solanums. The flower, though bright, is not large enough to be effective."

In warm soils in the southern counties it will grow against walls. At Kew a plant has stood against a south wall for the last seven or eight years, thriving well and flowering every year. The orange-yellow flowers are borne at the axils of the leaves. September.

Ammobium (Winged Everlasting).A. alatum is a handsome Everlasting, $\mathrm{I} \frac{1}{2}$ to $3 \mathrm{ft}$. high, with white chaffy flowers with yellow discs from May till September. In sandy soil it is perennial, but on heavy and damp soils it must be grown as annual or biennial; and among such plants it is worth a place. Seed. New Holland. The var. grandiflorum is a decided improvement on the old type, and has much larger flowers. Compositæ.

Amorphophallus.-Arum-like plants, of which one or two are used in summer in the open air. The species cultivated are A. Rivieri and A. nivosa, which require to be kept over the winter in a warm house, and put out-of-doors in rich soil at the end of May. Our country is not warm enough for them.

Ampelopsis (Virginian Creeper).Hardy and vigorous climbing plants of much value for covering walls, bowers, banks, trees, river or bluff rocks, quarries, and the like. The old Virginian Creeper is well known, and its fine colour in the autumn effective on trees and walls, though it is so free and hardy everywhere that there is scarcely any need to put it on walls with good aspect, for which there are so many choice climbers.

A. bipinnata. - Leaves bipinnate, stamping it as widely different from A. Veitchi. Much slower in growth than the Virginian Creeper (A. quinquefolia), and the decaying foliage is not so bright. U.S.A.

A. striata, unlike the others, is evergreen, and when introduced was expected to be a desirable climber, but, generally speaking, it seems to have fallen short of its early promise. It is of slow growth, and in many cases is arrested by the tips of the shoots becoming clubbed. I have not heard that it has produced here the red bright berries reported in S. America.
A. Veitchi, or tricuspidata, is useful for walls, to which it adheres closely by means of the foot-like appendages of the tendrils, instead of having to be nailed in position. It is rather slow in growing at first, but when once established it grows very freely. Two distinct types of foliage are to be found on the same plant, viz. large three-lobed leaves which appear to have nothing in common with the small heartshaped foliage that adheres so closely to the wall. If care be taken, large roots can readily be moved, though the roots are few, and are sparely furnished with fibres. Where I have moved them the plants were stripped from a wall, and when fixed in their new quarters, the stems were nailed in position; as soon as growth recommenced, the young shoots attached themselves to the wall, and before the end of the first season the plants looked as if they had been in the same position for years.

They are easy of increase, and may be struck from cuttings, and many can be raised from single eyes. A. Veitchi requires the most care, and does best when the young shoots are put in a frame during the growing season, and kept there till the following spring. It is an easy plan to layer some of the young shoots, which will root and form good little plants the first season.- $\mathrm{H}$. P.

Amsonia. - Perennials from N. America, 2 to $3 \mathrm{ft}$. high, with small pale blue or purple flowers in clusters in summer. Division or seeds. Of very little garden value, save for botanic gardens and curious collections.

Amygdalus (Almond). - The most welcome of early trees. The common sort has abundant pale pink and rather small flowers. This is the Bitter Almond (A. communis amara), and those of the Sweet Almond (var. dulcis) are very similar. The double variety (fl.-pl.) lasts longer in bloom than the single sorts. But the finest is the large-fruited Almond (A. macrocarpa), which has flowers larger than the common kind, and is also more erect in growth. The flowers are white, tinged with pink. It should always be planted in company with the others, and should have the preference, if space allows only one Almond, as it sometimes flowers before the end of February. Amygdalus nana (syn., A. Besseriana) grows from 2 to $3 \mathrm{ft}$. high, and bears rose-coloured flowers. The dwarf Almond makes a twiggy bush, which freely sends up suckers by which it may be propagated; but grafted trees I have found to quickly perish. 
Anacharis Alsinastrum (Canadian Water-weed $)$.-An American water-plant

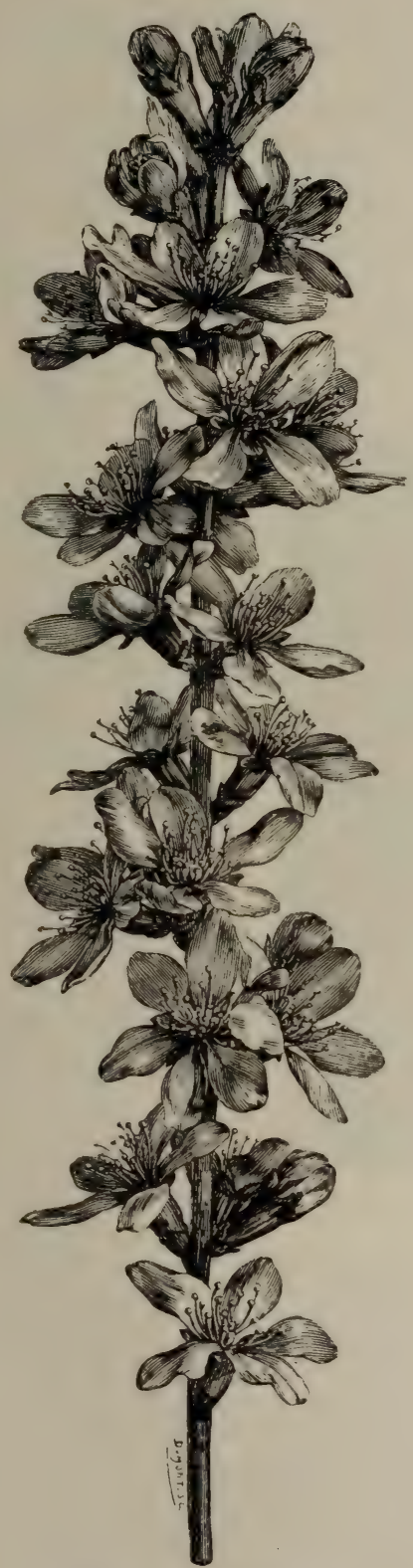

FLOWERS OF AMYGDALUS NANA.

now become a troublesome weed in lakes, rivers, and ponds. Swans eating it down is the best way to get rid of it.

Anacyclus Pyrethrum (Pellitory of Spain).-A Composite plant, native of
Syria and Arabia, the roots of which are used for medicinal purposes. For botanic gardens only.

Anagallis (Pimpernel).-The species in cultivation are chiefly half-hardy annuals; and the best-known is the Italian Pimpernel (A. Monelli), with large blossoms, deep blue, shaded with rose. There are several varieties of this plant, -rubra grandiflora, Wilmoreana, bright blue purple, yellow eye ; lilacina Phillipsi, deep blue, rose-coloured centre ; Breweri, intense blue ; Impératrice Eugénie, bright blue edged with white ; linifolia, fine blue, very dwarf; Napoleon III., maroon ; and sanguinea, bright ruby. These flower from July to September. A packet of mixed seed gives a good variety. The Indian Pimpernel (A. indica) is similar to A. Monelli, but has smaller flowers of a bright blue. It is a hardy annual, but the Italian Pimpernel is tender and should be grown as a half-hardy annual. The seed may be sown any time from March till July, the later sowings to be made in pots and put into a greenhouse or windew in autumn. Pimpernels grow well in ordinary garden soil, and are used with good effect in broad masses in borders, or edgings to beds, and make good potplants. The pretty little bog Pimpernel (A. tenella) is a native plant. It is a creeping plant, bearing slender stems with small round leaves, and myriads of tiny pink flowers. It is excellent for suspended pots or pans, and may be easily grown in the bog or a moist corner in the rock-garden.

Anchusa (Alkanet). - Borageworts, some deserving of garden culture. The finest species are :-A. italica is a vigorous plant, 3 to $4 \mathrm{ft}$. or more high, with beautiful blue blossoms. A. hybrida is similar, and probably no species of the genus better merits cultivation. It is dwarf, about $2 \mathrm{ft}$. high, with flowers of rich violet. It is biennial, and, like A. italica, a native of S. Europe. A. capensis is a pretty plant with large bright blue flowers, rather tender; it should be planted in a sheltered well-drained border. A. incarnata is a pretty plant, $2 \mathrm{ft}$. high. On the whole, the species not important as garden plants. A. sempervirens is a British species, $\mathrm{I} \frac{1}{2}$ to $2 \mathrm{ft}$. high, with blue flowers, not of great value as a border plant, but worth a place in the wild garden. Seeds or division. Flowering spring and summer.

Andromeda. - Handsome shrubs, the dwarfest of which are associated with rock-plants and hardy Heaths. Andromeda tetragona is one of the prettiest 
of tiny alpine shrubs, and seldom grows more than 8 in. high. It is a native of Northern Europe and America, quite hardy, and requires a moist peat or very fine sandy soil. It is a fitting ornament for the margins of beds of choice divarf shrubs planted in sandy peat; it loves abundance of moisture in summer, and is easily increased by division. If on the rock-garden, it ought to be in a deep bed of soil. A. fastigiata is one of the most rare and beautiful plants we have from the Himalayas. It should have sandy moist peat soil. It is most likely to thrive in moist and elevated districts; but safely planted on rock-

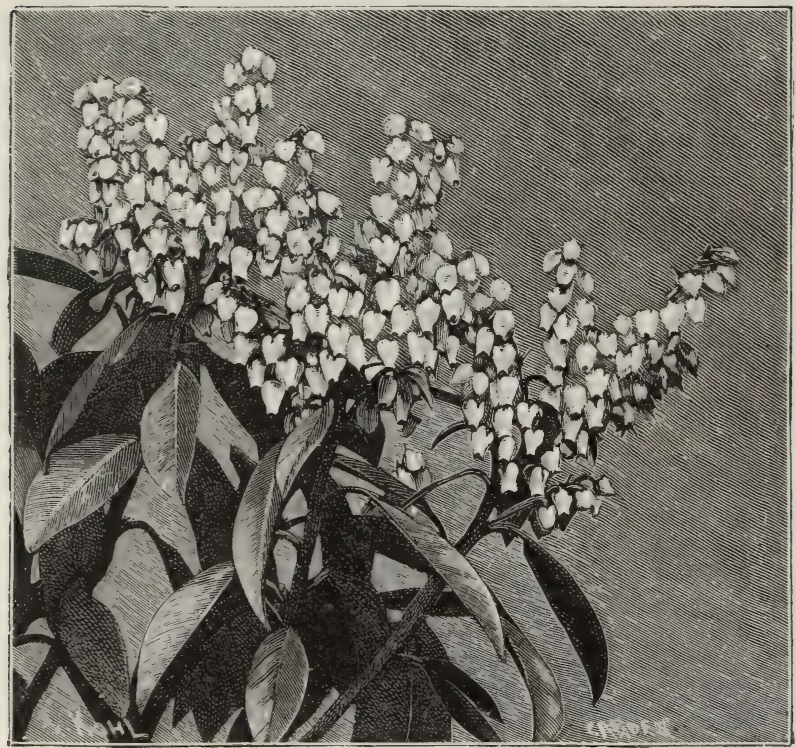

FLOWERS OF ANDROMEDA.

work in deep, moist, but well-drained soil, and carefully guarded against drought during the warm season, it may be grown. A. hypnoides is a minute Mosslike shrub, $\mathrm{I}$ in. to $4 \mathrm{in}$. high, one of the most beautiful of alpine plants, but one of the most difficult to grow, being very rarely seen in a healthy state. Drought is fatal to it. It is a native both of Europe and America, either far north in the coldest regions, or on the summits of high mountains. Carefully peg down the slender main branches, and place a few stones round the "neck" of the plant, so as to prevent evaporation. A. polifolia is easily grown in various soils, and is a good plant for the bog-garden. The dwarf Andromedas are among the plants of which the propagation is best left to nurserymen. The larger kinds, floribunda and japonica, are more easily grown and indispensable. They thrive well in the Matlock and the Edinburgh nurseries. Ericaceæ.

Andropogon.-Tall Grasses, suitable for planting singly on lawns or where their fine habit may be seen. A. halepensis is very ornamental, forming large tufts $6 \mathrm{ft}$. in height. A. strictus grows about $4 \mathrm{ft}$. high, and has graceful silky panicles of bloom. A. furcatus and A. scoparius are also in cultivation, but neither is so desirable as the others. All the kinds named thrive, provided the situation be not too exposed, or the soil too heavy and damp. They must be planted in a deep soil, well enriched and not wet. Our climate is not quite warm enough for them. A few degrees farther south they are among the best ornamental Grasses for gardens. In the Paris gardens effective use is occasionally made of them, particularly of A. squarrosus.

Androsace. - The most alpine of alpine plants. Other families, like Primroses and Hairbells, do send down representatives to the hillpastures, the sea-rocks, or the sunny heaths, but these do not. They are more alpine than even the Gentians, which are as handsome in a hill-meadow as on the highest slopes; and as Androsaces are, among flowering plants, the most confined to the snowy region, so they are the dwarfest of this class. They belong to the Primrose family and resemble it in their flowers, but even dwarf alpine Primroses are giants to these. Growing at elevations where the snow falls very early in autumn, they flower as soon as it melts. Sometimes, like some other alpine flowers, they frequent high cliffs with a vertical face, or with portions of the face receding here and there into shallow recesses. Here they must endure intense cold-cold which would destroy all shrub or tree life exposed to it. And here in spring they flower. As yet they 
are far from common in our gardens, but every lover of alpine flowers desires to possess them in good health. This is not difficult where there is a properly formed rock-garden in a pure air. They are almost sure to perish in a smoky atmosphere. Their small evergreen leaves, often downy, retain much more dust and soot than smoother and largerleaved evergreen alpine plants do. The Androsaces enjoy in cultivation small fissures between rocks or stones, firmly packed with pure sandy peat, or very sandy or gritty loam, not less than I5 in. deep. They should be so placed that no wet can gather or lie about them, and they should be so planted in between stones that, once well rooted into the deep earth-all the better if mingled with pieces of broken sandstone - they could never suffer from drought. It is easy to arrange rocks and soils so that, once the mass below is thoroughly moistened, an ordinary drought can have little effect in drying it.

A. carnea (Rose-coloured A.)-One of the prettiest alpine flowers from the summits of the Alps and Pyrenees; opening in our gardens in early spring. Known by small-pointed leaves, not in tiny rosettes, but clothing a stem like a small twig of Juniper; flowers, pink or rose, with yellow eye. It is not difficult to grow in sandy loam and peat-the spot to be exposed, and the soil deep and firm. Like most of the species, it may be raised from seed, sown in pans of sandy soil as soon as gathered; also by division. A. carnea var. examia is a large variety, likely to supersede the type, being more robust. A. brigantica resembles the variety of $A$. carnea, except that its flowers are white. The same sunny position and soil suits it; that is to say, sandy peat free from lime, well drained, but moist.

A. Chamæjasme (Rock Jasmine)- This does not nestle into close Moss-like cushions, like the Helvetian Androsace, but the foliage forms large rosettes of fringed leaves. The blooms are borne on stout little stems frequently not more than I in. high, but varying from that to $5 \mathrm{in}$. When in good health, it flowers abundantly. It is one of the best alpine plants, and easiest to grow on an open spot, in deep, well-drained light loam, nearly covered with small pieces of broken rock, to prevent evaporation and to protect the plant from injury. It should get abundance of water in summer, be fully exposed, and not be overrun by weeds or eaten down by slugs. Alps of
Europe. A. ciliata (Fringed A.) is a variety. A. cylindrica is another form, bearing white flowers in spring.

- A. foliosa is the handsomest species, and, though considered a variety of sarmentosa in the Indian Flora, is as distinct from that species as A. lanuginosa. The flowers are borne in large bunches; rosy-red, and larger than the others. Leaves broad, ovate, and pointed. Easily struck from cuttings. A charming hardy rock-plant. Flowers May and June. Himalayas.

\section{A. helvetica (Swiss A.) forms dense}

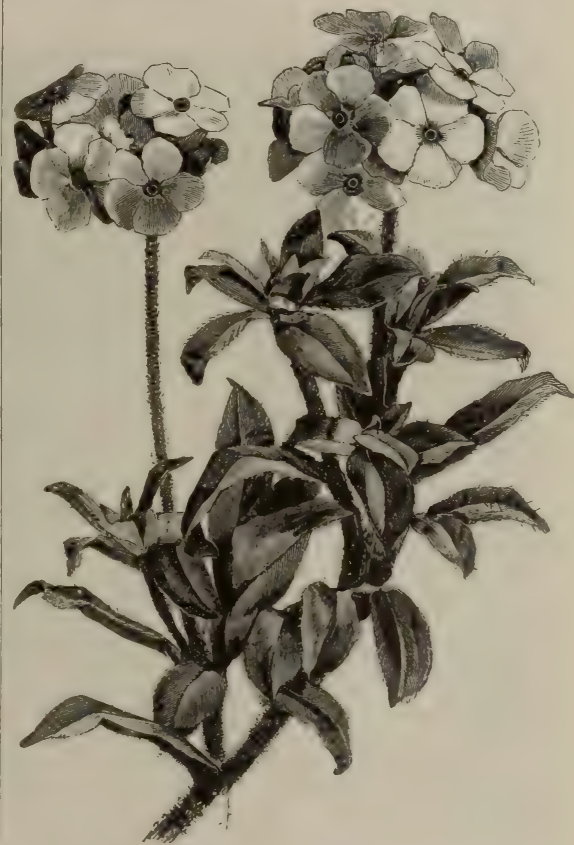

FLOIVERS OF ANDROSACE LANUGINOSA (HIMALAYAN ANDROSACE).

cushions, about $\frac{1}{2}$ in. high, of small leaves, tightly packed in little rosettes. Each rosette rests on the summit of a little column of old and dead, but hidden and half-dried leaves. A white flower, with a yellowish eye, rises from every tiny rosette, each flower being almost twice as large as the rosette. Requires care, exposure to sun, and a position well drained, but not dry.

A. imbricata (Silvery A.) differs from the Pyrenean and Swiss Androsaces in having rosettes of silvery white. The pretty white flowers rest so thickly on the rosettes as often to overlap each other. It grows freely in rich loamy soil in narrow well-drained fissures of rock. 
Pyrenees and Alps, flowering in summer. Seeds and division (A. argentea.).

A. Laggeri.-This little gem is one of the most distinct of the family, and is easily recognised by its tiny rosettes of sharp-pointed leaves. Pyrenees Alps, flowering as soon as the snow is melted. A lively pink, with the centre lighter.

A. lanuginosa (Himalayan A.), with spreading and long-trailing shoots, and umbels of flowers of a delicate rose, the leaves covered with silky hairs. When grown well it is a lovely plant. Some parts of the country are too cold for it, and warm places near the sea are where it is its rather large solitary white flowers, with pale yellow eyes, just rising above the densely-packed, slightly hoary leaves, covered with star-like hairs. The buds look like pearls set in a tiny cup, and are held on stems barely rising above the dwarf cushion formed by the plant; flowering in July and August in its native state, and in our gardens in spring or early summer. Grows in sunny fissures in deep sandy peat. Alps.

A. pyrenaica (Pyrenean A.)-Like the Swiss Androsace, but the white flowers with yellowish eyes are not quite so well formed, and the flower, instead of being

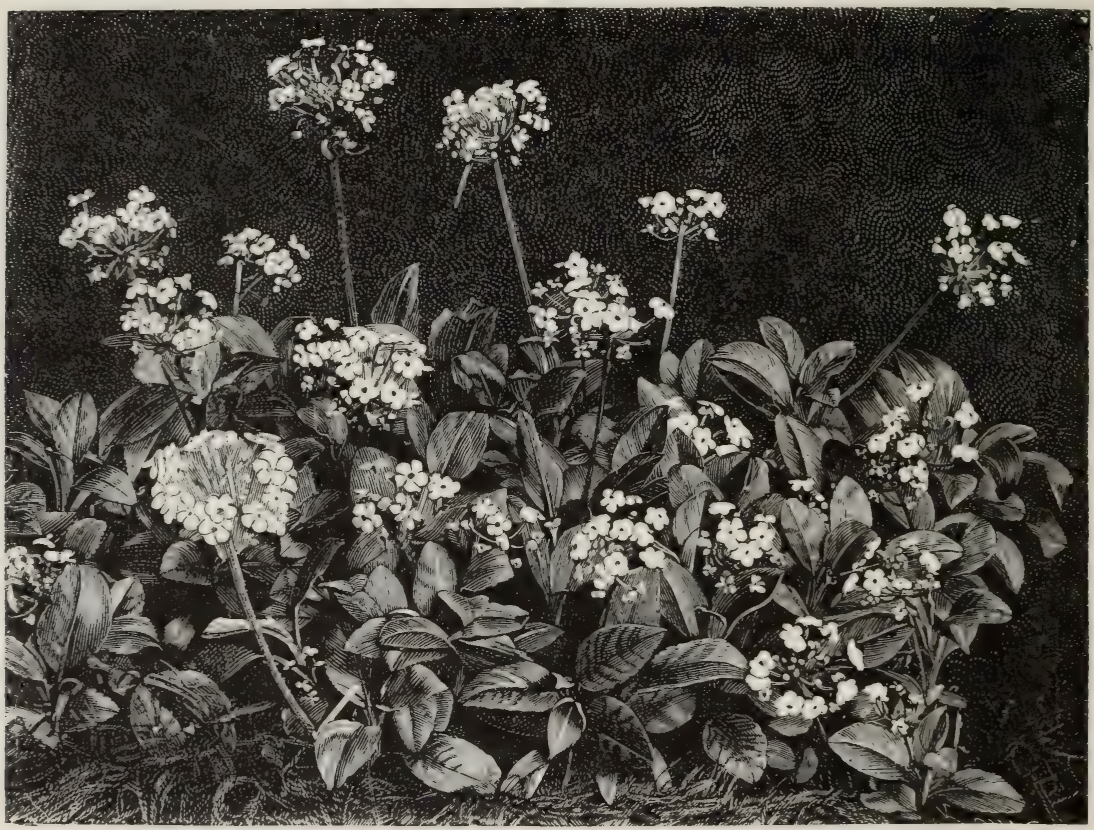

ANDROSACE FOLIOSA.

happiest. The best place for it is on the rock-garden, in sandy loam. Where the soil is free, and not wet in winter, it thrives as a border plant. It forms beautiful tufts on sandy borders in the College Gardens at Dublin. Cuttings. Flowers from June to October. Himalayas.

A. obtusifolia (Blunt-leaved A.)Allied to A. Chamæjasme, but has larger rosettes of leaves, and from two to five white or rose-coloured flowers with yellow eyes. It is more vigorous than A. Chamæjasme. European Alps. Culture the same as A. Chamæjasme.

A. pubescens (Downy A.).-Allied to the Swiss and Pyrenean Androsaces in seated in the rosettes of leaves, rises on a stem a quarter to half an inch high. In fissures between rocks, with deep firm rifts of sandy peat and loam in them. It will also grow on a level exposed spot, but in such a position should be surrounded by half-buried stones.

A. sarmentosa.-From the Himalayas, and at elevations of over I I,000 ft. The flowers are borne in trusses of ten to twenty, and at first sight resemble rosy white-eyed Verbena. Like many other woolly-leaved alpines, this is difficult to keep alive through our damp winters. A piece of glass in a slanting position, 
about 6 in. above the plant, preserves it. Care should also be taken to put sandstone broken fine immediately under the - rosettes of leaves and over the surface of the soil to keep every part of the plant, except the roots, from contact with the soil. A dry calcareous loam is best.

A. villosa (Shaggy A.)-A dwarf kind on many parts of the Alps, with leaves covered with soft white down. It spreads more than any of the nearly allied sorts, as it throws out runners. It should be planted in loam and a mixture of peat, in a fissure between stones, or on level spots with abundant moisture. In our gardens, flowers in May. Seeds.

A. Vitaliana (Yellow Androsace). Rarely above $\mathrm{I}$ in. high, and bears, scarcely above the leaves, rich yellow flowers, very large for so small a plant. It is lovely for association with dwarf Gentians, Primulas, in the rock-garden, and may even be grown on a border in a district not too dry where the soil is open. It should be kept moist during the dry months; and when tried on the level ground, as a border plant, it should be surrounded by stones, half-plunged in the ground, to prevent evaporation, and to save it from being trampled on. Abundant on the Alps, and increased by careful division, or by seeds. Androsace Heeri, bryoides, Charpentieri, Wulfeni, and Haussmanni are other kinds, and there are one or two annual and biennial kinds not of much value for the garden, except A. coronopifolia.

Androstephium.-N. American bulbous plants, about which little is known in this country. The kinds are breviflorum, flowers violet, borne in umbels of four to seven, in early spring; A. violaceum, a rare and showy species from Texas, 6 in. to $8 \mathrm{in}$. high, flowers violet, in umbels, slightly fragrant.

Andryala.-Small plants of the Dandelion order; some with woolly leaves. A. mogadorensis, shrubby, forms snowy masses on a little islet on the Morocco coast, and has not been found elsewhere. It bears flowers as large as a half-crown, of a bright yellow, the disc being bright orange. Little is known of its culture and hardiness. A. lanata has woolly silvery leaves, which make it useful in some arrangements. It grows well in any soil not too damp.

Anemiopsis californica.-A North American plant of little garden value.

Anemone (Windflower). - A noble family, to which is due much of the beauty of spring and early summer in northern and temperate countries. In early spring, or what is winter to us in Northern Europe, when the valleys of Southern Europe and sunny sheltered spots all round the great rocky basin of the Mediterranean are beginning to glow with colour, we see the earliest Windflowers in all their loveliness. Those arid mountains that look so barren have on their sunny sides carpets of Anemones in countless variety. These belong to old favourites in our gardens - the common Windflower (A. coronaria) and the Peacock Anemone. Later on the Star Anemone (A. stellata) begins, and troops in thousands over the terraces, meadows, and fields of the same regions. Climbing the mountains in April, the Anemone hepatica nestles in nooks all over the bushy parts of the hills, and later on springs from the snow in the Swiss Alps to welcome the early traveller. Farther east, while the common Anemones are aflame along the Riviera valleys and terraces, the blue Greek Anemone (A. blanda) is open on the hills of Greece ; a little later the Apennine Anemone (A. apennina) blossoms in Italy. Meanwhile our Wood Anemone adorns the woods and copses throughout the northern world, and often, too, open ground, ascending to high treeless places on the mountains; and at the same time the open begins to show the purple of the Pasque-flower (A. Pulsatilla) here and there through the brown Grass. The Grass has grown tall before the graceful Alpine Windflower (A. alpina) flowers in all the natural meadows of the Alps; as soon as its large flowers are succeeded by long silky heads of fruit, the snow is melting from off the high Alpine Windflowers, which soon flower and fruit, and are ready to sleep for nine months in the snow. These are but few examples of what is done for the northern and temperate world by these Windflowers.

Anemone alpina (Alpine Windflower). -On nearly every great mountain range in northern climes this is one of the handsomest plants, 18 in. to $2 \mathrm{ft}$. high. It is a slower plant in gardens than most of the other kinds. Vigorous, it should have deep soil. Where the soil is good it grows freely as a border plant. Flowers in its native countries as the snow disappears, and in our gardens at the end of April or beginning of May. Plants established may be taken up and divided; it may also be raised from seed. One form, A. sulphurea, has yellow flowers.

A. angulosa (Great Hepatica). - - Larger than the common Hepatica, with sky-blue flowers as large as a crown-piece, and known by its five-lobed leaves. It is a 
hardy native of Transylvania, enjoying partial shade. In rock-gardens, or near them, it will be easy to give it a home ; and it will succeed in spaces between choice divarf shrubs in beds; may be used as an edging to beds of spring flowers, and for open, bare, and unmown spots along the margins of wood walks. Seed and division.

A. Apennina (Apennine II indflower).Although figured in most works on British plants, and naturalised in various places, it is not a true native, but our hardiest native plants take not more kindly to our clime. It is one of the sweetest of spring flowers, and among the many lovely leaves, and blooms in early spring, during mild open winters, and in warm parts coming early. It should be grown in every rock-garden, and planted on banks that catch the early sun; it should adorn the spring-garden, and may be naturalised in Grassy places. Distinguished from A. apennina by carpels topped with a black-pointed style, and by round and bulb-like roots. Division and seed. Greece.

A. coronaria (Poppy Anemone).-One of the most admired flowers of our gardens from earliest times. There are many varieties, single and double. The single sorts may be readily grown from

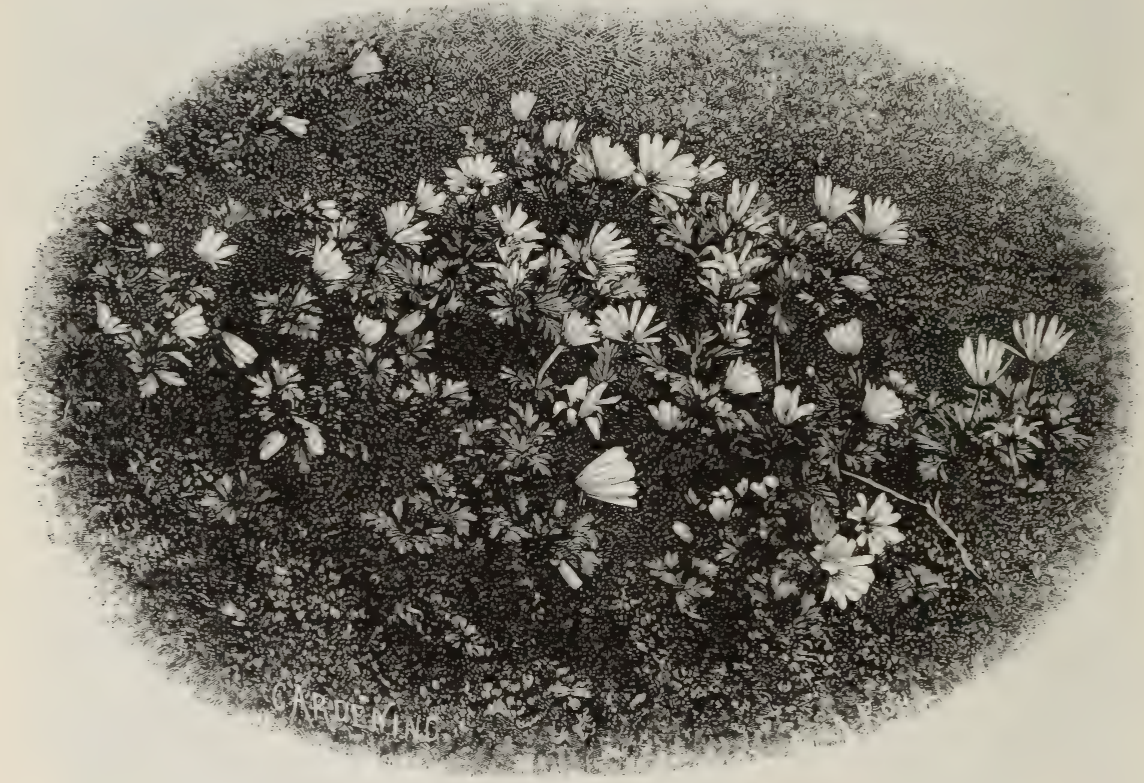

ANEMONE BLANDA (BLLE GREEK WINDFLOWER)

plants that gem the mountain pastures there is not one more worthy of being naturalised. It is welcome in the garden, but it is when we see it scattered among the native Anemones in our woods, or making pictures with Daffodils, or running free among dwarf plants in groves, that this Italian plant adds a new charm to our spring. Flowers in March and April, readily increased by division, and grows about 4 in. to $6 \mathrm{in.}$ in height. Italy.

A. blanda (Blue Winter Windflower). -A lovely plant, worth a place in every garden. It is of a deep sky-blue, like A. apennina, has larger and more finely rayed flowers, dwarfer, harder, and smoother seed sown in the open air in April. Infinitely varied in fine colour, they deserve to be cultivated, even more than many of the doubles. The planting of these double varieties may be made in autumn or in spring, or at interváls all through the winter, to secure a continuity of flowers; but the best bloom is secured by September or October planting. The Poppy Anemone thrives in rich deep loam, but is not fastidious. The roots of the more select kinds may be taken up when the leaves die down, but they are seldom worth this trouble, as many fine varieties may be grown from seed. If the seed be sown in June, and the plants pricked out in autumn, they will flower 
very well in the following spring, so that the plant is as easily raised as an annual. It flowers in April and May, and often through winter, red, white, and purple in variety, from 6 in. to 18 in. high. Propagated readily by seed or division. Apart from the old fiorists' or double Anemones and the single ones, there are certain races of French origin of much value - the Anemones de Caen, for example. These are raised from the same species, but are more vigorous and have larger flowers than the older Dutch kinds. Of the Caen Anemones there are both single and double kinds. The Chrysanthemum-flowered are another fine double race. The fine variety of the Poppy Anemones leads to mixed collections being much grown. While it is well to plant mixtures now and then, it is better to select and keep true some of the finer forms in any desired colour. A fine searlet, purple, or violet should be grown by itself and for itself; in that way the Poppy Anemone will be a greater aid to the garden artist. All kinds thrive in garden soils of fair quality, and, like most plants, repay manuring.

SEEDLINGS. - The following method will enable any one to raise these in a moist loam. To save time, I sow as soon as the seed is ripe, selecting it from the brightest flowers only. First, pains must be taken to separate the seed thoroughly. Spread a newspaper on the table, pour over it a quart of sand, dry ashes, or fine earth; sprinkle the seed over this, and rub the seed together till its separation is complete. The seed bed need not be larger than $3 \mathrm{ft}$. by $9 \mathrm{ft}$. Choose the sunniest part of the garden. Make the surface fine, tread it down, and give it a good watering. Wait until it is dry enough to scratch with a fine rake; then sow broadcast, covering the seed with a very thin coat of very fine earth, about the thickness of a shilling; beat flat with a spade, and give a light sprinkling of water. Now comes the most important point. Never let a ray of sunshine reach the bed ; cover it with newspapers, spreading a few Pea sticks or something to retain the covering in its place. Keep the surface of the bed moist. In about twenty days the young plants will begin to appear; when all seem up, remove the covering, and they will need no further care except watering. If the bed once gets thoroughly dry, the plants are apt, after forming small bulbs about the size of Peas, to stop growing, the foliage to die, and the bulbs to lie dormant for months; but if kept well watered through the summer, they will go on growing through the winter, and begin to blossom the following spring. The seedlings may be left to blossom where they are sown, or be transplanted in September or October.-J.

Culture of the Choicer Sorts.Although all the beauty of the Poppy Anemone in its brilliant variety of colour may be enjoyed by simple culture, especially in good or warm soils, it is desirable to describe what is considered the best way of growing the finer and named varieties, which have been favourite florists' flowers for a long time. Messrs. Vilmorin and Andrieux, writing to me from Paris (Sept. I88I), say that the growth "of the Anemone as a florists' flower in France is of ancient date. The

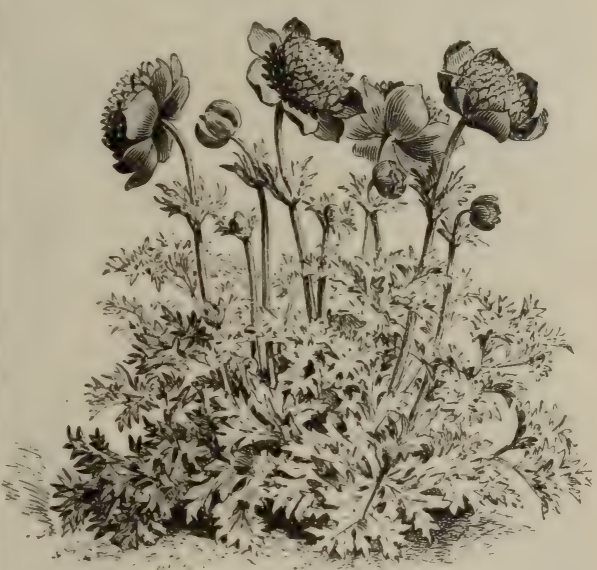

ANEMONE CORONARIA (DOUBLE-FLOWERED).

finest were known to come from Caen and Bayeux, nearly Ioo years ago, and it is there that the best in France are now cultivated." There is no better soil than a yellow, gritty, and friable loam ; but though there is in most gardens little or no choice, the choicest Anemones may be well grown in ordinary garden soil of fair quality, enriched with decayed leaf-mould or cow manure. In the more loamy soils old hot-bed manure will do. In some very heavy clayey soils the cultivation of the plant is not successful.

PLANTING.--The florists of past years had two seasons for this: the middle of October, and the end of January. "The early vegetation of such roots as are left in the ground shows that early autumn is the most natural season. Octoberplanted tubers make stronger plants, throw up more flower-buds, bloom earlier than those planted in spring. The draw- 
back is that the blossoms expand before the frosts have ceased, and hence some protection is necessary." It was generally held that a bed planted the first week in October would be in bloom about the second week in May; and as this is often a time of severe frosts, the blossoms are injured if not protected. It is important to remember that the best bloom is always from autumn-planted roots; the double ones should be planted in September in a sunny situation if possible, and even early in the month. It may be best for large growers to plant at several different times, particularly in the case of the single and semi-double kinds, but the glory of the plant is as a brave spring bloomer, and we do not gain by forcing from its natural season.

"Right planting of the choice kinds is important. A bed of prepared earth should be made; it matters not where the position is, so long as the subsoil is well drained. A stagnant soil is hurtful to the Anemone, which roots deeply, and the soil should be some 18 in. deep. During planting, the bed should be raked level, and marked in cross rows. Mr. Carey $\mathrm{T}$ yso recommends a bed $3 \mathrm{ft}$. $4 \mathrm{in}$. in width, with five roots in a row, so that each may be 6 in. or 7 in. apart. "As the tubers are varied in form and size, the hand or a trowel should be used in making the holes 2 in. deep, and large enough to allow the root to rest evenly on the soil, avoiding much pressure, as the limbs of the tubers are easily broken off." Tubers vary much in size and shape, according to the variety, and are "formed of irregular fleshy bunches, having a number of small protuberances called crowns. These crowns are obtuse points, often a shade darker in colour than the surrounding skin. They are in clusters near the centre, and sometimes singly at the extremities of the projecting limbs. As amateurs have been known to plant the crowns downwards, some attention is needful. The direction to plant the right side upwards seems trite, but is not superfluous."

In the days when the Anemone was more of a "florists" "flower than it is now, it was usual to spread over the bed 2 in. of half-decaved leaves for a protection against frost. The florist dreaded the effects of frost on his Anemones, Ranunculus, and Tulips.

Thinning the flowers was done with advantage when the Anemone was an exhibition plant; some flowers became blind, or were without the complement of centre petals that give symmetry to the double forms, and such were pinched off to strengthen the rest. Weeding and watering are important. On the rich soil weeds grow with vigour: they must be plucked out, and the bed kept stirred and tidy. Water should be given freely in dry weather, a good soaking at a time. When the plants show signs of ripening at the end of July, or in August, the roots should be dug up, put into boxes with some soil attached to the roots, and put away in a cool dry place for planting out another season. The roots should be looked over occasionally during the winter.

NAMED POPPy ANEMONES. - The Dutch growers send us every year collec-

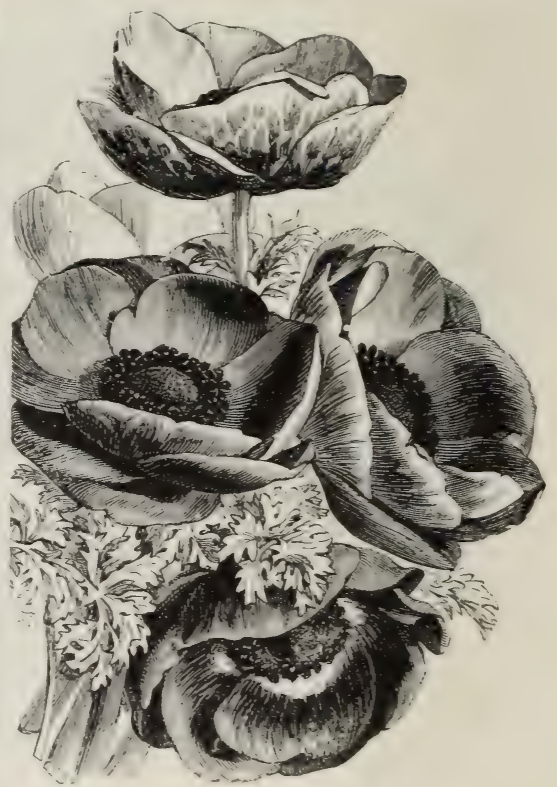

SINGLE POPPY ANEMONES.

tions of named varieties, both double and single. The old double and single scarlet Anemones are vivid in colour and beautiful, and there are also the double and single blue. Those who do not care for named varieties can have mixtures - the double forms by themselves, and the single ones by themselves. The Dutch growers evidently think the double more important than the single varieties, as in their lists the double varieties are much more numerous than the single forms, and each raiser has his own list of named flowers. Lists of these will be found in bulb catalogues.

What are termed French Anemones are thought an improvement on the Dutch, 
with large flowers of brilliant and varied colour; the plants vigorous.

Poppy Anemones, double and single, are useful for edgings and for the decoration of borders either singly or in tufts. They are cultivated alone in beds or in clumps in borders, and answer well for planting under standard Rose Trees or other light and thinly planted shrubs. The flowers cut when just open and as buds keep long in water.

A. fulgens (The Scarlet Windflower).A native of the south of France, over a

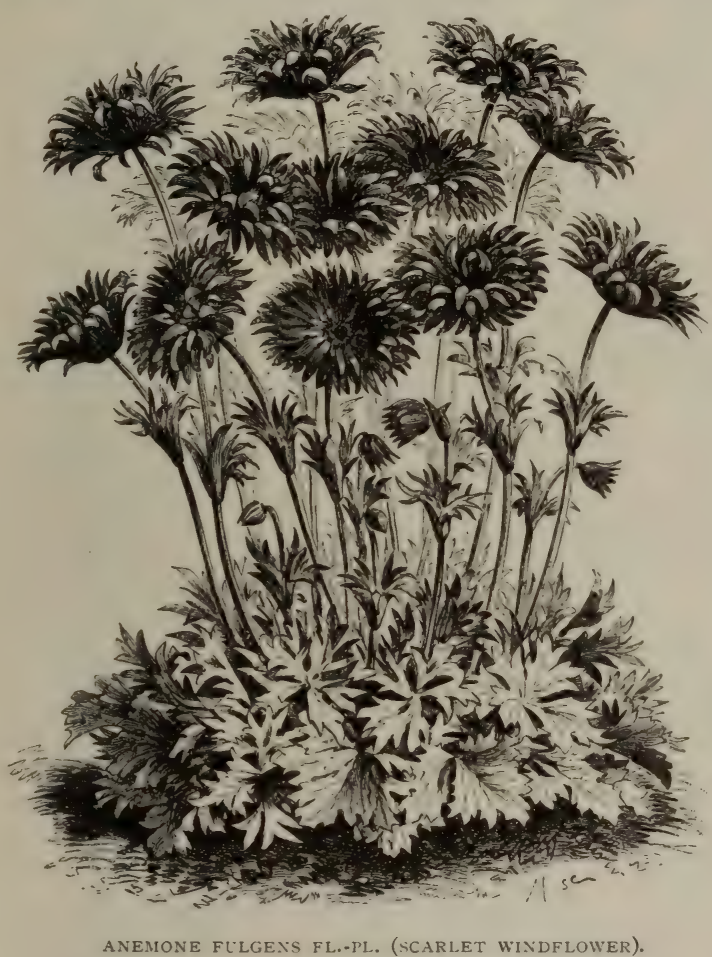

cultivation reverts to A. fulgens. The Scarlet Windflower withstands in the open border the severe frosts; it is scarcely, if ever, injured by mere cold, but stagnant moisture injures it. In good well-drained soils it will thrive, but it thrives best in a rich manured loam in a northern aspect and in a shaded situation. Division is the surest way of increasing it; it is liable to sport if raised from seeds. Roots may be transplanted almost all the year round, though the resting time extends only from June to August ; in order to ensure early and good flowers, they should be planted as early as possible in the autumn. In September or October some leaves will make their appearance; these will be succeeded in January by deeply-cut leaves, and soon afterwards by flowers. A large bed of well-grown plants in bloom is a brilliant sight. The cut flowers last for a week or more if cut when just coming into bloom and kept in water in a moderately warm room. H. V.

In the experiments made by M. Henri Vilmorin it was found that many of the seedling plants were not of the brilliant colour so striking in the true plant, but of a red with a shade of brick. We have seen many of these plants which were carefully separated from the pure stock. They are singularly alike in hue, and manifest no tendency towards A. stellata. On the other hand, plants of the true colour are raised from seed also, and

limited area, for the most part in vineyards. Although nearly related to Anemone stellata, there appears some ground for naming it a distinct species, as Gay did when he described it as A. fulgens. The localities of A. fulgens and A. stellata are far apart, and the seedlings of A. fulgens, although often varying, never revert to A. stellata. On the other hand, it seems certain that A. Pavonina is only the double-flowered form of A. fulgens. Its roots and leaves are identical with those of A. fulgens, and it often comes up among seedlings of fulgens. As A. Pavonina yields no seed, and is increased by roots, it is obvious why it never under sometimes fine ones, but seed is not to be depended on for reproducing the plant in its finest form. The Greek form of A. fulgens is larger, and very intense in colour. A fine strain was raised by the late Rev. J. G. Nelson, and called by him A. fulgens major.

A. hepatica (Common Hepatica).-A beautiful early hardy flower. In sheltered spots on porous soil the foliage will remain through the winter. The Hepatica is a deep rooter-hence it thrives so well upon made banks. It will do as well as Primroses or Violets in any good garden soil; and where let alone, and not often pulled to pieces, will make strong tufts. 
Clumps of the rich-coloured blues and reds when a mass of bloom in March are very beautiful. Few plants are more impatient of frequent removal. The best way is to put young plants in good soil, and let them remain until they become strong clumps-which would give perhaps twenty or more single crowns, and in this way a good stock may be obtained. The Hepatica is a native of many hilly parts of Europe and N. America. The best-known kinds are the double red and single blue, both amongst the hardiest of the section. Then there are the single white; single red; double blue, rich in colour; Barlowi, a rich-coloured sport from the single blue; splendens, a single red known; lilacina, a pretty mauve kind; and some others. Every variety of the Hepatica is worthy of care and culture. Usually found in copses and half-shady positions, which will suit it best in a cultivated state also. Where plants and space are to spare, there is little trouble in naturalising this in sandy or barish places, or in a thin shrubberyanywhere, in fact, where the plant would not be overrun by larger things. Mr. Frank Miles, who was very successful in raising seedlings, thus describes his practice.

HEPATICAS FROM SEED.-Sow the seed as soon as it is ready to fall, in light sandy loam. If it once gets dry before sowing, it does not grow readily. Put slates or bricks flat on the soil. Slates for roofing are the best ; the bed will not then require watering or weeding. In October or November the seed will begin to germinate. Remove the slates and put the boxes under glass without any heat. By spring-time every seed will have germinated. During the summer keep the seedlings in a shady place. Some will then make their first leaf and probably bloom the following spring, but it will take three years from the time of sowing for the plants to blossom well.

A. japonica (Japan Anemone).-A tall, autumn-blooming kind, $2 \mathrm{ft}$. to $4 \mathrm{ft}$. high, with fine foliage and large rose-coloured flowers. The variety named Honorine Jobert, with pure white flowers, is a beautiful plant. Both should be cultivated when cut flowers are required in autumn. Honorine Jobert is a sport from A. japonica. By having some on a north border, and some on a warm one, the bloom may be prolonged. Various hybrids raised between the Japan Anemone and A. vitifolia appear to have been lost. None that we have seen was so good as the type, or the best of all, the white. Some suppose that the white is the original form. Every bit of the root grows when divided.

"Anemone Honorine Jobert" is not a garden hybrid between $\mathrm{A}$. vitifolia and A. japonica. It originated at Verdun-surMeuse in the garden of M. Jobert. From a large tuft of A. japonica a stem arose with pure white flowers.

The various forms of the Japan Anemone are useful for borders, groups, fringes of shrubbery in rich soil, and here and there in half-shady places by wood walks. One of the best plants for cut flowers.

A. nemorosa (Wood Anemone).-In spring this native plant adorns our woods, and also those of nearly all Europe and Asia. It is so abundant in the British Isles that there is little need to plead for its culture. There are double varieties, and the colour of the flower is occasionally lilac, or reddish, or purplish. Flowers from March to May; white, and reddish outside. Height, 3 in. to 6 in. Division.

A sky-blue variety of the Wood Anemone, A. Robinsoniana, has of recent years become very much sought after. It is of easy culture and of peculiar beauty, especially if seen when the noonday sun is on the flowers. It is fitted to grace a ledge of the rock-garden as a colony or a wide-spreading tuft ; or for the margins of borders, or as a ground plant beneath taller subjects, or for a carpet for beds of choice shrubs, with ample space between, or for small beds beneath standard Roses, or for the wild garden, or for dotting through the Grass in the pleasure-ground in spots not mown early. In this case it requires some taste to get the groups or colonies into easy natural outline. After a time the plant will take care of itself.

The late Rev. H. Harpur Crewe wrote as follows concerning A. Robinsoniana: "Of a numerous and very beautiful family, this is, to my mind, the undoubted queen. There is a splendour about A. fulgens and Pavonina, and a dazzling beauty in A. stellata and coronaria; there is much delicate grace about A. bracteata, trifoliata, apennina, blanda, sulphurea, alpina, nemorosa, and narcissiflora; we all admire the purple and silk in which $\mathrm{A}$. Pulsatilla and vernalis love to clothe themselves, and the golden sheen of $\mathrm{A}$. palmata and ranunculoides; A. japonica and vitifolia, and their varieties and hybrids, have much pleasant autumnal brightness, - but, to my mind, all fade before the simple and innocent loveliness of A. Robinsoniana. Most botanists 
seem to agree that, though in many respects very distinct, it is a variety of the Wood Anemone, A. nemorosa. It is a dwarfer plant, blooms later, and both leaves and flowers possess more strength ; but its distinguishing characteristic is the pure, pale, cærulean blue of the inner surface of its petals. I know of nothing frequently spoke of its charms that it became a general favourite, and, in compliment to its champion, took the name of A. Robinsoniana."

As the origin of this plant is of some interest, I may state that I first saw it at the foot of a wall in the Botanic Gardens at Oxford. From roots given me by the

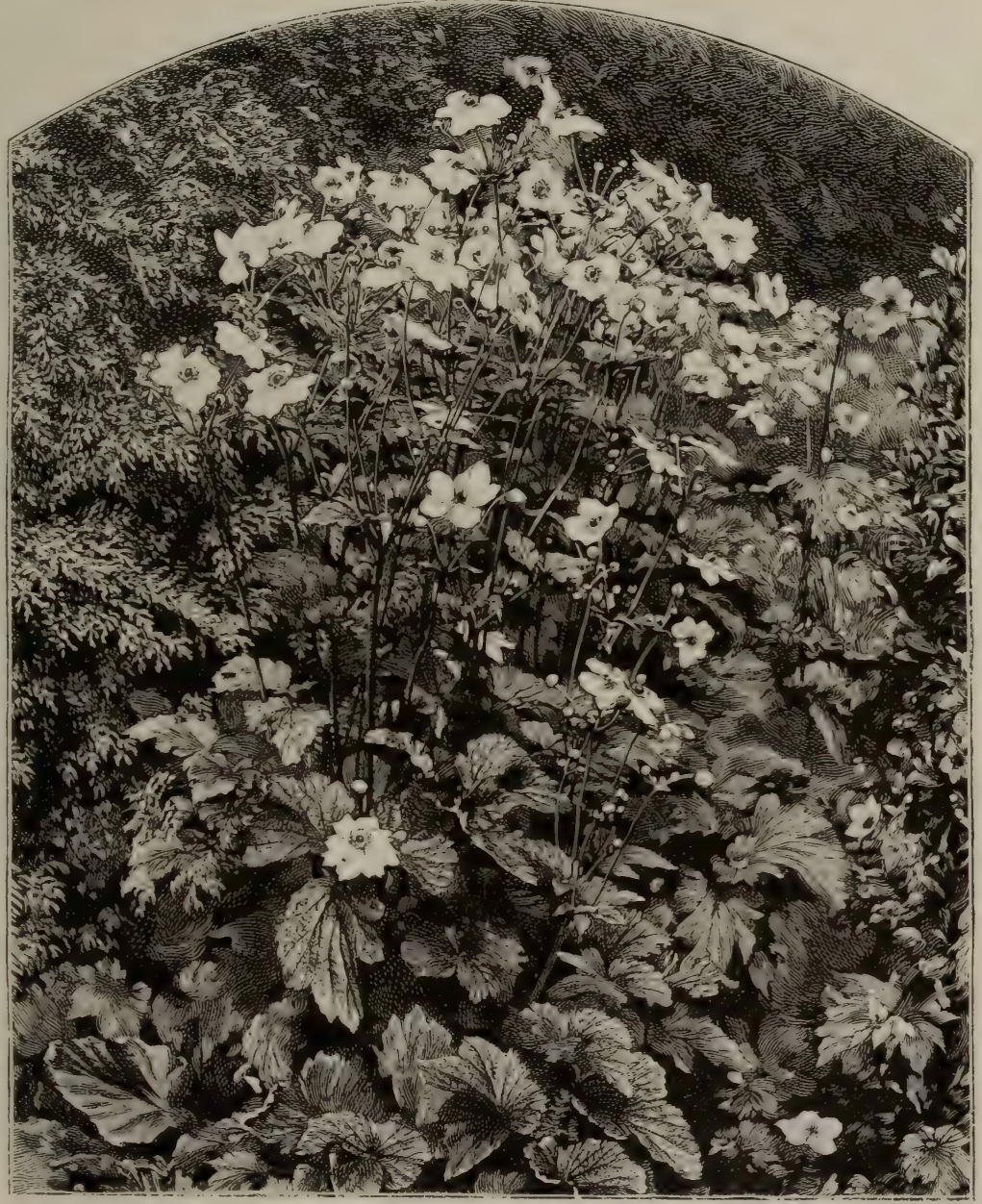

WHITE JAPAN ANEMONE IN SHRUBBERY.

more lovely than a fully-expanded patch of this beautiful flower on a bright spring forenoon. It is a rare British wild plant: I know of its occurrence in Norfolk and Essex, and I believe it has also been found in Kent, Sussex, and Oxford. It was unknown till a few years ago, when Mr. Robinson found it growing wild, and, struck with its marvellous beauty, so
Curator, Mr. Baxter, all the stock of the true plant now in gardens has come. I believe Mr. Baxter told me that it was sent him by a lady from Ireland, where a large form of the Wood Anemone is probably wild. It should be noted that the very pretty blue form of our Wood Anemone that I have seen in some abundance wild in Wales is not Robinsoniana.-W. R. 
A. palmata (Cyclamen-leaved Anemone).-A distinct kind, with leathery leaves and large handsome flowers, glossy, yellow, only opening to the sun. A native of $\mathrm{N}$. Africa and other places on the shores of the Mediterranean, this charming flower should be planted in deep turfy peat, or light fibrous loam with leaf-mould. It should not be placed on the face of rocks suited for Saxifrages and other plants content with mere crevices, but on level spots, where it can root deeply and grow into strong tufts. There is a double variety, A. palmata fl.-pl., and a white one, A. palmata alba. Flowers in May and June, 6 in. to I 4 in. high. Division or seeds.

A. Pulsatilla (Pasque-flower).-Though not common in Britain, this fine plant is native, and when it occurs on a bleak chalk down, it is generally freely dotted over the turf. There are few sights more pleasant to the lover of spring flowers than its purple blooms just showing through the dry Grass of a bleak down on an early spring day. It is smaller in a wild than in a cultivated state. In the garden it forms strong healthy tufts, but it is one of the plants more beautiful in a wild state than in a garden. In Normandy with Mr. Burbidge we came upon many plants of it on the grassy hill about Château Gaillard and also in the woods and by the roads near, and we thought we had never seen so fair a wild flower. There are several varieties, including red, lilac, and white kinds, but they are not common. There is also a double variety. It prefers well-drained and light but deep soil. Flowers in April and May; purplish with yellow stamens, 3 to 12 in. Division or seeds. A front border or rock-plant.

A. ranunculoides (Yellow Wood Anemone).- Not unlike the Apennine and the common Wood Anemone in habit, this is very distinct in its yellow flowers. It is S. European and usually less free on soils than the Apennine A., but on warm or chalky soil it is charming. I have not found it do well on clay, but on chalk soil it grows freely. It is charming for association with tufts of the Apennine or the Wood Anemone, the Pasque-flower, any of the varieties of $\mathrm{A}$. Hepatica, the Aubrietias, and such plants. It is a naturalised plant, and grows in Herts, Notts, and several other counties. Flowers March and April. 4 to 6 in. Division.

A. stellata (Star Windflower). - A native of Germany, France, Italy, and Greece, if not as showy as the common Anemone, is as beautiful. The star-like flowers, ruby, rosy purple, rosy, or whitish, vary in a charming way, and usually have a large white eye at the base, contrasting with the delicate colouring of the rest of the petals, and the brown violet of the stamens and styles of the flower. It is not so vigorous as the Poppy A., and requires a little more care-a sheltered warm position, a light, sandy, well-drained soil. It is suitable for grouping with the alpine kinds of Anemone on the rockwork, the mixed border, and the spring garden. As in the case of the finely-coloured Poppy Anemones, the best way will be to select and increase certain fine forms. Where the soil and district suits the plant, it is well to encourage it. $\mathrm{Mr}$. Ellacombe, of Bitton, speaks highly of the white variety: "At first it is rather stained with purple, but when fully out it is a pure white star, with pale purple under petals. This with the black eye and the pretty foliage make it a striking flower, and a very good addition to spring flowers." Flowers in May. Height, Io in. Division or by seeds. Syn., A. hortensis.

A. sulphurea is a beautiful soft yellow form of the Alpine Windflower (A. alpina).

A. sylvestris (Snowdrop Windflower). -A handsome plant, growing on almost any soil, with white flowers as large as a crown-piece and beautiful buds. A native of Siberia and Central Europe, it is at home in this country, and should be grown wherever good border flowers are desired; it will associate well with the Alpine Windflower, and plants of like size, about the lower parts of the rockgarden, along wood walks, and in shrubberies. The aspect of the drooping unopened buds suggested its English name - the Snowdrop Anemone. Flowers in April and May; white; I ft. to 15 in. high. Division of root.

\section{A. thalictroides (= Thalictrum ane-} monoides).

A. vitifolia (Vine-leaved Anemone).Like the Japanese Anemone, but more downy, and flowering a fortnight earlier. It is a native of the moist shady valleys of Nepaul. The name A. vitifolia occurs in many catalogues, but we have not often seen under the name any plant that differs from what is known as A. japonica or one of its forms. A plant in Mr. Elwes's garden has the leaves simple and Vine-like, as the name implies, whereas the white japonica has the leaves compound with the exception of a few root-leaves. A. vitifolia is earlier in flower, and the blossoms are not quite so large, the white having a slight tinge of pale purple outside. It really is in no 
way better than the white Japan Anemone, if so good.

The previously-named Anemones are the most beautiful of the family, which, however, contains many other interesting and useful plants. These, from their rarity, slowness of growth, or from various other causes, are only named here: A. acutipetala, A. alba, A. baldensis, A. collina, A. dichotoma, A. Halleri, A. Hudsoniana, A. montana, A. multifida, A. narcissiflora, A. Nuttalliana, A. obtusiloba, A. ochotensis, A. patens, A. penn- and spreading, the other forming a cone in the centre. It thrives in a rich soil in a shaded border well drained. Japan.

Angelica.-Plants of the Celery Order, which would be of some use for their form had we not so many finer hardy plants in the same family. One is a native of our woods and river banks, and another is a well-known plant grown in most kitchen gardens.

Anigosanthus coccineus.-An Australian plant with numerous crimson flowers with green tips, hardy in sheltered

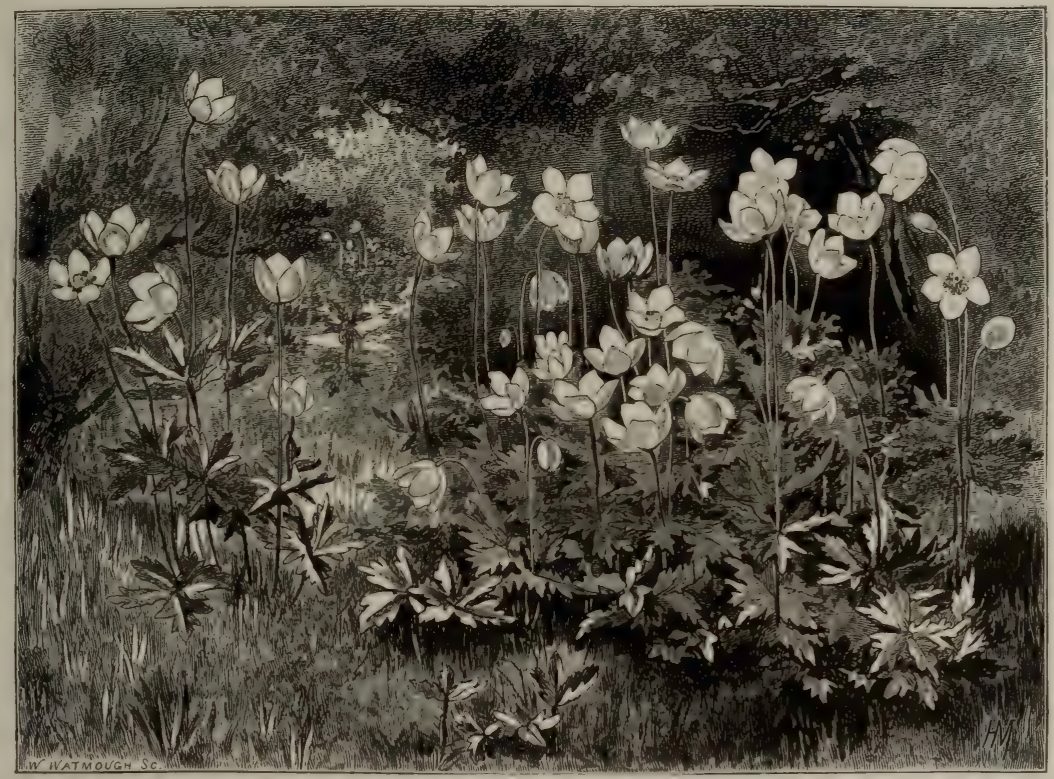

ANEMONE SYLVESTRIS (SNOWDROP ANEMONE).

sylvanica, A. Popeana, A. pratensis, A. rivularis, A. scaposa, A. sibirica, A. thalictroides, A. trifoliata, A. virginiana, and A. vernalis. There are also tender species not included here; most of the above are of easy culture with the exception of the alpine species, like $A$. vernalis, which are slow and require to be carefully grown in fully-exposed spots in moist, gritty soil.

Anemonopsis.-A. macrophylla is a beautiful plant somewhat like the Japanese Windflower, but smaller. The thick shining leaves rise to a height of 12 in. ; the flower-stems are slender, about 18 in. in height, on which are borne numerous drooping blossoms, about $I \frac{1}{2}$ in. across, of a pale purple colour. The flowers differ from those of the Anemone in having two rows of petals, one outside spots, but of little value out-of-doors in our climate.

Anisodus luridus. - A hardy perennial of the Solanum family from Nepaul. It has greenish-yellow bell-shaped flowers and ample bright green foliage. Of no garden value. Syn., Scopolia lurida.

Anomatheca cruenta.-A pretty little South African bulb, from 6 to 12 in. high, flowers $\frac{1}{2}$ in. across, carmine crimson, three of the lower segments marked with a dark spot; in loose clusters on slender stems and Grass-like leaves. Hardy on many soils, but in others it should be planted on warm slopes, in very sandy dry soil, or on warm borders; the bulbs planted rather deep. In many soils it increases rapidly.

Antennaria (Cat's-ear).-Mostly hardy alpine or border flowers. A. margaritacea, the Pearly Everlasting, is a North 
American plant, $2 \mathrm{ft}$. high, flowers in clusters, white and chaffy, hence are kept in a dry state, and dyed in various colours. The Mountain Cat's-ears, A. dioica and A. alpina, and varieties minima and tomentosa, are neat little plants with whitish foliage, used as carpeting. All are of the simplest culture in any ordinary soil in exposed positions. These are good rock-garden plants, and the pretty little rosy heads of one form of the Mountain

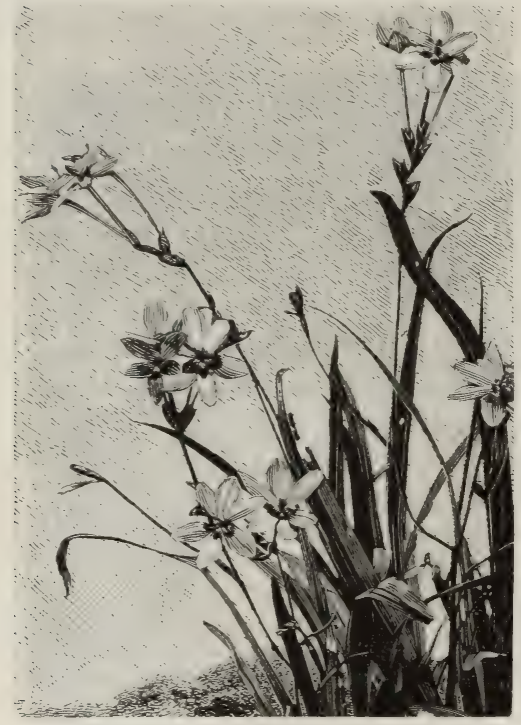

ANOMATHECA CRUENTA.

Everlasting may often be seen in the cottage gardens of Warwickshire. A. tomentosa is a plant of a similar character that has been much used as a dwarf silvery plant in the flower garden. It is hardy and of easy increase and culture in bare spots. Division.

Anthemis (Camomile).-Of the numerous kinds of these in cultivation there are but few worth growing. A. Aizoon is a dwarf silvery rock-plant -2 to $4 \mathrm{in}$. high, with Daisy-like flowers. Its chief beauty is the leaves, covered with a white downy substance. It should be grown in the rock-garden in exposed places. A. Kitaibeli is pretty in the mixed border, growing tall, with large, pale, lemon-coloured, Marguerite-like flowers. A. tinctoria is very similar, and both are excellent for cutting. The double-flowered form of the Corn Camomile (A. arvensis) is sometimes cultivated among annual plants.

Anthericum (St.Bruno's Lily).-Graceful plants of the Lily family, containing but few species hardy in this country. These are the European kinds, among the most beautiful of hardy flowers.

A. Hookeri (Chrysobactron Hookeri). -A distinct plant 15 to 20 in. high. Flowering in early summer, the blooms bright yellow, $\frac{1}{2}$ in. across, in long spikes; grows best in moist and deep soil, such as an artificial bog. New Zealand.

A. Liliago (The St. Bernard's Lily).About $2 \mathrm{ft}$. high, with flower-spikes bearing white flowers in early summer. It is known also as Phalangium Liliago. A. ramosum has the flower-stems about 2 ft. high, much branched, and small white flowers ; it has Grass-like leaves, and the plant soon grows into large tufts. It is sometimes called in gardens and nurseries A. graminifolium.

A. Liliastrum (St. Bruno's Lily).A graceful alpine meadow plant. Thriving in deep free sandy soil, and in early summer throwing up spikes of snowywhite Lily-like blossoms. In dry soils a covering with rotten manure helps it, in early spring the plants must be protected from slugs and caterpillars. It is increased by division of the roots in autumn, which is the best time to plant, or it may be raised from seed. It usually grows about 15 in. high, and is an excellent plant for choice borders, better still in a colony or group in spaces between dwarf shrubs. Where plentiful, it would be an interesting subject to naturalise in a Grassy place. This species is also known under the names of Paradisea and Czackia.

The major variety of the St. Bruno's Lily has much larger flowers ( 2 in. across) than the type, and sends up large single flowers from the root. These open before the flowers on the spike and are larger. Generally one solitary bloom of this kind grows on each plant at the root and far below the spike, as if strange flowers had come on the plants. Grows $3 \mathrm{ft}$. high in good soil, and is a fine border plant.

Antholyza.--Plants of the Iris family, natives of the Cape of Good Hope, with Iris-like leaves and tall flower-spikes that bear numerous flowers of a bright red. They are hardy in a warm sheltered border well drained, in rich sandy loam. It is advisable to lift the plants every autumn, so as to separate the small bulbs. This should be done about the end of August, and the bulbs should be replanted in October and November, or in February. A handful of litter over the bulbs during winter would be the best way to ensure the safety of the plants. Watsonia 
Meriana and others are known in some garden's as species of Antholyza, but they correctly belong to Watsonia. Offsets and seeds.

Anthyllis (Kidney Vetch).-Plants of the Pea family, of which few are worth growing. A. montanus, the Mountain Kidney Vetch, is a very hardy rock-plant $6 \mathrm{in}$. high, the leaves nearly white with
A. Vulneraria (Woundwort), a common native plant, is pretty and well worth growing on dry banks. There is a white variety and a red one.

\section{Anticlea (Zygadenus).}

Antirrhinum (Snapdragon). - The most popular of these is the handsome A. majus, the common Snapdragon. Like the Wallflower, this may be grown on

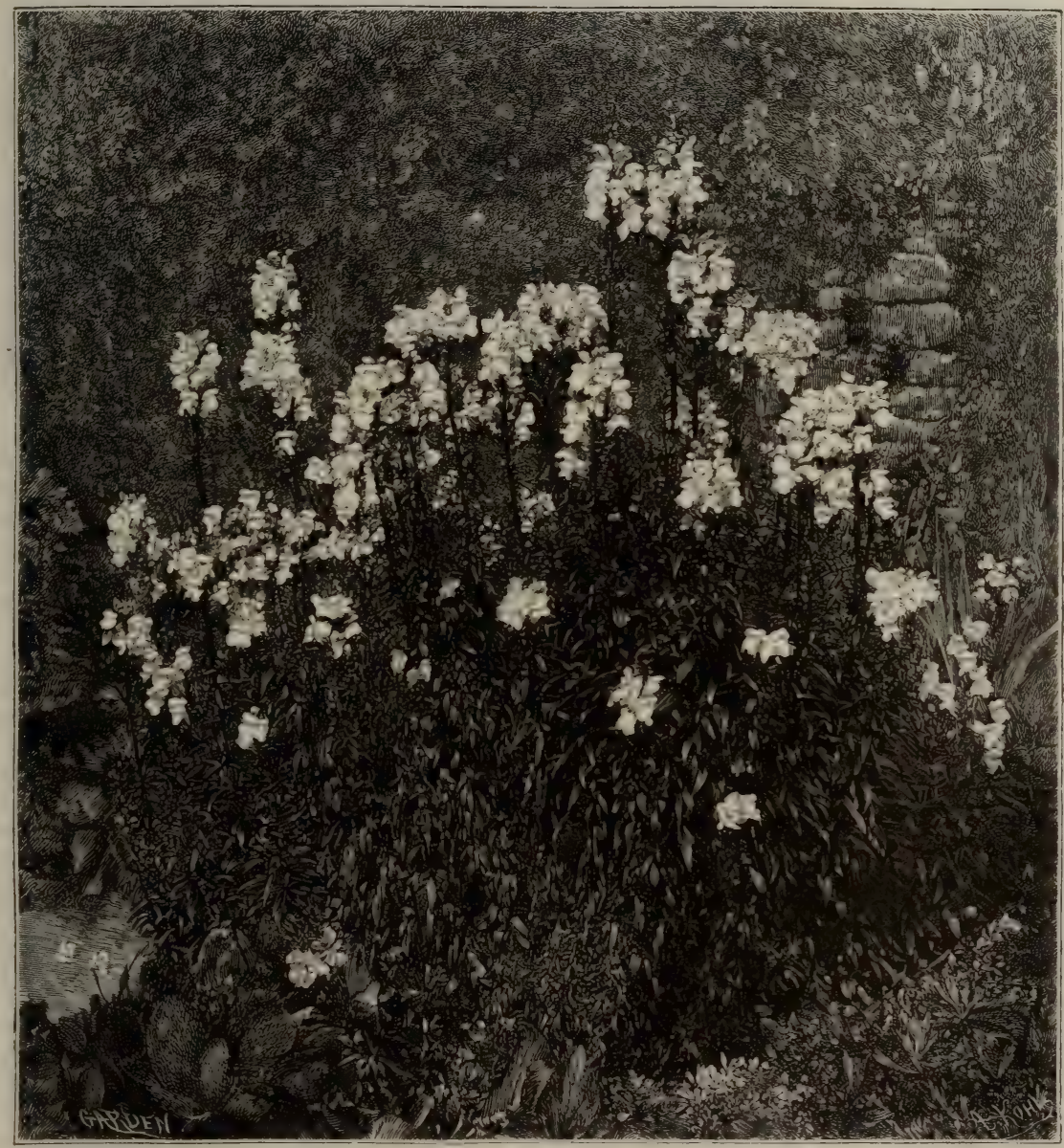

ANTIRRHINUM (SNAPDRAGON, WHITE SWAN)

down, the pinkish flowers in dense heads, rising little above the leaves, and forming with the hoary leaves pretty little tufts. This plant is useful for every kind of rockwork, thriving on cold and bad soils. Resisting cold and moisture, it is excellent in the front rank of the mixed border. Alps of Europe. A. erinacea is a singular spiny, almost leafless shrub, about I ft. high, with purplish flowers. old walls and ruins. The varieties have been improved of late years, and give a charming variety of fine brilliant colours. Good strains only should be grown, as it is waste of time to cultivate inferior forms. But self-coloured kinds should be selected as giving a better effect in masses. Cold springs have a bad effect on old plants grown in a wet soil, while those in light soil do well. Those who 
have a cold soil will do best to raise plants in the autumn, winter them in store boxes in cold frames, and plant them out in March and April. Hard frosts following a wet autumn are destructive to Snapdragons. Among the numerous species, some few are seen in cultivation from time to time, but they do not take a large place in gardens. Among the best are A. Asarina and rupestre.

Apera arundinacea. - A dainty slender-growing Grass, and one of the few which can compete with the Feather Grass in beauty. In growth it is almost Rush-like, bearing long weeping plumes of a glossy purplish-brown colour, and useful where graceful spray is in demand. The plumes dry well, and endure for a long time.-B.

Aphanostephus ramosissimus. - A pretty half-hardy annual from Texas. It grows scarcely more than 4 in. in height, very much branched, every shoot producing a flower-head about I in. across, with a yellow disc, and violet-blue ray florets. It has a close carpet-like growth, and gives an abundance of bloom throughout the summer. The same treatment as other half-hardy annuals.

Aphyllanthes monspeliensis. - A pretty Rush-like plant, forming dense tufts I ft. or more high. It flowers in summer, the blossoms deep blue and $\frac{3}{4} \mathrm{in}$. across. South of France. Borders, in light soil. Division and seed. A hardy slow-growing plant, mainly of botanical interest, though a tuft on the rougher slopes of the rock-garden will not be out of place.

Apios tuberosa (Ground Nut).-A climbing Pea-flower, with a tuberous root, from N. America. The flowers are a dull brownish-purple, sweet scented, coming in summer. It is useful for arbours or for rambling over shrubs; the fragrance of its flowers is like that of violets. Division of tubers.

Aplectrum hyemale (Adam and Eve.) - An interesting hardy Orchid, from 6 to 12 in. high. The thick bulb sends up a large oval leaf in late summer, which lasts until the next summer, when the flowerstalk appears with a raceme of large flowers, greenish-brown and speckled with purple. Sandy moist spots in rich leaf-mould. Eastern United States. Of little value for the garden.

Aplopappus. - North American Composites. Two species are in cultivation, one an annual, the other a perennial. A. ciliatus is a robust-growing annual, 3 to $4 \mathrm{ft}$. high, with flower-heads $2 \mathrm{in}$. across, bright yellow. It blooms in summer and autumn. It may be treated as a biennial, the seed sown about August, or as a half-hardy annual, the seeds being sown under glass in spring. A. Fremonti is from 6 to 12 in. high, with erect stems and flower-heads, of a bright yellow, I in. across. Colorado, in high ground.

Aplotaxis.-A Compositæ of no garden value.

Apocynum (Dogbane).-North American plants, of which there are four species in cultivation, but all are of little garden value. A. androsæmifolium (Flytrap or Spreading Dogbane) is a curious plant from 2 to $3 \mathrm{ft}$. high, with small rosecoloured blossoms. A. cannabinum, the Indian Hemp, is similar, and so are A. hypericifolium and A. pubescens, probably only varieties of A. cannabinum.

Aponogeton (Cape Pond-flower).-A beautiful and fragrant water-plant from the Cape of Good Hope, which, fortunately, is hardy in many parts of these islands. No one has been more successful with it than the late Jas. McNab, of the Botanic Gardens at Edinburgh, who wrote of it : "Aponogeton distachyon has been growing in the pond of the Royal Botanic Gardens at Edinburgh for the last 40 years, and now forms many large patches in various parts of it, the largest being $48 \mathrm{ft}$. in circumference. The situation where the pond stands was originally a marsh ; when it was made, the bottom was causewayed with stones, placed $\frac{1}{2}$ in. apart, in order to allow the numerous springs, peculiar to that portion of land, freedom to rise between them. The pond varies from $2 \mathrm{ft}$. to $5 \mathrm{ft}$. in depth, and the bottom is thickly coated with mud, arising from the tree-leaves which are annually blown into it. In this the Aponogeton thrives, and its seeds grow freely in the muddy bottom. In consequence of the number of springs, portions of the pond are never coated with ice, even during the most severe winters. The overflow is very large, and is never found to vary at any time throughout the year, not even during very dry summers. To these circumstances I attribute the healthy condition of the beautiful Pond Weed, which flowers abundantly, not only during the spring, summer, and autumn, but often during the winter, in mild weather. Plants of it have been sent from this garden to many ponds throughout Great Britain, but in few has it been successful, evidently owing to the want of constant springs bubbling up amongst their roots, which causes a continual change of water. Plants of it have, however, succeeded in several mill-ponds where the water is 
kept warm by the condensed steam constantly thrown into them."

About London during the severe winters there has been no more interesting sight than the profuse bloom of the fragrant Cape Aponogeton. In the open air, in

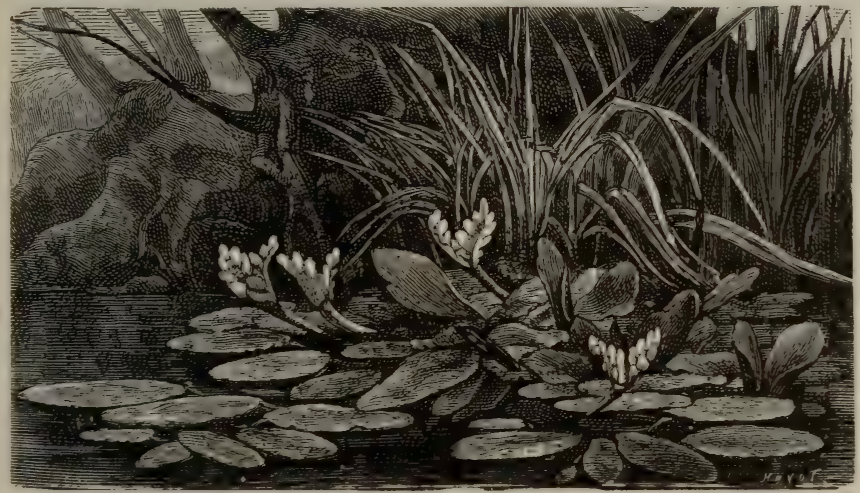

CAPE POND-FLOWER.

Mr. Parker's nursery at Tooting, myriads of its handsome flowers, with a scent like that of the Hawthorn, floated gracefully on the water, and long and graceful fresh green leaves quite flat on its surface. In the midland and cold districts it is necessary, for the perfect culture of this plant in the open air, to grow it in spring or other water that does not freeze; but in mild districts and in the south of England this is not needed. It may be flowered in an inverted bell-glass in a room. In Devonshire it is grown to greater perfection than in the home counties or near London. Failures often result from putting it in too shallow water.

A. spathaceum is a smaller-growing plant. Its flowers are tinged with rose. It is, in fact, a very poor relation of the Cape Pond-flower.

Aquilegia (Columbine). - Charming plants, often beautiful in habit, colour, and in form of flower, widely distributed over the northern and mountain regions of Europe, Asia, and America, and their flowering period extends throughout May and June. Among them may be found great variety in colour-white, rose, buff, blue, and purple, and also stripes and intermediate shades even in the same flower. Among the American kinds we have yellow and scarlet, and most delicate shades of blue.

The Columbines are frequently taller than most of the plants strictly termed alpine, but are nevertheless true alpine plants, and among the most singularly beautiful of the class. The blue, and blue and white alpine kinds, living in the high bushy places in the Alps and Pyrenees, and, indeed, of all European and North Asian mountain chains, are among the fairest of all flowers. Climbing the sunny hills of the sierras in California, one meets with a large scarlet Columbine (Aquilegia eximia) that has the vigour of a Lily and the grace of a Fuchsia; and in the mountains above Salt Lake City, in Utah, and on many others in the Rocky Mountain region, there is the Rocky Mountain Columbine (A. cœerulea), with its long and slender spurs and lovely cool tints in its erect flowers. Indeed, there is no family that has a wider share in adorning the mountains. The finer Columbines are to the smaller alpine flowers what the Birches are to the hill shrubs. Some of the alpine species, however, are much smaller than those commonly grown - for example, the Pyrenean Columbine. Although our cottage gardens are alive with Columbines in much beauty of colour in early summer, there is some difficulty experienced in cultivating the rarer alpine varieties. Hence such highlyvalued kinds as the Altaian Columbine (A. glandulosa) and the Alpine Columbine (A. alpina) are rarely seen flowering well in gardens, and frequently perish. They require to be carefully planted in sandy or gritty though moist ground, and in well-drained ledges in the rock-garden, in half-shady positions or northern exposures. Most rare Columbines, however, fail to form enduring tufts in our gardens, and they must be raised from seed as frequently as good seed can be got. It is the alpine character of the home of many of the Columbines which makes the culture of some of the lovely kinds so uncertain, and which causes them to thrive so well in the north of Scotland while they fail in our ordinary dry garden borders.

No plants are more capricious ; take, for instance, the charming A. glandulosa, grown like a weed at Forres, in Scotland, and so short-lived in most gardens. Nor is this an exception; it is characteristic of all the mountain kinds. Mr. Whittaker, 


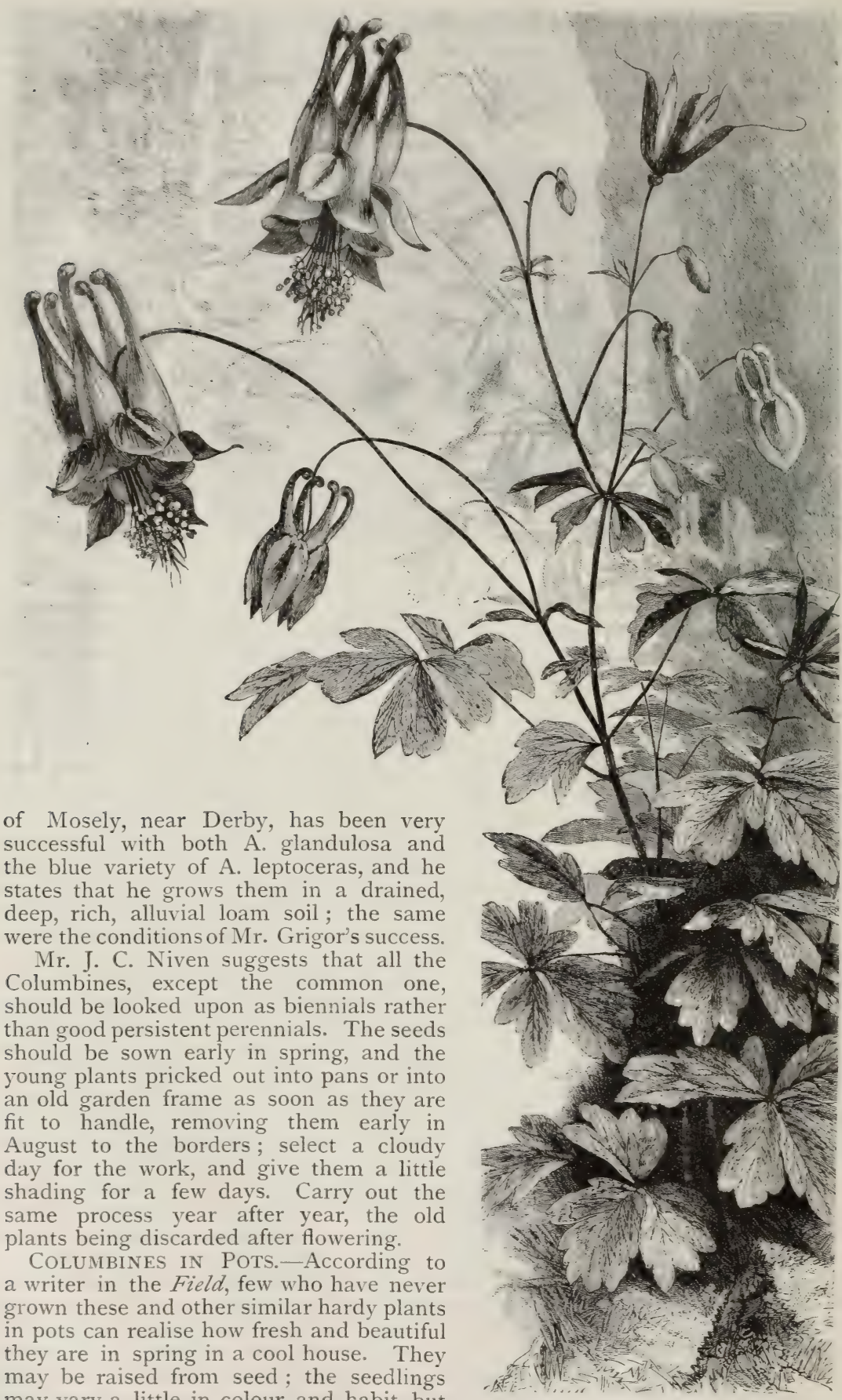

may vary a little in colour and habit, but that scarcely detracts from their value. Sow thinly in light sandy soil, place the

\section{AIDLILEGIA CALIFORNICA (CALIFORNIAN} COLUMBINE! 
seed pots or pans in a close frame, prick off when large enough, and, finally, pot into single pots and shift on during the summer into 6-in. pots, standing the pots on a coal-ash bed-or, better still, plunging them in the ashes to save watering. At the approach of cold weather, move them into a cold frame, and if the frost is very severe, lay some litter over the glass to keep the frost from breaking the pots.

A. alpina (Alpine Columbine).-This plant, widely distributed over the higher parts of the Alps of Europe, is from I foot to $2 \mathrm{ft}$. high, and has showy blue flowers. There is a lovely variety with a white centre to the flower, and many will say they have not got the "true" plant if they possess only the variety with blue flowers. It should have a place in the rock-garden, and be planted in a rather moist and sheltered, but not shady, spot in deep sandy loam or peat. Increased by seed or division. In moist districts, and in free soil, it is a good border plant.

A. californica (Californian Columbine). -One of the finest of the American species. The tendency of the plant is to produce one bold woody stem, which will rise to the height of $3 \mathrm{ft}$. The spurs are long and a bright orange ; and to appreciate the full beauty of the flower it must be turned up from its naturally pendent position, as then the beautiful shell-like arrangement of the petals becomes visible, the bright yellow marginal line gradually shading off into deep orange. The seeds of this species should be carefully looked after, as having once blossomed, the old plant may perish. This plant thrives best on a deep sandy loam and moist. Syn., A. eximia. A. truncata.

A. canadensis (Canadian Columbine). - This was once our only New World Columbine. It was introduced from Virginia by the younger Tradescant, and may be taken as the type of the scarletorange and yellow group. The flowers are smaller than the Western American kinds; but this is amply compensated for by the brilliancy of the scarlet colour of the sepals and of the erect spurs, and by the bright yellow of the petals. The true A. canadensis is a slender grower, scarcely exceeding I foot in height. The flower seen in cultivation is often a cross, with vigour of growth and brilliancy of colour. Easily raised from seed. There is a yellow form. It is a plant for borders, for placing here and there among dwarf shrubs and plants in the rougher parts of the rock-garden, but is not among the best species. Writing of it from Long Island, Mr. Falconer says : "To see it at its best you should see it among the rocks. The Canada Columbine grows in abundance in our woods, and always in rocky places ; there it springs from the narrowest chink, a little bush of leaves and flowers ; or may be in an earthy mat upon a rock you find a colony of Columbines, Virginian Saxifrages, and pale Corydalis; they usually grow together."

A. chrysantha (Golden Columbine).This tall and beautiful species is as lasting as a perennial on many soils where the other species perish. It was at first supposed to be a variety of Rocky Mountain Columbine, and was so named by Torrey and Gray. After cultivating it for several years, however, and comparing it in a living state with the Rocky Mountain Columbine (A. cœrulea), Dr. Gray described it as a new species, A. chrysantha. Like the Rocky Mountain Columbine, it has a very long slender spur, often over 2 in. in length. It is quite hardy and thrives even on the stiff clay soils north of London, though it is no less free in more happy situations. It comes true from seed, which is most safely raised under glass. Attaining a height of $4 \mathrm{ft}$. in good soil, it is an important plant for the centre of a bed of the finer perennials or for a group in the mixed border. Seed must be got from wild plants.

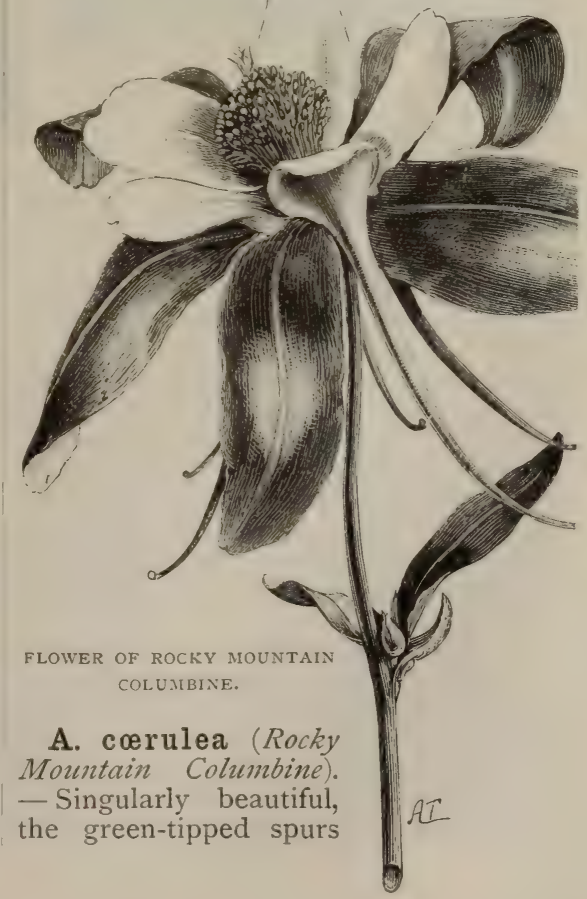


of the flower are as slender as a thread, a couple of inches long, and have a tendency to twist round each other. But it is in the blue and white erect flower that the beauty lies, the effect being even better than in the blue and white form of the alpine Columbine. It is a hardy herbaceous plant, flowering early in summer. I have seen it flowering freely on light soil in Suffolk in autumn. It is from 12 to $15 \mathrm{in}$. high, and is worthy of the best position on the rock-garden, and in choice mixed borders, where the soil is free and deep. Unlike the Golden Columbine, it is not perennial on many soils, though longer-lived in cool hill-gardens. To get healthy plants that will flower freely, seeds should be sown annually, as the plant rarely does well after the second year, and in many cases dies before that time. The flowers are so lovely that it merits attention to have it in good health.

This is one of the plants which deserve a second home in the nursery. It should have a little bed to itself, from which its lovely flowers could be gathered for cutting and its plants obtained when wanted. A coating of 2 in. of half-rotten leaves in summer would assist the bloom. As soon as the seed is ripe, it should be sown in cool frames near the glass, or in rough boxes in cool frames. With abundance of fresh seed and beds of fine soil there will be no difficulty in raising it in the open air, if it is protected from birds and slugs.

What is supposed to be a white variety of this plant is $\mathrm{A}$. leptoceras.

"M.," writing from Utah, says : "Some plants of this species seen in Utah seem to belong to a distinct variety; their colour is not blue, or blue and white, but white or yellowishwhite. They were flowering in great numbers $10,000 \mathrm{ft}$. above the sea whereever any tiny stream trickled down the mountain slopes; and the flowers at a little distance reminded one more of those of Eucharis amazonica than anything else. The plant grows in handsome tufts 2 to $3 \mathrm{ft}$. high, the flowers large, and the spurs very long, with a rounded knob at the top."

A. glandulosa (Altaian Columbine).A beautiful plant with handsome blue and white flowers and a tufted habit. Flowers in early summer-a fine blue, with tips of petals creamy-white, the spur curved backwards towards the stalk, the sepals dark blue, large, and nearly oval, with a long footstalk. A native of the Altai Mountains, and one of the most precious flowers for the rock-garden or the select border, in deep sandy soil. Increased by seed and by very careful division of the fleshy roots, when the plant is in full leaf. If divided when at rest, the roots are almost certain to perish, at least on cold soils.

The Forres Nurseries, in Morayshire, have long been famous for this plant; it has no special care, and there is no secret

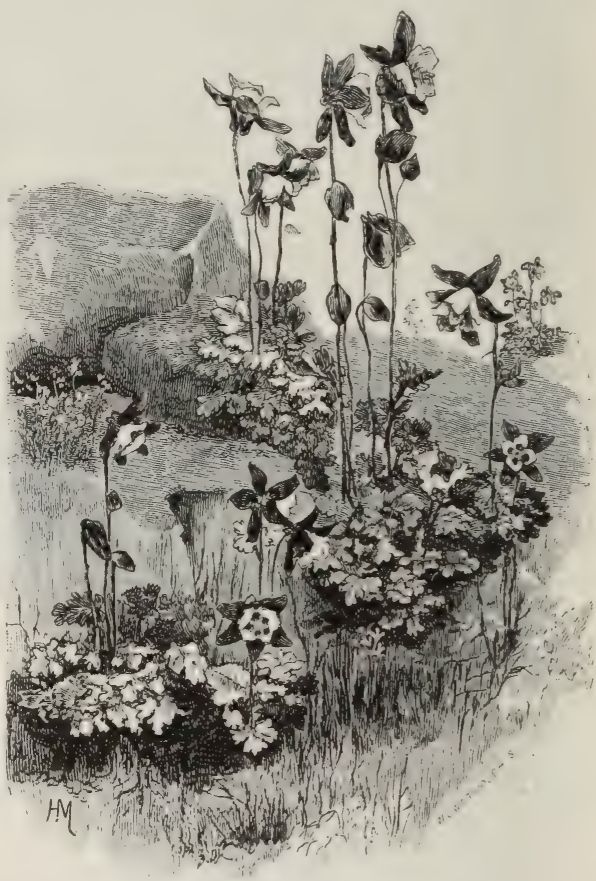

SIBERIAN COLUMBINE.

about the culture, which is wholly in the open air. The soil is "a rich mellow earth, partaking a little of bog or peat earth, and rather cool and moist than otherwise." It flowers the year after sowing, and like most Columbines is impatient of removal, but, if not transplanted when more than two years old, it when full grown flowers for at least five or six years, sometimes for more. Those who can get true seed will do well to raise this fine plant with care, and plant it cut when very young into moist, deep peaty or sandy beds, putting some of the plants in northern or cool positions. It would also be well to sow some seeds where the plants are to remain, and in 
other ways to try to overcome the difficulty hitherto attending the culture of this lovely plant.

In many cases an inferior plant bears the name glandulosa. Mr. Brockbank says: "I have referred to the original specimen of A. glandulosa, sent by Prof. Regel, of the St. Petersburg Botanic Gardens, from the Altai Mountains. It is a different plant from the A. glandulosa jucunda, being more than twice as tall and in every way more robust. The specimen at Kew is nearly $I \frac{1}{2}$ times the height of the large folio paper in which it is preserved, and the flower measured $4 \frac{1}{2}$ in. in diameter. The plants in Kew Gardens are not this variety-the true variety - of A. glandulosa, and, as far as I know, it is not to be found with any of our nurserymen."

A. Skinneri (Skinner's Columbine).A distinct plant, the flowers on slender pedicels, the sepals greenish, the petals small and yellow; the spurs are 2 in. long, bright orange-red, the leaves glaucous, their divisions sharply incised; the flower-stems $18 \mathrm{in}$. to $2 \mathrm{ft}$. high. Though coming from Guatemala, it comes from mountain districts, and is nearly hardy. It should be more often seen in gardens. Crossing with other kinds mars its beauty. While the name is often seen, the true plant is rare. It is a late bloomer.

A. viridiflora. - As a rule green flowers are not very much admired, but this Columbine is charming; the sage-green of the flower and the delicate tint of the leaf offering a singular contrast to other Columbines. In the border it may not be noticed, but if a spray or two are in a glass its beauty of form and colour is soon seen. There is a variety A. atropurpurea. The sepals are green, but the petals are a deep chocolate. The plant is vigorous, and is synonymous with $A$. dahurica. It is a plant for a quiet corner in a bed of shrubs or for any place among quiet-coloured plants, and for nursery beds of hardy flowers. It has a delicate and exquisite fragrance. Seed. Siberia.

A. vulgaris (Common Columbine.)One of the commonest inhabitants of cottage gardens. There are many forms in various colours, and double kinds, flowering from May till towards the end of summer. Mr. Niven states that at Broughton Woods, in North Lincolnshire, this Columbine raises its stately stems to a height of $3 \mathrm{ft}$. ; and in the month of May, when the Lily of the Valley, which grows there by acres, adds its delicious perfume, a walk is charming, especially after a gentle shower. But, however valuable for the wild garden, the many forms of the common Columbine are most useful for flower gardens, and it is now and then worth while to raise them from fresh seed of a good strain. It would also be well to select and fix varieties of distinct colours. One may often see a

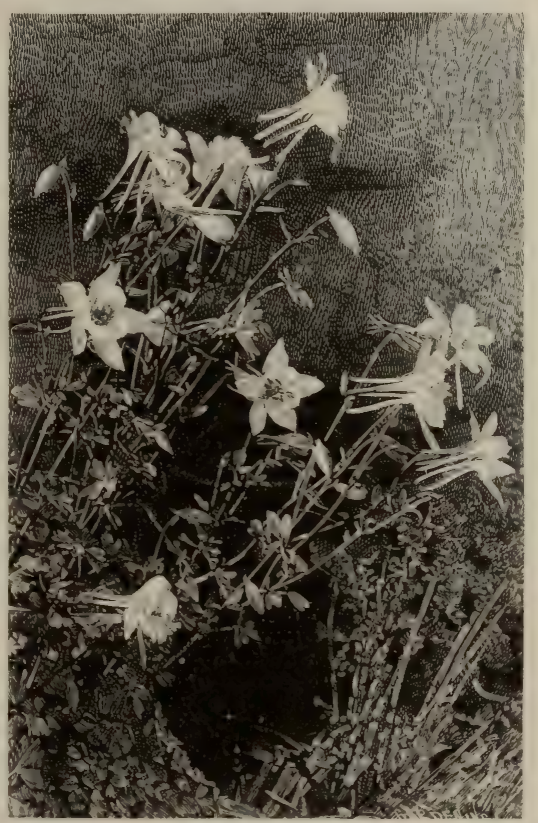

WHITE COLUMBINE.

variety of the common Columbine nearly as handsome as any of the finest alpine species. There is a bold white form which is very handsome. A. Vervæneana is a form with mottled leaves.

The varieties of our common Columbine and some hybrid forms are so free and hardy, that they may well be used in the wilder and more picturesque parts of large pleasure-grounds, by streams, in copses, or among Foxgloves, Geraniums, or long Grasses. The ground should be well dug if the vegetation is dense, and the seed sown on the spot. Where bare places occur, and seedlings have a chance of coming up without being strangled by other plants, seed may be scattered. Seed sown as soon as ripe.

A. Witmanniana.-Plants quite distinct from A. glandulosa, but often passing for it. It is one of the most vigorous and free-flowering of all the Columbines. A plant grew in the same spot in my garden for ten years, and bore five or 
six stems more than $3 \mathrm{ft}$. high, each with twenty or thirty flowers. The flowers have dark purple sepals and a white corolla, but far inferior to those of $\mathrm{A}$. glandulosa ; it is, in fact, less ornamental than many seedling varieties of $\mathrm{A}$. vulgaris which I have raised, but which, unfortunately, I can neither divide nor reproduce true from their own seed.-B.

It were easy to describe other species, but among those named will be found the highest beauty. Collectors will seek other species, but we have given the best for all artistic purposes. For the choice rock-garden some of the dwarfer and more delicate alpine species may be desirable. A. fragrans is praised for its scent and the green Columbine is delightfully fragrant.

Arabis (Rock Cress). - A large family of hill-plants, few of which are grown, though some are worth a place.

A. albida (White Rock Cress).Through long years of neglect of nearly all hardy plants, the white Arabis has held its own. It is the most popular plant in our gardens, and in the barrow of every London flower-hawker in spring. It will grow in any soil, in our cities as well as in the open country, where its sheets of snowy bloom may open in early spring. By seed, or cuttings, it is as easily increased as a weed, and is useful for the mixed border, the spring garden, and for naturalisation in wild and bare rocky spots. In the rock-garden it is useful for ledges; it may also be used as an edging to beds of shrubs, though it is better to associate it in such positions with groups of plants like the Aubrietias, the rock Alyssum, and other easily-grown alpine flowers that bloom early in the year. It is closely allied to the Alpine Rock Cress (A. alpina) so widely distributed on the Alps, but it is distinct, and by far the best kind. The variegated variety, Arabis albida variegata, is useful as an edging plant. It is the dwarfest and whitest of the variegated Rock Cresses grown under the name. The yellower and stronger variety, also frequently called A. albida variegata, and the best for general purposes, is a form of Arabis crispata, of which the green form is not worthy of cultivation.

A. blepharophylla (Rosy Rock Cress).Not unlike the white Arabis, but the flowers are a rosy purple. It varies a good deal, but there is no difficulty in selecting a strain of the deepest rose. Its healthy tufts are very effective in April. In mild districts and on light soils it should be tried out every winter.
It does not appear to have answered well after many trials, and its annual and tender character is against it as a rockplant. N. America. Seed.

A. procurrens - a dwarf spreading kind, with shining leaves and whitish flowersis often grown, but is not worthy of culture. There is, however, a fine variegated form (A. procurrens variegata) worthy of a collection of variegated plants. The prettiest of the variegated Rock Cresses is A. lucida variegata. It forms very neat edgings in spring and summer flower gardens, and from its distinct character is effective on borders. It thrives best and is easiest to increase by division in open and sandy yet moist soil. The best time to divide it is in early autumn, in April, or very early in May. The flowers should be removed when they appear. The green form (A. lucida) is a useful edging plant. A. purpurea is interesting for curious collections, but is not worthy of cultivation while we possess such brillant plants as the purple Aubrietias. A. arenosa, from the south of Europe, is a pretty annual kind useful in the spring garden. It might be naturalised on old ruins or dry bare banks. A. petræa is a neat sturdy little plant, with pure white flowers. It is a native of some of the higher Scottish mountains. It is rare in cultivation, but is very pretty when well grown on a moist well-exposed spot on the rockgarden.

A. stelleri, a Chinese species, is a much freer flowering plant than A. blepharophylla. It ripens in seed freely and is easily grown in the rock-garden.

Aralia.-Plants of diverse aspects, but few of them fitted for open air, except A. canescens and A. spinosa, which thrive in our gardens, and which in size and beauty of leaf are far before many "finefoliaged plants" carefully grown in hothouses. These and even the tender kinds may find a place in the flower garden, and the vigorous herbaceous ones in the woodland. By cutting the shrubby species down occasionally they may be kept in the condition of fine-leaved plants, like the Ailantus treated in like manner.

\section{A. papyrifera Chinese Rice-paper} plant).- This, though a native of the hot island of Formosa, grows well with us in the summer months, and is useful for the greenhouse in winter and the flower garden in summer. It is handsome in leaf, and, like all the large-leaved plants, must be protected from cutting winds. If planted in a young state, it does best. Prefer, therefore, dwarf stocky plants 
when planting it in early summer. It should have rich deep soil and plenty of

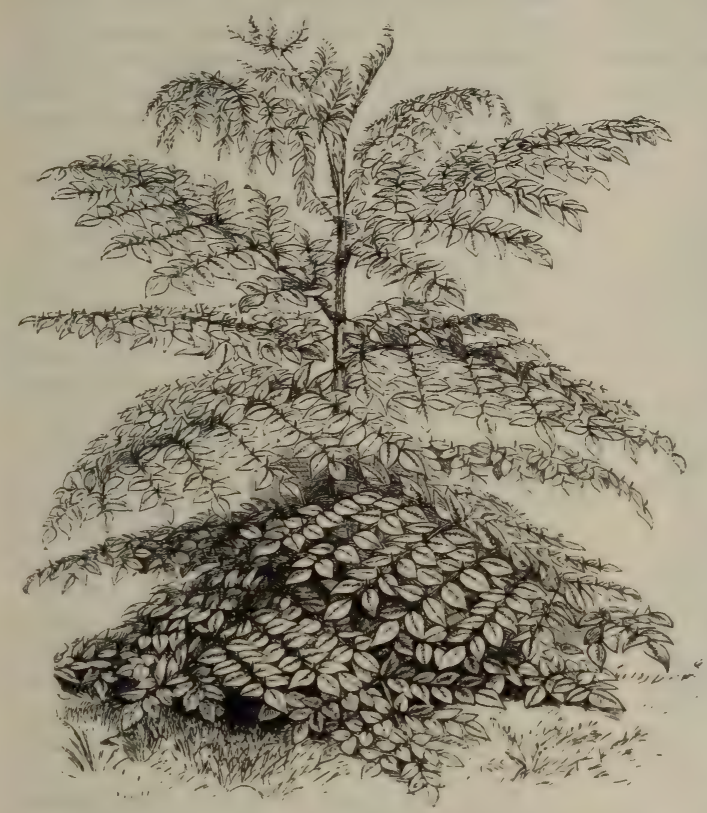

ARALIA SPINOSA (ANGELICA TREE).
A. Sieboldi.-A shrubby species, with fine green leaves, usually grown as a greenhouse plant, but nearly hardy, and a handsome bush on dry soils. It grows well in rooms; and, in fact, it is one of the few plants of like character that will carry leaves there in winter. It may be used in the flower garden or the pleasure-ground, for isolated specimens on the turf, or for association with fineleaved plants. Syn., Fatsia japonica.

A. spinosa (Angelica Tree) is useful among sub-tropical plants from the beauty of its foliage. Like many hardy things, it should not be placed where it would be necessary to remove it, or associated with tender plants requiring frequent removal. Flowers in autumn, small, white, in large umbels. In most cases it has a single erect stem, and it should be kept to this habit. The stem is clad with fierce spines. This fine shrub has often been put in exposed places, but is better planted where its great leaves will not be torn. Usually not more than Io $\mathrm{ft}$. high; and in

water during the hot summer months. In Battersea Park a bed, I $3 \mathrm{ft}$. in diameter, of cuttings struck in the spring, attained a height of $5 \mathrm{ft}$. The plants were left out all the winter, and, though killed to the ground, sent up many suckers in the following spring. It is so fine in leaf and habit that no one will be at a loss to place it where it will have a good effect. In the north it is not so useful in the open air as in the south and about London. "Its stem, being nearly all pith, does not strike readily; but if the roots near the stem are examined they will be found to be fleshy. When the plant is taken up, cut each root into pieces about $\mathrm{I}$ in. long ; insert them in light soil, cover the whole, and place them on a shelf near the glass in a temperature of $80^{\circ}$. They will throw out shoots, which should be left until 3 in. in length, when they may be potted, leaving them in heat, say of $70^{\circ}$, until established. They should then be removed to a colder temperature and thence to a frame to harden off. In the south of England this plant is almost hardy, and may be wintered in a cold frame, but should be kept dry."-J.

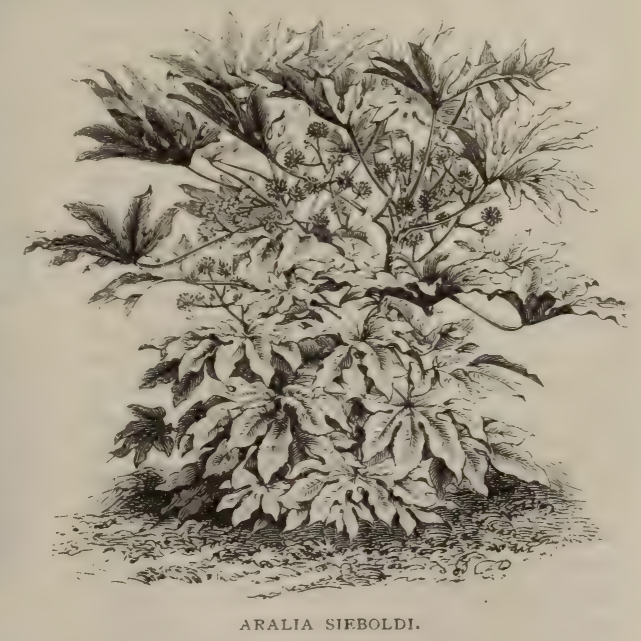

A. californica, edulis, and racemosa are vigorous herbaceous kinds of slight value, except where a large number of such 
perennials are desired in botanic gardens or very large collections.

Arbutus (Struiberry Tree). - This beautiful evergreen shrub (A. Unedo) is chiefly met with in warm and coast districts, where it grows $2 \mathrm{c} \mathrm{ft}$. high or

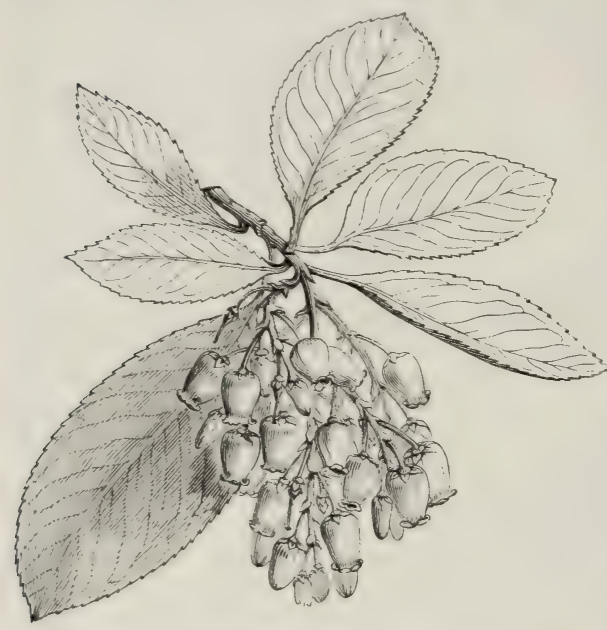

FLOWERS OF ARBUTUS UNEDO (STRAWBERRY TREE).

more. Inland it is cut down in severe winters. There are varieties of it. One of the best is A. Croomei, which has longer and broader leaves than the common kind. The variety rubra has flowers of almost a bright scarlet, coming in autumn. One variety has double flowers, while others differ from the original in the size and form of leaves. Thus there are the Oakleaved (quercifolia), Myrtle-leaved (myrtifolia or microphylla), Willow or narrowleaved (salicifolia), and the crimpledleaved form (crispa), all of which are interesting, but not so beautiful as the common sort, or as Croomei and rubra. S. Europe. Also wild in the south of Ireland.

The other species are not so important as flowering trees, though they are invaluable Evergreens. They are more treelike than A. Unedo. A. Andrachne, with smooth ruddy-tinged bark, is the commonest, and is hardy everywhere in the south and coast districts. About London it reaches a height of over $15 \mathrm{ft}$. It grows wild in Greece, and is a very old tree in gardens. A. hybrida, said to be a hybrid between A. Unedo and A. Andrachne, is hardy, and in growth resembles both its parents ; its flower-clusters are larger than those of A. Unedo and smaller than those of A. Andrachne. A. Milleri is handsome, its flowers are pink and its leaves large.
A. procera (also called A. Menziesi), from N.-W. America, is not common, and resembles A. Andrachne, but is less hardy. Other kinds named in catalogues-photinæfolia, magnifica, Rollissoni, serratifolia, laurifolia or andrachnoides-are either identical with the foregoing or varieties of them.

Arctomecon californicum.-A N. American plant of the Poppy family, of which little is known in cultivation.

Arctostaphylos alpina is useful for rocky banks, edging bog-beds, or even in bogs.

A. Uva-ursi (Bear-berry). - A dwarf evergreen mountain shrub, I foot high - often less-sometimes grown with rock-plants. Has small rose flowers in early summer and red berries in autumn. Abundant in hilly places in Europe and N. America. Borders and ledges. Grows in any soil, but prefers a moist one. Division.

Arctotis. - These Cape plants number between forty and fifty species; they are, however, little known, and although many have been cultivated, it would be difficult to find more than half-a-dozen distinct kinds in collections. Judging from coloured figures chiefly, the majority are of some beauty, and, if reintroduced, would form a collection of no small value, as most of

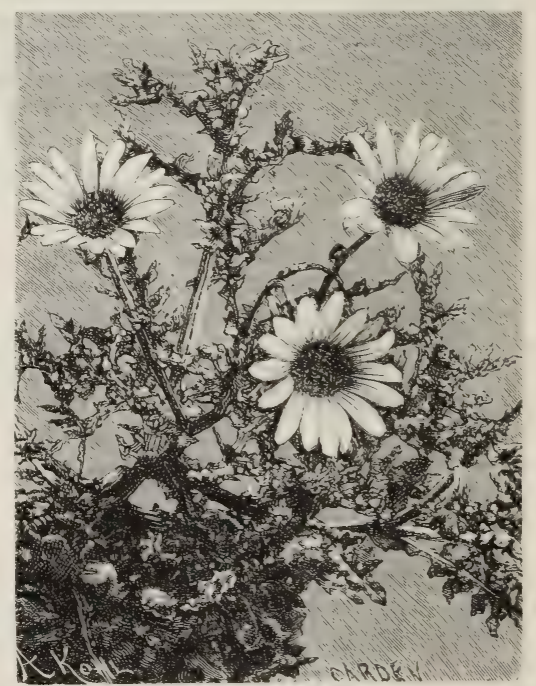

ARCTOTIS ARBORESCENS.

them may be grown out-of-doors in summer. The cultivation is much the same as that required for Calceolarias. The bright colours of many of the species 
are more intense with the light and exposure of the open air than when the plants are cramped in pots in a greenhouse. Dry sunny banks often devoid of plant life might be readily and beautifully clothed with A. acaulis, A. aureola, A. grandiflora, and A. aspera, all of which may be managed as easily as bedding plants. Cuttings may be taken off and rooted at any time during the summer, the old plants being left to flower until cut off by the autumn frosts. Although true sun-loving plants, they may be effectively used as a groundwork in spots where, unmindful of the shade if not too dense, they flower almost as freely as when fully exposed to the sun.

A. acaulis, figured in The Garden, Nov. I 889 , is apparently a very variable species. The form in cultivation, undoubtedly the finest of this species, is identical with the plant figured by Jacquin as A. undulata. It was first introduced about I759, and was reintroduced a few years ago through the Kew Gardens. The very attractive flowers are large, and of a deep rich orange. A. acaulis does not ripen seed freely, but is easily propagated from side shoots.

A. aspera, a half-shrubby species, with deeply cut and wrinkled leaves and creamy flowers, purplish outside. It may be used effectively in vases and hanging baskets, the exquisite pink buds being very pretty. Cuttings strike readily in heat.

A. aureola. - This beautiful species is known in gardens as A. grandiflora. It grows from I to $2 \mathrm{ft}$. in height, and is of a shrubby habit, producing its handsome orange flowers towards the end of the branches. Cuttings taken off towards the end of July and August root freely in a cold frame.

A. Leichtliniana.-This is known in gardens as A. speciosa. In habit it is similar to A. aureola, but is more straggling, and the golden-yellow flowers are not quite so large.

A. leptorhiza is one of the most showy annuals we grow. The flowers, of a rich orange, are borne freely. The seeds may be sown in the open air, the plant being treated as a hardy annual. A sunny spot should be chosen and the seedlings well thinned.-K.

Arenaria (Sandwort).-A very numerous family, of vast distribution over northern and alpine ranges, and in temperate countries. Few kinds of the great number known are in gardens, and these kinds are dwarf plants, easy to grow, and suited for the rock-garden.
A. balearica (Balearic Sandwort).-A pretty little plant, which coats rocks and stones with verdure, and scatters over the green mantle countless white starry flowers. Plant firmly in any common

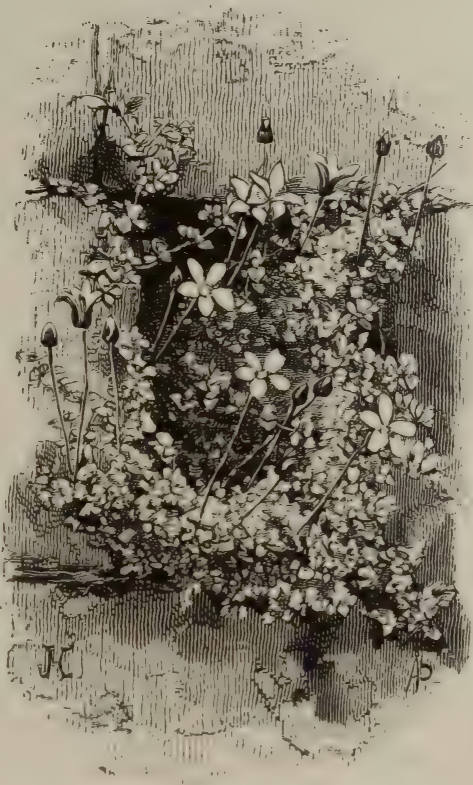

ARENARIA BALEARICA (BALEARIC SANDWORT).

soil near the stones or rocks it is to cover, and it will soon begin to clothe them. Flowers in spring, is readily increased by division, and is quite easy to grow. On cold soils it perishes in winter, but its home is the rock-garden. I first used it for carpets beneath tea roses at Gravetye, and also for low rough stone walls against banks, over which it spread in myriads. Corsica.

A. montana (Mountain Sandwort).-A pretty rock-plant, having the habit of a Cerastium, and fine large white flowers. It is the best of the large Sandworts, and should be in every collection of rockplants. It is hardy and free, and is therefore best to go with the more vigorous rock-plants. France. Seed or division.

A. norwegica is one of the best kinds, and quite hardy, forming dense cushions about 6 in. in diameter, covered with large white flowers all through the summer. A fine alpine plant. Norway.

A. purpurascens (Purplish Sandwort). -With purplish flowers, on a dwarf tufted mass of smooth, oval, pointed leaves. Plentiful over the Pyrenean 
chain, hardy, and, like the other kinds, increased by setd or division. It should be associated in the rock-garden with the smallest plants.

Of other Arenarias in cultivation, the best are $\mathrm{A}$. ciliata, a rare British plant; A. verna, A. triflora, a neat species; A. laricifolia, A. graminifolia, and A. tetraquetra. These, however, are scarcely worth growing except in botanical collections.

Arethusa bulbosa. - A beautiful American hardy Orchid, which grows in wet meadows or bog-land, blossoming in May and June. Each plant bears a bright rose-purple flower that shows well on its bed of Sphagnum, Cranberry, and Sedge. The little bulbs grow in a mossy mat formed by the roots and decaying herbage of plants and moss. In cultivation it requires the same soil. Care must be taken to get the leaf as well matured as possible. Coming after the flower, the leaf is apt to be neglected. A good outdoor position for growing it is a shady moist spot with a northern exposure; the soil should be a mixture of ivell-rotted manure and Sphagnum. During winter, the bed should be protected with some cover, for it is not so hardy in gardens as in its bog home. Bog-garden or a moist bed near the rock-garden.-F.

Aretia Vitaliana (Androsace).

Argemone (Prickly Poppy).-Handsome Poppy-like plants, said to be perennial, but perishing on moist soils after the first year. As they come from the warmer parts of California and

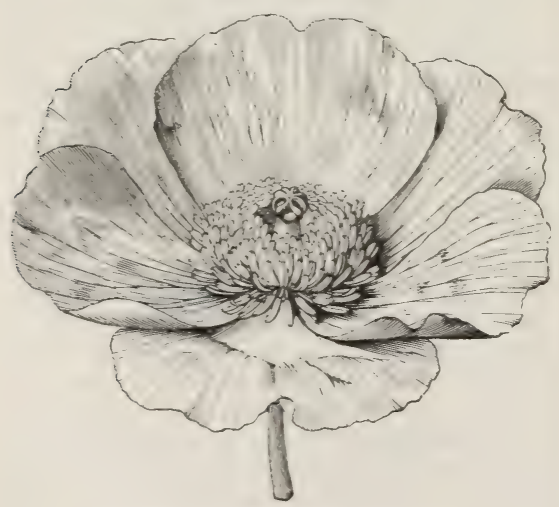

FLOWER OF ARGEMONE MEXICANA.

Mexico, and even there grow on dry hill-sides and in warm valleys, their perishing here may be understood. Usually about $2 \mathrm{ft}$. high, having large white flowers 4 in. across with a bunch of yellow stamens in the centre. They should have a warm loam, and go with the choicest annual flowers. The kinds mostly grown are A. mexicana, A. grandiflora, and A. hispida, which are so much alike in habit as not to need separate description. Seed in a warm frame.

Arisæma (Indian Turnip). - N American plants of the Arum Order, and though curious for the botanic garden, of little merit for the ordinary garden. In A. triphyllum the spathe is curiously marked with purple and white stripes. A. Dracontium is the "Green Dragon," and A. triphyllum is called "Jack in the Pulpit" in America. Arisæma are hardy and grow easily on the margins of beds of shrubs.

Aristolochia Sipho (Dutchman's Pipe). - This well-known large-leaved plant has an excellent effect where large foliage is desired. Generally used as a wall-plant, it is far finer for covering bowers, or any such structure, or for clambering up trees or over stumps. A. tomentosa is smaller,

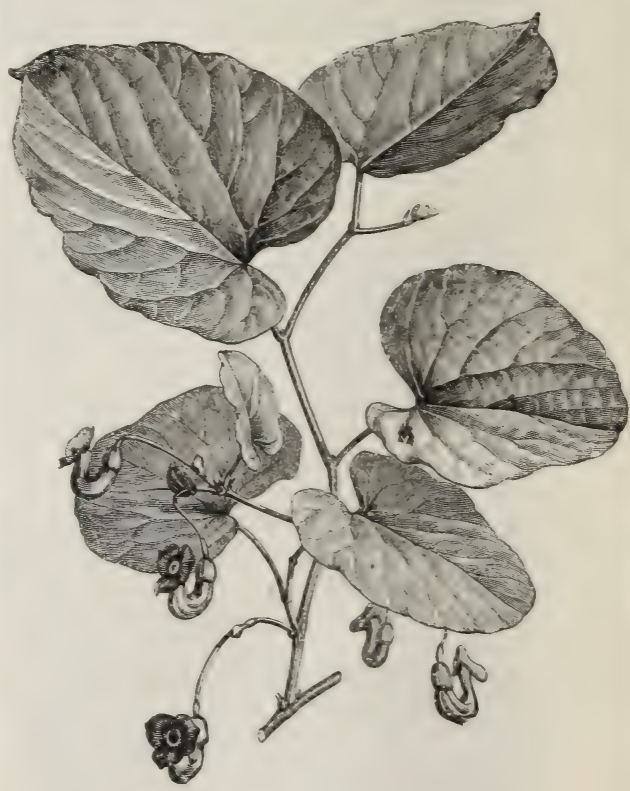

ARISTOLOCHIA SIPHO (DUTCHMAN'S PIPE).

but distinct in tone of green, and is well worthy to be employed in like manner. N. America. These plants grow with freedom in ordinary garden soil. The hardy non-climbing herbaceous kinds have no claim to cultivation. The genus is a large one, mainly tropical, but some 
of the species go into the northern countries. Cuttings.

Armeria (Thrift, Sea Pink).-Pretty plants of the Statice Order, most of which are worthy of culture. The best-known is the common A. vulgaris (Thrift). This native of our shores, and of the tops of the Scottish mountains, is very pretty with its flowers of soft lilac or white, springing from cushions of Grass-like leaves ; but it is the deep rosy form, rarely seen wild, that best deserves cultivation. It is like the common Thrift, save that the flowers are of a showy rose. It is useful for the spring garden, for banks or borders in shrubberies, for edgings, and for the rockgarden. Easily increased by division, and as old plants do not bloom so long as young ones, occasional replanting is desirable. In addition to the white variety and the old dark red one, there are Crimson King, grandiflora, pygmæa, and Pink Beauty.

A. cæspitosa.-A rose-coloured kind from the south of Europe, 5000 to 8000 $\mathrm{ft}$. above the sea-level. Its flower-heads, each from $\frac{3}{4}$ in. to $I$ in. in diameter, are borne on slender stems I to 2 in. high, from June to September. The leaves are in dense tufts, with a branching woody root-stock. A rock-garden plant, thriving in any well-drained, rather poor, sandy loam. In wet weather apt to damp off at the neck in rich soil. There are other good alpine species, but the above are the best. Seed.

A. cephalotes (Great Thrift).-One of the best hardy flowers, and should be in

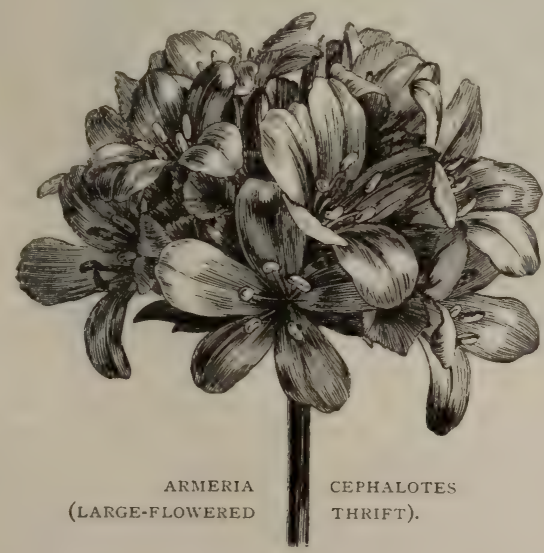

every good border and on every rockgarden among the taller plants. Hardy on free and well-drained soils, it now and then perishes in hard winters, especially on cold soils; it should therefore have good dry and sandy loam. It is known as Armeria formosa, A. latifolia, A. mauritanica, A. Pseudo-Armeria, Statice lusitanica, and Statice Pseudo-Armeria. Easily raised from seed; and as it is not so easily increased by division, it is well to sow some seed every year. Varies a little when raised from seed, but all the forms are worth growing. This species and its forms have flowers very much larger than the common Thrift. S. Europe and N. Africa.

A. setacea.-An alpine species. Its little globose heads of pink flowers are so numerous as almost to conceal the plant. Flower-stems from I to 3 in. high. This and A. juncea are found in the $S$. of France on barren stony mounds and on elevated tablelands. They are hardy and of easy culture, growing freely in stony earth, either in the open border, on rocks, or in pots.

Arnebia echioides (Prophet-flower).These Borage-worts are among the handsomest of border flowers. This, though not so showy as some, is among the most remarkable, growing I ft. to $\mathrm{I} 8 \mathrm{in}$. high. The flowers, of a bright primrose-yellow, have five black spots on the corolla, which gradually fade to a lighter shade, and finally disappear. It is perfectly hardy, and succeeds either on the rock-garden or in a well-drained border, and prefers partial shade. It is a native of the Caucasus and Northern Persia, and though long introduced, it is still among the rarest of hardy flowers. Young plants bloom long, which adds to their charms. Increased by seeds, which are not freely produced, and by cuttings. A. Griffithi is a tender annual, and though pretty, is not so valuable as A. echioides.

Arnica.-One or two at a timeare sometimes cultivated, but are of slight value, considering the great number of good plants of the same family there are in gardens. A. montana, with orange-yellow flowers, is occasionally grown in botanical collections.

Aronicum.-A genus of few species, some of which are in cultivation, but though striking when in flower, it is not of the first merit for gardens. A. glaciale (Glacier A.), 6 to 9 in. high, has large yellow flowers, one to a stem. A. scorpioides (Mountain A.), I ft. high, has large orange flowers, one to a stem. Alps of Europe ; seed and division.

Arrow-head (Sagittaria sagittifolia).

Artemisia (Wormwood).- Herbs and low bushes occupying a large part of the surface of northern and arid regions. Though often poor weeds, some have a 
use in gardens, though rarely for their flowers. A. anethifolia is one of the most graceful herbaceous perennials. It is 5 ft. in height. A. annua is a graceful plant with tall stems 5 or $6 \mathrm{ft}$. high, the foliage is fine, and the flowers though inconspicuous, arranged in elegant panicles. The hue is a fresh and pleasing green, and the plant is a graceful centre of a flower-bed or group. A. gracilis is graceful, 3 or $4 \mathrm{ft}$. high, with leaves cut into hair-like segments, having some resemblance to Fennel. Other kinds, like A. alpina and A. frigida, belong to an alpine group which is at home in the rock-garden; there are many taller herbaceous and half-woody plants of a silvery hue, such as A. Stelleriana, A. cana, A. maritima, and some with handsome Fern-like foliage like A. tanacetifolia. Other species are for the most part less ornamental than the common Wormwood and Southernwood. There is, however, what is called an Indian form of the common A. vulgaris, which is wonderfully graceful and very tall ( $8 \mathrm{ft}$.) Mostly raised from seed, but also from cuttings. The taller and more graceful kinds are effective and distinct among groups of plants of fine habit or graceful foliage. In districts too cold for half-hardy plants some of them might be of good service.

Artichoke, Globe (Cynara Scolymus).

\section{Arum, Bog (Calla palustris).}

Arum Lily (Calla athiopica).

Arum (Cuckoo Pint).-Plants mostly from warmer countries than ours. Some from South Europe are hardy, and of interest in our gardens ; for example, the Italian Arum (A. italica), the foliage of which is handsome in winter and spring. The old Dragon's Arum (A. Dracunculus) is curious, and Arum crinitum is still more so. They thrive best in warm borders and about the sunny side of garden walls, the Italian Arum thriving more freely. Some nine or ten kinds are found in South Europe, two coming as far north as our own country. Often growing with the Primroses, we find peering through the Moss or Ivy-clad bank, the shining green leaves of our native Wild Arum, familiarly known as "Lords and Ladies" and "Cuckoo Pint." Closely related to it is A. Arisarum of the South of Europe and A. azoricum of the Azores.

A. crinitum (Dragon's Mouth).-This plant when in flower is very grotesque from the singular shape of its broad speckled spathe. The leaves are cut into deep segments, and the leaf-stalks, overlapping each other, form a sort of spurious stem I ft. or I4 in. high, marbled and spotted with purplish-black. The treatment is similar to that for A. Dracunculus; but as it is rather more tender it will require a little more care and shelter in winter. Warm borders, fringes of shrubberies, or beds of the smaller sub-tropical plants suit it best. The appearance of the flower is rather repulsive. In this species the carrion-like smell known in other kinds is strongly developed, and doubtless gave rise to Linnæus's name of A. muscivorum, as it attracts the larger flies in quest of a suitable place for their eggs. It is a strange plant seen holding its awful "blossoms" out of a mass of low shrubs. Division of tubers. S. Europe.

A. Dracontium (Green Dragon Arum). - Abundant in the moist and swampy districts of Virginia and New England. The graceful curving of the veins, noticeable in all the species of this section, adds a special charm to the plant; the spathe is greenish. A. triphyllum, A. gramineum, A. spirale, A. corsicum, A. tenuifolium, and other species are in cultivation.

A. Dracunculus (Dragons, Snake Plant) generally attains a height, when growing vigorously, of 2 to $3 \mathrm{ft}$. ; the leaves large; the stalks and stem of a fleshy colour, deeply mottled with black, reminding one of the skin of a snake, whence its popular name of Snake Plant; the large spathe is a deep chocolate. At certain stages a disagreeable odour is given off by the flower, reminding one of decomposing animal matter ; this appears spasmodic, as at one time it may be sufficiently powerful to cause nausea, and in a few minutes every trace of it may have disappeared. It loves best a corner to itself in sandy loam at the foot of a south wall. Beyond use in this way it is only important as a curious and distinct plant. Many would not care for a plant having such an odour. Division. S. Europe.

A. italicum (Italian Arum) is larger than our native Arum; the veins, blotched with yellow, give the leaves a marbled appearance, and as they come very early in the season, they are attractive in the flower border. In the autumn, when the leaves have died away, the clusters of scarlet berries, on foot-stalks Io in. or 12 in. long, are showy. The true use for it is as a naturalised plant, or in the shrubbery, where its handsome leaves will come up bravely in spring. Although hardy, and thriving anywhere in moist soil and a shady place, it prefers sheltered positions along the sunny margins of shrubberies, amid low-spreading evergreens, and in 
cosy spots about ferneries, so as to prevent its handsome foliage from being disfigured by wintry winds. Division in the end of summer. South of Europe.

Aruncus (Spircea Aruncus).

Arundinaria (Bambusa).

Arundo (Great Reed).-An important family of Grasses, some of great value. where it grows well. It commences blooming in July, lasting until the end of October. The Pampas rarely comes out in full flower before November; the Arundo, therefore, as beautiful when well grown, has the great value of being so early. Grown in tubs in a cool greenhouse or winter garden, this noble Reed is very

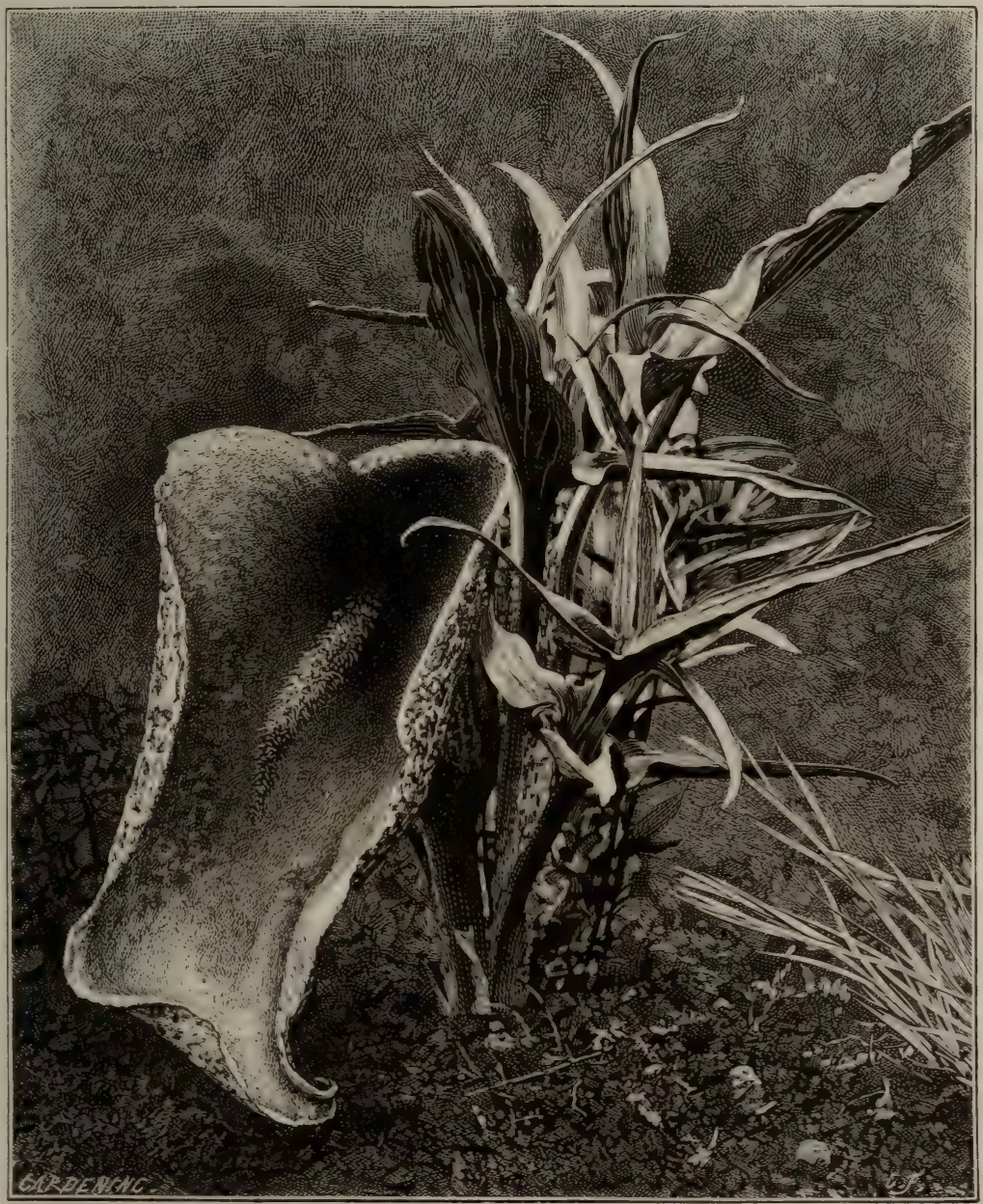

ARUM CRINITUM (DRAGON'S MOUTH).

A. conspicua (New Zealand Reed).A companion for the Pampas Grass, especially in the western counties and on good soils. In some very fine deep loams it reaches a height of nearly $12 \mathrm{ft}$. It is well worth growing, even where it does not grow very well. It flowers before the Pampas Grass, and is a forerunner of that magnificent plant. It makes a noble specimen for the lawn, handsome, and its silky plumes last in perfection much longer than in the open air. It likes strong, fibrous, loamy soil, and plenty of water nearly all the year round. Seeds or division. It requires careful planting, and generally several years' growth after transplanting before flowering.

A. Donax (Great Reed).-This great Reed of the south of Europe is a noble 
plant on good soils. In the south of England it makes canes Io ft. high, and has a very striking aspect. It will grow even higher in a rich deep soil in a warm

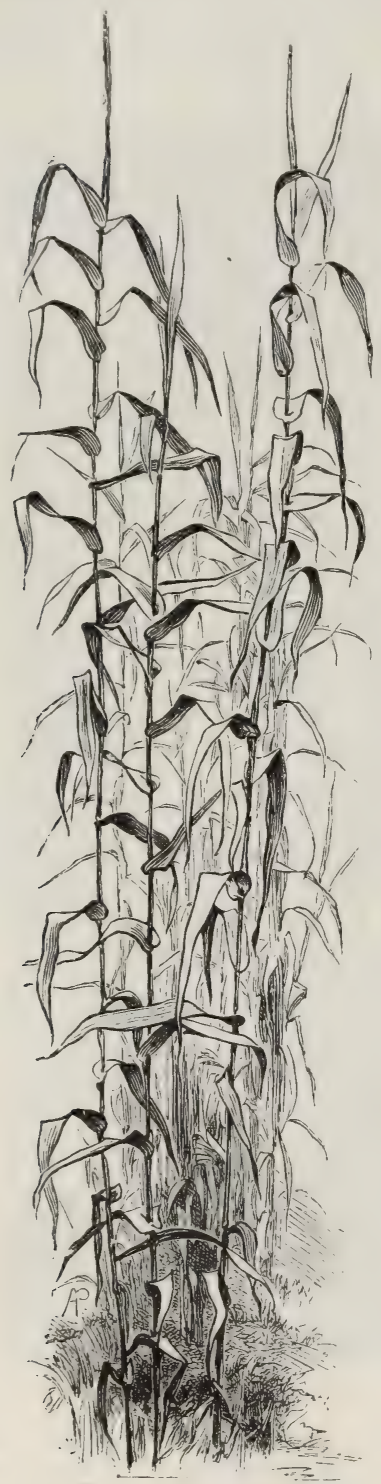

ARUNDO DONAX (GREAT REED).

garden. In our country it prefers deep sandy soil to heavy ones, and it loves shelter. It has suffered much in recent severe winters, perishing in some southern gardens where it was finest. But, fine as it is for effect and distinctness, its variegated variety is of more value for the flower garden proper.

A. Donax versicolor.-Nearly hardy in the southern counties, and north of London may be saved by a little mound of Cocoa-fibre, sifted coal-ashes, or like material. It is best suited to warm, free, and good soils, and abhors clay. As the centre of a circular bed nothing is better in the summer flower garden, while other charming uses may be made of it. Not the least happy of these would be a group on the turf, in a warm spot. It is better to leave it in the ground than to take it up annually. Protect the roots in the winter, whether in the middle of a flower-bed or alone on the Grass. Increased by placing a shoot or a stem in a tank of water, when little plants with roots will soon start from every joint; they should be cut off, potted, and placed in frames, where they will soon be strong enough for planting out.

A. mauritanica.-This is a fine Grass - a stately one but for its great relation A. Donax. It is a native of the southern shores of the Mediterranean, hardy in the neighbourhood of Paris, where it reaches a height of about $4 \mathrm{ft}$. Might be grown with a collection of aquatics or Grasses.

A. Phragmites (Common Reed).-A native marsh or water-plant, $6 \mathrm{ft}$. or more high, bearing when in flower a large, handsome, -spreading, purplish panicle. Useful for the margins of artificial waters, to which it may be brought from its wild haunts. It should, however, if possible, be kept in one spot and not allowed to spread too much. Where it grows wild there is usually no scarcity of it. An excellent cover for ducks.

Asarum (Asarabacca).-Curious little plants resembling Cyclamens in their leaves, but of little value except as curiosities, and occasionally as wood or shrubbery plants. A. canadense is the Canada Snake-root, which bears in spring curious brownish-purple flowers. Root strongly aromatic, like Ginger. A. virginicum is the Heart Snake-root. Leaves thick and leathery, with the upper surface mottled with white. Sometimes used as a spice; hence the common name Wild Ginger. The plants are more or less used in medicine. A. caudatum is from Oregon. Much like the others in habit, but the divisions of the flower have long tail-like appendages. A. europæum is the Asarabacca. Flowers greenish, about $\frac{1}{2}$ in. long, and close to the ground.

Asclepias (Milk-weed, Silk-queed).-A 
large group confined to the New World, and, with but few exceptions, to the northern part of it. Almost all are hardy and ornamental, though not showy; and are useful both in the wild garden and in shrubbery borders. The following are a few of the most distinct:-

A. Cornuti (The Common Milk-zveed).A vigorous plant, $4 \mathrm{ft}$. in height, bearing nodding umbels of deep purple fragrant flowers. Bees seem fond of it. It is quite hardy, being easily increased; and blooming a considerable time, it should prove a valuable bee-flower. Coarse for the border, but may be worth a place in the wild garden. Syn., A. syriaca.

A. incarnata (Swamp Milk-zeed).Three ft. in height, with long leaves and leafy stems, and umbels of rosy purple flowers in pairs. The variety called pulchra has broader foliage than that of the type. A good waterside plant.

A. purpurascens (Purple Milk-weed).A very distinct species, the stems slender, from 2 to $3 \mathrm{ft}$. high, with umbels of bright purple blossoms.

A. quadrifolia (Four-leaved Milkweed).-A deliciously fragrant flower, and the earliest to blossom-coming into bloom in early summer. One to two $\mathrm{ft}$. high, with one or two whorls of four leaves about ${ }^{\circ}$ the middle of the stem; but the other leaves-lower and upperare in pairs, and the terminal heads of lilac-tinged white flowers are sweet and pretty.-W. F.

A. rubra (Red Milk-weed).-A distinct kind with long bright green foliage, and stems 3 to $4 \mathrm{ft}$. in height; umbels large, and from two to five deep 'purplish-red flowers on a naked terminal peduncle. Syn., A. acuminata.

A. Sullivanti.Similar to A. Cornuti, but the fragrant flowers are larger, and deeper in colour.

A.tuberosa (The Butterfly $W e e d)$.One of the most beautiful of autumnal flowers. It is a hardy perennial, having a thick root, and erect leafy stems about $2 \mathrm{ft}$. in height, crowned with corymbs of bright orange-red flowers. It prefers sandy soil, and, when well established, is very pretty.
During hot autumns it bears seeds from which good flowering plants may be obtained in three years ; but it is mostly increased by division of tubers. A fine border plant, but only on warm soils.

A. variegata (Variegated Milk-weed). - Stems spotted and downy, 2 to $3 \mathrm{ft}$. high ; flowers white, with a reddish centre, in large umbels. One of the showiest of the family.

A. verticillata (Whorled Milk-weed). -Quite unlike the majority, in its slender habit, narrow leaves, and delicate, small white flowers, which are abundant in summer. In poor soil nearly $2 \mathrm{ft}$. high.

Asclepiodora decumbens (Green Milkweed). - A low stout herb with umbels of greenish and purplish flowers, resembling those of the Milk-weeds in appearance, but different in structure. Texas. Of little garden value.

Ascyrum (St. Peter's Wort).-A small genus of sub-shrubby plants of little garden value. The best-known, A. Crux Andreæ (St. Andrew's Cross), is a small yellow-flowered kind, often classed with the St. John's Wort (Hypericum).

Asimina (Virginian Papaw). - A North American shrub, interesting to those who like curious plants. A. triloba, with leaves like the Chimonanthus, forms a small tree, with dull purple flowers about 2 in. across. It bears fruits eaten by the inhabitants of the Southern States; hence the name. Usually grown against a wall in this country, but hardy as a standard, at least about London.

Asparagus.-Some species are inter-

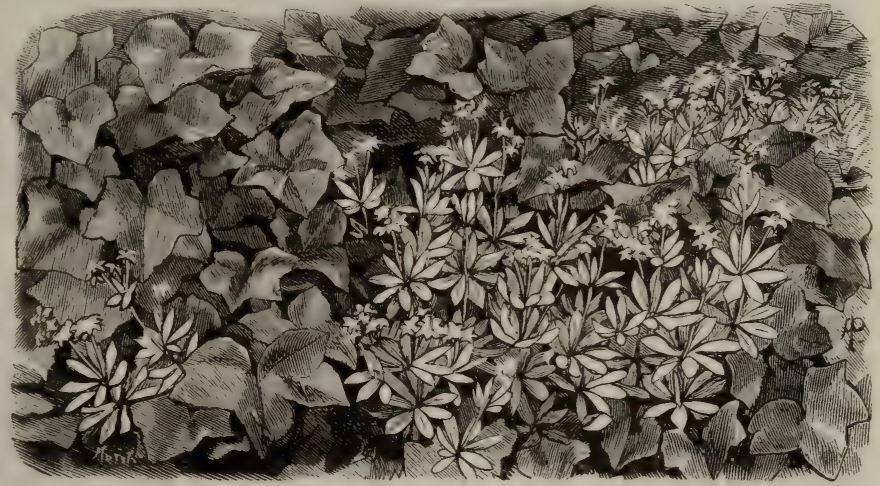

ASPERULA ODORATA (WOODRUFF). esting from their elegant leaves or bold habit. The vigorous and tall A. Broussoneti is quite hardy, and so are A. tenuifolius and others. The common Asparagus is as good as any, and a 
tuft or group of it is effective and graceful in a border of flowers or a bed of fineleaved plants.

Asperula odorata (Woodruff).-This little wood-plant, abundant in many parts of Britain, is worthy of the garden or shrubbery, especially in places where it does not occur wild. Many would like to preserve its stems and leaves for the fragrant hay-like odour they give off when dried; and in May the small white flowers, profusely dotted over the tufts of whorled leaves, look very pretty. It is one of the plants that will cover the earth in a shrubbery where the barbarous practice

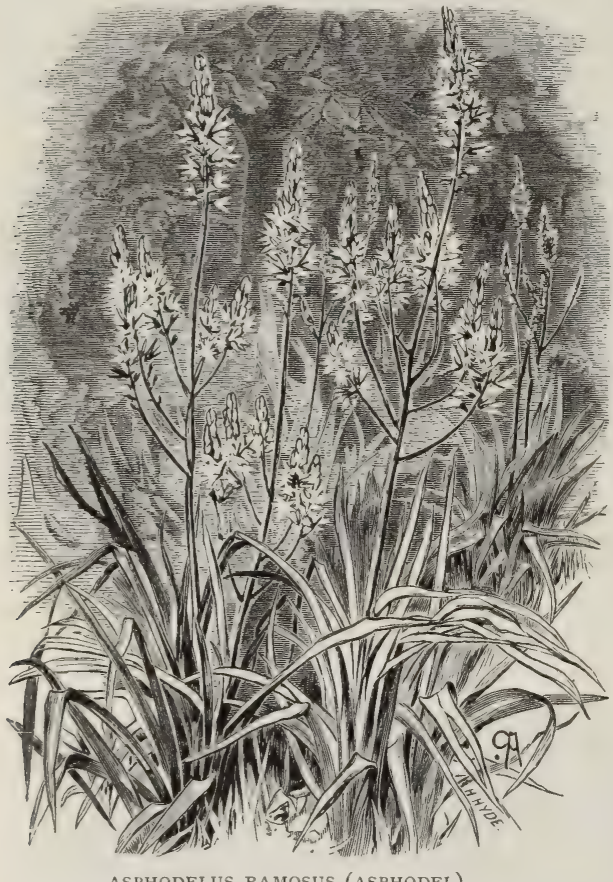

ASPHODELUS RAMOSUS (ASPHODEL)

of annually digging up the borders is not resorted to. It is sometimes used as an edging to beds in cottage gardens. It is, however, as a wood or shrubbery plantas a companion to the Wood Hyacinth and the Wood Anemone-that it will be at home. It is largely used in Germany for flavouring summer drinks. It mixes charmingly with Ivy where that clothes the ground.

A. azurea setosa is a pretty hardy blue annual, flowering in April and May. Sow in the previous autumn. A. cynanchica is a rosy-red perennial, and a good bank or rough rock-plant.

Asphodel (Asphodelus).-The name is also applied to Narcissus poeticus in some parts of the country.

A. Bog (Narthecium ossifragum).

Asphodelus (Asphodel). - Liliaceous plants, not long in bloom and not of the first order of beauty. There are some half-a-dozen kinds in cultivation. The best-known is the bold $\mathrm{A}$. ramosus (tall Asphodel), a South European species, familiar in most old herbaceous plant borders, but better fitted for the shrubbery or the wild garden. The stems grow from 3 to $5 \mathrm{ft}$. high, bearing numerous white flowers. Varieties are albus, cerasiferus, and microcarpus, similar to the type in general aspect. Other kinds are $\mathrm{A}$. fistulosus and tenuifolius, with white flowers, growing from $\mathrm{I} \frac{1}{2}$ to 3 $\mathrm{ft}$. high, and growing well in any border or position. The last-named kind has delicate feathery foliage and is a contrast to bold foliage plants. A. acaulis (the stemless Asphodel) is singularly interesting, being only an inch or so high, and bearing its flowers in a dense cluster, surrounded by a tuft of narrow Grass-like foliage.

Asphodeline.-Plants nearly allied to the preceding, but the stems of Asphodelus are leafless, while in Asphodeline the leaves are produced on erect stems. About six species are in cultivation, the best-known being A. lutea (tall yellow Asphodel), about $3 \mathrm{ft}$. high, with yellow flowers in dense clustered spikes. A. taurica has white flowers, on stems I to $2 \mathrm{ft}$. high. A. liburnica (A. cretica) and A. tenuior have yellow flowers in loose racemes. A. damascena has white blossoms in dense racemes, and A. brevicaulis has yellow flowers in loose racemes. These are all of vigorous growth and easy culture, thrive in any common garden soil, and may be used in bold masses with good effect among other tall plants.

Aspidistra lurida (Parlour Palm).A native of Japan, I8 to 24 in. high, with long graceful evergreen leaves and dull purple flowers on the surface of the soil. One of the most lasting of fineleaved plants in rooms. There is a variegated form. Both are used with good effect in some gardens, and the plant is hardy in certain districts. Of the two kinds we much prefer the evergreen one. Division.

Aspidium (Shield or Wood Fern).This genus now embraces the Polystichum and some species of Lastrea. There are numerous hardy kinds, including some of the finest hardy Ferns, 
among them the Male Fern (A. Filix-mas) and the Prickly Shield Fern. These are most useful plants, thriving even in small town-gardens and places similarly confined. All they require is plenty of water in hot dry weather. Either alone or in groups they have a fine effect, particularly as an undergrowth to trees in the pleasureground or in the shadier parts of the garden. These are evergreen, and therefore invaluable for the garden. Their varieties are endless, no fewer than a hundred named sorts of A. aculeatum (the Holly Fern) is one of the finest evergreen hardy Ferns. It grows in clefts of rocks, and in gardens should be planted between pieces of grit rock in a mixture of loamy turfy peat and sand. A. munitum is a beautiful North American species, requiring little beyond a peaty soil and a shady situation. Other good ferns are A. rigidum, A. Oreopteris, A. Thelypteris, A. spinulosum, A. cristatum, A. acrostichoides, A. montanum, which succeed in a mixture of loam, turfy peat, and sand, in moist and shady corners.

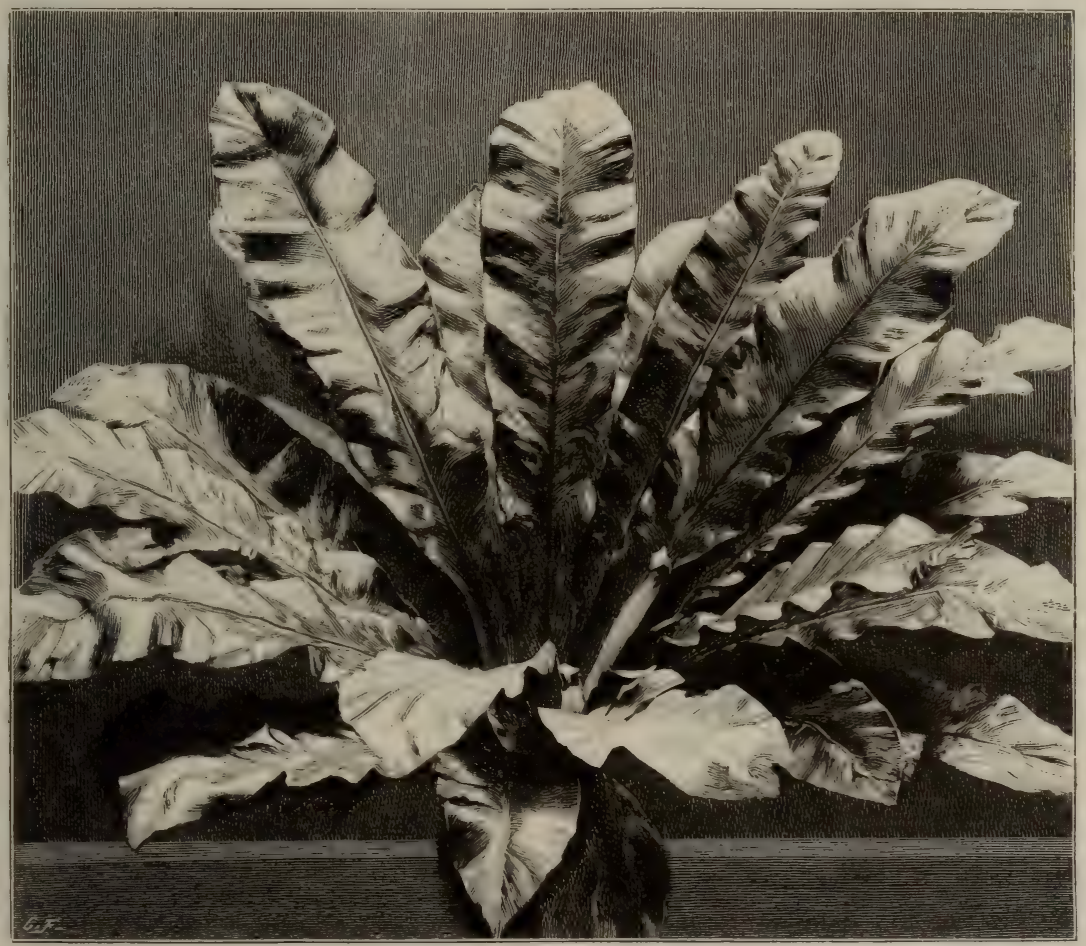

ASPLENIUM AUSTRALASICUM (AUSTRALIAN BIRD'S-NEST FERN).

and fifty of A. Filix-mas being enumerated in trade lists. The larger varieties are noble plants when well grown, and have a fine effect in shady spots, but the smaller and more delicate kinds require more care. A. aculeatum succeeds best in rich loam, with sand and leaf-mould, well drained; and so does the Male Fern.

A. dilatatum (Broad Buckler Fern) is a pretty Fern, of which there are some handsome varieties, especially the crested sorts. It requires a fibrous peat loam and sand and a moist situation. A. cristatum (Crested Shield Fern) is handsome and easily grown. A. Lonchitis
Asplenium (Spleenwort). - Few hardy evergreen Ferns are more useful than these, the fine dark green colour and free-growing character of most of the varieties making them favourites. The best soil for them is a well-drained mixture of peat, sand, and loam, just the sort of material in which the finer kinds of flowering shrubs, such as Kalmias and Andromedas, thrive. A. Adiantum-nigrum (the Black Spleenwort) would be at home amongst hardy Azaleas, because these lose their foliage in winter, and the Spleenwort would then carpet the surface. The shade, too, of Azaleas in the summer, 
if not planted too thickly, would suit this Spleenwort, which when wild fringes copses or is found on hedge-banks, where it gets a little protection from the summer sun. There are several distinct forms of this Asplenium, the most remarkable perhaps being grandiceps and microdon, both good kinds. A. fontanum is a lovely alpine Fern. It loves to grow beneath overhanging rocks. It does well in pots, in fibrous loam, with a mixture of calcareous chippings about the size of Walnuts. A. marinum is one of the most beautiful evergreen Ferns, but is far from being generally hardy. A. marinum imbricatum is a particularly fine variety, with beautifully fringed and crisped fronds. ordinary care, success is pretty certain. A few pieces of stone placed on the soil round the roots help much. The stones might be partly buried in the soil. Our smaller Ferns should be used amongst hardy flowers as carpets to the taller plants in shady parts of the rock-garden.

A. Nidus-avis.-This large Fern has been placed out-of-doors in summer from early in June to October, but it is not vigorous or hardy enough to be generally recommended for this purpose. Where large collections of tropical Ferns are grown it is a favourite plant, and may be tried in a warm, shady, and perfectly sheltered position. A. australasicum, a similar kind, is used in the same way. E. Indies.

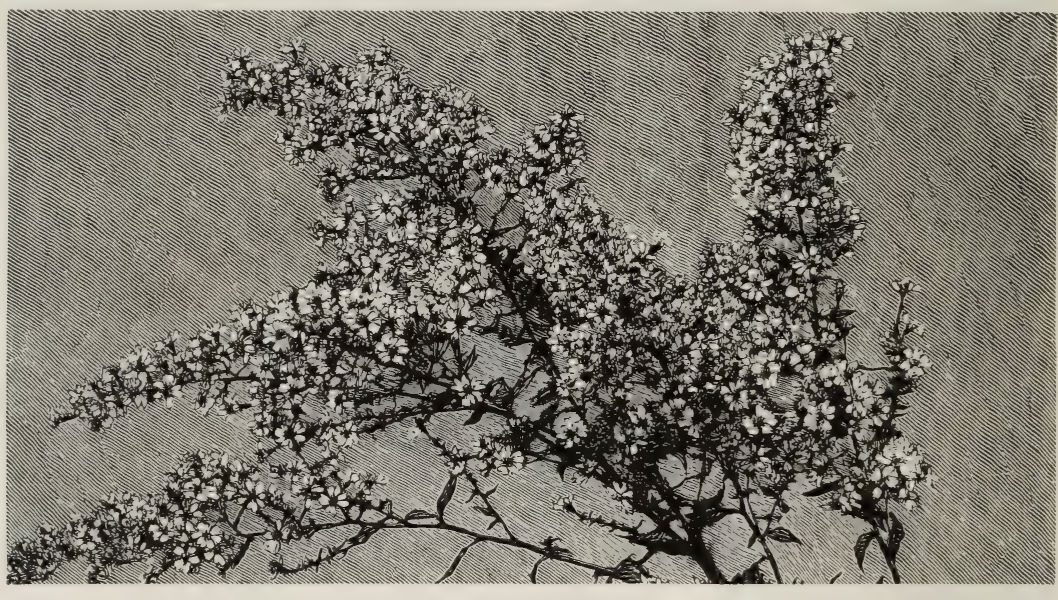

ASTER ELEGANS (LILAC STARWORT).

A. germanicum (alternifolium) is a rare kind, well suited for a shady spot in the alpine garden. It is hardy, and, although difficult to grow, is worthy of much care. A fine variety is A. g. acutidentatum, with elegant little fronds 2 to $3 \mathrm{in}$. in length. A. lanceolatum has abundance of dark shining green fronds, frequently 15 in. high. The variety microdon is distinct. A. Ruta-muraria, the Wall Rue, is a pretty little plant for walls, and for the chinks of rocks. Cristatum and crispum are pretty varieties of this little Fern. A. Trichomanes, the common Maiden-hair Spleenwort, is a handsome hardy species, the fronds dark green. The variety crispum is finely tasselled; incisum is a handsome variety, with fronds much divided; and multifidum is very distinct, each branchlet ending in a little crest. Like all the Spleenworts it requires free well-drained soil, and given this and
Aster (Michaelmas Daisy, Starwort). -We are apt to associate the name of Aster with the annuals known as China Asters, and to overlook the rightful owners of the name-those hardy flowers, literally stars of the earth, which shine out all the brighter owing to the time when they are in perfection. During the last days of autumn, when our gardens are nearly bare of bright colour, and when hardy flowers of nearly all kinds are at their lowest ebb, Michaelmas Daisies bloom bravely. They are not quite so showy at a distance as Chrysanthemums, but when closely examined they are more beautiful, their slenderrayed flowers having all the soft delicate tints between white, rose, and purple, while their bright yellow disc gives them an additional charm. Nearly all the species, of which there are at least two hundred in books, are natives of North 
America, and are hardy in this country, thriving in any soil, and requiring little attention. Their freedom of growth is indeed almost a fault, for they destroy other plants unless care be taken to place them properly. Scores of species have no merit for garden borders and would speedily overrun them.

CULTURE. - Their culture is simple; they like a good soil, but do not refuse to grow in any kind. The question is rather how they should be placed. The taller and more vigorous do well for naturalising, and many are valuable as cut flowers ; and, in fact, these Starworts are so beautiful in autumn, that if there be no place for them in the general scheme of garden decoration, it may be worth while to grow the best for the sake of their cut flowers alone. The better kinds are well worthy of the finest garden, and will do admirably with groups of later-flowering perennials sach as Flame-flowers (Tritoma), tall late Anemones, and Cardinal flowers (Lobelia). But selection must be rigidly kept in view, and a stiff ugly mode of staking the plants must be avoided. The plants should not be left too long in the same position or the tufts will get weak and too thick. I have had beautiful new effects from using many thousands of the best plants in large groups in newly-planted shrubberies.

The following are the best kinds so far as there is any knowledge of the names of a genus so large and so confusing. All are increased by division of the root or by seed.

A. alpinus (Blue Mountain Daisy). - A dwarf plant, the single blue heads of which scattered over high alpine meadows look like blue Daisies. In gardens it grows larger, forming vigorous tufts 6 to Io in. high. Flowering early; flowers nearly 2 in. across. There is a white variety. Mixed borders and rough rockgardens; it is used as a bedding-plant on the Continent. Division.

A. Amellus (Italian Starwort).-A handsome kind $\mathrm{I} \frac{1}{2}$ to $2 \frac{1}{2} \mathrm{ft}$. high. Flowering in late summer, flowers being numerous, showy, blue. The variety bessarabicus very much resembles it. A good border plant; I am fond of bold groups of it among shrubs. An excellent plant for cut flowers.

A. cordifolius (Drooping Starwort).A graceful plant, 3 to $4 \mathrm{ft}$. high, with stems often zigzag below, and flowers drooping. There is some doubt as to the name, but under the name given a very graceful plant was grown at Kew some years ago. In the Botanic Gardens, Regent's Park, the plant bore the name elegans. Valu- able for soft racemes of nearly white or pale lilac flowers, hanging soft as snowladen branchlets. Beds of finer autumn plants and borders, and also among shrubs.

A. discolor, rarely exceeding I foot in height, its numerous stems being often prostrate from their crowd of flowers. The older flowers change to rosy purple with a dark brown disc. A mass of it would

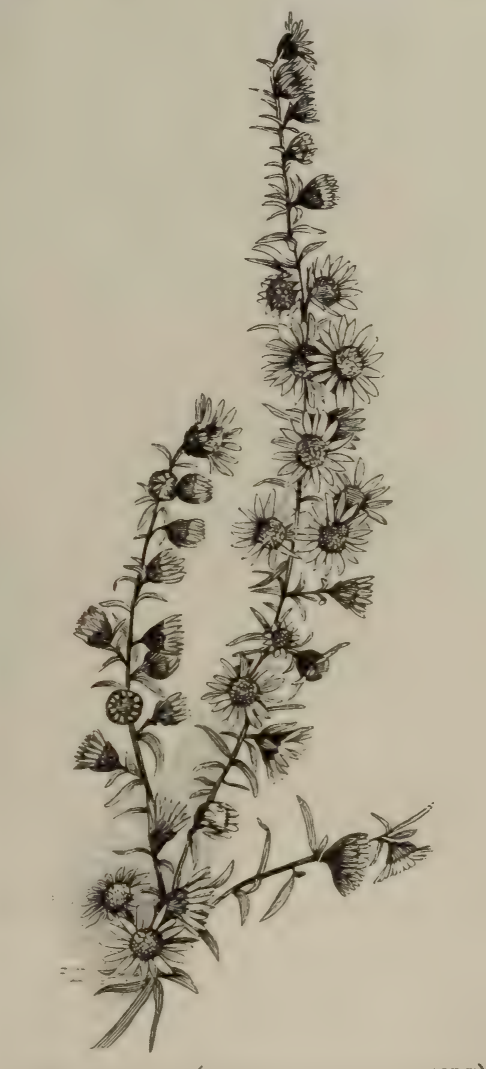

ASTER ERICOIDES (HEATH-LEAVED STARWORT).

be pretty in the garden during October. Rock, margins of beds of hardy flowers, and borders.

A. ericoides.-One of the most distinct kinds. Its flowers, barely $\frac{1}{2}$ in. in width, are clear white with a yellow eye. Dense in habit, 2 to $3 \mathrm{ft}$. high, and a profuse flowerer. Excellent among shrubs in groups.

A. grandiflorus (Christmas Starwort). -A handsome species, with stiff and wiry stems, $2 \frac{1}{2}$ to $3 \mathrm{ft}$. high ; flowering in November and December; purplish, large. Except on warm soils, it should be trained against a low south wall. One of the latest-blooming kinds, it is 
well suited for lifting and flowering in pots in the conservatory.

A. japonica, see Boltonia incisa.

A. lævis smeeth Stur'ort. - Variable and elegant, smooth throughout, about 3 ft. high. Flowers in autumn, bluish lilac flowers with yellow centre, in a large close panicle. Borders, naturalisation, margins of shrubberies, any soil.

A. longifolius (Rosy Starwort). -A good dwarf plant with masses of rosy lilac flowers. It is said to vary much in a wild state, but the kind usual in gardens is compact and not over $2 \mathrm{ft}$. high. It is an admirable border plant and fitted for beds or groups of the finer autumn hardy flowers.

A. Novæ-Angliæ (Nere England Starwort).-A tall and robust perennial, 5 to $8 \mathrm{ft}$. high, bearing violet-purple flowers, late in autumn. Among the tallest plants at the back of the mixed border, in warm soils and positions. It grows anywhere, but in cold soils and positions often blooms only in time to be destroyed by frosts. Seldom satisfactory in a garden, and takes up too much room for a late and uncertain bloom, but it is sometimes very fine in bold groups among shrubs-only failing, indeed, in very wet autumns. The var. pulchellus is said to be the best of all the late-blooming bluish-purple kinds. It forms strong tufts, 4 to $5 \mathrm{ft}$. in height, with a dense head of blue orangeeyed flowers. There is a deep rosecoloured variety of more value as a garden plant. Division.

A. Novi-Belgii (New York Starwort).The New York Starwort varies much, and many so-called species really belong to it. I find it very free and delightful in large groups and masses among shrubs and even in hedgerows and places never dug. The varieties range from 2 to $4 \mathrm{ft}$. high, and are pretty lavender or purplish-blue. Flourishes in any soil.

A. pyrenæus (Pyrenean Staru'ort).-A stout early autumn-flowering kind, 2 to 3 $\mathrm{ft}$. high, with large lilac-blue flowers. A Pyrenean plant, blooming earlier than the American kinds. After growing many thousand plants, and every kind in gardens among them, I found that the early kinds are far from the best. The Starworts that give most pleasure are those that wave their freshly-opened flowers in autumn winds. Borders, fringes of shrubberies, in any soil.
A. Shorti (Short's Starwort). -A pretty plant, with a slender spreading stem, 2 to $4 \mathrm{ft}$. high. Flowering in autumn; purplish-blue, about $\mathrm{I}$ in. across, numerous, in long panicles. Borders and groups.

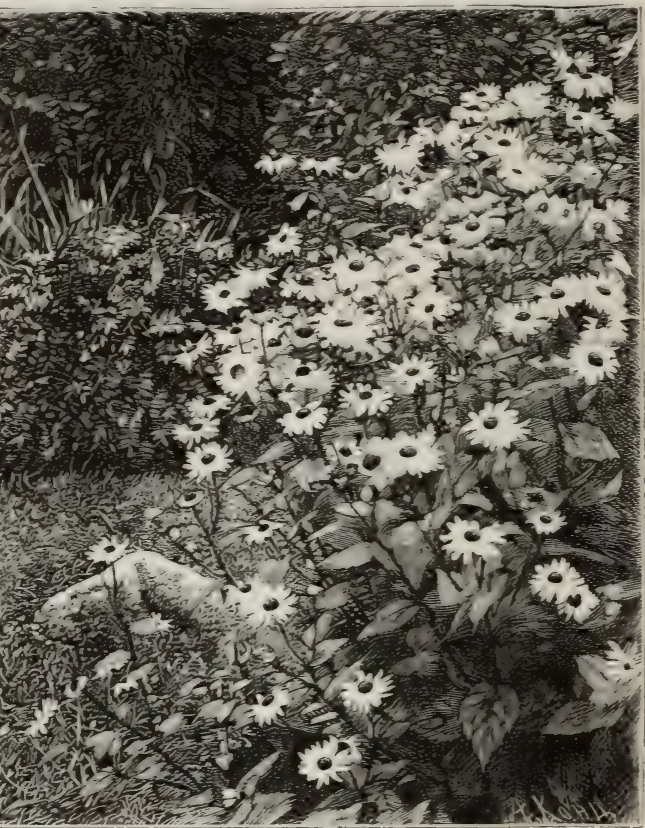

ASTER THUMPSONI.

A. turbinellus (Mauve Starwort).-A showy kind, 2 to $3 \mathrm{ft}$. high. Flowering late in summer and in autumn; delicate mauve, in panicles. Borders, with groups of handsomer autumn-flowering perennials, and naturalisation. Grows freely anywhere, but is worth a place in good soil.

A. versicolor (Changing Starwort). - A compact species, sometimes confused with A. discolor, though as garden plants at least they are different. Flowers in summer ; showy, white at first, changing into pink or purple. Said to have been found in N. America, but not recorded by recent American botanists. Borders in sandy loam, or beds of the finer perennials. There is a very tall and robust as well as a dwarf form.

It were easy to add many species, but the kinds mentioned include those that have proved best in cultivation. In the future the nomenclature of this family may be much altered; the above are the names by which they are best known in gardens.

Aster, China, see Callistephus chinensis. 
Asteriscus mauritanicus. - A dwarf, half-hardy, perennial Composite, allied to Buphthalmum, and producing throughout the summer abundance of deep yellow flower-heads, about $\mathrm{I} \frac{1}{2}$ in. in diameter. Closely allied to A. maritimus, and may be only a form of it; both are of doubtful value.

Astilbe. - A charming group of chiefly tall-branching herbaceous perennials of striking appearance both as flowering and foliaged plants. The robust kinds resemble the Spiræas of the Aruncus groups, but are bolder, and perhaps better suited for the margin of water. There are eight kinds in cultivation, the best-known of which are A. japonica and A. rivularis. Moist places in the wild garden will be found most suitable for A. decandra, A. rivularis, A. rubra, and A. Thunbergi, the last being also known as Spiræa. These plants group well ; the handsome foliage makes healthy undergrowth, over which the tall plumes of white or red flowers tower with good effect. Division of the roots, and some by the runners.

A. chinensis is a dwarf species like A. japonica. It rarely exceeds $I \frac{1}{2}$ to $2 \mathrm{ft}$. in height. The flower-stem is branched; the flowers, white tinged with rose or purple, are closely packed on shortish spikes, flowering in July. China. = A. odontophylla.

A. decandra. - Resembles Spiræa Aruncus, but is a stronger plant, 3 to 5 $\mathrm{ft}$. high. The leaves are glaucous, the flowers white in branched spikes. A handsome fine-leaved plant for shady places.

A. japonica is well known under the names of Spiræa and Hoteia japonica. The flowers appear in early summer, are white, and are effective on dark foliage. It is largely forced, and the plants, instead of being thrown away, should be planted out in groups in the open ground. Failure in the open air is due to dry and poor or cold soils. The charming plant repays a little trouble. The variety multiflora sent out a short time ago has a stiffer habit. The variegated form is a pretty sort, in which the flowers are more closely packed than in the Japan species.

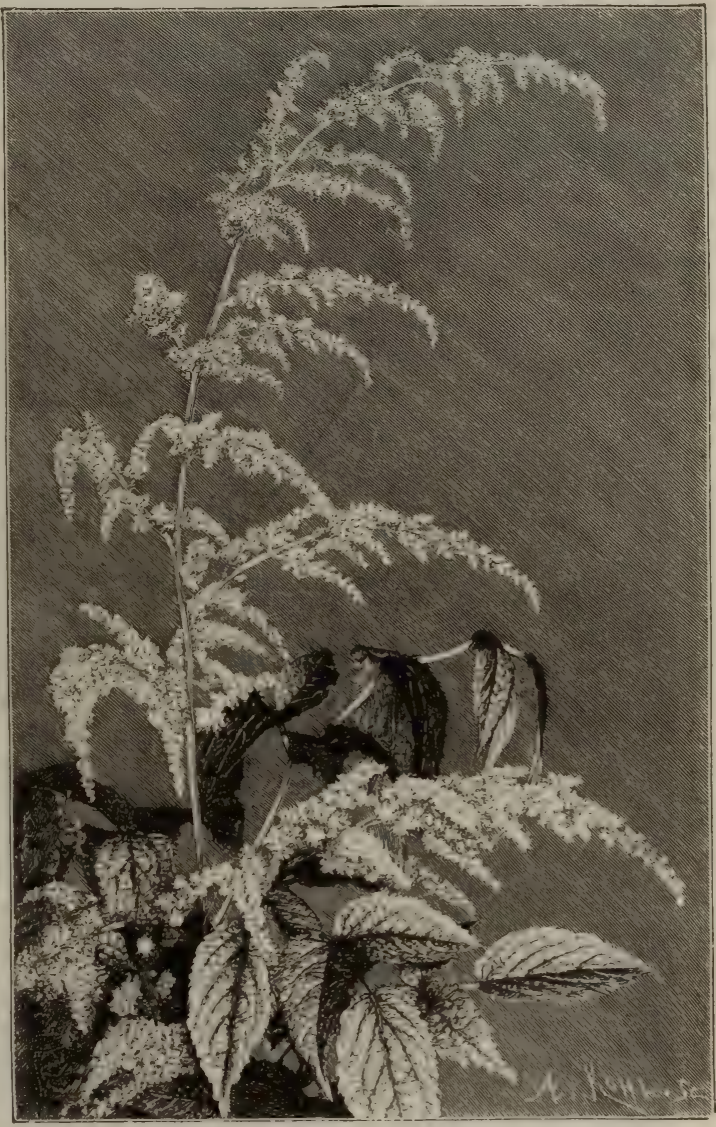

ASTILBE RIVULARIS (GOAT'S-BEARD).

A. rivularis is of airy elegant habit; is a useful associate of other bold-foliaged plants. It grows about $3 \mathrm{ft}$. in height ; the leaves, of a rusty green, last until late autumn. The flowers, tinged red, are on loose arching panicles. A useful plant for the margins, walks, and shady woods. Mountains of India.

A. rubra.-A beautiful plant from the Khasia Mountains, 4000 to $6000 \mathrm{ft}$. It has the habit of a Spiræa, flowering throughout late summer and autumn; the flower-stems, from 4 to $6 \mathrm{ft}$. high, are covered with brown hairs. The flowers, rose or deep red, are very numerous, in dense panicles. America and Japan.

A. Thunbergi (Hoteia Thunbergi) is a handsome Spiræa-like species from Japan, 2 to $3 \mathrm{ft}$. high, with a bold habit, resembling Spiræa Aruncus. A good plant for 
the mixed border, and better still in rich shady soil.-D. K.

Astragalus (Milk Vetch), - A numerous family, few of which attract cultivators. The best in cultivation are rock-plants, but they grow freely on the level ground in borders.

A. monspessulanus (Montpellier Aster).-A valuable plant for the front of borders. The vigorous shoots are prostrate, so that it is seen to greater advantage when its long heads of crimson and and microphyllus, are prostrate, and would probably prove valuable for the rockgarden. The plant is particularly suited for the rougher parts of the rock-garden, and for positions where a rich effect is sought rather than rare and minute beauty. There are white forms of all the varieties.

Other good kinds are A. vimineus, A. diphysus. Our own Purple Milk Vetch (A. hypoglottis) and its white form are also good for the rock-garden. A. pan-

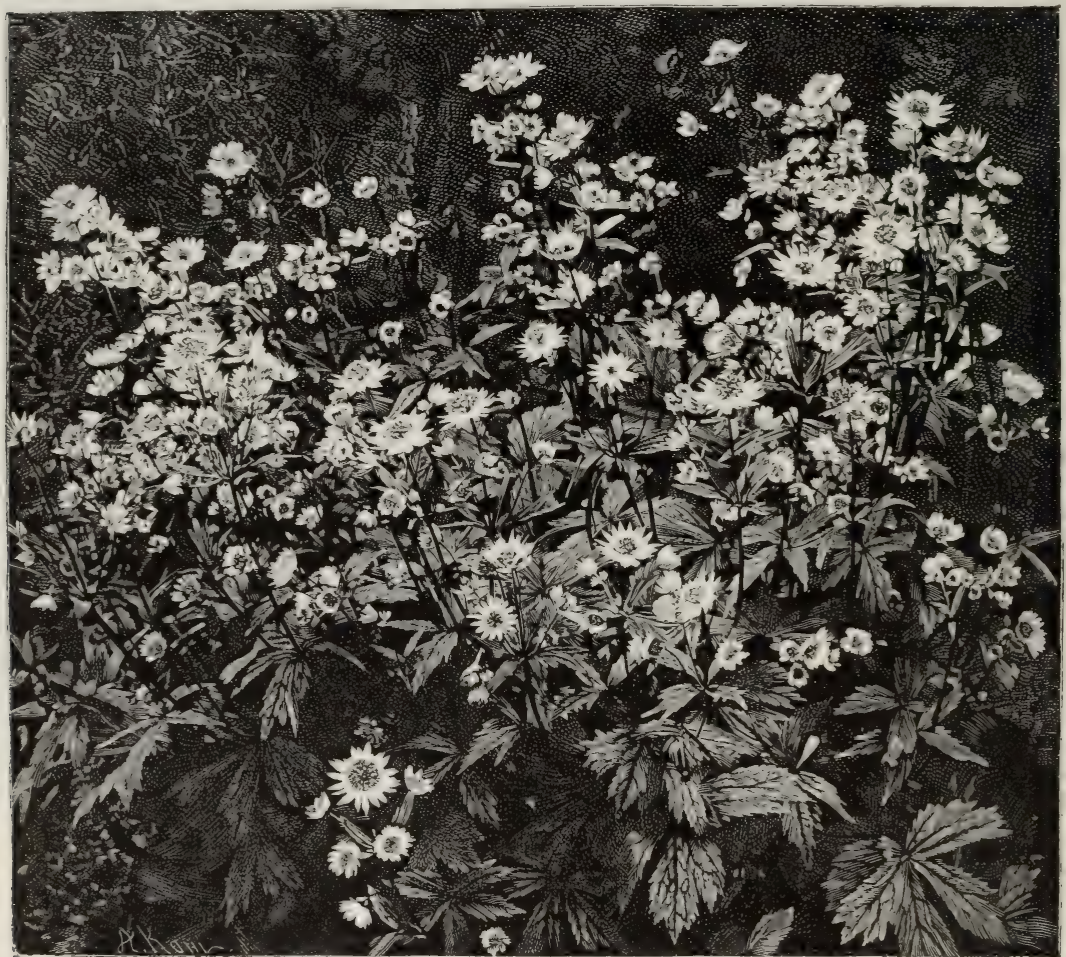

ASTRANTIA MAJOR.

rosy flowers droop over rocks. It grows well in any soil, and though not so vigorous in gravelly soil, yet in poor soil it will flower better. South of France. Seed. Several varieties.

A. onobrychis (Saintfoin MilkVetch).A handsome species (in some varieties spreading, and in others about $\mathrm{I} 8 \mathrm{in}$. high), with racemes of purplish-crimson flowers. Flowering in June, it is a hardy good perennial, thriving well on any good loam, and is a capital subject for the mixed border. Europe and Siberia. There are several varieties enumerated, one, major, grows erect, and three, alpinus, moldavicus, nosus (Shaggy Milk Vetch) has very silvery and woolly pinnate leaves, in compact and luxuriant tufts about a span high, which give the plant somewhat the appearance of a silvery Fern. A. dasyglottis is a very fine species, well suited for the rock-garden. Its numerous showy flower-heads, of a clear bright purple, are well set off by the fresh green foliage. A. adsurgens is a dwarf species with numbers of violet-carmine flowers, and is well worthy of a place in the rock-garden. A. vaginatus is a free grower, an abundant bloomer, and apparently succeeds in an exposed position in any ordinary border. 
The showy deep violet-purple flowers are borne in dense erect clusters. It flowers for a long time.

Astrantia.--The Astrantias are classed amongst umbelliferous plants, and their nearest allies in Europe are the Sea Hollies and the Sanicle, though in appearance and habit they come nearer to the Scabious, a more distant relation. The genus consists of not more than four or five true species, all natives of the mountains of Southern Europe. The two most distinct are A. major and A. helleborifolia. A. major has the widest range of the genus, extending from the Pyrenees into Western Asia, and is enumerated amongst the native plants of England, being found apparently wild in a wood near Ludlow, and perhaps in one or two other places; but as there is a wide gap between these places and its nearest Continental home, it is probably not indigenous to Britain. I have noticed it in great abundance in the hayfields of the Pyrenees, near L.uchon, flowering in June, in company with the blue Columbine, where the ground has just before been white with the Poet's Narcissus. A. helleborifolia is not a European plant, being from the Caucasus. It has the best and largest flower of any, the colour being clear pink, but the habit of the plant is straggling, and the flowers smell unpleasantly of sour milk. A third species is A. Biebersteini, called by some botanists $\mathrm{A}$. intermedia. In some of its characters it is intermediate between the other two, having more pink in the flower than $\mathrm{A}$. major, and a three-lobed leaf like A. helleborifolia. Its habit is good and compact, and it flowers freely. There are two or three smaller species, the commonest of which is A. minor, often brought from the Alps by collectors. The Astrantias have a quaint beauty of their own; they are not showy, but have the merit of not being particular about soil or aspect, and are easily established in woodland walks where the growth of weeds is not too rank. - C. W. D.

Atamasco Lily (Zephyranthes).

Athamanta (Spignel).-Graceful perennials of the Parsley Order with Fernlike leaves. They are worth a place among fine-leaved plants in borders or groups, in ordinary soil. Division or seed.

Athanasia.-Plants of the Compositæ. The annual kind has been frequently grown out-of-doors, but it is not of much value.

Athyrium (Lady Fern). - Beautiful Ferns, which A. Filix-fomina may be taken to represent. They like a compost of loam, leaf-mould, and peat, mixed in about equal proportions, with the addition of some sharp sand ; they require abundance of water during their growing period, but artificial moisture should be discontinued in winter, because all the varieties are deciduous, and the ground at that period is wet enough naturally. Among many fine hardy evergreen herbaceous plants Lady Ferns might be planted with advantage; they will thrive wherever they receive a little shade and protection from drying winds, being impatient of drought; therefore plants that afford shelter and like moisture should be chosen for intermixture with them. This genus exhibits a greater variety of form than any other native Ferns, except Scolopendriums. The principal varieties are A. Filix-fœmina plumosum, one of the most lovely hardy Ferns, its fronds reminding one of a plume of feathers in a lovely shade of green. A. Filix-fœmina corymbiferum is a fine crested variety, and A. Filixfœemina Victoriæ should be in every collection, as it is the finest of all the varied forms of Athyrium. There is a pretty and hardy Japanese Athyrium called A. Goringianum pictum.

Atragene.-The Atragenes resemble Clematises, but differ from them in various points, especially in putting forth leaves and one flower from the same bud contemporaneously in the spring.

A. alpina (The Alpine Atragene).-A beautiful slender hardy climber, 8 to $12 \mathrm{ft}$. high, found on mountains in various parts of Europe, especially on calcareous soil in Austria, Piedmont, and the Pyrenees. It is for trailing over a low bush or stump, and is an excellent early wall-plant, thriving on the north as well as the warm side of walls. Syns., Clematis cœrulea, C. alpina, and Atragene austriaca.

Atriplex(Purple Orach).-A. hortensis atro-sanguinea is a dark form of the common Orach. It is a hardy annual often used for its fine-coloured foliage. Sown in open air in April or May, it does well in almost any soil. It has been used among bedding plants, but has been almost given up for other plants. Growing to a height of $4 \mathrm{ft}$. or even considerably more when well treated, it has peculiar merit for those who know how to use it. It associates well with the Amarantus, annual Wormwood, Persicaria, and the bolder annuals grown for the flower garden.

Aubrietia (Purple Rock Cress).-A 
charming group of alpine plants from the mountains of South Europe. There are many varieties in gardens, but probably all may be reduced to some half-dozen species; all are beautiful. The oldest is called A. purpurea, a pretty flower, but surpassed by newer kinds. Then there is what is called deltoidea, which is very much like purpurea. We have also grandiflora, similar in colour to purpurea, but twice its size. It has a lax diffuse habit, which makes it a charming rockplant. There is a fine variety of it called græca, opening out a full purple, and
Some find Aubrietias difficult to propagate; my practice is to pull all the straggling side shoots off the old plants in June or July, securing as much of the stem as possible, and breaking it off close to the main root; then to dig in a cool shady border a piece of ground, into which is worked plenty of rough sand and leaf-mould; then to plant the shoots in lines, placing a little sandy soil about the portion put into the ground, and to tread all firmly down. The cuttings are occasionally sprinkled and kept shaded from the sun, and few failures occur.

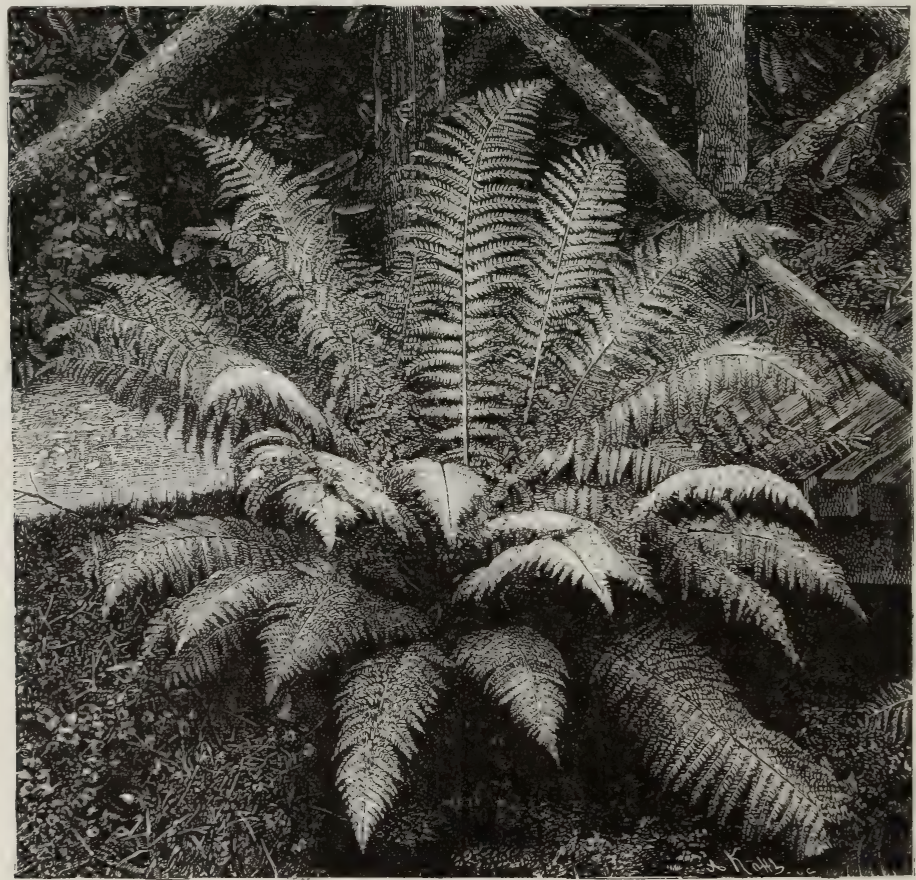

ATHYRIUM FILIX-FCEMINA (LADY FERN).

dying off a lavender colour. Masses of this, with its various shades of colour, are pretty. There is also a fine variegated large-flowered form of it. Then we have A. spathulata, erubescens, and hesperidifolia. The rest are Mooreana, Columnæ, and Campbelli. Mooreana is a compact little cushion-like plant, which, in its flowering season, is smothered with bloom. It has a shade of blue. Campbelli and Columnæ appear identical ; but, like Mooreana, they are among the loveliest of Aubrietias. The last three are well suited for spring-gardening. They are hardy, and flower from March until June.
One great advantage of getting cuttings put in in June or July is that by the end of the summer the plants become strong and well fitted for planting out.

The Aubrietia is excellent as a wallplant; I have seen a wall almost covered with its long wiry tufts, which were firmly rooted. The effect in spring is very beautiful. Imagine some of our old Fern-covered walls or sunk fences draped with the lovely blue tufts of the "purple Arabis," as they call it in London! We need only sow the seed in any mossy or earthy chinks in autumn or spring. Rockgardens, stony places, and sloping banks will suit Aubrietias perfectly. They make 
neat edgings, and may be used as such with good effect. Growing in common soil in the open border, or on any exposed spot, they thrive as luxuriantly as if on the rock-garden, and form round spreading tufts ; on fine days in spring the blue flowers come out in such crowds as to hide the leaves, and make hillocks of colour. Easy to naturalise in rocky places. Seeds, cuttings, or division. Aubrietias, as we know them in gardens, are so like each other, that it is hopeless to separate them. To A. purpurea (the A. macrostyla of Boissier) belong A. grandiflora, A. græca, and the fine variety A. Campbelli. Aubrietias vary much from seed, but agree in carpeting the earth with dense cushions clothed with beautiful flowers in spring, and, in the case of young plants in rich soils, almost throughout the year. There are one or two variegated varieties.

Aucuba.-Evergreen berry-bearing shrubs, which enliven our gardens through the dull season. When the pollenbearing variety of A. japonica was introduced, it was justly looked upon as a great gain, as the old spotted-leaved berry-bearing form would be clothed not only with bright red berries, but green ones as well. Yet, strange as it may seem, there are many gardens where this variety is too rare. Its influence is always most seen on the nearest plants, whose fruit is more plentiful than that of distant plants. The effect of the greenleaved kinds is much more striking than that of the variegated, the contrast between the bright fruit and the green foliage being better. Some seedlings have fine leaves, and a few of these may be desirable for the sake of variety, but mediumsized foliage produces a finer effect.

The Aucuba is one of the best shrubs for planting under trees, as its strong fleshy roots enable it to live where other shrubs would starve. We have lately substituted it for the common Laurel when we needed a thick screen in shade, and by planting a few of the male variety among the ordinary kinds, we find they set their blossoms abundantly. Although hardy enough to withstand severe winters, such winters somewhat arrested their growth. The Aucuba may be safely removed at midsummer or midwinter. We have shifted it in all weathers, and have never lost one. To have it in perfection it requires shelter and shade. If we desire a good crop of berries, we must plant males about $30 \mathrm{ft}$. apart among the ordinary form. The berries do not begin to colour until those of other berry-bear- ing shrubs are past; nevertheless they add a distinct charm to the shrubbery during the spring.- $G$.

Smoke and dust seem to have no effect upon Aucubas, making them valuable for town gardens even while we endure the present smoke of our towns. The variegated form is much more vigorous and rapid in growth than the green or plainleaved variety. Aucubas are suitable for masses, either alone or with other shrubs. Small plants of the green variety, well studded with berries, look very well here and there in front of larger shrubs or in mixed borders. Plants in pots are useful for balconies, or for plunging in vacant beds in winter.

Small compact plants of the various forms of Aucuba, well furnished with berries, are valued during winter in London for window decoration. They are obtained chiefly by fertilising old-established plants with male pollen, and then layering them, selecting good-sized branches with bushy heads. In a short time they root. They are then severed from the old plant, and in autumn lifted, potted, and placed indoors to colour the berries. Standard plants are obtained by grafting on the common Aucuba.

Auricula (Primula Auricula).

\section{Avens (Geum).}

Azalea (Swamp Honeysuckle).-We do not make enough use of the hardy Azalea in our gardens, many of which are over-planted with Rhododendrons. If only as a relief from the heaviness of Rhododendrons, the graceful growth of Azaleas is precious. There is nothing in the open garden so charming as old Azalea bushes in flower, with their branches in table-like tiers; but the brilliant tints always seem most effective in the subdued light of a shady wood, and happily few shrubs flower better in partial shade than Azaleas. They like shelter, even from southerly winds, and delight in quiet shaded nooks. A peaty soil suits them best, though they grow well in loam.

The hardy Azaleas, called Ghent Azaleas, have sprung chiefly from the wild Azaleas of North America-A. nudiflora, A. calendulacea, and A. viscosa. These and A. pontica have been so hybridised with the wild Azalea of South Europe, that we have a race in which the colours of the various species are blended and diversified in a great variety of tints, and they all intercross so freely that it is difficult to single out a variety identical with any of the wild species Fifty years ago, it was customary to give 
Latin names to every fine variety, but they could soon be numbered by the hundred from Belgian gardens alone, and now very few sorts are named. Every variation of tint, from the most fiery scarlets to delicate pinks, whites, and dark and pale yellows, is to be had in
It has bunches of fragrant white flowers and broad foliage. A. mollis, a dwarf deciduous shrub from Japan and China, has given rise to a variety of kinds, yellow, salmon-red, and orange-scarlet being the prevailing colours. But this beautiful little species has not yet been

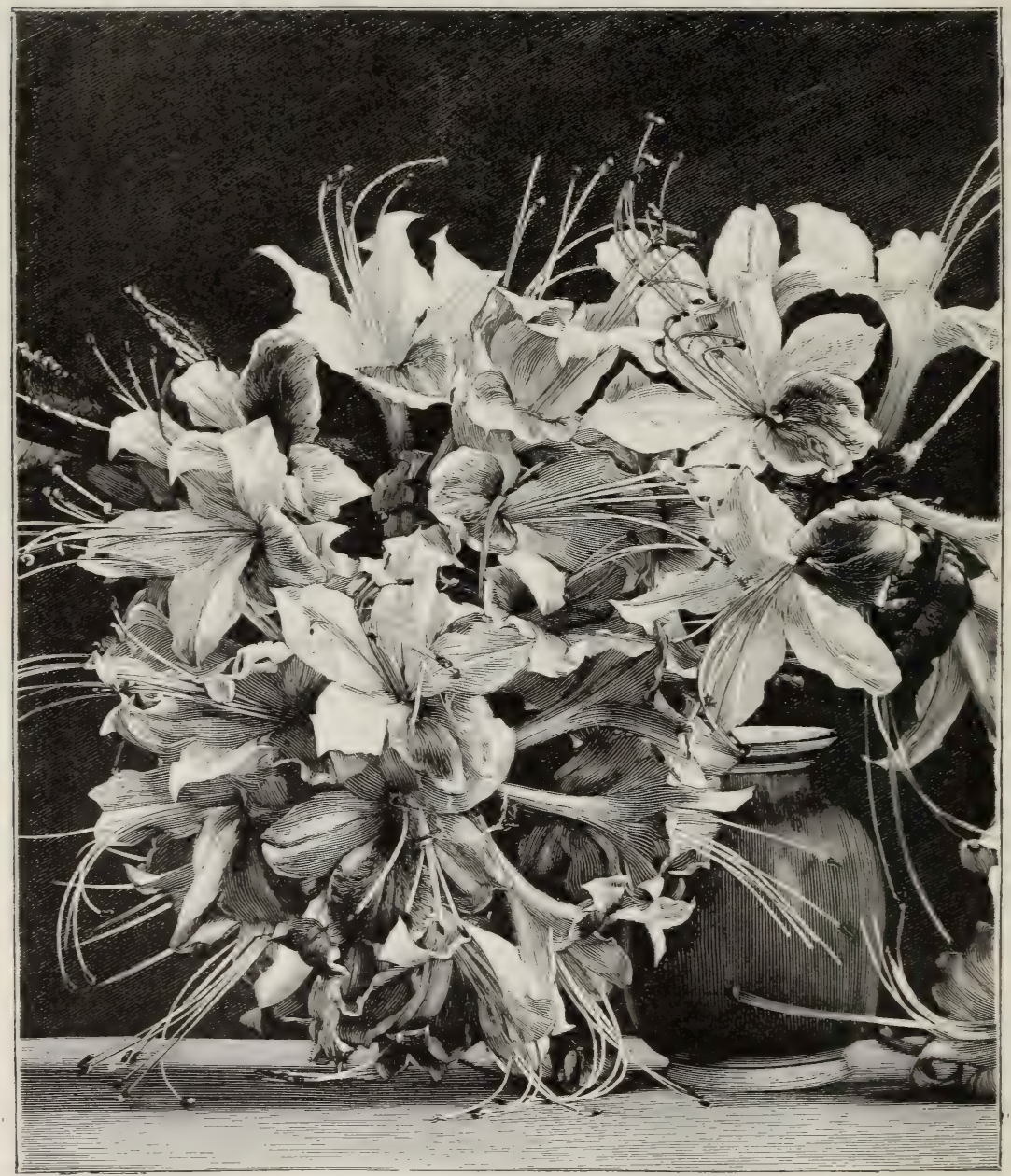

FLOWERS OF AZALEA MOLLIS.

Ghent Azaleas. Of late years there has sprung up a new race with double Hosein-hose flowers, collectively called the Narcissiflora group, the chief sorts of which number about a score-Graf von Meran, one of the first, being still among the best yellows. A Californian species named A. occidentalis stands out distinct from all the rest of the deciduous Azaleas, as it flowers after the others are past. crossed with the taller species of America and Europe. It is hardy, and being dwarf, may be grouped as a foreground to a mass of the tall kinds. The Chinese A. amœena, with small magenta flowers, common enough in greenhouses, is quite hardy in mild localities. The Chinese A. indica, the ordinary Azalea of greenhouses, is hardy in many places, especially the white variety, which, even in mid- 
Sussex, thrives in the open air. The Ledum-leaved Azalea (A. ledifolia) is a hardy evergreen shrub, also from China. It has white flowers, large and open, like A. indica. It grows from $5 \mathrm{ft}$. to $6 \mathrm{ft}$. high, and Loudon states that in Cornwall, on Sir Charles Lemon's estate at Carclew, it was planted in hedges, which flowered magnificently without the slightest protection.

Azara.-Distinct and graceful shrubs, hardy in favourable soils, unless in very hard winters. As wall-plants, particularly if the walls have an east or west aspect, they are fine, and flower freely ; while in the southern counties, at least, they do well in the open away from walls. Well-drained loam and the partial shade of taller shrubs suit them. Cuttings of the half-ripe wood in sand under a bell-glass.

A. Gilliesi is probably the handsomest. Ifs toothed leaves have the colour and texture of those of the Holly, the branches are tinged with red. In its native country it attains a height of $10 \mathrm{ft}$. Both in the open air and under glass it flowers in the late autumn and the winter. The blossoms are small, and, from the great number of rich orange-coloured stamens, resemble golden catkins. A. celastrina has rather smaller leaves, coarsely serrated and similar in outline ; its yellow blossoms are arranged in lax corymbs.

A. integrifolia has handsome, thick, leathery, dark green leaves and drooping spikes of fragrant yellow blossoms, which form a dense bush a few feet in height. A variegated form originated a few years ago at Kew. It is a beautiful plant of good habit, and very constant in its variegation.

A. microphylla.-A graceful shrub, and a pretty Evergreen. Its numerous small flowers are succeeded in autumn by small orange-red berries. In lowlying localities, such as Kew, this shrub is injured in severe winters. The best place for it is a sheltered position, not too low. For planting against a wall or trellis few shrubs are better. Among other kinds are A. dentata, a quick grower, forming a fine evergreen bush in a short time ; and A. serrata, with prettilyserrated leaves, and umbels of yellow blossoms.

Azolla caroliniana.-A very small and curious water-plant, which floats on water quite free of soil. The tufts of delicate green leaves appear like tiny emeralds. During summer it will grow out-of-doors, but then becomes bronzed, and perhaps it is prettier when light green, as it is in the greenhouses or window. Syn., A. rubra.

A. pinnata is a distinct species.

Babiana.-Charming Iridaceous bulbs from South Africa, allied to Sparaxis and Tritonia, but having broader foliage, often hairy and plaited, growing from 6 to 12 in. high, with spikes of brilliant flowers ranging in colour from blue to crimson-magenta; often sweet-scented. They should be planted from September to January, about 4 in. deep and 2 to 4 in. apart, in light loamy soil thoroughly drained, with a due south aspect. The early plantings make foliage in autumn, and require protection of mats against frost. The bulbs planted in December and January will only require a covering of Fern, which should be removed in spring as the foliage appears. In wet soils the bulbs should be surrounded with sand, and the beds raised above the level. Babianas are often grown in mixed varieties, but can be obtained in separate colours. One of the most distinct of the named varieties is $B$. rubro-cyanea, which has larger blooms and a ring of intense crimson dividing the centre from the outer blue. Among the varieties in cultivation are-Atro-cyanea, purple blue ; marked white; Attraction, dark blue, vigorous habit; Celia, rose, marked white; General Froome, violet, spotted white; General Scott, lavender, suffused white; General Slade, magenta ; Hellas, pale yellow, the outside suffused purple ; Julia, petals alternately white and blue; Kermesina, rich crimson-magenta ; Lady Carey, rose, marked white; Rosea grandis, rose-purple, marked white; Rubro-cyanea, blue, crimson centre; Speciosa, mauve, suffused blue ; Villosa, crimson. The Babianas, being tender and difficult unless in careful hands, are best fitted for a sheltered spot in the choice bulb-garden or border. The better climate of the south may make their culture more easy, but as a rule they are unsatisfactory, even in the best part of the country.

Bachelor's Buttons.-A term applied to some double hardy flowers, chiefly to double Ranunculus and double Daisies.

Bæria chrysostoma, a Californian Composite about I ft. high, with a dense tufted head, covered in early summer with a profusion of bright yellow flowers. It should be treated as a half-hardy annual.

Bahia lanata (Woolly Bahia).-A grayish herb 6 to I $5_{5}$ in. high, much branched from the base of the stem. It 
flowers in summer in great abundance, one yellow flower on each stalk. Suited for borders or banks, in light, sandy, well-drained loam, on which it flowers abundantly, and is much more ornamental than when on cold clay soils. Fitted for groups or beds of silvery or

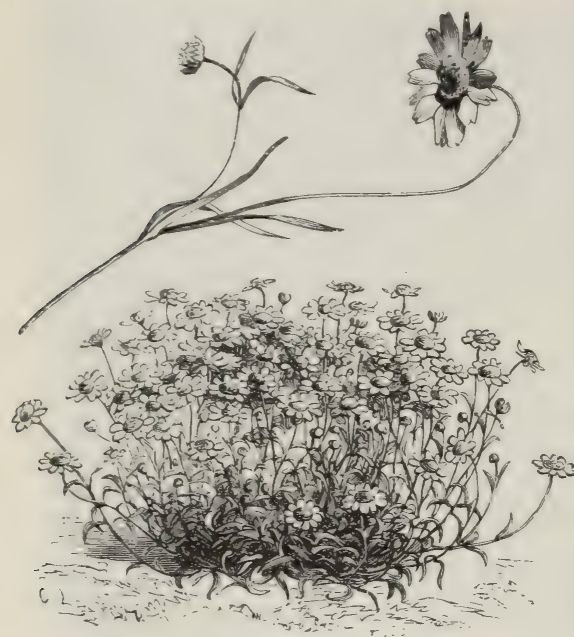

BERIA CHRYSOSTOMA.

variegated plants. Seed, or more readily by division. America. Compositæ.

Bald-money (Merm athamanticum).

Baldwinia uniflora.-A North American swamp-plant of the Composite family, of little garden interest.

Balm (Melissa).

Balm of Gilead (Cedronella triphylla).

Balsam (Impatiens).

Balsamita (Costmary). - A genus of Compositæ, which includes the Costmary, an old herb-garden plant, and B. grandiflora, a rather showy and singular freegrowing perennial. It is of easy culture, and worth a place among the stouter herbs in borders.

Balsamorhiza deltoidea (Balsam Root).-An American plant of the Composite family, of no garden value.

Bambusa (Bamboo).-These giant grasses are widely distributed in the warmer regions of the world, the larger species reigning in the torrid zone. Humbler but still remarkable representatives of the tribe are, however, pushed, like advanced sentries, to the northern parts of Japan and China, and to the south as far as the southern parts of Chili, many plants from which regions are quite hardy. With a single exception, perhaps, the hardy kinds intro- duced into modern gardens are natives of Japan and Northern China, and we are chiefly indebted to the French horticulturists for their introduction. The sub-tropical gardening, which originated in Paris, and which subsequently extended all over Europe, was indeed the principal cause of researches for plants of this tribe, many of which were first introduced at Paris. Bamboos are specially to be prized, as even in the middle of winter they retain the luxuriant gracefulness of tropical vegetation, and their foliage shines as bright as ever. Nothing can exceed the grace of a Bamboo if freely grown. In cold bad soils and exposed dry places Bamboos have little chance; but they will be found most graceful objects in many a sheltered nook in the south, southwestern, and milder parts of

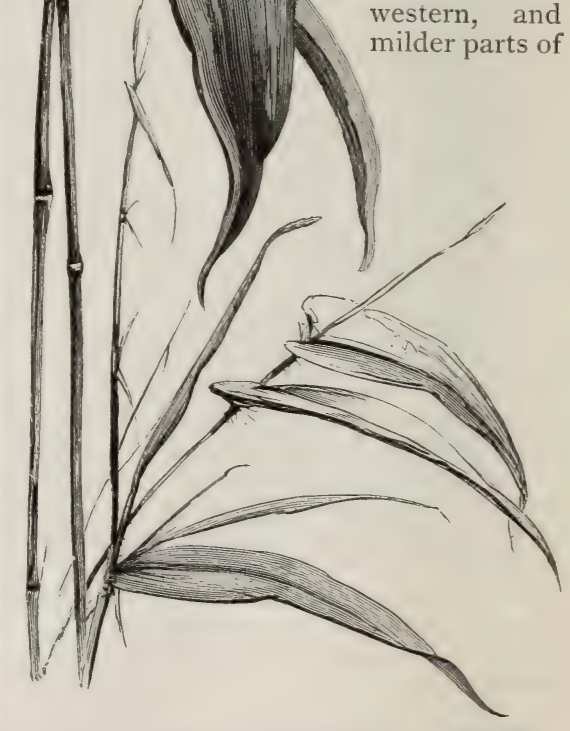

SPRAY OF BAMBUSA MAZELLI AND B. METAKE.

England and Ireland. Those who wish to be cautious had better commence with the hardiest, B. Simoni, viridi-glaucescens, Metake, and falcata. The best way to treat any of these plants, obtained in summer or autumn, is to grow them in 
a cool frame or pit till the end of April, then to harden them off for a fortnight or so, and plant out in a warm sheltered spot, with good free soil, carefully spreading out the roots and giving a good free watering to settle the soil. No plants are more worthy of attention where the climate is at all favourable, and there are moist nooks near the seaside where as well as in the south they will grow most satisfactorily. It is well to bear in mind that in the first year or two of a Bamboo after planting only poor shoots are produced. The following notes on the cultivated kinds (except B. Metake and B. falcata) are from an article in the Gardeners' Chronicle by M. Fenzi, of Florence, who has paid much attention to the genus.

B. aurea.-From its stems assuming with age a clear golden colour, and its foliage possessing a golden hue, this species has derived its name of Golden Bamboo. It looks something like a diminutive form of $\mathrm{B}$. mitis, the leaves being smaller and the stems thinner. It has, however, a rather straggling habit, new shoots often appearing several yards from the parent plant. It appears to be wild in Japan and China.

B. falcata (Arundinaria falcata, Thamnocalamus).-Nepaul and the Himalayas. The only Bamboo much planted with us, hardy over the greater part of England and Ireland, but only attains full development in the south and west. It has great luxuriance in Devon, and grows $20 \mathrm{ft}$. high near Cork, though, in many districts, it is stunted. It loves a deep, sandy, and rich soil, and when growing fast plenty of moisture. This is the most generally distributed Bamboo in British gardens, and is quite at home in them in many districts, though perhaps scarcely so hardy as B. Metake.

B. Fortunei fol. var.-A dwarf Bamboo never much more than I ft. high. The large leaves are striped with white. The habit is spreading, once established difficult to eradicate, its rhizomes running through the soil to the depth of $2 \mathrm{ft}$. and more. Thus the severest cold will but slightly injure its elegant foliage.

B. gracilis.-Hardy only in favourable situations, owing to the fact that it puts out new shoots in autumn, and these are too tender when the cold first appears. If treated like a perennial, it will put out early in spring new shoots full of vigour, which become quickly covered with rich foliage, and form a beautiful ornament well repaying the slight trouble of covering it in winter. Magnificent specimens are on the shores of Lakes Maggiore and Como. The B. graminea of many catalogues probably belongs to this species.

B. Metake (Metake).-A large-leaved sort from Japan, from 4 to $9 \mathrm{ft}$. high, with thickly-tufted stems, covered by the sheaths of the leaves. As tested in London and Paris gardens, it is a fine species, and seems the hardiest, thriving even in London. It is of very free growth and well furnished, and its leaves broader and larger than those of the other hardy Bamboos. It would be difficult to find a more graceful plant for the lawn. It loves a peat soil, or a free and deep loam, and runs a good deal at the root.

B. mitis, or edulis. - The largest of the hardy kinds, worthy of being placed first, the stems even of young plants soon becoming more than I in. thick, and about $16 \mathrm{ft}$. high. It has a more compact habit than many other kinds, its subterranean rhizomes not expanding so much, and the shoots forming a very small angle with the principal stem. According to Mr. Fortune, it attains, in the northern districts of the Chinese empire, the height of $60 \mathrm{ft} . ! \quad B$. mitis is a late grower, new shoots appearing only in June, and this confirms its northern origin.

B. nigra.-Among the Japanese species this, with its elegant stems and fine shoots, all of jet black, well deserved the attention of early botanical travellers and collectors. The young stems when first developing from their spathes are greenish, but gradually change to a brownish yellow, and towards the end of the second year change again to the beautiful dark colour, which makes the plant so suitable for umbrella handles and riding-whips. The foliage is very dense and of a deep green colour, the leaves being more narrow than those of the above-described species.

B. Ragamouski is a fine dwarf kind with ample leaves; hardy and excellent for peat beds and evergreen borders. Its foliage is so good in form that it is useful for the house.

B. Simoni or Maximowiczi.-This kind, introduced recently, and, I think, at the same time into France by M. Eugène Simon, and into St. Petersburg by Professor Maximowicz, appears to be very hardy, having been found in Manchuria.

B. violascens.-A new species has been recently introduced, which looks like an intermediate form between $B$. aurea and B. viridi-glaucescens. The 
young stems and shoots are beautifully tinged with a bright violaceous hue, and it seems to attain the size of the two species mentioned, and to be not less hardy than they. It was first introduced into the Paris Garden from China.

B. viridi-glaucescens.-In its habit it is widely different from the other kinds. Its slender culms, with rather long internodes, have their shoots nearly at right angles, so that they droop gracefully. The young stems are of darkish green, which changes gradually to a beautiful golden colour. Among the kinds as yet introduced this is certainly the most these plants are pretty, but two varieties of B. vulgaris, an indigenous species, are worthy of cultivation.

B. vulgaris fl.-pl. (Yellow Rocket).This is a beautiful and curious plant. The process of doubling is, according to Mr. Sutherland, "very peculiar in the flowers; I am not aware of any parallel to it in other double flowers. There appears to be no attempt to form either stamens or pistils. But the axis of the flower has the power of extending itself and producing numerous whorls of petals as it grows in length. A lengthened succession of flower is thus kept up. It

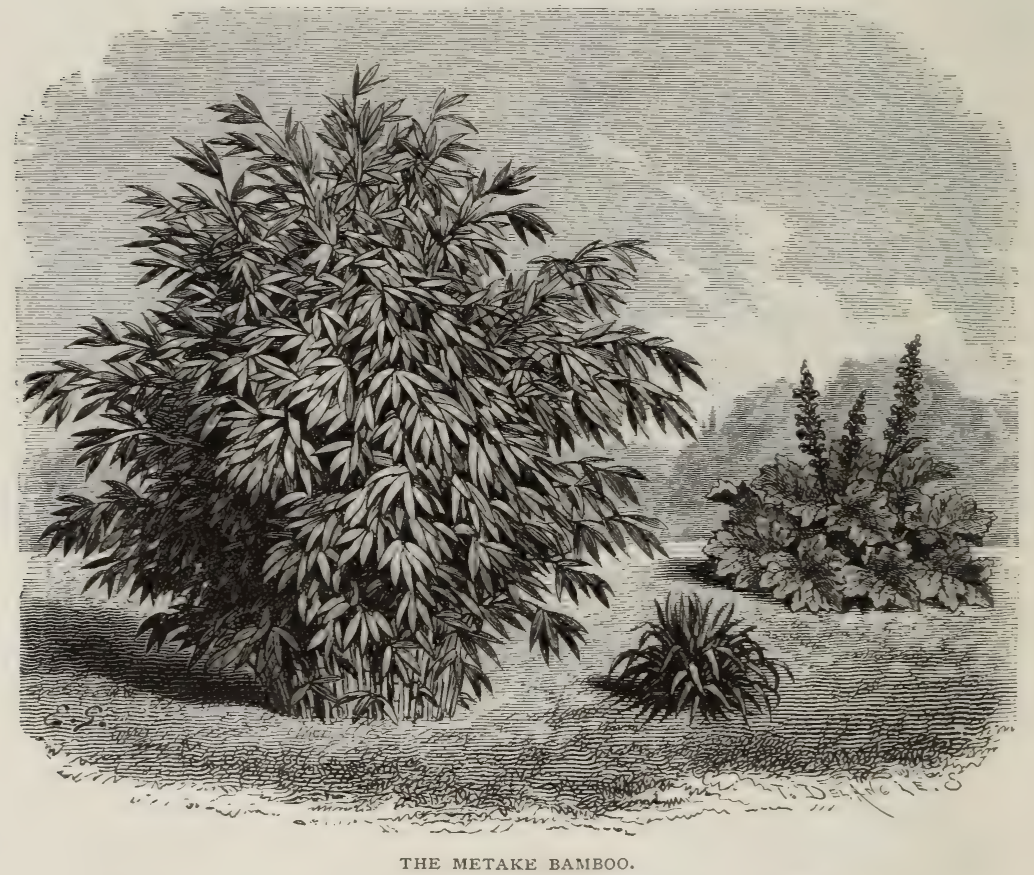

vigorous. Clumps taken up and potted are of decorative value. By artificial light they look like finely-cut Chamædoreas, their foliage being more elegant than that of any Palm.

Baneberry (Actea).

Baptisia (False Indigo).-A free and hardy Lupine-like group of plants, not very important in gardens. They are perennials from N. America, forming strong bushy tufts 3 to $5 \mathrm{ft}$. high, with sea-green leaves; the flowers, mostly of a delicate blue, in long spikes, grow well in ordinary deep soil. B. australis, exaltata, and alba are the best-known kinds.

Barbarea.-In the natural state few of is about $\mathrm{I} 8 \mathrm{in}$. high, flowers bright yellow, from June till late summer, and often till autumn." It is a pretty ornament of the mixed border, succeeds in almost any soil, preferring a rich light loam. Division of the root-stock. There is a variegated form of the single plant called the Blotchleaved Winter Cress, but it is not very important. It is said to come true from seed. folia).

Barbary Ragwort (Othonna Cheiri-

Barberry (Berberis).

Barnardia scilloides.-A pretty Scillalike bulb about 6 in. high with dense clusters of small flowers, flesh-tinted 
within and greenish on the exterior. It succeeds in any light sandy loam in warm borders or in the rock-garden. Macao.

\section{Barren-wort (Epimedium).}

Bartonia aurea.-A showy goldenflowered hardy annual, I to $2 \mathrm{ft}$. high. Should be sown in April in groups or patches where it is to remain in light soil and warm situations, the plants being thinned to about $\mathrm{I} \mathrm{ft}$. apart. As the seed is very small, care should be taken not to bury it too deep. The Bartonia is

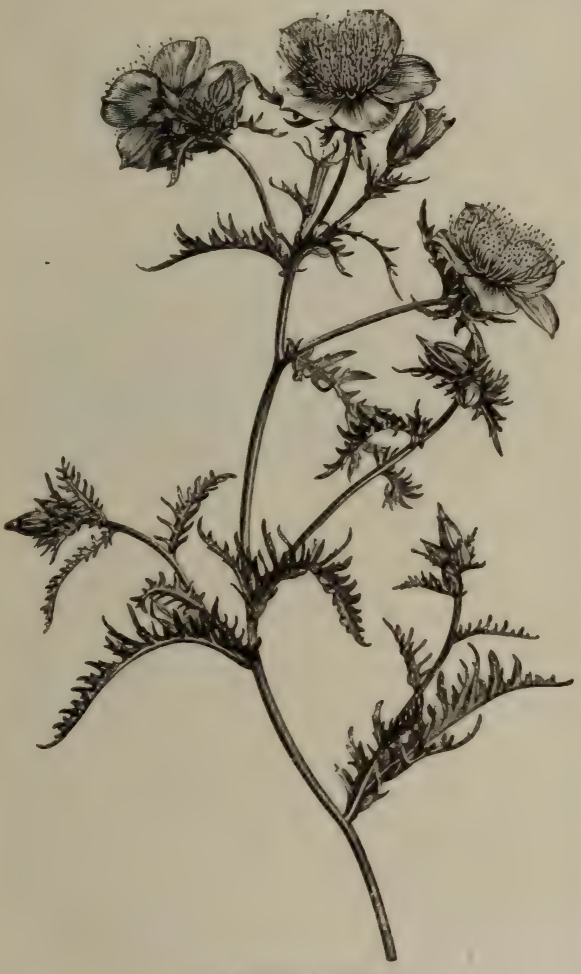

BARTONIA AUREA.

seldom used except as a patch in a border, but when well grown it might be used as a bold group, relieved here and there by tall plants. Chili. Loasaceæ. $=$ Mentzelia Bartonia.

\section{Iulli)}

Bay, Californian (Oreodaphne californica).

Bear's-breech (Acanthus).

Beaucarnea.-Graceful Dracæna-like plants, with swollen stem-bases, growing freely in a cool house, but sometimes placed in the flower garden for a few months in summer.

\section{Bed-straw (Galium).}

Bee Balm (Monarda didyma).

Bee Larkspur (Delphinium grandiflorum).

Bee Orchis (Ophrys apifera).

\section{Beech Fern (Phegopteris).}

Begonia. - A very extensive and beautiful genus till lately almost confined to hothouses, but the introduction of some hardy kinds and the raising of many hybrids and varieties by their aid has given a new feature to the garden. Beautiful, free-blooming, and easily cultivated, they are rapidly becoming great favourites, as they are the best plants to be obtained - in the first instance, during the months of June, July, August, and September as ornaments of the summer-bedding garden; and in the second, as soon as there is any danger of frost at night, as ornaments of the conservatory. By lifting them into pots from the beds, which can be done without the slightest check (as they lift with capital balls and masses of fibrous roots closely and compactly surrounding the tuber), they may be made to afford five months of continuous bloom, which is more than any other plant with which I am acquainted will give. All they require to make them thrive and grow luxuriantly and quickly into large free-branching tufts is a light rich soil, and if the summer be at all hot and dry, copious waterings while growing. The beds should not be at all hot or dry, and the plants should not be placed too thickly ; the tubers make such vigorous and abundant growth that they are soon liable to crowd. When this happens, every second one may with perfect safety be taken up even in the middle of summer and removed to another bed, where, after a good watering, the plants removed will next day appear as if they had never been transplanted, and the room afforded by their removal will allow those left in the bed to develop fully, and they will fill up the gaps. Begonias require a sheltered situation, fully exposed to the sun, but dislike exposure to high winds, which are apt to break off the soft succulent stems at their junction with the tuber. No heavy rains do them the slightest injury; the blooms are not knocked off, and though the heads droop and bend, they rise again absolutely uninjured as soon as the sun shines again. Those who wish to increase their stock of these lovely plants should begin to take off their cuttings about the middle of July, just as they would those of a zonal Pelargonium. In silver sand and 
water these cuttings will root freely in from a fortnight to three weeks, and before the end of the season make goodsized tubers, which may give a little bloom towards the end of autumn, and flower abundantly in the open ground the following year. Indeed, tubers in their second year often yield finer blooms than older and larger ones. Considering the immense number that are raised, we think it unnecessary to give a list of names of tuberous Begonias. They are all now raised from seed, and the varieties are constantly changing. Good unnamed seedlings are in every respect as valuable

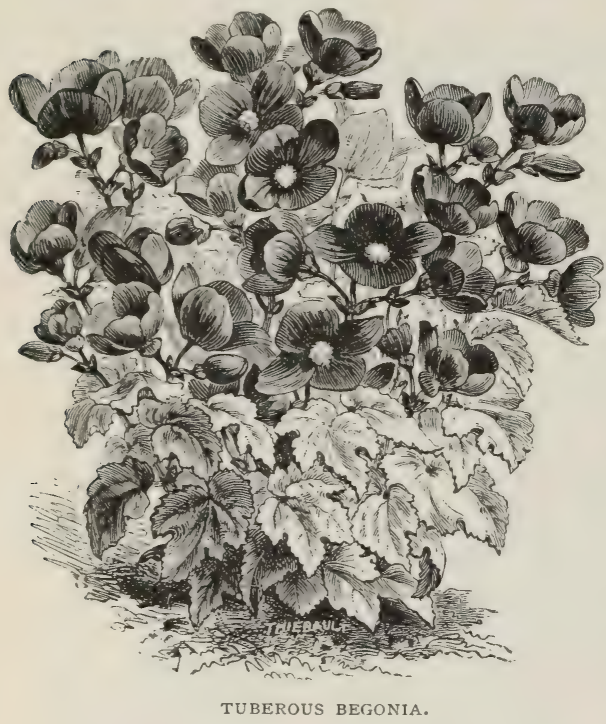

for bedding out as the named varieties, though many have their favourite named varieties.

Seed should be sown as soon as perfectly ripe, not between the middle of August and the following February. Sow in small pots, carefully prepared on fine sifted sandy loam and leaf-soil, on a perfectly flat surface. As the seed is very small, no covering is required excepting a slight sprinkling of silver sand. Plunge the pots in slight bottom heat, and, as soon as the seedlings are large enough to be handled, prick out into pans and keep in warm house near light until spring; transplant again in March into single pots, and many will show flower in May.

Tubers wintered in a cold house and potted in April should be grown on without forcing for culture in outdoor beds, in a free, light, fibrous mixture of loam and leaf-mould with a little coarse sand. They are very impatient of damp. Prepare the beds with plenty of well-rotted hot-bed manure, leaf-mould, and coarse sand to encourage free root-action, and after planting give a mulching of rotted manure or cocoa fibre to keep the soil moist and assist surface-rooting. Thus treated they will bloom from June to September, and if lifted before they are affected by frost, and put in a warm greenhouse, they will continue to bloom until December. -J. L.

Some other species are suitable for planting in the open during summer. The best are $B$. ricinifolia and heracleifolia, both with large palmately-divided leaves; B. ascotensis and castanæfolia, erect kinds with narrow leaves and bright red flowers. The first are effective in bedding out as an undergrowth to taller subjects which are not too dense.

Belladonna Lily (Amaryllis).

Bellevallia (Hyacinthus).

Bellflower.-A name for the various larger kinds of Campanula.

Bellis perennis (Daisy).-Daisies are among the most popular garden flowers. They need only simple culture, increase rapidly, and freely accommodate themselves to soils and situations. In the spring garden they are of great service, and when in large clumps or masses, the several varieties and hues of colour produce striking effects. The common double garden Daisy has sprung from the wild Daisy, just as the double Primrose has come from its wild single parent ; and both owe their origin to Continental florists of previous generations. Though we have numerous kinds, popular favour has adhered most closely to the old flatpetalled white and the old quilled red, both of which are grown by millions as market plants, and may be found in the spring in every costermonger's barrow. Beside these are the flat-petalled Pink Beauty, a charming pink of the quilled class ; a deep rich red or crimson quilled kind, called Rob Roy; White Globe, with large white quilled petals ; Virginia, an almost perpetual-flowered kind, of medium size, with flat white petals, most useful for bouquets; and several others. As the double Daisy sports freely and on the Continent seeds freely, new good kinds often arise, and it is by sporting that the yellow-blotched or Aucuba-leaved kinds have originated. Of these there are red, pink, and white-flowered sorts, the most effective being those with dark red flowers. These variegated forms regain the usual green hue in summer, 
and show their "colours" only in winter and spring. Though more tender than the green-leaved section, they will do well in winter on a free porous soil, and in summer in a cool shady border, if transplanted there. Heat and drought or excessive moisture standing about the plant are enemies of the double Daisy.

Propagating is simple, and may be done in spring and autumn. Well-dug soil suits well. The plants, pulled to pieces, should be dibbled 6 in. apart, and if a good mass of bloom is desired, they may be put a little closer. Where the soil is good, the Daisy increases so rapidly that it may be transplanted twice in the year. One of the prettiest effects we have ever seen was a bed of white

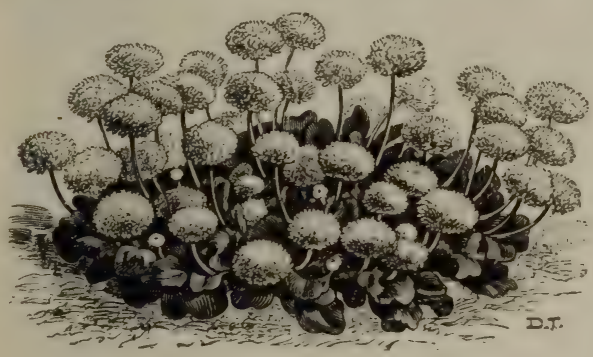

DOUBLE DAISY.

and red Daisies, planted in diamonds, with a strong blue King Pansy in the centre of each. The giant or crownflowered Daisies almost form a distinct section, and though very vigorous, they are much less free of bloom than the better-known kinds. These produce large and usually mottled red flowers upon long stalks, and are best suited for mixed borders. A very old favourite is the Hen-and-Chickens Daisy. It differs in no respect of habit or foliage from the double kinds, except that when the flowers are at their best they send out small ones from the axils of the scaleshence the designation Hen-and-Chickens. It is worth a place as a curiosity; its flowers are usually rosy pink, and before starting its progeny very pretty. Cultivated as easily as the common garden kinds.

Bellium.-Plants closely allied to the Daisy, of which some three or four species are in cultivation. Although from the south of Europe, they are hardy on the rock-garden. Like the beautiful Houstonia corulea, they are apt to exhaust themselves in flowering. B. bellidivides, $B$. crassifolium, and $\mathrm{B}$. minutum are much alike; B. minutum the best. Its numerous flowers are nearly as large as those of the Daisy. It is easily grown in light soil.

B. rotundifolium cœrulescens (Blue Daisy). - A native of Morocco, on rich soils on the hills about Tangier, and occurring in profusion by the watercourses of the Greater Atlas. First found by Balansa in Morocco in 1867 . It is a pretty rock-plant. Division or by seed.

Bellwort (Uvularia).

Belvedere (Chenopodium Scoparium).

Benthamia fragifera (Strawberry tree).

-An Indian tree, beautiful and precious in gardens. Though not hardy enough for the country generally, it is quite hardy in mild southern districts of England and Ireland, and in many other places near the sea. It is also suited for walls and sheltered banks. Where the climate is right, on an ordinary garden wall it sometimes assumes a handsome tree-like shape. There is a Japanese kind. Perhaps the following letter to The Garden, by Mr. J. B. Cockburn of Guernsey, about the very fine specimen here figured, will be interesting :-

"This tree is now thirty-five years old. As a small seedling of two years it was planted in the centre of a lawn exposed to the sun from early morning till late in the afternoon, but sheltered from the severe gales common in winter. It was quite two years before it took the ground; after that it shot up rather rapidly to its present height of $24 \mathrm{ft}$., beyond which it does not appear inclined to go, but the lower branches have spread out on the ground and are still spreading. The circumference at the base at present is 8I ft. It was some eight years old before it commenced to bloom; since then not a year has passed without its being covered with flowers, which are like those of the single Anemone, of much the same size, and of a greenish-white colour. The flowers open in May, and do not completely disappear till late in August; the sight of this mass of white bloom on so graceful a tree is singularly beautiful, and in the moonlight of the summer nights it has a weird and startling effect. In the centre of every flower is the fruit, and as the petals drop off, this enlarges and somewhat assumes the appearance of a Strawberry. It enlarges slowly, and towards the end of October turns a pinkish-red, the largest specimens being as large as a Mandarin Orange. At the moment of writing (28th October) a few are quite ripe and dropping from the tree, but fruit will be on the tree when the flowers open next year, and even now the 
buds of the future flowers, in the form of a small nodule, the size of a Pea, a miniature fruit, thickly stud all the new shoots; in fact, the tree has always either touch the ripe fruit, but now thrushes, and especially blackbirds, eat it with avidity. The tree sheds many of its leaves in January, and looks its worst in

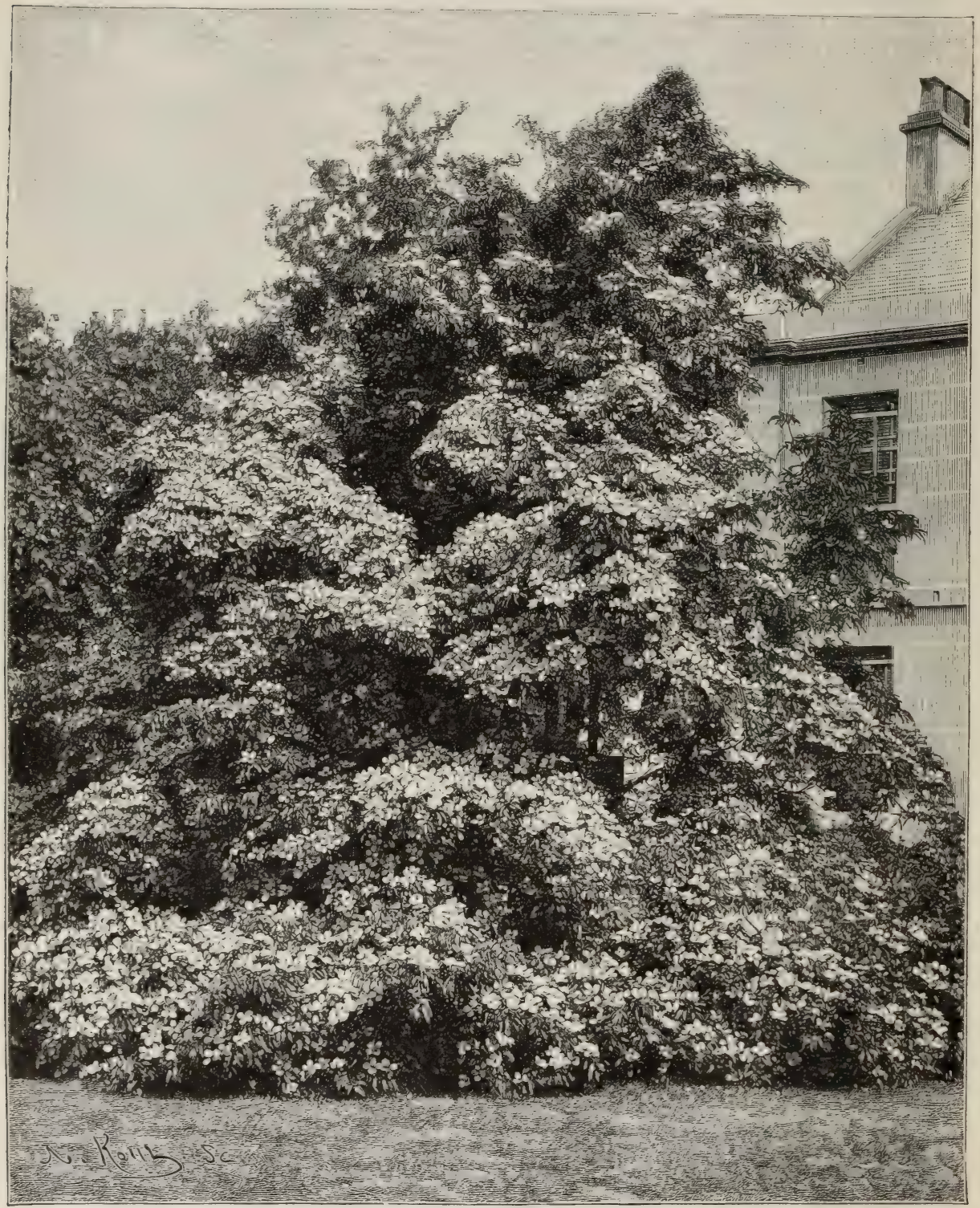

BENTHAMIA FRAGIFERA, ELM HOUSE, GUERNSEY.

fruit or flower, and for a long time shows both.

"The fruit is unpalatable; it makes a sort of jam which some people pretend to like. For many years no bird would
January and February, but it is never completely bare. It will stand any amount of rain, but suffers much from strong winds. It should be planted in an open space, well protected from pre- 
vailing winds. It cannot be propagated by layers or cuttings, but there is no difficulty in rearing seedlings; so freely does it propagate in this manner, that seedlings are constantly weeded out of the borders in the neighbourhood."

Berberidopsis corallina (Coral Barberry). - This is a beautiful evergreen climbing shrub from Chili, hardy enough for open walls in the southern counties. It has large spiny leaves very much like some Barberries. The flowers are a bright coral-red, and hang in clusters on slender stalks. It flowers for several weeks in summer, and is charming for a wall. It seems to prefer partial shade, such as that of a.wall facing east or west, and does best in peaty or sandy soil. Seeds or layers.

Berberis (Barberry).-A valuable family of hardy shrubs. In the chief nurseries only about half-a-dozen species besides the evergreen Barberries are grown extensively. One of the most beautiful, and certainly the most popular, is Darwin's Barberry (B. Darwini). The next best flowering Barberry is B. stenophylla, a hybrid between B. Darwini and the small B. empetrifolia.

B. empetrifolia is an interesting though not showy trailing shrub. Two or three specimens rising out of a mass of B. Darwini make a most effective evergreen shrub-group on a lawn. B. dulcis is a pretty Barberry, whose slender shoots are hung with tiny yellow flowers. It is from 6 to $8 \mathrm{ft}$. high, and has small partially evergreen leaves. B. buxifolia, a pretty South American species with evergreen foliage like the Box, also has yellow flowers. The common Barberry (B. vulgaris) is good enough for our selection, being very ornamental when in fruit in autumn. There are several varieties, some of which differ considerably in habit of growth and colour of the berries. One has berries of deep crimson, others have violet, yellow, and white fruits. A beautiful shrub-group could be formed of the fruiting Barberries alone, using $\mathrm{B}$. vulgaris, B. aristata (which has berries covered with white powder like Plums), and the small-growing B. sinensis (Thunbergi), also remarkable for the profusion of its scarlet berries, which remain on the bush throughout autumn. B. Wallichiana, called also B. Jamesoni and B. Hookeriana, has handsome flowers and 
M. japonica, or M. Beali as it is also called, is a good Evergreen in sheltered places, and a fine flowering shrub.

Bergamot (.1/onardir fistulosa).

Berkheya (Stohad).

Beta cicla variegata (Chilian Beet).A showy plant often used with effect. The leaves are often more than $3 \mathrm{ft}$. long, and present a vivid and most striking colouring. Their midribs are 4 in. or more across, and vary from dark deep waxy orange to vivid crimson. The splendid hue of the lower part of the leafstalks flows towards the point, and spreads in smaller streams through the main veins and ramifications of the great soft leaf, which is often I ft. and even 15 in. in diameter, if the plant be in rich ground. The under sides of the leaves are richly coloured, and these sides are well seen. The plant requires the treatment of an annual--to be raised in a gently-heated frame, and afterwards planted out in very rich ground, though it may also be kept over the winter in pots. It varies a good deal from seed, and the most striking individuals should be selected before the plants are put out. Used sparingly its effect would perhaps be more telling than if in quantity.

Betonica (Betony).-A large family of the Sage Order; not of much garden value. B. grandiflora is one amongst numerous kinds worth a place in a border, attaining greatest vigour and finest flower-spikes in rich loam not too damp. I2 to 18 in. high. Division.

Bidens (Bur Marigold).-North American annuals of the Composite family. Few worth cultivating. The desirable species are B. ferulæfolia, B. frondosa, and B. tripartita, from $I$ to $I \frac{1}{2} \mathrm{ft}$. high, and have yellow flowers and deeply-cut foliage. Treated as half-hardy annuals.

B. humilis is a handsome plant, dwarf and flowering profusely all summer, flowers orange-yellow.

Biebersteinia Orphanides.-A rare plant from South-eastern Europe, belonging to the Geranium family, about I ft. high: it has long finely-divided leaves and erect spikes of small rose-coloured flowers. It is sometimes met with in botanical collections.

Bignonia (Trumpet-flower). - The hardy species of this large family of climbers are graceful, showy in flower, and vigorous. There are three kinds hardy against sunny walls. They are B. radicans, B. grandiflora, and B. capreolata. The first two are strictly species of Tecoma, but are most generally known as Bignonias.
B. capreolata, a true Bignonia, is a native of the southern parts of North America, and is hardy in all but the coldest parts of England. It is commonly grown as a greenhouse climber, but it succeeds thoroughly against a warm wall. It has heart-shaped leaves, ending in curly vine-like tendrils, which enable it to climb high. The flowers, of a true trumpet shape, are large, reddish-yellow, and are produced, not in clusters, but singly. In a sheltered spot against a sunny wall it is a most satisfactory plant, and almost an evergreen. Other Bignonias from temperate countries, such as B. capensis and B. australis, might be planted against sunny and sheltered walls in the south, where they often flower as freely as in a greenhouse.

B. grandiflora, a Chinese plant, much more tender than $B$. radicans, and less common. It is much showier when in bloom, the drooping flowers being twice the size, of a bright orange-scarlet, and produced in large clusters. Its foliage, too, is larger, but the plant rarely grows so vigorously in this country. It is handsome in bloom on a warm sunny wall.

B. radicans is a native of the North American States, and is an old garden favourite. Its long wiry stems send out roots like Ivy, and cling to walls or any support. The foliage is graceful, and in late summer the shoots have showy clusters of scarlet and orange blossoms. There is a variety named major, with larger flowers of a paler tint, and more robust foliage. A strong plant will run up and cover a wall $40 \mathrm{ft}$. high. It is useful also for covering arbours and pergolas.

Bird Cherry (Cerasus padus).

Bird-foot Violet (Viola pedata).

Bindweed.-The English name for various kinds of Convolvulus.

Bird's-nest Fern (Asplenium).

Birthwort (Aristolochia).

Bitter Almond (Amygdalis).

Bitter Root (Lewisia rediviva).

Bitter Vetch (Orobus).

Black Lily (Lilium kamtschatkense).

Black Thorn (Prunus).

Bladder Fern (Cystopteris).

Blechnum (Hard Fern). - Several species in this genus of evergreen Ferns are hardy and worthy of culture. The common British kind (B. Spicant) is pretty and yields handsome varieties. Of these, crispum has the lobes of the fronds undulated and curled, and their points finely crested ; cristatum is dwarfer, and the crested fronds are more forked and branched; imbricatum has lance- 
shaped fronds of thick texture, and the top of pinnæ distinctly imbricated; serratum rigidum, is erect with crested fronds, distinct and handsome; multifurcatum has the fronds much divided and forked; and trinervium has the lowermost pinnce so arranged as to give the fronds a tripinnate appearance. The varieties of B. Spicant now number nearly fifty. Among the hardy exotic kinds B. alpinum is most desirable, as it is a rapid grower and its dense growth soon covers broad spaces on rockwork. The hardy Blechnums may be grown in loam, loam and peat, or a stiff clayey soil, but dislike chalky soils and dry situations. They love shady moist spots and abundance of water in the growing season. Under these conditions they attain a greater size and vigour than when wild. They are suitable for the hardy fernery and shady spots or rock-garden and in borders.

Bleeding Heart ( $D i$ centra).

Blennosperma californicum. - A dwarf annual from California, belonging to the Composite family, not much known in cultivation.

Blessed Thistle (Carduus benedictus).

\section{Bletia hyacinthina.}

- A beautiful Chinese Orchid, having ribbed leaves, and slender flower-stems I ft. or more high, bearing about half-adozen showy flowers of a deep rosy pink. It has proved hardy, and thrives well in sheltered and partially shaded situations in a peaty border well enriched by decayed leaf-mould. In some localities it would be advisable to cover the roots with a handful of protective material during severe cold. It is also known as B. japonica, and is very interesting for the bog-garden or a bed of hardy Orchids.

Blitum capitatum (Strazberry-blite). -A hardy annual of the Spinach family, $\mathrm{I} \frac{1}{2}$ to $2 \mathrm{ft}$. high. The flowers are small, but are followed by high-coloured fruit calyxes resembling small Strawberries. Treat as a hardy annual, sowing in April in the open air.

Bloodroot (Sanguinaria canadensis).

Bloomeria aurea.-An attractive little Californian plant, having umbels of small orange-coloured flowers striped with a deeper hue. From 6 to 18 in. high, and quite hardy in light garden soil in sunny positions, but should be protected during severe cold. Syns. - Nothoscordum aureum, Allium croceum.

Bluebell.-Various plants, principally Campanula rotundifolia and Scilla nutans.

Blue Berry (see Vaccinium).

Blue Cupidone (Catananche corulea).

Blue Daisy.-Certain blue flowersBellium and Kaulfussia.

Blue Spider-wort (Commelina coelestis). Bluets (Houstonia corrulea).

Blumenbachia coronata.-Has much to recommend it, the flowers being showy, the foliage elegant, and the growth dwarf and compact. Like all the Loasa family, the structure of the flowers is somewhat singular. The boat-shaped petals and the peculiar small scales between them, 
rock-garden and protected in winter when necessary. The bulbs should be lifted and separated after flowering, and replanted in autumn.

Bocconia cordata (Plume Poppy).Forms handsome erect tufts from 3 to over $8 \mathrm{ft}$. high, and is admirable if properly placed. The stems grow rather close together, and are thickly set with large, reflexed, deeply-veined, oval-cor-

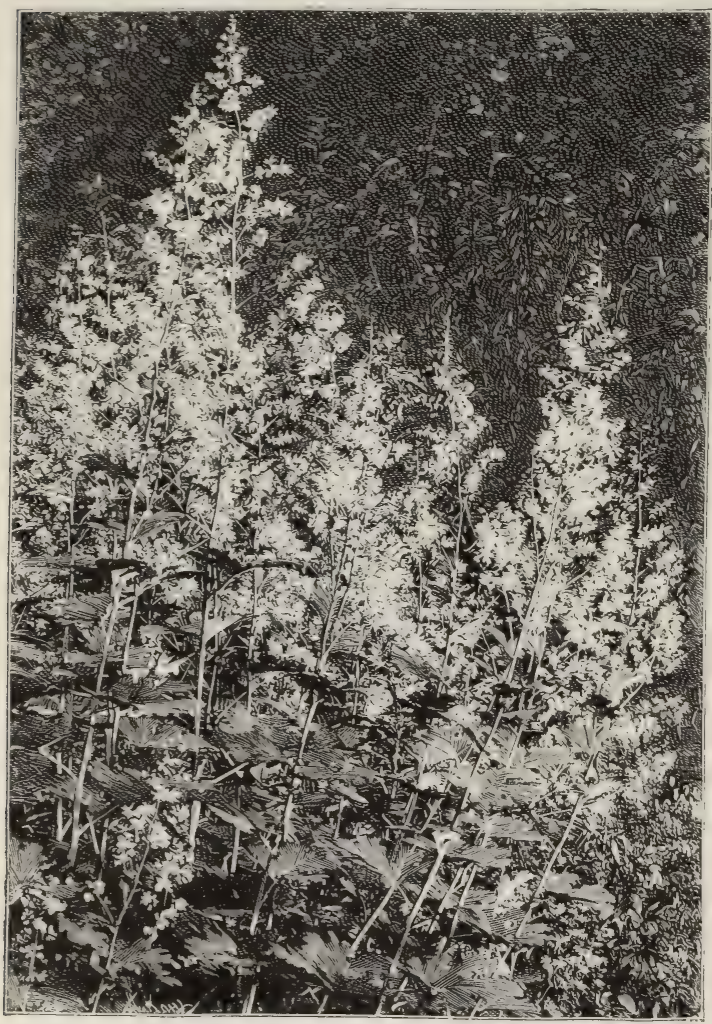

THE PLUME POPPY (BOCCONIA CORDATA).

date leaves, the edges of which are somewhat lobed or sinuated. The numerous flowers are in very large terminal panicles. The flowers are not showy, but the inflorescence, when the plant is well grown, has a fine effect. The plant is best in the shrubbery, and does well in ordinary garden soil. It is excellent in bold groups, the leaves being fine in form, and the plant handsomer when in groups than singly. Division. China.

B. frutescens.-A vigorous Mexican shrub, $3 \frac{1}{2}$ to nearly $6 \mathrm{ft}$. high, with few and very brittle branches, large, seagreen, handsome leaves, and greenish flowers. Very effective on Grass plats, in groups or as isolated specimens. It requires a somewhat warmer climate than ours to thrive well, though it is sometimes in fair condition in the London parks out of doors in summer. It may be placed out from June to the end of September. It is difficult to propagate by cuttings, and easier to raise from seed.

Bœhmeria nivea.-A stout shrubby perennial of the Nettle family, occasionally grown in botanic gardens, but scarcely suitable for the private garden, though distinct in habit, and with the under side of the leaves silvery. About London it grows 3 to 4 ft. high. Division. China.

Bœrkhausia (Crepis).

B. rubra (Red Hawkweed).

Bog Arum (Calla palustris).

Bog Asphodel (Narthecium ossifragumi).

Bog Bean (Menyanthes trifoliata). - Known also as Brookbean and Buckbean.

Bog Pimpernel (Anagallis tenella).

Bog Rhubarb (Petasites vulgaris).

Bog Violet (Pinguicula vulgaris).

Boltonia.-Very much like perennial Asters, and scarcely worth considering as distinct in a garden point of view. A recently introduced species, $\mathrm{B}$. latisquama, is said to be a great improvement on the others both in size of flower and brilliancy of colour. Its blossoms are a delicate rose.

Bomarea.-A most valuable genus allied to Alstroemeria. South America. Requiring greenhouse temperature so far as now known, Mr. Archer Hind, of Newton Abbot, has B. edulis (syn., oculata) out-of-doors, and it has flowered well after surviving a temperature of $25^{\circ}$ below freezing. If any of the other species should prove hardy in the southern counties, their fine bold twining habit and handsome flowers would be a gain.

Bongardia Rauwolfi.-A member of the Barberry family, though remarkably unlike one, as it has a depressed Cyclamen-like stem, from the apex of which spring the leaves, in three to eight pairs of leaflets, each of which is again divided, presenting the appearance of being arranged in whorls. These are wedge- 
shaped, of a pale glaucous green, and each has a conspicuous reddish-purple blotch at the base, which makes them very attractive. The flower-stem is much branched, $6 \mathrm{in}$. high, and bears roundish golden blossoms from $\frac{3}{4}$ to $I$ in. across, which droop gracefully from slender stalks. Though now rare, this beautiful plant was among the earliest occupants of the garden, and is mentioned by all the early writers. Found from the Greek Archipelago to Afghanistan. Hardy on dry soils. Seed.

Borago orientalis (The Cretan Borage). -A vigorous perennial of slight value, bearing pale blue flowers early in spring, and, in good soil, having very large leaves through the summer. Easily naturalised in any rough place, but not worth a place in the garden proper, being very coarse and occupying too much space. It should be associated with early spring flowers. The common Borage is very pretty, naturalised in dry places or banks, where it might often be welcome for purposes other than beauty. There is a white variety. B. laxiflora is pretty with numerous suspended blue flowers; it grows very freely on sandy soils. On the whole, the genus is of little interest, the common Borage being perhaps the most beautiful flower belonging to it.

\section{Borkhausia (Crepis).}

Botryanthus (Muscari).

Botrychium (Moonwort). - Inconspicuous Ferns, of which few are cultivated. The common native Moonwort (B. lunaria) is widely distributed, and generally found in moist sheltered meadows. B. lunarioides, B. virginicum, B. lanceolatum, B. simplex, and B. ternatum are hardy North American species. All the Botrychiums are deciduous, putting forth their fronds about the end of April, and dying down somewhat early in autumn. The fronds are of a beautiful dark green, and the plants produce small panicles of inflorescence. The best soil is a moist well-drained sandy mixture of loam and peat. Where the soil is little disturbed, and abundance of moisture is obtainable during their growing season, they would form, with Spirzeas, Lilies, etc., a very pleasing "groundwork."

Boussingaultia basselloides.-A very luxuriant trailing plant, I6 to $20 \mathrm{ft}$. long, and sometimes more. Flowers late in autumn, the flowers being small, white, fragrant, and becoming black as they fade. They are disposed in clusters 2 to $4 \mathrm{in.}$ long, springing from the axils of the leaves at the ends of the branches. The fine green leaves are smooth, shining, fleshy, and slightly wavy ; stems twining, tinged with red, growing with extraordinary rapidity, and bearing many tubercles. Quito. Suited only for dry banks and chalk-pits, associated with climbing and trailing plants. Tubercles of the stem; these break with the least shock, but the smallest fragment will vegetate.

Bowiea volubilis. - A Cape bulb, interesting only from a botanical point of view, being one of the few climbing Liliaceæ. It has no leaves, but has numerous fleshy terete branches, several feet high, and rising from a large Turniplike green bulb, half raised above the surface. The flowers are small and inconspicuous. It is a hardy perennial when planted in a sheltered situation against a wall, especially one with a southern aspect. It should be allowed to ramble over dead branches placed near it. Seeds.

\section{Box (Buxus).}

\section{Box Thorn (Lycium).}

Boykinia. - North American plants nearly allied to the Saxifrages, more curious than beautiful.

Brachycome iberidifolia (Swan River Daisy). - A pretty annual of simple culture, about 8 to 12 in. high. As it is

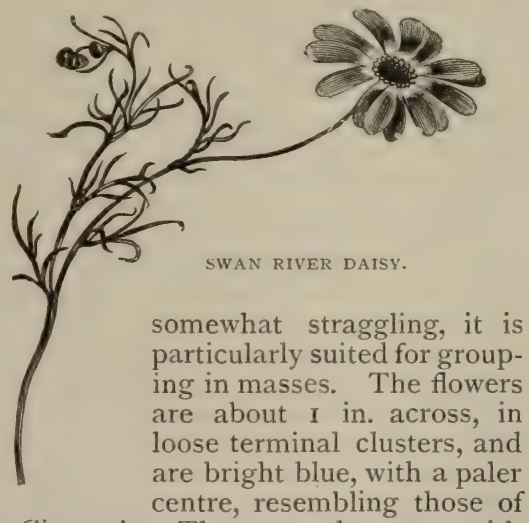
the Cineraria. There are other sorts, with flowers of various shades of blue and purple, and one of pure white. Sow in cool house in September as soon as ready, prick off 4 or 5 in a 4 -inch pot, keep in cold pits during winter, and guard against damp. Pot on again in March singly into 4 -in. pots, and finally at end of April plant out into open borders; or sow on slight hotbed in March, prick out into pits for transplanting into open in May; or sow in open in April and May.

Bracken (or Brake).-Applied to large 
Ferns generally, more particularly to Pteris aquilina.

Bramble (Rubus).

Brasenia (Water Shield).-A North American water-plant. The flowers are of a dull purple, and come to the surface to perfect themselves, but make little show. This plant has a remarkably wide distribution, being found in North America, Japan, Australia, and India.

Brassica.-Some forms of the Cabbage, particularly the variegated Kales, are used in the flower garden for winter effect. The secret in cultivating them is poor soil. This brings out their colours and keeps the plant dwarf and compact. Seed should be sown in May, and when fit to handle, the plants should be pricked out wide apart into a very sunny spot, and finally bedded out in October, after the summer stuff is cut down by frost ; and on clear days a clump, varied in colour and well planted, will have a charming effect on a lawn. In planting, the stems should be sunk in the ground up to the lower leaves, and care should be taken that they are of equal height. The dwarf curled variegated kind has the finest effect in beds. Its colours vary from pure white to deep purple, pass through cream, pink, pale and dark green. Plants of it have variously coloured veins and laced edges. The Ragged Jack stands next; when closely inspected the beautifully cut leaves give an additional charm. The seed must be of a good strain or selection, as the want of the finer laced and fringed light-coloured varieties quite spoils a good bed, the commoner colours being sombre dark greens with purple veins. The Carnationstriped Red Cabbage makes a splendid bed, but is not so hardy as the Kales.

B. oleracea crispa is a handsome Cabbage nearly $4 \mathrm{ft}$. high, with elegantly cut arching leaves, the divisions of which are finely curled or frizzled. It may be advantageously employed in the winter garden, the leaves being at their best during autumn and winter. Still more striking is B. o. palmifolia, $6 \frac{1}{2} \mathrm{ft}$. high, with leaves near the top of the stem, which have a Palm-like appearance in the end of summer and in autumn. It may be used in various positions, as its "Cabbage" character is not so evident. The fact of their being Cabbages prevents many people from using these plants.

Bravoa geminiflora (Scarlet Twinflower). - A pretty Mexican bulbous plant of the Amaryllis Order. It grows from I to $2 \mathrm{ft}$. high, the flower-stems being stout and erect, bearing on the upper part numerous pairs of nodding tubular flowers of a rich scarlet outside, but inclined to yellow within. The plant succeeds well in warm sheltered situations in borders of light and well-drained soil, but requires some protection over the bulbs in winter, except in mild seasons. It flowers in autumn, and remains a long time in bloom.

Brevoortia coccinea (Crimson Satinflower). - The name now applied to Brodiæa coccinea, one of the prettiest Californian plants in cultivation. The drooping umbels of flowers grow on terminating stems, $\mathrm{I} \frac{1}{2}$ to $2 \mathrm{ft}$. high. The flowers are tubular and of a deep crimsonred, the lips being a vivid green. This plant, like some other beautiful Liliaceæ

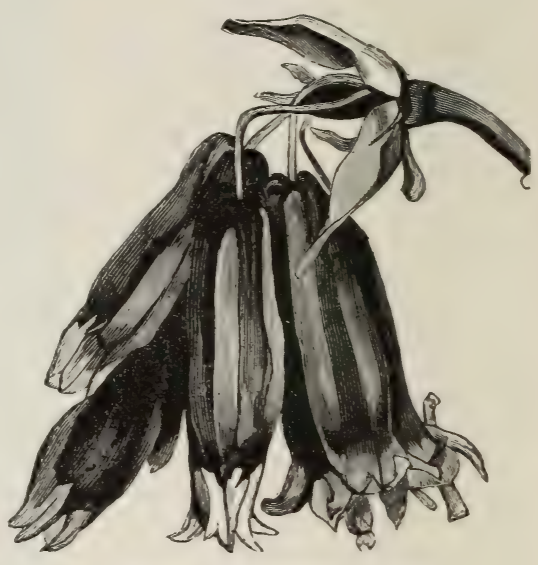

BREVOORTIA (SATIN-FLOWER).

from California, is uncommonly showy, but, unlike some of them-for instance, the Calochorti-is most manageable, and thrives in our fickle climate. It succeeds in soil of almost any description between the extremes of very light and very heavy, but makes the most vigorous growth in substantial but friable loam. The bulbs may be kept out of the soil from August to February, though it is not desirable to keep them so long. It is not desirable to delay planting after October, as flowers of late-planted bulbs are scarcely so fine as they otherwise would be. Once planted, they may remain undisturbed for several years, unless raised for division. Offsets are produced in some number, and the plant may also be increased by seed, which vegetates pretty freely after some weeks, the resulting bulbils attaining a flowering size in three to four years. As the plant is slender, the flowers being usually produced on a naked space, not 
less than three plants should be grouped together, and five or six will produce a still better effect; an Osier rod in their midst will support the fragile stems. In soils, notably those of a sandy character, the foliage may partially wither by the time the flowers are in perfection. This may partly be remedied by sowing a few seeds of some neat dwarf annual to carpet the soil round the stem, and bloom after its removal, or, in the case of the earlyflowering annuals, such as Limnanthes and Leptosiphon, simultaneously with the bulbs themselves.

Brexia madagascariensis.-A handsome shrub with a slender erect stem, clothed with long leathery leaves. It is one of the tropical stove-plants that stand the open air from June to early in October, but few places can spare it out-of-doors. It requires ordinary stove-culture during winter and spring, and should only be placed out after making a strong growth, which has been hardened off. Madagascar.

\section{Briar Green (Smilax). \\ Briar Sweet (Rosa).}

Briza (Quaking Grass).-A graceful family of Grasses, mostly American, but some European. B. maxima is one of the handsomest of the smaller ornamental Grasses, growing 12 to 18 in. high; may be sown in the open in March, is quite hardy and exceedingly graceful while growing, and most useful for decoration either green or dried. B. media (Common Quaking Grass) is smaller, 9 to ${ }_{5}$ in. high. Borders, and naturalised on bare banks and slopes. Seed.

Brizopyrum.-Grasses not ornamental enough to cultivate.

Brodiæa.-North American bulbous plants belonging to the Lily family. The genus has lately been thoroughly revised by the American botanists, whose nomenclature is followed in the subjoined account. It will be observed that the genera Calliprora, Triteleia, Milla, Seubertia, Hesperocordum are partly or entirely included among the Brodiæas, whilst B. coccinea is called Brevoortia coccinea, and Brodirea volubilis is Stropholirion californicum.

Brodiæas adapt themselves to the ordinary circumstances of mixed borders with wonderful readiness, and their presence in bold masses during the spring months is most welcome. Most of them increase yearly by means of offsets in favourable situations, and if they do not do so, it is a sign that the position is not to their liking. Plant them at first in wellprepared light rich soil, so as to give them a fair start and get them properly established.

B. congesta, of which there is a charming white variety which is scarce and very desirable. Both are hardy and establish themselves readily without any extra care, and as they increase much more rapidly than the other Brodiæas, a large patch is produced in a few years. B. congesta is also most useful for filling up low recesses in the rock-garden, which may be covered in summer with such creeping plants as Veronica repens, etc., without in the least affecting the bulbs. B. congesta has narrow ribbed leaves, slightly glaucous, and flower-stalks from I to 3 or $4 \mathrm{ft}$. long, on which the flowers are borne in umbels; they are about an inch long, somewhat funnel-shaped, of a bright purplish blue, and appear May to July. California, Colombia, etc.

B. grandiflora.-A handsome and useful plant, with the flower-stem about I foot high, terminated by an umbel of from 3 to Io flowers, varying from purple to a light rose. There is a taller and stouter variety called major, with larger blossoms. This flowers in early summer and lasts in bloom several weeks. The variety minor of Baker is ranked as a species by Watson. B. grandiflora requires to be planted in quantity to render the large umbels of flowers effective. Various parts of California.

B. lactea.-An elegant plant, with large umbels of white star-shaped blossoms on stout stems I foot or more high. The variety lilacina has lilac-tinted flowers. It is synonymous with Hesperocordum hyacinthinum and $\mathrm{H}$. lacteum.

B. multiflora, also called parviflora, in habit and position generally may be referred to $\mathrm{B}$. congesta. The leaves, which are few, are from I to $2 \mathrm{ft}$. long, and bright green, and the flower-stalks are shorter than the leaves. The bright blue blossoms appear in subglobose heads on a stem I to $2 \mathrm{ft}$. high, the divisions being much shorter than the tube and spreading, and lying nearly flat when open. California; flowers early in May. Called also B. grandiflora var. brachypoda.

B. volubilis.-A curious and interesting hardy bulb. Being of a climbing habit, it ordinarily reaches a height of 4 to Io or $12 \mathrm{ft}$., its scape or flower-stalk twisting in the most peculiar manner round everything that comes in its way. It is said to reach in this way enormous heights on trees before the flowers expand. It requires a rich light soil, and should always be planted near a bush or stakes 
on which it is to climb, or it will dwindle and have few flowers, badly coloured. The leaves are about I foot long, narrow, keeled at the back, and ribbed on the upper surface. The flower-stalk, which is green or pink, is very brittle, and the flowers are in umbels of from twelve to twenty. They are bright rose-coloured and very handsome. California, flowers in July.

The kinds either rare or not in cultivation are B. peduncularis, Douglasi, Bridgesi, crocea, and terrestris.

CUlTuRE AND POSITION.-These plants should be grown in a sunny open spot, never shaded. The border should be thoroughly drained, and if raised above the surface so much the better. The soil should be a rich garden mould, light and friable. The bulbs should be planted at a good depth, so as to be out of harm's way in winter, for, though most are hardy, severe winters injure them in many places. Apart from the ordinary borders, sunny borders or beds of choice shrubs devoted to the newer and choicer hardy bulbs offer suitable positions. In bold masses they have a much finer effect in flower than when there are only one or two together, and they can be readily protected in winter. The propagation and other details of culture are given more fully under Brevoortia.

Bromelia sphacelata (Hardy B.)-A rough curious plant, forming tufts of harsh, rigid, spiny leaves, I to $2 \mathrm{ft}$. high. Flowers in summer; purple, sessile, crowded, and overlapping each other, in axillary spikes. Leaves numerous, erect, sword-shaped, long-pointed, fringed with stiff spines pointing upwards. Chili. The rock-garden and warm borders in light perfectly-drained soil. Has stood out-of-doors several winters, and in the southern counties will probably prove hardy in the rock-garden.

Bromus.-At least one of this large genus of Grasses is very graceful and worthy of culture - that is B. brizæformis, a very hardy biennial about $2 \mathrm{ft}$. high, with large graceful and drooping heads. It is more valuable for cutting and drying than any of the Quaking Grasses (Briza). We have grown it as an annual sown outof-doors in spring and in pots, but probably autumnal-sown plants would give the best results. It is worth a place for the sake of cutting for preservation alone.

Broom (Cytisus).

Broom Rape (Orobanche).

Broom, Spanish (Spartium junceum).

Browallia elata.-This has generally been regarded only as a beautiful potplant in summer and autumn, but it does well in the open air, either in a bed by itself or in large patches with other things. It supplies a shade of colour difficult to obtain, and may be added to the list of bedding annuals that are continuous bloomers. Sow in March, prick off the young plants when large enough to handle, grow them on till they are strong, and plant out in May. In addition to its other good qualities, it is useful to cut from, the flowers being light and elegant. There is a white variety equally useful. B. grandiflora, a fine form of the old B. elata, is most useful for conservatory and indoor decoration. It comes true from seed. The flowers, being of a beautiful shade of blue, are very valuable for associating with the bright colours usual in such structures. It also succeeds out-of-doors. The new B. Roezli is a densecompact bush, I6 to 20 in. high, with shining green leaves. The flowers are of a delicate azure blue, or are white with a yellow tube, and are unusually large for the genus. They come in uninterrupted succession from spring till autumn. Rocky Mountains.

Brugmansia (Trumpet-flower).-Plants of fine form and large and beautiful flowers, more useful in warmer countries, but good for summer use in warm and sheltered gardens in the southern and milder districts. They are of easy cultivation, and soon make large plants. The best way of growing is as standards, so that their long drooping flowers may be better seen. In the flower garden a sheltered but sunny position should be chosen. The plants may be safely put out about the end of May in good warm soil. It would be best to pot them into large pots or tubs, and turn them out of these ; thus treated they would not die back so far in the winter, and when planting time again came round they would make a stronger growth. When cultivated in a house either in tubs or in the border, an annual pruning should be given early in the spring, and they should be kept within bounds. Under glass the chief enemy is green-fly, but fumigation soon disposes of this. For the open border of a large house a few standards with stems $8 \mathrm{ft}$. or so in height make a grand show. Their propagation is simple, the young shoots being merely taken off in spring and struck on a gentle heat, one cutting in a small pot. When struck do not let them starve, but grow on as fast as possible, keeping them to the one stem 
until of good height. They will yield a few flowers the first autumn when planted out, but the second season they should make a good show much earlier. As they become older they flower more profusely, the growth being less luxuriant. I remember taking up some about two years old from the open ground and
Knighti in the illustration is an instance of good effect when not overcrowded. This is one of the best varieties, with many large handsome double flowers. It is of more compact growth, yet very robust ; its foliage is of a darker green, and somewhat longer than that of other kinds. B. suaveolens, another good white variety,

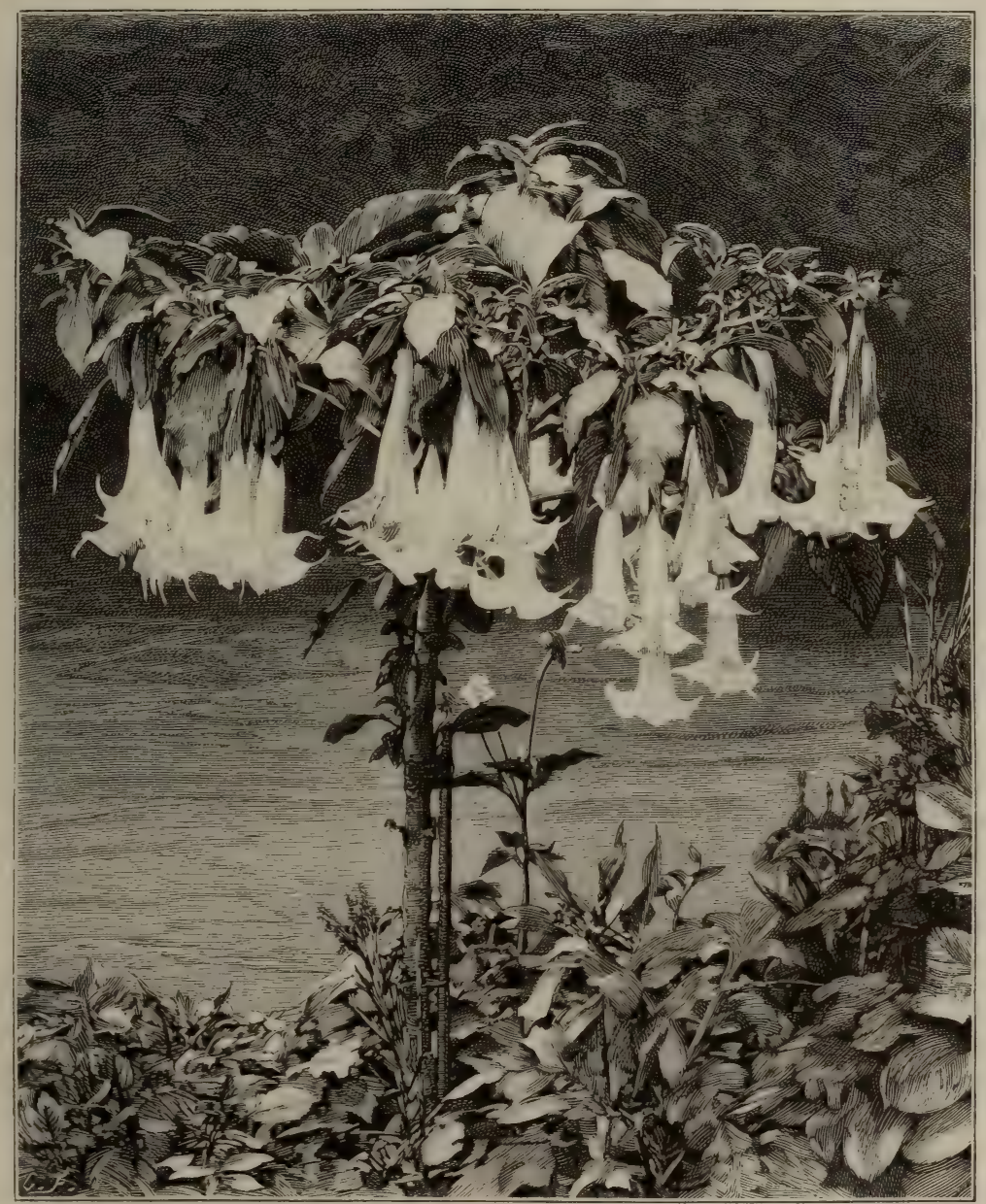

BRUGMANSIA KNIGHTI IN THE FLOWER GARDEN.

potting into 12 -inch pots. They were then put in a gentle heat, and gave several flowers during the early part of winter. When planted out in the open ground, Brugmansias are best as centre plants to fairly large beds, with a carpet of dwarf plants under them. They should not be smothered up with other tall things, which would create a sacrifice of flower. The example of Brugmansia is a profuse bloomer, its flowers being perhaps larger than those of B. Knighti, but single. B. sanguinea has flowers of a deep orange-yellow tinged with green towards the base; it does not flower quite so freely as the white kinds, but should be grown for its distinct character. There is also a double yellow variety of B. chlorantha, which is free-flowering and well worthy of being included.- J. H. 
Some years ago at Nuneham Park, Oxford, B. sauveolens was used with good effect in the flower garden during summer and autumn. Mr. Stewart the gardener used to raise plants annually by striking cuttings in autumn. They struck readily in bottom heat, were potted as soon as rooted, and kept growing gently in a warm greenhouse all through the winter. About the end of February it was the practice to
Out-of-doors the plants flowered freely, and a sweet perfume was exhaled during the evenings in July and August. They continued to flower until early autumn frosts came. Then they were dug up and the roots were trimmed, so that the plants would go into 12 -inch pots, and instead of being potted they were stored under a stage in one of the greenhouses. -R. D.

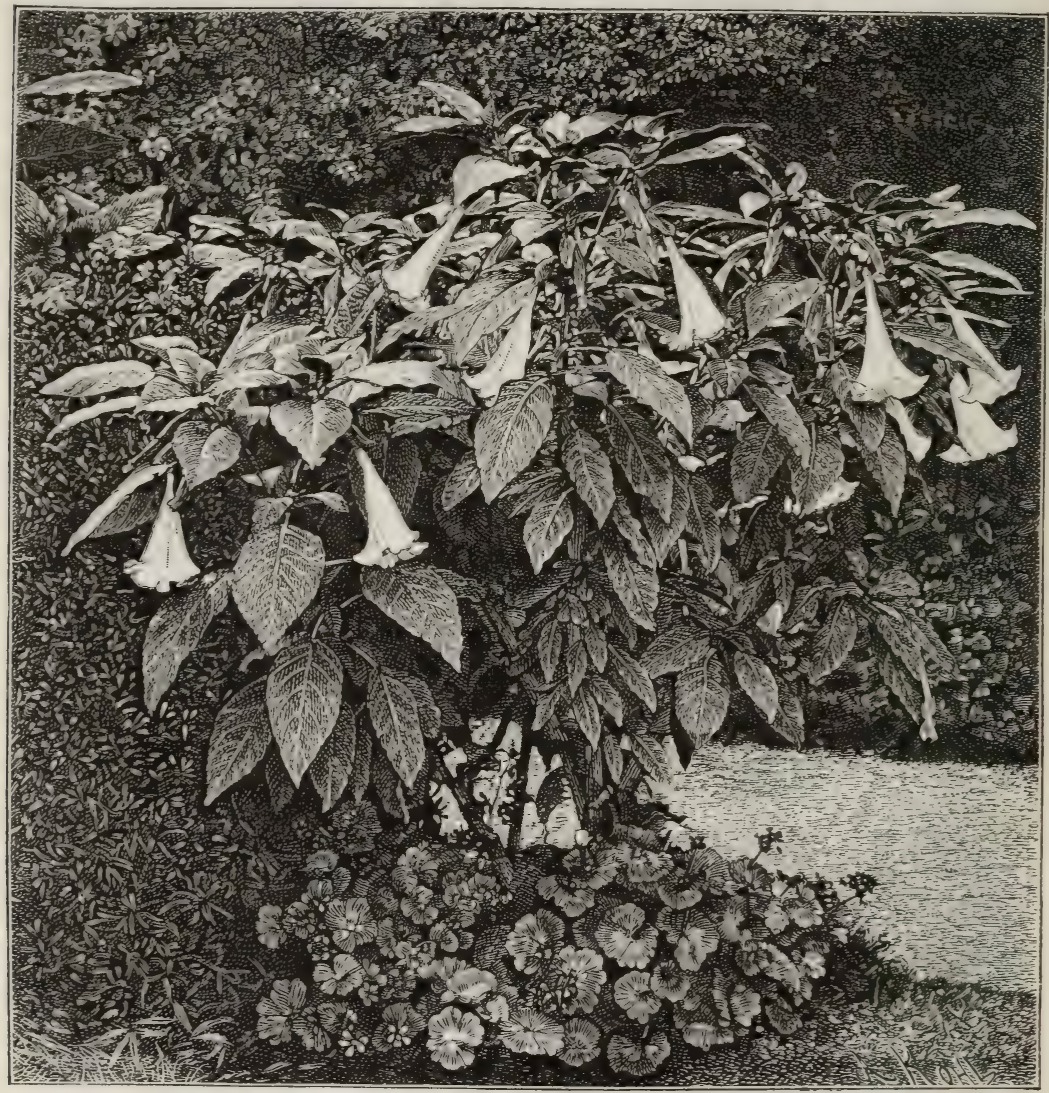

DATURA SUAVEOLENS, CUSHAM, HANTS,

shift them to an atmosphere of about $55^{\circ}$, when they were freely encouraged to grow. Being free-rooting plants, as soon as the roots appeared above the surface they were given liquid manure and sometimes a top-dressing of old cow manure. They were kept growing on in this way until the middle of May, when they were $2 \frac{1}{2} \mathrm{ft}$. high, after which they were gradually hardened off, and during a dull time were taken out-of-doors, placed in a sheltered corner, and screened from the sun preparatory to being planted out.
Bryanthus erectus (Hybrid B.)-A dwarf evergreen bush, from 8 in. to $\mathrm{I} f \mathrm{ft}$. high, bearing pretty pinkish flowers. It is said to be a hybrid, and is in appearance intermediate between Rhododendron Chamæcistus and Kalmia glauca. In very fine sandy soil or in that usually prepared for American plants, it grows well, and is worthy of a place in the rock-garden or in collections of very dwarf alpine shrubs, whether planted in the rock-garden or in neat beds. At least one pretty American alpine 
shrub of the same genus was once introduced, but it is now lost to our gardens.

Bryonia dioica (Bryony).--The modest merit of this wild British climber is acknowledged in various German gardens. It is chosen for its enduring verdure as well as for its graceful growth and foliage. It forms many wreaths in the town gardens of Vienna, and is trained up the angles of large statue pedestals in the garden of Count Schwarzenberg. So trained, it pleasantly relieves the mass of stone, but so common a plant will scarcely find a place in many gardens.

\section{Buckbean (Menyanthis).}

Buckeye (Pavia).

Bugle (Ajuga).

Bugloss (Anchusa officinalis).

Buddleia globosa (Orange Ball Tree). - A favourite shrub from Chili, often seen in the southern counties, where it is quite hardy, and in Ireland. The flowers are balls of bright yellow, very showy in early summer. It is of rapid growth, and if badly cut down during a severe winter, generally grows again in the following summer. Other species less satisfactory for open-air culture are $B$. crispa, Himalayas ; and B. Lindleyana, China.

Bulbine.-Plants of the Lily Order, of which only one species, B. annua, from South Africa, is grown in the open airan annual, about $\mathrm{I} \mathrm{ft}$. high, with narrow leaves and spikes of small yellow flowers, not very showy.

Bulbocodium vernum (Spring $\mathrm{Mea}$ dow Safron). - A pretty bulb from 4 to 6 in. high, flowering in early spring. If several tufts are put in good sandy soil, it will prove one of the best and earliest of spring bulbs. It sends up its large rosy purple flower-buds, distinct in colour from any other spring flower, earlier than Crocus susianus ; and, in fact, often shows for several weeks ere the snow leaves us. The tubular flowers are nearly 4 in. long, and are usually prettiest in the bud state, the colour being a violet-purple, the large buds appearing before the leaves, and the leaves growing large after the flowers are past. Associated with very early flowering plants like the Snowflake, Snowdrop, and Anemone blanda, it is very welcome in the rock-garden or in warm sunny borders. Alps. Easily increased by dividing the bulbs in July or August, and replanting them from 4 in. to 6 in. apart. There is a variegated leaved variety. One other species, B. trigynum, is sometimes met with 
same beauty of habit by planting in groups upon fully exposed knolls with the common Box, not too thickly set. Almost all the species and varieties have variegated forms, which, though pretty, are not so good as the natural forms. Easily increased from seed sown in the open ground, or from cuttings in the autumn. The following are the kinds:

The Common Box (Buxus sempervirens). - From its close bushy habit it is one of the most useful Evergreens for garden hedges. It may be pruned or clipped into any shape; and when topiary gardening was in fashion, it shared with the Yew in the formation of designs and figures of men and animals. While there are few soils in which it will not thrive, it prefers such as are light, with a warm gravelly subsoil. Of what is regarded as the typical species, there are in cultivation a remarkably large number of varieties, differing more or less in stature, habits of growth, and foliage. They are all very interesting, and in not a few cases quite equal, if not superior, to the parent as decorative shrubs. Of these the undermentioned are worthy of special attention. B. s. arborescens is a handsome form, with a more robust growth, longer branches, and larger leaves than the common species. The Handsworth variety, originated at, or at least was sent out from, the Handsworth Nurseries, near Sheffield, a few years ago. It has broad deep green leaves, and is one of the finest varieties. B. s. angustifolia, with much narrower leaves and a dwarfer growth than the species, is a compact shrub, valuable as a margin to stronger, or for borders or beds of smaller Evergreens. B. s. aurea marginata has leaves beautifully margined with gold, giving it a fine effect. B. s. japonica, by some writers regarded as a species, is probably a form of the species. It is quite hardy, and is a handsome shrub. The growth is like that of the common Box, but the leaves are nearly double the size, and of a dark green. B. s. latifolia has larger and broader leaves than the species, which it resembles. B. s. latifolia stricta has foliage similar to the preceding, but differs in its style of growth, which is more columnar. B. s. pendula has a weeping habit, and when left to itself has a rambling and not very elegant form. Trained, however, to a single stem, or grafted as a standard upon the upright varieties, it forms a fine specimen for a lawn. B. s. rosmarinifolia is a curious dwarf variety, with narrow leaves, giving it the look of a miniature Rosemary. B. s. suffruticosa or nana is the common dwarf Box used for edgings to garden walks. B. S. myrtifolia is a distinct plant with narrow leaves. B. s. thymifolia is a neat dwarf variety, with short tiny branches, and very small leaves. It is a good rockplant. The Minorca Box (B. balearica), is a native of Balearic and other islands in the Mediterranean, as well as Italy and Turkey, where it forms a fine tree of from 60 to $80 \mathrm{ft}$. in height. The leaves are larger than those of the common Box, and when exposed to the sun, are of a lighter green. In our gardens it is often seen as a shrub; and, though classed among hardy Evergreens, it only succeeds well in warm wellsheltered situations. It requires with us a dry soil and a warm subsoil. The Chinese Box (B. sinensis) is of a dwarf habit, not exceeding in its native habitats $3 \mathrm{ft}$. in height. The leaves are smaller than those of the common Box, and it is rather tender, but succeeds in sheltered situations, forming a compact bush, useful for small garden shrub beds. B. s. longifolia is of similar habit to the species, but has longer leaves. Though like its parent, scarcely equal to our winters, except in well-sheltered situations, it is a pretty little bush.

Box Edgings.-Where Box edgings are cared for, they must be clipped every year, and it is on this operation, and on the time of year it is done, that the look of the edging for the rest of the year depends. After trials of clipping at different seasons, I am confident that the end of May or the first week in June is the best time for it, for although the Box is hardy, its young growths often suffer from spring frosts during May, and, by clipping at the time named, all irregularities of surface are removed; the young growth very soon commences, and takes off that "strait-laced" appearance that follows the use of the garden-shears. The young growth looks fresh and becomes matured to stand the ensuing winter, which is not the case when clipping is done at the end of summer. The work, although simple in itself, requires some experience. For straight edgings, of whatever length, I stretch a line the whole distance, to show the centre: then I take the desired width off either side, and level off the top with long clean cuts made by sharp shears. I have seen edgings laid in in almost every month in the year, and, with attention to watering, they have succeeded; but I never saw them look well when the 
above date for cutting was not kept. Injury is done through salting the walks to destroy weeds, when a heavy fall of rain floats the salt to the edging, and destroys it. The next worst enemy to Box edgings is the foliage of garden crops or flowers overhanging them, and drawing them up weakly, so that they cannot withstand severe weather. Wheeling or treading on them also destroys them. Where proper attention is paid to Box edgings they are very charming to many, though they are not nearly so economical or good as the rough stone or flint edgings spoken of elserwhere in this book.

Cacalia.-Composite plants of little garden value. The pretty Emilia sagittata is also called $\mathrm{C}$. coccinea.

Caccinia glauca.-A dwarf hardy perennial belonging to the Borage family, from the highlands of Persia. It is about 9 in. high, and has short racemes of flowers, each about $\frac{1}{2}$ in. in diameter, resembling those of Borage in form, being pinkish when first expanding, but changing to blue. It is a neat border plant, interesting to the botanist and the general lover of plants, but hardly a showy plant.-W. T.

Cactus.-Under this name various plants belonging to the Cactus family have proved hardy in Europe and England, and have been much talked of. Opuntia, Echinocereus, Mammillaria, and Echinopsis are the hardiest, and the following general remarks may be useful and suggestive. Miss Rose G. Kingsley wrote to The Garden: "In Dr. W. A. Bell's garden at Manitou, Colorado, I saw a collection of 8 or Io species of hardy Cacti, which had been found in the neighbourhood, and which were grouped together on a bit of rough rockwork. I have seldom seen a finer display of all shades of yellow, crimson, and scarlet, and I cannot but think that the Colorado Cacti would succeed perfectly in England. They are undoubtedly hardy, as I have seen the thermometer at Manitou, seventy miles south of Denver, go down to $22^{\circ}$ below zero (Fahrenheit); and in parts of the State where Opuntia Rafinesqui grows freely, the snow sometimes lies for two or three months. The moisture and want of actual sunlight of our English climate would of course be somewhat against them, as in Colorado the sun is powerful even in winter, and is seldom obscured by clouds or mist for more than five or six days from November to April; the atmosphere, too, is extraordinarily dry.
As, however, O. Rafinesqui succeeds in England, I can see no reason why other kinds of Cacti growing in their native country under exactly similar circumstances should not thrive equally well with us. Professor Porter and $\mathrm{Mr}$. Coulter, in their Synopsis of the Flora of Colorado, mention the following kinds of Cactaceæ, viz. Echinocactus Simpsoni ; Mammillaria Nuttalli var. cæspitosa; M. vivipara (this latter species grows freely over the plains and foothills east of the Rocky Mountains, round Colorado Springs, and has been, I believe, successfully cultivated in England); Cereus viridiflorus, yellow ; C. Fendleri, flowers deep purple and fruit edible; C. gonacanthus, scarlet, open day and night; C. phœniceus ; C. conoideus ; C. paucispinus ; Opuntia Camanchica ; O. arborescens; O. Rafinesqui ; and O. missouriensis. All the above have been described or verified by Dr. Engelmann, of St. Louis, but the Cactaceæ of Colorado had been by no means thoroughly worked out when Professor Porter's Synopsis was published three years ago, and I do not doubt that by this time many species have been added to the list just given." Charming effects are afforded by Cacti in the open air in Southern England, the plants proving hardy and blooming freely when fully exposed to the sun on a low rock-garden.

When the foliage of a plant, or what answers to it, is perennial, as in Cacti, it is most important to place it so that it may be safe from injuries, apart from climate. The best places are, as a rule, on well-drained ledges in the rock-garden. So far as we know, the Chilian species have not been tried, and at present we have only a few of the northern outliers which may be termed hardy representatives of the family. These should be planted in the rock-garden in open airy situations, free from dripping water, and where the drainage is perfect. Probably hardy alpine species will be found farther south, and we may yet see, in warmer counties, a good collection of brightflowered Cactaceous plants on warm rocky borders or banks.

Caladium esculentum. - For outdoor decoration this species is the best of a large genus with very fine foliage. It is only in the midland and southern counties that it can be advantageously grown, but its grand outlines and aspect make it worthy of all attention and of a prominent position wherever the climate is warm enough. It may associate with many fine foliage plants; but Ferdinanda, Ricinus, 
and Wigandia are usually too strong for it, and, if planted too close, injure it. It requires, above all other plants, a thoroughly drained, light, rich, warm soil. In great heat it should be plentifully watered, and occasionally watered with liquid manure. May is the best time for planting it out, and, if groups are formed, the plants should be 2 or $2 \frac{1}{2} \mathrm{ft}$. apart. The foliage generally attains full beauty and development in August and September. At the approach of cold frosty weather, all the leaves, or all but the central one, should be cut down to within I or $2 \mathrm{in.}$ of the crown, and a few days afterwards the tubers should be taken up and left on the ground for a few hours to dry; they should then be stored on the shelves of a greenhouse, or in a cellar or some other place where they will be sheltered from frost and moisture. By placing the tubers in a hotbed in March, plants with well-grown leaves may be obtained for planting out in the open air about the end of May or the beginning of June. New Zealand. It has been used with good effect in London gardens, but owing to cold seasons its culture is to a great extent given up.

C. odorum (Colocasia odora).-A very fine plant, with stout stems usually from 3 to $8 \mathrm{ft}$. high. The heart-shaped leaves are erect, very broad, and marked with strong veinings, and are frequently more than $3 \frac{1}{4} \mathrm{ft}$. long. The flowers are very fragrant. It is a fine subject for isolation on Grass plats, its tall arborescent habit distinguishing it from the other species; but it is too tender to thrive except in sunny sheltered dells in the south, and should not be planted out until June. E. Indies.

C. virginicum (see Peltandra).

Calamintha. - The only species of this genus of Labiatæ to be recommended for the garden is C. glabella, a charming minute herbaceous plant, forming compact and neat little tufts about 3 in. high. Flowers in summer, bearing tubular lilacpurple scented blossoms, very numerous and large for its size. May be grown on the rock-garden in sandy loam and among the very dwarfest plants. Division.

\section{Calampelis (Eccremocarpus).}

Calandrinia.-This genus is large, and many species have been introduced. Few are sufficiently effective for general cultivation, but if well grown and placed they are pretty, and sometimes brilliant, flowergarden or rock plants.

C. discolor.-A beautiful S. American plant, from I to $\mathrm{I} \frac{1}{2} \mathrm{ft}$. high. Its fleshy leaves are pale green above and purple beneath. The bright rose flowers grow in a long raceme, and are $1 \frac{1}{2}$ in. across, their colour forming a beautiful contrast to the tuft of golden stamens in the centre. They expand only in sunshine, but in July and August they open several weeks in succession. They require a dry soil and a warm exposure. They may either be sown in the open border or in pots in April, but care must be taken in transplanting.

C. grandiflora.-This handsome annual somewhat resembles C. discolor, but is larger in all its parts, and has more showy blossoms and leaves of a different shape. It requires a similar situation, and attains the greatest perfection in a warm and moderately stiff soil. It flowers a little earlier, and continues to bear flowers throughout autumn.

C. nitida.-Closely allied to C. discolor, but dwarfer. It is a succulent annual, and forms a tuft from 4 to 6 in. across, in strong specimens, and bears on stems 6 to 9 in. high numerous large rose flowers in leafy racemes. The flowers are fully 2 in. across, and expand best in bright sunshine, like all the species of the genus, presenting a striking effect. It is best treated as a half-hardy annual, as it then blooms much earlier, but may be sown in the open air in May. Chili.

C. oppositifolia is a totally different class of plant, and is well marked by its larger, very thick, succulent leaves and delicate white flowers. The root is a thick fleshy tuber, and suggests a warm dry spot, where it proves quite hardy and where it has bloomed for two years. In habit it is somewhat straggling, but where it can be planted so as to overhang a small ledge, it will be found very beautiful and well worth attention. It first flowered at Kew, and it ripens seed freely.-K.

The plant figured in the accompanying woodcut will doubtless be new to many readers, although it has been in cultivation in a few gardens for several years. It is a native of Oregon and California, where it is found on the high mountains. It was first collected by Mr. Thomas Howell at Waldo, Oregon, and in the coast mountains of Del Norte County, California, near Smith River, and was first described in the Proceedings of the American Academy of Arts and Sciences, vol. xxii. p. 355 .

C. speciosa.-Has slender stems, much branched and prostrate; the showy flowers are from $\frac{1}{2}$ to $I$ in. across, and are of a deep purple-crimson. On sunny mornings they expand widely, and close early in the afternoon. It flowers con- 
tinuously from June to September. It succeeds well on dry soil, generally sows itself plentifully, and is suited for the rock-garden on account of its dwarf habit. California.

C. umbellata, a native of Chili, has reddish little stems, much branched, is half-shrubby at the base, and rarely more than 3 in. or 4 in. high. For vivid beauty and brilliant colour nothing surpasses it, the flowers being of a dazzling magentacrimson glow, yet soft and refined. In the evenings and in cloudy weather it and bright beds in the summer flower garden is to sow a few grains in each small pot in autumn, keep the pots in dry sunny pits or frames during the winter, and then without much disturbance turn the plants out into the beds in the end of April or beginning of May. Its beauty is concealed in dull or rainy weather, and this may prove a drawback to its use in the flower garden, but if it be employed as a groundwork for some taller plants this defect may not be so noticeable. Young plants flower more continuously

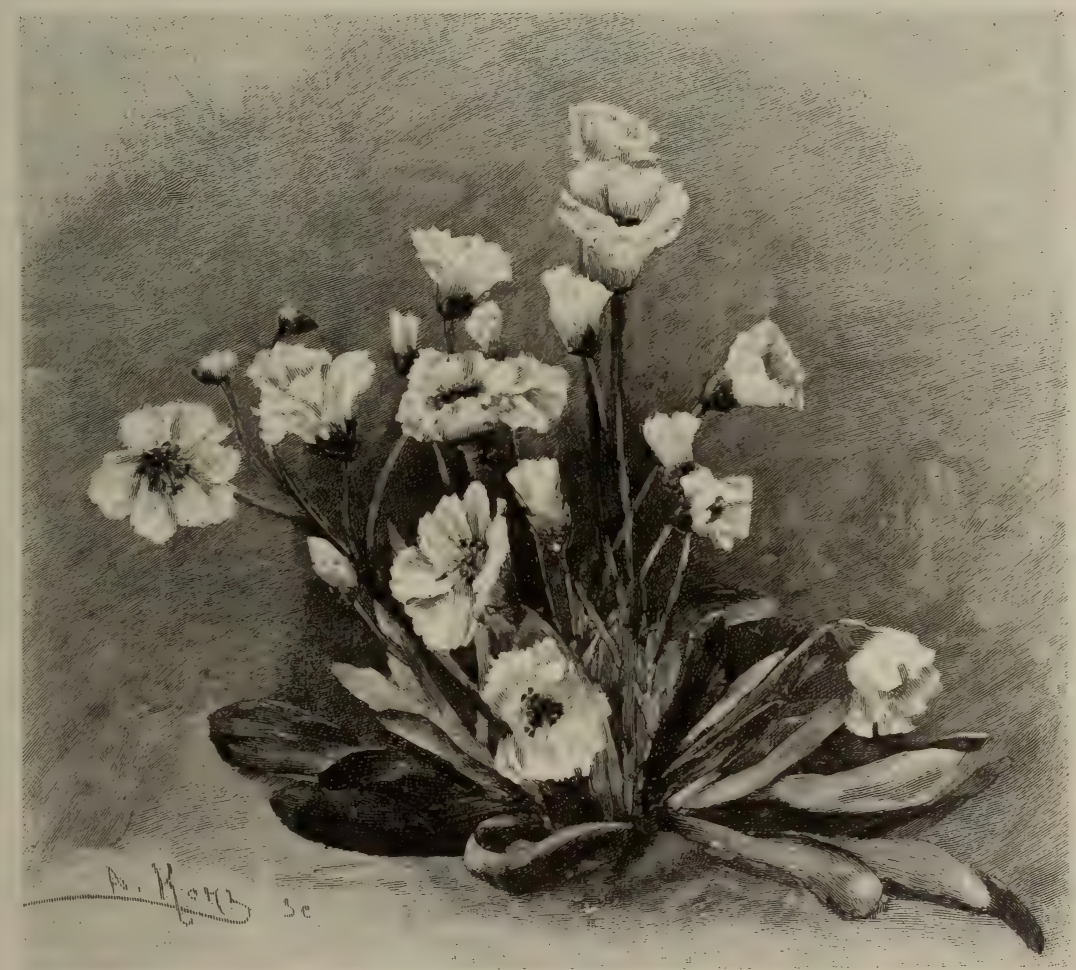

CALANDRINIA OPPOSITIFOLIA.

closes, and nothing is to be seen but the tips of the flowers. It does very well in any fine sandy peat or in other open earth, is a hardy perennial on dry soils and a well-drained rock-garden. It looks best in small beds, but may be used with advantage as a broad edging to large ones. It seems to live longest in chinks in a well-made rock-garden. It is as readily raised from seed as the common Wallflower, either in pots or in the open air in fine sandy soil. As it does not like to be transplanted, except very carefully, the best way to use it for neat than old-established specimens. It may also be treated as an annual, and sown in frames very early in spring.

There are other kinds, such as C. Lindleyana, C. Burridgi, C. procumbens, C. compressa, and C. micrantha, but their flowers are not so pretty as those of the kinds just mentioned.

Calceolaria. - Valuable and popular plants, though not so popular as they have been. In the London district they are employed very much less than they were some years ago, as many of the varieties perish from disease, or are short-lived as 
regards bloom. We used to see masses of the fine old Sultan (crimson) and Kentish Hero (rich brown) in almost every garden, and the many varieties sent out by Mr. Burley were at one time very popular; but they got a bad name, being liable to decay from a peculiar disease. We now seldom see the crimsons and maroons and crimsons with gold caps. The golden yellows, however, still hold their own, and the old variety Gaines's yellow has still perhaps the best constitution of any. C. aureo-floribunda is everywhere known, and the fine amplexicaulis, with its good habit and pure lemon flowers, is always a favourite. We think the main cause of deterioration has been neglect in cultivation and want of generous treatment. Both before and immediately after transplanting they should be kept in a vigorous state in good rich soil through the winter, and near the glass, but as far from fire-heat as possiblein cool pits where air is given at all possible times, by entirely uncovering or tilting the lights when the weather will allow ; for the object is to keep the foliage free from curl and free from insects, to which when fire-heat is applied it is very subject. Many of the newer highlycoloured varieties are most desirable additions to the flower garden, and will amply repay any extra trouble.

PROPAGATION.- The shrubby varieties bloom mostly in summer, and there is then scarcely a shoot that does not contain an embryo flower-spike. Such shoots make bad cuttings, and are too soft and watery to strike well. If we tried to propagate our next year's stock in summer, they would grow too much before winter, and would require transplanting, two months' extra attention and pinching, and would occupy more frame-room during winter than later-struck cuttings. The proper time for propagating such varieties is the end of September and October. For this purpose prepare a cold wooden or turf frame on a dry basis, fill it to within $6 \mathrm{in}$. of the top with sandy loam, and over that spread some clean silver sand. Then select nice stubby side shoots, as firm as possible, pick out any flower-spikes that are visible, remove one or two of the base leaves, cut horizontally below a joint with a sharp knife, and dibble them thickly, regularly, and firmly into the frames, giving a sprinkling of water through a fine rose to settle the soil and to prevent their flagging. Keep the frames close and shaded for a day or two, but afterwards remove the shading, and only use it during the succeeding month to counteract the effects of bright sunshine. Such cuttings take a long time to root, but if the atmosphere of the frame is kept dry, and the plants are kept free from damp by dredgings of wood ashes, dry dust, and old lime rubbish, they will root satisfactorily during winter, and in spring will yield tops for additional cuttings; whether these are employed for cuttings or not, they are best pinched off.

WINTERING.-These frames require no further care beyond protection against frost, by covering the sashes, and banking up the sides, if of wood, with soil. Wooden boxes, seed-pans, or pots might also be used for striking Calceolarias in; and in them the plants might be wintered in any pit, greenhouse, or conservatory. Whether propagated in frames or boxes, they should be transplanted, farther apart than previously, into other frames filled with rich open soil, where they will become fit for planting out by the middle of May, if the shoots have been attentively pinched when necessary. In autumn, too, it is a good plan to draw some earth round the necks of the old plants, so as to induce the emission of roots from that portion of their stems ; and at lifting time, in November, to separate every rooted branch, and plant them as independent plants in frames. They will yield abundance of cuttings in spring, but it is from a few old plants, lifted and saved in frames for the purpose, that we get our chief supply of such young-rooted plants.

SPRING PROPAGATION is often uncertain, but I once saw a very fine lot which had been struck in February. The cuttings were selected from old plants wintered in frames, fully exposed every fine day by having the sashes drawn completely off them, and consequently they were pretty hard and well seasoned. They had been inserted in cold frames, precisely as advised for autumn cuttings, and a failure could scarcely be found even in four lights of them, and by bedding-out time they had formed very serviceable, well-rooted, stocky plants. Spring cuttings, however, are mostly rooted in hotbeds, in boxes, or in pans, and often as many damp off as survive to become plants; nevertheless, where the stock is deficient, this mode must be resorted to. It is best to strike them after the middle of March in pure sand in a hotbed or propagating pit where there is no stagnant atmospheric moisture, and, when well rooted, to pot them, or put them in boxes in light sandy 
soil, still keeping them in warm quarters for a few days. After that, gradually shift them into places in which there is less heat. Powdered charcoal or wood ashes strewed on the soil among the cuttings prevents damp, and the wateringpot should be used judiciously.-W.

SPRING MANAGEMENT.-Mr. David Thomson, in his Handy Book of the Flower Garden, has some useful remarks. "When grown in beds or boxes, they generally thrive best after they are planted out, without ever having been put into small pots at all. What I recommend in the absence of cold pits and frames, and have adopted sometimes when suitable, is to throw out trenches like those generally used for Celery beds, putting 6 in. of rotten leaves in the bottom, and 6 in. of light rich soil on the top of that. Here the young plants, lifted with as little injury to their roots as possible, should be pricked out about the end of March, 6 in. apart each way. When all are planted, water well, and lay some trellis-work or common stakes across the trench, covering with mats or canvas when cold weather renders it necessary. For a fortnight after being transplanted they should be shaded when the sun shines. Thus managed, they make fine strong plants with very little attention. As they grow they should be looked over at intervals and topped, to keep them dwarf and well furnished. About three weeks before they are to be planted out, a spade, or any other sharp-edged tool, should be run between the lines each way, cutting to the depth of $6 \mathrm{in}$. This cuts the roots of each plant off from those of its fellow, checks them for the time, but causes them to make fresh roots 'nearer home ;' and the result is, that they lift with good balls, and scarcely receive any check when planted out. Should they droop when thus operated upon, give them a good soaking of water.

"Amateurs and others requiring small quantities of plants may transplant them into boxes 6 in. deep, prepared much the same as the trench already mentioned, and otherwise managing them in the way described. They can be lifted into any outhouse, or even covered over outside in case of spring frosts. When the stock is not equal to the demand, the points of the young plants in March and April strike freely in a gentle heat ; but autumn-struck plants are in all respects to be preferred.

"Soll.-Like the Verbena, Calceolarias require a deep, rich, loamy soil to grow and flower well throughout the season. They are very liable to die off in hot sandy soils, and at best do not bloom for any length of time. Tagetes signata pumila is the best substitute for Calceolarias on light sandy soils too poor for Violas.

"THE VARIETIES MOST SUITABLE FOR BEDS. - Those marked * are best. *Ambassador, bronze-crimson, the best of the crimsons, I ft. ; *aurantia multiflora, orange-yellow, extra fine, $\mathrm{I} \frac{1}{2} \mathrm{ft}$. ; *aureo-floribunda, orange-yellow, suitable for damp localities, I ft.; *Golden Gem, deep yellow, fine constitution and free bloomer, 15 in.; Invincible, lemon, very dwarf, compact habit, free bloomer ; *Prince of Orange, orange-brown, compact habit, I ft.; Princess Alexandra, buff, dwarf, compact habit, 9 in.; Princess Louise, sulphuryellow, dwarf, good habit ; Victor Emanuel, scarlet spotted with crimson, I 5 in."

SPECIES.-Apart from the varieties, a number of species are of some merit for the flower garden, and some that would be excellent are neglected and unknown. The genus presents a wealth of variety in form and colour. It comprises upwards of roo distinct species, including annual and perennial herbs and dwarf shrubs. In geographical area it almost exactly coincides with the Fuchsia, ranging from Mexico to the southernmost point of S. America, and reappearing in New Zealand; but unlike the Fuchsia, it is represented only in the extreme south of the eastern side of S. America. The greater number of the species inhabit mountain valleys, and ascend to an elevation of from 13,000 to $14,000 \mathrm{ft}$. within the tropics, where they enjoy a climate never very hot and never very cold. Some few occur in the arid districts of Chili ; they find their greatest concentration in Chili, Peru, and Ecuador. Only about four species are known to grow in Central America and Mexico, and two have been discovered in New Zealand. A full account of the family is published by Mr. Hemsley in The Garden for 29th March 1879, accompanying a plate of $\mathrm{C}$. fuchsiæfolia.

C. amplexicaulis.-A few years ago this was almost as familiar in the flower garden as any bedding Calceolaria. It is the one with soft green leaves clasping the stem and many lemon-yellow flowers. It inhabits Peru and Ecuador. It was introduced by Mr. W. Lobb about forty years ago, and is one of the handsomest plants we have. Its colour is a very soft lemon; it is very free in habit, and, where the soil suits it, sends up a number of suckers which keep up a constant succession of flowers till quite late in the autumn. During the long period for which I have known this variety I have never 
seen it diseased, a failing to which all others are exceedingly subject, and which makes them so uncertain. Owing to its tall habit it groups well with the numerous bold plants now invading our flower gardens, and it is usually handsomer in autumn than any of the newer kinds. In Hertfordshire it used to be in great esteem for bedding, for which it is one of the best and most continuous blooming kinds. In gardens in that county it is planted in small beds on the Grass, where it is tied and trained to sticks brought together at the top, something like the sticks over a basket of plants sent from a nursery. They form fine pyramids, and soon hide the supports; but it is only in moist cool soils that they do this, though they stand heat and drought better than any other plant.-S. D.

C. hyssopifolia is one of the finest of the small-growing kinds. It bears in profusion large loose clusters of lemonyellow blossoms continuously from early summer till autumn. The foliage is distinct, being narrow, and resembling that of the Hyssop.

C. Kellyana (Kelly's Calceolaria).-A curious hardy hybrid, with short downy stems, 6 to 9 in. high. Flowers in summer, having flowers nearly $\frac{3}{4}$ in. across, of a deep yellow with numerous small brown dots, and two or three grow together on the top of the stems. The leaves are in a rosette, with a toothed margin, and are more or less covered on both sides with soft white hairs. It was raised about $\mathrm{I} 840$ by a Mr. Kelly, propagator in the nurseries of Messrs. Dicksons \& Son, of Edinburgh. Its foliage resembles that of one of the Mimuli, creeping along the ground. It is a very interesting dwarf rock-garden plant.

C. Pavonia is a noble species, the largest in cultivation. It is from 2 to $4 \mathrm{ft}$. high, has large light green, much wrinkled foliage, and from June to September bears a profusion of large, pale yellow, slipper-shaped blossoms. It is a fine object against a warm south wall, but at the approach of winter it should either be lifted or protected with a thick covering.

C. violacea is an extremely pretty species, with small helmet-shaped flowers, which are rich purple and copiously spotted ; succeeds well on warm borders or the rock-garden, and, if slightly protected, withstands mild winters in the south.

Calendula officinalis (Pot Marigold). - An interesting old hardy biennial; one of the best for autumn and winter flowering. It is in almost every garden; the petals were formerly used to flavour dishes in old English cookery, hence its name. There has recently appeared simultaneously in England and France a very distinct double variety called Meteor, of which the flowers are much more double than those of the old variety, and the petals striped with lemon on an orange ground, the two colours varying in body and producing a very pretty effect. It comes true from seed. A variety of kinds is offered by the German seed houses. The plants are among the best biennials for autumn and winter flowering. Nothing short of severe frost will prevent an abundance of blossoms. For late blooming, seed should be sown in July. They usually sow themselves freely, and may be sown in the open ground either in spring or autumn.

Calimeris.-A genus of Composita, of no importance in the garden.

Calla æthiopica (Ethiopian Lily, Arum Lily). - This well-known greenhouse plant may be grown either as an aquatic in pieces of ornamental water and fountainbasins, or in cool moist soil in the open ground, and equally well in positions exposed to the full sun and in shaded positions. Being so distinct in leaf and beautiful in bloom, this old favourite will be seen to as much advantage when grouped in beds with the smaller fineleaved plants as ever it has been in our stoves or windows. It will do best in rich and well-moistened borders or beds. It is hardy when treated as an aquatic in some of the milder districts, but as an outdoor plant it is never likely to have the importance it has when flowered in the greenhouse. Some, however, succeed out - of - doors. Mr. Burwood Bodlee writes from Lewes: "I have had in my garden pond for more than twenty years past a large number of Arum Lilies (Callas) all the winter long, and I have never lost a plant. A moderate spring flows through the pond, which is not frozen over, unless with a sharp frost. The Lilies increase from year to year spontaneously from seedlings, as well as laterally from the old roots, which are planted in the natural soil and kept down by a few large stones. We have had from fifty to one hundred blossoms out at one time, and the fine tropical-like leaves are highly ornamental."

Another correspondent writes : "A few years ago I planted some pieces of this amphibious plant in water by the side of an embankment, and they have so increased that at the present time they form an immense mass, $120 \mathrm{ft}$. long and several feet broad, and when in flower they are 
a grand sight, hundreds of magnificent blooms being open at one time, and much finer than when carefully grown under the directions given in most gardening books. In severe winters they are cut down to the water's edge, but when mild weather returns, they always come up again as strong as ever and flower well,

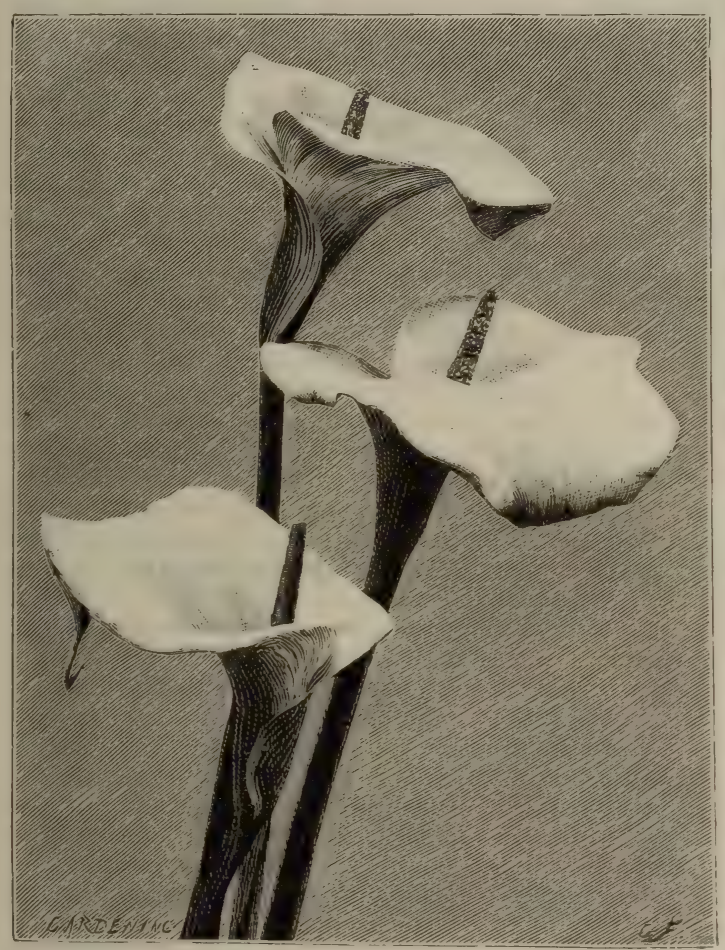

ARUM LILY (CALLA ETHIOPICA).

though much later than when not cut down by frost. In very mild seasons they commence flowering before Easter. A good plan is to fill some worn-out bushel baskets with refuse soil; plant the Arums in this, and plunge them into about $2 \mathrm{ft}$. of water, throwing a few barrowfuls of soil and stones around to keep them steady' and to form mounds. The baskets soon rot, and the plants become masses of foliage and flowers." -S.

Many who grow this plant for the greenhouse or market plant it out in trenches in early summer, and take the plants up in autumn - a simple and good way of growing them. S. Africa. Syn., Richardia.

C. albo-maculata is a similar kind, with deep green leaves handsomely spotted with white.
C. palustris (Bog Arum).-More beauty than is afforded by any native bog-plant results from planting in boggy places this small hardy trailing Arum, which has pretty little spathes of the same colour as those of its relative, the Ethiopian Lily. Though often grown in water, it much prefers a moist bog. In a bog or muddy place somewhat shaded by trees it will grow larger in flower and leaf, though it is quite at home even when fully exposed. A bog carpeted with its dwarf dark green leaves gives a very pleasing effect, as its white flowers crop up here and there along each rhizome, just raised above the leaves. It is very interesting for natural bogs, etc., while for moist spongy spots near the rockgarden, or by the side of a rill, it is one of the best things that can be used. Like many other bog-plants, it is often starved in cultivation. Its beauty is seen only when it is allowed to ramble over rich muddy soil. North of Europe. Abundant in cold bogs in North America. Flowering in summer, and increasing rapidly by its running stems; 3 to 8 in. high.

Callichroa platyglossa.-A showy Californian half-hardy annual; in March the seeds may be sown in slightly heated frames, or they may be sown in the middle or later part of April in the open border, in ordinary light soil not too rich, but the situation should be open. The seedlings should be well thinned, or if transplanted should not be less than 6 in. apart, so that each plant may fully develop. Treated thus, C. platyglossa flowers from July to September. It may be also sown in autumn on light warm soil to remain during winter, and flower in spring. In this case the plants need protection during severe weather. Compositæ.

\section{Calliopsis (see Coreopsis).}

Calliprora lutea (Brodica).

Callirhoe. - A small but handsome genus of North American Malvads, of which some half-dozen kinds are known in our gardens. They are hardy herbaceous perennials, and, in rich light soil, succeed well in the open border.

C. digitata. - A distinct-looking glaucous perennial herb, 2 or $3 \mathrm{ft}$. high, 
with reddish-purple flowers in summer; it is not so showy as the other species, but succeeds under similar conditions.

C. involucrata is a charming dwarf prostrate perennial, with large violetcrimson flowers 2 in. in diameter. It is indigenous to California. It is excellent for the rock-garden, as it bears a continuous crop of showy blossoms from early in summer till late in autumn. It has the best effect when allowed to fall over the ledge of a rock.

C. macrorhiza alba is a pure white form of a species with purplish-carmine flowers. It is neat, producing from a taproot, which ultimately attains some size, an erect stem from $\mathrm{I} \frac{1}{2}$ to $2 \frac{1}{2} \mathrm{ft}$. high, with a corymbose raceme of flowers. It occurs in several shades of colour, from rosypurple to pale rose and white. Sown early, it will bloom the first year. Southwestern States of North America.

C. pedata is one of the prettiest species of the genus. It has a perennial root, from which arise when unsupported several trailing stems bearing lobed foliage, variously incised; and on long foot-stalks, from the upper axils, very handsome crimson flowers, fully 2 in. in diameter. When sown early the plants bloom easily in the first season, and continue in flower until late in autumn. In dry soils the roots survive our average winters and increase in strength each season, though, were it otherwise, the plant might be cultivated as a half-hardy annual. Transplant the seedlings into the open ground by the middle of May, as they have a tap-root and do not succeed in pots. The shoots may be allowed to trail, or may be supported by sticks. It succeeds better in dry soils than in wet or highly-enriched soils, in which latter it too luxuriantly produces foliage at the expense of flowers. The varieties nana and compacta are desirable dwarfer varieties.

Callisace dahurica.-A large and ornamental umbelliferous plant, 8 to $\mathrm{Io} \mathrm{ft}$. high. The white flowers are produced late in summer, and in umbels frequently $2 \mathrm{ft}$. across. The lower leaves are about $6 \mathrm{ft}$. long and 4 wide. It is imposing when isolated on turf or in groups in deep rich loam. Division or seed. A native of Dahuria.

Callistephus chinensis (China Aster). - Among the many annuals now in cultivation Asters are among the best, and when well grown and cared for they do, at a small cost, as much to render a garden gay during summer and autumn as any plant. To see them in their beauty, however, they must be grown in masses, and well cultivated-not at any stage left to hap-hazard or poor culture. The China Aster was introduced towards the end of the last century, and was raised in the Jardin des Plantes of Paris from seeds sent from China. Numerous varieties have resulted. In the wild state the flowers of the type are single - that is to say, only the outer florets are strap-shaped, and usually of a rosy-lilac tint, with yellowish disc florets; but under cultivation all the florets have become ligulate or quilled, and there has developed a richness and variety of colouring scarcely surpassed in any species, and ranging from pure white to deep carmine, violet, and blue, though the yellow of the disc in the single form has not been reproduced in the double. For the great perfection to which the different races have been brought we are mainly indebted to the French horticulturists, notably Truffaut, Fontaine, and Vilmorin, and in this country to Mr. Betteridge, whose method of cultivation is described below. The different varieties are so far fixed that they will come true from carefully-selected and well-ripened seed.

VARIETIES.-Asters may be classed according to height, habit, character of flower, suitability for exhibition, for pot culture, or for bedding. Tall Asters comprise the fine. Pæony-flowered, the tall Chrysanthemum, the Emperor, the tall Victoria, the Quilled, and a few others. Kinds of medium height are the dwarfer forms of the Victoria, the fine Cocardeau, the Rose, and the Porcupine. The dwarf forms comprise the short Chrysanthemum, the dwarf pyramidal, and specially the dwarf bouquet, which is one of the most beautiful for pot culture. The best bedding kinds are the medium - growing Victoria, the Rose, and the dwarf Chrysanthemum, as these vary from 9 to 12 in. in height, and form good bunches of bloom on each plant, and fine masses of colour collectively. The dwarf bouquet kinds, whilst specially good for pot culture, are valuable as edgings to beds of taller kinds. For pot culture for exhibition the best are the medium-growing Victorias, as these, if of a good strain, possess quality, and handsome even heads of bloom. The distinctive forms are in request for exhibition, as it is the custom to invite exhibits under the heads of incurved, reflexed, and quilled flowers, or as it is sometimes expressed, flat-petalled and quilled, or French and German, the French being the flat-petalled 
and the German the quilled. These distinctions are, however, arbitrary, and are giving place to those previously named, which are easier to comprehend. The best example of incurved flowers is what is popularly known as Truffaut's Pæonyflowered Aster, formerly esteemed a grand exhibition strain, but which has given way to some extent to the more even and massive Victoria. An incurved flower shows all the tips of the petals converging inwards, as in a Chrysanthemum, and the more solid and rotund the flower, the better its prospect. These have flat petals, and, as a rule, broader petals than any other kinds. The best examples of solidity and perfection of form are found in the quilled varieties. Though not more than half the size of the flat-petalled kinds, they present a mass of quilled petals most evenly set, and almost semicircular in outline. One is almost inclined to believe that such perfection of evenness can be obtained only by artificial means. It is, however, but the result of constant care in seed selection. The Cocardeau or crown-flowered Asters are partly flat-petalled and partly quilled, the outer margin of the petals being of a dark red or blue, and the centre disc of pure white. These are grown for novelty more than merit. This bi-colour form is, however, found in some of the finest show quilled kinds, and renders them valuable and attractive. The charming bouquet Asters are also semi-quilled, the petals being stiff and closely set. The blooms are of medium size and very compact, and most acceptable for nosegays. For this purpose the later blooms starting out from the main stems of the Victoria are admirable, their clear bright hues and excellent forms being effective however employed.

Mr. James Betteridge writes :

"SOWING THE SEED.-For several years after I commenced the culture of quilled Asters I always sowed the seed in bottomheat; but during the last decade I have sowed it, between 26th March and 26th A pril, in a cold frame, under glass, in drills 6 in. apart, and not too thick in the drills. A few days suffice to bring the plants above the soil, when a liberal supply of air must be given, or they will be weak. When large enough, prick them out into another cold frame, slightly shaded, where they will soon be established, and after they are strong enough to handle, plant them out in wellmanured soil, and be careful not to break the tender fibres of the roots. Let the rows be $\mathrm{I} \mathrm{ft}$. apart, and plant the strongest plants I ft. from each other, in showery weather, and they will soon get established. If the weather be hot and drying, give them a little watering till rooted; afterwards keep them clear of weeds by hoeing among them. About the first week in August top-dress with rotten manure from an old hotbed, giving a good soaking all over if the weather continues dry. After this, if the blooms are required for exhibition, tie the plants out to small stakes. As soon as it can be determined

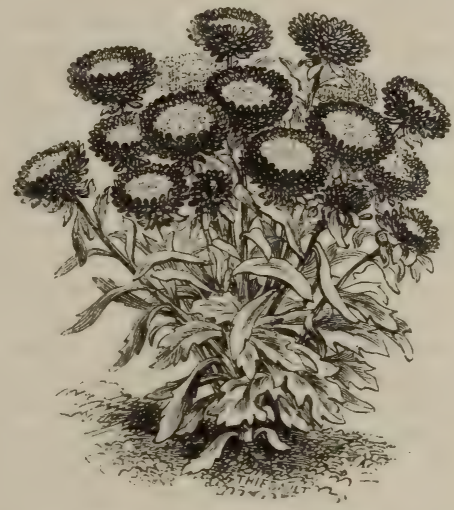

DWARF CROWN CHINA ASTER.

which buds will produce the best blooms, thin out or disbud, leaving about five or six blooms on each plant. Exhibition blooms should be large, with full high centre, and deep distinct colour, with solid petals. To secure these qualifications in England, shading of some kind is necessary. For this purpose I have tried many kinds; one of the most useful of these during a stormy season is a 'tin shade,' about $\mathbf{I} 2$ in. in diameter, with a spring socket to slide up a square stake, one which I formerly used for shading Dahlias, and, I believe, was sent out by Mr. C. Turner, of Slough, many years since. Wire frames covered with linen or other light material will do ; all that is required being perfect security against rain and hail. In arranging blooms for exhibition, the boxes or stands should be 6 or 7 in. high at the back, and 3 or $4 \mathrm{in}$. in front, painted green, and if the blooms are set in a frill of embossed or ornamental edged white paper, it will lend an air of elegance.

"SoIL.-Asters like a deep rich soil, and, should dry weather set in, it is only in such soil that really fine flowers can be obtained and the plants induced to hold out. Planted in the ordinary way, they are weeds in comparison with those that 
are well fed and can get their roots down deep in search of moisture; and when they can do this, the hotter the weather the better. Confined to the top shallow crust of earth, they soon dry up and starve ; and this is why we frequently see poor puny plants in borders, where, instead of being able to grow and develop, they can only struggle on for existence. The best way to manage them is to dig and cast off the top spit to one side, handy to be returned to its place again, and then to trench and break up the soil below, working in with it plenty of short manure, thoroughly decomposed, which will attract the roots and afford them ample assistance just as they most require it, when expanding and perfecting the bloom. Trenching, as usually done, brings the crude earth to the surface, and buries that which has been exposed to the ameliorating influences of the atmosphere - a fact that should be borne in mind, as it takes years to get it into the condition in which plants will lay hold of it and start freely. In very light soils a few barrow-loads of clay, chopped fine and mixed well in, will do more than any other help to produce fine Asters. The thing to aim at is to keep the bottom cool and moist; then, if the weather be favourable, the plants will take care of themselves. When grown in groups of three in a border, similar preparations must be made, or neighbouring plants already in possession are sure to rob them and cut short their beauty long before the autumn sets in.

"SAVING SEED.-If the autumn befairly genial, there is no difficulty in saving Aster seed. Allow a plant to carry only three or four of the finest blooms. If heavy rain render a covering needful, it should permit a free circulation of air among the flower-heads. Gather when ripe, and clean through a wire sieve. Carefully-selected seed usually produces as good blooms as those from which it was saved. The best kinds, and especially all the new forms and colours, are grown in beds, over which temporary lights are fixed, by means of which we are enabled to cut blooms of the purest shade or colour.

"Pot Culture.-Many have written about the kinds best suited for pots ; but my practice is to sow in the open in May, keeping the varieties separate, and then to lift them about the middle of September (when the buds have partially expanded). I put three plants into an 8-in. pot, pressing the soil firmly (shading for a few days), and then place them in a cold greenhouse, where they will bloom late on through the autumn. They have a splendid effect among the small kinds of foliaged plants in a conservatory, the only plants equal to them in point of colour being Chrysanthemums. If for exhibition purposes, the incurved and reflexed varieties are most effective; but among the other sections there are few better than, or equal to, the best quilled Asters."

Calluna (Erica vulgaris).

Calochortus (Mariposa Lily).-Lovely and valuable bulbs of the Lily family. Western North America. Not thoroughly hardy in the same sense as plants from the Eastern States. Only good garden plants are enumerated.

C. albus (Cyclobothra alba).--Branches deeply forked and spreading, I to $2 \frac{1}{2} \mathrm{ft}$. high, with three to twelve heads of flowers; the flowers, globose, white, and nodding. The variety paniculatus is dwarfer than the type, and has smaller flowers. Of easy culture.

C. elegans (Cyclobothra carulea).Stem slender, 3 to $6 \mathrm{in}$. high, with three to six heads of flowers, arranged in an umbellate manner; flowers erect, white or pale lilac, bearded with pale hairs on margin and face. The variety nanus has

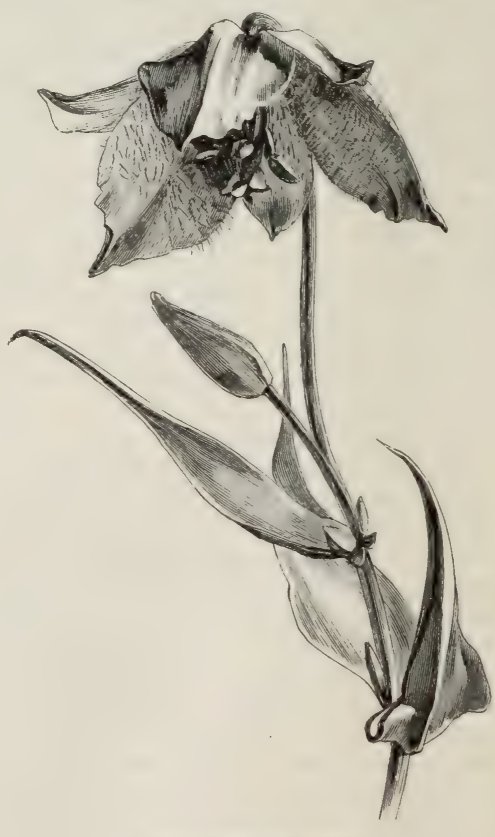

CALOCHORTUS FLAVUS.

dwarfer and more slender stems, and more hairy petals, and C. Tolmiei is stouter and taller (about I foot high), the 
flowers larger, and tinged or marked with lilac. One of the most satisfactory kinds, as it rarely fails, and bears a profusion of blossoms remaining in perfection for a week or two.

C. pulchellus (Cyclobothra pulchella). - I to $\mathrm{I} \frac{1}{2} \mathrm{ft}$. high, with six to twelve nodding flowers of a deep yellow. A most beautiful plant when well grown. It succeeds in the open border, and is one of the best for pot culture.

C. splendens.-Stem flexuose, $I \frac{1}{2}$ to 2 $\mathrm{ft}$. high, with three to five flowers, $\mathrm{I} \frac{1}{2}$ to $2 \mathrm{in}$. long and broad, of a deep lilac, and of the same colour in the middle, but occasionally with reddish spots, the third flower from the bottom having a purple beard round the glandular pit. Similar to venustus, but well worth growing, as it has a good constitution and is a profuse bloomer.

C. venustus.-A lovely species, I to 2 ft. high, with two to six flower-heads; with broad petals of white or pale lilac, and of the same colour in the centre, or spotted with orange-purple; claw, with an obscure bearded glandular pit, and a few hairs and red-brown spots above it. There are several varieties-purpureus, purpurascens, lilacinus, each name indicating the colour. This is the finest of the species, and one of the most beautiful open-air flowers in cultivation.

The above-mentioned are the best for ordinary culture out of about eighteen kinds; they are also the commonest, and may be readily procured. They represent all the types of flower and growth in the genus. Other kinds in cultivation are the following, though the majority are extremely rare and somewhat difficult to cultivate. They are - C. Benthami, Maweanus, Leichtlini, Gunnisoni, lilacinus, uniflorus, luteus, citrinus, macrocarpus, and flavus.

CUlture AND Position.-They love a sunny and well-drained situation, such as the rock-garden or a well-drained warm border. Planted well up on the rockgarden, where they are dry in winter and sufficiently moist to do without watering in summer, they make vigorous growth and flower freely. The principal requirement is protection from wet. For ordinary beds and borders it is expedient to lift the bulbs and store them until they begin to grow. For pot culture, a fibrous loam, with a little leaf-mould and plenty of silver sand, answers admirably. In short, although rather delicate, they will succeed if these precautions be taken, and will amply repay a little extra trouble. The best for pot culture are C. pulchellus, venustus, elegans, splendens, luteus, and Tolmiei.

The New Plant Company, of Colehester, who have grown them very well, speak as follows of their cultivation :

"With the exception of flavus, we grow all the species in a cold frame with a south aspect; the frame has a depth of soil of some $\mathbf{2} 2 \mathrm{in}$. It consists of ordinary peat (from which the stones are sifted), fibrous loam, and leaf-soil, with a good proportion of red sand. We plant the bulbs in November, and then, to protect from the heavy rains chiefly, place the lights on; but when the weather is suitable they are removed. During severe frosts the soil is frozen hard. In the spring the lights are removed entirely, and the plants are subject to whatever weather we get. If too dry, we water them. We get fine displays of flower, and vigorous healthy growth not to be surpassed. The bulbs after maturing are removed from the soil, to be sold, or replanted in November. The exception to this treatment is C. flavus. We plant this out-ofdoors in ordinary soil, with a little peat and sand round the bulbs, in April. It seldom commences growth until June, but in August and September the bed is literally covered with bright yellow flowers, although there are great demands on them for cut flowers, for which they are invaluable. The bulbs we remove in October, and keep them in a dry room until planting time comes round.

"Although we give a slight protection to most of these plants, it is not absolutely necessary. The great obstacle to their cultivation out-of-doors is the failure to choose suitable spots and to consider the nature of the subsoil; stagnant moisture in the ground and wet retentive soil are most injurious; but in a well-drained sunny border we have grown most of the family well. A good plan in a border not well drained is to take out the soil to the depth of I $\mathrm{ft}$., place 3 or $4 \mathrm{in}$. of broken brickbats in the bottom, and fill up with soil of half peat, one-fourth fibrous loam, and onefourth common red sand, well mixed together. Here not only Calochortus but many bulbs difficult to manage would present an appearance very different from what we frequently see, and well repay for the extra trouble. Try a space of 2 by $\mathrm{I} \mathrm{ft}$. as an experiment-in such a space several dozens of Calochorti would thrive."-F. H.

Calopogon pulchellus. - A beautiful hardy Orchid suitable for moist or boggy places. The flowers are pink, I in. in 
diameter, and are in clusters of two to six upon a stem. They are beautifully bearded with white, yellow, and purple hairs, rivalling in beauty some of the tropical Orchids. They will fail in dry soil. Well suited for a good position in the rock-garden, or for an open spot in the hardy fernery in peaty soil. Natives of wet prairies or the edges of Pine woods in many parts of the United States. Most abundant and thrifty in the Moss in Cranberry swamps, but also found in Grassy marshes, and occasionally seen on solid ground, in low, wet, woody situations.

Caltha (Marsh Marigold).-The Marsh Marigold (C. palustris) in early spring "shines like fire in swamps and hollows grey," and is one of our finest hardy plants, though it

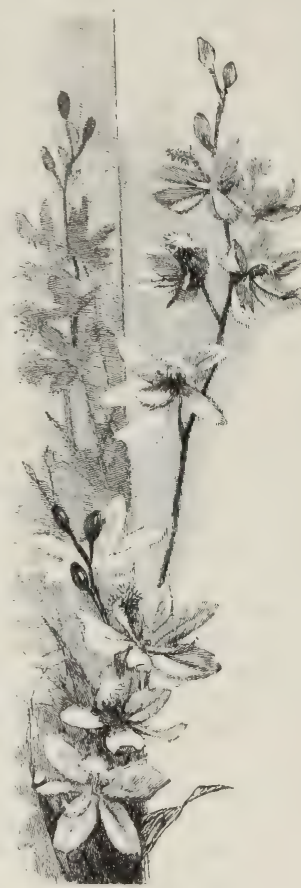

CALOPOGON PULCHELLUS. is so frequent in wet meadows and by streams that there is little need to give it a place, except on the margin of water. Its double varieties, however, are of much ralue, and well worth a place in a moist rich border, or, like the single form, by the water-side, or in the artificial bog. There is a double variety of the smaller creeping C. radicans, about half the size of the common plant. In addition to the common species, C. palustris, and the rarer variety, C. radicans, there are doubleflowered forms, C. monstrosa, bearing beautiful golden rosettes, and C. minor fl.-pl., a small kind, a free flowerer, and highly desirable. There are also C. leptosepala, the new Californian kind, and another new kind named C. purpurascens, very distinct and handsome, about I ft. high, with purplish stems, and a profusion of bright orange flowers, the outside of the petals being flushed with a purplish tinge.

The various forms of the Marsh Marigold are splendid in their massive golden blossoms, and in groups or bold masses will be found valuable to the tasteful gardener, and they are easily grown and increase freely.

Calycanthus (Allspice Tree).-A North American shrub, with handsome flowers of pleasant fragrance. C. occidentalis is from 6 to $8 \mathrm{ft}$. high, with large marooncrimson flowers of powerful fragrance. A fine shrub, worthy of cultivation in every garden. It requires ample room to spread. C. floridus is smaller and not so dense, with purplish-red flowers, strongly scented. The names in catalogues, such as C. glaucus, lævigatus, oblongifolius, macrophyllus, represent forms or

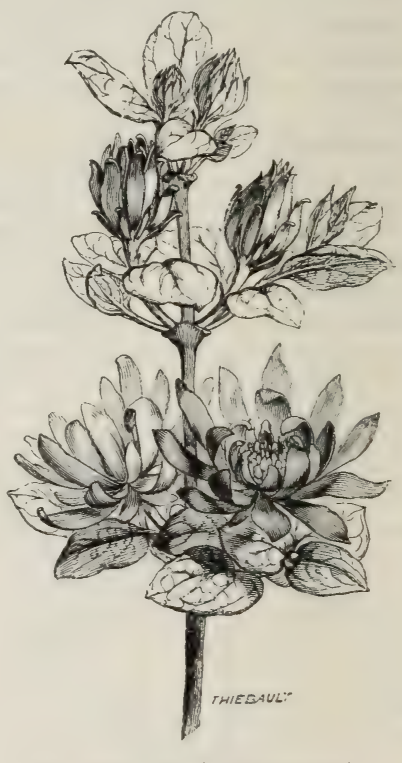

ALLSPiCE TREE (CALYCANTHUS).

varieties of either the eastern or the western species. The two described are hardy, the Carolina species having been grown since 1757 , while the Californian has been cultivated over fifty years. Their place is near a moist and shady walk, not in the open shrubbery, as they flourish best when overshadowed by other trees and where the ground is damp. They grow wild near streams and wet places.

Calypso borealis.-A pretty and interesting little hardy Orchid, with rosypurple sepals and petals, and a white lip, heavily blotched with cinnamon-brown. It is from the cold regions of North America. It succeeds in half-shady spots on the margin of the rock-garden or artificial bog, or in a select spot among 
choice shrubs in light, moist vegetable soil, mulched with Cocoa fibre or other material to keep the surface open.

Calystegia (see Convolvulus).

Camassia (Quamash). - A North American genus of Liliaceæ, with at least one first-class plant, hardy and extremely valuable for cutting. There are three species in cultivation, but with regard to two, C. Fraseri and C. Leichtlini, some botanists place the former with Scillas and the latter with the Chlorogalum.

C. esculenta (Quamash) is a native of meadows and marshes from Middle California to Washington Territory and northward, where it grows from I to $3 \mathrm{ft}$. high. Its stalks, which are stout, rise from bulbs $\mathrm{I}$ in. or more in diameter, bear a loose raceme of from ten to twenty flowers about 2 in. across. The colour varies from deep to pale blue, the deepest-coloured being Browni and atro-cœrulea, and the latter the finest of all the forms. C. esculenta thrives best in a moist situation, in a deep rich soil of a light sandy character. A bold group in flower has a fine effect in July, and it is excellent in the cut state, as the buds of the spike open in the house. A valuable summer flower for borders or groups and the bulb-garden. The bulbs are used by the Indians as food.

C. Fraseri (Eastern Quamash). - A native of the States east of the Mississippi. Its flowers are rather smaller than those of the western species. It grows about $\mathrm{I} \frac{1}{2} \mathrm{ft}$. high, with from six to eight leaves rather shorter than the scape, the latter bearing a raceme of ten to thirty pale blue flowers, each about I in. across when expanded. All the parts of the flower are smaller than in C. esculenta. Though of comparatively recent introduction, it will not compare with the older kinds in beauty, and is much inferior to C. esculenta, the flowers being smaller, of a pale purplish shade, and produced in short dense racemes. It is, however, later in flowering than other Scillas and Camassias, which may be desirable. It grows well in a light rich soil, sufficiently moist during the growing season. All Camassias may be propagated by dividing the bulbs or by seeds, but the latter is a slow process. -IV. G.

C. Leichtlini (White Camassia) is nearly related to the preceding; it often grows on open sandy ridge-tops, and is found in dry spots in ravines; its bulbs are generally deep in some stiff moistureretaining, soil. In lighter soils the flowerspike is large, being 9 in. long by 4 in diameter, while in heavier soils it is sometimes compound, and contains several hundred florets, which are creamy-white and about $I$ in. in diameter. It is often 3 or $4 \mathrm{ft}$. high. Vigorous in growth, but not so handsome as the common Quamash. British Columbia, where it was discovered by Mr. John Jeffrey in 1853 .

Camellia.-Those who live in inland and northern districts may well be surprised to see this shrub healthy out-ofdoors, even if it does not flower well; but in the Isle of Wight and the southern coasts of England and Ireland it is often as beautiful, and laden with as many flowers, as it is in Madeira. Most people who have Camellias in the open air find that they flower well five out of every six years, and that the plants are hardy -indeed, hardier than many shrubs that make their new growth early in the year. Rhododendrons, Laurels, and other shrubs often have their young shoots cut back by late spring frosts, but this does not happen to Camellias, because their young growth is made later. Their greatest enemy is fierce winds, which beat them about. Any one planting them out for the first time will do well to plant first some of the commoner kinds, and in sheltered spots; then, when these thrive, to continue with more valuable ones. The best aspect for Camellias is a south or south-west one, sheltered by a bank or wall, but in some districts they do best on a north wall. Planting from pots may take place at any period, but about July is the best time, as the wood is then well ripened. Duke of Devonshire, Halfida, Chandleri, Florida, imbricata, elegans, Alberti, Double White, Donkelaari, Countess of Orkney, Mathotiana, and Lady Hume's Blush are good varieties for outdoor culture. The late Robert Marnock, the landscape gardener, who was a keen observer of all garden things, wrote as follows to The Garden about Camellias out-of-doors: "Permit me to remind those who, like myself, have an affection for the great beauty of the Camellia, when in vigorous health in the open air, that although it is true that the plant will bear a greater degree of cold than the Common Laurel, and other evergreen shrubs which by common consent have long been regarded as hardy, yet the main stems and stouter branches of the Camellia are, nevertheless, liable to injury from severe frost. Now, all that is necessary to protect the plant at this weak point is to closely wrap the stem with straw or hay bands; and if a little Fern or other loose material be laid over 
the roots, so much the better. The portions of the stems near the ground are the most liable to suffer, while the leaves and branches, if not exposed to fierce gales, will bear much frost, provided the stems are protected. On the question of culture there is very little to be said. Give the Camellia the shade of a north wall protected from the wind, with a welldrained border, and almost any common garden earth will suit it-let the earth be fairly dry when the plants are put in, let them be firmly rammed round the roots in planting and then carefully watered for a time. No pot culture, however skilful, will compare with the beauty of the plants thus grown in the free soil of the open border." The advice of Mr. Marnock as to soil is sound enough if the climate be favourable; no doubt in some cases the moisture of peat and fibrous loam would help, but it is not easy to get such dainties for outdoor shrubs, and not always necessary. It will be best to try young healthy plants and not old pot-bound ones. It would be well also to try seedling plants in the open air.

\section{Camomile (see Anthemis)}

Campanula (Hair-bell, Bellflower).A large, very beautiful, and in every way a most important family. In Nature it has a wide distribution, and its various uses in gardens are also wide. The alpine species have obvious advantages for rock-gardens, being as a rule not difficult to cultivate. Some are very easy and free. A group of species somewhat larger than the true alpines may be seen adorning rocks and old bridges in some countries, and may be used for similar positions in this country. Some make charming window-plants, thriving in dry rooms and flowering gracefully. Numbers are good border and edging plants of easy culture; the tall and straggling kinds are admirable for the wild garden, or rough woody places or hedgerows. Some of the annual kinds, if well grown and treated as annuals, are showy and pretty; and certain groups, such as the finer forms of the Peach-leaved Bellflower, deserve good culture in the flower garden proper, and flower freely in early summer. The Canterbury Bell is one of the most useful and conspicuous of our biennials, while the tall chimney Campanula is one of our most striking and valuable hardy flowers. But the aspects and values of the plants are so different that it is only by looking at the species individually that they can be fairly estimated.
All are natives of temperate and of most tropical countries. There are about 280 species, mostly European and Asiatic; I IO are found in Europe, principally in the Mediterranean zone. Greece and its Archipelago, Italy, Crete, and Dalmatia offer a number of good kinds; Spain and Portugal also possess species peculiar to them. Fewer are found in Central Europe ; still, Saxony, Bohemia, Hungary, and several provinces of Austria have their types. They shun cold countries, but at the same time they occupy elevated mountain zones, and several charming Campanulas have selected the Alps, Piedmont, the Pyrenees, the Carpathians, and the mountains of Central France for their homes. Asia has at least 80 species ; America is poor, with about a dozen; Africa has fewer; and only one is found in Australia.

C. alliariæfolia is a strong and handsome plant with large heart-shaped leaves, covered with short hairs. The stems are somewhat erect, branching and leafy ; the flowers white, drooping, and generally disposed on one side of the stem. It is about $4 \mathrm{ft}$. high, and flowers in July and August. Sometimes called C. lamiifolia. Ripens seed freely, and may be readily increased by this means.

C. Allioni forms an underground network of succulent roots, or stems, surmounted by stemless rosettes of leaves, about an inch long, from which arise stalkless erect flowers, much resembling in shape and colour the common Canterbury Bell. Succeeds in exposed positions in the rock-garden in a moist, free, and sandy loam, but decidedly objects to limestone. It flowers in early spring. Division. Alps.

C. alpina (Alpine Hairbell).-Covered with stiff down, giving it a slightly gray appearance; erect, not spreading ; flowers of fine dark blue, scattered in a pyramidal manner along the stems. Carpathians. Valuable for front margins of mixed border, as well as the rock-garden, 5 to Io in. high. Readily increased by division or seeds.

C. barbata (Bearded Hairbell).-One of the sweet blue flowers that abound in the rich meadows of Alpine France, Switzerland, Italy, and Austria, and readily known by the long beard at the mouth of its pretty pale sky-blue flowers, nearly $I_{4}^{\frac{1}{4}}$ in. long, nodding gracefully from the stems, which usually bear two to five or more flowers. In elevated places in its native habitats it is sometimes only 4 to ro in. high, but in the lower parts of the valleys in Piedmont it is nearly twice 
as high. There is a white form which, like the type, is well worthy of culture, and thrives freely in rather moist welldrained loam on the rock-garden or in the front margin of a mixed border. Easily increased by seed or division.

C. Barrelieri, allied to C. fragilis, has procumbent one-flowered stems and roundish heart-shaped leaves. Blossoms blue. On rocks by the seaside about Naples ; a good trailing rock-plant, which thrives also in baskets or pots in windows.

C. cæspitosa (Tufted Hairbell).-This we take to be the true type, of which C. pumila is a dwarf variety. Its roots ramble very much, and it soon forms large patches in a border of moderately light garden soil. Its flowering stems rise from a mass of leaves to a height of 6 or 8 in., and when vigorous, bear five or six gracefully-pendent light blue flowers. It flowers in July and August, abundantly and continuously, and may be readily increased by division of the root. A native of the Alps. C. pumila, dwarfer, scarcely exceeding 3 or 4 in. in height, usually flowers in pairs on a stem. There is also a white form as pretty as the blue. Most easily increased by division and seed, but as a few tufts divided into small pieces quickly form a large stock, it is scarcely worth while to raise it from seed, except where plants cannot be got. This variety is also known as C. pusilla-a distinct species.

C. carpatica (Carpathian Hairbell).An old and deservedly popular garden plant of free-flowering habit. The light blue flowers are large and cup-shaped, and are borne on erect foot-stalks 12 to 15 in. high. Through July and August there is a succession of blooms, so constant that it was once considered to have established a claim as a "bedder," and it is a border plant of such value that no garden should be without it. Readily increased by seeds, which are abundant. Pallida, a very pale blue, and alba, a pure white, are desirable varieties ; these, however, must be propagated by spring cuttings or root division, as the variation does not come true itself from seed. There is also a rare dark blue sort named Bowoodiana, and a blue-and-white variety, which is excellent and showy, but scarcely so free in blooming as the species.

C. celtidifolia.-A first-rate perennial species, the branches rising from a somewhat fleshy underground stem, and bearing many light blue flowers well expanded. When well established, it attains a height of 3 to $4 \mathrm{ft}$., but requires three years to assume its true character. Siberia. Flowers through June and July.

C. cenisia (Mont Cenis Hairbell).-A high alpine plant growing among the fine Saxifraga biflora on the sides of glaciers on the high Alps. It scarcely ever makes much show above the ground, but is very vigorous below, and sends a great number of runners under the soil. Here and there it sends up a compact rosette of light green leaves. The blue flowers are solitary, and somewhat funnel-shaped, but open, and cut nearly to the base into five lobes. It merits a place in the rockgarden. It should have a sandy or gritty and moist soil, and be near the eye if the rockwork be on a large scale. Alps.

C. collina (Sage-leaved Hairbell) is a species with a creeping root, sending up stems to a height of 12 or 15 in., each bearing a few narrow leaves, from whose axils the pendent flowers are produced; the flowers are blue, and appear in May and June. It blooms somewhat sparsely, but is a desirable border plant. Caucasus.

C. fragilis (Brittle Hairbell) is a glabrous plant, except that the young branches are coated with soft down; the flowering branches are prostrate, or hang down where the position will admit. Where growing freely they attain a length of 12 or 15 in. The flowers are I in. or more in diameter, of a delicate blue. Of all the species this is the best adapted for a suspended basket, and it does admirably in a cottage window. It is rather tender, coming, as it does, from the seaside rocks in the south of Italy and Sicily. It should be increased by cuttings of the young shoots taken in spring. To divide the plants is a rash experiment, at once suggesting how appropriate is the name. If planted in the rockgarden, a watchful eye must be kept against snails. C. hirsuta is quite covered with hair or stiff down, and looks almost woolly. It is of about equal value with the normal smooth form.

C. garganica (Gargano Hairbell).This compact and tufty plant somewhat resembles C. muralis, but is larger in all its parts. The flowers grow in irregular branching racemes, pale blue, towards the centre shading off to white. It blooms abundantly, and thrives in a rock-garden or a border; but, owing to its pendent flowering branches, its proper place is against a rocky ledge, over which its masses of flowers may hang. It blooms in June, and is valuable for suspension in a window or a conservatory. It may be readily increased by division or by cuttings taken in early spring. C. hirsuta 
is hairy and differs from the type by having root-leaves more pointed and by being downy. C. floribunda receives its name from its free flowering. It is smaller, the corolla is more campanulate, and the racemes are more erect. There is also a pure white form. The Gargano Hairbell is frequently called C. fragilis, from which, however, it is quite distinct.

C. glomerata (Clustered Bellflower).About $2 \mathrm{ft}$. high, the erect stems being terminated by dense clusters of pretty flowers, varying in shade from a deep intense purple and pure white. The pure white form is somewhat rare. C. glomerata is generally found throughout Europe in scattered isolated tufts in nearly all calcareous soils, and flowering in June and July. In the border it is very compact and useful. C. dahurica is larger, and is sometimes cultivated under the specific titles of C. speciosa and C. Cephalotes. It was introduced from Siberia by Fischer under the impression that it was a distinct species, but in cultivation it proves to be only a showy variety. One of the finest of all the Bellflowers. The variety cervicariodes differs by its taller and more straggling growth.

C. grandiflora (Platycodon).

C. grandis. - A distinct and beautiful species, with masses of barren shoots (each forming a rosette of numerous leaves, laxly arranged, and close to the ground), so rapidly extending that by the third year a small plant will cover a circle $3 \mathrm{ft}$. in diameter with a dense leafy carpet, from which a dozen or more flower-stems have developed to a height of $2 \mathrm{ft}$. or even more. The flowers are wide, somewhat shallow, and densely arranged along the flowering branch. It flowers in June and July, and is exceedingly partial to slight shade; the blue flowers are fully 2 in. in diameter. It is a border plant of somewhat short duration in flower. $=\mathrm{C}$. latiloba.

C. hederacea (see Wahlenbergia).

C. isophylla (Ligurian Hairbell).-A very ornamental and profusely flowering Italian species. The leaves are roundish or heart-shaped, and the flowers of a pale but very bright blue, and with whitish centre. A charming ornament for the rock-garden, and should be placed in sunny positions in welldrained, rather dry fissures, in sandy loam, and it will repay the cultivator by a brilliant bloom. It is one of many kinds that might with great advantage be naturalised in rocky spots -the sunny walls of old quarries, chalk pits, and such places.
C. lactiflora.-This plant, of Caucasian origin, is one of the bolder and larger Bellflowers, and is better suited for naturalisation than for the flower garden or border, where its time of flower is short and its habit stiff. The flowers are large and of a milky-white colour, produced in loose pyramidal manner.

C. Langsdorffiana.-A plant scarcely exceeding $4 \mathrm{in}$. in height. The blue flowers are borne singly, and are nearly pendent. It is a rather shy grower, and does not increase rapidly at the root; but, no doubt, cuttings from the early spring growth would strike freely. Russia.

C. latifolia (Broad-leaved Bellflower). - The stems rise to a height of 3 or $4 \mathrm{ft}$. The flowers are large, pendent, with slightly reflexed segments, and vary between white and blue in colour. C. latifolia is certainly one of the stateliest of our wild Bellflowers. Britain, generally found in woods; abundant throughout Northern and Central Europe. It flowers in June, and is good for woods, copses, and rough places or hedgerows, and above all for the water-side or ditch.

C. Lœfflingi.-A showy dwarf species, rarely exceeding 4 in. in height, producing many violet-blue blossoms $\frac{3}{4}$ in. across. It is capital for the rock-garden, or for front spaces in ordinary borders. Portugal and Spain, in cornfields.

C. Loreyi.-An annual from Mount Baldi, in North Italy, 9 in. to $I \mathrm{ft}$. high, has numerous branches, and small, stalkless, shining leaves. Its blossoms are of a blue-violet, and are produced in sufficient number to render it a pretty border annual; it is best seen in masses. A variety called alba, with blossoms of silvery gray, is also very attractive. It is an annual of easy culture if sown out-ofdoors in spring.

C. macrantha.-The stems of this handsome plant rise to a height of $5 \mathrm{ft}$., and at the base are well furnished with ovate leaves. The vigorous stems are terminated by clusters of large deep blue flowers almost as large as Canterbury Bells, but less contracted at the mouth of the tube. It is a free vigorous perennial from Russia, and perpetuates its giant character from seed. C. eriocarpa is probably synonymous.

\section{C. macrostyla (Candelabra Bellflower).} -A singular plant, having large flowers, with blue netted veins on a white ground which gets purple at the edges, and with a huge stigma. It is wholly distinct from any of the Campanulas in our gardens, and well deserves culture. It is readily 
recognised by its candelabra habit of growth. A native of Asia Minor, and an annual of easy culture.

C. Medium (Canterbury Bell). - A familiar old biennial that should find a place in every garden. It is too well known to need description, but there are now a host of beautiful varieties bearing flowers with a great diversity of colours. These may be classed in three sectionssingle flowers, like the old-fashioned single Bells; doubles, like the stout massive flowers in which two, three, and even- four bells seem to be compressed into the outer one; and duplex flowers, like the calycanthema forms, in which one bell grows in the other, the two combined resembling a cup standing in a saucer. The single varieties are still to be had, but no one would care to be dependent upon these after having once seen the beautiful products of a fine moidern double and semi-double strain, especially if it also bear good single forms. Whilst the old single strains comprise only white and blue, the modern strains include nearly a score of hues: such as white, lavender, mauve, several shades of purple, pink, rose, salmon, and blue. The duplex strains have hitherto been confined chiefly to white and blue, but other colours are now being introduced. It is a curious fact that whilst the seed of the white form is pale and the seed of the blue form is dark, the seed of the double and semi-double forms of all colours is of the same glossy brown. The habit of the latter section is compact and good, the plants in bloom ranging from 18 to 24 in. in height, and forming perfect pyramids of flowers. They may be lifted and placed in pots without injury even in full bloom, and as they invariably flower from the middle of June to the middle of July, according to place and season, it would be possible to introduce to some of the midsummer shows a very novel and interesting feature in the shape of a large group in pots. If required for this purpose, or for corridor, house, or conservatory, it would be best to lift the plants early in May and pot them in 6-in. pots to enable them to get well established before blooming. The calycanthema section usually exhibits a taller and a looser growth, and should be planted in borders behind the double and single kinds.

March or April is the best time to sow seed of C. Medium and its varieties if you desire large massive plants with several spikes of flowers, which display to the best advantage the beauties of one of our finest hardy border plants. The seed is small, and, if plentiful, may be sown in a warm spot in the open ground, but it is much safer to sow it in shallow pans or boxes placed in a frame or on a shelf in the greenhouse, as all the seed will probably germinate and produce an abundance of plants. When these are large enough to handle conveniently, prick them out into some shady spot, and keep them watered until well rooted. From that time they may be safely left to take care of themselves until September, when they should be transplanted into their permanent places in the flower borders, where they will get well established before the winter and develop blooming crowns for the next year. The following are the principal varieties : Rosea, r. plena, cœrulea, c. plena, alba, a. plena, cœrulea striata, albo lilacea, a. 1. plena, rosea lilacina plena, azurea, a. plena, calycanthema, c. alba, c. lilacina, c. 1. plena.

C. nobilis (Noble Bell-flower).-A largeflowered kind, and, in general habit of growth, allied to C. punctata, having creeping underground stems. The flower-stems rise to a height of 18 to $20 \mathrm{in}$., and have a few narrow leaves from the axils of which hang large pendent flowers almost 3 in. long. Their colour is light chocolate with a shade of blue; and there is also a creamy white variety. C. nobilis blossoms in May, and rarely seeds, but may be readily increased by the underground stems. China. Of easy culture in any soil.

C. persicifolia (Peach-leaved Bellflower). - A beautiful species, the cupshaped flowers of which are fully 2 in. across. The stems, though wiry, are often weak at the base, owing to the rosettes of the previous year (from which they spring) having lost their vigour during growth, and having no root-hold-hence, when the flowers are in full bloom, the stems, if not provided with some artificial support, lie about in an untidy manner. C. persicifolia is $I \frac{1}{2}$ to $2 \mathrm{ft}$. high, and flowers in July and August-the early removal of the flowerstems frequently causing a few scattered autumnal blooms. It is abundant throughout Northern and Central Europe, and appears to thrive best and bloom most freely on calcareous soils. C. p. maxima is a giant form, also called C. suaveolens. Besides the double blue and white forms, there is an interesting variety named coronata, in which the corolla appears doubled. These three varieties are 
admirable for borders, and should have a place in every selection of herbaceous plants; the double white variety being particularly desirable not only for the
The latter are in dense rosettes, from the centre of which the stem rises to a height of about 9 in. The flowers are a deep slaty-blue. One of the few species

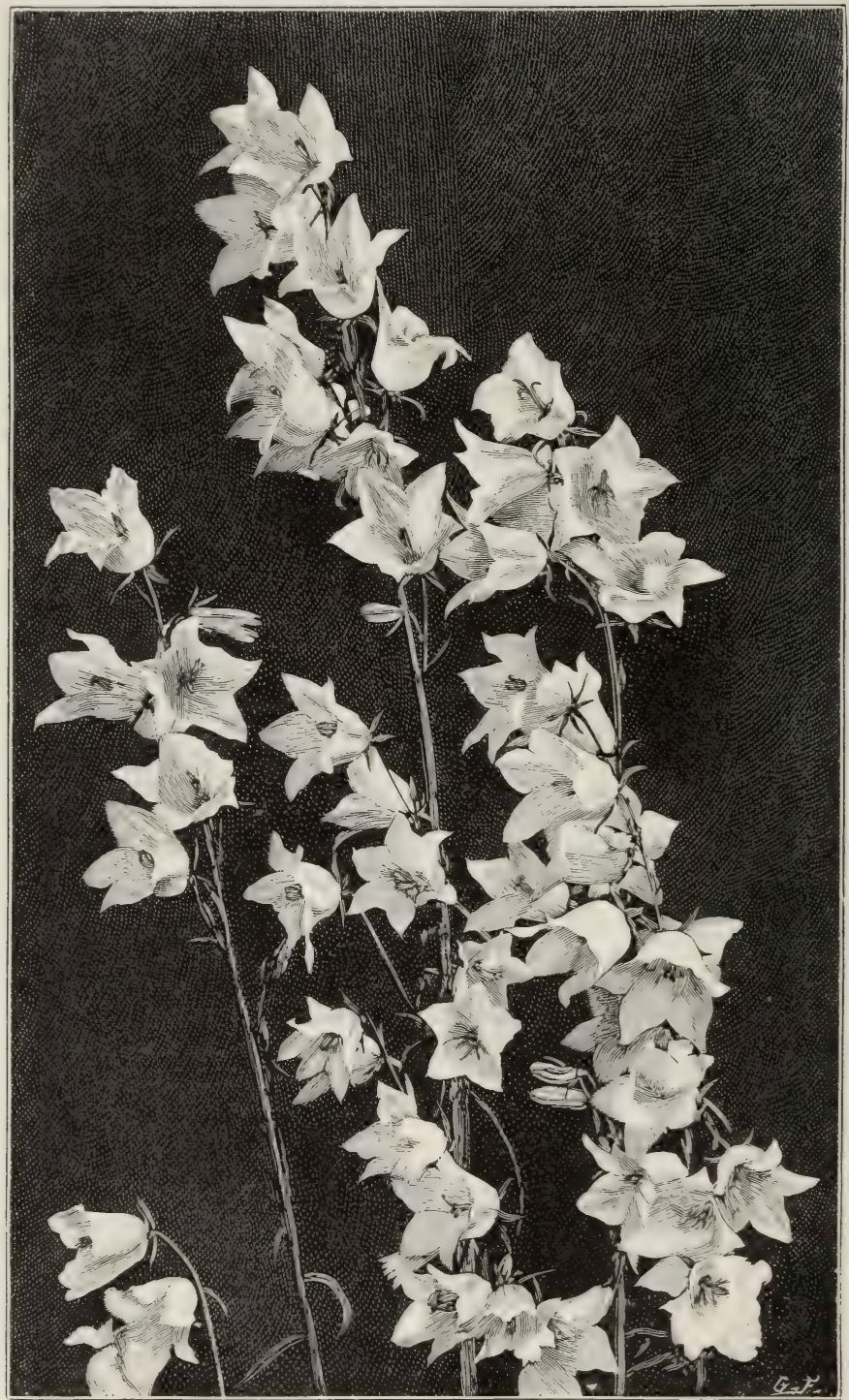

CAMPANULA PERSICIFOLIA ALBA (PEACH-LEAVED BELL-FLOWER).

border, but for pots. All the varieties well repay good culture. Plants occasionally divided and kept in rich beds give very fine crops of flowers.

C. planiflora (Shining Bell-flower).-A rigid plant, as regards stem and leaves. that are natives of North America; it sometimes goes by the name of $C$. americana, a species of annual duration only, whereas C. planiflora is a longlived perennial. There is a pure white and a double form, both desirable 
varieties. It likes a well-drained sunny corner of the rockery, being rather liable to damp off in the winter. Increased by division of the rosettes at the base of the flowering stem. $=\mathrm{C}$. nitida.

C. Portenschlagiana (Wall Hairbell).A dense tufty evergreen species, with small bright green leaves, broadly cordate and irregularly notched, cucullate in shape, so dense as to obscure the foot-stalks, $I$ in. or more in length, by which they are supported. The flowers are pale blue. The plant has been long in cultivation. It is of free growth, equally suited for pot culture or the rock-garden. It spreads slowly by the development of underground stems, and hence succeeds in fissures or crevices of the rock-garden. Dalmatia. Flowers in August or September. =C. muralis.

C. primulæfolia (Primrose-leaved BellAlower).-Like the Canterbury Bell, this is little better than a biennial, the flowering process almost invariably exhausting its energies. In general contour it is quite distinct, as the stem rises erect and unbranched to a height of $2 \mathrm{ft}$. from a mass of broadly ovate leaves, roughly corrugated and serrated, resembling those of a coarse Polyanthus; the flowers are wide, of a slaty-blue, and gradually shade to white at the base of the corolla. Portugal. Flowers in July and August. Seeds, which it produces freely. $=$ C. peregrina.

C. pulla (Austrian Hairbell).-This, when grown freely, is one of the most charming of the group; its neat growth, its deep purple drooping bells, and its simple unifloral character are all elements of beauty. It is a native of the Austrian Alps, and is generally found in the high mountain pastures, where its tendency to produce rambling ground stems is not checked or limited; if planted in the rock-garden, therefore, it should have to itself a good wide shelf of moderately flat soil in which a little peat and sand have been mixed. It is usually considered shy, and consequently is generally grown in a pot, which is not at all suited for its peculiar mode of growth; during the first season it will do, but the second will bring disappointment. It may be enormously increased in the spring by taking off young shoots and placing them in a gentle bottom heat. They will strike as freely as those of a Lobelia, and make fine compact autumnal flowering plants, but success depends greatly on the vigour of the plant from which the cuttings are taken. After blooming the foliage disappears and the plant goes to rest. An excellent rock-plant.
C. pumila (=C. cæspitosa).

C. punctata (Spotted Bell-flower).-Like many similar creeping plants, difficult to establish, but when once established it is equally difficult to keep within bounds. Its leaves are rough; the flower-stems rise from the mass of foliage to a height of 8 or 9 in., each stem carrying two or three pendent milk-white flowers, fully 2 in. long, the spotted character of which, though slightly shown externally, is well seen inside. Siberia. Blooms in July. It does not produce seeds, but its creeping roots afford a ready means of propagation.

C. pusilla.-Smaller than C. cæspitosa, rarely exceeding $4 \mathrm{in}$. in height. The smooth shining green leaves are roundish, heart-shaped, and toothed. The flowers are pale blue, in few-flowered racemes, and appear in June and July. Suitable only for rock-garden. Switzerland. Very gritty moist loam is best. $=$ C. modesta.

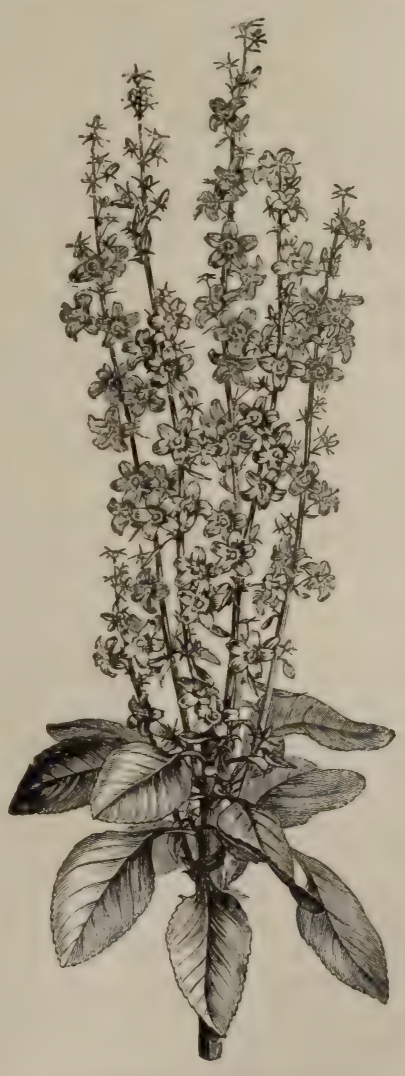

CAMPANULA PYRAMIDALIS.

C. pyramidalis (Steeple Bell-flower).A vigorous plant, with thick and fleshy 
flower-stems, rising to a height of 4 or 5 ft., and furnished with numerous broad ovate leaves; the flowers are on peduncles of varying length, closely adpressed to the stem, giving the inflorescence more the appearance of a steeple than a pyramid. The flowers are blue or white; the corolla is widely expanded, and its segments broad; the flowers are rather erect than pendent, and, owing to the secondary floral branches developing their flowers gradually in succession, the blooming period is extended over a considerable time, in July, August, and September. This plant loves the shade, and is well suited to the flower border, or the conservatory, where, during the later summer months, its blue colour and bold character are desirable, and where its columnar spikes contrast with the lines of the Ferns or Palms. Though not absolutely a biennial, it is better in general cultivation to consider it as such, as from seedling plants, well grown on during the first year, the finest stems are developed. It matures seed freely, but care should be taken that it is not sown too thick, as it is liable to damp off ; and one may lose the crop altogether. A border perennial of the highest merit in favourable soils; so important indeed, that occasional batches of seed should be sown to keep up a vigorous supply. Carolina.

C. Raineri (Rainer's Bell-flower).-A dwarf, compact, sturdy plant, varying in height from 3 to 6 in., each branch bearing a large dark blue flower. It thrives best in sunny positions in loam freely intermingled with pieces of stone, and well watered in dry weather. A gem for the rock-garden. Alps of Northern Italy.

C. Rapunculus (Rampion Bell-flower). -A biennial with foliaceous stems, rising to a height of $2 \mathrm{ft}$., and with thick fleshy roots, which were once much cultivated for cooking. The purplish-blue flowers are loose on the stem, and widely expanded. It is a native of Britain, and extends across the whole of Central and Southern Europe, where it is generally found in hedgerows and open country districts. Flowers in May or June. Not as showy as some of its congeners. It is desirable for woods or rough places.

C. rotundifolia (English Hairbell).Although wild, this loses none of its beauty by reason of its familiarity ; in it we have the true type of the Hairbell. In early spring its round-leaved character is fully developed, and the little tufts of radical leaves indicate at a glance the origin of its title, but as the flower-stems become developed, these gradually die away, and the leaves which accompany the flowers are long and narrow; hence its name surprises those who only know it in bloom. So well known is the plant that it is almost needless to describe it. There is a white variety, generally dwarfer and more slender. There are several

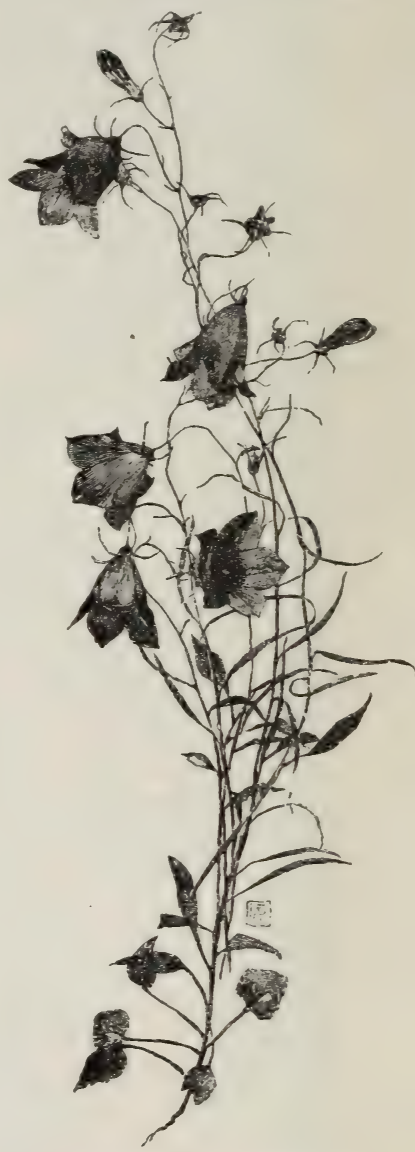

CAMPANULA ROTUNDIFOLIA.

forms, all beautiful, and of easy culture in any soil. C. Hostii is a variety.

C. r. soldanellæflora (Double fringed Hairbell).-A double variety reminding one of the beautifully-fringed flowers of the Soldanella. When in the border or the rock-garden and growing freely, it attains a height of 15 in., or even more. The upper portion of each stem is well furnished with pendent dark blue flowers, on a somewhat irregularly branching raceme. All the leaves are linear, even those which spring from the root, and these are scarcely broader than those of the flowering stems. 
C. sarmatica (Sarmatian Bell-flower).A free herbaceous plant, with flower-stems rising to a height of about $2 \mathrm{ft}$., and furnished with flowers almost throughout their entire length ; the lower blooms are supported singly on longish foot-stalks, but the upper ones are almost stalkless; the colour is a light blue. Owing to the weight of its masses of flowers, it frequently is decumbent in cultivation, and it requires staking to guide its early growth. It flowers in July and August, and increases readily from seed, which comes quite true. Rocky sub-alpine regions of the Caucasus. $=\mathrm{C}$. gummifera, whose only difference apparently is slightly narrower leaves.

C. Thomasiniana. - A handsome dwarf species nearly related to C. Waldsteiniana, but much superior as a garden plant. Although it has been some time in cultivation, it is scarce, probably from the difficulty of propagating it by cuttings, as it seldom ripens seed. It forms a dense tuft, narrow toothed leaves covering wiry stems. The flowers, 6 to 12 in number, are tubular and about an inch long. They are borne on the points, in the axils of the leaves, weigh down the stalk, and give the plant a drooping habit. July, August, September. Very useful for rock-garden, and loving a shady position, not too damp. Istria.

C. Trachelium (Rough Bell-flower).-A sturdy, compact herbaceous plant, with erect flower-stems, which attain a height of $2 \mathrm{ft}$. or more ; the flowers are in twos or threes; they are large and blue; but there are white and double varieties; it blooms in July. Britain.

C. turbinata (Turban Bell-flower) is a dwarf compact plant with deltoid leaves, of grayish-green. In the type the flowers are borne singly on naked stems about 6 in. long, are of a deep blue, and fully $I \frac{1}{2}$ in. across. The flowering extends over June and July, in continuous succession; and if the plant be cut back, a second autumnal blooming frequently follows. Mountains of Transylvania; a charming plant for border or rock culture. Though distinct from the Carpathian Bell-flower, yet if propagated by seed (which it produces pretty freely), it develops a vigour of growth that, but for its larger leaves and dwarfer habit, would render its specific identity doubtful; this too occurs where there is no possibility of hybridisation. C. $t$. elegans is a hybrid between $C . t$. and C. carpatica, and it is superior to both as a summer flowerer. The variety pelviformis bears saucer-shaped flowers very freely.
C. urticæfolia (Nettle-leaved Bellflower) has much of the aspect of $C$. Trachelium, but is smaller; the flowers are blue or white, and there are double forms of each. Germany. It loves the partial shade of woods. The double white variety is particularly desirable on account of its distinctness and chaste beauty.

C. Van Houttei is handsome and desirable. It is strong, its flower-stems attaining a height of $\mathrm{I}$ to $2 \mathrm{ft}$.; its large pendent leaden-blue flowers are like those of C. nobilis.

C. Waldsteiniana (Waldstein's Hairbell).-A charming little free-flowering species, of compact habit, producing wiry stems from 3 to $6 \mathrm{in}$. high, which bear pale blue flowers. Hungary. Introduced in 1824 , then for years lost to the country, but recently re-introduced. It appears to be free and cultivable, and is readily increased by cuttings taken from the early spring growth and placed in a gentle bottom heat. It thrives in limestone soil in a sunny position.

C. Zoysi.-A dense tufty plant allied to C. cenisia, but more compact. Its flower-stems are 2 or 3 in. high, and terminate in one perfect bloom. Flowers large in proportion to the size of the plant, and of azure blue. Carinthia and Styria. Luxuriates in sandy loam in exposed parts of the rock-garden, for which it is best suited.

The following are mentioned in catalogues, but they are not much known or are too much like others to be of value : C. aggregata, azurea, altaica, americana, attica, carnica, Cervicaria, divergens, Elatines, laciniata, linifolia, macrorhiza, peregrina, retrorsa, speciosa, strigosa, Scheuchzeri, tenella, Tenori, Tommasini, thyrsoidea, Vidali.

Campernelle (Narcissus odorus).

Campion (Lychnis).

Camptosorus rhizophyllus (Walking Leaf). - A small N. American Fern, remarkable for its narrow fronds, which taper into slender prolongations, and take root at the tips like runners, giving rise to new plants. It is of easy growth in gritty loamy soil in a somewhat shaded position. Suitable for a shady nook in rock-garden or for the select hardy fernery.

Canary Creeper (Tropacoleum aduncum).

\section{Candytuft (Iberis).}

Canna (Indian Shot).-A very important tropical genus with fine foliage, which nevertheless makes good growth out-ofdoors in warm positions in our southern gardens. The larger kinds make rich 
masses of foliage, yet all may be intimately associated with flowering plants - an advantage not possessed by free-growing things like the Castor-oil plant. The tendency of most of our flower-garden plants is to flatness, and the special quality of the Cannas for counteracting this makes them valuable. Another good quality is their power of withstanding the cold and storms of autumn. They do so better than many of our hardy shrubs, so that we may see them waving graceful and verdant when the last leaves have been blown from the Lime and the

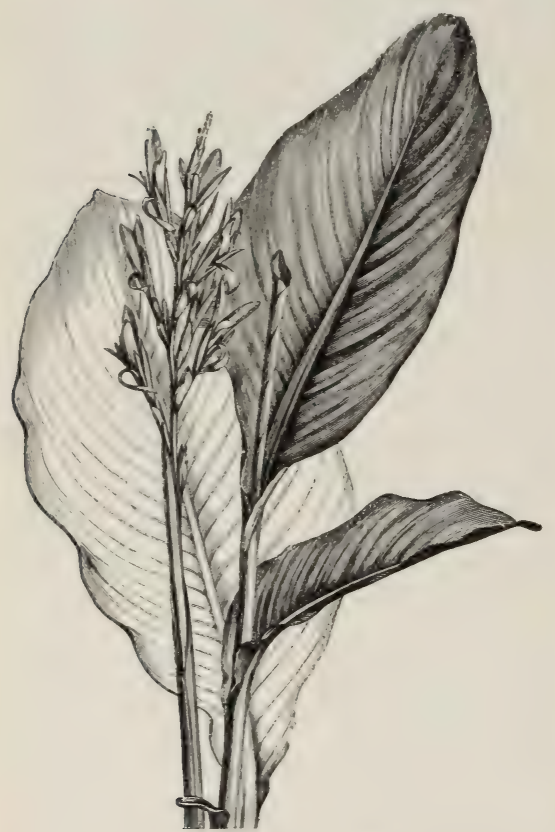

INDIAN SHOT (CANNA INDICA), FLOWERS AND LEAVES.

Dahlia, and the Heliotrope has been hurt by frost. Sheltered situations, places near warm walls, and nice snugly-warmed dells are suitable. They are generally used about Paris and London in huge ugly masses, but to see their true beauty we must place them here and there among the flowering plants. A bed or two solely devoted to them will occasionally prove very effective ; but enormous flat masses, containing hundreds of plants of one variety, are very bad. As to culture and propagation, nothing can be more simple; they may be stored in winter under shelves in the houses, in the root-room,--in fact, anywhere, if covered up to protect them from frost. In spring nothing is easier than pulling the roots in pieces and potting them separately. Afterwards it is usual to bring them on in heat, and finally to harden them off previous to planting out in the middle of May. A modification of this practice is desirable, as some kinds are remarkably hardy, and make a beautiful growth if put out without a leaf on them. The soil should be deep, rich, and light. Cannas, protected by a coating of litter, have been left out in Battersea Park through severe winters, and during the unfavourable summer of I 867 attained a height of nearly $12 \mathrm{ft}$. Where it is desired to change the arrangements every year, it may be no advantage to leave them in the ground, and they may be taken up with the bedding-plants and stored as easily as Carrots. Wherever they are grown as isolated tufts, in small groups, or in small beds, it will be best not to take them up oftener than every second or third year if the ground be warm and well drained. These noble plants would also adorn the conservatory, which is often as devoid of graceful vegetation as the unhappy flower gardens all over the country. Few subjects would be more effective, and none more easily obtained.

The only really hardy species is C. Achiras, a rather handsome plant, but less desirable than the more tender. Those available for massing or mixed planting are exceedingly numerous. In the first place, the wild forms described amount to nearly-roo, whilst the garden hybrids and seminal varieties are practically innumerable. Foremost among the raisers of new varieties may be named M. Année, a French amateur. He commenced many years ago, and several varieties bear his name, as $C$. Annei rosea, C. Annei floribunda. The species are fully described in The Garden for 2 Ist October 1878 , and the varieties are described in the "Subtropical Garden." The Iris-flowered Canna is a lovely kind which is not seen out-of-doors in England; it has flowered out-of-doors in Paris gardens, but it requires a warm moist house to develop its full size and beauty.

Cannabis sativa (Hemp Plant).-A well-known annual, a native of India and Persia, and largely cultivated in Europe for its fibre. In ordinary situations it is 4 to Io $\mathrm{ft}$. high, but in Italy, under favourable circumstances, it is sometimes $20 \mathrm{ft}$. high. In plants growing singly, the stem is frequently much branched, but in masses it is generally straight and unbranched. It is useful where the tenderer sub-tropical plants cannot be enjoyed. Single well-grown plants look 
very imposing and distinct, and are good for the backs of borders and mixed groups; and a few look well as a separate group. For these purposes it should be sown in the open ground early in April. To get large plants it would be worth

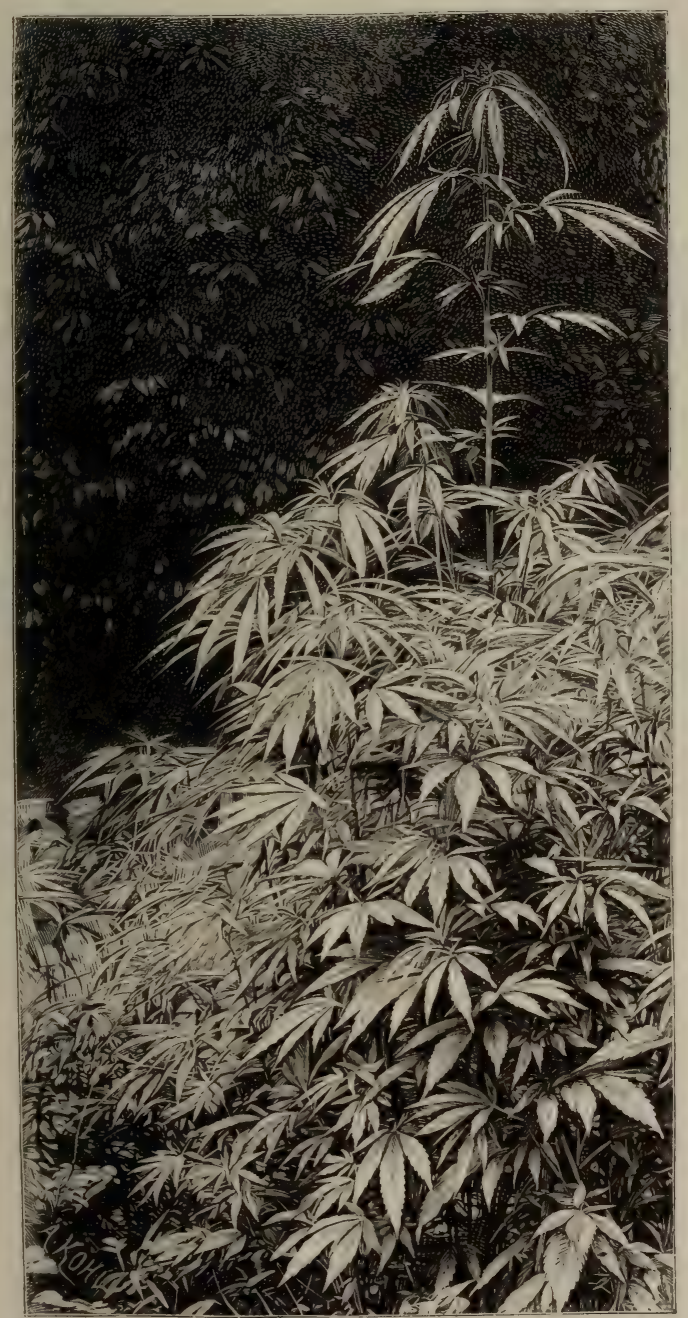

CANNABIS SATIVA (HEMP PLANT)

while raising it in frames. It loves a warm sandy loam, and is one of the few plants that thrive in small London gardens, where its effect is both distinct and graceful. There are several varieties mentioned in seed catalogues, but not differing much in habit-at least in our climate.

Canterbury Bell(Campanula Medium).

\section{Cape Honey-flower (Melianthus}

Major).

Cape Pond-flower (Aponogeton).

Caragana. - A hardy but not showy pea-flowered shrub. Interesting in collections of hardy shrubs, but of less value from a flower-garden point of view.

Cardamine (Cuckoo-flower or Lady's Smock). - A large genus of the Crucifer family, few of which are cultivated, the best being the native Cuckoo-flower in its double form. Amongst hardy flowers few give more satisfaction, and it will grow well almost anywhere, although, like the type which, in many districts, colours the meadows with softhued flowers, it delights in damp and almost swampy situations. The single kind is too common to need cultivation ; the double kind is a pretty subject for the spring garden and for borders. Division. C. trifolia is a pretty species, with white flowers, from Switzerland; 9 to $\mathrm{I} 2 \mathrm{in.} \mathrm{high;} \mathrm{a} \mathrm{border} \mathrm{or} \mathrm{rough}$ rock-plant. C. latifolia, C. asarifolia, and C. rotundifolia are pretty dwarf plants when in flower, but not likely to be popular in gardens.

Cardinal-flower (Lobelia cardinalis).

Carduus.-A genus of Composites of Thistle-like appearance. The finest is C. eriophorus, the Woolly-headed Thistle, a remarkably conspicuous native plant, with a much-branched hairy stem 3 to $5 \mathrm{ft}$. high; and very deeply-cut, undulated, and spiny leaves, the lower ones often $2 \mathrm{ft}$. long. The flower-heads are large, of a purplish-red, and surrounded on the under side by a dense white cottony web. Few plants are more handsome or novel in appearance. It is suitable for borders, or groups of hardy finefoliaged plants, and grows well in any common soil. It is a native of the limestone districts of the south of England and elsewhere. An interesting plant to naturalise. C. altissimus and acanthoides are also met with in botanical collections. Various plants synonymous with this genus are described in this book under other names.

C. Benedictus (Blessed Thistle).

Carex (Sedge).-An enormous genus of plants well known in all northern and 
temperate countries. Few have a place in the garden, though some have much merit, apart from botanical interest.

C. paniculata is a very large Sedge, something like a dwarf Tree Fern, with strong thick stems and luxuriant masses of drooping leaves. The roots form dense tufts, frequently I to $3 \mathrm{ft}$. high, and when the plant is in flower it generally has a large and spreading panicle. A few tufts are very effective on the margins of water near groups of picturesque plants. The finer specimens are of great age, and must be procured from the bogs where the plant is wild.

C. pendula.-A very graceful plant, and unlike any other British Carex. It grows in large round tufts, with numerous flowering stems and barren shoots, which attain a height of from 3 to $6 \mathrm{ft}$. The leaves are often $2 \mathrm{ft}$. or more in length, and are chiefly at the base of the plant. When in flower the graceful disposition of its pendent spikes renders it most attractive. These spikes are from 4 to 7 in. long, and are usually about half a dozen in number. Very suitable for the margin of water or for boggy or moist spots. Some of the kinds are variegated, as C. riparia, and there are some striking forms, such as C. Fraseriana, but compared with the above these are mainly of botanical interest.

Carlina acaulis.-A dwarf Thistle-like perennial, rather interesting from its foliage, which has some resemblance to the leaves of a miniature Acanthus, and grows in a broad, handsome, regular rosette very close to the ground. Its single yellowish flower, 3 in. or more across, is on a very short erect stalk in the centre of the rosette. Although too dwarf for association with more imposing plants, it is worthy of a bank or slope or the margins of low beds or groups, where its distinct habit will be seen to great advantage. It thrives best in dry, stony, calcareous soil, and is easily multiplied by seeds. Central Europe.

Carludovica palmata.-A palm-like plant, 4 to $7 \mathrm{ft}$. high, with dark green leaves 2 to $3 \mathrm{ft}$. broad, divided into four lobes, each of which is again divided at the apex into narrow segments. In warm gardens this interesting plant will endure the open air from early June till October, but requires warm house treatment in winter, with plenty of water at all times. Seed. Peru and New Granada.

Carnation (Dianthus Caryophyllus).

Carpenteria californica.-A lovely and distinct shrub which lives out - of doors against walls in favoured situations. It is new to our gardens. A few years ago it was not perfectly known even to American botanists, for no flowers (only fruits) had been seen upon the specimens then collected. It is 6 to $\mathrm{Io} \mathrm{ft}$. high, having slender branches with long narrow leaves of pale green, and great clusters of large white fragrant flowers. It comes from the mountains of the

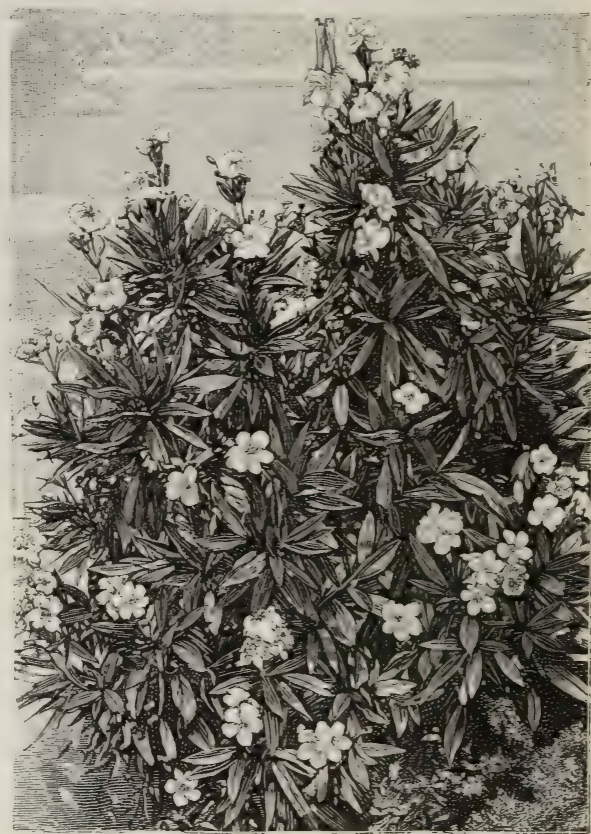

CARPENTERIA CALIFORNICA IN A SLSSEX GARDEN

Sierra Nevada, particularly about the head waters of the San Joaquin River. It crept into English gardens without the trumpet-flourish that usually heralds the advent of a beautiful new plant. The first heard of it in England was from Mr. Saul, of Washington City, D.C., U.S.A., who sent dried specimens of it to The Garden in I880, and from these pressed flowers and leaves the first drawing of the plant seen in this country was made. It is, botanically, nearly related to the Mock Oranges (Philadelphus), which it somewhat resembles, but is larger and handsomer. It should have light warm soil, and is increased from suckers, cuttings, or seeds.

Carthamus tinctorius (Safflower).An annual of the Composite family, of little ornamental value. The yellow flowers yield Safflower, largely used as a dye. Easily grown as an annual, but mainly of interest for the botanical or economical collection. 
Caryota.-Elegant East Indian Palms, generally small in this country; and though they endure the open air in summer, from June till the end of September, pretty well, they can never be important for open-air gardening.

Cassandra calyculata (Leather Leaf). -A modest little evergreen shrub, bearing in spring tiny waxy white flowers, like those of some of the Andromedas, and doing best in moist peat soil.

Cassia marilandica (American Senna). -A hardy graceful perennial, $3 \frac{1}{2}$ to $5 \mathrm{ft}$. high, with pinnate leaves, resembling those of the Acacia, and slender stems bearing yellow flowers in numerous small clusters in autumn. It is somewhat late in growth, but when once it has commenced, grows with great rapidity. It thrives best in a position with a south aspect, and may be multiplied either by division in spring or by seed. It should alwàys be planted in a warm, deep, sandy loam, and is suitable for borders or association in groups with the finer hardy subjects, its graceful leaves qualifying it for a place in a group of hardy foliage plants. Recent experience seems to show that our climate is not warm enough for it to bloom it well. N. America.

C. corymbosa is a pretty free-flowering greenhouse variety often used with good effect in the flower garden in summer, and for that purpose requiring to be stored in the greenhouse in winter.

Castilleja.-Curious and showy Californian herbs which will not, we think, bear cultivation in the open air for any length of time. We introduced seeds which grew, and the plants flowered, but they were not very ornamental, and they soon disappeared. Seed imported yearly seems the only way of increasing them.

C. Coccinea (Scarlet-painted Cup).

Castor-oil plant (Ricinus communis).

Catalpa.-As a lawn tree the Catalpa is valuable, as it flowers in August when other trees are flowerless. The commonest is the North American C. bignonioides (also called C. syringæfolia). C. speciosa, a newly-discovered species, also a native of North America, is said to be much hardier, and bears larger flowers earlier in the year. The golden-leaved variety of C. bignonioides is effective if kept dwarf by annual pruning. It is then suitable for associating with other fineleaved plants of sub-tropical aspect. C. Kæmpferi and C. Bungei, natives of Japan and China, are a good deal like C. bignonioides in growth, but being less hardy are of less importance. All the Catalpas thrive best in moist ground and in sheltered positions, while the common kind may be planted even at the margin of a lake or stream, where it flourishes best, though it is more liable to be injured by severe winters.

Catananche cœrulea (Blue Cupidone). - An old border plant, about $2 \mathrm{ft}$. high, flowering in summer; fine blue, each stalk being terminated by a single head. South of France and Italy. Suitable for borders, margins of shrubberies, or naturalisation in well-drained warm soil. Seed. Generally a "middling" plant only, but

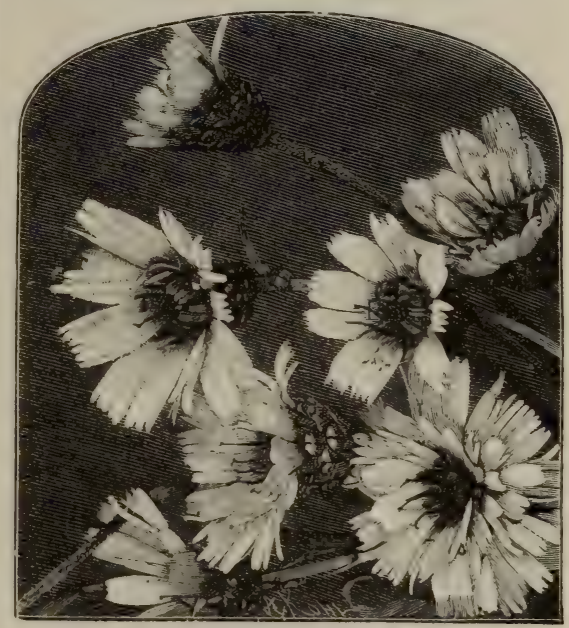

CATANANCHE CERULEA.

good when well grown. There is a white variety as common as the blue, and a bi-colour one. It is easily grown in any soil, and quickly raised from seed.

\section{Compositæ.}

Catchfly (Silene).

Caterpillar plant (Scorpiurus subvillosus).

Cathcartia villosa.-A beautiful perennial Poppy from the eastern Himalayas, somewhat resembling the Welsh Poppy (Meconopsis cambrica). It has densely hairy and lobed leaves in flat dwarf tufts, from which arise the slender flower-stalks from 6 to $\mathrm{I} 2 \mathrm{in}$. high, bearing drooping cup-shaped blossoms of a golden yellow. It is quite hardy in a well-drained rockgarden, and succeeds best in shady damp spots not exposed.

Cat-mint (Nepeta).

Cat's-ear (Phleum).

Cat's-tail (Phleum).

Cat-Thyme (Teucrium Marum).

Caulophyllum thalictroides.-An interesting perennial herbaceous plant of the Barberry family, of dwarf growth, 
with finely-cut foliage and small white flowers, succeeded by deep blue berries. Thrives in partially-shaded borders in peaty soil. N. America.

Ceanothus (Mountain Sweet). - - Though these beautiful shrubs are not quite hardy, they are so important that they must not be overlooked by those who are fond of flowering shrubs. Some, however, of the varieties of the $C$. azureus race are hardy enough on light soils in sunny places to withstand our climate even if fully exposed as bush plants. The majority form most beautiful wall shrubs, and, from their free growth, their handsome foliage, and profusion of bloom, give pretty effects. In all the species the flowers are exceedingly small, but this is compensated for by their abundance, as they come out in succession during the greater part of the summer. As wall shrubs it is necessary to prune them. This should be done in April, or as soon as danger from frost is over; and as all the sorts flower on the shoots of the current year's growth, from one to three eyes of the preceding year's wood should beleft, reserving, or at most only topping, such shoots as are required for filling up the open spaces on the wall. All the species are of free growth in good garden soil, if it is dry, and the subsoil is porous ; and they will ripen their wood best and flower most freely in warm sunny exposures. As they are often natives of a charming climate - the Pacific slope of $\mathrm{N}$. America, - no one should attempt their culture except in warm soil. The following are very distinct and desirable species :-

C. AZUREUS. - Temperate regions of Mexico, where it grows as a straggling bush about Io $\mathrm{ft}$. high. It is one of our prettiest wall-shrubs, flowering abundantly, when planted in a dry, sheltered, sunny situation. The flowers are bright blue, and are in perfection from June till September, and in mild autumns till November. C. pallidus is a handsome variety, with pale blue flowers. It has been the means of obtaining a very beautiful race of hardy Ceanothuses by inter-crossing it with the hardier C. americanus. The result may be seen in such lovely shrubs as C. Gloire des Versailles, Arnoldii, Lucie Simon, Theodore Froebel, Bertinii, President Reveil, Lucie Moser, and others, all of which have flowers in large plumy clusters, some white, others rose, but mostly of some shade of blue.

C. Americanus (New Jersey Tea). Though one of the hardiest, this thrives best against a wall, and in a dry porous soil. The flowers, which come in succession from about the middle of June till August, are white, and numerous. It is found in abundance over a wide area in Canada and the United States as a dwarf deciduous bush 3 to $4 \mathrm{ft}$. high.

C. RIGIDUS is a sub-evergreen, or in sheltered places an evergreen, rarely exceeding $6 \mathrm{ft}$. in height, the branches stiff and wiry; the flowers, in clusters on the sides of the young shoots, are deep purple, and come out in April and May.

C. PAPILlosus is a very pretty species from the mountains of California, where it is a densely-branched straggling bush 6 to $10 \mathrm{ft}$. high. Like the other species, it requires the protection of a wall, on which it blooms in summer. The panicles of pale blue flowers are borne on long foot-stalks from the sides of the young shoots.

C. DIVARICATUS grows as a dense broad evergreen bush of about Io $\mathrm{ft}$. high. It is a free-growing handsome wall plant, flowering from May to autumn. The flowers are a bright blue.

C. Dentatus is an elegant little evergreen shrub, rarely higher than about $3 \mathrm{ft}$. The numerous showy flowers, which appear in May or June, are deep blue, and continue the greater part of the season.

C. VERRUCOSUS forms a thickly-branched evergreen bush about $6 \mathrm{ft}$. high. As a wall plant it is of free growth, and has a good effect. The flowers appear early in May, and continue during the summer months. They are borne in corymbs along the whole length of the young branches, often so profusely as to hide the foliage.

C. Veitchianus is one of the best of the genus, the flowers being of a rich deep blue, in dense clusters at the ends of leafy branches. C. integerrimus and velutinus Fontanesianus are in cultivation, but those described include the best for general cultivation.-G.

Cedronella triphylla (Balm of Gilead). -A distinct half-bushy herb, tall, the leaves with a somewhat pungent but very grateful odour. In our country usually $2 \frac{1}{2}$ or $3 \mathrm{ft}$. high, varying much according to soil, and not hardy, but living out-of-doors most winters if in dry free soil and planted against walls. A few plants against a wall are worth having where curious plants are cared for. The flowers are not showy. Canary Islands. Easily raised from seed. There are other species, but not of high garden value, the most interesting being $\mathrm{C}$. cana.

Cedrus (Cedar).-Noble trees of the mountains of Asia Minor and India, some happily hardy and often planted on lawns and within sight of the flowers. The India Cedar (Deodar) is really tender generally, and though it may seem to promise well in sea-shore and favoured districts, planters should never forget that it is to the Cedars of the northern mountains they must look. Look at the beautiful Cedars that endure-the Lebanon 
and Atlas Cedars, which have been proved so hardy, and so well fitted for our country in the noble trees they form. No finer things can be near the flower garden, but they should never be planted near the house or their great branches will darken it, and in small flower gardens they are sure to be in the way. Plant or group them within sight, but not where they can overshadow flowers or windows. Young healthy seedling plants, 5 or $6 \mathrm{ft}$. high, are the best to plant, and in this state people, not imagining how quickly they will grow, often put them in the wrong place; while the most experienced planter can hardly avoid placing them too thickly. The late Mr. Robert Marnock, the landscape gardener, who planted many thousand Cedars of Lebanon in his lifetime, wrote me as follows about them:- "During a daily occupation amongst trees extending over a period of more than forty years, I have felt quite a growing affection for this noble gift of nature. The grand old Cedars at Upper Gatton and Warwick Castle are examples of what the Cedar becomes under favourable circumstances. Similar examples in various localities could be easily given, and notably those at Pains Hill, Surrey. During all these years I have, as often as opportunity offered, felt it an obligation laid upon me to influence all whom I could persuade to plant Cedars, and I look back with satisfaction at what I have been permitted to do in this way.

"With ample evidence to the contrary, it is marvellous to find so many persons clinging to the fallacy that the Cedar is a tree of slow growth. It is quite true that a Cedar or any other tree will grow slowly, planted, as they very often are, in exposed and draughty situations on open lawns-a treatment to which many Cedars have been cruelly subjected. If Cedars are planted like other ordinary trees, with the usual shelter of common plantations, and the latter properly attended to and duly thinned, they will soon surpass both in height and bulk of growth the ordinary evergreen trees with which they are surrounded.

"The Cedar is thoroughly hardy, and free from any capricious preference as to the soil in which it grows, provided it is fairly good of its kind. There are two localities within 30 or 40 miles of London where a considerable number of Cedars had been heedlessly planted along with the common mixed trees of the ordinary plantations, one of these extending over an area of about 40 and the other 25 or 30 acres. In both cases these plantations may have been made fifty or sixty years ago. In one case the soil is a mixture of gravel and clay, and the other a thin covering of heavy loam on a subsoil of chalk. In both cases the Cedars are the larger trees."

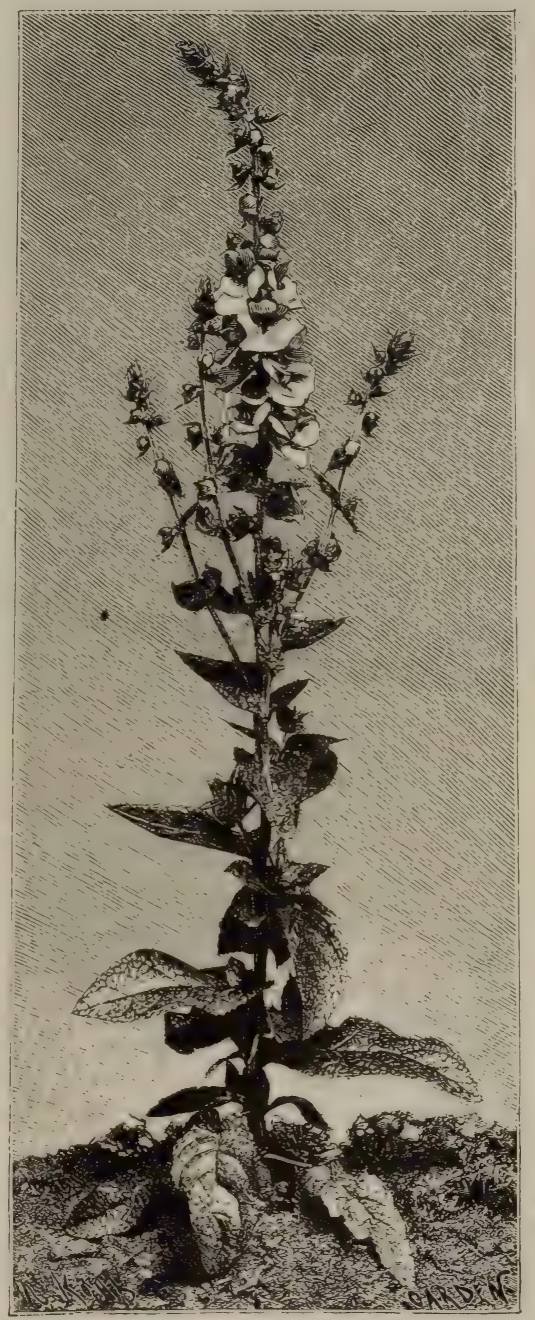

CELsia CRETICA (CRETAN MULLEin).

\section{Celandine (Chelidonium).}

Celandine, Lesser (Ficaria).

Celastrus scandens (Staff Vine).-A shrubby climber, a native of North America. Valuable solely for its rapid twining growth, which is excellent for trailing over trellis-work, arbours, etc. It is also beautiful when allowed to spread on a lawn or to run over other shrubs and 
trees to a height of 12 or $15 \mathrm{ft}$. The flowers are inconspicuous, and the fruits orange-red, like those of the Spindle Tree.

Celosia (Cockscomb).--Indian annuals of the Amaranth family. They are generally too tender for the open air, though we have occasionally seen the dwarf and tall varieties used with fine effect in bold groups. For this purpose they should be sown in pans in March and kept near the glass to prevent the seedlings being drawn. As soon as they are large enough to handle, they should be pricked off into small pots, grown on fast in gentle heat until the crowns are formed, planted out in June in rich soil, and liberally supplied with water. They will continue in good condition for a long time.

Celsia cretica.-A plant of the Figwort family. Once seldom seen away from the houses or pits of botanic gardens ; now, grown freely, it is distinct and handsome, with rich yellow flowers and massive polished yellow buds. Treated as an annual, and well grown in good soil, it is stout and effective. Candia, N. Africa.

Cenia turbinata.-Low-growing halfhardy annuals of the Composite Order, from the Cape. The white and yellow varieties are sometimes grown, but are not ornamental.

Centaurea (Knapreed).-A very large genus, a great number inhabiting Southern and Middle Europe, some being good garden plants. Most are hardy. Some of the southern species require the greenhouse in winter, but make free growth out-of-doors in summer, and are freely used for their distinct form and silvery foliage. As to the flowers, the most valuable is the corn-flower (C. Cyanus), which as a market-flower has merits possessed by few, and by no other hardy annual.

C. argentea has elegant silvery Fernlike leaves, compact, and when planted out or plunged in pots has a good effect either as a bedding-plant or for conservatory decoration; for bedding it must be plunged and partly starved to bring out its whiteness. Plumosa is an excellent variety.

C. babylonica.-A few of the Centaureas might be used among hardy fine-leaved plants, and the most distinct and remarkable is the silvery-leaved $\mathrm{C}$. babylonica. This is quite hardy, and when planted in good ground it sends up strong shoots with yellow flowers to a height of Io or $12 \mathrm{ft}$. The bloom, which continues from July to September, is less attractive than the leaves, but the plant is at all times picturesque. In groups or in rough or undulating parts

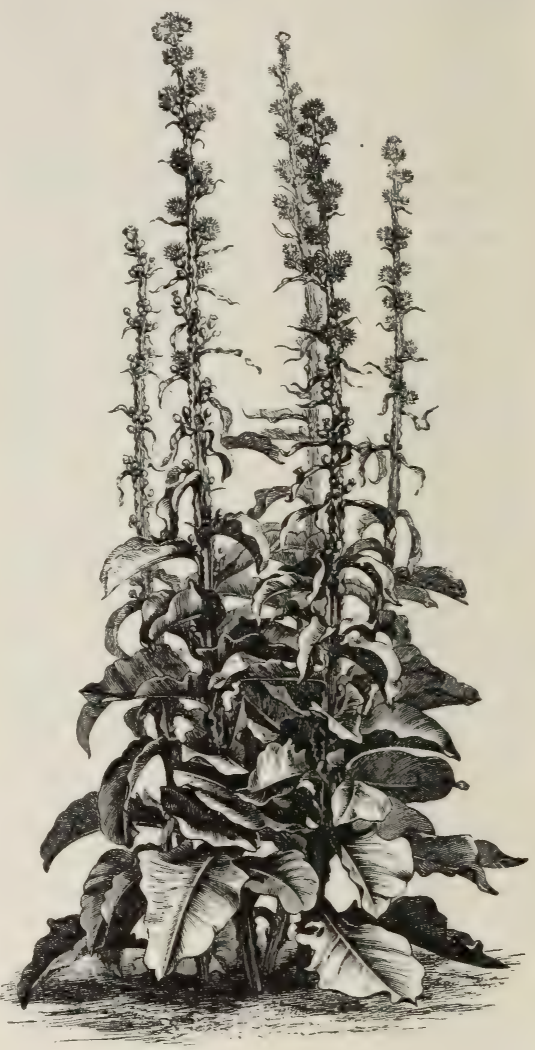

CENTAUREA BABYLONICA.

of pleasure-grounds it has a very fine effect. Suited for association with the tallest plants. A free sandy loam suits it best. Seed. Levant.

C. Clementei.-This fine silver-grayleaved plant forms a companion to the Acanthuses, whose deep green enhances the peculiar beauty of the Centaurea. It is preferable to the Artichoke, which is sometimes recommended as an early gray-leaved plant, as it is of better habit and retains its foliage throughout the season. Small plants from seed are most serviceable for edging sub-tropical or other beds, and when too large for that purpose, they may be transferred to shrubbery or mixed borders, or planted out singly on Grass. The blossoms are best picked off, as they detract from the beauty of the plant.

C. Cyanus (Corn-flower).-A beautiful native flower, which deserves a place in 
every garden. It is an annual of very easy culture ; in fact, it sows itself. The young plants stand our hardest winters, and flower better grown thus than if sown with the annuals in spring. The spring plants are weaker and shorter than the autumn or summerraised ones, attaining a height of $2 \mathrm{ft}$. In Prussia this plant is called Kaiser Blume, and is a great favourite. The typical colour is a beautiful blue, but there are white and purplish forms. The many garden varieties range through white, rose, sky-blue, striped, to dark purple, the delicate tints of which are most attractive. They are all much esteemed in the flower market, the long wiry stems being so manageable. The plants will flourish in almost any soil or position, but best, perhaps, in strong soil.

C. dealbata.-A very hardy perennial with graceful and somewhat silvery leaves, 15 to 18 in. high. Flowers in summer; flowers rosecoloured. Caucasus. Borders. Division.

C. gymnocarpa.-A half-shrubby plant from the south of Europe, nearly $2 \mathrm{ft}$. high, with hard, branching, bushy stems, and elegantly-cut arching leaves, covered with short whitishsatiny down. A variety (C. plumosa) has leaves much more divided and not so white. This plant is somewhat hardier than C. ragusina, but both require greenhouse treatment in winter, same soil, positions, and treatment as C. ragusina. Useful as it is for edging or bedding, it is when grown in fine single specimens that its beauty is most seen.

C. macrocephala (Great Golden Knapweed). - A strong plant from 4 to $5 \mathrm{ft}$. high, with a great golden head of bloom. In the back part of a herbaceous border, in semi-wild nooks and corners, or where herbaceous plants must compete with the roots of trees and shrubs, this robust and vigorous species deserves a place as the largest and most effective of all the yellow Centaureas. In deep rich soils it forms an effective mass, and when cut the flower-heads are very effective with other flowers, or even with their own leaves when alone in a vessel.

C. montana (Mountain Knapreed).A handsome border plant, I to $2 \frac{1}{2} \mathrm{ft}$. high, with slightly cottony leaves, and flowers resembling those of the Cornflower (C. Cyanus). There is a white and a red variety in cultivation. Europe. Borders, margins of shrubberies, or the wild garden in any soil.
This species is somewhat coarse in borders, and scarcely worth a place therein, but grows anywhere, and, when cut, its flowers are pretty. They are

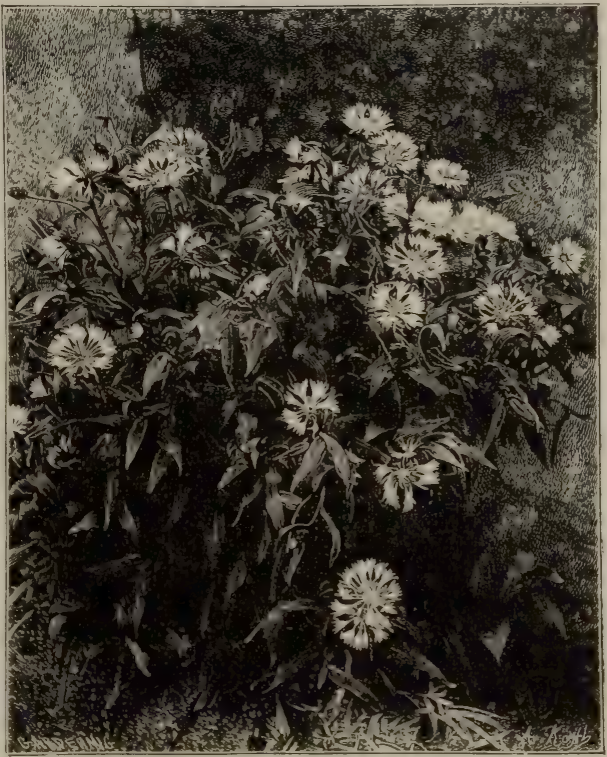

CENTAUREA MONTANA (MOUNTAIN KNAPWEED).

grown by market-gardeners for their flowers, which are larger than those of the Corn-flower (C. Cyanus). Division.

C. moschata (Sweet Sultan).-A valuable old annual, well deserving a place if only for cut flowers. There are two shades-delicate purple and creamy white. The first produces the finest flowers; but both are valuable during summer and winter. They are somewhat "miffy" in growth until well established, and are fastidious as to soil. Aphides are very partial to the young seedlings, and unless the pests are quickly cleared off, the plants soon dwindle away. The first essential is a calcareous soil, and any soil deficient in lime should have lime rubble worked into it. The best time to sow is about the middle of April, and the position should be open and sunny. Sow the seed where the plants are intended to remain, as they are very impatient of being transplanted. After the seedlings are up they should be thinned out early, leaving three plants in each patch, and giving them a distance of $\mathrm{I} \mathrm{ft}$. each. Water them when necessary. They are now to a large extent grown for market. 
The plants attain a height of somewhat over I ft. Persia. Syn., Amberboa.J. R.

C. ragusina.-A favourite silveryleaved plant, tender, but strong out-ofdoors in summer and autumn. For toning down glaring colours nothing could be finer. Solitary plants look well in the centres of small circles and surrounded by any bright colour. On large groundworks of scarlet, purple, or blue, an elevated plant placed here and there breaks up the monotony, and greatly enhances the effect of the outlying colours. Wherever any vivid or intense colour appears this plant should never be far away. The pale silvery foliage of isolated plants judiciously dotted on lawns of bright green Grass and amongst dwarf dusky-leaved shrubs has also a good effect. C. ragusina is never injured by wet, and its robust compact habit prevents the wind from tarnishing it. It thrives in the coldest situation throughout the summer. Its propagation is often attended with indifferent results. It is, however, as easy as that of Zonal Pelargoniums, and the plants may be as successfully rooted. When taking cuttings, they should not be cut away, but pulled off with a heel so as to have a hard base. Small firm shoots should be preferred to large ones. In taking them the knife should be used as little as possible. Each cutting should be put singly into a small $2 \frac{1}{2}$-in. pot filled with a mixture of loam, leaf-mould, and sand, and placed in a cold frame. One good watering is sufficient until they are rooted; and if the weather is excessively damp, the lights may be drawn over them, and tilted up back and front ; otherwise they may remain fully exposed. Treated in this manner I have rooted a batch of 2000 without losing twenty. Autumn is the best time to propagate them. They will fill their pots with roots in three weeks, and, if there is plenty of house room, they will make all the better plants by being shifted into 4-in. pots, where they will grow a little in autumn, and be strong for bedding out next year. A cold frame from which frost can be excluded is suitable for their winter quarters. The leaves should be kept dry, as they are rather liable to damp during the short days. Every opportunity should be taken for giving them air. They also winter well in an airy vinery or greenhouse. Old plants are sometimes lifted and kept over the winter. Where large plants are required this is a sure means of obtaining them ; but for ordinary bedding purposes autumn-struck cuttings are the best. Syn., C. candidissima.J. M.

C. ragusina compacta.-This is more compact in habit and shorter in leaf than C. ragusina. It is not so easily increased from cuttings, but produces seeds much more freely, and although the seedlings from them are not all of the same habit, they are easily classified as to size. Cuttings put in in March root freely, and make good plants by May. Place those kept for stock in a greenhouse, with a temperature of about $55^{\circ} \mathrm{Fahr}$. in February, and, as soon as they make a few leaves, nip out the points. This will induce them to throw out a number of young shoots, which, in a sandy soil on a brisk bottom heat, will emit roots in about ten days. Care must be taken not to water over the leaves, and the soil must not be allowed to get dry at the bottom.

C. rutæfolia.-A hardy perennial $2 \mathrm{ft}$. high, with branching stems amply clothed with deeply pinnatifid foliage, the entire plant being covered with a dense white tomentum, as in C. ragusina. It is, however, of freer growth than that species, increasing in size through the summer till checked by the cold of autumn. The flower-heads are pure white, about onehalf the size of those of C. ragusina, but much more abundant. The plant derives its ornamental value from the whiteness of its foliage, which suffers less from rain than that of the species previously named. It succeeds in any soil, but its growth is more compact in rather dry soils or in rock-garden.-W. $\mathrm{T}$.

C. suaveolens (Yellow Sweet Sultan)Syn., Amberboa odorata.-A desirable citron-yellow hardy annual and favourite border flower, thriving best in light dry soil ; should be sown and treated like C. moschata. Sow in beds in April with flowers grown for cutting, raising one batch in frames, and sowing another in the open air in light rich earth where it is to remain.

C. uniflora.-The flower-heads, previous to opening, look like withered balls, for each of the scales is terminated by a dark brown feather-like point; and as these develop, they lie down close upon the head, and appear to enclose it in a net. The stems rise 6 to 15 in. high, each bearing a solitary flower of lilac-rose, 2 in. or more across. C. uniflora is distinct and curious, grows freely in well-drained and sandy soil, and merits a place in the rockgarden or in borders.

Centauridium Drummondi.-A showy 
half-hardy annual Composite from Texas, from $2 \frac{1}{2}$ to $3 \mathrm{ft}$. high, and flowering from July to September. It should be sown in a frame on slight heat in April, and planted out in May. It has large citronyellow flowers, much resembling those of Centaurea. = Xanthisma texanum.

Centaury (Erythrea).

Centranthus macrosiphon is a hardy annual with pretty rose-coloured flowers. It is useful for the rock-garden or flower border. It may be sown in September and pricked off into pots for winter for transplanting in spring. It may be sown again in the open ground in March and April, the seedlings being thinned out about I ft. apart. There are several varieties-white, red, and two-coloured, besides a dwarf variety (pygmæus).

C. ruber (Red Valerian).-A handsome hardy border plant, and an old inhabitant

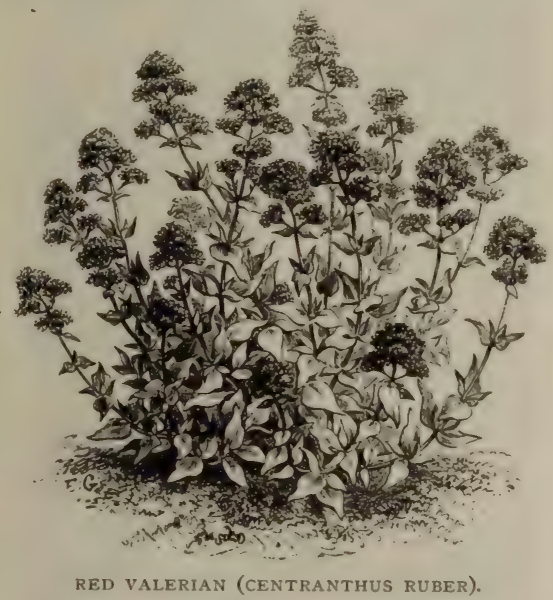

of British gardens. It belongs to the Valerian family and comes from the Mediterranean. There are two or three varieties - white, purple, and red or crimson. It has stout erect stems, rather woody at the base, which terminate in bold clusters of numerous small flowers. It begins to bloom in June, and continues through the summer. It requires only ordinary garden soil, and occasional lifting and cutting in, without which it is apt to become weak and to die out after a few years. It grows well on the crumbling walls of an old ruin, and is useful for a dry rock-garden, and rocky or stony banks. Propagated by seeds, by division, and by cuttings of side shoots in autumn under a hand-glass.

Cephalanthera. - A small genus of Orchids, of which two or three are natives, but none are worth cultivating.
Cephalaria.-Plants of the Scabious family, of large coarse growth, and only suitable for the wild garden. Their

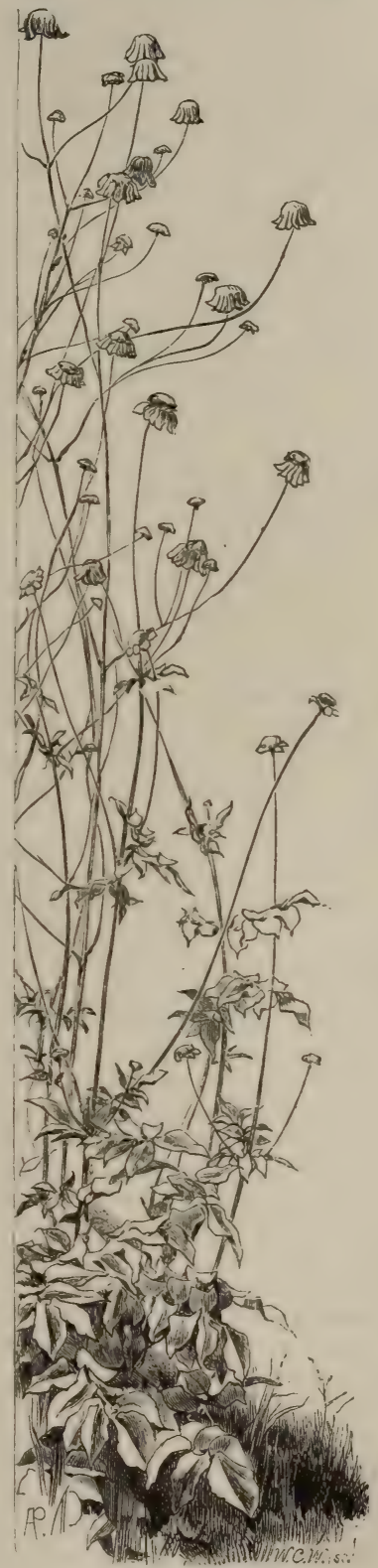

CEPHALARIA PROCERA.

handsome large flowers are, however, desirable for cutting from, and for this purpose a plant might occupy a place in the rougher parts of the garden. The 
best species are C. tatarica and C. procera, with white or yellowish flowers like a Scabious ; of easy culture.

Cerastium (Mouse-car Chickaved). A numerous genus of the Chickweed family, containing few garden plants of value in proportion to its number.

C. alpinum.-An interesting British plant, found on the Scottish mountains, and more sparsely on those of England and Wales. Dwarf, seldom more than 2 in. high, with leaves clothed with a dewy-looking silky down, which cause a singularly shaggy appearance. It bears large white flowers in early summer. It is at all times a pretty and distinct-looking object on those parts of the rock-garden that come near the eye. It is not, like the common garden species, fitted for forming edgings. Readily increased by division, cuttings, or seeds.

C. Biebersteini.-A very silvery species. Useful for the same purposes, and propagated and cultivated with the same facility as C. tomentosum, with which it is closely allied. It was once expected to surpass the common kind in utility, but this it has failed to do. A very good plant for borders or rough rock or rootwork, and, being seen seldomer than the common one, deserves a little more attention, and a better position in the mixed border or the lower and rougher parts of the rock-garden. Higher mountains of Tauria, flowering in early summer.

C. grandiflorum.-Less downy and silvery than the following, producing in early summer pure white flowers in great abundance. A fine plant for the front margin of a mixed border, or for the rougher parts of the rock-garden, but only to be associated with other strong and fast-growing things, as it spreads so quickly as to overrun and injure delicate and tiny plants if placed near them. Hungary and neighbouring countries, on dry hills and mountains.

C. tomentosum (Snow in Summer).Now used in almost every garden for forming compact silvery edgings to flower-beds and borders. Its hardiness, power of bearing clipping and mutilation, and great facility of propagation make it worth all the attention it receives. It is also very useful as a border plant, and for rootwork or the rough rock-garden, but is too common for a place on a small or choice rock-garden that might be devoted to some of the many beautiful alpine plants which are rarely seen. Mountains in the south of Europe, flowering freely in early summer. Those mentioned are all the kinds worth growing, except in botanical and unusually extensive collections.

Cerasus (Cherry). - Our lawns and shrubberies owe so much of their early summer beauty to the Cherries, that these must be ranked among the best flowering trees we have. The most beautiful for lawns and shrubberies are the double-flowered Cherries, as they endure longer in flower than the single forms. The finest is $\mathrm{C}$. serrulata, a Chinese species recognised

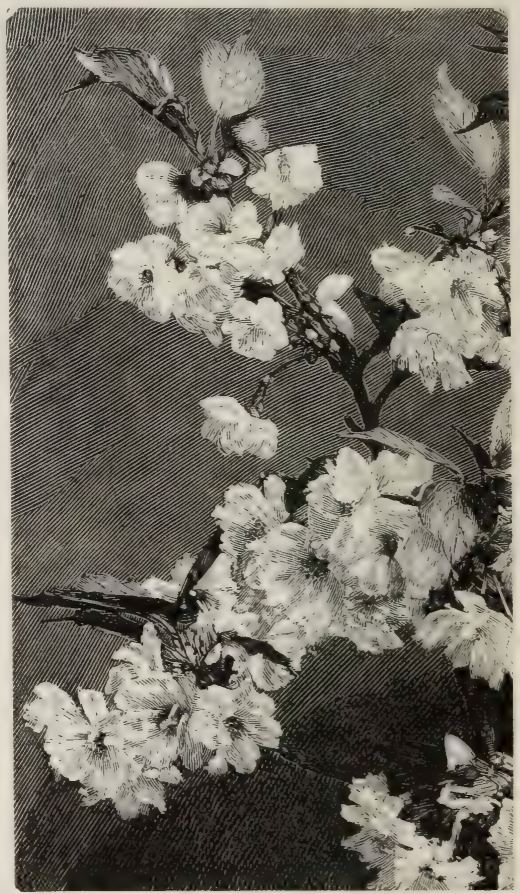

CHERRY FLOWERS (CERASUS WATERERI).

at a glance by its long rigid branches, which invariably spread in an ascending direction, and rarely have a central leader. The flowers are very double, like rosettes, white, and suffused with a delicate pink, and are produced in clusters completely wreathing the branches. C. Sieboldi is synonymous with this species, and that known as Waterer's double-flowered Cherry is very similar to, if not identical with it. C. Juliana is another very beautiful doubleflowered Cherry, with large rosette-like blossoms of a delicate blush pink. It is known as St. Julian's Cherry. The double forms of the common Cherry, C. Caproniana and C. Avium, are handsome, and are both known under the name 
multiplex. In both varieties the flowers are very double and of pure white. The earliest to bloom is C. Avium multiplex, and this is quickly followed by $C$. Caproniana multiplex, which is known also as ranunculiflora. The names of the various double Cherries are so much confused that one can never be sure of obtaining the correct sort by asking for it under a particular name. The best way is to choose it when in flower.

The single-flowered Cherries are not so numerous in nurseries, as the demand for them is not great. An indispensable tree, because of its graceful habit of growth, is C. Mahaleb, and in May the profusion of its white flower-clusters makes it highly attractive. The weeping variety (pendula) is one of the most elegant of deciduous trees, and is preferable to the original. The All Saints' Cherry is a graceful lawn tree, and interesting because it flowers from spring to autumn, and carries blossom and ripe fruit at the same time. In some years it flowers again in autumn. The graceful natural growth of the dwarf C. Chamæcerasus and $\mathrm{C}$. depressa renders them useful for the margins of shrub groups or for associating with bold rocks. The Bird Cherries, of which our native C. Padus is the type, are valuable ornamental trees of large growth. Where the Bird Cherry does not grow naturally, it is quite handsome enough for a lawn tree, or for shrubberies. Still finer are the North American Bird Cherries, C. virginiana and $C$. serotina, both large deciduous trees, of regular form and with dense heads. Their flowers are in long clusters, like those of our own Bird Cherry, but are produced later and last longer, especially those of C. serotina, which is the finer of the two kinds, being hardier and more vigorous. The common evergreen Laurel (C. Laurocerasus) and the Portugal Laurel (C. lusitanica) cannot be strictly called flowering shrubs, though when in flower and fruit they are beautiful.

Cercis (Judas Tree). - Of the three different kinds of Judas Tree in gardens, the commonest and the most beautiful is C. siliquastrum from South Europe, which for nearly 300 years has been a favourite in English gardens. It is of low stature, and when old makes a picturesque head, usually about $15 \mathrm{ft}$. in height. It succeeds in most soils, but prefers a light deep loam. There are several varieties, differing chiefly in the colour of the flowers. There is a white (alba), a deep pink (carnea), besides a form with variegated leaves (variegata), but this is not recommended. It is of slow growth, and though young specimens flower profusely, only very old ones show the picturesque growth of the tree.

Cerinthe (Honeyzort). - A small genus of the Borage family, of which there are two or three interesting plants. C. aspera, probably the best species, produces abundance of yellow flowers, the tube of which is black at the base. In general habit it closely agrees with the other species, but the seed is somewhat larger. C. minor is curved and branching, and the flower-stems arch over considerably, so that at the apex of the stem the delicate yellow tube-shaped bloom is entirely hidden by the long and closelyimbricated pale green leaves with which the stem is furnished. C. retorta is by far the best and most beautiful variety of the genus. These species are half-hardy annuals, requiring to be sown in early spring and in frames, and afterwards to be planted out in good soil. They are, however, not likely to be much in favour owing to their quiet colours. Natives of Greece, but pretty general in Italy and other countries of Southern Europe.

Ceterach officinarum.-A distinct and beautiful little native Fern, admirably suited for rock or alpine gardens, as it thrives best when planted between the chinks of rocks or stone walls. It is a Fern that, unlike most varieties, dislikes a confined damp position; hence it can be planted in the most exposed places with good effect, and, with a little careful attention to its simple requirements at the outset, with almost certain success. The chinks and crevices should be filled with a mixture of sandy peat and pounded limestone. It might be associated with some of the little flowering Sedums, and various other plants for walls and stony places.

Chænostoma.-A small genus of the Figwort family, natives of the Cape. They are naturally perennial, but in the open air must be treated as half-hardy annuals. C. fastigiatum is the prettiest. It is from 6 to 9 in. high, forming a dense compact tuft, and produces an abundance of small pinkish, and sometimes white, blossoms. It is a neat annual for the front margins of borders. The seeds should be sown in warm frames in spring or in August, when the seedlings require to be wintered in a pit. Flowers from June to November.

Chamæbatia foliolosa (Tarweed).-A little shrubby plant of the Rose family, remarkable for the Fern-like beauty of its leaves. The flowers are white and some- 
thing like those of a Bramble. It grows about I ft. high, forming a dense spreading tuft, and covering the ground in California, its native country. It has not proved hardy in our climate, but I have seen it growing in mountain districts often covered with snow, and believe it to be worth trial on the rock-garden in the milder part of the country.

Chamædorea.-Graceful Mexican palms, with slender stems, resembling bamboos, seldom more than 15 or $20 \mathrm{ft}$. high, and I or 2 in. thick, surmounted by tufts of eight or nine graceful leaves, nearly $8 \mathrm{ft}$. long. Among the best are C. elatior, C. elegans, and C. Ernesti-Augusti. These handsome palms may, with advantage, be placed in the open air in early summer, in sunny sheltered nooks, and taken in at the end of September. Their elegant heads fit them for placing here and there among groups of fine-leaved plants, or among masses of cannas, etc., though obviously their open-air use must be very limited.

Chamælirium luteum (Blazing Star). -A North American plant of the Lily family, but unimportant for the garden. It has unattractive yellowish flowers.

Chamæpeuce (Fish-bone Thistle).Spiny-leaved plants allied to the Thistle, valuable for the flower garden, as their foliage is distinct and handsome. There are two kinds in cultivation - C. diacantha and Cassabonæ. C. diacantha has foliage of shining green, marking with silvery lines, and the spines are ivory white. C. Cassabonæ has deep green white-veined leaves with brown spines. Both kinds grow in compact rosette-like masses about 9 in. high, till the second year, when they produce their thistle-like flowers, and the flower-stems grow 2 to $3 \mathrm{ft}$. high. They require light well-drained soil and a warm position, and should seldom be watered. As the stems are not produced until the second year, the radical rosettes of the first year may be advantageously used for edgings, or the margins of groups, for which their light green silver-veined leaves are very suitable, or they may fill a vacant place in the mixed border. Seed sown in February and carefully attended to will furnish good plants by May, but the best for immediate effect are those sown in a border in the open ground in September, potted up carefully, and given greenhouse treatment during winter.

Chamærops. - Handsome palms remarkable for hardiness, and, if judiciously used, capable of good and distinct effects in the garden.

C. Fortunei (The Chusan Palm).-A most valuable Palm, often confounded with C. excelsa. It is, however, stouter, and has a more profuse matted network of fibres round the bases of the leaves and crown; the segments of the leaves are much broader, and the leaf-stalks shorter and stouter, being from I to $2 \mathrm{ft}$. long, and quite unarmed. It grows $12 \mathrm{ft}$. or more high, and has a handsome spreading head of fan-like leaves, slit into segments about half-way down. It is perfectly hardy. A plant in the garden at Osborne has stood out for many winters and attained a considerable height. C. Fortunei is also placed out at Kew, though protected in winter. On the water-side of the high mound in the Royal Botanic Gardens, Regent's Park, it is in even better health than at Kew, though it has had no protection; and severe frosts have not hurt it. If small plants are procured, grow them on freely for a year or two in the greenhouse, and then turn them out in April, spreading the roots a little and giving them a deep loamy soil. Plant in a sheltered place, so that the leaves may not be injured by winds when they get large. A gentle hollow, or among shrubs on the sides of some sheltered glade, is the best place. The establishment of the Palm among our monotonous shrubbery and garden vegetation is worth a little trouble, and the precautions indicated are sufficient. C. humilis is also hardy-at least on sandy soil.

Chamomile (Anthemis nobilis).

Chaste Tree (Vitex Agmus-castus).

Checkered Lily (Fritillaria Meleagris).

Cheddar Pink (Dianthus casius).

Cheiranthus (Wallflower).-Beautiful cruciferous plants made familiar by the favourite Wallflower (C. Cheiri), which is almost the only species grown in gardens, as other well-known plants that bear the name of Cheiranthus belong to the genus Erysimum. The Wallflower is a native of Southern Europe, growing on old walls, in quarries, and on sea-cliffs. It loves a wall better than any garden ; it grows coarsely in garden soil, but forms a dwarf enduring bush on an old wall if planted in mortar, and grows even on walls quite new. No variety is unworthy of cultivation ; but the choice old double kinds - the double yellow, double purple, double orange, dark, etc.,-are worthy of a place among the finest border plants, being highly ornamental, and endeared to us by many associations. These are the varieties most worthy of a place on dry stony banks near the rock-garden, and also on old ruins, on which the common kind is likely to find a home for itself. The fine mixed "German" kinds - so 
easily raised from seed-are also worthy of ruins and stony places.

W ALLFLOWERS are classed thus: Single biennials, double biennials, and double perennials. Of these the first and last are well known; the second, of Continental origin, are grown almost, if not entirely, from imported seed. The single biennial yellow flowers, and specially suitable for spring bedding. It is easily recognised by its dwarf growth, pale green foliage, and pale flower-buds. The Golden Yellow -or, as it has been misnamed, Tom Thumb Yellow-is as robust and tall as the crimson kinds, and produces in great abundance masses of rich orange-yellow

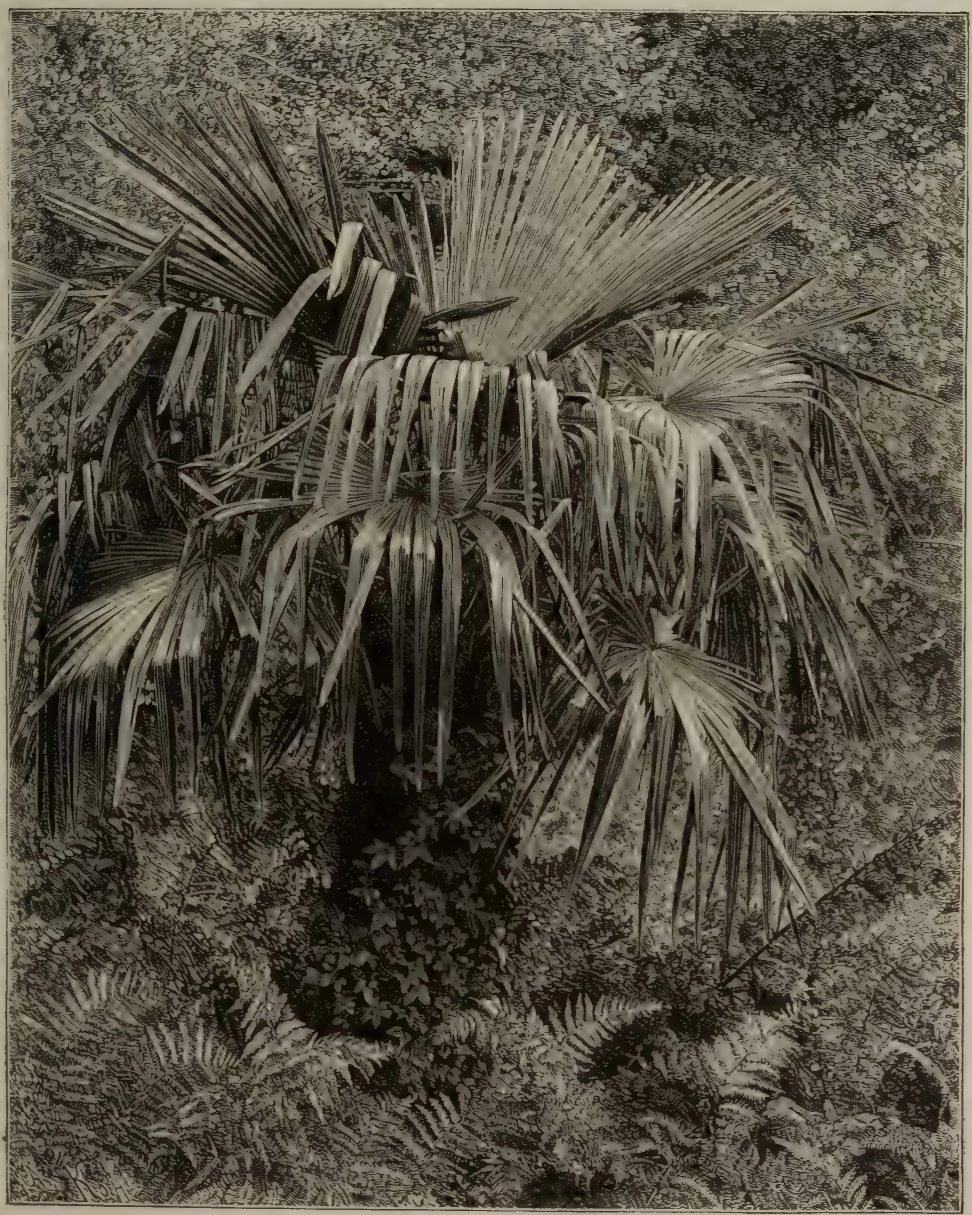

CHAMIEROPS FORTUNEI IN A SURREY GARDEN.

section is the most popular, and our best strains of it are unequalled for richness of colouring and sweetness of perfume. The superb dark crimson-marked kinds grown around London need no description, and can be bought in the seed trade under the designations of Young's Bloodred, Harbinger, and Saunders' Dark, all good strains. The Belvoir Castle Yellow is a close compact kind, with bright bloom. This is a grand kind and well worth the attention of marketgrowers. In country districts the common single Wallflower is usually a compound of all these, and therefore deficient in that rich and effective colouring so peculiar to good pure strains of the single Wallflower. The double biennials are remarkable for the variety of their colours and their stout woodiness of habit; in- 
deed, in these respects they resemble a distinct species, but probably this is due to their hybrid character.

The double perennials familiar to us are the yellow, dark crimson, red, and dwarf yellow. The yellow is most common, and a beautiful clear-coloured kind it is, a great favourite with cottagers, who propagate it by putting in slips after their peculiar and usually successful fashion about the time the plants are in flower. It can be propagated freely by means of slips put in under hand-lights in sharp sandy soil, and will produce plants capable of flowering the next spring. The other kinds are amenable to the same mode of propagation, the most common being the red, an intermediate form resembling the tall yellow, but having a shade of colour neither striking nor pleasing. The old dark crimson is now almost extinct; in colour the flowers are almost black and very striking. The dwarf yellow has flowers of a dull, almost buff tint, but is fairly well adapted for pot culture. The Raby Castle is valuable and sturdy.

INCREASE AND CULTURE-Many persons sow seed too late,-in June and July instead of April and May. If dry weather follows close on the sowing, or after the plants have grown 2 or 3 in., they receive a check, and, instead of being dwarf, vigorous, and bushy, they are thin and poor. The winter will sometimes injure the Wallflower severely, especially when very severe frost follows close on heavy rains, and the stronger and better rooted the plants are, the more likely are they to stand the weather. The plants used for filling beds should have been once transplanted at least, because the moving induces them to throw out fibry roots near the surface, and they can be lifted with soil adhering to them. When the Wallflower is allowed to grow where it is sown, a strong taproot is formed, which strikes deep into the soil, and but few surface roots are put forth. In transplanting from the seed-beds, it is well to pinch off the taproot, and thereby induce fibry roots. The great advantage of fibry roots is that the plants can be transplanted at any time during the winter when the weather is open. Mr. Ingram, of Belvoir Castle gardens, used to take precautions to induce fibry roots previous to transplantation, and would transplant into trenches and lines in soil, with slates or bricks buried a little in the soil to prevent the formation of the tap-roots, as he found that plants with taproots and with little fibre stood badly.
In London market-gardens, where the Wallflower is invariably well cultivated, seed is sown in the open ground early in February; the young plants are put out into their permanent quarters in May, and by Christmas, if the winter be mild, they produce bloom, and are so large that they could not be covered by a bushel basket. For spring bedding, they should be sown early and planted out about 12 in. apart in some spare ground. These plants will lift with good balls of earth early in winter, and in spring will produce superb masses of bloom. Some market-growers sow seed late in summer, allow the young plants to remain in the seed-bed all the winter, plant out in March, and, if the season be favourable, reap a good crop of flowers all through the next winter.

Save seeds from plants with the best branching habit and the darkest blossoms. When the plants are in flower, place a stake by each possessing those qualities, so as to mark it. Allow these to remain undisturbed until the seed is ripe; they may then be pulled up, roots and all, and housed in a dry place until a convenient season for threshing out the seed. Cuttings of the double kinds may be put in as soon as they can be got after the plants go out of bloom. Put them in firm sandy soil under a hand-light, and, when struck, plant them out. Cuttings put in in August, September, or October strike freely without any protection, in a shady border, or in pots or boxes of sandy soil.

Besides the Wallflower there are several perennial species of doubtful hardiness, such as C. arbuscula and mutabilis, natives of a warmer climate, which therefore, though pretty pot plants, cannot be recommended for open-air culture. Besides these there are various hybrids, such as C. Sermoneri, Delahaynus, Bocconi, and Marshalli, which is the finest of the hybrid kinds said to have been raised between C. Cheiri and Erysimum ochroleucum. It is compact, from 9 in. to I ft. high, and has many bright orange-scented blossoms. It is a brilliant ornament of the border, and a good plant for massing in spring bedding ; few plants indeed, so hardy and easy to cultivate, equal it in showy beauty from April till July.

All these perennials prefer dry and slightly elevated positions during winter, but a cool moist soil in summer. Propagation is necessarily by cuttings, but top dressing with fine soil often induces the summer wood to root freely, and then in autumn the production of a good stock is 
easy. Cuttings should be taken off just as the plants are passing out of flower, put in under a hand-light, and treated as Pink pipings until rooted.

C. alpinus, ochroleucus, and others belong to Erysimum, which see.

Chelidonium (Celandine). - The best species of these Poppyworts is the native C. majus, a showy plant with yellow flowers, and desirable for rough places, where little else will grow. The variety laciniatum, with deeply-cut Fern-like foliage, is elegant, and there is another variety with double flowers, and another with variegated foliage. The Japanese Celandine (Stylophorum diphyllum) is known as C. japonicum. The native kinds are of easy culture, but not fit for a place in the garden proper.

Chelone (Turtle-head). - A small North American genus nearly allied to the Pentstemon. The two species in cultivation are handsome border plants, flowering in late summer and in autumn. C. Lyoni grows from 2 to $3 \mathrm{ft}$. high, forms a dense mass of stems, with deep green foliage, and from July to September bears plentifully dense clusters of showy pink blossoms. C. obliqua is taller and more slender. It is similar to the preceding, but the colour of the typical form is a richer pink. There is also a white-flowered variety. C. obliqua generally flowers earlier than C. Lyoni, and continues till the autumn. Both are of easy culture, thriving in open borders of good deep soil, and readily propagated by seeds, cuttings, or division of the roots. These plants, though bearing pretty flowers, and though free in growth, do not possess any particular garden value. The more striking and graceful Pentstemon barbatus is also known as C. barbata.

Chenopodium (Goosefoot). - A large genus consisting chiefly of weeds. Few are of garden value, except C. Atriplicis, a vigorous Chinese annual, with erect reddish stem, slightiy branched, over 3 $\mathrm{ft}$. in height, and with its young shoots and leaves covered with a rosy-violet powder. This plant is ornamental in foliage, and well adapted for grouping with plants of fine foliage. C. scoparium (Belvedere) is a curious and graceful annual plant.

Cherry (Ccrasus).

Cherry-pie (Heliotropium).

Chickweed (Stellarea).

Chickweed Mouse-ear (Cerastium).

Chimaphila (Pipsisserwa). - Smal shrubby plants, natives of the dry woods of North America. There are in cultiva- tion two species somewhat difficult to cultivate. C. maculata (Spotted Wintergreen) has small leatheryleaves variegated with white. It is 3 to $6 \mathrm{in}$. high, and is very suitable for a half-shady and mossy, but not wet, place in the rock-garden, and associates well with such plants as the dwarf Andromedas and the Pyrolas. and succeeds best in very sandy leaf-soil. C. umbellata, with glossy unspotted leaves and somewhat larger reddish flowers, is also suited for such positions. Both are rare in cultivation and very seldom well grown. They flower in summer, and are increased by careful division. We believe the difficulty lies chiefly in the fact that a good patch is rarely if ever imported, or if imported it becomes divided to such an extent that its life is endangered, and it has no strength for vigorous growth.-N.

Chimonanthus Fragrans (Winter Sweet) is a lovely shrub which in our country requires a wall. It flowers in December and January ; beautiful, and of delicious fragrance. It was introduced from Japan more than I2O years ago. The flowers appearing upon young wood after the leaves have fallen, are of a brownish-yellow, marked with purple inside ; and are so precious for gathering for the house that every warm garden or house-wall should be adorned with the shrub that is least afraid of our winter's cold and skies of gloom. The best variety is grandiflora, its flowers being longer and more open. This shrub is not quite so accommodating as the first-named, and does best on a wall with a southern or western aspect, where it may grow higher. The blossoms coming on the previous season's growth, pruning should be performed when the flowering is over; then the shoots that have blossomed should be cut back to the main branches, and when growth recommences, abundance of young shoots will flower the following season, and these afterwards should be pruned away in the same manner. A few twigs with blooms upon them placed in a room last a long time, and diffuse their pleasant fragrance. No harm is done by cutting these twigs, as in the ordinary course they would be pruned away after their flowers have faded. Layering in autumn.

Chionanthus (Fringe Tree).-A beautiful small tree, brought to England from North America a century ago. In some old English gardens there are fine specimens, but it is rarely met with in modern gardens. Fully grown in this country, it is generally a dense bush about Io ft. high, but in its native 
country it is said to make quite a tree. In early summer it bears long clusters of white flowers, with petals long and narrow like a fringe. A newer species is the Chinese, C. retusus, which is not so pretty, though its flowers are white and fringy.

Chionodoxa (Glory of the Snow).-A small genus allied to Puschkinia and Scilla, which may include two or three species found in the high mountains of Western Anatolia and Crete, but not distinguishable by any well-marked characters.

C. Luciliæ.-This and C. Forbesi are considered forms of one plant, which, without doubt, is among the loveliest of hardy flowers. Its habit is similar to the

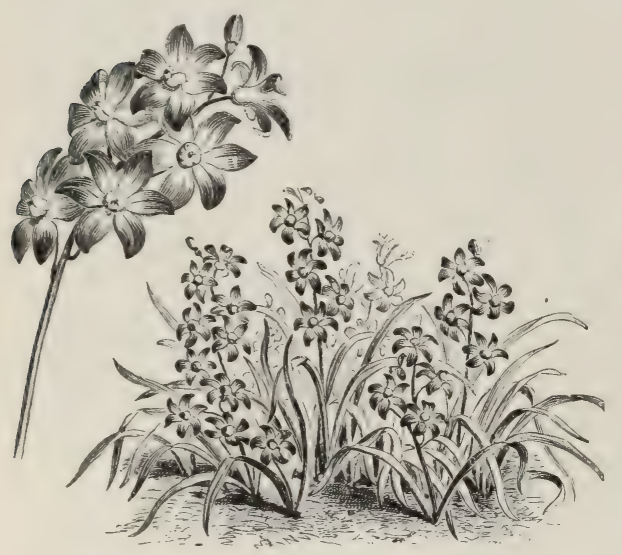

SNOW GLORY (CHIONODOXA).

two-leaved Squill (Scilla bifolia), as it rarely develops more than a pair of leaves. The blossoms, five to ten in number, are on gracefully arching stems, from 4 to $8 \mathrm{in}$. high, and are nearly $\mathrm{I}$ in. across, star-like in form, and of a beautiful clear blue outside, gradually merging into pure white in the centre, like Nemophila insignis, but even brighter. There is a pure white variety, which, however, is very rare even in its native habitat. C. Lucilix has recently proved perfectly hardy during severe seasons, and, as in cultivation it readily produces seed, we may hope soon to see it widely distributed, and taking a place amongst early springflowering bulbs. It flowers in the end of March and the beginning of April. It succeeds well in any ordinary garden soil not too heavy and damp. It may be propagated by seed or by separating the bulblets from the parent bulbs in autumn, and replanting them in fresh soil. Nymph Dagh and of other moun- tainous districts near Smyrna, at elevations of from $3000 \mathrm{ft}$. to $4300 \mathrm{ft}$., whence in 1877 it was introduced by Mr. Maw of Broseley.

C. nana.-This pretty little species has been long in cultivation, under the name of Puschkinia scilloides. Its slender flower-stems bear from four to ten delicate azure-blue blossoms. It flowers in March and April, according to the season. It is a native of the hilly woods of the Caucasus (Armenia), and is perfectly hardy, thriving in light rich soil in an open sunny situation. C. cretica is not in cultivation. It is similar to the last, and would probably be as hardy.

C. sardensis is nearly allied to C. Luciliæ. The flowers are much smaller. They are of a lovely blue, deeper than C. Luciliæ, from which it is quite distinct in effect. It is also quite hardy and free with me, even in poor soils, and I have naturalised it in the grass as well. Mount Sardis.

Chlora perfoliata (Yellow-wort).-A pretty slender native plant abundant in some places by the seaside. It is about I ft. high, having grayish-green leaves, and bright yellow flowers as large as a shilling. There is a large flowered variety called grandiflora which is less common. C. perfoliata delights in stiff rich soil with plenty of moisture. It is only of biennial duration, but freely yields seeds, which either sow themselves, or may be sown as soon as ripe or in early spring. Not of high garden value, though beautiful when wild, and it does not readily submit to cultivation.

Chlorogalum Pomeridianum (Soap Plant). - A Liliaceous bulb, native of California. It is not by any means showy, the flowers being small and white on slender branching stems a yard or so in height. It requires warm dry soil to thrive well in the open border. Bulblets or seeds. A botanic garden plant if grown at all.

Choisya ternata (Mexican Orangeflower).-Although not thoroughly hardy, yet in the south and west, however, it may be planted in the open air, with the shelter of a wall and a southern or western aspect. It is fast-growing. The flowers are a lovely contrast to the deep rich green foliage, which is abundant and good. It is easily increased by cuttings inserted in warmth in spring and summer. The illustration shows it as a garden wall shrub in Devonshire, a county that can grow many beautiful things that in more northern districts are known only as glass-house plants. It is not only in the extreme south and west that one may 
succeed with it. In thrives in many Sussex gardens. In Major Gaisford's garden at Offington, near Worthing, it flowers twice a year, in spring and autumn. At colder Wakehurst it has reached the top of a wall $6 \mathrm{ft}$. high, and at Lydhurst there are several thriving

bush exposed on every side, and should receive protection during winter. Those who intend to try it in the open air should plant it in a sunny place, so that the growth may be ripened up before winter. Plants with well-ripened wood never get cut back in the same way as those in a "green"

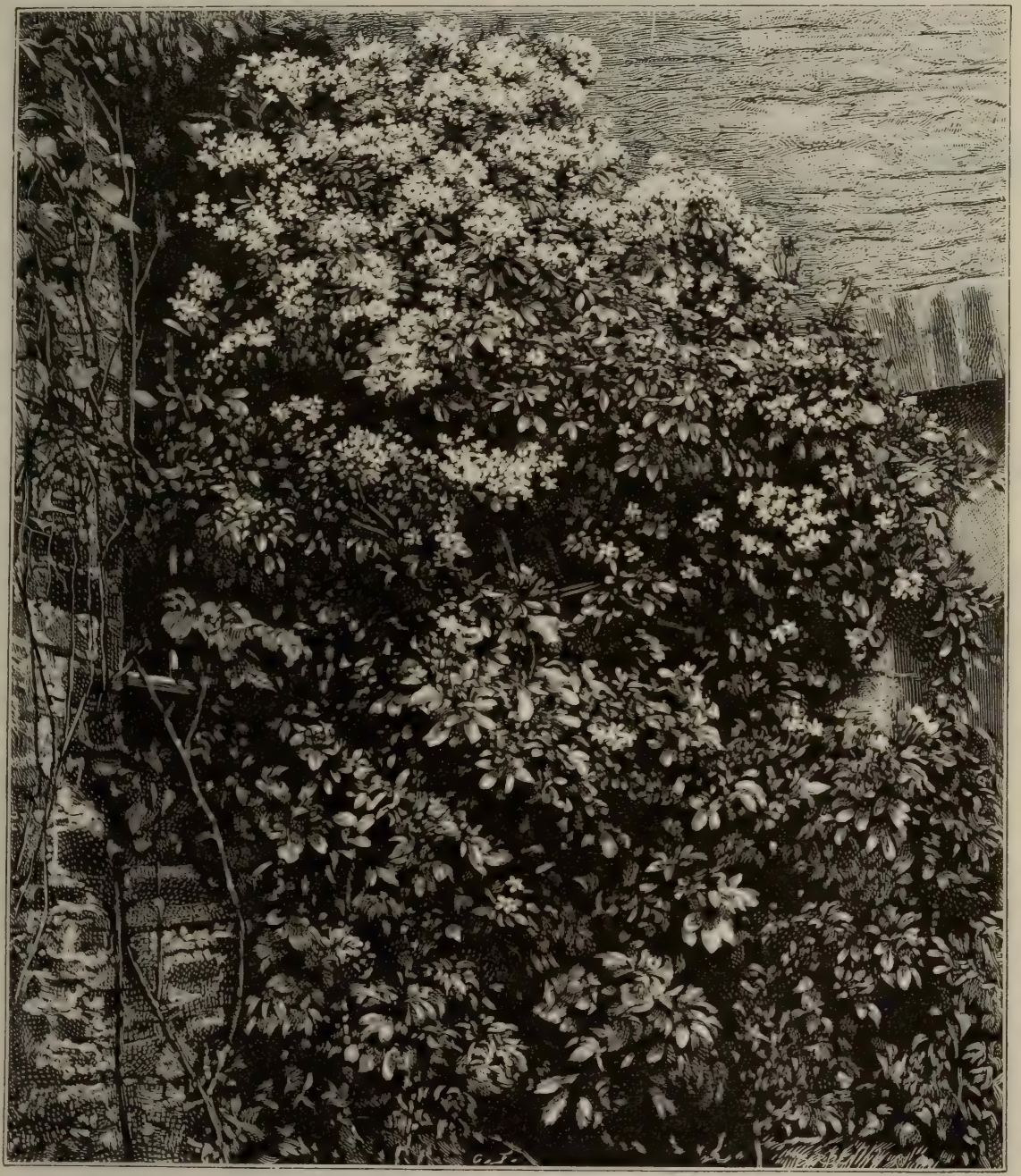

CHOISYA TERNATA (MEXICAN ORANGE-FLOWER) IN DEVON GARDEN,

specimens both in the open and against a wall. Those fortunate enough to have a bush near the house will know the pleasure of the strong, but not too powerful, Hawthorn-like fragrance. Bushes like this can only be expected in the southern and western counties, and outside these it should be planted against a wall, not as a condition. It was brought to England about 1825 from Mexico, where it grows freely on the hillsides, forming a delightful picture during the flowering season.

Christmas Rose (Helleborus niger).

Chrysanthemum.-An extensive genus of perennials and annuals, a few of which are valuable garden plants. Besides those 
mentioned below, there are in cultivation several kinds, such as C. arcticum absinthifolium, which have little claim for general culture.

C. arcticum.-A good plant for the rock-garden. It is about a foot high, and flowers abundantly all the summer. Flowers white tinged with lilac or rose. C. Zawardskii of Continental gardens is very nearly allied.

C. carinatum (Tricolor Chrysanthemum).-A showy annual from N. Africa,

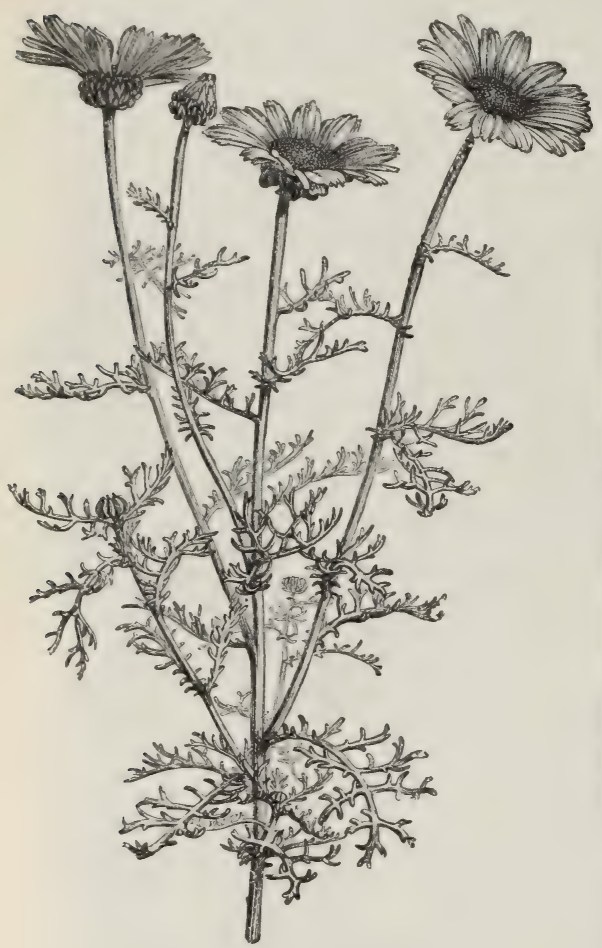

CHRYSANTHEMUM TRICOLOR.

which varies much in cultivation and is valuable, if only for its yield of flowers for cutting. There are double white and yellow forms; and the showy ones known as C. Burridgeanum, raised from seeds by Mr. Burridge, a seed-grower in Suffolk. C. Burridgeanum is compact, and bears large golden yellow flowers, with a dark purplish-brown zone, a purple eye or disc, and bright and well-defined colours. Dunnett's varieties of the same plant are also good. C. carinatum is propagated from seeds sown in April or early in May in open beds or borders where the plants are to flower; or they may be sown earlier in pans or boxes of light rich earth in a pit or frame, from which they can be transplanted after all danger from frost is over. Planted singly in rich soil in an open and sunny position, C. carinatum forms one of the most beautiful of conposite-flowered annuals, and well deserves culture. It generally blooms in August, and lasts in beauty several months, or until cut down by frost.

C. coronarium (Crown Daisy).- A bold and handsome annual 2 to $3 \mathrm{ft}$. high in its wild form in N. Africa, and, in cultivation, breaking into a number of forms, few of them, to my thinking, so fine as the single wild flower, pale yellow or buff. Treat it as a half-hardy annual, and sow in good ground in April or early in May. In warm soil and mild winters one might hope to have autumn-sown plants survive, in which case there would be a stronger and better bloom.

C. frutescens (Paris Daisy, Marguerite). - A vigorous half-hardy plant; in one

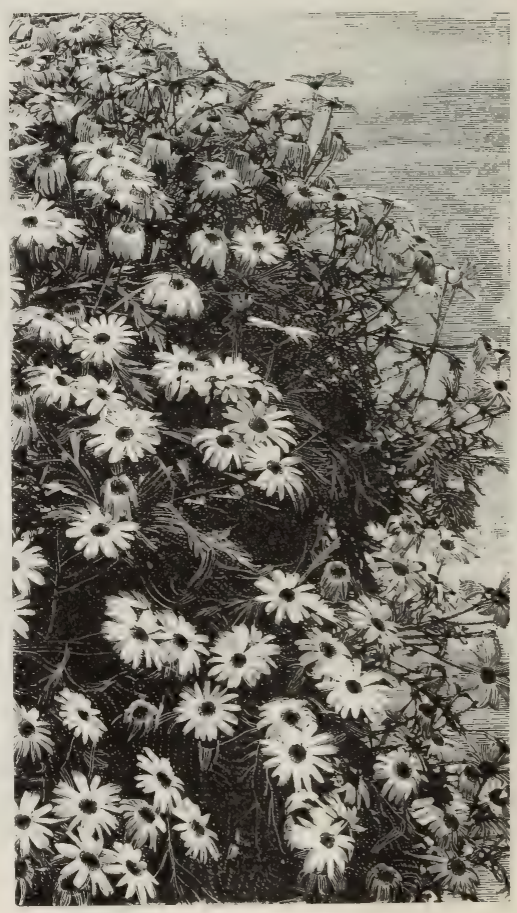

CHRYSANTHEMUM FRUTESCENS (PARTS DAISY).

season forming, when planted out, bushes $3 \mathrm{ft}$. in height and as much in diameter. It is much branched, and very symmetrical; the foliage is pinnate, fleshy, and glaucous; the flowers are large, pure white, with a yellow centre, and produced 
in great profusion from June until cut down by frost. Extensively grown on the Continent for summer bedding and for pots. It is a fine Daisy-like plant, and several forms or allies are also valuable, such as the yellow Etoile d'Or, Comtesse de Chambord, and C. frutescens aureum. These plants are of easy culture and propagation, being for the outdoor garden best treated as bedding plants and put out in May, though in certain sea-shore and favoured districts they survive the winter.

C. indicum (Common Chrysanthemum). - The numerous beautiful varieties of this species, so popular as pot plants in autumn, deserve to be more extensively grown in the open air, as many varieties are quite suited to the purpose, and add a wealth of beauty to the garden in October and November when little else is in bloom. The varieties for open-air culture must be well selected, but their culture is simple.

CUlTURE. - The Chrysanthemum is hardy, and will grow in almost any soil or situation. The varieties vary a good deal, and the treatment necessary for one is often unsuitable for another; for instance, the summer-flowering varieties are spoiled by exposure to hot sunshine, and succeed best in the north of England and Scotland; while the Pompones and the large flowering kinds require all the warmth that the south can furnish. As the climate of some parts of China is much warmer than ours, particularly in autumn (the thermometer often standing at $100^{\circ}$ Fahr. in the shade), a south or south-westerly aspect should be selected for a plantation, and the shade of trees or buildings avoided. In town gardens this is not always possible, but the nearer we approach these conditions, the greater our success. None, however, need despair, for, in spite of smoke and fog, some of the finest flowers at the autumn shows are grown in the small gardens and yards of densely-populated cities. Much, however, depends upon soil ; the Chrysanthemum is a voracious feeder; and where vigorous foliage and fine flowers are desired, the soil cannot be too good. If practicable, it should consist of equal parts of fresh loam, rotten manure, leafmould, and sand. These, well mixed in the autumn, and allowed to remain in ridges during the winter, will be in condition to receive the plants in March or April. Many prefer autumn-made cuttings, and if the plants are intended for pot culture these are best, but for open-air culture strong suckers should be selected. Strong cuttings receive no check when planted, and in order to allow free circulation of air, the plants should stand at least $3 \mathrm{ft}$. apart. The same roots never produce fine flowers if left undisturbed for two seasons in succession. They should therefore be replanted every year towards the end of May. Strong stakes should be placed to each plant, and the main stem should be firmly secured thereto during the growing season, the laterals being neatly tied in their proper placesbut not too stiffly - and all unsightly branches removed. The beauty of the foliage and size of the flowers may be increased by the application of liquid manure during the summer months. Early in October disbudding should be commenced. The centre, or crown bud, if perfect, should be left, and all the others removed. One fine flower is preferable to many small ones.

VARIETIES.-The following varieties are good in habit, free-flowering, and well adapted for open-air culture :-

White.-Vesta, Mrs. Rundle, Virgin Queen, Eve, White Venus, Mrs. Haliburton, Beverley.

Red.-Cardinal Wiseman, Julie Lagravère, Prince Albert, Triomphe du Nord, Pio Nono, Jewess, Duc de Corregliano.

Yellow and Orange.-Aurea multiflora, Chevalier Domage, Golden Beverley, Jardin des Plantes, Sulphurea superba, Guernsey Nugget, Abbé Passaglia, John Salter.

Blush and Rose.-Belladonna, Ariadne, Hermine, Christine, Princess of Teck, Venus, Lady Talfourd, Lady Harding, Lady Slade.

Crimson-Purple.-Alma, Mr. Murray, Prince of Wales, Progne, Prince Alfred, Dr. Rozas, Lord Derby, Mulberry.

WALL CHRYSANTHEMUMS. - In many well-kept town gardens the eye is offended by unsightly brick walls, and one is often asked how to hide them. The answer is, train Chrysanthemums upon them; if well nailed in they take up little room and afford a pleasing background to the borders. Strong cuttings or suckers planted early in March at the base of the wall I ft. apart in soil similar to that just recommended will make rapid growth, and if they are kept neatly nailed in and all the side shoots removed as they appear, the plants will soon cover a wall of ordinary height. Liquid manure from time to time will strengthen them and improve their foliage, and if they are carefully disbudded in September, a grand show of large flowers will result. 
The blossoms can be effectually protected from wind and weather by nailing a 12 -in. board on the top of the wall, so as to form a coping. This, supported by a few poles in front, is all that is required, and, if practicable, a canvas covering fastened
Virgin Queen, Princess of Wales, White Venus.

Yellow and Orange.-Mr. G. Glenny, Guernsey Nugget, Jardin des Plantes, Golden Beverley, John Salter, General Slade, Nil Desperandum, Dr. Brock.

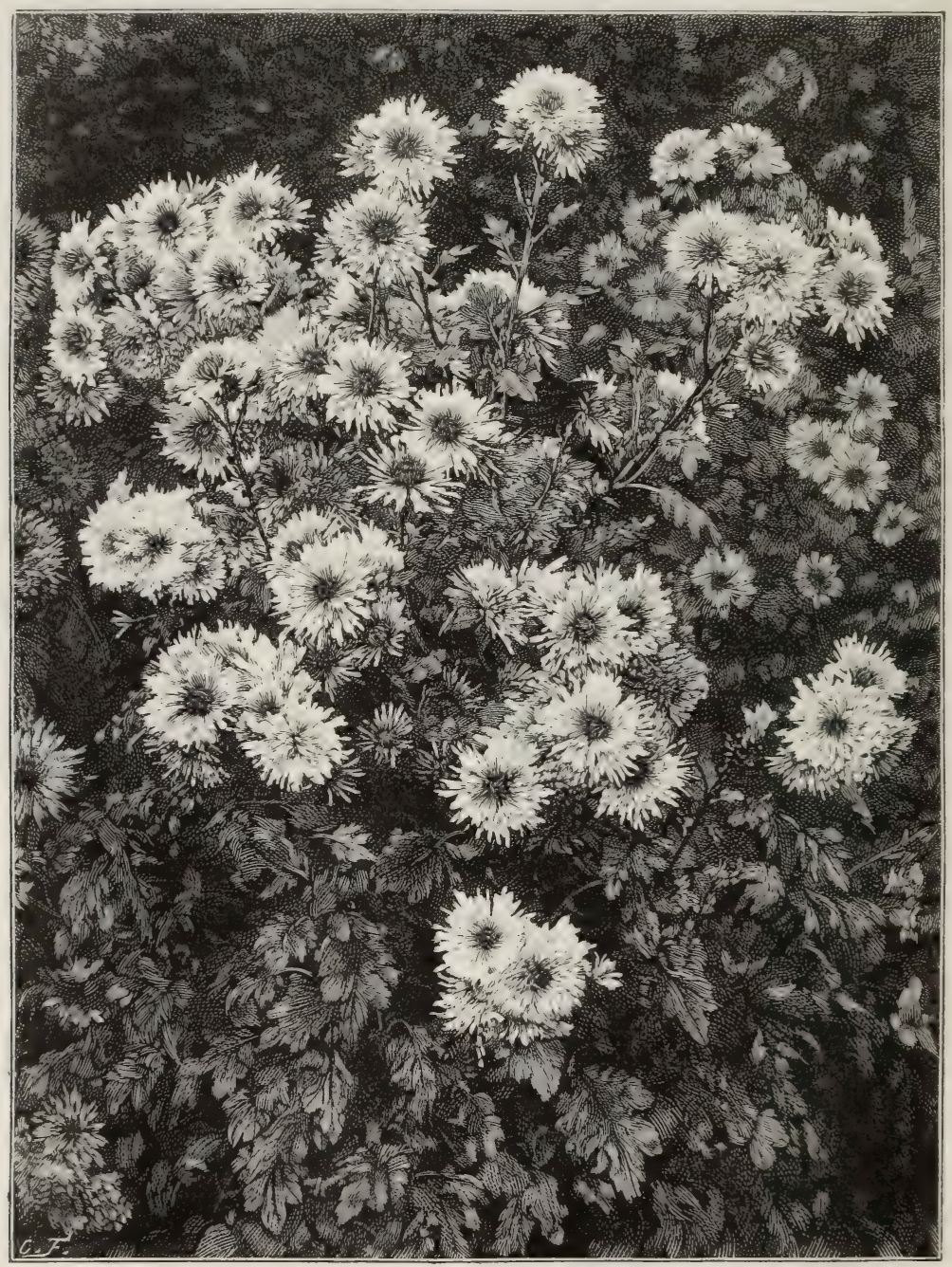

CHRYSANTHEMUM "COTTAGE PINK."

in front when the nights are cold will generally prove a sufficient protection; by these simple precautions the duration of the flowers will be greatly prolonged. The varieties named below are best for wall culture :-

White--Beverley, White Globe, White Queen of England, Vesta, Mrs. Rundle,
Blush and Rose.-Aimée Ferrière, Belladonna, Princess of Teck, Venus, Pink Perfection, Duchess of Manchester, Lady Harding, Lady Slade.

Crimson.-Prince of Wales, Prince Alfred, Lord Derby, Lady Talfourd, Alma, Progne, Aregena.

Red and Brown.-Triomphe du Nord, 
Prince Albert, Bernard Palissy, Mr. Brunlees, Julie Lagravère, Hercules, Sanguinea, Pio Nono.

POMPONES.-These require the same treatment as the large flowering varieties. They may be advantageously planted in front of tall kinds or in beds by themselves. If the latter, they should be planted in April. The roots should be about 12 in. apart, and the head or leader should be taken off when about 8 in. high, and all lateral branches encouraged. When sufficiently developed these should be pegged down like ordinary bedding plants, and this must be continued during the summer, all strong shoots being shortened or regulated to ensure an equal surface of bloom. Liquid manure may be given occasionally. Effect greatly depends on judicious arrangement of the colours. The following are all good free flowering kinds :-

White.-Mdlle. Marthe, Miss Talfourd, Argentine, White Trevenna, Cedo Nulli, Mme. Domage, Modèle.

Blush and Rose.-Adonis, Andromeda, Mme. Roussilon, Mrs. Dix, Hélène, Rose Trevenna, Trophée.

Red and Brown.-Bob, Brilliant, Miss Julia, Mustapha, Aureole, Firefly.

Yellow and Orange.-Aigle d'Or, DrinDrin, Mr. Astie, General Canrobert, Golden Cedo Nulli, Aurore Boreale, La Vogue.

Crimson.-Salomon, Duruflet, President Decaisne, Miranda, Crimson Perfection, James Forsyth.

SUMMER-FLOWERING KINDS.-This is a most important class, furnishing a number of beautiful varieties valuable for cutting, which enliven the borders when other hardy flowers are on the wane. They do not appear to advantage in open borders unless shaded from hot sunshine in August and September. They are very dwarf and of various shades, but for outdoor decoration in the South of England they are of little value. The climate of the north and of Scotland suits them admirably, and there they are invaluable when mixed with herbaceous plants or in ribbon borders. Their free habit and their profusion of brightlycoloured flowers render them very attractive. The following are worth a place in every garden :-

Early Pompones. - Nanum, white ; Mme. Dufoy, white; Souvenir d'un Ami, white; St. Mary, white; Chromatella, yellow ; Hendersoni, yellow ; Le Luxembourg, yellow; Mdme. Pecoul, rose; Adrastrus, rose; Delphine Cabouche, rose ; Frederick Pele, red; Scarlet Gem, red.
The Japanese varieties are too late for open-air culture.-A. S.

C. lacustre (Marsh Ox-eye Daisy) resembles the large Ox-eye Daisy of our pastures, but is much larger in every way. It is about $2 \mathrm{ft}$. high, and thus may be distinguished at a glance from Pyrethrum serotinum, a plant with flowers strikingly similar, but which is much taller, growing in a good soil from 6 to $8 \mathrm{ft}$. high. The Marsh Ox-eye Daisy is a stout perennial and fit for a large collection, but somewhat coarse for choice positions. Some may give it a place for its yield of cut flowers.

C. segetum (Corn Marigold).-A showy yellow native plant, as worthy of cultivation as many an exotic, and in certain cases worth growing for cutting. The flowers are yellow. Give it the treatment of a hardy annual, preferring autumnsown plants.

Chrysobactron Hookeri (Anthericum). Chrysocephalum.-Composite plants; of slight value for gardens.

Chrysocoma.-A small genus belonging to the Composite family; of little garden value.

Chrysopsis (Golden Aster).-North American plants of the Composite family, suitable mainly for botanical collections. C. Mariana is, however, worth cultivation.

Chrysurus (Lamarckia).

Cichorium Intybus (Chicory).- A wellknown native plant, from 2 to $5 \mathrm{ft}$. high, bearing in summer and autumn handsome bright blue flowers. It is worth introducing as a wild plant into localities where it is not native. It is a rampant grower, and will take care of itself under almost any conditions.

Cigar Plant (Cuphea platycentra).

Cimicifuga (Bugbane).-A genus of the Crowfoot Order, nearly allied to the Baneberry (Actæa). They are all tall herbaceous plants; one at least is very handsome and well worth cultivating. This is C. racemosa (Black Snakeroot), 3 to $8 \mathrm{ft}$. high, with feathery racemes of white blossoms I to $3 \mathrm{ft}$. long, which, being slender, droop gracefully. C. Serpentaria, a variety of the preceding, is also a handsome plant. Both are of easy culture in ordinary good garden soil, and make striking objects for the mixed shrubbery border, but are better as groups in the wild garden. Being strong and vigorous, they are well fitted for naturalising on the outskirts of woods, by woodland walks, and such places. Some have an odour which does not recommend them for the garden. North America.

Cineraria maritima. - A very hand- 
some bushy peremial with fincly-cut leaves, covered on the under side with silvery down. It bears in summer numerous heads of bright vellow Howers. If the effect of its foliage only is desired, the flowering stems should be pinched off on their first appearance. The plant then becomes more leafy and branching. On the margins of shrubberies, isolated on banks, or on the turf of the pleasureground, it would form an agreeable variety among the dark green subjects recommended for groups. It is also used with good effect for edgings to flower-
Roses (Helianthemums), the Rock Roses are among the most beautiful of shrubs. The hardiest is C. laurifolius, which can be grown as far north as Scotland. Next in point of hardiness are C. purpureus, C. ladaniferus, C. Clusi, C. monspeliensis, C. florentinus, C. salvifolius, C. crispus, C. hirsutus, C. creticus. All charming for warm banks and choice beds of dwarf shrubs. These are among the best, and in warm localities in the south they may be well grown on dry sunny banks facing directly south. When small, it is advisable to surround them

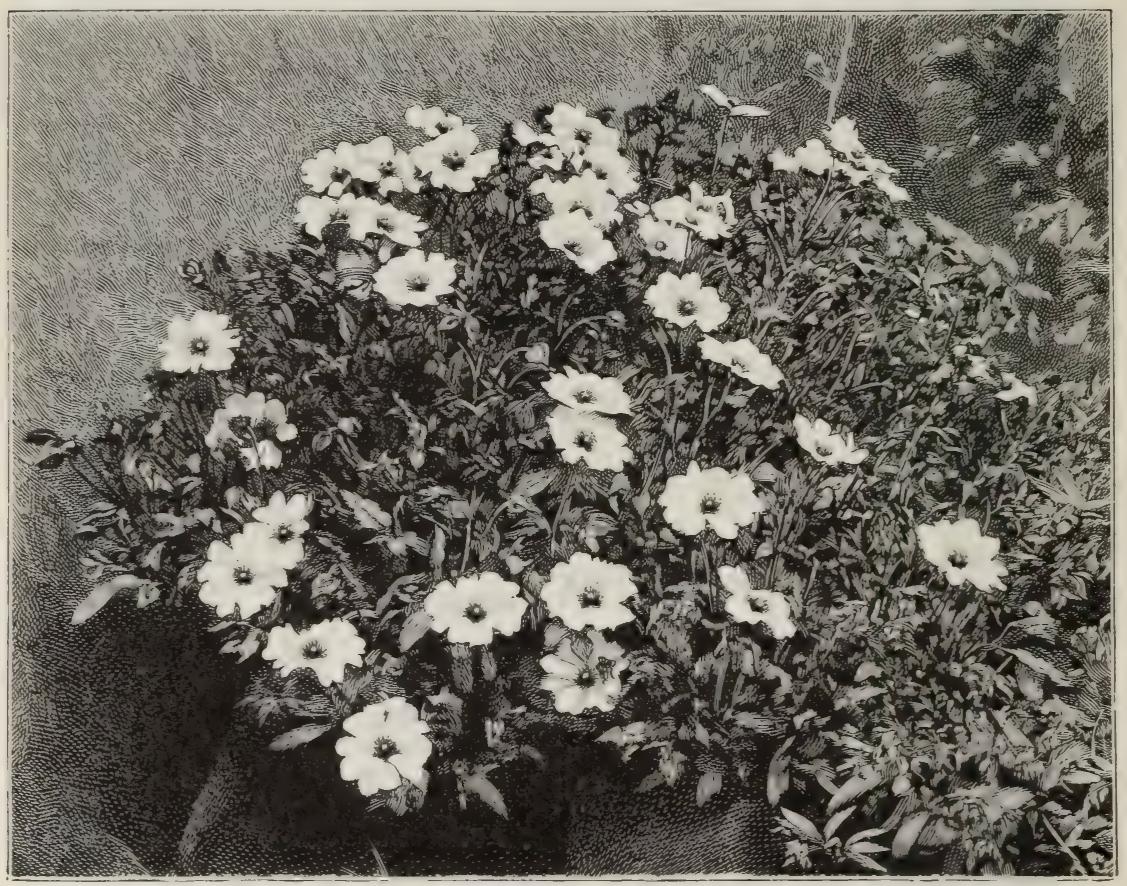

ROCK ROSE (CISTUS FLORENTINUS).

beds, but the superiority of the silvery Centaureas has lessened its value in this respect. The best way to increase it is from cuttings in spring, choosing the twiggy side shoots; but the quickest way to obtain plants is to sow seed in heat in February and transplant in the open in May. C. acanthifolia is a variety of C. maritima.

Cinna.-A small genus of Grasses of no ornamental value.

Cinquefoil (Potentilla).

Cirsium.-Thistle-like plants, few of which are fit for the garden proper.

Cistus (Rock Rose). - Like the Sun with large stones, to keep the roots moist before they pierce the bank. If in a compact mass, the plants may be readily protected by litter and mats during severe frosts, and certainly such a charming family of shrubs will repay any care and attention.

Cladium Mariscus.-A vigorous native fen plant, 2 to $6 \mathrm{ft}$. high. When in flower it is crowned with dense, close chestnutcoloured panicles, sometimes $3 \mathrm{ft}$. in length. The radical leaves are glaucous, rigid, and often $4 \mathrm{ft}$. long. Worthy of a place on the margin of water, near such subjects as Carex pendula or the Typhas. 
Cladrastis. - This name strictly includes the beautiful North American Yellowwood Tree (C. tinctoria), but as the common name in gardens for that tree is Virgilia lutea, it will be noticed under that name. The only other Cladrastis in cultivation is $\mathrm{C}$. amurensis, a shrub introduced a few years ago from the Amoor Valley, and known also under the name Maackia amurensis. In foliage it resembles the Yellow-wood, but it is of thicker texture, not so large, and of a duller green. In late summer it produces a plentiful crop of flowers, even when only a few feet high. The spikes are dense, the blossoms white, and inclined to yellow, and endure a long time. Small bushes flower freely. It is hardy.

Clarkia.-These Californian plants are among the prettiest of hardy annuals. They are robust, of easy culture, and flower profusely for a long time. There are two species from which the numerous varieties now in cultivation have been obtained. C. elegans, about $2 \mathrm{ft}$. high, erect, and much branched, bears long leafy racemes of flowers with undivided petals, varying from purple to pale red or a salmon colour. The principal varieties of this species have double flowers, and two-Purple King (deep purple) and Salmon Queen (salmon-pink) -have flowers produced freely on strong branching plants, and are very effective border flowers. The other species, C. pulchella, may be readily distinguished from the preceding by deeply-cut petals. It varies in height from about $\mathrm{I} \mathrm{ft}$. in the Tom Thumb sorts to $2 \mathrm{ft}$. It has magenta flowers normally, but there is every variation between deep purple and pure white. There are also several very pretty double-flowered forms of C. pulchella. There is also a very distinct variety called integripetala, from which have been obtained some beautiful varieties, and notably limbata and marginata, the former dark rose and white, the other pale rose and white. Altogether about a score of varieties are mentioned in seed lists, most of which are distinct from each other, and well worthy of culture.

CUlture.-All the varieties are suitable for borders; the dwarfer kinds, by their habit of growth, being well suited for sunny spots in the rock-garden or on the ridge of sloping banks. Their growth is much affected by the nature of the soil. Like all other hardy annuals, they may be sown either in autumn or spring. By sowing in the beginning of September the seedlings gain strength before the winter, and flower well in early spring. The first spring sowing should take place in the middle of March, when the plants would flower in July. Until about the middle of June other sowings may be made for flowering in September and October. The best soil is ordinary garden mould, not too rich or too dry.-G.

\section{Clary (Salvia Sclarea).}

Claytonia.-A small genus of the Purslane family, of which three species are pretty garden plants. C. caroliniana is a spreading dwarf species bearing in spring loose racemes of pretty rose flowers, and C. virginica (Spring Beauty) is a slender erect plant, with pink blossoms. Both are suitable for warm spots in the rock-garden in loamy soil, but C. sibirica, also a dwarf species with pink flowers, requires a damp peaty soil like an artificial bog. C. perfoliata and C. alsinoides are weeds in many localities.

Clematis (Virgin's Bower).-Although with few exceptions these are shrubby climbing plants, yet their use in the flower garden, often in a dwarf or frequently cut-down condition, is so frequent and important that they cannot be omitted. There are over a hundred species, mostly from cold or temperate climates. They are widespread, in Europe from Russia to Portugal and the Balearic Isles; in Asia from the Ural range to India and Java, and even to China and Japan. They show themselves in both Americas, in several Polynesian islands, and even in New Zealand. Thus they extend from pole to pole, from the sea-shores to the slopes of the highest mountains. So graceful is their habit, so bold and showy their flowers, that scarcely a species is without beauty. The earliestflowering hardy species commence unfolding their blossoms in April, and are succeeded by other species and varieties throughout the summer and autumn, some of them continuing in bloom up to Christmas in mild localities. In colour they present almost every shade and combination of red and blue, while pure scarlets and crimsons are not wanting. The lilac, pale blue, purple, mauve, claret, and violetpurple varieties are connected by every intermediate shade. There are also yellow species and varieties, and many pure white-flowered ones, the flowers varying from less than I to 8 or 9 in. in diameter. It is not only as climbers on trees or for covering walls, trellises, etc., that Clematises are useful. They trail or creep quite as well as they climb, and are also admirably suited for bedding, 
festooning, and other garden purposes. With all the wealth of variety in our gardens, Clematises were once not extensively planted; but about 1863 Mr. Jackman, of Woking, commenced hybridising them, employing C. Viticella and the largeflowered Japanese sorts. Among the earliest acquisitions were the beautiful C.

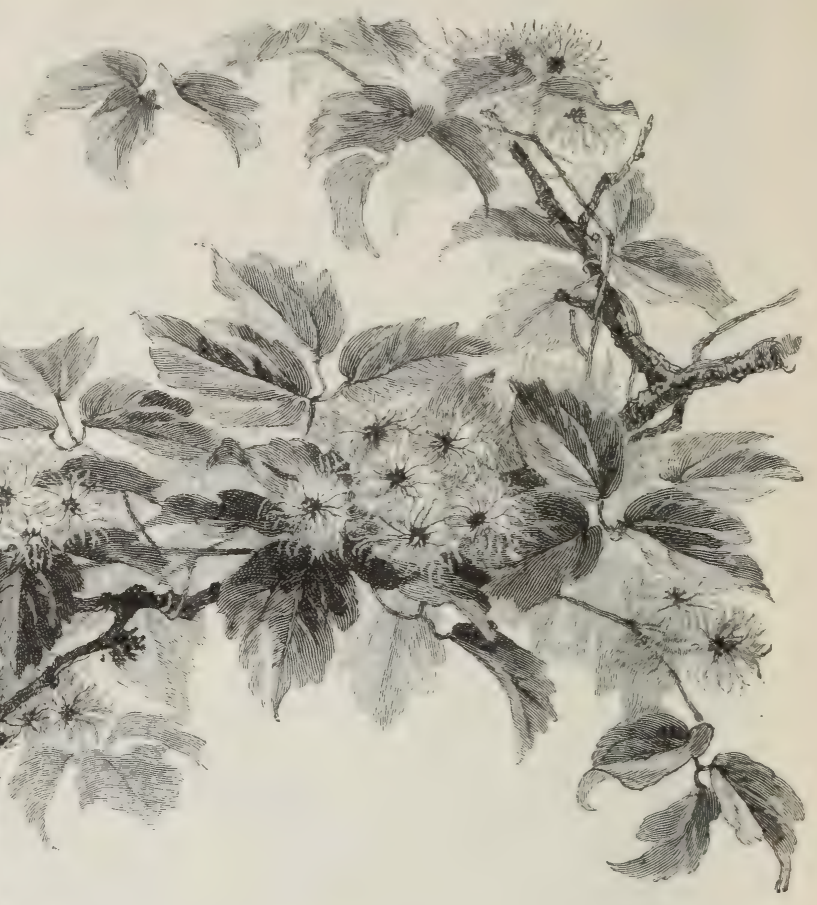

Jackmani and rubro-violacea, and since then other raisers have reared an almost endless variety. Special descriptive catalogues of varieties are now issued, and every year new varieties are sent out, so that intending purchasers should contrive to see, and make their own choice. The original largeflowered Japanese kinds are more or less tender, and in severe winters are often cut to the ground; but many of the hybridsJackmani, for example - will bear severe frosts. However, whether cut down by frost or knife, they will grow again in spring, and flower perhaps even more profusely. They never form very thick stems, and are not suitable for permanently covering large spaces, particularly where the height is considerable. To obtain their flowers in perfection the plants must be freely pruned. On the other hand, such species as C. Flammula, montana, and Vitalba, especially the last two, grow quickly to a great height or length. A few, such as C. erecta, tubulosa, and integrifolia, are herbaceous.

The sections into which this family may be grouped for garden use are well treated of in Moore and Jackman's "Clematis as a Garden Flower," which we quote.

The Montana, Patens, and Florida Types. - These sections include the earliest or spring-flowering divisions of the family. The majority of the species and varieties of which they consist come A wit. ct.mitis. into blossom naturally about May; but some few of them, such as C. calycina and its allies blossom from the commencement 
of the year onwards. These latter are best suited for planting against walls, in warm sheltered situations, where their opening flowers may in some degree be protected against inclement weather.

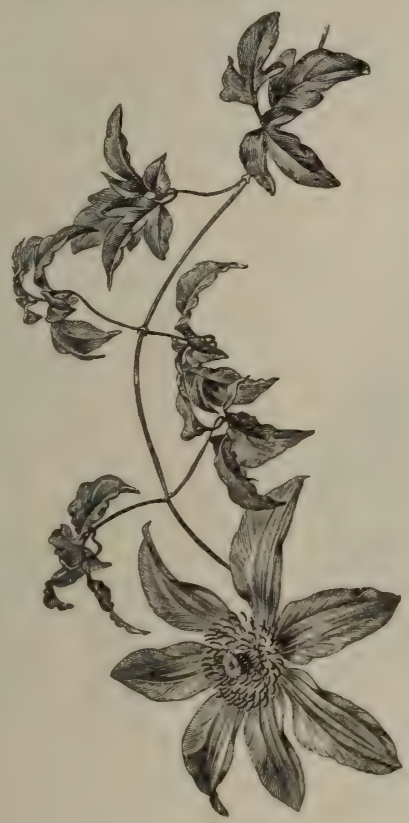

CLEMATIS PATENS.

The varieties of C. patens and C. florida (represented by C. Sieboldi, one of the same type) are perfectly suited for planting against walls or in corridors; and some of them make elegant earlyblooming beds, especially where their blossoms are thoroughly sheltered either naturally or artificially from severe spring frosts, which occasionally, though rarely, somewhat injure them. C. montana, also a spring or May bloomer, is vigorous and hardy, and specially suited for covering walls, trellises, or arbours, or, in fact, for any position where rapidity of growth is desired. These plants, especially those of the montana type, are not particular as to soil, but will grow in any good garden earth fairly enriched, efficiently drained, and maintained in a healthy state. Where it can be provided, a rich soil of a light loamy texture is the best for all these plants, especially if mixed with chalk or lime. Mulching, which consists in covering the surface of the soil for some little distance round the plants with half-rotten manure, is very beneficial. When growth commences in the spring the young shoots must be attended to, and trained around or against the supports provided for them. The weaker shoots may, if necessary to prevent entanglement, be cut away during the summer; but all the vigorous shoots for which there is space should be trained in, since it is these, when thoroughly developed and matured, which furnish the flowers for the ensuing year. The strong montana is a good verandah plant, and suited for rapidly covering bare spaces; but the less robust plants of the florida and patens types are better suited for training on walls or for furnishing corridors, or for any similar positions where their blossoms may be brought more closely into view. The pruning should take place in February or March, after the severe frosts of winter.

The GRaveolens TyPe.-This small group comprises a series of hardy fastgrowing species, which require scarcely any cultivation. They grow freely enough in any ordinary garden earth of sound texture and fairly drained, though many, probably most of them, prefer calcareous soil. They will scramble over trellises or thickets, or clamber up snaggy poles, or among the boughs of trees, and therefore may be employed in any position where a summer screen is wanted; but being deciduous they are not suited for winter screens. As to training, they make holdfasts of their leaf-stalks, and take care of themselves; and the natural growth thus made and thus disposed would, in most cases, be of a more picturesque character than would result from artificial training. When, however, they are planted near large trees, or at all within their influence, it is desirable, in order to promote vigorous and rapid growth, to mulch the soil during winter, forking in the manure about March. In such situations, too, drought may overtake the roots, since the trees will suck up much moisture, and in a greater or less degree keep off the rain. In dry weather, therefore, and especially until the plants become tolerably well established, watering should not be forgotten.

The LANUGinosa TyPe.-These plants are hardy and tolerably vigorous, and have enormous blossoms, so that liberal cultivation is an absolute necessity. They will, indeed, succeed in any good, sound, well-drained garden soil which is freely and annually manured, but would no doubt prefer a light mellow loam, and therefore in very light soils it would be a material benefit, in trenching up and preparing the ground before setting them 
out, to resort to the admixture of the best loam available. The more fertile the soil the less the manuring necessary, and vice versa ; but in any case a really wellenriched soil, either natural or artificial, should be secured if the full beauty of this race of the Clematis is to be developed.

C. lanuginosa and its varieties are well suited for conservatory walls or trellis-

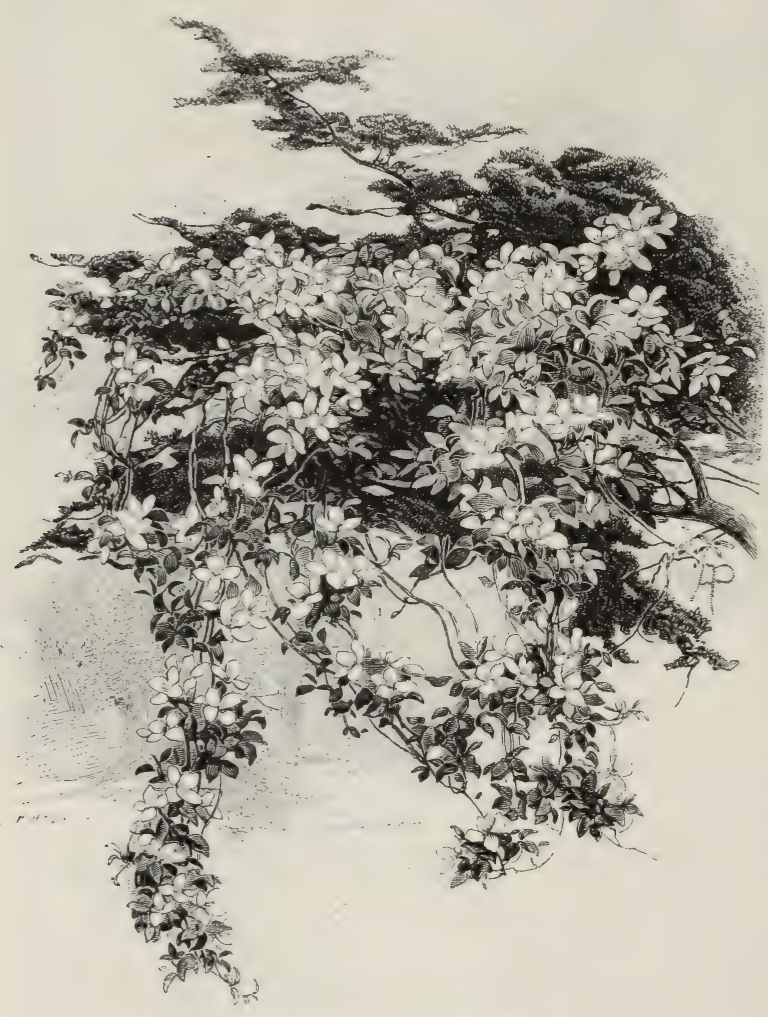

CLEMATIS MONTANA ON YEW.

work, whether the latter be put up in the form of a screen or a verandah, and also for poles or pyramids. In the case of poles and pyramids especially, they should be annually pruned down to about $3 \mathrm{ft}$. from the ground, to prevent their becoming lanky and bare of new shoots near the base, the tendency of the new growth being to develop itself with excessive vigour at the extremities. When thus cut rather low, so as to secure a supply of foliage near to the base, the beauty of the plants is much enhanced. The same remarks apply to those on walls and trellises, if they are required to cover a space; but it frequently happens that the lower part can be filled out by less aspiring subjects, and then it is as well to utilise the more rigorous growth towards the top. In any case the successional summer growths should be trained in so as to secure the later crops of blossoms, the habit in this race being to throw out a sprinkling of flowers at intervals till the frost comes to arrest further growth.

PRUNING.--From what has been said it will be evident that comparatively slight pruning is here required. The type itself and those varieties nearest to it in habit, indeed, die back almost sufficiently to render pruning unnecessary ; but where a mixture of blood has led to a more extended growth it will be necessary to remove the weak and illripened portions of the year-old wood. Under favourable conditions the plants will make an annual growth of 8 to $10 \mathrm{ft}$. in length, and of this the unripened extremities, together with the weak or superfluous shoots and the dead wood, are the only parts to be removed. This pruning is best done in February, after the severe winterfrosts, and before the plants burst out into new growth. We have said that these plants are hardy, and for all practical purposes they may be so regarded. They are, however, less robust than some of the allied groups, and hence, in their case, the mulching which has been recommended as an advantage to all may be looked upon as being rather more of necessity, provided they are where it is at all admissible. The annual feeding, by working in some halfdecayed manure during the early spring, should on no account be omitted, as the size and succession of the blossoms depend entirely upon the vigour kept up in the plants; but where mulching would be unsightly, a covering of some other material, such as the refuse of the fibre of the Cocoa-nut, would be a desirable substitute.

The Viticella and Jackmani Types. - These groups represent some of the hardiest as well as some of the noblest 
of the whole family. The severest winters do not materially injure them, and, from their wonderful fertility of flowers, the plants, in the late summer and the autumn, literally become masses of blossoms, which are successively and continuously renewed. In regard to soil, the same free, welldrained, deep, and well-enriched staple, which has been noted as suitable for the preceding groups, will be found equally suited for these. A friable loam is the best they can have; if the soil is less suitable in quality, it should at least be deep, so that the roots may penetrate freely. A loamy soil is the best, because the plants must have manure liberally supplied to them to keep up their strength; and, in a loamy staple, the fertilising properties of the manure are not liable to be dissipated, as in one which is poor and porous. When, however, the soil approaches this latter description, it is all the more necessary that manure should be abundantly applied. In the case of light soils, a good proportion of loam-made friable by frosts if at all heavy or clayey - should be incorporated to render it more holding; deep trenching should also be resorted to for the same purpose. Heavy soils should be ameliorated by the free intermixture of friable soil or of any sharp gritty material, the drainage being made efficient, and the soil well aerated before planting.

When the ground has been prepared, the plants may be put out in any open weather between the middle of September and the end of April. After planting, it is beneficial, though not absolutely necessary, to apply a mulching of a few inches of partially rotten manure ; this will protect the newlydisturbed roots and fertilise the ground. The varieties of these types of Clematis are essentially outdoor or border plants requiring abundance of root-space ; they may, indeed, be grown for exhibition, but, even then, they require liberal rootaccommodation and high feeding. To sum up, the Viticella and Jackmani types require to be grown in rich deep soil, to be manured freely every season, and to be planted out in the open ground, that their roots may have free pasturage.

These forms of Clematis flower on the vigorous summer shoots, and form dense masses of blossom. The object in pruning, therefore, should be to favour to the utmost the development of these vigorous young shoots, by cutting the summer growth back to within about 6 in. of the soil, early in the season as soon as the frosts have disfigured the plants, say about November. The mulching, which is then to be applied with a liberal hand, serves to prevent the soil from becoming 
indeed, and especially those of the true Jackmani type, producing a startling impression in consequence of the gorgeous masses of their rich Tirian hues. One of the most useful purposes to which these varieties could be put would be to drape a mural ruin or to cover an unsightly bank or slope. They grow in almost any situation if the soil is not absolutely destitute of food, or if the roots of other plants do not rob them of nutriment; and they require nothing but a few tree roots or rough branches for them to scramble over. Thus planted, a layer of manure worked in annually with the fork, and a supply of water in very dry weather, would secure a good result. Again, they rank among the noblest of ornaments for low walls, trellises, etc., to which they must be nailed or tied; but once firmly fixed, they should be allowed to fall down in rich picturesque masses. Probably, however, their simplest and grandest use would be to plant them on large masses of the rock-garden, giving them a good depth of rich, light, and sandy earth, and allowing their shoots to fall over the face of the rocks without any training or pruning. We shall find among the varieties of the Viticella and Jackmani types those kinds especially suited for bedding out for summer and autumn flowering.

NON-CLIMBING TYPES. - The nonclimbing species and varieties of Clematis consist of two small but distinct groups, the one herbaceous, the other sub-shrubby.

The herbaceous species thrive best in good, rich, deep, loamy soil, and, when well established, they form somewhat striking plants for the mixed border, though scarcely any of them stand in the front rank of herbaceous perennials. The single and double-flowered varieties of C. erecta and C. maritima are most ornamental, and are well worth introducing even into a select collection. These herbaceous species grow freely enough in any tolerably fertile garden soil, but it should be of good depth, as the roots are strong and strike downwards. A free application of manure is beneficial, especially if the soil is not naturally fertile.

The sub-shrubby varieties of the nonclimbing group include some exceedingly ornamental plants. They are especially suited for the back rows in mixed flower borders where plants 5 to $6 \mathrm{ft}$. high would not be obtrusive; for prominent positions in the front parts of shrubbery borders; or for dwarf standards or iron trainers in beds, whether of Clematis or of other plants. They require a good preparation of the soil, which should be deep and rich, exactly as recommended for the varieties of the Jackmani and lanuginosa groups. In spring, before growth recommences, the plants should be pruned back to the well-ripened wood $I \frac{1}{2}$ to 2 ft. from the ground, and a firm stake or support provided for each. To this support, as they grow, the young shoots must be tied. When the branches begin to ramify, which they do at a height of 3 or $4 \mathrm{ft}$., they may be allowed to fall down on all sides, and in this way they will ultimately form a mass of flowers like a huge bouquet. C. cœrulea odorata is a most desirable plant of this group, for its abundant well-contrasted blossoms, and for their fine scent.

The various forms and allies of the erect Clematis (C. erecta) are very fragrant and hardy; they are from 3 to $4 \mathrm{ft}$.

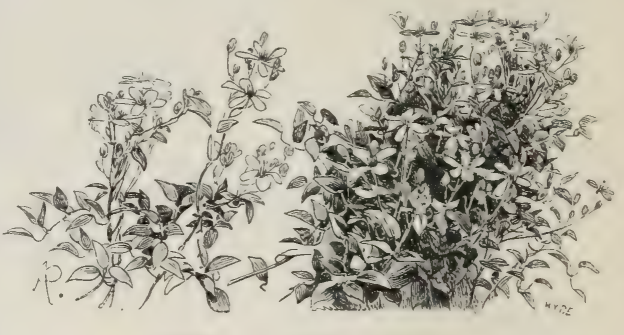

FLOWERS OF CLEMATIS ERECTA.

high, and bear large umbel-like clusters of white blossoms, with an agreeable perfume. They are admirably suited for the sides of frequented walks, etc., but delight in full exposure. The principal varieties are the double-flowered kind, with many small button-like blossoms, lasting longer than the single blossoms; pumila, much dwarfer than the type; and pauciflora, producing smaller flowers in less dense clusters. C. erecta inhabits various parts in South Central Europe.

The Clematis as a Bedding Plant. -As a bedding plant the Clematis should be permanently planted out, so that the roots may not be disturbed. The soil should be rich, open, and deep, and if possible of a calcareous, loamy character. If it be heavy, it must be well drained and ameliorated by the admixture, in moderate quantities, of gritty matter, such as road-scrapings, the sand washed up by the roadside, burnt clay, or even ashes; an admixture of half-rotten leaf-mould would also be beneficial. If on the contrary the soil be light and dry, it should be strengthened by the admixture of 
good and rather heavy loam. trenching and liberal manuring shou be resorted to before planting; and a thorough dressing of good sound manure should be forked in every November, when the summer growth may usually be cut back.

The young plants, when planted out, should be set about $2 \mathrm{ft}$. apart, so that they may cover the surface quickly. When they become strong and well established some of them may be removed, as the more vigorous growth of established plants will branch more freely and spread more quickly. The growing shoots should be looked to at least once a week, and pegged down or trained where they are required to cover the surface most. Their clasping leaf-stalks cling together so firmly that this should always be done before they get entangled, for the young shoots would suffer from disentanglement. The plants should be raised so as to give a convex surface to the bed, and the better to display their flowers. This may be done by raising the surface of the bed, by pegging down a layer of twiggy branches, such as pea-sticks, for the plants to grow over, by fixing a common hooped trellis of rods to which the shoots should at the first be tied, or by arranging, on the surface of the beds, root-masses of a suitable bulk for the plants to scramble over; which last would be the best plan of all in many situations, but would be scarcely admissible in a dressed parterre. Whatever plan be adopted, the plants must be trained as already recommended till they have furnished the space to be covered, when they may be allowed to grow more at random. As they do not throw up flowers from the lower portion of their stems, it is desirable that the points of one series should be arranged so as to overlap the portions of the adjoining ones which remain bare. This should be borne in mind until the whole surface is evenly covered with flowering wood.

Continuity of flowering is dependent upon continuity of growth. This at once suggests summer feeding. Thus, in dry weather, manure water should be given alternately with pure water, the water not being applied over the leaves and flowers, but beneath them. If the summer is at all dry, it is well to have the beds thoroughly saturated with pure water just as the buds begin to acquire size ; if done thoroughly, this will increase the size of the flowers, and will carry the plants on for a considerable period. If the season is such as to require it, one or two such thorough waterings may be given subsequently, applying at least one dose of liquid manure when the plants have been flowering for a considerable period. No other attention is required till the frosts of November, after which the plants may be pruned hard back.

The Clematis as a Wall Plant.When grown on walls the plants of the early-flowering section are not liable to injury from frost, being hardy, and flourishing even in exposed situations. Their chief risk arises from the incidence of the morning sun upon them when a sharp late spring frost has caught the expanded flowers. In moderately-sheltered positions, however, this risk is slight, and the plants will grow freely and flower satisfactorily, coming into blossom about the middle or end of May, and continuing to flower up to the end of June or beginning of July, more or less abundantly, according to situation. In very sheltered situations, some of the varieties of the montana group, notably C. calycina, may be had still earlier; while as a May bloomer, vigorous, hardy, and most prolific of flower, C. montana - with its variety - is strongly to be recommended as a distinct type.

The summer and autumnal flowering groups are gorgeous wall plants, and include not only the nobler forms bred from C. lanuginosa, but the descendants of C. Viticella. They bloom in July, and continue till October or November. The lanuginosa breed is specially effective when grown on walls, on account of the immense size of the blossoms of many of the varieties. These varieties require, in such positions, the most liberal feeding and moderate pruning, the summer growths being carefully trained in to secure the successional flowers they produce.

The Viticella and Jackmani varieties attract rather by the profusion than by the size of their flowers. These plants, while fed to the utmost, to meet the demand upon their powers, should be pruned hard back every autumn (unless a considerable space is intended to be covered), and, in the early part of the summer, the young shoots should be trained up to their full extent, until flowers begin to appear, when, as all the lateral growths develop flowers, it may be better to let them fall in graceful wreaths of pendent spray. Very good results have been obtained for a time by not pruning back.

PILlaRs, Rock-GARDEN, AND ROOTWORK.-For pillars we recommend the varieties of the C. Jackmani type--hardy, 
free-flowering, and continuous-blooming. Such pillars of purple are amongst the most beautiful objects which can be dotted about a garden. Deep soil and thorough drainage greatly conduce to success. The plants, being perfectly hardy, may be planted out during any open weather between September and April, and will be all the better if mulched. Mulching will afford shelter to the newly-embedded roots, and will, by continuous infiltration, furnish, as the rains descend, a supply of congenial food. This may result in free rapid growth. Before starting, the plants should be cut back to within a few buds of their base-say within from 4 to 6 in. of the ground-and then all is ready for the spring growth. At some convenient time after planting, and before the necessity for training has arisen, poles should be placed about the plants. A single snaggy pole, well provided with short lateral branches, may be inserted, and the plant trained about it ; or three or four poles may form a pyramid; but the plan best suited to the character of the plants is to set three or four poles a little distance apart, much as Hop poles are set up, and to train the plants over and about them. While the plants are at home in dressed ground, as bedding plants, pillar plants, or umbrella plants, in single specimens or in masses, they are as much at home in wilderness scenery, about ruins or rock-gardens, or among those grotesque arrangements of old tree stumps to which the term rootery is commonly applied. In fact, the bed, the pillar, the wall, the rock, or whatever it may be, is merely the skeleton or foundation on which the glorious blossoms of the Clematis may be displayed. A deep rich soil must be provided, and this will, in the present case, be facilitated by throwing up irregular mounds, on which to arrange, as taste may direct, the stumps or stony masses which are to give name to the spot. In both cases there will exist the same necessity for ample feeding. The same general rule as to close pruning must also be followed, unless the rootery requires more filling up, when it may be desirable to leave the whole of the matured bine of the previous season until the plants are sufficiently extended to entirely cover the prescribed space with their annual growth. In regard to training, all usually required is to lead the young shoots, during their spring and early summer growth, as evenly as possible over the masses of roots-or rocks if planted in a rock-garden-leaving them to fill out the picture in their own natural way. The result, unshackled by formality, will certainly not be the least pleasing of those in the several departments of the garden to which the Clematis may be introduced. Catalogues abound with the names of the newer and finer hybrid forms. The following selections for outdoor work are given by Messrs. Moore and Jackman :-

FOR PLANTING AGAINST CONSERVATORY WALLS AND IN CORRIDORS. Spring-flowering sorts (for S., W., or N.-W. aspects only).-C. Albert Victor, barbellata, calycina, Countess of Lovelace,

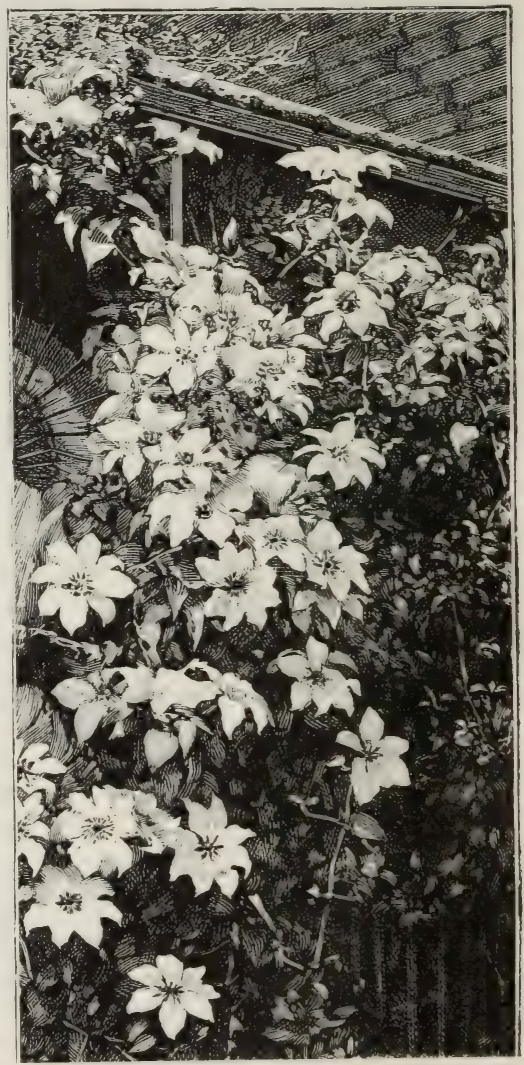

CLEMATIS, LADY CAROLINE NEVILL.

Edith Jackman, Fair Rosamond, George Cubitt, Lady Londesborough, Lord Derby, Lord Londesborough, Lord Mayo, Maiden's Blush, Miss Bateman, monstrosa, montana (any aspect), montana grandiflora, patens floribunda, Sophia plena, Standishi, Stella, The Queen, Vesta.

Late summer-flowering and autumnflowering sorts.-C. Alexandra, cœrulea odorata, Flammula, Gem, Gloire de St. 
Julien, Henryi, Jackmani, Jeanne d'Arc, Lady Bovill, Lady Caroline Nevill, Lady Maria Meade, lanuginosa, lanuginosa candida, lanuginosa nivea, Lawsoniana, Madame Van Houtte, magnifica, marmorata, Mrs. James Bateman, Otto Frobel, perfecta, Prince of Wales, purpurea hybrida, reginæ, Renaulti cœerulea grandiflora, rubella, rubro-violacea, Sensation, splendida, Star of India, Thomas Moore, tunbridgensis, velutina purpurea, Victoria, Viticella rubra grandiflora, Viticella venosa.

FOR PERMANENT BEDDING-OUT.C. Helena patens, Sophia, Standishi, Alexandra, Jackmani, magnifica, Prince of Wales, rubella, rubro-violacea, Star of India, tunbridgensis, velutina purpurea.

FOR GROWING ON PILLARS AND POLES. -C. Alexandra, Beauty of Surrey, Excelsior, Flammula, Gem, Gloire de St. Julien, Henryi, Jackmani, Jeanne d'Arc, Lady Bovill, Lady Caroline Nevill, Lady Maria Meade, lanuginosa, lanuginosa candida, lanuginosa nivea, Lawsoniana, Madame Van Houtte, magnifica, Marie Lefebvre, marmorata, Mrs. James Bateman, Otto Froebel, Prince of Wales, reginæ, rubella, Sensation, Sir Robert Napier, Star of India, Thomas Moore, tunbridgensis, velutina purpurea, Victoria, Viticella rubra grandiflora, Viticella venosa.

FOR PLANTING ON ROOTERIES.-C. Alexandra, Flammula, graveolens, Hendersoni, Jackmani, Lady Bovill, magnifica, marmorata, modesta, Mrs. James Bateman, orientalis, Prince of Wales, purpurea hybrida, Renaulti cœrulea grandiflora, rubella, rubro-violacea, splendida, Star of India, Thomas Moore, tunbridgensis, velutina purpurea, Viticella atrorubens, Viticella major, Viticella purpurea plena, Viticella rubra grandiflora, Viticella venosa.

The only remarkable novelty recently added to the genus is C. coccinea, a redflowered kind, very distinct, which promises to be a beautiful species.

Cleome (Spider-flower). - A genus of the Caper family, several species of which are often enumerated in seed catalogues; but though vigorous and distinct they are not likely to take any useful place in the flower garden. They are mostly annuals doing best with the treatment of half-hardy annuals.

Clerodendron.-Only two species in this beautiful genus, for the main part tropical, have any claim to hardiness, but both are worth growing. They are C. foetidum, a native of China, and $\mathrm{C}$. trichotomum, a Japanese plant. C. fœitum is an old garden plant usually seen in greenhouses, but hardy enough for open-air culture in all southern and warm parts. In southern gardens, especially near the sea, it grows $5 \mathrm{ft}$. high, and is handsome for the several weeks it is in bloom. The other species, C. trichotomum, is less common. It is a free-growing shrub, $6 \mathrm{ft}$. high or more, bearing large loose clusters of flowers, the corollas of which are white, the calyces being a deep brownish-red. It blooms in September.

Clethra (Sweet Pepper Bush).--Small shrubs and small trees, the hardy species of which are natives of North America. The Alder-leaved Clethra (C. alnifolia) in the wet copses of Virginia reaches a height of ro ft. or more. With us it grows from 3 to $5 \mathrm{ft}$., makes a dense bush, bearing in summer white sweet-scented flowers in feathery spikes. C. acuminata has more pointed leaves. It also has spikes of white scented flowers, not erect like those of C. alnifolia, but drooping. It is inclined to grow taller; and, in fact, it is quite a small tree in the woods of the Alleghanies. Both are valuable shrubs, suitable for wet places; their place is by the lake, pond, or stream, or in any low-lying position. They prefer peat, but any light soil will do.

Clianthus (Glory Pea). - Brilliant plants seldom seen out-of-doors in the London district or home counties, but one kind is quite free as a wall plant in Irish and west-country gardens, and should be more frequently planted in sea-shore and warm places. C. puniceus is as handsome and free-flowering an evergreen as one could wish. Its splendid crimson blooms appear in large bunches during summer. Good sandy loam will grow it well. It is easily increased by cuttings of the young shoots. Winter protection about the root is desirable except in the most favoured districts.

Climbing Fern (Lygodium).

Clintonia.-The pretty annual species of this duplicate genus are now referred to Downingia, which see.

Clintonia.-A small genus of the Lily family, natives of North America. C. borealis is unattractive with greenishyellow flowers, but C. Andrewsiana is pretty, with a tuft of ample bright green leaves about I ft. long and about 4 in. wide, from which arises a stout flowerstem some 6 in. high, terminated by a dense umbel of deep rose blossoms, produced from April to June. C. Andrewsiana thrives well in a peaty soil in a partially shady position, in just such a place as suits the Mocasson flower. It 
is yet scarce in cultivation, not having been introduced long.

Cloudberry (Kuhus).

Cloud Grass (Agrostis).

Clove Carnation (Dianthus).

Cnicus benedictus (Blessed Thistle).A handsome biennial, having bold deep green foliage, blotched and marbled with silvery white. It is useful for associating with plants of fine foliage, but must have good deep soil and plenty of space. It grows freely and luxuriantly in a thin shrubbery, or on any bank of rubbish.

Cobæa scandens.- In favourable localities in the southern and western counties, this well-known greenhouse plant thrives against an outside wall, and will cover a considerable space of trellis-work during summer. It should be planted in light rich soil, and, if watered liberally during the growing season, will soon cover a large space and flower freely. With some protection it will survive an ordinary winter. Plants may easily be raised from seeds, which should be sown during spring in a frame or hand-light. Cuttings also strike readily in a brisk heat in spring. The variegated form must be raised from cuttings.

Cocculus carolinus.--Like the Moonseed (Menispermum canadense), this is a twining shrub with inconspicuous flowers. It is useful as a trailer for arbours, pergolas, and the like, but of no great value.

Cockscomb (Celosia).

Cocksfoot (Dactylis).

Codonopsis. - Interesting and sometimes pretty plants of the Bell-flower order, easy to cultivate in light and warm soils, C. ovata (known as Glossocomiæ ovata) being a fine bushy plant. They are suited for warm borders and full collections of hardy herbaceous plants. Some are annuals, but most are hardy perennial flowers from the mountains of India.

Colchicum (Meadow Saffron).-- Hardy bulbs, which are often erroneously termed "autumn Crocuses," and which flower in the autumn just when the summer-blooming plants have lost their freshness, and when the days begin to shorten. Unlike many bulbs, their presence early in spring, when the borders are being prepared for summer-flowering plants, is not likely to be overlooked, for their leaves, bearing with them the seed-pod, are amongst the earliest harbingers of spring. The individual flowers do not, as a rule, last long, but, as they are produced in succession, there is a long season of bloom. The flowers are often destroyed through being grown in unsuitable positions, viz. in bare beds of soil, where the splashing of the blooms during heavy rainfalls impairs their beauty. The best places are grassy places near shrubberies and trees, where the soil is well drained and rich. In the

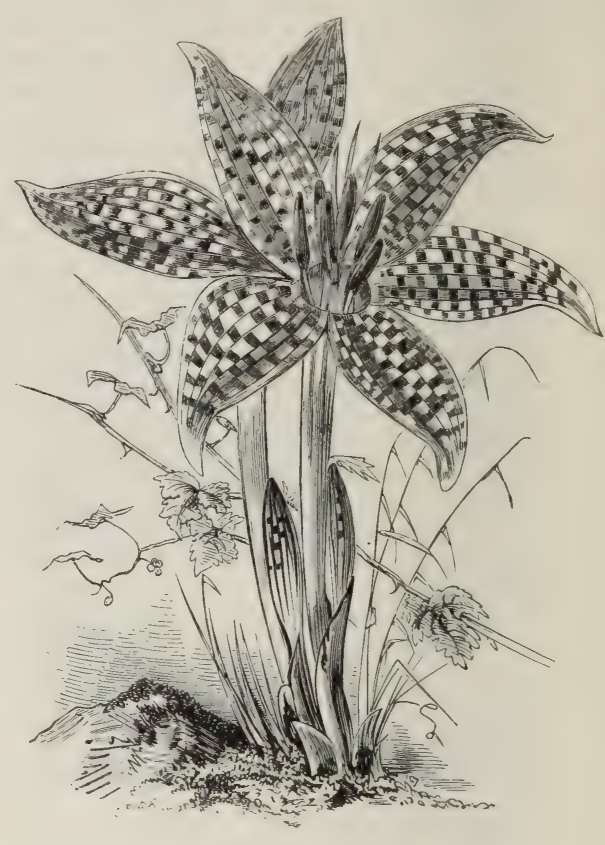

COLCHICUM PARKINSONI.

rock-garden, too, among dwarf Sedums and similar subjects, Colchicums thrive, and make a show in autumn, when rockgardens are comparativelý flowerless. They look better in grassy places or in the wild garden than in any formal bed or border. Their naked flowers want the relief and grace of Grass and foliage. Choice and rare sorts, or those which we want to increase, should be grown in nursery beds, but the true use of the plants is as pretty groups and colonies in turf not often mown. There are about 30 kinds, though only about half of them are in cultivation. Among these there are some whose differences are so slight as to be scarcely worth growing, except in a very full collection. The genus has a rather wide range, some species extending to the Himalayas; others are found in North Africa; but the majority are natives of Central and Southern Europe. Though there are so many names to be found in catalogues, the really distinct kinds are few, and there is such a striking similarity among these, that for cultural purposes they may be con- 
veniently classed in groups. The best known is

C. autumnale, commonly known as the autumn Crocus. The flowers appear before the leaves, are of a rosy purple colour, and rise in clusters of about six, 2 or $3 \mathrm{in}$. above the surface. C. autumnale flowers from September till November. There are several varieties, the chief being the double purple, white and striped ; roseum, rose-lilac ; striatum, rose-lilac, striped with white; pallidum, pale rose; album, pure white; and atropurpureum, deep purple. Similar to C. autumnale are C. arenarium, byzantinum, montanum, crociflorum, lætum, lusitanicum, neapolitanum, alpinum, hymetticum ; all, like autumnale, are natives of Europe, and from a garden standpoint are identical with each other.

C. Parkinsoni.-A most distinct and beautiful plant, readily distinguished from any of the foregoing by the peculiar chequered markings of its violet-purple flowers. It produces its flowers in autumn and its leaves in spring. Other similar kinds are Bivonæ, variegatum, Agrippinum, chionense, tessellatum, all of which have the flowers chequered with dark purple on a white ground.

C. speciosum, from the Caucasus, is the noblest of the genus, and is beautiful, and is valuable for the garden in autumn, when it produces large rosy-purple flowers, nearly I ft. above the surface. Its foliage, too, is broad and handsome, but is not so noticeable because it does not appear till spring. Like the rest of the Colchicums, C. speciosum is as well suited for the rock-garden as the border, and it thrives well in any soil, provided it be not too poor or too heavy ; but to have it in perfection, choose a situation fully exposed to the sun, with sandy soil-in fact, a spot likely to dry up during summer; here the plants will luxuriate, and enjoy the autumn, winter, and early spring rains.

Coleus.--A few kinds of these handsome-leaved plants succeed in the open air in summer, and, when used judiciously, they produce a fine effect. In some of the London parks they are arranged by themselves in large masses, generally of one kind only. Though there is a host of varieties, few succeed in the open air. Mr. Wildsmith, of Heckfield, writes: "We have tried at least a score of varieties for bedding-out, with the result that the first kind recommended (Verschaffelti) is still the only one that succeeds well. The culture of all the varieties is of the simplest nature; cuttings strike freely in any sandy soil, in a moist heat of $70^{\circ}$. As soon as struck, pot them in light loam, containing a tenth part of well-rotted manure ; grow them on in a moist heat of from $65^{\circ}$ to $70^{\circ}$, not allowing them to get pot-bound till they have attained the size desired, and at all times well exposing them to the light, to bring out their colour. For bedding-out, they should be struck in March, grown on in warmth till about the middle of May, and then gradually inured to full exposure in readiness for planting out the first week in June."

Colletia.-Shrubs from Chili, some species of which are hardy enough for the open air in all but the coldest parts. They have spiny branches that are naked, or with a few minute leaves. C. cruciata is the commonest; its stems are armed with stout flattened spines, and its flowers are white and small. It makes a bush about $4 \mathrm{ft}$. high. C. bictoniensis is the same as C. cruciata. C. spinosa has its spines round or awl-shaped, and, when in bloom, is prettier than C. cruciata, as the white flowers, though small, are very numerous. They are produced in summer. Under favourable conditions, C. spinosa grows much taller than C. cruciata, and against a wall will attain a height of $\mathrm{Io} \mathrm{ft}$. The names of C. ferox, C. horrida, C. armata all stand for C. spinosa. It makes a formidable hedge in the southern counties, where it flourishes to perfection. C. serratifolia is less common than the others, but is extremely pretty when in bloom, the whole bush being a complete mass of tiny white blooms. It grows tall and slender, either planted in the open or against a wall.

Collinsia.-A very pretty family of $\mathrm{N}$. American annuals, belonging to the Pentstemon Order, and very dressy and pretty in spring where well grown and tastefully used. If sown in autumn, they will, on many soils, survive the winter, and flower much better than spring-sown plants; and flower very early, if the spring is at all favourable. They are of the easiest culture if sown in the open air ; if sown in spring, they flower some tivelve weeks afterwards. There are from nine to a dozen species or varieties in cultivation and enumerated in the catalogues, the only one requiring special treatment being C. verna, which must be sown in autumn. "The seeds (says Mr. W. Thompson) must be sown about the end of August, or from that time to the middle of September, in pans 
of light vegetable soil kept thoroughly damp. In a fortnight the seedlings will show themselves, and when they have made their first pair of leaves (besides the seed-lobes) they are to be pricked out singly in pans, boxes, or pots ; in pots if they are intended for blooming under glass. From this moment it is important to keep them cool and damp, and as near the glass as practicable, so that their growth may not be forced. If intended to bloom in the open ground, they may be planted out in light rich soil, in partially-shaded situations, or on a north or north-west aspect, and they will require no attention but slight protection during severe weather. Thus treated they will, in ordinary seasons, commence blooming early in April, and continue in flower six or eight weeks." Notwithstanding its charming colour, C. verna has never become so well known as C. bicolor, grandiflora, violacea, heterophylla, and the other forms. The prettiest use for these plants is for the spring-garden in beds, or occasionally as a broad edging.

Collinsonia canadensis (Horse Balm). -An unattractive plant of the Sage family ; native of N. America.

Collomia coccinea.-A bright annual, but of no great value or beauty, $\mathrm{I} \mathrm{ft}$. to I 8 in. high, flowering in summer and autumn. Better culture than it usually gets may improve it. Sow it in April in open ground; or sow it in a dry pit in autumn and protect it during winter, if good plants are desired either for pots or planting out. On warm soils it grows higher and sows itself every year, surviving the winter, and, consequently, growing much stronger and taller.

Colt's-foot (Tussilago).

Columbine (Aquilegia).

Colutea (Bladder Senna).-The Bladder Sennas cannot be called choice flowering shrubs, but they are very useful for poor hungry soils, particularly for dry sunny banks where few other plants can exist. Like the Gorse and a few other shrubs of the Pea family, they delight in a dry sandy soil, and, when in flower, which is during several weeks in late summer and in autumn, they have a pretty appearance, their foliage being light and elegant. They have numerous names, but there are only one or two distinct kinds. The commonest is $\mathrm{C}$. arborescens, which, under favourable conditions, grows 6 or $8 \mathrm{ft}$. high, has large flowers, varying in different varieties from yellow to a deep reddishyellow. C. cruenta, C. haleppica, and C. media are smaller, and have bright yellow flowers; but all have much the same aspect.

\section{Comfrey (Symphytum).}

Commelina cœlestis (Blue Commelisse).-A pretty and continuous-blooming blue Gentian. There is a white variety, C. c. alba, about $2 \mathrm{ft}$. high, more or less profusely covered with blossoms from early summer till autumn. C. cœlestis delights in light, sandy, well-drained soils. The roots are fleshy, and liable to suffer from severe frosts ; and, in some districts, it is advisable to cover them with coal-ashes on the approach of winter. In cold wet districts the roots may be lifted, and stored in dry leaf-mould, or the plant may be treated as a half-hardy annual; the seed being sown in heat, the seedlings being pricked off into small pots as soon as they are fit to handle, and planted out about the end of May. The roots, if lifted and stored in winter, will be the better for a start in slight heat in spring, and may be increased by division. On some warm or stony soils, and in districts near the sea where light soil prevails, C. colestis grows like a weed. It is so fine in colour that a group or small bed is always welcome. Mexico. Tradescantia.

Compass-plant (Silphium laciniatum).

Comptonia asplenifolia (Sweet Fern). - This is a quaint little shrub about a yard high, fern-like in leaf, the leaves long and cut into rounded lobes, somewhat like those of the Ceterach. They are aromatic when bruised. It likes peaty soil, it spreads freely in sandy soils, and may be increased by layers, suckers, or seeds. A pretty plant in the woods of New Jersey, and many other parts of $\mathrm{N}$. America. It would be happy in like places in this country, if we had it plentiful enough to naturalise. In gardens its place is among small shrubs and on the margins of peat beds.

Conandron ramondioides.-A small Japanese plant allied to Ramondia, having thick wrinkled leaves, in flat tufts, from which arise erect flower-stems some 6 in. high, bearing numerous lilac-purple and white blossoms. Though said to be quite hardy, it requires a sheltered position, such as is afforded by snug nooks in the rock-garden. Plants placed between blocks of stone thrive capitally, provided there is a good depth of soil in the chink and the position is tolerably moist.

Convallaria majalis (Lily of the $\mathrm{Val}$ $l e y)$.- This universal favourite delights in partial shade and moisture, and in a rich light soil that can be readily penetrated by its fibrous roots. It is found in the valley sheltered by shrubs, and in the 
forest luxuriating under trees. The best situation to plant it is where it will receive partial shelter and shade from wall, fence, or trees. It is advantageous to have a plantation of Lilies of the Valley upon a south aspect, for the sake of earliness and of producing them in succession, for, by this means, blooms may be gathered a fortnight or three weeks earlier than otherwise. The best places are those under shady walls. Give liberal surfacedressings of rotten manure, and an abundant supply of moisture throughout active growth. The chief point to guard against is frost, which is destructive to may be planted 2 or even 3 in. apart, as they do not become crowded so soon as to require thinning out. Cover the surface after planting with I or 2 in. of rotten manure, bearing in mind that thorough maturity can be ensured only by repeated applications of water - weak manure-water being the most effective. Treated thus, with annual surface-dressings of manure, the beds will keep in good condition for years, and bear fine blossoms in abundance. When the plants become crowded with shoots they should be thinned out, or, better still, lifted and replanted, for weakly, abortive crowns tend to retard

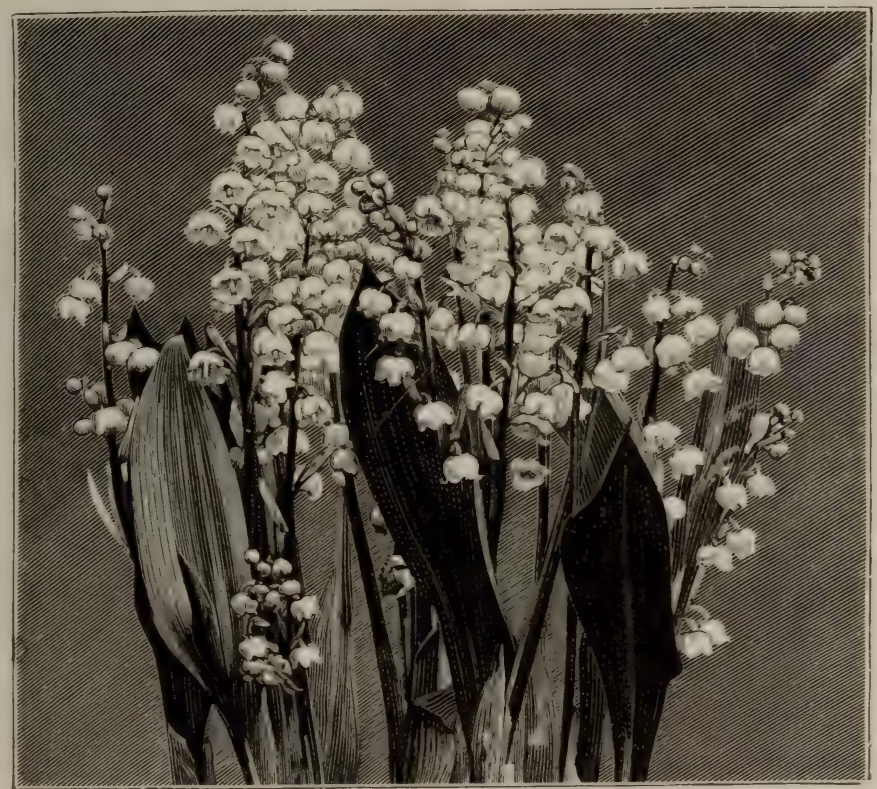

CONVALLARIA MAJALIS (LILY OF THE VALLEY).

the blooms, which appear with the leaves. A few Spruce or other evergreen branches placed sparsely over the beds are an efficient protection, and afford a beneficial shelter, encouraging growth. Preference should be given to a soft loamy soil well enriched with rotten manure, though fine Lilies may be grown in rather heavy loam. In preparing soft loam it will be best to give a liberal admixture of leaf-soil and sharp sand. Whatever the soil, it should be moderately firm before planting

The best time to plant is early in autumn, immediately after the foliage decays, selecting the crowns singly and dividing them. For beds likely to remain undisturbed for several years, the crowns vigorous development. C. majalis is now largely forced into flower early, the roots being usually imported from the Continent, where they are grown and prepared for the purpose. This plant may be naturalised on any place sufficiently moist and shaded, and it soon spreads its broad masses. There is a variety called rosea, the blossoms of which, however, are not rosy, but are of a purplish tinge, and are not nearly so pleasing as the white kind ; and there is also a variety with gold-striped foliage, and another with double flowers.

Convolvulus (Bindweed).-Handsome climbing herbs; very hardy, and where properly used very effective.

C. althæoides (Riviera Bindweed).This pretty Bindweed grows in many 
places around the basin of the Mediterranean, but is quite happy in an English garden. It is cheery in the colour of its rosy-pink cups, and graceful and distinct in leaf and growth. It is hardy, and is good for a border or a bank, or for the rough rock-garden.

C. dahuricus (Dahurian C.).-A showy twining perennial, bearing in summer rosy-purple flowers. Excellent for covering bowers, railings, stumps, cottages, etc., and also for naturalisation in hedgerows and copses. It grows in almost any soil, and, like its relation the Bindweed, is readily increased by division of the roots, which creep. Caucasus.

C. major (=Ipomcea).

C. mauritanicus (Blue Rock Bindweed).-A prostrate twining plant, with very slender stems. Flowers, a good blue, I in. across, with a white throat and yellow anthers. The rock-garden, and raised borders-but always in sunny, somewhat raised positions, and in sandy, well-drained soil. A lovely N. African plant, well repaying attention. Division or cuttings.

\section{C. minor, see C. tricolor.}

C. pubescens fl.-pl. (Double Bindweed). - Very handsome and useful for clothing trellises, stumps, porches, and rustic-work. It grows rapidly to the height of $6 \mathrm{ft}$. The flowers are large, double, and of a pale rose. They appear in June and onward, and continue for some months. The Double Bindweed likes a light rich soil and a warm aspect. It may be grown in large pots, tubs, or boxes, and may be used for forming small bowers on balconies, to hide small fences, or to climb round posts. Division. China.

C. Scammonia (Scammony) is a beautiful slender plant, having, throughout the summer, a profusion of large white blossoms. It grows well in any position or soil, and is a capital plant for rambling over roots, low shrubs, and such objects. There are in gardens other species such as C. Cneorum, lineatus, Cantabrica, dorycnoides, and erubescens, but they are either too tender or too inconspicuous for general cultivation.

C. sepium (The Greater Bindweed).This, although generally a great pest, may be a most useful and beautiful auxiliary in certain spots where it would not be a nuisance; but it is surpassed by the larger and stouter white C. sylvaticus.

C. Soldanella (Sea Bindweed). - A distinct trailing species with fleshy leaves ; flowering in summer; with pale red flowers, large and handsome. The rockgarden, if planted so that its shoots droop over the brows of rocks. Also suited for borders, in ordinary soil. Division. Europe and Britain.

C. sylvaticus.-No plants form more beautiful and delicate curtains of foliage and flowers, and none grow more vigorously in any soil. The wild garden is the place where it is most at home, and where its vigorous

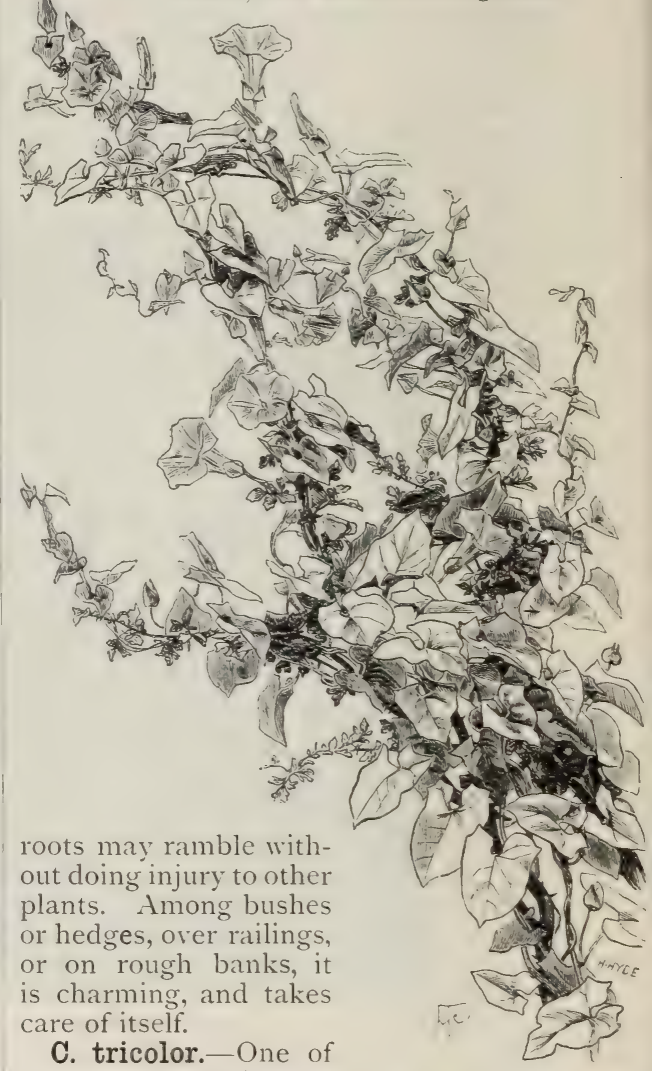
the most beautiful of hardy annuals, too well CONVOLVULUS SYLVATICLS. known to need descrip-

tion. There are now in cultivation numerous varieties, varying more or less in colour of flowers or in habit of growth. The flowers of the type are blue, yellow, and white, but there are varieties entirely white (albus), striped violet and white (striatus), and rich purple (splendens). Others again differ in habit of growth, like unicaulis, which has flowers crowded at the tips of the branches. The forms monstrosus, undulatus, quadricolor, kermesinus are desirable; in fact, every variety is worth growing. C. tricolor being perfectly hardy, may be sown in the open ground in September for flowering in 
spring, or sown in February, in a heated frame, for transplanting in May for midsummer flowering, and in the open ground from April to the end of May for flowering in late summer and autumn. C. tricolor likes good warm soil, not too dry or too wet, especially for the autumnsown plants, which have to stand the winter. (= C. minor.)

Cooperia.-A small genus of bulbs of the Amaryllis family. There are in cultivation two kinds-C. Drummondi and C. pedunculata. C. Drummondi has small bulbs, narrow leaves, and flower-stalks produced late in summer. These stalks are terminated by a single flower with long tubular blossoms of pure white, and fragrant like a Primrose. C. pedunculata is somewhat similar, but is a night-flowering plant. They are both natives of Texas, and are not perfectly hardy. They, however, thrive in the warmer parts of England, in sunny sheltered borders of light soil, but it is advisable to give them frameprotection in winter. They are lovely plants and certainly deserve any amount of care. They thrive well in pots and in frames, but are as yet little known in general cultivation in this country.

Coprosma Baueriana variegata is a tender shrubby plant, with shining green leaves broadly banded with creamy yellow. It is useful for margins of large beds or borders. It requires to be pegged down, when it soon grows into shape, and forms a very pretty margin. It is easily increased by cuttings put in in spring or early in summer, on a gentle bottom heat under bell-glasses, and not allowed to get too dry. Often used in the flower-garden with good effect. It should be taken up and housed in autumn to keep it from severe frosts. New Zealand. Cinchona Order.

Coptis trifoliata (Gold Thread).-A little evergreen bog plant 3 or 4 in. high, with three-leafleted or trifoliate shining leaves. It derives its common name from its long bright yellow roots. It is occasionally grown in botanic gardens. Northern parts of America, Asia, and Europe, flowering in summer; flowers white. Easily grown in moist peat or very moist sandy soil. Dirision.

Coral berry (Symphoricarpus inlgaris). Coral Root (Dentaria bulbifera).

Cordyline.-Although common in greenhouses, and also frequently in subtropical gardening, it is only in the mildest parts of England and Ireland that Cordyline can be grown well in the open air. In the neighbourhood of London it has occasionally been tried, but, although it may survive a mild winter, it succumbs to hard frost. In the Isle of Wight, and from thence along the shores of Devonshire and Cornwall to the Scilly Isles, it succeeds well, forming a fine feature even in cottage gardens, whilst in some larger gardens whole avenues of it are planted. What an addition it is to the outdoor vegetation of these places is admirably shown by the illustration on p. 348. But, in far less favoured places, it is often seen thriving for years in the open air, though it is not worth trying in cold, high, and inland places, especially on clay soils. Judging by the numerous specimens growing in the temperate house at Kew, the species is a variable one, some forms having gracefully arching leaves, whilst in others the leaves are rigid, giving the plant a Yucca-like appearance. In some varieties, again, the foliage is of a glaucous hue, whilst in others it is bright green. This variation has given rise to confusion in names, many of those that have specific names being only varieties. Others of reputedly hybrid origin are also common in these southern gardens. C. australis does not flower in a small state, and I have not seen plants under 10 feet in height in bloom. The racemes are 4 to $5 \mathrm{ft}$. long, the flowers white and thickly crowded, and the effect of the whole raceme is very striking. Indoors it is usually at its best in June and July. Until it commences to flower, it grows up in a single straight stem, the leaves being 2 to $4 \mathrm{ft}$. long, and forming a rounded head. The check caused by flowering frequently, but not always, induces the growing point to divide, and large specimens form in consequence a huge many-branched mass. One of the most beautiful varieties is known in gardens as C. indivisa Veitchi, but it is quite distinct from the true $C$. indivisa, and has the midrib and sheathing bases of the leaves coloured a rich red.

A species which will certainly prove as hardy as $C$. australis, and it may be hardier, is the true $C$. indivisa. It is distinct and very handsome, and a large number of specimens have at different times been in cultivation; owing, however, to their being treated as tropical or semitropical plants they usually proved shortlived, and C. indivisa is now a rare plant. One of the finest specimens in the country is in Mr. Rashleigh's garden at Menabilly, Cornwall. At Kew several plants are cultivated in the temperate house and other cool houses. The species has been tried there in the open, but without lasting success. Its habit is rather remarkable, being of so very dwarf a 
growth that plants old enough to have become numerously branched have not attained a height of more than 3 or $4 \mathrm{ft}$., forming a compact, rounded head, that may be compared to the stiff-leaved variety of $\mathrm{C}$. australis in miniature. C. indivisa is

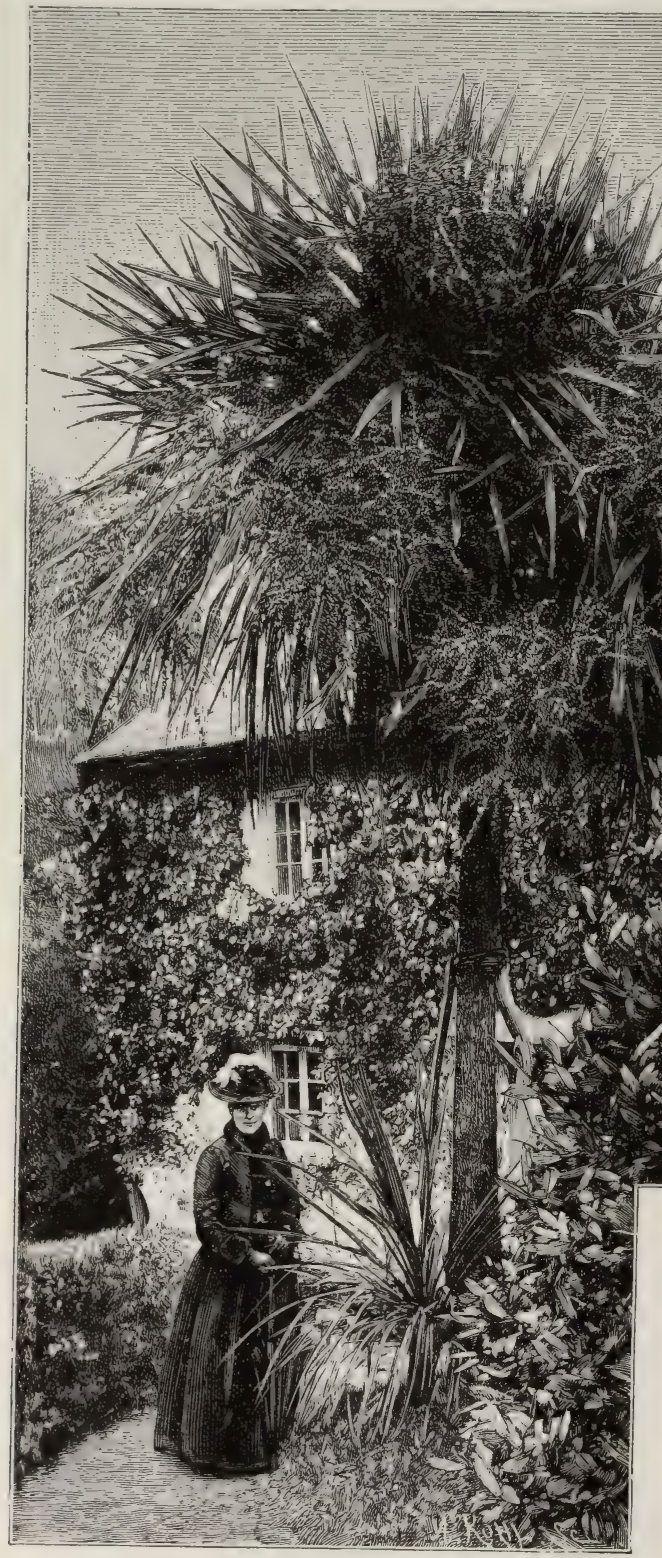

CORDYLINE AUSTRALIS, BOSAKAN, CORNWALL. but form low spreading bushes. Even in the greenhouse it displays the same stunted appearance. The leaves are 6 to 9 in. long, pointed, and dark green, to about ro ft. The head, which is much divided, measures I I $\mathrm{ft}$. through, and this season produced twenty-one beautiful flower-spikes, varying from 5 to $6 \mathrm{ft}$. long, 
and thickly studded with white bellshaped flowers. This plant is also very interesting while the seed is passing through the various stages of ripeness, from white, pale pink, to dark brown, and the fertility of it is proved by the many
North American Composites, which now includes Calliopsis, contains several important garden plants - the annuals being showy summer flowers, and the perennials valuable late-blooming plants. The choicest of the perennials is C. auriculata,

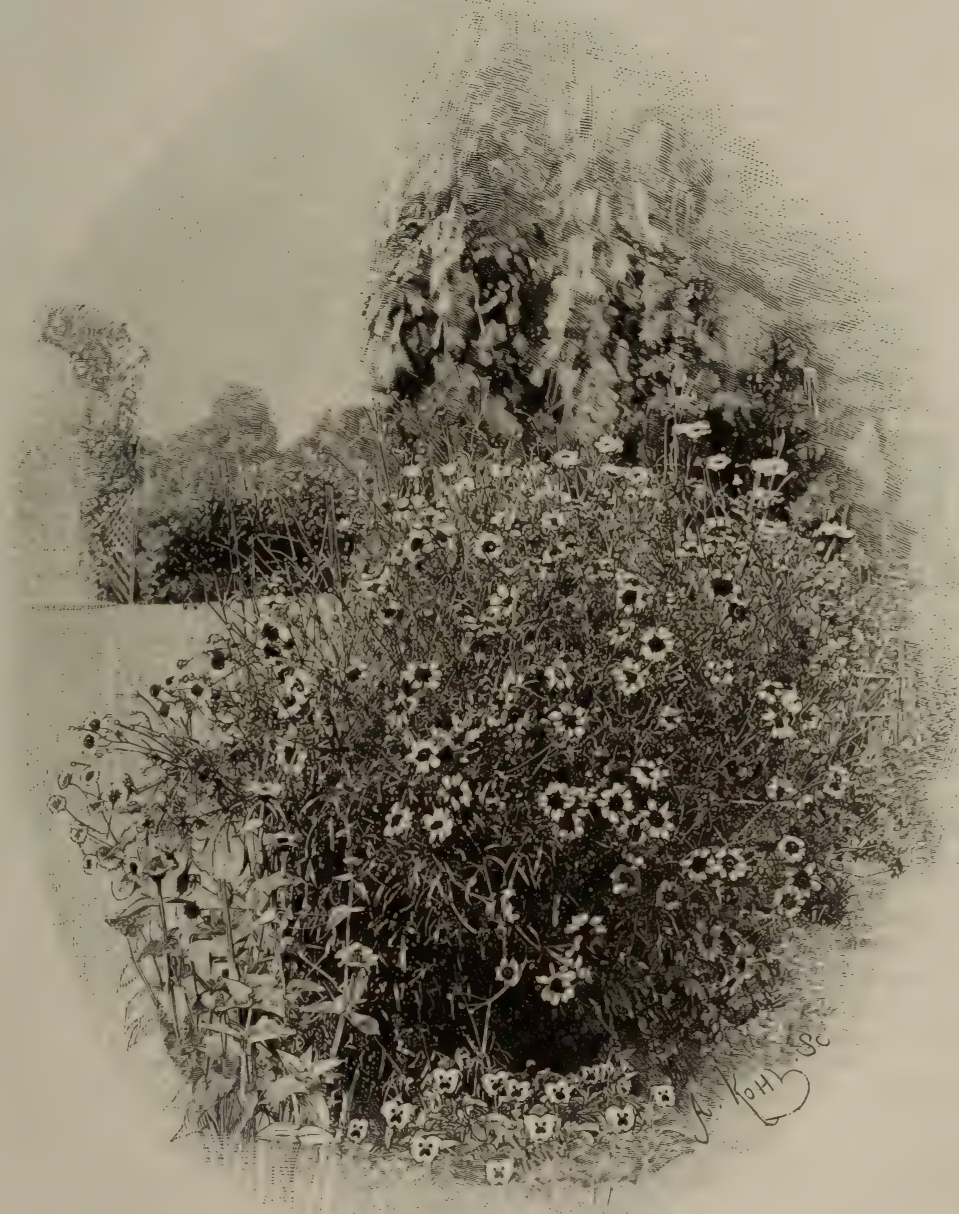

COREOPSIS TINCTORIA (TICKSEED).

fine specimens to be found here that have been raised from it within the last few years. It also throws up suckers, which, if carefully divided, do very well. As a pot plant for house or table decoration it has few equals, and, with a little attention, it will last in good condition for many weeks."

Coreopsis (Tickseed).-This genus of about $2 \mathrm{ft}$. high, with a spreading growth, and bearing, in autumn, abundance of rich yellow blossoms on slender stalks. A useful plant for cutting from; grows well in any ordinary soil, and freely propagated by seed or division. Nearly allied and very similar to it is C. lanceolata, an equally showy plant, also delighting in a rich damp soil. C. tenuifolia 
is a pretty plant, with elegant feathery foliage and rich golden-yellow blossoms from summer till autumn. C. verticillata is similar to it, and is also a showy border plant. Neither of these is so robust as the taller kinds, and they therefore require more select spots, such as the front rows of a mixed border in the rougher parts of the rock-garden. Other perennials in cultivation are C. palmata, senifolia, nudata, maritima, tripteris, gladiata, and delphinifolia, but none can be recommended generally. The annuals are among the showiest summer flowers, and are most valuable for garden adornment. Being quite hardy, they make a fine display in spring from seeds sown in September; while an almost continuous bloom may be had from July to October by sowing successively from early March till the middle of June in ordinary garden soil-that of a moist description being preferable for the spring sowings. The following are the principal annuals: C. aristosa, 2 to $3 \mathrm{ft}$. high, with large golden-yellow blossoms; C. Atkinsoniana, I to $3 \mathrm{ft}$. high, flowers orange-yellow spotted with brown in centre; C. coronata, orangeyellow, with a circle of brownish-crimson in centre; C. Drummondi, I to $\mathrm{I} \frac{1}{2} \mathrm{ft}$. high, golden yellow; C. tinctoria, I to $3 \mathrm{ft}$. high, flowers crimson-brown tipped with orangevellow.

Coris monspeliensis (Montpelier C.).A rather pretty dwarf branching plant, about 6 in. high, usually biennial in our gardens. South of France. Does on dry and sunny parts of rock-garden, in sandy soil, and among dwarf plants. Seed.

Cornel, Dwarf (Cornus).

Corn-fiower (Centaurea Cyanus).

Cornish Heath (Erica vagans).

Cornish Moneywort Sibthorpia euro$p e(x)$

Corn Marigold (Chrysanthemum segetum:

Cornus (Dogrwood).-The only Dogwood which can be considered a flowering shrub is C. florida, called the Virginian or Florida Dogwood, a very old garden shrub, introduced early in the last century. In its native country it is a small tree, often 30 or $40 \mathrm{ft}$. high, but in England it is only a moderate shrub, and does not flourish-our climate not being warm enough for it. Among the other Dogwoods worth growing for their flowers is the Cornelian Cherry (Cornus mas), one of the earliest shrubs to bloom, being covered with tufts of tiny flowers as early as February in mild seasons, and succeeded in autumn by cherry-red berries.
C. canadensis (Dwarf Cornel). - A pretty miniature shrub, of which each little shoot is tipped with white bracts, pointed with a tint of rose. It is lost among coarse herbaceous plants, and is entirely obscured by ordinary shrubs; and should therefore be placed among alpine plants in a rock-garden near the edge of a bed of very dwarf Heaths or American plants, or in the bog-garden. It grows to about the size of the Partridge Berry, or somewhat larger. North America, in damp cold woods. Growers of British plants may like to possess C. suecica, a tiny native species, which grows well in a bog or moist peat bed among very dwarf plants.

Coronilla, a small genus of the Pea family, consisting chiefly of shrubs, but containing at least two really good herbaceous plants, which are valuable for the rock-garden and the mixed border. They are C. iberica and C. variæ.

C. Emerus (Scorpion Senna).-An elegant loose bush, 3 to $6 \mathrm{ft}$. high, with small pinnate leaves, which, in mild seasons, remain green through the winter. The flowers are reddish when first expanded, but become quite yellow. It blooms freely in early summer, and flowers again in autumn. This is the only bushy Coronilla that can be satisfactorily grown in the open air generally, but, in warm parts, C. glauca, a beautiful old shrub with glaucous foliage and yellow flowers, usually seen in greenhouses, may be grown well near the sea.

C. iberica is about I ft. high, and has a dense tuft of slender stems that trail on the ground or fall gracefully over the ledge of a rock. It makes a glorious show in early summer with its profusion of bright yellow blossoms, resting on deep green foliage. Its place is the rock-garden, where it delights to send its roots down the side of a big stone, to plenty of good soil, not less than is in. deep. A dozen or so of small plants, placed in such a position in groups of three or four, will, in a year or two, result in glowing masses of colour that will compare with any alpine flower. It also does well on the margins of borders, but not so well as on a bank or in the rock-garden. Cuttings inserted in early spring.

C. varia.-A very handsome, free, and graceful plant, with a profusion of pretty rose-coloured flowers. It is widely distributed on the Continent, and is found on many railway banks in France and Northern Italy. It forms low dense tufts, sheeted with rosy-pink, which attract 
the traveller's eye, their beauty marking them out among the weeds. It ought to be in every garden as a border flower, or used for naturalising in semi-wild spots. Perhaps, however, the most graceful use for it would be to plant it on some tall bare rock, and allow its vigorous shoots and bright little coronets to teem over and form a lovely curtain to the stone. It is also admirable for chalky banks, or for running among low trailing shrubs like the common Cotoneaster. In good soil its shoots are $5 \mathrm{ft}$. long, and it thrives on almost any soil. It is readily increased by seeds, which are frequently offered in our seed catalogues. There is a fine deep rose-coloured variety named Hauskneckti well worthy of culture, and another of compact growth called compacta. Other species in cultivation are, montana, libanotica, minima, valentina, ramosissima, and vaginalis, but these are only suited for botanical collections.

Cortusa (Alpine Sanicle).-Plants resembling Primroses of the cortusoides type, but which have become less important since the introduction of finer forms of primroses. C. Matthioli is a Piedmontese plant, about I ft. high, and thrives in peat, in shady or half-shady spots. C. pubens, more recently introduced, requires the same treatment.

Corydalis (Fumitory). - A numerous family, but not many of the species worth cultivation, though some are important.

C. Ledebouriana (Ledebour's Fumitory).--The newest species of Corydalis in cultivation; it is unlike any other, on account of its peculiar glaucous leaves. These are arranged in a whorl about half-way up the stem. The stem is 9 to 12 in. high. The flowers are a deep vinouspurple, with pinkish spurs. It is early and hardy.

C. lutea (Yellow Fumitory). - This well-known plant is not so much esteemed as it deserves, for its graceful masses of delicate pale green leaves are profusely dotted with spurred yellow flowers. It is pretty in borders, and grows to perfection on walls, and the tufts, when emerging from some chink in a fortress wall where rain never falls upon them, are often as full of flower as when planted in fertile soil. It is well suited for the rougher rock and root work. A naturalised plant in England, and widely spread over Continental Europe. Division or seeds. In any stony position it spreads about with weed-like rapidity.

C. nobilis (Noble Fumitory).-A distinct and handsome plant, Io in. or I ft. high; the flower-stems are stout and leafy to the top, and bear a massive head of rich golden-yellow flowers with a small reddish-chocolate protuberance in the centre of each. This protuberance, with the yellow flowers, and the green rosette when the bloom is young, is very ornamental. C. nobilis is easy of culture in light borders, but is rather slow of increase. Where it does not thrive as a border plant, it should be placed in deep, light, rich soil on the lower flanks of the rockgarden, and associated with plants of the vigour and stature of the Vernal Adonis, the American Cowslip, and the Rocky Mountain Columbine. Siberia. Division. Flowers in early summer.

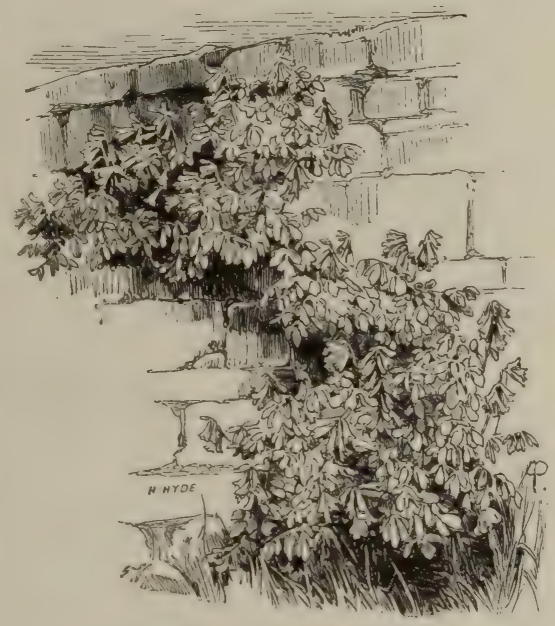

VELLOW FUMITORY (CORYIALIS LUTEA) ON WALL.

C. solida (Bulbous Fumitory). - A compact tuberous-rooted species, 4 in. to 6 or 7 in. high, and freely producing dull purplish flowers. It has a solid bulbous root, is quite hardy, and is of easy culture in almost any soil. A pretty little plant for borders, for naturalising in open spots in woods, and also for the spring garden. It is naturalised in several parts of England, but its home is in the warmer parts of Europe. Division. It flowers in April. (Syn., Fumaria solida.) Very like it in appearance is C. tuberosa $(=\mathrm{C}$. cava), with the small floral leaves entire. It has a good white variety, C. tuberosa albiflora.

The preceding are the most distinct and useful species. C. aurea, C. bracteata, C. pallida, C. Marschalli, and C. Semenowi are cultivated, but are less desirable for general cultivation.

Corylopsis.-A small and little-known 
group of hardy shrubs, allied to the Witch Hazel (Hamamelis), from China, Japan, and N. India. They are thin and dwarf, have ribbed leaves resembling the Hazel, and bear flowers in drooping racemes. The oldest and best-known is the Japanese C. spicata, 3 or $4 \mathrm{ft}$. high, with cowslip-coloured and cowslip-scented flowers, in spikes produced before the leaves in spring, like the Witch Hazel. It is quite hardy, though, being rare, it is generally grown against a wall. C. pauciflora, also a native of Japan, is similar to C. spicata. C. himalayana, from the Khasya hill region, has yellow and white flowers, and is very rare. As these are early spring-flowering shrubs, they should be planted in spots sheltered from cold winds, but the most satisfactory way is to plant them against a wall.

Corypha australis.-A noble Australian palm, over $30 \mathrm{ft}$. high in its native country, and very effective for the sub-tropical garden in summer, from June till October. Its leaves are nearly circular, often more than $5 \mathrm{ft}$. broad, on spiny leaf-stalks, from $6 \frac{1}{2}$ to nearly Io $\mathrm{ft}$. long. It requires abundance of water, and should have a warm, sunny, and sheltered position. Few places, however, can have tropical subjects of this character in the open air, except where there are large conservatories.

Cosmidium filiforme. - Similar to Coreopsis, having erect stems I to $2 \mathrm{ft}$. high, and producing in autumn numerous light orange-yellow flowers 2 in. across. It thrives best in a light sandy loam, and should be sown in heat in February or March. It is a pretty border flower, but there are so many perennial plants of the same stamp that it may be dispensed with. Texas. C. Burridgeanum is a species with yellow flowers, and a variety of it (atro-purpureum) with dark purple flowers is a showy half-hardy annual of easy culture, and well worth growing.

Cosmos.-Mexican plants of the Composite family. One species, C. bipinnatus, is a handsome annual, 3 to $5 \mathrm{ft}$. high, having finely-divided feathery foliage, and large Dahlia-like blossoms of a bright red-purple with yellow centres. It requires to be treated as a tender annual. The seeds should be sown in February or March in a heated frame, and the seedlings transplanted in May in good, rich, moist soil, with a warm exposure. Flowers from August to October. Good for grouping with bold and graceful annuals, and better than many more popular ones.
C. atropurpurea, called the "Black Dahlia," is a "very handsome perennial, with nearly black Dahlia-like flowersdoes well in ordinary soil.

\section{Costmary (Balsamita vulgaris).}

Cotoneaster. - None of the Cotoneasters can strictly be called flowering shrubs, but make beautiful wall-climbers. The best for wall-coverings is C. microphylla, common enough in most gardens and needing no description. Other kinds suitable for walls are C. Simonsi, with orange-scarlet berries; C. buxifolia, and $\mathrm{C}$. thymifolia. The last two as well as C. microphylla are evergreen and perfectly hardy, and are useful for planting in rock-gardens, on steep banks, and against open walls, or for a margin to borders and shrubberies.

\section{Cotton Grass (Eriophorum).}

Cotton Thistle (Carduus eviophorus). Cotyledon Umbilicus (Wall Navelwort).-A native of Britain, Ireland, and many parts of Western Europe, and very common on walls. Of little importance for cultivation, except perhaps now and then in a hardy fernery or a bog.

Cousinia Hystrix.-A bold and singular plant, mainly of botanical interest.

\section{Compositæ.}

Cowslip (Primula veris).

Crambe cordifolia.- One of the finest of hardy and large-leaved herbaceous plants. It is as easily grown as the common Seakale, and, in heavy rich ground, makes a fine rich growth of leaves, surmounted in summer by a dense spray of small white flowers. The deeper and richer the soil the finer the result. C. cordifolia may be planted wherever a bold though low type of vegetation is desired. There is another species, C. juncea, a dwarf kind, with white flowers and much-branched stems, the ramifications of which are very slender and elegant. This is also effective, but not so valuable as C. cordifolia.

\section{Cranberry, American (Vaccinium macrocarpum).}

Cranesbill (Geranium).

Crassula alpestris. - A pretty rock plant, lately brought into notice here by Herr Max Leichtlin, of Baden-Baden, who sent it to Kew under the name of Sedum alpestre. It is a neat perennial, with creeping and slightly branched stems, which are of a bright reddish tint. The flowers are in terminal clusters; they are white, of wax-like substance, and have orange-red tipped stamens, producing a pretty effect. Though it is a native of the Cape, from whence we have so many tender species of Crassula, 
it proved at Kew quite hardy enough to live unprotected in this climate. It thrives well in the rock-garden, in a thoroughly drained and open position, and continues to flower throughout the summer.

Cratægus (Thorns).-A few of the Thorns are familiar trees in most gardens, and are very valuable ornaments, but the genus, numbering over fifty species, is not nearly so well represented as it should be. Some of the most beautiful kinds are seldom seen-outside botanical gardens. scarlet (punicea), rose (carminata or rosea), and various others. Some varieties, like the graceful pendula, are remarkable for their habit, others have foliage different from the type, and a few differ as regards fruit, there being yellow-berried varieties as well as whiteberried.

The list of other species deserving of attention in gardens is long; a selection of the very best includes the following: The Cockspur Thorn (C. Crus-galli) from North America, usually about Io ft. high,

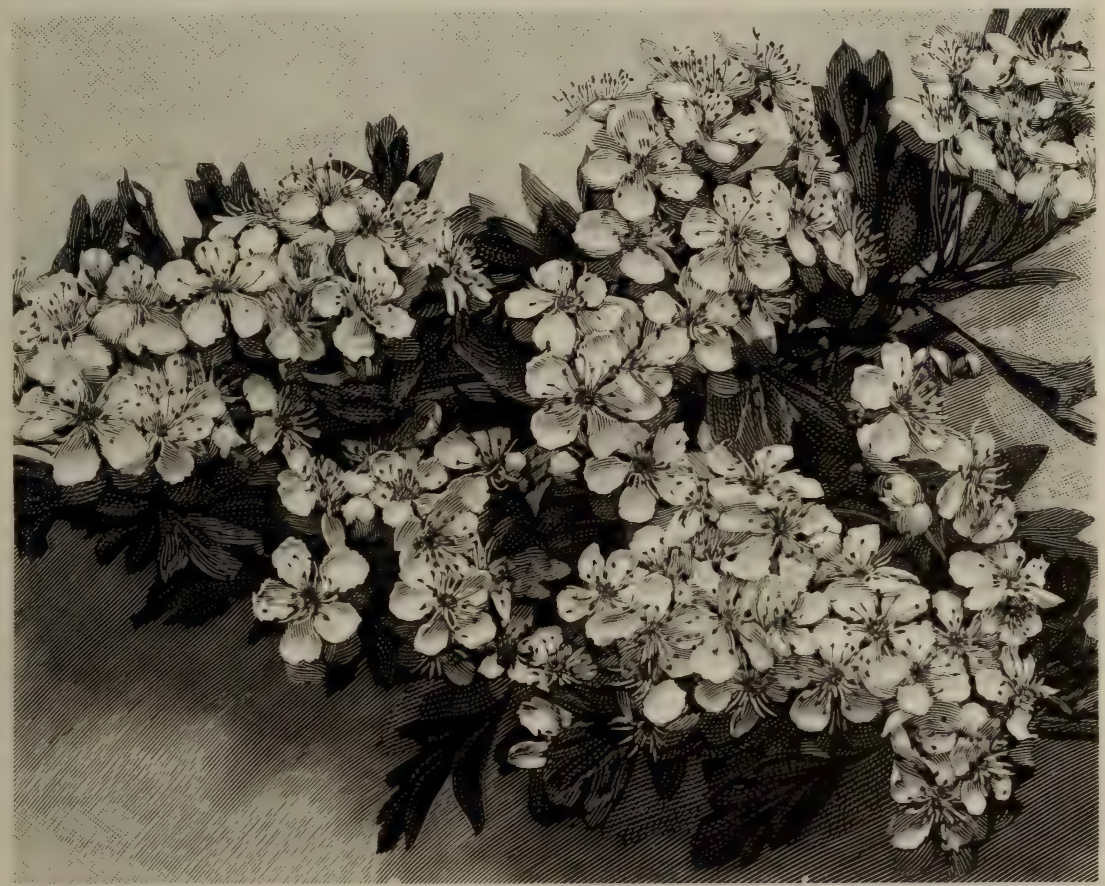

MAY, HAWTHORN.

Almost every Thorn is hardy ; some are remarkable for their flowers, others for their ornamental fruits, while in a few the habit renders them most important to the landscape gardener. The commonest and perhaps the most beautiful of all is C. Oxyacantha, the native Hawthorn or Whitethorn. The typical white kind is lovely enough, but being everywhere its varieties are most important. We have now every gradation of tint in the Hawthorn, from the deepest crimson, through pinks and carmines, to the snowy whiteness of the double sort. Every one now knows Paul's Double Scarlet, undoubtedly the best of all. Then there are the double pink, double white, the single is remarkable for peculiar growth, especially the variety pyracanthifolia. In this the branches spread out like a table, and the older the tree becomes the more pronounced the table-like growth. Other distinct sorts of the Cockspur Thorn are nana, linearis, ovalifolia, and prunifolia. The Scarlet-fruited Thorn, also North American, is beautiful both when covered with white bloom in early summer or with scarlet fruits in autumn. The Tansy-leaved Thorn (C. tanacetifolia) is handsome in foliage. It may always be recognised by its cut leaves of a whitish hue, and by its being one of the latest Thorns to flower. C. Azarolus, Aronia, and orientalis are all natives of the 
Levant, and they are so beautiful in autumn, with fine-coloured fruits as big as Hazel-nuts, that they deserve attention. One specimen of any of these on a lawn would be sufficient in a small garden, as they are spreading, and in good soils 15 or $20 \mathrm{ft}$. high. The Washington Thorn (C. cordata) flowers when all the others are past; hence its value. C. glandulosa, also known as C. flava, has yellow fruits. C. Douglasi has dark purple haws, and C. melanocarpa and C. nigra have black haws. The Pyracantha (C. Pyracantha), so common as a wall climber, is a general favourite because of its profuse crop of orangescarlet berries and luxuriant evergreen foliage. It is suitable for planting in the open, and some beautiful effects may be made by making its spreading and trailing growth serve as a margin to groups of taller Thorns, or other small trees. - The variety Lælandi fruits more freely than the common Pyracanth when planted as a bush. The hardy Thorns are suitable for nearly all kinds of soils, flourishing with equal vigour in light and in heavy soils, while the majority are quite at home on chalk.

Creeping Jenny (Lysimachia Nummularict).

Creeping Vervain (Zapania nodiflora). Creeping Wintergreen (Gaultheria procumbens).

Crepis (Hawk's-beard).--Of this genus of Compositæ few save B. rubra, the Red Hawk's-beard, are worthy of culture. It is a hardy Italian annual bearing pretty pink flowers about the size and form of the Dandelion. It should be sown in spring or autumn like other hardy annuals in any ordinary garden soil. It flowers from June to September, and is suitable for borders or beds of annual flowers. There is also a variety with white flowers. C. aurea is a perennial 6 to 12 in. high, with small orange blossoms, but seldom more than one to each slender stem. C. incisa is a good species for border, owing to its compact habit and large showy light purple flowers, as is also indica, a dwarf species, free-flowering and pretty, called Calimens incisa, and also known as Aster japonicus. Division and seed.

\section{Cress Violet (Ionopsidium acaule).}

Crinum.-A few South African species of this genus are quite hardy, and very beautiful. One of the best-known and the hardiest is $C$. capense, a noble bulbous plant, 2 to $3 \mathrm{ft}$. high. It flowers late in summer, the large funnel-shaped pink blossoms being produced in umbels of ten or fifteen blooms terminating a stout erect stem. There are several varieties: album, pure white; riparium, deep purple; fortuitum, white ; and striatum, striped pink and white. Several fine hybrids have also been raised. They are specially suited for growing in the pleasure-ground, in isolated tufts or small beds, with groups of hardy fragrant plants or with the nobler herbaceous subjects, especially those that flower in late summer and early autumn; or for grouping and massing near the margin. of water, or on small islands or parts of islands on which a distinct and choice type of vegetation is sought. Few plants repay better a sheltered and warm position, and deep, very rich soil, with abundance of water in summer. In very cold situations a little pile of leaves may be desirable over the roots in winter, and by planting the top of the bulbs 6 in. deep there need not be any fear of the weather. Division and seed. C. campanulatum is also hardy, but as it is rare, and scarcely ever flowers, it is not worth growing in the open. C. Moorei and ornatum are said to be hardy in Ireland, and certain hybrids of recent origin may prove hardy.

Crocosma aurea (Tritonia).

Crocus.-Of a genus of nearly seventy species, it is surprising that only three or four are generally used for garden decoration; and these-C. aureus and C. vernus and their varieties, and perhaps one or two other species-have been in cultivation at least three hundred years. Crocuses flower at a time when every flower is of value; and we do not doubt that ere long species recently introduced will largely add to our means of garden decoration during the dull months from late autumn to early spring.

Cultural Directions seem almost superfluous; but there are a few points to which it may be convenient to refer. The genus must be viewed as in succession, from the beginning of August till April; but of these only the earlier autumnal, or the distinctly vernal, species can be relied upon for open-air decoration. Although all are hardy, those that flower in November, December, and January are so liable to injury by frost and rain, that they are practically worthless.

Crocuses are easily multiplied by seed, which should be sown in July as soon as ripe, though germination will not take place till the natural growing period of the species. Seedlings take from two to three years to arrive at maturity, and should be left for the first two years 


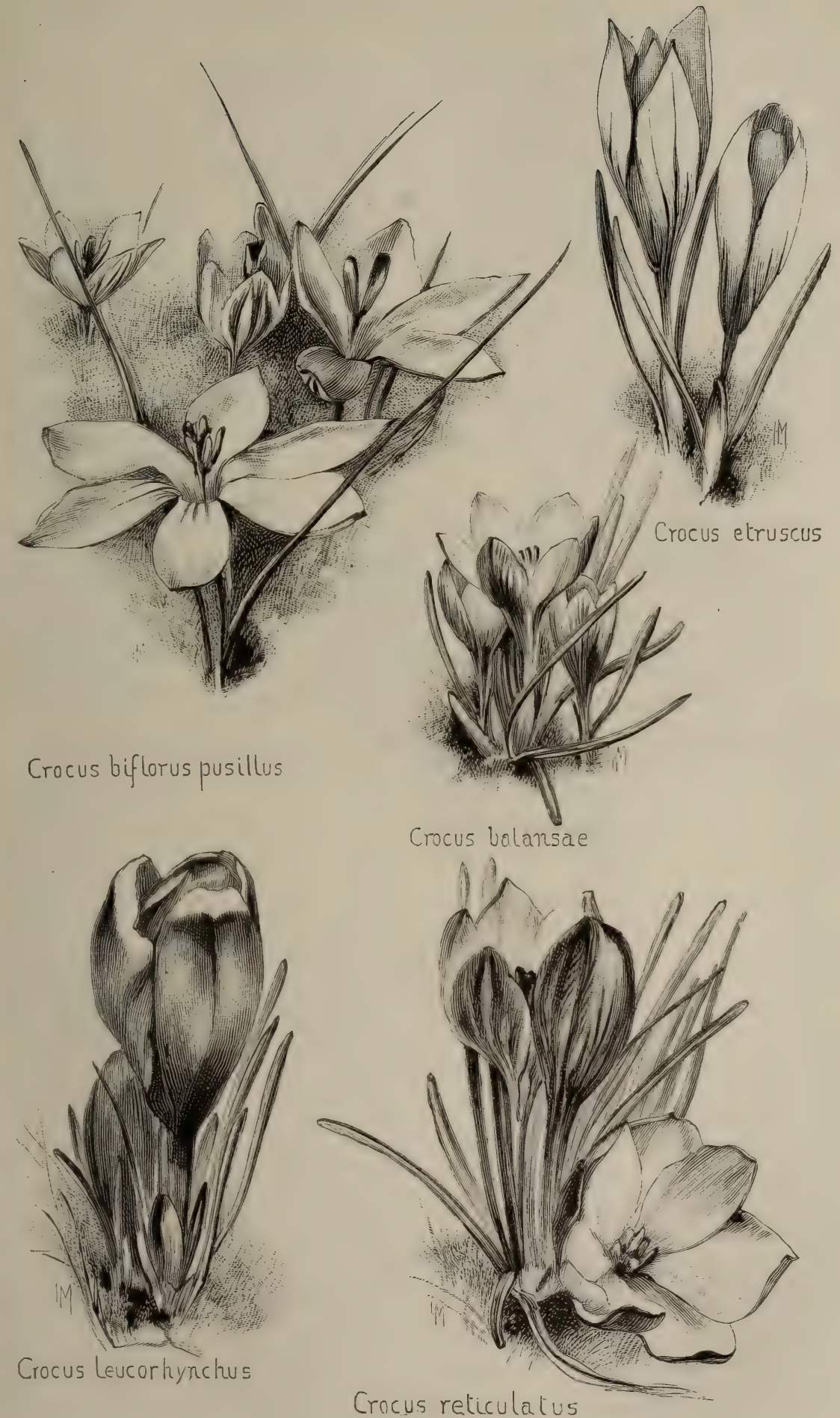


undisturbed in the seed-bed, and then taken up and replanted. Holland, with its rich light alluvial soil, and I.incolnshire, with its "Trent warp," have for many generations been the sources from which the English market has been supplied with the varieties of the three or four species grown in English gardens. The last five or six years have put us in possession of nearly the whole of the known species, and we must commend them to the Dutch and Lincolnshire bulbgrowers.

For the less robust and less floriferous species, a brick pit is necessary. The bottom of this should be well below the level of the ground, and it should be filled up with about $\mathrm{I} \mathrm{ft}$. in depth of fine river silt or sandy loam, the surface of which should be a little below the level of the adjacent ground. Proper drainage is essential, but Crocuses delight in a uniformly moist subsoil during their period of growth. It is convenient to separate the different species by strips of slate or tiles, buried below the surface, the corms being planted about 3 in. deep. A mulching of rotted Cocoa-nut fibre or finely-sifted peat keeps the surface moist, and prevents the loam from clogging or caking on the surface. At the time of the maturity of the foliage, generally about the end of May, water should be withheld and the bed covered up and allowed to get quite dry till the end of July, when a copious watering may be given, or the pit may be exposed to rain.

Of the earlier autumnal species suitable for the open border the following may be enumerated for successional flowering :-

C. Scharojani, orange; early in August. .. vallicola, straw-coloured; late in August and early in September.

., nudiflorus, blue; September.

", pulchellus, lilac; Sept. and Oct.

", speciosus, blue; Sept. and Oct.

", iridiflorus, blue; Sept. and Oct.

"Salzmanni I lilac or blue ; October

.. Clusi $\}$ and November.

". cancellatus

.. Cambessidesii $\}$ in the early autumn.

., hadriaticus

These are succeeded by a long series of

late autumnal, winter, and early vernal species, which are grown to best advantage in a brick pit.

Of the vernal species suitable for the border, the earliest is C. Imperati, flowering in February, followed by

C. susianus, or Cloth of Gold, in February

\section{C. biflorus}

.. etruscus

.. suaveolens

.. versicolor

.. vernus

.. Tommasinianus

.. dalmaticus

.. banaticus

.. Sieberi and var, versicolor

.. chrysanthus

.. aureus

" sulphureus

"vars. pallidus and striatus

.. stellaris

". Olivieri

" minimus

Of the Croci recently introduced, many vernal species will probably be suitable for the spring garden, but as they are rare and scarcely procurable, we give those more generally known and easy to obtain.

C. alatavicus.-The flowers of this new Asiatic species are white, yellow towards the throat, the outer surface of the outer segments being freckled with rich purple. It is a free-flowering species, but from its early flowering time, January and February, it can only be grown to advantage under a cold frame. A white variety without external purple freckling is not uncommon. The leaves are produced at the flowering time in early spring.

C. aureus. - A handsome plant. The Banat, Transylvania, European Turkey, Greece, and Western Bithynia, generally at low elevations, flowering in February: It was one of the first introduced to cultivation, and is the parent of our yellow garden or Dutch yellow Crocus, and of a number of old varieties-lacteus, sulphureus, pallidus, striatus, etc., the history of which is unknown; they are not found wild, and are sterile. The wild plant varies considerably, from unstriped orange to varieties striped with gray lines, like those in the Dutch yellow Crocus. The stig. mata are short, unbranched, pale yellow, and much shorter than the anthers; in the Transylvanian plant the stigmata are occasionally orange. The anthers are wedgeshaped,tapering towards the point, and notably divergent. The unstriped form readily produces seed when in cultivation, but the striped Dutch yellow is sterile, though effete capsules are occasionally formed. C. Olivieri resembles C. aureus, but is smaller.

C. banaticus.-Common in the Banat, Hungary, and Transylvania, where it takes the place of $\mathrm{C}$. vernus, to which it is allied. It is highly ornamental; the flowers are a deep rich purple, occasionally varied with white, with a darker purple blotch near the end of the segments. The throat 
is glabrous, which easily distinguishes it from C. vernus. It is cultivated in several Continental and English gardens under the name of $C$. veluchensis - a distinct species. Flowers in February and March.

C. biflorus.-The Scotch, or Cloth of Silver, Crocus is a large variety of the typical form, and is abundant throughout a large portion of Italy. The segments vary from white to a pale lavender, the outer surface of the outer segments being distinctly feathered with purple markings. In var. estriatus, from Florence, the flowers are a uniform pale lavender, orange towards the base. In var. Weldeni, from Trieste and Dalmatia, the outer segments are externally freckled with bright purple. In $\mathrm{C}$. nubigenus, a very small variety from Asia Minor, the outer segments are suffused and freckled with brown; C. Pestalozzæ is an albino of this variety. In C. Adami, from the Caucasus, the segments are pale purple, either self-coloured or externally feathered with dark purple. C. biflorus is an early flowering spring species, and is highly ornamental for border decoration.

C. Boryi. - Flowers white, but bright orange at the throat. Abundant at Corfu and in the neighbourhood of Patras, flowers in October, but it does not bloom freely in cultivation, and requires the protection of glass for the development of its flowers.

C. byzantinus, see C. iridiflorus.

C. cancellatus. - A beautiful autumnal species, varying from white to pale bluishpurple. The flowers are generally veined or feathered towards the base of the segments. They appear without the leaves, which come in spring. The flowering time is from the end of October to December. A robust species, easy of culture, but, like many late autumnal species, is seen to best advantage under a cold frame. It is known as C. Schimperi, C. Spruneri, C. cilicicus, and C. damascenus. The western forms are nearly white, and the eastern are either blue or purple; but the differences of colour are not sufficient to distinguish them as species.

C. chrysanthus. - A vernal Crocus, flowering from January to March accord- ing to elevation, which varies from a little above the sea-level to a height of three or four thousand feet. The flowers are smaller than those of C. aureus, and are usually of bright orange, but occasionally bronzed and feathered externally. A white variety is also found in Bithynia and on Mount Olympus above Broussa; this species also varies with pale sulphur-coloured flowers, occasionally suffused with blue towards the ends of the segments, dying out towards the orange throat. There are four varieties of this Crocus, distinct in colouring; they are fusco-tinctus, fusco-lineatus, albidus, and cœrulescens.

C. Imperati. - One of the earliest 
flowers are somewhat smaller and the segments more acute than in C. Imperati. It is hardy and free-flowering, and under bright sunshine is a good ornament to the early spring garden.

C. iridiflorus.-The Banat and Transylvania. Bears in September and October bright purple flowers before the leaves. Remarkable for purple stigma and the marked difference between the size of the inner and the outer segments of the perianth. This beautiful plant should be secured if possible. It is often sold as C. byzantinus.

\section{C. lævigatus.-} A pretty species from the mountains of Greece and the Cyclades. The flowers vary from white to lilac, being distinctly feathered with purple markings. Its usual flowering time is from the end of October to Christmas, but through the winter to March under cultivation. It does not flower freely in cultivation, and, like the allied species, it is seen to best advantage under a cold frame.

C. longiflorus. Abundant in the south of Italy, Sicily, and Malta; flowers in October. The flowers are light purple, yellow at the throat. In general aspect it

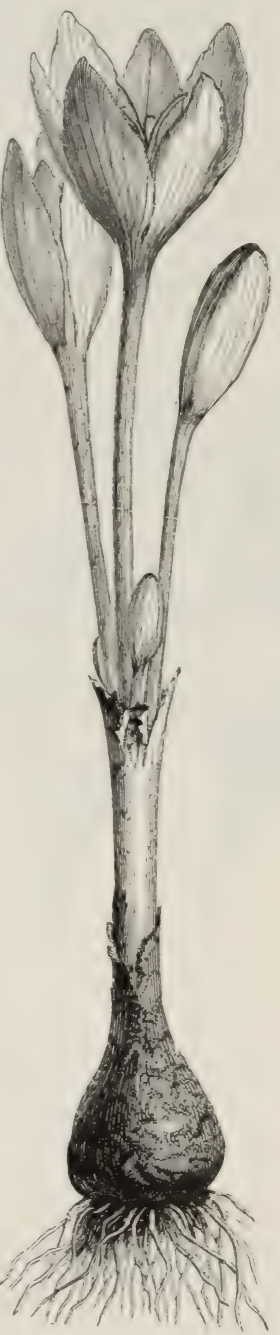

CROCUS NUDIFLORUS. somewhat resembles C. sativus, especially in the stigmata, which are usually bright scarlet and entire, but occasionally broken up in fine capillary divisions. In Sicily the stigmata are collected from the wild plant for saffron. It is free-flowering, and very ornamental.

C. medius.-A beautiful purple autumnflowering species, limited to the Riviera and the adjacent spurs of the Maritime Alps. The flowers are produced in October before the leaves, which appear in the following spring, and rarely exceed two or three to a corm; the blossoms are bright purple, veined at the base; the stigmata bright scarlet and much branched.

C. nudiflorus.--A pretty and wellknown species. Pyrenees and North of Spain. Naturalised at Nottingham and elsewhere in the midland counties. Its large bluish-purple flowers are produced in September and October before the leaves. Where established it is difficult to eradicate; the corms produce long stolon-like shoots, which form independent corms on the death of the parent, and the plant soon spreads to considerable distances.

C. ochroleucus bears many creamywhite flowers, with orange throat, from the end of October to the end of December. It well deserves a cold frame, to preserve its showy flowers from frost and rain.

C. pulchellus.-An autumnal species, invaluable for decorative purposes. The pale lavender flowers, with bright yellow throat, are freely produced from the middle of September to early in December. Seed.

C. serotinus.-S. of Spain. Flowers in November. The blossoms are more or less distinctly feathered with darker purple. C. Salzmanni is closely allied to C. serotinus, but is of larger stature, flowering with the leaves in October and November. It is robust and readily multiplied. As the flowers are liable to injury by frost and snow, it is seen to best advantage under a cold frame. C. Clusi closely resembles C. serotinus, and flowers with the leaves in October.

C. Sieberi.-A vernal species common in the Greek Archipelago and the mountains of Greece. The flower is usually bright lilac, orange at the base, but the form found in Crete and the Cyclades presents a great variety of colour, from white to purple, and these colours are mottled, intermixed, and striped in endless variety, contrasting with the bright orange throat. The Cretan variety is of exceptional beauty. It flowers in cultivation from the end of February to the middle of March.

C. speciosus.-Among the handsomest autumn Crocuses. Flowers at the end of September and early in October. Ranges from North Persia, through Georgia, the Caucasus, and the Crimea, to Hungary. The perianth segments, 2 in. high, are 
rich bluish-purple, suffused with darker purple veins, with which the bright orange much-divided stigmata form a beautiful contrast. It has been long in cultivation, and readily multiplies by small bulbels at the base of the corm.

C. susianus.-The well-known Cloth of Gold Crocus, an early importation from the Crimea. Both the orange and bronzed susianus are among the earliest vernal Crocuses, flowering in the open border in February. C. stellaris is an old garden plant, somewhat resembling C. susianus. The flower is orange, distinctly feathered with bronze on the outer coat of the outer segments. It is sterile, and never produces seed. It flowers early in March.

C. vernus (Spring Crocus).--One of the earliest cultivated species. Alps, Pyrenees, Tyrol, Carpathians, Italy, and Dalmatia. Naturalised in several parts of England. Remarkable for its range of colour, from pure white to deep purple, endless varieties being generally intermixed in its native habitats, and corresponding with the horticultural varieties of our gardens. Flowers early in March at low elevations, and as late as June and July in the higher Alps. The parent of nearly all the purple, white, and striped Crocuses grown in Holland.

C. versicolor.-This well-known species has long been in cultivation. The flowers present a great variety of colouring, from purple to white, and are variously striped and feathered. It differs from the two preceding species in having the whole of the perianth segments similarly coloured, and the external buff coating of C. Imperati and C. suaveolens is absent. Its flowering time is March.

C. zonatus.--Mountains of Cilicia. Bright vinous lilac flowers, golden at the base, abundant about the middle of September. It is highly ornamental and freeflowering, and easy of culture. The flowers come before the leaves, which do not appear till spring. It has been in cultivation about fourteen years.

This account of the genus is condensed from an article in The Garden of 28 th January 1882 , by Mr. Geo. Maw, of Benthall Hall, near Broseley. The article contains a full account of the family, with descriptions of species not in cultivation, giving botanical authorities, and fuller technical descriptions.

Croomia paucifiora.-A North American plant of little garden value.

Crowberry (Empetrum nigrum).

Crowfoot (Ranunculus).

Crown Imperial (Fritillaria imperialis).
Crucianella stylosa (Fotid C.) - A pretty dwarf herb, with leaves arranged in whorls 9 to 12 in. high. Flowering in summer; pale rose, flowers small, but freely produced. Persia and the Caucasus. Thrives on borders, rock-garden, or bare banks, in sandy or calcareous soil, but in certain states of the atmosphere its foxlike odour is offensive, and hence it does not deserve a place in the choice garden.

Division.

\section{Cuckoo-flower (Cardamine pratensis). Cuckoo-pint (Arum). \\ Cucubalus.-A small genus of the} Catchfly family, only suitable for botanic gardens.

Cucumis. - Certain of the hardier species-for example, the Gooseberry Gourd (C. grossularoides) - may be worthy of a place, but they have no essential place in gardens generally.

Cucurbita (Gourd).-The Gourd tribe is capable of adding remarkable beauty and character to the garden, yet it is seldom used. There is no Order more wonderful in the variety and shape of its fruit than that to which the Melon, Cucumber, and Vegetable Marrow belong. From the writhing Snake Cucumber, which hangs down 4 or $5 \mathrm{ft}$. long from its stem, to the enormous round Giant Pumpkin or Gourd, the grotesque variation in colour, shape, and size, is marvellous. There are some pretty little Gourds which do not weigh more than $\frac{1}{2} \mathrm{oz}$. while, on the other hand, there are kinds almost large enough to make a sponge bath. Eggs, bottles, gooseberries, clubs, caskets, folded umbrellas, balls, vases, urns, balloons, all have their likenesses in the family. Those who have seen a good collection will understand Nathaniel Hawthorne's enthusiasm when he says: "A hundred Gourds in my garden were worthy, in my eyes at least, of being rendered indestructible in marble. If ever Providence (but I know it never will) should assign me a superfluity of gold, part of it should be expended for a service of plate, or most delicate porcelain, to be wrought into the shape of Gourds gathered in my garden. As dishes for containing vegetables they would be peculiarly appropriate. Gazing at them, I felt that by my agency something worth living for had been done. A new substance was born into the world. They were real and tangible existences which the mind could seize hold of and rejoice in." It is satisfactory to know that they may be readily and beautifully grown in this country. There are many ways in which they may be grown with great advantage- - on low 
trellises; depending from the edges of raised beds; the smaller and mediumsized trained over arches or arched trelliswork, covering banks, or growing on the level earth. Isolated, too, some kinds would look very effective ; in fact there is hardly any limit to their use. In the Royal Botanic Gardens at Dublin there is and showy fruit so well that the eye enjoys the picture. A bold and effective use may now and then be made of them on walls.

A Selection of Gourds.-Amongst the most beautiful are the Turk'scap varieties, such as Grand Mogul, Pasha of Egypt, Viceroy, Empress, Bishop's Hat, etc. ; the Serpent Gourd,

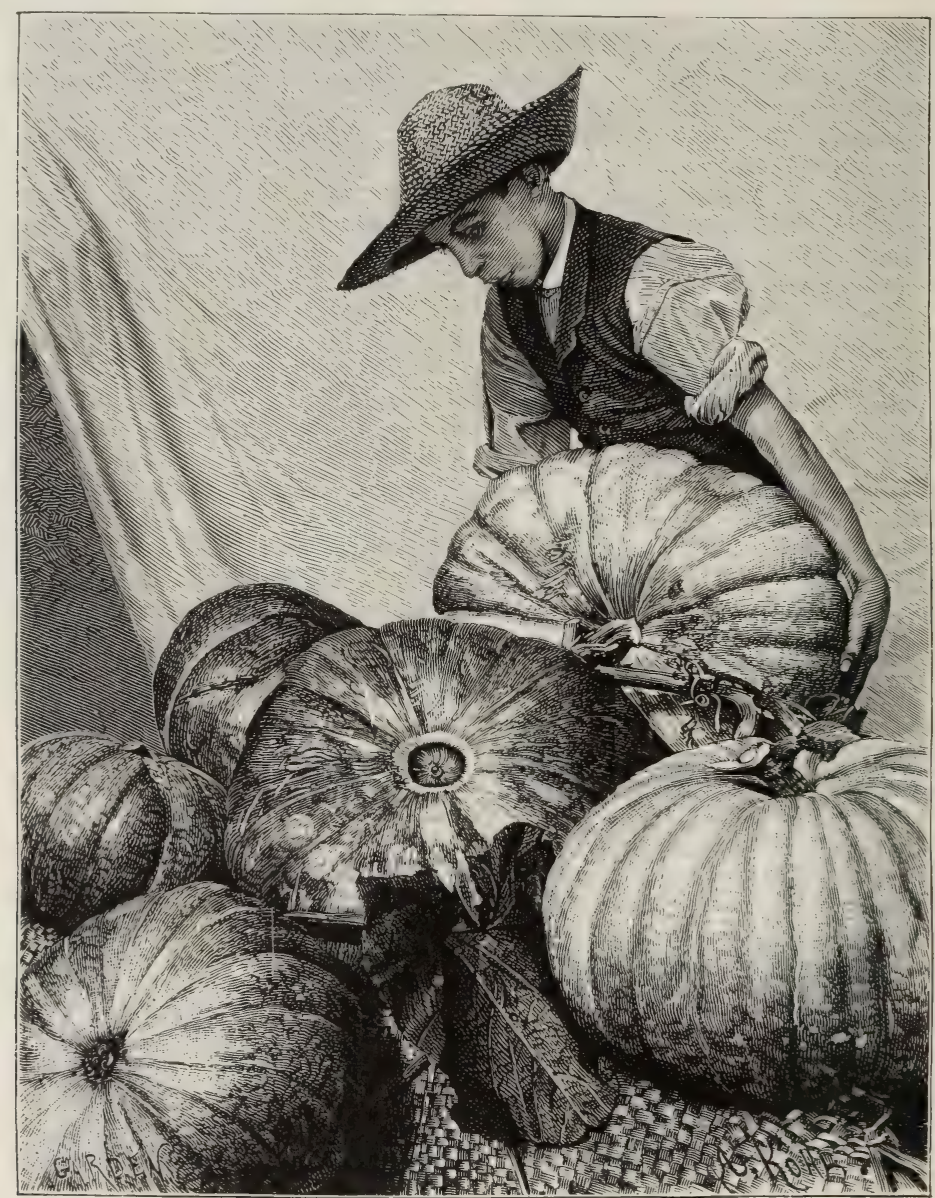

GOURDS IN A SURREY GARDEN.

a singular wigwam made of a framework of dead branches, with Aristolochia Sipho planted all round them. It runs over them, and its large leaves make a perfect summer roof. A similar tent might be made with free-growing Gourds, and it would have the additional merit of suspending some of the most singular, graceful, and gigantic of fruits from the roof. A very good way is to train them over sheds or outhouses. These "carry" the foliage
Gooseberry Gourd, Hercules' Club, Gorilla, St. Aignan, M. Fould, Siphon, Halfmoon, Giant's Punchbowl, and the Mammoth, weighing from I 70 lbs. to upwards of 200 lbs. ; while amongst the miniature varieties the Fig, Cricket-ball, Thumb, Cherry, Striped Custard, Hen's-egg, Pear, Bottle, Orange, Plover's-egg, etc., are very pretty examples, and very serviceable for ornament. All these are well suited to our climate, and there are many others 
equally suitable. Mr. W. Young, indeed, exhibited a collection of 500 varieties, all English grown, the greater number of which had been sown where grown, and had come to maturity without protection. The ground being manured and dug one spit deep, the seed was sown the second week in May. Many of the plants had no water through the season, but others had it in various quantities, and the more the water the larger, freer, and better the produce. Sowing in a frame at the end of April, and exposing the plants to the air during the day to prevent their being drawn, and then removing the frame altogether to harden them off before planting out, is the best way to secure an early growth. Sowing in the open ground under hand-lights would do, but not so well. Where there are waste heaps of rubbish or manure it is a good plan to cover them with Gourds. Although they grow under the conditions described above, they do best with plenty of manure, and should be mulched or well watered if the soil be not deep and rich.

C. perennis (Perennial Cucumber).A remarkable-looking and vigorous hardy trailing plant, with large hoary leaves, chiefly valuable for the botanical collection. Seed and careful division.

Cup-flower (Scyphanthus elegans).

Cuphea.-Interesting plants of the family Lythraceæ, of which C. platycentra (Cigar-plant) is perhaps the most useful for the summer flower garden. It is a dwarf compact bush, about 12 in. high, and bears a profusion of vermilion tube-shaped blossoms, with black lower lip and edged with white on the tip. Easily propagated by cuttings taken in September or April, and put in slight heat like Verbenas. Also raised from seed sown in heat in spring. C. strigulosa is a pretty variety, useful for planting out in single plants in the mixed border for cutting from, but chiefly used as a pot plant for autumn greenhouse flowering. C. Zimapani is a most useful annual, nearly allied to the old-fashioned $C$. silenoides, but better. It grows about $\mathbf{1} \frac{1}{2} \mathrm{ft}$. high, has numerous branches rising from the base, and when it is only a few inches high in early summer it begins to bear flowers of a rich deep purple bordered with a lighter hue, and resembling those of a Sweet Pea, and of about the same size, which appear till the frosts cut the plants down. They are well fitted for cutting, as the branches lengthen and the flowers expand a long time in water. Altogether it is very desirable, especially in autumn, when most annuals are gone, and even perennials are scarce. Other kinds are C. eminens, Galeottiana, miniata, ocymoides, purpurea, Roezli, and silenoides, all of smaller importance for the flower garden than those before named.

\section{Cupidone, Blue (Catanach corulea).}

Cupressus (Cypress).-Graceful low trees that often figure in the garden landscape, and form charming backgrounds to secluded and special gardens. Not many, however, are really hardy, save on sea-shore and in warm southern districts, and even there they often perish in hard winters. They are often beautiful in Ireland and the western coasts, but there we have seen the Californian Cypress, C. macrocarpa, perish after looking happy for years. The beautiful Eastern Cypress, so marked a feature in the Italian garden and landscape, is worth planting under the best conditions ; but so distinct and fine a tree would, if hardy, have been everywhere planted long ago. We have seen very fine specimens here and there, as at White Knights. The graceful Cypress of Goa is charming in Irish seashore gardens.

\section{Currant, Flowering (Ribes).}

Cushion Pink (Silene acaulis).

Cyananthus lobatus (Lobed C.)-A brilliant Himalayan rock-plant, about 4 in. high. Flowering in August and September ; purplish-blue flower, with a whitish centre. Thrives in sunny chinks in the rockgarden. Grows best in a mixture of sandy peat and leaf-mould, with plenty of moisture during growth. Increased freely by cuttings. The seed requires a dry season; in wet weather the large, erect, persistent calyx becomes filled with water, which remains and rots the seed-vessel. Polemoniaceæ.

C. incanus.- This is much more floriferous than C. lobatus; like that species, it should be planted in a dry, sunny, welldrained position, as, if the situation be too damp, the fleshy root-stock is liable to rot. It is even a good plan to place something over the plant during the resting season. The flowers are not so large as those of the other species, but are more charming in colour, the beauty of which is enhanced by the white tuft of sericeous hairs in the throat of the corolla. Campanulaceæ.

Cyathea dealbata (Silver Tree-fern). - This very handsome fern, known in N. Zealand as the Silver Tree-fern, has a slender, almost black stem, 4 to $8 \mathrm{ft}$. high, ending in a fine crown of fronds, dark green above and milk-white below. It may be placed in the open air, in the 
southern and milder districts, from the end of May till the end of September.

Cycas revoluta. - A tropical plant, with a very stout stem, sometimes 6 to Io $\mathrm{ft}$. high, from the top of which issues a beautiful crown of superb dark green leaves 2 to $6 \mathrm{ft}$. long. It is one of the most valuable greenhouse plants that may be placed out from the end of May till October, and is particularly graceful in the centre of a bed of flowering plants, or isolated with the pot or tub plunged to the rim in the turf, always in a warm
Ivy-leaved Cyclamen is in full leaf through winter and early spring, and for the sake of the beauty of the leaves alone it is desirable to place it so that it may be safe from injury. It is easy to naturalise the hardier Cyclamens in many parts of the country. Good drainage is necessary to their open-air culture. They grow naturally among broken rocks and stones mixed with vegetable soil, grit, etc., where they are not surrounded by stagnant water. Mr. Atkins, of Painswick, who paid much attention to their culture,

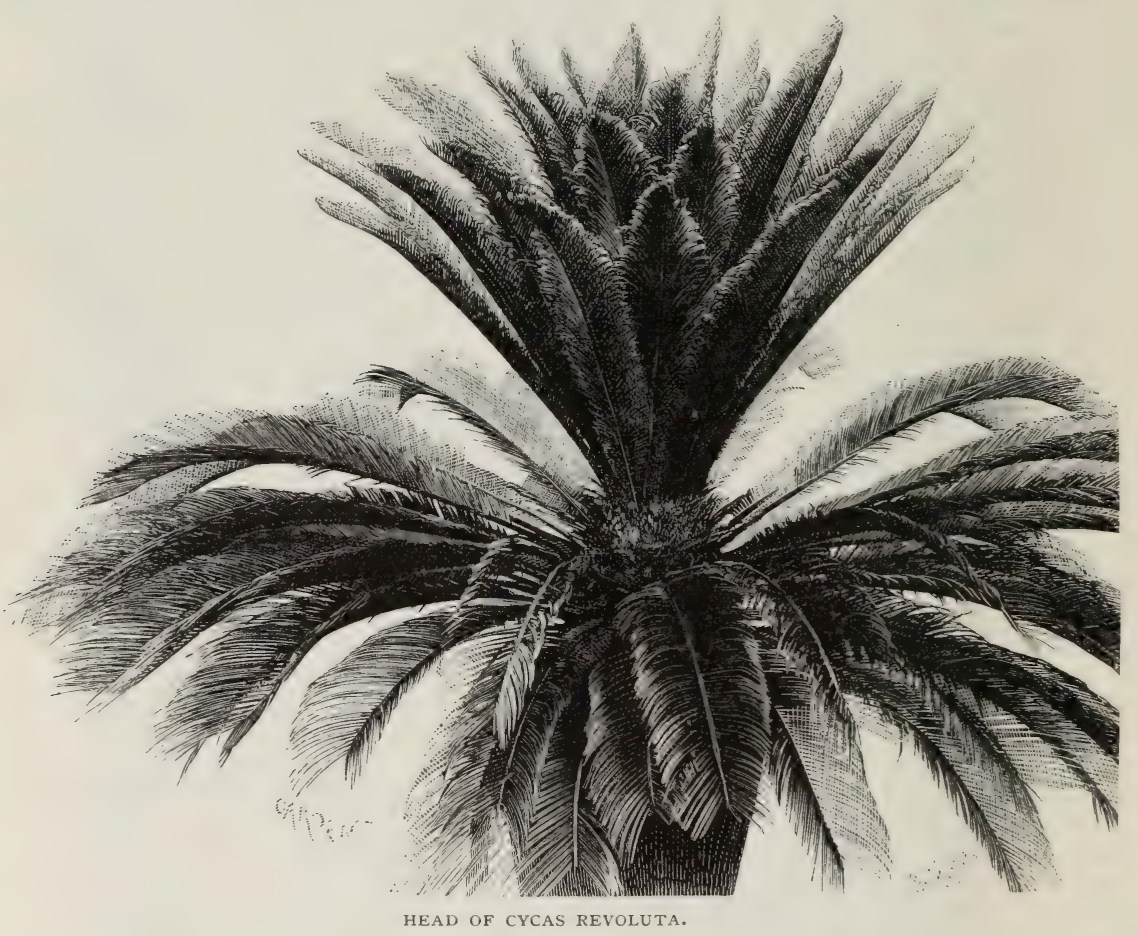

position. Seeds, or separation of suckers, which are occasionally thrown up.

Cyclamen (Sowbread).-We are so accustomed to see the bright flowers of the Persian Cyclamens in our greenhouses that we never think of Cyclamens as hardy. Except the Persian, however, they are as hardy as Primroses; but they love the shelter and shade of low bushes or hill copses, where they may nestle and bloom in security. Their hardiness is no reason why they should thrive in a bare exposed border. In the places they naturally inhabit there is usually the friendly shelter of Grasses or branchlets about them, so that their large leaves are not torn to pieces by wind or hail. The and succeeded in a remarkable degree, thought that the tuber should be buried, and not exposed like the Persian Cyclamen in pots. His chief reason was that in some species the roots issue from the upper surface of the tuber only. They enjoy plenty of moisture at the root at all seasons, and thrive best in a rich, friable, open soil, with plenty of well-decayed vegetable matter in it. They are admirably suited for the rock-garden, and enjoy warm nooks, partial shade, and shelter from dry, cutting winds. They may be grown on any aspect if the conditions above mentioned be secured, but an eastern or south-eastern one is best. We have seen them under trees among Grass, 
where they flowered profusely every year without attention.

They are best propagated by seed sown, as soon as it is ripe, in well-drained pots of light soil. Cover the soil after sowing with a little Moss, to ensure uniform dampness, and place them in shelter outof-doors. As soon as they begin to appear, which may be in a month or six weeks, gradually remove the Moss. When the first leaf is tolerably developed, they should be transplanted about I in. apart in seed-pans of rich light earth, and encouraged to grow as long as possible, being sheltered in a cold frame, but always allowed abundance of air. When the leaves have perished in the following summer, the tubers may be planted out or potted, according to their strength.

There appears to have always been great difficulty in defining the species of Cyclamen, from the great variation in shape and colour of the leaves both above and below. Too much dependence on these characteristics has caused confusion and an undue multiplication of species. Some of the varieties become so fixed, and reproduce themselves so truly from seed, as to be regarded as species by some cultivators. The following are the more important species and varieties.

C. Atkinsi. - A hybrid variety of the Coum section. The flowers are larger than in the type, varying in colour from deep red to pure white, and are plentiful in winter.

C. Coum (Round-leaved Cyclamen).This, like the others of the same section, is perfectly hardy, and frequently in bloom in the open ground before the Snowdrop; yet, to preserve the flowers from unfavourable weather, the plants will be better for slight protection, or a pit or frame in which to plant them out. Grown in this way during the early spring, from January to the middle of March, they are one sheet of bloom. When so cultivated, take out the soil, say $I \frac{1}{2}$ to $2 \mathrm{ft}$. deep, place at the bottom a layer of rough stones 9 to 12 in. deep, and cover them with inverted turf to keep the soil from washing down and injuring the drainage; then fill up with soil composed of about one-third of good free loam, one-third of well-decayed leaf-mould, and one-third of thoroughly decomposed cow manure. Plant $1 \frac{1}{2}$ to 2 in. deep; and, every year, soon after the leaves die down, take off the surface as far as the tops of the tubers, and fresh surface them with the same compost, or in alternate years give them only a surface dressing of well-decayed leaves or cow inanure. During summer, or indeed after
April, the glass should be removed, and they ought to be slightly shaded with Larch Fir boughs (cut before the leaves expand) laid over them, to shelter from the extreme heat of the sun. As soon as they begin to appear in the autumn, gradually take these off. Do not use the glass until severe weather sets in-at all times, both day and night, admitting air at back and front-and in fine weather draw the lights off, remembering that the plants are hardy, and are soon injured if kept too close. They do not like frequent removal. There is a pretty white variety of C. Coum, which is extremely desirable. (=C. hyemale.)

C. cyprium.-This well-defined species has rather small heart-shaped leaves of dark green, marbled on the upper surface with bluish-gray, and of a deep purple beneath. The flowers, which are pure white, tinted with soft lilac (the restricted mouth being spotted with carmine-purple), are well elevated above the foliage. This distinguishes it from most of its allies, except C. persicum, and its foliage distinguishes it from that at a glance. It is one of the most chaste and beautiful of the hardy kinds. Cyprus and other places in South Europe. It is found on shaded rocks in mountainous districts. $\quad(=\mathrm{C}$. neapolitanum.)

C. europæum (European Cyclamen).The leaves of this species appear before and with the flowers, and remain during the greater part of the year. Flowers from June to November, or, with slight protection, until the end of the year. The flowers are a reddish-purple. Some of the southern varieties, by attention to cultivation under glass, may even assume a perpetual flowering character. C. Clusi, littorale, and Peakeanum are varieties of this section. The flowers are much longer, and of a more delicate colour, often approaching peach colour, and are almost the size of those of C. persicum ; pure white are rare, but pale ones are not uncommon : they are very fragrant. C. europæum thrives freely in various parts of the country in light, loamy, welldrained soil, as a choice border and rockgarden plant. Where it does badly in ordinary soil it should be tried in a deep bed of light loam, mingled with pieces of broken stone. In all cases it is best to cover the ground with Cocoa fibre. It is very desirable on account of its fragrance and long succession of flowers. They luxuriate in the débris of old walls and on the mountain side, with a very sparing quantity of vegetable earth to grow in. The bulb varies considerably in size and 
shape; sometimes it is elongated and irregular, and the plant is then the $\mathrm{C}$. anemonoides of old authors. ( $=\mathrm{C}$. odoratum, C. æstivum.) which it well deserves. It does not like frequent removal. It has been naturalised on the mossy floor of a thin wood, on very sandy poor soil and may be naturalised

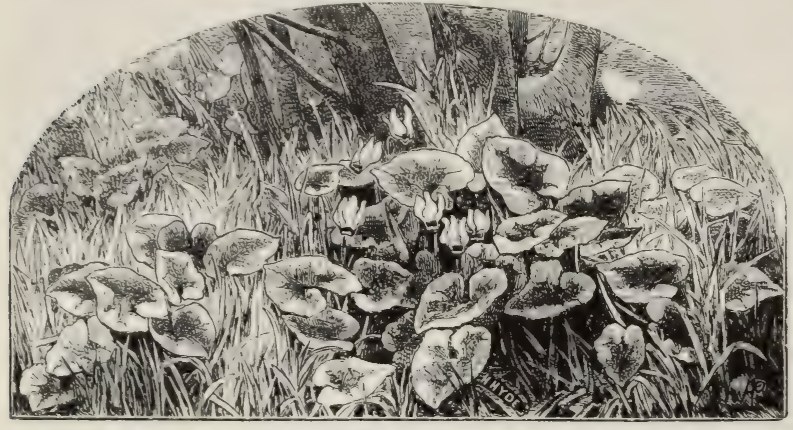

ELRUPEAN CICLAMEN, SOWBREAD (C. EUROPAUN). almost everywhere. It would be peculiarly attractive in a semi-wild state in pleasure-grounds and by wood walks. C. græcum is a very near ally, if more than a variety, and requires the same treatment. The foliage is more like C. persicum, or the southern form of C. europæum. C. africanum (algeriense macrophyllum) is hardy in warm sheltered situations. It is much larger in all parts than $\mathrm{C}$.

C. hederæfolium (Iry-leaved Cyclamen).-Switzerland, South Europe, and the north coast of Africa. Tuber not unfrequently I ft. in diameter, and covered with a brownish rough rind, which cracks irregularly so as to form little scales. The root-fibres emerge from the whole of the upper surface of the tuber, but principally from the rim; few or none issue from the lower surface. The leaves and flowers generally spring direct from the tuber without any stem (there is sometimes, however, a small stem, especially if the tuber be planted deep); at first they spread horizontally, but ultimately become erect. The leaves are variously marked; the greater portion appear after the flowers, and continue in great beauty the whole winter and early spring, when, if well grown, they are one of the greatest ornaments of borders and rock-gardens. Often these leaves are 6 in. long, $5 \frac{1}{2}$ in diameter, and 100 to 150 spring from one tuber. They are admirable for table decoration during winter. The flowers continue from the end of August until October, and are purplish-red, frequently with a stripe of lighter colour. There is a pure white variety, and also a white one with pink base or mouth of corolla ; these reproduce themselves tolerably true from seed. Strong tubers will produce 200 to 300 flowers. Some are delightfully fragrant. They are quite hardy, but are worthy of a little protection to preserve the late blooms, which often continue to spring up till the end of the year. This species is so perfectly hardy as to make it very desirable for the rock-garden and the open borders. It will grow in almost any soil and situation, though best in a well-drained rich border or rock-garden, hederæfolium, but otherwise is very nearly allied.

C. ibericum (Iberian Cyclamen).Belongs to the Coum section. There is some obscurity respecting the authority for the species and its native country. The leaves are very various. It flowers in spring, the flowers varying from deep red-purple to rose, lilac, and white, with intensely dark mouth; and are more abundant than those of C. Coum.

C. vernum (Spring Cyclamen).-The leaves rise before the flowers in spring; they are generally more or less white on the upper surface, and are often purplish beneath. Though one of the most interesting species, and perfectly hardy, it is seldom cultivated successfully in the open border or rock-garden; it is impatient of excessive wet about the tubers, and likes a light soil, in a rather shady nook sheltered from winds, its fleshy leaves being soon injured. The tubers should be planted deep, say not less than 2 to $2 \frac{1}{2}$ in. below the surface. C. vernum of Sweet is considered by many as only a variety of Coum, and it is known as C. Coum var. zonale. It is also known as C. repandum. There is a white-flowered variety.

Cyclobothra (Calochortus).

Cydonia (Quince).-There is perhaps not a commoner exotic flowering shrub in English gardens than the Japanese Quince (C. japonica), which, though introduced only about half a century ago, may be seen adorning the walls alike of the cottage and mansion. The old sort is beautiful enough, with brilliant crimson flowers, but the newer varieties are preferable in point of colour, the finest being cardinalis, deep rich crimson; nivalis, 
snow-white; alba, white, slightly tinged with pink ; rosea, delicate rose-pink ; and princeps, deep scarlet. These are all distinct in colour, and would make a beautiful lawn group in one mass, with their low rounded outline broken by a taller plant, such as Pyrus floribunda. When soil and climate favour the Japanese Quince, it forms a wide-spreading bush 6 or $8 \mathrm{ft}$. high. C. Maulei, a newer introduction from Japan, is less vigorous than C. japonica, has more slender branches, smaller foliage and flowers, which, however, are produced in abundance on every young twig. The flowers are a vivid orange-scarlet, a tint entirely different from that of any other Quince. Golden-yellow fruits of spicy fragrance and about the size of small Pippins succeed the flowers in autumn and remain on the bushes a long time. It is perfectly hardy, and makes a capital hedge on account of its spiny branches. C. chinensis, the Chinese Quince, is somewhat similar to C. japonica, but less desirable, and is rarely seen beyond botanical gardens. The common Quince, familiar as it is, is really a beautiful ornament in any garden, particularly in the picturesque growth of old age. It is so common that nothing need be said about it beyond that it well deserves a place on a lawn in company with the Medlar, Mulberry, Apple, and Pear.

Cynanchum.-A genus of little value for the flower garden, though sometimes grown.

Cynara Scolymus (French Artichoke). - This plant, chiefly grown for cooking, possesses sufficient merit as a foliageplant to entitle it to a place. Its long deeply-divided leaves, white and downy beneath, its height ( 4 to $5 \mathrm{ft}$.), its purplish flower-heads, and distinct habit render it very suitable for the irregular and rougher parts of pleasure-grounds, grass plats, etc., which are often occupied by objects far less striking.

Cynoglossum (Hound's-tongue). - A genus of the Forget-me-not Order, some of which are in cultivation, but are seldom of essential use in the flower garden.

Cyperus longus (Galingale). - The stiff, erect, tapering, triangular stem of this plant, which is from 2 to $3 \mathrm{ft}$. high, is crowned by a handsome, loose, umbellate panicle of chestnut-coloured flowerspikes, at the base of which there are three or more leaves. These are often I or $2 \mathrm{ft}$. long, the lower ones of a bright shining green, arching gracefully and giving a very pleasing aspect. The rootstock is thick and aromatic, and was formerly much used as a tonic. A rare native plant, suitable for the bog-bed, or the margin of water.

Cypress Spurge (Euphorbia Cyparissias).

Cypripedium (Lady's Slipper). - A genus of hardy Orchids, containing several beautiful species perfectly hardy, of which the Mocasson Flower (C. spectabile) is by far the most important. This indeed is one of the handsomest of all hardy flowers, and, fortunately, of easy culture. The following are a few of the cultivated kinds, of which most are worthy of general culture.

C. acaule (Stemless Lady's Slipper).-A dwarf species with a naked downy flower-stalk, 8 to 12 in. high, and bearing a green bract at the top. Flowers early in summer and bears large, solitary purplish flowers with a rosy purple (rarely white) lip, nearly 2 in. long, which has a singular closed fissure down its whole length in front. Leaves two, at the base of the flower-stem, oblong, obtuse, downy. Northern States of North America, in woods and bogs. Requires a shady position in moist peaty soil or leaf-mould.

C. Calceolus (English Lady's Slipper). - The only British species of Cypripedium, and the largest flowered of our native Orchids, I to $I \frac{1}{2} \mathrm{ft}$. high. Flowers in summer, bearing solitary (sometimes two) large flowers of a dark brown colour, with an inflated clear yellow lip netted with darker veins, and about $I$ in. in length. Leaves, generally three or four in number, large, ovate, pointed, and veined. North Europe, and occasional in the northern counties of England, where, however, it is now almost exterminated by unscrupulous plant-gatherers. Very ornamental for the rock-garden, where it should be planted in sunny sheltered nooks of calcareous soil, or in narrow fissures of limestone rock, in well-drained, rich, fibrous loam. It prefers an east aspect.

C. guttatum (Spotted Lady's Slipper). -A handsome rare kind, seldom seen in gardens, 6 to 9 in. high. Flowers in summer, with solitary flowers, which are rather small, but beautiful, white, heavily blotched, or spotted with deep rosy purple. Leaves two, alternate, oval-elliptical, pointed, and downy. Found in Canada, N. Europe (near Moscow), and N. Asia, in dense forests amongst the roots of trees in moist, black vegetable mould. Requires a shady position in leaf-mould, moss, and sand, and should be kept rather dry in winter.

C. japonicum (Japanese Lady's Slipper).-About I ft. high, and its hairy 
stems, which are as thick as one's little finger, bear two plicate fan-shaped leaves of bright green, rather jagged or erosely cut round the margins. The flowers are solitary, on hairy scapes, the sepals being of an apple-green tint; the petals, too, are of the same colour, but are dotted with purplish-crimson at the base ; the lip is large, and curiously folded in front, as in the better-known C. (humile) acaule, to which it seems most nearly allied; the pubescent stem, seldom more than $2 \mathrm{ft}$. high. Flowers early in summer, bearing on each stem one to three flowers ; scentless, greenish-yellow, more or less spotted with brown, with a pale yellow lip from I $\frac{1}{2}$ to $2 \mathrm{in}$. long, and flattened at the sides. Leaves broadly oval, pointed, pubescent. America, found in bogs and low woods, from Pennsylvania to Carolina. Does well on dry sunny banks, among loam, stones, and grit.

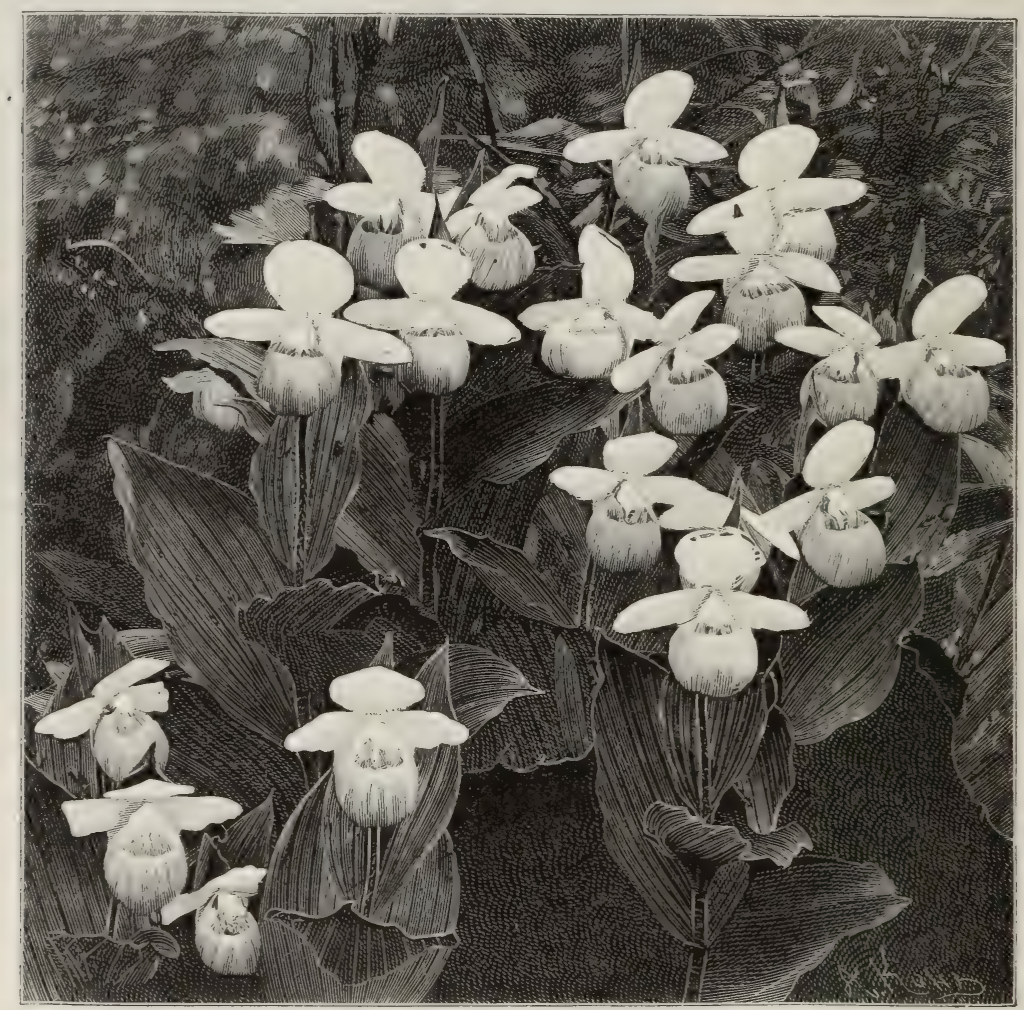

MOCASSON-FLOWER (CYPRIPEDIUM SPECTABILE).

colour of the lip is a soft creamy-yellow, with bold purple dots and lines.

C. macranthum (Large Lady's Slipper). - This species bears a considerable resemblance to $C$. ventricosum, but has lighter-coloured flowers. About I ft. high. Flowers early in June, bearing large flowers of a uniform purplish-rose with deepercoloured veins. Lip globose, inflated, and finely marked with deep purple reticulations. Siberia. This handsome, and at present rare, plant grows best in pure loam of a heavy rather than a light nature.

C. pubescens.-A dwarf species with a
C. spectabile (Mocasson-flower).-The most beautiful of the hardy plants of this genus; 15 in. to $2 \frac{1}{2} \mathrm{ft}$. high. Flowers in summer on each stem, one or two (rarely three) large, handsome, white, and much inflated, rounded lip, about $I \frac{1}{2}$ in. long, white, and marked with a large blotch of bright rosy carmine in front. A variety (C. s. album) has the lip entirely white. In America it luxuriates in woods, moist meadows, and also in peaty bogs in the Northern States. Good native specimens produce from fifty to seventy flowers on a single tuft, $3 \mathrm{ft}$. across, formed on a thick mat of fleshy roots. The plant is hardy. 
It succeeds if planted out in a deep, rich peaty soil, and if a few nodules of sandstone or rough sandstone grit be mixed with the soil, so much the better. It also thrives in turfy loam on a moist peaty bottom ; in any case, however, deep planting is necessary, as the roots are then cool and moist during the hot summer weather, and do not suffer from frost in the winter. It also succeeds in a deep bed of peaty compost, and in sunny districts would be the better for a shaded position if not robbed at the root by trees or shrubs.

Cystopteris (Bladder Fern).--The cultivated species of this native genus are small elegant Ferns of a very delicate fragile texture. They grow on rocks and walls, chiefly in mountainous districts. The best-known are: C. fragilis, which has finely-cut fronds about 6 in. high. It is of easy culture, succeeding in an ordinary border, though seen to best advantage on shady parts of the rockgarden in a well-drained soil. There are two or three varieties, Dickieana being the best. C. alpina is much smaller, and when once established not difficult to cultivate or increase, but more affected by excessive moisture than $\mathrm{C}$. fragilis. A sheltered situation in a well-drained part of the rock-garden suits it. C. montana is another elegant plant requiring the same treatment as $\mathrm{C}$. fragilis.

Cytisus (Broom).-The few species of hardy Cytisus are all valuable ornamental shrubs. Common as the British Broom (C. Scoparius) is, it should certainly be in gardens in places where it does not grow wild; and in company with Heath and Furze it is most useful for dry sandy banks where other shrubs would fail. It is easily raised from seed, and the best way to cover a bank with it is to sow seeds of it in spring. The White Spanish Broom (C. albus) is well known as one of the finest of all early-flowering shrubs. It is a strong bush, particularly in light soils, and frequently Io ft. high. Towards the end of May every slender twig is wreathed with small white flowers, C. nigricans is also a beautiful shrub. The purple Broom is naturally a long trailing shrub with purplish flowers, but is generally seen grafted mop fashion on Laburnum stems. It is really an alpine shrub, and its place is among rocks and boulders, where its wiry branches can fall over and make dense cushion-like tufts. The foregoing are the most important kinds. Others, suitable for a fuller collection, are C. austriacus, biflorus, sessilifolius, capitatus, and C. Ardoini. The last is a pretty alpine shrub a few inches high, and suitable for the rock-garden; its tufted growth is covered in summer with yellow flowers like the Dyer's-weed (Genista tinctoria).

Dabocia polifolia (St. Dabeoc's Heath). -A beautiful heath-like shrub growing I2 to 24 in., the stems bearing beautiful crimson-purple blooms in graceful drooping racemes. There is a white variety much less common and no less beautiful, and also a pretty variety, with purple and white flowers, called bicolor. They flower in summer, and may be obtained from most nurserymen. The white variety is sometimes sold under the name of $M$. globosa and alba major. Abundant in some parts of Ireland, hence called Irish Heath.

Dactylis (Cocksfoot).-The variegated forms of this native Grass are excellent. D. glomerata variegata is one of the most useful of edging plants. It is easily increased by division, either in autumn or spring. It likes a heavy soil, but thrives in almost any kind. If the soil be too poor, the plant is apt to look rusty in dry autumns. It bears clipping to keep it dwarfer, but is prettier if untouched, except to the extent of cutting the flowerstems. D. g. v. elegantissima is said to be superior to this variety. The yellow variegated Cocksfoot is a new form which is likely to be at least as popular as the old variegated form. The variegation is soft yellow; it is regular, and has free growth. These Grasses are graceful as edgings to beds, as carpets or mixtures, or as tufts in borders. The graceful pointed leaves should not be clipped.

Daffodil (Narcissus).

Dahlia.-A noble race of plants, not so much or so well used as it deserves to be. The "bedding-out" fever threw them into the background, and also led to the origin of the dwarfest of the varieties - the "bedders." The old Dahlia bank or large Dahlia bed-one of the best features in gardens of twenty-five years agodisappeared in the rage for lines and cakes of colour! It deserves to be seen again. The compact form sought by the raiser of "bedding" Dahlias is a poor one. The bolder the form the better. There are now various classes of Dahlias, and the more variety the better. It is not well to heap up the various artificial distinctions into classes. In saving seedlings some are led to destroy the forms that do not fall into any of the various "classes." The aim should rather be to keep these deviations and to break down the hard 
and fast lines of " bedders," "pompones," "show," "fancy," and so on. A plant so vigorous in growth and profuse in bold masses of flower cannot fail to be well grouped by those who care for it, if they remember that the highest garden beauty comes to us in broken or tossing surfaces, not in flat or shorn ones! The new and rightly popular race of single Dahlias helps to secure variety of bloom, and to afford flowers for cutting. To get a good result it is essential to have rich, deep, and moist soil, and to put out strong plants as early as may be safe, so as to get a good growth in time for a rich and early autumn bloom. Where weak plants are put out a little too late, they may only give a few poor blooms before the fatal frost comes. If planted in May, and frost is feared, it is easy to protect the young plants at night by turning a garden pot over them. If the soil is not deep, rich, and moist, manure water should be used. Watering is usually necessary in early growth. Afterwards it is not so in moist districts, where the plant is well treated as far as regards depth and quality of soil. In dry places water is essential in most seasons. Staking and tying out the shoots must be particularly attended to, as the stems are brittle, and break under little wind-pressure.

Earwigs are great enemies to Dahlias, but can be trapped in small round troughs, which may be procured at any pottery. They may also be caught on pieces of Hemlock stems, 6 in. long, by leaving a joint at one end, and sticking the pieces here and there through the Dahlias. Small pots, with a little bit of dry Sphagnum Moss inside, inverted on the tops of stakes, also form good traps. After the plants show flower, manure water may be safely used in the evening. Some Dahlias will produce nearly all their flowers perfect, but others, to be fit for show purposes, require their shoots to be well thinned, and all their blooms except three or four to be cut off; but, as a general rule, all may be more or less thinned.

INCREASE. - Dahlia roots have kept well and have flowered for years, especially in dry soils, when the plants have been cut down to the ground and covered with some protection against frost; but the usual practice is to take up the roots and store them in winter. Dahlias may be propagated by cuttings, layers, rootdivision, or seeds, the last being used only where new varieties are sought.

Cuttings are the best means of multiplying Dahlias, though division of the roots is commonly practised. Each cutting has its own self-formed tubers, and on that account is less liable to rot during the winter. If started in Februaly or March, in a temperature of $65^{\circ}$ to $70^{\circ}$ Fahr., each crown will produce three or four cuttings every two or three days. These may be taken off even as early as March; they should be removed close to the crown, without injuring it, as others will come up at the base of those removed. It is also necessary not to let the cuttings become too long before they are taken off the tubers, as long cuttings are more apt to flag, need more room, and are not so convenient for planting out as short cuttings. When the crowns have supplied all the cuttings that can be got from them, they may be divided, and therefore nothing is lost. Cuttings may be successfully struck during the summer months; but this is unusual, except in the case of choice varieties. Three-inch pots are best for putting the cuttings into, six cuttings being put in each pot. They should be plunged in a brisk bottom-heat, covered with hand-glasses, and shaded from bright sunshine ; in less than a fortnight they will all be rooted, and may be potted off singly into large 3 -in. pots, put gradually into lower temperatures until, say, Ist May, when they may be inured to the open air for planting.

To raise seedlings the seed should be sown in heat in February, and the young plants should be treated in the same way as cuttings. The sowing of one seed the right way up in a $2 \frac{1}{2}$-in. pot saves pricking out, and secures the plant in its entirety, without losing a fibre of a root.

To propagate from layers the lowest branches of the plant should be pegged down; if the soil be of a sandy nature, they will root freely; in the absence of sandy soil, a quantity of leaf-mould, with a mixture of sand, may be laid down for them to root in. Pure white sand alone is best suited for striking them in, and a mixture of leaf-mould and sand is very good to start the crowns in.

WINTERING.-As long as the weather keeps mild, Dahlia roots are best in the soil, and need not be taken up till the end of November; but should sharp frosts be followed by heavy rain, they should be promptly removed from the ground. A dry day should be chosen for lifting the roots. The stems should be cut off to within 2 or $3 \mathrm{in}$. of the crown of the roots, and the roots themselves placed on some sticks or boughs to dry, with their necks downwards, and arranged so that the air can pass under them. Soil may be 
allowed to adhere to the tubers, but the greater portion of it is better removed. If the weather be fine and dry, the roots may remain in this position for about three days, but they should be covered with a mat at night to screen them from frost. The floor of a greenhouse where frost can be excluded, or a dry cellar, is a capital place to store the roots in. A little ventilation is necessary to keep them from getting mouldy; but a hot dry atmosphere must also be avoided, as the tubers might shrivel in it. By lifting the roots with some soil adhering to them, they are kept plump during the winter, which is desirable when they are required for early forcing. They will generally keep remarkably well on the floor of a greenhouse, as it is light and airy, and during the depth of winter much water should not, as a rule, be given. Nurserymen who cultivate the Dahlia largely for sale, winter the roots in a close shed that is airy without being very light, and from which frost can be excluded at will. Broad shelves form receptacles for stowing away the roots, which are carefully looked over at intervals. The tubers of some sorts are more difficult of preservation than others, and choice varieties are frequently bad keepers.

CLASSES AND VARIETIES.-The recognised classification of Dahlias is convenient, but it is very artificial, and the sooner its arbitrary lines are broken down the better. A few years ago the two leading classes were the show and fancy Dahlias-distinctions confusing to some, as a white or yellow Dahlia, edged or tipped with a dark colour, was classed as an edged, tipped, or laced Dahlia, and included among the show flowers; but if the disposition of colours was reversed, and dark-coloured flowerets were tipped with a light colour, the plant was denominated a fancy Dahlia. All the kinds with Carnationlike stripe were fancy Dahlias. The catalogues abound with names of varieties. It is best for the grower to make his own selection, especially as new forms are often raised. Where weedy or useless things are offered we note them as such, but here all are good. Varieties that do not attain to the ideal of the hard-shell florist sometimes please the artist or the gardener best. All the show and fancy Dahlias are splendid flowerers, and form a wonderful illustration of the range and change which may be developed from one or two single species.

BOUQUeT OR POMPONE Dahlias have recently become very popular; the small and compact blooms, resembling those of a Persian Ranunculus more than those of a Dahlia, make them more useful in some cut-flower decoration than large Dahlias. They are effective as a background in mixed borders or for large beds. The roots, left in the open ground all the winter, are quite safe if a good coating of coal-ashes be put over them when the tops are cut down. If lifted for propagation, they may be safely stored in any shed secure from frost, and if covered with any partially dry material, such as old tan, Cocoa-nut fibre, or leaf-mould, they will start more strongly into growth than if over-dried. In autumn the flowers are especially useful in large floral decorations, where delicate or fragile blossoms are much less effective. We do not name varieties, as they change often and new ones are frequently raised. The gardener will consult his own taste as to varieties, and the catalogues that name them are numerous. He may also raise seedlings with the hope of having new forms as well as good flowers. The same may be said of the bedding Dahlias, some of which have valuable and distinct qualities.

SINGLE DAHLIAS. - The single varieties are the great gain of the day, and show a good variety of colour with a better form than the double kinds. We do not mean by this that one race should be preferred to the other, except for certain uses, for all are worth growing. Half a dozen good single kinds are alba, Paragon, Yellow Gem, Pink Beauty, Morning Star, Glory, and White Queen. As single Dahlias seed freely, and seedlings are easily raised, the named kinds cannot expect to have any lengthened popularity. We hope many more good kinds may be raised.

There are about six or seven species of Dahlia, all natives of Mexico, and from these the different garden varieties have been obtained. Those in cultivation are-

D. coccinea, a tall plant with bright scarlet flowers that rarely vary. Nearly related to it, and differing only in some slight points, is D. Cervantesi, also with showy scarlet flowers.

D. glabrata is a beautiful plant of dwatf spreading growth, more slender than any of the other species. The flowers are smaller than those of other kinds, and vary from pure white to deep purple. It is hardier than any other Dahlia, and plants left in the ground are generally uninjured throughout the winter. Its dwarf growth suits it for positions unsuitable for the taller kinds, and it has a good effect in masses, its colour being quite unlike that of any other Dahlia. 
It is known also as D. Merki, repens, and Decaisneana.

D. gracilis is a distinct and graceful plant with slender stems, and finelydivided foliage, which gives it a freer in the open air, but it is of service both in the flower garden and the conservatory. Planted in rich soil, and placed in a warm sheltered position in the open air at the end of May, it grows well in

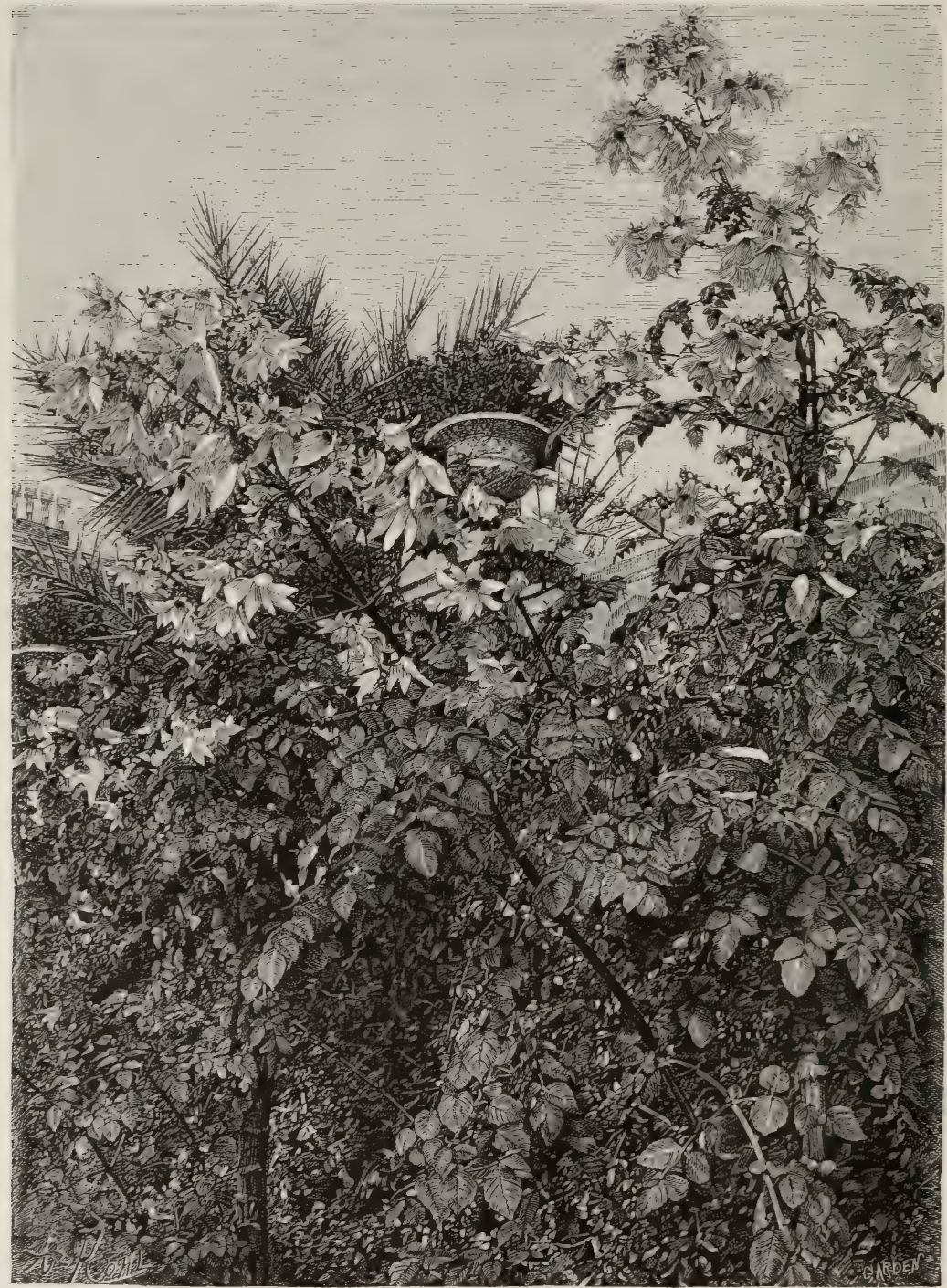

DAHLIA IMPERIALIS.

habit than any other Dahlia. The bright scarlet flowers are of the ordinary size.

D. imperialis has large and graceful much-divided leaves, and flowers, of a beautiful French white, thrown up in a great cone-like mass. It rarely flowers summer, and its large and graceful leaves make it an ornament worthy of being used as a "fine-foliaged " plant. Similiar to this, but not so fine, is D. Maximiliana.

D. Juarezi is one of the most important flowers introduced of late years, and 
it is the more desirable because of its easy culture, as it requires no different treatment from ordinary Dahlias. It is not quite double, but is very fine in form and brilliant in colour. It flowers somewhat sparsely. Probably if pot roots of the preceding year only were planted, the plants would bloom earlier and in greater profusion.

D. variabilis is the supposed parent of all the garden varieties. The wild plant has scarlet flowers like coccinea, and is of similar growth. A packet of seed, however, will yield plants with flowers of all shades, from crimson to white and yellow.

D. Zimapani (Cosmos).

Daisy, Blue.-Applied to various plants - Agathæa, Kaulfussia, and Bellis.

Daisy (Bellis perennis).

Daisy, Bush (Olearia).

Daisy, Crown (Chrysanthemum coronarium).

Daisy, Marsh Ox-eye (Chrysanthemum licustre).

Daisy, New Holland (Vittadenia triloba).

Daisy, Ox-eye (Chrysanthemum leucanthemum).

Daisy, Paris (Chrysanthemum fruitescens).

\section{Daisy, Tree (Olearia).}

Dalibardia fragarioides. - A dwarf creeping plant of the Rose family, bearing clusters of bright yellow flowers in summer. Grows freely anywhere, but is not of any distinct value. N. America. Syn., Waldsteinia.

\section{Dames' Rocket (Hesperis).}

\section{Damson (Prunus).}

Danes' Blood (Sambucus Ebulus), also called Dane Weed and Dane Wort.

Daphne.-Most of the hardy Daphnes are beautiful flowering shrubs, besides being among the finest of Evergreens. There is a group of small-growing species among them that claims a place in the rock-garden. The best-known and the most popular Daphne is the old Mezereon (D. Mezereum), whose leafless branches are wreathed with fragrant blossoms before winter is past. The common sort has reddish-purple blooms, but there are pink and white, single and double flowered forms. It is indispensable for every garden, and should always be planted where its beauty can be enjoyed in early spring. It dislikes shade, and does best in an open sunny place in almost any soil. In some seasons it flowers from the end of January until April. The pretty D. Cneorum (the Garland-flower) is a favourite little shrub, 6 to $\mathrm{I} 2 \mathrm{in}$. high, more suited for the rock-garden than the shrubbery. The deep pink flowers are deliciously fragrant, and appear in dense clusters at the tips of the shoots, the unopened buds being crimson. It flowers in April and September, often twice a year, the deliciously fragrant flowers being borne in dense terminal umbels. A native of most of the great mountain

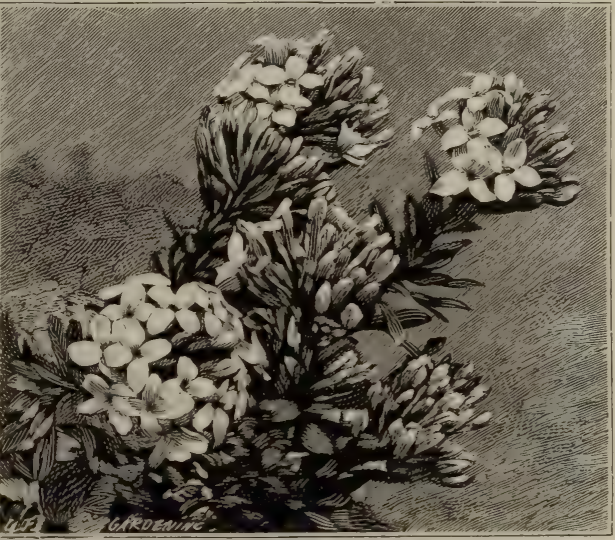

GARLAND-FLOWER (DAHHNE CNEORUM).

chains of Europe, and suitable for the rock-garden, for the front margin of the mixed border, or as an edging to beds of choice low shrubs. It is of trailing growth, and makes dense cushion-like masses of evergreen foliage a few inches high. Thrives best in an open situation in sandy peaty soil, kept rather moist in summer. Increased by layers. D. rupestris (Rock Daphne) is a neat little shrub, with erect shoots forming dense, compact tufts, 2 in. high and I ft. or more across, which are covered with bloom which sometimes almost eclipses the plant. Its colour is a soft-shaded pink or rose, and its flowers are larger and more waxy than those of D. Cneorum, but form clustered heads in the same way. It is essentially a rock-plant, growing wild in fissures of limestone in peaty loam. In cultivation it is of slow growth, and it takes some years to form a moderate-sized tuft, but the plant is a gem worth waiting for. It seems to thrive in very stony and peaty earth with abundance of white sand, and should be planted in a well-drained, but not in a dry position. D. Blagayana is a beautiful new dwarf alpine shrub, 3 to 6 in. high, also suitable for the rock-garden. It is of straggling growth. The leaves 
form rosette-like tufts at the tips of the branches, and encircle dense clusters of deliciously-scented white flowers. It blooms in spring for several weeks. It is of easy culture, thriving on the rock-garden in well-drained spots surrounded by stones for its wiry roots to ramble among. It is very hardy, and in open spots thrives in any good soil. It may be increased by layers pegged down in spring and separated from the plants as soon as roots are emitted. Another Daphne is the Japanese D. Genkwa, introduced about twenty years ago, but still uncommon. In spring, before the leaves appear, it bears freely large lilac fragrant flowers. D. Fortunei, from China, is similar to it. The foregoing are the best hardy Daphnes; others in cultivation are: D. alpina, a dwarf deciduous shrub, about $2 \mathrm{ft}$. high, with clusters of fragrant white flowers; D. collinum, from South Europe, a dwarf evergreen form, 2 or $3 \mathrm{ft}$. high, bearing dense clusters of very fragrant pink blossoms during the first half of the year; D. neapolitana, from Italy, similar to this, and probably only a variety of it ; D. altaica, with neat growth, like that of D. Mezereum, has white scentless flowers; D. pontica and Laureola are good Evergreens, although not remarkable for blossom; while the pretty $D$. odora and its variety Mazelli are scarcely hardy enough for open-air culture. Such a beautiful family deserves the best attention.

Darlingtonia californica (Californian Pitcher-plant).-A most singular plant, resembling the Sarracenias, but very distinct. The leaves, which rise to a height of $2 \mathrm{ft}$. or more, are hollow, and terminate in a curiously-shaped hood, from which hang two ribbon-like appendages. The greater part of the leaf is green, but, in a mature state, the hood is a deep crimson-red. The flowers are almost as curious. This remarkable plant is now better understood, and is found to grow in our climate if care be taken with it; and it would be difficult to name a more interesting plant for a sheltered bog-garden. It is less trouble out-of-doors than under glass; indeed it only requires a moderately wet bog in a light spongy soil of fibrous peat and chopped Sphagnum Moss. A place should be selected by the side of a stream, in an artificial bog or in any moist place, and the plants should be fully exposed to direct sunlight, but sheltered from the cold winds of early spring when they are throwing up their young leaves. They require frequent watering in dry seasons, unless they are in a naturally wet spot.
When they become large they develop side shoots, which, if taken off and potted, soon make good plants. The plant is also raised from seed, but this requires several years.

Dasylirion.-Remarkable plants, better fitted for a temperate climate than for our own; but useful in places where many plants have to be turned out of greenhouses for the summer. They are related to the Yuccas and Beaucarneas, forming with these genera a well-marked group of the great Lily order, all of them North American plants. Dasylirions aie found only in Mexico and the Southern States. They grow to a large size, forming stout woody stems and large heads of elegant foliage. They are, however, very slow growers, which is an advantage where space is very limited and where they must be kept indoors. But there is no reason whatever for treating Dasylirions as semi-tropical plants; they are certainly as hardy as Agave americana, and they may be used for outdoor effect in summer in the same way as the Agaves and some of the Yuccas are employed. Along the Riviera there are fine specimens of Dasylirion and Beaucarnea. In the winter garden at Kew there is a plant of D. acrotrichumthe species represented in the accompanying woodcut-which has been in its present position two years, and is in the best of health. The temperature of this house sinks as low as $35^{\circ}$ in severe weather, and it never gets as warm in summer as the air outside. This fact is important, as showing that the Dasylirion may certainly be placed outside in summer. Some of the plants of this species at Kew have trunks $5 \mathrm{ft}$. high, and they flower now and again. The flowering spikes are erect, about Io $\mathrm{ft}$. long, and the flowers are arranged in a narrow panicle. The male flowers are very small and crowded with pollen, whilst the female ones bear small triangular brown nut-like ovaries. Male and female flowers are borne by different plants, the genus being diøecious. A female plant in the Kew collection has produced fine spikes of blossoms. D. graminifolium has a short trunk and a large head of leaves, which are similar to those of D. accotrichum, except that they have not the tuft on the end, which is characteristic of that species. D. glaucophyllum, sometimes called D. glaucum, has stiffer, broader leaves than the preceding, almost silvery. D. serratifolium is similar, but shorter in the leaf. D. quadrangulatum is sometimes met with under the name of Xanthorrhœa 
hastilis, the leaves resembling those of Xanthorthoea in being narrow and rushlike. D. quadrangulatum is a fine plant, the leaves, from 3 to $4 \mathrm{ft}$. long, forming a large head, the lower ones recurved and
Date Palm (Phonix).

Datisca cannabina.-A tall and graceful herbaceous perennial from 4 to $7 \mathrm{ft}$. high. The long stems are clothed with large pinnate leaves; and the yellowish-

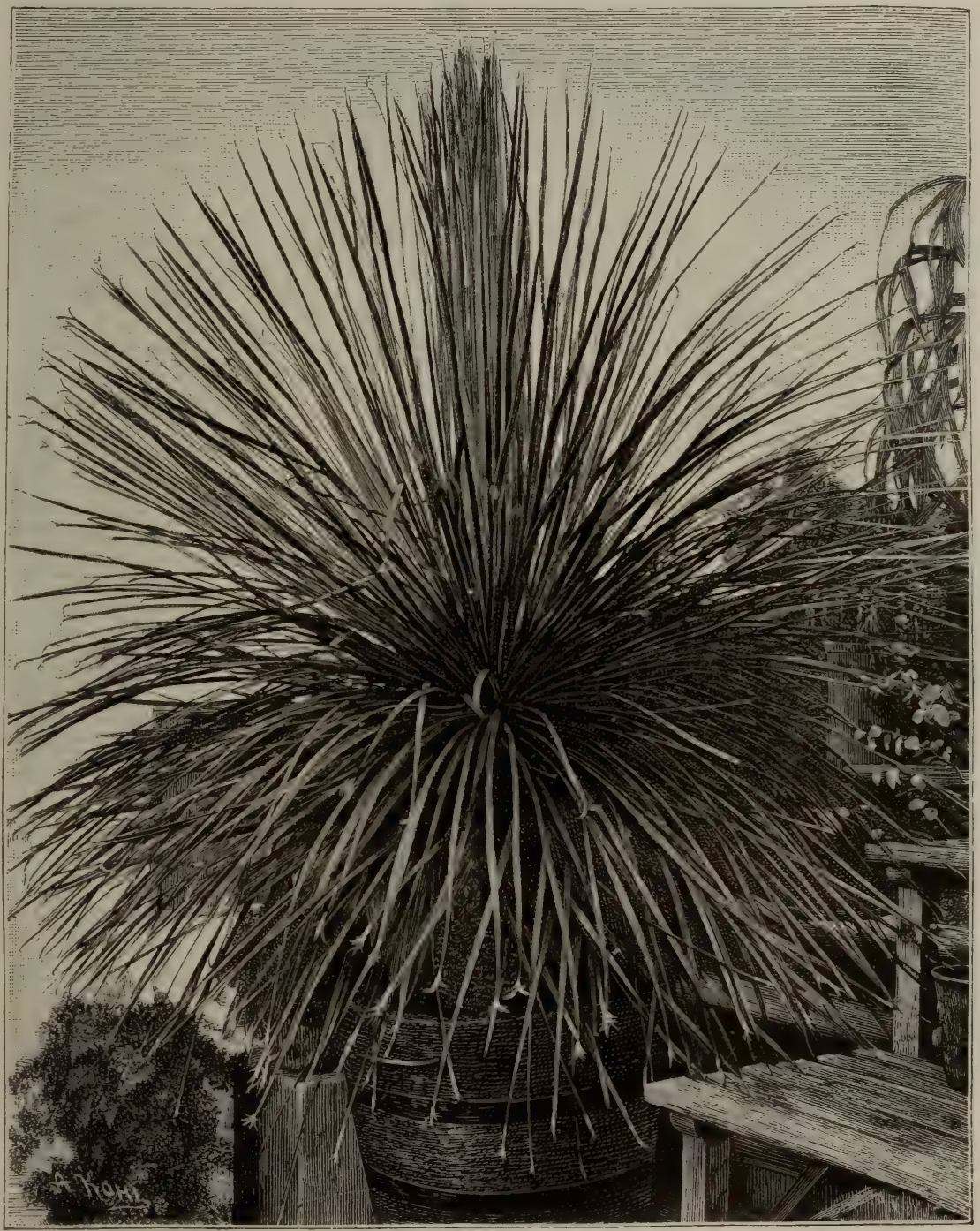

DASYLIRION ACROTRICHUM.

elegant. D. Hookeri has a bole-like stem, not unlike that of Testudinaria, with tufts of glaucous leaves springing from the upper part, and elegant in a young.state. These plants like plenty of water in summer, little or none in winter, and they do not require much root-room. green flowers appear towards the end of summer. The male plant is very strong and graceful in habit. The female remains green much longer than the male, and, when it is profusely laden with fruit, each shoot droops and the plant is very effective. Datisca cannabina should 
be included in any selection of hardy plants of fine habit. Seed will probably be found the best way to increase it, and would probably secure plants of both sexes. The border is not its proper place ; it is, above other plants, suited for the grassy margin of an irregular shrubbery, and will be all the more effective if planted on a grassy slope, where its deepseeking roots will soon defy the most protracted drought; nor need any open soil come between it and the adjacent turf. It grows to a height of $5 \mathrm{ft}$. in clay soil, and attains a greater size in light and warm soil.

Datura (Thorn Apple).-This genus of the Nightshade family contains several handsome garden plants that well deserve cultivation. Being natives of Mexico and similar countries, none are hardy, but owing to rapid growth they all succeed well if treated as half-hardy annuals, and make bold effective plants in a short season. The best are: D. ceratocaula, which grows from 2 to $3 \mathrm{ft}$. high, and produces large, sweet-scented, trumpetlike flowers, often 6 in. in length, and 4 or 5 in. across. They are white, tinged with violet-purple, expanding in the afternoon and closing on the following morning. D. fastuosa is a handsome species, having white blossoms smaller than the preceding. There is a fine variety of it with the tube of the flower violet and the inside white. The most striking forms of this species bear double flowers, the primary corolla having a second and sometimes a third corolla arising from its tube, all being perfectly regular in form, and often being parti-coloured, as in the single variety with violet flowers. D. fastuosa Huberiana of the seed catalogues, and several varieties of it that are offered, are reputed to be hybrids of this species with the dwarf $\mathrm{D}$. chlorantha flore-pleno or D. humilis flava of the gardens; but although they offer a greater variety of colour, they are less hardy than the older forms just described, and appear to require a warmer climate for their complete development. D. meteloides is a handsome Mexican plant, called in gardens Wright's Datura. Isolated specimens have a fine aspect in sunny, but sheltered nooks. It is from 3 to $4 \mathrm{ft}$. high, and has wide-spreading branches that bloom profusely from the middle of July till frost sets in. The flowers are white, tinged with mauve; they are from 4 to 6 in. across, and are showy and sweet, but the leaves emit a disagreeable odour. Besides these there are several others in cultivation, such as D. ferox and quercifolia, but those described are the finest. The culture of these Daturas offers no special difficulty. Fresh seeds are readily raised, in an ordinary hot-bed; the young plants while small should be pricked out singly in pots, and finally planted out where they are to stand. They need ample space for their full development, and should be grown in light warm soils. (See also Brugmansia.)

\section{Day Lily (Hemerocallis).}

Decumaria. - Two species of this interesting genus are in cultivation; both are quite hardy, and useful climbers for walls and buildings. D. barbara, a native of Carolina, where it is found in shady places along the margins of swamps, is a very elegant plant. The branches cling to the wall by small rootlets, as in the Ivy, and when allowed to ramble at will are very grotesque. They ascend trees or walls to a considerable height, and require no nailing and little attention. The leaves are variable in form, opposite, and nearly entire. The flowers are produced in large bunches, pure white and delightfully fragrant, resembling Hydrangea. Flowers May and June. D. sinensis is a native of Central China, and a very beautiful hardy species. It is a climber, and was found by Dr. Henry covering the cliffs of the Ichang Gorge with beautiful clusters of fragant white flowers. Habit somewhat similar to D. barbara. The leaves stalked, elliptic, blunt, and entire or slightly serrated. Flowers June.

\section{Deer Berry (Mitchella).}

Delphinium (Larkspur).-Few plants contribute so much to the beauty of the garden as the Larkspur. There are in cultivation many species, both annual and perennial, but the most important are the tall hybrid perennials, of which there is a wealth of varieties embodying a wonderful range of lovely colour. Their stateliness of habit and fine blue and purple shades are unequalled. They are very valuable for their great variety in height, from I to $9 \mathrm{ft}$. ; for their greater variety in shades of colour, which range from almost scarlet to pure white, from the palest and most chaste lavender up through every conceivable shade of blue to deep indigo ; and for the variety of size and form of their individual blooms, some of which are single, some semi-double, and some perfectly double, and all set on spikes ranging from $\mathrm{I}$ to $6 \mathrm{ft}$. in length. About a dozen species have given rise to the cultivated varieties, the chief species being D. grandiflorum, formosum, lasiostachyum, cheilanthum, elatum, and peregrinum. 
Culture and Position.-The combinations in which they can be placed are numerous. They are splendid objects in various positions, and may be used in various ways-in the mixed border, in masses or groups in one or several colours, or associated with other flowering plants or with shrubs. Perennial Larkspurs thrive in almost any situation or soil ; they are easily increased, and are quite hardy. A deep friable loam, enriched with rotten manure, is their favourite compost. The character of the soil seems, however, of little importance, as they will grow luxuriantly in a hot sandy soil if it be heavily manured and watered, but good loam requires less attention in this way. Every three or four years they should be replanted and divided at the same time. This is best done in spring, just as they are started into growth, or in summer; if it is done in summer, cut down the plants intended for division, and let them remain for a week or ten days until they start afresh; then carefully divide and replant them, shading and watering until they are established. Late autumn division is not advisable. Delphiniums can be made to bloom for several months by continually cutting off the spikes immediately after they have done flowering. If the central spike be removed, the side shoots will flower, and by thus cutting off the old flowers before they form. seeds, you cause fresh shoots to issue from the base, and to keep up a succession of bloom. Another plan is to let the shoots remain intact until all have nearly done flowering, and then to cut the entire plant to the ground, when in about three weeks there will be a fresh bloom. In this case, however, to keep the plants from becoming exhausted, they must have a heavy dressing of manure or a liberal supply of manure water. Topdressings keep the soil cool and moist, give the plants a healthier growth, and greatly increase the number and improve the quality of the flowers.

The following is a selection of the finest kinds: Single Varieties.-Belladonna, Hendersoni, Cambridge, Granville, Gloire de St. Mande, Barlowi, versicolor, Coronet, magnificum, Lavender, pulchrum, formosum, lilacinum, Celestial, Madame Hock, mesoleucum superbum, Montmorence, Defiance, and Attraction. 'The

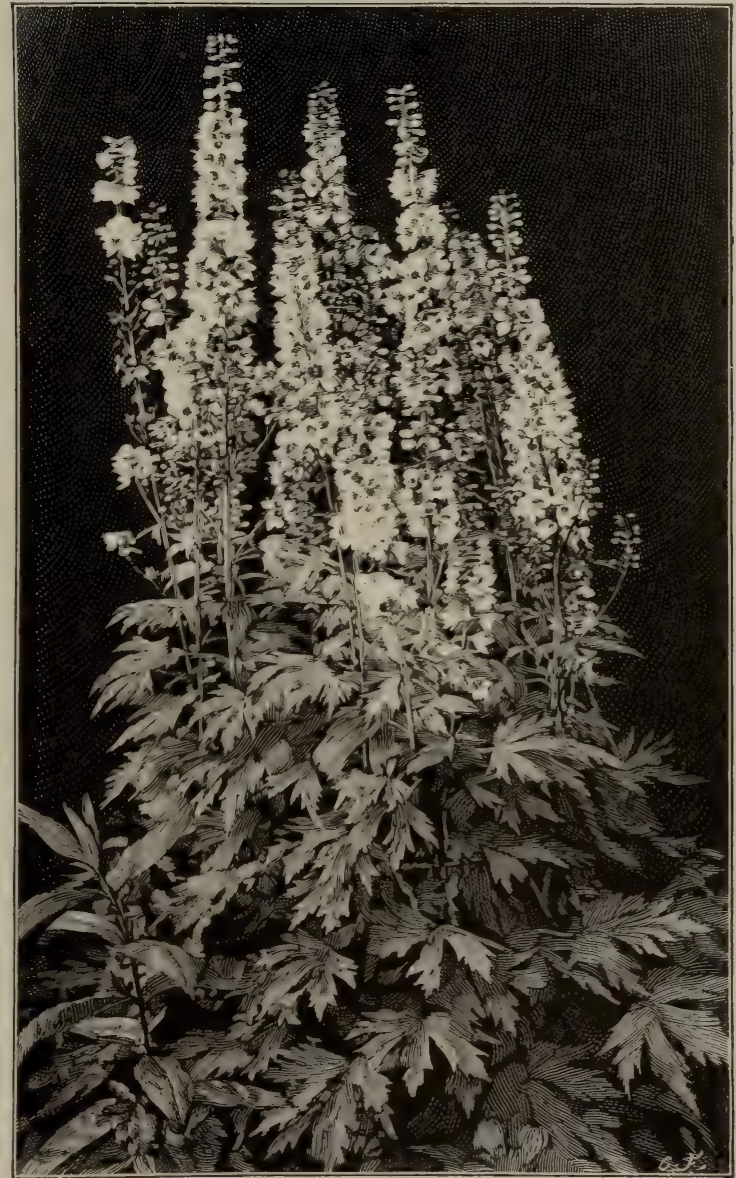

DELPHINIUM.

grower should consult his own taste, and raise seedlings of his own, taking care to have a good stock of the standard varieties he likes best. Double Varieties.-Madame E. Geny, Madame Henri Jacotot, Madame Richalet, Pompon Brilliant, Roi Leopold, Hermann Stenger, Claire Courant, George Taylor, Roncevaux, Le XIXe. Siècle, Keteleeri, Prince of Wales, General Ulrich, Arc en Ciel, Sphere, Michael Angelo, Delight, Glynn, Barlowi vittatum, Star, Perfectum novum, Triomphe de Pontoise, Pompon de Tirlemont, Victor 
Lemoine, Trophée, Madame Henri Galotat, Louis Figuer, Azureum plenum, and Madame Ravillana. The beautiful old D. grandiflorum fl.-pl., another double variety, is one of the most charming of all hardy plants.

The best of the numerous perennial species distinct from the hybrids are-D. cashmerianum, with flowers nearly as large as those of $\mathrm{D}$. formosum, and with stems about 15 in. in height. The flowers are $I$ in. in diameter, and are usually of a light blue-purple, but they vary in shade to mauve and dark blue, and are produced in terminal corymbs of six or more. D. cashmerianum is well suited for the border or for a large rockery ; in either case, perfect drainage is essential, and this is best attained in rock-garden culture. Its branches have a prostrate habit, apparently adapting it to such conditions. It is best increased from seed. D. cardinale is a beautiful species of tall elegantly-spreading growth, having large bright scarlet flowers, like those of $D$. nudicaule. It blossoms later in summer, and continues longer in flower than D. nudicaule, owing in part to its slower development. It is a most desirable plant, and as hardy as D. nudicaule. Seedlings will probably not flower till the second season. In very damp soil it would be prudent in winter to protect the root with a hand-light or inverted pot. D. chinense is distinct from other Larkspurs, and is neat and rather dwarf in growth, having finely-cut feathery foliage, and freely producing spikes of large blossoms, usually of a rich bluepurple, but sometimes white. It is a good perennial, is easily raised from seed, and continues to flower throughout the summer till late in autumn. It is suited for borders and beds. D. nudicaule is another species, with scarlet blossoms, having a dwarf, compact, branching growth, a hardy constitution, and a free blooming habit. Its usual height is about 12 to 15 in., but it is occasionally dwarfer; while it sometimes reaches $2 \frac{1}{2}$ or $3 \mathrm{ft}$. The flowers are produced in loose spikes, each blossom being about I in. in length; and the colour varies from light scarlet to a shade verging closely on crimson, and when seen in the open air, especially in sunshine, dazzles the eye by its brilliancy. D. nudicaule is perfectly hardy, and commences growth so early that it may almost be termed a spring flower, but it may be had in bloom during several of the summer months, and is handsome for warm borders. Although somewhat apt to damp off on level ground, it is a perennial on raised ground, and keeps up a succession of bloom. It is as easy to raise from seed as other Larkspurs. A tall variety of nudicaule is called elatius. D. tricorne is a new dwarf perennial species, 6 to 12 in. high, but apparently of little value.

THE ANNUAL LARKSPURS.-In these well-known hardy annuals there is also a wealth of beauty for the summer garden. We have a host of beautiful sorts with a wide range of colour. There is great diversity too in the habit of growth, some being as dwarf as a Hyacinth, others 3 or $4 \frac{1}{2} \mathrm{ft}$. high, others with a branching habit resembling a candelabrum. The species which have given rise to these varieties are D. Ajacis (Rocket Larkspur) and D. Consolida. D. Ajacis has the flowers in long loose spikes forming an erect and spreading panicle. The stem, which rises to a considerable height, is vigorous and has open spreading branches. All the varieties of the Rocket Larkspur may be arranged in three great groups: I. D. Ajacis majus (large Larkspur). - The stem of this is single, and varies in height, from 3 to $4 \mathrm{ft}$. 6 in.; the flowers are double, and form a long, single, and compact spike, generally rounded off at the extremity. This kind has produced the following varieties - white, flesh - coloured, rose, mauve or puce-coloured, pale violet, violet, ash-coloured, claret, and brown. 2. D. Ajacis mintis (dwarf Larkspur).The stem of this is from 20 to 24 in. in height, and is even shorter when the plant is sown thickly or in dry or poor soils. The flowers are very double, and are produced in a single well-furnished spike, which is usually cylindrical, and rounded off at the extremity, but rarely tapering. The principal varieties arewhite, mother-of-pearl, flesh colour, rose, mauve, pale mauve, peach-blossom, light violet, violet, blue-violet, pale blue, ashgray, brown, light brown, white striped with rose, white striped with gray, rose and white, and flax-coloured and white. 3. D. Ajacis hyacinthiflorum (dwarf Hyacinth-flowered Larkspur).--The varieties of this group have been for the most part produced in Belgium and Germany. They do not differ from other kinds in form of flower, but only in disposition of inflorescence, the spike on which the flowers are set being more tapering, and the flowers themselves being farther apart than those of the two previouslymentioned groups. There is a strain called the Tall Hyacinth Larkspur. Other strains mentioned in catalogues are the Ranunculus-flowered (ranunculi- 
florum) and the Stock-flowered, all of which are worth cultivating.

D. Consolida (Branched Larkspur).This species has branching stems and beautiful violet-blue flowers, hung on slender elongated peduncles, and produced later than those of D. Ajacis. It embraces several varieties, both single and double, all of which may be reproduced from seed. The principal sorts are white, flesh colour, red, lilac, violet, flaxen, and variegated. The varieties especially worthy of cultivation are candelabrum, bearing pyramidal spikes of flowers of various colours; and the Emperor varieties, of symmetrical bushy habit, which form fine, compact, and well-proportioned specimens, $\mathrm{I} \frac{1}{2} \mathrm{ft}$. high by $3 \frac{1}{2} \mathrm{ft}$. in circumference. In habit and doubleness of flowers this strain possesses great constancy. There are three colours, viz. dark blue, tricolored, and red-striped. In D. tricolor elegans the flowers are rose-coloured, streaked with blue or purple, and about $3 \mathrm{ft}$. high.

CULTURE. - These Larkspurs should be sown where they are to remain at any time after February when the weather permits - usually between March and April. They may also be sown in September and October, and even later when the ground is not frozen. The produce of winter sowings is, however, liable to be devoured by slugs and grubs. The sowing may be made either broadcast or in rows 4 in. to $8 \mathrm{in}$. apart, and the plants should stand 4 in. or 5 in. asunder. The branching varieties may be sown in reserve beds, and in March when about 12 in. or 16 in. high should be transferred to the beds, being lifted carefully with balls of earth round the roots, so that they may not suffer. These branching varieties are well suited for garden decoration either in masses of one colour or of various colours. They may be planted in borders or among clumps of young trees thinly planted. One great advantage of this class is that it flowers earlier and longer than Ajacisthat is to say, it flowers throughout the summer, and, according to the period of sowing, from the end of June or July to September, and even to October if the flower-stems that have shed their blossoms be cut off. They succeed, moreover, in the driest calcareous soils, and even upon the declivities of hills. By pinching, dwarf plants useful under certain circumstances may be obtained. Seed should be taken only from flowers perfectly double; and for this purpose singleflowered plants should be carefully weeded out. Larkspurs are at their best in June and July; they bloom almost anywhere, especially in dry localities, and do not require much attention. They look well whether they are all of one colour, or of all the colours mixed, and, by separately using varieties possessing different colours, striking contrasts may be produced. Other annual Larkspurs, such as D. orientale and D. cardiopetalum, are scarcely worth cultivating, now that we have so many beautiful varieties.

\section{Dendromecon rigidum (Shrubby} Poppy).-A rare shrubby Poppy from the summits of mountains near St. Barbara, North America, where it was first found by Nuttall. David Douglas, when collecting for the Royal Horticultural Society in $1831-32-33$, sent specimens home. Very little is known in this country about it, but there can be little doubt about its hardiness; and as it has lately been introduced at Kew, we hope soon to be able to give it a place amongst hardy shrubs. A large bush with bright yellow Poppy flowers, as large or larger than P. nudicaule, is indeed a novelty. The leaves are entire; lance-shaped, and reticulated. It flowers in June, and should be planted in a sandy loam.

Dentaria (Toothwort). - Pretty and interesting spring-flowering plants of the Crucifer family, not grown as much as they deserve. There are in cultivation some half a dozen species all worth growing in half-shaded positions in peat beds, among shrubs, on the margins of borders, or in the cool shrubbery. They grow best in a light sandy soil well enriched by decayed leaf-mould, or in soil of a peaty nature. Their flowers are welcome in early spring, and remain some time in beauty. They are easily increased from the small tuber-like roots. Some, like D. bulbifera, bear bulblets on the stem, and from these the plant may be increased. None of them ripen seed freely. The species are-D. bulbifera, $\mathbf{i}$ to $2 \mathrm{ft}$. high. It flowers in spring; its flowers are purple, sometimes nearly white, are rather large, and are produced in a raceme at the top of the stem. D. digitata, a handsome dwarf kind, about 12 in. high, flowers in April; its flowers are a rich purple, and are produced in flat racemes at the top of the stem. A native of Europe. D. diphylla is a pretty plant, from 6 to 12 in. high, bearing but two leaves. The flowers are purple, but sometimes white, and occasionally yellowish. N. America. D. enneaphylla is about I ft. high; produces in April and June clusters of creamy-white flowers. A pretty plant for a shady border. Mountain woods in Central Europe. D. maxima 
is the largest of the species, being $2 \mathrm{ft}$. high. It has many flower-heads of pale purple flowers, and is a native of $\mathrm{N}$. America. D. pinnata is a stout species at once distinguished by its pinnate leaves; it is from I4 to 20 in. high, and flowers from April to June, bearing large pale purple, lilac, or white flowers, in a cluster. It is a native of mountain and sub-alpine woods in Switzerland. D. polyphylla, similar to D. enneaphylla, is about I ft. high, with cream-coloured flowers in clusters. It is a handsome plant ; from woods in Hungary. their general culture. These are D canadense, marilandica, and Dilleni, all from 2 to $4 \mathrm{ft}$. high, with slender stems, terminated by dense racemes of small purplish flowers. D. penduliflorum is a really pretty shrub and quite hardy if the stems are annually cut down. It has long graceful shoots, bearing along their upper portions numerous rich violet - purple blossoms. It blooms in September, and has a graceful effect though it is not showy.

D. penduliflorum is the name by which the beautiful Lespedeza bicolor is generally known. It is a slender shrub,

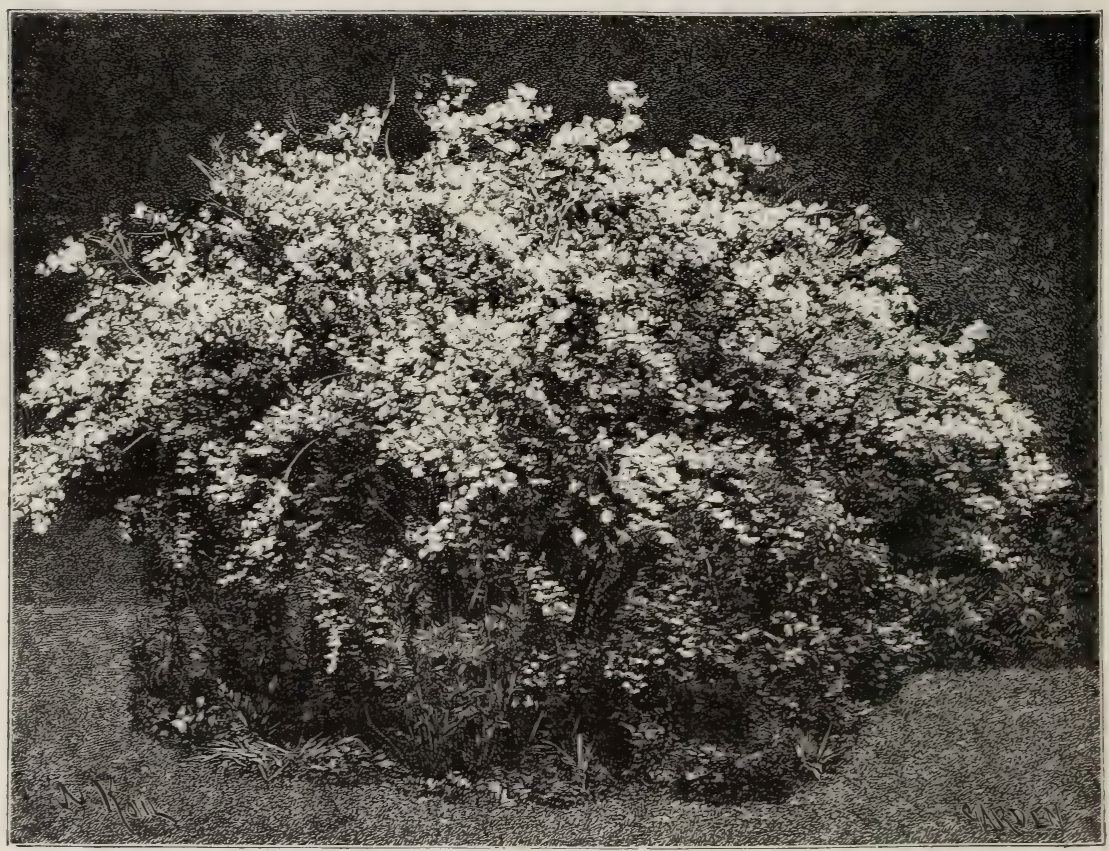

DEUTZIA.

\section{Deodar (Cedrus)}

Deptford Pink (Dianthus Armeria).

Desfontainea spinosa. - In favoured gardens along the southern coast and in other mild parts this very beautiful evergreen shrub from Chili can be grown and flowered out-of-doors. It is of moderate growth, having foliage very much like the Holly. The handsome flowers are in the form of a tube, and are of bright scarlet tipped with yellow. It usually flowers about the end of summer, and in some parts of Devonshire it blooms profusely. It thrives in a light loamy soil.

Desmodium (Tick Trefoil).-A few of the North American species are cultivated, but their weedy appearance prevents graceful when in. flower. It is $6 \mathrm{ft}$. or more in height, and bears drooping racemes of small Pea-shaped flowers of a carmine-purple colour. It is a native of China and Japan, and hardy enough for open-air culture except in cold districts. It makes a good wall shrub.

Deutzia.-The best of the few species in cultivation are D. gracilis and D. crenata, both common and well-known shrubs, the first generally seen in greenhouses, the second in almost every shrubbery. D. gracilis, though usually grown in pots, is perfectly hardy, and, under suitable conditions, makes a dense bush about $2 \mathrm{ft}$. high. When planted in a free soil it flowers as freely as when in pots. 
D. crenata (commonly called D. scabra) is a much larger bush, reaching to a height of 6 to $8 \mathrm{ft}$. or more. Its leaves are large and rough, and, when in flower, its slender stems are wreathed with racemes and panicles of pure white blossoms. There are two very distinct and beautiful varieties of it, viz.-florepleno, with double flowers, tinged with purple, and candidissima, which produces an abundance of double snow-white flowers. This is one of the finest hardy flowering shrubs, and is called the Pride of Rochester. Deutzias grow in any good soil, and are partial to slight shade. If too exposed they are liable to suffer during drought. Deutzias should be pruned annually, the old wood being cut away, and the young growths thinned:

Devil-in-a-Bush (Nigclla).

Dew-Berry (Rubus).

Dew-Grass (Dactylis).

Dew - plant (Mesembryanthemum).

Dianthera americana (Water Willow).-A perennial herb, from 2 to $3 \mathrm{ft}$. high, with erect slender stems and small purplish flowers. It grows in streams and ponds in North America, and being quite hardy is suitable for such places here. Acanthaceæ.

Dianthus (Pink).-A genus of the highest garden value, containing several of our finest families of hardy flowers -the Carnation, Pink, and Sweet William - besides numerous alpine and rock species that are among the most charming of mountain plants. The genus is very large. Many of the species are plants of the heath, dry meadow, or maritime Alps; or shore plants, such as the Fringed Pink (D. superbus); and, so far as our climate is concerned, they are almost at home in lowland gardens. On the other hand, some are among the very highest alpine plants, like the Glacier Pink and the Alpine Pink.

The following is a selection of the finest species.

D. alpinus (Alpine Pink).-A beautiful and distinct plant, distinguished at a glance from any other cultivated Pink by blunt-pointed shining green leaves. The stems bear solitary circular flowers, of deep rose spotted with crimson, and when the plant is in good health they are produced so freely as to hide the leaves. In poor, moist, and very sandy loam on rockwork this Pink thrives and forms a dwarf carpet, though the flower-stems are little more than I in. in height; but both leaves and stems are much more vigorous and tall in deep, moist peaty soil. Wireworms cause its death more frequently than unsuitable soil. It should be placed in an exposed position, and carefully guarded against drought, especially when it is recently planted. It is not difficult to increase from seed, as it comes true ;

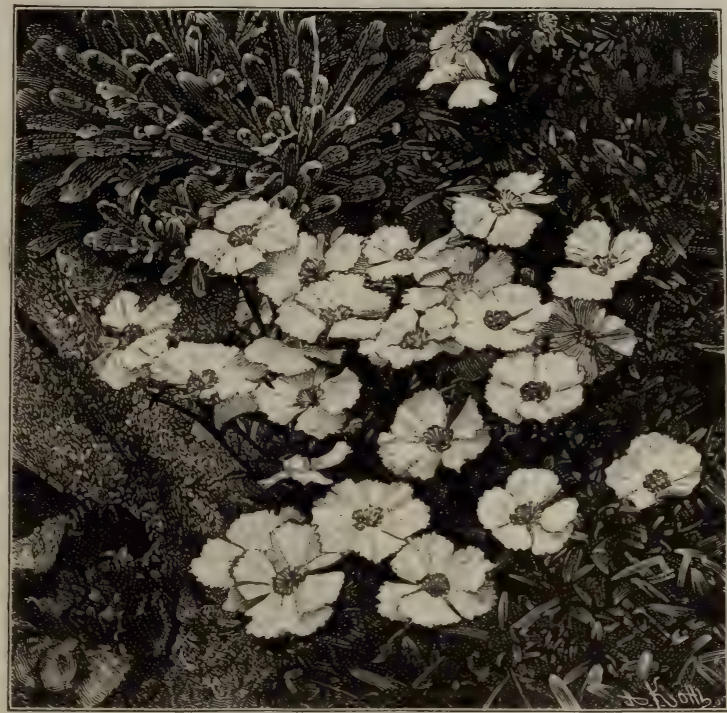

DIANTHUS ALPINUS (ALPINE PINK).

and it may be increased by division where it grows freely. Alps of Austria, and flowers in summer. It is a choice rockgarden plant.

D. barbatus (Sweet William).-One of the most admired of garden flowers. Few flowers repay care better, and it should be in every garden. It is hardy and vigorous ; and has a rich profusion of bright-coloured flowers, which form sheets of bloom, the colours being vivid and chaste, and the flowers finely and distinctly marked. What renders the Sweet William of such high value for small gardens is that its culture is extremely easy, as it may be raised from seed without the aid of glass.

The Sweet William has been greatly improved of late years, and the old varieties are far surpassed. The points the "florist" improver aims at are a circular flower, with no indentation where the petals meet, thick in petal, and with 
all the petals marked alike, the colours meeting each other in clearly-defined lines without any feathering or flushing into each other; but in this, as in other flowers, the more variety of form the better. In the Sweet William colours vary, and they may be classed under two

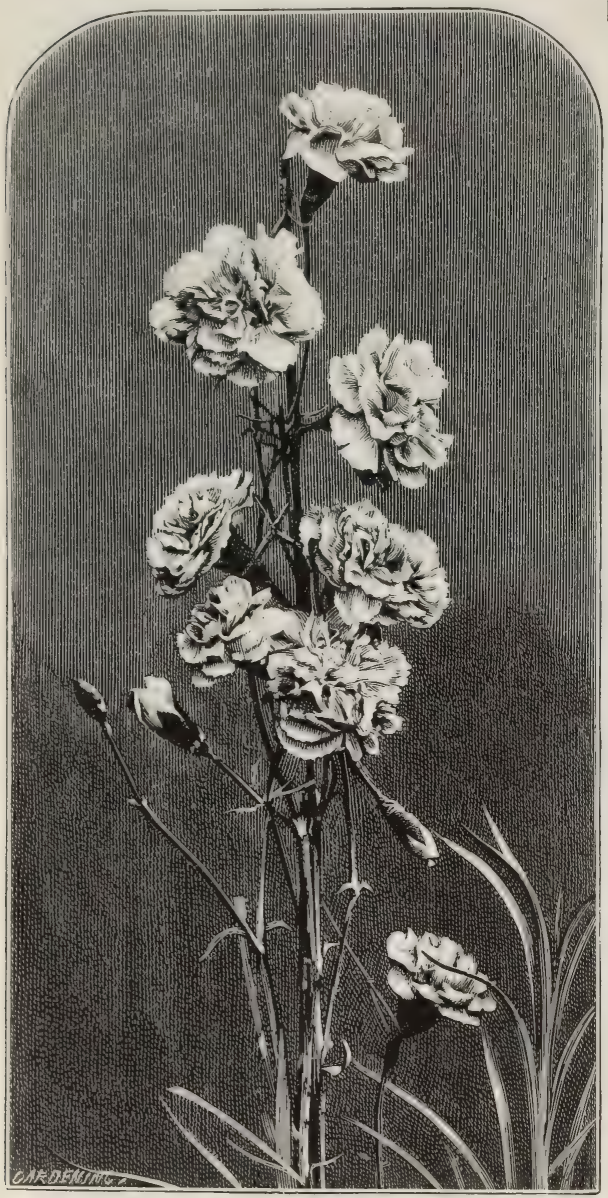

CARNATION.

heads - dark and light kinds. Of the latter there is a strain known as the Auricula-eyed, the blooms of which have a clear white eye in a setting of red or purple or some other rich dark colour. Smooth-edged flowers, such as Hunt's strain, have their admirers. Fine, evenlyrounded trusses are always present in a good strain, but size is generally allied to high culture. Except for show purposes, however, very large trusses are undesirable, as they usually need support. The finest strain is usually found where year after year the greatest care has been exercised in selecting only the finest flowers, with the largest trusses and most varied markings. The only self-coloured flowers are those of pure white, pink, or crimson; all the others are parti-coloured or variously marked, some very prettily mottled, others more or less edged with white or pale pink.

CULTURE.-This is very simple, for it is only necessary to sow the seed in April, in a well-prepared bed in a sunny situation, thinning out the young plants when they are large enough, or, if a large stock is required, planting them out about 6 in. apart in good soil. About the end of September transplant them to their permanent quarters, and in the following summer they will yield an abundance of bloom. When, however, any particular strain is to be rapidly increased the following plan is a good one: Sow in pots, and allow the seedlings to become a little drawn and lanky before planting out. Plant out in light loam, dressed only with a little leaf-mould or loam from rotted turfs, placing the seedlings so that a few of the lower joints are under the soil. When the blooming stems are well above the foliage, prick in a dressing of guano all round the plants, give plenty of water in dry weather, and a further slight dressing of guano just before the flowers begin to open. The result will be vigorous stocky shoots from the buried joints, all rooted and ready to plant out as soon as the bloom is over. Sweet Williams may also be propagated by cuttings taken off in early summer; for the main stems, which should rise for bloom, creep along the ground, and throw up from every joint shoots suitable for cuttings; and a little sheaf of cuttings may be taken from the tips of the main stems, so that each plant would furnish over a hundred cuttings.

Double-flowered kinds, as a rule, are not desirable, except the double dwarf magnificus, the deep velvety crimson flowers of which are by far the finest we have met with among the double kinds. The large heads of flower are produced in profusion, and the colour is rich and effective. Its dwarfness, too, is a recommendation, and it is, moreover, a vigorous grower, and soon forms a strong tuft.

D. Caryophyllus (Carnation) is so well known, and is such a universal favourite, that it seems superfluous to write a description of it. As early as 1769 the Carnation was divided into four classes, viz. Flakes, Bizarres, Picotees, and 
Painted Ladies. The Flakes had two colours only, the stripes going the whole length of the petals. Bizarres (from the French, meaning odd or irregular) were spotted or striped with three distinct colours. Picotees (from the French, piquotée) had a white ground with additional colours in spots, giving the flowers the appearance of being dusted with colour. Painted Ladies had the under side of the petals white and the upper side red or purple, so laid on as to appear as if really painted. Unfortunately this class has so entirely disappeared that many growers are not aware that it ever existed. The first two classes still remain unchanged; but the Picotee, instead of being spotted, has the colours confined to the edge of the petals, and any spot on the ground colour (which may be either white or yellow) would detract from the merits of the flower as an exhibition flower.

Another class, too long neglected, consists of self-coloured kinds. A familiar type is the old crimson Clove, a sweet and lovely thing, which may be had also in several different shades of self-colour. The florists of the old school did not pay much attention to self-coloured Carnations, and till recently there was a scarcity of fine varieties. We may now have them in all shades of colour. They combine hardiness and vigour with free blooming and great effect. For the flower garden they are the most important. They should be grown in bold groups or simple masses associated with roses or choice hardy flowers.

The Tree Carnation is another class of recent introduction, and is very valuable as a pot plant; or if planted out in a greenhouse border, it produces flowers in winter and spring, when none can be had out-of-doors. The most popular of this class is Souvenir de la Malmaison, with large cream-coloured blossoms and delightful fragrance, and from this have been obtained sports of different colours ; so that, with these and other varieties, there is now no difficulty in obtaining all colours, from pure white to bright scarlet.

As a rule, the choice-named varieties of Picotees and Carnations for show are grown in pots, but we confine our remarks to their culture in the garden, also treating of it, shortly, from the exhibiting florist's point of view.

CULTURE FOR BORDERS AND BEDS.First, then, of the wants of the general grower, who rightly esteems a good crimson or white Clove as it grows in the open garden as much as the most exact staged flower.
And rightly so, because, in the opinion of those who have thought and studied most about it, the superiority in form is wholly with the bold, free, undressed flower. What applies to the individual flower applies with greater force to its culture in the garden. It does not appear at its best in lines, or circles, or dotted here and there as in pattern gardening; but good kinds planted in groups of from twelve to fifty, according to room, will give us when in flower the truest idea of the value of fine Carnations for ornamenting the garden. These groups should be renewed annually, or fresh ones should be made elsewhere, a stock of plants having been raised from layers. Only in a few cases are Carnations likely to spread and make healthy tufts, able to stand for two or three years. It is generally advisable to destroy the old plants after flowering, and if we do not, the frost often does. Young strong layers, about 9 in. apart, will produce an effect hardly to be surpassed. Layering has to be performed when the plants are in full flower, and as it is undesirable to interfere with the groups in flower, the best plan is to have a few plants of each kind grown in nursery quarters solely for layering. We can then enjoy all that is gained from planting groups thickly and suffer no inconvenience. We shall also have plenty of flowers, and can cut great numbers without missing them. Varied colour is the distinctive charm of the florist varieties. Few of them are likely to produce bold effects like the selfs, but they may be grown in special beds and borders in a less prominent spot. Some nurserymen are beginning to see the mistake of neglecting a noble flower like this, and are trying to raise bold, free, and varied border flowers easily grown in every garden. They will succeed, and our gardens will be all the better of it. In specially cultivating the better kinds in beds, it is usual to cover the surface with I inch or more of fine rotten manure passed through a sieve, and in dry weather to give plenty of water; but as many will not pay more attention than is necessary, it may be stated that neither water nor top-dressing is usually required in good garden soil, and without either, the result will be quite as valuable from an ornamental point of view. But when a good collection is grown in special little beds in a warm border of the kitchen garden, a top-dressing of one barrow of mould to three of decayed manure could be given in a very short time, and if the weather or soil were very dry, an occasional heavy watering 
would improve matters. Varieties are endless; and as English, Continental, and American florists are busy raising seedlings, these varieties are likely to be much added to, though enough attention has not as yet been paid to the raising of vigorous border and flower-garden kinds with a great range of colour, form, continuity of bloom, and fragrance. It would be well for raisers to discard the kinds which burst their flowers. This is a great defect, number will be largely added to by the efforts of raisers in all gardening countries: Captain Webb, Colonel Arnet, Countess of Ellesmere, Delicata, Dora, Duke of Wellington, Emperor, Erebus, Fanny Archer, Flamer, Garibaldi, Knight, Lady Armstrong, Maximilian, Miss Wheeler, Mrs. Mathews, Mrs. Raynor, Nigger, Novgorod, Old Clove, Pilrig Park, Prince of Orange, Prince of Wales Clove, Quadricolor, Redbraes

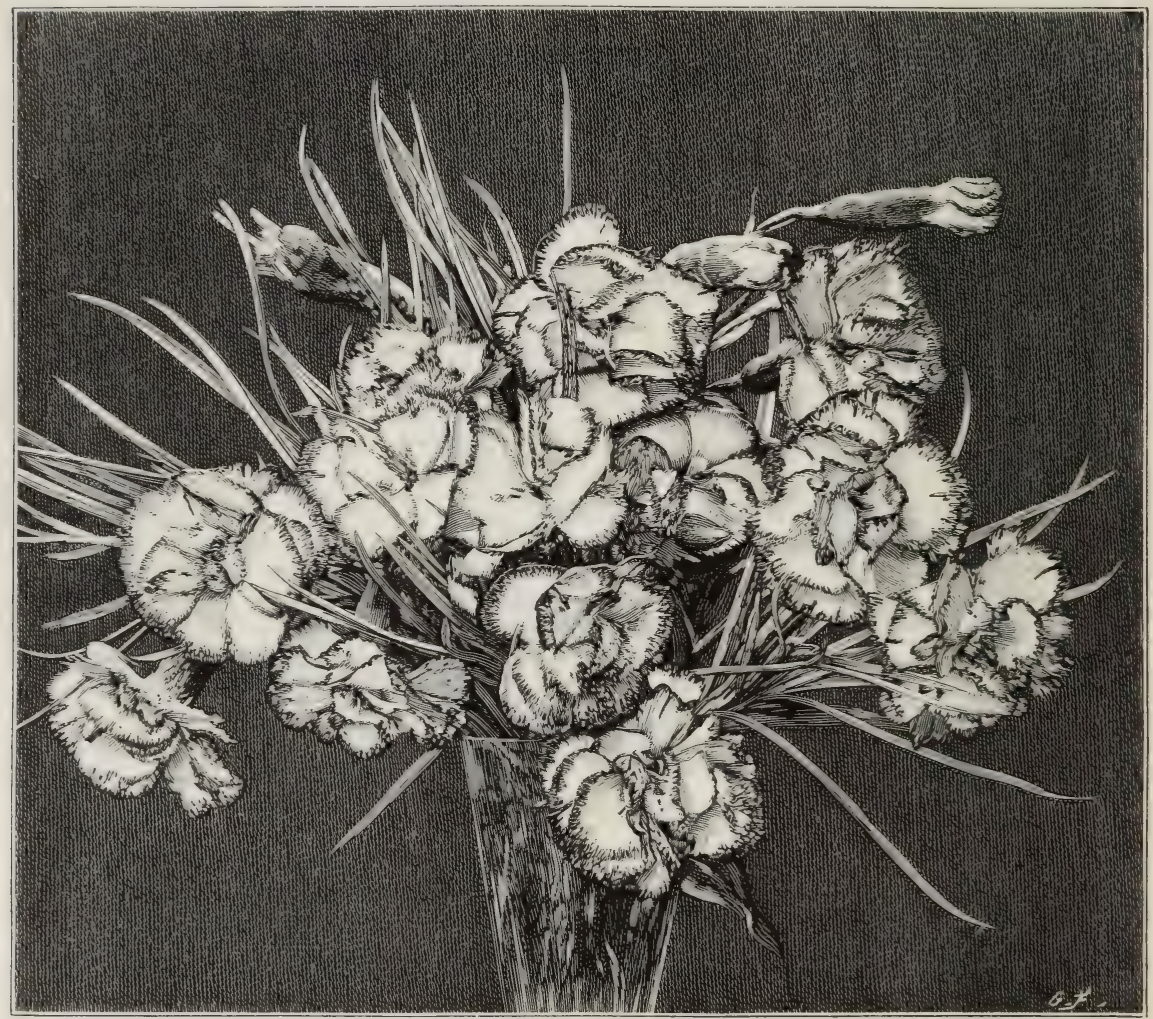

REDBRAES PICOTEE.

an unnatural habit too long condoned, and its evils are most manifest in the flower garden. In ordering, the public should distinctly make known their wishes as to colour, form, and fragrance. The Carnation does not depend for its beauty on elaborate instructions, which only the special grower for exhibition cares to master.

Border Carnations and Picotees. -Although we prefer to leave selections of varieties to the reader, assisted by the catalogues of the day, we mention some of these border kinds in the hope that the
Picotee, Red Rover, Red King, Rosy Gem, Scarlet Gem, Stranger, Taglioni, The Bride, Turk, Utility, Violette. Although the above are described as "border" kinds, they are also well worthy of special culture in good beds, either for the purpose of cutting their flowers, or for their beauty where they grow.

PERPETUAL CARNATIONS IN THE OPEN AIR.-These, if from a good strain of French seed, are very satisfactory plants and useful for cutting. Their drawback is the habit of flowering in winter, but this can be obviated by sow- 
ing early, so as to get them to a good size by autumn, when they will flower in the spring and continue in bloom all the summer. Pipings struck in the spring and planted out in the autumn will behave in the same way. Old plants are difficult to manage in the open air, but survive the winter if well thinned out; the only danger is damp cold, which rots them at the surface of the ground. They grow very well in light rich soil on chalk. On chalk hills, far from damp soil and where no damp rises in winter, they survive most winters. "My plants were in a light soil on chalk, but so near clay soil that the wind brought the cold air from the clay fields. It is impossible to say what colours will be produced from Carnation seed. My seed was of self kinds, but quite a third of the plants turned out Flakes and Picotees; only four were single, and three of these were worth keeping for their brilliancy and free flowering as well as for their smoothedged petals. One plant was merely a perpetual flowering form of the common white Pink of the cottage garden; another assumed a dwarf, almost creeping habit, with very large flowers on short stalks; some developed a climbing habit, but the greater number spread into large bushes $3 \mathrm{ft}$. across, sending up 60 or 70 flowering shoots at one time; and nearly all were Clove scented. The best flowers were produced from plants of moderate and sturdy habit. Most of these had very large petals, and resembled a Gardenia in general appearance. Their free-rooting habit makes them unsuitable for pots. Many of my plants filled almost $3 \mathrm{ft}$. of soil with their roots; it is manifest waste to cramp such free-growing plants in pots."-J. D.

GARDEN CUlTuRE FOR EXHIBITION. -About the end of July cover the bed intended to be devoted to Carnations, etc., about 2 in. with good rotten manure, and, if the soil be sandy, add to this 2 in. of good mellow loam, or, if it be stiff, add the same quantity of sand. Then, whenever time can be spared, fork in the dressing well and dig it over. Then put the plants in firmly, putting all of the same sort in a row with a good legible label at the end. Being perfectly hardy, they will need no attention till next spring. At the same time take up and put in in the same way any seedlings sown in the spring, which will now be fine strong plants. The next spring, when the severe cold has ceased (about March or April), fork the beds over carefully between the rows, and in fine weather water them if they are dry. When the flower-stems begin to rise, place a stick about $30 \mathrm{in}$. long to each plant. These sticks should be painted a light whitish-green. The flower-stems must be kept well tied up as they grow, but they must be tied quite loosely, for if they are tied tightly they will knee and bend, and finally break. About 2oth June (or later), when the buds appear, take off all but three on each shoot, so as to leave each bud a little footstalk to itself when it grows (what is lost by this in quantity will be regained twenty-fold in quality). From this time until the buds are near showing colour, give occasionally a little weak manure water, - a handful of wellrotted stable manure to a large pot of water. As soon as they show colour at the top, tie them round with a little strip of bass about half-way down. This should be done every morning in July, as it saves much trouble as well as the unsightly peculiarity termed a "split pod." If in spite of this the pods split on one side, carefully open the bud all round at the other segments, using the flat wedge handle of a knife used for layering. Unless it is intended to save seed, cut off dead blooms as soon as they wither, and the flower-stems as soon as all the buds have come out, which will be about the end of August or beginning of September. Not later than the last week in July see to layering. As soon as the layers are rooted, which will be early in September, take them off and lay them in by the heels for a time, while taking up and throwing away the old stools, top-dress and fork over the bed with $2 \mathrm{in}$. of wellrotted stable litter or cow-house sweepings, replace the layers, and they will be in the same condition as at the beginning.

Propagation by SEeD.-The proper time to sow is about April or May. Prepare a compost of equal parts of loam, leaf-mould, and silver sand, sift it fine, and fill a number of 3 -in. pots (as many as you have sorts of seed) to within $\mathrm{I}$ in. of the rim. Sprinkle each pot with a fine rose, flatten the surface, and with the point of a knife put down the seeds separately about $\frac{1}{2} \mathrm{in}$. apart. Cover them very lightly with finely-sifted compost, and put then in a cold frame or house out of danger of frost. When they show three pairs of leaves, prick them about 2 in. apart out round the edges of 5 -in. pots filled with the same compost, and keep them still in the cool house till there is no fear of frost. When they are about 3 in. high, prick them out into beds, keeping them about 4 in. apart. The beds may be enriched with a little sand 
and manure. In the autumn they will be nice little plants, and may be put into beds when they flower, which will be the next year. Keep and name any really good kind, discarding all singles, and using the rest for borders or beds for cutting from.

By Pipings.-When the plants throw up shoots too numerous to layer, or when the root is attacked by disease, the shoots may be taken off as follows: Take the shoot just above the fourth or fifth joint from the top, and with a sharp pull draw it out from the socket formed by the next joint, which it will pull away with it. Just through the joint make a little upward slit in the cutting, and thrust it firmly into a pot filled to within I in. of the top with the compost described, and the rest with silver sand. Water the pot and plunge it in fibre under a hand-light for three or four weeks, when the pipings will be rooted. They may then be potted off singly or bedded like layers, and will flower the next year. Plants thus struck are never so good as those propagated by layers, but this method is a useful expedient to save a good sort or to get up a good stock.

BY LAYERS. - This is the best and most generally accepted method of propagating Carnations and Picotees. It should be commenced at latest the last week in July, and finished by the second week in August. It is performed as follows : Scrape away the earth round the plant to the depth of 2 in., and substitute for the earth removed the compost prescribed. Then strip each shoot up to the top three or four joints, going all round the plant before proceeding farther. Then with a fine sharp knife cut half through a shoot, just above a joint, make a slanting cut down through the joint, and bring the knife out just below it; then take a peg with a hook in it, and thrust it into the fresh compost just above the tongue, so that as the peg comes down it will catch the tongue and peg it into the earth. Then cover it with a little more compost placed firmly. Proceed thus all round the plant, finally watering carefully with a fine rose water-pot to settle the soil around the layers. In about a month the layers will be rooted, and by the second week in October all the young plants ought to be in their winter quarters.

DISEASES.-Carnations are subject to three fatal diseases-canker, mildew, and gout. Canker is produced by damp, and the first symptom is a change in the colour of the Grass, or the non-formation of shoots, or a stoppage in their growth. The roots will be found rotted through, and decay creeping up the centre of the shoots, which should at once be taken off, well above the affected part, and piped. The only safeguard is to have the compost sweet and well mixed, and not to give too much water early in the year. Mildew is of two sorts, the white and the black. White mildew appears like flour on the leaves. It should be sprinkled one morning with water, and then dusted with sulphur, and the sulphur should be carefully washed off the next morning. Black mildew appears as little black specks on the Grass, and means death. It is the Carnation's cholera. The instant it appears every shoot bearing the slightest spot should be cut off and burned with the root and earth, only the shoots quite untainted being saved for piping. If this is not done, the disease will spread like wildfire, and ruin the whole stock. Gout is generally the result of twisted stems and damp atmosphere. The soft wood just above the ground swells into a cavernous goître. It does not seem to spoil the flowers. Though a gouty plant can never be layered, all the shoots should be cut off and piped. Damp is the greatest enemy of the Carnation, and produces in the first instance all these ills. It must be particularly guarded against, especially when the young plants are in the frame in winter. Hundreds have been lost by a single injudicious watering.-A.

D. cæsius (Cheddar Pink).- - One of the neatest and prettiest of the dwarf Pinks. The large, fragant, and rosy flowers appear in spring, on stems which are 6 in. high, and in rich soil sometimes taller. This pink requires peculiar treatment, as in winter it perishes in the ordinary border, but flourishes freely on an old wall. It is a native of Europe, and of the rocks at Cheddar, in Somersetshire. To establish it on the top or any part of an old wall sow the seeds on the wall in a little cushion of Moss, if such exist, or, if not, place a little earth in a chink with the seed. The Pink may also be grown upon a rockwork in firm, calcareous, sandy or gritty earth, if placed in a chink between two small rocks.

D. deltoides (Maiden Pink). - A pretty native plant, with bright pinkspotted or white flowers, which are produced rather freely on stems from 6 to I 2 in. long. It grows almost anywhere, in borders or on rockwork, and does not appear to suffer from wireworm, like most other Pinks. It frequently flowers several times during the summer. It may be readily raised from seed, and is easily 
increased by division. The variety glauca has white flowers with a pink eye. It is abundant on Arthur's Seat, near Edinburgh, and forms a charming contrast to the crimson kind.

D. dentosus (Amoor Pink).-A distinct and pretty dwarf species, with violet-lilac flowers more than I in. across, the margins being toothed, and the base of each petal having a regular dark violet spot, which produces a dark eye nearly $\frac{1}{2}$ in. across

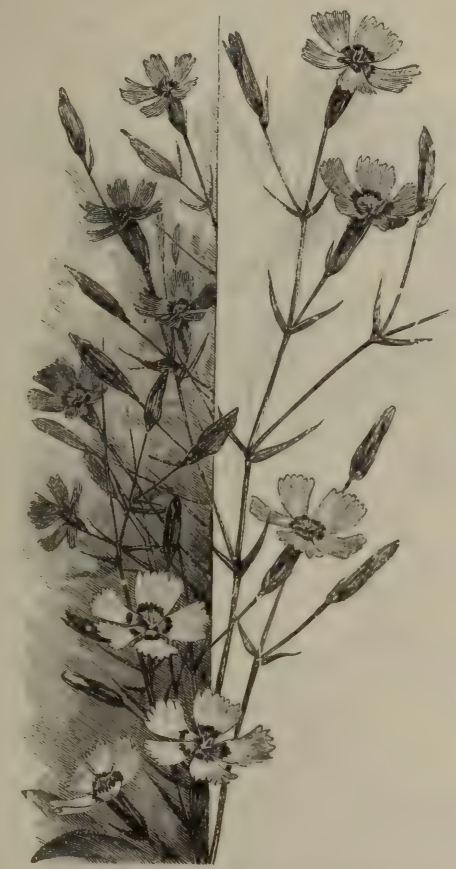

DIANTHUS DELTOIDES (MAIDEN PINK).

in the centre of the flower. The plant flowers from May or June till autumn, and thrives well in sandy soil, in borders, or on rockwork; seed; South Russia.

D. neglectus (Glacier Pink). - It is impossible to exaggerate the beauty of this plant. It forms, very close to the ground, tufts resembling short wiry grass, from which spring many brilliant flowers, I in. across, and of a deep and bright rose. It grows freely in very sandy loam, either in pots or on rockwork, rooting into the sand through the bottom of the pots as freely as any weed, and is perfectly hardy and easily grown. It is a native of the Alps and Pyrenees, and is easily increased by division and seed. Syn., D. glacialis.

D. petræus (Rock Pink). - A charming species, forming hard tufts, I or 2 in. high, from which spring numerous flowerstems, each bearing a fine rose-coloured flower. It seems to escape the attacks of wireworm. It flowers in summer, and should be planted on the rock-garden in sandy and rather poor moist loam. Hungary ; seed or division.

D. plumarius (The Pink).-This plant is considered the parent of our numerous varieties of Pinks. It has single purple flowers, rather deeply cut at the margin, and though naturalised on old walls in various parts of England, it is not a true native. The wild plant is rather handsome when grown in healthy tufts, but on the level ground it is apt to perish or to get shabby. But the many fragrant double varieties are welcome everywhere, and should be cultivated as rock or bank plants, as they live longer and thrive better on such elevations, though they grow well in any ordinary soil or position. They are so well known, so hardy and so fragrant, that praise would seem quite unnecessary; but they have been almost driven away by common bedding-plants. They have for many years been amongst the favourite "florists" flowers in European countries. They are hardier and dwarfer than the Carnation. In August the finest kinds should be planted 9 in. apart, the ground being rich and well prepared beforehand. If the winter be very severe, a little litter should be put over them. In spring the surface of the beds should be stirred a little, and given a top-dressing of fine old manure and a slight dusting of guano. As they push up their flower-spikes they should be staked, and if they are for exhibition the buds should be thinned, as many varieties produce buds too freely. The culture of Pinks, however, either for exhibition or for the garden, is very simple, and the outlay very small. We can get newly-struck pipings in August and September - the best months to plant. Place them at once in a sunny situation. In a smoky town a cold frame will be needed; but if the air be clear, an open bed will do. When the pipings are once planted in the open garden, they require little care till they begin to push up their flower-stems. Spring-planting should be commenced as early as the weather permits, and, as soon as the plants begin to grow, the bed should be mulched about $I$ in. deep with equal quantities of well-rotted horse manure and leaf-mould. The plants will then fast push on their new growth.

INCREASING STOCK.-If the plants have made good growth in July, cut the 
strongest shoots with a sharp knife, cut off the ends of the grass, and cut the shoot two or three joints below the grass or leaves. Prepare a bit of ground as follows: Scatter a little salt on the surface, then riddle on 2 in. deep of fresh soil, prick in the pipings, and put a light or hand-glass over them; and they will be rooted in a few weeks. Where seed is wanted, protect the flowers from wet, and as they decay remove the withered petals, which encourage damp and form a harbour for insects. Seed should be saved only from the finest and most
(Mule Pink), Marie Paré (Mule Pink), Napoleon III., Multiflora, Newmarket, Pluto, Purity, Robusta, Rubens, Thalia, White Queen, Wm. Bruce, High Clére, Multiflora flore-pleno, Multiflora rosea, Striatiflorus, Speciosa fl.-pl., Coccinea, Early Blush, Fimbriata alba (old white), Lord Lyons, Miss Joliffe, Nellie, White Perpetual, the Clove Pink.

DWARF SINGLE AND DOUBle PINKS. -Messrs. Dicksons \& Co., of Edinburgh, have raised some dwarf profuse-blooming Pinks so compact in habit and stiff in stem that they do without stakes. Most

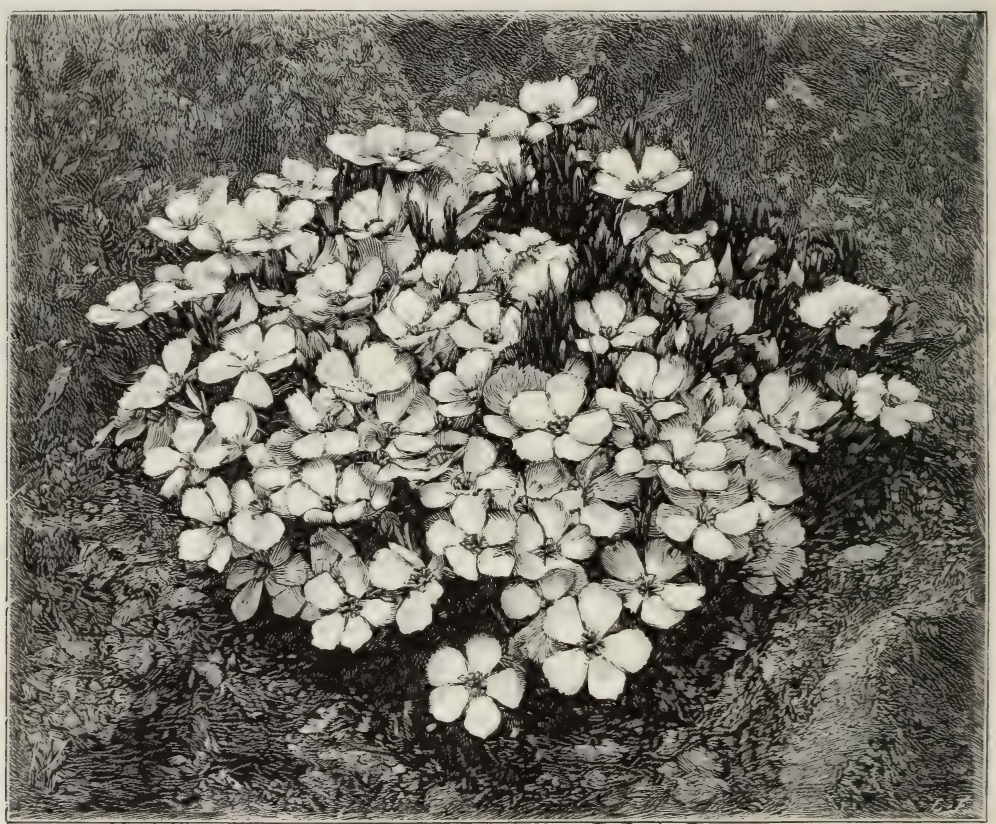

DIANTHUS NEGLECTUS (GLACIER PINK).

constant varieties, with a vigorous and hardy habit of growth, and may be sown early in June in pots, or in the open ground.

GARDEN OR BORDER PINKS.-The show Pinks may be left to the exhibitor. There are certain kinds both old and new which must be taken care of by the "general lover" of flowers. These are the vigorous and hardier border kinds, grown for their beauty and fragrance. As in the case of the hardier border and clove Carnations, we must encourage these. Some of the best of the hardier kinds are-Anne Boleyn, Ascot (soft pink), Fimbriata major, Fragrans (pure), George White, Hercules, Lady Blanche, Mrs. Moore, Mrs. Pettifer, Mrs. Sinkins
Pinks are better without stakes, especially when their foliage is healthy, and is in such wide tufts as to shield the flowers from splashed earth; but these new dwarf sorts may be compact enough for the rock-garden. Mr. J. Grieve, who raised them, says: "Both the single and the dwarf double varieties will prove quite a boon to the flower-gardener and for bouquets. To the ordinary eye all florists' Pinks consist of but one variety ; whereas amongst the single and dwarf sorts there are endless colours, and the petals of many of the flowers are so finely cut and so varied in tint as to render them easily mistaken by the uninitiated for other plants. Numbers of the single sorts look like miniature Petunias, and we 
have a few not unlike Calochortus venustus. What flower, too, can rival single Pinks of any colour for table decoration?" Carnea, Beauty, Delicata, Rosea, Spicata, and Odorata are among the best of these new dwarf Pinks, and the class will no doubt be added to.

D. sinensis (Chinese Pink).--This species has given rise to a race of beautiful flowers. It is an annual, biennial, or perennial, according to the way it is sown and grown. If sown early, the plants will flower the first year; if late, the isecond. On dry soils, and if the winters be mild, they will live for two or three years. The varieties, both single and double, are now very numerous and beautiful; and may be classed under D. Heddewigi and D. laciniatus. The forms of Heddewigi, the Japanese variety, are dwarf and very handsome, while there are double-flowered forms, particularly Diadematus, the flowers of which are large and very double. The petals of the laciniated section are very deeply cut into a fine fringe. Of this class there are also double-flowered forms. The colours of both are much varied, and there are striped crimson and white sorts. There is a very desirable dwarf class (nanus), about 6 in. high, but it is less useful than the taller varieties for cutting from. Two beautiful and distinct selected sorts, Crimson Belle and Eastern Queen, are among the best varieties. Sow D. sinensis under glass in February, with very little or no bottom-heat; give air freely during open weather, and in April plant out in well-cultivated soil, which need not be rich. Place the plants 9 in. to 12 in. apart each way, and they will form compact tufts. Encourage the laterals by pinching off decayed flowers, and the result will be a mass of blossom throughout the summer, and probably till November. Some sow in autumn, and winter the young plants in frames or under hand-glasses, - hardening them off by degrees in spring, until they have become fully established. These Pinks are admirable for the flower garden, either in beds by themselves, or mixed, or in decided colours; they may be well used with taller plants of a different character dotted sparsely among them.

D. superbus (Fringed Pink). - A handsome and fragrant species, easily known by its petals being cut into strips for more than half their length. It inhabits many parts of Europe from Norway to the Pyrenees, and is a true perennial, though when very young it perishes so often that many regard it as a biennial. It is more likely to perish in winter on rich and moist soil than on poor, light and well-drained soil, and, when it is desired to establish it as a perennial, it should be planted in fibry loam, well mixed with sand or grit. It grows, however, on nearly any soil ; and, by raising it every year from seed, an abundant stock may be kept up even where the plant perishes in winter. It comes true from seed, and is generally more than I ft. high ; it flowers in summer or in early autumn, and is better suited for mixed beds and borders than for the rock-garden.

Diapensia lapponica.-A sturdy and very dwarf evergreen alpine shrub, often under 2 in. in height. It grows in dense rounded tufts, having narrow closelypacked leaves, and bearing in summer solitary white flowers, about half an inch across. It may be grown well on fullyexposed spots on the rock-garden, in deep sandy and stony peat which is kept well moistened during the warm season. It is a native of N. Europe and N. America, being found on high mountains or in arctic latitudes.

Dicentra (Bleeding Heart).- This genus of the Fumitory Order includes several important plants. There are about half-a-dozen cultivated species, of which the finest are-

D. chrysantha.--This handsome plant forms a spreading tuft of rigid glaucous foliage, from which arises a stiff leafy stem, 3 to $4 \mathrm{ft}$. high, with long branching panicles of bright golden-yellow blossoms, about I in. long. It flowers in August and September; but the seedlings do not bloom till the second year. Its hardiness has not yet been fully tested, but it seems quite hardy in light rich soil if warm and sheltered. It is worthy of a trial. California.

D. cucullaria (Dutchman's-breeches) and D. thalictrifolia are less important, and rather belong to the curious garden.

D. eximia combines a Fern-like grace with the flowering qualities of a good hardy perennial. It is from $\mathrm{I}$ to $\mathrm{I} \frac{1}{2} \mathrm{ft}$. high, and bears numerous reddish-purple blossoms in long drooping racemes. It is useful for the rock-garden and the mixed border, or for naturalising by woodland walks. It most enjoys a rich sandy soil, but will grow anywhere. It is a native of $\mathrm{N}$. America. Division.

D. formosa is similar to the preceding, having alşo Fern-like foliage, but is dwarfer in growth. Its racemes are shorter and more crowded, and its flowers are lighter. Suitable for same positions as D. eximia. California. 
D. spectabilis is a beautiful plant, too well known to need description. Nearly every garden is embellished with its singularly beautiful flowers, which resemble rosy hearts, and, in strings of a dozen or more, are gracefully suspended on slender stalks. It succeeds best in warm, light, rich soils, if in sheltered positions, being liable to be cut down by late spring frosts. It is moreover suited for the mixed border, but is of such remarkable beauty and grace that it may be used with the best effect near the lower flanks of rockwork, in bushy places
$20 \mathrm{ft}$. long, are beautifully arched, and become pendulous with age. It is the hardiest of Tree Ferns, and the most suitable for the open air, especially in sheltered shady dells. It should be put out from the middle of May to the beginning of October. In favourable localities it may even be left out all the winter.

Dictamnus fraxinella (Fraxinella).A favourite old plant, worthy of a place in every garden. It is about $2 \mathrm{ft}$. high, and its erect stems form dense tufts. The large flowers are pale purple, pencilled with darker lines, and are borne in racemes

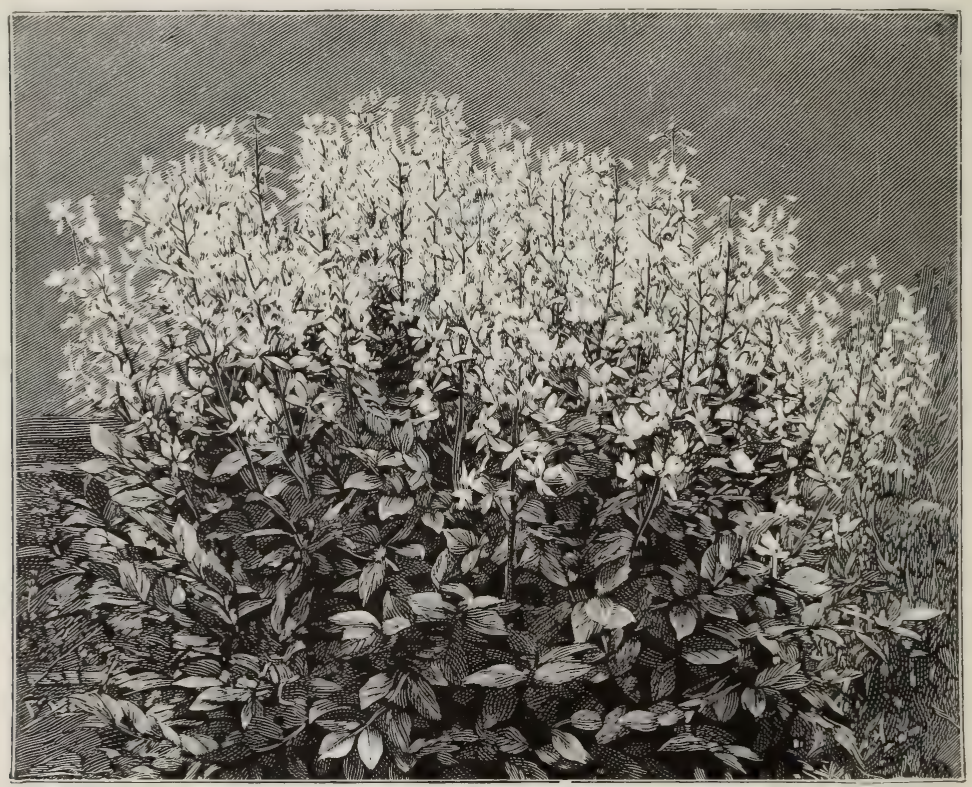

DICTAMNUS FRAXINELLA.

near it, or on low parts where the stone or "rock" is suggested rather than shown. It is worthy of naturalisation on light rich soils by wood walks. It is also excellent for mixed borders, and even more so for snug corners on the fringes of choice shrubs in peat, as such soil suits it well. There is a "white" variety, which is by no means so ornamental, though worth growing for variety's sake. Propagated by division in autumn.

Dichondra repanda.-A small trailer resembling a Convolvulus, and of no general value.

Dicksonia antarctica.-A noble evergreen Tree Fern, with a stout trunk, attaining a height of $30 \mathrm{ft}$. or more. The fronds form a magnificent crown, often 20 to $30 \mathrm{ft}$. across. They are from 6 to in June and July. There is a variety with white flowers. It succeeds best in a light dry soil, in partially shaded borders. It is propagated by seeds sown as soon as they are ripe, or by its fleshy roots, which, if cut into pieces in spring, will strike freely and will form good plants much quicker than seedlings will. It is proverbially a slow-growing plant in most gardens, though it is freer in some warm chalky soils. It is a native of the Taurian and Caucasian Mountains.

Didiscus cœruleus.-A native of New Holland, and from I to $2 \mathrm{ft}$. high. Its stems are erect and much branched, each branch terminating in a flat umbel of small flowers, of a pleasing clear blue colour, which are borne freely from August to October. It is a half-hardy 
annual, and requires rather careful treatment, as it is impatient of excessive moisture, especially in the early stages of its growth. It requires to be raised in a gentle hotbed, and the seedlings should be transplanted in May to a warm friable soil, in which they will flower freely. Those who seek distinct and novel effects might use this plant, as its pretty blue flowers are uncommon in the Parsley order, which usually has pale or poor flowers. A little bed or groundwork would be charming if only as a change. Syn., Trachymene cœrulea.

Dielytra (Dicentra).-A name erroneously given to Dicentra.

Diervilla (see Weigela).

Digitalis (Foxglove).- The most important plant of this genus is our native Foxglove, for it is the handsomest of the several species in cultivation. The best of the exotics is D. grandiflora, a tall slender plant, bearing large bell-shaped yellow blossoms in long racemes. The other garden kinds are D. ferruginea, aurea, eriostachys, fulva, lævigata, lanata, lutea, ochioleuca, parviflora, Thapsus, tomentosa, but these are suited mainly for botanical collections.

D. purpurea (Foxglove).-Wild Foxgloves seldom differ in colour, but cultivated ones assume a variety of colours, including white, cream, rose, red, deep red, and other shades. The charm of these varieties, however, lies in their pretty throat-markingsspots and blotchings of deep purple and maroon, which make large flowers resembling those of Gloxinia ; hence the name gloxiniflora is applied to some finely-spotted kinds. The garden plants make grand border flowers ; they are more robust than the wild plant, and have stouter stems and stronger flowers. If associated with other tall plants, they look well as a background to mixed borders; and the improved varieties have a fine effect in the wild garden, if planted or sown in bold masses. They are good, too, among Rhododendrons, where these bushes are not too thick, and they charmingly break the masses of foliage. The seed is small, and is best sown in pans or boxes, under glass, early in May. When the young plants are well up they should be placed out of doors to get thoroughly hardened before being finally planted out. In shrubbery borders varied clumps of several plants produce a finer effect than when set singly. The Foxglove frequently blooms two years in succession : but it always is well to sow a little seed annually; and if there be any to spare, it may be scattered in woods or copses where it is desired to establish the plants. Those who do not require seed should cut out the centre spike as soon as it gets shabby, and the side shoots will be considerably benefited, especially if a good supply of water be given in dry weather. In a good variety a side shoot will supply an abundance of seed.-D.

Digraphis (Ribbon Grass).-A genus of Grasses, of which the Ribbon Grass (D. arundinacea variegata) is the most familiar. Being perfectly hardy and perennial, it is valuable for producing a variety of good effects in the flower garden. It should be treated liberally, and should be renewed by young plants every other year. If it be not desired in the flower garden proper, a few tufts by a back shrubbery will suffice. It grows anywhere.

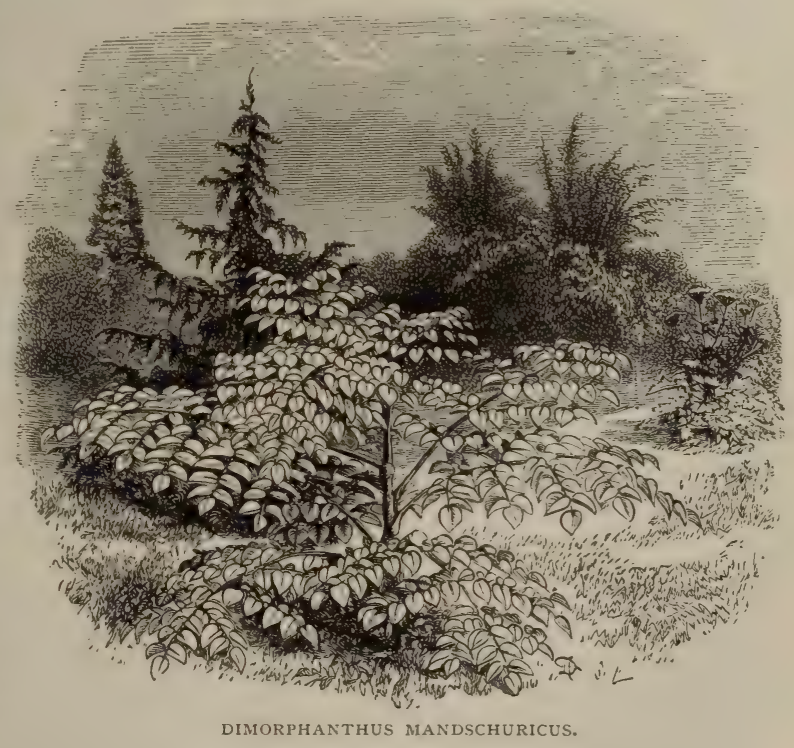

Dimorphanthus mandschuricus.-A handsome hardy shrub, with very large much-divided spiny leaves, resembling those of the Angelica tree of North America. In this country it attains a height of from 6 to $10 \mathrm{ft}$., and probably 
much more when well established in favourable positions. It is of the highest importance for the sub-tropical garden. In a well-drained deep loam it thrives with the greatest vigour, and in ordinary garden soil grows well in some sheltered but sunny spot; it may also be grouped with similar subjects, if space be allowed for the spread of its great leaves. Although a shrub, we group it here because, like the Ailantus, its fine foliage may be useful in a flower garden where tender fine-leaved plants will not thrive.

Dimorphotheca pluvialis (Cape Marigold).-A hardy annual from the Cape; the flowers, white and purplish-violet beneath, expand in fine weather and thrive in any good soil. Plants from spring-sown seed flower from July to September. It is a bold free annual, and an effective ground or carpet plant with the larger flower-garden subjects; even alone, however, it is well worth growing in a good position. Compositæ. I 8 to 24 in. high.

Dioscorea ( $\mathrm{Yam}$ ).-Climbing plants with inconspicuous flowers, but with elegant foliage and graceful growth which make them suitable for covering trellises and the like. D. Batatas, D. villosa, and D. japonica are the species in cultivation ; and all of these grow in good garden soil. They may occasionally find a place in the curious garden, but we have so many climbers with fair flowers and good foliage, that there is scarcely room for these in the select garden.

Diotis maritima (Sea Cotton-weed).A dwarf cottony herb suitable for the rock-garden, and sometimes employed in the flower garden as an edging plant. It is apt to grow rather straggling, and to prevent this it should be kept neatly pegged down and cut in well. It should have deep sandy soil. Increased by cuttings, as it seldom seeds in gardens. Native of our southern shores.

Diphylleia cymosa (Umbrella-leaf).An interesting perennial of the Barberry family, about $\mathbf{I} \frac{1}{2} \mathrm{ft}$. high, with pairs of large umbrella-like leaves. In summer it has loose clusters of white flowers, which are succeeded by bluish-black berries. N. America, on the borders of rivulets and on mountains. It thrives in the moister spots of peat borders and fringes of beds of American plants. Division in spring. Hitherto only seen in single weak specimens, this plant, if more plentiful, might be made good use of in a choice garden of American plants and flowers.

Diplopappus. - Perennial plants re- sembling the Michaelmas Daisy. They are natives of $\mathrm{N}$. America; but so many fine Asters flower at the same time, that the species of this genus are scarcely worth growing. D. linearifolius is perhaps an exception. It is an erect plant from I ft. high, with stiff narrow foliage and dense heads of violet blossoms. Other cultivated kinds are D. umbellatus, amygdalinus, chrysophyllus, and cornifolius. They grow freely in any soil.

Diplotaxis tenuifolia.-These plants, though sometimes mentioned in seed catalogues, are all weeds, except, perhaps, a variegated-leaved form, which is superseded by other variegated plants.

Dipsacus (Teasel).-Coarse - growing plants, but fine in form, in woods and hedgerows, where their fine foliage and habit have a good effect. There are

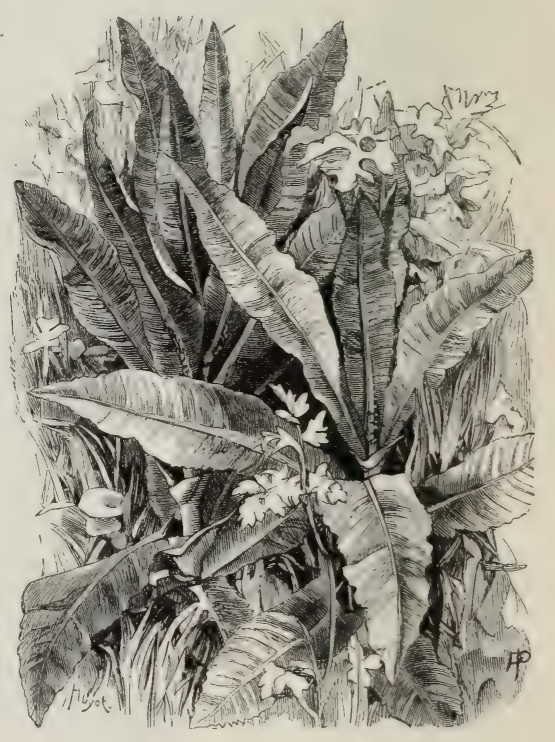

FOI.IAGE OF TEASEL.

three native species, D. Fullonum, pilosus, and sylvestris; but the boldest is $D$. laciniatus, a European species growing 5 to $8 \mathrm{ft}$. high, and with large deeplycut foliage ; seeds.

Dittany of Crete (Origanum).

Diuris. - Australian terrestrial Orchids, about which little is known. D. lilacina is an attractive plant recently introduced.

\section{Dock, Water (Rumex).}

Dodecatheon (American Cowslip).All the species of this beautiful genus of the Primrose family are perennials of $\mathrm{N}$. America, where they were called Shooting 
Stars. They are all perfectly hardy, requiring a cool situation and light loamy soil. The nature of the soil is, however, of small importance, as they grow almost as freely in peat or leaf-mould as in loam ; situation is the principal point. In borders where Primulas and Soldanellas thrive, Dodecatheons will soon establish themselves, and in spring form lovely and attractive objects. All the species and varieties grow freely in sandy loam, and soon form large tufts, which require to be divided every third or fourth year. The best time for transplanting them is the end of January or the beginning of February, when the roots are becoming active; but care must be taken not to divide them into pieces too small, for fear of losing the plants while they are in a weakly condition. All may be easily raised from seed.

D. integrifolium.-A lovely and gailycoloured flower; the petals have a white base, and spring from a yellow and dark orange cup. The flowers are of a deep rosy crimson, and are produced on stems from 4 to 6 in. high. They appear in March. The leaves are much smaller than those of D. Meadia, are oval, and quite entire. It is a native of the Rocky Mountains, and a gem for the rock-garden, if planted in sandy peat or sandy loam with leafmould. It is increased by careful division of the root and by seed. It is easily grown in pots placed in the open air in some sheltered and half-shady spot during summer, and kept in shallow cold frames during winter. Strong well-established plants produce abundance of seed, which should be sown immediately after it is gathered.

D. Jeffreyanum.-A stout kind, which grows more than $2 \mathrm{ft}$. high in good soil. It has larger and thicker leaves than D. Meadia, together with reddish midribs very strong and conspicuous. The flower is like that of the old kind, but is somewhat larger and darker. D. Jeffreyanum is a hardy and first-class plant, flourishing freely in light, rich, and deep loam, and thriving best in a warm and sheltered spot, where its great leaves are not broken by high winds. Syn., D. lancifolium.

D. Meadia (American Coreslip) is bright, graceful, and hardy, and is second to none of our old border flowers. Its straight slender stems are from io to I6 in. high, and support umbels of elegantly drooping flowers, the purplish petals springing up vertically from the pointed centre of the flower, something like those of the common greenhouse Cyclamen. It loves a rich light loam, and is one of the most suitable plants for the rockgarden, for well-arranged mixed borders, or for the fringes of beds of American plants. In many deep light loams it flourishes without any preparation, but where a place is prepared for it, as is often necessary, it is very desirable to add plenty of leaf-mould. In somewhat shaded and sheltered positions it attains its greatest size and beauty, though it often thrives in exposed borders. It is best increased by division when the plants die down in autumn; but if seed is sown, it should be sown soon after it is gathered. There are numbers of pretty and distinct varieties, differing more or less in height of plant and size and colour of flower. Among the best are D. giganteum, elegans, albiflorum, splendidum, and violaceum. D. californicum, though sometimes thought a species, is probably only a variety of $D$. Meadia. It is, however, a distinct and pretty plant, and worth growing.

Dog Rose (Rosa).

Dog's-tooth Violet (Erythronium

\section{Dens-canis).}

\section{Dog Violet (Viola canina). \\ Dogwood (Cornus). \\ Dolomiæa macrocephala.-A bold and} curious stemless plant somewhat resembling a Thistle. It has a tuft of deeplycut leaves, from the centre of which springs a cluster of short-stalked purple flowers, an inch or more across. It is rare in cultivation, and is difficult to grow well, as it is somewhat tender. N.W. India. This and another species, D. lucida, are best in botanical collections.

Dondia Epipactis. - A singular and pleasing little herb, from 3 to 6 in. high, producing small heads of greenish-yellow flowers in early spring. It is suitable for the rock-garden, for margins of borders, for banks, or for any place where such a small and modestly-pretty plant may be seen. It is increased by division after flowering. Carinthia and Carniola. Syn., Hacquetia Epipactis.

Dorema. - Umbelliferous plants of little use. D. ammoniacum is rarely cultivated. It yields the ammoniacum of commerce.

Doronicum (Leopard's Bane). - A genus of Composites, of which half-adozen species are in gardens. They are all of somewhat coarse growth, their chief merit being that they flower in early spring. They are all of vigorous growth, and thrive in any soil or position; 'they are therefore excellent for rough places, for naturalising, or for dry banks, where little else will thrive. All are readily increased by division of the roots. They 
range in height from 9 to 12 in., and have large, bright yellow Daisy-like flowers. The best species are D. austriacum and caucasicum, both of which are neater than the rest and produce in early spring a profusion of blossoms that enliven the borders besides being useful for cutting. The other kinds are D. Clusi, carpatanum, Columnæ Pardalianches, and plantagineum, all natives of Europe. D. plantagineum var. excelsum (syn., Harpur Crewe) is by far the best.-D.

Down-Thistle (Onorpordon? earlier. Each plant should be allowed quite $8 \mathrm{in}$. for development, and in hot weather those from the last sowing should be well mulched and watered. The flowers of the several varieties of $D$. pulchella differ in colour, the best variety being alba (white), rubra (red), and atropurpurea (dark purple).

Draba (Whitlow Grass). - Minute alpine plants, most of them having bright yellow or white flowers, and leaves often in singularly neat rosettes. They are too dwarf to take care of themselves

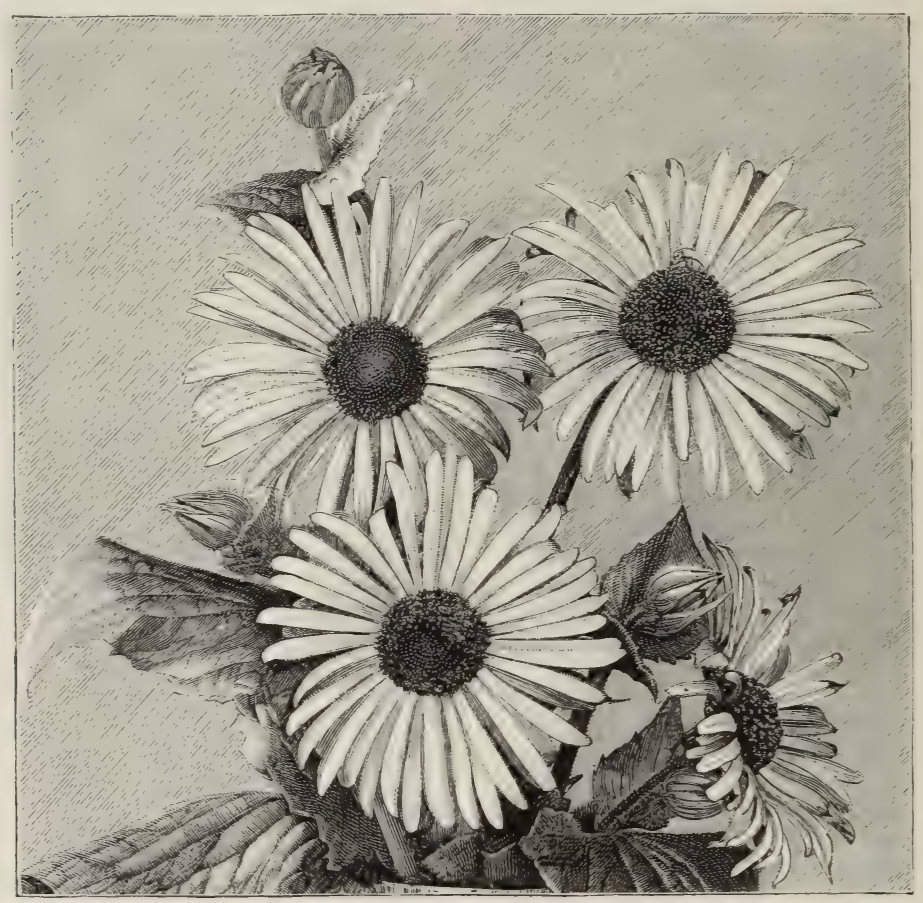

DORONICUM (LEOPARD'S BANE).

Downingia.-Charming little Californian half-hardy annuals, generally known as Clintonia. There are two species, D. pulchella and elegans, similar to each other, resembling the common bedding Lobelias in habit, but more brilliant in colour. D. pulchella is the more desirable. It is of dwarf habit, rarely exceeding 6 in. in height, and is suitable for edging small beds or borders. When covered with its bright blue flowers it is very pretty. It likes a free well-enriched soil and an open situation. In March and April the seed should be sown in the open ground, but, if the plants are intended for pot culture, the sowing should be two months among plants much bigger than Mosses, and therefore there are few positions suitable for them; but it would be very interesting to try them on mossy walls, ruins, or bits of mountain ground with sparse vegetation. The best-known and showiest is D. aizoides, found on old walls and rocks in the west of England. It forms a dwarf, spreading, cushion-like tuft, which, in spring, is covered with bright yellow blossoms. D. aizoon, alpina, ciliaris, cuspidata, lapponica, rupestris, frigida, and helvetica are very dwarf, compact-growing plants. In each the small flowers, white or yellow, are produced abundantly. Rarer kinds 
are D. Mawi, glacialis, and bruniifolia, all worth growing in a full collection of alpine flowers for a choice rock-garden.

Dracæna (Dragon's-blood). - These plants are among the best of those that may be brought from the conservatory or the greenhouse in early summer, and placed in the flower-garden till it is time to replace them in the houses where they are to pass the winter. The hardier kinds, like indivisa and Draco, may be placed out in the summer very far north. D. indivisa is very graceful, with pendent and dark green leaves, long, narrow, and tapering to a point. They are from 2 to $4 \mathrm{ft}$. in length, and from $\mathrm{I}$ to 2 in. in width. D. indivisa is perfectly hardy in the south and west of England and Ireland, and should not be confounded with the conservatory plant known as Cordyline indivisa, which is too tender for the open air, and somewhat difficult to grow. D. indivisa lineata is a fine variety, with leaves much broader than those of the type. They are sometimes 4 in. across, and are coloured with reddish pink at the sheathing base. Other good varieties are: $\mathrm{D}$. indivisa atro-purpurea, with the base of the leaf and the midrib on the under side of a dark purple; D. $i$. lineata ; and D. indivisa Veitchi, in which the habit and size of the leaf are the same as in the species, but with a sheathing base in addition, and with the midrib on the under side of a beautiful deep red. It would be difficult to find a plant more worthy of cultivation. Where it does well in the garden or pleasure-ground in the southern or western counties it surpasses any Yucca in distinctness and grace. At Knockmaroon Lodge, near Dublin, a plant, $16 \mathrm{ft}$. high, with a stem some 6 in. in diameter, annually flowered and bore an abundance of seeds, from which Mr. Pressly, the gardener, easily raised seedlings in a cold frame. In the Scilly Islands the plant becomes a great tree, luxuriating in the mildness and moisture from the Gulf Stream. The fact that in Dublin young plants annually flower and ripen seed is sufficient proof of its hardiness and of its prospects of success in many districts. It is readily increased from seed, from pieces of the stem, and offsets. If a plant is cut overclose to the ground, there soon spring up a number of young shoots, which can be taken off as cuttings, and which strike with freedom. Recent severe winters may have hurt it in many places; but after so many years' success no one in a likely district will give up its culture.

Dracocephalum (Dragon's-head). - A genus of the Sage family, among which are a few choice perennials, suitable for the rock-garden or the mixed border, succeeding in light garden soil and easily increased by division or seed. D. altaiense has bright green leaves, and axillary clusters of large tubular flowers of a dense Gentian-like blue, spotted with red in the throat. D. austriacum has flowerstems nearly I ft. in height, densely covered with rich purple blossoms ; D. Ruyschiana, a handsome species, has narrow Hyssoplike leaves and purplish-blue flowers, but its variety japonicum, a new introduction from Japan, is even more showy. D. peregrinum, with pretty blue flowers always produced in pairs, is desirable, and so is D. argunense, which is a variety of $D$. Ruyschiana. The most beautiful of all is D. grandiflorum, a beautiful rock-garden plant, which is the earliest to flower. It is very dwarf, and has large clusters of intensely blue flowers, which scarcely over-

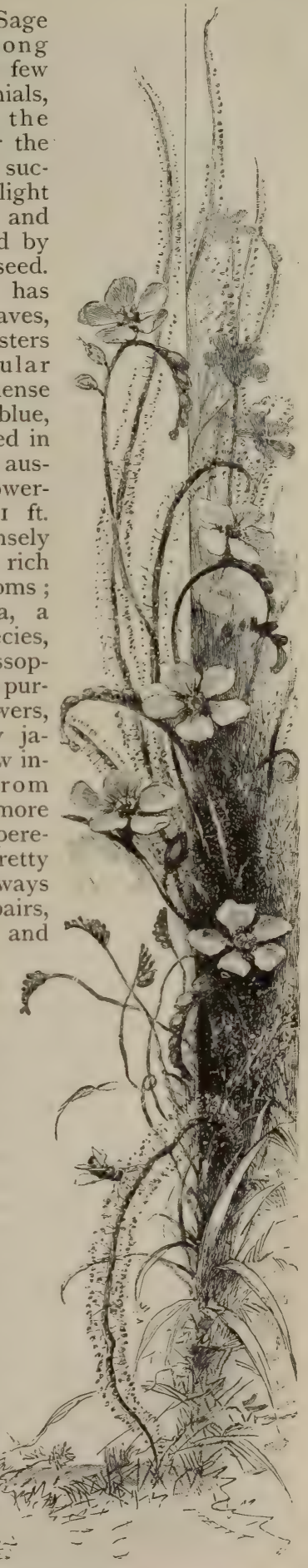

DROSERA FILIFORMIS. 
top the foliage. In D. speciosum, a Himalayan species, the small deep purple flowers are nearly smothered by the large green bracts. The hardy annual kinds, such as Moldavica and $D$. canescens, are ornamental, and worth a place in a full collection. lus)

Dragons (Arum Dracuncu-

Dragon's - head phalum

Dragon's - mouth crinitum).

Drimys Winteri (Winter Bark).-An interesting evergreen shrub from South America, not hardy enough for open-air culture except against a wall. In mild districts its fragrant milk-white flowers appear, but its outdoor culture should not be attempted in cold localities.

Drooping Tulip (Fritillaria.

\section{Drop-wort (Spircea Filipendula).}

Drosera (Sundew).-Most interesting little bog-plants, of which all the hardy species but one are natives of Britain. All are characterised by tufts of leaves and have their surfaces covered with dense glandular hairs. When the native kinds are grown artificially the condition of their natural home should be imitated as far as possible. In a bog on a very small scale it is not easy to secure the humid atmosphere they have at home, but they will grow wherever Sphagnum grows. The native kinds are intermedia, longifolia, obovata, and rotundifolia. The North American Thread-leaved Sundew (D. filiformis) is a beautiful bog-plant, with very long slender leaves covered with glandular hairs, the flowers purplerose colour, half an inch wide, and opening only in the sunshine. It is quite hardy, but appears difficult to cultivate.

Dryas (Dryad, Mountain Avens).-A genus of the Rose family, containing two or three dwarf alpine plants of spreading growth and neat evergreen foliage. They succeed in cultivation and thrive on level borders in light soil, though they are seen to best advantage in the rock-garden, where they can spread over the brows and surfaces of limestone rocks. They like an exposed spot, not too dry, though when well established they will flourish under almost any conditions. They are propagated by seed or division in spring. The kinds are D. Drummondi. a dwarf, hardy, evergreen trailer, with flower-stems
3 to 8 in. high. Its golden-yellow flowers, I in. across, appear in summer. N. America. D. octopetala, a creeping ever-

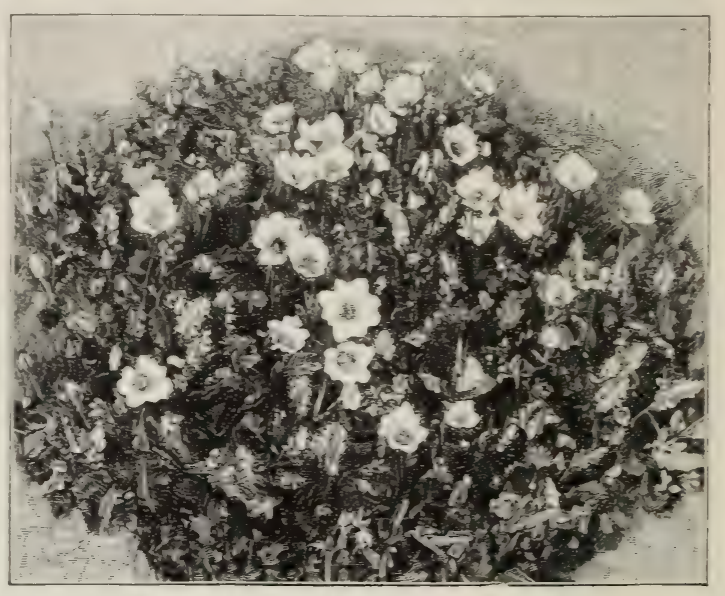

DRYAS OCTOPETALA (MOTNTAIN AVENS). green, forming dense tufts. A very small form of octopetala called minima is useful for covering stones in the rock-garden. It has white flowers with yellow centre, which are I in. or more across, borne on stalks 3 to 8 in. high. A British mountain plant.

Duckweed, Fruiting (Nertera depressa).

Dusty Miller (Primula auricula).

Dutch Agrimony (Eupatorium cannabinum

Dutchman's-breeches (Dicentra).

Dutchman's-pipe (Aristolochia sipho).

Dutch-Myrtle (Myrica Gale).

Dwarf Cornel (Cornus suecica).

Dyckia rariflora.--An interesting plant of the Bromeliad family, which is for the most part tropical. Though this is a native of Brazil, it is hardy in sheltered localities if planted in sandy loam in dry snug nooks of a well-drained rock-garden. It is about $2 \mathrm{ft}$. high, with a rosette of spiny leaves and spikes of orange-coloured flowers, which here, however, are but seldom produced in the open air.

Dyer's-weed (Genista tinctoria).

Eccremocarpus scaber.-A delightful old climber for walls, trellises, and pillars, and for association with other climbing plants. Its orange-red flowers are beautiful, and its rambling shoots charming. If the roots are protected during winter, they are uninjured, and the plant annually increases in size. Increased freely by seed. = Calampelis.

Echeveria.-Dwarf succulent plants, much used in the flower garden, especially 
the half-hardy species like secunda. Other species are tenderer and need a greenhouse to keep them through the winter, and a warm house or frame to propagate them in the spring. E. secunda is well known by its pale green rosette, leaves tipped with red. E. s. major is but a mealy form of the same. E. s. glauca differs only in having leaves rather more pointed and glaucous. E. s. pumila is a smaller form, with narrow leaves of the same colour as E. s. major. E. glauca metallica is intermediate between the well-known E. metallica and E. secunda glauca. It is dwarf and massive, the leaves are very solid and fleshy, and it is very distinct and useful. E. metallica is a noble species, and distinct in the size of its leaves and in their rich metallic hue. The dwarfer kinds are used mostly as edgings or panels. The fine E. metallica is very effective on the margins of beds and groups of the dwarfer foliage plants, or here and there among hardy succulents. It should be planted out about the middle of May.

INCREASE.-As soon as the seed is ripe prepare to sow it. Fill some 4 -in. pots to within $\frac{1}{4}$ in. of the rim with equal proportions of leaf-mould and well-sanded loam. Make the surface very firm, and water the soil so that the whole body of it becomes thoroughly moistened. Having allowed the moisture to drain away, scatter the seed thinly and cover it thinly with silver sand. Place the pot in a hand-light or in a close frame; cover with a pane of glass and shade. The seed will germinate before the soil can dry, and if it is sown as soon as it is ripe every seed will come up. As soon as the seedlings are large enough to handle, prick them out thinly into pans or 6-in. pots ; keep them close until they are fairly established, and then allow them the full benefit of sun and air. After the middle of September give no water, and take care to remove all decay as soon as it is perceived. If planted early in April in wellworked and fairly-enriched soil, these little plants will make good strong plants by the autumn. There is another method of increasing them. With a sharp knife cut out the heart of the plant, so as to induce offshoots. These taken off will speedily make good specimens. E. metallica may be increased in the following manner: Take off the flower-stems which come early in the season; cut off the embryo flowers and place the stems in pots of sandy soil. These stems will strike and will produce little offsets from the axils of the flower-stem leaves. If these are taken off they will readily strike. E. metallica may also be raised from seed in the manner above described.

\section{Echinacea (see Rudbeckia).}

Echinocactus Simpsoni.-A beautiful little Cactaceous plant, a native of Colorado, occurring at great elevations, and believed to be hardy. It grows in a globular mass, 3 or 4 in. across, which is covered with white spines. It flowers early in March, bearing large pale purple blossoms which are very beautiful. No one appears to have had any lengthened experience in cultivating it, but, so far, it seems to thrive. Its natural conditions should be imitated as far as may be. In its native habitat it enjoys a dry climate, and, in some seasons at least, is more or less protected from frost by a covering of snow. In this country, however, it has withstood $32^{\circ}$ of frost, and therefore in a dry spot may escape and flourish.

Echinocereus.-Plants of the Cactus family (from arid regions in N. America), some of which have been said to be hardy. Mr. E. G. Loder, of Weedon, Northamptonshire, grows and flowers them successfully. He thus writes to The Garden: "I have a wall here where the Ivy hangs over in such a way that it keeps a large portion of the winter's snow and rain off the plants growing underneath. In this position I have grown several species of Echinocereus and Opuntia, an Echinocactus, and a Mammillaria. Only small plants were tried, yet several flowered in spite of our very severe winters and not favourable summers. We had $4 \mathrm{I}^{\circ}$ of frost here last winter, but none of these Cacti were injured by it. No species of Cactus which I have tried does well in a level border. A narrow rock border, raised about I. ft. high, against a south wall, would be a capital position, but it is much improved if the wall has a good wide coping. The most attractive is a natural one of Ivy. What success I have in the culture of these plants has amply repaid me for all the trouble and care spent upon them; but much greater success may reasonably be expected by any one who will undertake their cultivation in a more sunny part of England. All of them are beautiful, and some quite splendid when in flower. E. Fendleri bears some of the brightest-coloured flowers that I have ever seen-a rich purple." The species of Echinocereus that $\mathrm{Mr}$. Loder grows are E. nœephiceus, gonacanthus, Fendleri, viridiflorus, and paucispinus. We have no doubt that various hardy Cacti of N. America would flower 
well on raised stony borders and sunny banks in rock-gardens. Give them soil which is well drained and sunny, but exposed, away from all coping or artificial protection, but take great care so to place them in relation to surrounding objects that their stems cannot easily be hurt in clearing or passing. A few friendly stones and low evergreens can be grouped so as to keep off the digger and other dangerous animals. A close turf of some dwarf clean alpine will prevent earth-splashings and will improve the effect.

\section{Echinochloa (Panicum).}

Echinocystis lobata (Wild Balsam Apple). - A tall climbing annual of the Gourd family, having greenish-yellow flowers, succeeded by large oval fruits. Useful for covering arbours, but scarcely worth growing. N. America.

Echinops ruthenicus (Globe Thistle). -A fine hardy plant from S. Russia, 3

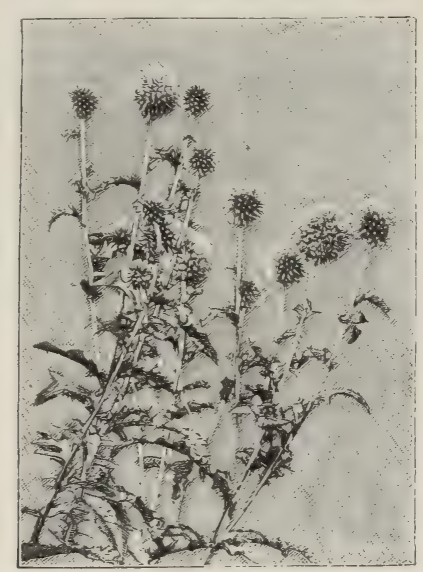

ECHINOPS RUTHENICUS (GLOBE THISTLE).

to $5 \mathrm{ft}$. high, covered with a silvery down, the flowers blue, in round heads. Thrives in ordinary soil. Easily multiplied by division of the tufts, or by cuttings of the roots in spring. It is the most ornamental of its distinct family, and is highly suitable for grouping with the bolder herbaceous plants. It would also look well when isolated on the turf. There are other species, mostly from S. Europe and the Levant, among which are E. Ritro and E. banaticus; but we have never seen any so good as E. ruthenicus, and, as the species are very much alike, it is enough to grow the best. E. sphærocephalus is a fine species, tall and handsome ; giganteus is a garden variety of the above, more robust, and with larger heads.
Echinospermum.-Sometimes mentioned in seed catalogues, but the species at present introduced are of little value.

Echium (Viper's Bugloss). - Noble plants of the Forget-me-not Order, the finer kinds of which, though superb in the open gardens of S. Europe, are too tender for ours. E. plantagineum is one of the handsomest of the annual or biennial species. Its showy flowers, of rich purplish-violet, are in long slender wreaths that rise erect from a tuft of broad leaves. It is handsomer than our indigenous species, E. pustulatum and $\mathrm{E}$. vulgare, which, were they not so common, would be included among our hardy flowers. E. rubrum is a scarce and handsome species. Its habit is similar to those above mentioned, but its colour is a reddish-violet, similar to the attractive E. creticum. The Salamanca Viper's Bugloss (E. salmanticum) is another fine species, but difficult to obtain, except from its native locality. These five species are now in cultivation, and are representative of the annual and biennial Echiums. They are all showy and worthy of a place in a full collection. They are of the simplest culture. The seeds should be sown in ordinary garden soil, either in spring for the current year's flowering, or late in autumn for flowering in early summer. Our native E. vulgare is good in certain positions; its long racemes of blue flowers are handsomer than those of the Italian Anchusa. Against a hot wall, where nothing else would grow, Dr. Acland, of the Grammar School, Colchester, planted some, and they gave a beautiful bloom. It is valuable for such positions, particularly on hot gravelly or chalky soils.

\section{Edelweiss (Leontopodium alpinum).}

Edraianthus comprises about half-adozen species, resembling alpine Hairbells and inhabiting the mountains of S.E. Europe and Asia Minor. All have the tufted habit and narrow leaves of $E$. Pumilio, the smallest of the series. In habit E. Pumilio closely resembles Silene acaulis, and the wild specimens, including the flowers, are only 2 to $3 \mathrm{in}$. high. The shining foliage is hairy and of a silverygrey. E. Pumilio is a true rock-plant, and requires to be grown with the choicer alpine plants in a well-formed rock-garden or border devoted to dwarf plants. E. tenuifolius and graminifolius, natives of Greece and Bosnia, grow from 3 to 6 in. or more high, and have narrow grasslike leaves, chiefly radical, together with flowers nearly double the size of those of E. Pumilio. E. serpyllifolius has, as the 
name indicates, Thyme-like foliage ; and E. Kitaibeli, a native of Bosnia, is about $6 \mathrm{in}$. high, and has proportionately large flowers. E. dalmaticus is one of the best of the cultivated kinds.

Edwardsia tetraptera (New Zealand Laburnum).-Edwardsia is now classed with Sophora, but for the garden it is well to retain the old name, as there is one shrub belonging to it. This is E. tetraptera, which has been aptly called the New Zealand Laburnum. It is quite a large tree in its own country, and makes a charming wall-plant here. The variety markets under the name of Ighidé agághi, and is sweet and pleasant to the taste, abounding as it does in a dry, mealy, saccharine substance; it possesses the property of retaining, for a considerable time after being gathered, its usual size and form. The general aspect of this form is much more that of a Willow than an Olive, the long lanceolate leaves being greyish above and silvery-white beneath. Under cultivation I have seen this thrive in a dry, hungry, sandy soil, and attain tree-like proportions with a stem as much as a foot in diameter. This deciduous

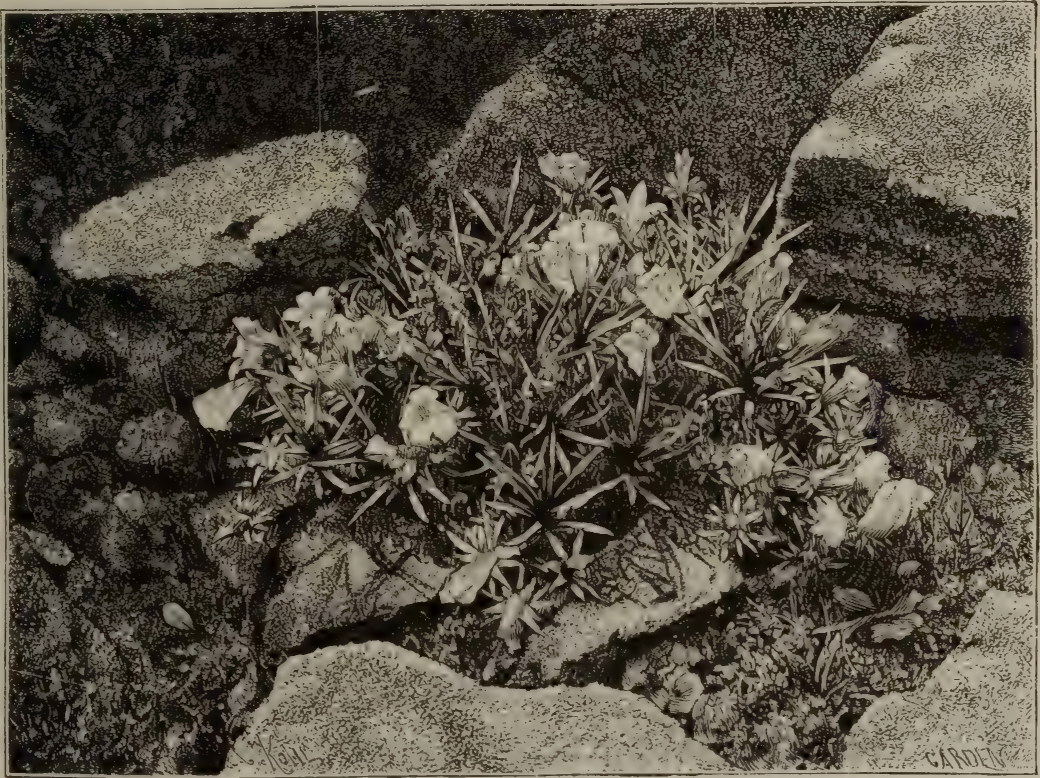

EDRAIANTHLS PUMILIO.

grandiflora has larger flowers and is more robust, while the variety microphylla is remarkable for finely-divided leaves and smaller flowers. In sheltered gardens against walls in the southern and the mild parts all may be grown, though they may need extra protection in severe winters. Another species in cultivation is E. chilensis, which also needs protection.

Elæagnus (Oleaster). - Several of the Oleasters are beautiful shrubs, and deserve to be much more widely cultivated than they now are.

E. angustifolia, the form which grows wild in South-eastern Europe, is the wild Olive of the old Greek authors, and in some modern books is called Jerusalem Willow. The long silvery-grey fruit is constantly sold in the Constantinople species is capable of being turned to good account by the landscape gardener; the yellow tubular flowers are produced in profusion.

E. argentea, or $\mathbf{E}$. canadensis (the Silver Berry, or Missouri Silver Tree), has very fragrant tubular yellow flowers, followed by an abundance of nearly globular, dry, mealy, edible fruit. This species gives a characteristic feature to the vegetation of the Upper Missouri valley, and in a wild state grows 8 or Io $\mathrm{ft}$. in height, and throws up an abundance of suckers, a habit which, at any rate in a young state, does not appear to obtain so much under cultivation. The oval leaves are silvery-white. In nearly all British and foreign nurseries this species is confused with the Buffalo Berry 
(Shepherdia argentea), a genus belonging to the same natural order as the Elragnus, but altogether different from it.

E. hortensis, a somewhat variable plant with a wide geographical distribution, is cultivated in many countries for the sake of its fruit. In Dr. Aitchison's Botany of the Afghan Delimitation Commission it is described as a shrub or tree occurring at an elevation of 3000 $\mathrm{ft}$. and upwards, near running streams, and cultivated largely in orchards for its fruit.

E. longipes, a thoroughly deciduous Japanese species, is one of the most desirable members of the genus. Mr. Sargent thus writes of it in Garden and Forest: "The plant may well be grown for the beauty of its fruit alone, which, moreover, is juicy and edible, with a sharp, rather pungent, agreeable flavour. Both the size and the flavour can doubtless be improved by careful selection, and it is quite within the range of possibility that it may become a highly esteemed and popular dessert and culinary fruit. To some persons, even in its present state, the flavour is far preferable to that of the Currant or the Gooseberry." The fruit, as implied by the specific name, is borne on long stalks; it is bright red in colour and covered with minute white dots. The branches are covered with rusty brown scales, and the somewhat leathery leaves are dark green above and silvery-white beneath. Pheasants are said to be very fond of the fruit, and I can vouch for the fact that blackbirds and other fruit-eating birds will soon strip a bush unless it be netted. Some French growers make a preserve of the fruit, and this is said to be very similar to that made from the fruit of the Cornelian Cherry (Cornus mas); a spirit, too, with a taste like kirsch, has also been made from the fruit. $E$. longipes, known in some gardens under the names of $\mathrm{E}$. edulis, E. odorata edulis, and E. rotundifolia, is apparently as hardy as the firstnamed species.

E. macrophylla, an evergreen species from China and Japan, has large roundish leaves, greyish above and silvery beneath. Old plants are said to produce suckers freely, but the species is a somewhat recent introduction to British gardens, and all the specimens which I have seen up to the present have not shown any tendency to sucker. It is quite distinct in appearance from any other hardy cultivated shrub, and is worthy of much more general employment in the ornamental shrubbery. In its native habitats it is said to sometimes attain tree-like dimensions ; under cultivation I have only seen it as a dense bush.

E. pungens, E. glabra, and E. reflexa are beautiful evergreens, which are not very dissimilar in general aspect, and which without long dry scientific descriptions it would be impossible to distinguish. Variegated forms exist of all three, and any of them, as well as the types, are thoroughly well worthy of a place in the garden or pleasure-ground. They are all natives of Japan, etc., but do not appear to be quite as hardy as the species previously mentioned; all could be tried, however, with every prospect of success in the southern counties. Some of them in the south of Europe assume a somewhat climbing habit, and round the North Italian lakes, for example, grow up to the tops of high Fir and Pine trees.

E. Simoni, said to be a native of China, seems quite hardy, but is the least ornamental of those which have been mentioned in these notes. A variegated form of this, with leaves margined with dark green and with the centres constantly variegated with golden-yellow and yellowish-green, originated in the Belgian nurseries a few years ago; it is highly spoken of in some of the Belgian periodicals.

E. umbellata is a beautiful bush. The leaves are deep green and glabrous on the upper surface $;$ in a young state earlier in the season they are silvery-grey, and silvery-white beneath. The creamy-white flowers are produced in the greatest profusion in June. In some localities the plant is practically evergreen; in the neighbourhood of London, however, it is--at any rate during such winters as the two last - to all intents and purposes deciduous. It is probably perfectly hardy throughout Britain, as it withstands the much severer winters of Northern Germany without protection. In a wild state it occurs from the Himalayas to China and Japan. Elæagnus parvifolia is a name under which this species occurs in some gardens, $-\mathrm{G}$. N.

Elecampane (Inula).

Eleusine (=Poa)

Elsholtzia cristata.-A coarse, weedy plant of the Sage family, of little garden value.

Elymus arenarius (Lyme Grass).This wild British Grass is strong-rooting and distinct, and often adds a feature to the garden. If planted in deep soil a short distance from the margin of a shrubbery, or on a bank on the Grass, and allowed to have its own way, it makes 
an effective plant. It is hardy in all parts of these islands. In very good soil it will grow $4 \mathrm{ft}$. high ; and as we should cultivate it for the leaves, there would be no loss if the flowers were removed. It is frequent on our shores, but more frequent in the north than in the south. E. condensatus (Bunch Grass) is a vigorous perennial Grass from British Columbia, forming a dense, compact, column-like growth, and more than $8 \mathrm{ft}$. high. It is covered from the base almost to the top with long arching leaves, and in the flowering season is crowned with erect rigid spikes $6 \frac{1}{2} \mathrm{in}$. long, so that it resembles an elongated ear of wheat. It is very ornamental, and may be grown in the same way as the Lyme Grass. Other kinds might be mentioned, but one or two give us the best effect of the race.

Embothrium coccineum (Fire Bush). -A very beautiful South American evergreen shrub of the Protea family. It is hardy in warm parts, even without the protection of a wall. At Coombe Royal, in South Devon, it grows quite $20 \mathrm{ft}$. high, and is a spectacle of wondrous beauty about the end of April or the beginning of May, when every twig carries a cluster of fiery flowers. Even on the favoured Devonshire coast a sharp late frost will sometimes injure the flowers. It is, therefore, only suited for warm gardens on the south coast.

Emilia sagittata. -A pretty half-hardy annual, 9 to 18 in. high. It has slender flower-stems, terminated by bright orangescarlet heads nearly I in. across. It likes a light rich soil. It flowers from July to September if the seed be sown in heat in

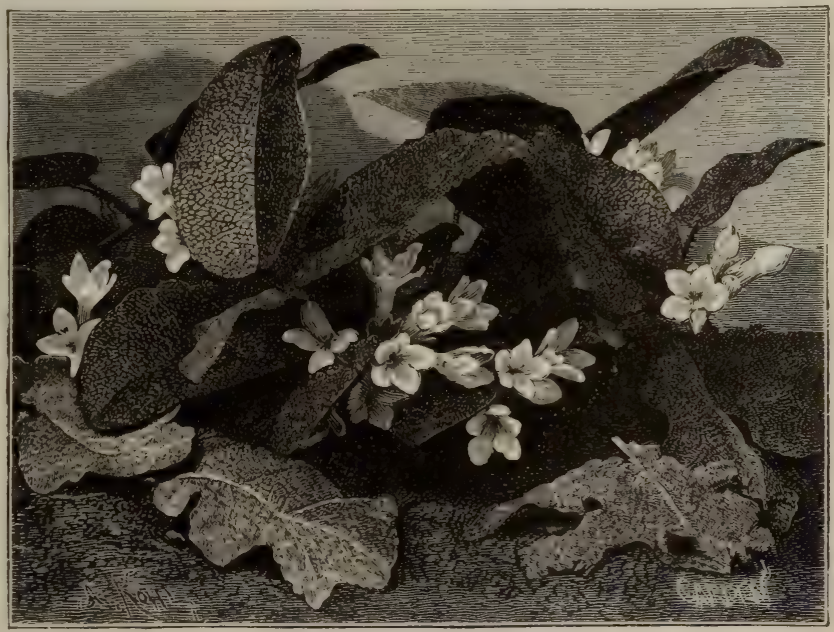

EPIGEA REPENS (MAYFLOWER).

February and March, and the seedlings are put out in May. East Indies. Syn., Cacalia. Compositæ.

Emmenanthe penduliflora.-A Californian annual, about I ft. high, and of neat tufted habit, like a Nemophila; the pale primrose-yellow flowers are in loose racemes. Succeeds best as a hardy annual on any ordinary soil.

Empetrum nigrum (Crowberry).-A small evergreen Heath-like bush, of the easiest culture. May be planted with the dwarfer rock shrubs. It is a native plant, and the badge of the Scotch clan McLean.

Eomecon chionantha (Cyclamen Poppy).- - A very charming hardy perennial Poppy intermediate between Stylophorum and Sanguinaria. The rootstocks are usually as thick as the finger; they run freely underground, and increase rapidly; leaves all from the base, longstalked, and resembling those of the hardy Cyclamen. The flowers, 2 to 3 in. in diameter, are pure white, with a bunch of yellow anthers in the centre; several borne on stems about one foot high. It is a native of China, and will be found perfectly hardy out-of-doors; it has stood the winters of 1890 and I89I without injury. This Poppy will be found a delightful plant in moist situations in free soil, and fully exposed to the sun. The pure pearly-white Poppy flowers, in a setting of bold yellow-green foliage, make an elegant picture, and as it continues in flower all through the summer, it is a very valuable subject for the rock-garden. It can be increased to any extent by division.
Epigæa repens (Mayflower).-A small Evergreen found in sandy soil in the shade of Pines. It is common in many parts of N. America, and has pretty rosetinted flowers in small clusters, which exhale a rich odour, and appear in spring. Its natural habitat is under trees, and it would be well to plant some of it in the shade of Pines or shrubs. It was at one time lost to our nurseries and gardens, owing to the habit 
of planting all things in the same kind of exposed situation. It is a charming plant for the wild garden, in sandy or peaty soil under trees, growing only a few inches high. Caprifoliacea.

Epilobium (rrith Irillow).- Few of these plants are worthy of cultivation, but these are important, and the best perhaps is the showy crimson native E. angustifolium, of which there is a pure white variety. This plant runs in a border so quickly as to soon become a troublesome weed, but is fine when allowed to run wild in a rough shrubbery or copse, where it may bloom with the Foxglove. Europe and Siberia, and many parts of Britain. Division. Other kinds somewhat less vigorous are E. angustissimum, E. Dodonæi, and E. rosmarinifolium. The common native $\mathrm{E}$. hirsutum is stouter than the French Willow, and is only useful by the margins of streams and ponds, associated with the Loosestrife and such plants. There is a variegated form. The Rocky Mountain Willow Herb (E. obcordatum) is a beautiful rock-plant. The Willow Herbs of our own latitudes are very tall and vigorous, but on the dreary summits of the Rocky Mountains and the Californian Sierras one species has succeeded in contending against the elements by reason of its very dwarf stature; it has imitated the Phloxes and Pentstemons of the same region; though not more than 3 in. high, it has retained the size and beauty of flower of the finest species, the colour being rosy-crimson. It is hardy, and thrives in ordinary sandy soil in the rock-garden. Some of the small New Zealand species, such as glabellum nummularifolium, longipes, etc., are very useful for draping stones on rockgardens.-D.

Epimedium (Barren-wort).-Interesting and, when well grown, elegant plants of the Barberry Order, but not shrubby. E. pinnatum is a hardy dwarf perennial from Asia Minor, 8 in. to $2 \frac{1}{2} \mathrm{ft}$. high, with handsome tufts, and bearing long clusters of yellow flowers. The old leaves remain fine until the new ones appear in the ensuing spring. It is not well to remove them, as they shelter the buds of the new leaves during the winter, and the plants flower better when they are allowed to remain. Cool peaty soil and a slightly shaded position are most suitable. Other species are alpinum, macranthum, Musschianum, purpureum, rubrum, niveum, and violaceum, all loving half-shady spots in peat, or in moist sandy soil. None are so valuable for general culture as the first-mentioned.

Epipactis palustris (Marsh E.)-A somewhat showy hardy Orchid, I to $\mathrm{I} \frac{1}{2}$ $\mathrm{ft}$. high, flowering late in summer, and bearing rather handsome purplish flowers. A native of moist grassy places in all parts of temperate and southern Europe. A good plant for the bog-garden, or for moist spots near a rivulet, in soft peat. In moist districts it thrives very well in ordinary moist soil.

Equisetum Telmateia (Giant Horsetail).--A tall British plant, of much grace

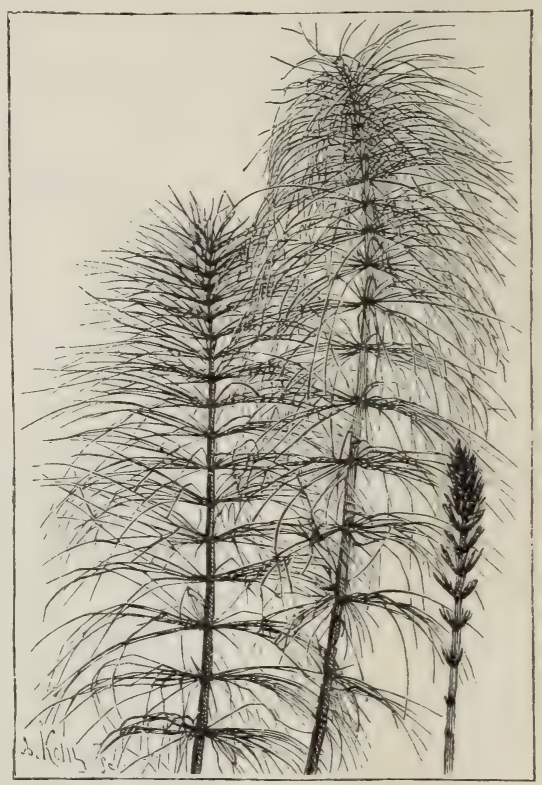

EQUISETUM TELMATEIA (GIANT HORSE-TAIL).

of character when well developed, and from 3 to $6 \mathrm{ft}$. high in favourable spots. The stem is furnished from top to bottom with spreading whorls of slender branches, slightly drooping, the whole forming a graceful pyramid. It is fit for the hardy fernery, shady peat borders, near cascades, or among shrubs, and grows best in deep vegetable soil. Division. E. sylvaticum is another native Horse-tail, much dwarfer, but graceful when well grown, the stem standing 8 to $\mathrm{I} 5 \mathrm{in}$. high, and being covered with slender branches.

Eragrostis (Love Grass).-Grasses, some of which are worth cultivating for their elegant feathery panicles. E. ægyptiaca, with silvery-white plumes, maxima, elegans, pilosa, amabilis, pellucida, capillaris, plumosa, are all elegant annuals. They are useful for cutting for 
the house during summer. Seed may be sown in autumn or spring in the open air, on or in a slightly heated frame. For preserving, the stems should be gathered before the seeds are too ripe.

Eranthis hyemalis (Winter Aconite). -A pretty early plant with yellow flowers surrounded by a whorl of shining green. It is 3 to $8 \mathrm{in.} \mathrm{high,} \mathrm{and} \mathrm{flowers} \mathrm{from}$ January to March. It is seen best in a halfwild state, under trees or on banks in woody places, though it is occasionally worthy of a place among the earliest border flowers. It often naturalises itself freely in Grass, and is very beautiful when the little yellow flowers peep out in early spring. When the branches of large trees are allowed to rest on the turf of the lawn, a few roots of it scattered beneath will soon form a carpet, glowing in sheets of yellow in winter or spring. We may therefore enjoy it without giving it positions suited for more delicate plants, or taking any trouble about it, but it is more vigorous on chalky or warm soils, and dwindles on some cold soils.

Eremostachys.-Perennials of the Sage family, suitable only for botanical collections. E. laciniata has deeply-cut leaves, and flower-stems about $4 \mathrm{ft}$. high, with numerous leafy bracts enclosing large purplish flowers arranged in whorls. E. iberica differs from E. laciniata in having the flowers yellow. Both seem difficult to cultivate, and we have never seen them well grown.

Eremurus. - Noble bulbous flowers from Northern India, Persia, and Central Asia, as yet little known in our gardens. Of their culture or fitness for our climate generally little can be said with certainty. Most of the forms are extremely handsome, and well suited for the warm sheltered glades of gardens where hardy flowers and plants are grown in a natural and informal way. In such a home they can be associated in bold groups with some of the finest hardy plants, with a background of fine-foliaged subjects and choice shrubs. In planting, however, care should be taken to place the roots where they would not be overgrown or shaded by other plants, so that the crowns should receive the greatest possible amount of sunshine during the ripening period previous to going to rest. They thrive admirably in deep, rich, sandy loam, such as would suit Lilium auratum, with the addition of some thoroughly decayed cow manure. My own plants were grown in a bed filled in $3 \mathrm{ft}$. deep with a compost of good fibrous loam, sharp river-sand, peat, decayed cow manure, and charcoal, with a well-drained sheltered situation facing due south. Once well planted, they should never be disturbed, as the roots are extremely brittle and very liable to injury. The surface soil above the roots should be kept clean by hand weeding and enriched by occasional surfacings of old manure, leaf-soil, and a little grit, thoroughly broken up and mixed together. Autumn is the best period for planting, which should take place as soon as the young plants have ripened their growth, the sites being well and deeply prepared some little time beforehand, so as to allow the soil to thoroughly settle before the plants are placed in it. As the whole family dislike stagnant moisture, care should be taken to avoid this at the time of planting, and in any favourable situation this can be managed by spreading out the roots of the young plants upon the prepared surface of the bed and covering them with soil so as to form a mound. This can be afterwards surfaced with Cocoa-nut fibre refuse to exclude frost. In any case it is a great advantage to keep the crown of the plant slightly above the soil. I found a plan adopted by Mr. Gumbleton, who is a most successful cultivator of these plants, to be an excellent protection during winter and early spring, especially at the latter period, when the young growth is liable to be injured by frost and the plants to be disfigured for the whole season, if not permanently injured. The shelter, in fact, is very simple and is easily managed - being merely the placing over each plant of a hand-light upon supports. As it takes some of the forms several years to flower, old plants are valuable, but are difficult to move. It is better, therefore, to begin with threeyear-old plants if possible, and care should be taken to obtain the plants from a trustworthy source, or, after waiting patiently, cultivators may find that instead of the beautiful $\mathrm{E}$. robustus or $\mathrm{E}$. himalaicus, they have the uninteresting E. spectabilis, or some other species that they do not care for.

Owing to losing my garden, I had, unfortunately, to break up my collection in the finest possible condition, before all the forms I had collected had flowered. I, however, flowered E. robustus, Olgæ, himalaicus, Bungei, all of which are very beautiful, and thoroughly amenable to cultivation in the manner indicated, and obtainable either from the best hardy plant nurseries at home, or from at least two sources on the Continent.

These four forms all flowered finely, 
and throve admirably in a Herefordshire garden, where with several others no doubt they were extremely happy. A most interesting account of this family, with a list of the species and varieties known to cultivation, may be found in vol. xxix. (p. 96) of The Garden, which cannot fail to assist those who contemplate the introduction of these noble and beautiful plants into their gardens.-W. J. G.

E. Aitchisonii.-This is a very fine species, nearly allied to E. robustus. It was introduced a few years ago from Karshátal, Afghanistan, where it grows on ridges of the hills nearly $12,000 \mathrm{ft}$. above sea-level, flowering in June. It is a rather fine species, producing dense spikes of pale reddish flowers. The robust and very striking stems vary from 3 to $5 \mathrm{ft}$. high.

E. aurantiacus.-A charming dwarf plant somewhat resembling E. Bungei, and perfectly hardy in gardens. It flowers in April, the numerous spikes of bright citron-yellow flowers giving quite a character to part of the Hariab district, where it is one of the commonest plants on rough stony ground. It is very interesting as the vegetable proper of the Hariab district, and is said to be the sole vegetable upon which the inhabitants depend for at least two months of the year. The leaves are simply cut from the root-stock, as close to the ground as possible, and cooked. It is extremely palatable, and Dr. Aitchison recommends its growth as an early spring vegetable.

E. Bungei.-A pretty dwarf species now plentiful in nurseries. The leaves, contemporary with the flowers, are narrow, linear, and about I ft. long. Flowerstem somewhat slender, I to $3 \mathrm{ft}$. long. Flowers bright yellow, the segments reflexing from above the base, and having a distinct green keel. The stamens are about twice as long as the perianth. Native of Persia, flowering in July.

E. himalaicus is a beautiful whiteflowered species, introduced to cultivation by Mr. Gumbleton, and is one of the most lovely hardy plants in cultivation. In form and height it reminds one of $\mathrm{E}$. robustus, but it starts into growth later, escaping spring frosts. The flowerstems are 4 to $8 \mathrm{ft}$. high, the dense raceme taking up quite $2 \mathrm{ft}$. of the upper portion, with flowers as large as a florin. It is one of the hardiest and best of the known species. It flowers May and June, and is a native of the temperate Himalayas.
E. Olgæ is a comparatively dwarf form, received with $E$. Bungei from Herr Max Leichtlin, and one of the latest to flower. The flower-stem is nearly $4 \mathrm{ft}$. high, and is densely set with handsome lilac flowers as large as a five-shilling piece. It is certainly one of the handsomest and most conspicuous flowered species. It was introduced about eight years ago by Dr. Regel. A native of Turkestan, flowering June and July.

E. robustus, a lovely species, and one of the best-known in gardens. It produces a huge flower-stem 6 to $\mathrm{Io} \mathrm{ft}$. high, bearing on its summit a dense raceme of peach-shaded lilac flowers nearly 2 in. in diameter. It is perfectly hardy. and may often be seen forcing its shoots through frozen ground. It is one of the easiest to manage. Native of Turkestan, flowering in June.-D.

In addition to those mentioned above, the following, some of which are in cultivation, may be noted: E. caucasicus, albocitrinus, aucherianus, inderiensis, Kauffmanni, Korolkowi, luteus, pauciflorus, turkestanicus, tauricus, kurdistanicus, etc.

Erianthus Ravennæ.-A fine Grass from S. Europe, somewhat like the Pampas Grass in habit, but smaller in size, having violet-tinged leaves. The flowering-stems grow from 5 to $6 \frac{1}{2} \mathrm{ft}$. high, but as it only flowers with us in a very warm season, it must be valued for its foliage alone. Its dense tufts are strongest with us in light or warm soil, in positions with a south aspect. It is poor on cold soils, and will probably not grow well north of London. It is fitted for association with such Grasses as Arundo conspicua. Division of the tufts in spring or autumn. E. strictus is another species, but is not so good as E. Ravennæ.

Erica (Heath).-These are so dwarf, so pretty, and so essential in any scheme of bold rock or hardy flower gardening, and so valuable for their flowers, that we must give them much attention. The late Mr. James M'Nab, who was fond of them, wrote to me concerning hardy Heaths in gardens: "The beauty belonging to clumps of hardy Heaths, some of them of great age, seen on our highland moors and pastures, is owing to the plants being annually eaten over by sheep, particularly in winter and spring-a circumstance that makes them branch and flower in dense hemispherical masses. When under cultivation, clipping has exactly the same tendency. If regularly cut they will keep in good flowering condition for many years; but if left to themselves, a very few years will see 
them long and lanky. If the autumnflowering hardy Heaths are regularly clipped over in spring, they will form neat patches and flower abundantly, while the spring-flowering and summerflowering varieties should always be cut over as soon as possible after the flowering is past, and they will branch out freely and regularly and flower abundantly the following season. When the plants become old, they are apt to assume a tall and wiry condition and to flower imperfectly. It is therefore necessary that young plants should always be coming on to take their place. Peat soil is not absolutely necessary. A mixture of peat and loam, or leaf-mould and sand, will answer the purpose. Where peat is scarce, sand should predominate. In nurseries, hardy Heaths are generally propagated by layers, which is easily done by placing some peat, freely mixed with sand, in the middle of the plants, which, when rooted, are torn in pieces and planted out in nursery rows. Many kinds do well in this way, but most of them flower better when raised from cuttings, and are better shaped. Cuttingmade plants have single stems, which seem to favour the shape and the flowering, while in many cases layers have several stems, and scarcely two plants are of exactly the same shape.

"Cuttings make by far the best-shaped plants, and are readily struck if placed any time during the autumn in a sand bath in a cold pit, not exposed to the sun. They soon root and start into growth. When rooted and hardened they could be planted out in lines, but I prefer putting them round the edges of pots, and placing them in a cold frame partially shaded from the sun for a time. As soon as they are established, all the points of the top shoots should be cut off, and side branches will be freely produced, and a compact habit will be induced. After being some months established in pots and sufficiently hardened, they can be planted out in rows in open-air beds, leaving about 6 or 7 in. between the plants. When the young shoots have pushed about a couple of inches, cut the tops off again. This is generally done in the following spring with a pair of spring or sheep shears."

Though sandy peat, for the most part, forms their natural soil, and they grow in it with the greatest luxuriance, there are (says Mr. Hugh Fraser) few loams rich in vegetable matter and free from chalk or lime where they will not succeed, while the worst may be adapted to their wants by the application of peat or old leaf-soil, or even a liberal allowance of well - rotted manure. Several of the showiest sorts - such as the varieties of herbacea, mediterranea, and australisflower in the order indicated from February till April, giving a gaiety and effect which no other plants could at that season, and contrasting admirably with the early bulbs with which they are associated. The other sorts-varieties of tetralix, cinerea, and vulgaris - are in perfection from May to September, succeeding each other, until vagans begins to develop. Vagans continues till late in autumn. Transplanting is safe between September and April, but is preferable in February and March if the weather is open and the soil in good working condition, as then the work is done before growth commences. For a list of species and varieties we adopt that of Mr. Fraser's book on trees and shrubs.

E. ciliaris, indigenous to Portugal, to the south of England, and to some parts of Ireland, is a neat dwarf species 9 to 12 in. high. Its pale red flowers are borne in terminal racemes from June to July. It is one of the finest hardy Heaths.

E. cinerea.-Abundant in many of the northern countries of Europe and all over Britain. Rarely above I foot high. Its flowers of reddish-purple, changing to blue, begin to expand early in June. Among its varieties are-alba, atropurpurea, bicolor, coccinea, monstrosa, pallida, purpurea, rosea, and spicata.

E. herbacea, indigenous to a wide area in Central Europe and to some localities in North Wales, is one of the finest of our hardy Heaths. It produces lovely pale red blossoms from the beginning of March (and in some seasons much earlier) till the beginning of April ; and as it may be clipped freely, it is valuable as an edging in flower gardens. It is about I ft. high. The var. carnea, according to some botanists, is the same species, differing only in having bright red or flesh-coloured flowers.

E. Mackiana. - Indigenous to the Continent, and found in Connemara. It has broad ovate leaves, silvery on the under surface, and is about I ft. high. The flowers are pale red, expanding in July and August. It is remarkably showy. Possibly a variety of tetralix.

E. mediterranea is so named from being abundant in the countries bordering the Mediterranean. It is also found in several districts in Ireland. In appearance it resembles the preceding, which, it has been suggested, is only a form of this species. Its flowers are pale red, the 
anthers being darker and very prominent, and the blooms are usually in perfection in April. The vars. are - alba, carnea, glauca, nana, rubra, and stricta.

E. tetralix.-This beautiful species is wild in all northern Europe, is abundant on the moors and heaths of Britain, and is $\mathrm{I}$ to $2 \mathrm{ft}$. high. It is readily distinguished by ciliated leaves in four whorls round the stem. The flowers, delicate pink, are in terminal racemes, and are generally in perfection from July to August. Among its varieties are-rubra and alba.

$\mathbf{E}$. vagans. - This species is wild in the south of France, and in some parts of Ireland, and is very abundant on the moors of Cornwall. It is 6 in. to $I \mathrm{ft}$. high, and forms a neat bush. The flowers are pale purplish-red, and are borne abundantly along the branches. They are generally in perfection in August and September. It is exceedingly showy, is invaluable for margins to clumps of the larger peat-soil shrubs, and forms a neat close edging for flower gardens. The varieties are-alba, alba nana, carnea, and rubra.

E. vulgaris (Calluna).-This is the Heather of our moors. Its numerous beautiful varieties should never be overlooked in a collection of hardy Heaths. They are all sports from the species, and have been found from time to time associated with it either wild or in gardens. The varieties are alba, Alporti, argentea, aurea, coccinea, decumbens, dumosa florepleno, Hammondi, pumila, pygmæa, rigida, Searlei, and tomentosa. The tall Heaths, more strictly shrubs, are omitted from our selection.

Erigeron (Fleabane). - Michaelmas Daisy-like plants of dwarf growth, somewhat alike in general appearance, and having pink or purple flowers with yellow centres. They flourish in any garden soil, but one or two are best suited for the rock-garden. Of these, E. alpinum grandiflorum is the finest. It is similar to the alpine Aster, having large heads of purplish flowers in late summer, and remaining in beauty a long time. Suitable for the rock-garden and well-drained borders. Division or seed. E. Roylei, a Himalayan plant, is another good alpine, of very dwarf, tufted growth, having large blossoms of a bluish-purple, with yellow eye. By far the best of the taller kinds is E. (Stenactis) speciosus, a vigorous species, with erect stems, that grows about $2 \frac{1}{2} \mathrm{ft}$. high, and bears during June and July many large purplishlilac Aster-like flowers, with conspicuous orange centres. E. Macranthus, another showy species, is of a neat habit, and about I ft. high. It bears abundance of large, purple, yellow-eyed blossoms in summer, and, like $\mathrm{E}$. speciosus, will grow in any soil. E. mucronatus, known also as Vittadenia triloba, is a valuable border flower, neat and compact, and for several weeks in summer is a dense rounded mass of bloom about 9 in. high. The flowers are pink when first expanded, and afterwards change to white, and the plant therefore presents every intermediate shade. Other kinds in gardens are E. multiradiatus, glabellus, glaucus, bellidifolius, strigosus, and philadelphicus - the last two being the prettiest. All are easily increased by division in autumn or spring. The most effective and useful of the genus is E. speciosus, which is excellent for groups or borders.

Erinus alpinus (Wall E.) - A pretty alpine plant, with racemes of violet-purple flowers, which are abundantly produced over very dwarf tufts of leaves. A native of the Alps and Pyrenees. In winter it perishes on the level ground in most gardens, but it is permanent when allowed to run wild on old walls or ruins. It is easily established on old ruins by sowing seeds in mossy or earthy chinks, and is well suited for the rock-garden, where it grows in any position, and often flowers bravely on earthless mossy rocks and stones. E. hirsutus is a-variety covered with down. There is a white variety.

Eriobotrya japonica (Loquat). - A large-leaved shrub from Japan, but tender, and only suitable for walls. Its large evergreen leaves are handsome at all seasons, and in warm districts it flowers freely, the blossoms being white, but does not fruit in the open air in England.

Eriogonum.-North American plants which, on the Rocky Mountains and in the alpine regions of California, are of much beauty, but are never good in cultivation, with the exception perhaps of E. umbellatum. From a dense tuft of leaves E. umbellatum throws up numerous stems, 6 to 8 in. high, on which goldenyellow blooms, in umbels 4 in. or more across, form a neat and conspicuous tuft. In light sandy soil of the rockgarden it has never failed to bloom profusely. The variety Sileri is much better than the type. Other species are E. compositum, flavum, racemosum, ursinum.

Eriophorum (Cotton Grass).-Sedgelike plants whose heads of white cottony seeds make them interesting in the arti- 
ficial bog or by lake margins. E. polystachyon is the best for a garden; it is plentiful in some marshy districts.

Eritrichium nanum (Fairy Forgetme-not). - An alpine gem, closely allied to the Forget-me-nots, which, however, it far excels in the intensity of the azureblue of its blossoms. Though reputed to be difficult to cultivate, a fair amount of success may be ensured by planting it in broken limestone or sandstone, mixed with a small quantity of rich these should be removed early in spring. Alps, at high elevations.-G.

Erodium (Stork's-bill).--Like the Geranium, but usually smaller and more southern in origin than the hardy Geranium. Suited for chalky banks or the rockgarden; some are suited for borders, while others may be naturalised in the Grass in warm soil. Among the best species are-

E. macradenium.-A charming dwarf Pyrenean plant, 6 to Io in. high, with the

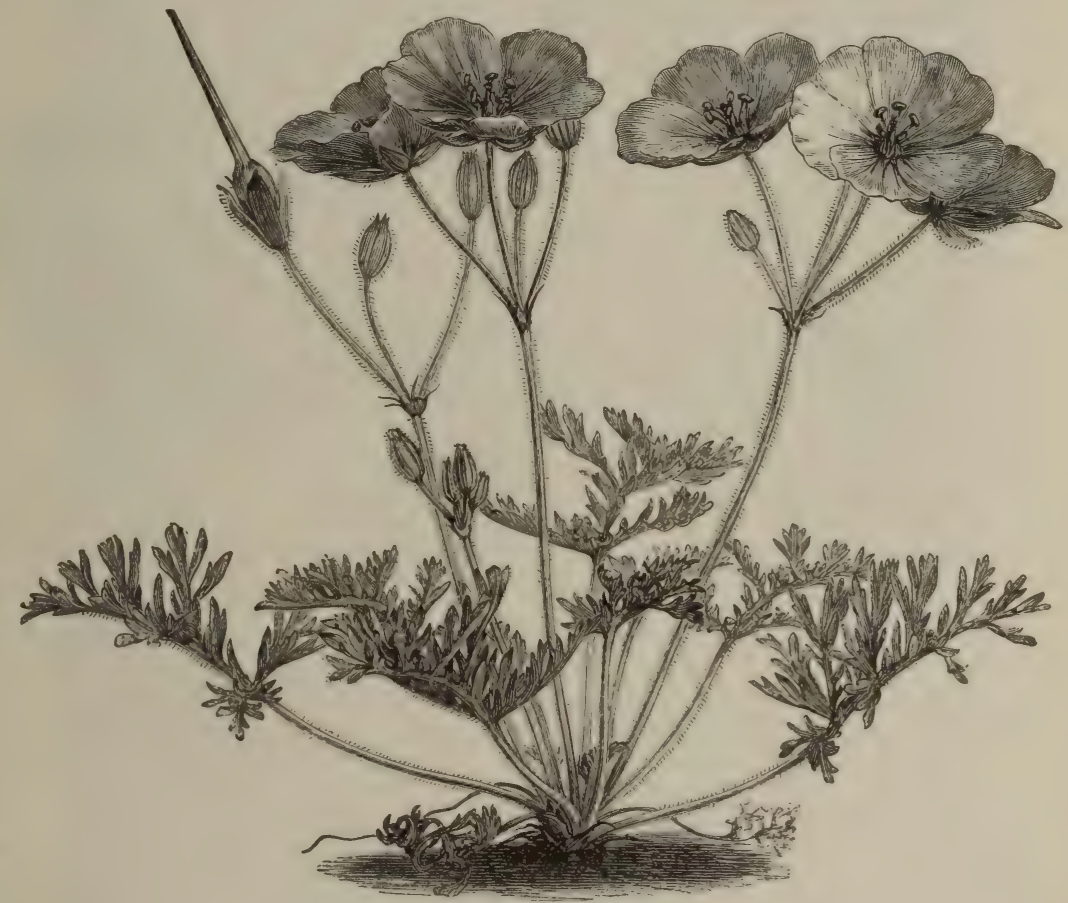

ERODIUM PETRAUM.

fibry loam and peat, in a spot in the rock-garden where it will be fully exposed and where the roots will be near masses of half-buried rock, to the sides of which they delight to cling. The chief enemy of this little plant, and indeed of all alpine plants with silky or cottony foliage, is moisture in winter, which soon causes it to damp off. In its native habitat it is covered with dry snow during that period. Some, therefore, recommend an overhanging ledge, but if such protection be not removed during summer, it causes too much shade and dryness. A better plan is to place two pieces of glass in a ridge over the plant, thus keeping it dry and allowing a free access of air, but blooms of French white delicately tinged with purple, and veined with purplishrose; the lower petals are larger than the others; the two upper ones have each a dark spot, which at once distinguishes them from other Erodiums. This plant should be exposed to the hottest sun. The best position for it is a crevice where it is tightly placed between two rocks, and where the roots can penetrate dry, sandy, or stony soil to the depth of $3 \mathrm{ft}$. When grown in this way, it is extremely pretty; the dryness of the situation keeps the leaves dwarf, they nestle to the rock, and the flowers are in great abundance during the summer months. The plant has an aromatic fragrance. 
E. Manescavi is a vigorous herbaceous plant, and the most showy of the Erodiums. It is I to $\mathrm{I} \frac{1}{2} \mathrm{ft}$. high, and throws up strong flower-stalks above the foliage, each with seven to fifteen showy purplish flowers, $I$ to $I \frac{1}{2}$ in. across. It is not fastidious as to soil or situation, but its best place is in dry, hard soil, fully exposed to the sun. If the soil be too rich, the plant bears so many leaves that the flowers are hidden. Seed, or careful division.

E. petræum (now Moltkia petræa).This has three to five purplish-rose flowers on each stalk, which are 4 to 6 in. high. The leaves and flower-stalks are densely clothed with minute hairs. It thrives best among the dwarfer alpine plants, in warm positions, in deep sandy or gravelly soil.

E. Reichardi.-A miniature species, 2 to 3 in. high when in flower. The small heart-shaped leaves lie close to the ground, and form little tufts from which arise slender stalks, each bearing a solitary white flower, marked with delicate pink veins. It often continues in flower for many weeks. It should be grown in gritty peat mixed with a small portion of loam, such as Androsaces and Gentians.

To the foregoing may be added: E. caruifolium, 6 to Io in. high ; flowers, red, about $\frac{1}{2}$ in. in diameter, and in umbels of nine or ten blossoms. E. alpinum, which resembles E. Manescavi, but is much dwarfer, growing 6 to 8 in. high, and flowering continuously from spring to autumn. E. strictum is a fine annual with deep azure-blue flowers from India. E. romanum, allied to the British E. cicutarium, but with larger flowers, growing 6 to 9 in. high ; flowers, purplish, appearing in spring and early summer. E. trichomanefolium, a very pretty dwarf kind, 4 to $6 \mathrm{in}$. high, with leaves so deeply cut as to resemble a Fern; flowers, flesh-coloured, marked with darker veins. All the preceding, with the exception of E. Manescavi and E. hymenodes, are suited for the rock-garden or borders, in light sandy or calcareous loam. E. Manescavi should, perhaps, be confined to the border, as it is somewhat too tall and spreading for the rock-garden.

Erpetion reniforme (New Holland Violet).- This mantles the ground with a mass of small leaves, has numerous slender creeping stems, and bears throughout the summer blue and white flowers of exquisite beauty, which are only a couple of inches from the ground. It is peculiarly fitted for planting out over a bed of peat or very light earth, where handsome plants are put out in a scattered manner during the summer, and the little herb is allowed to crawl rapidly over the surface. Being very small and delicate, as well as pretty, it should not be used with coarse subjects.

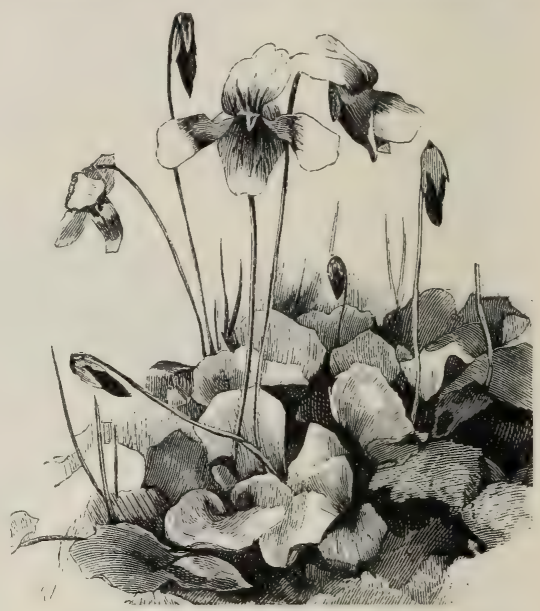

ERPETION RENIFORME (NEW HOLLAND VIOLET),

It must be treated like a tender bedding plant-taken up or propagated in autumn, and put out in May or June. Australia. Division. Erp. r. grandiflora is a larger plant in all its parts.

Eryngium (Sea: Holly).-Remarkably distinct Umbelliferæ, some of the varieties being beautiful and hardy. Some of the S. American kinds are very striking, but the palm of beauty, so far as our gardens are concerned, goes to the northern and mountain kinds.

E. alpinum.-A singularly fine plant, 2 to nearly $3 \mathrm{ft}$. high, forming a rather stiff bush, with very spiny leathery leaves of a sea-green colour, and with numerous roundish heads of bluish flowers, the stems beneath them also being for some inches down, of a very handsome blue. Suitable for borders for groups in pleasuregrounds, or groups with the finest and most distinct hardy plants.

E. amethystinum is not so tall, being seldom more than $2 \frac{1}{2} \mathrm{ft}$. high. It is remarkable for the beautiful amethystine bloom of the leaves in July, which they preserve until the approach of frost. It is suited for the positions recommended for the preceding kind. Various other members of this family are similarly useful, and so, indeed, is almost every one of them, including our own common Sea Holly (E. maritimum). Other kinds are E. spina-elba (dwarf and excellent), E. 
Bourgati, E. giganteum, and E. planum. The plants are frequently mis-named, and other species are probably worthy of cultivation.

E. Leavenworthi.-The annual species are few, and probably include but one possessing any garden value-E. Leavenworthi. It is 2 to $2 \frac{1}{2} \mathrm{ft}$. high, and has an erect grooved stem, branched in its upper or in a greenhouse, where it will produce flower-heads in September and October. Texas.

The LARGe American Species.The most extraordinary forms of the Sea Hollies are a group belonging exclusively to America, and particularly to Brazil, the Argentine Republic, and Mexico. Of this class are E. aquaticum (E. yuccæ-

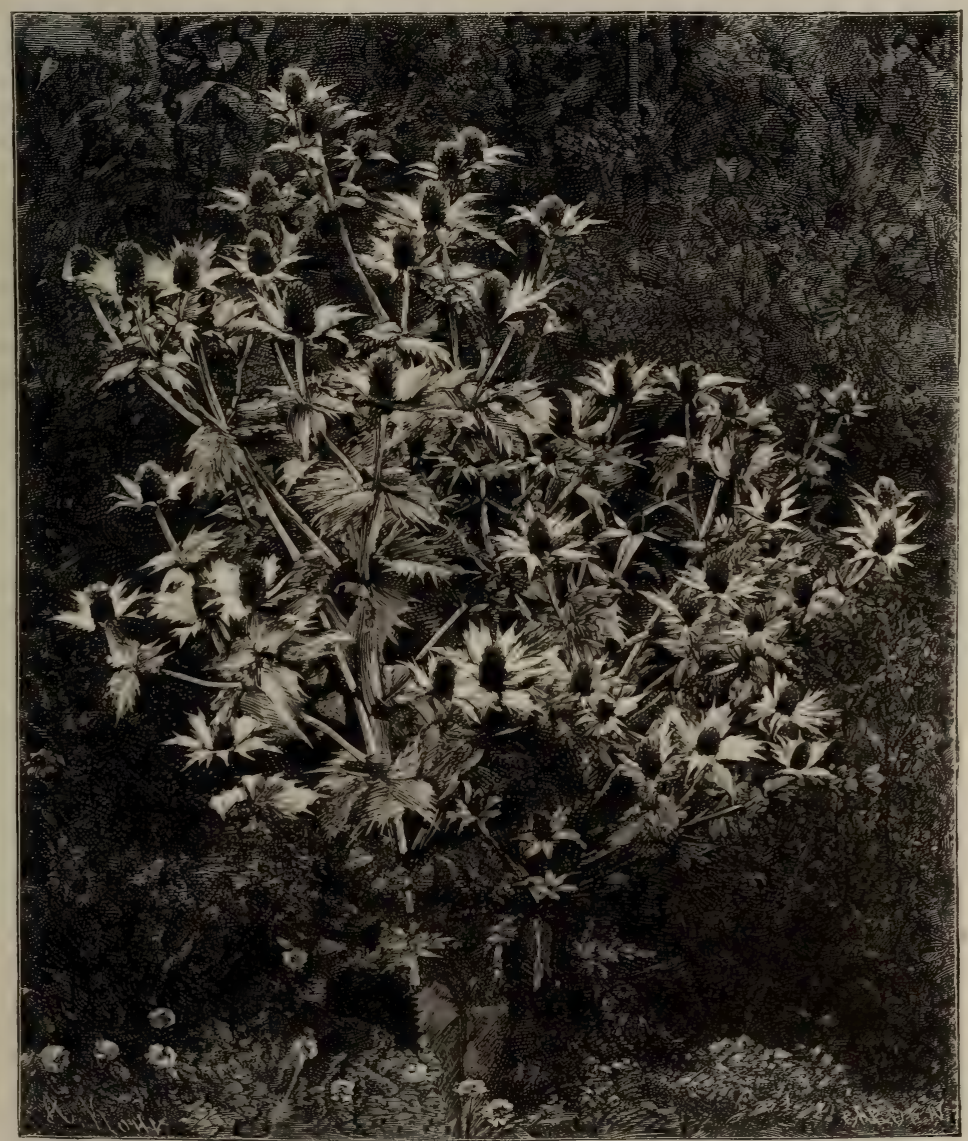

ERYNGIUM ALPINUM (SEA HOLLY).

half, and bearing flower-heads that are green in their early stages, but which, after attaining full growth, assume a rich deep violet tint; as do the involucrum, coronal tuft, and foot-stalk, which have, in addition, a fine metallic lustre. As in the case of $\mathrm{E}$. amethystinum and other species, the heads preserve their colour for some time after being cut. E. Leavenworthi requires the treatment of a half-hardy annual, and, being a late bloomer, should be sown early in heat, folium), from Pennsylvania and Virginia ; E. paniculatum, originally from Brazil, and frequently cultivated as E. bromeliæfolium; and the true E. bromeliæfolium, from the humid forests of Mexico. But none of all the long narrow-leaved kinds equal those raised from seeds which $\mathrm{M}$. Lasseaux sent to Paris some years ago. These seeds were sown immediately, and soon germinated; and the young plants soon developed their true character. In three years many flowered, and were 
described by M. Decaisne, who recognised, besides $\mathrm{E}$. pandanifolium and E. bracteatum, three new species : E. Lasseauxi, eburneum, and platyphyllum. E. Lasseauxi much resembles E. pandanifolium in foliage, but it is more upright and crlaucous underneath, and, above all, has flowers of whitish, instead of reddish, violet. The most remarkable are $\mathrm{E}$. Lasseauxi, pandanifolium, and eburneum. E. platyphyllum is characterised by large leaves, spreading in a rosette upon the soil, and if its foliage were more abundant might be classed among the preceding. Seedlings produce striking effects, but striking on account of their vigorous habit rather than their flowers, which have not the charm of the hardy European kinds. Moreover, they are not really hardy, though, by means of protection and planting in warm soils, some success may be attained.

Erysimum. - Wallflower-like perennials, biennials, and annuals, mostly of dwarf growth. Of the perennials the following are the finest :-

E. ochroleucum (Alpine Wallflower). -This handsome plant forms, under cultivation, neat rich green tufts, 6 to 12 in. high, and in spring is covered with beautiful sulphur-coloured flowers. The rock-garden is most congenial to it; but it does very well on good level ground, though it is apt to get naked about the base, and may perish on heavy soils during an unusually severe winter. It thrives best when rather frequently divided. Division and cuttings. A capital dwarf border plant on light soils. Alps and Pyrenees. Flowers in spring. There are several varieties. = Cheiranthus alpinus.

E. pumilum (Fairy Wallflower).-A very small plant, rare in cultivation, resembling the alpine Wallflower in the size and colour of its flowers, but lacking its vigorous and rich green foliage. It is often only I in. high, and it bears very large flowers for its size. They appear above a few narrow sparsely-toothed leaves which barely rise from the ground. High bare places in Alps and Pyrenees. It requires an exposed spot of very sandy or gritty loam in the rock-garden, where it must be surrounded by a few small stones to guard it from excessive drought and from accident, and must be associated with the most minute alpine plants. It is nearly related to the alpine Wallflower, E. ochroleucum, but is separated from it by its minuteness, and by its greyish-green leaves.

\section{E. rhæticum (Rhatian Wallflower).-}

A pretty mountain flower which, though rare in cultivation, is a common alpine in Rhætia and the neighbouring districts, where in early summer its broad densetufted masses are aglow with pretty clear yellow blossoms. It is somewhat similar to the Dwarf Alpine Wallflower (E. pumilum) of the Swiss mountains. It also resembles the Lance-leaved Wallflower (E. lanceolatum), a common European plant with major and minor varieties, which are, however, less desirable than the kind under notice. E. canescens, a South European species with scentless yellow flowers, is also a neat alpine, and so is E. rupestre, which is exceptionally desirable for the rock-garden. All of them are easy to grow, and delight in gritty soil and a well-drained and sunny position on the rockery. Among the biennial and annual kinds the best is $\mathrm{E}$. Perofskianum, I to $\mathbf{I} \frac{1}{2} \mathrm{ft}$. high, with dense racemes of orange-yellow flowers. For early flowering it should be sown in autumn, and again in March and April for later bloom. E. arkansanum and pachycarpum are similar to E. Perofskianum.

\section{E. Barbarea (Barbarea vulgaris).}

Erythræa (Centaury).-A small genus of rather pretty dwarf biennials belonging to the Gentian family. The native species, E. littoralis, common in some shore districts, is worth cultivating. It is 4 to 6 in. high, and bears an abundance of rich pink flowers, which last a considerable time in beauty and will withstand full exposure to the sun, though partial shade is beneficial. The very beautiful $\mathrm{E}$. diffusa is a similar species. It is a rapid grower, with a profusion of pink blossoms in summer.

E. Muhlenbergi is another beautiful plant. It is neat and about 8 in. high, putting out many slender branches. It bears many flowers, and the blossoms are $3 \frac{1}{2}$ in. across. They are of a deep pink, with a greenish-white star in the centre. Seeds should be sown in autumn, and grown under liberal treatment till the spring; the plants will then flower much earlier and produce finer flowers than spring-sown plants. They are excellent for the rock-garden and the margins of a loamy border, but the soil must be moist. On account of their duration or other peculiarities, they are of more botanical than garden importance.

Erythrina. - These beautiful trees or shrubs are pretty general through the tropics. Some attain great dimensions, while others are dwarf bushes with woody root-stocks. Many produce beautiful large Pea flowers, usually of a blood-red or 
scarlet colour, in terminal racemes. The varieties have proved very hardy and useful in the summer garden, flowering freely and showing considerable beauty of foliage. E. ornata, Marie Belanger, laurifolia, Crista-galli, profusa, Madame Belanger, ruberrima, Hendersoni, have stood out with slight protection. The common old E. Crista-galli will thrive for years against a warm south wall in a light soil, if protected about the roots in winter, and when so grown, it is often very handsome in the warmer countries. How far E. herbacea will prove an efficient substitute for the older and better-known species remains to be seen, but, having resisted a New York winter, it may be assumed to be hardy enough for England, and it deserves a trial. It is rather dwarfer than the old species, and has a woody rootstock, which under favourable conditions throws up in summer stems 2 to $4 \mathrm{ft}$. high. These stems are of two kinds, one bearing leaves only, the other bearing flowers with few leaves. The flowering stems have a raceme, I to $2 \mathrm{ft}$. long, of narrow flowers about 2 in. in length, the deep scarlet standard, erect in so many genera, being horizontal and folded over the wings and keel. The seeds are bright scarlet, and should be sown in heat as early as practicable, the seedlings being kept in a frame for the first winter. This species is a native of Texas, and is found as far north as Carolina, and as far west as Sonora.

Erythrochæte palmatifida (Senecio japonicus).

Erythronium (Dog's-tooth Violet).Lilaceous bulbs, among the loveliest of our hardy flowers, though the old favourite Dens-canis is the only one commonly cultivated. The genus contains only about a dozen species and varieties. These belong to N. America, with the exception of

E. Dens-canis, a beautiful plant found in various parts of Europe. It has handsome oval leaves, with patches of reddishbrown. The rosy-purple or lilac flowers are borne singly on stems 4 to 6 in. high, and droop gracefully. One variety has white flowers, one rose-coloured, and one flesh-coloured. E. longifolium has longer and narrower leaves and larger flowers, and the sorts enumerated in catalogues under the name of majus are apparently derived from this variety. E. Dens-canis thrives in moist sandy or peaty soil, when fully exposed to the sun. It is most valuable for the spring or rock garden, or for a border of choice hardy bulbs, and, where it is sufficiently plentiful, for edgings to American plants in peat soil. The bulbs are white and oblong, resembling a dog's tooth, hence its name. It is increased by dividing the bulbs every two or three years, and replanting rather deeply. Central Europe. The varieties sibiricum, a robust plant from the Altaian Mountains, and japonicum, with violetpurple flowers, are not, so far as we are aware, yet in cultivation.

E. americanum (Yellow Adder'stongue) is common in the woods and low copses of the Eastern States of N. America, where it flowers in May. Its pale green leaves are mottled, and commonly dotted with purple and white. Flowers I in. across, pale yellow, and spotted near the base ; they appear on slender stalks 6 to 9 in. high. A variety (E. bracteatum) differs in having a bract developed, as E. grandiflorum sometimes has. It is very pretty, but, being a somewhat shy flowerer, is seldom seen in cultivation. The late Mr. $M^{\prime} \mathrm{Nab}$ was very successful with it in the Edinburgh Botanic Garden, and writes in an early volume of The Garden: "This interesting plant formerly grew in the open border here, but its flowers were rarely seen. Some years ago I put a tuft of the bulbs in one of the stone compartments of the rock-garden, with a southern aspect, the soil being a mixture of peat and loam. As soon as the space became filled with roots, flowers were freely produced, and on the 2oth of April it was covered with yellow blooms. In these confined spaces the bulbs are better matured than in open borders, where the ground is generally covered with small green leaves growing from unmatured bulbs, and there are few of the larger spotted leaves which generally accompany the flowers." The rich soil of our gardens probably develops growth at the expense of flower. In poor sandy soil, in copses, or in the wild garden, this little plant may bloom better.

E. giganteum.-This, the noblest of the genus, is considered a variety of $\mathrm{E}$. grandiflorum. Its showy flowers of pure white have a ring of bright orange-red, and measure $3 \mathrm{in}$. in diameter. It is found in California at an elevation of six to ten thousand feet, and also in Vancouver's Island. It was called E. maximum by Douglas, and E. speciosum by Nuttall.

E. grandiflorum.-'The only cultivated kind with more than one flower on a stem. It is extremely handsome when well grown. In a peat bed, with Lilies and other peat-loving plants, it is very fine, and produces as many as five flowers on a stem. The late Mr. M'Nab used to grow the larger American kinds as well 
as the European Dens-canis very successfully in grass. Writing of them in spring, he says, "Many Dog's-tooth Violets are in bloom on the northern grassy slopes of the rock-garden ; they were thickly dibbled in, here and there, when the turf was first laid, and, being placed in all exposures, a longer flowering season has been obtained. In such places they do not multiply fast, as only single flowers proceeding from the two or three spotted leaves are produced. On grass banks with a southern aspect the leaves are all ripened off before the first grass cutting, which is not the case on grass slopes with a northern aspect.'

I have planted them largely in grass, and find they thrive in every soil in that way, and are very early and pretty both in leaf and flower, scattered in groups and colonies in turf.

Little known or rarer kinds are $\mathrm{E}$. revolutum, albidum, purpurascens, propullans, and Hartwegi.

Escallonia.-The commonest of the numerous Escallonias in cultivation are extremely beautiful and valuable shrubs. There are few finer shrubs (evergreen and flowering combined) than the popular E. macrantha, which has made a home for itself in many an English garden, especially in coast districts. Its dark green glossy leaves give it a handsome appearance all the winter, while clusters of crimson-red flowers adorn it in summer for several weeks. In mild places it succeeds in the open, but, as a rule, it must be regarded as a wall shrub. Even in the mild districts it is cut down during severe winters, but it usually shoots up again strongly in the returning spring. There is a variety called sanguinea with deeper - coloured flowers. Somewhat similar to E. macrantha is E. rubra, but the foliage is less handsome and the flowers are paler. E. Philippiana is very beautiful and hardy, as it may be grown as a bush in the neighbourhood of London. It is an Evergreen with small leaves, and bears a profusion of large panicles of small white flowers. It is a first-rate shrub, and one of the best of the Escallonias. E. pterocladon is very free-flowering, the small flowers being white and pink, while E. punctata has dark red flowers, somewhat similar to those of $\mathrm{E}$. rubra. Another species, E. montevidensis, also known as E. floribunda, bears large loose clusters of white flowers, and there are varieties - usually seedling formsknown under different names, especially in seaside gardens. Among these, that called $\mathrm{E}$. Ingrami is one of the best, being hardier than E. macrantha, though not so handsome.

Eschscholtzia (Californian Poppy).Brilliant annuals, long and favourably known. The beautiful new forms recently seen are acquisitions; the rich reddish-orange of Mandarin and the unique form of double crocea are of real value, and they make, with crocea, alba, and the orange aurantiaca, a most attractive batch. What is known as $\mathrm{E}$. rosea is pretty, but apt to revert to the white form from which it sprang. To have these showy flowers in all their beauty, they should be sown in August and September for early summer bloom. They may be sown even later-and should then be allowed to bloom where they are sown. They get deeply and firmly rooted, and flower much longer than if sown in spring. They are very hardy, and snails and slugs do not molest them. There are some half a dozen kinds, well worth growing, viz. E. californica, orange, very strong ; E. crocea, saffron colour ; E. C. alba, white ; E. c. Mandarin, orange and crimson, very fine; E. c. fl.-pl., double ; E. c. rosea, and E. tenuifolia; and new forms are raised from time to time.

Eucalyptus.-Large and handsome Australian trees and shrubs, of which a number of species grow to a great height. The leaves are thick and leathery, and vary much in shape. In the south of England and Ireland a few of the species live in the open air. About London some grow them for their aspect in the open air after a single year's growth, and in that case they should be put out about the middle of May. Some letters in the Times, by persons unaware of the results of planting the tree in this country, induced many to plant the common Gum tree, which perished with the first severe frost. Only in the more favoured districts have these trees any chance, and they never present the graceful and stately port which they show in countries that really suit them, such as parts of Italy and California. What the higher mountain species may do remains to be seen, and the common Gum tree is sometimes made fair use of in the London parks among the larger plants put out for summer.

Eucharidium.-Pretty hardy annuals of the Evening Primrose family. California. They require the same treatment as all annuals from that region. They may be sown in autumn for early summerflowering, or from March to June for late summer and autumn bloom. They flower about eight weeks after sowing, and remain in flower a long time. Three species 
are cultivated-E. concinnum, about 9 inches high, with many rosy purple blooms ; E. grandiflorum, larger rosypurple flowers, streaked with white, which has a white variety (album), and a variety with pink flowers (roseum); and E. Breweri, an elegant new annual, more robust, and with red flowers of a deeper, richer colour than E. grandiflorum. These species are of secondary importance in the flower garden, but may occasionally be used as surface plants or in bold masses. Like many other annuals, they suffer in general estimation through being judged by spring-sown plants, with poor and short-lived bloom.

Eucnide bartonioides.-A half-hardy annual of the Loasa family, from Mexico. The stems are about I ft. high, and bear sulphur-yellow flowers, $I \frac{1}{2}$ in. across, showy in August and September when several are expanded. Seeds should be sown in heated frames in early spring, but the seedlings should be very carefully transplanted to the open border in May, as they are then very liable to injury. = Microsperma.

Eucomis.-Cape bulbs, not very showy, though deserving of cultivation in the outdoor garden, on account of their broad handsome foliage, more or less spotted with purple at the base, from which rise tall cylindrical spikes of blossoms surmounted by a crown of leaves. Like many Cape plants, they are hardy on light and dry soils. There are four species, all of which are in cultivation. E. undulata has leaves 18 in. long, wavy at the margins, and profusely marked on the under surface with dark purple blotches which, in the variety striata, assume the form of stripes. The flower-spike is 2 to $4 \mathrm{ft}$. high. On the upper half are densely arranged, in a cylindrical manner, numerous greenish-white blossoms, with purplish centre, crowned by a tuft of narrow green leaves. E. punctata is the largest kind, having leaves about $3 \mathrm{ft}$. long. E. regia is dwarfer than either of the preceding. The raceme of flowers is about I ft. high, and the tuft of leaves at the top is larger than in the other kinds. E. nana is the smallest. The spreading leaves lie horizontally, while in the others they are more erect. They thrive best in light sandy soil, the roots are protected by a covering during winter. The foot of a south wall suits them if they are associated with the larger hardy bulbs, but they are not the most effective or graceful of the Lily family.

Eucryphia pinnatifolia (The Brush Bush). - A distinct shrub, and probably hardy, though a native of South America. It belongs to the Rose family, but the flowers remind us in size and form of those of St. John's Wort, except that they are white, and the central tuft of stamens is very conspicuous. The flowers, borne plentifully, are very pretty, among foliage resembling that of some of the Roses.

It is one of the most beautiful shrubs of recent introduction, and valuable on account of producing its flowers about the end of the summer, when blooming shrubs are getting scarce. It is deciduous, somewhat upright, and has pinnate leaves, and large white flowers about 3 in. in diameter. It is of rather slow growth, but has withstood severe winters in the neighbourhood of London; and may therefore fairly be classed as hardy. It can only be satisfactorily propagated by layers, which will, to a certain extent, account for its scarcity. Till more plentiful, it should be placed in warm positions and in good free soil. Chili. There is another species in cultivation, E. cordifolia, but it is rarer.

Eulalia japonica.-A hardy and ornamental perennial Grass of robust growth, 6 to $7 \mathrm{ft}$. high. Established plants form clumps 17 to $18 \mathrm{ft}$. in circumference. The brownish-violet flower-panicles haveat first erect branches, but as the flowers open, these branches curve over gracefully, and resemble a Prince of Wales's Feather. Each of the numerous flowers has at its base a tuft of long silky hairs, which contribute greatly to the feathery lightness of the whole. For isolated positions on lawns it is excellent; or it might be used in groups, or on the margin of the shrubbery. Even more valuable than the type are the two variegated forms, variegata, with leaves longitudinally striped with white and green; and zebrina, with distinct cross bars of yellow on the green, which render it singularly attractive. These variegated forms, particularly zebrina, are not quite so hardy as the type. Division or seed. Japan.

Euonymus (Spindle Tree).-All these have small flowers, with little beauty, but this defect is amply compensated for by their foliage, habit, and bright fruit which some of the sorts produce. They grow well in almost every variety of soil, but are most luxuriant in such as are rich in vegetable matter, and, as a rule, they prefer open sunny situations, particularly the evergreen sorts. They all thrive well in the vicinity of the sea. The following are among the most distinct of the kinds at present in cultivation :-

Euonymus europæus

(Common 
Spindle Tree). - This is indigenous to England, as well as to the Continent of Europe, and is a bushy tree, from io to $25 \mathrm{ft}$. high. The leaves are of a warm green colour, changing as they decay to a reddish tint. When bruised they have a most interesting are the white fruited kind, which differs from the species in producing white instead of pink capsules; the variety with scarlet leaves; and nanus or pumilis, a neat little plant, very bushy, and one which never grows higher

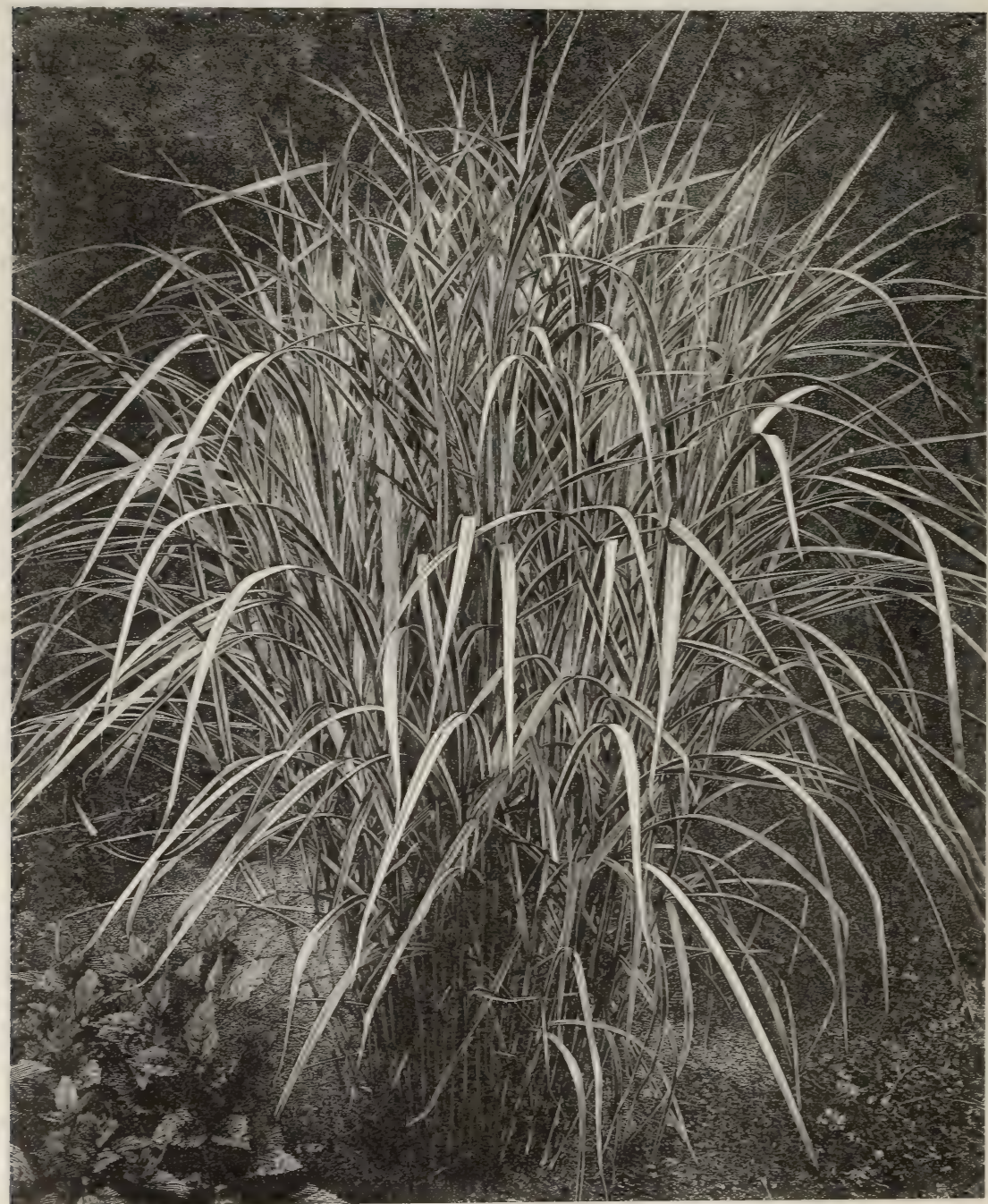

ELLALIA JAPONICA.

disagreeable odour. Its small greenishwhite flowers expand in May, and are followed almost always by an abundant crop of fruit, produced in bright pink capsules, which, opening up in the autumn, reveal the orange-coloured sac which envelops the seeds, producing a beautiful effect. Of several varieties, the than about $2 \mathrm{ft}$. and is admirably suited for a rock-garden, or any situation where a compact dwarf plant is desirable.

E. latifolius (Broad-leaved Spindle Tree).- This is another European species, found wild in the south of France and in some parts of Germany, and is a tree of from 10 to $20 \mathrm{ft}$. high. The bark on the 
young wood is of a reddish-green colour. The leaves are bright shining green, and much larger than those of the common Euonymus. The flowers, which expand in June, are of a purplish-white ; the capsules large, and deep red, contrasting, as they open, most effectively with the bright orange sacs or arils, with which

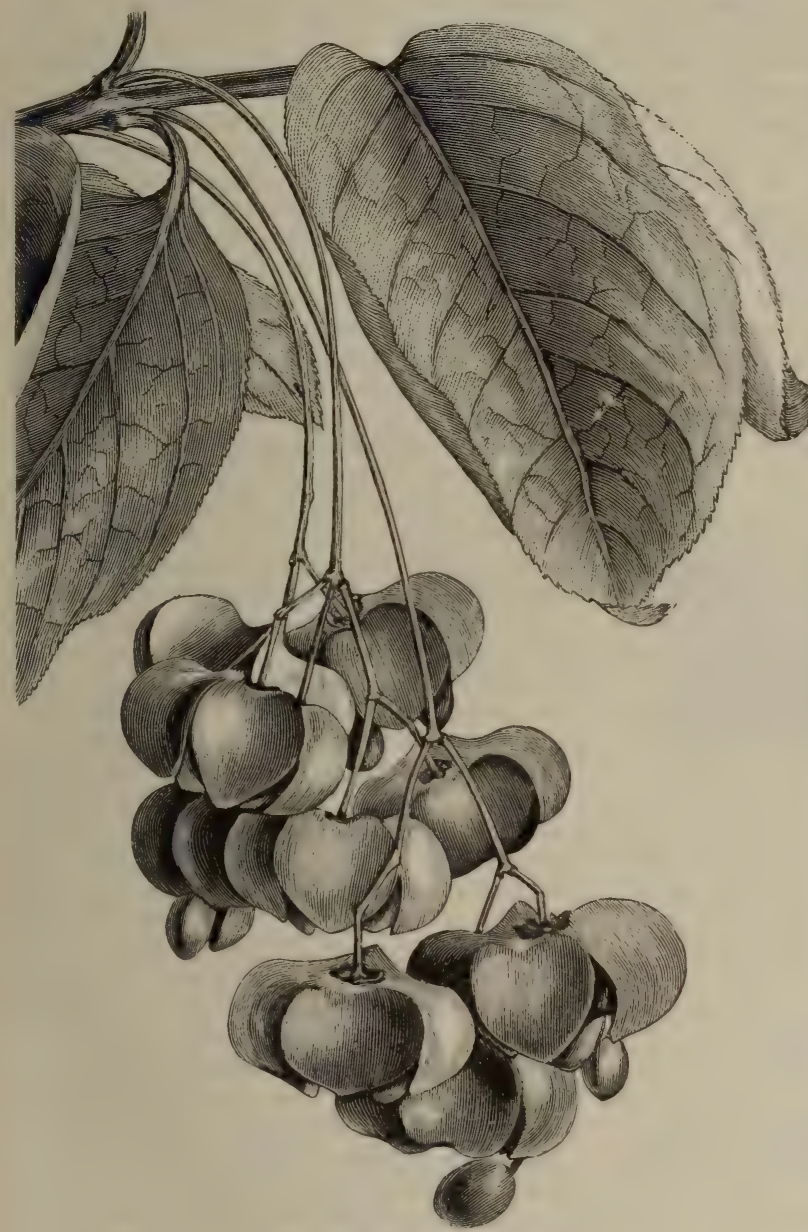

EUONYMUS LATIFOLIUS (FRUITING BRANCH).

slender branches covered with a smooth light green bark. The leaves are of a deep shining green. The flowers expand in June, and are succeeded by rough warted brilliant crimson capsules, which in its native habitats are so showy and abundant that it is popularly called the Burning Bush. In this country it is generally cultivated as a wall plant, and as such it is very ornamental. It succeeds best on the shady side, and prefers a moist rather than a dry porous soil.

E. angustifolius (Narroze-leaved Spindle Tree). - This is also indigenous to North America, and is found in similar localities as the preceding. It is a twiggy or sub-evergreen shrub of about $4 \mathrm{ft}$. in height, with long wiry branches, abundantly clothed with remarkably narrow oblong leaves, of a deep green colour in summer, changing in autumn to a dull red tint. The flowers are very small, of a greenish-white colour, followed by red fruit capsules. It is a very distinct and interesting shrub for a low wall, and has a pretty effect on raised banks, growing freely in shady sheltered aspects, and in damp heavy soils.

E. japonicus (Japan Spindle Tree).-This is an evergreen species 4 to $6 \mathrm{ft}$. in height. It has a bushy habit, the branches long and slender, and clothed with numerous leaves

the seed is enveloped. It is quite hardy, but thrives best in moderate shelter, and forms an ornamental tree, well fitted for a lawn or small park.

E. americanus (American Spindle Tree).-This is a small deciduous, or, in mild winters and sheltered situations, subevergreen shrub, of about $6 \mathrm{ft}$. in height, found wild over a wide area in Canada and the United States. It has an erect habit of growth, with numerous long of a dark glossy green colour. Tho!ngh hardy in sheltered districts, it seldom flowers in this country. Few evergreens thrive better near the sea than this does; and either it or some of its varieties are frequently met with on the west and south coasts of England, and west coast of Scotland, forming handsome specimen shrubs on lawns and shrubberies. In the inland districts it suffers from frosts, and can only be depended upon on walls or 
in favoured situations. During recent years a number of varieties have been sent home from Japan; several of these, and particularly the variegated forms, are favourites.

All the sorts thrive best in warm sunny exposures, and in well-drained soils. The kind called argenteus variegatus has leaves clothed with silver; aureus variegatus, leaves blotched with yellow ; ovatus aureus, leaves margined with deep yellow ; latifolius argenteus and latifolius aureus, leaves with white and yellow variegations respectively ; and randicans variegatus, a dwarf creeping variety, its leaves are variegated with white; it is hardy, and useful for planting as an edging. On rockeries or low walls it has a pretty effect ; and as it forms roots similar to those of the Ivy, it requires little care to keep it to the wall or other support.-The Gardener.

Eupatorium (Thorough - wort).Coarse Composite plants, most of which

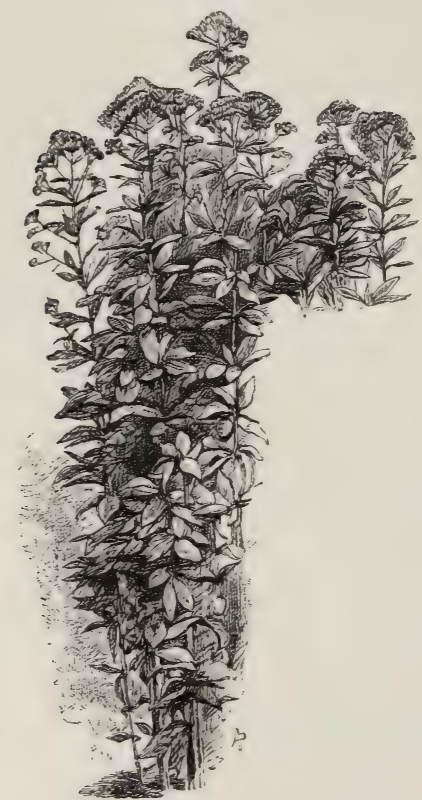

EUPATORIUM PURPUREUM (THOROUGH-WORT).

are better suited for the wild garden than for borders, though two or three kinds are worth a place for supplying cut flowers in autumn. The most suitable are E. ageratoides, altissimum, and aromaticum, which are 3 to $5 \mathrm{ft}$. high, and bear a profusion of white blossoms in dense flat heads. E. cannabinum (Hemp Agrimony). E. perfoliatum. E. purpureum (Trumpet-weed) forms a fine object in the rougher parts of a garden, being $\mathbf{2} \mathbf{f t}$. high, with stems terminated by huge clusters of purple flowers. All grow in any kind of soil.

Euphorbia (Spurge). - This genus is very largely cultivated, but contains few hardy species of value for the flower garden. The foliage of some, such as E. Cyparissia (Cypress Spurge) is very elegant. In spring, E. pilosa and amygdaloides are made somewhat attractive by yellow flowers appearing when little else is in bloom, but they are scarcely worth growing in a general way. Some of the dwarf kinds, such as E. Myrsinites, portlandica, capitata, and triflora, are neat. All grow in any soil or position. There are a few variegated forms. The well-known Caper Spurge (E. Lathyris) is often seen in cottage gardens, and in habit is a distinct plant, with a certain beauty of foliage and port. A few plants of it on a bank or rough place are not amiss.

Eurya latifolia variegata.-This fine half-hardy variegated shrub, grown in pots or tubs, is useful and ornamental for outdoor decoration during summer; it would also be useful intermixed with such things as Agapanthus for the adornment of steps, corridors, etc. It is best increased by means of cuttings. The cuttings should be taken off the plants in the greenhouse in March; then take welldrained pots -5 -in. ones are best-and fill them with a compost of yellow loam and a little peat and leaf-soil, with a good admixture of sand sifted fine and pressed down rather firmly. In this insert the cuttings with a small peg or dibber, tightening them well in. A moderately warm manure bed, in which the pots can be plunged half-way up, is the best place in which to strike them. If the wood is about half-ripe, they generally emit roots in about eight weeks, when they may be potted off, replaced in the bed, and kept close for a few days; then they may be gradually hardened off to stand in a cold frame. Like most shrubby evergreens, the Eurya will stand hard prunins, and may therefore be kept compact by an annual cutting back, which should be done early in spring, when the buds soon start again and refurnish the plants with new foliage. As to soil, the Eurya will grow freely in either peat or loam, but the variegation comes out best with plants growing in the former, or a mixture of the two if plenty of sand be added, as when growing liquid manure can be given to assist in the full development of leaf. To strike cuttings, the best way is to take them off with a heel, and to put them in 
early in the autumn, and stand them in a cold frame for the winter to callus, when by subjecting them to a little artificial warmth in the spring they root at once, and start rapidly off into growth. The plants can be wintered easily in a cool greenhouse or conservatory, and when planted out in such a structure they are highly ornamental.

Eurybia (Olearia)

Eustylis = Nemastylus .

Eutoca. - These Californian plants, numbering about four species, are pretty annuals. E. viscida is the best. It grows about I ft. high, and has erect branches with coarsely-toothed leaves. The flowers, borne on curling racemes, are a deep blue, flushed in the centre with violet, and appear from July to September. There is a variety with white (albida) and another with lilac (lilacina) flowers, both pretty. They are so modest in colour that they are not much used, though a surfacing of the best kinds would be pretty in certain circumstances; but the spring-sown plants are too short in duration for general use in gardens. The plant thrives best in sandy loam. It is best sown early in the season under glass, or in the preceding autumn. The other kinds are E. divaricata, E. Menziesi, and E. Wrangeliana, but they are scarcely worth cultivating.

Evening Primrose (Enothera).

Everlasting Flower (Helichrysum).

Everlasting Pea (Lathyrus).

Exochorda grandiflora (Pearl Bush). -One of the loveliest of hardy shrubs. Allied to the Spiræas, it has larger flowers. It is a large shrub, of dense growth, making when full grown a rounded bush of about Io ft. high and as much through. It flowers about the middle of May, just after the foliage unfolds, and affords a charming contrast between tender green leaves and snow-white flowers as large as florins. It likes shelter, and grows best in rich loam.

Exogonium Purga (Jalap Plant).Of autumn-flowering hardy plants there is, perhaps, none more beautiful. Of its hardiness there can be little doubt. It has lived for years at Bitton, Gloucestershire, without any protection, and each year it has flowered beautifully. It has also done well at Drayton-Beauchamp, Kew, Fulham, and in the Edinburgh Botanic Gardens. Mr. Ellacombe grows it in a sheltered corner, and provides a tall wire trellis with a spreading top for it to grow up. It does not flower in the lower parts, but the entire top and the pendent shoots become a mass of most lovely blossoms. If not checked by late spring frosts at Bitton, it comes into blossom early in September, and continues to flower till cut down by frost. Mr. Ellacombe states that if he were to plant another, he should place it under a south wall, near a Peach or Apricot tree, and let it wind its way through the branches. A very little training would prevent its injuring the tree, and it would probably flower earlier, and perfect its seeds. It has roundish tubers of variable size, those of mature growth being about as large as an orange and of a dark colour. These are the true Jalap tubers. The plant gets its name from Xalapa, in Mexico, its native region. Division of tubers.

Fabiana imbricata.-A pretty shrub of the Potato family (Solanacer), but so much resembling a Heath, that it might well be mistaken for one. It is slender, with evergreen leaves, and in early summer every shoot is wreathed with small white trumpet-shaped flowers. A native of Chili, it is not perfectly hardy as a bush except in the southern counties.

Fair Maids of France (Ranunculus aconitifolius).

Fairy Forget-me-not (Evitrichium).

Farfugium grande.-A vigorous perennial, with fleshy stems I to $2 \mathrm{ft}$. high, and with broad leaves of light green variously streaked, spotted with yellow in one variety, and having white and rose in another. It does best in a half-shady position in free moist soil. During the heats of summer it requires frequent watering, and at the approach of winter it should be removed to the greenhouse, except in mild districts. In colder parts it is scarcely worth planting out, as it grows slowly; but where it thrives it is handsome in borders, or on the margins of beds. Multiplied by division in spring; the offsets being potted and kept in a frame until they are well rooted.

\section{Feather Grass (Stipa pennata).}

Feather Hyacinth (Muscari comosum monstrosum).

Felicia tenella.-A neat little halfhardy plant of the Starwort family. It has dwarf slender stems, terminated by flower-heads, the flowers being $\frac{1}{2} \mathrm{in}$. across, and of pale violet-blue with yellow centre. It should be raised as a halfhardy annual, but as it becomes shrubby, it may be kept over the winter like halfhardy bedding plants. Flowers in light soil from July to September. Would form a graceful blue carpet to Gladioli, Tuberoses, standard Fuchsias, or other tall slender plants. Cape of Good Hope. Syn., Aster tenellus. 


\section{Fennel Flower (Nigellar).}

Fenzlia dianthiflora.-A charming Californian annual, forming compact tufts, I to 4 in. high. Its many large flowers vary from purple and lilac to nearly white. It is perfectly hardy, and, like several Californian annuals, does best if sown in autumn. It thrives in any ordinary soil, but the warmer and more sheltered the situation the better. A lovely ground or carpet plant, if some slender bulbs or other taller plants are scattered through it. Syn., Gilia dianthoides.

Ferdinanda eminens. - One of the finest "sub - tropical" plants, growing well in the southern counties when in rich moist soil. It is the better for shelter. Where the soil is rich, and humid, and the position warm, it is sometimes over $12 \mathrm{ft}$. high, suspends pairs of immense opposite leaves, and is a good companion to the Castor-oil plant. It requires to be planted out, when young, about the middle of May ; it grows freely from cuttings ; and greenhouse treatment will do in winter. It is better to keep a stock in pots through the summer, for cuttings, though the old ones may be used.

Fern, Beech (Polypodium phegopteris).

Bird's-nest, Australian (Asplenium nidus-avis).

Broad Buckler (Asplenium dilatatum).

Climbing (Lygodium palmatum). Filmy (Hymenophyllum).

Hard (Blechnum boreale).

Holly (Aspidium Lonchitis).

Lady (Athyrium).

Maidenhair (Adiantum).

Male (Aspidium Filix-mas).

Mountain (Aspidium Oreopteris).

Oak (Polypodium Dryopteris).

Ostrich (Struthiopteris).

Parsley (Altsorus crispus).

Royal (Osmunda regalis).

Scaly (Ceterach officinarum).

Sensitive (Onoclea sensibilis).

Shield (Aspidium).

Ferraria.-Plants of the Iris order from the Cape of Good Hope. F. undulata is the only hardy species. It is a curious plant with flowers like the Tiger-flower (Tigridia) in shape, but small, of a dull plum colour, and wavy-edged. It requires a light sandy soil, on a warm sunny border, and if close to a south wall it is all the better. The bulbs require protection during winter or lifting in autumn, when they may be divided.

Ferula (Giant Fennel).-Among the finest umbelliferous plants that have so long remained unnoticed in our botanic gardens. Their chief charm consists in large tufts of the freshest green leaves in early spring. The leaf is apt to lose beauty and to fade early in autumn, but this may be retarded by cutting out the flower-shoots the moment they appear, though these are not ugly, but on the contrary the plants are striking when in flower. Ferulas should be well planted at first, and it is only when established that their good effect is seen. Where bold spring flowers are naturalised or planted in colonies, a group of these fineleaved plants will be valuable, with their fine plumes rising in early spring. They are among the true hardy plants of the northern world, never suffering from cold. Their fine forms in summer or autumn, when they throw up flowering-shoots to a height of Io ft. or so, are remarkable enough; but their appearance when breaking up in spring charms us most. A good way is to place them singly or in small groups, just outside a shrubbery, or isolated on the Grass, so that their verdure may be seen in early spring. Deep free soil should be supplied before planting, if the soil be not good and deep. Ferulas are readily raised from seed, which as soon as gathered should be sown in a nursery bed in the open air. The plants, even when well established, do not bear division well, though with care they may be transplanted. One of the best-known and most valuable is $\mathrm{F}$. tingitana, which is elegant and vigorous. It takes several years to form strong plants, and the plants look like massive plumes of large filmy Ferns. F. communis is also a good species, and others, including F. glauca, neapolitana, Ferulago, and persica, may be added where variety is sought, but the first two are not surpassed. The flower-stems developed the second or third year from seed are 6 to $10 \mathrm{ft}$. high, are branched, and bear numbers of small inconspicuous flowers. S. Europe and N. Africa.

Festuca (Fescue Grass). - A large genus of annual and perennial Grasses, but containing few species for the garden. A variety of Sheep's Fescue (F. ovina), named glauca, is a pretty dwarf hardy Grass, forming dense tufts of leaves of a glaucous hue or soft blue, and on this account sometimes called "blue" Grass. It makes good edgings, and when it is used for this purpose the flower-spikes should be cut away. F. ovina viridis is also a pretty edging plant, and, being of slow growth, does not require renewal for years. 
Feverfew (Pyrethrum Parthenium).

Ficaria (Pilewort). - Plants of the Crowfoot family, much resembling some kinds of Buttercup : F. ranunculoides (Lesser Celandine) is a common British plant, 3 to 6 in. high, producing goldenyellow flowers in early spring. It is so common that it would not be mentioned but for its pretty double and white varieties. Moist borders, in any soil. A good plant for growing under trees. Division.

F. grandiflora.-A large-flowered kind, about twice the size of our own, the flowers being nearly 2 in. across. It is easily grown and showy, and could be naturalised. Southern Europe and Northern Africa.

Ficus elastica (India-rubber Plant).This is not only in fair health in the open air in summer, but sometimes makes a good growth under our weak northern sun. It is best suited for select mixed groups, and in small gardens, for isolating among low bedding-plants. It will best enjoy stove treatment in winter. It should be put out at the end of May. In all cases it is best to use plants with single stems. The trailing $\mathrm{F}$. repens and F. stipulata also thrive in the open air in summer, and have a pretty effect, trailing up stems of trees in the subtropical garden. In mild districts they are hardy against walls or rocks. Cuttings.

\section{Fire Bush (Embothrium coccineum).}

\section{Fire Pink (Silene virginica).}

Flag, Common Water (Iris pseudacorus).

Flag, Spanish (Iris Xiphium).

\section{Flag, Sweet (Acorus).}

Flame-flower (Kniphofia).

Flax (Linum).

Flax, New Zealand (Phormium tenax).

Floss-flower (Ageratum).

Flowering Ash (Ormus europaca).

Flowering Rush (Butomus umbellatus).

Fluggea japonica (Ophiopogon).

Fly Orchis (Ophrys muscifera).

Fœniculum (Fennel). - The common Fennel is graceful, and were there not many other plants of much grace of foliage, it would be of value for its leaves. $\mathrm{F}$. dulce is a nearly allied kind. Grows in any soil or on any waste bank.

Forget-me-not (Myosotis palustris).

Forget-me-not, Creeping (Omphalodes verna).

Forget-me-not, Fairy (Eritrichium).

Forsythia (Golden Bell). - Very beautiful spring-flowering shrubs, especially F. suspensa, whose long, slender, wand-like shoots are studded for a considerable distance with bright golden blossoms. F. suspensa is certainly one of our finest shrubs, and should be found in any garden, however small. It is at home under various conditions. Being of a rather loose rambling habit, it is well suited for training on a wall ; indeed, few subjects are superior to it for a sunny spot, where the wood will thoroughly ripen, and a good display of spring bloom will be ensured. F. suspensa should not be employed as a wall plant in a shady position, as the yield of flowers will be meagre; nor where a close-fitting subject is required, as it is seen to the greatest advantage when the principal branches are secured to the wall till the allotted space is covered, and the shoots are afterwards allowed to grow at will, since by this mode of treatment the long slender branchlets dispose themselves in a very graceful manner, and the upper ones hang down for a long distance. A wall treated in this way is quite a mass of gold. If any pruning is required, it should be done as soon as the flowers are over, so that the young shoots may have as long a growing and ripening season as possible As a rule, however, they need little pruning beyond the removal of weak or exhausted shoots. When rambling about in a semiwild state, or when hanging over a bank or a cutting, this Forsythia is seen to very great advantage. It also forms a most ornamental specimen in the open if it is secured to a good stout stick when planted, and is afterwards allowed to grow at will; for the long slender shoots, which are produced in considerable numbers, will dispose themselves in a graceful manner, and in favourable situations many of them will root at the points, and will soon form quite a colony around the central plant. A large mass of Forsythia grown in this way is most striking. $\mathrm{F}$. viridissima, another species, is quite a shrub. It needs a spot fully exposed to the sun, so that a good display of bloom may be ensured. A certain Forsythia was sent here from the Continent two or three years since under the name of $\mathrm{F}$. intermedia, and was announced as a hybrid between $F$. suspensa and $F$. viridissima. Though at first very little disposed in its favour, I have recently seen it in a better light. Its general appearance is about midway between its alleged parents. Forsythias may be flowered under glass in the greenhouse or the conservatory during the early months of the year, and, if so treated, they will bloom in a very satisfactory 
manner. Owing to the time the blossoms expand when in the open ground, very little forcing is necessary to have them in bloom quite early. Fortunei and Sieboldi are names often used; but these represent only vigorous forms of $F$. suspensa. As the shoots of the rambling kinds root from the points almost as readily as a bramble, and cuttings strike freely, there are no obstacles in the way of their rapid propagation. The shrubby $F$. viridissima also strikes without difficulty from cuttings, though scarcely to the same extent as the others.

Fothergilla alnifolia.-A North American dwarf shrub, desirable on account of its flowering early in spring. Its feathery tufts of fragrant white flowers appear before the leaves, which resemble those of the common Alder. Suitable for a moist peat border or the low part of the rock-garden.

Foxglove (Digitalis purpurea).

Fragaria (Strawberry). - The Strawberry is much more useful in the fruit garden than in the flower garden, yet some kinds are pretty in the rock-garden. The common English strawberry is very pretty on banks, and occasionally most useful on old mossy garden walls where it establishes itself. One kind, F. monophylla, is a beautiful rock-garden plant, with large white flowers. The Indian strawberry, F. indica, is a pretty little trailer, bearing many red berries and flowering late. All are of the easiest culture in any not too wet soil, and of facile increase by division.

Fragrant Flowers. - Some sweetsmelling plants are lavish of fragrance, and give it spontaneously. Of these we have in the shrubbery, Lilacs, Mock Orange, Azaleas, Sweet Briars, double Gorse, various Brooms and Thorns, Acacias, and Honeysuckles; in the borders, Tulips, Hyacinths, and Daffodils, Triteleias, alpine Auriculas, Musk, double Rockets, Lupines (annual and perennial), Fraxinella, White Lily, Musk Mallow, Phloxes, Mignonette, and Sweet Peas, with several kinds of Scotch and other Briar Roses; for wilder parts, common Gorse, Broom, and Hawthorn, wood Hyacinths, Cowslips, Agrimony, Meadow Sweet, and Marsh Marigold. A delightful fragrance rises from a sunbaked bank of Heather in late summer, and who does not know the sweetness of a Clover field, and of a warm breeze perfumed with Pine trees? Better still, perhaps less commonly known, is the night-air of April, full of the sweet breath of the young Larch. All these are plants and trees that give off their sweetness bountifully, but the fragrance of many others can only be enjoyed by touching, or, at least, by closely approaching them. Of these the most important are Myrtle, Lavender, Rosemary, Balm of Gilead, Southernwood, Escallonia macrantha, Bay, Bog Myrtle and the Fern-leaved Gale (Comptonia asplenifolia), Juniper, Thyme, Marjoram, and other sweet herbs. A good plan would be to plant these in a rough place with narrow walks or spaces of turf between good groups of each, so that one would brush against the living masses of sweetness, the turf being full of Thyme, and the free-smelling shrubs and trees being beyond.

The Gum Cistus in autumn gives off a pungent and agreeable smell, though its flowers have no scent, and in early winter the foliage of Violets and Woodruff and the dying Strawberry leaves are sweet good-byes of the garden year. There are many smaller treasures which we must either stoop to or gather if we are to enjoy their sweetness. Linnæa borealis, whose tiny twin flowers smell like Almonds, the New Zealand Mayflower (Epigæa repens), Polygala Chamæbuxus, Almondscented Pyrolas, the sweet-scented Orchis (Gymnadenia conopsea) like white Lilac blossom, and the Butterfly Orchis, fragrant in the evening; Iris graminea, whose flowers, hiding low among the grassy leaves, have exactly the smell of ripe plums. The Pond Flower (Aponogeton distachyon) is strongly perfumed. The Lily of the Valley need hardly be named. Of other sweet border flowers there are Chinese Pæonies, delicately Tulip-scented; Grape Hyacinths, the Musk Hyacinth, Snapdragons, Salvias, including the variegated-leaved Yuccas; the flowers of the white Plantain Lily, as sweet as those of the white Lily and more delicate, smell like those of the Crocus, Water Forget-me-not, and Pansy. The Rose family gives' a whole scale of sweet notes. The wild Roses have a scent as tender as their colouring. The Burnet Rose and its descendants, the whole race of Scotch Briars, have a delicate smell quite peculiar among roses. It is distinct again in the Damask Rose and in the sweet old Provence; while in Hybrid Perpetuals we have at least three distinct types of perfume, and as many in the Teas, the most marked type among the latter being Gloire de Dijon. The scent differs again in China Roses, and again in the clustered climbing kinds. In Moss Roses the very peculiar and delightful smell seems to come mostly from the 
viscid matter on the mossy calyx and stalk. This is also the case with some of the garden Brambles, notably Rubus speciosus and with Fraxinella and Gum Cistus. Among sweet-smelling plants we must not omit those of a wholesome aromatic character, such as Wormwood, on stalks. The plants are raised from seed, and in spring furnish flowers for a long time. F. ramosa, bearing white or pink flowers, and having a short stem, differs from $F$. appendiculata, which is stemless, and has flowers deeper in colour than the others. F. sonchifolia has also

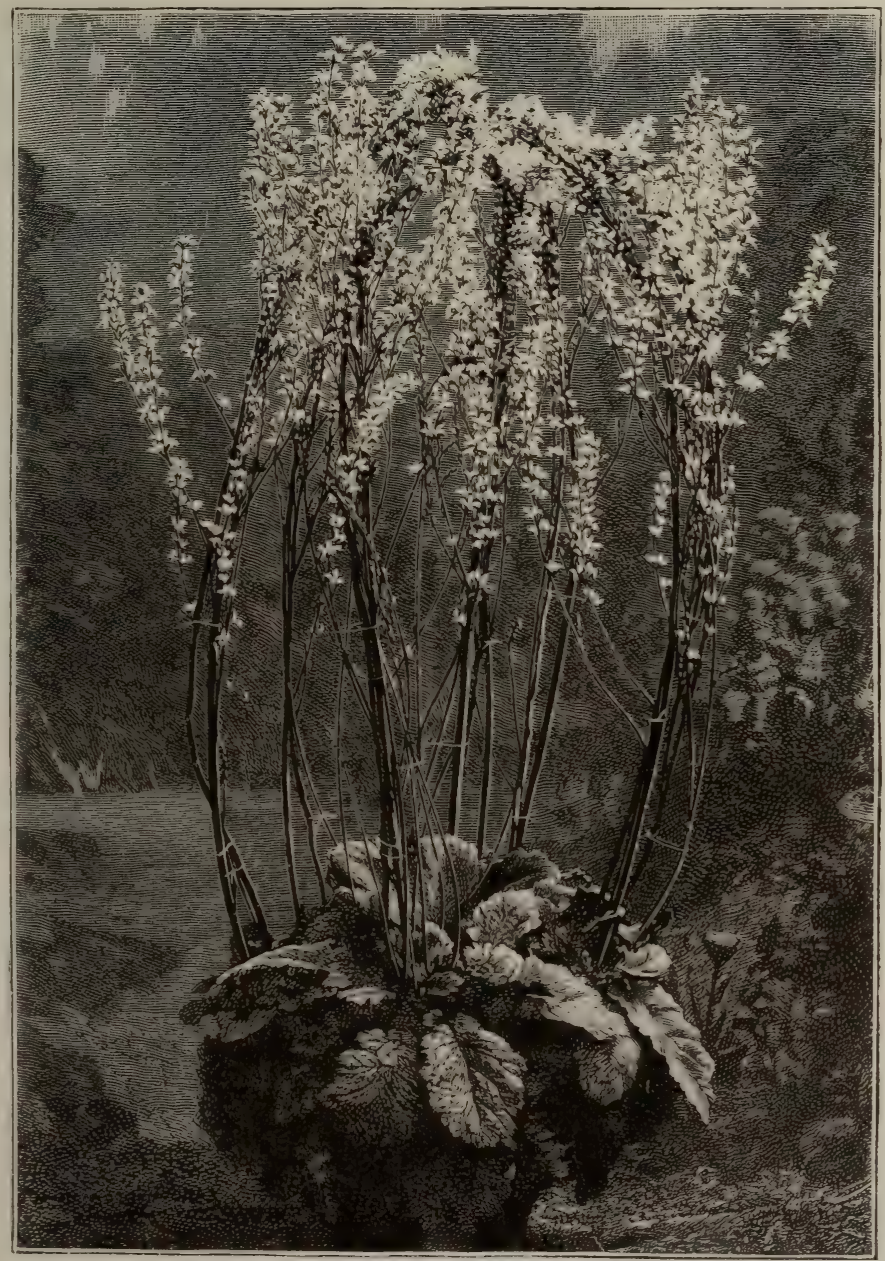

FRANCOA RAMOSA (MAIDEN'S WREATH).

Chrysanthemum, Chamomile, Santolina, and Tansy.-G. J.

Francoa (Maiden's Wreath).-Chilian plants of the Saxifrage family, alike in general appearance. They are rather tender, being suitable only for dry sheltered positions on warm sunny borders or banks, and preferring a light loam. They are good for cutting, as the long branching stems, 18 in. to $2 \mathrm{ft}$. high, bear numerous white or pink blossoms a short stem, but its leaves are sessile and not stalked, and its flowers are rosecoloured. They are often grown as window plants, and are best as such where they do not thrive in the open air.

Frankenia lævis (Sea Heath).-A very small evergreen, with crowded leaves like a Heath. Common in marshes by the sea in many parts of Europe and on the east coast of England. Best for the rockgarden, but mainly of botanical interest. 
Frasera (American Columbo). - Rare North American biennials of the Gentian family, little known in cultivation.

\section{Fraxinella (Dictammus).}

Fremontia californica.-A handsome deciduous Californian shrub, but scarcely hardy enough for the open air without protection. There are few more beautiful wall shrubs. It has large bright yellow bowl-shaped flowers, 2 in. across, the deep green leaves being lobed. In favourable spots it reaches 10 or $\mathrm{I} 2 \mathrm{ft}$. in height, and flowers in early summer. It succeeds best against a north, west, or east wall, a southern exposure being usually too hot and dry.

French Honeysuckle (Hedysarum coroncrium).

\section{French Willow (Epilobium).}

Fringe Tree (Chionanthus).

Fritillaria (Fritillary).-Bulbs of the Lily family, several of which are valuable,

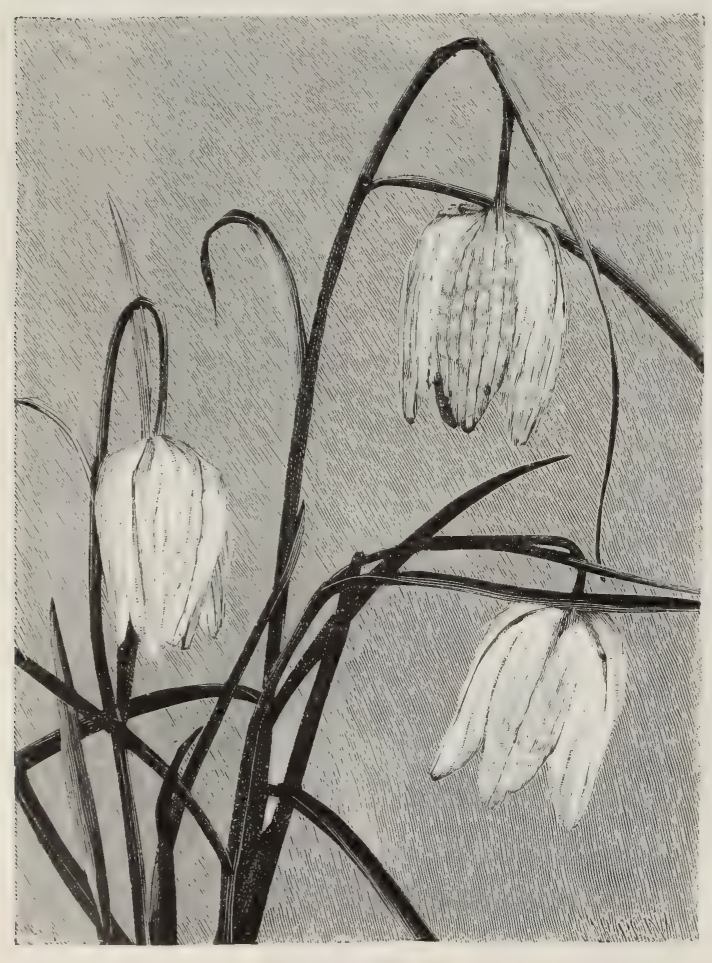

WHITE FRITILLARY.

some, such as the Crown Imperial, being stately, others, such as F. recurva, being delicate and pretty, but most have dulltinted curiously interesting flowers. They may be put to many uses: the Crown Imperial is a fine plant for the mixed border or the shrubbery, and, being vigorous, is able to take care of itself in the wild garden. Its early spring growth makes it valuable. The Snake's-head (F. Meleagris) and others, such as F. latifolia, pyrenaica, together with the choicer kinds, are fitted for the bulb border and for grassy places. Only one or two require special treatment; all the others thrive in ordinary garden soil. They may all be readily increased by offsets from the old bulbs, which should be lifted every three or four years and planted in fresh soil-a process very beneficial to the plants. The lifting should be done in autumn, and the bulbs replanted without delay. The following are among the most desirable for general cultivation:-

$\boldsymbol{F}$. aurea, one of the prettiest of the genus, is quite hardy, is about 5 in. high, and has a stem of four to six thick, fleshy, deep green leaves, with a nodding flower, which is pale yellow spotted, or chequered with brown. Silesia.

F. Burnati, a handsome hardy plant about 9 in. high, with solitary drooping blossoms, 2 in. long, which are of a plum colour chequered with yellowish-green. Alps. Flowers with the Snowdrop, and is as easy to grow.

F. imperialis (Crown Imperial). - A showy and stately plant, from 3 to $4 \mathrm{ft}$. high, with stout bright green shoots, crested by large dense whorls of drooping bell-like flowers and a crown of foliage. There are several varieties, differing chiefly in the colour of the flowers. The principal are-lutea (yellow), rubra (red), double red and double yellow, rubra maxima (very large red flowers), Aurora (bronzy orange), sulphurine (large sulphur-yellow), Orange Crown (orange-red), Stagzwaard (a fasciated stem form, with very large deep red blossoms), and aurea marginata (gold-striped foliage); every leaf being margined with a broad golden - yellow band, blending with the rest of the foliage. This plant thrives best in a rich deep loam, especially if the bulbs remain undisturbed for years. Its best place, perhaps, is in a group on the fringe of the shrubbery or a group of American plants. For artistic effects it is not so 
valuable as the common Snake's-head; and its odour is against it when gathered.

F. Karelini.--An interesting kind, 4 to 5 in. high, with two or three broad leaves clasping its stem, and having a terminal raceme of slightly-drooping belllike flowers. These flowers, about I in. across, are of a pale purple, with darker veins, a few darker spots, and a distinct yellowish-green pit at the base of each reflexed segment. It is a native of Central Asia, and, flowering in late autumn or early winter, is valuable for a collection of winter-flowering outdoor plants. According to Dr. Regel it must be kept in dry sand until November, and should not grow or show bloom before spring. If planted in November, growth is retarded, and it does bloom in spring, which it ought to do ; while those flowering in autumn invariably dwindle away, and do not produce any new bulbs. It should be planted in light soil in well-drained borders with a warm exposure.

F. latifolia. - A most variable species as regards the colour of the flowers, which are larger than those of our native F. Meleagris. They are borne on stems about I ft. high, are pendulous, and vary in colour through various shades of purple, black, lilac, and yellow. The principal named varieties are-Black Knight, Captain Marryat, Caroline Chisholm, Cooper, Dandy, Jerome, Maria Goldsmith, Marianne, Mellina, Pharaoh, Rembrandt, Shakespeare, Van Speyk, each representing a different shade of colour. They grow freely in an open situation in any soil, and are excellent for naturalising. Caucasus.

F. Meleagris (Snake's-head) is an elegant native species, of which there are numerous varieties. It is 9 to $\mathrm{I} 8 \mathrm{in}$. high, and in early summer bears a solitary drooping flower, beautifully tesselated with purple or purplish-maroon on a pale ground. The chief varieties are - the white (alba), which has scarcely any dark markings; nigra, a deep purplish-black; pallida, light purple; angustifolia, with long narrow leaves; major, with flowers larger than the type; præcox, which flowers about a week earlier than the other forms ; flavida, yellowish; and the rare double variety. All forms of this beautiful plant may be used with excellent effect. It grows freely in grass not mown early, and is therefore admirable for the wild garden; its various forms are among the most beautiful inhabitants of the hardy bulb garden, and tufts of the chequered or white-flowered variety are among the most graceful plants in cottage gardens.

F. Moggridgei (Golden Snake's-head).
-A beautiful plant with pendulous blossoms, 2 in. long, which are of fine golden-yellow, chequered with brownishcrimson on the inner surface of the bell. It may be seen on its native Alps, at an elevation of five to seven thousand feet, among the short stunted Grass, accompanied by alpine plants, and giving the slopes the appearance of a sheet of golden bloom. It is hardy, and flowers early in spring. It is a lovely flower for planting in the choice bulb portions of the rockgarden, and, when plentiful, for dotting in groups in Grass where it may escape the mower.

$\boldsymbol{F}$. pudica is one of the most charming of hardy bulbs, and takes a place among yellow flowers similar to that of the Snowdrop among white ones. It is a native of the Rocky Mountains and the Sierra Nevada of California, where it grows in a dry barren soil. It is one of the principal spring ornaments of the flora, being nearly 6 in. high, and having bright goldenyellow flowers, graceful in form and drooping like a Snowflake. It thrives in warm sunny borders of loamy soil.

F. recurva. - The showiest of the Fritillaries, its red colour being as bright as some Lilies, and mixed with bright yellow especially on the inside of the flower. It flowers early in May or towards the end of April. The bulbs consist of a slightly flattened tuberous stock, covered by articulated scales, somewhat widely placed, which at first sight resemble those of Lilium philadelphicum. A tuft of bright green linear leaves appears above the soil, and from this rises a slender purplish stem, 6 in. to $2 \frac{1}{2} \mathrm{ft}$. high, with several pendent Lily-like flowers. It is not robust, and has succeeded only under careful cultivation, growing best in fibry loam, on a warm sunny border, near a wall. In winter it is advisable to cover the bulbs with some protective material or with a hand-light. California.

F. Sewerzowi.-A singular-looking plant, growing from I to $\mathrm{I} \frac{1}{2} \mathrm{ft}$. high, having broad glaucous leaves and nodding flowers that are greenish outside and vinous-purple within. A native of the mountains of Turcomania, quite hardy in our climate. Propagated by bulblets or seed.

Many others are in cultivation, but the majority are unattractive, though some are useful for naturalising among Grass in the wild garden; the most suitable are $-\mathrm{F}$. delphinensis, a robust plant with stems I ft. or more high, bearing brownishpurple flowers, more or less chequered 
with greenish-yellow; F. pyrenaica, a similar species, but more robust; F. liliacea, liliorhiza, lanceolata, lusitanica, pallidiflora, tulipifolia, ruthenica, and tristis, all with dull brownish-purple or greenish flowers.

\section{Frog-bit (Hydrochuris IIorsus-rana).}

Fruiting Duckweed Nertera depressicy.

Fuchsia.-This, a most beautiful ornament when well grown, is too seldom seen in our flower gardens. All round our coasts, and especially in the southern and western parts, several species are hardy, and are perhaps the most beautiful objects in gardens. In other districts Fuchsias are cut down by frost, but spring up again vigorously and, in fact, live the life of herbaceous plants; but in mild districts, and near the coast, they frequently escape being cut down for years, and become large and handsome bushes. No plants are more likely to improve the garden. Not showy in mass of flower, they are of the highest beauty; the drooping shoots of most kinds afford a grace that no garden should be without. Even in dwarf kinds, where this drooping tendency is not seen to such advantage, or, it may be, is seen to a disadvantage, the Fuchsia is very valuable; but its full beauty is seen when we use plants with rather tall stems or pyramids. In the milder districts, where it is a shrub, we see it to perfection; in others the tallstemmed or pyramidal plants have to be placed out in summer. The right way to manage Fuchsias put out for the summer only is to induce them, as far as possible, to produce all their growth in the open air ; for if you start them, nurture them, and make them full of leaves and strong young growth in the spring, they will be disappointing; but if you keep them back and do not let them burst into leaf until put in the open air in May, they will go on and retain all the strength they gather, suspending graceful blossoms until the leaves desert the trees. They should then be taken up and put in a dry cave, cellar, or shed for the winter, and it would not be difficult to "keep them back" in spring. And even if they seem inclined to push forth before the time to put them in the flower garden, there should be no difficulty in placing them in some quiet sheltered nook, where they may receive more protection than in the flower garden proper, and yet have full opportunity to make growth in the open air - the great point to be attained. In many places refuse plants may be turned to good account in this way. Nothing is simpler than to make of these standards for the flower garden by cutting away the lower and middle side-shoots and leaving the head. All may be freely propagated from cuttings in spring or autumn. There are about a dozen more or less hardy kinds that succeed in the open air in the south and midland counties, and many more in warm seaside localities; in fact, there is not a Fuchsia in cultivation that will not thrive in the open air in summer; if used judiciously they give an air of grace afforded by no other plants. The following are among the hardiest kinds :-

F. coccinea. - A well-known bushy plant, graceful and beautiful in growth and bloom, readily adapting itself to any locality, unless the soil be of the wettest and coldest description, and even then a slight covering of coal ashes after the stems are cut down in autumn will protect the roots in winter. In favourable situations it is often $6 \mathrm{ft}$. high. From the axils of the leaves, which are a fine green, beautifully tinged or veined with red, the flowers, which before they fully open are not unlike crimson drops, are produced in profusion during the greater part of the summer. Chili.

F. conica.-A vigorous compact species 3 to $6 \mathrm{ft}$. high, but not such a free flowerer as some of the others. The flowers have scarlet sepals, and dark purple petals. Chili.

F. corallina.-A beautiful plant, taller and more slender than the others, and therefore specially suited for walls and houses. The flowers are large and of a showy, red colour, and the plant is a vigorous grower and free bloomer.

$\mathbf{F}$. discolor is a dwarf variety with numerous small scarlet flowers. It is the hardiest of all, not being injured by the winters in the milder parts of Scotland if treated as a herbaceous plant. F. pumila is similar, but more slender, and equally desirable.

F. globosa.-One of the best of the hardy Fuchsias. The flowers are globose in bud, and retain their shape for some time after they begin to expand, on account of the petals continuing to adhere at the tips. It is a profuse bloomer, and the flowers are richly coloured. It forms a sturdy and often a large shrub in seashore districts. There is no reason why it should not be grown in drier districts, even if cut down by frost every year, as it is always handsome.

F. gracilis.-A very distinct slender plant, with flowers on remarkably long slender stalks. The young shoots are a purplish-red, the calyx is a brighter 
scarlet, and the corolla has a greater infusion of red than other hardy kinds. In mild and moist districts it is nearly 7 $\mathrm{ft}$. high, from 12 to $\mathrm{I} 5 \mathrm{ft}$. in circumference, and is of rapid growth. In some winters it is not cut down by frost. There is a variety called multiflora, which is very free-flowering, and which has shorter flowers and of darker crimson. F. tenella is a seedling variety of $\mathrm{F}$. gracilis. Chili.

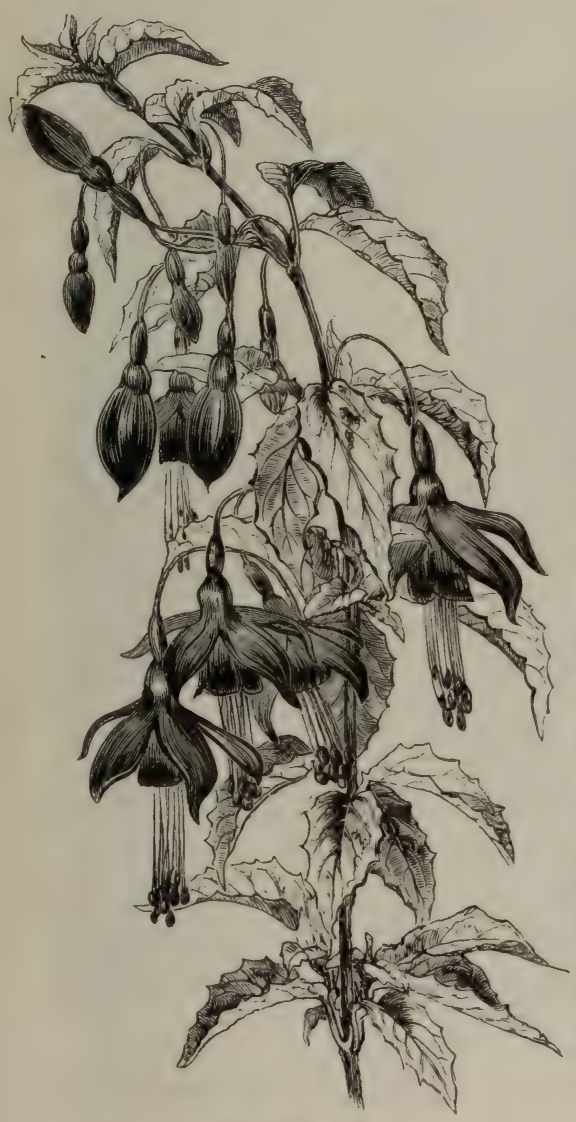

FUCHSIA PUMILA.

F. Riccartoni.-One of the prettiest and hardiest sorts, growing well without protection even in parts of Scotland. It is compact and twiggy, and in summer bears many bright red blossoms. A garden hybrid.

Besides these, other kinds are in cultivation, such as procumbens - a curious little New Zealand species-serratifolia, magellanica, thymifolia, and microphylla, and nearly all the hybrid kinds do out-ofdoors in summer, and bloom well, though they may be cut down in winter. Among the most distinct and pretty are the dwarf and fragile kinds, such as F. microphylla, F. pumila, and several hardy hybrids of the globosa section, all of which seem to flourish unusually well near the sea, and to grow almost anywhere.

Fumaria (Fumitory).-Mostly annual plants of a weedy nature. One is perennial. The species of Corydalis are sometimes placed under this genus, especially in Continental gardens and nurseries.

\section{Fumitory, Climbing (Adlumia).}

Funkia (Plantain Lily). - A most valuable genus of Japanese plants of the Lily family, containing about half a dozen species and numerous varieties. We owe to it some of the boldest effects in our gardens and public parks. Its chief value is in its handsome foliage, but in addition to that, the different species are free-flowering herbaceous plants, with spikes of bell-shaped flowers. They are noble plants, most useful for many positions in the garden, while few lend such a tropical effect as F. Sieboldi when finely developed. They are highly suitable for grouping, and few plants thrive better in open places in shrubberies. The bold striking foliage of some of the strongest plain-leaved section renders them very effective for edging large beds, while the kinds with variegated foliage, such as $\mathrm{F}$. undulata variegata, make good groups, or are suitable for edgings. They are best seen in well-drained deep soil. All are easily multiplied by division in spring or autumn. The best are-

F. Fortunei.-This strong species has smaller and more leathery leaves than $\mathrm{F}$. Sieboldi, and they are of a much more bluish or glaucous tint. The flowers are pure white or pale mauve.

F. grandifiora is 12 to 18 in. high, producing in August and September numerous large, handsome, pure white, sweet-scented flowers. In some places it is used for edging, but is best seen in tufts, in beds or borders, in a well-drained sandy loam. About Paris it is grown as a flower-garden plant, but with us it does not flower regularly unless in sunny spots and warm, well-drained, and very sandy loam. The young leaves are a favourite prey of slugs and snails. It is also known as F. japonica.

F. lancifolia is a small species, with tufts of lance-shaped leaves, narrowing from the middle towards both ends. There are some interesting varieties, chief among which are the white-flowered variety (alba or speciosa as it is more commonly called), a beautiful plant, 
spathulatia, and plantaginifolia, with long narrow leaves. There are some very pretty varieties with leaves of different variegation, all well worth growing; notably albo-marginata, with a narrow white line along the margin of the leaf; undulata variegata, in which the leaves are undulated on the margin and variegated on the greater part of the surface; and umvittata, with a broad white midrib to the leaf.

F. ovata has large tufts of broad, deep, shining green leaves. Flower-stems 12 or
Gagea.-Small plants of the Lily order, with flowers somewhat like a Star of Bethlehem, but yellow. They are not generally admired, but are pretty in grassy places in sandy soil. Europe, G. lutea being British.

Gaillardia.-Very important plants for the flower garden, which include some of the showiest flowers, valuable for their long duration both on the plants and in a cut state. North America. The genus numbers some half-a-dozen species and many garden varieties. The numerous

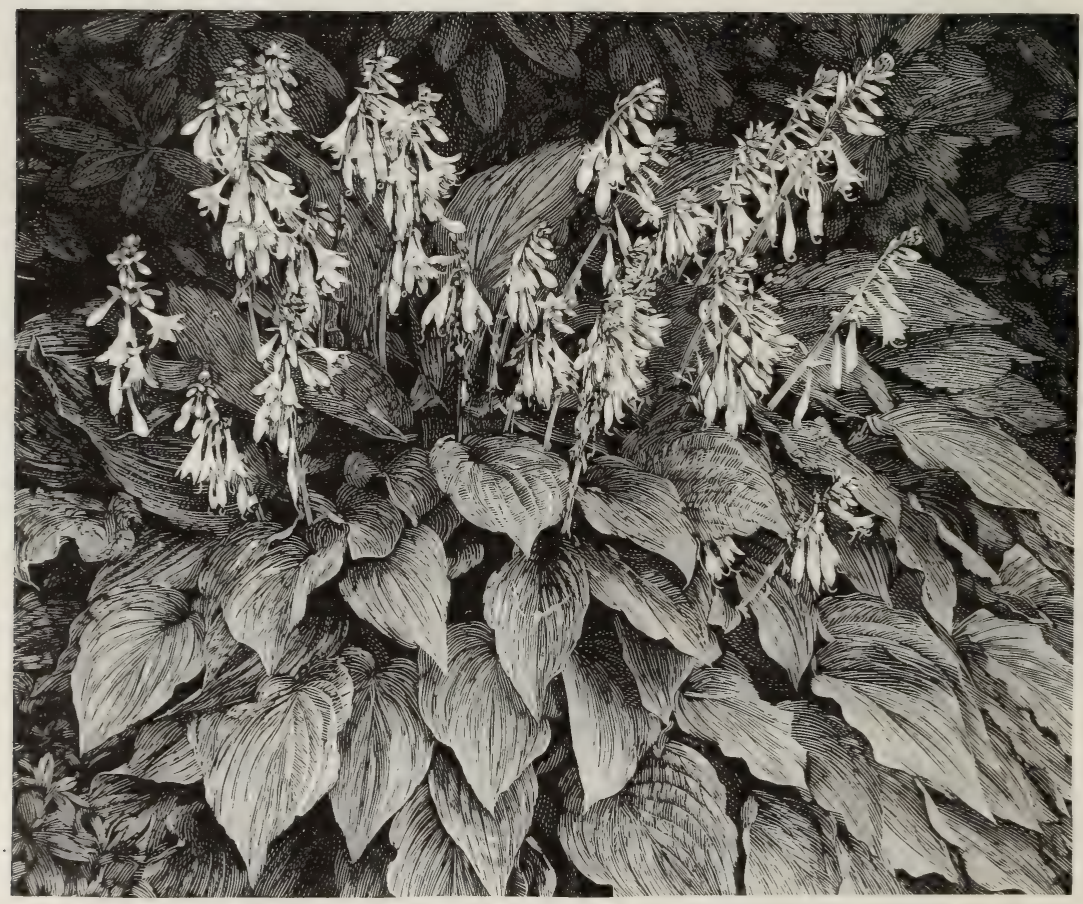

PLANTAIN LILY (FUNKIA SIEBOLDI).

$18 \mathrm{in.} \mathrm{high,} \mathrm{terminating} \mathrm{in} \mathrm{a} \mathrm{short} \mathrm{raceme}$ of lilac-blue flowers, which appear in late summer and autumn. One of the strongest species, and when in flower is very handsome. There is a variegated-leaved form.

F. Sieboldi is the most ornamental of the species. It is $18 \mathrm{in}$. to $3 \mathrm{ft}$. high, and has large glaucous leaves, somewhat heart-shaped, often over $\mathrm{I} \mathrm{ft}$. across. The flowers are in tall one-sided racemes well above the foliage, and are a creamy-lilac. There is an interesting variety with yellowmargined foliage. Admirable in tasteful hands for picturesque groups or massive edgings.

Furze, see Ulex. kinds now in gardens appear to fall under three species, but there is a strong family likeness throughout the series. The kinds are

G. aristata, a perennial, $\mathrm{I}$ to $\mathrm{I} \frac{1}{2} \mathrm{ft}$. high, with narrow leaves, sometimes deeply cut. The flowers are $1 \frac{1}{2}$ to $4 \mathrm{in}$. across, the ray florets having an outer zone of orange-yellow and an inner one of brownish-red, while the centre is deep bluish-purple. It is the commonest kind, and having been raised largely from seed, has many varieties, differing more or less widely from the type, and of various names. G. picta somewhat resembles G. aristata, but has smaller flowers, and is a 
biennial. It is dwarfer, and its flowers are brighter. G. amblyodon is a beautiful Texan annual, introduced a few years ago. Its flowers are even smaller than those of G. picta, and are of a deep cinnabar red. On strong plants they are borne plentifully towards the close of the summer for several weeks. G. pulchella is the oldest cultivated, and was introduced about a which are only surpassed by its variety maxima. It is by far the finest of all.

G. hybrida is another garden cross, much resembling $G$. grandiflora; the variety splendens has brighter flowers. G. Telemachi, Drummondi, Loiselli, and Bosselari appear to be synonymous with some of the preceding, and G. Richardsoni scarcely differs from them.

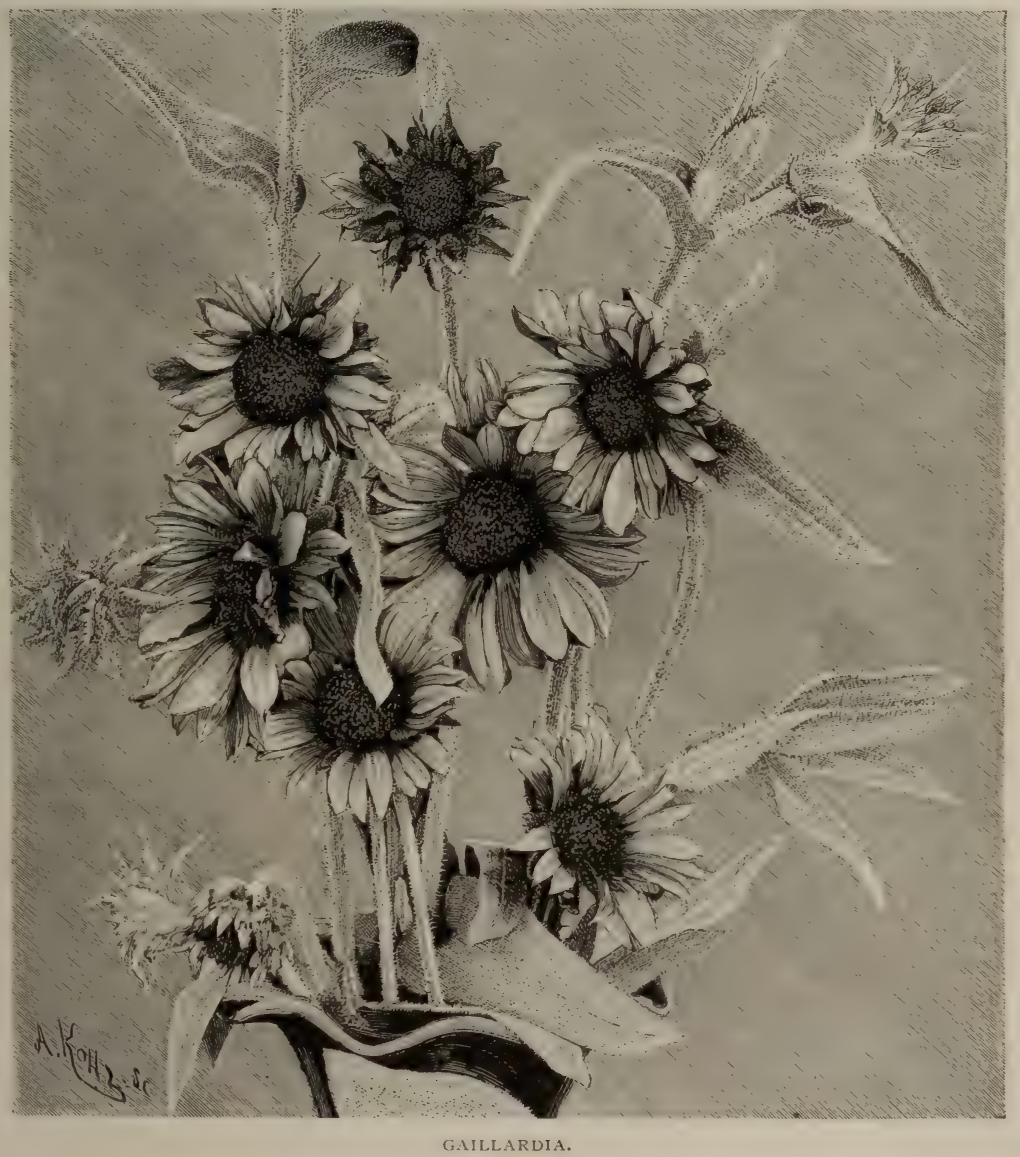

century ago. It is $\mathrm{I}$ to $\mathrm{I} \frac{\mathrm{I}}{2} \mathrm{ft}$. high, and bears bright yellow and purplish - red flowers, 2 in. across. It is only an annual, and seems to be very scarce. G. bicolor and pinnatifida are seldom seen in gardens, probably owing to their being somewhat tender. The garden varieties, as has been stated, are numerous, but the most distinct of those named are--

G. grandiflora, said to be a hybrid, presumably between $\mathrm{G}$. picta and $\mathrm{G}$. aristata. It is a beautiful and vigorous plant with large brightly-coloured flowers,
All thrive in good friable garden soil, but not on a cold stiff soil or on one that is too light or dry. Where possible they should be grown in bold groups, for they thrive better if so placed than as solitary plants in a parched border, and no plants have a finer effect in a bed by themselves. Where apt to die in winter, they may be used in mixed borders, if treated as halfhardy annuals ; for if sown in a mild hotbed at the end of February or the beginning of March, they may be grown into good plants, and give a full display of their fine 
flower-heads as early as those that have withstood the winter in the borders. Cuttings in autumn or spring, and division in spring, assisted afterwards by slight heat in a cold locality.

Galactites tomentosa.-A Composite, from the shores of the Mediterranean, 2 to $3 \mathrm{ft}$. high, with spiny foliage, blotched with white, and cottony-white on the under surface. The flower-heads are lilac-purple. If sown as early as February, on Grass. The leaves complete their functions so early that it may be planted in Grass repeatedly mown, as well as grown on banks in pleasure-grounds or half-wild places. The bulbs may be inserted a couple of inches in the turf, and the spot may be afterwards made firm and level, especially if it be on a trimly-kept lawn. Almost any soil suits the Snowdrop, but deep, rich, well-drained gravellybottomed soils are most suitable, though

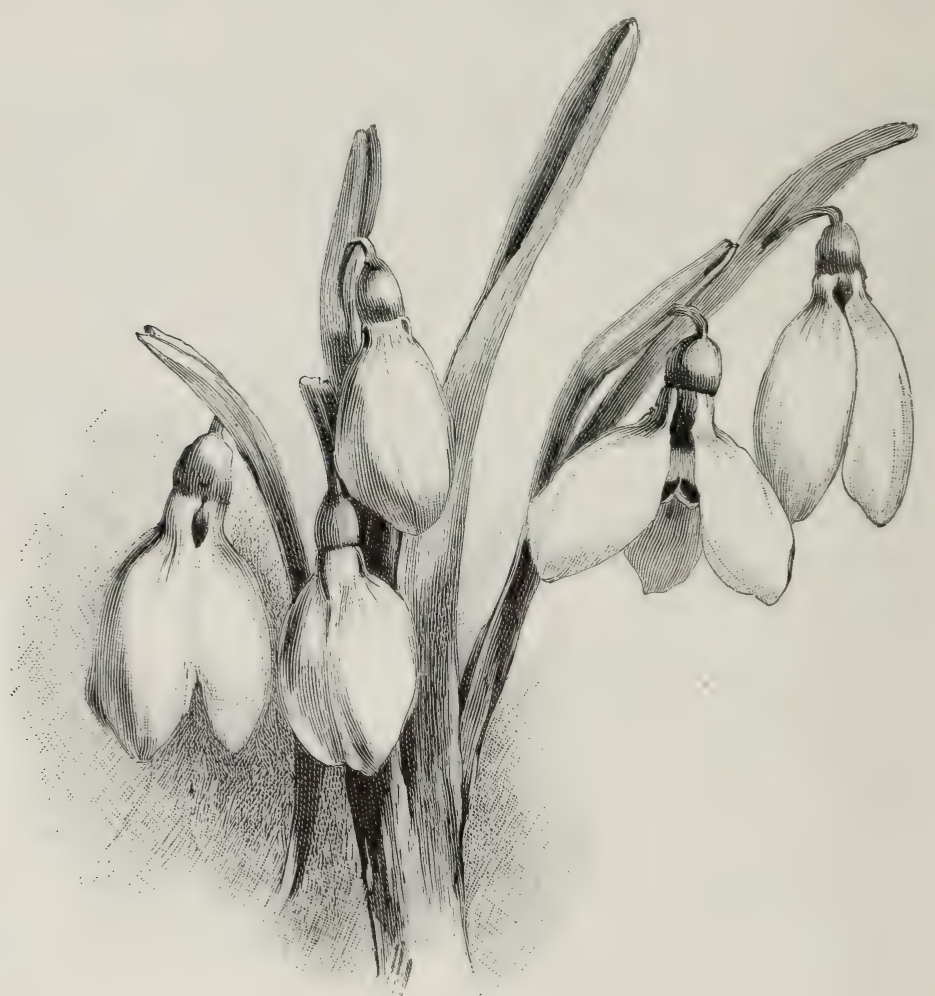

SNOWDROP.

it blooms the first season, but stronger plants are got by sowing in autumn. It succeeds best in good loamy soil, and is effective in small masses in the sub-tropical garden.

\section{Galangale (Cyperus longus).}

Galanthus (Snowdrop).--Although one of the most abundant of hardy bulbs, one never tires of its modest beauty whatever its surroundings. It never looks better than when naturalised amid tender herbage in old-fashioned orchards and paddocks, on the margins of lawns, or beside woodland walks, and it propagates itself when in a semi-wild state or in Nottinghamshire and Leicestershire it grows luxuriantly on the coldest and wettest clay soils of hedge-banks and old orchards. All the Snowdrops are hardy, and may be used in isolated masses on the Grass, or grouped in well-made rootwork or rock-gardens, or in the wild garden, where they may be tastefully associated with Anemone fulgens, A. coronaria, A. hortensis, A. blanda, early purple and yellow Crocuses, Winter Aconites, and Irises of various kinds (such as $\mathrm{I}$. reticulata, I. Histrio, and I. stylosa), all of which bloom in January and February in mild winters. As cut flowers, Snowdrops 
are most attractive, since they may be grouped with sprays of Box or Fern, or associated in bouquets and wreaths with Orchids, Rose-buds, Forget-me-nots, and other choice cut flowers. To cull the flowers in bud is, however, essential to ensuring perfect beauty, as they can be carried better and open fresher in water than if cut from fully-expanded plants. Buds so gathered will remain beautiful for ten days or longer, while flowers cut after expansion will fade in about a week.

There are several species in cultivation, all bearing a strong resemblance. The common native, G. nivalis, has dwarf narrow leaves and small flowers. There are two varieties of this species-Shaylocki and virescens. G. Shaylocki has the outside tips of the outer petals green, and the upper portions white; it has, moreover, a two-leaved spathe. G. virescens has the tips of the outer petals white, but the whole of the upper portion is suffused with green. The Crimean Snowdrop, G. plicatus, has very broad leaves, with margins curiously turned down or deflected, and flowers larger than those of nivalis. G. Imperati is the most stately of the group, varying from 6 to 12 in. in height, the sepals being about $I$ in. long. G. Elwesi, perhaps the finest, has a very globular flower, twice as broad as G. Imperati, and the green base of the inner segments shows between the outer ones. The leaves are also very glaucous, and can be distinguished at a glance from those of any other Snowdrop. G. Redoutei is a most distinct and robust kind, but is rare in gardens like G. latifolius and reflexus. Mr. Melville, of Dunrobin Castle, has raised interesting varieties of Snowdrops, which differ chiefly in time of flowering. They are G. Melvillei, proculiformis, serotinus (a late-flowering kind), and præcox, which flowers about Christmas. A variety of G. nivalis, with yellowish flowers, is called lutescens.

The present very interesting and growing state of our knowledge of Snowdrops may best be gleaned from a paper read by Mr. Jas. Allen before the Royal Horticultural Society, of which the following is an abstract:-

Less than twenty years ago there was, practically, but one kind of Snowdrop grown in England, G. nivalis, in its single and double forms. G. plicatus was introduced soon after the Crimean war, but it was not often seen unless in botanic gardens. Early in the '70's G. Elwesi was introduced, and in $1875 \mathrm{Mr}$. Barr offered, under the name of G. Imperati, a very fine form which the late Mr. James Atkins, of Painswick, procured "from somewhere in the kingdom of Naples." This is much finer than the G. Imperati offered by Messrs. Backhouse and others some two or three years later, and now generally grown under that name. I propose that the earlier form be called G. n. Atkinsi. Then G. latifolius (first offered as G. Redoutei), a Snowdrop with the leaves of a Scilla, was followed later on by G. caucasicus, and finally by G. Fosteri. We have also discovered that a few forms of G. nivalis, from the mountains of Greece, hurry into flower in September or October instead of January, and some of their little cousins in Corfu try to do the same, but cannot get their wardrobes ready until a few weeks later.

In speaking of Snowdrops we must not forget that, besides the division into species and sub-species, we have the arrangements into classes, according to colours and other peculiarities. Consequently we hear of white Snowdrops and yellow Snowdrops, and also green Snowdrops.

G. IMPERATI. - I think no botanist would be able to say where nivalis ended and Imperati commenced. In the section to which $\mathrm{G}$. nivalis and $\mathrm{G}$. Imperati belong there are some most lovely Snowdrops, amongst which I would mention first Mr. Melville's Dunrobin form, now known as G. Melvillei major. G. n. Atkinsi is second to none in size, form, quality, and freedom of growth. It is the plant known to some as Imperati of Atkins, or true Imperati. A year or two since I selected from some imported roots of G. Imperati a lovely dwarf very lateflowering form, which I named Afterglow. This is the most beautiful of the late class.

G. PLICATUS is very distinct, and its best forms possess great beauty. The foremost place in this section belongs to G. p. maximus, found a few years since in a garden at Chapel, in Berwickshire, by Mr. W. B. Boyd, of Melrose. This wonderful variety, under favourable conditions, gives flowers the petals of which are fully 2 in. long. It is a very late bloomer and a good grower. In the same garden Mr. Boyd found another good variety, which he named G. p. Chapeli. This is not nearly so large, but it has very broad petals and is of fine form, and ranks with the best. G. plicatus usually flowers late, but I have a selected form, G. p. præcox, which flowers with the early varieties of $\mathrm{G}$. nivalis. This is very distinct. Another selected form, G. p. Omega, flowers with the very latest. 
G. ElwEsI. - The best varieties of this are large and handsome, but still it is not a universal favourite. It wants the most sheltered spots in the garden, otherwise the wind is too much for the topheavy flowers, and their purity and beauty are soon gone. I am trying to get a race of finely-shaped flowers, with short sturdy stems to enable them to carry their heads erect. Many find G. Elwesi difficult to manage, but with me it grows very freely, especially in one bed of very light soil, where the seedlings are almost a nuisance.

G. LATIFOliUs.-This is the most distinct of all Snowdrops, with its broad grass-green foliage and small pure white flowers, and it has a delicate beauty all its own, more especially just before the bud expands, when the two leaves curve so lovingly round the flower-stem. I have obtained roots of this species from many quarters, but there seems to be little or no variation in the flowers.

G. FOSTERI.-I understand that in the favoured spots of their native country the bulbs of G. Fosteri are as large as those of a good-sized Narcissus. This seems to be the most sportive of all the Galanthi as to size, form, and marking of the flowers. From the few bulbs I have bloomed, I have had flowers with petals of every imaginable shape, some showing points of great beauty, and others quite the reverse. We must be patient and weed out unsparingly, and then in a few years we shall be proud of G. Fosteri. The markings on the inner petals are very similar to those of G. Elwesi, but the foliage is quite different, being broad and somewhat blunt, and in shape and colour much like the leaves of Scilla sibirica. M. Max Leichtlin thinks very highly of G. Fosteri, and considers it to be the "king of Snowdrops."

G. AllenI.-Mr. Baker thinks this is probably a hybrid between G. latifolius and G. caucasicus, as it has some of the features of each species. The flower is of much the same character as that of G. latifolius, but nearly twice as large, and the foliage corresponds in size with the blossoms. It is somewhat glaucous and of a much darker green than that of G. latifolius, but of exactly the same elegant form. G. Alleni is very hardy, robust, and free-flowering.

Autumal Snowdrops.-In Greece and the adjacent countries several Snowdrops have been found which flower in the autumn or early winter. They seem to belong to the nivalis section. One peculiarity I have noticed in them is that they have a glaucous line running down the centre of each leaf, and by this they can be at once distinguished from the spring-flowering forms of nivalis. So far as I can learn, all these Snowdrops grow on high ground, mostly on mountains. I understand that the Snowdrops on the lower grounds do not flower until early in the year.

G. OLGÆ.-This autumnal-flowering Snowdrop was found on Mount Taygetus by Orphanides, the Greek botanist. From the descriptions given of it, G. Olgæ must have been a fine variety, and it is very unfortunate that it is lost to cultivation. M. Tanka, the Hungarian botanist, asserts that this and $G$. octobrensis are identical, but I do not think so; and the difference between $\mathrm{G}$. octobrensis and G. Rachelæ confirms my opinion.

G. OCTOBRENSIS.-Lord Walsingham, when travelling in Albania about the year I 875 , collected some bulbs on one of the mountains and sent them to the late Rev. H. Harpur-Crewe. Amongst these was a bulb which proved to be a Snowdrop flowering in the autumn, usually in October. I am sorry to say that it is somewhat delicate and increases very slowly with me. In Mr. Boyd's garden at Melrose it seems quite at home, a single bulb having given five blooming roots the first year after planting.

G. RACHEL. Æ. When travelling in Greece in 1886, Professor Mahaffy collected a quantity of bulbs and tubers on Mount Hymettus, which he sent home to Mr. F. W. Burbidge, who sent me the original bulb. G. Rachelæ is of the same type as G. octobrensis, but the flower is a little larger, and the leaves are quite a third broader, and it seems to have a stronger constitution than that variety. It also differs in being a week or ten days later in flowering.

G. CORCYRENSIS.- This usually flowers from the middle to the end of December, according to the mildness of the season. It is evidently a form of $\mathrm{G}$. nivalis, small in size and delicate in constitution. Being the connecting link between the autumn and spring flowering kinds, it is valuable and well worth the extra care required in its cultivation. The late Mr. HarpurCrewe received it from the English chaplain at Corfu.

G. ELSÆ.-Amongst some roots collected by Dr. Mahaffy on Mount Athos, in Greece, in April I889 (?), were a few bulbs of a Snowdrop which pushed through the soil in October of that year. Mr. Burbidge noticed these, and kindly sent one of them to me. This opened 
its flower on the 17 th December. It is a dwarf variety with small flowers of good form, but I fear it is not very robust or hardy, as the frosts of last season injured the leaves, and it has not flowered this spring.

THE YELLOW SNOWDROPS form but a small class, two varieties only being known at present. It must not be supposed that the petals of the flower are yellow; the name is given because of the rich yellow colour of the ovary, and the markings on the inner petals are also of that colour, instead of the usual green, and even the flower-stalks are more yellow than green. G. lutescens was found some fifteen years ago by Mr. Sanders, of Cambridge, in an old-fashioned garden in Northumberland. When Mr. HarpurCrewe first saw it he thought it was the "long-looked-for G. reflexus," but further observation convinced him that it was not. This is a very beautiful and unique variety of small size and of delicate constitution, but the reward of success amply repays a little loving care and trouble. G. flavescens was discovered quite recently by $\mathrm{Mr}$. W. B. Boyd, of Melrose, in a cottage garden, also in Northumberland, but in quite a different part of the county. This variety is rather larger than $G$. lutescens, and all the yellow points are brighter in colour with the exception of the flower-stem, which in my two plants seems rather paler. G. flavescens is a very beautiful variety, and will be a great favourite when it becomes known. It also has the recommendation of growing and increasing freely.

THE WHITE SNOWDROPS also consist, at present, of two varieties only. G. poculiformis was first brought into notice by Mr. D. Melville, who found it in the grounds at Dunrobin Castle. It has since been found in Wales by Mr. A. D. Webster, and I have also received bulbs of a very similar form from a lady near Ayr, in whose garden it grew with several other peculiar forms. When in character the inner petals are almost the same length as the outer ones, and the green markings are entirely absent, thus giving the flower an elegance and purity not found in any other Snowdrop. Unfortunately, a good many of the flowers come with some of the inner petals reverting more or less to the normal form, and in this state they are not beautiful. G. n. albus is smaller than most of this section, and is very distinct from Snowdrops in general, its peculiarity being that the usual green markings on the inner petals are replaced by small dots, which are scarcely observable at a short distance. The flower is generally of perfect shape, and is then very pretty. An occasional flower sports in the way of poculiformis. It grows freely, but increases slowly.

GREEN SNOWDROPS form quite a large class, but none of the blossoms are entirely, or even mostly, green in colour. They come into this class in consequence of having more or less green on the outer petals, somewhat in the style of the Leucojum. G. Scharloki was so named in 1868 by Professor Caspary in honour of its discoverer, Herr Julius Scharlok, who found it in the valley of the Nahe, a tributary of the Rhine. This variety, in addition to large pale green spots towards the tips of the outer petals, has the peculiarity of a twin or divided spathe, which curves down on the two sides much like a pair of wings. This variety grows and increases very freely. G. virescens is a very singular-looking Snowdrop, reminding one somewhat of an Ornithogalum. The outer petals are pale green, shading off to pure white at the edges, and especially at the tips; the inner petals are entirely green. At first I did not care much for this variety, but it has a quiet beauty which grows on me, and I should not now like to lose it. It is very late in flowering, coming in quite at the end of the season. I do not know its history, but I believe M. Max Leichtlin had his bulbs from the Vienna Botanic Gardens. G. Warei has green spots on the outer petals like G. Scharloki, but has not the divided spathe, and the markings on the interior petals are larger. Mr. Boyd, of Melrose, kindly sent me my root of this variety, and he obtained it from Mr. Ware under the name of $G$. Scharloki, and I imagine it must be a seedling from that kind. Mr. Ware is unable to account for the variation from the type. It is a strong-growing handsome plant. G. Fosteri Leopard is a great curiosity, having flowers of quite unusual shape, and at the tip of each outer petal a large dark green spot, in the style of Leucojum vernum. M. Max Leichtlin kindly sent me ten collected bulbs of G. Fosteri in January I890, and one of these flowered as described, and has kept true this season. G. Fosteri Spot is quite distinct from Leopard. It has long outer petals, somewhat pearshaped, and at the tip of each is a small pale green spot. The spots are not sufficiently prominent to give a decided character to the flower, but it is valuable as a variety. 
RAISING SNOWDROPS FROM SEED.The raising of seedling Snowdrops is not at all difficult. After the seed is gathered it should be kept in an airy place for a week or two to thoroughly ripen, and then it should be sown as soon as possible. I have not met with much success from sowings in the open ground, so I now always use boxes, and I find that brandycases are very suitable for the purpose, as they are strongly made of good wood, and are not so deep as most boxes of the size. I bore twenty-five three-quarter inch holes in the bottom, and then nail a 2 -inch square strip of red deal about 3 in. from each end. This keeps the boxes off the ground, makes them handy to move, and prevents stagnation. I use ample drainage and a free soil with plenty of grit in it to keep it sweet. The seed is sown in drills about a quarter of an inch deep, the drills filled up with silver sand, and then a quarter of an inch of sifted soil put over the whole. These boxes are placed about $2 \mathrm{ft}$. from a low north wall, and are never protected in any way. They require but little attention; of course, the weeds must be kept down, and a little fresh soil added after the second year. The Marchantia and Spergula are the greatest pests in this work. I usually let the seedlings remain in the boxes until some of them begin to flower, which generally occurs the fourth season. Galanthus seed comes up very irregularly, and when seedlings are removed from the boxes they will be found to vary from the size of a wheatcorn to that of blooming bulbs. Seed of G. lutescens does not germinate for several years as a rule. Last spring, in the same box, and from seed sown at the same time, I had G. Imperati in flower and $\mathrm{G}$. lutescens making its first appearance. If Snowdrop seed is kept till the spring, it will not germinate until the following spring. The true quality and size of seedlings cannot be ascertained until the third or fourth year of flowering.

SOIL FOR SNOWDROPS.-With me G. nivalis grows freely in all soils and situations. G. plicatus is not very particular, but still some of its varieties require extra care, as they have an unpleasant way of disappearing. G. Elwesi does not do well in close retentive soil. G. latifolius and G. caucasicus, I believe, prefer gritty loam, and I should say that G. Fosteri would also like it. Mr. A. D. Webster tells me that peat has quite a magical effect on Snowdrops, but I have not tried it. My ideal soil for Snowdrops in general would be half good sweet yellow loam and almost half unsifted rivergrit and a little leaf-mould. The situation I should choose would be a gently sloping bank, more or less shaded by trees whose roots were allowed to wander freely among the Snowdrops. I believe that all bulbs are healthier when planted amongst active roots than in ordinary beds. When the bulbs are at rest it is very essential that the soil should be kept sweet by the activity of other roots. We too often lose sight of this fact. I think the autumnal-flowering Snowdrops should be treated as alpine plants. All my best Snowdrops are grown under trees, the soil being quite full of their roots. I do not use manure for them. The only drawback to my situation for these spring gems is the soiling of the flowers from the drippings of the trees. I should mention that the climate is so trying that I cannot grow such hardy plants as Primroses, Pinks, Daisies, etc. All these disappear after a season or two. I move most of my Snowdrops when in full flower, and do not find they are injured by it in any way. This is also the best time for moving Leucojum vernum. I have noticed that the more green colour there is in any Snowdrop the more freely it grows and the more rapidly it increases, while the absence of green, or the substitution of yellow for the green, makes the plant delicate and slow of increase.

Galatella hyssopifolia (Hyssop-leaved G.)-A pretty Aster-like North American plant, suited for borders in any soil. Division. From a garden point of view, it is not distinct from the Starworts (Aster), and is inferior to them.

Galax aphylla (Wand Plant).-One of the neatest little plants for the rockgarden; its white wand-like flowers must have suggested its common name; its stout round evergreen leaves are beautifully toothed and tinted, are on slender stems 6 or 8 in. high, though, from a specimen sent from its native habitat, it would seem more than I ft. high. Of easy culture in somewhat moist peat or leaf-soil, in the bog-garden, or on the margins of beds of dwarf shrubs in peat. America.

Galega (Goat's Rue).-Graceful and hardy plants of the Pea-flower order, flourishing in any soil. On account of their free growth they are good subjects for the wild garden, and are very effective in colonies or groups. They are herbaceous perennials, growing from 2 to $5 \mathrm{ft}$. in height, according to position and soil. All are excellent for affording plenty of 
cut flowers of varied hues. Seeds or division. The species and varieties areG. officinalis, or Common Goat's Rue, a native of Southern Europe, and 3 to $5 \mathrm{ft}$. high, which in summer bears dense clusters of Pea-shaped blossoms of a pretty pink. There is a white-flowered variety named alba, also desirable for cut
Galingale (Cyperus longus).

Galium (Lady's Bedstraw). - These plants are numerous in botanical collections, but are weedy, though the whites and pale yellows intermingled are beautiful and have a pleasant odour. They seem to delight in the sun, and they flower freely. They do well on banks

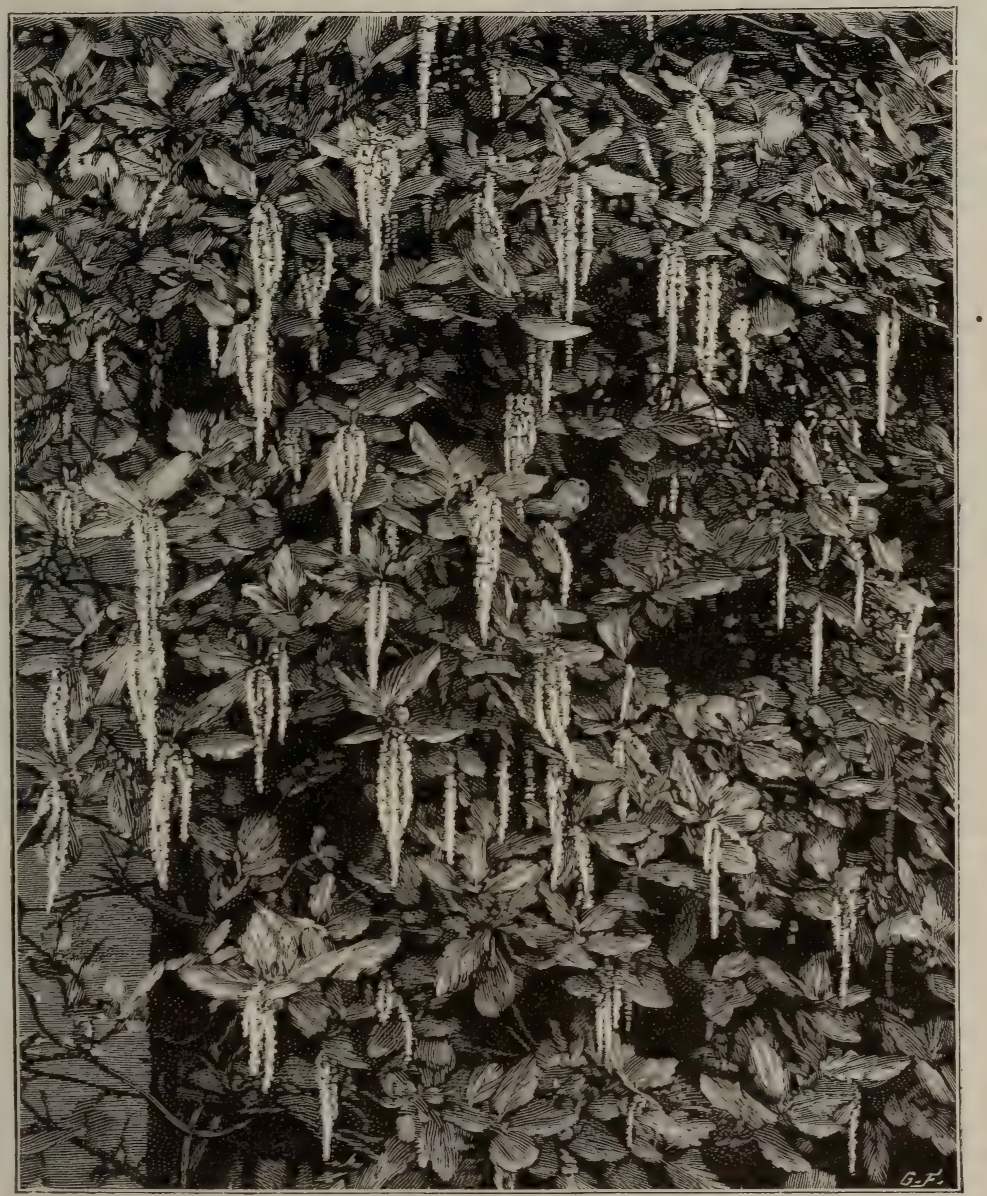

GARRYA ELLIPTICA.

flowers. A variety called africana has longer racemes and blossoms of a purple tinge. $\mathrm{G}$. orientalis is a handsome plant from the Caucasus. It is 2 to $4 \mathrm{ft}$. high, and has flowers of a bluish-purple. G. persica is a rather later-flowering kind, from 2 to $4 \mathrm{ft}$. high. Its white flowers are in dense racemes on slender axillary stalks. G. biloba is a species with pretty bluish-lilac flowers, but though an old inhabitant of gardens, is now scarce.

Gale, Sweet (Myrica). where many other things would not grow.

Galtonia candicans (Cape Hyacinth).A noble bulb from the Cape, having autumnal flower-spikes 4 to $6 \mathrm{ft}$. high, with spires of waxy, white bell-like blossoms, I $\frac{1}{2}$ in. long. Of easy culture, quite hardy in light soils, and valuable for bold groups in the mixed border, or in the flower garden. Increased by offsets from the bulbs, or trom seeds, which flower about the fourth year. The distinct habit 
of this plant makes it valuable. A group well grown in good deep soil is striking and novel in the late summer garden. A group rising from a bed of choice dwarf shrubs tells well, as indeed does the plant almost wherever it is well grown. = Hyacinthus candicans.

Gardoquia.-Rarely-grown Labiates. Most of them require greenhouse culture, and $\mathrm{G}$. betonicoides is the only one fit for the open air. It is 2 to $3 \mathrm{ft}$. high, has tubular flowers of bright rosy-magenta, and should be treated as a half-hardy annual.

Garland-flower (Daphne Cneorum).

Garrya elliptica.-A fine Californian Evergreen, beautiful as a winter-flowering shrub. In mild winters it begins to flower as early as December, and bears among handsome deep green leaves gracefullydrooping tufts of pale green catkins. Flowering twigs endure a long time in vases, and are very acceptable in winter. Though generally a wall shrub, it is hardy and makes a dense bush, 5 to $8 \mathrm{ft}$. high, according to situation. In cold parts it is advisable to give it shelter, but in the south and west it does not require this. If planted in a shrubbery near the path and not allowed to become crowded, its beauty can be best enjoyed. There are various other kinds of Garrya in cultivation, but G. elliptica is the best. There are male and female forms, the most elegant being the pollen-bearing or male plant.

Gaultheria procumbens (Partridge Berry).-This neat little shrub is pretty of itself, but the berries give it a charm through autumn and winter, when it is, or ought to be, one of the most attractive objects in the rock-garden. Its drooping white flowers are also pretty. A native of sandy places and cool damp woods from Canada to Virginia, and often found in the shade of evergreens in N. America. It does well in moist peat, and forms edgings to beds in some places where the soil is of that description, or of a loamy nature. Easily increased by division or seeds. Suitable for the rock-garden, for the front margins of borders, and occasionally for use as an edging to beds of choice and dwarf American plants, but it is best where well exposed. G. Shallon is too large for all but the rougher flanks of the rock-garden, being a vigorous shrub where it has root-room.

Gaura Lindheimeri.-A graceful perennial, 3 to $4 \frac{1}{2} \mathrm{ft}$. high, flowering in summer and autumn; has long slender spikes bearing numerous white and rose flowers which droop slightly. Borders, in sandy loam. May be used with the larger bedding plants. Division and seed.

Gazania.-Very handsome and distinct dwarf Composites; of much value, though only hardy enough for summer growth. They strike freely in a cold frame in August, but later on require bottom-heat. Unless struck very early, spring-struck plants are almost worthless, so that it is advisable to put in the stock in August and let them stand in cutting-pots till potting-off time in spring. They will then come well into flower when put out in May; whereas, if they are topped for a spring batch, both lots will be small and late. Short young tops should be used for cuttings, and may be inserted pretty thickly in the cutting pots. When fairly established, they must be just protected from frost, and kept in dry airy quarters. If kept warm, they grow too much, and are in spring poor lanky specimens that can hardly be handled; but cool treatment keeps them short and sturdy.

G. rigens is the best known. It has long deep-green leaves, silvery beneath, and bears flowers 2 in. across, which are of bright orange-yellow, with a dark centre. G. splendens is a fine variety, and there is also one with leaves effectively variegated.

Geissorrhiza. - Handsome Ixia-like bulbs ; natives of the Cape. G. violacea has flowers of a rich scarlet, on slender stems about I ft. high. G. Hookeri has large white flowers, with purple centre. They require the same treatment as Ixias.

Genista (Rock Broom). - A very large family of the Pea-flower order, containing several beautiful garden shrubs, more suitable, however, for the rock-garden than the shrubbery; the best being $G$. sagittalis, G. pilosa, G. prostrata, and G. tinctoria - all of the easiest culture. Where not to be had in nurseries, they are easily raised from seed sown in the open air. They are from 6 to $18 \mathrm{in}$. high, and in groups or masses are very effective. G. sagittalis is a good marginal plant in borders. They are suitable for spots in the rock-garden, where they can be fully exposed, and can ramble over boulders, and in such positions their beauty is fully seen. The taller kinds are few, but valuable. $G$. elata is one of the most noteworthy, but is not much known. It is a tall spreading bush, often 8 or Io $\mathrm{ft}$. high. It is suitable for light soils, and in late summer is covered with small peashaped flowers which make the bushes glow with yellow. It thrives as an under- 
growth to large trees, unless it is too densely shaded, and is altogether a firstrate flowering shrub. The Etna Broom (G. ætnensis) is a tall slender shrub, 3 to I $2 \mathrm{ft}$. high, and a most elegant plant, in August a mass of yellow bloom. Other

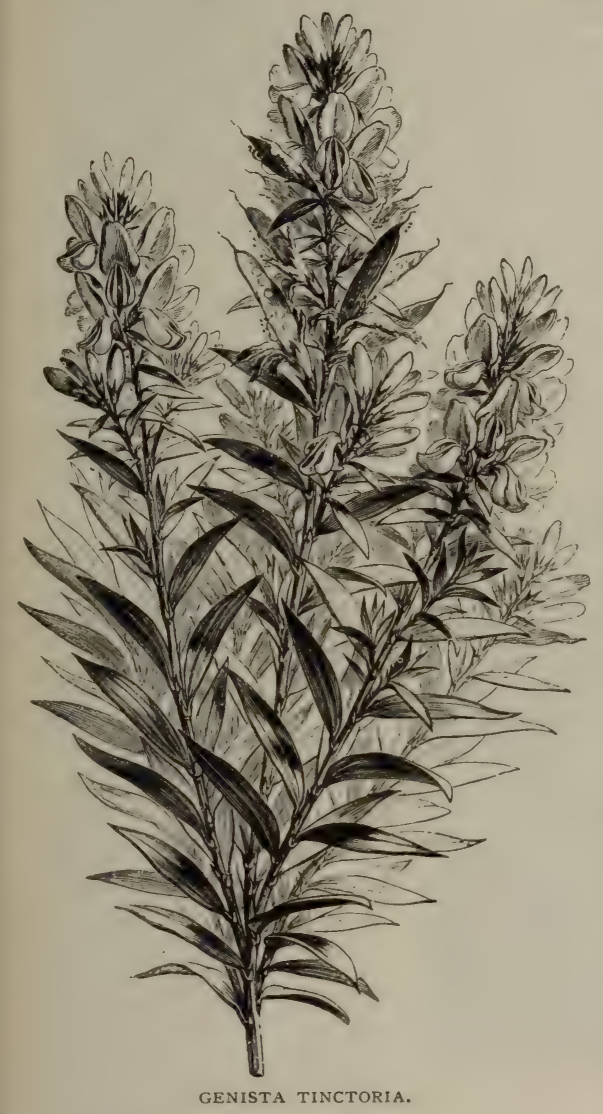

Genistas are in collections, among them G. ephedroides and monosperma, but those described are the best for general culture. Natives of Europe, they are quite hardy, and suitable for almost any soil.

Gentiana (Gentian).-Of these beautiful hardy plants there are two sectionsthe first, strong easily-grown kinds, suitable for borders ; and the second, dwarfer kinds, which should be grown in the rock-garden, or in borders or beds of choice dwarf plants. The Willow Gentian, some of the American perennials, and those with herbaceous shoots generally grow freely in borders, in good moist soil. So does the well-known Gentianella (G. acaulis). The other type of Gentian is represented most familiarly by the Vernal Gentian (G. verna).

G. acaulis (Gentianella).-A wellknown old inhabitant of our gardens, among the most beautiful of the Gentians, and easily cultivated, except on very dry soils. In some places edgings are made of it, and where it does well it should be used in every garden, as, when in flower, edgings of it are of great beauty, and when not in flower, the masses of little leaves, gathered into compact rosettes, form a dwarf and firm edging. It is at home on the rock-garden, where there are good masses of moist loam in which it can root, and it is particularly well suited for parts where the stone is suggested here and there rather than exposed. It is also good to form carpets in the rock-garden or on raised borders. It is abundant in many parts of the Alps and Pyrenees. With us the flowers open in spring and in early summer, but on its native hills they open according to position, like the Vernal Gentian. G. alpina is a marked variety, with small broad leaves, and there are several other varieties. Mr. $\mathrm{H}$. Gusmus, of Laibach, Austria, has also numerous varieties. Their beautiful colours vary from the deepest blue to pure white, and in one white flower the tips of the corolla are a rich blue. In all the forms except the white the throat of the corolla is copiously spotted with blue on a greenish ground, and all have greenish marks on the outside. We hope they soon will adorn our rock-gardens and flowerborders.

G. asclepiadea (Willow Gentian) prefers shelter, and slight shade is beneficial to it. Being herbaceous, it gives no trouble, but dies down out of harm's way in winter. Properly grown, it will spring up to $2 \mathrm{ft}$. and freely produce good-sized flowers of a deep purple-blue along nearly the whole stem. In Mr. Rawson's garden at Bromley, in Kent, it has grown 3 to $4 \mathrm{ft}$. in diameter. Its white variety is, with the exception of the colour of the flowers, almost the same as the purple one, and requires similar treatment. This Gentian will grow in woods. It may therefore be naturalised, and its effect among the Grass in a wood is charming. Division. Flowering in autumn. Europe.

G. bavarica (Bavarian Gentian).-In size and flower this species resembles the Vernal Gentian, but it has smaller Box-like leaves of yellowish-green, and its tiny stems are thickly clothed with dense little tufts of foliage, from which arise flowers of the most lovely and 
iridescent blue. While G. verna is found on dry ground, or on ground not overflowed by water, G. bavarica is in perfection in spongy, boggy spots, by some little rill. We must imitate these conditions if we desire to succeed, and a moist peat bed, occasionally well watered and with no coarse plants to give injurious shade, will enable us to grow this lovely plant.

G. septemfida (Cristed Genticnn).-.A lovely plant, bearing on stems 6 to $\mathrm{I} 2$ in. high clusters of cylindrical flowers widening towards the mouth, and a beautiful blue-white inside, and greenishbrown outside, having between each of the larger segments one smaller and finely cut. Division. One of the most desirable species for the rock-garden, and thriving best in moist sandy peat. Caucasus.

G. verna (Vernal Gentian).-The type

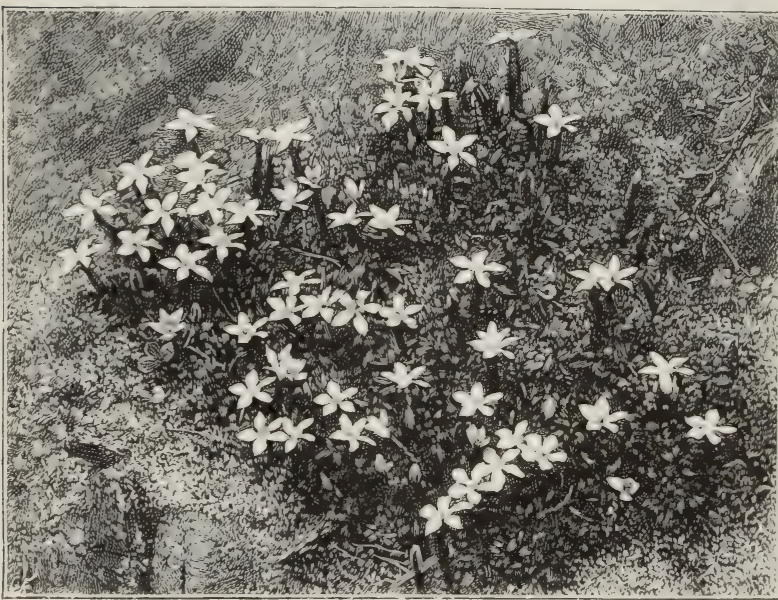

GENTIANA VERNA.

of much beautiful alpine vegetation. Few things are essential to its successful cultivation, and these are far from difficult to secure. It requires good, deep sandy loam on a level spot, abundance of water during the warm and dry months, and perfect exposure to the sun. The absence of these conditions is a frequent cause of failure; but it thrives wild in cool pastures and uplands, where it is rarely subjected to such drought as it is in a parched border. Grit or broken limestone may be advantageously mingled with the soil, but if there be plenty of sand this is not essential; a few pieces half buried in the ground will tend to prevent evaporation and guard the plant till it has taken root. It is so dwarf, that if weeds be allowed to grow round it they soon injure it, and tall plants overshadow or overrun it. In moist districts it may be grown in a good, deep sandy loam, on the front edge of a border carefully surrounded by half-plunged stones. Well-rooted specimens should be secured to begin with, as failure often occurs from imperfectly-rooted, half-dead plants. The necessary conditions being observed, the Vernal Gentian will soon spread into healthy little tufts, and will take care of itself from year to year. It is abundant in mountain pastures on the Alps, in Asia, and also in Britain.

There are other Gentians in cultivation, such as G. caucasica, adscendens, gelida, cruciata, affinis, algida, arvernensis, crinita, and Andrewsi ; but the species described represent the beauty of the family as now known in cultivation. New and beautiful kinds may be added. Most Gentians may be raised from seed, but it is a slow process.

\section{Gentianella (Gentiana} acaulis).

Geranium (Crane'sbill). - The hardy Geraniums are usually stout perennials and natives of the fields and woods of Europe and Britain, though some are dainty alpine flowers. The handsomest of them is probably G. armenum. It is sometimes $3 \mathrm{ft}$. in height, flowering in midsummer abundantly, and sometimes till late in autumn to a less degree. Its flowers are large and handsome. It requires only ordinary garden soil, and is well suited for the mixed border, or for grouping with the finer perennials in beds or on the margins of shrubberies. Some other kinds are very ornamental, and the best of these are: the dwarf magenta G. sanguineum; its beautiful Lancashire variety, with rose-coloured blossoms finely marked with dark lines: G. pratense, a tall kind, with large purple flowers; and its pure white variety. There is also an intermediate form with white and purple flowers. The Caucasian species, G. gymnocaulon and ibericum are beautiful, with their rich purple blossoms, 2 in. across, delicately pencilled with black. G. platypetalum, striatum, ibericum, and Lamberti are suited for shrubbery borders, and most 
of them are free and vigorous enough for naturalisation. G. Endressi, a tall kind with rose-coloured blossoms, is also very attractive. All the above-mentioned Geraniums are perfectly hardy, easily cultivated, and as they grow in any ordinary soil, they should be included in every collection of hardy flowers. The pretty rock-garden kinds, G. cinereum and $\mathrm{G}$. argenteum, are both dwarf and charming alpine plants, and, unlike stout perennials, they must be associated with very dwarf rock and border plants. All the Geraniums are increased by seed, and with the exception perhaps of the G. cinereum, and G. argenteum, all are freely multiplied by division.

\section{German Ivy (Mikania scandens).}

Geum (Avens).-Perennial and sometimes alpine plants. By far the finest is $\mathrm{G}$. coccineum (inhabiting the Bithynian Mount Olympus), which has long been a favourite. Probably the Chilian Avens (G. chilense) is but a mere form of it, as it differs only in the darker colour of the blossoms, which are sometimes coppery. The double variety of $\mathrm{G}$. coccineum is more valuable than the type. Its blossoms last much longer, for it commences to flower in May, and produces blossoms till October. There are several forms of the double kind. It is one of the most easily managed of hardy plants, growing vigorously in ordinary garden soil, and readily multiplied by seeds, which are freely borne, or by division in spring. The most desirable of the other kinds in cultivation are $G$. montanum and $G$. reptans. G. montanum is dwarf and tufted, with deeply-lobed leaves. The large yellow flowers are borne singly on erect stalks about I ft. high. Central Europe. A good rock or choice border flower. G. reptans is a trailing kind with deeply-cut foliage, and an erect flower-stalk about 6 in. high, with a blossom larger than the preceding, but of the same colour.

Gilia.-Hardy annuals, I to $2 \mathrm{ft}$. high, and bearing for a long time a succession of blossoms either blue, white, lavender, or rose-coloured. Seed may be sown in autumn for spring-blooming, and in April for summer and autumn blooming. Gilia should be grown in masses, and the soil should be light and enriched with decomposed manure. They are useful for small bouquets or vases, and last for a long time in water. The best are $G$. achilleæfolia major (blue), G. a. alba (white), G. capitata (lavender), G. tricolor (white and purple), G. rosea splendens (rose), G. nivalis (white), G. liniflora, and $\mathrm{G}$. laciniata. A mixed packet of seed will give a fine variety of colours. They may occasionally be made graceful use of as carpet plants, or used effectively among annuals.

Gillenia trifoliata.-A Spiræa-like plant with numerous erect slender stems, some $2 \mathrm{ft}$. high, and branching in the upper part into a loose panicle of white flowers. G. stipulacea is another species. Though distinct and graceful, neither of them is of special value for the garden. They grow in peat or free loamy soil, are hardy, and may perhaps be given a place in the shrubbery, or in the wild garden. North America. Division.

Gilliflower.-A term applied to the Carnation in Shakespeare's time, and belonging originally to that flower, or to one of its groups of races; but given to stocks in later days. In the West of England it is popularly applied to the Wallflower.

Gladiolus. - Beautiful bulbs, for the most part natives of the Cape. Every species introduced is of ornamental value, is easily grown, and is suitable for many garden uses. The chief charm of the Gladiolus is derived from the beautiful hybrid varieties now in cultivation. G. gandavensis and brenchleyensis are the principal kinds from which these hybrids come, and are by far the most important class, though the earlier-flowering kinds (descendants of G. ramosus, Colvillei, trimaculatus, and others) are becoming valuable for early summer-flowering. The gandavensis section suffers from cold autumn rains, and the bulbs must be lifted in autumn.

In growing Gladioli it is necessary to prepare soil where they will be most effective. They are happy in clumps between Dahlias, Phloxes, Roses, and subjects of a somewhat similar character, and are very effective in clumps alternating with Tritomas, and also when associated with masses of Cannas; while they are suitable for intermixing with American plants, whose dark foliage shows off rich flowers to good advantage. The position should be marked out in the autumn or winter, and a few spadefuls of manure should be dug in. As a rule, the space of each clump should be 18 in. in diameter, and the soil should be turned up to a depth of 18 to 24 in. March and April are the best months for planting, as Gladioli planted then are at their best during August and the early part of September. A succession of planting is desirable to secure a late bloom. Those who desire their gardens to be beautiful late in the autumn should 
not fail to employ the Gladiolus largely, as it is the handsomest of late-blooming garden plants, and its spikes are seen to great advantage about the time of heavy autumn rains and gales. When spikes of extra fine bloom are required, it is necessary to give special treatment, and an open situation is of the utmost importance. A deep loamy soil, not too heavy, is the most suitable for spikes for exhibition, but very satisfactory results even may be obtained by deep digging and liberal manuring in soils of an uncongenial character. Early in autumn the soil should be liberally dressed with manure from an old hotbed. After it is spread regularly over the surface, trench the soil up to a depth of $2 \mathrm{ft}$., and leave the surfaceas rough as possible, so as to expose a large body of it to winter frost and rain; this is of special importance in the case of heavy soils, which should be thoroughly pulverised by the weather. If this is done, the soil will be fit for working in spring, and a pricking over with the fork will reduce it to a fine tilth, and will admit of the bulbs being planted, even in wet seasons, without unnecessary delay. Planting should commence in March, and be continued until June, at intervals of a fortnight. By this means will be obtained a succession of bloom, from the earliest moment at which the show varieties may be had in flower until the end of the season. In beds, the rows should be $\mathrm{I} 8 \mathrm{in}$. apart, and $4 \mathrm{ft}$. in width. They will then admit of a row down the centre, and one on each side, these outside rows being $6 \mathrm{in}$. from the edge of the bed. As soon as the plants have made sufficient progress to require support, stout stakes should be put to them. The top of the stake must not be higher than the first bloom, and the stem should have one tie only, a strong one of bast. After staking, the bed should be covered with partly-decayed manure, to a uniform depth of 2 to 3 in. This dressing materially assists during hot weather in keeping the soil cool and moist about the roots. As soon as the plants show bloom, liquid manure promotes full development of the flowers. For exhibition, the spikes should be cut when about two-thirds of the blooms are expanded, as the lower flowers are generally finer than those towards the top.

To ensure a given number of spikes at a particular date, a number of different sorts should be planted: for example, instead of six to twelve bulbs of a sort, it is preferable to plant one to three, and to increase the number of sorts; and, in purchasing a hundred bulbs, to select fifty to seventy varieties. For decoration it is also better to have a large number of sorts, because of the greater variety of colour they afford. The improvements of the last few years have been so rapid that many sorts which, a few years ago, occupied a foremost position are now surpassed, and for exhibition purposes are comparatively worthless. Most large nurseries and seed houses supply the finest exhibition bulbs, as well as bulbs for ordinary planting.

EARLY-FLOWERING KINDS.-During the past few years these beautiful flowers have rapidly become popular on account of their great value for cutting. They have been obtained by hybridising several South African species, particularly G. ramosus (the branching kinds which are a distinct group), G. trimaculatus, G. blandus, G. venustus, and G. Colvillei forming what is known as the nanus section. Of G. ramosus a great number of varieties are dwarfer in habit, more graceful in appearance, earlier in flower, than those of $\mathrm{G}$. gandavensis, and almost as variable in colour; they are, moreover, much hardier, and beds of them may be left unprotected during winter, so as to afford early flowers for cutting, for, unless the weather is very severe, these beds never require any covering. This remark applies only to bulbs established in the ground, for fresh bulbs are as tender as other Gladioli, and must be protected from frost. Amateurs often make a mistake in this matter. Many plants are hardy only after they are well established. The nanus section has a great many varieties of almost every shade of colour, I to $2 \mathrm{ft}$. high, and invariably having the three characteristic blotches of G. trimaculatus on the lower segments of the flower. G. Colvillei is one of the prettiest and hardiest of all, and is most valuable for cutting, particularly the white variety, which has many beautiful white flowers in early summer. The time of flowering depends upon the time of planting, but the dwarf sections are the earliest. If the varieties of $G$. ramosus are planted at the same time as the dwarfs, the dwarfs are in flower a fortnight before the others.

These early-flowering kinds are of simple culture, and succeed best in welldrained raised beds of good loamy soil, in a sunny position. Some varieties, such as Colvillei, are safe if undisturbed, but some persons prefer to take the bulbs up and thoroughly dry them, and then to plant them again about November; in which case they will flower early in 
June. If the bulbs remain in the ground through the winter, care must be taken to protect them in severe cold. Propagation may be effected rapidly by seeds and offsets. By seeds, flowering bulbs are produced the second season, and can be left in the ground during the winter, provided the soil is light and dry and the bulbs are protected from frost. These Gladioli are extremely useful for pot culture, and, by gentle forcing, can be had in flower at mid-winter, and, for securing bloom between the flowering of the forced plants and of the plants in the open beds, they may be grown in cold frames. For this purpose a bed of loam, leaf-mould, and sand in nearly equal proportions should be made up in October. It should be about I ft. deep and well drained, and in it the bulbs may be planted thickly 4 in. in depth. The lights should then be replaced, and air left on always, except during severe frosts. No water should be given until the leaves appear (which will be about February, or earlier if the season be mild), and then only enough to keep the soil moist. The lights should be removed during mild weather, and altogether in April. During the latter part of May and in June plenty of bloom may be cut for decoration. Besides those named, the following are some of the best kinds: The Bride, Grootvoorst, Rubens, Maori Chief, The Fairy, Elvira, Rembrandt, Philip Miller, Beatrice, Baron von Humboldt, Sir Walter Raleigh, and Rose Distinctive.

Another interesting race of hybrids has lately been obtained between G. gandavensis and G. purpureo-auratus, a Cape species, with yellow and purple flowers. These hybrids have large flowers of a creamy-white and a deep purplish-crimson. The named kinds are G. hybridus Frœbeli, G. h. Lemoinei, and Marie Lemoine. Although by no means so showy as many others, they are most graceful and distinct in port, and in the shape and colour of their flowers. In deep sandy soil they attain a height of nearly $5 \mathrm{ft}$., and the gradual development of the flowers renders them effective for at least five weeks after the first and lowermost blossom. As graceful plants they well deserve culture, being hardier than many home-raised hybrids ; but a warm deep soil and a sheltered position near the foot of a south or west wall are the most congenial to their strong growth.

A few of the true species almost equal

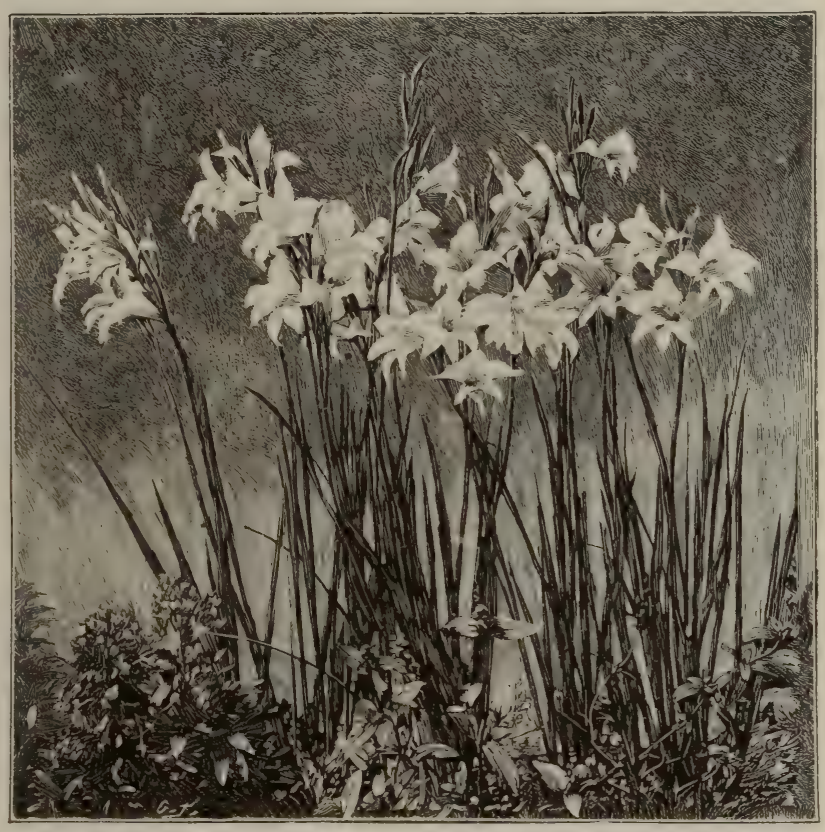

GLADIOLUS THE BRIDE.

the hybrids in beauty. One of the finest is G. Saundersi, about $2 \mathrm{ft}$. high, with large flowers of a brilliant scarlet and a conspicuous pure white centre. It is not often grown, though hardy and of very easy culture, and only requiring a sunny position in a light rich soil. G. purpureo-auratus is another good species, though not so showy. Its flowers are of a creamy-white, heavily blotched with vinous - purple on the lower divisions. Also a native of the Cape.

The European Gladioli are pretty plants for the mixed border. There is a strong similarity among them, all of them being from I to $I \frac{1}{2} \mathrm{ft}$. high, and bearing rather small rosy-purple flowers. The best-known are G. byzantinus, communis, segetus, illyricus, neglectus, serotinus. They like warm dry soil and a 
sunny situation. They are of particular interest from their free and hardy habit, which makes them as easy to grow as native plants. They are admirable for the wild garden, as they thrive in copses, open warm woods, in snug spots in

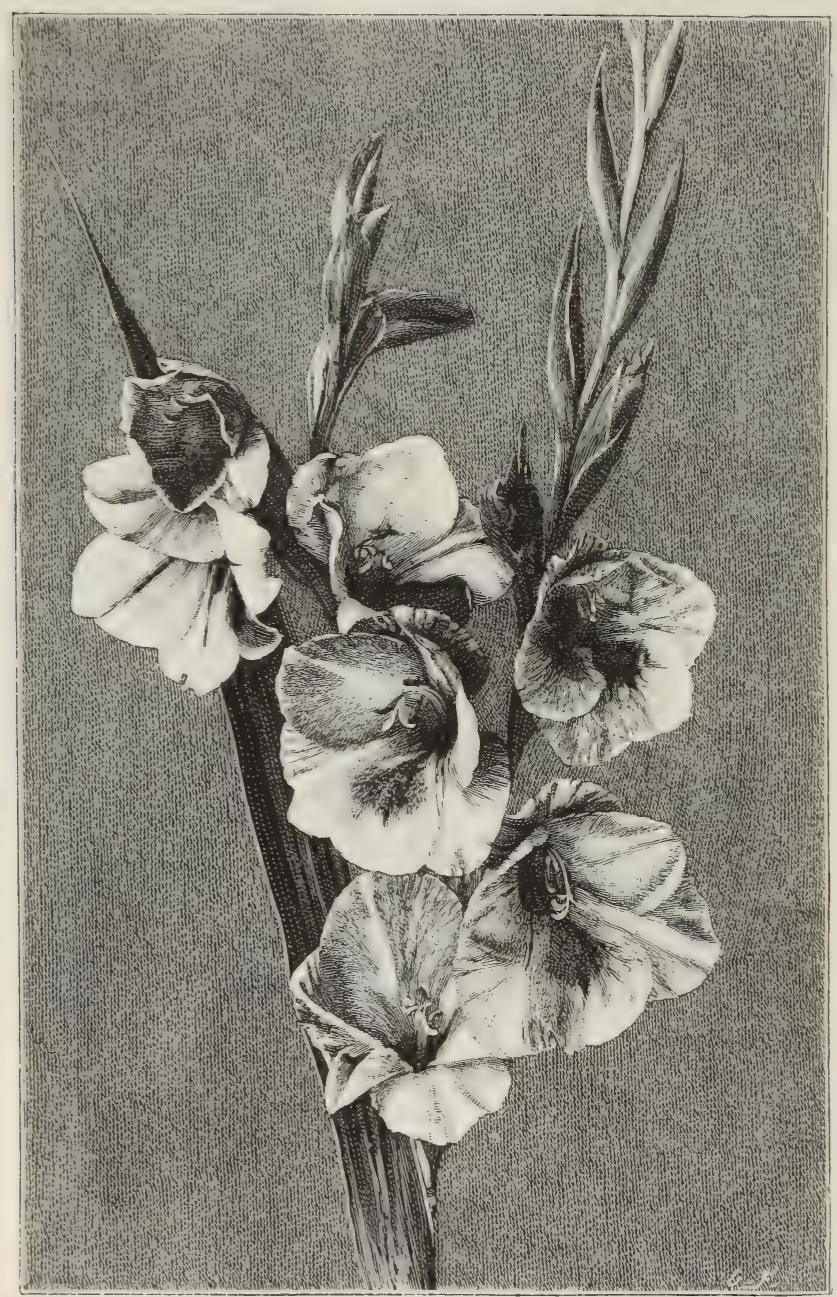

HYBRID GLADIOLLS (LEMOINE' $)$ ).

good deal of attention was paid to it in I876, when Mr. G. W. Smith detected in abundance the curious fungus named by him Urocystis Gladioli. The Urocystis and Rhizoctonia are probably two conditions of the same thing, the Rhizoctonia being possibly the spawn and the Urocystis the fruit. The latter Urocystis is capable of remaining in a resting state for a year or more, and is frequently found in the decayed redbrown portions of the diseased corm. No attempts have been made in the direction of a cure, as far as we know. The disease is confined to certain localities and to certain gardens, and is unknown in some districts.

Gladwin (Iris fotidissima).

Glaucium (Horned Poppy). - Plants of the Poppy family, mostly biennials. G. luteum may be useful for winter decorative bedding, as it is quite hardy and has handsome silver foliage, almost as white as the Centaurea. The leaves are much more deeply cut, and, planted close, are effective either in masses or lines. To ensure strong plants for winter, seed should be sown about May, as the plant is a biennial. When in bloom it makes a striking border plant, the flowers beinglarge and orange-red. G.

broken hedgerow banks, and on fringes of shrubbery in the garden.

DISEASE.-This is frequently, if not always, accompanied by some condition of the fungus known as Copper-web, the Rhizoctonia crocorum of De Candolle, which is known in France under the name of Tacon. The fungus attacks also the Narcissus, the Crocus, Asparagus, Potatoes, and other bulbs, roots, etc. A
Fischeri is a handsome plant; its snowwhite woolly foliage is very telling, and its blossom is an unusual flame colour. G. corniculatum is similar, but not so handsome. Both require the same treatment as G. luteum.

Glechoma hederacea (Ground Ivy).A small British creeper, almost too common to deserve notice here; but it has one or two finely-variegated varieties 
worthy of a place on the edges of raised borders or in beds of plants with variegated leaves.

\section{Globe Flower (Trollius).}

Globe Thistle (Echinops).

Globularia. - Interesting and dwarf alpine plants, good on the rock-garden in light and peaty soils. G. Alypum is among the best; it inhabits dry rocks. Other kinds are G. cordifolia, G. nana, G. nudicaulis, and $G$. trichosantha.

Glossocomia ovata.-A rare little perennial of the Bell-flower family. It has showy blue flowers, but is rare and difficult to cultivate. North India.

Glycirrhiza (Liquorice).-Coarse plants of the Pea family, with pinnate leaves and bluish flowers. G. glabra yields the liquorice of commerce. It is an easilygrown perennial.

Gnaphalium. - Composites, usually with downy foliage, but of little value, except that $G$. lanatum, a silvery-foliaged plant, I ft. high, is suitable for edgings. $\mathrm{G}$. lanatum is very easily propagated by division in spring, and is whitest and most compact when on dry poor soils. It bears pegging down, and should never be allowed to bloom. It is somewhat tender, and requires to be propagated annually. (See Antennaria.)

Goat's Rue (Galega).

Godetia.-Among the most beautiful of hardy annuals for spring and summer flowering. They require sowing in September to secure strong plants before severe weather. If well thinned out in rich soil, they will give a grand display of blossom during May and June; and if seed be sown again in April, a succession of bloom may be easily kept up. Among the best are G. Whitneyi, G. Lady Albemarle, G. Lindleyana, G. The Bride, G. rubicunda, G. Princess of Wales, G. Tom Thumb, and good new varieties are being added to these. These admirable annuals are Io to $20 \mathrm{in}$. high, and so free and vigorous, so profuse in striking and delicate colours, as to be of effective use in the early summer garden. Evening Primrose family. North America.

Golden Club (Orontium).

Golden Drop (Onosma tauricum).

Golden Rod (Solidago).

\section{Golden Saxifrage (Chrysosplenium).}

Goldfussia isophylla.-A correspondent writes: "We always grow a few, not so much for the sake of the pale blue tubular flowers, which are produced in the dull winter months, as because when the plant is put out in summer its leaves become a shining black, and, being narrow and numerous, give it a prettier appearance than Perilla and the usual funereal plants with dark leaves that one sees."

Goldilocks (Linosyris vulgaris).

Gold Thread (Coptis trifoliata).

Goodyera pubescens (Rattlesnake Plantain). - A beautiful little Orchid, with leaves close to the ground and delicately veined with silver; it is, in fact, hardy and variegated, and particularly distinct and pleasing, though its flowers are not showy. It has long been grown in botanic and choice collections. It thrives well in any shady position, such as may be found in a good rock-garden, but should be planted in moist peaty soil, with here and there a soft sandstone for its roots to cling to and run among. Eastern United States. G. repens and Menziesi are less desirable and much rarer.

Gordonia (Loblolly Bay).-The two Gordonias in cultivation, G. pubescens and G. lasianthus, are very beautiful shrubs, very old garden plants, introduced during the last century, but far too rare in gardens, owing probably to difficulty of propagation. The genus is allied to the Camellia. G. pubescens is of Camellia-like growth, $6 \mathrm{ft}$. high, and bears in late summer beautiful flowers, 3 in. across, pure white, with a centre tuft of yellow stamens. G. lasianthus is taller and more robust and has larger and more fragrant flowers. Both are natives of the swamps near the coast of the southern States of North America, and therefore are not among the hardiest shrubs, but they may do with us in very favoured places. I have only seen them in flower near Philadelphia.

\section{Gourd (Cucurbita).}

Grammanthes gentianoides.-A pretty half-hardy annual, and a capital plant for the dry parts of a rock-garden, or any other exposed place. It is about 2 in. high, and forms a dense muchbranched tuft, with fleshy leaves about $\frac{1}{2}$ inch long. It produces many flowers, about two-thirds of an inch across : orange when first expanded, with a distinct $\mathbf{V}$-shaped mark at the base of each petal, but finally assuming a deep red. G. gentianoides is sometimes used with good effect in the flower garden, and succeeds in dry warm soil. Seeds should be sown in heat in February and March, and the seedlings planted out in May. Stonecrop family. Cape of Good Hope.

\section{Grape Hyacinth (Muscari).}

Grass of Parnassus (Parnassia palustris).

Gratiola.-Dwarf perennials of the 
Figwort family. Of little use outside of botanic gardens.

Great Reed (Arundo Donax).

Grevillea.-Australian shrubs, generally grown in the greenhouse, but a few are quite hardy enough for wall culture; and $G$. sulphurea, the hardiest in cultivation, flourishes freely against walls about London. Its pale yellow flowers, of curious shape, as in all Grevilleas, are produced at no particular season, but appear continuously throughout the summer. G. rosmarinifolia is another hardy kind with Rosemary-like leaves and clusters of red flowers. The Grevilleas, like other half-hardy shrubs, prefer a warm wall in a sheltered situation.

Grindelia. - Yellow - flowered, North American Composites of little garden spring these dry leaves should be removed, and the tender growth slightly protected by a piece of canvas-shading or by an ordinary mat. In mild winters this precaution is scarcely necessary, especially in the south and other favoured localities. The Gunnera should be planted in an isolated spot, and not as a rule in the "flower garden proper," as it must not be disturbed if well planted, and would associate badly with the ordinary occupants of the parterre. It cannot have too much sun or warmth, but makes little progress if its huge leaves are torn by storms. Where there is any diversity of surface it will be easy to select a spot well open to the sun and yet sheltered by shrubs and clumps. These plants should be planted well at the outset. A large

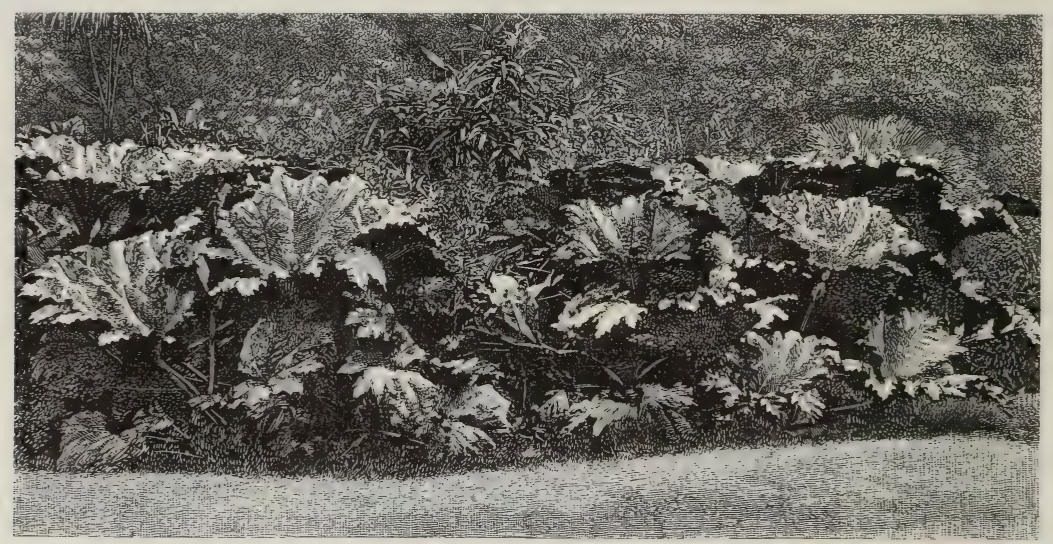

GUNNERA SCABRA.

value. G. grandiflora grows 3 or $4 \mathrm{ft}$. high, and G. squarrosa is dwarfer; both are hardy, and succeed in any soil. They flower from July till late in autumn.

Ground Laurel (Epigaa repens).

Ground Nut (Apios tuberosa).

Ground Pine (Lycopodium dendroideum).

Guernsey Lily (Nerine sarniensis).

Gunnera.-South American plants remarkable for large and handsome foliage, somewhat resembling that of gigantic Rhubarb. There are two kinds in cultivation-G. scabra and G. manicata. Both are handsome, especially the former, with leaves sometimes $6 \mathrm{ft}$. across. Both deserve a place in any garden, for no plants in cultivation are so stately as wellgrown specimens. They are quite hardy if slightly protected during the severest cold, for instance by a layer of dry leaves placed among the stems, and having their own leaves bent down upon them. In hole, about 6 by $4 \mathrm{ft}$. deep, should be dug out, a good layer of drainage material put at the bottom, and the hole filled with a rich compost of loam and manure. In summer the plants ought to have plenty of water, and a ridge of turf should be placed round them, to compel the water to sink down about their roots. They should also have a mulching of wellrotted manure early in every spring. They thrive on the margins of ponds or lakes where their roots can penetrate the moist soil, and if judiciously placed in such a position, they have a fine effect. Perhaps the finest plant of G. scabra in the country is the noble specimen at the head of the herbaceous ground at Kewfrom Io to $\mathrm{I} 5 \mathrm{ft}$. through and $8 \mathrm{ft}$. high, and often developing leaves 3 to $4 \mathrm{ft}$. across. It has attained these dimensions in a few years. Though the two kinds G. scabra and G. manicata greatly resemble each other, they have well-marked character- 
istics. The leaves of G. manicata are more kidney-shaped and attain a much larger size, often measuring 4 to $6 \mathrm{ft}$. across. The spikes of fruit are also much longer, and the secondary spikes are long and flexuose, whereas in G. scabra they are short and stiff. Propagated by seed or division of established plants.

Gymnadenia conopsea. - A sweetscented native Orchid, 6 in. to nearly 2 $\mathrm{ft}$. high. Its flowers are pale purple, in a dense, cylindrical, tapering spike, I to 4 in. long, and appear in summer. It is suitable for grassy places, and for drier parts of the bog-bed, or for borders; worth growing for its fragrance only. Increased by separation of the root knobs.

Gymnothrix latifolia.-A fine perennial Grass from Monte Video, not hardy enough to show its true character in the open air. Mr. Ellacombe, however, informs us that it is valuable on account of its rich green foliage and excellent habit. It is particularly suitable for the centre of a bed. Mr. W. Gumbleton, writing from Cork, says it does not do well with him, and does not flower, and attains a height of less than $3 \mathrm{ft}$.

Gynerium argenteum (Pampas Grass). -This noble Grass, 4 to $14 \mathrm{ft}$. high, according to strength of plant, soil, or district, is well known. There is reason to believe that some varieties are better in habit than others, and flower earlier. In such cases it would be better to patiently divide them than to trust to seedlings. There are a number of varieties, some of a delicate rosy colour, one variegated, and several dwarf and neat. Some of these seem somewhat more tender than the type. It is not enough to place the plant in out-of-theway spots, but the landscape, so to say, of every garden and pleasure-ground should be influenced by it. It should be planted far more extensively than at present, and given very deep and good soil. The soils of many gardens are insufficient to give it the highest vigour, and no plant better repays a thorough preparation, especially since one preparation suffices for many years. If convenient, give it a somewhat sheltered position in the flower garden, so as to prevent as much as possible that ceaseless searing away of the foliage which occurs wherever it is much exposed to the breeze ; and because, when backed with shrubs, its bright silvery plumes are less liable to be injured. We rarely see such fine specimens as in quiet nooks where it is sheltered by the surrounding vegetation.
It should be planted about the beginning of April, mulched with rotten manure, and watered copiously in hot dry weather. G. jubatum is very well spoken of, but as yet has not been tried much except in favoured spots. The leaves resemble those of $\mathrm{G}$. argenteum, but are of deeper green, and droop elegantly at the extremities. From the centre of the tuft, and exceeding it by 2 or $3 \mathrm{ft}$, arise numerous stems, each bearing an immense loose panicle of long filamentous silvery flowers, of a rosy tint with silvery sheen. It is a native of Ecuador, and is earlier in bloom than G. argenteum. The sexes are borne on separate plants in all the species, and the plumes of male flowers are neither so handsome nor so durable as the plumes of female flowers.

Gypsophila.-Plants of the Stitchwort family, not without value for the garden. The larger kinds are usually very elegant, and bear myriads of tiny white blossoms on slender spreading panicles. Of this type the best is $G$. paniculata, which forms a dense compact bush, $3 \mathrm{ft}$. or more high, and as much across. The numerous flowers are small and white, and are arranged on thread-like stalks in much-branched stems, with the light, airy, graceful effect of certain ornamental Grasses. Very useful for cutting. G. paniculata thrives in any soil, and is suitable for borders and for naturalisation in woods and copses, or by streams. Division or seed. G. fastigiata, perfoliata, altissima Steveni, are very similar. G. prostrata is a pretty species for the rockgarden or the mixed border. It grows in spreading masses, and from midsummer to September has loose graceful panicles of small white or pink flowers, on slender stems. G. cerastioides is about 2 in. high, and has a spreading habit. The leaves are about $I_{2} \frac{1}{2}$ in. long, and from their axils are produced small clusters of blossoms, $\frac{1}{2}$ in. across, white with violet streaks. It is from Northern India, and quite unlike any of the group now in our gardens, being dwarfer and having larger flowers. It is a rapid grower, and in good soil and an open position on the rockgarden soon spreads into a broad tuft. Seeds or cuttings in spring.

Habenaria (Rein Orchis).-Terrestrial Orchids from N. America, I to $2 \mathrm{ft}$. high, some of which are inconspicuous, while others, including those named below, are pretty and interesting. For out-door culture, a partially-shaded spot should be prepared with about equal parts of leaf-mould or peat and sand, and well 
mulched with leaves, grass, or other material, to keep it moist, and to protect the roots from the heat of the sun. $H$. blephariglottis bears in July spikes of white flowers beautifully fringed. $\mathrm{H}$. ciliaris is the handsomest species. The flowers are bright orange-yellow with a conspicuous fringe, and appear from July to September. H. fimbriata has a long spike of lilac-purple flowers beautifully fringed. $H$. psycodes produces spikes 4 to 10 in. long of very handsome and fragrant purple flowers. They are charming plants for the bog-garden, or for a quiet nook with moist peaty soil.

Haberlea rhodopensis.-A pretty little rock-plant resembling a Gloxinia in miniature. It forms dense tufts of small rosettes of leaves, which somewhat resemble those of the Pyrenean Ramondia (R. pyrenaica), every rosette bearing in spring one to five slender flower-stalks, each with two to four blossoms nearly I in. long, of a bluish-lilac colour with a rellowish throat. Messrs Frœbel, of Zurich, who grow it well, write to us: "We have treated this plant in the same manner as the Pyrenean Ramondia, i.e. we have planted it on the north side of the rock-garden; so that the sun never directly reaches it. We grow it in fibrous peat, and fix the plants, if possible, in the fissures of the rock-garden, so that its rosettes hang in an oblique position, just as they do in their native country. It succeeds well in this way; but if no rock-garden be at hand, it may be grown equally well on the north side of a Rhododendron bed. We have it thus situated quite close to a stone edging - a way in which we also grow the Ramondia,--and the Haberlea flowers profusely every year in May and June. The plant is very hardy, having withstood our often very hard winters, without any protection." It is a native of the Balkan Mountains, where it is found among moss and leaves on damp, shady, steep declivities at high elevations.

Hablitzia tamnoides. - A hardy, climbing, herbaceous plant, producing clusters of greenish-yellow flowers in the greatest profusion. When tied to a strong stake or trellis it reaches a height of 8 or Io ft., and has a graceful appearance. It continues in flower throughout the summer and the greater part of the autumn, but requires a good soil, plenty of moisture in summer, and freedom from stagnant water in winter. It forms a good subject for open situations in the wild garden, for the rock-garden or rootwork, or for clothing the stems of naked trunks of trees.
Habranthus pratensis.-A brilliant bulb of the Amaryllis family, hardy, at least in the southern and eastern parts of the country. It has stout and erect flower-stems, about I ft. high, and the brightest scarlet flowers, feathered here and there at the base with yellow. The variety fulgens is the finest form. It blooms freely in the open border of the Rev. Mr. Nelson's garden at Aldborough, in Norfolk, flowering at the end of May or beginning of June. It grows very freely in strong loam improved by the addition of a little leaf-mould and sand. Its propagation is too easy, for in many soils it is said to split up into offsets instead of growing to a flowering size. At Aldborough it makes numerous offsets. A choice plant for the select bulb-garden or rock-garden. Chili. H. Andersoni is much inferior.

Hairbell.-The name applied to the slender Campanulas, principally our native C. rotundifolia. It is also spelled "Harebell," and though there seems no authority for either spelling, "Hairbell" appears to us the more appropriate.

Halesia (Snozudrop Tree).-Beautiful North American trees, hardy in this country. The commonest is H. tetraptera, one of the prettiest of flowering trees. It grows in England from 20 to $30 \mathrm{ft}$. high, has a rounded head, with sharplytoothed leaves. In spring, generally in the early part of May, it bears a profusion of small pure white blossoms, which in form resemble the Snowdrop, hence its popular name. It is of moderately rapid growth, and flourishes in any good garden soil. As it grows naturally by river banks, it enjoys a moist, but not waterlogged, soil. In some parts it ripens its seed in abundance. A similar species, distinguished in having but two wings to the seed-vessel (tetraptera having four), is A. diptera, of smaller growth than the preceding, and not such a suitable tree for this climate; neither is $H$. parviflora, which, like the others, has small bell-like flowers. As a lawn tree, or planted near the margin of a lake or stream, H. tetraptera is very beautiful.

Halimondendron argenteum. - A small dwarf-growing shrub belonging to the Pea family. It has elegant foliage, silky and whitish, the flowers being purplish and coming in early summer. This, a native of Asiatic Russia, is perfectly hardy, and grows from 5 to $6 \mathrm{ft}$. high, but sometimes is grafted on to the tall stems of the Laburnum.

Hamamelis (Witch Hazel).-Hardy shrubs with singular blossoms flowering 
in winter. They have a peculiar value as ornamental shrubs, and one species at least is worth planting in all good gardens. This is $\mathrm{H}$. arborea, or Tree Witch Hazel, though in this country it does not rise generally above $\delta \mathrm{ft}$. high. In January, and sometimes before, its leafless branches are covered with flowers, which have twisted, bright yellow petals and crimson calyces, so that a wellflowered plant is very pretty. It is a hardy Japanese shrub, and thrives in most kinds of soil, but must have an open situation. Another Japanese species is H. japonica, a smaller and dwarfer plant than $\mathrm{H}$. arborea, and bearing flowers of a lighter yellow colour, while that called $\mathrm{H}$. Zuccariniana is very similar to it. Of less value perhaps is the American Witch Hazel, which has small yellowish flowers in winter, and sometimes in autumn. Though not so showy when in flower as the Japanese species, it is a pretty shrub, and, like the others, thrives in any soil.

Hard Fern (Blechnum boreale).

Hare's-tail Grass (Lagurus ovatus).

Harpalium rigidum (Helianthus).

Hart's-tongue (Scolopendrium).

Hawkweed (Hieracium).

Hawthorn (Cratcegus).

Hawthorn, Japanese (Rhaphiolepis).

Hazel Witch (Hamamelis).

Heart's-ease (Viola tricolor).

Heath (Erica).

Heath, St. Dabeoc's (Dabcecia).

Heath, Sea (Frankenia).

Hebenstretia.-Interesting little plants allied to the Labiates, but only suitable for botanical collections.

Hedera Helix (Ivy). - The most beautiful evergreen climber of our northern and temperate world is a noble garden plant that may be used in many ways. The common Ivy of the woods is familiar to all, but its many beautiful varieties are not so common as this. All are not of the same vigorous habit, as will easily be seen by cultivating a collection; but the rich self green-leaved kinds are usually as free and as hardy as the wild plant. Although there are many varieties, there are only two accepted species - the Australian, that is confined to the continent of Australia ; and Hedera Helix, which is found wild in the British Isles, and spreads over Europe, reaching into N. Africa and Central Asia. It is under our English Ivy that the large number of forms in cultivation are classed. Although there are only two species, we can classify the Ivies in several groups, after the variation in the leaves. If we want Ivies in their fullest beauty, it is necessary to pay some attention to position, soil, and training. This applies to all the kinds, but especially to the more delicate varieties. Ordinary garden soil will grow the Ivy well, and the strong growers, as Emerald Gem, Rægneriana, algeriensis, canariensis or the Irish Ivy, sagittæfolia, lucida, palmata, gracilis, dentata, digitata, pedata, and angularis, will need no special position; but in the case of kinds like madierensis variegata, a showy form, some little care is needed. It is better to plant these kinds as edgings to a bed of shrubs or permit them to clamber over a rootstump, arbour, or form a pyramid of them, where they will be less exposed to the full force of wind than if they were stiffly trained on walls. Cuttings may be struck in the latter part of the summer, and quickly root if put in a shady border where the soil is fairly good. It is sometimes well to cut the plants down to the ground after the first year, as often the shoots are very weak; but this severe pruning induces a stronger growth later on. As regards the best time to plant, the spring months are the most suitable: but the Ivy may be planted any time if it is in a pot, and during the first summer, if the weather is hot, give plenty of water. In the case of variegated sorts, it is advisable to plant in a poor soil, so as to bring out the variegation. A word should be said for Tree Ivies, which make fine bushes in the garden, and may be associated with other shrubs in beds. Healthy plants make dense rounded heads of foliage, relieved during the blooming season with many flowers. By far the most important Ivies, however, are the green-leaved forms, - many, various, and nearly all beautiful in form. Whatever kinds among these we may prefer, a fuller and more graceful use of the Ivy in or near the flower garden and its surroundings is desirable. As much more use is made of the Ivy in French flower gardens than in our own, the following, from the Parks and Gardens of Paris, may be worth quoting here :-

"It would be difficult to give any adequate idea of the charms Ivy imparts to many surfaces that would otherwise be hard and bare. In any city or town, where the air is not much polluted by smoke, the same effects may be easily produced. In cold districts, where evergreens are liable to suffer, it is all the more desirable to make good use of the best of all evergreen climbers for northern countries. To rob the monotonous garden-railings of their nakedness, the French use it most extensively, so that even in the dead 
of winter it is refreshing to walk along by them. Instead of the inmates of the house gazing from the windows into the street swarming with dust, or splashing with mud, a wall of verdure encloses the garden ; privacy is secured ; the effect of any flowers contained in the garden is heightened; and lastly, the heavier clouds bare earth more conspicuous than the bedding-plants, as is so often the case early in the summer, the belt of fresh Ivy, rising as it does several inches above the level of the earth, effects great improvement. Near at hand this is not so evident, but when a little way off, the nakedness of the earth is hidden by the

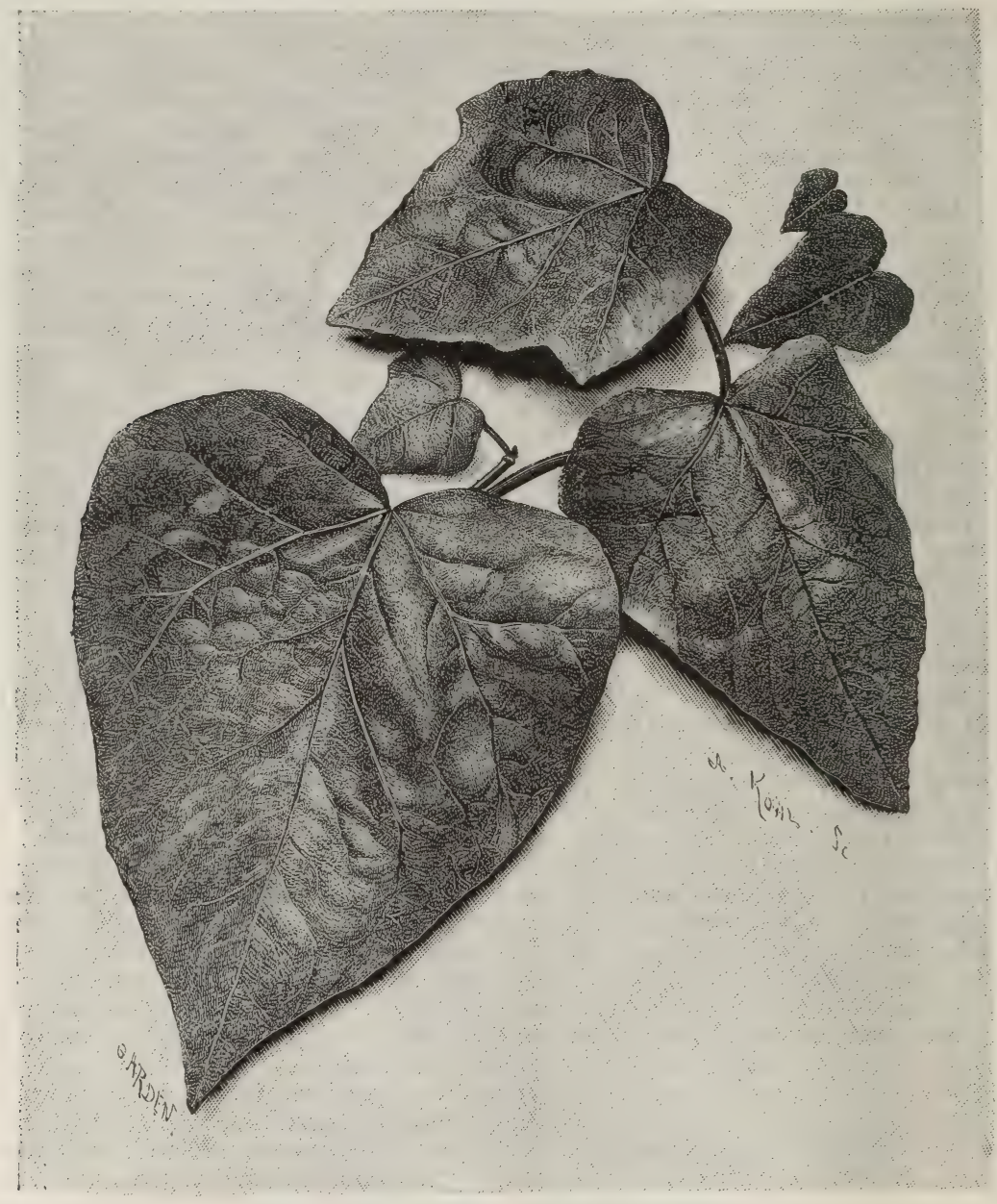

LARGE-LEATED IVY, ONE OF MANY FINE FORMS.

of dust are kept out in summer, for so well are the railings covered by planting the Ivy rather thickly, and giving it some rich light soil to grow. in, that a dense screen is soon formed. Ivy-edgings also make excellent margins to beds on grasslawns. In this case one would have thought the turf sufficient, and so it is, if the subjects fill the bed properly and come flush to the margin; but, with the
Ivy, and the flowers peep above it. The best kind for this purpose is the Irish Ivy, but where many edgings are made, it would be very desirable to produce some variety by using other healthy greenleaved kinds; and the variegated ones, too, should be attractive, though no charm of theirs can ever equal the unmatched verdure of the green Ivies in early summer. It should be observed 
that an Ivy-band of the width of an ordinary edging is not at all so desirable as when its sheet of green is allowed to spread out to a breadth of more than a foot. In nearly every courtyard in Paris the Ivy is tastefully used. Scarlet Pelargoniums are seen to great advantage when grown in boxes placed against a wall densely covered with Ivy, and with it also planted along their front edges so as to hang down and cover the face of the boxes. In the garden of the Paris Exhibition of $\mathbf{1} 867$, a pretty circular bower was shown perfectly covered with Ivy, the whole springing from a large tub. Such a bower could readily be made on a roof, or on a wide balcony.

"Where there are tall bare walls near a unchangeable geometrical patterns, are as much improved by being fringed here and there with Ivy and the like, as are the rocks on a river's bank.

"In the Square St. Jacques there is an example of the way in which the smallleaved Ivy may be used for covering the trunks of trees; the effect being more lace-like than that of the ordinary kinds. It would be well to plant a variety of the green-leaved kinds at the foot of trees. It is not, however, advisable to cover very young trees in this way, as it is apt to interfere with their growth. With regard to growing Ivy on trees, Mr. George Berry of Longleat wrote-

" 'In almost every park, however small, there are some few trees-old trees that

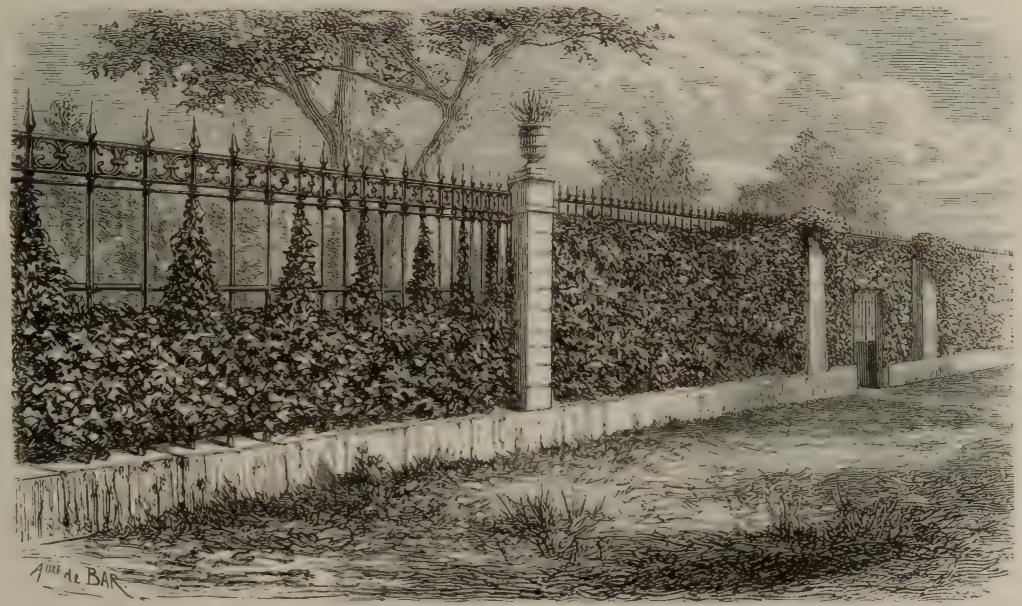

IVY IN WREATHS AND SHEETS ON RAILINGS OF SUBURBAN GARDENS.

house, they are quickly covered with a close tapestry of Ivy. If the margin of the grass around some clump of shrubs or flower-beds looks bare, some young plants of Ivy will soon make a wide and graceful edging which will look well throughout the year with slight attention. When Ivy is planted thickly and kept neatly to a breadth of from 12 to 20 in., it forms a dense carpet of leaves on the ground. The effect of Ivy-bands outside masses of gay flowers is excellent, forming as they do a graceful setting for the flower-borders. In some geometrical gardens panels are edged with stone. These Ivy-edgings associate well with such stone borderings, while they may be used with advantage in any style of garden. A garden pleases in direct proportion to the variety and life that are in it ; and all bands and circles of stone, all are of no value, and that have matured their growth-that may be given up to Ivy by those who wish to grow it in this manner. It may also be allowed freedom on any inferior undergrowing trees that have been overtopped by better ones, of which there are generally too many on nearly every property, particularly where judicious thinning has been neglected until too late to be of any benefit. In natural copses, when not grown for profit, Ivy forms an ornamental feature, especially on the Birch, to whose white bark and brown airy twigs the Ivy offers a charming contrast. Lovers of creeperclad trees should, however, take care not to allow young trees or any fine ornamental sorts to be taken possession of by Ivy. It is an indisputable fact that when Ivy is permitted to cling to and cover growing young trees, it prevents develop- 
ment of the stem; while its tightly-laced and interwoven mass of dense plaits also excludes light, air, and moisture. The foliage, too, gradually diminishes, and when Ivy has established itself on young trees, the result is often premature death.

"Ivy may be grown and used in a dwelling-house, especially in making living screens for rooms. This is usually done occurs, and the contrast of colour between the delicate lilac blossoms and light green leaves of the Wistaria and the deep glossy green of the Ivy is charming. Ivy also forms an admirable frame for windows in situations where little else will grow. A deep box, filled with rich light soil, suits these Ivies best.

"The Ivy used by the City of Paris for ornamenting the flower-beds in the squares, the trunks of trees, etc., is grown at the nurseries in the Bois de Boulogne. Towards the end of the summer the propagation of the Ivy by means of cuttings is carried on. Three or four leaves are left on each cutting, and they are planted very thickly in lines in a half-shady position. When they have taken root sufficiently, which generally takes place in the following spring, they are transplanted into pots of 4 or 5 in. in diameter. Afterwards stakes are fixed along the rows of pots, and from these are stretched lines of thin galvanised wire; to this slender but firm trellis of from 3 to $5 \mathrm{ft}$. high the plants are trained during the growing season. At the end of the second or third year they are strong enough to be employed to cover railings, and for many similar purposes. The nurserymen in the suburbs of Paris generally propagate them by layers, which are often rooted in pots. If a wide belt of Ivy is desired, the young plants may be ar-

PYRAMID OF LARGE-LEAVED IVY, 7 FT. HIGH.

ranged in two or three
French do when making

by planting it in narrow boxes and training it up wirework trellises. The boxes being portable, a screen may be formed in a few minutes in any part of a room. Sometimes, however, it is permanently planted, and it is not unfrequently used to embellish glass partitions between large apartments.

"When used as a screen, Ivy may often be combined with other creepers so as to produce a variety of pretty effects. A happy combination of Wistaria above and Ivy below in the same railing often rows, as the French do when making
the excellent Ivy edgings which are here described. In any case, after the plants are inserted the shoots must be neatly pegged down all in one direction.

"The reason why Ivy edgings when seen in England look so poor as compared with those in Paris, is that we allow them to grow uncontrolled, and they get overgrown, wild, and entangled, whereas the French keep them down to the desired size by pinching or cutting the little shoots well in, two or even three 
times every summer, after the edging has once attained size and health. The abundant supply of established plants in small pots obtainable in the markets enables them to lay down these edgings so as to look well almost from the first day."

Hedychium Gardnerianum. - This, though usually grown in the greenhouse, will flower out-of-doors, and live through an ordinary winter without much protection. It should be planted out in May, so as to make its summer growth where it is to stand, as then its roots penetrate deep and become established before the top dies off in autumn. It thrives best in a loose sandy loam, enriched with manure. While the plant is making its growth a mulching should be given, and in dry weather an occasional watering of liquid manure. It is excellent for choice groups in the sub-tropical garden, in warm sheltered spots. A heap of cinders or half-rotten leaves laid over the crowns in winter will ensure their safety; or the roots may be lifted in autumn and wintered in any dry place with Dahlias and Cannas. Increased by dividing the roots in spring, but each piece must have a young crown attached.

Hedysarum (French Honeysuckle).Plants of the Pea family, mostly weedy, only a few perennials being ornamental. H. coronarium, a popular and rather showy plant, grows 3 or $4 \mathrm{ft}$. high, and bears in summer dense spikes of red flowers. It grows in any ordinary soil, but is not a perennial, though it usually sows itself where it is established. There is a white variety. Among the dwarfer kinds the two following are desirable: $\mathrm{H}$. obscurum, a brilliant and compact perennial; 6 to 12 in. high, with racemes of showy purple flowers. It is suitable for the rock-garden, for borders, and for naturalisation amongst vegetation not more than I ft. high, chiefly on banks and slopes in sandy loam. Division or seed. H. Mackenzii is said to be the handsomest of the genus. It grows about $2 \mathrm{ft}$. high and has long racemes of from seven to thirty rather large rosy-purple Pea-like flowers. It is perfectly hardy in any situation, and flowers in June and July. It is rather too tall for the rockgarden, and is more suited for the mixed border.

Heimia salicifolia.-A pretty halfhardy shrub from Mexico, useful for planting against a dwarf wall unsuitable for tall climbers. It has narrow Willowlike leaves, and bears in late summer an abundance of small yellow flowers. It grows from 3 to $5 \mathrm{ft}$. high.
Helenium (Sneeze-weed). - Vigorous composites, flowering in autumn, and thriving in any soil, and where rightly used, excellent plants. There are two or three species, the most useful being $\mathrm{H}$. autumnale, about $6 \mathrm{ft}$. high, bearing yellow flower-heads. The varieties grandiceps and pumilum are very distinct : grandiceps being of gigantic growth with a fasciated head of bloom, which makes it very showy; pumilum being much dwarfer and more desirable than the type. $H$. atropurpureum grows 3 or $4 \mathrm{ft}$. high, and has reddish-brown flower-heads. $\mathrm{H}$. Hoopesi is desirable, as it flowers in early summer. It is a rather coarse grower, but has large yellow flowers. The first-mentioned species and its varieties are excellent border plants, and, though vigorous, remain long in bloom. They are very useful for cutting, as they remain a long time fresh when cut. N. America.

Helianthemum (Sun Rose).-Though strictly shrubby plants for the most part,

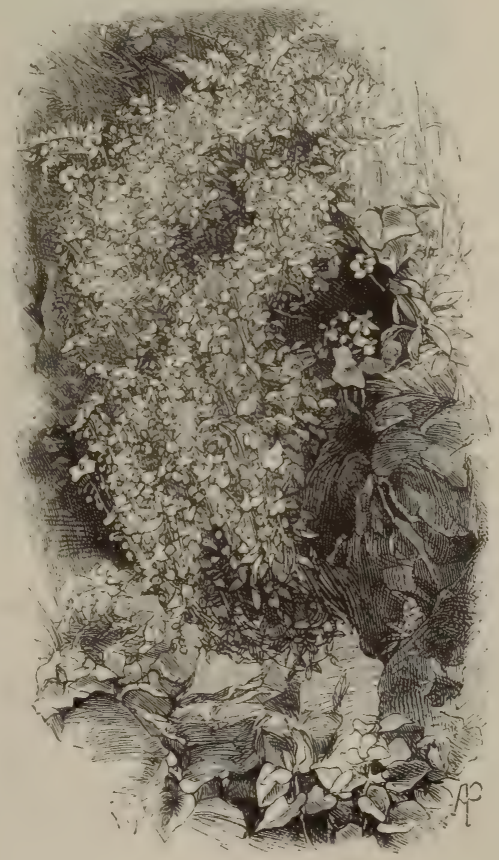

SUN ROSE ON ROCKS (CHEDDAR).

these dwarf evergreens possess so much the aspect of rock-plants, that they cannot well be separated from them. They are extremely valuable ornamental plants, and there are few more brilliant sights than masses of them when in full beauty. 
They are of the easiest possible culture, and, with few exceptions, are dwarf and compact, bearing in great profusion flowers with a remarkable diversity of colour. The common Sun Rose ( $H$. vulgare) is extremely variable in habit and colour, and from it have sprung the hosts of varieties enumerated in trade lists ; indeed, we need only this species to represent, for garden purposes, the variation in all the dwarf shrubby species of the family. The colours range from white and yellow to deep crimson. There are also double-flowered kinds and one with variegated foliage. Other pretty, dwarf, shrubby species, similar to $H$. vulgare, are H. rosmarinifolium, pilosum, and croceum. There is also a herbaceous perennial species, H. Tuberaria (Truffle Sun Rose), which in aspect differs completely from the shrubby species, and is second to none in beauty. It grows 6 to 12 in. high, with flowers 2 in. across resembling a single yellow Rose, with dark centre, and drooping when in bud. It is suited for warm ledges on the rockgarden in well-drained sandy or calcareous soil. When sufficiently plentiful it should be used in the mixed border. Seed and careful division. When a full collection is required there are other species introduced, but the above fairly represent the beauty of the family.

Helianthus (Sunflower)-PERENNIAL SUNFLOWERS.-Usually stout, vigorous, and showy plants, typical of the coarse yellow Composites abounding in North America, of which not a few have found their way into English gardens. All the perennials are vigorous growers, and generally attain a great height, being most precious for the autumnal garden when well placed. Sunflowers may be cultivated with the greatest ease; they are gross feeders, and the richer the soil the better the result. It is true that not a few of this genus are coarse and weedy, unfitted for the flower garden, but a good many, some of which are not yet in general cultivation, could be utilised with striking effect in the best-kept flower garden ; and for mixed borders, etc., they are valuable. The tall sorts, such as $\mathrm{H}$. læetiflorus, the forms of $H$. rigidus, $H$. decapetalus, $H$. orgyalis, $H$. divaricatus, etc., make telling groups in borders, or, better still, grouped boldly without their stems being made unsightly with staking.

H. ORGYALIS, which is grown for the grace of its foliage more than for its small yellow flowers, is an effective kind. In warm seasons it flowers with the pro- fusion of its family, and is one of the most elegant plants among them.

H. LETIFLORUS is also a handsome kind, resembling the taller forms of H. rigidus so much that many have considered it a variety. This plant, whatever it may ultimately prove to be, and there are two or three forms, is the finest of the late autumnal Sunflowers. The ray florets are of a rich dark yellow, and the disc yellowish, not black, as in H. rigidus.

H. RIGIDUS is a handsome Sunflower of medium height, and a most useful garden plant, valuable from its colour, the size of its flowers, and also in its time of flowering. An early-flowering variety has been sold under the wrong name of H. japonicus. This is, however, an excellent border plant of medium height, and flowers in early August. The tall forms are also useful, and do in almost any kind of soil. It was at first grown in our gardens under the name of Harpalium rigidum, and the first form introduced, which grows from 3 to $4 \mathrm{ft}$. high, is a splendid plant among autumn-blooming perennials.

H. MULTIFLORUS is one of the best Sunflowers in cultivation. It is an extremely variable plant, and there are dwarf and tall varieties; it is the most generally grown of all the Sunflowers. There are several varieties in gardens, one known as $H$. multiflorus fl.-pl. is good, another as major or maximus, with larger flowers, the old double, besides a fine double form found in an old garden in Ireland, and sent out as Soleil d'Or. All the forms are of easy culture, quite hardy in any soil, and easy to increase by division.

H. DECAPETALUS, which flowers towards the end of August, grows from 4 to $5 \mathrm{ft}$. in height, bearing abundance of pale sulphur-yellow flowers. H. divaricatus, a small-flowered variety, is much inferior as a garden plant.

H. ANGUSTIFOLIUS is only seen at its best in very hot summers; the average season is too cold for this species, and the flowers often get destroyed by the early autumn frosts. It is, however, an elegant plant, with abundance of Willowshaped leaves and yellow flowers.

H. MOLLIS is rather a rare species, but pretty, and well worth growing. It grows about $3 \mathrm{ft}$. in height, with leaves woolly, soft to the touch, flowers $I \frac{1}{2}$ to 2 in. in diameter, rich yellow, distinct and handsome when well grown. H. occidentalis is another somewhat rare species, with orange-yellow flowers and compact habit. Others, all more or less desirable, 
are $H$. giganteus, $H$. doronicoides, $H$. strumosus, $\mathrm{H}$. tuberosus, $\mathrm{H}$. trachelifolius, etc. -D. K.

AnNuAL Sunflowers.-All the larger species and varieties are noble plants, requiring plenty of space, a sheltered position, and a good background. They are all easily raised from seed, which may be sown in pans in early March or in the open air in April where they are intended to flower, and thinned out to from a foot to a yard apart according to the vigour of the plant. The regulation row of Sunflowers along a choice mixed border often cow manure just before planting. There are many varieties in gardens, the most notable being one called californicus, a more robust and darker-flowered form. Macrocarpus, lenticularis, ovatus, etc., are synonyms or slight varieties of the cultivated annual Sunflower; sulphureus, multiflorus, globosus, grandiflorus, fistulosus, etc., are garden variations. The sulphur-coloured variety is charming. North America.

H. ARGOPHYLLUS, little more than a variety of $H$. annuus, is a charming plant for the back of mixed borders, open

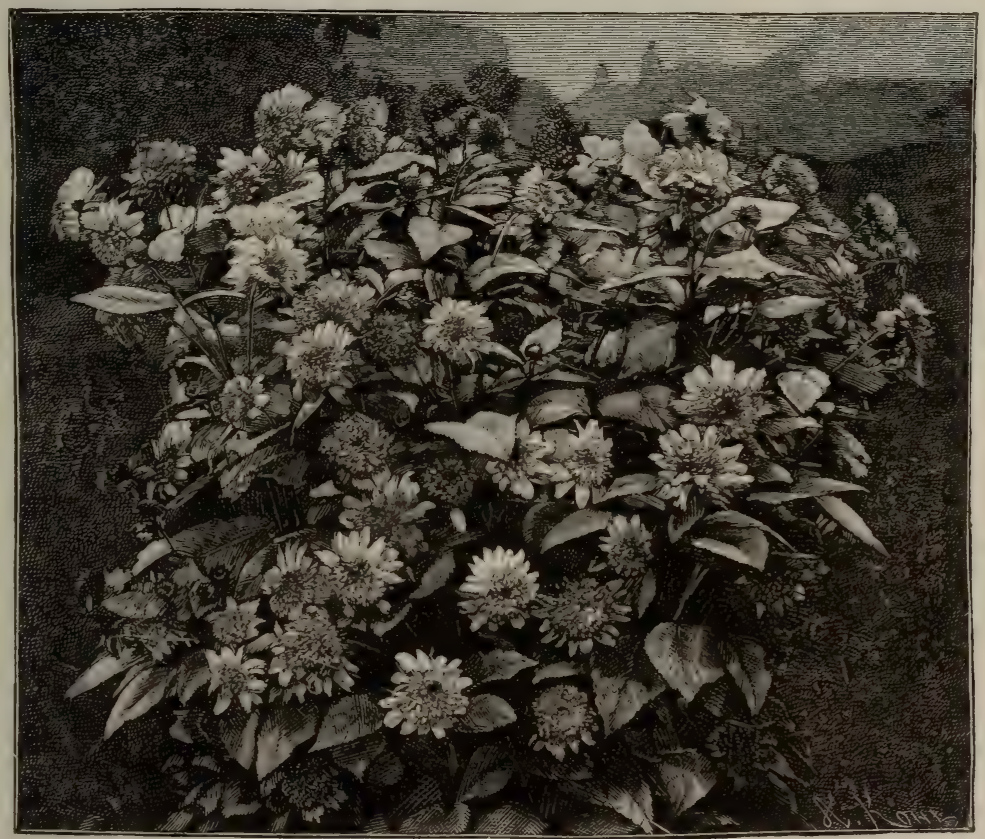

DOUBLE PERENNIAL SUNFLOWER.

ruins its effect, but there are various ways of arranging the annual Sunflowers with excellent effect-among large beds of fine-leaved plants being one of them.

H. ANNUUS (Common Sunflower).Although often regarded only as a cottagers' flower, the annual Sunflower is one of the noblest plants we have, and one of the most effective for various positions. In order to dispense with support, it should be planted in a sheltered place, that among tall shrubs being preferable to any other. Here it assumes a dense branching tree-like habit, and often produces flowers each over a foot in diameter. It requires a strong rich soil, to which may be added a quantity of old borders, and in thin shrubberies. The whole plant is white, being covered with soft and silky wool, the flowers large with very broad ray florets. H. Dammanni and $H$. D. var. sulphureus are said to be garden hybrids between $\mathrm{H}$. argophyllus and $\mathrm{H}$. annuus. Texas.

H. DEBILIS we have not seen in cultivation, but its charming variety $H$. cucumerifolius, the miniature Sunflower, is a good annual, growing from 2 to $3 \mathrm{ft}$. high, usually with purple mottling on the stems, leaves thin, and bright apple-green. The stems are much branched, and when allowed plenty of room the plants form perfect symmetrical specimens. The flowers are yellow, about 3 in. in diameter, 
nicely set off with the almost black disc. Sandy soil in woods from Texas westwards.

H. ExiLIs.-A very slender species, rarely more than a couple of feet in height, with lance-shaped leaves and yellow flowers about $2 \mathrm{in}$. in diameter. N. California.

H. PETIOLARIS. - A fine kind rarely seen in gardens, though from its neat habit and profusion of flowers it should be a welcome addition to the mixed border. It grows about a yard high, loosely branched, the stem as well as the leaves being covered with stiff hairs; flowers yellow, 3 to $4 \mathrm{in}$. in diameter. The variety canescens is covered with white pubescence. Texas.

H. SCABERRIMUS. - A very distinct plant with large deep yellow flowers, stout branching stems, and broad, oval, coarsely-toothed leaves. California.-D.

Helichrysum (Everlasting Flower).Composites, mostly natives of the Cape of Good Hope, of which a few are cultivated. The most important garden plants are $\mathrm{H}$. macranthum and $\mathrm{H}$. bracteatum. They are generally treated as annuals, and, unless exceptionally well managed by being sown early under glass, they commence flowering so late that the best period for laying on the brightest colours is lost, and early frosts find them just approaching their best. During mild winters they are uninjured, and they are the most continuous flowerers next year even in the driest and hottest of summers. They are particularly suited for background plants on dry borders. If they are sown in pans or boxes where they can be slightly protected during winter, and are planted out early in April, they have a chance of producing a good crop of flowers for drying. The colours vary from deep crimson to yellow and white. The hardy perennials are not important, and seldom succeed. $H$. orientale, which furnishes the Immortelle of the French, flowers poorly except in very hot seasons. None of the other hardy kinds are worth growing, except perhaps $H$. arenarium, which has bright golden-yellow flowers.

Heliophila. - Small and charming Cruciferous annuals. $H$. araboides is a pretty blue annual, of which occasional use might be made. It is dwarf, and free in growth and flower. Another kind is $\mathrm{H}$. pilosa.

Heliopsis.-Stout yellow Composites not of essential value considering the good plants of the same order now in cultivation. There are several kinds.

Heliotrope, Winter (Tussilago).
Heliotropium (Cherry Pie).-A great favourite for flower gardens on account of its delicate fragrance. For the flower garden spring-struck plants are the best. It is a good plan to lift a few plants from the beds in September, winter them in a warm greenhouse, and in spring to put them in a warm place, where they will soon produce plenty of cuttings. These cuttings may be struck on slight heat like Verbenas, potted on, made to grow rapidly, so as to be fit to plant out at the end of May when danger of frost is past. Heliotropes may be raised from seed and flowered the same year-in fact, treated as annuals. Sown early-in February or the beginning of March-they become sturdy little plants before planting time. When bedded out they should be placed in good dry soil. The following are good varieties, and new varieties are raised from time to time: Anna Turrell, General Garfield, Roi des Noirs, Triomphe de Liège, and the old species $\mathrm{H}$. peruvianum, which many like from its associations if for no other reason. Heliotropes, though quiet in colour, are charming flower-garden plants, either when grown for their own sakes as simple masses or when associated with tall plants which grow above them.

Helipterum Sanfordi.-A dwarf, branched, pretty yellow half-hardy annual Composite. Its merits have not been considered remarkable, though it has been well introduced. The short life of the spring-raised everlasting annuals leads to a poor result.

Helleborus (Christmas Rose).-One of the most valuable classes of hardy perennials we have, as they flower in the open air when there is little else in bloom. They appear in succession from October till April, beginning with the Christmas Rose ( $\mathrm{H}$. niger), and ending with the handsome crimson kinds. The old white Christmas Rose is well known and much admired, but the handsome kinds with coloured flowers have, hitherto, not been much known. Recently too there have appeared some really beautiful hybrids, which add a great deal of beauty to our winter and spring garden, for their flowers withstand the winter, and their verdure and the vigorous growth of their leaves distinguish them throughout the year.

The Hellebores, besides being excellent border flowers, are specially suited for naturalising. There are a few kindsthose with inconspicuous flowers, but handsome foliage-whose only place is the wild garden, such as the native $H$. foetidus, $H$. lividus, viridis, and $H$. 
Bocconi, which have elegant foliage when well developed in a shady place in rich soil, like that usually found in woods. The Hellebores may be classed in three groups, according to the colour

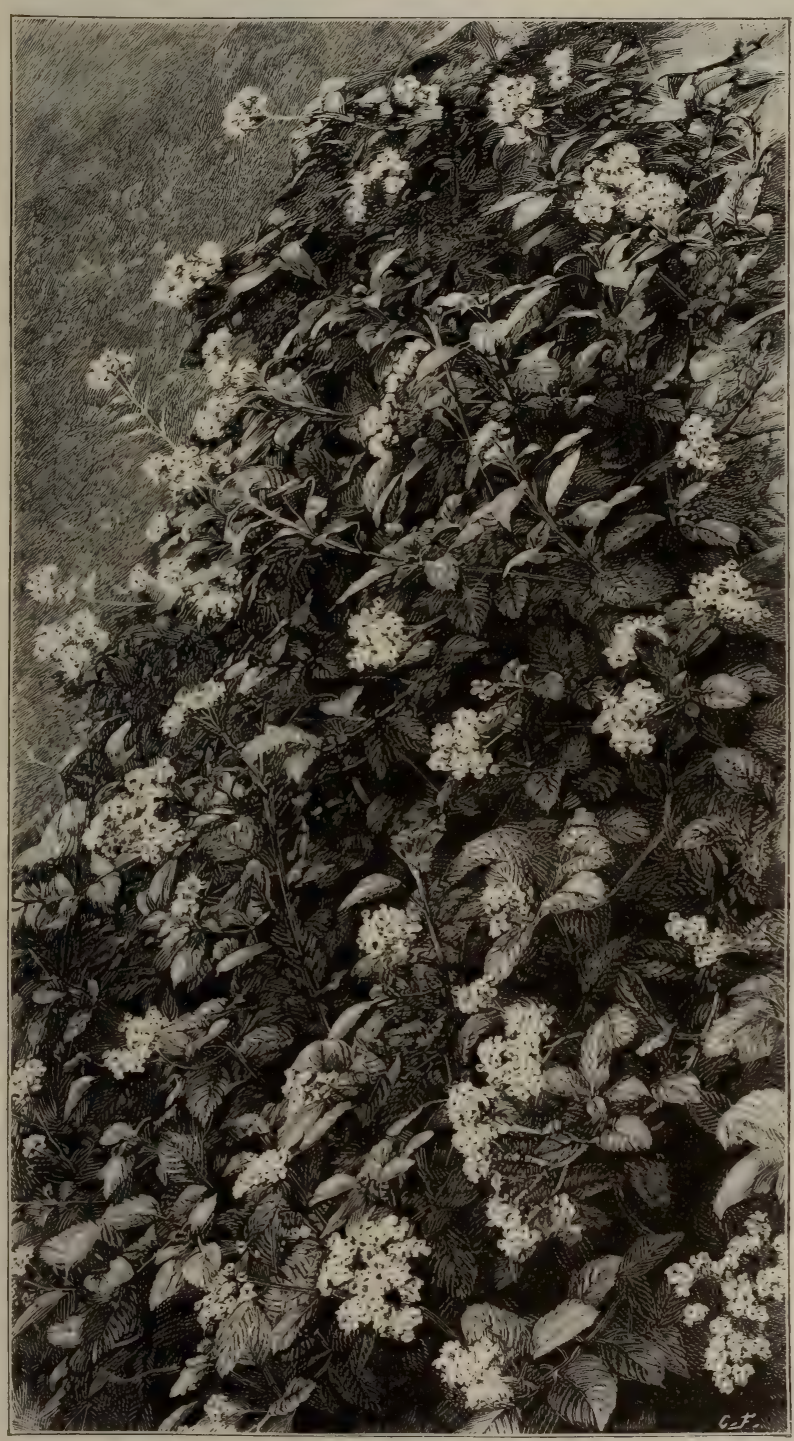

HELIOTROPE.

of the flowers - those with white flowers, those with red, and those with green, which last will get little place in the garden. The white-flowered group is the most important, as it contains the beautiful old Christmas Rose.

$\mathrm{H}$. niger is a well-known kind, scarcely needing description. It may be recognised at once by its pale green smooth leathery leaves, divided into seven or nine segments, 3 to 6 in. long and $\mathrm{I}$ to $2 \mathrm{in}$. broad. The blossoms, which are usually borne singly on stems 6 in. long, are about 3 in. across, and vary from a waxy-white to a delicate blush tint. The variety minor is smaller in every part, and is also known as $H$. angustifolius. $H$. altifolius, though sometimes considered a variety of $\mathrm{H}$. niger, is a distinct kind, and much larger than $H$. niger. It has leaf-stalks over I $\mathrm{ft}$. long, and blossoms 3 to 5 in. across, which are borne on branching stems, each stem bearing from two to seven flowers, which have a stronger tendency to assume a rosy hue than the ordinary kind have. Another characteristic is that the leaf and flower stems are beautifully mottled with purple and green, while in $\mathrm{H}$. niger they are of a pale green. H. altifolius also flowers much earlier - in some seasons in the beginning of October. It has been known a long time under the names of $H$. niger var. major, maximus, giganteus, and grandiflorus.

Other white kinds are H. olympicus - a tall slender species with cupshaped blossoms that vary from pure white to greenish-white-and also known as $\mathrm{H}$. abchasicus albus, and kamtschatkensis albus. Flowers from February to March. H. guttatus is like it, but has the inside of the blossoms spotted with purple. There are several forms : in some the markings assume the form of small dots, in others of thin streaks. It is one of the parents of the beautiful hybrids lately obtained, the best of which are Herr Leichtlin, F. C. Heinemann, and C. Benary.

The finest of the red or crimson kinds 
is $H$. colchicus, one of the finest of all. It is larger than any other, and may be readily recognised by thick dark green leaves, with five to seven broad and coarsely-toothed divisions, the veins of which are raised on the under sides, and are of a dark purple when young. The blossoms, borne on forked stems rising and $H$. altifolius resulted in a form with larger flowers of a lighter purple. $\mathrm{H}$. atro-rubens has leaves much thinner and flowers much smaller than $H$. colchicus. The colour is dull purple on the outside and greenish-purple within. It is a native of Hungary, and is common in gardens, but is often confused with $\mathrm{H}$.

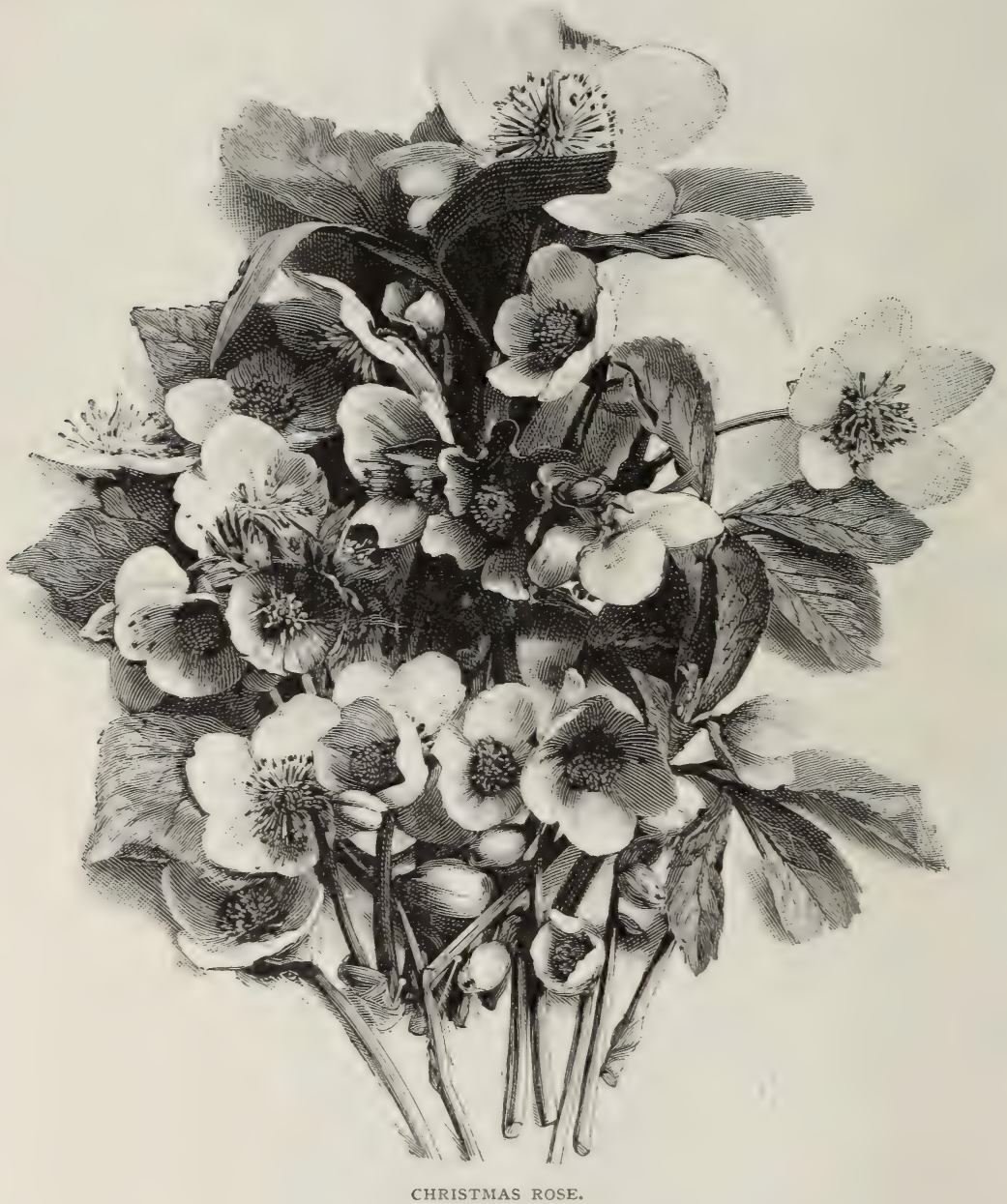

considerably above the foliage, are of a dark purple. Under good cultivation the leaves attain the length of $I \frac{1}{2}$ and $2 \mathrm{ft}$., forming fine specimens, and flowers are produced from the end of January to the end of March. A fine hybrid has been obtained by crossing it with $\mathrm{H}$. guttatus, the result being a form with large spreading flowers lighter than in $\mathrm{H}$. colchicus, and profusely marked with dark carmine streaks. Another hybrid between this abchasicus, a taller and more slender plant, the flower-stems of which are longer, and the blossoms nodding and smaller. H. abchasicus is much superior to atro-rubens, the colour of the blossoms -a deep ruby-crimson-making them very attractive. Other fine varieties of the red-flowered group are Gretchen Heinemann, James Atkins, and Apotheker Bogren, all worthy of culture. Other reddish kinds, such as $H$. purpurascens 
and H. cupreus, are not worth growing.

All the kinds will thrive in ordinary garden soil, but for the choicer kinds a prepared soil is preferable. This should consist of equal parts of good fibry loam and well-decomposed manure, half fibry peat and half coarse sand. Thorough drainage should always be given, as stagnant moisture is very injurious. A moist and sheltered situation, where they will obtain partial shade, such as the margins of high shrubberies, etc., is best, but care should be taken to keep the roots of

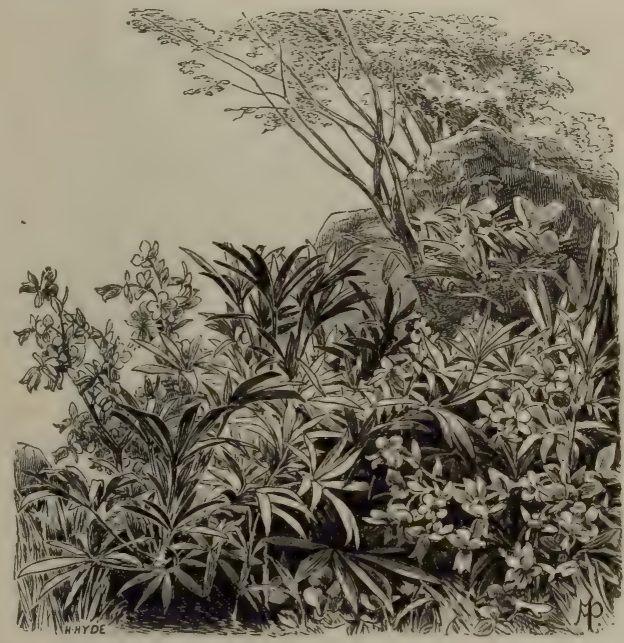

HELLEBORUS VIRIDIS.

shrubs from exhausting the border. In the flowering season a thin mulching of moss or similar material should be placed on the soil round the plants, as this prevents the blossoms from being spattered by heavy rains, etc. Any one beginning to grow these useful plants should give the soil a good preparation. If well trenched and manured, they will not require replanting for at least seven years ; but a top-dressing of well-decayed manure and a little liquid manure might be given during the growing season when the plants are making their foliage, as upon the size and substance of the leaves will depend the size of the flowers. The common white Christmas Rose is a favourite pot-plant, and if required for potting its foliage should be protected from injury ; when the blooming season is over it should be protected by a frame until genial weather permits it to be plunged in the open air. Hardy subjects like the Christmas Rose frequently suffer when removed from under glass, for although hardy enough to withstand our severest winters when continuously exposed, their growth, when made under more exciting circumstances, will not withstand sudden variation of temperature. For this reason it is advisable to keep them in as cool a position as possible when in flower, so that the growth of young foliage may not be excited before its natural season.

Propagation may be effected by division or by seeds, which, in favourable seasons, are plentiful; as soon as thoroughly ripened they should be sown in pans under glass, for they soon lose their vitality. As soon as the seedlings are large enough they should be pricked off thickly into a shady border, in a light rich soil ; the second year they should be transplanted to their permanent place, and in the third season most of them will produce blossoms. In division the clumps operated on must be well-established plants, with rootstocks large enough to be worth cutting up. The divided plants, if placed in a bed of good light soil, and undisturbed, will be good flowering plants in a couple of years, but four years are required to bring a Christmas Rose to perfection, By July the Hellebore is in its strongest vigour, and the operation of lifting and dividing the plants should then be carried out.

Helonias bullata. - A distinct and handsome bog perennial, 12 to 16 in. high, having handsome purplish-rose flowers in an oval spike. It is suitable for the artificial bog, or for moist ground near a rivulet. In fine sandy and very moist soil it thrives as a border plant. N. America. Syn., H. latifolia.

Hemerocallis (Day Lily). - The Day Lilies, though not numbering many distinct species, are varied both in habit and flower, and are very useful in the mixed border and in groups by the water-side. Few plants surpass a strong well-flowered clump of Hemerocallis fulva, as we have seen it mixed with a group of male Fern near a brook. The leaves of this Day Lily were overhanging the banks of the stream, intermingled with the Fern fronds, while the flower-heads, tall and straight, were towering upwards. If the ground is well broken up and some lasting manure supplied at planting time, they may be left undisturbed for years. The forms of $\mathrm{H}$. disticha, both single and double, are also useful for clumps by water, or intermixed with other robust or bold-foliaged plants; indeed, there seems no reason why all the Day Lilies could not be treated in this picturesque way, the 
trouble entailed being small, and that chiefly at planting time only. For cutting, H. flava, minor, and Dumortieri are useful, the flowers lasting a few days and the buds opening well in water. The fragrance of these flowers is delightful, they are readily increased by division, and grow with such rapidity that in the course of a few years they may be increased to almost any extent.

The following are the species as they are now recognised, with the principal varieties :-

H. Dumortieri (Dumortier's Day plant is divided and replanted it will amply repay the trouble by increased vigour and flowers. It is closely allied to H. minor, also known as H. graminea, but it is a much stronger plant, however, with leaves twice as broad, the flowerstems short, and the divisions of the perianth divided almost or entirely to their base. The leaves are about five or six to a growth, about 18 in. long and half an inch broad, bright green above and pale but not glaucous on the under surface; flower-stem I to $2 \mathrm{ft}$. in height, bearing a corymb of large

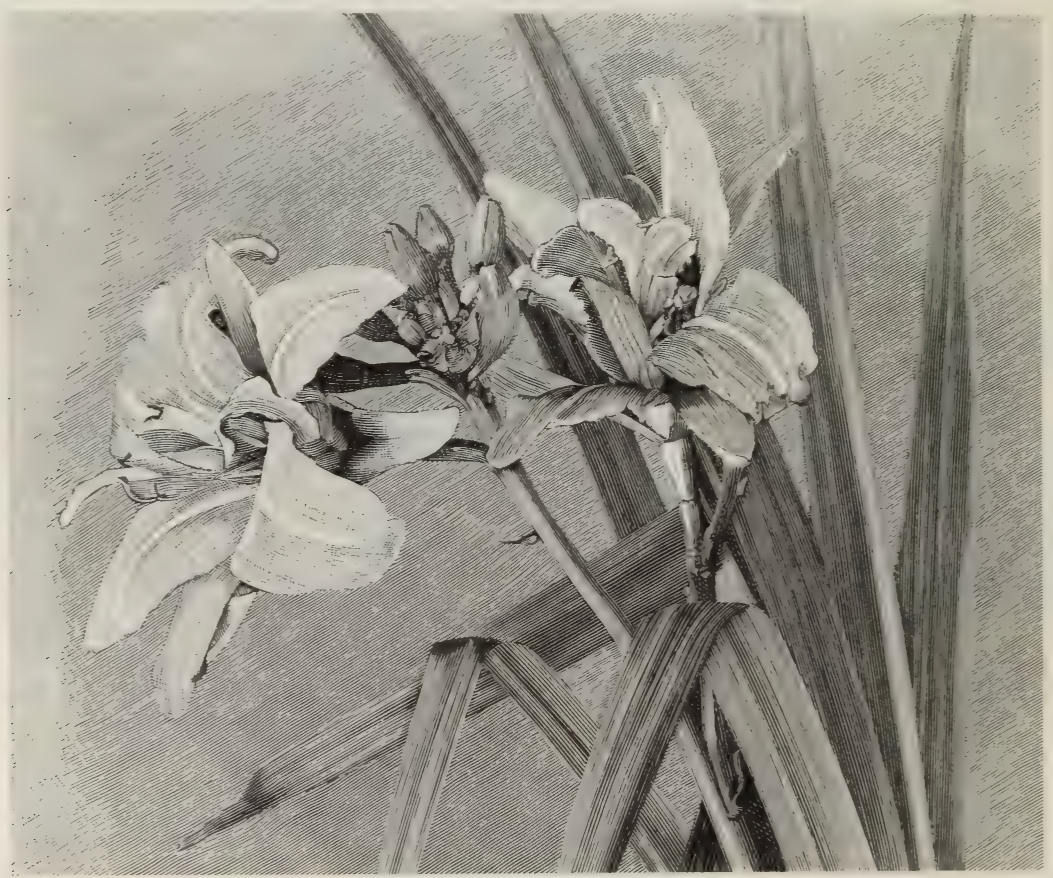

HEMEROCALLIS FULVA (DAY I.ILY).

Lily).-This valuable kind is the first to flower of all the Day Lilies. Coming as it does from Japan and W. Siberia, it proves hardy in the open air. It does not require protection during winter, and we have never known it fail to bear freely its charming and fragrant flowers. The blooms are short-lived, but the reserves are so numerous as to keep up the succession for a long time. The Day Lilies dwindle in vigour of the plants and size of the flowers if allowed to remain too long in one place. If the plants are examined, the centres will be found to be matted together, the stronger shoots appearing on the outside. If the whole orange-yellow flowers; $H$. rutilans and Sieboldi of gardens belong to the same species.

H. FLAva (the yellow Day Lily).-Few plants can be grown with so little trouble in the border, and give such a valuable return as this one. The flowers large and in such quantities, emitting such an agreeable fragrance, as to earn the name of yellow Tuberose. The length of time the flowers last enhances its value as a border plant. It is hardy, and though not so robust in habit as $\mathrm{H}$. fulva, it increases rapidly, and where the soil is good might be naturalised. On banks the beautiful light green curving leaves 
hang gracefully, surmounted by bunches of large yellow heads of flower in June and July. Europe and N. Asia. H. Thunbergi and japonica are forms of this species.

H. FULVA (copper-coloured Day Lily) is a much larger plant than $\mathrm{H}$. flava, and more suitable for extensive planting in semi-wild or rough parts of the garden. It is variable under cultivation, and the numerous forms now grown, many without names, are all worthy of attention. $H$. disticha is a well-known garden variety of this species, notable for the fan-like form of its growths. The flower-stem is forked near the summit, and carries two or three heads of flowers, six to eight blooms on each, of a brown-orange colour. There is also a double-flowered variety of this. H. Kwanso is a variety with variegated or striated leaves. It is a handsome plant for edgings or for the rockery. Of this there is also a double-flowered form. H. f. var. angustifolia, narrow-leaved; longituba, crocea, natives of China, flowering in July and August, belong to this section.

H. Middendorfiana is from Amurland, in appearance resembling $H$. Dumortieri; the leaves are, however, broader, the flowers about the same size, closer, and paler in colour, and with a distinct cylindrical tube half an inch or so long. It is of easy cultivation, and the gracefully-curving bright green leaves and pretty delicate flowers give it a unique place even among its fellows.

H. MINOR, also known in many gardens under the highly characteristic name of H. graminea, from its Grass-like foliage, was formerly classed by the older botanists as a variety of $H$. flava, though now considered distinct. It is the smallest, though not the least showy, and, like flava, sweetly scented, the flowers lasting two or three days. It makes a handsome plant for a rocky bank, and even when flowers are absent the pretty Grass-like leaves are welcome. It flowers during June and july. It is also known under the names graminifolia and pumila. Siberia.-D.

Hemiphragma heterophylla.-A dwarf trailer of the Figwort family, with slender creeping stems of inconspicuous flowers, succeeded by bright red berries about the size of small Peas. It is rather tender, and requires a sheltered and welldrained spot in the rock-garden. Himalayas.

\section{Hemp (Cannabis).}

Hemp Agrimony (Eupatorium cannabinum).

Hepatica (Anemone).
Heracleum (Giant Parsnip).-Umbelliferous perennials, mostly of gigantic growth, having huge spreading leaves and tall flower-stems with umbelled clusters, I $\mathrm{ft}$. or more across, of small white flowers. Though well-developed plants of the large kinds have a fine effect when isolated in a position not too obstructive, they are generally suitable only for the rougher parts of pleasuregrounds, the banks of rivers or lakes, and other places where they can grow freely and well, and can show their stately growth to advantage. The finest are $\mathrm{H}$. giganteum, lanatum, sibiricum, eminens, Wilhelmsi, and pubescens, all of which, when in flower, are 5 to $10 \mathrm{ft}$. high. All are increased by seed, plentifully produced. A plant, group, or colony, on an island or rough spot, is effective, but quite enough. If allowed to seed and increase, the Giant Cow Parsnip becomes a nuisance.

\section{Herb Christopher (Actca).}

Herb Paris (Paris quadrifolia).

Herniaria.-Dwarf perennial trailers, forming a dense turfy mass, green throughout the year. There are two or three species, but the most important is $H$. glabra, which has been largely used lately in geometrical gardening on account of its dwarf compact growth. It rarely requires clipping, and is always a deep green, even in a hot and dry season. $H$. grow in any soil.

Hesperaloe yuccæfolia. - A North American Liliaceous plant with Yuccalike leaves, and a flower-spike upwards of $4 \mathrm{ft}$. in height, furnished thickly on the upper half with orange-red flowers nearly I in. in length. Its hardiness has not been tested, but little is known of its requirements under cultivation.

Hesperis matronalis (Rocket). - A popular old garden plant, and among the most desirable of hardy flowers. It bears showy, varied, and fragrant flower-spikes. The original single-flowered kind grows I to $3 \mathrm{ft}$. high, and has pinkish flowers, but the double kinds are much more valued. There are two distinct forms of the double white Rocket, as well as of the double purple Rocket in cultivation. One is a tall white, turning to a pale flesh colour with age; the other is the old white variety, of dwarfer growth, with smaller and more compact flowers. It is met with in the north, but is little known in the south, where it does not flourish so well as the common variety. There is the old purple double Rocket and a freegrowing dwarf form known as Compactness, which has also larger and darker 
flowers. Rockets require care in cultivating, and will soon be lost if left to themselves. They should be divided at least every second year and transplanted, for they seem to tire of the soil and to require more change than most perennials. If the young shoots are formed into cuttings when they are about 3 in. long, they strike very freely in the open ground, and the spikes of bloom on the remaining stems are all the finer when some of the others have been removed. When shaded from the sun for about three weeks with a few Laurel branches, the cuttings do better than when covered with a pot or box, as has been advised. They like a rich soil, rather moist, and are all the better for repeated applications of liquid manure if the soil is not as deep and good as it should be. Double Rockets really belong to a most important set of garden plants, requiring annual and biennial attention, and they therefore cannot well be used in groups of true perennials. It is always worth while having a bed of them in the reserve garden in case the plants should be lost or neglected in the borders. We have seen them best grown where there was a yearly transfer of plants from the reserved garden to the mixed border, and the groups look very well. The single Rocket is easily naturalised, and is a showy plant in woods or shrubberies.

H. tristis (Night-scented Stock).-A quaint plant with dull-coloured flowers, sweet-scented at night. It is rather tender, and requires a light warm soil and a sheltered position.

Hesperochiron pumilus. - A pretty Californian dwarf rock-plant. It is stemless, with leaves on slender stalks, in a rosulate tuft. The bell-shaped flowers, $\frac{1}{2}$ in. across, are of white, varying to a purplish tinge. H. grows in marshy ground, and in damp places in the Rocky Mountains and Northern Utah, and is apparently quite hardy, as it thrives in ordinary soil in well-drained parts of the rock-garden. $H$. californicus is a species of somewhat the same type.

Hesperocordon lacteum.-A Californian bulb, now placed with the Brodiæas. $H$. lilacinum is a variety.

Heuchera (Alum Root).-At first sight obscure if interesting plants, I have found them excellent in effect of new and good colours, when grouped. Some are precious in winter from the pretty claret colour showing well throughout that season. Some are excellent as leaves for cutting to go with cut flowers or fruit instead of vine leaves. I tried them in large groups among shrubs at Gravetye, and found them very useful for covering the ground between newly-set shrubs: quite hardy and of the simplest culture.

The Heucheras are nearly all natives of a climate as cold as our own, and therefore they are better able to withstand our worst winters. The more common kinds, such as H. americana and H. Richardsoni, may be used with effect for massing in the wild garden, and for edging evergreen shrubberies few plants will be found more suitable. For the rougher part of rock-gardens, too, they are useful, and grow well in ordinary soil.

H. AMERICANA. - This is the most common kind. It is very useful for massing under trees or in shady places, to which indeed it may be said to be partial. The leaves are seven-lobed, of a beautiful green colour, which gets deeper toward the winter season. The flower-stems are generally about I ft. high, dividing towards the top into loose panicles, on which are borne the dull purplish flowers. June and July.

H. MICRANTHA has much the same habit as the above. It is pretty generally distributed under the name of rubescens, from which, however, it is different. It grows from I to $2 \mathrm{ft}$. in height, and the flowers, which are borne in loose panicles and of a bright purplish colour, though small, are numerous and attractive; the leaves are round, and from 2 to 4 in. in diameter. N. California.

H. RICHARDSONI.-As a fine-leaved plant this claims a first place, and on that account it has lately become popular under the name of Satin-leaf. It is a handsome plant for any open place, where it forms graceful masses that are as pretty in winter as in summer. It grows from I ft. to $\mathrm{I} 8$ in. high, and the flowers, which are borne in loose panicles and of a pale brownish colour, are large and hairy on both sides. N. America, flowering in June and July.

H. MENZIESI.-This is a distinct plant, and a companion for $\mathrm{H}$. americana, being easily distinguished from the others, inasmuch as it has leafy stems. It grows about $2 \mathrm{ft}$. high ; leaves large, and deeply serrated; and the flowers, which are without petals, are curious. It comes from the north-west coast of America, and flowers in July. A variety of it, nearly quite devoid of hairs, is also in cultivation.

H.PUBESCENS.-This is a pretty species, being covered all over with a soft powdery down; the flowers, in clustered panicles, are large and of a pale red colour, intermixed with a yellowish tint. 
It grows about $\mathrm{I} \mathrm{ft}$. in height, and flowers from May to July.

H. SANGUINEA is perhaps the most beautiful of all. It grows in the ordinary border, without special care. When seen in masses it has a charming effect, having a neat bushy habit, numerous loose and graceful flower-spikes about I ft. in height, and covered with red blossoms. The leaves circular, five to seven-lobed, of a light green colour and slightly hairy. The anthers are darker than the flowers, which enhances their beauty. It is a native of the Porphey Mountains of Llanos, and flowers in July and August. Division.

The only others worth mentioning are H. glabra and longipetala, the latter with white flowers.-D. K.

Hibiscus (Rose Mallow).--Shrubby and herbaceous perennials and annuals. They are numerous in hothouses, but few are suited for the flower-garden. The splendid hardy Rose Mallows of the woods and swamps of $\mathbf{N}$. America will grow with us, but probably our climate is not warm enough for them, though it would be very desirable to try tufts of them in warm sunny places in the southern parts of England, in deep, rich, moist soil. They have splendid crimson or rosy flowers, as large as saucers, and are from 4 to $7 \mathrm{ft}$. high. The finest are H. Moscheutos, H. palustris, H. grandiflorus, and $H$. coccineus. They seldom bloom in the open air in England, as they flower late in the season. There are two or three annual kinds, the finest being H. Manihot, which forms handsome pyramids 4 to $6 \mathrm{ft}$. high, the flowers being 3 or 4 in. across, and pale yellow with a dark centre. H. Manihot should be treated as a half-hardy annual, sown in heat in February, and in May planted out in good deep soil. $H$. africanus is a hardy annual with showy pale yellow flowers that only open in fine weather. In light soil it usually sows itself. $H$. Trionum is similar, but inferior to the preceding.

H. Syriacus (Syrian Mallow, Rose of Sharon).-A beautiful shrub, bearing large showy blossoms in late summer and in autumn, when shrubberies would otherwise be flowerless. It is a very old favourite, and in strong moist soils it rises 6 and even Io ft. high, and as much through. It is a miserable shrub on poor dry soils, but attains perfection in deep ground fairly rich, and always moist. The typical form has bluish-purple flowers with crimson centres, but now there are forms representing every tint from pure white (totus albus) to crimson and purple, while the blooms of one sort (Celeste) are almost pure blue. There are also double flowers of varied colours. The best kinds, single and double, are Totus albus, Celeste, Violet Clair, Leopoldi, bicolor, roseus plenus, Pompon Rouge, carneoplenus, Duc de Brabant, albus plenus, puniceus plenus, and anemonæflorus. A few bushes nicely grouped on a lawn with one or two taller trees or shrubs make a pretty feature, and under the partial shade of trees the effect of the flowering bushes is more striking in autumn. The old name for this shrub is Althæa frutex, by which it is now also known.

Hieracium (Hawkweed). - A very extensive genus of Composites, consisting chiefly of perennial herbs with yellow flowers. The best for the garden is $\mathrm{H}$. aurantiacum, which is distinct among plants of a similar character on account of its deep orange-red colour. It is a vigorous grower, I or $\mathrm{I} \frac{1}{2} \mathrm{ft}$. high, and soon forms a spreading mass. W. Europe. Some of the yellow alpine and other kinds are valuable in botanical collections, and some of them are beautiful, but the prevalence of yellow flowers of the same type makes them less important.

Hippocrepis comosa (Horse-shoe Vetch). - A small prostrate British evergreen herb about 6 in. high. Its yellow flowers, of which 5 to 8 are borne together in a crown, resemble those of the Common Bird's-foot Trefoil, but are paler and rather smaller. It grows freely in any exposed part of the rock-garden and borders, in any soil. Seed and division.

Hippuris (Mare's-tail). - A British water-weed, worth growing with the Equisetums and the like by ponds where the growth near is not too rank.

Holbœllia latifolia.-A beautiful evergreen climbing shrub from the Himalayas, hardy against walls in the southern and the warm districts. The foliage is thick with three or five leaflets of a deep shining green. The flowers are a deliciously fragrant dull purplish green, but it does not bloom so freely out of doors as in a cool conservatory. As it is of tall growth, it must be planted against a high wall, such as that of a house or stable. It is known also as Stauntonia latifolia. The variety angustifolia has smaller and more numerous leaflets.

Holcus.-British Grasses, of which one, H. mollis, affords a pretty variegatedleaved form for lines and edgings, retaining its markings very well.

Holly (Ilex).

Holly Fern (Aspidium Lonchitis). 


\section{Hollyhock (Althea). \\ Honesty (Lunaria bicnnis). \\ Honeysuckle (Lonicera). \\ Honeysuckle, Bush (Weigela). \\ Honeysuckle, French (Hedysarum). \\ Honeywort (Cerinthe). \\ Hoop Petticoat (Narcissus Bulboco- diume.}

\section{Hop (Humulus).}

Hordeum. - Grasses, of which the Barley is the most familiar type. Of no ornamental value except $H$. jubatum (Squirrel-tail Grass), which has long feathery spikes. It grows in any soil in open places, and is easily raised as an annual. It is one of the most distinct dwarfer ornamental Grasses. Sow in autumn or spring.

Horminum pyrenaicum. - A Pyrenean plant, forming dense tufts of foliage, and having spikes about 9 in. high of purplish-blue flowers, which appear in July or August. It is quite hardy and of easy culture, but is not of much character from a garden point of view, though botanically interesting. Labiatæ.

Horned Poppy (Glaucium lutcum).

\section{Horsetail (Equisetum).}

Hoteia japonica.-A fine tufted herbaceous plant $\mathrm{I} \mathrm{ft}$. to $\mathrm{I} 6 \mathrm{in}$. high. Its silvery-white flowers appear early in summer in a panicled cluster. In a rich soil it is excellent for a shady border. Strong clumps planted in autumn will flower in the following spring. Where there are forced plants to spare they may be planted out when they have done blooming, but will not make much show in the following season. Much used indoors, is seldom good in the open garden, partly because it does badly in heavy and poor soils. Where it thrives and flowers well it would be a graceful aid in the varied flower garden. Increased by division in autumn. Japan. Syns., Spiræa japonica, Astilbe barbata.

Hottonia palustris (Water Violet).A pretty British water-plant, which, however, thrives better on soft mud-banks than when submerged. The deep-cut leaves form a dwarf deep-green tuft over the mud, and from this tuft arise stems bearing at intervals whorls of handsome pale lilac or pink flowers. As waterand bog may be associated with the rock-garden, this plant may with advantage be grown at its margin in the water or on a bank of wet soil. It grows from 9 in. to $2 \mathrm{ft}$. high, flowers in early summer, and is abundant in many parts of England.
House Leek (Sempervivum).

Houstonia cœrulea (Bluets).-A very pretty little American plant, forming small, dense cushion-like tufts, and from late spring to autumn bearing crowds of tiny slender stems, about 3 in. high. The flowers are pale blue, changing to white. There is also a white variety. It succeeds best in peaty or sandy soil, in sheltered shady nooks on well-drained parts of the rock-garden. As it sometimes perishes

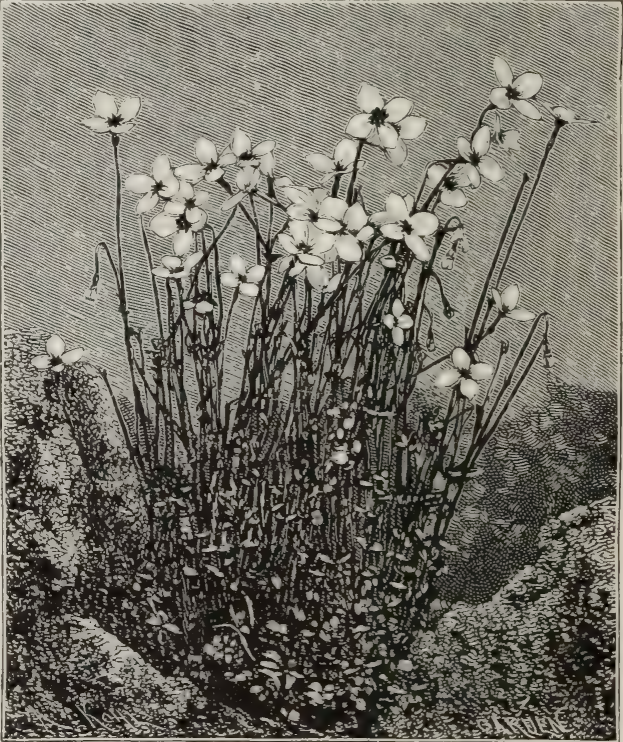

HOUSTONIA CERULEA. in winter, it is advisable to keep reserve plants in pots. Propagated by careful division in spring, or by seed. H. serpyllifolia is not so good.

Houttynia.-Remarkable plants allied to Saururus, and the only hardy representatives of the natural order Piperaceæ. They are graceful as well as curious plants, and are suited for the bog-garden, where in a rich peaty soil they thrive. They are hardy in the south.

H. CALIFORNICA. - This plant is also known in gardens as Anemiopsis californica ; it is now, however, placed under Houttynia. It was first found by Nuttall in Upper California, and later by Douglas, who sent specimens home. It is perennial, on long stalks. The flower-stem very hairy, and bearing numerous small inconspicuous flowers on oval cone. This is surrounded by six large bracts, the inner three spotted with red, the others white. It is a useful plant for the bog-garden, and easily managed, and flowers June to August. 
H. CORDATA is a perennial, with a creeping root, the stems I to $2 \mathrm{ft}$. high, the bracts resembling a corolla, and formed of four large pure white spreading leaves from the base of the cone of flowers. Thunberg found this curious plant in Japan growing in great abundance in ditches by the wayside. It is also found in Nepaul and Cochin China, where Loureiro found it only growing in gardens.

H. CHINENSIS, which was first named Gymnotheca chinensis by Decaisne, is a native of China, and appears to be a good plant, but we have not seen it in cultivation.-D.

Humea elegans.-A very graceful half-hardy biennial, 3 to $8 \mathrm{ft}$. high, having large leaves with a strong balsamic odour, and forming, when in flower, an elegant feathery pyramid of reddish-brown blossoms. It is highly ornamental as a back line to a long border, as a single specimen to let into the lawn, as the centre of a bed or vase, or in masses with other elegant foliage plants. Excellent effects may be obtained by combining it in masses or groups with other good plants. For cutting, its light feathery sprays are useful. The proper time to sow seed is July or August, as plants do not bloom the first year, and, if raised before those months, get too large to winter conveniently, often becoming leafless below, and the nakedness of stem detracts from their beauty. To prevent this, they should be well fed during winter with weak liquid manure, and be shifted into larger pots early in spring. Rich soil should be used, as they can only be kept healthy by. good feeding. When planting them out in beds, which may be done by the first week in June, put under each a spadeful of rotten manure and mix it up with the soil. As the plants, when large, hold a good deal of wind, they must be securely staked to prevent their being damaged. Compositæ. Australia.

Humulus Lupulus (Common Hop).This well-known vigorous twining perennial is admirable for bowers, especially when vegetation that disappears in winter is desired; and is also valuable when allowed to run wild in almost any soil, among shrubs or hedgerows. A slender plant climbing up an Apple or other fruit tree, near the mixed border, looks well. Division.

Hunnemannia fumariæfolia. - An erect perennial, 2 to $3 \mathrm{ft}$. high, with glaucous foliage, like some of the Fumitories. Its flowers are large and showy, of a rich orange, and in form are like Eschscholtzia californica. They continue long in perfection. Being a native of Mexico, it is rather tender, and not satisfactory for open-air culture. Papaveraceæ.

\section{Huntsman's-horn (Sarracenia).}

Hutchinsia alpina. - A neat little plant, with shining leaves and pure white flowers, which are produced abundantly in clusters about I in. high. Quite free in sandy soil, and easily increased by division or seeds. In an open spot, either in the rock-garden or in good free border soil, it becomes a compact mass of white flowers. Its proper home is the rockgarden, though in borders of dwarf and choice hardy plants it may be grown with success. Central and S. Europe. Cruciferæ. Syn., Smelowskia alpina.

\section{Hyacinth, Cape (Galtonia).}

$\begin{array}{ll} & \text { Feather (Muscari) } \\ \text { ", } & \text { Grape (Muscari). } \\ \text { " } & \text { Musk (Muscari). }\end{array}$

Hyäcinthus (Hyacinth).-The familiar garden Hyacinth is not generally included among hardy plants, though it is perfectly hardy, and, when treated as it should be, is most important. The parent of all the varieties is $H$. orientalis ; this is as hardy as a Daffodil, and its varieties are scarcely less hardy. Hyacinths in the open air are generally the refuse, as it were, of the forced bulbs of preceding years, but even these create a good display in suitable positions. To have a fine bloom of Hyacinths in the open air, however, it is essential that the bulbs should be good and sound, and due regard paid to assortment of colour, as tints massed by themselves are far more effective than a confusion of various colours. Now that bulbs may be obtained cheap there is no difficulty. The Hyacinth will grow well in any good garden soil, but a light rich soil suits it best, and the bed should be effectually drained, for though the plant loves moisture, it cannot stand in a bog during the winter. It is advisable to plant early and deep. If a rich effect is required, the bulbs should be 6 in. apart, but a good effect may be produced by planting them 9 in. or even more apart. The time of blooming may to some extent be influenced by the time and manner of planting, but no rules can be given to suit particular cases. Late planting and deep planting both tend to defer the bloom, but make no great difference, and as a rule late bloom is to be preferred, being less liable to injury from frost. The shallowest planting should ensure a depth of $3 \mathrm{in}$. of earth above the crown of the bulb, but, generally speaking, they will 
flower better, be a few days later, and come up better bulbs after flowering, if there is fully 6 in. of earth over the crowns. The Hyacinth is so hardy that protection need not be thought of except in peculiar cases of unusual exposure, or on the occurrence of excessively low temperature when they are growing freely. There is usually no protection so effectual as dry litter, but a thin coat of half-rotten manure spread over the bed is to be preferred in the event of danger being apprehended at any time before the growth has fairly pushed through. The bulbs need no further attention until the flower-stems disturbed until the leaves wither or die. The bulbs should then be taken up, dried in a stack for a week or two, and finally placed in the sun for a few hours, the dry leaves being pulled off. Offsets should likewise be removed from the bulbs, and stored in dry sand or earth till the next planting time. Some lay it down that the bulbs should be taken up every year, but we have seen handsome beds that were not disturbed for several years. Offsets, carefully cultivated in rich light soil for two or three years, will produce a good many flowering bulbs, but, as a rule, imported bulbs are stronger. However

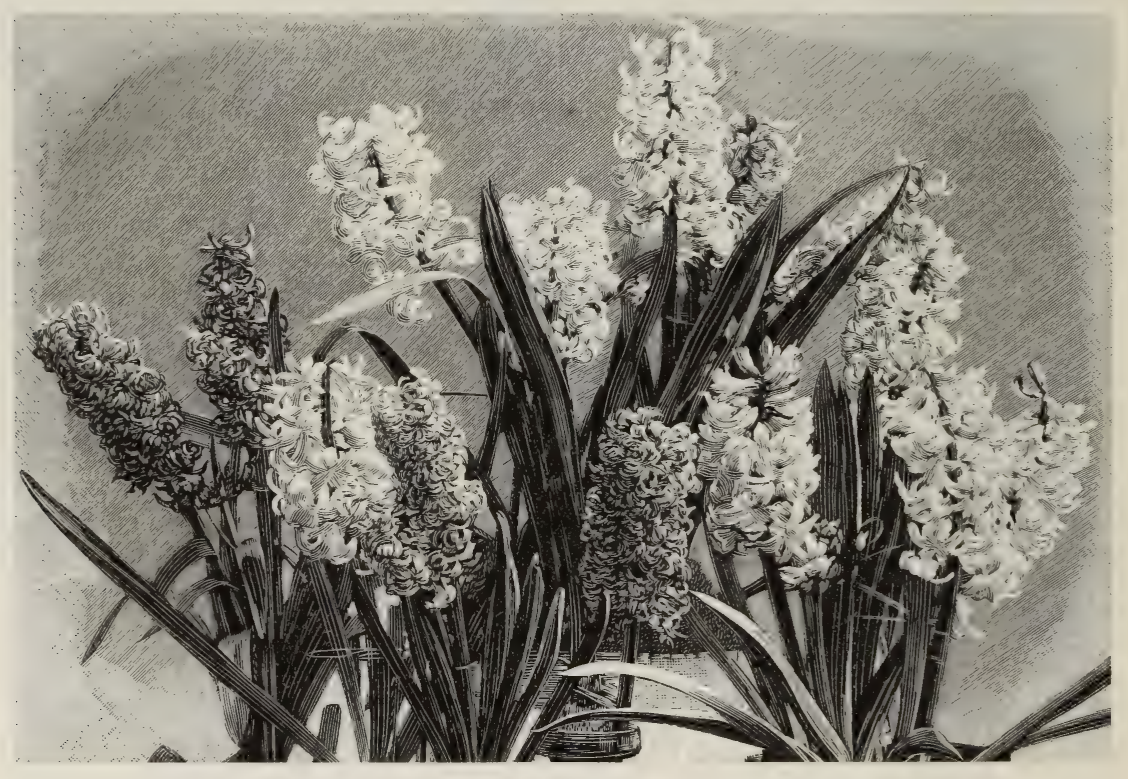

HYACINTH.

are much advanced, unless very severe weather intervenes, when a mat or some oiled calico should be thrown over them. Waterproof calico is also useful in very wet weather, as excess of water, especially when iced by February frosts and March winds, is by no means good for Hyacinths, which will thrive all the better for a waterproof covering. Hyacinths in the open air hardly ever require artificial watering, the natural moisture of the soil and the strength of the manure mixed with it being sufficient. When grown in beds they do not require sticks or ties; all they need is proper planting, and they will take care of themselves until the cultivator lifts them to appropriate the ground to other plants. After blooming, the bulbs, if intended to flower again, must be left un- carefully cultivated in England, they seldom flower again so well as in the first season, but it is a great mistake to throw them away, as many people do. Selections for bedding in distinct colours of red, yellow, white, blue, or mixed are to be bought cheap.

$\mathrm{H}$. amethystinus is a beautiful plant, with deep sky-blue bells, gracefully disposed on stems 8 in. to I ft. high, and taller when the plant is in very light rich soil, and not too cold or exposed. It is a hardy native of the Pyrenees and Southern Europe, and flowers in early summer. In stature and general appearance it is something like a graceful Scilla, but its pretty bells are not divided into segments. It is worthy of association with the choicest hardy bulbs and inhabit- 
ants of the rock-garden. The lovely white variety (albus) is worth growing in every select collection.

\section{H. candicans (Galtonia).}

Hydrangea. - Handsome flowering shrubs, some well known in gardens, others neglected. In warm districts and on good warm soils it would be well worth while to grow many of the rarer and finer forms of the common Hydrangea, which always flowers best in seashore districts where its shoots are not cut down by frost or by the knife every winter.

H. HoRTENSIA.- The common Hydrangea (H. Hortensia), from China, may be grown well out-of-doors, but is not always satisfactory in the midlands and the north, being liable to injury in winter. It likes a sheltered yet sunny spot and good soil. In order to get good heads of bloom, the Hydrangea must be pruned so as to induce the growth of strong shoots. In favoured spots it reaches a height of $6 \mathrm{ft}$., and is as much through, making a beautiful object on a lawn or in the shrubbery margin. From time to time, and especially in recent years, other forms have been introduced and described, some of them as distinct species. Dr. Maximowicz, who has had opportunities of studying them both in European and Japanese gardens, and also in a wild state, arranges the following forms under H. Hortensia :-

(a) H. HoRtensia ACUMinAtA.-A much-branched shrub, 2 to $5 \mathrm{ft}$. high ; flowers blue. It sports according to locality, etc., and Maximowicz enumerates four such sports, viz.: In open places and in a rich soil it is stouter, with erect thick branches, large, broad, firm leaves, and larger flowers with somewhat fleshy sepals ; under cultivation it becomes more showy, passing into $H$. Belzonii. In woods and on the shady banks of rivers it grows taller with slender stems, pointed leaves, and much smaller flowers. In a very fertile soil, a stout plant with toothed sepals in the barren flowers, which are commonly of a blue colour. This is the true H. Buergeri of Siebold and Zuccarini's Flora Japonica, and the $H$. japonica cœerulescens of Regel. Sometimes it produces white or rose-coloured flowers, and then it is the H. roseo-alba, as figured in the Flore des Serres. These variations are all beautiful, but perhaps not constant.

(b) H. HoRTENSIA JAPONICA.-This is the H. japonica of Siebold and Zuccarini's Flora Japonica, and the $H$. Japonica macrosepala of Regel's Gartenflora. It is exactly like acuminata, save that the flowers are tinged with red, and the sepals of the barren flowers are elegantly toothed.

(c) H. Hortensia BelzoniI. - A short stout plant, with beautiful flowers, the inner sterile ones being of an indigoblue, and the enlarged sterile ones white, or only slightly tinged with blue, and having entire sepals. There is a sport of this in which the leaves are elegantly variegated with white. This was raised by Messrs. Rovelli, of Pallanza.

(d) H. HoRTENSIA OTAKSA. - This has all the flowers sterile and enlarged. A very handsome variety with rich dark green leaves nearly as broad as long, and large hemispherical heads of pale pink or flesh-coloured flowers, very fine when well grown.

(e) H. Hortensia COMMUNIS.-This is the old variety with rose-pink flowers, commonly cultivated in European gardens. It differs from the last in being perfectly glabrous in its longer, less-rounded leaves, and in its deeper-coloured flowers.

(f) H. Hortensia Azisia.-This is not in cultivation, but it differs remarkably from all of the preceding varieties in the sterile flowers, which have a very long, slender calyx tube.

(g) H. Hortensia stellata.-The chief character of this variety is in the flowers, which are all sterile and double. The variety in cultivation has pink flowers, but they are described as being either pale blue or rose, finally changing to a greenish colour, and distinctly net-veined.

The white variety Thomas Hogg is a very fine one, now widely cultivated. Most of the above-named deserve the attention of all who have soil and climate suited to these shrubs.

H. PANiculata (Plumed Hydrangea). - A shrub or small tree. According to Maximowicz, the only Japanese Hydrangea which becomes a tree. It grows as much as $25 \mathrm{ft}$. high, with a dense rounded head and a straight trunk 6 in. in diameter. But it more commonly forms a shrub a few feet high, bearing enormous panicles of flower. With the exception of $\mathrm{H}$. Hortensia, it is the commonest species in Japan, growing throughout that country both in the mountains and the plains, being more abundant in the northern parts, and it is said to vary very much. It is commonly cultivated by the Japanese. The massive clusters of pure white blossoms, terminating every shoot in autumn, are very beautiful, and there are few finer autumn effects than a well-flowered mass of this shrub. It must have a good soil, and be well mulched with manure in winter. To 
encourage the new growth the old and useless shoots must be cut away. It is from 3 to $4 \mathrm{ft}$. high, and spreads its branches gracefully and widely on all sides. The clusters are often I ft. long and half as much in diameter, but to get such flowers we must cultivate well and prune the shrubs hard down in winter.

H. HIRTA (Nettle-leaved H.) - A dwarf straight, slender, and polished, bearing small, thin, deeply-toothed leaves, 2 to 3 in. long, yellowish-green above, and pale beneath, with small clusters of flowers, some of which are sterile. Altogether this is a pretty little shrub, and it is somewhat surprising that it has not been introduced, as it is common in the neighbourhood of Nagasaki, in Japan.

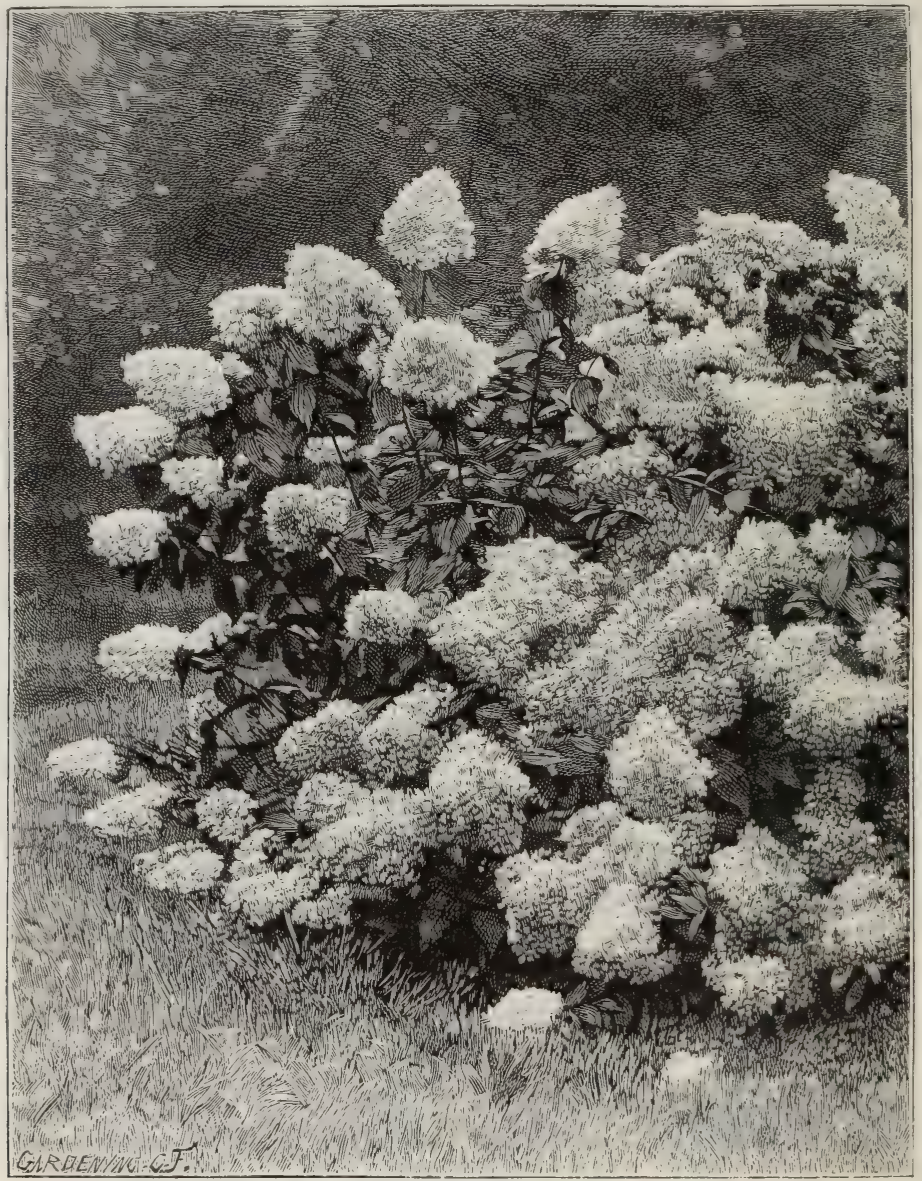

THE PLUMED HYDRANGEA.

shrub, 3 or $4 \mathrm{ft}$. high, with slender hairy branches and Nettle-like leaves. The leaves and branches become nearly or quite glabrous with age. This, although not a showy species, seems to be a pretty, compact dwarf shrub, with numerous clusters of white flowers. A native of the mountains of Japan.

H. VIRENS (Changing $H$.) - This is a remarkable and elegant shrub, varying in height from 2 to $6 \mathrm{ft}$. The branches,
H. CHInensis (Fortune's H.) - Near the last, but of more robust habit, with leaves 3 to 5 in. long, and with cymes of flowers much larger. It differs from $H$. virens in the leaves being green on both sides, and in the enlarged sepals being nearly equal in size, much thicker, in fact almost fleshy in substance, and remaining on the branches until the fruit of the fertile flowers is ripe. This species was collected by $\mathrm{Mr}$ Fortune in N. China. 
H. ThunBergI.-A small shrub with slender branches, small leaves, and small cymes of flowers. A few only of the outermost ones are sterile, and these are not more than $\frac{1}{2}$ in. in diameter. According to the Gardeners' Chronicle, Messrs. Cripps, of Tunbridge Wells, flowered this species in June I870. They describe it as hardy, though not so showy as some of the varieties of $H$. paniculata and $H$. Hortensia. The sterile flowers are of a delicate Peach-blossom colour. It is a native of the mountains of Sikok and Nippon, Japan.

H.QUERCIFOLIA (Oak-leaved H.)-This is a fine distinct kind, and though not showy like the popular kinds, it is an excellent shrub, and one I have noticed growing with fine vigour in sea-shore gardens. The leaves have a good deep colour in the autumn, and the flowers are beautiful, while old plants have a picturesque habit.

The whole family is in want of looking up by some enthusiastic admirers who have good soil and other conditions favourable. Although there is a large range of land in great Britain in which Hydrangeas seem happy, there are other inland and cold districts in which they make poor growth, or are cut down so frequently that experiments come to little. I made a trial myself on a cool hill-side in Sussex without getting any bloom or a healthy growth; but on the other hand we see, especially in the South of England and Ireland, beautiful results in warm valleys and on sandy and alluvial soils even from the use of one kind, so that I have often thought that any one who should take up the Hydrangeas in earnest, and grow them and group them well, might have some very interesting results.

Hydrocharis Morsus-ranæ (Frog-bit). -A pretty native water-plant, having floating leaves and attractive yellow flowers, and well worth introducing in artificial water. It may often be gathered from ponds or streams in spring, when it floats after being submerged in winter.

Hydrocotyle (Pennywort). - Small creepers, usually with round leaves and inconspicuous flowers. There are several kinds grown, but their only use is as a surface growth to the artificial bog. The most desirable are $\mathrm{H}$. moschata and microphylla, two New Zealand species, and nitidula, though all of these are somewhat tender. The common $\mathrm{H}$. vulgaris is rather too rank. Umbelliferæ.

Hymenophyllum (Filmy Fern).-Although these Filmy Ferns are hardy and very beautiful, yet the conditions of their success are such that in a general sense they cannot be used with effect in the open air. Still, as two kinds are abundant in certain hilly districts, in moist, shady, or rocky situations, there is no reason why they should not be inmates of the garden, at least in hilly districts or in some places in the west or in the north.

Hymenoxys californica. - A hardy annual Composite, about 6 in. high, with a compact tufted habit, and bearing in summer a profusion of bright yellow Daisy-like blossoms. Sow in autumn in light dry soil for early flowering, and in spring for later bloom. = Shortia.

Hyoscyamus (Henbane). - Plants of the Nightshade family, of no garden value. $(H$. physaloides $=$ Nicandra. $)$

Hypericum (St. John's Wort).-Often handsome plants, for the most part shrubs and under-shrubs, but including a few herbaceous perennials and annuals. The Rose of Sharon (H. calycinum) is probably the most familiar, but there are other shrubby species of some beauty. Some of the perennials are good border and rock-garden plants, and the best of these is H. olympicum, one of the largest flowered kinds, though not more than I $\mathrm{ft}$. high. It is known by its very glaucous foliage and erect single stems, with bright yellow flowers about 2 in. across. It forms handsome specimens that flower early, and its value as a choice border plant can scarcely be over-rated. It may be propagated easily by cuttings, which should be put in when the shoots are fully ripened, so that the young plants may become well established before winter. $H$. Elodes is a pretty native plant suitable for the banks of pools and lakes. H. nummularium and humifusum, both dwarf trailers, are also desirable for the rock-garden. Owing to their dwarf compact growth, several of the shrubby species are well suited for the rock-garden. Of these, the best are $\mathrm{H}$. ægyptiacum, balearicum, empetrifolium, Coris, patulum, uralum, and oblongifolium. The last three are larger than the others, but as they droop they have a good effect among the boulders of a large rock-garden, or on banks. H. Hookerianum, triflorum, aureum, orientale are among the kinds having some beauty, but the species from warmer countries than ours are apt to disappear after hard winters.

Hypolepis millefolium (New Zealand Bracken).-A very elegant New Zealand Fern, with a stout and wide-spreading rhizome, from which arise erect light green fronds, I to $1 \frac{1}{2} \mathrm{ft}$. high, very finely 
cut. As to its hardiness, there can be no doubt, as it has flourished for two or three years in a Surrey garden in an open rock-garden, and I also saw it lately quite hardy and vigorous in $\mathrm{Mr}$. F. Lubbock's garden in Kent. It requires a sheltered nook and peaty soil.

Hypoxis.--Low-growing plants, mostly natives of South Africa. They have grassy foliage and yellow flowers, are tender, but in summer sometimes planted out in the light sandy soil of warm borders.

Ianthe bugulifolia. - An interesting plant resembling a Mullein, having a rosette of leaves, from which springs an erect flower-spike, 8 to 12 in. high, thickly set with curiously-coloured blossoms of chocolate-brown and yellow. It is hardy, but not a true perennial, and it is therefore advisable to raise seedlings yearly in frames, and afterwards to transfer them to the border or rock-garden. Turkey. Scrophulariaceæ. = Celsia .

Iberidella rotundifolia. - A dwarf evergreen plant, with leathery leaves of an olive-green. It is 3 to $6 \mathrm{in}$. high, and flowers in early summer, the blossoms rosy - lilac, sweet, and numerous in racemes. Suitable for the rock-garden, succeeding best in gritty loam in deep fissures; being tap-rooted, it is not readily increased by division, but is easily raised by seed sown in small pots in a cold frame. European Alps. Cruciferæe. $=$ Thlaspi rotundifolium.

Iberis (Candytuft).-Well-known and valuable hardy perennials and annuals. All the perennials are somewhat shrubby and have evergreen foliage, so that they are useful winter plants. The principal kinds are those treated of.

I. corifolia.-A very dwarf kind only 3 or 4 in. high when in flower, and covered with small white blooms early in May. Few alpine plants are more worthy of general culture either in the rock-garden or the mixed border-for the front rank of which it is admirably suited. It is probably a small variety of I. sempervirens, but is distinct and remarkably true to its character. A native of Sicily and probably of other parts of Southern Europe. Easily propagated by seeds or cuttings, and thriving in any soil.

I. correæfolia is readily known from any other cultivated kind by its large leaves, its compact heads of large white flowers, and by its flowering later than other common white kinds. Both the flowers and the corymb are larger and denser than in the other species. It is an invaluable hardy plant, and useful in coming into full beauty about the end of May when the other kinds are fading. It is excellent for the rock-garden, the mixed border, and the spring garden. It is especially well suited for the margins of choice shrubberies, as it will bring them neatly down to the grass line, and may be used as an edging to beds. Said to be a hybrid. Increased by cuttings, it loses its true character when raised from seed.

I. gibraltarica is a beautiful plant, larger in all its parts than the other kinds. Its large flowers of delicate lilac are arranged in low close heads, and appear in spring and early summer. It is an ornamental species, but will never rival the well-known white border kinds. Its hardiness is doubtful, and it should, therefore, be planted on sunny spots in the rock-garden or on banks in light soil, and wintered in frames. A native of the south of Spain; increased by cuttings, as it rarely produces seeds in our climate.

I. jucunda is distinct from any other, as it only grows about $2 \frac{1}{2}$ in. high. The leaves are small, and the flowers, in small clusters, are of a pleasing flesh colour and prettily veined with rose in early summer. It does not possess the vigour of common evergreen Iberises, but although unlike them, it is none the less valuable as a rock-plant, and is fitted for association with dwarfer and more select subjects. It should be planted on warm and sunny parts of the rock-garden in well-drained sandy loam. = Æthionema.

I. petræa, another pretty dwarf alpine species, bears a flat cluster of pure white flowers, relieved in the centre by a tinge of red. It only grows about 3 in. high; and therefore requires to be placed among the choicest flowers in the rock-garden. Many cultivators cannot succeed with it, but it thrives finely in a well-drained position, with plenty of moisture at the roots.

I. semperflorens is an upright shrubby plant, with large dense corymbs of pure white flowers. It is not suited for general border culture, but is hardy enough to stand our winters when grown at the foot of a south wall or in a very sunny corner of the rock-garden. Under those favourable conditions it forms a pretty evergreen bush in bloom almost all the year round. Sicily and other Mediterranean islands There is in cultivation a pretty variegated form which appears to retain its variegation with constancy.

I. sempervirens.-This is the common rock or perennial Candytuft, and is as popular as the yellow Alyssum and the 
white Arabis. Half-shrubby, dwarf, spreading, evergreen, and perfectly hardy, it escapes destruction where many herbaceous plants are destroyed; and in April and May its neat tufts of dark green are transformed into masses of snowy white. Where a very dwarf evergreen edging is required for a shrubbery, or for beds of shrubs, it is one of the most suitable plants known, as on any soil it quickly forms a spreading band almost as ow as the lawn-grass, finishing off the plantation very neatly at all times, and changing to dense wreaths of snowy-white flowers in spring and early summer. When in good soil and fully exposed, it forms
I. Tenoreana will be more valuable from its purplish tone as well as its neat habit. It has not, however, the perfect hardiness and fine constitution of the white kinds, and seems very apt to perish on heavy soils in winter; but on light sandy soils and in well-drained positions on the rockgarden it is a gem. Where no rock-garden exists it should be placed on raised beds or banks. A native of Naples, and early raised from seed; it should be treated as a biennial.

I. umbellata (Annual Candytuft).This species and its ally (I. coronaria) yield the popular hardy annual Candytufts. They are extremely varied in

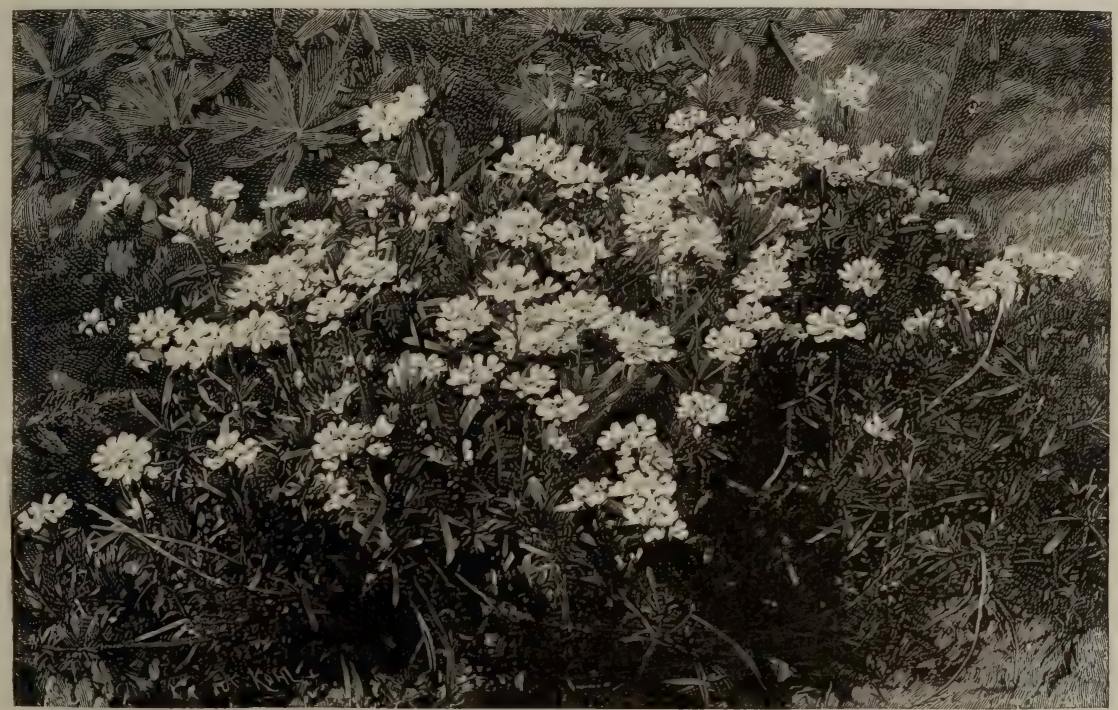

IBERIS GIBRALTARICA.

spreading tufts nearly I ft. high, which last for many years. Like all its relatives, it should be exposed to the full sun rather than shaded. Readily increased by seeds or cuttings. Its common garden name is I. saxatilis. I. Garrexiana is not sufficiently distinct to be worthy of cultivation; in fact, it and several other Iberises prove, when grown side by side, to be very slight varieties of I. sempervirens; it, however, seeds more abundantly, and is less spreading. I. superba, another variety, is the finest of the perennial kinds, as it is of good bushy habit and bears many large dense heads of pure white flowers.

I. Tenoreana is a neat dwarf species, bearing in summer a profusion of white flowers, changing to purple. As the commonly-cultivated kinds are pure white, colour, and are among the most beautiful of open-air flowers. They are very hardy and may be sown at all seasons, but, as in the case of most other hardy annuals, the finest displays are obtained from autumn-sown plants, which flower from May to July. They require a rich moist soil and plenty of room between them to develop themselves and flower freely. There are a great number of varieties, differing both in growth and colour. What are known as the dwarf or nana strain are very desirable, as they are neat and dwarf in growth, are abundant bloomers, and very showy. I. umbellata nana rosea and alba are two of the most distinct, being only about 9 in. high; their names indicate their colours. The dark crimson, carmine, lilac, and purple sorts, about I ft. high, 
are also very fine. The Rocket Candytuft (I. coronaria) in good soil grows 12 to $16 \mathrm{in}$. high, and has pure white flowers in long dense heads. There is a dwarf variety of the Rocket Candytuft called pumila, only 4 to 6 in. high, forming spreading tufts I ft. or more across. The Giant Snowflake is also an excellent variety. These Rocket Candytufts require the same treatment as the common varieties. I. pinnata and I. linifolia are not worth growing.

\section{Ice-plant (Mesembryanthemum).}

Ilex (Holly).-Beautiful evergreen shrubs of the northern temperate countries, of which by far the most important is our own native Holly, Ilex Aquifolium. It would be impossible to give an idea of the value of this plant, whether as the evergreen tree common in our woods, as the best of all fence-shelters for our fields, or as a lovely protection and ornament of our gardens; whether grown naturally or clipped as it must be to form fences; embracing also in its numerous varieties the most beautiful and enduring of the variegated kinds known,-variegation in most other things being mere manifestations of disease, whereas in the Holly it is quite consistent with health and beauty. No other shrub known to us may be so often used with good effect near the house and garden, and it will be clear, therefore, how much one should consider the common Holly in all its forms and ways. Valuable as many varieties are, probably none is quite so good as seedlings of the common kind. Good seedling plants are the easiest to transplant and establish. The art of grafting-most delusive as well as most curious of arts-should be carefully guarded against as regards Hollies. Hitherto the way has been to graft the many variegated kinds on the common Holly, and although we often see good results in that way, it is by far the safer plan to insist on the variegated and curious kinds being raised from layers or cuttings. Nurserymen are very apt, having large quantities of stocks of common things, to graft indiscriminately ; and though time seems at first to be gained by it, it is dead against the cultivator in the end in almost every case. It will perhaps take a long time to recognise the immense superiority of layered or cutting plants, but if purchasers inquire for and insist upon getting them, it will very much hasten progress. My own experience is that old plants grafted are extremely difficult to move with safety, and, generally, Hollies and other trees are best not moved when old. It is an expensive and troublesome business, and very often a great failure. Young healthy bushes, seedling or layer, will in a few years beat old grafted and established trees,- that at least is my experience. Very often old specimens from the nursery live for a number of years, but their appearance is deplorable, whereas healthy well-grown young plants, from 3 to $5 \mathrm{ft}$. high, when transplanted at the proper season, are often beautiful from the first. The time for transplanting Hollies is a very important consideration. No doubt healthy seedling plants might be transplanted at various times, but experience has proved that there is a distinct gain in transplanting Hollies in May; and if we transplant them rapidly and carefully at that time we shall probably notice no difference whatever as regards going back, but, on the contrary, good healthy growth the same year.

As regards the uses of the Holly, they are so many in the garden that it is difficult even to generalise them. As shelter in bold groups, dividing lines, hedges, beautiful effects of berry in autumn, distinct and close masses of evergreen foliage, bright and beautiful colour from variegated elegant groups and masses of the most beautiful variety,every kind of delightful use may be found in them in cottage gardens or in large gardens equally.

Mr. Shirley Hibberd, who was a very keen observer of the Holly, wrote as follows conceming it in the Gardeners Magazine :-

"The Holly will thrive in any ordinarily good soil that is free from stagnant water. We have found it make a surprisingly strong growth on clay land that had been improved by cultivation; but the finest Hollies usually occur on deep, fertile, sandy soils, and in districts where the yearly rainfall exceeds 25 in. It is accounted a slow - growing tree, and as compared with many trees that are less beautiful it is so, but its reputed slowness should never be allowed to stand in the way of its adoption where a substantial fence or noble undergrowth is wanted, and a reasonable time can be allowed for the trees to become established. From observations continued through a period of nearly thirty years, we have arrived at the conclusion that the average growth may be reckoned at 6 in. per annum. In a cool showery summer a hedge that has not been cut or interfered with will increase in height as much as 18 in., but in a dry hot season the increase 
will be scarcely appreciable, the growth of the most vigorous shoots amounting to only 2 or $3 \mathrm{in}$. It is certainly the finest tree we possess for a protective fence, whether to give a fine finish to the boundaries of a property or to screen off keen winds or exclude trespassers.
The months of April and May are also suitable. To ensure a rapid formation of a good hedge, plant a double row of strong nursery trees, 3 to $4 \mathrm{ft}$. high, cutting back any side branches that interfere with close planting. When the planting is finished, spread a mulch of half-rotten manure

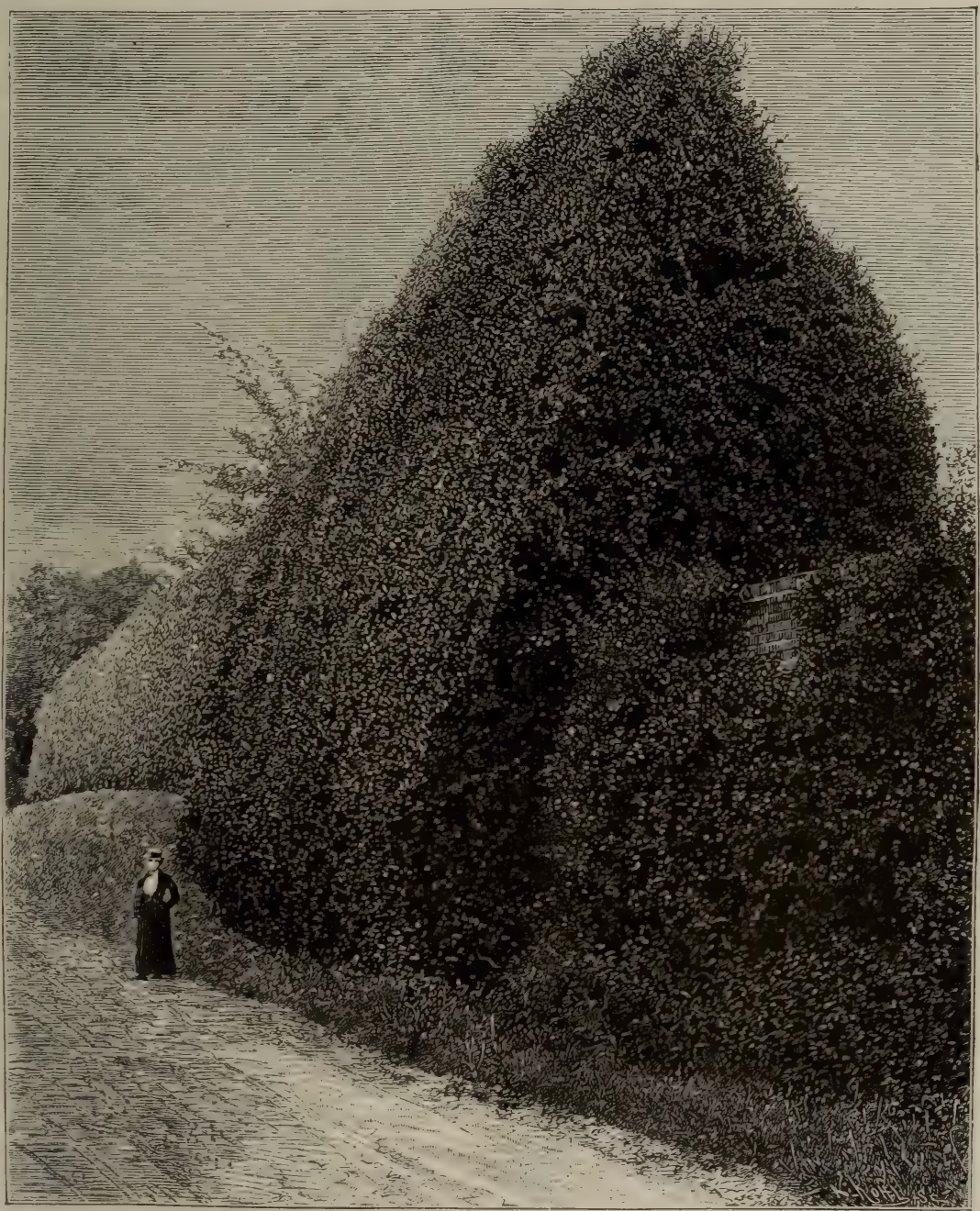

HOLLY HEDGE AT BAGSHOT.

"Holly Hedges. - Holly hedges are not only the most compact, impenetrable, and the handsomest of all live hedges, but they may be safely employed under the shade of large trees, where Thorn and other hedge trees might not thrive. The best time to plant is about the middle of August, and thence to the end of September.
2 or 3 in. thick over the roots. They should not be touched with knife or shears for at least three years, for every leaf removed will check the growth. The subsequent management will consist chiefly in cutting to line in the month of April, and the less severely this is done the better, unless severe primness 
is required, in which case the shears must be put into the hands of a man who may be trusted. It is far better, however, to rough prune with the knife. It is right to add, because it might not occur to the owner of a property, that noble Holly hedges may be secured by leaving the trees to grow entirely unchecked and without any pruning whatever. An instance of this has become familar to the inhabitants of Hornsey, in the property known as "Quaker's Folly." In this case Holly hedges had been planted to prepare the land for building on, and being for many years entirely neglected, they grew into gigantic and magnificent walls of the richest deep green verdure, solid to the ground line, very regular in general both as to height and breadth, but delightfully varied with undulations and bosses, chequering the surface with alternations of light and shade.

"In the garden-culture of the Holly the perpetuation of choice varieties is the matter of chief importance. The stock employed is the common seedling Holly. On this the varieties are placed by grafting in March or by budding in July, the last-named process being preferable. Propagation by cuttings is not often resorted to, but it may be accomplished with ease and certainty. Young shoots of the season are selected in the month of August and planted close in sandy soil in frames or under hand-glasses; they should be kept moderately moist and somewhat shaded, and have but little ventilation until the month of May following, when the protection may be removed to enable them to make their first growth fully exposed to the light and air. Variegated Hollies raised in this way grow slowly for the first few years, but when established grow as fast as grafted trees, and branch densely from the ground line.

"SElECTION OF VARIETIES.-In the selection of Hollies it will be well to bear in mind that the variety known as Scotica answers best of any plant near the sea. The variety known as Hodgins's is the most free in growth in a town garden, being less affected by smoke than most others. The most fruitful varieties are catalogued as fomina, glabra, madeirensis, balearica, lutea, and flava. The most distinct and beautiful of the variegated kinds are Golden Queen, Silver Queen, Painted Lady, Broad-leaved Silver, Gold Milkmaid, Watereriana, and Argentea marginata. The following classification of Hollies in relation to their several characters will be useful :-

"Male-Flowering Hollies.-Cili- ata, Heterophylla, Latispina, Laurifolia, Tortuosa, Gold Tortuosa, Beetii, Cookii, Gold Cookii, Cornuta, Doningtonensis, Ferox, Ferox fol. arg., Ferox aurea, Foxii, Furcata, Ovata, Picta marginata, Golden Queen, Longifolia aurea, Longifolia argentea, Watereriana, Gold Few-spined, Silver Queen, Shepherdii.

"FEMALE - FLOWERING Hollies.Angustifolia, Angustifolia aurea pendula, Angustifolia medio picta pendula, Balearica, Broad leaf, Dark shoot, Fisherii, Flava fructo aurea, Fœmina, Golden Milkmaid, Glabra, Handsworthiana, Silver Handsworthiana, Heterophylla, Hodginsii, Latifolia argentea, Latifolia aurea, Lutea, Madame Briot, Madeirensis, Madeirensis nigrescens, Madeirensis variegata, Myrtifolia, Milkmaid, red berry ; Milkmaid, yellow berry; Moonlight, Perry's Weeping, Picta aurea, Platyphylla, Scotica, Watereriana, Weeping.

"HERMAPHRODITE-FLOWERING HOLLIES. - Shepherdii, Smithiana, Silver Queen, Heterophylla, Hodginsii, Laurifolia, Handsworthiana, Lutea, Flava, Scotica, Balearica, Rotundifolia."

By far the best of all known Hollies is our native Holly, but there are other Japanese and American kinds worth growing, such as Ilex crenata, and the fine I. latifolia. This, however, requires our most temperate districts to thrive.

Illicium floridanum.-An interesting half-hardy evergreen shrub from the Southern States of N. America, bearing fragrant flowers of a deep red, like those of the Carolina Allspice. I. religiosum, also known as I. anisatum, from China and Japan, with pale yellow flowers, is also interesting, but scarcely worthy of general culture. It may be grown against walls in warm localities.

\section{Immortelle (Helichrysum).}

Impatiens (Balsam). - The species of Impatiens that thrive in the open air are all annual and hardy, and sow themselves freely where they get a chance. The best are-the common I. glandulifera, which attains a height of 4 to $6 \mathrm{ft}$., and bears numerous flowers, varying in colour from white to rose. It will soon take possession of the shrubbery if not checked; it is seen to advantage in cottage gardens. I. longicornu is beautiful, and has the same habit as glandulifera, but the lower part of its helmet-shaped flowers is bright yellow, marked by transverse lines of dark brown; while the upper part is rose colour. I. Roylei is much dwarfer than the preceding, and has blossoms of a deep rose. I. cristata has light rose-coloured blossoms. 
I. balsamina (Common Garden Balsam) may be grown in the open air, and makes a beautiful display in warm places. The plants should be raised in a frame and transplanted. Soil which is too rich should be avoided; but soil manured for a previous crop, and which has been well pulverised by forking, produces the finest flowers and a less sappy growth. If it were proposed to plant a bed of Balsams in colours, it would be desirable to know the habits of the various colours, so that the plants may be arranged to the best advantage. Some colours are produced on the taller plants, which have the same habit from year to year, so that if the colours be obtained they may be relied upon when properly planted. Colours and markings in any good and valued strain include the following, and probably a few others, as some sorts sport continually: Pure white, buff-white, rosywhite, lavender-white, pale mauve, peach, pink, carmine, scarlet, cerise, crimson, violet, purple, purplewhite blotch, scarlet-white blotch, carmine-white blotch, crimson-white blotch, white-carmine flake, white-purple flake, carmine bizarre, and crimson bizarre. A bed of good Balsams is a novelty, and might be made tasteful use of, not so much for the colour of their flowers as for their beauty near at hand.

Imperate, sacchariflora. - A hardy Grass, from the region of the Amoor. It has graceful curved foliage, and forms a tuft, about $3 \mathrm{ft}$. high, which throws up numerous flower-spikes about $5 \mathrm{ft}$. high, bearing silvery plumes of flowers. The leaves are of a lively green, with a broad white stripe down the mid-rib. It is scarcely ornamental enough for the garden.

Indian Corn ( $\left.Z_{e} a\right)$.

Indian Cress (Tropceolum).

Indian Pink (Dianthus sinensis).

Indian Shot (Canna).

Indian Strawberry (Fragaria).

Indiarubber-plant (Ficus).

Indigofera Gerardiana. - This is the only species of the genus suitable for openair culture. It is quite hardy, and may be grown as a bush or against a wall, which it clothes in a most graceful way with feathery pinnate foliage. Towards the close of summer it bears small Pea- like blooms in dense racemes. The flowers are bright pink, so that a wellflowered bush has a pretty effect. In very cold districts it may be advisable to give it protection in cold winters if not against a wall, and the only attention it requires is close pruning in early winter. The kinds known as I. floribunda; I. coronillæfolia, and by other names, are either synonymous with I. Gerardiana or varieties of it. I. decora, from China, is sometimes grown against a wall in warm parts, but is much less hardy than I. Gerardiana, which comes from the Himalayas.

Inula.-Perennial Composites, none of

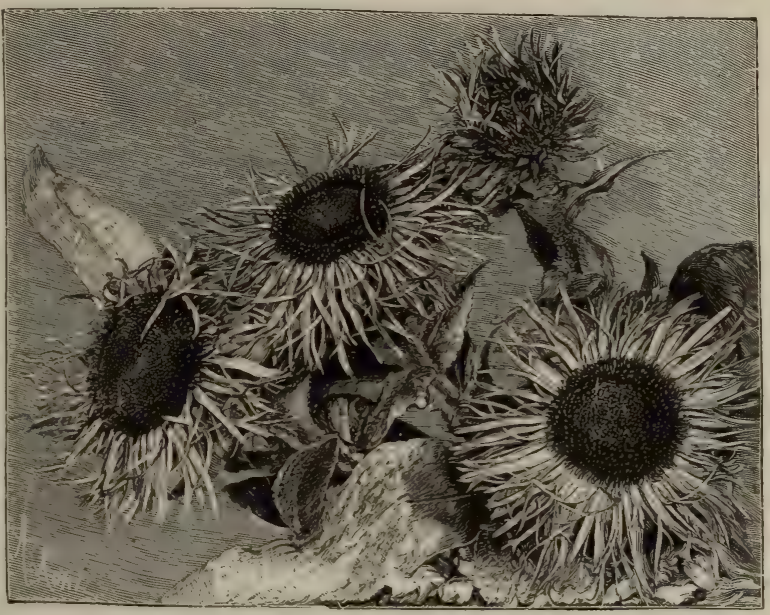

I.NULA GLANDULOSA.

which are very important for the garden. I. Helenium (Elecampane) is a vigorous British plant, 3 or $4 \mathrm{ft}$. high, with a stout stem, large leaves, and yellow flowers. It is well suited for planting with other largeleaved plants, or in isolated specimens on rough slopes or wild places, in free, moist, good soil. I. Oculus Christi grows $I \frac{1}{2}$ to $2 \mathrm{ft}$. high, and bears orange flowers in summer. I. salicina, montana, and glandulosa are similar, the last being the finest. All succeed in any soil, and are suited for naturalising. Easily propagated by division or seed.

Ionopsidium acaule (Violet Cress).A charming little Portuguese annual not 2 in. high, whose dense tufts of violet flowers spring up in all directions where plants of it have existed the previous season. Like a weed it sows itself, and therefore has the advantages of a perennial. Its peculiar beauty suits it for various purposes. On the rock-garden, associated with even the choicest of 
alpine plants, it holds its own as regards beauty, and never overruns its neighbours. It is particularly suitable for sowing near pathways, rugged steps, or similar positions, and grows freely in such places ; indeed, it would even flourish on a hard gravel walk. It flowers a couple of months after sowing, and often produces a second crop of blossoms in the autumn. Portugal and Morocco. Cruciferæ.

Ipomæa (Moming Glory).-Beautiful, slender, twining plants of the Convolvulus family, for the most part tropical. A few succeed in the open air when treated as half-hardy annuals. The most popular of these is -

I. purpurea, or Convolvulus major as it is called, which is too well known to need description, as it is one of the oldest cultivated plants. Its varieties but may be distinguished by lobed leaves resembling those of the Ivy. Its flowers, too, are smaller, and are of a deep blue striped with red. The varieties grandiflora (light blue), superba (light blue, bordered with white), and atroviolacea (dark violet and white) are all worth cultivating, and so are the new Japanese variety, Huberi, and its variegated-leaved form. The Ivy-leaved Morning Glory is somewhat hardier than I. purpurea, and seeds may be sown in the open border in April, in light rich soil, where it will flower from July to September. It is also known as I. Nil.-North America. Other kinds of I pomæas for open-air culture are I. rubrocœerulea, a half-hardy annual, and I. leptophylla, a hardy perennial from North America, but neither is so desirable as those mentioned above.

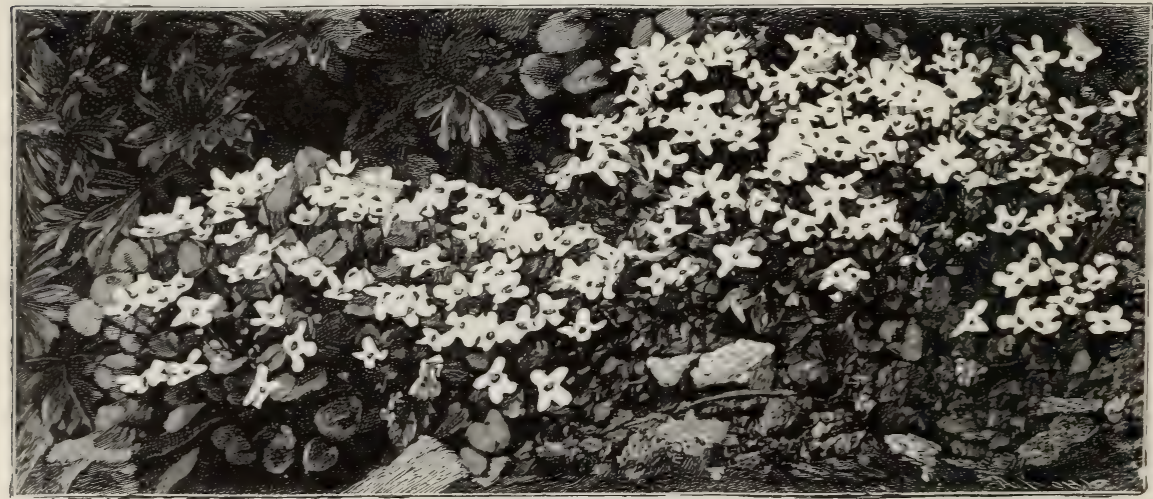

IONOPSIDIUM ACAULE

are numerous; there are white, rose, and deep violet varieties, while Burridgei is crimson, Dicksoni deep blue, and tricolor striped with red, white, and blue. A mixed packet of seed would contain most of these. This beautiful though common plant deserves much attention, as its uses are various. It may be used for the open border, for festooning branches, for covering arbours, trellises, and the like, or for rambling over shrubs. It grows freely in any good ordinary garden soil. Seeds should be sown in heat in early spring, and the seedlings transplanted in May as soon as large enough. In some localities seed may be sown at once in the open border, but as a rule plants raised under glass succeed best. It is known also as Pharbitis hispida. Tropical America and Asia.

I. hederacea (Ivy-leaved Morning Glory) is somewhat similar to the common Morning Glory (I. purpurea),
Ipomopsis. - Graceful biennials from California, hardy in light, dry, and warm soils in the milder parts. There are three kinds; each forms a tuft of finelycut feathery foliage, and has slender flower-spikes from 2 to $3 \mathrm{ft}$. high thickly set with flowers that open in succession. In I. elegans the flowers are scarlet and thickly spotted, and in I. superba they are much the same, while in the rosea variety they are a deep pink. The seeds should be sown in spring in pots in the open border in ordinary soil. During the first year the plants make growth, and early the following summer they flower. If planted out to stand the winter it is advisable to give a little protection. Other kinds mentioned in catalogues belong to Gilia, of which Ipomopsis is really a synonym. On light soils early autumn-sowing should be tried. These plants are very seldom well grown.

Iresine. - Dwarf half-hardy plants, 
remarkable for their handsome foliage, and therefore much used in the flower garden with other tender plants in summer. There are two types, from which have sprung several varieties. I. Herbsti grows from I to $2 \mathrm{ft}$. high, and has crimson stems and rich carmine-veined foliage, the brilliancy of which continues until late in autumn, and is more effective in wet than in hot dry seasons. It requires a moist rich soil, and is readily increased by cuttings taken in September and wintered in pots in a warm greenhouse. In early spring the plants should be repotted, and grown on in heat, and fresh cuttings taken in March and April will make them fit to put out in May. I. brilliantissima and Wallisi are two varieties possessing more brightness of colour in their foliage. Lindeni is quite distinct from the foregoing, having more pointed leaves, which are of a deep blood-red. It is compact and graceful, and bears pinching back and pegging down to any height. It makes a good edging plant, and requires the same treatment as $I$. Herbsti. Amarantaceæ.

Iris.--Every one admires the common Iris, but every one is not aware of the beauty and the delight to be found in the many Irises now in cultivation. No other class of hardy flowers possesses that union of grace of outline with delicacy of colouring which is the charm of these flowers. The majority are lovely, and all are worthy of the attention of those who love flowers as flowers, and who do not regard them as material for the gaudy or grotesque patchworks sometimes called gardens. By some, Irises have been compared to Orchids, and those who delight in singular and beautiful combinations of colour, and to whom greenhouses and hothouses are denied, may find a good substitute for Orchids in a selection of hardy Irises. The genus is well represented in our gardens by species for the most part hardy and possessing a considerable diversity of habit and colour. They vary in height from a few inches to $6 \mathrm{ft}$., and may be conveniently divided into two classes - those with bulbous roots, which are now called Xiphions, and those (the greatest number) with creeping stems. In treating of culture it is well to consider these separately, as they require different treatment. The bulbous kinds should have a warm and sheltered situation, such as the protection of a south wall. They succeed in almost any light garden soil, but prefer one that is loose, friable, and sandy, not too poor, but well enriched with thoroughly rotten leaf- mould and manure. Sun they must have, and the protection or shelter must be without shade. They need an autumn drought to ripen, and a dry soil in winter to preserve the bulbs and keep them at rest, but in spring, when the leaves are pushing up, they love rain that is not excessive. These observations apply to the Spanish and English Irises as well as the rarer species, but they will be found, as a rule, more robust than those of smaller growth. The great point is not to meddle with the bulbs as long as the plants are doing well, for they dislike disturbance, and, when the soil is exhausted and it is necessary to transplant, care should be taken that the bulbs are not allowed to become dry or shrivelled. It is advisable to place a thin layer of Cocoa-nut fibre refuse or some similar material to serve for protection during severe weather, and to prevent the flowers from being bespattered by mud during heavy rain. Some kinds produce seeds very freely in some seasons; these seeds should be carefully collected, and when well ripened should be sown at once. This will be found a wholesale mode of increasing the stock, as they will make strong flowering bulbs in about three years.

Most of the non-bulbous Irises like rich soil, full of decomposed vegetable matter. The coarser and stronger forms will feed even on rank manure, but to the more delicate ones this is almost poison; and all indeed thrive the better if their food is given in a well-decayed state. If it is well rotted they can hardly have too much of it. As regards moisture, they vary a good deal. The common Pseudacorus and many of the spuria group thrive best in the damp. Others, again, hate the damp - at least in winter-and stand considerable drought in summer. The condition that suits most is comparative dryness in winter and an abundance of water in summer. Unfortunately, this is the very reverse of what they generally get. They also vary a good deal as to the nature of the soil they like best. Some like a deep, somewhat stiff, but rich loam, and their long thong-like roots reach down an amazing distance, while others prefer a lighter, looser soil, proportionately richer in vegetable matter. Most of these plants have every good quality as regards hardiness, freedom of bloom, and easy culture. Like a good many other plants, their season of bloom is not long enough to please everybody; but, if cultivated where they are not in the way when out of flower, this is not a drawback. The 
more vigorous kinds are suited for planting among large shrubs, which ought to be wider apart than they generally are in thin copses; they may be enjoyed in tufts near water and in isolated groups on the Grass, and also on mixed borders and beds, but they should not be placed in masses of shrubs. In the places recommended they would mark the season agreeably, and would not be in the way when their bloom was over, as they sometimes are in borders. In the smallest gardens, where there is not space to plant them in these various ways, one of the best modes would be to establish healthy tufts in the fringes of the shrubbery. Another good way is to place them here and there in carpets of low evergreens, above which their flowers would be seen in early summer. All who care for bardy flowers should devote a little attention to establishing a good stock of these plants in their gardens. They have all the beauty of the finest tropical flowers without their cost, and will repay the trouble of arranging and planting them so that their beauty may be seen to the best advantage, and so that they may not be in the way of "bedding out." Tufts of the finest kinds look very beautiful here and there among dwarf Roses. The flowering season of the Iris extends over the greater part of the year-indeed, if the winter be mild, it is not uncommon to have Iris flowers all through the year. The following are among the finest kinds, and are easily procured in nurseries:-

I. alata (Scorpion Iris). - This is a beautiful bulbous species with fine large blossoms, the ground colour of which is a delicate lilac-blue, with showy blotches of bright yellow, copiously spotted with a darker hue. The foliage much resembles that of a Leek, and is produced at the same time as the flowers. I. alata generally commences to bloom in October, and, if the weather is not too severe, it produces other flowers about Christmas time. It is very easy to grow, as it merely requires a warm, dry, sunny border; but the bulbs should be planted in autumn in ordinary garden soil. The greatest drawback to its culture is that the flowers are spoilt by soil-splashings during heavy rains. If, however, the bulbs are planted among Stonecrop, or in Grass, on warm sheltered banks, their pale blue blossoms remain uninjured, and prove a source of attraction when the garden is comparatively flowerless. The beauty of the flowers may also be much preserved if a hand-light were placed over them during severe cold, snow, or wet. Native of the Mediterranean region. Syn., Xiphion planifolium.

I. biflora.-A handsome, rather dwarf plant, 9 to $15 \mathrm{in}$. high, bearing large violet flowers on stout stems. Similar to this are I. sub-biflora and I. nudicaulis, which latter is one of the finest of all the dwarf Irises. It grows from 4 to ro in. high ; its flowers are large, of a rich violetblue, and are produced four to seven on a stem in early summer. It has the vigour of the German Iris and the dwarfness of the old Crimean Iris. It is, however, much sturdier, and is, in a word, second to no hardy plant lately introduced. It is suited for the front ranks of the herbaceous border, and, being so dwarf, well deserves a position among the more vigorous plants in the rock-garden. It should be in every garden where early summer flowers are valued. There are several other species similar to the three mentioned above, but they are not so beautiful, and are rare in cultivation.

I. cristata is one of the best of the dwarf Irises, with flowers of a delicate blue and richly marked. It is a quaint delicate plant, 4 to $6 \mathrm{in}$. high, with leaves very broad for its size. Its growth is peculiar; it throws out long slender rhizomes, wholly above ground; hence, though very humble, it soon covers a considerable space. The way to manage it is to plant it among stones, with little or no soil. Thus situated, it seems at home, and the blooms last longer and keep in better condition than when it is growing on the ground. It loves a warm sandy loam, such as that in the Edinburgh nurseries.

I. fœtidissima (Gladwin).-A wellknown but undeservedly neglected British plant, $\mathrm{I} \frac{1}{2}$ to $2 \mathrm{ft}$. high. Its flowers are lead-coloured or bluish, and rarely yellow. A variety with variegated leaves forms a pleasing border-plant, and is an excellent house-plant. The common green form is worthy of being grown in semi-wild places for the effect of its brilliant coral-red seeds, which are plentifully produced in autumn in gaping capsules. Division and seeds. Seeds, scattered in semi-wild places, will soon spring into plants.

I. germanica (German Iris) is the commonest of all, and is too familar to need description. There are many varieties, the principal being atroviolacea, of a deep rich violet-purple; Telfordi, with unusually large flowers of a velvety dark purple; and major, similar to the last. I. squalens, flavescens, sambucina, neglecta, hybrida, 
and amœena come under the same group as the German Iris, being about the same growth, but the colours of the numerous varieties are so varied and rich as to be indescribable. Like all the large robust kinds, they are good border plants,

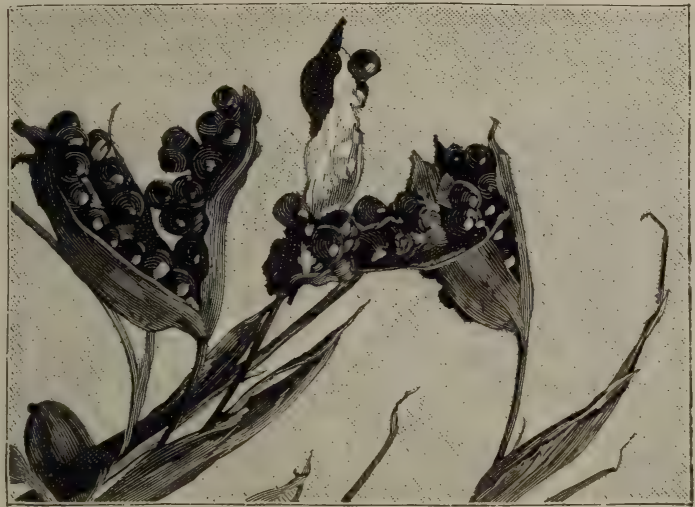

IRIS FCETIDISSIMA (GLADWIN).

but thrive best in a good deep soil in an open situation. Most of the named sorts of the so-called German Iris belong to this.

I. Histrio.- This very beautiful bulbous species, when peeping through the ground in winter or early spring, reminds one of I. reticulata, but it is rather taller, and its petals are broader and more conspicuously spotted or blotched. Its colour is rich bluish-purple, flushed towards the base of the petals with rosepink, the markings being of the deepest purple, relieved by a crest of gold. The blossoms are delicately scented. It is one of the earliest Irises, being usually in bloom with the first Snowdrops. Its culture is simple, and it succeeds under the same treatment as I. reticulata. Though a native of Mount Lebanon, it is perfectly hardy, but during severe frosts it is advisable to cover the bulbs with a thin protective material, such as Cocoanut fibre refuse.

I. iberica.-One of the most singular of the Irises, and very handsome. The flowers are large, the upright petals are white, pencilled and spotted with purple or violet, while the drooping petals or falls are veined with dark purple or purple-black on a yellowish ground, with a conspicuous dark blotch in the centre. This is the colour of the commonest form, but there are several, and one, ochracea, is very distinct. It is handsome, and far easier to cultivate than most persons imagine, being perfectly hardy and not at all fastidious as to its requirements. It thrives best in a rich fibrous loam, where it can send its long roots deep into the soil. The rhizome does not require to be planted deep, but only just below the surface. In most cases the roots perish when planted deeply. The rhizome, during the winter, is very impatient of moisture, and should be kept comparatively dry. Coarse river sand should be used, the rhizome being planted completely in it, in the same way as many other bulbs are planted. By this means it is kept rather dry during the winter and great assistance is given to the plant in summer, as the young shoots can easily force their way through. Under this treatment the plant grows more freely, and can be easily multiplied by division of the rhizome. It is admirably suited for the rock-garden, or for the select border, and, when better known, it will find a place in every garden. It flowers in spring, and though the blossoms are of somewhat short duration, their extreme beauty amply compensates for this drawback.

I. Kæmpferi (Japanese Iris).-The large number of varieties in cultivation

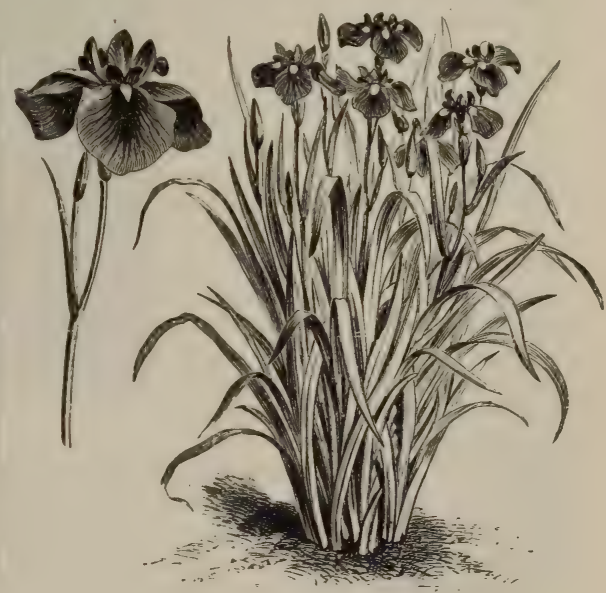

IRIS KEMYFERI (JAPANESE IRIS).

under this name have sprung from I. lævigata and I. setosa. They form quite a new race of garden plants, and every year many beautiful sorts are added. These are obtained chiefly from Japan, though many seedlings have been raised 
in this country. The flowers are extremely variable both in size and colour, some measuring as much as 9 and Io in. across. The large and double-flowered varieties, produced by the Japanese, and also, of late, in some European gardens, are magnificent; the flowers appear rather flat, presenting the outer segments in their entire dimensions; the colours are very striking, and vary from white to lilac and violet, and from sky-

blue to indigo, brown, and blackish-maroon. The varieties of $I$. setosa differ from those of I. lævigata in having broader and lessdrooping petals, and the three inner petals are often of the same size as the outer, so that the flower is symmetrical. I. Kæmpferi will grow in almost any soil, but succeeds best in a good loam, provided a quantity of peat be added to it. The peat is not so much to afford nourishment as to retain moisture during the hot and dry summer months, for this Iris likes moisture, and its numerous roots will often go $2 \mathrm{ft}$. deep in search of it. It dislikes shade, and prefers a sunny hot situation. Two-year-old seedling plants of it flower in June and July, and among them will be found endless variations of colour, from white to dark blue, and from pale rose and lilac to deep maroon and brown. Complaints are often heard that these Irises are difficult to flower, and indeed, if not carefully transplanted, they do not flower the first year, but they are all the finer the second season. In short, they must be well estab-

lished before they can produce fine flowers. Division and seeds. Seeds should be sown as soon as gathered either in pots or in the open ground, when they will vegetate in the following spring.

I. Monnieri.-A noble kind, quite distinct from any other in cultivation. The leaves are dark green, and the flowerstem is nearly $4 \mathrm{ft}$. high. The outer divisions of the flowers, which are very fragrant, are recurved, and are of a rich golden-yellow, margined with white. It is not by any means common. I. aurea, an allied species, is a noble plant, 3 to 5 ft. high, with large foliage and long stout flower-stems, bearing large blossoms of a uniform bright golden-yellow. I. ochroleuca is of similar growth and habit, but has white and yellow falls and deep yellow standards. It is most distinct, and is one of the largest Irises; on this account it passes under the name of $I$. gigantea. All these kinds are suitable for

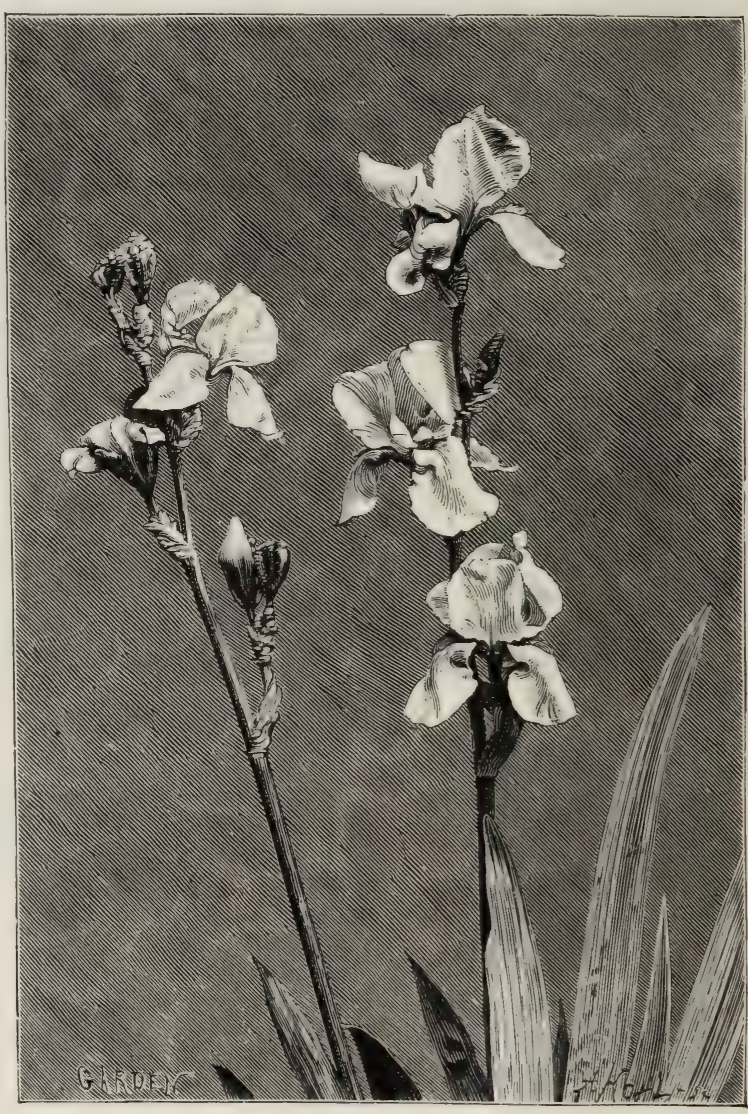

IRIS PALLIDA.

borders among the taller herbaceous plants, and for tufts which are 2 or $3 \mathrm{ft}$. within the margin of shrubberies. They thrive best in rather moist soil. Easily propagated by division or seed.

I. pallida (Great Purple Iris).-A tall and noble Iris, 2 to $4 \mathrm{ft}$. high, having large pale mauve flowers, with a whitish beard. The blossoms are sweetly scented, and appear in early summer. There are a few varieties that vary slightly in the depth of colour, a very fine one being the large Dalmatian form. They are all very 
beautiful. Similar in growth and size is the common Florentine Iris (I. florentina), which has large white flowers tinged with lavender. I. albicans is a pure white variety of it, very handsome. I. plicata and Swerti come under the same group, being tall, and having deeply-forked stems and large light flowers, mottled and veined with purple. These fine plants for borders or groups on lawns grow well in any soil.

I. pavonia (Vieusseuxia).

I. persica (Persian Iris) is one of the most attractive and distinct of the early kinds, and deserves a place wherever the soil is warm and dry. Its blossoms, pro-

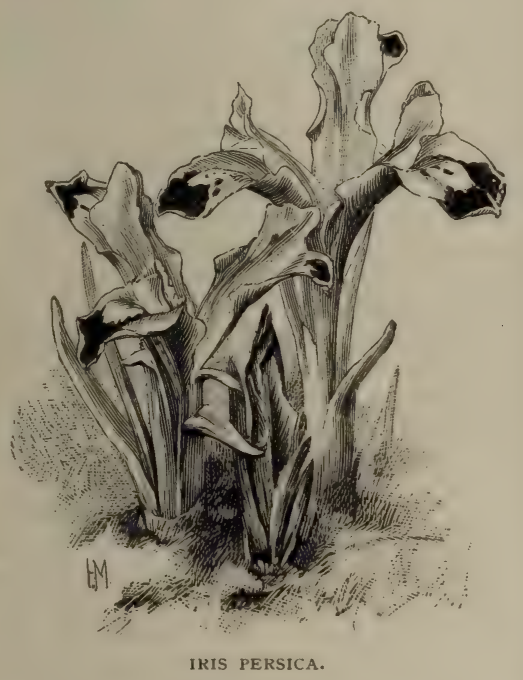

duced from a tuft of bright green leaves that just peep over the soil, are white, suffused with pale Prussian blue, and blotched with velvety purple. It is a native of Persia, and therefore somewhat tender, but in warm sheltered spots, in light sandy soil, it succeeds well enough, and flowers in winter and spring, according to the weather. =Xiphion persicum.

I. Pseud-acorus (Common Water Flag). - Common as is Pseud-acorus, every one who has grown it fairly will admit its beauty. Whoever has in his garden a pond or a ditch, or even a thoroughly damp spot, ought to plant this Iris largely. Few things, indeed, are more beautiful than a great clump of this yellow Flag, with its tall leaves starting up from the side of a pool, and clusters of golden flowers gleaming in a midsummer sun. Three things it loves-a rich soil, plenty of water, and abundance of sunlight. It is cruel to place it, as it is sometimes placed, in some dank, dark hole, where the sun's beams never reach it ; it is disappointing to plant tit in a dry and stony spot, where summer is to it one long thirst. But put it where its roots can run at will in rich black mud, and let its head raise itself to the full light of a summer sky, and it will be a golden glory throughout the long days of June.

I. pumila.- The best of the dwarf Irises, for to it we owe the many lovely varieties that create such a rich display of bloom in spring. It grows from 4 to $8 \mathrm{in}$. high, and has deep violet flowers, unusually large for its size. All the varieties flower profusely, but to be appreciated they should be planted in large masses (a goodsized bed of each sort) or in broad lines. There are several named varieties, the best being the white, the straw-coloured, the pale blue, and the blush-coloured; all of which are described in catalogues under Latin names. The most attractive is the sky-blue (cœrulea), which in early spring forms sheets of bright colour. Similar in growth to I. pumila, but with larger flowers, is I. olbiensis, which normally has rich violet-purple flowers, but which also occurs with flowers of white, blue, yellow, and various other colours. I. Chamæris is also in this dwarf group, and so is I. verna (a handsome, but rare North American species), I. italica, and several others. These all flower about the end of April, or the beginning of May, if in warm localities, in light soil.

I. reticulata.-One of the most beautiful of hardy flowers. While the snow is still on the ground-in January, or even earlier-its leaves begin to shoot, and while these are only a few inches high, the bud opens to the pale wintry sun a beauty of violet and gold. After the flower has faded, the erect narrow leaves grow apace, attaining a height of $\mathrm{I} \mathrm{ft}$. or more, and, as in the Crocus, the ripe ovary is in due time thrust upwards from the soil. This little treasure is indeed the Iris companion of the Crocus, and those who have seen large clumps of it growing in some sheltered but sunny spot in the bright and gusty days of February or March, may well wish that its netted bulbs were as plentiful as Crocus corms. Two very distinct forms are known. One, the typical form, may be recognised by its deep dark violet colour and the brightness of its yellow. This kind comes from some parts of the Caucasus and from Palestine. The other form is known as Krelagei, the well-known horticulturist Krelage having first called attention to it. 
It may be recognised by flowers of a purple or plum colour, with the yellow marking less vivid and the whole flower smaller. Krelagei seems to be more abundant than the type, and is represented in many of the illustrations as I. reticulata. It is common in the Caucasus, the Transcaucasus, and Persia. It is a matter of some importance to distinguish between the type and its variety, for the type is not only far more beautiful-its deep dark violet and lustrous yellow producing an exquisite effect far surpassing

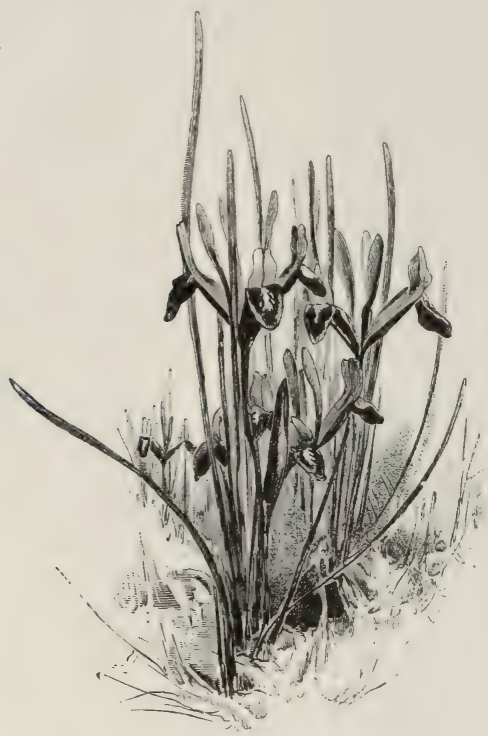

IRIS RETICULATA.

the duller purple of Krelagei, - but it possesses a delightful violet fragrance which Krelagei is absolutely without. One advantage, however, Krelagei possessesit invariably flowers ten or fourteen days earlier than the type. Concerning its culture very little need be said. It is absolutely hardy, and may be planted wherever the Crocus is found. A sunny sheltered spot is, however, advisable, that its tall narrow leaves may, after flowering, flourish protected from the wind. It flourishes in sandy soil ; it thrives in peat, which is dry and warm in summer; it does well in common garden-ground, and in a stiff heavy clay, so that it is not particular about soil. Sometimes, however, it refuses to grow, and in damp places the bulbs rot in summer. Since the flowers come before the leaves grow tall it makes a good pot-plant, and a well-grown clump of the fragrant sort is a charming addition to the Christmas table. Some care, however, is needed to make it bloom more than one year in pots, and it is advisable that those who cannot give it the requisite attention should harden off the pot-plant when it has flowered and plant it in the open, seeking a fresh supply for the next winter from some old clump, or from bought bulbs. I. Kolpakowskyana is also a lovely plant, smaller than, though similar to, I. reticulata. There is more white in the flowers, and this makes it distinct. It is a new introduction, but quite hardy, and thrives under the same conditions as I. reticulata.

I. ruthenica.-One of the smallest Irises. Its flowers, about 2 in. across and of a bright lilac-purple with a white lip, are borne on stems about I in. above the surface, and nestle snugly among the bright green slender foliage. It blooms nearly every month, though mostly in the autumn, but the blooms are hidden among the foliage, and ordinary observers are unaware of its being in blossom. It is of easy culture in an open situation.

I. sibirica (Siberian Flag).-A tall slender plant, 2 to $3 \mathrm{ft}$. high, with narrow grassy leaves and somewhat small showy blue flowers, beautifully veined with white and violet. There are several varieties, some very handsome. The white variety, also called I. flexuosa, is pretty, and so is I. acuta, but the double-flowered form is not. The finest variety is I. orientalis, having larger flowers of a deeper colour, with a different veining, and the falls especially broad and expanding. It derives its name from the bright scarlet or crimson tinge of the spathe sheaths, which gives the bud a remarkable beauty, even before the flower has opened. Melpomene and nigrescens are also very beautiful varieties in the way of orientalis, but finer than the type. The Siberian Iris thrives best in rich damp soil, and this is, perhaps, especially the case with orientalis and some of the other largeflowered varieties. But to flower well it must have plenty of sunshine ; it will not show its real beauty in dampness begotten of shade; nor is it, like $I$. Pseud-acorus and other forms, absolutely devoted to damp, for when thoroughly established it will bear without even flinching an amount of drought which would be fatal to it when newly planted. In planting, secure good ground to start with, for it has a very great objection to being moved. Transplantation will in most cases prevent the bloom of the succeeding summer; and, moreover, its real beauty does not become apparent 
till it has grown into a good-sized tuft. Place it, then, in thoroughly good soil, with appropriate surroundings, so that its head of flowers may be seen above dwarfer plants, and standing out against still taller foliage, and then let it alone. It is capital for naturalising, for though it flourishes best under the conditions indicated, it will grow and thrive in almost any soil, even in the worst description of clayey soils. Flowers in May and June.

I. spuria.-Not a very attractive plant, though in some forms, like spuria major, and also in the Algerian variety known as Reichenbachi, the colouring is bright and handsome, especially in masses; but the mixture of blue or purple and yellow which they offer is not pleasing, and there is a certain stiffness and want of elegance in their outlines. The smaller flowers of such varieties, as desertorum, with - paler flowers, narrow falls, and, in some cases, marked fragrance, and the white Güldenstädti, are pretty. I. graminea is of no great value as a border plant ; the flowers are too much hidden by the overtopping leaves, and are themselves, singly, of no great beauty. Nevertheless, their mixed blue and purple tints will be found to render them of value as cut blooms; and they can then be made to harmonise with other flowers.

I. stylosa.-A beautiful plant, whose charm is enhanced by its flowering in midwinter, which no others do except one or two of the bulbous class. Though not very attractive, on account of its flowers being hidden in its grassy foliage, it should be grown in every garden, for, when mixed with even the most delicate flowers of the stove or Orchid-house, its silky sky-blue flowers possess a charm and softness equalled by scarcely any other flower of the same colour. They are fragrant, and are produced from Christmas to the end of January. Although the plant is quite hardy, its flowers are so large and delicate that some slight protection from rain and rough winds is desirable, unless the position is well sheltered and the weather is mild. It succeeds in almost any soil. It is also called I. unguicularis, but not often.

I. susiana (Morning Iris).-One of the most singular of all the flowers of temperate and northern climes. It grows $\mathrm{I} \frac{1}{2}$ to $2 \frac{1}{2} \mathrm{ft}$. high; the flowers, produced in early summer, are very large and are densely spotted and striped with dark purple on a grey ground. It should be grown in sunny nooks in the rock-garden, or on sheltered banks or borders, but always in light, warm, and thoroughlydrained soil. We have seen it thriving as a border plant and flowering well in the Archbishop of Canterbury's garden near Broadstairs. It may be treated as perfectly hardy in some parts of the country; but a dry bottom and a free soil are essential. In cold districts or on heavy soil a hand-light would be desirable in winter. Asia Minor and Persia. Division.

I. tectorum is a charming species, second to none in beauty, and should find a place in the most select collections ; its blossoms are large and of a bright purple, beautifully mottled with dark purple, and, unlike those of most Irises, all the six divisions are on the same plane, which much enhances their beauty. Being a native of Japan, it is somewhat tender, but in a sunny warm situation it will flower abundantly, and show off its strongly-crested blue and dark blue blotched flowers to great advantage. A rich soil, much sun, and some dampness are the best conditions for it. In Japan it grows on the top of straw-covered house-roofs, feeding on the decomposing straw, and is exposed to sun and weather all the year round.

I. tridentata. - A North American form, the falls of which are largely developed, highly coloured, and manifest real beauty in form and markings. It is an abundant bloomer, a strong grower, spreads rapidly, and is in every way desirable. It occurs in the Northern States. The closely-allied I. setosa from Asia is far less beautiful. I. tenax, also a North American form, is a close neighbour of sibirica, and is very desirable. Allied to tenax is the Californian form I. longipetala. This is a showy plant, but the various cultivated specimens of it vary not a little. Its rather long and straggling falls, in spite of their charming light violet or lavender colour and their graceful markings, give it a more or less unfinished look.

I. tuberosa (Snake's-head).-This is an interesting but dull-coloured kind, I 2 or 13 in. high. Its flowers are small, of a brownish-green streaked with yellow, and have a purplish-brown tinge on the upper part. There are usually two tubers. It is not worthy of a place in the garden, but where admired it may be naturalised in light soil. S. Europe.

I. variegata is a handsome rich-toned kind, I to $2 \mathrm{ft}$. high, with large, slightly fragrant flowers, having bright yellow standards and claret-red falls beautifully 
veined. The varieties are numerous, one of the finest and most distinct being De Berghi, with deep brown-purple falls and bright yellow standards. Similar in aspect is I. aphylla, with deep lilac falls and white standards veined with purple. This, too, has numerous varieties, the colours of which are indescribable, but blooms which prevents it from being considered really attractive. More highly coloured and frequently very striking from the juxtaposition of a pure white and a deep rose, is the very closely-allied I. versicolor; but this lacks a certain elegance, and in looking at it one is led to wonder why a flower so beautiful gives

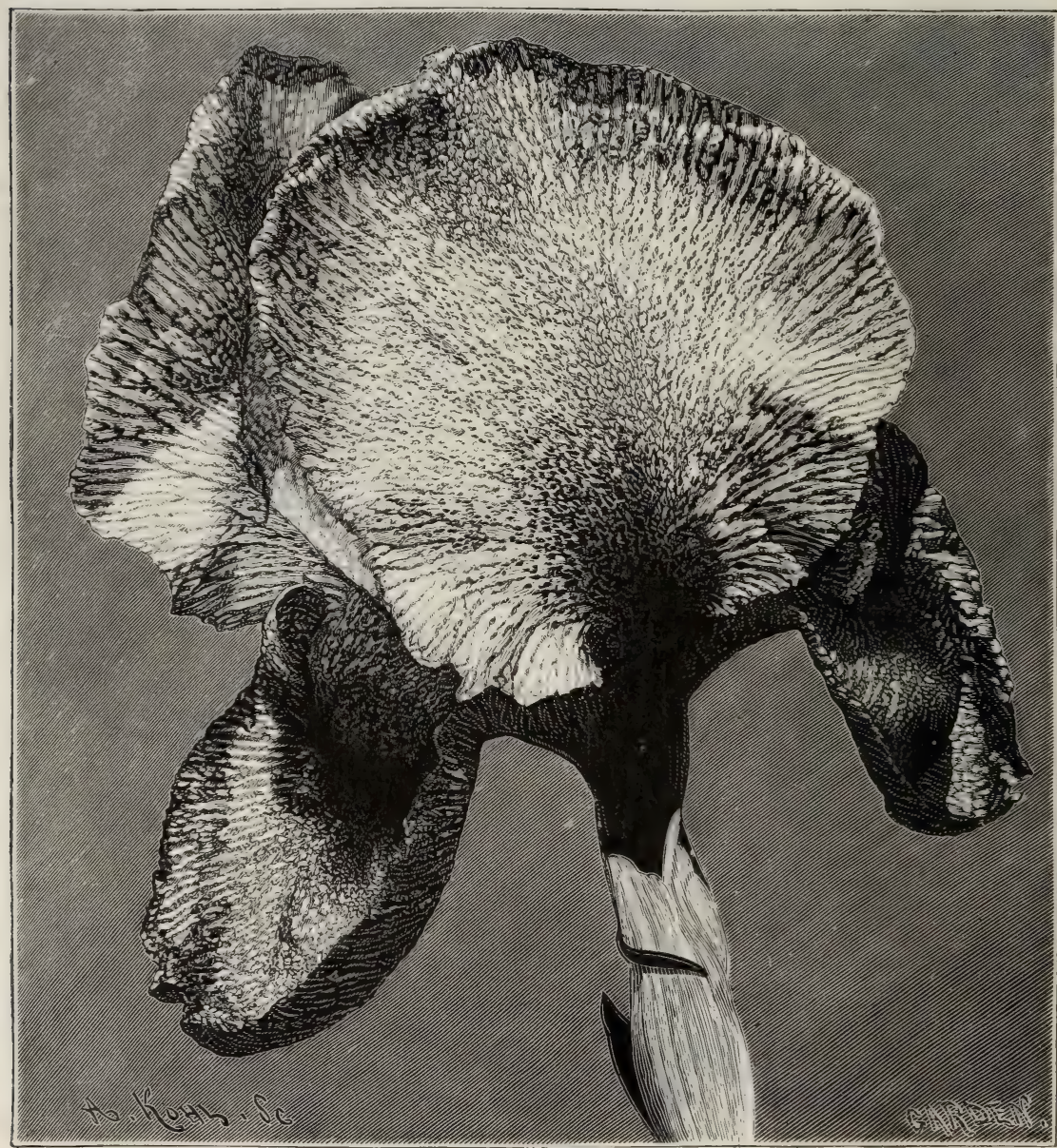

IRIS SUSIANA.

all are beautiful. I. lurida and its varieties come also under this group. The remarks as to culture and position which apply to I. germanica apply to these also.

I. virginica.-A vigorous plant, spreading very rapidly in somewhat moist rich soil. The flowers vary considerably in tint, and some of the more deeply-coloured forms are not unhandsome. There is, however, a certain stiffness about the so little pleasure. Many seedlings, both of virginica and versicolor, are in cultivation; and though what may be perhaps considered as the typical forms are very distinct, almost every intermediate stage may be seen. They thrive in any moist soil, and are perfectly hardy. N. America.

I. xiphioides (English Iris).-Like the Spanish Iris, this is one of the bulbous species. It is very handsome, possessing an infinite variety of tints in the blossoms, 
which are large and have broader outer petals than I. Xiphium. The colours vary from white, through pink and mauve, to the deepest purple, and some are beautifully flaked and spotted. All may be had in a mixed collection. It comes into flower a week or so later than the Spanish Iris, but requires exactly the same treatment. Spain and the Pyrenees. = Iris anglica, Xiphion latifolium.

I. Xiphium (The Spanish Flag or Iris). -A very old inhabitant of gardens. It and the so-called English Iris are the spring the tall narrow leaves grow apace, and late in May or in June a stalk, almost wholly ensheathed by clasping leaves and spathe valves, bears one or two flowers whose great beauty consists in the vividness, and yet chasteness, of their colouring. The bulb, which produces offsets in great abundance, is much smaller than that of the Pyrenean Iris, and its coat, though it may be spoken of as fibro-membraneous, is not nearly so thick and rough as the coat of that species. The plant having for many generations been in the hands

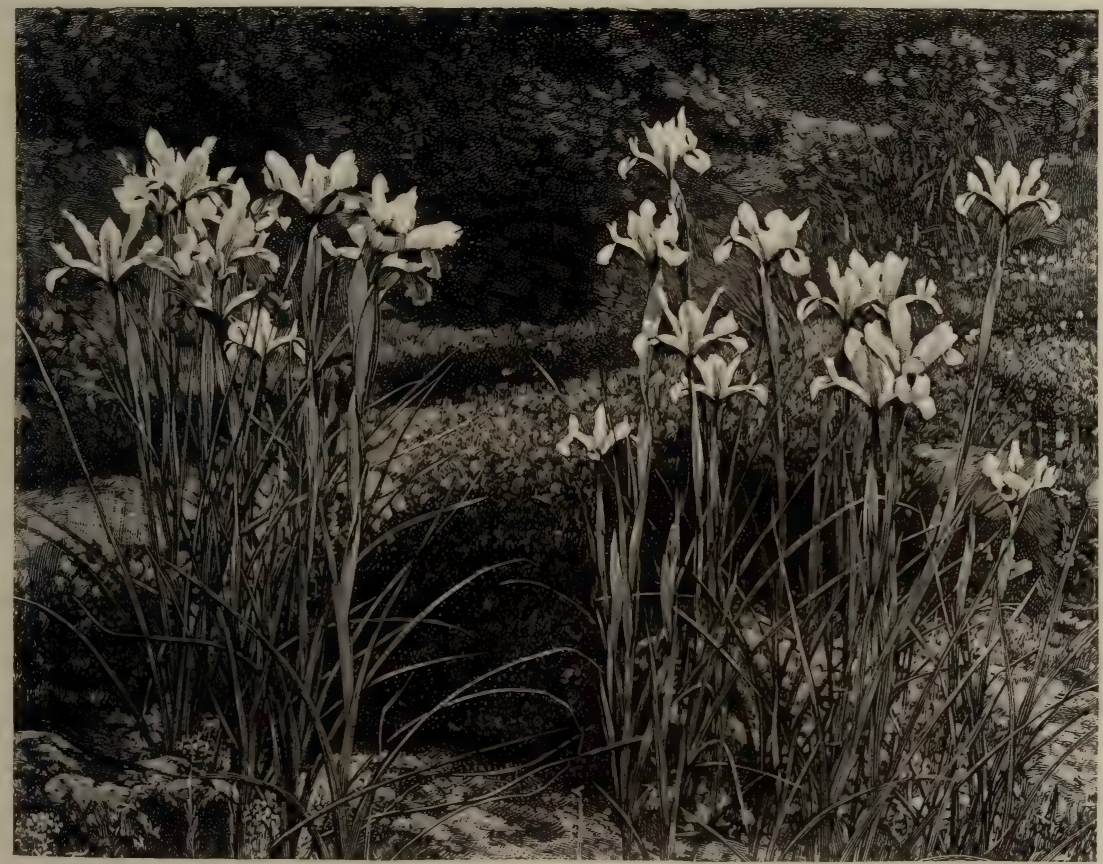

SPANISH IRIS (I. XIPHIUM).

bulbous Irises most commonly cultivated. The native habitat of each is extremely limited, the Spanish Iris being found in Spain and Portugal, and only here and there in the South of France, while the Pyrenean form, as its name denotes, comes from the Pyrenees. The misleading title of English Iris applied to the Pyrenean form appears to have arisen from its having been introduced to the Dutch gardeners in a roundabout way through some Bristol merchants, in whose gardens it was a favourite long ago. The Spanish Iris begins growth early, and having attained a few inches in height remains stationary during the winter, regardless of even biting frosts. In the of the Dutch florists, many seedlings have been raised, and much variety of colouring has been gained, though the number of named varieties is not so great as in the case of the Pyrenean Iris. The prevailing colours are blue, with various shades of purple or violet, yellow, and white. There is a form, known by different names in different florists' lists, the opaque snowwhite hue of which renders it very charming. The blue tints of the cultivated seedlings seem to be derived from the typical Spanish plant; the yellow hues may be traced to the Portugal variety, sometimes known as I. lusitanica. The Portuguese plants are for the most part yellow, and generally have more funnel- 
shaped flowers, while the Spanish plants are generally blue and have more spreading flowers; but the distinction is not absolute, and the cultivated varieties are mixed both in colour and form. I. sordida is simply, a form of the Portuguese variety, in which the yellow is blotched with purple or violet, a phase of colouring which is not at all uncommon in the Dutch seedlings.

SOIL AND Situation. - The Spanish Iris must not be waterlogged in autumn and winter. It prefers a loose, friable, sandy soil, which, however, should not be too poor, for it repays feeding with rich well-decomposed stuff-thoroughly rotten leaf-mould or manure - by fuller and richer bloom. Sun it must have, but as its slender stalks suffer from winds it should have shelter without shade. It needs an autumn drought to ripen its bulbs, and a winter dryness to keep it at rest; but in spring, when it is rapidly pushing its slender leaves and shoots, it loves any rain that is not excessive. On the whole it flourishes in dry places much better than the Pyrenean Iris, which will stand much more wet. The Thunderbolt, or clouded variety, is much more robust than either the typical form or the Portuguese kind, and will flourish even grandly in stiff damp soils, where the Portuguese would speedily perish. The golden rule of not meddling over-much applies distinctly to the Spanish Iris. The new roots begin to shoot out almost before the old stalk has withered, and the bulb hates to be kept out of the ground. Plant, then, the Spanish Iris in clumps on some rich, loose, friable plot, where their bright colour may be shown to advantage, and let them stay there year after year until the dwindling foliage tells you that they have exhausted their soil; but it will be some time before that comes to pass.

\section{Iron-weed (Vernonia).}

Isopyrum thalictroides.-A graceful little plant allied to the Meadow Rues, but with white flowers prettier than Thalictrums. It is chiefly valuable for Maiden-hair Fern-like foliage, and is worthy of culture in the flower garden for this alone. When grown for its elegant dwarf leaves, the flower-stem should be pinched out. It is well suited for the rock-garden, and particularly suited for the front edge of the mixed border, is hardy, and easy to grow on any soil. It is easily propagated by division or seed, Europe. Ranunculaceæ.

Isotoma axillaris.-A showy halfhardy plant, resembling some of the dwarfer Lobelias. Its habit of growth is dense and compact, and the flowers are so profuse as to form a mass. They are $\frac{1}{2}$ in. across, star-shaped, and of a pale blue. It continues to flower a long time, even till cut off by frosts. If preserved in a frame during winter, after the manner of bedding Lobelias, it is perennial, and may be propagated in spring by cuttings. New Holland. Lobeliaceæ.

Itea virginica. - A little North American shrub, often catalogued by nurserymen, but scarcely worth attention. It is dwarf and deciduous, and in autumn produces clusters of small white flowers. Suitable for a damp spot at the foot of a rocky bank in an alpine garden.

\section{Ithuriel's Spear (Triteleia laxa). \\ Ivy (Hedera). \\ Ivy Hairbell (Wahlenbergia). \\ Ivy Toadflax (Linaria Cymbalaria). \\ Ixia.-Charming South African bulbs,} very slender and elegant in growth, and brilliant in flower. They are not grown so much as they deserve, probably because they are considered tender and require treatment under glass. They are most valuable open-air plants, as they yield in summer an abundance of bright bloom for cutting. For culture outdoors, choose a light loamy soil, thoroughly drained, and with a due south aspect; if backed by a wall or a greenhouse so much the better. Plant from September to January, 3 to $4 \mathrm{in}$. deep, and $\mathrm{I}$ to $3 \mathrm{in}$. apart. As the early plantings make foliage during the autumn, it is necessary to give. protection during severe frost, and this may be best accomplished by hooping the beds over and covering when necessary with mats; or if tiffany is used it may be allowed to remain till the danger of severe frosts has ceased. The December and January plantings require no protection in winter, but as they will flower later in the summer than the early plantings, an aspect where the sun's rays are somewhat broken will prolong the blooming period. On stiff soil, or on soils that lie rather wet in winter, the beds should be raised, and the bulbs should be surrounded with sand, care being taken that they are planted I or 2 in. above the level of the path; and, where protection cannot conveniently be given, planting should not take place till December or January. A large number of varieties are now in cultivation. The chief species from which they appear to be derived are I. crateroides, patens, maculata, fusco-citrina, ochroleuca, columellaris, speciosa, and viridiflora, which last is of a beautiful sea-green, a colour 
quite unique among cultivated plants, and in no case to be omitted. A representative collection of varieties would include the following: Achievement, Amanda, $\mathrm{Au}$ rantiaca, Cleopatra, Conqueror, Duchess of Edinburgh, Glory, Gracchus, Hercules, Hypatia, Isabelle, Impératrice Eugénie, Lady Carey, Lady of the Lake, La Fiancée, Lesbia, Loela, Miralba, Nosegay, Pallas, Pearl, Prestios, Princess Alexandra, Sarnia's Glory, Sunbeam, Surprise, Theseus, Titian, and Vulcan.

Ixiolirion (Ixia Lily).-A small genus, numbering about four kinds. The varieties strongly resemble each other, appearing to differ only in the depth of colour of the flowers, which are of a bright violet-blue. They are all I to $I \frac{1}{2}$ ft. high, have grassy foliage, and bear large trumpet-shaped flowers in a loose elegant manner. I. Pallasi has flowers of the deepest shade, and I. tataricum of the palest, the intermediate shades being I. montanum and I. Ledebouri. Such beautiful hardy plants are deserving of the most select collection, for the flowers last long in good condition on the plants, and are very enduring in a cut state. They should be treated like the rarer bulbs, such as Calochorti, Habranthi, Zephyranthes, and similar families, for though they may be quite hardy, it is not advisable to plant out such rare bulbs in ordinary borders. They should be grown in an open and dry position-in a sunny border, for example, which is all the better with a wall at the back, so as to catch all the sun-heat possible in early spring, when the bulbs are pushing up their young leaves and flowers. The border should be well drained, and a bed of light, rich loamy soil, about I ft. in depth, placed upon the drainage. When the young growth appears, place a common hand-light over the plants-even two panes of glass will be beneficial-and if similar protection is afforded at the latter part of summer, it will tend to keep the soil dry and warm, and so ripen the bulbs. A handful of dry sharp sand placed in a layer under and around the bulbs is conducive to the formation of roots. It is probable that when more established these will be as hardy as some of our commonest hardy bulbs. Western Asia.

Jaborosa integrifolia.-An interesting dwarf perennial, allied to the Mandrake. It grows 9 to 12 in. high, has broad ample leaves, and large pure white tubular flowers about 2 in. long, fragrant and handsome. A native of Buenos
Ayres, it is somewhat tender, and succeeds well only in light warm soils in sheltered situations. It is best close to the foot of a south wall in good loamy soil. Here it makes a good plant, but spreads so rapidly as to become troublesome. When flourishing it may be easily propagated by division of the long creeping stems. Solanaceæ.

Jacobea (Senecio elegans).

Jacob's - ladder (Polemonium coruleum).

\section{Jalap-plant (Exogonium).}

Jamesia americana.-A dwarf compact shrub from the Rocky Mountains, with deciduous leaves, and 2 to $3 \mathrm{ft}$. high. In summer every shoot carries a cluster of white flowers, which, with the whitish foliage, give the plant a pretty appearance. It is hardy, of easy culture, and fitted for association with flowering shrubs of a medium size.

Japan Medlar (Photinia).

Japan Pear (Pyrus japonica).

Jasione (Sheep's Scabious).-A small genus of dwarf perennials and annuals of the Bell-flower family. J. humilis is a creeping tufted plant, about 6 in. high, bearing small heads of pretty blue flowers in July and August. Though a native of the high Pyrenees, it often succumbs to the damp and frosts of our climate, and it therefore requires a dry well-drained part of the rock-garden, and should have a little protection in winter during severe cold and wet. In summer, however, it likes plenty of moisture. J. perennis is taller, often above I ft. high. It has dense heads of bright blue flowers, which appear from June to August; it is a rock-garden plant, stronger than the preceding, and flourishes best in good light loam. Native of mountains of Central and South Europe. These perennial kinds may be propagated best from seed, as they do not divide well. J. montana is a neat, but not showy, hardy annual with small, pretty bright blue flowerheads, produced in summer in light warm soils. Sow seed in autumn or spring. A native plant.

Jasmine (Jasminum).-The common hardy Jasmines are so well known that little need be said about them, but there are a few others equally important that deserve attention. The bright yellow $\mathrm{J}$. revolutum from India is too little known, it being quite hardy enough for wall culture in all parts; and it has evergreen foliage, which adds to its value. It flowers profusely, and its cloud of golden bloom amidst the deep green foliage is most welcome in summer and 
autumn. It is a common plant in some tree nurseries, but is seldom sold. Another hardy evergreen shrub, J. fruticans, has yellow flowers, and may be grown as a bush, or supported by a tree-stump. It comes from South Europe, as does J. humile, also with yellow flowers, and is quite hardy. The Chinese J. floridum, with yellow flowers in summer, is of less value, but worth growing in a collection. The common white J. officinale should be planted in every garden against a wall, or used for trailing over tree-stumps or
Blood-root, and from 6 to ro in. high. The flowers are white, about I in. across, and are freely produced in early spring when the plant is in vigorous health. It is a good plant for peaty and somewhat shady spots on rock-work, and in a minor degree for the margins of beds of dwarf American plants. Seed should be sown in sandy soil as soon as gathered, but careful division of the root in winter is the best way to increase the plant. A native of rich shady woods in $\mathrm{N}$. America.

Jerusalem Sage (Phlomis).

Jessamine (Jasminum).

Jew's Mallow (Kerria).

Jew's Mallow, White (Rhodotypos).

Jonquil (Narcissus Jonquilla). arbours. It is one of the most important of all climbing shrubs on account of its extreme hardiness and its vigorous and rapid growth in almost any soil or situation. There are several.beautiful varieties of it, the best being J. affine, whose flowers are larger and more numerous than those of the ordinary kind. There is a variegated-leaved kind, not of much importance, and another with golden foliage which is pretty. There is a rare doubleflowered form. J. officinale is an Evergreen, except in cold exposed localities. The winter Jasmine, J. nudiflorum, is another indispensable shrub for every garden. Though its flowers wreathe the leafless twigs, they are so bright and cheerful in the depth of winter, that a space should always be found for it against the house walls. When its branches are allowed to trail among Ivy or other evergreen growth, the golden blossom is well shown.

Jeffersonia diphylla (Twin-leaf). - A very interesting dwarf plant, allied to the
Jubæa spectabilis. - A handsome nearly hardy S. American palm, with a smooth stem, which sometimes attains a height of nearly $40 \mathrm{ft}$., and spreading pinnate leaves, of a full deep green colour, from 6 to $\mathrm{I} 2 \mathrm{ft}$. long, the leaflets being from $I$ to $I \frac{I}{2} \mathrm{ft}$. long, and about $I$ in. wide, springing in pairs from nearly the same spot. The leaf-stalks are very thick at the base, where they are enclosed in a dense mass of rough brown fibres, which grow upon their lower edges. This palm exists in the open air throughout the winter, near London, but not in such a condition as to encourage many to try it in this way. Grown in tubs in the conservatory in winter, and placed in the open air in summer, it will be useful for association with the hardier palms.

Judas Tree (Cercis).

Juncus (Rush).-Aquatic and marsh plants, generally with long round leaves. J. effusus spiralis is a very singular plant, whose spreading tufts of leaves, instead of growing straight, are twisted in a cork- 
screw form. Its appearance makes it well worthy of cultivation, and it may be planted with advantage on the margins of pieces of water, near cascades, etc., or in the artificial bog. It is easily multiplied by division of the tufts. J. zebrinus is apparently a form of the common Rush pleasure-ground and as background plants for the flower garden than for woodland or forest planting, though some kinds are trees, as ithe Red "Cedar" (J. virginiana). The dwarf Savin, rightly placed and grown, throws a mass of very pretty evergreen growth over banks and places

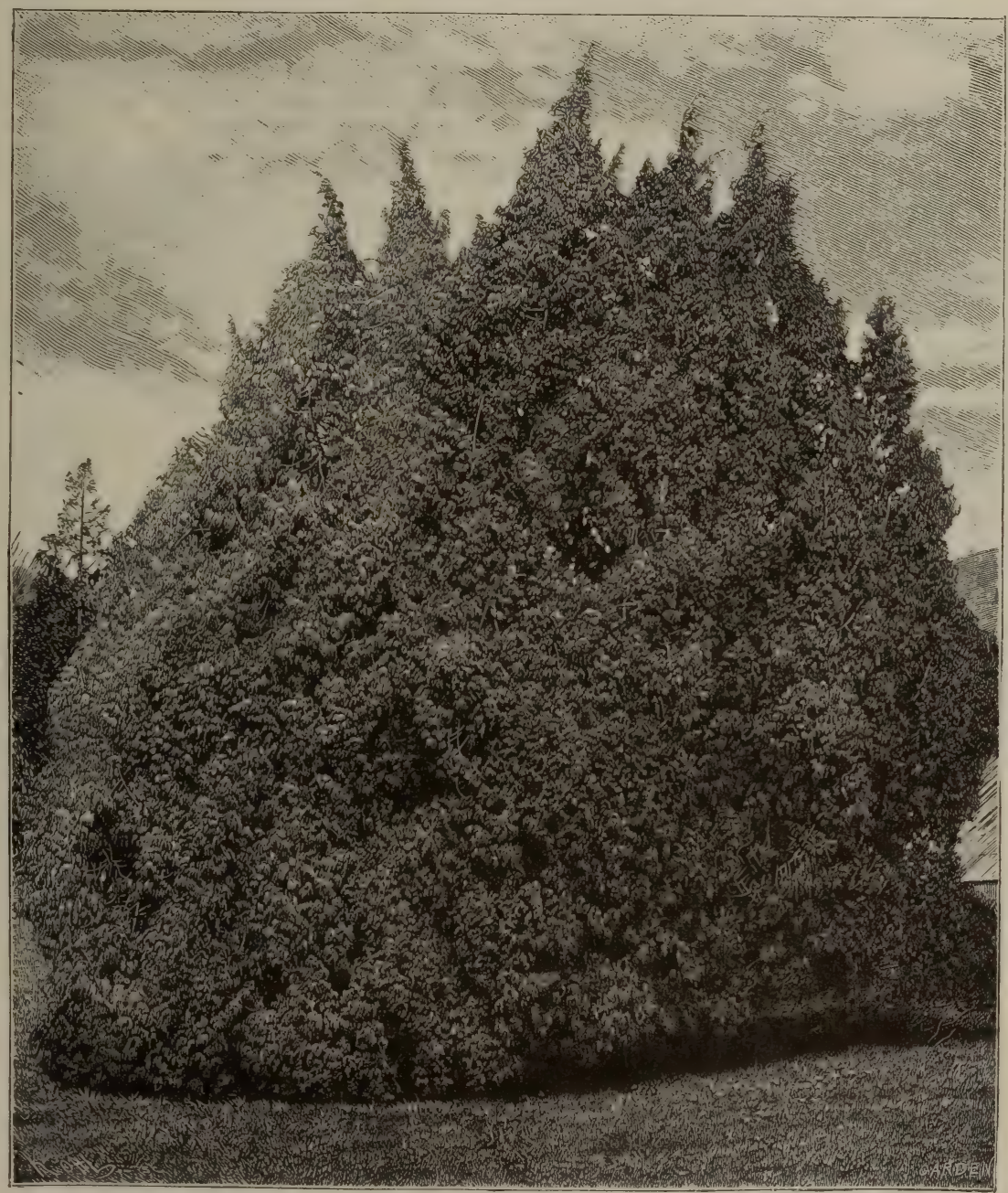

JUNIPERUS RECURVA AT CASTLEWELLAN.

(J. communis). The long round leaves are barred with bands of yellow and green. It is a striking plant, as its rigid habit and singular markings stand out in bold relief.

\section{June Berry (Amelanchier).}

Juniperus (Juniper),-Often graceful members of the great coniferous family, but frequently more shrubby than treelike, and therefore more fitted for the that desire a low growth, or that too rare quality in gardens-a little repose!

THE COMMON JUNIPER (J.communis) is chiefly found growing in England on sandy or chalky soils or on open downs, while in Scotland, its native home is amongst the granite or trap hill and mountain sides. It is, with us, usually low and small, seldom much larger than 
the furze; but where it attains some size the wood is very fine. It is now seldom used, although in former times spits and drinking vessels were made of it, as it was thought to impart a pleasant flavour to meat or liquid.

THE DWARF JUNIPER ( $J$. nana) is a very distinct and pretty plant, seldom found over a foot in height, but more commonly half that size. It is of a low dense mode of growth, and soon spreads to a great width. It is less common than J. communis. On the high rocks above Ogwen Lake I have frequently met in with this plant, but never found it very abundant.

THE IRISH JUNIPER ( $J$. communis hibernica) is a distinct variety, and of value in landscape gardening. The growth is close and compact, as in the Irish Yew, and the foliage of a peculiar silvery-grey tint. It succeeds best on rather damp soils ; indeed, the healthiest with which I am acquainted are growing on well-drained peat soil, on an estate in the North of Ireland. A dwarf and very compact variety of this Juniper, named compressa, is extensively used for rock-planting.

THE WEEPING INDIAN JUNIPER ( $J$. recurva) succeeds well in Britain. At Brynmeirig, near the Penrhyn slate quarries, there is a number of these gracefully drooping plants, which for size are perhaps not excelled in Britain. The soil is loam and peat resting on shaly slate rock. The situation is shady and with a northern aspect, which, by the bye, seems to suit not only this species but the male form ( $J$. recurva densa) as well. It should never be planted on dry warm soils, as in such situations it presents a rusty appearance and soon dies.

THE WINTER-FLOWERING JUNIPER $(J$. chinensis).-This is certainly the most ornamental; indeed, in this respect it is perhaps not excelled by any evergreen shrub. During winter or in early spring, when covered with its golden male flowers, this shrub is particularly beautiful. It is hardy and of the easiest culture, succeeding well on loamy soil and in a sheltered situation. Several distinct varieties of this plant are in cultivation.

ThE FRANKINCENSE JUNiPER $(J$. thurifera). - In this we have another distinct and good plant-or rather tree, for in its native country it attains a height of $40 \mathrm{ft}$. As a lawn specimen it is invaluable, and from its dense conical shape associates well with trees of a more loose and spreading appearance.
It should be often planted, for apart from its value as an ornamental tree it is very hardy.

THE PRICKLY CEDAR ( $J$. oxycedrus) is by many writers supposed to be the tree (rather than the so-called Cedar of Lebanon) from which the Cedar-wood, so famed in former times for its durability, and of which statues were made before the use of marble was introduced, was obtained. It is found plentifully along the Mediterranean coast, and is highly valued as well for its ornamental appearance as effect for planting in groups. Perhaps, amongst the whole range of Junipers none is more highly esteemed than-

THE RED CEDAR (J. virginiana).--It is of the easiest culture and seems to succeed in almost any situation, though attaining greatest perfection when planted near the sea-coast. It is a native of North America, where it becomes a tree, with a bright red aromatic wood, the value of which is well known from its use in cabinet work and the manufacture of pencils. J. argentea, or glauca, is a variety of the Red Cedar, and, from its peculiar whitish-silvery appearance, is useful for contrast.

Plum-Fruited JUniper ( $J$. drupacea) is a native of Syria and Asia Minor. On the mountains there, at a rather high elevation, it attains a height of some I 5 $\mathrm{ft}$. Since it was introduced in 1820 , it has proved itself perfectly hardy with us. It thrives best on good well-drained soil in a moderately sheltered situation, and is unsuitable for planting on peat bog. It has a close, narrow conical habit of growth, clothed with sharp-pointed leaves arranged in six distinct rows along the branch, which are of a light grassy-green colour. This Juniper makes a handsome specimen for a lawn, its only fault being that when it attains a height of some Io or I2. ft. it is apt to lose its under branches.

SWEDISH JUNIPER ( $J$. suecica), a native of Denmark, Norway, and other parts of Northern Europe, is very hardy in this country, and makes excellent covert. It has a compact, upright habit of growth, and the branches are well clothed with leaves which are rather longer and of a brighter green colour than those of our native species. It is said to sometimes attain a height of about $50 \mathrm{ft}$. in the Forest of Fontainebleau, but we have never seen it of such a size in this country.

ThE SAviN (Juniperus Sabina).Amongst small-growing Conifers few are more beautiful and useful than the 
common Savin and its forms, but particularly that known popularly as the Tamarix-leaved (J. tamariscifolia). For carpeting the ground, planting on dry banks where little else save the Furze could grow, along the margins of thick shrubberies, or beneath the not too dense shade of our half-standard park trees, the Savins are amongst the most useful of dwarf-growing coniferous shrubs. A pretty combination is afforded in the interesting garden at Goddendene, near Bromley, by the free use of the Tamarix- space occurred near at hand, were pegged firmly down. A heavy roller was passed over the ground twice a week, pruning and pegging were regularly attended to, and now the lawn is as level as could well be desired and can be walked across with perfect ease. The idea was certainly a novel one, but that it has been a decided success cannot be denied.

Growing alone as a garden or lawn shrub the Savin is a plant of the greatest interest, the neat, not stiff habit of growth and peculiar blue-grey of the shoots being

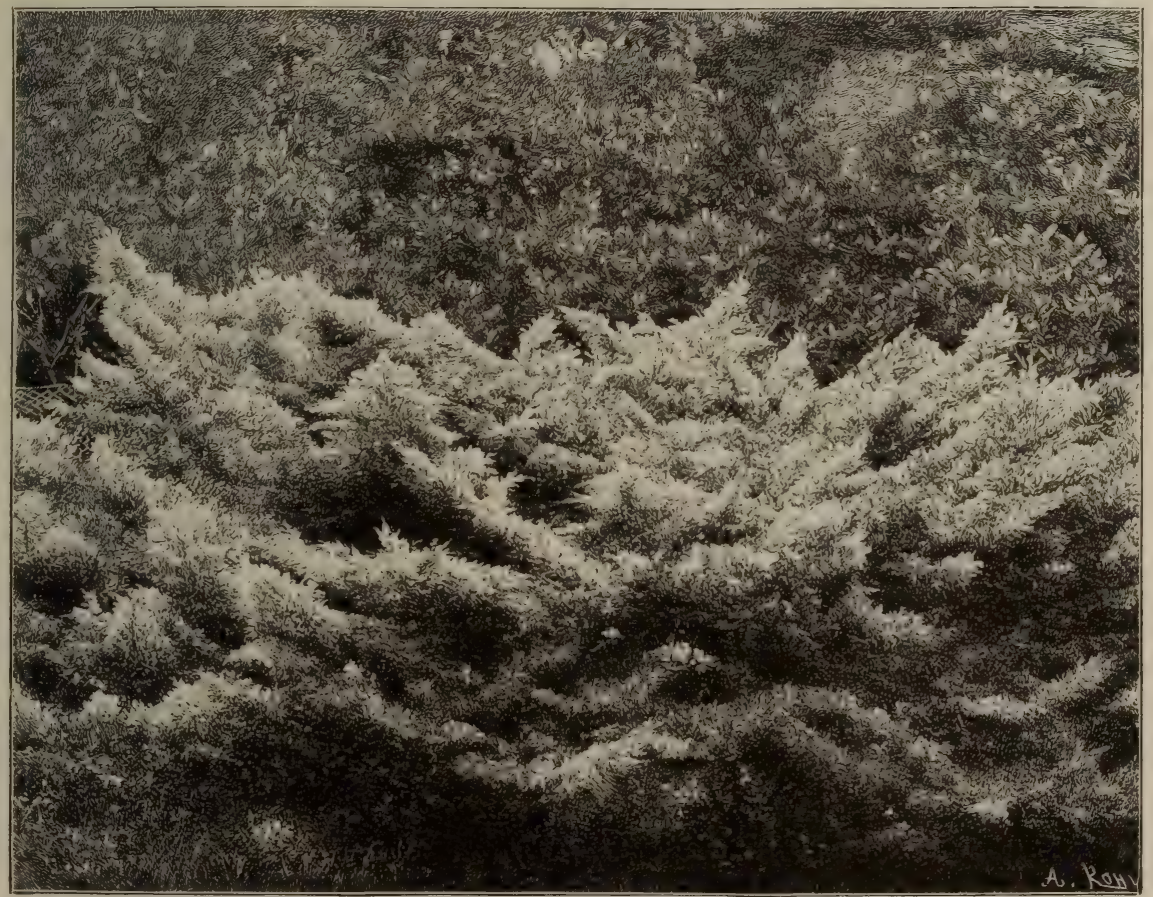

JUNIPERUS SABINA (THE SAVIN).

leaved Juniper with herbaceous plants, fine broad masses breaking up the beds every here and there, and lending quite an unusual charm to that class of gardening. But to see this same Juniper used as a lawn plant instead of Grass is certainly remarkably strange, and yet that it can be so used, every one who has been privileged to see that velvety lawn has frankly admitted. The plants were inserted when hardly $I$ ft. in spread of shoots, and at about $\mathrm{I}_{5}$ in. apart, the most procumbent in a nursery border being chosen for the purpose. Great care and attention was necessary for the first three years, so that all upward shoots were either cut off entirely, or, where a bare so uncommon and contrasting markedly with the general run of our garden and shrubbery occupants. The mode of growth is quite decumbent, while the tips of the shoots ramify and jut out here and there in a most agreeable manner. A description of the plant's habit is quite unnecessary, it being truthfully depicted in the annexed illustration. There is a variegated form of sometimes pleasing appearance, but in some specimens the variegation is sickly and repulsive.A. D. W.

Jussiæa natans. - A curious aquatic plant bearing large yellow blossoms a few inches above the water. It is valuable for still artificial water, such as a pool or 
small lake, and, being hardy, it takes care of itself. Onagraceæ.

Kalmia (Mountain Laurel).-The Kalmias are among the most beautiful of North American shrubs, being handsome in foliage and charming in flower. The broad-leaved K. (large K. latifolia) is the finest, as it is the commonest in gardens, and should be planted wherever the soil is suitable. Like the Rhododendron and Azalea, the Kalmia must be grown in a moist peaty soil, or one light or sandy. It will not thrive in stiff or chalky soils. Its lovely clusters of pink wax-like flowers open about the end of June, when the bloom of the Rhododendron and Azalea is on the wane, and last for a fortnight or longer. The broad foliage makes it almost as valuable an evergreen shrub as the Rhododendron. There are varieties of the common kind having, in some cases, larger flowers, and in others, flowers of a deeper colour, the finest being maxima, which is much superior in size of flower and richness of tint. The Myrtle-leaved Kalmia (K. myrtifolia) seems to be only a variety of $\mathrm{K}$. latifolia, with smaller Myrtlelike foliage. The growth is dwarf and compact, and the flowers are almost as large as those of $\mathrm{K}$. latifolia. The other species of Kalmia, though very beautiful, are of less value, because they are smaller, more delicate, and less showy, but in peatsoil gardens they should be grown. K. angustifolia grows about $\mathrm{I} \frac{1}{2} \mathrm{ft}$. high, and bears in early June dense clusters of rosy pink flowers. K. glauca and K. hirsuta are also pretty shrubs, K. glauca flowering in early summer, and $K$. hirsuta in August.

Kaulfussia amelloides.-A charming dwarfish hardy annual, with Daisy-like flowers, of a deep purple, but with white, rose, scarlet, and violet varieties, which are named in catalogues alba, rosea, kermesina, and atro-violacea. It forms a compact tuft, suitable for lines or masses, and here and there would help to brighten up the border. If sown in the open in April, it flowers in June, and there is not much advantage in sowing it earlier. It makes a pretty ground or "carpet" plant with taller plants here and there through it. Cape of Good Hope. Compositæ. Syn., Amellus annuus.

Kernera saxatilis.-A neat little plant very like the dwarf Scurvy Grass (Cochlearia). It forms a compact tuft of foliage, and in early summer is a dense mass of tiny white blooms. In the rock-garden it grows in any soil in an open position, and is attractive in spring. It may be freely propagated by seeds. Europe. Cruciferze.

Kerria japonica (Jew's Mallow).-The double variety of this Japanese shrub is a very old favourite, especially in cottage gardens, where it is most commonly seen. The large bright yellow rosette flowers are much more showy than those of the

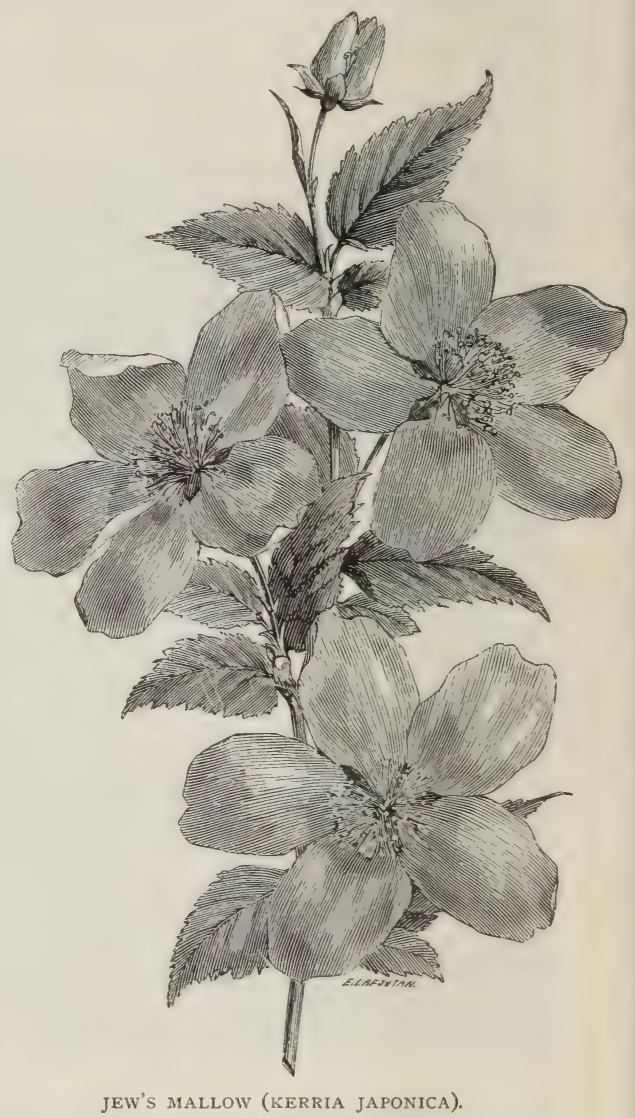

single kind, which is rarely seen. Though usually planted against walls, the Kerria is quite hardy, and may be grown as a bush except in the coldest parts. The variegated-leaved form of the single variety is more delicate than the double form, or the green-leaved single form.

Kitaibelia vitifolia.-A large coarse plant, 4 to $6 \mathrm{ft}$. high or more, with vinelike foliage. It produces in summer large white blooms from the upper parts of the stems. The plant is not delicate or showy enough for border culture, but is suited for growing among shrubs, or for naturalising in the wild garden. Seed or division. Malvaceæ. Hungary. 
Kleinia repens.-A dwarf succulent plant, with cylindrical leaves of a bluish glaucous grey. It is used for geometrical beds in summer, but is not hardy. Propagated by division in early spring in heat, followed by potting and by planting out in light dry soil in May.

Knautia (Scabiosa).

Kniphofia (Flame Flower). - Those beautiful flowers have attained a very prominent place in gardens since the introduction of $\mathrm{K}$. Uvaria in 1707 and of $K$. pumila in 1774 . They are, for the most part, hardy plants. The genus, as understood by botanists, is restricted to the mountains of Abyssinia and the Cape, with the exception of one species found by Speke and Grant near the Equator, and one or two kinds indigenous to the mountains of Madagascar. There are twenty or thirty species, and none of the six found in Abyssinia is identical with any sort found at the Cape. The Kniphofias, and especially the forms of $\mathrm{K}$. Uvaria, are among the grandest and the most striking of autumn flowers. We do not see Kniphofias so often as we should in the Grass, in the wild garden, or by woodland walks. Large irregular groups in the more open exposed spots give a very brilliant effect in autumn, and require no attention beyond an occasional top-dressing of rich soil or well-rotted manure. During the last two winters many kinds have suffered severely from frost and damp, particularly from damp, but these dangers may be averted by a covering of dry leaves when the leaves begin to turn yellow in autumn. All the stemless kinds are easily propagated by division and by seed when produced in favourable seasons ; but not the stemmed or caulescent kinds. However, those who wish to increase their stock of the stemmed kinds need not fear to behead them; in fact, this is the only way in which K. caulescens can be propagated, as, otherwise, it seldom develops offshoots. When so treated it will throw up a large number of shoots, which, if allowed to remain until a few roots are produced, may be taken off and kept in a close frame for a time, and then potted in a sandy compost. $\mathrm{K}$. sarmentosa is the easiest to increase, as it throws out underground shoots, which may be taken off at any time. K. Quartiniana develops small shoots almost at right angles with the base of the stem, and if these be taken off and treated as cuttings they will strike freely. The following are amongst the best of those in cultivation :-

K. aloides (Common Flame Flower), or Tritoma Uvaria as it is still called in many gardens, is perhaps the oldest, and is certainly one of the very best of all Kniphofias. It is the Flame Flower of old English cottage gardens, and is an extremely valuable plant, being one of the noblest and most brilliant of autumn Lily-worts. It is an excellent border plant, and is suitable for all soils and all conditions, while few plants are better suited for picturesque grouping in the wild garden. In the shrubbery, with a fairly open space and with deep rich soil, it forms large and handsome groups. It begins to flower in late summer and lasts for many weeks in perfection. It is the most valuable of the Kniphofias, and nearly 70 per cent of the garden forms are traceable to it. It is a native of the Cape. $\mathrm{K}$. pumila is a pretty dwarf form. The variety præcox, discovered and introduced by Mr. Cooper, flowers much earlier than any other form of $\mathrm{K}$. aloides, and is in perfection from the middle to the end of May. Its leaves are broader than those of the type, and are not glaucous, while the raceme is shorter. The stem is only about half as long as the leaves. The stamens of the flowers do not protrude, while the flowers themselves are bright red, passing into yellow tinged with red. The variety nobilis, which very much resembles grandis, if indeed it is not the same kind, is a very robust and noble plant. Its leaves are more distinctly serrated and more deeply keeled than those of grandis. Its flowering stem is 5 to $8 \mathrm{ft}$. in height. Its flowers vary from scarlet to orange-scarlet, and their anthers are prominent. Nobilis blooms throughout August. The variety serotina is interesting from blooming a month or so after all the other Kniphofias are over. Its flowers are greenish-yellow, occasionally tinged with red. The variety Saundersi has bright green leaves and very rich orange-scarlet flowers; the variety longiscapa has very long flowerheads, and is a most desirable form ; the variety maxima globosa has globose heads of yellow and red flowers; and the variety glaucescens has large flowerspikes, the flowers being vermilion-scarlet shading to orange. It is a free-flowering plant, and is one of the best for heavy rich soil.

K. Burchelli, introduced by $\mathrm{Mr}$. Burchell from the Cape, is a very distinct and beautiful plant. It has a purplespotted stem and bright green leaves, firm in texture, 2 to $3 \mathrm{ft}$. long, which taper gradually to the apex. It flowers soon after midsummer, and just between 
præcox and the other forms of $\mathrm{K}$. aloides. The flower-heads are moderately dense, and the flowers are bright red, excepting those at the lower end of the head, which are bright yellow. The style protrudes, the stamens being included in the tube. A useful and distinct plant, suited for dry banks, etc.

$\mathrm{K}$. carnosa is a beautiful plant. It forms several low spreading leaf-rosettes,

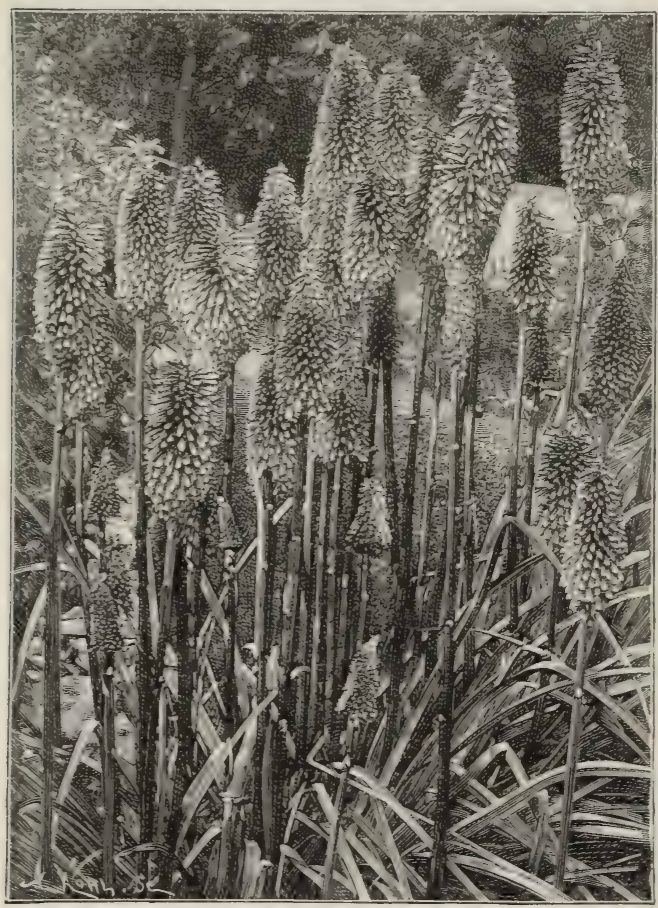

KNIPHOFIA GRANDIS.

from the midst of which a number of flower-stalks rise to the height of $\mathrm{I} \mathrm{ft}$., producing a completely cylindrical flowerspike about 3 by $\mathbf{I} \frac{1}{2}$ in. ; but the comparative smallness of the flowers is compensated by their glowing apricot colour, enhanced by bright yellow anthers. The flowers open first on the top side. Taking it for all in all, it is a lovely, striking plant. It flowers in September, and is a native of Abyssinia.

K. caulescens and K. Northiæ differ from all other cultivated Flame Flowers in their caulescent habit. K. caulescens differs from all the forms of aloides in being smaller, and in having very glaucous leaves, short heads, and smaller and less curved flowers. The stem, at 5 or 6 in. from the ground, can just be spanned by both hands ; the scape is about $4 \frac{1}{2} \mathrm{ft}$. high, with a dense head of flower 6 in. in length. This head is of a reddish-salmon colour in its earlier stages, but in the fully-expanded flower it gradually becomes white, faintly tinged with greenish-yellow, producing an effective contrast. The glaucous blue-grey foliage affords a distinctive feature. Though less brilliant than most of the other species, it is one of the hardiest we have, and is very distinct and robust. As a rule it flowers early, and this is a specially welcome feature. It was first found, we believe, by Mr. Cooper in 1860 in the Stormbergen Mountains, South Africa. It is a very striking plant for the rock-garden, where it does well and flowers freely on dry slopes. It succeeds in light warm soils, in open sunny positions, and, though hardy enough, should have a little protection in severe cold. Its cultivation, indeed, may be said to be one of the easiest, and it may be propagated freely from suckers or by cutting up the short stem. Suckers or offsets taken off in early autumn root freely in sand in a cold frame.

K. comosa seems to be closely allied to $K$. pumila. It has a peculiar appearance with its long protruding style and anthers. It is much dwarfer than $K$. aloides, its leaves are much narrower, while its flowers are smaller. Its bright green leaves are in dense rosettes. They are erect, narrow, very pointed, and almost three-cornered. The bright yellow flowers droop in a dense oblong head, which is much narrowed above the base. The stamens and style are about twice the length of the flower tube. $\mathrm{K}$. comosa is a showy plant, flowering in September, but is rather tender.

$\mathrm{K}$. foliosa may be said to be the counterpart of $K$. caulescens, but it has distinct stems instead of being stemless. It is one of the most robust of all the Kniphofias, and is easily distinguished by its broadish leaves and its protruding stamens. It was first flowered in England by Elwes about I88I, but Max Leichtlin's specimen was more robust and the flowers had a tinge of bright red such as is rarely seen in England. The leaves form a dense tuft on the top of a stem I to $3 \mathrm{ft}$. high. They are 3 or $4 \mathrm{in}$. broad at the base, and they taper to a long point. They are green or very slightly glaucous, 
and are obscurely serrated. The flowers are borne in a dense oblong head nearly I ft. long, and are bright yellow or tinged red. They appear in late autumn. Cape. =K. Quartiniana.

K. Leichtlini was named after Herr Max Leichtlin, of Baden-Baden, who has done so much to furnish English gardens with rare and beautiful hardy plants. It is a native of Abyssinia, and requires winter protection even in the South of England. It was discovered by Schimper, and was first flowered in the Royal Gardens, Kew, in September r88I. It is, perhaps, nearest to K. pumila. Its spreading bright green leaves form a dense tuft ; they are 2 to $4 \mathrm{ft}$. long, and are dilated at the base into a broad clasping shield, gradually narrowing to a point. They are three-cornered, with entire margins. The flower-stems are 2 to $4 \mathrm{ft}$. high, and the flower-head is about $6 \mathrm{in}$. long: The drooping flowers are of a dull vermilion-red and yellow, while the stamens are slightly protruding. The variety disticha, which is quite distinct from the type, is more robust. Its leaves are broader, its flower-tube is shorter, and the stamens of the flowers are decidedly longer. Two or three heads of bright deep yellow flowers are produced on the same stem. Disticha flowers in August. Abyssinia. Some have suggested that it is a hybrid between $\mathrm{K}$. Leichtlini and $\mathrm{K}$. comosa.

K. Macowani.-A distinct plant. It differs from most Kniphofias in having the segments of its corolla reflexed, and in being of dwarf habit. It is indeed only I 2 to I 8 in. high. It was discovered by Professor Macowan in grassy places on the Boschberg Mountains, at an elevation of four or five thousand feet above the sealevel. The narrow grassy leaves are $I$ to $2 \mathrm{ft}$. long. They are distinctly keeled, and have deeply-grooved margins. The flower-heads are small, and the flowers are of a bright orange-red. K. Macowani is perfectly hardy, and is suitable for rockgardens. Rigidissima and maroccana are garden names. The variety longiflora has much longer flowers. $K$. corallina is a very fine robust hybrid raised by Deleuil, of Marseilles. It is exactly intermediate between $\mathrm{K}$. Macowani and $\mathrm{K}$. aloides, and is a very desirable plant.

K. Northiæ. - A new species from Grahamstown, discovered by Mr. Dugmore. It is of undoubted hardiness in the neighbourhood of London; and the plants sent to Kew flowered in the Cactus house in I889. It is most nearly allied to $\mathrm{K}$. caulescens, but its leaves are much broader, are not keeled, and are serrulate on the margins. The dense flower-heads are about I $\mathrm{ft}$. long, the flowers being pale yellow, but the upper are tinged red towards the tips.

K. Rooperi is one of the best Kniphofias in cultivation. It is nearly allied to $\mathrm{K}$. aloides, but is an early, or summer, flowering plant, while the stamens are included in the tube, the flowers are paler and less curved, and the leaves are broad and very glaucous. K. Rooperi is a native of Caffraria, and requires a little protection during severe winters. It has a fine bold appearance when in full flower, the flowerheads, 6 in. to I ft. long, being crowded with bright orange-red flowers, which get yellowish with age. The plant usually called Rooperi flowers in November and December, and is a variety of $K$. aloides.

$\mathbf{K}$. sarmentosa is a distinct and useful plant. It is readily distinguished from $\mathrm{K}$. aloides by its smaller glaucous leaves, with edges and keel unserrated. The cylindrical flower-heads are from 6 in. to I ft. long. The flowers are red in the upper half, and yellow, or yellow tinged red in the lower. $K$. sarmentosa was introduced by Mr. Williams, nurseryman, Turnham Green. It is perfectly hardy. Suckers. There is an excellent hybrid between $\mathrm{K}$. sarmentosa and $\mathrm{K}$. aloides. Cape.

K. triangularis, at first sight, reminds one of K. Macowani, especially as regards the flower-spike, which is about the same size and of a similar tint. The foliage, however, is broader and longer, and in this respect it resembles $\mathrm{K}$. Uvaria. It is desirable because it is earlier in flower than most varieties, and also because it is a free grower and flowerer.

\section{K. Uvaria ( $=K$. aloides)}

Other species not noticed in detail are K. pumila, pallidiflora, pauciflora, natalensis, Kirki, Tysoni, modesta, Granti.D. K.

\section{Knotweed (Polygonum).}

Kochia scoparia. - A curious and seldom-grown annual plant of the Goosefoot family, forming a neat pointed bush, from 3 to $5 \mathrm{ft}$. high. The flowers are insignificant, but the graceful habit of the plant makes it valuable, placed either singly or in groups, especially from July to September, the time of its full development. It should be sown in April, in a hot-bed, and afterwards planted out in beds or borders. S. Europe.

Kolreuteria paniculata. - A small tree, handsome in foliage, and beautiful when in flower. The long-divided leaves are elegant throughout summer, and in 
autumn die off a rich yellow. The yellow flowers are small but abundant, and form large clusters over the spreading mass of foliage. The Kolreuteria is picturesque, and valuable for groups. It is a native of China, quite hardy, and thriving in any grood soil.

\section{Koniga (Alyssum).}

\section{Labrador Tea (Ledum).}

Laburnum.-There are many named Laburnums, and of these undoubtedly the finest are the following : that named Watereri or Waterer's Laburnum, as regards bloom, the spikes being $\mathbf{I} \mathrm{ft}$. or more long, and the colour the brighest yellow. It is also of excellent habit and very free-flowering. Parkesi has also very long racemes, and may be identified by flowers of a deeper yellow; Carlieri and grandifforum have good flowers, while quercifolium, bullatum, and others have peculiar leaves. The drooping variety (pendulum) is a graceful tree, with weeping branches. Serotinum comes into bloom later than the ordinary kinds, and Autumnale is said to flower in autumn. There are twenty other sorts enumerated in catalogues. As with other very showyflowered trees, considerable taste and judgment is required to plant the Laburnum effectively. Instead of dotting it about in a meaningless way, distinct groups should be planted in widelyseparated spots, or, at least, where from any given point one cannot see the tree repeated more than once. It is best not to plant large specimens, for few trees are so difficult to transplant when large. Other species are L. alpinum, the Scotch Laburnum, a most valuable kind, as it usually flowers when the others are past. It may be recognised by its broader and deeper-green leaves, and by the very rich yellow of the racemes, which are also longer than those of the ordinary sorts of L. vulgare. There are several named varieties of $\mathrm{L}$. alpinum, among them being a drooping kind, pendulum, and fragrans, which is said to be more strongly scented than the type. L. Adami has long been a puzzle to botanists, who even now cannot account for its peculiar character. It is supposed that it originated by grafting the purple-flowered Cytisus purpureus upon the common Laburnum, a graft hybrid being the result. The same tree, and even the same branch, bear racemes of both yellow and purple flowers, and sometimes the colour is a dull purple, like yellow mixed with purple. Old trees of these are singularly quaint and not without beauty.
Lactuca (Lettuce).-Composite plants, oftener seen in the kitchen than in the flower garden. There are one or two blue perennial kinds, grown in full collections, which are not without beauty.

Lady Fern (Asplenium Filix-formina). Lady's Bedstraw (Galium).

Lady's Fingers (Anthyllis).

Lady's Slipper (Cypripedium Calceolus).

Lagurus ovatus (Hare's-tail Grass).A pretty annual Grass, about I ft. high, and forming hare's-tail-like plumes, which are useful for bouquets. It should be sown in pots in August, wintered in frames, and divided and transplanted in spring, or sown in open ground in April. It flowers from July to September. It would be pretty in the flower garden in groups and large patches as a relief to showy-flowering things.

Lamarckia aurea. - A small hardy annual Grass, with silky plumes, which become golden as they mature. It is suitable for bouquets, and may be dried for winter use. Seeds should be sown in spring or autumn, in the open border in light soil. = Chrysurus cynosuroides.

Lamium (Dead Nettle).-In this genus there are a few plants occasionally worth a place in poor dry soils, where little else will grow-such as are found on dry banks or beneath trees. L. garganicum, from I to $I \frac{1}{2} \mathrm{ft}$. high, has in summer whorls of purplish blossoms. L. Orvala is taller and has deep red flowers in early summer. L. maculatum, a native plant, has leaves blotched with silvery-white. Of this species the variety aureum is one of the best golden-leaved plants for edgings. It does not withstand the full exposure that suits the yellow Feverfew, but in sandy or moist soils its peculiar tint is unequalled by any other hardy plant, and its blooms are pretty. It does not require to be constantly trimmed like the Feverfew. It is known also as L. striatum aureum.

Lancea tibetica.-A little alpine Labiate from the Himalayas. It is rare, and no one has proved its merits, though it is said to be pretty.

Lantana.-Pretty S. American plants, usually grown in greenhouses, but valuable for the summer border. The Verbena-like heads of bloom are rich and varied in colour, and range from crimson, through scarlet, orange, and yellow, to white, the colours varying in the same head, but the odour is not so good. They flower profusely for about nine months, and are as easy to grow as Pelargoniums. They require the pro- 
tection of the greenhouse during winter, after. being lifted in autumn, and may be propagated in spring by cuttings or seeds, the plants being grown in rich light soil till planted out in a warm position. There are many sorts grown, and a selection should include Phosphore, Don Calmet, Distinction, Eclat, Victoire, La Neige, Feu Follet, Pluie d'Or, Ver Luisant, Ne Plus Ultra, Eldorado, and Heroine. Like many dwarf half-hardy plants, they have various uses in the flower garden, and may be trained as standards. The pretty L. Sellowi is a good dwarf plant ; but the odour of the Lantana is somewhat objectionable, and they are not likely to be much used. West Indies. Verbenaceæ.

Lardizabala biternata.-A very handsome evergreen climber from Chili, hardy enough for walls in the south and coast districts. The foliage is a deep green, and the leaflets are thick. Along the south coast it makes a dense and beautiful wall-covering, reaching a height of $20 \mathrm{ft}$. or more. Its inconspicuous purple flowers are seldom produced in the open air. It should be planted in light or well-drained soil.

\section{Larkspur (Delphinium).}

Lasthenia glabrata.-A pretty hardy annual, from $9 \mathrm{in}$. to $1 \frac{1}{2} \mathrm{ft}$. high, producing a profusion of rich orange-yellow blossoms. It should be sown in autumn or early summer, or in spring for later bloom. Like other annuals, it looks best in broad tufts, but care must be taken that the plants are properly thinned. The autumnsown plants come in with the Iberis, Wallflowers, early Phloxes, and the like. L. californica is a slightly-marked variety. California. Compositæ.

Lastrea.-See Aspidium and Nephrodium.

Lathræa Squamaria.-A curious leafless parasite, often found growing from the roots of trees in woods.

Lathyrus. - A genus of annual and perennial plants, several of them very beautiful and valuable for the garden. The perennials - or Everlasting Peasare particularly valuable, for few plants are of more elegant growth. As a screen in summer, for shutting out unsightly objects, for rapidly covering arbours or trellis-work, or as floral fences for the protection of more tender plants, they are unsurpassed; and they are charming plants for the flower garden when associated with the Canary Creeper, the various kinds of Convolvulus and Clematis, and other climbing plants. The chief of the perennials is -
L. latifolius, one of the hardiest and most easily cultivated of plants, thriving almost anywhere, even in courtyards amongst flags and boulders. It may be made to ornament any dead naked walls, for a few bits of it, dibbled in among the stones under a wall, will take care of themselves, as the long leathery roots penetrate to a great depth. There is a pure white variety, and a striped one, and there are varieties with deeper flowers than the type. All are peculiarly suited for wild rough places, and will ramble and scramble over bushes and stones. Staking, tying, and training only spoil them. An old tree-stump, or the side of a trellis or summer-house is where they delight to grow undisturbed.

Other Everlasting Peas are L. grandiflorus, less rampant in growth but handsomer in bloom than L. latifolius; the stems are weaker, but the flowers, produced in pairs, are twice the size. Another species, L. rotundifolius, grows lower than the rest of the family, and has some affinity to L. latifolius, but is neater; it is suited for stony banks. L. pyrenaicus is the most rampant of the family, growing $20 \mathrm{ft}$. in a single season, and bearing a prodigious quantity of yellowish blossoms veined with purple. It is a good kind for running over the trunks of dead trees and similar places. L. sylvestris is a native plant. Its flowers are large and greenish, with purple veins, and it is pleasant to see it festooning the bushes in open places in woods. L. Sibthorpi is remarkable for the early period at which it blooms, and no less so for the tender rosy-purple or deep mauve of its flowers. It is dwarf, compared with $L$. latifolius and its varieties, and rarely exceeds $3 \mathrm{ft}$. in height. In very young plants the merits of this species are not so evident, but when thoroughly established in good loamy soil it forms one of the greatest attractions of the spring border. L. Drummondi is very robust, and perfectly hardy. The flowers are borne in clusters like those of L. latifolius, and are of very bright carmine. The dwarf non-climbing species are generally known under the name of Orobus.

L. odoratus (Sweet Pea).-This beautiful and popular annual needs no description. There are many ways in which it can be turned to account in a garden. A common method is to sow little patches in borders, the seed being generally that of mixed varieties, and, by placing some stakes against them, to secure pillars of flower. Where it can be done, a hedge 
of Sweet Peas is an attractive sight, and sometimes Sweet Peas can be used to hide an unsightly place during the summer. Many people grow a hedge in the same way in order to yield a supply of cut flowers, which are always produced abundantly. It is useless to grow the Sweet Pea except in good soil. Some sow in late autumn ; this is not always satisfactory, though, when it succeeds, the result is very fine. By sowing indoors in pots or boxes about the middle of February, and gradually hardening off the young plants when they are I in. high, Sweet Peas may be made to acquire a sturdiness and toughness which, when they are planted out in good well-manured soil in April, conduces to rapid growth and to immunity from birds and slugs, which would otherwise attack the tender shoots the moment they appeared above the ground. The soil should be well trenched, and plenty of good stable manure should be worked in; and after the plants have been rather thickly dibbled in, supports of hazel stakes or netting should be placed round them. Then, with a little attention during dry weather and the regular removal of incipient pods, they will produce an abundance of beautiful and fragrant flowers all through the summer and autumn. When getting past their best, they should be cut down level with the tops of the sticks, and the result will be that from the bottom to the top a new growth will spring up, and there will be an abundance of bloom until the end of October. There are many varieties of the Sweet Pea, varying chiefly in colour; the best of the named sorts are Butterfly, Black and Scarlet, Invincible, Painted Lady, Purple Striped, Princess of Prussia, and Fairy Queen.

Though none of the other annual kinds of Lathyrus can surpass the Sweet Pea, there are several that make pretty border plants. Of these the best is the Tangier Pea (L. tingitanus), which grows about $3 \mathrm{ft}$. high, and produces small dark redpurple flowers in abundance. The Chickling Vetch (L. sativus) is another pretty kind, with flowers varying from pure white to deep purple. The variety azureus is a remarkably elegant dwarf kind with many clear blue flowers; L. s. coloratus has flowers white, purple, and blue; L. Gorgoni, about $2 \mathrm{ft}$. high, is very desirable for its pale salmon-coloured flowers ; L. articulatus, Clymenum, and calcaratus are other pretty kinds for borders.

\section{Laurel, Alexandrian (Ruscus)} " Common (Cerasus).

\section{Laurel, Ground (Epigaa). " Mountain (Kalmia). Poet's (Laurus).}

Laurestinus (Viburnum).

Laurus nobilis (Poet's Laurel).-More generally known as Sweet Bay. It is the true Poet's Laurel, the vigorous Cherry Laurel having wrongly taken the name. Perhaps there is no evergreen shrub we oftener see in cottage and other little gardens, the owners of which seem

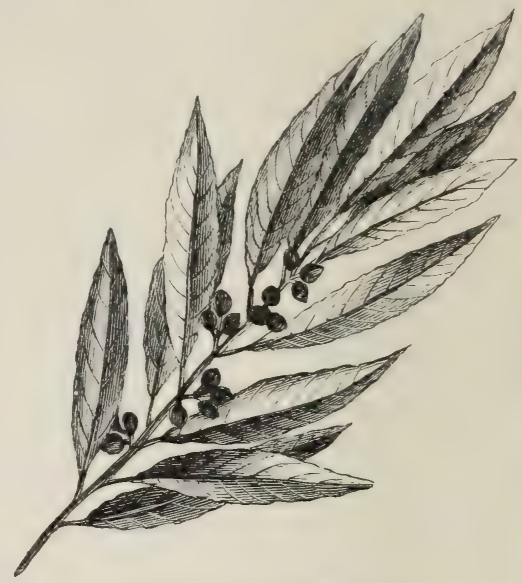

LAURUS NOBILIS (SWEET BAY).

to know its great value. In England it is hardy over large areas, if it suffers occasionally, especially on heavy and cold soils, where the ripening of the shoots is not completed. Gardeners in the larger places rather neglect it, and seldom plant it in groups and colonies, as they might well do on dry banks. The plant is interesting in every way for its associations as well as for its beauty. There are several slight varieties, in addition to the common form. It requires some care in transplanting or it will be a long time rooting well. Warm and sheltered places are best for it, if possible on sandy or free soil ; and it might be planted in different aspects with advantage.

Lavatera (Tree Mallow).-For the most part vigorous and somewhat coarse annuals, biennials, and perennials, few of which are desirable in the garden. The most useful is L. trimestris, a beautiful South European annual, from 2 to $3 \mathrm{ft}$. high, bearing in summer a profusion of large pale rose or white blossoms. It thrives in ordinary soil, but especially in one that is rich and light. It may be sown in the open border in autumn or early spring. Among the taller kinds the best is $L$. arborea, which has the 
appearance of a small tree, and in the southern counties is nearly ro $\mathrm{ft}$. high. The stem branches into a broad, compact, roundish, and very leafy head. It may be used for warm and sheltered parts of pleasure-grounds and rough places. In rich well-drained beds it would be a worthy companion for the Ricinus and the Cannas. It is most at home on dry soils, but during the summer months it thrives on all kinds of soil. Being a biennial, it requires to be raised from seed annually. L. cashmeriana, unguiculata, thuringiaca, sylvestris, and others of a similar character are not worth growing except in the wild garden, or unless naturalised elsewhere.

Lavender-Cotton (Santolina).

Lavender, Sea (Statice).

Lavendula. - The common Lavender L. vera needs no description, but should on no account be omitted. It succeeds best in an open sunny position, in light soil. The white-flowered variety is as sweet as the blue, and flowers at the same time. Though a bush, the Lavender has been for centuries associated with our old garden-flowers. For low hedges, as dividing lines in or around ground devoted to nursery beds of hardy flowers, and many other purposes, it would be admirable. It is excellent for the embellishment of dry banks and warm slopes. The Sage order. S. Europe. L. lanata, dentata, and Stœchas may also be seen in botanic gardens.

Lawn Pearlwort (Sagina glabra var. corsica).

Leavenworthia aurea. - A pretty cruciferous annual of very dwarf habit, forming a neat rosette-like tuft, from which arise numerous stalks 4 to 5 in. high, each bearing a single flower about $\frac{1}{2}$ in. across, with white petals stained at the base with deep yellow. Occasionally, when strongly grown, a short stem is thrown up, bearing the flowers on long pedicels. It blooms in May and June and should be treated as a half-hardy annual. Arkansas.

Ledum (Labrador Tea).-The best of the few species of Ledum grown in gardens is L. latifolium, which represents the genus well. Its usual height is under 2 $\mathrm{ft}$. but sometimes it reaches $3 \mathrm{ft}$. It is dense and compact, and has small dull green leaves, of a rusty brown beneath. During the latter part of May it bears clusters of small white flowers, which being abundant are showy. It is a very old garden plant, and was brought from North America more than a century ago. The Canadian form of it (canadense) is found in some gardens, but does not differ materially from the type. A form called globosum is finer, as the flower-clusters are larger and more globular. L. palustre is commoner than L. latifolium, but being smaller in every part is much inferior. It is dwarf and spreading, and its flowers are white. A native of both North America and Northern Europe. The Ledums thrive best in a peaty soil or sandy loam, and are usually included in a collection of so-called American plants. They are charming grouped in the boggarden, fully exposed if possible.

\section{Leiophyllum buxifolium (Sand} Myrtle).-A neat, pretty, and tiny shrub, forming compact bushes 4 to $6 \mathrm{in}$. high, with evergreen leaves resembling those of the Box. The small white flowers are borne in dense clusters in early summer, the unopened buds being of a delicate pink hue. It is particularly suited for grouping with diminutive shrubs, such as the Partridge Berry, the sweet Daphne Cneorum, the small Andromedas, and with Willows like S. reticulata and serpyllifolia, that rise little above the ground. It is generally planted on the margins of peat beds with other American peat-loving shrubs, but it is also a good plant for the rock-garden. A native of sandy "pine barrens" in New Jersey, and easily had in our nurseries under the name of $\mathrm{L}$. thymifolium. There is more than one variety in cultivation.

Leontice (Lion's Leaf).-Dwarf perennials of the Barberry family, natives of Europe and Asia. There are some three or four species in cultivation, but found only in botanical collections. They are all pretty plants, about I ft. high, and bear in spring numerous bright yellow blossoms. L. Leontopetalum, Chrysogonum, vesicaria, and odessana are the kinds grown, and are all perfectly hardy; but, as they seem to be injured by the excessive moisture of our winters, they are generally cultivated in frames or under hand-lights, to shelter them and to preserve their flowers from the effects of the weather in spring. A light friable soil is best to plant them in. The large depressed root-stocks, which resemble the corms of a Cyclamen, should not be placed beneath the soil, but fastened by some means, so that only the bases, from which the fibry roots are emitted, should be in contact with the ground.

Leontodon (Dandelion).-Besides the common Dandelion, others of this genus are enumerated in catalogues, but none is of much garden value.

Leontopodium alpinum (Edelweiss).A charming and well-known alpine plant. 
This hoary little herb, so well known to alpine tourists, is well worthy of culture. The small yellow inconspicuous flowers are surrounded by star-like heads of leaves clothed with a dense white woolly substance, rendering the plant distinct and pretty. Its culture is not difficult in any way, on sandy soils, or even as a border

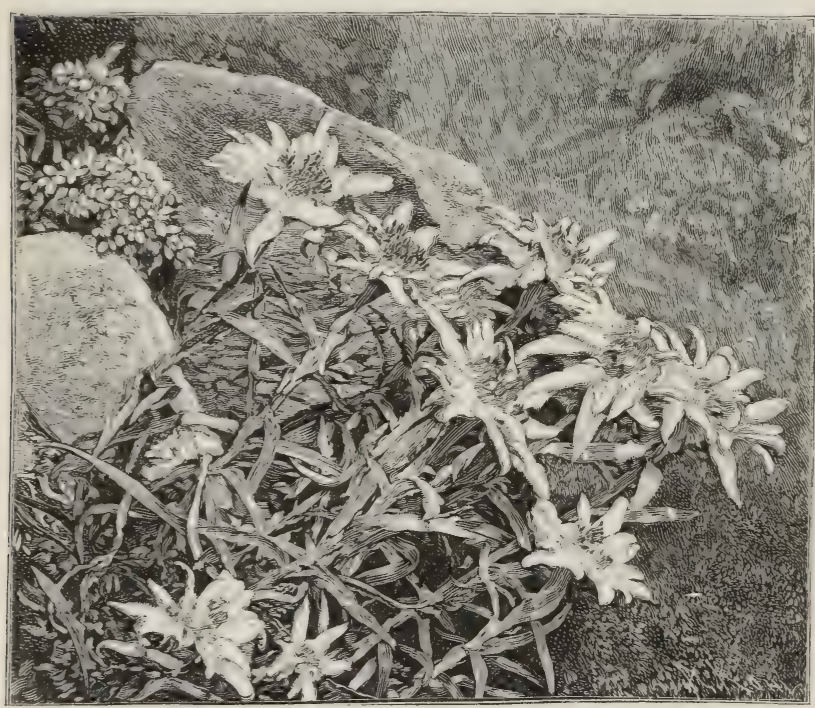

LEONTOPODIUM ALPINUM (EDELIVEISS).

tings strike freely in spring-more freely than in autumn -in a slight bottom-heat. They are obtained by merely removing the young shoots from a growing plant.

Leopard's Bane (Doronicum).

Leptinella scariosa. - A very dwarf Chilian plant, with small deeply-cut foliage. It forms a dense compact carpet, on which account it is employed for flat geometrical bedding, for, though a fast grower, it does not require clipping or any other attention. It will grow in any soil or situation, and is useful for clothing places in the rock-garden where choicer subjects would fail. Its flowers are inconspicuous. Division. Compositæ. L. filicaulis and $\mathrm{L}$. dioica, if not the same, are very similar.

Leptosiphon. - All the species of this genus deserve cultivation. To produce the best results these charming annuals must be strongly grown, and robust specimens can only be obtained by thin sowing.

plant, but it grows most luxuriantly in moist rich soils. To keep a good stock of flowering plants, the old ones should be divided annually or young ones raised from seeds, which in some seasons ripen plentifully. It succeeds either on exposed spots of the rock-garden or in an ordinary border, if not placed too near rank-growing things. = Gnaphalium alpinum. Compositæ.

Leonurus Leonitis (Lion's-tail).-A plant of the Labiate family, allied to Phlomis, about $2 \mathrm{ft}$. high, and bearing in summer whorls of very showy bright scarlet flowers. It is a Cape plant, and is not hardy enough for our climate during the winter, even when protected by a cold frame, though in warm light soils, in the southern parts of the country, we have observed it thriving out-of-doors in summer. Where it will not bloom out-of-doors, it is worthy of a place as a cool greenhouse plant. Near Paris, established plants placed out for the summer flower profusely. Wherever it can be grown in the open air, it would be valuable for association with the finer bedding and sub-tropical plants. Cut-
In light dry soils early autumn sowing is strongly recommended. It is not enough to sow the seed at any period of autumn ; it must be sown sufficiently early to permit the young plants to attain some size before the setting-in of winter. In short, a good framework must be laid, which, on the return of spring, will develop an effective tuft. When the sowing has been deferred until late in the summer, it is better to sow the seed in pans or boxes, in a frame or orchardhouse, and to plant out seedlings in April; or, if this be thought to involve too much trouble, the sowing may be put off till early spring. Fair success may be looked for, especially in good soils, where spring-sowing will often yield excellent results; while the advantages of autumn-sowing are best seen in light sandy soils. Of the numerous kinds in cultivation the best is $\mathrm{L}$. roseus, which is one of the most charming of hardy annuals. It forms dense compact tufts, profusely studded with rosy-carmine flowers. The very pretty L. luteus and its deeper-coloured variety aureus are scarcely inferior to $\mathrm{L}$. roseus, which they 
closely resemble in general habit, though they have somewhat smaller flowers. The hybrid varieties of these, introduced by Messrs. Vilmorin, are also interesting for the singular variety of shades occurring among them. The larger-flowered species, L. densiflorus and L. androsaceus should be too well known to need description or eulogium. Both have lilacpurple flowers, and are most attractive annuals which never fail to delight. Of both species there are good white varieties deserving of especial recommendation; and L. densiflorus is particularly desirable. All natives of California. Polemoniaceæ.

Leptosyne.-Californian plants of the Composite family, much resembling some of the Coreopsis. L. Douglasi is a pretty half-hardy annual, about I ft. high, and having large yellow flowers. L. Stillmanni much resembles it, but is smaller. L. maritima, though a perennial, is somewhat tender, and requires to be treated as an annual. It is a showy plant, about 6 in. high, and bears large bright yellow flowers. All these plants thrive best in an open sunny position in a light warm soil. The seeds should be sown early in heat, and the seedlings transplanted in May.

Lespedeza bicolor.-A name for the beautiful Chinese shrub usually called Desmodium penduliflorum, and described under that name.

Leucanthemum alpinum (Alpine Feverfew). - A very dwarf plant. The leaves are small, and the abundant flowers are supported on hoary little stems I to 3 in. long, are pure white with yellow centres, and are more than I in. across. It is rather quaint and pretty, and well deserves cultivation in bare level places, on poor sandy or gravelly soil in the rock-garden. It is sometimes known as Chrysanthemum arcticum and Pyrethrum alpinum. It is a native of the Alps, and is readily increased by division or seed. For other species of Leucanthemum see Chrysanthemum.

Leucojum (Snowflake).-Pretty bulbs allied to the Snowdrop. There are several species in cultivation, but the only common ones are $\mathrm{L}$. xstivum and $\mathrm{L}$. vernum, with their varieties.

L. æstivum (Summer Snowflake) is a tall and vigorous plant, and bears flowers on stalks I to $\mathrm{I} \frac{1}{2} \mathrm{ft}$. high. These flowers are white drooping bells, marked with green inside and out, and appear in clusters of four to eight blooms on a stem. The leaves of the plant are very numerous, and shaped like those of Daffodils. It blooms early in summer (in many places before the end of spring), and forms a pleasing object either in the mixed border or on the margins of shrubberies. In company with Solomon's Seal its graceful pendent flowers may be even better appreciated. It thrives in almost any soil, and is readily multiplied by separation of the bulbs. It is excellent for the wild garden, and increases as rapidly as the common Daffodil. A form of $\mathrm{L}$. æstivum, known in gardens as L. pulchellum, is L. Hernandezi, a native of Majorca and Minorca. This grows to about the same height as $\mathrm{L}$. restivum, but has narrower leaves, flowers only half the size, and usually not more than three flowers on each stem; it also flowers nearly a month earlier. Being greatly inferior in appearance to L. æstivum, it is not much cultivated, but if grown, it can be treated like L. æstivum. The latter is naturalised in some parts of England.

I. vernum (Spring Snowflake) bears flowers on stalks 4 to 6 in. high. The fragrant drooping flower resembles a large Snowdrop, the tips of the petals being well marked with a green or yellowish spot. It is excellent for the rock-garden, valuable for the border, and thrives in a light, rich, and well-drained soil. Imported bulbs make little show for the first year or two, but afterwards, when established in sandy loam and peat in a somewhat shady border, they flower very freely and regularly. Probably the vitality of the bulbs is impaired by the drying process to which all bulbs are subjected in going through a market, but this process has a beneficial effect on some species. L. carpaticum flowers a month or six weeks later than L. vernum, and, unlike that species, begins to expand its blossoms when the stalk and the leaves are scarcely above the ground; the petals, too, are tipped with yellow instead of green. Other cultivated Snowflakes are L. hyemale and L. roseum; but these are very rare, and somewhat difficult to cultivate.

Leucophyta Brownei.-A New Holland plant, with slender hoary stems, in a small state largely used for flat geometrical beds in summer. Propagated by cuttings in éarly spring. Compositæ.

Leucothoë.-Beautiful evergreen shrubs of the Heath family, most of them very old garden plants, and common in collections of American plants. There is a striking family likeness between the common kinds, the best-known being L. acuminata, which grows from $I \frac{1}{2}$ to $2 \frac{1}{2} \mathrm{ft}$. high, and has slender arching stems clothed with long pointed leaves. In early summer the 
stems are profusely wreathed with tiny white bell-shaped flowers, extremely pretty. L. axillaris is similar, and so are L. Catesbæi and L. racemosa, all of which are known under the generic name Andromeda. They are natives of North America, are perfectly hardy, and thrive in any light soil, but prefer peat or leafmould. They are suitable for the margins of groups of large-growing American plants, for low parts of rockgardens, and for root-work or ornamental coverts. A newer and very beautiful species is L. Davisiæ, introduced a few years since from California, and therefore neither so common nor so hardy as the others. It makes a neat little evergreen bush 2 or $3 \mathrm{ft}$. high, and has small leaves on slender stems, which in May are terminated by dense clusters of small white flowers in short erect spikes. It is one of the choicest of evergreen hardy shrubs, is thoroughly deserving of general cultivation, and thrives with Rhododendrons and Azaleas in peat soil. The lovely shrub known as L. speciosa and its variety pulverulenta will be described under their correct name of Zenobia.

Lewisia rediviva (Spatlum).-A most remarkable and beautiful rock-garden plant, similar to the Portulaca. It is very dwarf, being only I in. or so high, and has a small tuft of narrow leaves, from the centre of which the flower-stalks arise. The blossoms are large for the size of the plant, being from I to $2 \frac{1}{2}$ in. across, and vary from deep rose to white. The roots are succulent, and can retain life under the most unfavourable conditions. It sometimes fails to develop leaves annually, and hence is often considered to be dead and as difficult to deal with, which is not the case. It should be grown in sunshine, for it cannot be flowered in shade, and should be kept high and dry, though the roots should have plenty of moisture. A crevice in the rock-garden is the best situation for it. If grown in pots, the plant should be on broken stones, and the roots in light sandy loam with peat. After flowering, it shrivels up and becomes a withered twisted mass, like so many bits of string; but this is its nature, and hence its name. Oregon, Utah, and Rocky Mountains.

Leycesteria formosa. - A beautiful and most valuable flowering shrub, a native of the Himalayas, nearly hardy throughout these islands. It is much commoner in Ireland and the west than in the home counties, probably owing to the milder temperature. It is graceful in flower and growth, and reaches $6 \mathrm{ft}$. high where it thrives. The flowers are white, tinged with purple; the conspicuous leafy bracts are purple. The flowers are succeeded in autumn by purple berries, which are much relished by pheasants and other winged game, and therefore it is planted as a covert shrub. In mild districts it is an evergreen, but it generally loses its leaves in late autumn. It thrives well in various soils, and does well under trees.

Liatris (Snakeroot).-North American Composites, characterised by having the flower-heads, generally purple, arranged in long dense spikes. Some are effective border flowers when well grown, and well repay good cultivation. L. elegans grows about $2 \mathrm{ft}$. high, and has pale purple spikes I ft. or more in length. L. pycnostachya, 2 to $4 \mathrm{ft}$. high, has deep purple flower-spikes from August to October. L. spicata is one of the handsomest and neatest. It grows I to $2 \mathrm{ft}$. high, and its violet-purple spikes continue long in beauty. L. scariosa, squarrosa, cylindracea, elegans, and pumila much resemble the foregoing, and, like them, succeed in any rich light soil. Propagated by division in spring or by seed.

Libertia.-Beautiful iridaceous plants, of which three or four are hardy enough for the open border. L. formosa is beautiful at all seasons, even in the depth of winter, owing to the colour of its foliage, which is as green as the Holly; and it produces spikes of flowers of snowy whiteness more like some delicate Orchid than an outdoor plant. It is neat, dwarf, and compact, and has flowers twice as large as the other kinds. They lie close together on the stem, and remind one of the old double white Rocket. L. ixioides, a New Zealand plant, is also a handsome evergreen species, with narrow grassy foliage and small white blossoms. L. magellanica is also attractive when in flower. All of these thrive in warm borders of light soil, and in the rougher parts of the rock-garden. I find these plants grow very slowly on certain loamy soils, living perhaps, but never showing the freedom and grace which they do on free or peaty soils. The foliage being good, they look very well grouped in peat borders. Increased by seed or by careful division in spring.

Ligularia. - Large perennial Composites, remarkable for bold handsome foliage, one or two for great size, and strikingly distinct aspect, though not beautiful in flower. L. macrophylla is vigorous, 
with an erect stem nearly $3 \frac{1}{2} \mathrm{ft}$. high, and very large glaucous erect leaves. The yellow flowers are borne in a dense long spike at the end of the stem. Free, moist, and somewhat peaty soil is the most suitable for this plant. Multiplied by careful division in autumn or in spring, it is useful for grouping with fine-leaved herbaceous plants, but will seldom command a place in the select flower garden. Caucasus. L. sibirica, Fischeri, and thyrsoidea are similarly fine-leaved plants, and worth growing with L. macrophylla for their foliage alone. The Japanese species, L. Kæmpferi and Hodgsoni, are better grown under glass, except in
- especially for the Rhododendron bedswhile not a few are so robust that they are at home in the wild garden, holding their own against native plants. Their true place, however, is the garden proper, and, when their uses are understood and expressed, there will be a total change in the aspect of the flower garden. Culture is important, but arrangement and grouping are even more so. There are Lilies which will grow in any ordinary soil; a good, rich loamy soil suits the greater number; others want plenty of sand, so as to keep the soil free; while others can be easily grown in ordinary soil if it is mixed with leaf-mould or peat. It will

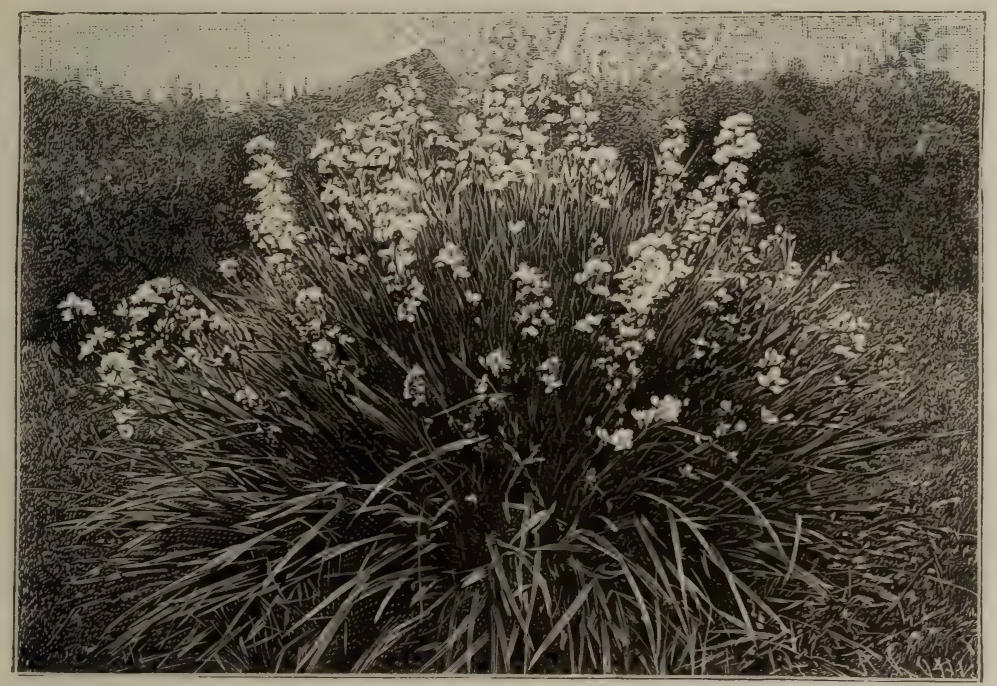

LIBERTIA FORMOSA.

summer, when they may be profitably used among fine-leaved plants in the sub-tropical garden; but the hardy kinds are most interesting and are very vigorous.

Lilac (Syringa).

Liliorhiza lanceolata ( = Fritillaria liliaceer).

Lilium (Lily). - The Lilies are such beautiful plants that no garden should be without a variety of them, combining as they do stateliness and grace with brilliant and delicately-coloured flowers. The many kinds in cultivation afford a rich choice. All are beautiful, but some are better suited for particular localities than others. The habit and general character of the plants being so varied, their uses are likewise varied. Some are suited for the rock-garden, others for the mixed border, many for the shrubbery thus be seen that there are no great difficulties in the way of growing a large number of kinds. In nearly all cases Lilies are more vigorous and brilliant where partially protected from severe frosts; and the flowers last longer when sheltered from the scorching rays of the mid-day sun. The shrubbery border, among Rhododendrons (for those requiring peat), and the mixed border between shrubs and herbaceous plants, where the young shoots get a slight protection from the early frosts, are among the best situations. A very safe place is near the edge of a Rhododendron bed; soil that will grow Rhododendrons will grow most sorts of Lilies, and afford protection from "blight and spot," which in some seasons, notably when cold and wet follow drought, greatly injure the growth and flowering of some species, even though 
the bulbs be unhurt. It should be remembered that bulbs of nearly all Lilies occasionally lie dormant a whole season, and push out luxuriantly the following summer.

Manure should never be dug in with the bulbs, though they accept it gratefully if liberally applied as a top-dressing after they have been established a year. The only manure to be dug in at planting is rich peat and sand, in the proportion of two parts of peat to one of sand. This is advisedly called manure. In light soils L. auratum and some others are all the better for a top-dressing of dry clay broken small. Though to each brief description below we have appended a word or two upon cultivation, it is, perhaps, advisable to add a few general remarks. It should be borne in mind that, however beautiful nearly all the known Lilies are, some are extremely fastidious; but there is a rare choice of beauty among those that are easily cultivated. Lilies may be divided into three classes-first, those that are best grown in pots, such as neilgherrense, Wallichianum, philippinense, and nepalense, and, in many soils and climates, speciosum, auratum, and longiflorum ; secondly, those that are best grown outof-doors in loamy soil; thirdly, those that are best grown out-of-doors in peaty soil. On light soils the following kinds do remarkably well : $\mathrm{L}$. candidum, longiflorum and its varieties, chalcedonicum, excelsum, and the speciosum section; all of the umbellatum, croceum, and elegans type; also tigrinum sinense. For deep loamy soil the best kinds are L. auratum, Szovitzianum, Humboldti, the Tiger family, most of the Martagon group; while in an intermediate soil of leaf-mould, loam, and sand, we advise the planting of Buschianum, philadelphicum, pulchellum, Browni, giganteum, tenuifolium, Krameri, etc. The North American forms require more peat and more moisture than the other groups. Lilies require, so far as their roots are concerned, a cool bottom, abundant moisture, and, for most kinds, a free drainage. The slope of a hill facing south-east or south-west, for instance, with water from above percolating through the sub-soil, so as to always afford a supply, without stagnation, would be an admirable site.

PROPAGATION.- This is generally and most readily effected by separating the bulblets or offsets from the parent bulbs, and these, detached and grown in the same way as the parent, in the course of a year or two make good flowering plants.
The scales of the bulbs afford a means of propagation; but this is a slower method. Raising Lilies from seed is somewhat tedious, though many kinds in this country perfect seed in plenty, and in the case of such kinds as L. tenuifolium the seedlings flower in three or four years; though others will not flower for several years. The finest kinds, such as the Japanese and Californian Lilies, are now so cheap that it is scarcely necessary to propagate from home-grown plants. It will be well, however, if, by rapid increase, or otherwise, they become plentiful enough to adorn the smallest cottage-gardens. Several Lilies, chiefly Japanese and Californian, are largely imported every year. As soon as received, all bulbs should be examined, and decaying matter should be removed. They should then be laid in soil, or, better still, Cocoa-nut fibre in a moderate condition of moisture, until the bulb recovers its plumpness and the roots are on the point of starting from the base. Then they should be potted or planted out as required ; but, before this, decaying scales should again be removed, as a few of the outside ones are often bruised in transit, and after they have been in the soil a little time decay sets in, which if not then taken off may contaminate the whole bulb. Of those so imported, L. auratum and Krameri should, when potted, be surrounded with sand, but some do well without it. The most difficult to import among the N. American Lilies are L. Washingtonianum and L. rubescens, since, as a rule, they suffer much more than the large, solid bulbs of L. Humboldti, or than those of pardalinum, canadense, and superbum. These solid bulbs should be treated as above directed, but L. Washingtonianum, rubescens, and Humboldti should not be potted, as they never succeed in that way; and indeed all the N. American Lilies do much better if planted out. Those from Holland, such as the varieties of davuricum, elegans, and speciosum, etc., arrive plump and sound, but it is much better to lay even these in soil a little while before potting.

L. auratum.-One of the grandest of Lilies, and now too well known to need description. It is most valuable both as regards size and colour of the blossoms. Some forms have flowers nearly I $\mathrm{ft}$. across, with broad white petals copiously spotted with reddish-brown and having broad bands of golden-yellow down the centre. The poorest forms have starry flowers and scarcely any markings. Several named varieties are particularly 
distinct; and the chief are cruentum and rubro-vittatum, which have deep crimson instead of yellow bands down the petals; Wittei or virginale, the flowers of which have no colour but the golden bands; rubro-pictum, with a red stripe and spots; platyphyllum, with very large flowers and broad leaves; and Emperor, a grand written upon the culture of this Lily, but it is not so difficult as many suppose, if a good start be made. It will thrive in ordinary soil, if well drained and fairly enriched. It grows freely in peat or loam, a mixture of both with a little road-scrapings best fulfilling its requirements. Where the soil is naturally poor, light,

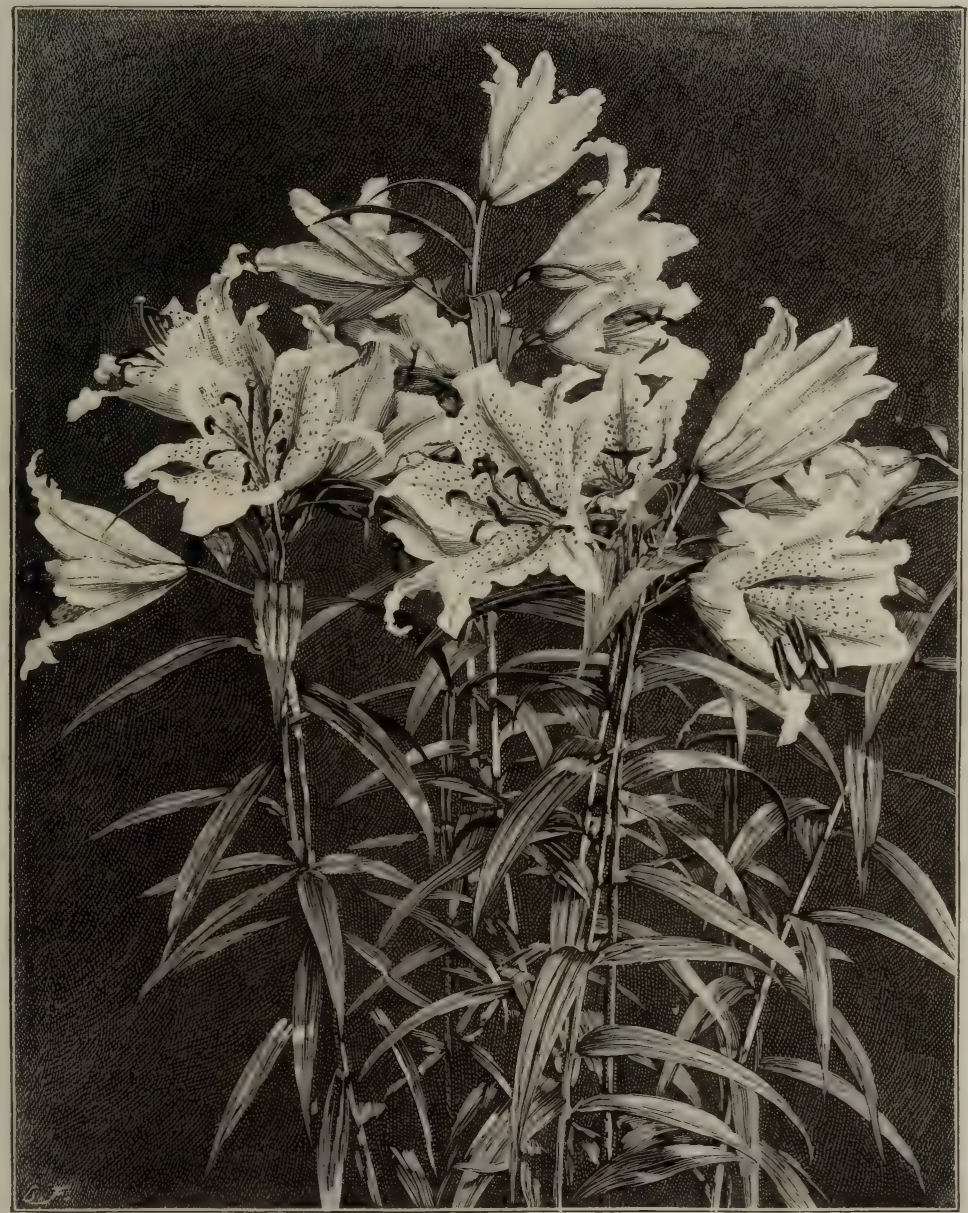

LILIUM AURATUM.

flower, with reddish spots and centre. There are also some beautiful hybrids raised between $\mathrm{L}$. auratum and some of the other species; for example, L. Parkmanni (between L. auratum and L. speciosum), which has large white flowers banded and spotted with carmine-crimson. The bulbs of this Lily are regularly imported in large quantities from Japan and sold at a cheap rate every autumn, so that it is readily procurable. Much has been and sandy, it should be taken out to a depth of 18 in., and replaced with the compost above mentioned, or some fine, well-enriched mould. The bulbs should be planted in this, and, as soon as growth commences in spring, should be mulched with decomposed manure or short Grass. If the garden soil be fairly good, it need only be well stirred and manured, but the manure should be thoroughly decomposed. A sheltered situation should be chosen, 
and if possible screened from the midday sun, and protected from westerly and southerly gales and from heavy driving rains; for this Lily is very susceptible to injury by cold draughts and cutting winds. No better place can be chosen than a snug nook sheltered from the north and east by shrubs, but at the same time open to the sun. The best examples that have been grown were grown in a Rhododendron bed, and planted in a deep, moist, peaty soil, where they have been for years undisturbed. When planted among other things the young and tender uprising shoots are greatly protected in spring. As to propagation, there is scarcely any need to enlarge upon that, as bulbs are imported so plentifully; and it is only necessary to separate the young bulbs and replant them in good soil. Those who increase this Lily from seed must be prepared to exercise a little patience, as the seed is long germinating and the seedlings are several years before flowering. The seed should be sown, as soon as ripe, in a frame. The seedlings should be planted out as soon as the bulbs are of an appreciable size.

L. Browni is a fine Lily in the way of L. japonicum, but with larger flowers. It is readily distinguished from any other kind by the rich brownish-purple markings on the exterior of the blossoms, which in well-grown plants are sometimes 9 in. in length. It is hardy and vigorous, and succeeds without giving much trouble. In a soil and position which suits L. auratum it flourishes, and need only be lifted every few years and replanted in fresh rich soil. It grows from 2 to $4 \mathrm{ft}$. high, and has deep green foliage distinct from allied kinds. The variety Colchesteri is handsome.

$\mathrm{L}$. bulbiferum is one of the handsomest of European Lilies, and is about $2 \mathrm{ft}$. high. It bears large crimson flowers shading to orange. The variety umbellatum is finer and stronger, and has large umbelled clusters of flowers. This Lily is generally distinguished from its congeners by bulblets on the axils of the leaves. It grows freely in ordinary soil, and flowers in early summer. A capital plant for bold groups, and thriving under partial shade or in the open.

I. canadense (Canadian Lily).-This beautiful flower is among the oldest of cultivated Lilies. It is 2 to $4 \mathrm{ft}$. high, and bears, on slender stems, terminal clusters of drooping blossoms usually orange, and copiously spotted with deep brown. It also occurs with red flowers (rubrum) and with yellow flowers (flavum).
L. parvum, L. nitidum, and L. columbianum resemble it, and like it require a partially shaded position and a moist, deep peaty soil enriched by decayed leaf-mould. It flowers late in summer, and is very attractive in bold masses, such as are often seen in nurseries about London. Like its allied forms it makes elegant groups among choice shrubs such as Azaleas and Rhododendrons; and by such an arrangement we get a second bloom and a variety of form from beds that had only one blossoming season, and were poor and stiff in outline; we prevent senseless digging when the groups are once in place; and we keep the shrubs from growing into a solid ugly mass, while they shelter our Lilies.

L. candidum.-One of the best-known and loveliest Lilies, seen in almost every cottage-garden, and producing snowwhite blooms in summer. It dislikes coddling or being meddled with, and thrives best when undisturbed for years in good garden soil. Any attempt to deal with it like the more delicate ones generally results in failure. The bestflowered plants are in old gardens, where the bulbs are allowed to run as they like with no attention whatever. In bold masses, no plants can compare with the common white Lily when in bloom. It is so fair a flower that there is scarcely a place which a good plant or well-grown group of it will not adorn. But the careful growth and the proper placing of such lovely hardy plants give the highest charm to the garden. For years it has been difficult to find even a miserable tuft in many "show" gardens, though they displayed nothing there so good as a tall white Lily in a cottage-garden. Moist loam seems to suit it generally, though, like other Lilies, it will grow in a variety of soils. The varieties peregrinum, striatum, and monstrosum are not so fine, but the striped-leaved variety aureo-marginatis is valuable for its foliage in winter.

L. chalcedonicum (Scarlet Martagon) is a very old and handsome Lily, of tall and graceful growth, and bears several pendulous, vermilion, turban - shaped blossoms about the end of July. It is one of the easiest to cultivate, thrives in almost any soil, and is best when well established and left undisturbed. There are a few varieties, majus being the largest and best. The others are græcum, rather taller than the type and having smaller flowers; pyrenaicum, with yellow flowers ; Heldreichi, tall and rubust, flowering a week or two earlier; and maculatum, a 
very handsome form. Native of Greece and Ionian Isles. Similar to the scarlet Martagon is the Japanese L. callosum, a pretty Lily, $\mathrm{I} \frac{1}{2}$ to $3 \mathrm{ft}$. high, with slender stems, bearing in summer several brilliant scarlet blossoms. cum, of a similar character, is I to $3 \mathrm{ft}$. high, and produces in early summer turban - shaped nodding blossoms of bright vermilion or yellow. Both these thrive under the same conditions as L. chalcedonicum.

L. concolor. - A pretty little Lily from Japan, I to $3 \mathrm{ft}$. high, bearing three to six bright scarlet flowers, which are spotted with black, star - shaped, and erect. There are some three or four varieties pulchellum, or Buschianum, an early variety from Siberia, $\mathrm{I} \frac{1}{2}$ to $2 \mathrm{ft}$. high, with crimson blossoms; Coridion, with flowers somewhat larger than the type, and of a rich yellow spotted with brown; sinicum, a Chinese form, with four to six crimson flowers heavily spotted and larger than the type ; and Partheneion, with scarlet flowers flushed with yellow. This charming Lily and its varieties are quite hardy, though they require some attention in cultivating. They succeed in half-shady places in a soil composed of two parts of peat, one of loam, and one of road-scrapings; but seem to require renewing every few years. This Lily and its allies are suited for grouping among the smaller and choicer evergreen shrubs where not in a special Lily bed.

\section{L. croceum (Orange Lily)}

is one of the sturdiest and hardiest, and therefore one of the commonest of Lilies. It grows in almost any soil or position, and bears in early summer huge heads of large rich orange flowers. In the mixed border it is attractive, but shows best on the margin of a shrubbery, where its stems just overtop the surrounding foliage. It is always best after some years' growth. A native of the colder moun- tains of Europe, it is one of the Lilies that may be naturalised, but is never so strong as in rich garden-ground. Lilies are said not to like manure, but we have never seen this one so fine as when in wellmanured ground after several years'

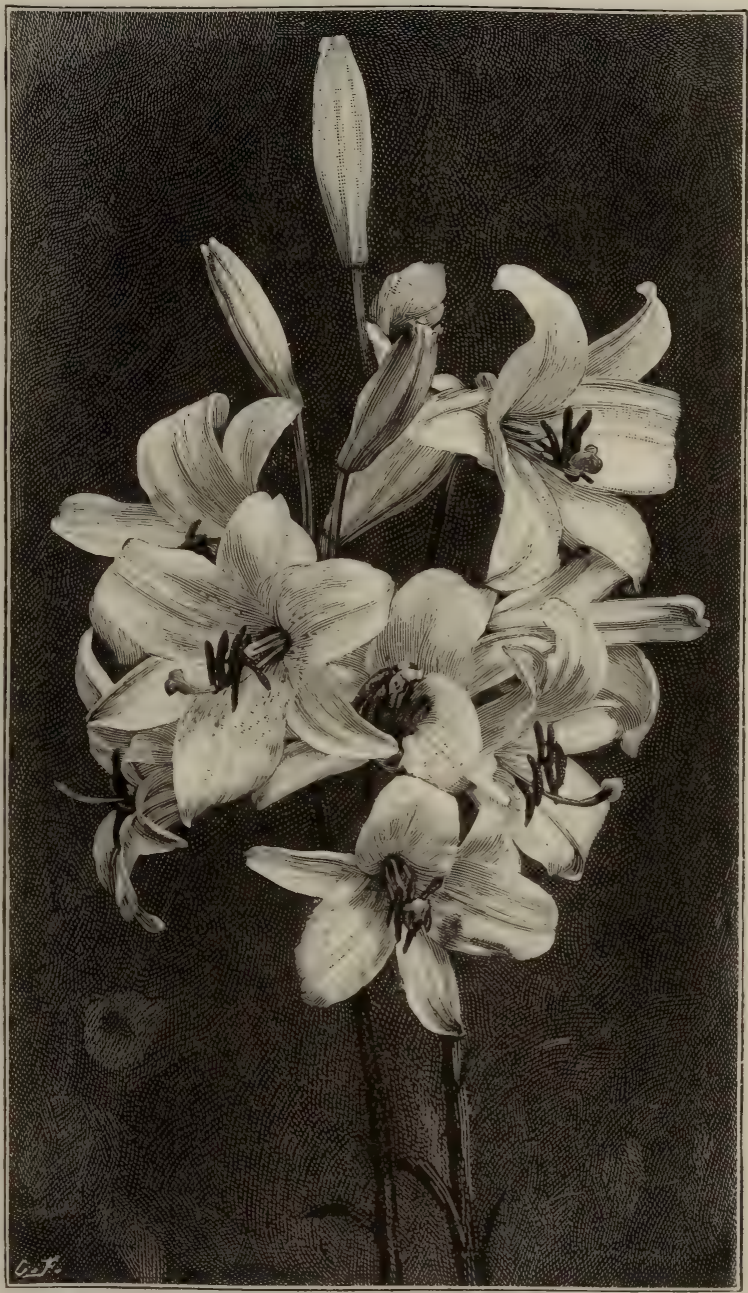

LITIUM CANDIDUM (WHITE OR MADONNA LILY).

growth. Indeed, we have planted it over a subsoil, so to say, of solid cow manure, and have had bulbs and flowers of enormous size in two years. It is much grown in cottage-gardens in the North of Ireland. A group in an open space among low evergreen shrubs is superb.

L. davuricum is a slender European Lily with moderate-sized red flowers, spotted with black. Like L. elegans, it has 
several varieties, the chief being Sappho, incomparable, erectum, multiflorum, Don Juan, and Rubens. Being strong growers and flowering freely, they are fine plants for the mixed border, for margins of shrubberies, or for groups or masses, thriving in partial shade as well as in sunny places.

L. elegans.--One of the best and most generally grown of the early Lilies. It is commonly known by the name of Thunbergianum. It is very variable, and there are about a dozen named varieties. The type grows about I ft. high, and has stout erect stems, which bear numerous narrow leaves, and are terminated by a bright orange-red flower, 5 or 6 in. across. A native of Japan, flowering with us about the beginning of July. Most of the varieties are so distinct as to merit a slight description. They are-alutaceum, not more than 9 in. high, with a large pale apricot-coloured flower, copiously spotted ; armenaicum (venustum), about $\mathrm{I} \frac{1}{2} \mathrm{ft}$. high, with several moderate-sized flowers (in autumn) of a rich glowing orange-red; atrosanguineum, about $\mathrm{I}_{2}^{\frac{\mathrm{g}}{2}} \mathrm{ft}$. high, with large flowers of rich deep crimson; Batemanniæ, about $4 \mathrm{ft}$. high, with several moderate-sized flowers, in late summer, of a rich unspotted apricot tint ; bicolor, about I ft. high, with large flowers orangered, flamed with a deeper hue; brevifolium, II $\mathrm{ft}$. high, with flowers pale red and slightly spotted; citrinum, like armenaicum, but taller; fulgens, $\mathrm{I}$ to $\mathrm{I} \frac{\mathrm{I}}{2}$ $\mathrm{ft}$. high, with four to six large flowers of a deep red; sanguineum, I to $\mathrm{I} \frac{1}{2} \mathrm{ft}$. high, with one or two large blood-red flowers; Van Houttei, I $\frac{1}{2} \mathrm{ft}$. high, with very deep crimson-red flowers, spotted with black; Wallacei, $2 \frac{1}{2} \mathrm{ft}$. high, with rich orange-red flowers, spotted with black; Wilsoni, $2 \mathrm{ft}$. high, with large apricot-tinted flowers-one of the latest to bloom. All the L. elegans group are perfectly hardy; they grow vigorously in almost any soil, but prefer a deep loamy one with an admixture of peat. They like an open position, and are suitable for planting around the margins of shrubberies. Small groups are beautiful in the open spaces that should exist in every shrubbery or Rhododendron bed. They are all excellent border plants, and the dwarf kinds may be introduced into the rock-garden. In all cases they must be placed in sunny situations.

L. giganteum. - A noble Lily of huge growth and in aspect different from any other. Its bulb is large and conical, and develops spreading tufts of handsome shining heart-shaped foliage. The flower- stems are stout and erect, 6 to Io ft. high, terminated by a huge raceme, $\mathrm{I}$ to $2 \mathrm{ft}$. in length, of about a dozen long nodding fragrant flowers, which are white and tinged with purple on the inside. It is one of the hardiest Lilies, and gives very little trouble. It flourishes best in a sheltered position, where there is an undergrowth of thin shrubs to protect the growth in spring. The soil must be deep and well drained, and must consist of sandy peat and leaf-mould, strengthened by a little rich loam. Years sometimes

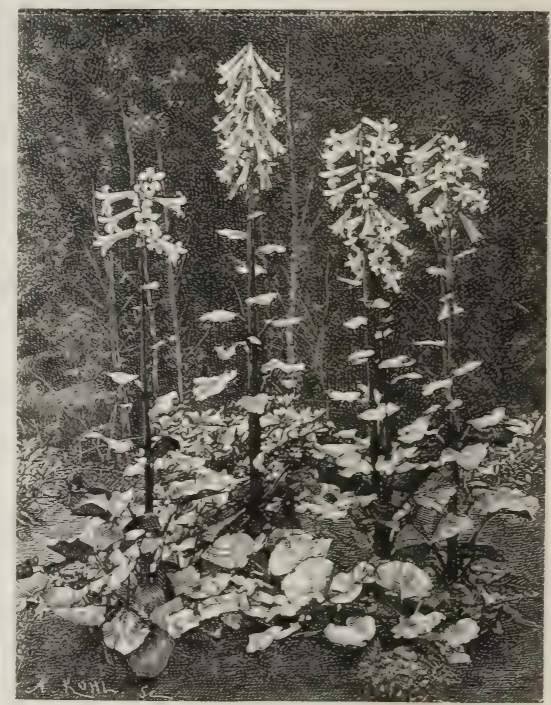

LILIUMI GIGANTEU.M.

elapse before the tufts of foliage send up bloom. Nepaul. L. cordifolium, a Japanese plant, is a similar, but inferior, species, very rare in cultivation. It requires the same treatment. A small group of three or four plants will do well in an open spot among shrubs, in a free peaty soil, and when in flower the effect will be all that can be desired.

L. Hansoni.-A handsome Japanese species, about $4 \mathrm{ft}$. high, having whorls of bright green leaves and a terminal spike of about a dozen bright, orange - yellow, brown-spotted flowers. It flowers about the beginning of June, is quite hardy, and succeeds in sheltered situations in a soil consisting of two parts of peat, one of loam, and one of road-scrapings.

L. Humboldti is very graceful. The singular beauty of the blossoms and the elegant manner in which they droop from their slender stalks, make it most desirable, and its flowers, on account of their great 
substance, are more lasting than any other Californian Lily. The stout and purplish stems attain a height of 4 to $8 \mathrm{ft}$. The leaves are in whorls of from ten to twenty each, and are of a bright green. The flowers differ considerably in colour and

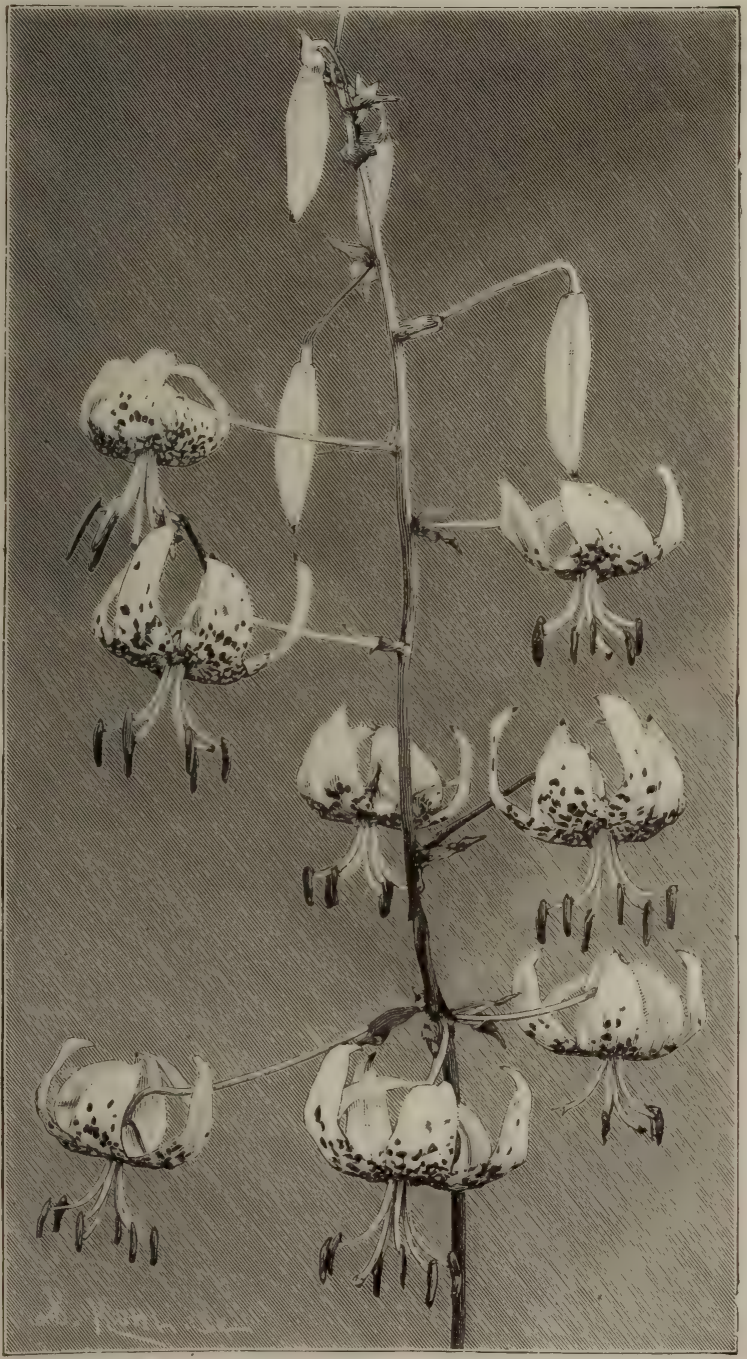

LILIUM HUMBOLDTI.

markings, but are usually bright goldenyellow, richly spotted with crimson-purple. The variety ocellatum or Bloomerianum is dwarf, and has petals tipped with brownish-crimson. It grows best in an open border of rich peaty or leafy soil of a good depth.

L. japonicum, or Krameri as it is more often called, possesses the most delicate beauty of any. The flowers are of the shape and nearly as large as those of $\mathrm{L}$. auratum. They are either pure white or delicate rosy-pink-generally the latter. $\mathrm{L}$. japonicum is I to $3 \mathrm{ft}$. high, and sometimes bears five bloomsbut generally only one or two. It is somewhat difficult to grow, owing to its delicate constitution, but the best specimens produced in this country were grown under the same conditions as $\mathrm{L}$. auratum and speciosum. On account of its beauty it deserves the most careful attention. It is a lovely plant for a select spot between choice dwarf shrubs, in free peaty soil or deep sandy loam with vegetable soil in it.

L. longiflorum (White Trumpet Lily). - This is among the most beautiful and most valuable of garden Lilies. The typical form is $\mathrm{I}$ to $3 \mathrm{ft}$. high, the stems in summer being terminated by long, tubular waxy-white flowers, which are sweetly scented. There are several varieties, the best being eximium, which flower's a fortnight earlier than the type, bears larger and more numerous flowers, and is in every way superior to it. Takesima is recognised by a purplish tint on the exterior of the blossoms and on the stem. Wilsoni is a grand Lily, nearly $4 \mathrm{ft}$. high, with numerous flowers about 9 in. in length. Madame Von Siebold is also a fine variety, with smaller blooms than eximium, and flowering a week or so earlier. Jama-Jura and Liukiu are native names for the varieties mentioned. The variegated-leaved form (albo-marginatum) is desirable, as the variegation is distinct and constant. L. longiflorum and its varieties sometimes bloom well in borders, but care should be taken that they are not injured by spring frosts. L. longiflorum is so early that, unless protected by the leaves of evergreens, its growth is apt to be checked. A well-drained light loam, 
well enriched with leaf-mould, suits it admirably. L. Wilsoni is benefited by a lighter soil and by a warmer and more sheltered position. When just pushing the growth in spring it is advisable to encircle the plants with a few dead branches, if unprotected by shrubs. Where this fine species and its forms fail in the ordinary soil of the garden, success may be ensured by making a special soil of rotten manure, leaf-mould, or cocoa fibre. In such a mixture, so free and open that the hand could be pushed down below the bulb, we have seen them perfectly grown where the natural soil was too stiff and impervious. The hardier varieties are admirable for artistic gardening, their fine forms being very effective when tastefully grouped on the fringe of beds of choice bushes and when touching and seeming to spring out of the Grass. They are also good in beds either specially devoted to them alone or in combination with other plants. Similar to L. longiflorum are L. neilgherrense, philippinense, Wallichianum, and nepalense, but none is hardy and all are poor and unsatisfactory, except, perhaps, for the greenhouse.

L. Martagon (Turk's-cap Lily).-This is so common that we need only mention

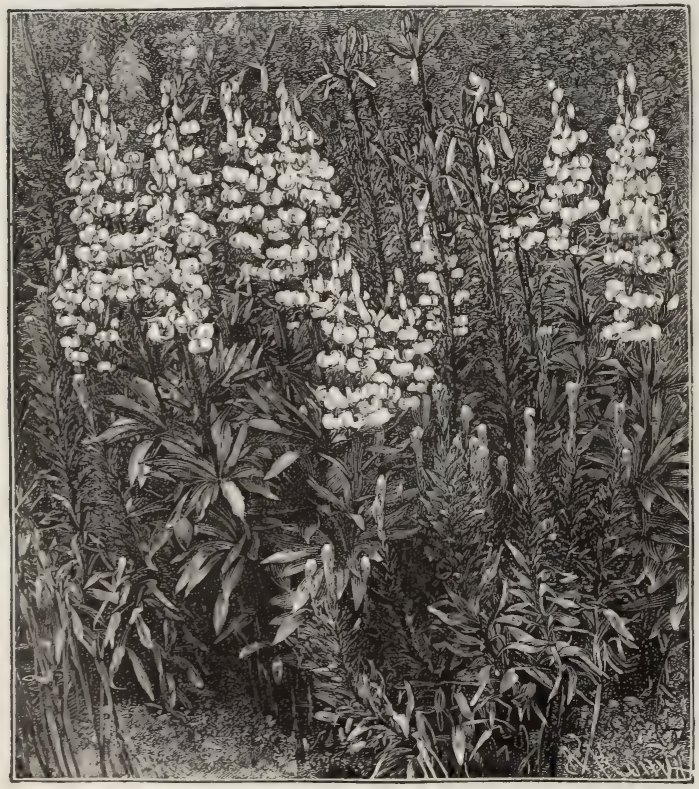

WHITE MARTAGON LILIES.

its varieties. These are very fine, especially dalmaticum, which has flowers larger than the type and of a shining blackish- purple, a contrast to the loveliness of the pure white variety (album). Cattaniæ is only a form of dalmaticum and scarcely differs from it. Like the type, the varieties thrive freely in a good loamy soil ; they are perfectly hardy and are rather partial to shade, growing freely in grassy places, open woods, or copses. Some of the finer varieties are good garden plants, and should be grouped in the spaces between hardy Azaleas or similar flowering bushes.

L. monadelphum is a magnificent Lily of noble growth. The stout flower-stems vary from 3 to $5 \mathrm{ft}$. in height, and are terminated by a pyramid of six to twenty turban-shaped flowers, ranging in colour from a rich canary-yellow to a pale lemonyellow. Some forms have spotted flowers, and some are much larger than others. The varieties are known as L. Szovitzianum, colchicum, and Loddigesianum. L. monadelphum thrives best in moist, deep loamy soil, well enriched with good manure at the time of planting ; but does not show its true character till it has been planted several years. It rarely fails, and is one of the least disappointing of all. It may be readily increased from root-scales, a fact which is taken advantage of by many cultivators, and is the only method of increasing and keeping pure any really good or marked variety. Seed is, however, the readiest way of acquiring a stock of this truly charming plant. The seeds are usually sown in large shallow pans as soon as ripe, and remain there for two years, by which time the bulbs have attained a considerable size ; they are then planted in beds in rows 6 in. apart, with 4 in. between the bulbs, replanting when necessary. By this treatment flowers are frequently produced by seedling plants four or five years after sowing.

L. Parryi is a new and distinct species from California. It is of elegant slender growth, and 2 to $4 \mathrm{ft}$. high, bearing graceful trumpet-shaped flowers of rich yellow, copiously spotted with chocolate-red, and delicately perfumed. The flowers being borne horizontally, render it very distinct. It grows in elevated districts in South California, in boggy ground. Not much is known of its culture, but the finest plants have been produced where the soil was 
two-thirds common peat and one-third loam, with plenty of coarse sand. A bed in a shady spot was selected, in which the bulbs were placed at a depth of 4 in., having underneath about I ft. of the soil. Here the strongest bulbs threw up stems

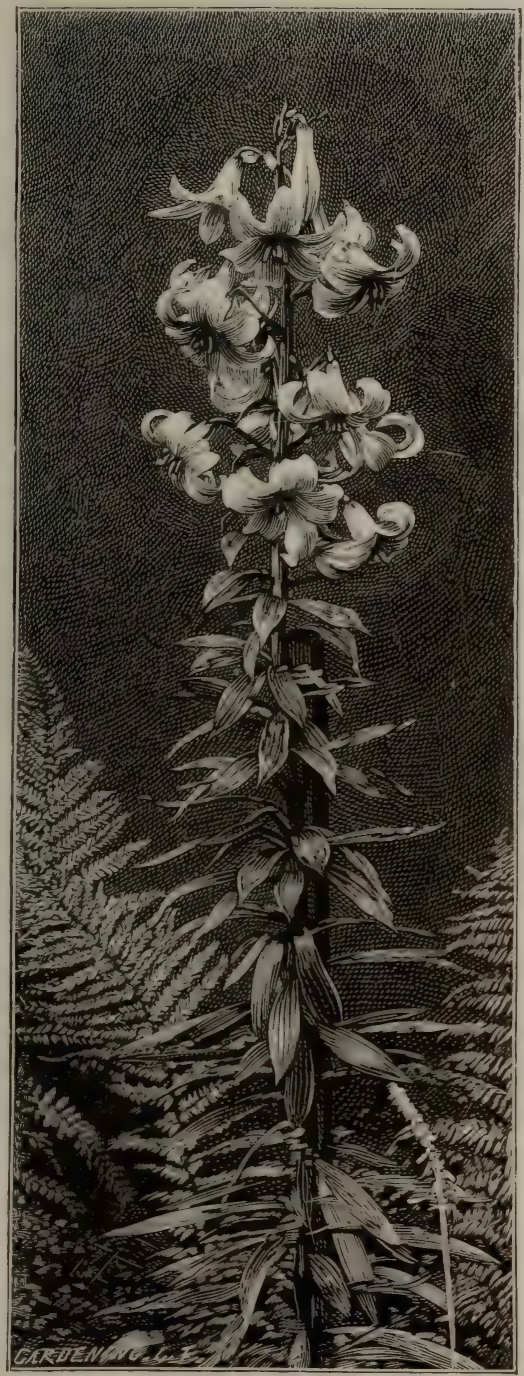

LILIUM MUNADELPHUM, VAR. SZOVITZIANUM.

$4 \mathrm{ft}$. in height, and the greatest number of blossoms on one stem for the first season was six.

L. pardalinum (Panther Lily).-One of the handsomest of the Californian Lilies, and one of the most valuable for English gardens, as it makes itself thoroughly at home in them and grows as vigorously as in its native habitat. It is 6 to $8 \mathrm{ft}$. high, and has large drooping flowers of bright orange, spotted with maroon. There are several varieties, the most distinct being-Bourgæi, one of the finest, having stout stems 6 to $7 \mathrm{ft}$. high, with twelve to twenty flowers of bright crimson, shading to orange, and freely spotted with maroon, and blooming a fortnight later than any other; pallida, a dwarf variety, scarcely $5 \mathrm{ft}$. high, bears flowers nearly double the size of the type, and paler in colour ; californicum, a more slender variety, 3 to $4 \mathrm{ft}$. high, and the brightest in colour; pallidifolium (puberulum), a small form, with lighter flowers ; and Robinsoni, a robust variety, with stout stems 7 to $8 \mathrm{ft}$. high, and with massive foliage, large flowers of a bright vermilion shading to yellow, and freely spotted. This last is the noblest, and should be grown if possible. The Panther Lily is one of the most satisfactory of all Lilies; it has a strong constitution, increases rapidly, soon becomes established, and rarely pines away, as many kinds do. It likes a deep, light, good soil, enriched with plenty of decayed manure and leafsoil, where the roots can receive ample moisture. It should always be in a sheltered position, like the sunny side of a bold group of shrubs or low trees. In a special bed the near shelter of hedges is desirable, though their roots should be kept away. Bare borders are not the places where this noble Lily does or looks best - there is no shelter or support for plants which in their own country have many shrubs for companions and are sheltered by the finest trees of the northern world.

L. polyphyllum.-A rare and beautiful Lily, 2 to $4 \mathrm{ft}$. high, and having large turban-shaped flowers of a waxy-white, copiously spotted and lined with purple. North India. : Mr. M'Intosh, of Duneevan, Weybridge, who has been most successful with it, writes: "Sandy loam, peat. or leaf-mould, sand, and charcoal, with a slight admixture of pulverised horse-droppings, and good drainage under the bulbs, are all I have to tell ; and I think early staking and tying may have something to do with many growing taller than they otherwise might."

L. pomponium.-This lovely Lily must not be confounded with the L. pomponium usually sold as such, this latter being simply the red variety of $\mathrm{L}$. pyrenaicum. L. pomponium is elegant and vigorous, and blooms earlier than the varieties of chalcedonicum and pyrenaicum to which it is related. It is about $3 \mathrm{ft}$. high, is 
erect, and has long linear leaves. The flowers appear in a lax raceme $\mathrm{I} f \mathrm{ft}$. through, and a well-established plant will bear as many as twenty flowers. In rich loam it grows luxuriantly in sunshine or shade, and no difficulty is experienced with either home-grown or imported roots. Maritime Alps. L. pyrenaicum, a similar but smaller plant, with small yellow flowers, is a variety of L. pomponium, and the red form is much inferior to the true L. pomponium, though generally sold pink; punctatum, white spotted with pink; Krætzeri, very large white flowers with greenish stripe on the exterior; fasciatum album and fasciatum rubrum, two monstrous varieties bearing numerous flowers on flattened stems. Other fine varieties have originated in America, and among these Melpomene is very distinct. The beautiful hybrid, Mrs. A. Waterer, is large, white, and spotted with pink. All the varieties require shelter from winds and draughts, and a rich loamy soil

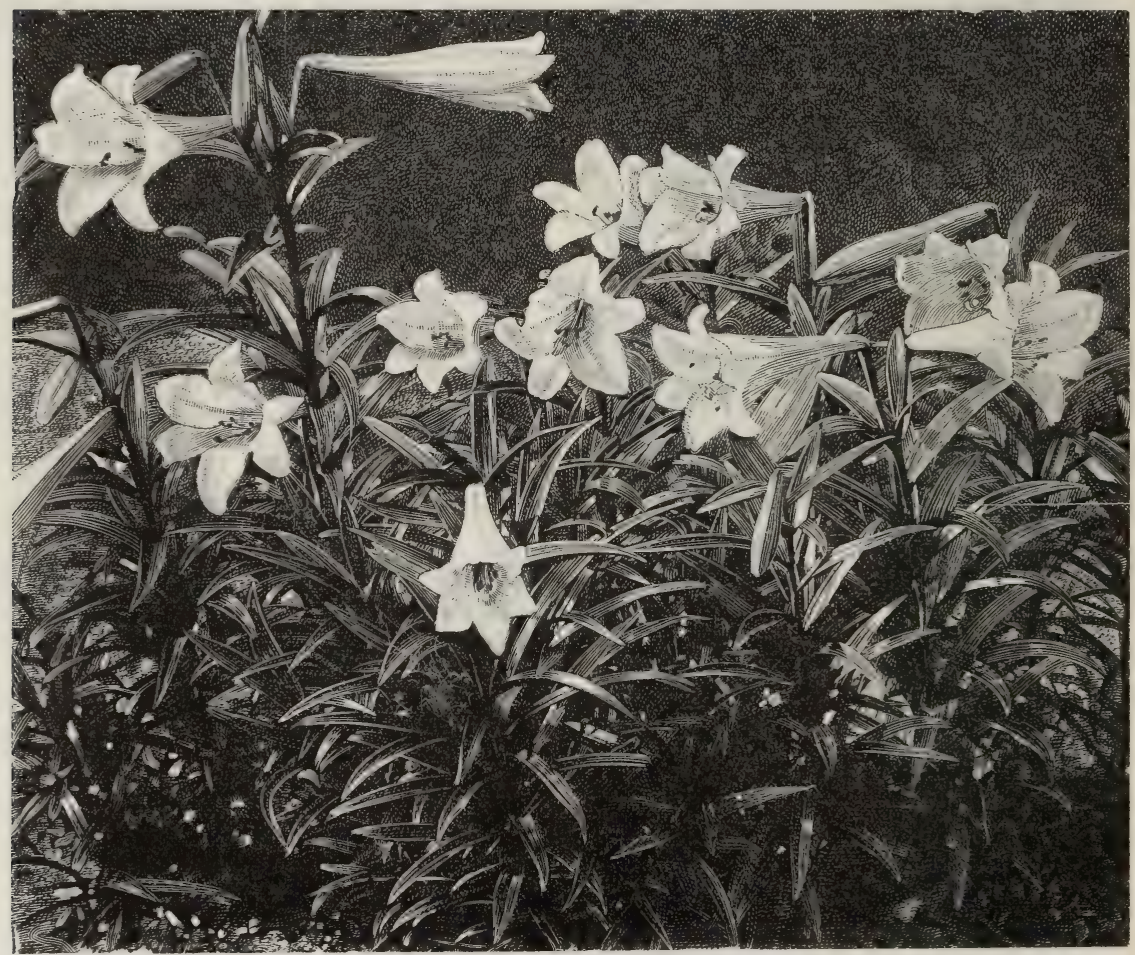

LILIUM LONGIFLORLM VAR. (WHITE TRUMPET LILY).

for it. These varieties require the same culture as L. pomponium. L. pomponium has an extremely offensive odour, and is not, therefore, likely to be used for cutting.

L. speciosum, or lancifolium as it is erroneously called, is one of the most popular for pot-culture, and is no less desirable for the open air, though, being somewhat delicate, it is grown to perfection under glass. It is well known, and we need not describe it, but we will mention the chief varieties. There is the true speciosum, which has large deep rosy blossoms, richly spotted; vestale, pure white; album, white or faintly tinged with pink; rubrum, deep red; roseum, rosy- mixed with peat and leaf-manure. They flower for the most part in September, and last longer in bloom than many other Lilies. In good soils, very happy use can be made of these handsome Lilies in warm and sheltered places where their blooms may be fully developed.

L. superbum (Swamp Lily).--One of the stateliest of $\mathrm{N}$. American Lilies, bearing late in summer beautiful orangered flowers, thickly spotted. It may be recognised at once by its purple-tinged stems, which rise 5 to $10 \mathrm{ft}$. high, and which are very graceful, waving with the slightest breeze. A pyramid of flowers terminates each stem. L. superbum 
delights in moist deep soil consisting chiefly of peaty and decayed leaf-manure, and is one of the best Lilies for growing in shady woods when the undergrowth is not too rank. In the garden it should have snug glades and nooks protected by shrubs, and moist rich soil. L. carolinianum is a less showy form.

L. tenuifolium.-A most elegant dwarf Lily, especially valuable for earliness in flowering. It is I to $\mathrm{I} \frac{\mathrm{l}}{2} \mathrm{ft}$. high, and has narrow leaves on slender stems, furnished with a cluster of about a dozen brilliant red turban-shaped flowers, which shine like sealing-wax. It succeeds in open known to need description. No garden should be without it, for few plants are so attractive or have such stately growth. The common kind is handsome, but the variety splendens is much finer, having larger flowers with larger spots, is produced later, and grows $7 \mathrm{ft}$. high. Fortunei is an early form and as desirable as splendens. The double-flowered variety (flore-pleno) is showy and vigorous. Erectum also is distinct and desirable. L. pseudo-tigrinum and the varieties of Maximowiczi, though referred to other species, much resemble L. tigrinum. The Tiger Lily is very easy of cultivation,

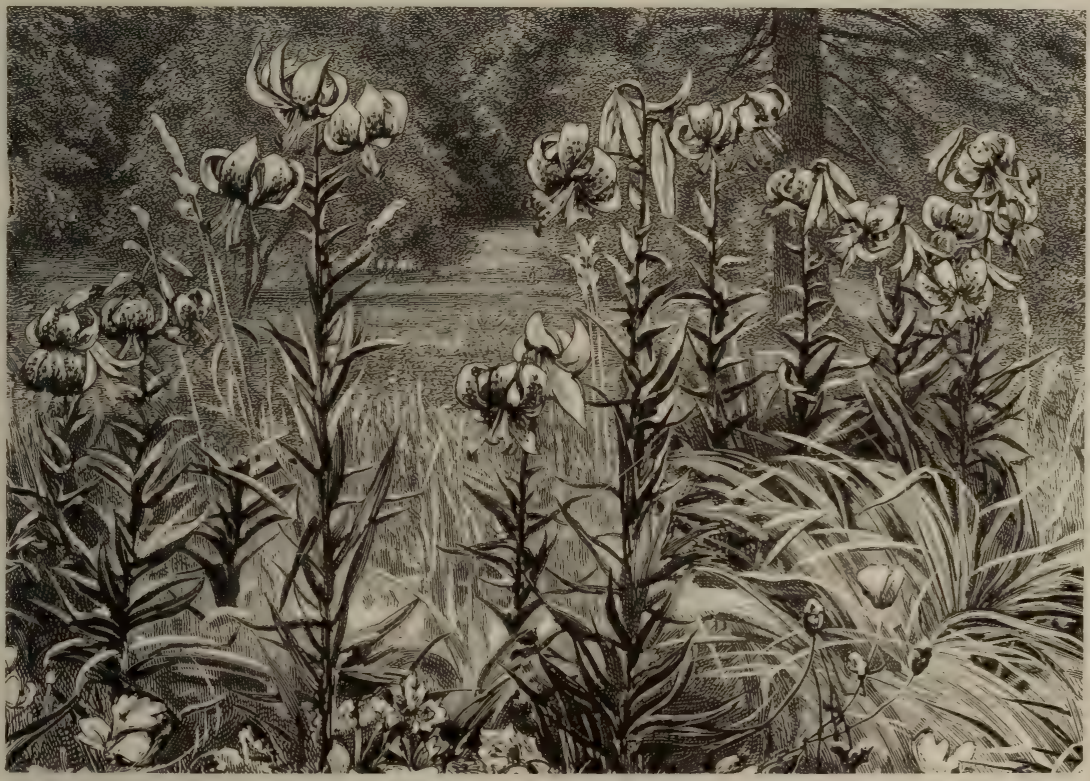

LILIUM TIGRINUM (TIGER LILIES AMONGST GRASS).

warm borders of light sandy loam, but is all the better for a hand-light or frame, as it flowers very early. Siberia and $\mathrm{N}$. China. L. callosum and its form, stenophyllum, are similar but less showy.

L. testaceum (Nankeen Lily).-This is a distinct-coloured Lily, and should always be grown, being of easy culture and thriving in any ordinary soil, though preferring one that is peaty. It has the growth of the white L. candidum, but the flowers are a delicate apricot, or nankeen, colour. When well grown it is 6 or $7 \mathrm{ft}$. high, and bears several flowers in a large head. Other names for this Lily are L. excelsum and isabellinum. It is one of the plants that grow freely in London.

L. tigrinum (Tiger Lily).-This is one of the commonest kinds, and is too well thriving best in deep sandy loam with an open, but sheltered position. The earliest varieties begin to flower at the end of August, and the latest last till the end of October. The Tiger Lily may be quickly propagated by the bulblets, which form in the axils of the leaves.

L. Washingtonianum.-A lovely Californian Lily, 2 to $5 \mathrm{ft}$. high, bearing a cluster of large, white, purple-spotted flowers that become tinged with purple after expansion. Nearly allied to this, and by some considered a variety, is $L$. rubescens, which has smaller flowers which are of a pale lilac or nearly white. These flowers are erect-not horizontal, as in the Washington Lily. Neither L. Washingtonianum nor $\mathrm{L}$. rubescens is easy to grow, owing, probably, to their 
being but little understood at present. The best results have been obtained in partially-shaded situations, in loose, peaty, well-drained, but moist soil. The wonderfully brilliant series of Lilies introduced from N. America and Japan of recent years, which have given wholly new aspects of vegetation in the flower garden, are figured in colour and life-size in the volumes of The Garden, and will be found enumerated in the general index to that work.

\section{Lily (Lilium).}

\begin{tabular}{|c|c|}
\hline 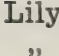 & $\begin{array}{l}\text { African (Agapanthus). } \\
\text { Arum (Calla). }\end{array}$ \\
\hline & Atamaxo (Zephyranthes). \\
\hline & Belladonna (Amaryllis). \\
\hline & Bernard's, Saint (Anthericum). \\
\hline & Bruno's, Saint \\
\hline & Bruno's Great \\
\hline & $\begin{array}{l}\text { Cape (Crinum capense). } \\
\text { Day (Hemerocallis). }\end{array}$ \\
\hline & Ethiopian (Calla). \\
\hline & Guernsey (Nerine). \\
\hline$"$ & Lent (Narcissus). \\
\hline$"$ & $\begin{array}{l}\text { Madonna (Litium candidum). } \\
\text { Mariposa (Calochortus). }\end{array}$ \\
\hline & Orange $(L$. croceum). \\
\hline & Panther (L. pardinalum). \\
\hline " & Peruvian (Alströmeria). \\
\hline$"$ & Plantain (Funkia). \\
\hline$"$ & $\begin{array}{l}\text { Pond, Yellow (Nuphar). } \\
\text { Scarborough (Valotta). }\end{array}$ \\
\hline & $\begin{array}{l}\text { Scarlet Martagon (L. chalce- } \\
\text { donicum). }\end{array}$ \\
\hline " & Swamp (L. superbum). \\
\hline " & $\begin{array}{l}\text { Tiger (L. tzgrnum). } \\
\text { Turk's-cap (Martion). }\end{array}$ \\
\hline & White ( $L$. candidum). \\
\hline & White Trumpet (L. longiflorum) \\
\hline
\end{tabular}

Lily of the Valley (Convallaria majalis).

Limnanthemum nymphæoides. - A pretty native water-plant, sometimes seen in ponds or by slow streams. It has floating tufts of leaves, and bright yellow flowers I in. or more across. Where not plentiful in a wild state it is desirable for lakes and other artificial water, or for treating like Limnocharis. Propagated by division or seed sown in mud, as soon as gathered. Gentianaceæ. Syn., Villarsia.

Limnanthes Douglasi.--A beautiful Californian hardy annual, particularly valuable because so early. The flowers are yellow and white, and there is a pure white variety. Few annuals are more hardy, as the most severe winter does not injure it, and the seed germinates at a very low temperature. It is compact and vigorous, a single plant in bloom covering a square foot of soil : it should, therefore, be allowed quite that space for development. Unlike most annuals, it requires neither a deep nor a rich soil, but thrives admirably where the natural staple is poor and inclined to burn in the early summer months. This makes it valuable for dry banks or similar situations, where it flowers more freely than in rich soils. It generally sows itself on light soils, and gives no further trouble ; but if wanted for a special purpose in spring, the seed should be sown in autumn in boxes or in the open ground; for summer-flowering sow in the spring.

\section{Tropæolaceæ.}

Limnocharis Humboldti.-An interesting and pretty aquatic plant which in summer covers the surface of the water with broad heart-shaped leaves, of a beautiful glistening green, and soft yellow flowers, which continue for several months. It commences, as a rule, to flower in August, and continues in blossom till late in the season; it will thrive either in running or still water, if planted 6 to 9 in. below the surface, and may also be grown in tubs sunk in the ground. These tubs should be about $I \frac{1}{2} \mathrm{ft}$. in depth, should be half-filled with loamy soil, and then filled up with water. In fountainbasins and clear, rather still, waters, where the plant is fully exposed to the sun, it thrives and flowers freely during summer. It will not survive out-of-doors in winter, except in the mildest districts, and unless placed at least 18 in. below the surface. It might, however, survive in water that does not freeze. Plants put out of a warm aquatic house in May soon begin to grow in the open air. It is, or used to be, most frequently seen in the aquatic stove. Division. Butomaceæ.

Linaria (Toadflax).--A very large genus of Figworts, which includes some beautiful garden annuals and perennials varying from very dwarf alpines to tall coarse plants. Among the alpine perennials the most desirable are the following :-

L. alpina, from the Alps and Pyrenees, is found on moraines and in the débris of the mountains. It forms dense, dwarf, smooth, and silvery tufts, covered with bluish-violet flowers, with two bosses of intense orange. It is spreading, but neat and very dwarf, being rarely more than a few inches high. It is usually biennial ; but in favourable spots, alike in a wild and cultivated state, becomes perennial. Its duration, however, is not of much consequence, as it sows itself freely, and is one of the most charming subjects that we can allow to "go wild" in sandy, 
gritty, and rather moist earth, or in chinks in the rock-garden. In moist districts it will sometimes establish itself even in gravel walks. It is readily increased from seed, which should be sown in early spring in cold frames, or in the places it is destined to embellish out-of-doors. L. pilosa and pallida are very dwarf creeping plants with conspicuous purple blossoms; both are suitable for moist spots in the rock-garden, where they can trail over the surface. L. origanifolia and its near ally, L. crassifolia, both of which are dwarf and have pretty purple flowers, are suitable for the same purpose, as also is the common wild Ivy-leaved Toadflax (L. Cymbalaria), which drapes many walls so gracefully. The lastnamed has a white variety and a pretty variegated variety, and would be fully described were it not that it usually takes possession of old walls and other suitable places. The best of the taller kinds for the border or for naturalisation are :-

L. dalmatica, a really handsome plant, 3 to $5 \mathrm{ft}$. high, with very glaucous foliage. It is much branched, and bears in summer a profusion of large showy sulphuryellow blossoms. It thrives best in warm places in light well-drained soil, and when once established can be eradicated with difficulty. L. genistæelia is a similar species, but much inferior, and also has yellow flowers.

L. purpurea, though not showy, is worth growing, as it thrives in dry places, and is a capital subject for old walls. Even the common yellow Toadflax (L. vulgaris) is worth cultivating, particularly the singular and handsome Peloria variety, which has five spurs, and is curious as well as ornamental.

L. triornithophora is a beautiful plant when well grown. Fully developed, it is I to $\mathrm{I} \frac{1}{2} \mathrm{ft}$. high, and bears large purple long-spurred flowers in whorls of three. It is rather delicate, and, though perennial, should be raised yearly from seed. L. triphylla is similar.

Some of the annual species are among our prettiest border flowers. All grow about I ft. high, are profuse flowerers, very showy, and most effective in broad masses. They should be sown in ordinary garden soil in early spring, and will flower in July and August. The best are L. reticulata, with small purple flowers; the variety, aureo-purpurea, is a charming plant, producing flowers in great variety, which vary from rose-purple to dark orange. L. bipartita is also very variable, the colours ranging from deep purple to white. Perezi has small yellow flowers; the flowers of maroccana vary from violet to pink; and multipunctata, the dwarfest of the group, has blackspotted yellow flowers.

Lindelophia spectabilis. - A rather showy perennial Borage-wort, about $\mathbf{I}_{2} \frac{1}{\mathrm{ft}}$. high, bearing in early summer drooping clusters of deep purple-blue flowers. It is suitable for borders in sandy loam, and is quite hardy in well-drained places, but is not so valuable as many of the same order. Seed or division. North India. $=$ Cynoglossum longiflorum.

Linnæa borealis (Twin Flower).-A little evergreen creeper of the Honeysuckle family, and, as the slender upright stalks bear two flowers each, commonly called Twin Flower. The delicately fragrant flowers are white, often tinged with pink or purple, and droop with a charming modesty. It is usually found in moist woods, where it forms a dense carpet. It is wrongly supposed to be difficult to cultivate. Little need be done beyond planting healthy young plants in a moist sandy border or rockgarden, or on a slightly raised bank. We have repeatedly seen it thriving freely in the open, where the air was pure and the soil suitable. It is excellent for a moist rock-garden, and when once established grows rapidly. It forms a charming fringe or carpet to a group or bed of the smallest alpine and rock shrubs, in cool borders or on northern slopes of the rockgarden. N. Europe, Asia, and America.

Linosyris vulgaris (Goldilocks). - A showy native herb, I to $2 \mathrm{ft}$. high, which in late summer and autumn bears terminal clusters of bright yellow flowers. It grows in any ordinary soil, but is scarcely a garden plant. = Chrysocoma Linosyris. Compositæ.

Linum (Flax). - A genus chiefly characterised by elegance and lightness of growth; there is a striking similarity in most of the species, especially the blue-flowered kinds, so that only a few are suitable garden plants. The most desirable are the following :-

L. campanulatum (Yellow Herbaceous Flax).-A herbaceous plant with goldenyellow flowers on stems 12 to 18 in. high, distinct from anything else in cultivation, and well worthy of a place in collections of alpine and herbaceous plants. A native of the south of Europe, it flowers in summer, and flourishes freely in dry soil on the warm sides of banks or rock-gardens. Propagated by seed. Similar to it is L. flavum, or tauricum, also a handsome and perfectly hardy plant with yellow flowers; but L. arboreum, a 
shrubby kind, also with yellow flowers, is not hardy in all districts, though where it thrives it is a charming little evergreen bush for the rock-garden.

L. grandiflorum is a showy hardy annual from Algeria, with deep red blossoms. By successive sowings it may be had in bloom from May till October. Seed sown in autumn will produce plants for early spring-blooming, and sowings made from March to June will yield a display through the summer and autumn. By sowing seed in pots in good rich soil in summer, and plunging in a sunny border with plenty of water, plants may be obtained for the greenhouse or window during October and November. If protected from frost the plant is perennial.

L. monogynum. - A beautiful kind with large pure white blossoms blooming in summer. It grows about $\mathrm{I} \frac{\mathrm{I}}{2} \mathrm{ft}$. high in good light soil, and its neat and slender habit renders it particularly pleasing for the borders of the rock-garden or for potculture. It may readily be increased by seed or division; it is hardy in the more temperate parts of England, but in the colder districts is said to require some protection. L. candidissimum is a finer and hardier variety. Both are natives of New Zealand.

L. narbonnense. - A beautiful and distinct sort, bearing during the summer many large light sky-blue flowers, with violet-blue veins. It grows best on rich light soils, and is a fine ornament for borders, for the flower garden, or for the lower flanks of the rock-garden, and forms lovely blue masses 15 to 20 in. high. Southern Europe. Other similar but inferior blue-flowered kinds are the common L. perenne, usitatissimum, alpinum, sibiricum, alpicola, collinum, austriacum, and crystallinum; all are hardy European species, and make showy border or rock-garden plants. The white and rose varieties of $\mathrm{L}$. perenne are pretty plants.

L. salsoloides (White Rock Flax) is a procumbent half-shrubby species, and essentially a rock-garden plant. Its flowers are white, with a purplish eye, and, when abundant, remind one of some of our creeping white Phloxes. In the rock-garden, in a well-exposed sunny nook, the plant is perfectly hardy, and trails freely over adjacent stones, under which conditions it flowers abundantly. It produces seeds rarely, so that it must be increased by cuttings of the short shoots taken off with a heel about midsummer, just as they are hardening off; these will strike freely, and make vigorous plants when potted off in the following spring. Mountains of Europe. L. viscosum, with pink flowers, is a close ally, but much less desirable.

Lion's-leaf (Leontice).

Lion's-tail (Leonitis Leonurus).

Liparis.-Orchids, for the most part inconspicuous and suitable for botanical collections only.

Lippia.-A genus of Verbenaceæ, of which the common Lemon Plant (L. citriodora), sometimes called Aloysia, is the most familiar. L. nodiflora is a dwarf perennial creeper bearing, in summer, heads of pretty pink blooms. It grows in any situation or soil, and is a capital plant for quickly covering bare spaces in the rock-garden where choicer subjects will not thrive.

\section{Liriodendron tulipiferum (Tulip}

Tree).--One of the noblest of fine flowering trees. It is only when the tree has reached maturity that it bears its beautiful Tulip-like flowers of pale green and yellow. Young Tulip trees should be planted, though only future generations can enjoy their maturity.

\section{Liquorice (Glycirrhiza).}

\section{Liquorice, Wild (Ononis).}

Listera.-Terrestrial Orchids, only of botanical interest.

Lithospermum (Gromwell). - A few of these Borage-worts are pretty and worth growing. One of the finest is $\mathrm{L}$. prostratum, a spreading little evergreen having rich flowers of a lovely blue, with faint reddish-violet stripes, in great profusion when the plant is well grown. It is very hardy, and peculiarly valuable as a rock-plant from its prostrate habit and the fine blue of its flowers - a blue scarcely surpassed by that of the Gentians. Its shoots may be allowed to fall down the sunny face of a rocky nook, or to spread into flat tufts on level parts of the rockgarden. On dry sandy soils it forms an excellent border plant, and becomes, if the soil is deep and good, a round spreading mass, I ft. or more high. In such soils; it is suited for the margins of beds of choice and dwarf shrubs, either as a single plant or in groups. In heavy or wet soil it should occupy an elevated position in the rock-garden, or on banks, and be planted in sandy earth. It is sometimes grown as L. fruticosum, but the true L. fruticosum is a little bush, and not prostrate. It flowers in early summer, and often continues a long time; the leaves are nearly oblong, and are covered with short bristling hairs. Easily propagated by cuttings. S. Europe.

L. petræum (Rock Gromwell).-A neat 
dressy dwarf shrub, something like a Liliputian Lavender bush, with small greyish leaves like those of the Lavender. Late in May, or early in June, all the little grey shoots begin to exhibit a profusion of small oblong purplish heads, and early in July the plant is in full blossom, the full-blown flowers being a beautiful violet-blue. The best position for it is in the rock-garden somewhere near or on a level with the eye, on a well-drained, deep, rather dry sandy soil on the sunny side. Native of dry rocky places in Dalmatia and Southern Europe. Propagated by cuttings, or seeds if they can be obtained.

L. purpureum-cœruleum, a British plant, L. Gastoni, and L. canescens are also worthy of culture.

\section{Liver Leaf (Hepatica).}

Lizard Orchis (Orchis hircina).

Lloydia serotina.-A small bulbous Liliaceous plant, suitable for association with smaller bulbs. Alps.

Loasa.-All the species of Loasa are remarkable for their singular flowers and their stinging foliage. There are few in cultivation. L hispida is very ornamental, growing about 18 in. high, branching considerably when strong, and bearing deeply-cut foliage, with short stinging hairs. The flowers are I in. across, of a clear bright lemonyellow, with the centre prettily variegated with green and white. It blossoms several weeks in succession during August and September. The other kinds in cultivation are the beautiful new I. vulcanica, with its pure white flowers and red and white striped centres; L. lateritia, a twining species, with orange-red flowers ; and L. triloba. All are natives of the cool regions of Peru and Brazil, and can be grown in the open air during summer. Treated as half-hardy annuals, and grown in a light fertile soil, they are interesting for open borders; but the climbing species, such as lateritia, require branches to twine among. All may be freely raised from seed, which, in favourable seasons, is borne abundantly.

Lobelia.-A genus containing few garden plants, but these few are of great beauty and are indispensable. The species are annual and perennial. Of the perennials the best are-

L. fulgens (Cardinal Flower).-This is one of the handsomest of all open-air flowers, for nothing can surpass the brilliancy of its rich vermilion blossoms, which with its bold erect habit adapt it for situations where bright colours are desirable. In groups, backed up by, or near to, evergreens, it has a gorgeous effect. Its most congenial situation is among the lower shrubs in a border, as it thereby receives just the shelter necessary to ensure its flowering in perfection. The reason it is not more in cultivation is that in many localities it is very liable to rot off

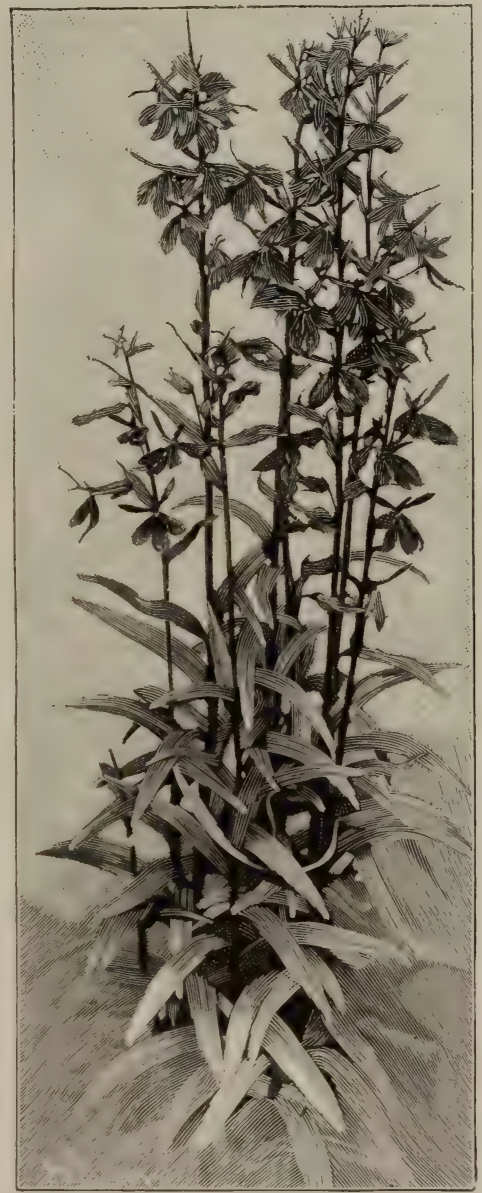

LOBELIA FULGENS (CARDINAL FLOWER).

in winter, while in an unusually damp season it is not uncommon to hear of the whole stock disappearing. Its enemy is a kind of rust, which fastens on the main fleshy roots when the plants are gone to rest, and, quickly eating them away, thoroughly rots them. This disease, working as it does from the bottom at a time when growth is at a standstill, is not perceived in time to be checked, and the whole plant will in two or three weeks be completely ruined. The disease makes its appearance towards the end of October 
or the beginning of November, especially if the weather be cold and wet. The plants should then be carefully taken up, reserving as much of the roots as possible, the soil being shaken off, and the roots well washed. The disease will be readily discovered by its rusty-looking spots, which must be cut out with a sharp knife, as the least portion will suffice to destroy the plant. After the plants are examined they may be potted or laid in a frame in some free sandy soil, and very fine specimens may be obtained by potting and plunging in a slight bottom-heat, keeping the top quite cool. In about a fortnight they will have made fresh fibre, and all danger will be past. They may then be kept in a cold frame during the winter, and planted out where desired in spring. The bottom-heat, however, is not indispensable; for they will succeed if carefully and sparingly watered after potting. Similar to L. fulgens is L. cardinalis, splendens, and ignea. They differ chiefly in the depth of colour, but L. fulgens is the finest.

L. Erinus. - The dwarf section of Lobelia is one of the largest and most important. Hardly any garden is considered complete unless one at least of the beds or borders is plentifully supplied with this beautiful Lobelia, or with some of its many varieties, and few features in the flower-beds or borders are more enjoyable and satisfactory than a perfect band or small bed from the middle of June till the frost clears the garden of its autumnal beauty. The chief points to start with are good soil and well-grown established plants. The soil should be light and rich, and rest on a dry bottom perfectly drained. It enjoys abundance of water when in robust and free growth, but nothing is more fatal to its well-being than stagnant water at the roots. On a porous bottom it may be plentifully watered during a dry time in summer without fear of injuring the roots. The roots cannot make way nor can the plants thrive in a strong adhesive soil of clay or heavy loam, and if the compost be heavy, it must be lightened by a plentiful addition of leaf-mould, sand, or peat. This Lobelia thrives admirably in equal parts of rather sandy loam and leaf-mould with a fair admixture of sand to keep it open. Charcoal dust and peat form capital additions to loam, as also does spent manure from Mushroom beds. A slight mulching of one-year-old sifted hotbed manure will be found capital for keeping out the drought and nourishing the roots through a dry season. One of the greatest difficulties in carrying dwarf Lobelias in full beauty through the season is the freedom with which they seed. The moment the flowers fade they should be picked off persistently every week or ten days throughout the season. The labour is great, but so is the reward. Dwarf Lobelias may be propagated by seeds or cuttings, or by lifting the plant, potting it, and placing it in a gentle bottom - heat until established; then setting it on a light airy greenhouse or forcing-house shelf, when it may be increased to any extent by cuttings and root-division in the spring. A stock should be planted for seed on a piece of reserve ground. Increase by cuttings, and conservation of the old plants by potting a few in autumn, is the best method of preserving and increasing special varieties. They strike freely in a brisk heat in a moist propagating pit or frame in spring. The cuttings should be potted by the end of May in the same way as seedlings sown in heat in September, October, or February. Those who want early Lobelias from seed should sow in the autumn, and prick the seedlings off in boxes or pans, or shift them into $2 \frac{1}{2}$-in. pots before winter; store them on shelves near the light, and well exposed to air ; shift them again in March into 6-in. pots of equal parts of leaf-mould and loam, and they will be perfect for planting by the end of May. Spring-sown seedlings may go into smaller pots, and be planted rather more closely, but will not flower so early nor so well. On the whole, autumnal propagation, by cuttings or seeds, is preferable to sowing in spring. The varieties are numerous, and it is difficult to make a selection to suit every locality. L. Erinus is divided into five sections, viz. compacta, of which there is a white form; speciosa, of which the best are Blue Stone, Ebor, Blue Beauty, Emperor William, Blue King, Lustrous, Brilliant; ramosoides; pumila, of which grandiflora and magnifica are fine forms, as is also the pure white Mrs. Murphy ; and Paxtoniana, which is a lovely blue. The double variety is also beautiful where it succeeds, but it is hardly to be depended upon. Sometimes it forms a sheet of bloom, and at others the shoots run up through it, as it were, and prevent it from blooming, giving it the appearance of tufts of Grass. Other dwarf Lobelias are ramosa, with large light-blue flowers, and coronopifolia, also with large blue flowers. Both are halfhardy annuals, requiring the same treatment as L. Erinus. L. lutea is a yellowflowered perennial, which has not been 
sufficiently tested. It is very dwarf, flowers freely, but is not showy. L. subnuda is a tender little species from Mexico, having handsomely - marked foliage. It is not worth growing in a general way. L. ilicifolia is another dwarf trailing species, a native of the Cape, and is best suited for growing in suspended pots in greenhouses, though in some localities it succeeds as a rock-garden plant.

L. syphilitica is a hardy perennial, about $2 \mathrm{ft}$. high, bearing, from July to September, erect flower-stems, thickly furnished with light blue blossoms. It is not very showy, but its varieties and the hybrids from it are ornamental. These occur in various shades-deep purple, blue, and light rose, and the hybrids Milleri and speciosa are also handsome. All thrive best in moist borders, and are so partial to moisture that they flourish in the artificial bog. They are never so fine, however, as the forms of $\mathrm{L}$. fulgens or $\mathrm{L}$. ignea, which are really splendid in colour and fine in form when well grown.

\section{Locust Tree (Robinia).}

Loiseleuria procumbens. - A wiry trailing shrub, growing close to the ground, the plants occasionally forming in spring a rather dense tuft with small reddish flowers. Its bloom is never very attractive, rarely thrives in cultivation, and the plants transferred to gardens from the mountains usually perish. This sometimes occurs because the strongestrooted and finest specimens are selected for transplantation instead of the younger ones. Its true home is the rock-garden, and it prefers deep sandy peat. = Azalea procumbens. Ericaceæ.

Lomaria. - Ferns, for the most part tropical, and requiring artificial heat ; but in mild parts two or three thrive in the open air. L. alpina, a native of New Zealand, is dwarf and compact, and produces, from a creeping rhizome, abundance of dark shining green fronds, 4 to 6 in. in height. It is specially adapted for the rock-garden, and should receive similar treatment to the Ceterach (to which it forms a charming companion), and should, like it, be associated with Sedums and such alpine flowering plants. L. crenulata is similar, but not quite so hardy, though it succeeds in the mildest localities, as will also the Chili L. chilensis, a Tree Fern of noble growth. These Ferns should be placed in the snuggest quarters of the hardy fernery, and care should be taken to protect them during severe cold.

London Pride (Saxifraga umbrosa).

Lonicera (Honeysuckle). - These grace- ful, fragrant, and beautiful plants may be made a charming aid to the flower garden or the pleasure-ground. Wherever picturesque gardening is attempted they are beautiful if isolated and allowed to ramble as tufts in their own way ; while occasionally in bold rock-gardening on banks, in groups, or in tufts, they would be charming. The common native Woodbine or Honeysuckle (L. Periclymenum), particularly its fine varieties, the Dutch and late Dutch, are as beautiful as any. Both varieties bear dense clusters of fragrant red and yellow blossoms and are vigorous ramblers. The late Dutch variety blooms throughout the autumn, and hence is preferable to the other. In Continental gardens it is sometimes the custom to train common Honeysuckles as low standards for borders, and when in flower their appearance is pleasing. L. Caprifolium, also found wild in England, makes a beautiful garden climber, and is a good deal like the other native form. A very charming climber is L. flexuosa from Japan. It can always be recognised by its dark purple stems and very hairy purple-stained leaves. The flowers are purplish-yellow and very sweet-scented. L. japonica (also called L. Halleana) is one of the loveliest of all, being very elegant in growth and profuse in bloom. It has broad pale green foliage, and its deliciously-scented flowers are first white and then pale yellow. It is an extremely vigorous grower and free bloomer, continuing in flower for several weeks in July and August. L. etrusca, with very sweet-scented flowers of a yellow and purplish hue, is a strong twiner; and so is the North American L. flava, the flowers of which are a rich yellow, though it requires the warm shelter of a wall. A variety of $L$. flexuosa, having foliage netted with yellow veins, is called aureoreticulata. It is an elegant and effective climber, but not so desirable a flowering variety as the typical flexuosa. The North American Trumpet Honeysuckle (L. sempervirens), though usually grown as a greenhouse climber, is quite hardy enough for open walls in the south, and a very cheerful climber it is throughout June, when covered with an abundant crop of orange-scarlet flower-clusters, which are often borne again in September. It must have a light warm soil, and grows admirably in sandy peat. The commonest variety of it is that called minor, which blooms more freely than the type. A little-known but elegant Honeysuckle is L. acuminata, from the Himalayas, - a tall strong shrub with large leaves, which bears 
its large purple flowers in pairs from the leaf axils throughout July. Besides the twining Honeysuckles, there is a group of Honeysuckles which do not climb, called Bush. They are numerous, and several are worthy of attention. The in the open shrubbery. L. Ledebouri is a common bush Honeysuckle of strong wide-spreading growth, bearing in summer an abundance of yellow and redtinged flowers, and, as it rapidly spreads in a graceful mass, is an admirable lawn

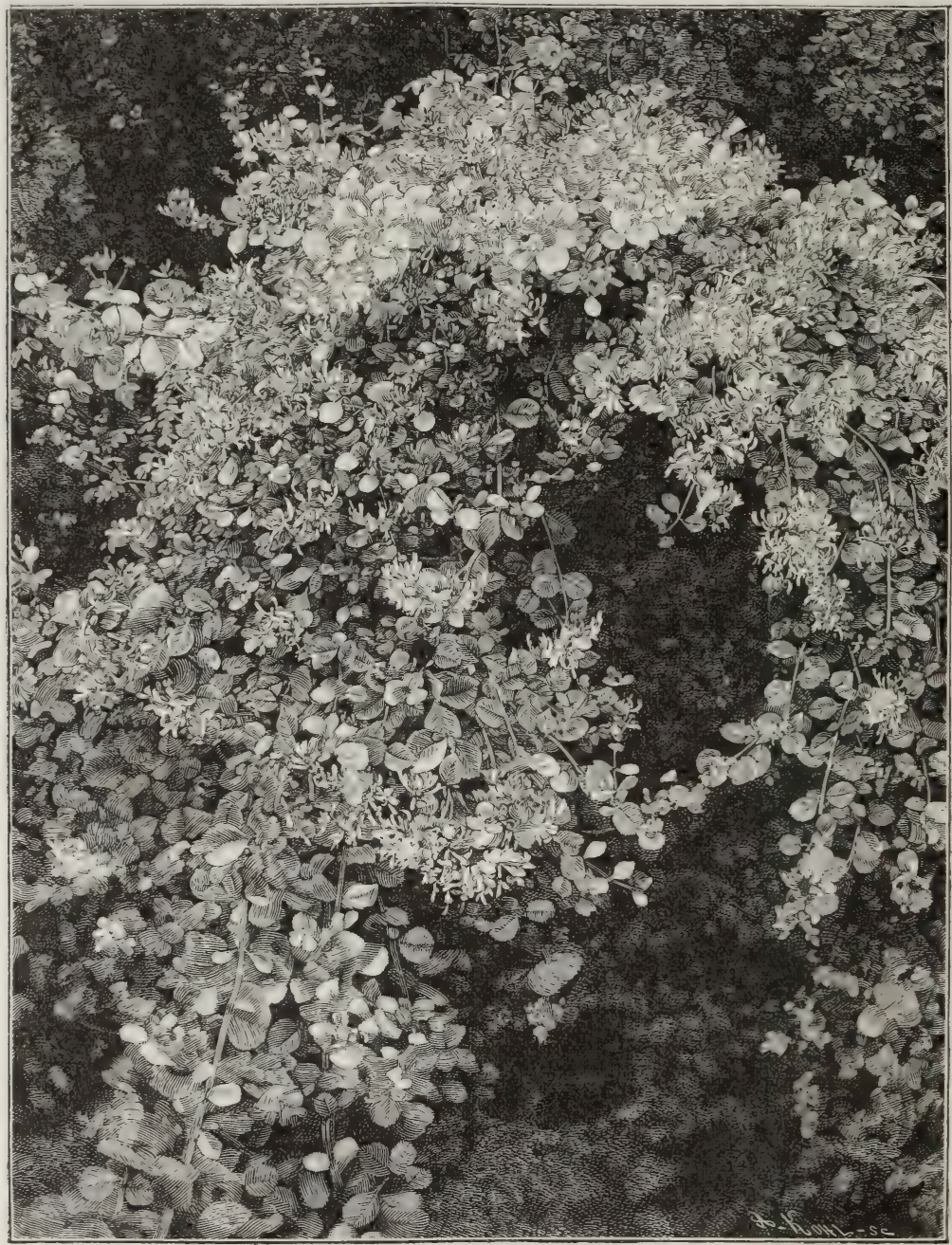

LONICERA PERICLYMENUM (HONEYSUCKLE),

winter-flowering L. Standishi and fragrantissima belong to this group. Though strictly non-climbers, they are usually grown against walls or trellises. Their very fragrant white flowers, sometimes produced in midwinter, make them most desirable for the walls of a house or garden, where their fragrance may be enjoyed; or they may be grown as bushes or bank shrub. L. tatarica and Xylosteum are common shrubs not so important as the foregoing; the first bears pink flowers; the other, a native plant, has white flowers.

Loosestrife (Lysimachia vulgaris).

Lopezia. - Mexican annuals of the Fuchsia family, not one of which is very showy. L. coronata grows $\mathrm{I}$ to $\mathrm{I} \frac{1}{2} \mathrm{ft}$. 
high, and produces small red flowers from July to September in abundance. L. racemosa is similar, but inferior. They thrive in ordinary soil, but are only useful where annual plants are much grown. Seed should be sown in March in the open border.

Lophospermum scandens.-A tender climber with long slender stems, pale green hairy leaves, and large pink flowers. It thrives in the open air in summer, and is a beautiful plant for festooning old tree-stumps, trellis arbours, and the like, or for trailing over dead branches placed against a warm south wall. It may be easily raised from seed in heat in early spring or autumn and kept through the winter, but the best plan is to lift the plants in autumn and to winter them in a greenhouse.

\section{Lords and Ladies (Arum).}

Lotus (Bird's - foot Trefoil). - Most plants of this genus are weedy, the only one worth growing being the common L. corniculatus, which occurs in almost every lawn, meadow, or pasture, and forms tufts of bright yellow flowers with the upper part often red on the outside. Though so common, it is worthy of a place in the garden. The doubleflowered variety is the best, as the flowers continue longest in perfection. L. creticus, maroccanus, sericeus, are found in botanical gardens, but are not nearly so showy. L. Jacobæus, a tender species with almost black flowers, succeeds in the open air in summer, and is all the better for planting out. The Lotus is best planted so that its shoots may fall in long and dense tufts over the face of rocks or stumps. It varies a good deal.

Love-in-a-mist (Nigella damascena).

Love-lies-bleeding (Amarantus caudatus).

Lunaria biennis (Honesty). - When well grown this old-fashioned plant is beautiful, not only on account of its sweet-scented purple blossoms, but also on account of the singular silvery flat seed-pods that succeed them. In borders, on the margins of shrubberies, and in halfshady situations, it is very effective in April and May, and it thrives well in any ordinary light garden soil. The Honesty is charming in a semi-wild state on chalky or dry banks and in open bushy places. Seed should be sown every spring, and the plants should be thinned out during growth in order to make good ones for the next year. L. rediviva is a perennial similar to the Honesty, but with larger and more showy flowers. It is 2 or $3 \mathrm{ft}$. high, and flowers in early summer. It thrives best in half-shady borders of good light soil. Division or seed. Mountain woods of Europe. Cruciferæ.

\section{Lungwort (Pulmonaria).} " Smooth (Mertensia). " Virginian (Mertensia).

Lupinus (Lupine).-Well - known and beautiful annuals, biennials, and perennials, coming chiefly from $\mathrm{N}$. America. The species in cultivation are few, though the names occurring in catalogues are numerous. The best of the perennials are-

I. arboreus (Tree Lupine).-The large yellow Tree Lupine is a most precious plant. One can imagine nothing more beautiful for rough rocky banks or slopes. It flowers most profusely, and the scent of a single bush reminds one of a field of Beans. Its purplish variety is good, though not nearly so valuable, and there are some inferior yellowish varieties. The best variety is the yellow, because while there are good blue perennial Lupines, there is no other good yellow. It forms a roundish bush, 2 to $4 \mathrm{ft}$. high, and is easily raised from seed, though the true form is best increased from cuttings. It may be killed in severe winters, but is worth another trial.

L. polyphyllus, one of the handsomest of all hardy plants. It grows 3 to $6 \mathrm{ft}$. high, has elegant foliage, and tall stately flower-spikes crowded with small blossoms, varying from blue and purple to reddish purple and white. It flowers in summer, continues long in beauty, and thrives in open positions in any kind of garden soil. It is a fine subject for naturalising, as it holds its own against stout weeds. The principal varieties are argenteus, flexuosus, laxiflorus, Lachmanni, rivularis, and grandiflorus. L. nootkatensis is dwarfer, and has large spikes of blue and white blossoms. It flowers earlier than L. polyphyllus, and continues in bloom for a long time, but it is not a good perennial, and requires to be frequently raised from seeds.

ANNUAL LUPINES are among the most beautiful and popular of hardy annuals, being extremely varied in colour, and all of the simplest culture. As they grow quickly, they need not be sown till about the middle of April. They thrive in any common soil. L. nanus is a handsome dwarf variety. L. sub-carnosus is a beautiful ultramarine blue, and should always be grown. L. hybridus atrococcineus is the finest of all, having long and graceful spikes of flowers of a bright crimson scarlet, with white tips. Other excellent sorts are mutabilis, Cruikshanki, 
Menziesi, luteus, superbus, pubescens, Hartwegi, and the varieties of Dunnetti. Many other sorts are so much alike that

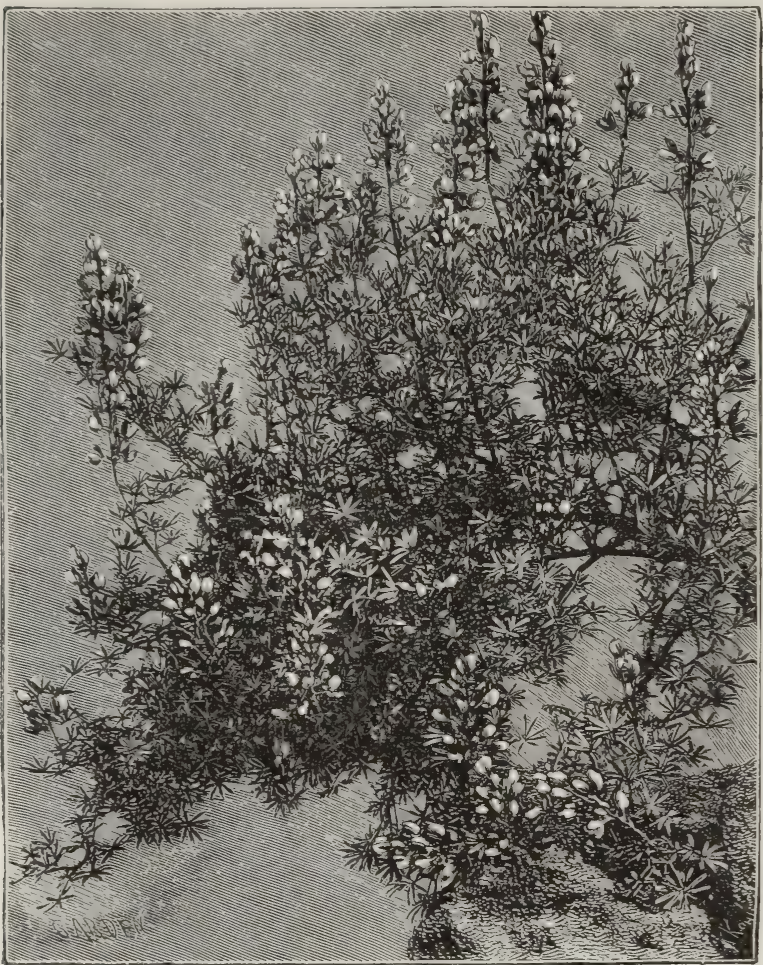

LUPINUS ARBOREUS (TREE LUPINE).

they are not worth separating. The smaller annual Lupines are very pretty, and could be charmingly used to precede late-blooming and taller plants.

Luzuriaga radicans. - A small Liliaceous evergreen from Chili. It is tolerably hardy in the mildest localities, though even in these it does not thrive so well as in a cool house. It is worthy of a trial in a cool bed of peat, on the north side of the rock-garden, among the larger alpine shrubs.

Lychnis (Campion). - Plants of the Pink family, among which are a few well suited for the garden. All are perennial.

L. alpina is a diminutive form of $\mathrm{L}$. Viscaria, the tufts being seldom more than a few inches high and not clammy. In cultivation it is pretty and interesting, if not brilliant, and may be grown without difficulty in the rock-garden, or in rather moist, sandy soil. A British plant.

L. chalcedonica.-An old border plant, $\mathrm{I} \frac{1}{2}$ to $4 \mathrm{ft}$. high, with large dense heads of brilliant scarlet flowers. It is of easy culture in any good ordinary soil. There is a handsome double scarlet variety. The double white and single white kinds are less desirable.

L. diurna.-The double deep purple-red sort of this common native plant is very desirable, being very hardy, and very showy, and never failing in any soil to produce a fine crop of bloom in early summer. The double red variety of $\mathrm{L}$. Flos-cuculi (Ragged Robin), another British plant, is also a very ornamental border plant. Both should be propagated by division.

L. grandifiora.-A remarkably handsome plant, typical of the numerous varieties now in cultivation under the names of Bungeana, Haageana, etc., which all grow I to $2 \mathrm{ft}$. high, and bear flowers in a cluster of a dozen or so, each flower being $\mathrm{I}$ to 2 in. across, fringed at the edges, and varying from vivid scarlet to deep crimson, and from pink to white. If fully exposed to the mid-day sun the colour of the flowers soon fades, but in a partially-shaded place they retain their true colour for a considerable time. They are all desirable border flowers, thriving best in warm sheltered situations in good light soil, for though quite hardy they are apt to suffer from excessive moisture and cold combined. They are greatly benefited by frequent transplanting, say every other year. All the varieties may be raised by seeds or from cuttings. L. fulgens, a Siberian plant, is similar to the forms of L. grandiflora or coronata.

L. Lagascæ.-A lovely dwarf alpine plant, with a profusion of bright rosecoloured flowers, about $\frac{3}{4}$ in. across. It is peculiarly suited for adorning fissures on the exposed faces of rocks, and should be associated with the smallest alpine flowers. It is easily cultivated in the rock-garden in any free sandy or gritty soil. A thoroughly-exposed position in the open air should always be preferred, as the plant is very free in growth, as well as 
neat and hardy. Since the introduction of the present subject, the pale-flowered L. pyrenaica, which comes nearest to it, has ceased to be worthy of a place in any but a botanical or a very full collection. The flowers appear in early summer, and if not drawn and weakened by shade, or by being placed in frames, are in perfect condition when the plant is about 3 in. high. Readily increased by seed. Syn., Petrocoptis Lagascæ.

L. Viscaria (German Catchfly). - A British plant, with long Grass-like leaves, and bearing in June many showy panicles of rosy-red flowers, on stems ro to nearly I 8 in. high. The bright-coloured variety called splendens is the most worthy of cultivation. L. V. alba, a charming white variety, is worthy of a place in garden cultivation, as also is the double variety, which has rocket-like blooms. They are excellent for the rougher parts of the rock-garden, and as border plants on dry soils. The double variety is used with good effect as an edging plant about Paris. Any of the kinds are worthy of naturalisation on dryish slopes, or rather open banks, on which they form the largest, healthiest, and most enduring tufts. Easily propagated by seed or division.

Lycium (Box Thorn or Tea Plant).A small genus of rambling shrubs, the best-known being L. europæum, a common climber, especially on cottage walls and porches. Though not a showy flowering shrub, few others are so rapid in growth, so graceful, and so indifferent to the nature of the soil. It will grow anywhere, and will quickly clothe an ugly bank where scarcely another shrub would thrive. It is also suited for covering porches, pergolas, arbours, verandahs, and the like, and in late summer and autumn, when every long drooping branch is thickly hung with small orange-scarlet berries, it has an extremely pretty appearance. The flowers are small, purple and white, and the unripe berries are of the same tints. The description of L. europæum may be taken as applying to the other kinds in gardens, as they are all much alike, though differing more or less in a botanical sense. The commonest kinds are L. chinense, from China; L. barbarum, from North Asia : L. afrum, from North Africa; L. Trewianum, and L. ruthenicum. They are of graceful and rapid growth, and therefore suitable for covering high walls, though all are deciduous. Sometimes hedges are made of Box Thorns, for, as they all throw up numerous suckers, the hedge soon becomes thick. There is a species named $L$. chilense against one of the walls at Kew, which seems to be more rapid in growth than the rest.

Lycopodium dendroideum (Ground Pine.-A Club Moss, which is worth a place in the rock-garden. Its little stems, 6 to $9 \mathrm{in}$. high, are much branched, and are clothed with small, bright, shining green leaves. It flourishes best in a deep bed of moist peat in a low part of the rock-garden, where its distinct habit is attractive at all seasons. It is apparently difficult to increase, and is exceedingly rare in this country. The chief point is the selection of sound well-rooted plants, since small specimens may retain a deceptive verdure after the root has perished. $\mathrm{N}$. America, in moist woods.

\section{Lygodium palmatum (Climbing Fern).} -An elegant North American twining fern, perfectly hardy in a deep, peaty, moist soil if in a sheltered and partially shady position. The wiry stems are furnished with delicate green finger-like fronds. It may be allowed to trail on the ground, but it prefers to twine around a rough branch, or the branches of some choice shrub.

Lyonia.-A genus nearly allied to Andromeda; indeed the species belonging to it, numbering about three, are still called Andromedas. They are not important, but would add interest to a collection of peat-loving shrubs. The chief are L. ligustrina, frondosa, and rubiginosa, which have evergreen foliage and small white blossoms.

Lysimachia (Loosestrife). - A small genus of the Primrose family of considerable diversity of growth. The most familiar example is the common creeping Jenny (L. Nummularia), than which there is no hardy flower more suitable for any position where long-drooping, flowerladen shoots are desired, whether on points of the rock-garden, or rootwork, or in rustic vases, or on steep banks. We have few creepers and trailers that flower so profusely. Grows in any soil ; in moist and deep soil the shoots attain a length of nearly $3 \mathrm{ft}$., flowering throughout their extent. Rarely or never seeds, but is as easily increased by division as the common Twitch. It flowers in early summer and often throughout the season, more especially in the case of young plants. There is a golden-leaved variety (L. N. aurea), which, though not quite so vigorous as the type, is still hardy. It retains its colour well, can be readily increased, is useful for rock-gardens or borders, and merits the name golden. The other kinds are tall and erect. 
L. vulgaris, thyrsiflora, lanceolata, ciliata, verticillata, punctata, and davurica are all 2 to $3 \mathrm{ft}$. high, have spikes of yellow flowers, and, delighting in wet places, are suitable for the sides of ponds, lakes, streams, and similar spots. Indeed, they grow almost anywhere, but in a border they must have a place to themselves, as by their spreading they soon destroy weaker subjects. L. clethroides, a Japanese species, is a graceful and beautiful plant, 2 to $3 \mathrm{ft}$. high, with long nodding dense spikes of white blossoms, and the leaves when decaying in autumn display brilliant tints. L. Ephemerum is a similar plant, from S. Europe, but is scarcely so fine. Both are excellent plants for naturalising, as, indeed, are all the others. There are some beautiful species, such as L. atropurpurea and lupinoides, which, though rare, are desirable. L. barystachya is a new species not much known.

Lythrum (Purple Loosestrife). - The common waterside L. Salicaria is the most familiar plant of this genus, and one of the showiest. It is well worthy of culture where it is not plentiful. The beauty of the ordinary wild kind is far surpassed by the varieties originated in gardens, of which superbum and roseum, both of which may be obtained in the hardy plant nurseries round London, are the finest. The colour of these is a much clearer rose than that of the common kind, and the spikes are larger, particularly those of superbum, which, undergood cultivation, are 5 or $6 \mathrm{ft}$. high. They are well worth growing by lakes or in marshy land, and are easily and rapidly increased by cuttings, which soon make good flowering specimens. Isolated plants in good soil make well-shaped bushes, 3 or $4 \mathrm{ft}$. high and as much through, and look better than when planted closely in rows. L. virgatum, alatum, Græfferi, flexuosum, and diffusum, smaller plants, and not so showy, are not without beauty.

\section{Macleaya (Bocconia).}

Madaria elegans.-A hardy Californian annual with showy yellow and brown flowers. It succeeds in half-shady places, requiring the treatment of hardy annuals.

Madwort (Alyssum).

Magnolia (Lily Tree). - There are about twenty species of Magnolia known to botanists, and all but some half-dozen or so are in cultivation in this country. The headquarters of these trees are in China and Japan, a few are peculiar to the Himalayan region, and a few more to North America. All are handsome trees or shrubs; some may be classed amongst the most beautiful objects to be met with in the gardens of temperate climates. A glance at the engraving, representing a very fine specimen of the Yulan, will show what glorious effects may be obtained in spring, in the South of England at any rate, by its use. It is true enough, unfortunately, that frosts sometimes injure the flowers and change their snowy whiteness into an unsightly brown. Perhaps the reason that this Magnolia and its allies are not more often met with in gardens is owing to the fact of their not transplanting readily. The best results are obtained if the plants are planted just as growth begins in spring. The fleshy roots when injured rot rapidly, and when autumn-planting has been practised, many succumb to the ordeal, those that do not do so outright often struggling on in a pitiful plight for years. A little care in transplanting in spring, in sheltering with mats from dry winds or hot sun, and in syringing the wood to prevent shrivelling, until the plants are established, would do much to prove that the Magnolias can be planted with every prospect of success. Some species occasionally ripen seed freely in this country, and it is well worth while to sow this seed at once. If dried and kept like other seeds until the following season, all chance of germination will have passed. All the species of the natural order Magnoliaceæ have seeds which retain their vitality for but a very limited period.

M. acuminata (Cucumber Tree) makes a noble specimen when planted singly in the park or pleasure-ground. It is deciduous, the leaves varying from $5 \mathrm{in}$. to I ft. in length, and glaucous green, the flowers yellow-tinged, bell-shaped, and slightly fragrant. There are fine examples of this tree at Kew, in the gardens of Syon House, Claremont, etc. In its native country it attains a height of from 60 to $90 \mathrm{ft}$., with a trunk from 2 to $4 \mathrm{ft}$. in diameter. The yellow Cucumber tree (M. cordata) is regarded by Professor C. S. Sargent as a variety of M. acuminata. It is a rare plant in a wild state, as it does not appear to have been collected since Michaux found it in Georgia.

M. Campbelli, one of the most gorgeous of Indian forest trees, has not fulfilled the expectations of those who took so much trouble in introducing the species to British gardens. In a wild state it attains a height of $150 \mathrm{ft}$., and the fragrant flowers, varying from deep rose to crimson, come before the leaves. Probably the finest 
specimen in the British Islands' is the one at Lakelands, near Cork, which ten years ago was $35 \mathrm{ft}$. high. In I884 it

against some high building in a warm sunny position. As it occurs in a wild state along the outer Himalayas at eleva-

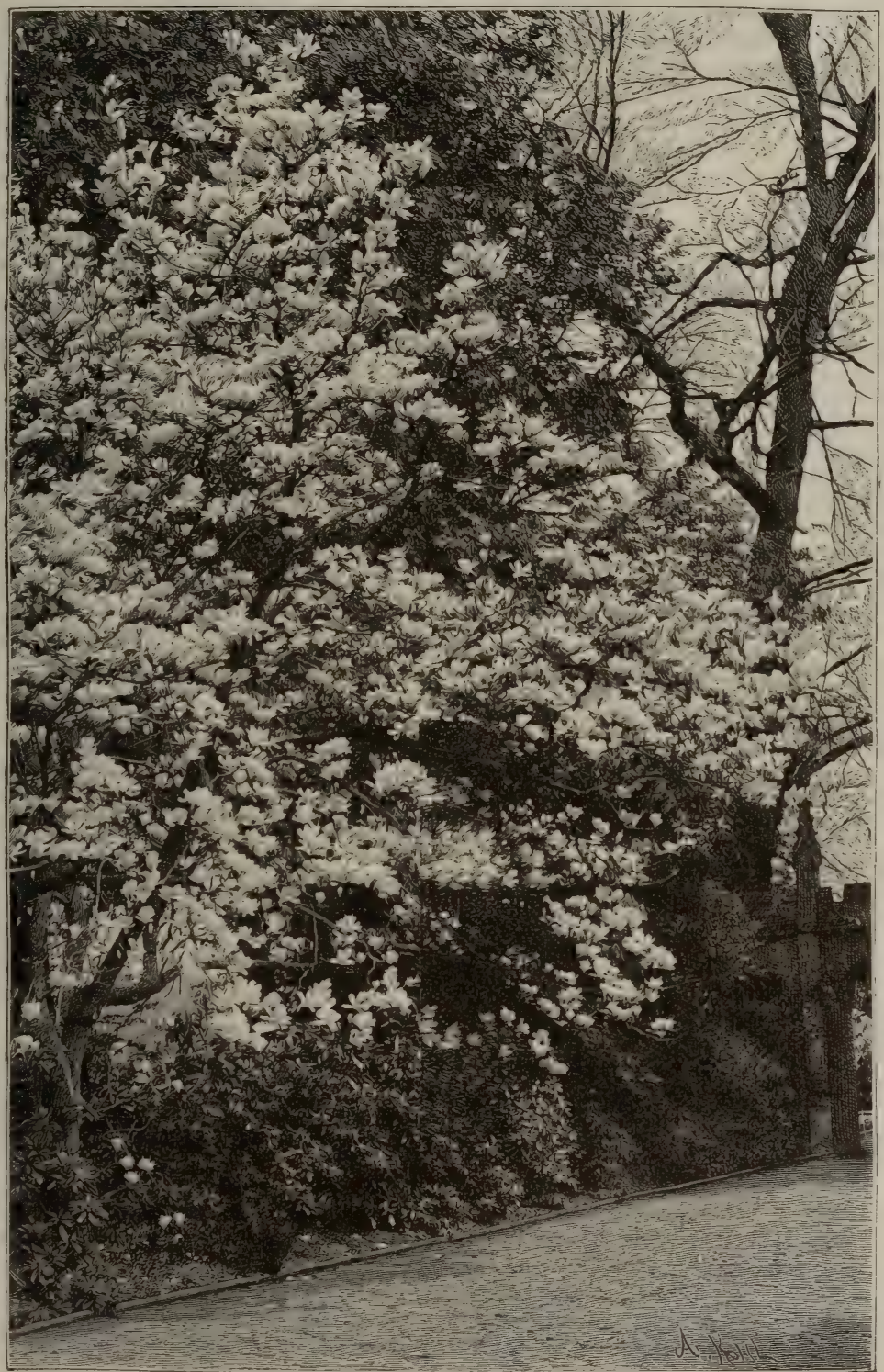

THE YULAN (MAGNOLIA CONSPICUA) AT GUNNERSBURY HOUSE.

flowered for the first time, and a figure was prepared for the Botanical Magazine from material forwarded to Kew by the late Mr. Crawfurd. Considering the beauty of M. Campbelli, it would appear worth while to treat it as a wall-plant tions of from 800 to $1000 \mathrm{ft}$. above sealevel, there seems every probability that the treatment suggested would prove successful.

M. conspicua.-In its typical form this has snowy-white flowers, which are borne 
in the greatest profusion in the latter part of April and beginning of May. Splendid specimens of this beautiful Chinese and Japanese tree are to be seen at Gunnersbury House, Syon House, Kew, etc. M. Yulan and M. precia are names under which this is found in some books and gardens. Several hybrid forms between this species and M. obovata occur in gardens; of two of these, M. Lenné and M. Soulangeana nigra, coloured plates have been published in The Garden. M. Soulangeana has flowers similar in shape and size to those of typical M. conspicua, but they are deeply tinged with red; M. Soulangeana nigra has dark plum-coloured flowers. Both these bloom a week or ten days later than the type. Other seedling forms or slight varieties of the Yulan are M. Alexandrina, M. cyathiformis, M. speciosa, M. spectabilis, M. superba, M. triumphans, and M. Yulan grandis.

M. Fraseri, a native of the southern United States, is easily recognised by its light green spathulate leaves, auricled at the base ; they each measure about $8 \mathrm{in}$. to I ft. in length, and about 3 or 4 in. across at the widest part. The flowers, each of which measures 3 or 4 in. in diameter, are creamy-white in colour, and are produced later than those of any other cultivated species. In a wild state the tree attains a height of from 30 to $50 \mathrm{ft}$.

M. glauca, the Laurel Magnolia or Sweet Bay of the eastern United States, is a delightful sub-evergreen shrub, with leathery leaves, bluish-green above and silvery below. The flowers are globular in shape, very fragrant, opening of a rich cream colour and gradually acquiring a pale apricot tint with age. In a wild state this species occurs in swamps and attains a height of $20 \mathrm{ft}$. It is hardy and easily grown in Britain in peat soil.

M. grandiflora, the great Laurel Magnolia of the southern United States, isin England---best treated as a wall-plant; under these conditions it thrives well and flowers freely. In order to form some idea of the beauty of this species it is necessary to see it in large symmetrical stately trees in the west of France, etc., where climatic conditions obtain which more nearly approach those of its native habitats. A correspondent in the West of England writes to The Garden as to the culture of this plant: "At one time it was thought necessary to protect the trees with mats during the winter, but this practice, which necessitated restricting the growth considerably, has largely ceased, and the trees in some instances have attained a very great height. For instance, there is one under my charge that is now fully $50 \mathrm{ft}$. high. The bole of the stem is slightly over a yard in circumference. In some seasons several scores of blooms are borne by this tree, but during the winters of I89I and 1892 many of the more exposed points were badly injured by frosts, and the bloom lessened in quality accordingly. A very exposed position is not suitable for this heavy-foliaged tree, and shelter from cold winds is desirable. Where magnolias succeed best is in the nooks between bay windows or irregular fronts of dwelling-houses, buttresses on extra high walls also affording a good shelter. The best instance of what can be done in the way of clothing extra high yet sheltered walls with evergreen magnolias is to be seen at Canford Manor, Wimborne, Dorset, while there are also several fine specimens against high walls at Ashton Court, near Bristol. It is quite useless to plant them in a tiny hole, but the site should be well prepared by trenching or forking peat and leaf soil freely into common garden soil, or, better still, fresh loam, a space not less than $3 \mathrm{ft}$. by $30 \mathrm{in}$. being prepared for each tree. Once the trees have attained a good size, no further trouble need be taken with the roots, as they are quite capable of foraging for themselves. In planting, it is advisable to moisten and then slightly loosen the ball of soil, some of the roots being spread out. During the first summer the soil about the roots should be examined occasionally and watered thoroughly when dry. The tops branch naturally, and all that need be done is to spread them out thinly, and to keep the growths secured to the walls or trellis. In after years the strongest branches will require to be kept to the walls by means of strips of leather and strong nails, the side shoots being tied to these with tar twine. They ought not to be very closely trained, or so much so as to present' a painfully neat appearance, but if the branches or shoots are left too long the strong winds may break them off."

IM. hypoleuca. - This is the wood commonly used by the Japanese in the manufacture of objects to be lacquered; it is preferred for sword sheaths, and the charcoal made from it is used for polishing lac. In the southern part of Yesso it is abundant in the forests, and forms fine trees $60 \mathrm{ft}$. or more in height, with a trunk diameter of $2 \mathrm{ft}$. The leaves are $\mathrm{I} f \mathrm{ft}$. or more long, and 6 or 7 in. wide, dark green and smooth above, and clothed with white hairs beneath. The flowers are 
creamy - white in colour, deliciously fragrant, and when fully expanded measure 6 or 7 in. across, the brilliant scarlet filaments forming a striking contrast to the petals. There are no large specimens as yet in this country, but as the species thrives well in the north-eastern United States, it is fair to assume that it will do well in Britain.

M. Kobus, a Japanese species, grown in the United States under the name of forms a tree from 20 to $40 \mathrm{ft}$. in height, with a trunk rarely exceeding $\mathrm{I} \mathrm{ft}$. in diameter.

M. obovata is a native of China; in Japan it only occurs in cultivation. It is a dwarf-growing bush, perfectly hardy in the South of England, and bears freely its purple sweet-scented flowers, though not in the same profusion as are those of the white-flowered M. conspicua. This species has a number of synonyms,

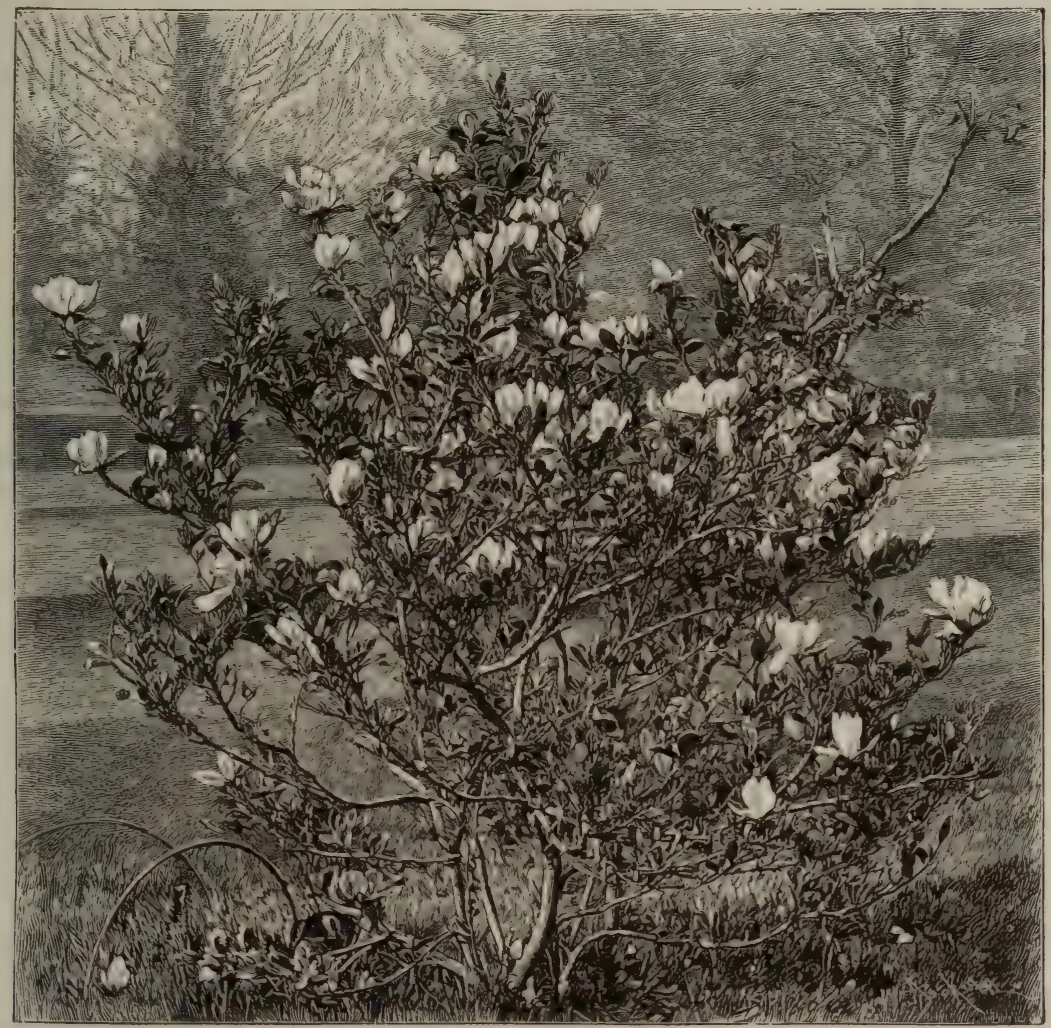

MAGNOLIA PURPUREA.

M. Thurberi, is as yet very uncommon in this country, and we have not yet seen it in flower. In habit it seems to approach dwarf-growing forms of $\mathrm{M}$. conspicua.

M. macrophylla.-This, unfortunately somewhat tender in a young state, is worth growing simply for its beautiful leaves, which are green above and clothed with white hairs beneath, and attain a length of upwards of $3 \mathrm{ft}$. The open bell-shaped fragrant flowers are white with a purple blotch at the base of the inner petals, and measure 8 or Io in. across. In its native habitats-the southern United States-it amongst which the following are the most frequently met with in books and nursery catalogues: M. discolor, M. denudata, M. liliflora, M. purpurea, Talauma Sieboldi, etc. There are several varieties, but these differ so slightly from each other and from the type, that descriptions without good coloured figures would be next to useless. The best are Borreri, angustifolia, and erubescens.

M. stellata.-An excellent coloured plate of this very beautiful Japanese shrub was published in The Garden in June 1878 , under the name of M. Halle- 
ana. This species is the earliest of the Magnolias to flower, and it should be extensively grown for the beauty of its starry white flowers. A variety with blush-coloured flowers, sent from Japan by Mr. Maries, has not yet been sent out by Messrs. Veitch, but it grows freely in their Coombe Wood Nurseries, and will doubtless become a favourite. Both are dwarf-growing deciduous shrubs.

II. tripetala, a native of the southern United States, has large slightly-scented white flowers, from 5 to 8 in. across, and obovate-lanceolate leaves, from I to $3 \mathrm{ft}$. in length. In a wild state the tree rarely exceeds $40 \mathrm{ft}$. in height. Philip Miller was the first to introduce this fine species to British gardens. Other names for it are M. Umbrella and M. frondosa.

M. Watsoni.-A coloured plate of this very beautiful Japanese species was published in The Garden in December I883, under the name of M. parviflora; at that time it had not flowered in British gardens. It is quite hardy. It has large creamy-white fragrant flowers with petals of great substance and deep red filaments, which add materially to the beauty of the blossoms. The true M. parviflora is probably not in cultivation in Britain.-N.

Maianthemum bifolium (Twin-leaved Lily of the Valley). - A plant allied to the Lily of the Valley, and a native of our own country. Its habit and relationship make it interesting, and it is easily grown in shady or half-shady spots, and under or near Hollies or other bushes. It is not fitted for the border, and is scarcely suitable for the rock-garden. Syn., Convallaria bifolia.

\section{Maiden-hair (Adiantum).}

Maize (Zea).

\section{Mahonia (Berberis).}

Malaxis. - Terrestrial Orchids, of botanical interest mainly, and thriving in the bog-garden.

Malcolmia (Virginian Stock). - The old M. maritima is a charming dwarf hardy annual, and grows in any soil and situation. The varieties are-the white (alba), alba nana, a dwarfer white than the other, and Crimson King (kermesina), a dwarf deep red sort. These varieties are all worthy of culture, and some are preferred to the type. The Virginian Stock, like many other annuals, does not show its full beauty from spring-sown seedlings, though these are pretty. Where it sows itself in the gravel it is often handsome. Being easily raised and somewhat fleeting in bloom, it is a good surfacing plant in the spring or early summer garden, allowing bolder flowers to stand up from its pretty sheets of bloom. In flakes or masses, beds or lines, it is pretty and effective.
Male Fern (Aspidium Filix-mas).
Mallow (Malva).
Mallow, Jew's (Kerria).
, Rose (Hibiscus).
, Syrian (Hibiscus).
" Tree (Lavatera).
" White Jew's (Rhodotypos).

Malope grandiflora. - This is one of the most showy of hardy annuals, and well deserves a place wherever a bold, showy crimson flower is desired. It is I 8 to 24 in. high, and the better its treatment in regard to soil the finer will be its bloom. If the Malope be sown in the open, the ground should be prepared by digging and manuring, the seeds being sown to the depth of a $\frac{1}{2}$ in. in light rich soil, and gently pressed down. Annuals often root superficially, and in hot dry weather soon go out of bloom. There is a white variety named M. g. alba, which is the counterpart of M. grandiflora, except for the colour. The variety called M. g. rosea, which is white flushed with rose, is very pretty and quite distinct. M. trifida is smaller in every part, but showy. These bold annuals are rarely used with good effect; though for variety's sake they may be occasionally worth a place in the garden. Like all annuals, they lend themselves to what we call rotation in the flower garden. If from any cause the garden gets monotonous or uninteresting, it is worth while to try the effect of a batch of the best annuals, the more so as they are generally left out of our plans. The Malopes, being vigorous plants, are, as a rule, best in masses or groups. S. Europe. Malvaceæ.

Malva (Mallow).-Of this genus there are a few ornamental garden plants; the majority are coarse and weedy. One of the most beautiful is the pure white variety of the native Musk Mallow (M. moschata), which is highly attractive when in flower. It is a branching pyramidal bush, composed of numerous stems about $2 \mathrm{ft}$. high, and bears many flowers I to $I \frac{1}{2}$ in. in diameter. It is a hardy perennial, and will grow in almost any soil or situation, and is useful for cutting for the house. The whole plant is slightly Musk-scented. M. campanulata is a beautiful dwarf plant, but rare and diffcult to grow, as it is not quite hardy except in very mild districts. It is dwarf and spreading, and bears numerous lilac bell-shaped flowers. M. Alcea, Moreni, and mauritanica are worth growing in a 
full collection, and so is the annual $\mathrm{M}$. crispa, 3 to $6 \mathrm{ft}$. high-an erect pyramidal bush of broad leaves, with a curled or frizzled margin, which is pretty in groups, beds, or borders. By sowing in cool frames and putting it out early in May, strong plants may be obtained early in the season.

Malvastrum. - These are similar to Mallows, but none are thoroughly hardy, being natives of the warmer parts of America. M. Munroanum is a dwarf plant with rather small orange-red flowers, and M. lateritium, a dwarf native of Buenos Ayres, has brick-red flowers. Sometimes in mild localities these plants thrive in the rock-garden or well-clrained borders, in light warm soil.

Mandragora (Mandrake). - Curious plants of the Solanum family, mainly suitable for botanical collections. They are easily grown in warm free soil, and enjoy borders at the foot of south walls.

Man Orchis (Aceras anthropophora).

Marguerite.-The old French name for the Daisy, and now commonly applied to Chrysanthemum frutescens.

\section{Marguerite, Blue (Agathcea) \\ Marigold, African (Tagetes).}

\section{" Cape (Demorphotheca).}

" Corn (Chrysanthemum segetumin). Fig (Mesembryanthemum).

" French (Tagetes).

" Marsh (Caltha).

" Pot (Calendula).

Marshallia cæspitosa.-An interesting Texan composite, 6 to 9 in. high, each stem having a Scabious-like white flowerhead, about $I \frac{1}{2}$ in. across. It is a perennial, and flowers in the second season from seed, blooming in June and July. It makes a very neat border plant in light garden soil. Although not particularly showy, its flower-heads are so distinct that it is well worth a place in the herbaceous border.

\section{Marsh Fern (Aspidium Thelypteris).}

" Mallow (Althrea officinalis).

Martynia lutea.-A very pretty Brazilian annual, about $\mathrm{I} \frac{1}{2} \mathrm{ft}$. high, with roundish leaves and handsome yellow flowers in clusters. Its large leaves and ornamental bloom make it desirable for beds, groups, and borders. Increased by seed. It requires a light, rich, cool soil, a warm position, and frequent watering in summer. M. fragrans, another species, has sweetscented flowers, and, under similar conditions, thrives in the open air in summer. It is best in rich borders, or among groups or beds of curious or distinct plants. M. proboscidea and others are suitable for the same purposes, but are less desirable.

\section{Marvel of Peru (Mirabilis Jalapa).}

Mask Flower (Alonsoa).

Matricaria (Mayweed).-Weeds, excepting the double variety of M. inodora, which is a pretty plant with feathery foliage somewhat like Fennel, and having large white flowers, perfectly double. It is creeping, and requires considerable space. If pegged down it forms a dense mass which has a pretty effect when in flower in autumn. It is hardy, and perennial on most soils, and is easily propagated by cuttings or division in autumn or spring. = Chrysanthemum inodorum fl.-pl.

Matthiola (Stock).-From a few species have been obtained the numerous varieties of the garden Stocks, which have so long been popular as hardy flowers. The principal of these species are M. incana, M. annua, and M. sinuata. M. incana grows wild on cliffs in the Isle of Wight, and is the origin of the Biennial, or Brompton and Queen Stocks; M. annua has yielded the Ten-week Stocks, and M. sinuata the others. These three primary divisions - the Ten-week, Intermediate, and Biennials-require different treatment. Stocks are easily grown, are fragrant and handsome, and have so many good qualities that they will ever deserve a place in our gardens.

TEN-WEEK STOCKS, if sown in spring, will flower continuously during the summer and autumn. The finest strain is the large-flowering Pyramidal Ten-week, comprising large vigorous plants, each branching freely, and producing a huge main spike of double flowers and numerous branching spikes in succession. A bed of these Stocks should be grown if cut flowers are in request during the summer. The seed may be sown at any time from the middle of March onward, but it is always well to get Stocks from seed early. The seed can be sown thinly in pans or shallow boxes, in a gentle heat, and, as soon as the plants can be handled without injury, they should be transplanted to other pans or boxes and grown on quickly, care being taken not to draw them so as to make them weak and lanky. There are various places in most gardens where a bed or patch of Stocks might be grown with advantage. Given good rich soil, they will amply reward the cultivator. The German growers have a formidable list of kinds, many of which are more curious than showy. There are, however, sufficient leading colours among them, such as crimson, rose, purple, violet, and white, to 
yield distinct and pleasing hues. There is a strain of English-selected Stocks, known as Pyramidal, which are of tall growth, and remarkable for their large pyramids of fine flowers, but they are not so generally cultivated as they deserve to be. There is a very distinct type known as Wallflower-leaved, which was introduced many years ago from the Grecian Archipelago, and which has shining deepgreen leaves, not unlike a Wallflower. In all other respects the type is like the ordinary German Stock. One of the finest varieties of this type, and one of the most beautiful Stocks in cultivation, is known as Mauve Beauty. It is remarkable for huge compact heads of pale, lustrous, mauve-coloured flowers. The treatment recommended for the Ten-week Stock will answer for this type. The autumn-flowering strain is very desirable, as the plants succeed the German varieties, and so prolong the season.

INTERMEDIATE STOCKS may be sown either in July or August, to stand the winter and flower early in the spring, or in March, to flower in the following autumn. This strain is dwarf and bushy, and is very free-blooming. The varieties may be said to be confined to scarlet, purple, and white. There is a fine strain grown in Scotland under the name of the East Lothian Intermediate Stock, and much used there for beds and borders, the climate exactly suiting it. This effective strain is mainly used for late summer blooming. It is sown in the usual way about the end of March, planted out at the end of May when 3 or 4 in. high, and blooms finely through August and September, and even later, as the numerous side shoots produce spikes of flowers. Thus, by using the autumn-sown Intermediate Stocks for early blooming, the ordinary large-flowering German Tenweek Stock for summer flowering, and the later East Lothian Intermediate Stock for late summer, Stocks can be had in flower for eight or nine months of the year without intermission.

Biennial StOcks comprise the Brompton and the Queen. They should be sown in June and July to flower in the following spring or summer. They are closely allied, and are probably only varieties of the same kind; but it is curious to note that the seed of the white Brompton is pale in colour whilst that of the Queen is quite dark. Old growers of the Stock assert that while the under side of the leaf of the Queen Stock is rough and woolly, the leaf of the Brompton Stock is smooth on both sides. Of the
Queen Stock there are three colourspurple, scarlet, and white; and of the Brompton Stock the same, with the addition of a selected crimson variety of great beauty, but somewhat difficult to perpetuate. Both types are really biennials. The seed should be sown at the end of July in beds, and the plants transplanted to the open ground in the autumn. The difficulty of wintering the Brompton Stocks deters many from attempting their cultivation. Many die, even in a mild winter. A well-drained subsoil with a porous surface soil suits them best. Shelter from hard frosts and nipping winds is of great service. A second transplantation of the seedlings about December has been tried with considerable success.

Maurandia Barclayana is an elegant Mexican twining plant. It is grown in a greenhouse, but is hardy enough for the open air in summer. It is admirably suited for covering trellises, fences, pillars, and the like. The deep violet flowers are very showy. There are also white (alba), deep purple (atropurpurea), and rosypurple (rosea) varieties. Easily raised from seed sown in early spring in heat; they will flower in the following summer if planted out in May in good soil and sheltered situations. Scrophulariaceæ.

\section{May Apple (Podophyllum peltatum). \\ Mayflower (Epigaa).}

Mazus Pumilio.-A distinct little New Zealand plant, vigorous in habit, and creeping underground so as rapidly to form wide and dense tufts, yet rarely more than $\frac{1}{2}$ in. high; the pale violet flowers are borne on very short stems, and the leaves lie flat on the soil. M. Pumilio thrives in pots, cold frames, or the open air, and does best in firm, open, bare spots in the rock-garden, in warm positions in free sandy soil. Though not showy, it is an interesting plant, easily increased by division. Flowers in early summer. Figwort family.

Meadow Beauty (Rhexia virginica). Rue (Thalictrum).

" Saffron (Colchicum autum-

" Saxifrage (Saxifraga granulata).

\section{Sweet (Spircea).}

Meconopsis (Indian Poppy).-Handsome Poppyworts, the most familiar of which is the common Welsh Poppy (M. cambrica), the others, about four in number, being all natives of the Himalayas. All are hardy, but only of biennial duration, and require some attention. They may be easily raised from seed sown 
in spring; and, indeed, a good stock of strong plants can be ensured only by annual sowings. The following is the most successful mode of cultivating them: A piece of ground is prepared by digging in good loam and well-rotted stable manure ; a two-light frame is placed over it, and seedlings are put in about March. As soon as the plants are fairly established the sashes are removed (unless the weather is frosty), and throughout the summer the plants are well supplied with water. In the following April and May they will have become large plants, often 2 to $3 \mathrm{ft}$. in diameter, and are then removed to where they are wanted to flower. This may be readily done without needlessly checking them, as they form so many fibrous roots that a good ball of soil usually adheres to them. They are thus grown on as quickly as possible, being treated like biennials. They should be planted out in a welldrained rock-garden in good soil, with plenty of water in summer, but they must be kept as dry as possible in the winter, as excessive moisture in cold weather soon kills them. Sandstone broken fine should be placed under the leaves, to prevent contact with the damp soil. A piece of glass placed over the leaves in a slanting position helps to protect them from moisture. Many plants take three or four years to flower, and some may be kept in store pots for five or six years without showing any tendency to flower, but they are never so fine planted out after being cramped in this way. After flowering they all die.

M. aculeata is a singularly beautiful plant, with purple petals, like shot silk, which contrast charmingly with the numerous yellow stamens. The flowers are 2 in. across, on stems about $2 \mathrm{ft}$. high.

M. cambrica.-For the wild garden or wilderness the Welsh Poppy is one of the most suitable and charming of plants. It is a cheerful plant in all seasons, and on an old dry wall its masses of cut foliage are very refreshing; but loaded with large orange-yellow blossoms it is strikingly handsome. It is a determined coloniser, holding its own under the most adverse circumstances. Its home is the wall, the rock, and the ruin. In many places it grows freely at the bottom of walls, or even in gravel walks if allowed a chance. A plant so easily naturalised needs no special care or place in the garden.

M. nepalensis has flower-stems 3 to 5 ft. high, which are not much branched. The nodding blossoms, produced freely, are 2 to $3 \frac{1}{2}$ in. across, and are of a pale golden-yellow.

M. simplicifolia produces a tuft of lance-shaped root leaves, 3 to 5 in. long, very slightly toothed, and covered with a short, dense, brownish pubescence. The unbranched flower-stalk is about I ft. high, and bears at its apex a single violetpurple blossom, 2 to 3 in. in diameter.

M. Wallichi is the finest of all Poppies, and is really a handsome plant, between 4 and $5 \mathrm{ft}$. high. It forms an erect pyramid, the upper half of which is covered with pretty pale blue blossoms, drooping gracefully from slender branchlets. It is a most conspicuous plant in the rockgarden, where it withstands the winter without the least injury. Well-grown specimens have leaves 12 to 15 in. long, and a great number of pale blue flowers, opening terminally. Separate flowers do not last long, but a few expand at a time, and it is fully a month before they are all expanded at the base, by which time the seeds of those which opened first are nearly ripe.

Medicago (Medick).-A large genus, containing few, if any, good garden plants. One or two are useful on banks or slopes, where their spreading masses are seen to advantage, or on very rough rock or rootwork, so placed that the long shoots may fall over the brows of rocks. For these purposes the most suitable are M. falcata and elegans, vigorous herbs with yellow flowers, which thrive in almost any soil. They are not suited for choice collections, but would give good effects in special cases.

\section{Medlar (Mespilus).}

Megarrhiza californica (Californian Big Root).-A twining Bryony-like plant, having an enormous root. Mainly suitable for botanical gardens.

Megasea.-A section of the genus Saxifraga, mostly having large broad foliage. See Saxifraga.

Melanoselinum decipiens.-An umbelliferous shrub from Madeira, with large spreading compound leaves, and a round simple stem which is bare below. The white flowers are borne in umbels. Should be planted out in May. Useful for isolation on grass-plats, but requiring greenhouse or warm frame treatment in winter. Young plants are best for placing out. Seed.

Melanthium triquetrum.-A bulb little cultivated. It has long round leaves, like some of the Alliums, and its pretty little flowers, with delicate mauve petals and purple centre, appear on spikes 5 to 6 in. long. It is half-hardy-hardy, perhaps, in favoured districts. 
Melianthus major.-An effective halfhardy plant for the summer. Its finelycut, large, glaticous leaves contrast effectively with the general vegetation, and being of the easiest cultivation, it has become a favourite in sub-tropical gardening. Freely produced by seed. Plants raised from seed early in the season make good growth by planting-out time, and by midsummer attain a height of 3 to $4 \mathrm{ft}$. When it is desirable to have larger plants by planting-out time, it is best to sow the seeds in autumn and to keep them growing through the winter, for a stronger and earlier development will result. The Melianthus is all but hardy on a well-drained subsoil in sheltered nooks in the south and west districts, for though the stems may be cut down by frost, the roots survive and push up in spring. Like Cannas, Arundo Donax, and similar plants, however, this plant cannot be depended upon in wet hard winters, even when carefully mulched and otherwise protected, since they frequently suffer from accumulated damp. It is far safer to lift the roots and store them under the stage of a cool house or shed.

Melissa officinalis (Common Balm).A well-known old garden plant emitting a very grateful odour when bruised. It is 2 to $3 \mathrm{ft}$. high. The variegated form is sometimes used for edging, and the common one may be naturalised in any soil by those who admire fragrant plants. Division. Europe.

Melittis Melissophyllum. - (Bastard Balm).-A distinct plant of the Salvia order, with one to three flowers about $1 \frac{1}{2}$ in. long. The peculiarly handsome purple lip reminds one of some Orchids rather than of a Labiate plant. M. grandiflora is a slight variety, differing in colour from the normal form. The plant is entirely distinct fiom any other in cultivation, and merits a position by shady wood and pleasure-ground walks, as it naturally inhabits woods. Woody spots near a fernery or a rock-garden suit it to perfection, and it grows readily among shrubs, and in the mixed border. It is found in a few southern localities, and is widely distributed over Europe and Asia. Seed or division. Flowers in May about London. Labiatæ.

Menispermum canadense (Canadian Moonseed). - A perfectly hardy climber, of rapid growth. It is slender, twining, and clothed with large roundish leaves, and in summer bears long feathery clusters of yellowish flowers. It is capital for covering a wall quickly for summer effect, or for arbours, trellises, and pergolas. It is suitable for almost any position, thriving well in shade or sun.

Mentha (Mint).- There are few ornamental plants of this genus. One, the variegated form of M. rotundifolia, is common in most gardens, and useful for edgings or for clothing any bare dry spots, and thriving almost anywhere. Another is M. gibraltarica, a variety of the native M. Pulegium, largely used in summer for flat geometrical beds on account of its dwarf compact growth and deep green foliage, which retains its freshness throughout the season. It is one of the easiest plants to propagate, and may be increased with wonderful rapidity, as it bears rapid forcing for early spring cuttings. Inasmuch as its growth hugs the soil, and throws out roots at every joint, all that is necessary is to keep cutting off little plants and potting them, or planting them in shallow boxes, and in a very short time they will in their turn bear cutting up in like manner. Being a native of S. Europe, it is somewhat tender, and is generally killed in winter. M. Requieni is a minute creeping plant with a strong odour of Peppermint. It should be allowed to trail about among other similar plants in the rock-garden. I use it often for covering the ground beneath tea roses, and it spreads and grows everywhere. It is, I think, the smallest flowering plant grown in gardens.

Mentzelia.-Lovely Californian plants, mostly of biennial duration. No one has yet succeeded in growing them well. They require more attention than most half-hardy plants, but their beautiful bloom well repays the trouble. The most successful cultivator of them writes to The Garden: "I find it necessary to sow the seed as early in the season as possible, and to grow the seedlings on in a frame, giving liberal shifts, and using a compost of fibry loam and a small quantity of leaf-mould and sand. After the final shift they should be plunged in a sunny border until autumn, and then removed to a frame for wintering. In the spring they should again be plunged in the open air, and by occasionally assisting them with weak manure water, strong and healthy flowering specimens will be produced. When beginning to show flower they should be removed to a cool greenhouse or frame, as excessive humidity at this stage is injurious to them. They may indeed be grown entirely in the open air if the weather be favourable, but in our climate the former 
mode is by far the most satisfactory." The following is a selection of the most showy Mentzelias in cultivation. The flowers of the others are rather small, and, on the whole, they are scarcely worth cultivating.

M. Iævicaulis is a fine kind, with whitish stem, I to $3 \mathrm{ft}$. high, and leaves much resembling M. ornata. Both stems and leaves are covered with short and stout bristles. The rich deep yellow flowers open only in bright sunshine. M. nuda is 2 to $4 \mathrm{ft}$. high, with flowers much resembling the last. $M$. oligosperma is a perennial, I to $3 \mathrm{ft}$. high, with bright yellow flowers 3 in. across, opening in sunshine. M. ornata is a biennial, 2 to $4 \mathrm{ft}$. in height. The creamy-white fragrant flowers are $2 \frac{1}{2}$ to 4 in. across. It belongs to the vespertine section, that is to those in which the flowers fully expand only towards evening.

Menyanthes trifoliata (Buckbean, or Marsh Trefoit).-A beautiful and fragrant native of Britain, found in shallow streams or pools, in very wet marshy ground, and in bogs. Its strong, creeping, rooting stems often float in deeper water. The flowers are borne on stout stalks, which vary in length with the depth of the water, and are arranged in racemes, beautifully fringed and suffused with pink. $M$. trifoliata is easy to establish wherever the necessary conditions-shallow water or bog-are available, by introducing pieces of stems, and securing them till, by the emission of roots, they have secured themselves. In some moist soils it thrives in the ordinary mixed border.

Menziesia.-Dwarf shrubs, resembling Heaths, and, like them, admirably suited for large rock-gardens or wherever there is a moist peaty soil. They are all of neat growth, and bear pretty drooping flowers. M. corulea is 4 to 6 in. high, and has pinkish-lilac flowers. It is not so beautiful or so brilliant as M. empetriformis, but merits a place in full collections. Flowers rather late in summer and in autumn. Europe.

M. empetriformis.-A dwarf Heathlike bush, seldom more than 6 in. high, and producing clusters of rosy-purple bells. Though very rare in gardens, it is one of the brightest gems for the choice rock-garden, and thrives best in fullyexposed positions in a rather moist sandy peat soil. It flowers in summer, is sometimes known as Phyllodoce empetriformis, and, unlike the rather tall and spreading M. polifolia, may be associated with the dwarfest alpine plants. N. America.

M. polifolia (St. Dabeoc's Heath) is
12 to $20 \mathrm{in.} \mathrm{high.} \mathrm{Its} \mathrm{erect} \mathrm{flower-stems}$ bear graceful, one-sided, drooping racemes of beautiful crimson-purple blooms. The pure white variety, though much less common, is quite as beautiful as the type,

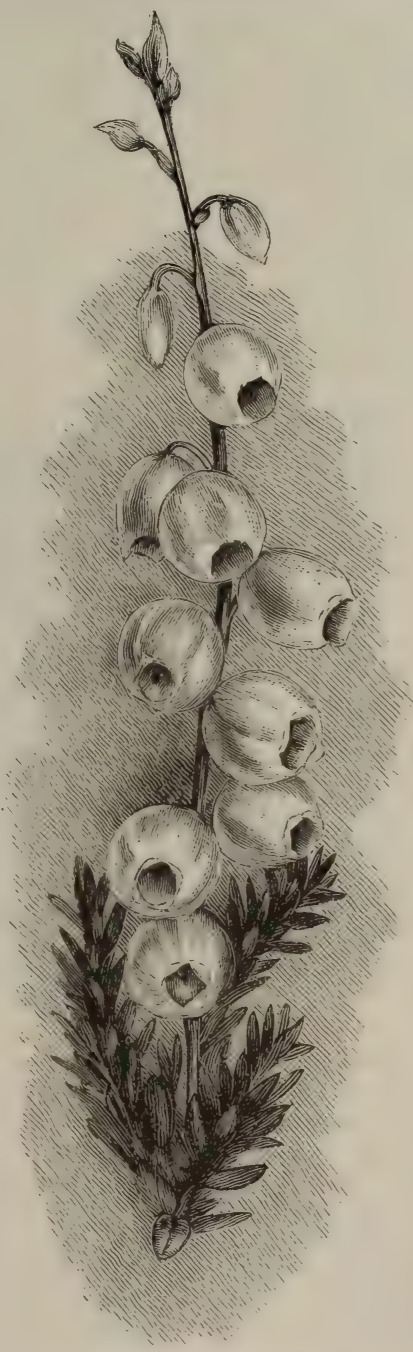

MIENZIESIA POLIFOLIA ALBA.

and there is a pretty variety, with purple and white flowers, called bicolor. M. polifolia flowers in summer, and forms charming bushes, thriving best, no doubt, in peat, but doing well in various other soils. They should be grown in bold groups. The white variety is sometimes sold as M. globosa and alba major. Abundant in some parts of Ireland, and hence called Irish Heath. 
Merendera Bulbocodium. - A bulb, very much like Bulbocodium vernum, but flowering in autumn. The large handsome flowers are of a pale pinkish-lilac. Suitable for the rock-garden and the bulbgarden till plentiful enough for borders. Increased by separation of the new bulbs and by seed. S. Europe.

Mertensia. - Beautiful Borageworts, formerly known as Pulmonarias. There is something about them more beautiful in form of foliage and stem, and in the graceful way in which they rise to beautiful panicles of blue, than in almost any other family. There are in cultivation above half-a-dozen species, all of which are desirable garden plants.

M. alpina is a beautiful alpine kind,
M. sibirica.-This species has the beauty of colour and the grace of habit of the old M. virginica, and grows and flowers for a long period in ordinary garden soil. The small bell-shaped flowers are borne in loose drooping clusters, gracefully terminating in arching stems. The colour varies from a delicate pale purple-blue to a rosy-pink in the young flowers. It is more vigorous than the Virginian Lungwort (M. virginica), an older and better-known kind. A perfectly hardy perennial, propagated by division.

M. virginica (Virginian Cowslip). The handsomest of all, bearing in early spring drooping clusters of purple-blue blossoms on stems I to $I \frac{1}{2} \mathrm{ft}$. high. The leaves are large and of bluish-grey. In

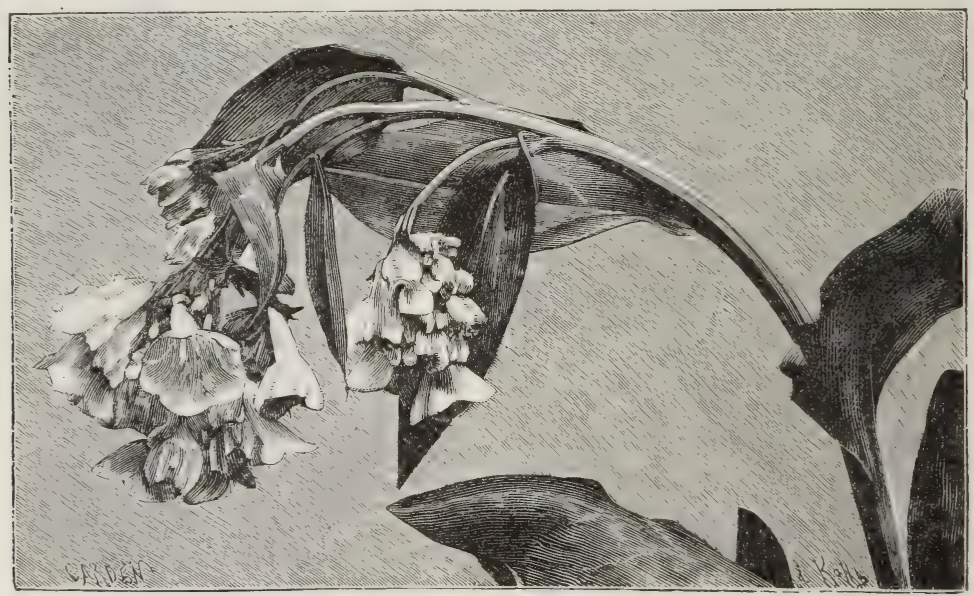

MERTENSIA VIRGINICA (VIRGINIAN COWSLIP).

and should only be associated with the choicest alpine plants. The leaves are bluish-green; the stem is only 6 to Io in. high, and has in spring or early summer one to three drooping terminal clusters of light blue flowers.

M. dahurica, although very slender and liable to be broken by high winds, is perfectly hardy. It is 6 to 12 in. high, has erect branching stems, and bears in June racemose panicles of handsome drooping bright azure-blue flowers. It is very pretty, and suited for the rock-garden or borders, and should be planted in a sheltered nook in a mixture of peat and loam. Easily propagated by division or seed. = Pulmonaria dahurica.

M. oblongifolia is another dwarf species. The stems are 6 to $9 \mathrm{in}$. high, and they bear handsome clustered heads of brilliant blue flowers, and deep green fleshy leaves. many gardens it never makes the slightest progress; but a sheltered, moist, peaty nook seems a most suitable, and, from what we know of its native habitat, a natural place for it. The finest specimens are grown in moist, sandy peat beds with shelter near ; but even then the bloom is early and short, and the plant is not nearly so important for gardens as M. sibirica.

Mesembryanthemum (Fig Marigold).- Of this large genus there are several showy species well suited for the open air, though none can be considered perfectly hardy. The Common Ice Plant (M. crystallinum) is grown for garnishing purposes in most large gardens; it is also sometimes used as a pot-plant; but it is most effective when planted out in the rockgarden or on an old wall. In a sunny situation, however, it will grow in any good soil, and it might be used as a band 
to a sunny border. It will grow from 3 to $4 \mathrm{ft}$. in a season, and on warm days has a cool and refreshing look. Its flowers, unimportant compared with the stems and foliage, are bespangled with crystal ; and the richer the ground the greater the crystal development. Seeds should be sown in heat in March, and the seedlings planted out 6 to 8 in. apart. There are two varieties - one red and the other white. M. cordifolium is a perennial, the variegated form of which is largely used in carpet-gardening. M. Pomeridianum is a strong species with broad foliage and large purple and rose flowers. It is not so common as the last, but it deserves a place on a south border. M. tricolor is the most showy of the annual Mesembryanthemums. It is a neat plant with cylindrical foliage, and is not a creeper. It grows in neat compact tufts 4 to 6 in. in height; its abundant flowers, of purple rose or white, afford good contrast. It should be sown in sandy soil in the open garden about the end of April ; it dislikes transplantation, and it lasts longer in the ground than in a pot. Those who possess a large collection of this genus should turn the whole out on banks or the rock-garden and leave them there, taking cuttings off them yearly. Out-of-doors they attain characters never seen in pots. Their foliage is singular and diversified, and the brilliant lustre of their gorgeous flowers -white, orange, rose, pink, crimson-is unequalled. They are children of the sun, and a rock-garden devoted to a collection in an open sunny spot is worth seeing, and can be compared only to a display of variously-coloured fire. A soil consisting of little besides sand and gravel suits them perfectly. As the plants have been so little grown in the open we scarcely know which are hardy and which are tender, but experiments would be interesting, for many would probably prove almost, if not quite, hardy in suitable situations.

Mespilus (Medlar). - The common Medlar, M. germanica, is a beautiful tree, and deserves to be planted on lawns. Every one knows how picturesque an old Medlar tree is, what a wide-spreading umbrageous head it has, and how beautiful it is in early summer when studded with great white flowers among large pale green leaves. The only other species in gardens is the fine M. grandiflora, also called M. Smithi. It is a perfect lawn tree, as its great rounded head weeps gracefully on all sides, and its branches sweep the turf. It flowers about the middle of May, and is then very beautiful, with its numerous white flowers. In some nurseries (especially on the Continent) it is called Cratægus lobata and other names under Cratægus. It is a medium-sized tree.

Meum athamanticum. - A graceful fine-leaved perennial, dwarf and neat in habit, 6 to 12 in. high, easy of growth in ordinary soils, and perfectly hardy. Probably in dry seasons it might wither too soon for association with autumnflowering plants, but it is invaluable for the rock-garden, borders, or for mixed arrangements of any sort. A British plant, easily increased by division.

\section{Mezereon (Daphne Mezereum). \\ Michaelmas Daisy (Aster).}

Michauxia campanuloides. - A remarkable plant of the Bell-flower family, 3 to $8 \mathrm{ft}$. high, the flowers white, tinged with purple, and arranged in a pyramidal candelabra-like head. Sometimes it flowers in the third or even in the fourth year, but is usually considered a biennial, and should be treated as a hardy one. Seedlings should be raised annually, so as to always have good flowering plants. It flourishes best in a deep moist sandy loam. It is only occasionally good, and therefore the enthusiastic cultivator will take all the more pride in trying to grow it well. Its fine stately form and tall stature are very effective when it is tastefully placed in the mixed border or in a nook in a choice bed of evergreen shrubs. Warm sheltered borders and borders on the south side of walls seem to suit it best. Levant.

Microlepia anthriscifolia. - An elegant Fern, 6 to 12 in. high, and perfectly hardy, even at York. It is deciduous, but charming in spring and summer, and is of easy culture. It thrives in the open as well as in the shade, and may be used with good effect as an edging to a sheltered border.

Microsperma bartonioides (Eucnide). Mignonette (Reseda odorata).

Mikania scandens (German Ivy).-A slender twining perennial, with Ivy-like foliage and small flesh-coloured flowers. It is hardy in light warm soils and situations, and is suitable for covering trellises and the like. N. America. Compositæ.

\section{Milfoil (Achillea).}

Milium (Millet Grass).-A small genus of Grasses. The native M. effusum is worth cultivating for its feathery plumes. It is suitable for associating with flowers in summer, and grows in any soil or position, but prefers moist places. There are one or two other kinds worth growing. 
Milk Thistle (Silybum).

Milk Vetch (Astragalus).

Milkweed (Asclepias).

Milkwort (Polygala).

Milla. - The bulbous plants formerly known under this name are now described under the name of Brodiæa. The only true Milla is said to be M. biflora, a natives of California. They are all partial to moisture, and suitable for damp places, such as artificial bogs, moist borders, and the margins of streams and artificial water. The old M. cardinalis is showy when well grown, and is deserving of a place in any garden. There are several varieties of it. The common

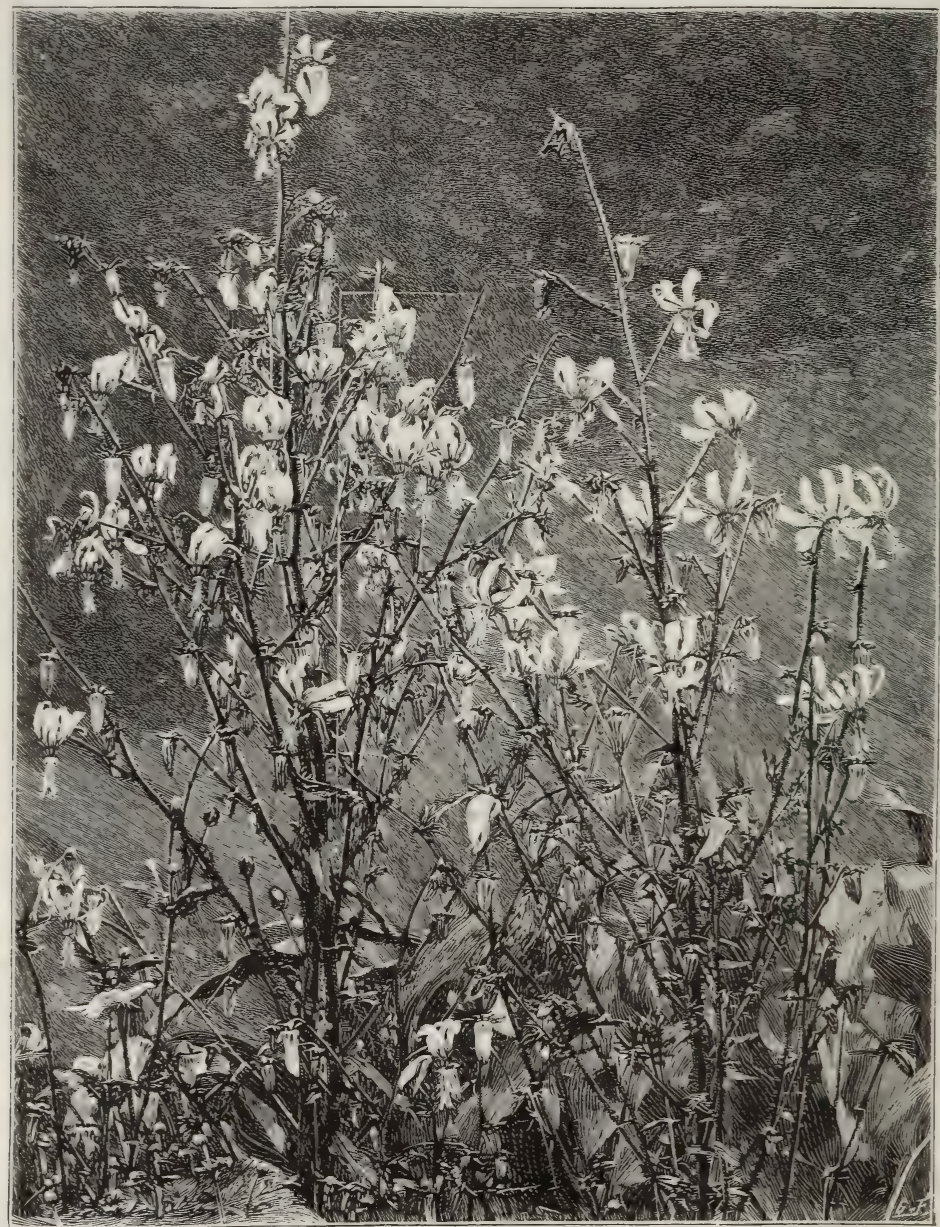

MICHAUXIA CAMPANULOIDES.

beautiful plant with large snow-white blossoms deliciously scented. It is rather difficult to cultivate, but it is well worth any care. Even if it be quite hardy, which is doubtful, it is too choice to risk in the open border.

Millet Grass (Milium).

Mimulus (Monkey-flower). - The cultivated species are valuable showy border flowers, and are for the most part
Musk (M. moschatus) is very hardy and enduring in moist soil. It is worth a corner in heavy or wet soil. M. luteus and its varieties, variegatus, cupreus, Tilingi, guttatus, and others are typical of the beautiful hybrids which are now in gardens, and which combine the dwart habit and hardiness of M. cupreus with the large flowers, richly spotted and blotched, of the other parent, the old 
M. variegatus. These hybrids, which are known as M. maculosus, bear exposure to the sun better than the parents. There is also a strain with Hose-in-hose flowers, sometimes called double. These sorts should be grown in every garden, and a packet of seed affords a wonderful variety. The seeds of the Mimulus should be merely sprinkled on the soil; if covered by it they may vegetate less quickly and abundantly. A little damp moss may, however, be laid over the surface, but should be removed as soon as the seeds have germinated. Other cultivated species are M. primuloides, repens, etc., but these are only fit for botanical collections.

Mirabilis (Marvel of Peru).-Handsome herbaceous plants, the most familiar of which is M. Jalapa, a dense, compact, round bush covered with flowers, and nearly $3 \mathrm{ft}$. high and the same across. The flowers are about I in. across, and their usual colours are white, rose, lilac, yellow, crimson (of various shades), and purple-striped, mottled, and selfs. The plants may be treated as half-hardy annuals, raised from seed in a warm frame, potted on, and planted out in May. They are, however, perennial, and when the leaves are killed by frost the tapering black root must be lifted and stored in sand during the winter. The plants should be started in pots in spring and planted out as before. After the second year the roots become unwieldy, and should be discarded. The plants require a light warm soil and all the sunshine they can get. The seeds ripen rapidly and readily; each flower produces one seed only, and as the seeds are large they can be gathered from the ground beneath the plants. M. multiflora is newly introduced from California. It is somewhat similar to M. Jalapa, but dwarfer, and the bright crimson-purple flowers are produced abundantly in large clusters, and they expand in bright sunshine. It is a hardy perennial in light warm soils, and is a most desirable border plant. M. longiflora, having long tubular flowers with carmine centres, is capital for the foot of a warm south wall. Mexico.

Mitchella repens (Silvery Partridge Berry, Deer Berry). - A neat trailing, small evergreen herb, 2 or 3 in. high. The white flowers are produced in summer, and are succeeded by small bright red berries. Thrives in shady spots near the rock-garden or the hardy fernery, in sandy peat and leaf-mould. Division. N. America.

Mitella
American plants of the Saxifrage family. M. diphylla is rather pretty, with small white blossoms on spikes 8 to 12 in. high. M. nuda and M. Breweri are suitable only for botanical gardens. They grow best in moist peaty soil in half-shady situations.

Mitraria coccinea (Mitre-flower).-A bright charming little shrub from Chili, hardy in very mild districts, but generally requiring winter protection. It is a small evergreen shrub, bearing in summer numerous urn-shaped flowers about $\mathrm{I} \frac{1}{2}$ in. long and of a brilliant scarlet. It likes a mixture of sandy peat and loam, in a moist sheltered spot, elevated so as to ensure perfect drainage.

\section{Mocassin-flower (Cypripedium). \\ Mock Orange (Philadelphus).}

Modiola.-The prettiest of this genus is M. geranioides, a hardy perennial, about 6 in. high, and forming a dense trailing tuft of elegantly-cut foliage, which in summer is studded with showy purplishcrimson flowers. It delights in a warm open place in the rock-garden, and in such a position, if well drained, it is perfectly hardy. The best kind was figured in The Garden some years ago. Malvaceæ. North America.

Mœhringia muscosa.-A somewhat inconspicuous alpine evergreen herb, 2 or 3 in. high. It is best in very fine sandy loam, on the rock-garden and in borders. Division and seed.

Molinia cœrulea.-A native Grass, of which there is a variegated form not unfrequently used as an edging for flowerbeds, but there are other Grasses better suited for this purpose.

Molopospermum cicutarium. - A hardy ornamental umbelliferous plant, 5 $\mathrm{ft}$. or more high, with large handsome leaves which form a dense irregular bush. It is easily increased by seed or division, but as yet is rare. It loves a deep moist soil, but thrives in any good garden soil. It is a fine plant for grouping with other hardy and graceful-leaved umbelliferous plants. Carniola.

Monarda (Horse Balm).-- Showy border flowers of the simplest culture, thriving and flowering in any position or soil ; and therefore, besides being admirably suited for garden borders, they are excellent subjects for naturalisation in woods, shrubberies, and various wild places. All may be readily divided, and every division will grow. The perfume of the leaves of many of them increases their value; and some are called Balms, Bergamots, etc. They have a great range of colour, and the 
varieties of M. fistulosa alone represent more than half-a-dozen different shades. There are about six species in cultivation, but some are rare. The red kind scattered through American woods in autumn is very handsome.

M. fistulosa (Wild Bergamot) is a very handsome robust perennial, 2 to $4 \mathrm{ft}$. high. The flowers are very variable; the typical colour appears to be pale red,

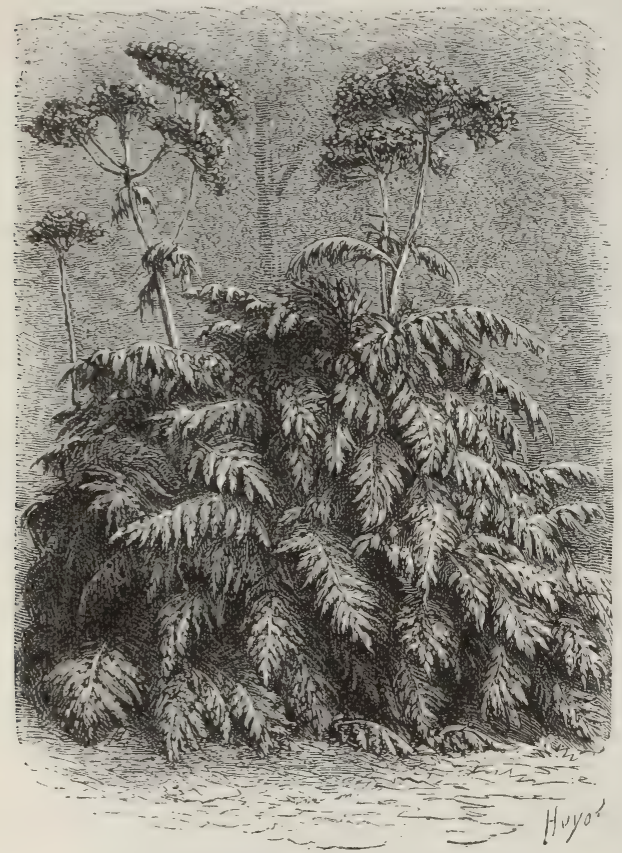

MOLOPOSPERMUM CICUTARIUM.

but is sometimes purple-rose colour, and, in fact, every gradation almost to white may be found in the cultivated kinds. M. fistulosa is in full beauty during the summer months.' M. didyma (Oswego Tea or Bee Balm) is another highly ornamental kind, equally robust. It grows about $3 \mathrm{ft}$. high, and the deep red flowers, borne in head-like whorls, continue in perfection for a considerable part of summer. M. Kalmiana is a showy plant, taller and more robust than the preceding, and is often $4 \mathrm{ft}$. high. The deep crimson flowers, somewhat downy, are produced in dense whorls. M. purpurea is somewhat similar in habit to the last, but the deep purplish-crimson flowers are smaller. All are natives of $\mathrm{N}$. America, and may be readily increased by division in spring, or by seed.

Monardella macrantha.-Acharming little perennial from California, 4 to 6 in. high, with slightly fragrant orange-scarlet blooms. It is not well known in this country, but is said to be worth cultivation. Labiatie.

\section{Monkey-flower (Mimulus).}

Monkshood (Aconitum Napellus).

Montbretia.-Iridaceous plants from the Cape of Good Hope. Two species are in cultivation. M. Pottsi, the bestknown, is 2 to $2 \frac{1}{2} \mathrm{ft}$. high, and bears abundance of bright green leaves, resembling those of a Gladiolus in their form and in their singular plaited appearance. The flowers, about $I$ in. long, are on branching stems, each branch bearing about three dozen closely-arranged flowers. They are of a bright orange-red, with darker spots inside the tube, and when in profusion render the plant highly attractive either out-of-doors or in the greenhouse. During November or December, after the foliage has died down and the bulbs are matured for the season, a few plants may be taken up, separated, and put in pots for conservatory decoration. Any bulbs out of the ground may then be planted and covered with 2 or 3 in. of equal parts of well-mixed leaf-mould and sandy loam, to which may be added a third part of decomposed cow manure. In severe weather, a light covering of straw will prevent the bulbs from being uplifted by the frost. As soon as the season seems promising, the straw should be removed and a top-dressing with a light covering of sand given. If the season is dry, an occasional watering with liquid manure would be advantageous, if care be taken not to discolour the foliage. A new kind, M. crocosmæflora, has deeper-coloured flowers, four or five times the size, and borne on the spike in the same manner. It is a hybrid between Tritonia aurea and M. Pottsi, and requires the same treatment as M. Pottsi.

\section{Moonseed (Menispermum).}

Moonwort (Botrychium).

Morina longifolia.-A handsome and singular hardy perennial, with large spiny leaves, resembling those of certain Thistles, and with long spikes of whorled flowers, 2 to $3 \mathrm{ft}$. high. It grows well in ordinary well-drained soil, but prefers soil which is mellow, deep, and moist ; and it is easily multiplied by sowing the seed as soon as ripe in light, peaty, sandy soil. Being a fine-flowering plant, as well as remarkable for its leaves, it is excellent for every kind of mixed border, and for grouping with 
the smaller and medium-sized perennials that have fine foliage or singular appearance. Nepaul. M. Wallichiana is probably the same, or a slight variety. Dipsacaceæ.

Morna nitida.-A half-hardy annual from Swan River, about I ft. high. In late summer it bears terminal clusters of bright yellow blossoms, nearly $\mathbf{I}$ in. across, and similar to those of the Helichrysum. It is an attractive plant well worthy of cultivation. Seeds should be sown in early spring in a heated frame, and to make strong plants the seedlings should be transferred from small to larger pots before planting out. Two or three seedlings may be placed in each pot. It thrives best in a sandy peaty soil. $=\mathrm{M}$. elegans. Compositæ.

Morning Glory (Ipomaca).

Morphixia.-Iridaceous plants of the Cape of Good Hope, nearly allied to Sparaxis. There is only one cultivated species, M. paniculata, a plant about $\mathrm{I} \mathrm{ft}$. high. It has long narrow leaves and slender flower-spikes of showy buff-white blossoms with remarkably long tubes. The variety alba has white flowers with black centres; and rosea is of a rosyapricot hue. It flowers in April and June, and requires the same treatment as Ixia and Sparaxis.

Moss Campion (Silene acaulis).

Moss Pink (Phlox subulata).

Moth Mullein (Verbascum Blattaria).

Mother of Thousands (Saxifraga Sarmentosa).

Mountain Avens (Dryas octopetala).

Mountain Cat's-foot (Antennaria dioica).

Muhlenbeckia.-These graceful freegrowing evergreen trailers are useful as coverings for trellis-work or as isolated specimens on stumps, etc. The kinds in cultivation are all natives of New Zealand. The best-known is M. complexa, a very rapid grower, with long wiry and entangled branches, and small oval leaves. The white waxy flowers are rather inconspicuous, being about $\frac{1}{2}$ in. across. M. adpressa is larger and has heart-shaped leaves, and long racemes of whitish flowers. M. varia is a small kind, with fiddle-shaped leaves, and is very distinct from either of the above. They are all indifferent to quality of soil, but grow best in rich compost. In severe winters it is advisable to give a little protection like dried Fern, but this is not necessary in ordinary seasons. M. complexa is not difficult to propagate. It strikes freely in a cold frame, if the cuttings are put in in September, and the only point to observe is that they should be selected not from the twiggy shoots, but from the thicker shoots that are generally sent up from the ground in the form of suckers, for such shoots strike freely and form snug little plants the first season; while the twiggy shoots, if they strike at all, will be at least two years before they form well-established plants. This plant grows freely in some mild districts, though it is not common out-of-doors near London.

Mulgedium Plumieri (Blue Thistle) is a native of the Pyrenees, where it is 4 or $5 \mathrm{ft}$. high, but in our borders, and under the influence of a deep strong clay,

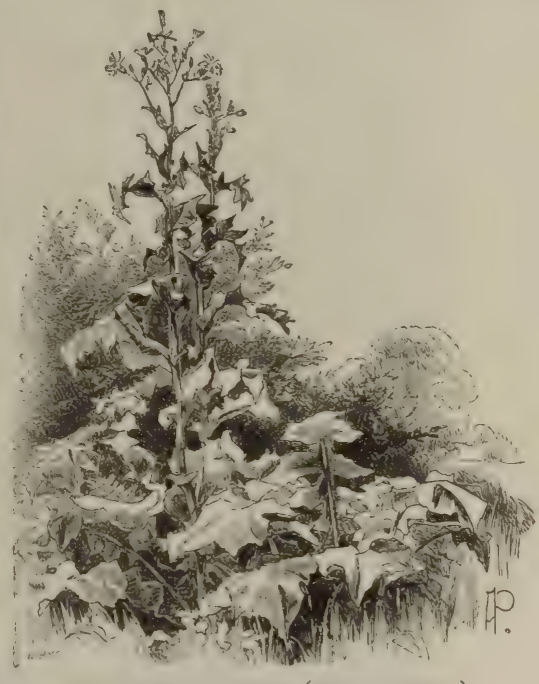

MULGEDIUM PLUMIERI (BLUE THISTLE).

it is frequently as much as 8 or $9 \mathrm{ft}$. high. Its foliage is beautifully varied in outline. It should be planted in the rougher parts of a wild garden, and left to itself, as nothing seems to interfere with its rapid growth. As an isolated plant on Grass it presents a bold and uncommon appearance, and among other plants its remarkable foliage at once arrests observation, while its blue flowers are pretty.' M. alpinum is a smaller plant. Seed or division.

Mullein (Verbascum Thapsus).

Muluccella lævis.-A singular plant of the Dead Nettle family. It is by no means showy, and its only recommendation for the garden is the singular form of its calyces, which are shallowly bellshaped and densely arranged on erect stems about $\mathrm{I} \mathrm{ft}$. in height. It is a fine subject for skeletonising, and the stems, bracts, and calyces may be skeletonised intact. For this purpose they should not 
be cut before autumn, when the plant is fully matured. Eastern Mediterranean. Should be treated as a half-hardy annual.

Musa.-These have recently come to be used extensively in our parks during summer, but, even where sub-tropical gardening is attempted, they are less frequent in private gardens. The cause is probably the general idea that great difficulties are experienced in preserving them through the winter. In the London parks Musas, especially the smaller ones, are often plunged in the ground in their pots during the summer, but the larger
M. Ensete is the kind generally used in the open air, and is one of the noblest plants in the sub-tropical garden. Any one with a warm frame or greenhouse may grow it, and when planted out in June, in deep, warm, rich soil, and a sheltered position, it will grow well during summer; such, at least, is our experience in London and the home counties.

Muscari (Grape Hyacinth). - Pretty bulbs of the Lily family, all of the easiest culture and flowering in spring and early summer. Their proper position is either the front row of the choice border or the

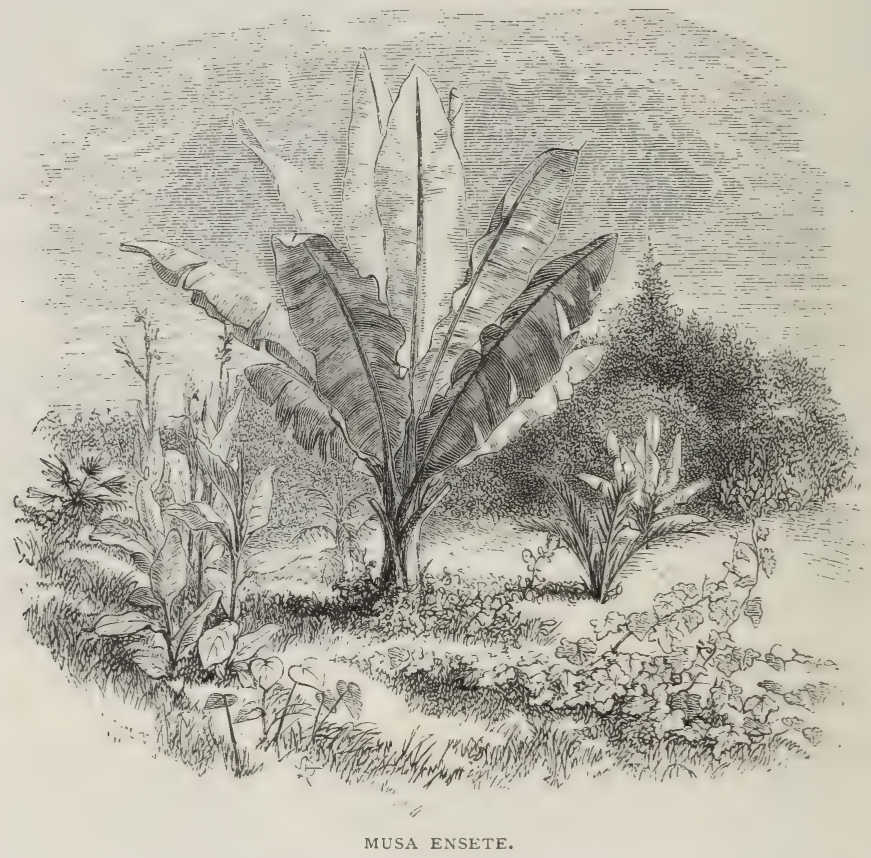

ones are usually planted out. When they are lifted in autumn, those in pots are stored away in houses, but the larger ones are lifted with small balls of earth and placed on shelves in houses with a temperature not less than $45^{\circ}$. Here they are laid on their sides, their leaves being kept close together, and they are allowed to remain throughout the winter, with only a mat thrown over the roots. In February the roots are examined, planted in trenches, and subjected to an increased temperature, when new roots soon form and begin to grow afresh. In June, after being gradually hardened by the air, the leaves are tied up, the plants are lifted with as good balls as possible, and placed in their summer quarters. rock-garden, but they may be advantageously grown as window-plants in pots or boxes. In all cases they thrive best in rich, deep, sandy loam, and are easily multiplied by separating the bulbs every third or fourth year. There are many names, but few really distinct kinds.

M. armeniacum is one of the most handsome, and its beauty is enhanced by its flowering when most other kinds have finished doing so. Its flower-stems are 8 in. high, and are terminated by dense racemes 3 to $4 \mathrm{in}$. long, of bright dark blue flowers, with small whitish teeth. The foliage is much the same as the ordinary M. racemosum. Another beautiful kind is M. Szovitzianum, which comes into bloom early and continues in blossom 
till the latest kinds have done flowering. The blooms are a beautifully clear blue, and the teeth of the corolla are white. The spike is oval and is larger than in other species.

M. botryoides is a deservedly favourite bulb, with little white teeth on blue globose clusters, which give it a distinctly dressy appearance. It is about 9 in. high, and is therefore suitable for the front line of the border. The varieties pallidum and album are distinct, and even more beautiful; and pallidum has pale sky-blue clusters. M. Heldreichi re-
M. racemosum is a familiar old kind, with dark purple clusters and a strong smell of Plums. Its long and weak leaves are almost prostrate, while in M. botryoides and its varieties they stand erect. It will hold its own anywhere, and will wander all over the mixed border, growing like a weed, and in any soil. It has near relatives in $\mathrm{M}$. commutatum (with blue flowers, darkening by degrees into purple) and M. neglectum - also a handsome kind. There are several other varieties mentioned in catalogues, but the best are those mentioned above. Though coming

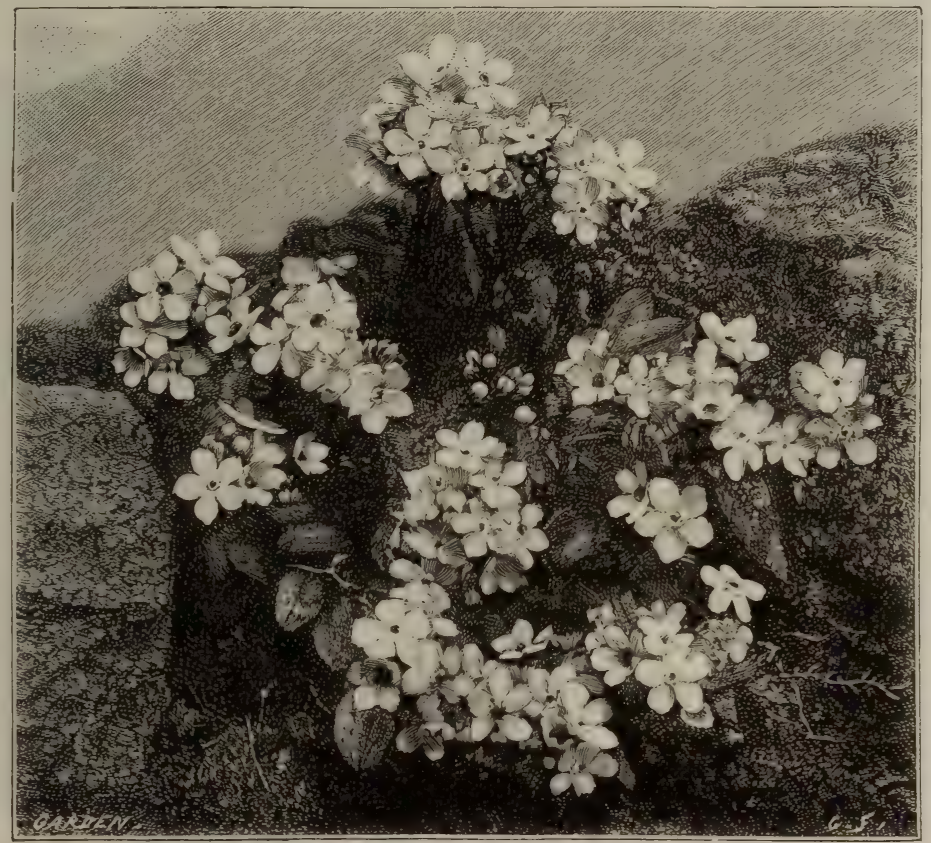

MYOSOTIS ALPESTRIS.

sembles M. botryoides, but is finer, being larger, and having a longer spike of flowers. It also flowers later.

M. comosum monstrosum (Feather Hyacinth) is distinct from any of the foregoing. It is I ft. or more in height ; and its beautiful mauve flowers, being cut into clusters of wavy filaments, bear a close resemblance to purple feathers. Though now seldom seen, it is in every way suited for a collection of hardy flowers. M. moschatum has clusters of dirty yellow flowers, very inconspicuous, but its delicious fragrance amply atones for this. Another sweet-smelling Muscari is M. luteum, with flowers fading by degrees from a dull purplish hue to a clear yellow. chiefly from the south of Europe, they are all perfectly hardy, and grow in any position in ordinary garden soil.

Musk (Mimulus moschatus).

Musk Hyacinth (Muscarimoschatum). Musk Mallow (Malva moschata).

Mutisia decurrens.--In good soil at the end of a glass-house or against an open wall this handsome Composite is an attractive object during the summer. It is at present little grown, although there is no reason why in conjunction with the smaller Nasturtiums or Convolvuluses, and similar plants, it should not be used for covering fences, walls, or bare stones on the rock-garden. Its bright cinnamonorange flowers are very showy, and last a considerable time. Chili. 
Myosotideum nobile.-A New Zealand plant about which very little is known. In its native habitat it is a seaside plant, and is fond of damp sand, heavily manured with seaweed. It is said not to be difficult to grow, but to be short-lived. In New Zealand it produces leaves 18 in. across, and heads 6 in. through of blue and white flowers. It is a gigantic Forget-me-not, introduced once or oftener, but lost.

Myosotis.-Lovely plants of the Borage order, the cultivated species being alpine or dwarf plants with blue flowers.

M. alpestris (Alpine Forget-me-not) is an exquisite plant, forming a low cushion of the loveliest blue. It is essentially a rock-garden plant, enjoying moist gritty soil, and not bearing drought. It is so dwarf that it should be surrounded only by half-buried pieces of sandstone or the like, to prevent evaporation and to preserve it from accident. It is easily raised from seed.

M. azorica (Azorean Forgetme-not) is a beautiful but somewhat tender kind, and is known at once by its deep blue blooms not having "eyes" of different colour. It is 6 to Io in. high, and the flowers, which appear in summer, are rich purple when they first open and afterwards change to indigo-blue. Being a native of the extreme western Azores, it is rather tender save in exceptionally sheltered localities. The beauty of its dark flowers, combined with the successional manner in which its flowering branches are produced, makes it most desirable for the border. It grows vigorously in good light soil, and may be raised from seed or cuttings. Impératrice Elizabeth is an allied plant.

M. dissitiflora (Early Forget-me-not) is a beautiful plant, very early-flowering, and 6 to $12 \mathrm{in}$. high. The numerous large handsome flowers are of a deep sky-blue, and continue to bloom till the middle of summer. They resemble those of $\mathrm{M}$. sylvatica more than any other, but are farther apart on the spike. It is a beautiful border flower, and worthy of being planted in broad masses in open spots of the rock-garden. It is also invaluable as a spring bedding-plant, or wherever spring flowers are much valued; and in such a case should be naturalised on all desirable spots. This is easy if the soil is toler- ably good and moist, for the plant will sow itself freely; but it is difficult in dry gravelly ground in exposed places.

M. palustris.-Although so common in wet ditches and by streams and canals throughout Britain, M. palustris deserves a place among shrubs in peat beds. Used for edgings, or as a carpet to taller subjects, in small beds or borders in moist soil. Division.

M. sylvatica (Wood Forget-me-not) is now popular in consequence of being used for flower-beds in spring. There is a white, a rose-coloured, and a striped variety. Besides being grown in beds in the flower-garden in spring, they

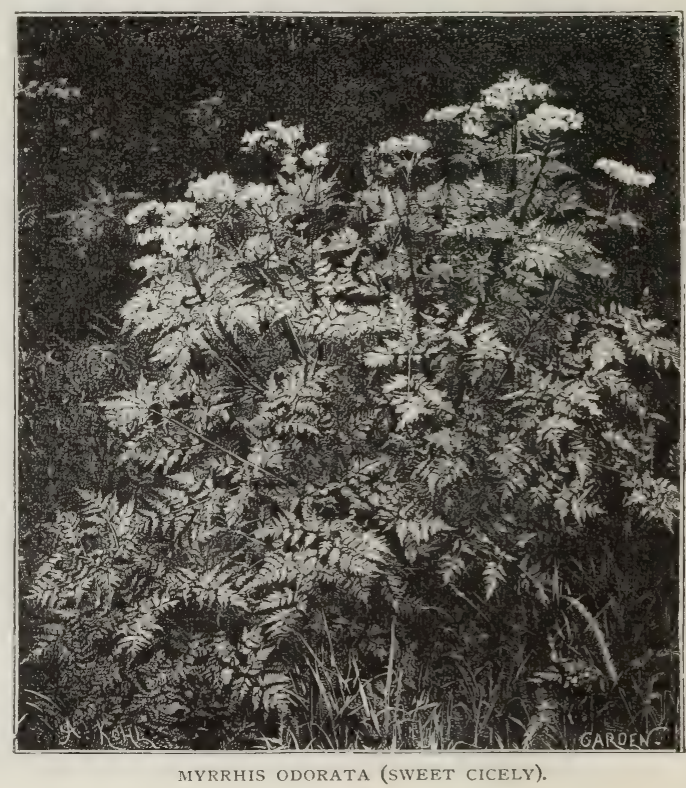

should be found abundantly in a wild state by wood walks, in copses, etc. It sows itself freely in woods, and for garden use is best sown in beds in August every year.

Myrica (Sweet Gale).-The Myricas, though not showy flowering shrubs, are desirable on account of their scented foliage. The native Sweet Gale or Dutch Myrtle (M. Gale) should be wherever sweet-smelling plants are cared for. It is a thin bush, 2 or $3 \mathrm{ft}$. high, having fragrant leaves with toothed margins. In a moist spot, such as a bog, it spreads by underground shoots and makes a large mass. The North American species, M. cerifera (Wax Myrtle or Bayberry), M. pennsylvanica, and M. californica, are less common. The last is a good evergreen 
of dense growth, with fragrant leaves, that keep green through the winter. It is a vigorous plant, especially in light soils, and is quite hardy, but is little known outside botanical collections. The Wax Myrtle is met with in old gardens, where it was planted for its spicy foliage. I find the Sweet Gale free and vigorous in stiff poor soils where few things grow well.

Myricaria germanica (German Tamarisk).-An elegant shrub, hardly differing from the common Tamarisk of our seacoasts. It has similar feathery foliage, and bears many long plume-like clusters of small pink flowers. It grows 6 or $8 \mathrm{ft}$. high in light, warm, sandy soils, and, like the true Tamarisk, is a capital shrub for dry banks where few shrubs would flourish.

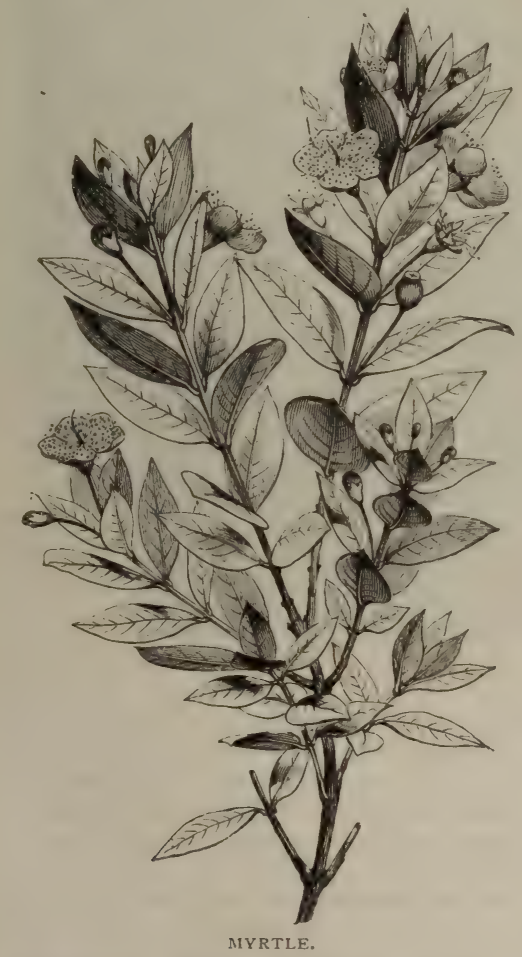

[ Myrrhis odorata (Sweet Cicely).-A graceful native plant, with a peculiar but grateful odour and sweet - tasting stems. It is 2 to $3 \mathrm{ft}$. high. The white flowers are produced in early summer, in terminal compound umbels. Suitable for naturalising near wood walks and in open shrubberies in any soil, and may occasionally be used among fine-leaved perennials. Division.

Myrtle, Wax (Myrica).
Myrtus (Myrtle). - In southern and coast counties the Myrtle is hardy enough to be planted as a bush, for if its shoots are killed by frosts it recovers the following season. But the common Myrtle is most generally grown as a wall-shrub, and house walls could not have a denser or more beautiful covering, especially if some pretty-flowered creeper like Clematis or Honeysuckle be allowed to ramble amongst the Myrtle. There are many varieties of the common Myrtle, every one with beautiful sweet-smelling foliage, and all with white flowers more or less abundant. The chief are the Dutch, Italian, Roman, Rosemary or Thymeleaved, Nutmeg, Box-leaved, and Andalusian. Besides these there are some with variegated leaves, the leaves being striped with gold or silver, or spotted and blotched. In planting a Myrtle against a wall, choice should, if possible, be given to a space protected from northerly and easterly winds, which in early spring are so injurious to the tender foliage. In old gardens the Myrtle is often grown in tubs or pots for placing on lawns or terraces in summer, and is put under protection during winter.

Narcissus (Daffodil).-These are the hardiest, showiest, and most variable of early spring flowers. They are to the spring what Roses, Irises, and Lilies are to summer, what Sunflowers and Chrysanthemums are to autumn, and what Hellebores and Aconite are to winter. No good garden should be without the best of the lovely varieties now known. Narcissi vary so much in form, size, colour, and in time of flowering, that a most attractive spring garden could be made with them alone; provided one had suitable soil, and a background of fresh turf, shrubs, and trees. The best of the commoner kinds should be planted by the thousand, and, indeed, in many cases this has been done with the best results. On grassy banks, on turfy bosses near the roots of lawn-trees, or in meadows near the house, their effect is delightful. All the best Narcissi, and practically all the forms of the yellow and the bicolor daffodils, may be planted in June, July, or August, in three ways. In the lawn or meadow, in the beds and borders of the garden, or in 6 or $8 \mathrm{in}$. pots. Five bulbs should be planted in a pot, and covered over with coal-ashes or sand until January, when they may be placed in a sunny frame, pit, or greenhouse, or even in a sunshiny window, and a crop of flowers can be secured earlier 
than on the open ground. The main points in beginning the culture of Narcissi are to get sound and healthy bulbs as early as possible after June, and to plant or pot them at once in good fibrous, sandy, or gravelly loam, or in any virgin soil. They like fresh deep-tilled loam, and the strongest of the bicolor and star Narcissi do not object to soils rich in manure; but it is as well to remember that no manure should be used in its raw or crude state, and that wild species and wild-collected varieties suffer and often fail if planted at once in heavilymanured soils.

In naturalising the Daffodil on the Grass, dig and replant Daffodils too soon than too late. The best time is when the leaves turn yellow in June or July. On well-drained loams resting on gravel, the bulbs lose both leaves and roots in June or July, and may be taken up. and removed with advantage; and, indeed, where good round presentable sale bulbs are grown, the rule is to dig them every summer as soon as the leaves wither. Whenever an amateur's stock of bulbs is divided, it is wise to replant some in fresh ground, and any surplus may be naturalised in grass. The rate of increase on good soils is surprising, such splendid sorts as N. John Horsfield, N.

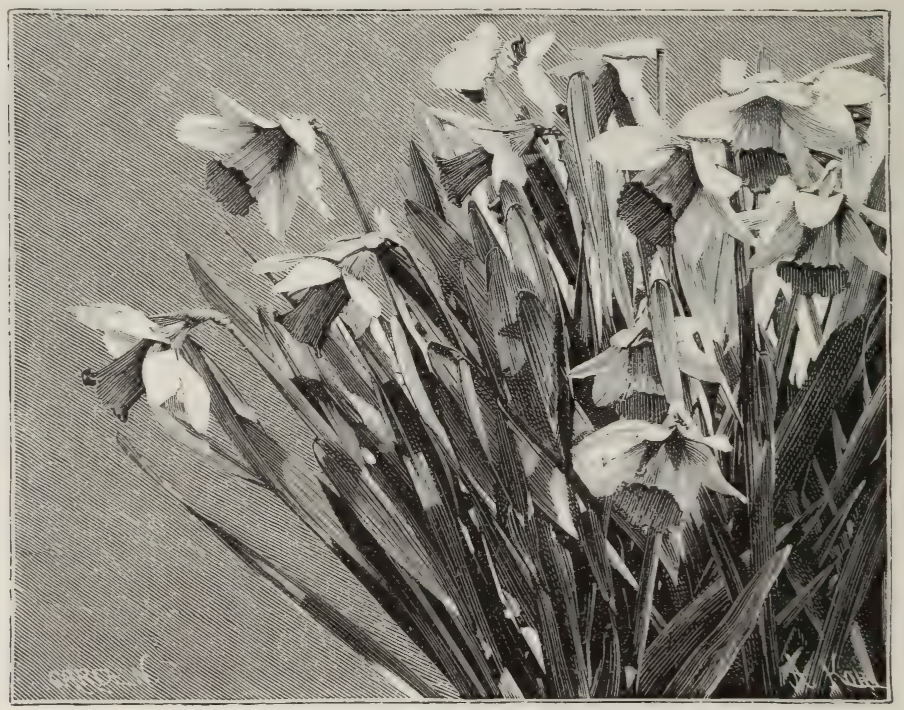

NARCISSUS HORSFIELDI.

the Poet's Narcissus, or the Star Narcissus (N. incomparabilis in all its forms), do not begin as late as November or December by planting the sweepings out of the bulb-stores, since such bulbs are weak and flabby, and are liable to rot in the frozen ground. The time to begin planting is June and July, and it is a good rule to refuse to plant in number after August or September.

In grouping border Narcissi it will usually be found advisable to lift and replant the clumps every three or four years, but if any delicate varieties do not flower well, or if they show signs of weakness or of disease, they should be lifted notlater than July, and, after being cleaned, at once replanted, in fresh and good soil, and, if possible, in sandy or gravelly loam free from fresh manures. It is better to
Empress, N. Grandee, N. Emperor, and N. Sir Watkin actually trebling themselves the second year after planting. The depth at which the bulbs should be planted varies according to the texture and the drainage of the soil. In strong or wet and retentive soils, shallow planting, say 3 to 5 in. beneath the surface, is ample, but on light, sandy, and welldrained soils, or on what are known as warm soils, the depth may vary from 6 to 12 in.-in a word, the bulbs should be as far as possible below the drought and frost line.

If cut flowers are desired, then bold groups on borders, in beds, or on Grass sheltered by hedges or shrubs are desirable. The first crop can be obtained from pots or boxes in the greenhouse, and these will be followed by fully- 
formed and bursting buds, in sheltered and sunny places. These buds will open large, fresh, and fair if placed in pots of water in a warm greenhouse or a sunny frame or window. In cutting Daffodils or Narcissi for indoor decoration, cut the flowers when the buds are opening, or even just before, and let the stalks be long, as the flowers group better with long stalks. Do not cut the leaves of choice

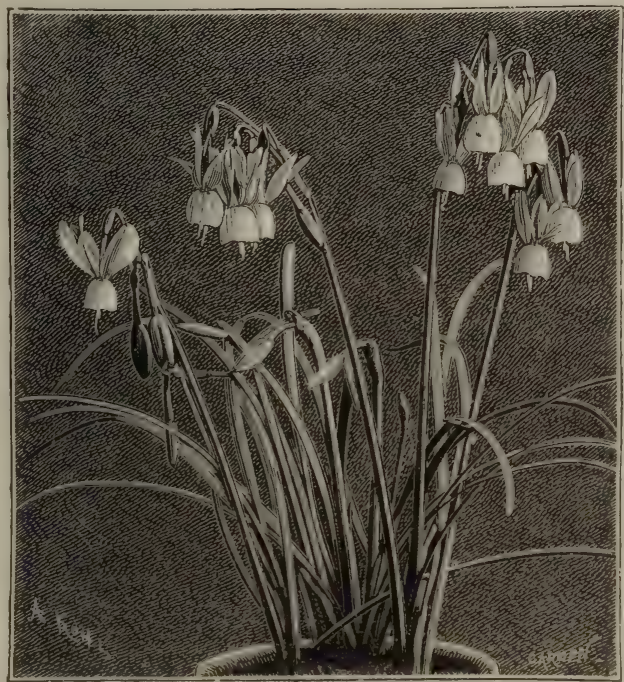

NARCISSUS CALATHINLS.

kinds, but use leaves of common sorts with choice flowers. Put each kind in a separate glass, but put together as many of the same kind as you like.

In March and April comes the prolific harvest of golden open-air blossoms. Such delicate southern kinds as N. Bulbocodium, $\mathrm{N}$. triandrus, $\mathrm{N}$. calathinus, $\mathrm{N}$. juncifolius, and most of the varieties of $N$. Tazetta may be grown in front of sunny walls on prepared peaty or on sandy borders, or else in glass-houses in the garden; but even in such places their flowers often suffer from spring storms, and the surest plan is to adopt pot-culture in a sunny frame. $\mathrm{N}$. viridiflorus, $\mathrm{N}$. serotinus, $\mathrm{N}$. intermedius, N. elegans, N. pachybolbos, N. Broussoneti, etc., are interesting to experts; but the difficulties of their culture are out of all proportion to their beauty, and those who only wish for large and beautiful flowers had better ignore them. Practically, we have only six species of Narcissus worth cultivating-N. Bulbocodium, N. pseudo-narcissus, N. poeticus, $\mathrm{N}$. Tazetta, $\mathrm{N}$. jonquilla, and $\mathrm{N}$. triandrus. Then for naturalisation, or for ordinary rough-and-tumble garden culture, these six may be reduced to three-N. pseudonarcissus, or the Ajax Daffodils; $N$. poeticus ; and the natural hybrid between these two species, the ubiquitous Star Narcissus - N. incomparabilis. These kinds are really the only free and hardy open-air Narcissi, and are of course the best for the meadow or the lawn.

Of the newer seedlings, perhaps the finest is the exquisite cream-tinted N. Madame de Graaff, which first flowered at Leyden in I883. N. Glory of Leyden is a yellow counterpart of it. The two were offered, one bulb of each, for 7 guineas only a year or two ago. They are so vigorous, and they increase so fast in good soil, that buyers were amply repaid, high as these prices appear. N. Weardale Perfection, N. Monarch, and some others are so splendid and so rare that they are practically not to be had, anything less than Io guineas having been refused for a single bulb of N. Weardale Perfection. These are only show flowers, however, and many others not much less handsome may be had by the hundred or the thousand at a moderate price.

Narcissi flower in continuous succession from February until June ; and when pot-culture and warm-house treatment is adopted, the double Roman Narcissus and the Italian paper-white Narcissus flower in November, and there are always some Narcissi in flower from that time to June.

HYBRID NARCISSI. - The species which have best lent themselves to the hybridiser's art are $\mathrm{N}$. pseudo-narcissus, $\mathrm{N}$. poeticus, $\mathrm{N}$. montanus, $\mathrm{N}$. triandrus, $\mathrm{N}$. jonquilla, and N. Tazetta. The type hybrids are N. incomparabilis, N. Bernardi (both found wild), N. Nelsoni, N. Barrii, N. Burbidgei, N. Humei, N. Leedsii, N. Milneri, N. tridymus, and N. odorus. There are wild and garden hybrids between N. Bulbocodium and pseudo-narcissus ; N. triandrus and N. pseudo-narcissus; $\mathrm{N}$. jonquilla and $\mathrm{N}$. pseudo-narcissus, $\mathrm{N}$. pucifolius and N. pseudo-narcissus; $\mathrm{N}$. Tazetta and N. pseudo-narcissus ; N. Tazetta and N. poeticus; N. poeticus and $\mathrm{N}$. pseudo-narcissus; and N. montanus and $\mathrm{N}$. poeticus ; and also N. pseudonarcissus and $\mathrm{N}$. montanus, while derivative hybrids have been obtained between some of these hybrids and some of the parent species. It is remarkable that while wild hybrids and garden seedlings usually enjoy richly-manured soils, wild species, and the white varieties of $\mathrm{N}$. 
Ajax, N. triandrus, and N. Bulbocodium usually die out on deep richly-manured borders, but frequently live on poor, stony, or sandy soils, on dry grassy banks, or amongst the roots on the sunny sides of hedges, shrubs, stone walls, and trees.

\section{PRINCIPAL SPECIES OF NARCISSI.}

N. biflorus (Primrose Peerless), now referred to $\mathrm{N}$. Tazetta, is similar in habit to $N$. poeticus, but has creamy-white flowers, two on a scape, and the rim of the primrose corona is scariose but colourless (i.e. not purple). N. biflorus is naturalised in England and Ireland, but is a native of Europe. It is one of the easiest of all the kinds to naturalise, and spreads rapidly, but is usually supposed not to bear seed.

N. (Corbularia) Bulbocodium (The a large early-blooming form, found by Mr. Barr in Spain; N. citrinus, a pale sulphur form, varying much in size; $\mathrm{N}$. Græellsii, the European white; and N. monophyllus, the African white. These are dainty bulbs for pots or for choice borders on warm dry soils. They can rarely be naturalised.

N. cyclamineus (Cyclamen Daffodil). - A dainty but not showy species, easily grown in a peat-earth rockgarden or in pots of peaty compost. It seldom exists from year to year in the open air. It has lived on Grass in peat, and, no doubt, could be naturalised easily enough on sandy peat soils which are wet in winter and spring, and dry in summer and autumn. This April (I892) I saw a most lovely specimen low down in a damp little grassy bay beside a mill-race

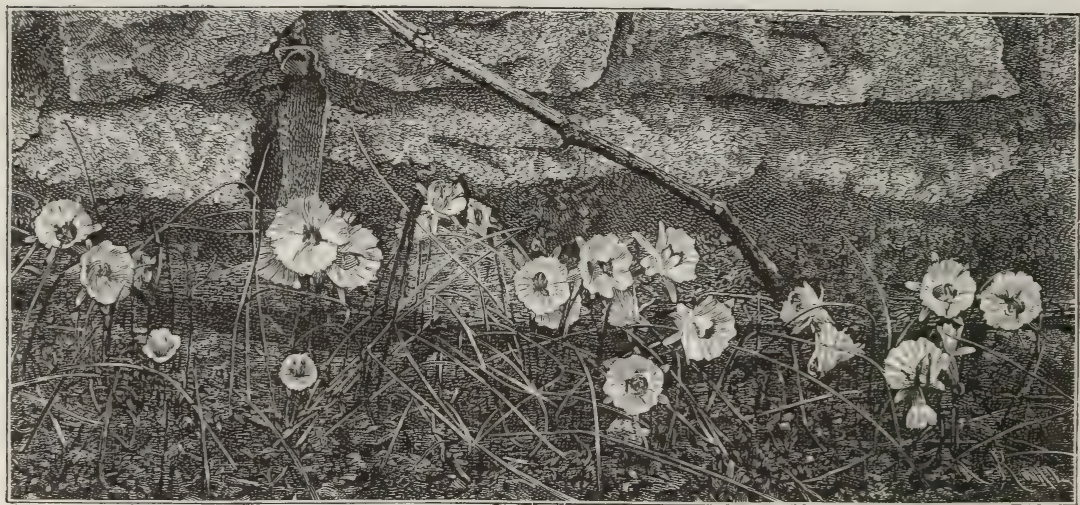

NARCISSUS BULBOCODIUM (HOOP PETTICOAT NARCISSUS).

Hooped Petticoat or Crinoline Daffodil) represents a kind having slender rushlike leaves. In Spain it grows in wet meadows during winter and spring, but is dried up throughout summer and autumn. The types are goldenyellow in Spain and Portugal, sulphuryellow in S. France, as at Biarritz and Bayonne, one variety in the Pyrenean district (N. Grællsii) is whitish, but in Algeria grows the exquisite snowy-white N. monophyllus. Hybrids between N. Bulbocodium, N. triandrus, and the Daffodil have been obtained in gardens, and are also found wild. The main varieties are N. conspicuus, a large, rich, goldenyellow kind with green rushy leaves; $\mathrm{N}$. tenuifolius, a small golden form, having a six-lobed rim to the corona, and very long rushy leaves, which lie on the ground; N. nivalis, abundant in Portugal and near Leon in Spain, a small golden kind with short erect leaves; N. præcox, at Mount Usher. N. cyclamineus likes the side of a stream, and is found by streams in Portugal. Like N. triandrus, it is readily raised from seed, and the seedlings flower the third year. It is 6 to $8 \mathrm{in}$. high, and the scapes are about the same length, each bearing a bright golden reflexed flower. It has sap-green leaves. There are large and small forms, and a bicolor variety seems to have been known long ago. N. cyclamineus, although but lately re-discovered, was figured in French books early in the seventeenth century. Like N. Johnstoni, it came from Oporto in I 884-85.

N. incomparabilis (Star Daffodil).To this group belong $\mathrm{N}$. incomparabilis, N. Barrii, N. Burbidgei, N. odorus, N. Sabinei, and N. Backhousei, N. Nelsoni, $\mathrm{N}$. tridymus, and the Pyrenean wild hybrid, N. Bernardi, which is found wherever $\mathrm{N}$. variiformis and $\mathrm{N}$. poeticus occur together. Of $\mathrm{N}$. incomparabilis there 
are over a hundred named kinds, the best being: N. Sir Watkin or Welsh Peerless, N. Gloria Mundi, N. Queen Sophia, N. C. J. Backhouse, N. Princess Mary, N.Gwyther, N. splendens, N. Autocrat, N. Beauty, N. King of the Netherlands, N. Commander, N. Figaro, N. Goliath, N. Mabel Cowan, N. James Bateman, N. Mary Anderson (delicate, but of a splendid colour), N. Fair Helen, and N. Queen Bess. There are three or four handsome double forms of $\mathrm{N}$. incomparabilis, long known in gardens. The most abundant of these is N. incomparabilis fl.pl. (Butter and Eggs). There is a white variety, with vermilion chalice segments, known as Eggs and Bacon or Orange Phœenix ; and a pale sulphur double called Sulphur Kroon, which is exquisite if well grown. Sulphur Kroon is often known as Codlins and Cream. Of Barr's Peerless (N. Barrii, hybrids), the best are N. conspicuus and N. Sensation, but N. Golden Star, N. Crown Prince, N. Flora Wilson, N. Miriam, N. Barton, N. Orphée, N. General Murray, N. Maurice Vilmorin, and N. Dorothy E. Wemyss are all good, and are useful for extended culture on Grass, or for cut flowers. The Burbidge hybrids are like the N. Barrii forms, but have small crowns. Their chief value lies in the freedom and earliness of their bloom, as they open days before even N. ornatus, -the early April N. poeticus. The best varieties are N. Burbidgei (type), N.Agnes Barr, N. Beatrice Heseltine, N. Baroness Heath, N. Constance, N. Crown Princess, N. Ellen Barr, N. John Bain, N. Little Dirk, N. Model, N. Mrs. Krelage, and N. Mary. Of Leed's silver star forms the best are exquisite on good sandy soils, and their whiteness and delicate purity and grace render. them most acceptable as cut flowers. The best are: N. Leedsii (type), N. amabilis, N. Beatrice, N. Hon. Mrs. Barton, N. Katherine Spurrell, N. Duchess of Westminster, N. Madge Matthew, N. elegans, N. Minnie Hume, N. superbus, N. Princess of Wales, N. Magdalina de Graaff, N. Gem, N. Grand Duchess, N. Acis, and N. Palmerston. Hume's hybrids are deformed Daffodils, the best being N. Giant, and N. concolor. Sabin's hybrid (N. Sabini) is a bold white bicolor, with a shortened trumpet, and so are the so-called Backhouse hybrids ( $N$. Backhousei), N. Wolley Dod, and N. William Wilks. N. William Wilks is a shapely and effective flower of good substance and has vigorous leaves. More starry, but with smaller cups, are Nelson's hybrids (N. Nelsoni). They are tall, free, and handsome kinds of distinct habit.
The best are N. Nelsoni major, N. minor, N. pulchellus (perfect shape), N. Mrs. C. J. Backhouse, N. aurantius (orangered cup), and N. William Backhouse. Collected bulbs of $\mathrm{N}$. Bernardi are very variable in size and form, and some, like E. Buxton, have fine orange-red cups, which resemble Nelson's aurantius.

N. jonquilla (Jonquil).--Long known in gardens, and imported from Italy and Holland for forcing in pots. N. stellaris has narrow perianth lobes, and $\mathrm{N}$. jonquilloides is a robust form from Spain. The varieties gracilis and tenuior are now sup-

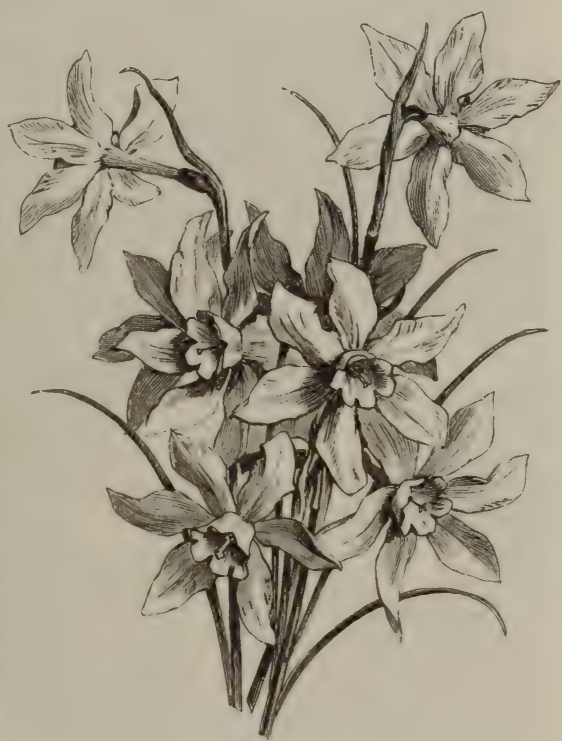

NARCISSL'S JONQUILLA.

posed to be hybrids between the Jonquil and some other species, or between $\mathrm{N}$. intermedius and juncifolius, $\mathrm{N}$. intermedius itself being a hybrid between some form of N. Tazetta and the Jonquil. The Jonquil, when strongly grown on a warm border, is handsome and very sweet, and $\mathrm{N}$. gracilis is the latest of all single Narcissi, as it blooms with $\mathrm{N}$. poeticus fl.-pl. in May or early June. The double Jonquil is rarely seen doing well in open ground, but as a pot-plant it is handsome. S. France and Spain.

N. juncifolius (Rush Jonquil). - A small plant, suitable only for sheltered borders, for stone edgings, and for potculture in a cold frame. It is very variable, and rupicola, minutiflorus, and scaberulus are well-known variations. Its small Jonquil-scented flowers have very large cups, often widely expanded, which are crenulate 
at their edges. The var. rupicola flowers and seeds annually in the rock-garden at Edinburgh Botanical Gardens, and seems hardier than the type.

N. odorus (Great Jonquil). - This plant, although found wild in S. France, Portugal, and N. Spain, is now believed to be a hybrid $=\mathrm{N}$. jonquilla $\times \mathrm{N}$. pseudonarcissus. The leaves are rushy, and two or three yellow starry flowers are borne on each scape. The best kinds are $\mathrm{N}$. odorus (Campernelle), and rugulosus, a more robust form, with larger flowers. A double form, very handsome on warm soils, is known as Queen Anne's Jonquil.

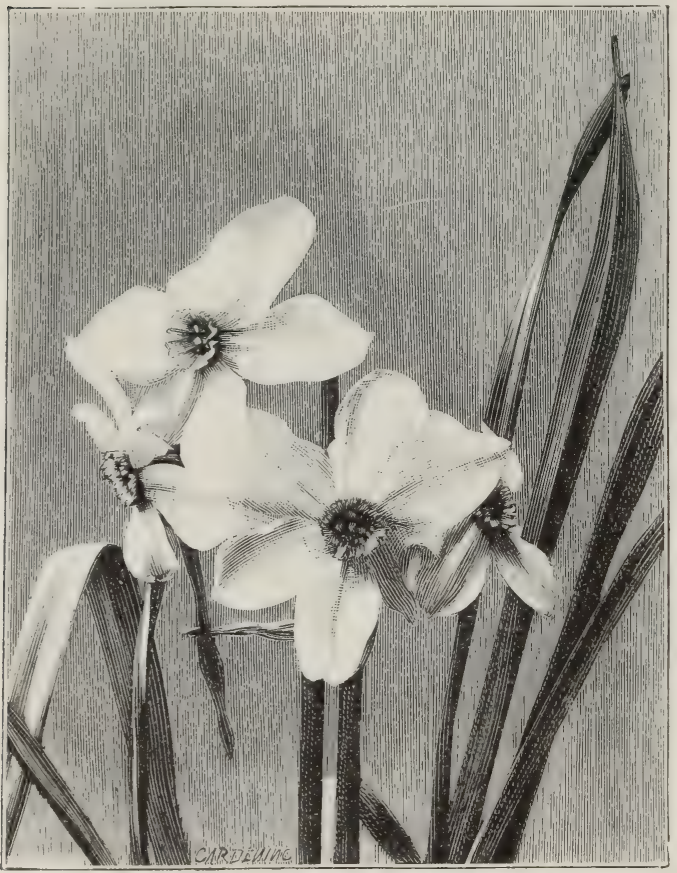

NARCISSUS POETICUS.

N. poeticus (Poet's or Pheasant's-eye Narcissus).--One of the oldest, sweetest, and most popular of garden flowers, and erroneously supposed to be the Narcissus of the Greek poets. It is widely distributed in France and Germany, and extends to the Pyrenees. In upland meadows of the Pyrenees it is very abundant in June and July. It flowers from the beginning of April until June. $\mathrm{N}$. ornatus is now grown by the million for Easter decoration. $\mathrm{N}$. grandiflorus is a very large floppy variety, N. poetarum has a saffron-red crown, and $\mathrm{N}$. tripodalis has reflexed segments, and a bold crimson-scarlet ring. The typical N. poeticus is a tall plant, with a small shapely flower, but is not often seen. N. Marvel has a bladder-like spathe like an Allium, and a pale and shapely flower. N. patellaris has a broad crown and a saffion rim, and blooms late; but the form usually met with early in May is N. recurvus, the Pheasant's-eye of cottage-gardens. $\mathrm{N}$. recurvus has a green eye and a crimsonfringed crown. All the forms, especially ornatus and recurvus, naturalise perfectly, and of recent years bulbs have been dug on the Pyrenees by the thousand for naturalisation. They are so variable in habit, size, shape, and colour that any number of varieties could be selected from them. The June-flowering double form of $\mathrm{N}$. patellaris, or Gardenia Narcissus, is very fine. It does well on deep sandy borders. It is a shy flowerer, and many of its buds go blind, so that half the stock should be transplanted every year in August. $\mathrm{N}$. stellaris, the latest single form of $\mathrm{N}$. poeticus, flowers in June.

N. pseudo-narcissus (Common Daffodil).- There are several hundred varieties of the Common Daffodil, either wild or cultivated. The only native of Britain is the common English kind, which extends from Cornwall to Fife, and is specially plentiful in the southeastern counties. In Normandy we have seen Daffodils light up the woods in April, while many fine forms are wild in Spain and in the Pyrenean region, and the richest of golden Daffodils come from Spain and Portugal. Nearly all Daffodils do well on Grass, if the soil be at all suitable ; and as regards our wild English Daffodil, the Grass is the only place in which to grow it permanently. Daffodils are usually divided into three groups: first, golden Daffodils, such as $\mathrm{N}$. maximus, $\mathrm{N}$. Tenby, and N. spurius; secondly, bicolors, such as N. John Horsfield, N. Empress, N. Grandee, etc. ; thirdly, sulphur and white kinds, such as N. Exquisite, and the white Daffodils, such as the wild Pyrenean, N. moschatus, etc. Nearly all the golden kinds are robust and easily grown, and the bicolor group are even more so, but, speaking broadly, the delicate sulphur and the white sorts are tender and unsatisfactory, except on the most favourable soils. The following are the best in each group: Golden Daffodil GroupN. abscissus (muticus), N. Ard Righ, N. Emperor, N. Countess of Annesley, N. Bastemil, N. Captain Nelson, N. spurius 
coronatus (General Gordon), N. Golden Spur, N. Distinction, N. obvallaris, N. Henry Irving, N. Glory of Leyden, N. Golden Prince, N. Golden Plover, N. Golden Vase, N. Her Majesty, N. John Nelson, N. spurius, N. major, N. maximus, N. M. J. Berkeley and N. Mrs. Elwes. $\mathrm{N}$. nanus and N. minor are dwarf varieties. N. minimus is the smallest of all the Daffodils. N. P. R. Barr, N. rugilobus, N. Santa Maria, N. Samson, N. Sir W. Harcourt, N. Townshend, N. Boscawen, pulcher, N. C. W. Cowan, N. Dr. Hogg, N. Exquisite, N. J. G. Baker (volutus), N. F. W. Burbidge, N. Lady Grosvenor, N. Galatea, N. Mme. de Graaff, N. Mrs. F. W. Burbidge, N. Mrs. J. B. M. Camm, N. Mrs. Thompson, N. Helen Falkiner, N. pallidus præcox (the variable sulphur Daffodil of Biarritz and Bayonne), $\mathrm{N}$. pallidus asturicus, N. Princess Ida, N. Sarnian Belle, N. tortuosus, N. Wm. Goldring, N. W. P. Milner, N. Minnie Warren, N. Countess of Desmond, N.

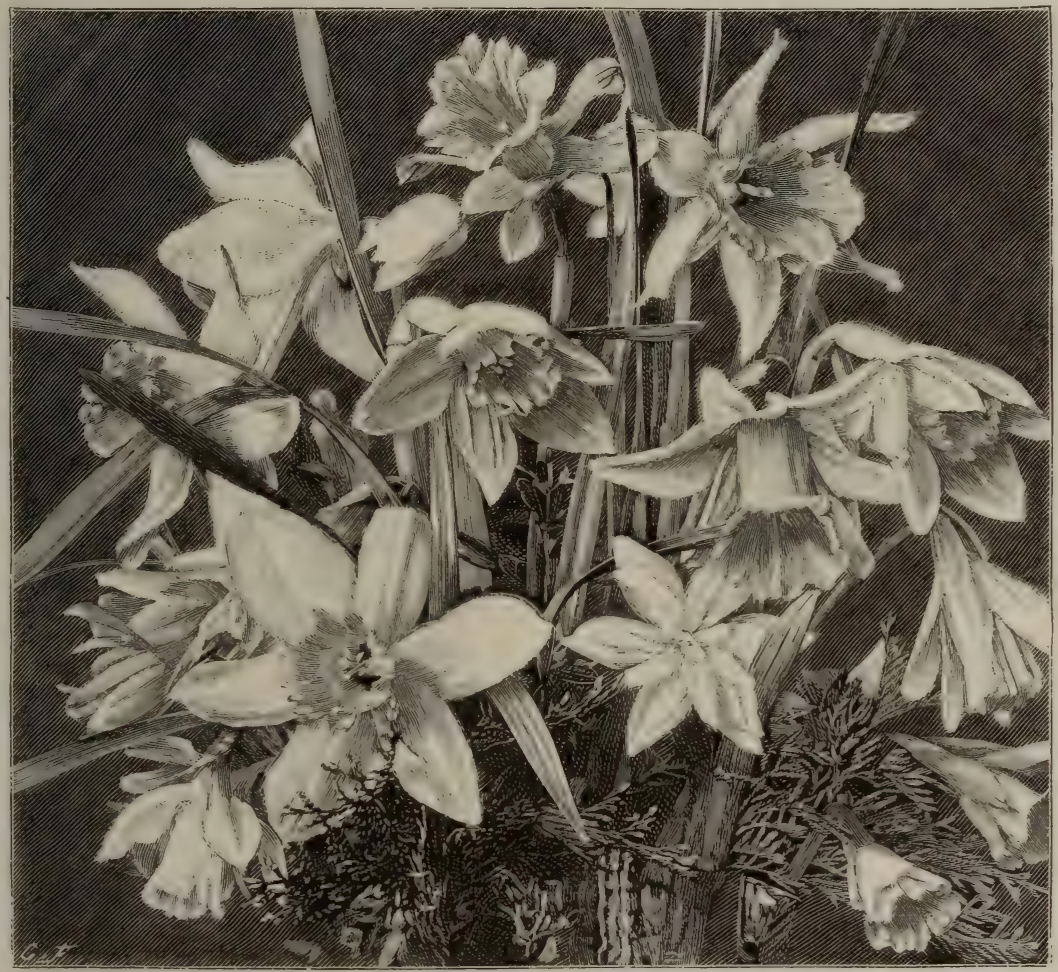

GROUP OF DAFFODILS.

N. Stanfield, N. Croom a Boo (Ard Righ with a frilled trumpet), N. Weardale Perfection, N. Monarch, and many others are not as yet much grown. Bicolor Group-N. Empress, N. John Horsfield, N. Grandee, N. Dean Herbert, N. Michael Foster, N. Alfred Parsons, N. George C. Barr, N. Harrison Weir, N. J. B. M. Camm, N. John Parkinson, N. Mrs. Walter Ware, N. Mad. Plemp., N. T. A. Dorien Smith, and N. variiformis. White and Sulphur-flowered Group$\mathrm{N}$. moschatus, N. albicans (Leda), N. cernuus (very variable), N. Cecelia de Graaff, N. Colleen Bawn, N. cernuus
Robert Boyle, N. Silver Bar, N. Matson Vincent. The best of the double Daffodils are-N. Telamonius plenus (Van Sion), very free and robust, naturalised everywhere; double English, minor plenus (Rip van Winkle); N. lobularis plenus; N. Scoticus plenus; N. plenissimus (Parkinson's great rose double); capax plenus (Eystettensis), an exquisitely pretty and pale six-rowed double, but requiring a warm sandy soil, and remarkable as being a distinct double, of which the single type is unknown; N. Cernuus, C. bicinctus ; the last do well in warm, stony soils, and, like other delicate kinds, enjoy the company 
of trees, shrubs, or Rose roots. N. Johnstoni (Johnston's hybrid Daffodil) was found by Mr. A. W. Tait near Oporto in 1885, and figured in Bot. Mag., 7012; it is a natural hybrid, between N. pseudonarcissus and $\mathrm{N}$. triandrus, and is variable, Mr. Tait having, in March 1892 , sent me a bicolor form (Garrett $\times \mathrm{N}$. triandrus albus). The best forms are $\mathrm{N}$. Johnstoni (type), N. Queen of Spain, N. Mrs. Geo. Cammell, N. Pelayo, and Mr. Tait's new bicolor form to which I have above alluded. The Rev. G. H. Engleheart has repeated crosses between the parent species, and has produced a pale sulphur or white Johnstoni, and others.

N. Tazetta (Bunch or Cluster Narcissus).- This is the classical Narcissus of Homer and other poets, Greek and Roman-the flower of a hundred heads that delights all men, and lends a glory to the sea and the sky. N. Tazetta is focused in the Mediterranean Basin, but extends from the Canary Islands to the north of India and to Japan. It has long been naturalised in the Scilly Isles and in Cornwall; but its early habit of growth, acquired in more sunny climes, often causes the flowers to be injured by the frosts and storms of winter. Cluster Narcissi are hardy on warm dry soils, and as pot-plants many of them are very handsome, while in deep, warm, sandy borders, which are sheltered by sunny walls or by plant-houses, they frequently do well, but as a rule bulbs must be imported from Italy or Holland every year. The earliest are the double Roman and the paperwhite (N. papyraceus). One variety from China may be grown in a sunny window if placed in water, and the bulbs submerged and held in position by gravel or stones. The growth of this variety is rapid, and good bulbs produce five to eight spikes. Its shop name is "Sacred Narcissus" or Chinese "Joss Lily." The best varieties are N. Grande Monarque, N. States-General, N. Newton, N. Scilly White (White Pearl), N. Soleil d'Or, N. Bathurst, N. Baselman major (Trewianus), N. Goloriosus, N. Sulphurine, N. Czar de Muscovie, N. Grand Sultana, N. Grand Primo Citroniere, N. Luna, N. Her Majesty, N. Queen of the Netherlands, N. Lord Canning, and N. Golden Era. N. Baselman minor is now proved to be a hybrid between N. Tazetta and N. poeticus, and a similar hybrid has been found wild near Montpelier.

N. triandrus (Gonymedi's Cup).-A very distinct and elegant species which is rarely happy out-of-doors except on warm, moist, and sheltered borders, or in nooks of the rock-garden, but which as a potbulb has no superior for delicate beauty, its flowers rivalling in texture those of the Cape Freezias. The late Mr. Rawson, of Fallbarrow, Windermere, grew it in pots, and his specimens bore fifty to a hundred flowers. His plan was to rest it thoroughly after the leaves faded, and then to topdress the bulbs, and rarely or never to re-pot them. As a rule N. triandrus is short-lived, but it naturally reproduces itself from seeds, which bloom the second or third year after sowing. The principal kinds are N. albus (Angel's Tears), N. calathinus (a robust form from the Isle de Glennans), and N. L'Ile St. Nicholas. On the coast of Brittany $\mathrm{N}$. calathinus and $\mathrm{N}$. L'Ile St. Nicholas grow among rocks and short sandy sward close to the sea, and within reach of its spray during rough weather. N. pulchellus has a primrose perianth and a white cup, and is very pretty. In the late Mr. R. Parker's nursery at Lower Tooting, in 1874 , it was very strong and healthy in an open-air bed resting on the gravel, and some of its scapes bore seven or nine flowers. No other Narcissus has a cup paler than the perianth segments. N. pulchellus has recently been found wild in Portugal and Spain.

Diseases AND Insects.-As Narcissi may be grown on dry warm soils, or in grassy lawns and meadows, the insects and fungoid diseases that would affect them on deep-dug and highly-manured borders are few and far between. Neither cattle nor sheep molest them, and game and poultry, and even the most voracious of rabbits and the most impudent of townsparrows leave the flowers alone. That their leaves and roots are poisonous, or acridly narcotic, may account for this. In some gardens and nurseries the larva of the Narcissus Fly (Merodon equestris) infests old bulbs, and whenever bulbs are imported from abroad or are dug for replanting, this larva should be searched for and exterminated. The bulbs affected may generally be known by their necks feeling soft when pinched. All such bulbs should be cut open and the larvæe extracted and killed. Such means are the only cure, as no insecticides will kill the pest without destroying the bulbs. The pest checks both root and bulb growth, but after the larvæ are removed the rare bulbs recently infected may be planted for stock, for although the heart be eaten away, the lateral buds at the base of the bulb-scales often produce young bulbs.

$\mathrm{N}$. poeticus and its varieties have rarely been infected by a leaf fungus (Puccinia 
Schroteri), and so far its ravages have been limited.

Bulbs of Narcissus are now and then found to be afflicted with black canker or "black-rot," probably caused by Peziza cibovioides, but so far little serious injury has been done. The most insidious disease that affects Narcissi is one to which Mr. C. W. Dod some few years ago originally drew attention, under the name of "basal rot." The stunted flowers come up prematurely, while the leaves have a diseased appearance, and are much dwarfed and contorted. The base of the bulb rots away, while no roots are formed from the disc, and the wet and flabby bulb-coats are more or less discoloured, as if parboiled. This disease is most prevalent among white Daffodils, white single and double; but yellow kinds such as Ard Righ and maximus are affected on wet and cold soils, and even N. Tazetta, N. Leedsii, and N. jonquilla are also affected. In many cases this disease is checked by annual digging and re-planting in July or August; and sometimes bulbs, affected on deep rich borders, have recovered on being transplanted to Grass or beds of Moss and Briar Roses. Cold and wet, or even richly-manured soils, seem especially conducive to this disease, and the only remedy is to alter the conditions of growth as soon as the leaves have died away. A celebrated northern grower of Narcissi tells me that some sorts that formerly failed on level borders do well on the drier and warmer grassy banks to which he transferred them. Facility in altering conditions of growth is often the best way to save plants that show signs of disease or failing in any way. It is a great consolation to know that many of the best and most showy kinds, if broadly and naturally grown on the Grass of meadow or of outlying lawn, are rarely, if ever, afflicted seriously with the above pests.-F. W. B.

\section{Nardosmia (Tussilago).}

Narthecium ossifragum (Bog Asphodel).-A small native plant, like an Iris, with a spike of small yellow flowers. It is interesting for the artificial bog.

Nasturtium (Tropceolum).

Neillia opulifolia (Nine Bark). - A common shrub generally known as Spiræa opulifolia. It is usually 3 to $5 \mathrm{ft}$. in height, but in good soils and in sheltered places it makes a bush 8 or Io $\mathrm{ft}$. high and as much through. It blooms about midsummer, the small white flowers being borne in dense feathery clusters. A more important shrub for ornamental planting is the variety aurea, with golden leaves. The yellow tinge of the foliage is extremely bright, and, at a distance, looks like a glowing mass of yellow bloom. This variety is a hardy and vigorous shrub suitable for planting anywhere.

Neja. - Small half - shrubby Composites. N. gracilis makes a pretty rockgarden plant on account of its elegant feathery foliage and its bright yellow, Daisy-like blossoms. It thrives in the open air from spring to autumn, but should be wintered in the greenhouse. Brazil.

Nelumbium luteum (Yellow Sacred Bean).--This noble water-plant reminds one of luxuriant tropical vegetation. Its huge blossoms are a pale yellow, and its large round leaves, which are borne on tall stalks, push boldly out of the water for about $3 \mathrm{ft}$. It has been known to flower strongly, and to stand over $3 \mathrm{ft}$. out of the water in the Garden of Plants at Paris. In the Garden of Plants it used to remain out all the winter when standing in a fountain basin of rather deep water. It would probably flower out-of-doors in a sunny and sheltered spot in the south of England. It is rare, but may be procured from some nurseries, or from America. The beautiful $N$. speciosum is another noble aquatic, and is well worth a trial wherever there is a contrivance for heating the water of a small pond or tank in the open air.

Nemastylus.-Bulbous plants of the Iris family. They are natives of the warm parts of N. America, and consequently are not quite hardy with us, though they may be grown in the same manner as the Ixia. There are three species introduced-N. geminiflora (N. acutus) and N. purpureus from Texas, and $\mathrm{N}$. coelestinus from Florida. All are of dwarf growth and bear showy blossoms, which are fugacious, though produced continuously.

Nemesia floribunda. - A pretty hardy annual of the simplest culture. It grows about I ft. high, and bears in summer a profusion of fragrant Linaria-like blossoms, which are white with yellow throats. N. versicolor has blue, lilac, or yellow and white blossoms; and its variety compacta, with blue and white flowers, is a most desirable plant. If sown in ordinary soil in masses in early spring and then well thinned, the plants will have a pretty effect for several weeks after June. Cape of Good Hope. Scrophulariaceæ.

Nemophila.-These pretty Californian plants are among the most popular of hardy annuals. From the many varieties enumerated in catalogues a good selection may be made. The species from which 
these varieties have been derived are $\mathrm{N}$. insignis, N. atomaria, N. discoidalis, and $\mathrm{N}$. maculata. N. insignis has sky-blue flowers, and its varieties are grandiflora, alba, purpurea-rubra, and striata. N. atomaria has white flowers speckled with blue. Its varieties are colestis, (sky-blue margin), oculata (pale blue and black centre), and alba nigra (white and black centre). N. discoidalis has dark purple flowers edged with white, and the flowers of its variety elegans are maroon margined with white. N. maculata has large white flowers blotched with violet, and its variety purpurea is of a mauve colour. These kinds are all worth growing. They thrive in any soil, and are of the simplest culture. In spring some pretty combinations may be effected byarranging the masses in harmonising colours. All Nemophilas are well suited for edgings and for filling small beds, as they are compact in growth. The insignis section should always be preferred to the others. Seeds should be sown early in August for spring-flowering, and in April for summer-blooming. To secure a good display of flower, however, the best time to sow is in August, and the soil should be a light one, where the seed can germinate freely, and where the plants will not become too robust before winter sets in. If the seed be sown where the plants are to flower, the results will be most satisfactory; but if transplanting be necessary, it should be done early in the winter. A ball of earth should be attached to each plant, and to secure this thin sowing is indispensable. Hydrophyllaceæ.

Nepeta (Cat Mint). - Though the ordinary Ground Ivy (N. Glechoma) is too common to cultivate, it is an elegant plant in the rougher parts of the rockgarden. N. macrantha has rather showy purple flowers, but is too tall and coarse for the border. N. Mussini is an old plant, and was once used a good deal for edgings to borders, a purpose for which its compact growth suits it well.

Nephrodium. - The native Nephrodiums are alluded to under the head of Aspidium. Besides these native kinds there are a few North American species that are quite hardy, and very handsome, and these thrive perfectly under the same conditions as the native kinds. The chief sorts are N. Goldieanum, N. intermedium, N. marginale, and $\mathrm{N}$. noveboracense. Several Japanese and Chinese species thrive without protection in mild localities, but they cannot be recommended for general culture. $\mathrm{N}$. fragrans is a sweet-scented little form. It is somewhat delicate, but thrives in a sheltered situation.

Nerine. - Beautiful bulbous plants, mostly from S. Africa. The hardiest is the Guernsey Lily (N. sarniensis). The Guernsey Lily has long been a favourite object of culture in the Channel Islands, and there, though it is a native of Japan, it is quite hardy in light soil, and thrives without any attention. Its flower-stems are about I ft. high, and are surmounted by a large umbelled cluster of showy blossoms of a rich crimson. The bulbs are imported from the Channel Isles in large quantities. They require a sunny position in a light warm soil, a border at the foot of a south wall being the best. They are usually sent over about August. They should be planted as soon as they are received, and they will flower in September or later. After the flower is past leaves will be produced. These leaves must be protected against frosts, either by lifting the plants and placing them under glass, or by preserving them with a hand-light or with other protective material. Plants protected in this way have in some localities withstood the winters for years. Several other Nerines are less hardy than the Guernsey Lily, but they succeed in the open in summer, and, if protected, will flower in September or October, but they should not be left out during the winter except in extremely mild localities. The kinds that should be tried out are N. corusca, N. Fothergilli, N. pulchella, N. pudica, N. undulata, and their varieties.

Nertera depressa (Fruiting Duckweed).-An extremely pretty plant, thickly studded with tiny reddish-orange berries, and with minute round leaves which are suggestive of the Duckweed of our stagnant pools. It forms densely-matted tufts, and soon spreads into a large mass. It is grown best under glass, but it flourishes in the open air, and it is an excellent plant for level spots in the rockgarden. It requires a little protection during severe cold. N. depressa may be propagated by dividing old plants into small portions and placing them in small pots in a gentle heat until they start into growth, and then removing them to a cooler atmosphere. If a stock is required, the points of the young shoots should be taken off, and inserted in pans filled with equal portions of leaf-mould and sand. After watering, a square of glass or a bell-glass should be placed over the pan. Thus treated, the cuttings will take root in a few days. They 
should then be potted off into $2 \frac{1}{2}$-in. pots, and again placed in a gentle heat until they are established. When established they should be removed to a shelf in a greenhouse until the fruit is set. Rubiacer. New Zealand.

\section{New Holland Daisy (Vittadenia tri-} loba).

New Holland Violet (Erpetion reniforme).

New Zealand Flax (Phormium tenax).

Nicandra physaloides. - A pretty Peruvian half-hardy annual, about $2 \mathrm{ft}$. high. It is of stout growth, and bears in summer numerous showy blue and white bell-like flowers. It thrives in an open position in light soil. Seed should be sown in heat in early spring or in the open air about the end of March, and the seedlings should be transplanted in May. One plant is sufficient for a square yard. Solanaceæ.

Nicotiana (Tobacco). - Stout half -

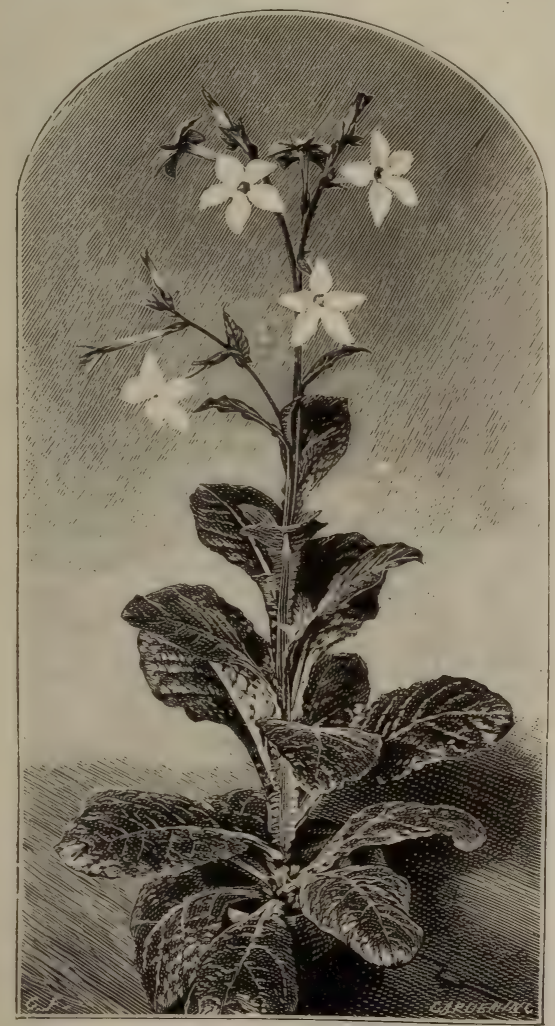

NICOTIANA AFFINIS.

hardy annuals of rapid growth, and excellent subjects for associating with other stately plants in the sub-tropical garden. The varieties differ chiefly in the stoutness and the height of their stems, and in size of their leaves and flowers, but these differences largely depend on cultivation. The deeper and richer the ground and the more sheltered the position, the larger the plants become. N. macrophylla is the best. Scarcely any plants equal the Tobaccos in rapidity of growth. They form noble groups, and they mix well with most other fine-foliaged plants. If possible they should have a deep soil, rich in vegetable and animal matter, near the margin of a lake or a stream. They form capital backs to masses of Reeds, Pampas Grass, Bamboos, Rushes, or other semi-aquatic plants. They are tender, and must be sown in February in a warm house or frame. Prick off the plants as soon as they appear, and pot them in a genial heat of, say, $60^{\circ}$. This will, about the end of May, allow of turning out fine plants from 6 or 8 in. pots. They will start off at once, and will not cease growing until frost comes.

Nierembergia. - Extremely pretty plants. The only Nierembergia that is quite hardy is $N$. rivularis (White Cup), which is one of the handsomest of all Nierembergias. The stems and foliage of this kind trail along the ground as dwarfly as those of the New Holland Violet, while barely pushed above the foliage are open cup-like flowers of a creamy-white. These flowers are usually nearly 2 in. across. They are faintly tinged with rose and have yellow centres, and they continue blooming during the summer and autumn. They have a pleasing effect in the distance, as they suggest Snowdrops at first, and they are quite as pretty when closely viewed. No collection of rock-plants or herbaceous plants is complete without $\mathrm{N}$. rivularis, while the flower-gardener may well use it in his smaller designs. Two things are requisite, a heavy soil and absolute firmness of the ground; and these, accompanied by a sunny aspect and by culture on a level surface, will in all probability secure success. The tender Nierembergias are $\mathrm{N}$. frutescens, a sub-shrubby plant of erect growth, and N. filicaulis, or gracilis as it is called, which has slender drooping branches. Both have pretty white flowers pencilled with purple, and both are suitable for the rock-garden in summer or for drooping over the edges of vases. Cuttings in spring in heat.

Nigella (Fiennel Flower). - Hardy annuals of the Crowfoot family. All are curious and pretty. They have feathery Fennel-like foliage and bluish or yellowish 
blossoms. N. sativa, N. orientalis, N. damascena (Devil in a Bush), and $\mathrm{N}$. hispanica are the kinds cultivated, N. hispanica being the most ornamental. $\mathrm{N}$. hispanica grows about I ft. high, and has showy blue flowers, and it blooms from July onwards. There is a white

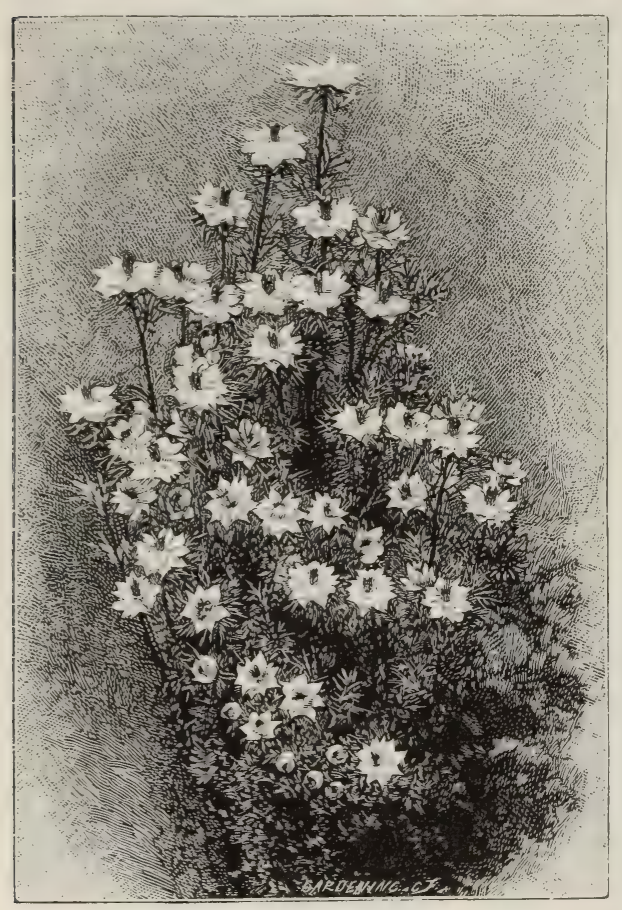

NIGELLA DAMASCENA.

variety and a variety with deep purple blossoms. All the Nigellas should be sown in March, in light warm soil in the open border. They should be sown in the spot which they are to occupy, as they do not succeed if transplanted. If sown in autumn the seedlings often survive the winter and flower early.

\section{Night-Scented Rocket (Hesperis} tristis).

\section{Nightshade (Solanum).}

Nolana.-Small hardy annuals from S. America. N. paradoxa, N. prostrata, and N. atriplicifolia are cultivated. They have slender trailing stems, and flowers generally blue, which are similar to those of a Convolvulus. N. atriplicifolia is by far the best. It has beautiful and very showy blue flowers with a white centre. There is a white variety (N. a. alba). The Nolanas are suitable for borders or for the rock-garden, as they thrive in any warm open situation in good light soil. As seedlings do not transplant well, seed should be sown in the open in March, and the plants well thinned out. Nolanaceæ.

Nothochlæna Marantæ.-An elegant hardy New Holland Fern, with dark green erect fronds, 6 to 12 in. high, which proceed from a creeping rhizome. It requires a moist peaty soil and a sheltered shady spot in the rockgarden or the fernery, or on a wall made for the smaller Ferns.

Nuphar. - The most familiar Nuphar is the common yellow Water-Lily (N. lutea), which inhabits many of our lakes and slow-running rivers, and is too well known to need description. It has a very interesting little variety called pumila or minima, which is found wild in some of the Highland lakes, and which has the same vinous perfume as the type. $\mathrm{N}$. advena is the N. American representative of the yellow Water-Lily, and resembles it in general aspect, but is larger and has leaves which stand erect out of the water if the water be shallow. It is altogether a much finer plant. N. Kalmiana, also a North American kind, much resembles the small variety of $\mathrm{N}$. lutea, and is a very interesting plant to grow in company with it. The cultivation is the same as that of the Nymphæa.

Nuttallia cerasiformis (Osoberry). - A deciduous shrub worthy of attention on account of being one of the earliest shrubs to flower. Hardly before winter is past its abundant drooping racemes of white flowers are produced, and they usually appear before the new leaves. When in bloom it bears a resemblance to the Flowering Currant (Ribes sanguineum), and is sometimes called the early white Flowering Currant. It is a dense round-headed bush, 6 to $\mathrm{I} 2 \mathrm{ft}$. high. It grows anywhere, in almost any kind of soil, and is thoroughly hardy, but not at all showy. California.

Nycterinia.-Pretty half-hardy annuals from the Cape of Good Hope. N. selaginoides grows about 9 in. high. It forms a dense compact tuft of slender stems, which, in late autumn, are profusely set with small white, orange-centred blossoms. These blossoms are fragrant at night. N. capensis is about the same size as N. selaginoides, and is of similar growth. Its flowers, however, though larger, are not of so pure a white. N. selaginoides and $\mathrm{N}$. capensis require to be sown early in heat, and to be transplanted in May in 
light, rich, sandy loam in warm borders. N. Lychnidea is a small shrubby perennial with yellowish-white blossoms. It thrives in warm borders in summer. It should be propagated either by cuttings in autumn, or by seeds in spring. Scrophulariaceæ.

Nymphæa (Water-Lily).--Though the common $\mathrm{N}$. alba may be met with in almost any lake and river, every piece of ornamental water should have a few Water-Lilies. Water-Lilies are seen to the greatest advantage in small groups a few yards from the water's edge, but groups or single plants look well wherever they are placed, and always produce finer foliage and finer flowers than plants crowded together. Even in the smallest garden it is easy to grow Water-Lilies in a tank sunk in the Grass, or even in a large tub, with very moist soil. Water-Lilies sunk in a little lawn, and having the tubs hidden, look better than where a crowd of them is spread over an acre of pond. Their culture is of the simplest kind. If properly planted, they seldom give any trouble. Where it is convenient to drain off the water, the best mode of planting the larger Water-Lilies is to make a hillock with a compost consisting of good loam and a small quantity of well-decomposed manure and river sand, and on this to place some large stones to prevent the soil from being washed off by the water. On the hillock the plant should be placed so that its crown may not be more than $2 \mathrm{ft}$. below the water. If the water cannot be lowered, the best alternative is to put the plants into large baskets, and to sink them to the proper depth. If the bottom be gravelly, the plants will not spread much, but if it be not gravelly they should be kept within bounds, or they will soon grow into a mass, which will considerably mar the effect'of isolated patches. Young plants and small kinds should be put in small baskets and in shallow water. The hardy kinds are--

N. alba.-Of the common Water-Lily, there are three or four varieties. By far the finest is the rose-coloured variety (rosea) which has lately come into cultivation. The rose-coloured variety is exactly like the type except in the colour of the flowers. It should in all cases be preferred to the type, being simple to grow, and quite hardy. There are two other varieties of $\mathrm{N}$. alba-minor and candida. Minor is very interesting on account of its small size, the blossoms being but $\mathrm{I} \frac{1}{2}$ to 2 in. across, and the leaves being small in proportion. The variety candida is intermediate in size between minor and the type.
N. odorata.-This N. American species is closely allied to N. alba, and the principal difference is that $\mathrm{N}$. odorata has larger blossoms-its blossoms measuring 6 to 9 in. across. Its flowers are sweetly scented. They have a tendency to assume a red colour, and the full development of this tendency is admirably shown in the variety rosea, or minor, but the flowers of rosea are much smaller than those of the type. The variety maxima differs from the type only in having larger flowers. The variety reniformis has the lobes of the leaf much rounded, so that the leaves assume a kidney shape, but there is no difference in the flower. This variety requires the same treatment as N. alba, and is quite as hardy in the southern counties.

$\mathrm{N}$. tuberosa is also a native of $\mathrm{N}$. America. It resembles N. alba, but its roots have tubers which spontaneously detach themselves, and afford a ready means of propagation. N. nitida is a near relative of $\mathrm{N}$. alba, but it has very shining leaves, and its blossoms are smaller and are scentless. It inhabits the lakes and still waters of Siberia, and also the river Lena. The pigmy WaterLily (N. pygmæa) is a native of China and of some parts of Siberia. It is the smallest of all the Nymphras, its leaves not being more than 2 in. across, and its flowers being very small. The yellow kind ( $\mathrm{N}$. flava) is one of the most interesting of all the Nymphæas. No other sort, either tropical or temperate, is of the same colour. N. flava is in cultivation, but it is rare, and no one has experience in its culture. It is a North American species.

Oak Fern (Polypodium Dryopteris).

Oak, Poison (Rhus Toxicodendron).

Obeliscaria (Rudbeckia).

Enothera (Evening Primrose).-

These are amongst the most showy and hardy of late summer flowers, and are easily grown. From June onward they are in their glory, but from increased growth many species and varieties become more full of flowers in late summer. They have large bright yellow or white flowers, which in many of the species are produced so freely and continuously as to make them of great value. Their name notwithstanding, many are open by day ; as, for instance, $\mathrm{E}$. linearis, speciosa, taraxacifolia, and trichocalyx. Many of our finest Evening Primroses are natives of States west of the Mississippi, such as California, Utah, Missouri, and Texas. They all bloom the first season 
from early seedlings. Some of the true perennials, and particularly the prostrate ones, are shy seeders, but the tall ones seed freely. They will grow in any good soil, but the richer and deeper the better. The largest are very beautiful in any position. From their height and boldness, however, and from the freedom with trichocalyx and cæspitosa, and white flowers, as in the last-named two, while coronopifolia and speciosa often change with age to pink or rose. Few plants have more brilliant yellow blooms than missouriensis and Lamarckiana; and, moreover, they are very large -4 to 6 in. across. Nearly all are more or

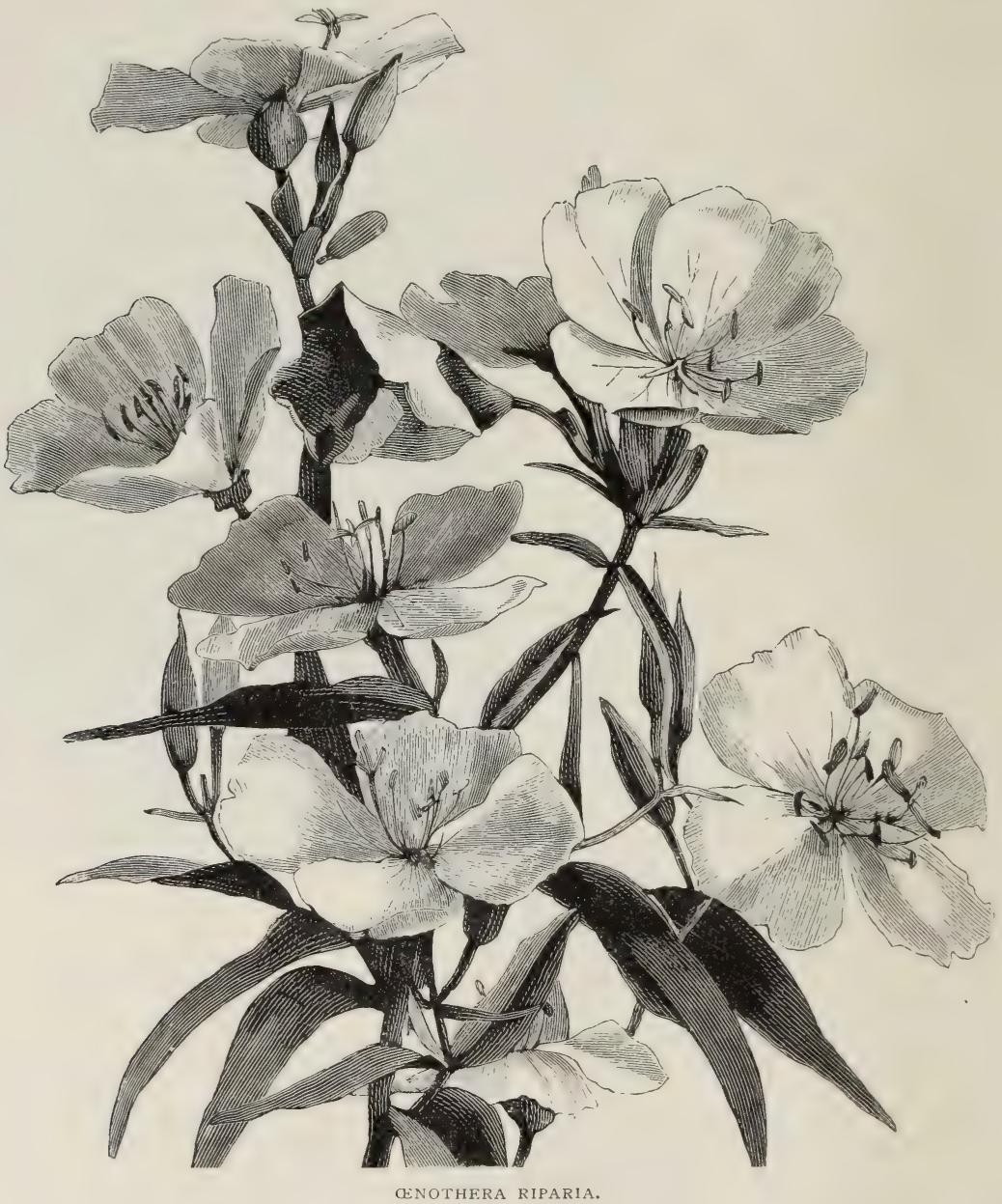

which they grow, they are peculiarly suited for the wild garden, for shrubberies, copses, and the like. Sowing themselves freely, they are apt to become too numerous and somewhat "starved," so that they are best when confined to large groups. In any flower garden not confined to flat beds only, a small isolated bed of them looks well. Amongst them we have tall sorts like $\mathrm{E}$. I Lamarckiana and fragrans, decumbent carpets, as in less fragrant, particularly cæspitosa, marginata, fragrans, and eximia.

G. biennis, one of the commonest, may be seen in almost every garden. It is a handsome biennial, 3 to $5 \mathrm{ft}$. high, with large bright yellow flowers. The variety grandiflora or Lamarckiana should always be preferred to the ordinary kind, as the flowers are larger and of a finer colour. They are excellent border flowers, have a bold effect in large masses, and 
are specially suited for the wild yarden, as they sow themselves and require very little care.

(E. fruticosa (Sundrops). - This and its varieties are among the finest of hardy perennials. They are I to $3 \mathrm{ft}$. high, and bear a profusion of showy bright yellow blossoms. There are about half-a-dozen distinct varieties, the best being linearis, or, as it is usually called, riparia. It is a plant about $\mathrm{I} \frac{1}{2} \mathrm{ft}$. high, and bears an abundance of yellow blossoms, smaller than the type. It is one of the best of yellow Evening Primroses for small beds, for edgings, or as a ground-work for other plants. It becomes a mass of delicate flowers, and being perfectly hardy goes on flowering even after the first frosts. It is always prudent to lift a few or strike a potful of cuttings in case of accident, though in spring the old plants may be divided to any extent. Given sandy loam, these plants thrive in borders or in the margins of shrubberies. N. America.

E. glauca is a handsome N. American species similar to fruticosa. It is of subshrubby growth, becomes bushy, and bears a profusion of yellow flowers. The variety Fraseri is a still finer plant, and where an attractive mass of yellow is desired through the summer there are few hardy plants of easy cultivation so effective. In a large rock-garden a few plants here and there will give colour. The hue is a most pleasing one, and the plants bloom long.

GE. marginata. - This dwarf plant, never more than 12 in. high, blooms as nobly as any native of the Tropics, and bears flowers 4 to 5 in. across. From white they gradually change to a delicate rose ; and, as evening approaches, come well above the jagged leaves. They retain their beauty all night, and emit a Magnolia-like odour. Tastefully arranged in the rock-garden or in some quiet border, they are as welcome as the nightingale. E. marginata is a hardy perennial, and is increased by suckers, which are freely produced from the roots, and by cuttings which root readily. Flowers in May. Syn., EE. cæspitosa. E. trichocalyx, a similar species, but probably only an annual, is a beautiful plant well worth growing.

E. missouriensis. - A fine yellow herbaceous plant from N. America, with prostrate downy stems, and rich, clear golden-yellow flowers. These are sometimes 5 in. in diameter, and so freely produced that they may be said to cover the ground with tufts of gold. There is no more valuable border flower, and when well placed in the rock-garden it is handsome, especially if the luxuriant shoots are allowed to hang down. As seed is rarely perfected, the plant is better increased by careful division, or by cuttings taken in April. As a border plant it does not grow so freely in cold clayey soils as in warm light ones. The blooms open best in the evening. Syn., E. macrocarpa.

E. speciosa.-A very handsome plant, with an abundance of large flowers, which, at first white, change to a delicate rose. In this respect it somewhat resembles E. taraxacifolia, save that the plant is erect, and its stems are almost shrubby. It forms neat tufts, usually 14 to 18 in. high, and is a true perennial, exceedingly valuable for borders, or the lower and rougher parts of the rock-garden. It is a native of North America, and is increased by division, cuttings, or seeds, but does not produce seeds freely in this country. It flourishes vigorously in well-drained rich loam, and grows best in a border of rich light soil, where, if undisturbed, it will soon spread into a large tuft. The soil must be warm and light, as in heavy soils it is apt to be injured during severe winters.

EE. taraxacifolia, a Chilian plant, is one of the finest of those Evening Primroses characterised by a low trailing growth and large blossoms, which attain their fullest expansion towards evening. E. acaulis, a much inferior plant, has smaller flowers, but possibly is only a variety of $\mathrm{E}$. taraxacifolia. Both are quite hardy and perennial in light soils, but in wet and heavy soils they often perish during winter. $\mathrm{E}$. taraxacifolia has a fine effect in rich deep soil in the rock-garden, where its trailing stems can droop over the ledge of a block of stone. The flowers, $2 \frac{1}{2}$ to $3 \frac{1}{2}$ in. across, are pure white when they open, but gradually change to a delicate pink.

E. triloba is a handsome hardy annual species, of dwarf growth, with large and showy yellow blossoms. It is also called E. rhizocarpa. Other showy annuals are E. sinuata and its variety maxima, $\mathrm{E}$. macrantha, odorata, bistorta, Veitchiana, and Drummondi. These are all worthy of culture, requiring the treatment of halfhardy annuals, and ordinary garden soil.

Olearia (Daisy Bush).-Australian and New Zealand shrubs, mostly evergreen, some of which are quite hardy without protection. O. Haasti is the most valuable, being the hardiest and most beautiful in flower, and blooming in early autumn, when most other shrubs 
are flowerless. It is a dense compact bush, 2 to $4 \mathrm{ft}$. high, with small round pale green leaves, very thick, and not unlike those of the large-leaved Box. Its small white Daisy-like flowers are very abundant, and are borne in broad flat clusters, the whole bush generally being for the open, make capital wall-shrubs. O. Gunniana (called also Eurybia Gunniana) is an evergreen, bearing a profusion of white flowers in early autumn. Other varieties are $O$. ramulosa, very abundant small white flowers, O. Forsteri and $\mathrm{O}$. dentata, excellent for adorning warm walls

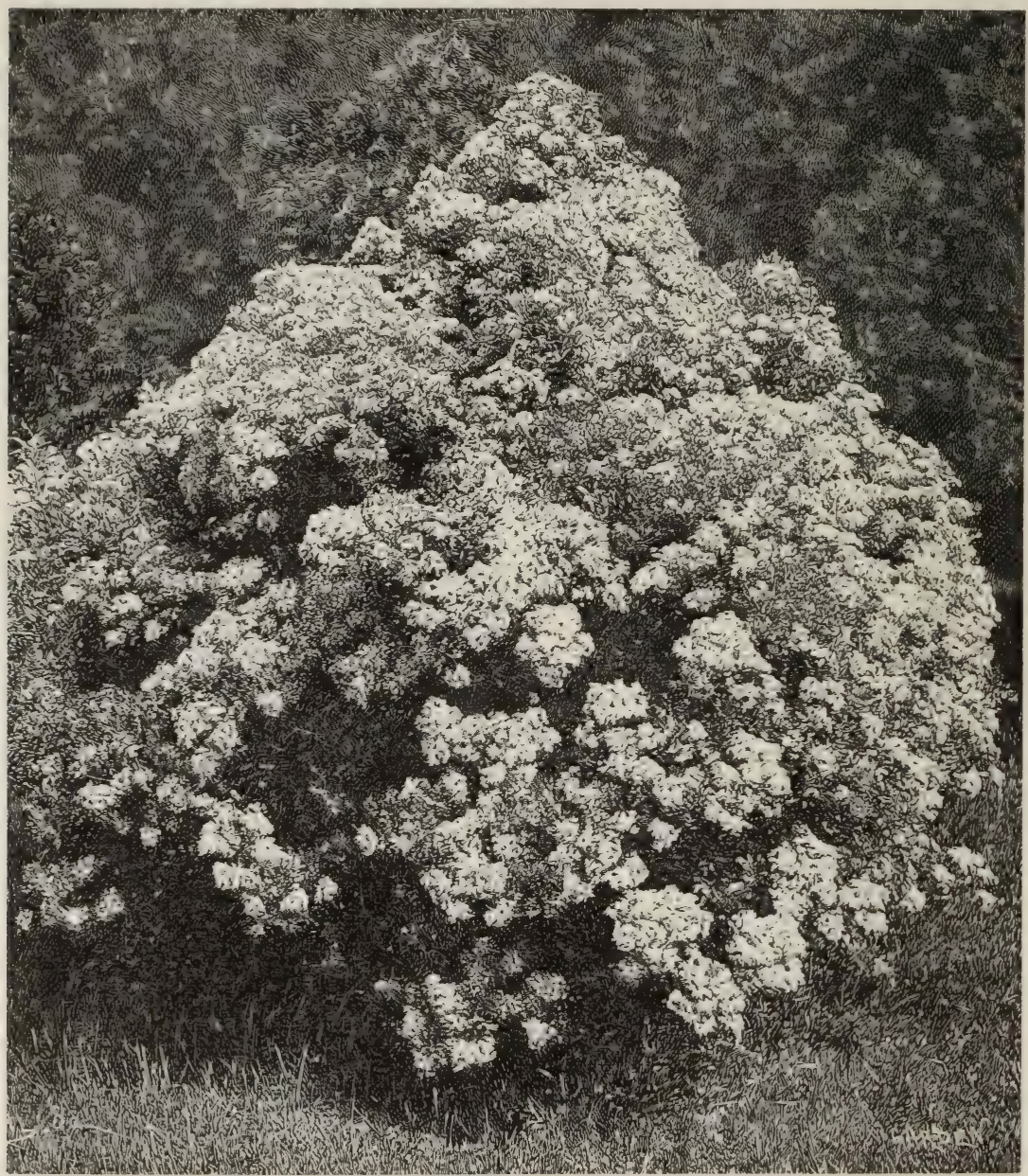

OLEARIA HAASTI.

covered with bloom. It begins to flower early in August, and continues in bloom for a month or longer. It is of quick growth, flourishing everywhere in light well-drained soils, and makes a beautiful lawn-shrub. A very effective group can be made by planting several specimens together and intermixing the scarlet Gladiolus brenchleyensis, which flowers at the same time. The other Olearias now in gardens, though not hardy enough with white blossoms in autumn. In the southern counties and warm coast districts all the half-hardy Olearias may be planted out in the open, and only require slight winter protection.

Omphalodes (Navelwort).-A small genus belonging to the Borage family. There are but three species in gardens; these are-

O. linifolia, a beautiful Portuguese hardy annual, 9 to 12 in. high, and 
furnished with leaves of a smooth glaucous-green colour. The pure white flowers are produced abundantly from June to August, and resemble in form those of the common Forget-me-not, but are considerably larger. O. linifolia may be grown in any ordinary garden soil. The seeds should be sown at intervals from April to June, or in September and October; but the plant often sows itself.

O. Luciliæ, a charming rock-plant, has flowers twice the size of O. verna, of

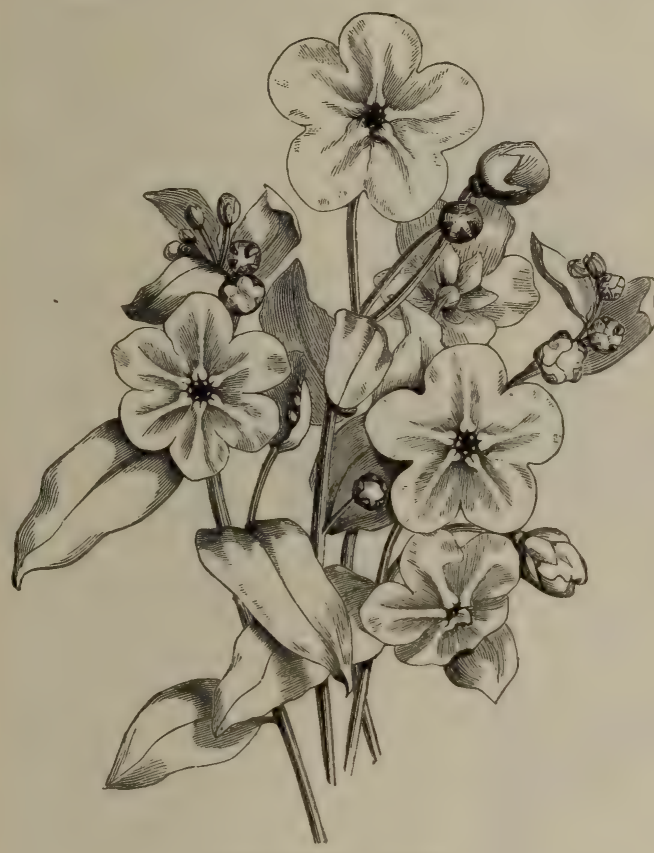

OMPHALODES LUCILIE.

a peculiar lilac-blue, and unlike that of any other flower, and harmonising beautifully with the glaucous grey of the foliage. O. Luciliæ is perfectly hardy, and succeeds in a border or the rock-garden, where its branches hang over the ledges, but the place must be thoroughly drained, for though the plant requires abundance of water during growth, it is very impatient of stagnant moisture at the roots or about the crowns. To protect it against slugs, which are particularly fond of its foliage, strips of perforated zinc, about 3 in. wide, bent so as to form rings round the plants, will be effectual. $O$. Luciliæ is readily propagated by division or by seeds, which in some seasons are produced freely. It grows freely in some soils, as, for example, in Wheeler's nursery at Warminster. Asia Minor.
0. verna (Creeping Forget-me-not) is a charming little plant, bearing in early spring handsome flowers of a deep clear blue with white throats. These flowers remind one of the finest Forget-me-nots, but are larger and a more intense blue, and are further distinguished by the runners which spring from the base of the stems. $O$. verna is indispensable for the rock and spring garden, and no plant is more worthy of naturalisation in halfwild places under shrubs or beneath Rhododendrons and the like. In cool, moist, thin woods it runs about as vigorously as any native plant, but it thrives by every woodwalk, and in any position is one of the prettiest plants. There is a white variety, but not so pretty as the blue kind.

Onoclea sensibilis.-This handsome hardy Fern belongs to the group known as "flowering Ferns," from the fact of the fertile frond being contracted so as to give it the appearance of an unopened spike of flowers. The fronds are a beautiful fresh light green, especially on their first appearance in spring. $O$. sensibilis, though not very fastidious as to soil and position, succeeds best in a cool and moist situation, such as the base of the rock-garden, or a place among the occupants of the American garden, especially if a little sheltered by neighbouring plants. In such a position the pale green of the fronds contrasts charmingly with the dark foliage of its associates. One thing to be observed by those who are desirous of raising this class of Ferns from spores is this, if the fronds are allowed to remain on the plants until they appear to be ripe, it will be found that the spore-cases are open and the spores shed, as they drop while the fronds look quite green, therefore the best way is to cut off the frond as soon as indications of bursting are perceived, and to lay it in a sheet of paper for a few days, when all the spores will drop out. N. America.

Ononis (Rest Harrow). - A genus of the Pea family. The wild Liquorice (O. arvensis) is one of the prettiest of our wild plants and is well worthy of cultivation on banks and in the rough rock-garden. It forms dense spreading tufts which are covered in summer with racemes of pink flowers. The white variety is even more valuable, and is worthy of a better position and soil than the common 
form, which grows in any soil. No plants are more readily increased from seed or by division. It is distinct from the spiny O. campestris, which has stems nearly $2 \mathrm{ft}$. high, and sometimes more. $\mathrm{O}$. rotundifolia is a distinct and pretty plant, which is hardy, and easily cultivated. It flowers in May and June and through the summer. It attains a height of 12 to 20 in. according to soil and position, increasing in height as the season advances. Suitable for the mixed border or the rougher parts of the rock-garden ; comes stout branching stems, often more than $5 \mathrm{ft}$. high, covered with long, whitish web-like hairs, and bears large terminal heads of purplish flowers. The habit of C. illyricum is more branching, the leaves and stems are much more spiny, the stems are stiffer and the leaves are greener and more deeply cut. O. arabicum is nearly $8 \mathrm{ft}$. high, is erect and very slightly branching, and both sides of the leaves, as well as the stems, are covered with white down. O. græcum is also handsome.

Onosma (Golden Drop).-A genus of

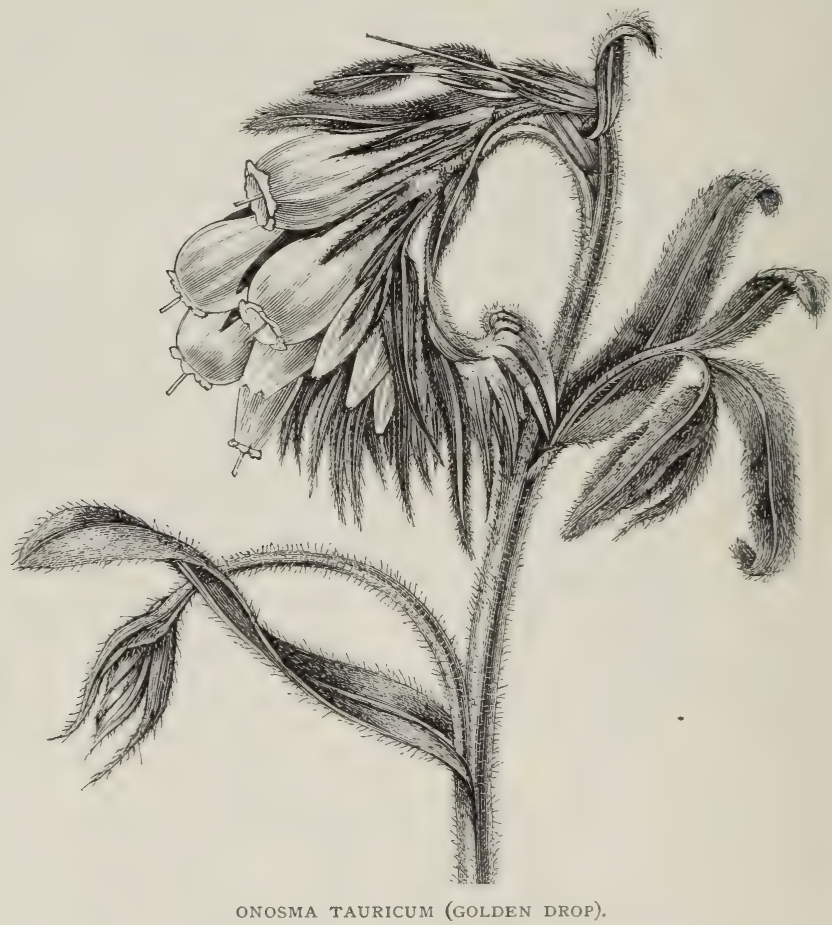

from the Pyrenees and Alps, and is easily propagated by seeds or division. These are the best of about half-a-dozen garden species, which also include $\mathrm{O}$. fruticosa, Natrix, and viscosa.

Onopordon (Cotton Thistle). - These noble plants, usually left to the botanic gardener, are valuable for their stately port and large showy flowers. They thrive in exposed places and among shrubs in sheltered ones, and may be effectively used in a variety of ways. Moderation in their use, however, is desirable, as in some situations they seed so freely as to require judicious keeping down. $\mathrm{O}$. Acanthium (Down Thistle) is a bold and vigorous native plant. It has very large,
Borageworts, of which two species are in cultivation. These are $\mathrm{O}$. tauricum and O. echioides; the former was introduced about the beginning of the present century, but the latter has been in cultivation for nearly two hundred years. These two kinds much resemble each other, but $\mathrm{O}$. tauricum is decidedly the finer, and should be grown in preference to $\mathrm{O}$. echioides. There is no doubt, indeed, that $\mathrm{O}$. tauricum is among the finest of all the Onosmas, for none other possesses flowers of such lovely citron-yellow. It is an evergreen perennial, 6 to 12 in. high, and soon forms a dense tuft of stems. It bears in summer drooping clusters of clear yellow almondscented blossoms, which have gained for 
it the name of "Golden Drop." Mountains of Greece and Tauria. The best place for $O$. tauricum is a good rockgarden, thoroughly drained, with a good depth of soil, so that the plants may root strongly between the blocks of stone. The soil should be a good sandy loam, mixed with broken grit, and the plant should be placed between large blocks of stone, near which the roots may ramify and be kept cool and moist. Propagated by seeds or cuttings. O. echioides requires similar treatment, excepting that the plants must be raised every year and planted out in the rock-garden to flower. It seeds freely in favourable seasons. It is biennial, and therefore less valuable for the garden than $\mathrm{O}$. tauricum, which it resembles in habit, save that its flowers are paler yellow and not nearly so attractive.

Onychium japonicum.-This elegant Japanese Fern, though frequently grown in the greenhouse, and even in the stove, is perfectly hardy in most situations. In severe winters, however, some common Brake may be thrown over it. The fronds are very finely divided, the segments being linear and an intensely dark green. They vary from $\mathrm{I}$ to $2 \mathrm{ft}$. high, and are very useful for bouquets, or for placing loosely in vases with cut flowers.

Ophioglossum vulgatum (Adder'stongue) is a native Fern not often seen in gardens. It is found in moist meadows; and the best position for it therefore is in colonies, among groups of ornamental Grasses, with Botrychiums and flowering plants like Snowdrops and Anemones. O. lusitanicum, a dwarf variety, is interesting, but wayward and capricious, and very difficult to cultivate.

Ophiopogon (Snake's-beard).-Fibrousrooted, herbaceous perennials, about $\mathrm{I} \frac{1}{2}$ ft. high. The numerous flowers, usually small and lilac-coloured, appear late in summer and in autumn in spikes, 2 to 5 in. long, rising from grassy tufts of evergreen foliage. They are suitable for borders or margins of shrubberies in sandy loam, but are scarcely ornamental. O. japonicus, Jaburan, spicatus, Muscari, and longifolius are the best-known, but are mainly suitable for botanical collections. All are easily propagated by division. In Italy they are used to make green tufts, in lieu of Grass, which perishes from the heat.

Ophrys. - Small terrestrial Orchids singularly beautiful, and among the most curious of plants. Many have been in cultivation, but these being tender plants, chiefly from S. Europe, they must have protection, and even then require great attention. A few native species, however, can be grown successfully, and of these one of the most singularly beautiful is the Bee Orchis (O. apifera). This varies from 6 in. to more than $\mathrm{I} \mathrm{ft}$. in height; it has a few glaucous leaves near the ground; and the lip of the flower is of a rich ve vety brown with yellow markings, so that it bears a fanciful resemblance to a bee. It is usually considered difficult to grow, but it may be easily kept on rather warm dry banks in the rock-garden, in a deep firm bed of calcareous soil, or if that be inconvenient, of loam mixed with broken limestone. It thrives best if the soil be carpeted with some very dwarf plant, or failing this, with $I$ in. or so of Cocoa-fibre and sand, so as to keep it moist and compact about the plants. Flowers in early summer. Other interesting species for a collection of hardy Orchids are O. muscifera, arachnites, aranifera, and Trolli.

Opuntia (Prickly Fig). - There are several species of Opuntia in cultivation, but few are hardy enough for the open air. The hardiest are $O$. vulgaris, missouriensis, humilis, brachyantha, and Rafinesquei. The finest of these, and one of the hardiest of all, is O. Rafinesquei, an evergreen well worthy of culture, bearing in summer large showy yellow blossoms on singular fleshy branches. Many gardens in the south of England furnish good conditions for its growth. And a little group would thrive in a sunny corner of the rock-garden, if able to root in good soil, not wet, and sheltered from any passing danger to the stems, for it is rather fragile and anything brushing against it would injure it; but, by the skilful placing of a few rough stones or little bushes around it, it is easy to prevent injury without shading it. To obviate splashings, and to secure a better effect, the ground might be surfaced with some dwarf mossy Saxifrage or Sandwort. Snails and slugs are extremely fond of this plant, and in the spring, and even in mild winters, will completely destroy it if not prevented. A liberal dressing of soot will keep away these pests, and impart luxuriance to the plants; for although the Cactus family object to manure in the soil, they fully appreciate a top-dressing of some concentrated manure, soot, or guano. The propagation of the hardy Cactus is easily effected. The cutting, consisting of a single joint, is potted in very sandy soil, and the pot placed in a sunny airy situation under glass and watered very 
sparingly. In a short time it will form roots, and commence to push out several young shoots, which also may be taken off. See also Cactus.

Orange Ball-tree (Buddleia).

Orchis.-These terrestrial Orchids are succeed with them, chiefly because the plants are transplanted at a season when such an operation is most harmful. Success depends on transplanting. The usual plan is to transplant just when the first or second flower has opened, so as

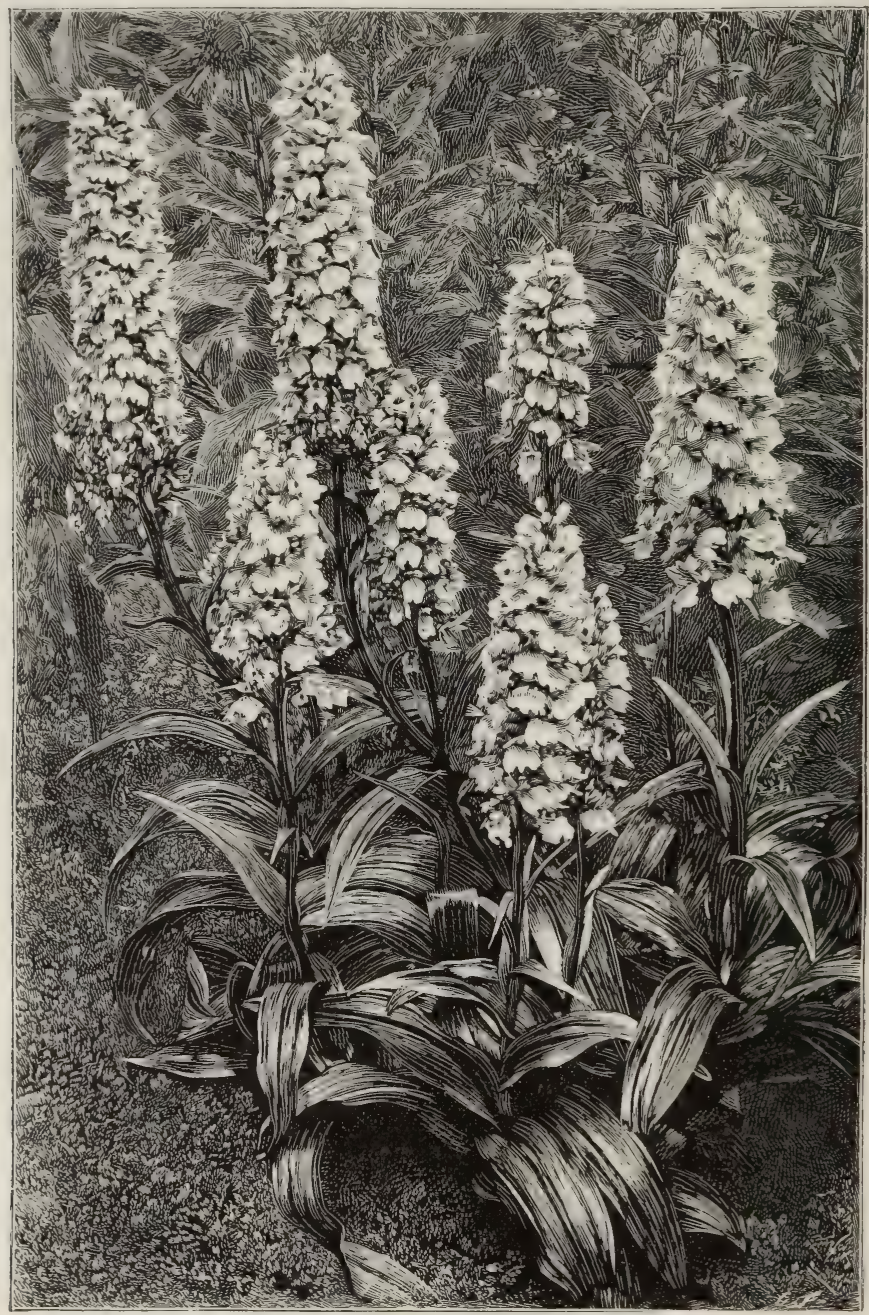

ORCHIS FOLIOSA (MADEIRA ORCHIS).

singularly beautiful, some being really showy plants and well worth attention on that account alone. Those who do not want a full collection will find the species mentioned below beautiful and easily grown if placed under the necessary conditions at the outset. Many of our native Orchids are very interesting and deserving of culture, but few cultivators to enjoy the remaining few, and there the cultivation begins and ends. This is a most mischievous plan, for at this period of growth the plant is forming a new tuber for the following year, and, if this is in any way injured, it shrinks and dies. If, instead of this, the plants are marked when in flower and allowed to remain until August or September, when 
the newly-formed tuber will be thoroughly matured, the risk of transplanting is considerably lessened, provided the plant be taken up with a good deep sod. It is advisable to remove the roots of other plants, though they are sometimes allowed to spread over the Orchid border, thus imitating natural conditions by protecting the roots in winter and preventing evaporation in summer. This, however, presents an untidy appearance, and besides there is a risk of cutting away the Orchids with the Grass, etc., in the flowering season. Good substitutes for Grass may be found in such plants as the pretty Balearic Sandwort (Arenaria balearica), Lawn Pearlwort (Sagina glabra), the mossy and tufted Saxifrages, and many others, which at all seasons are green and suitable. The situation for Orchids generally should be a partially shady one, and the soil a deep, rich, fibry loam in a thoroughly drained border. The following are the kinds most worthy of culture :-

O. foliosa.-This handsome terrestrial Orchid is one of the finest of the hardy kinds. It is from $\mathrm{I}$ to $2 \mathrm{ft}$. or more in height, and has long dense spikes of rosypurple blossoms, with dark spots. It begins to flower about the middle of May, and continues a considerable time in full beauty. It delights in moist sheltered nooks at the base of the rock-garden, or in similar places, and should be planted in deep light soil. Madeira.

0. latifolia (Marsh Orchis). - A very ornamental native kind, I to $\mathrm{I} \frac{1}{2} \mathrm{ft}$. high. The long dense spikes of purple flowers are produced in early summer. It is one of our commonest species, and is easily grown. It forms luxuriant specimens in damp boggy situations, with peat or leaf-mould. There are several beautiful varieties, the best being præcox and sesquipedalis; and the latter is one of the finest of all hardy Orchids. It is about $I \frac{1}{2} \mathrm{ft}$. high, and fully a third of the stem is densely covered with large purplish-violet flowers.

o. laxiflora is a handsome species, I $\mathrm{ft}$. to $\mathrm{I} 8$ in. high, with long loose spikes of rich purplish-red flowers which open in May and June. Jersey and Guernsey. Suited for a moist spot in the rock-garden or the artificial bog ; it may also be naturalised. Division.

o. maculata (Hand Orchis).-One of the handsomest of British Orchids, and usually tinted prettily in the poorest and driest soils, but a very different object in a rich soil. If well grown in moist and rather stiff garden-loam it will surprise even those who know it well in a wild state. Obtain it at any season, and carefully plant a patch of twelve or twenty tubers in a half-shady and sheltered position in moist deep soil. When the plants form dense patches two or three years afterwards they will prove more beautiful than any other Orchids from warmer climes. They flower in summer, and may be associated with Cypripediums, or planted in tufts in borders or on the margins of shrubberies. The variety superba is a much finer plant and should in all cases be preferred.

Other beautiful kinds but more or less difficult to manage are $O$. papilionacea, purpurea, militaris, mascula, pyramidalis, spectabilis, tephrosanthos, and Robertiana.
O. Bee (Ophrys).
O. Butterfiy (Habenaria).
O. Fly (Ophrys).
O. Grass Pink (Calopogon).
O. Hand (Orchis maculata).
O. Lady (Orchis purpurea).

Oreocome Candollei is very effective for the margins of shrubberies, or for planting singly on a lawn. It makes a fine pyramid, $5 \mathrm{ft}$. in height, and has large leaves which are divided as finely as those of a Todea, which are spread out horizontally, and which recurve gracefully. They are of a fresh green colour, and the umbels of pure white flowers rise well above the foliage. It grows well in any ordinary garden soil, and is quite hardy. Himalayas. Umbelliferæ.

Oreodaphne californica (Californian Bay). - The specimens of the Californian Bay to be found in this country are few, yet it is a handsome and a deliciously fragrant tree, and by no means difficult to cultivate. Though it is not quite hardy in every part of the country, there are many places suitable for it where it would grow freely and add quite a charm to its surroundings. It is most distinct and readily recognised, and if in their native country full-grown specimens maintain the habit of saplings here, then the tree must be one of a thousand. The leaves have a pleasing outline and a depth of colour which render them distinct from the majority of trees commonly grown. When pressed they emit a powerful and agreeable odour. They are largely used for making bay water. Free in this country it can hardly be styled, for the biggest specimen I have seen was not $20 \mathrm{ft}$. high, and from the rate of growth I should hardly think that it would ever attain that height. In California trees of nearly Ioo ft. in height and as much as $6 \mathrm{ft}$. in diameter are to be found.-A. D. W.

Origanum (Marjoram).-The common 
O. vulgare is scarcely ornamental, but another species, O. Dictamnus (Dittany of Crete), is a pretty little plant. It is somewha tender, and is more suitable for growing under glass than entirely in the open air, though during mild winters it survives unprotected. It has mottled foliage, and its small purplish flowers, in heads like the Hop, have procured it the name of the Hop-plant. O. Sipyleum is similar, and is quite as pretty. In the open these plants must have a warm welldrained spot in the rock-garden. strictly a hardy bulb, it does well out-ofdoors in sheltered situations, and in the south especially rarely gets destroyed. It produces its large green ornamental leaves early in October, and flowers towards the middle of March or beginning of April. The flowers are borne in spikes, and are each from $\mathrm{I}$ to $2 \mathrm{in}$. in diameter, pure white, and very attractive. A native of Algiers, and well worth trying in collections of hardy Ornithogalums.

0. armeniacum. - A well - marked hardy species discovered in Armenia

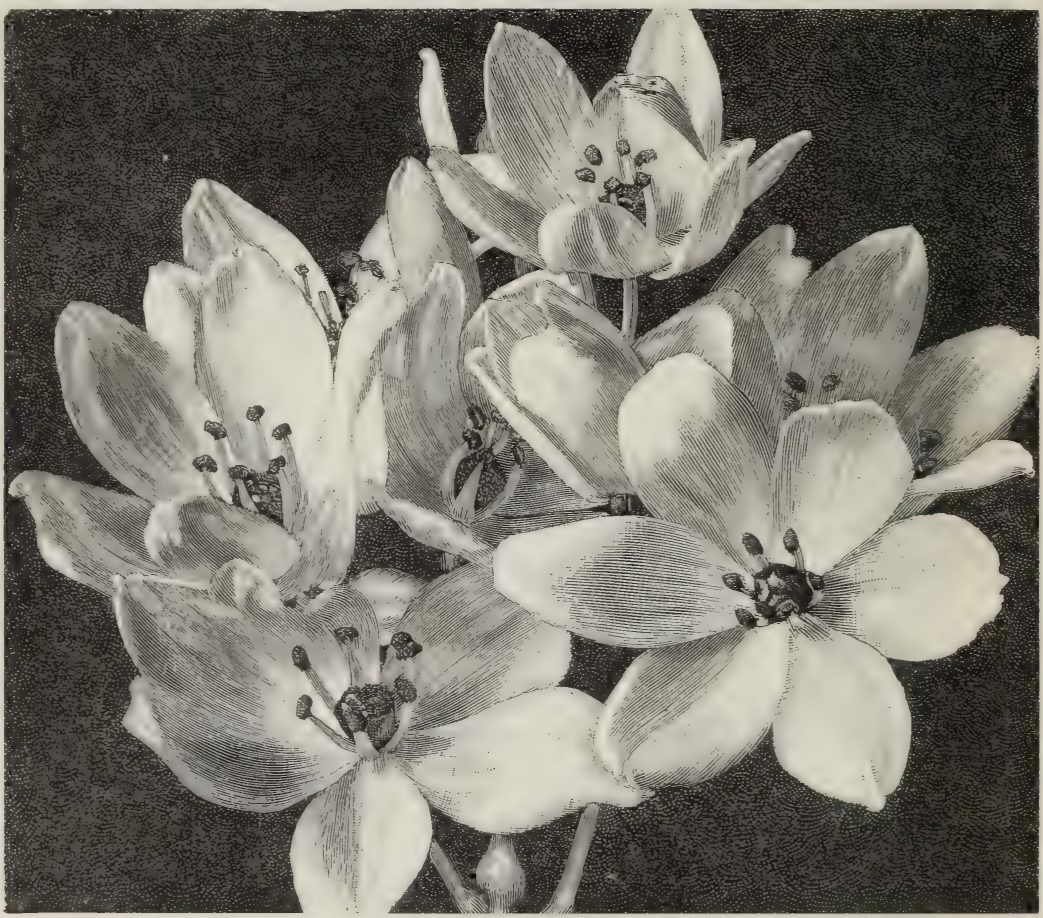

ARABIAX STAR OF BETHLEHEM (ORNITHOGALUM ARABICLM).

Ornithogalum (Star of Bethlehem).A very large group of bulbous plants, some of them striking and handsome, others of the hardy ones not very distinct, but all useful in quiet ways and in the Grass and in borders. Any good garden soil suits them well. A rich sandy soil will be found most suitable, and as they are readily raised from seed, a few years only are needed to get up a stock. The seeds of $O$. nutans may be scattered about the woods or shrubberies, anywhere indeed, and in a few years they will be in flower.

0. arabicum.-This is one of the most charming of the genus, and although not by Kotschy, and introduced a few years ago by Max Leichtlin, of Baden-Baden. It belongs to the umbellatum group, is a free flowerer, and very attractive. The flowers are borne from six to ten in a dense corymb, pure white, with the exception of a broad green keel. The leaves are grey-green with incurved margins, and each about 6 in. long. It flowers in May in England.

o. aureum is perhaps not hardy out-ofdoors anywhere in England, but is worth trying on account of its bright orange or golden flowers. It may, however, be managed with frame-treatment.

0 . comosum. - This is a pretty little 
plant and extremely useful for odd corners and shallow ledges on the rockery. It rarely exceeds 4 to 6 in. in height. The leaves are narrow, thick, and recurved, flowers very numerous in coryambose head, milk-white with purplish stems and yellowish anthers. It flowers in May and June. It may be planted on bare banks and such spots in full sun.

0. exscapum. - The dwarfest perhaps of all the species in cultivation at the present time. It never exceeds a couple of inches in height, producing umbels of large white flowers just above the neck of the bulb. The leaves are a little longer, very narrow and reflexed. A native of Southern Europe, flowering in March and April. It succeeds well on dry stony ground, and should always be planted in full sun.

0. fimbriatum.-A dwarf species with very hairy leaves and smallish white flowers, useful for planting in Grass, etc.

o. glaucophyllum.-A comparatively rare species introduced from Asia Minor by Mr. Elwes a few years ago, and flowering with us in May and June. It is a close ally of $\mathrm{O}$. umbellatum, which it resembles in habit. From all the other species it may readily be distinguished by its flat, narrow, glaucous leaves, without any trace of a central marking; flowers ten to twenty in a corymb, pure white on the inside, the outside being entirely green.

o. latifolium. - A very handsome species, of the $\mathrm{O}$. pyramidale section, and a useful addition to our hardy spring or early summer bulbs. The root-leaves are numerous, broad, sword-shaped, and usually spreading on the ground. The flower-stems grow I to $3 \mathrm{ft}$. in height, bearing a long spicate head of large white flowers. I have counted over a hundred on a robust plant. It flowers in May and June, and is a native of Tauria, from whence it was introduced in 1629 , as appears from Parkinson. It is perfectly hardy, and makes a charming plant for grouping in clumps of dwarf shrubs, etc.

O. montanum.-A dwarf species of no particular merit. It grows 2 to 4 in. high, bearing numerous greenish-white flowers. A native of Italy, flowering in May.

O. narbonense.-A tall-growing species from Southern Europe, and nearly allied to $\mathrm{O}$. pyrenaicum; indeed it has been considered a variety of that species. It differs, however, in its dwarfer habit, its longer flower-stalks, no yellow in the flower-colouring, in the styles being shorter than the stamens, and in the bracts being a fifth part instead of half the length of the flower-stalks. It is a showier and more desirable plant than $O$. pyrenaicum, and should be in every collection of hardy flowers. Leaves channelled, each $\mathrm{I} \frac{1}{2}$ to $2 \mathrm{ft}$. long, and half an inch broad, withering at the points when the plant is in flower. Flower-stem I to $2 \mathrm{ft}$. high, bearing about fifty blooms in a dense raceme. The flowers are white with a green stripe along the mid-rib, about I in. in diameter, and with the alternative segments toothed. Introduced in I8Io, flowering spring and early summer. The form $\mathrm{O}$. stachyoides is very near, if not identical with other forms of the type.

o. nutans.-A very popular species, and one of the most easily managed of all the Ornithogalums. In borders amongst other named bulbs, however, it becomes a great nuisance, on account of the freedom with which its innumerable bulbils are formed. In a semi-wild or uncultivated spot it is a capital subject for groundwork; it requires no attention whatever, and flowers freely all through April and May. The flowers are borne in racemes, drooping, green on the outside, whitish-green inside, peculiarly attractive. O. Boucheanum is a mere form of the above with larger flowers. Southern Europe.

O. pyramidale is a very old inhabitant of our gardens, having been introduced from Spain early in 1752. All botanists are doubtful as to giving it a specific distinction, Nyman in Flora Europe describing it as a garden or cultivated form of $\mathrm{O}$. narbonense. It differs widely from any $O$. narbonense $I$ have ever seen, and as it is said to grow naturally on the hills of Spain and Portugal, there seems no reason why the Linnean name should not be kept up. In robust plants the flower-stems grow 3 to $4 \mathrm{ft}$. in height, bearing pyramidal clusters of pure white flowers, marked with green stripes on the back. The long narrow leaves often wither before the flowers are fully open. It is a charming species for borders and for massing amongst shrubs, where, if left undisturbed, it forms large bold masses.

o. pyrenaicum is found in many localities in Britain, but is not a showy species. The flowers are yellow and green, borne on long racemes, the leaves fleshy, bright green. Flowers in June and July.

O. sororium.-A charming dwarf species allied to $O$. exscapum, discovered in the Cicilian Taurus, and introduced by Max 
Leichtlin in 1875. The flowers are borne in sessile crowded bunches, pure white, with a broad stripe of green down the back. Flowers in May.

0. umbellatum. - This is one of the best-known and most beautiful of the dwarf species of Ornithogalums, useful alike in bed or border, a first-rate bulb for naturalising in Grass, it being a sure flowerer, distinct and very attractive. It may be taken as the type of the dwarf or umbellate section. Its flowers, which are pure white, are borne in loose umbels on stems rarely exceeding 6 in. in height, leaves channelled, bright green, with a whitish stripe along the centre. Native of Europe, flowering in May and June.

o. unifolium.-A pretty dwarf species, suitable for rockeries. It grows in the greatest abundance on the barren hills and wilds of Portugal. As its name implies, it is only one-leaved, but it makes up for lack of leaves in abundance of flowers. These are borne in loose racemes, pure white throughout, and though not very large they will be found attractive in groups among the rocks.-D. K.

Ornus europæa (Flowering Ash).-A handsome flowering tree of medium growth, suitable for small lawns, or for grouping with larger trees. It makes a dense round-headed tree, generally not exceeding $30 \mathrm{ft}$. in height. Its foliage resembles that of the common Ash, and in early summer, usually about the end of May, it produces large plume-like clusters of tiny flowers of a yellowish-white. It is a South European tree, and perfectly hardy, although its young foliage is sometimes injured by late frosts. There are various so-called species of Ornus (now placed in the genus Fraxinus) which do not differ materially from the common $\mathrm{O}$. europæa. O. floribunda is a native of the Himalayas, though it is more tender than the European species, and flourishes well in southern districts. It is named floribunda because of the profusion of its feathery blossom. Names such as O. argentea, O. rotundifolia, and $\mathrm{O}$. globifera, etc., apply to Flowering Ashes similar to those described, if not identical with them.

Orobanche (Broom Rape). - Curious leafless parasitical plants often found on the roots of Furze and Broom. They cannot be cultivated.

Orobus (Bitter Vetch).-This genus is distinguished from Lathyrus chiefly by not climbing. All the species are perennial, and most of them are handsome when they flower, which they usually do in spring. They are suitable for the mixed border, for the rougher parts of the rock-garden, or for naturalising. Many of them are similar to each other, and therefore we mention only the most distinct kinds.

0. aurantius is a handsome plant, I 8 to $24 \mathrm{in}$. high. The orange-yellow flowers appear early in summer. O. tauricus is a nearly-allied species, also with orange flowers. Both require to be wellestablished before they bloom freely and are in perfection. They are suitable for borders in ordinary soil.

0 . lathyroides is a lovely border plant. Its height, when vigorous, is 18 to $24 \mathrm{in.}$; its bright blue flowers are borne in dense racemes, and its general habit is all that can be desired. It is increased freely by seeds, which it produces abundantly. It is capital for the wild garden, as it flourishes in any soil.

0. vernus (Spring Bitter Vetch).--One of the most charming of the border flowers that usually begin to open about the end of April. From black roots spring rich healthy tufts of leaves with two or three pairs of shining leaflets; the flower-buds appear soon afterwards, and eventually almost cover the plant with beautiful blooms of purple and blue. These blue and purple flowers have red veins and keels tinted with green, and change to blue. Besides the type there are-tenuifolius, with very narrow leaflets and flowers very similar to the type, though the general habit is more lax; flaccidus, somewhat similar to tenuifolius, but brighter and denser, and with broader leaves ; cyaneus, the most attractive, being larger and possessing a strange intermixture of colours, some a bright blue, others a greenish-blue, and some having distinct colours in the same flower. Then there is a double-flowered kind and a pure white variety, both desirable-the one on account of the lasting nature of the flowers, the other on account of its purity. All attain their greatest development in deep warm soils in sunny sheltered positions.

Some other species useful for borders and the rock-garden are-O. pubescens, $\mathrm{O}$. canescens, $\mathrm{O}$. varius, and $\mathrm{O}$. Fischeri, but $\mathrm{O}$. vernus and its forms are the handsomest. All are of easy culture in ordinary garden soil, and are increased by seeds or division of the root.

Orontium aquaticum (Golden Club). -A handsome aquatic perennial of the Arum family, 12 to 18 in. high. In early summer the narrow spadix is densely covered with yellow flowers, which emit a singular odour. The plant may be grown on the margins of ponds and fountain- 
basins, or in the very wettest part of the artificial bog. North America, in rivulets and bogs.

Orychophragmus sonchifolia. - A scarcely hardy plant of the Crucifer family. Though an annual, it is under certain conditions a biennial, or even perennial. It is a showy plant, as under good culture it attains a height of $2 \mathrm{ft}$. ; its bright violet-blue flowers are borne in loose terminal racemes of flowers, being about I ft. high. It is worth growing in mild localities as a half-hardy annual. = Moricandia. China.

Osmunda (Royal Fern). - This genus of so-called flowering Ferns is made familiar by the common native Royal Fern (O. regalis), which is found in many bogs and marshy woods. It is well worth cultivating, as it is the largest and most striking of our native Ferns (sometimes attaining a height of $8 \mathrm{ft}$.), and it is one of the most ornamental subjects that can be grown in certain positions. It should be planted in moist peaty soil, and the most suitable spots are half-shady places on the banks of streams or of pieces of water. It may also be planted in the water. When exposed to the full sun, it does well, with its roots in a constantly moist, porous, moss-covered soil, if sheltered from strong winds. In shady positions and in deep rich soil it attains a great height. The various North American Osmundas may be associated with it. There are several varieties in gardens. Popular and almost universally cultivated as Ferns are, the Royal Fern and several other Osmundas are rarely met in other than a shabby, or at best, half-developed condition. There are other hardy species not British. $\mathrm{O}$. cinnamomea is an elegant N. American plant with pale green fronds; the variety angustata is smaller, and the fronds are less inclined to droop. This species, like O. regalis, is deciduous. O. Claytoniana is another deciduous species, and has vivid green fronds, 2 to $3 \mathrm{ft}$. high. $\mathrm{O}$. interrupta is the same. $\mathrm{O}$. gracilis is a native of Canada, somewhat resembling a dwarf form of our Royal Fern; the fronds are about $2 \mathrm{ft}$. high. O. spectabilis is a slender form of $\mathrm{O}$. regalis ; its fronds are smaller, and the young ones always come up reddish-purple, which is its distinguishing feature. North America. These exotic species are of the simplest culture in any shady fernery, in moist peaty soil.

Ostrich Fern (Struthiopteris).

Othonna cheirifolia (Barbary Ragwort).-A distinct Composite plant with whitish-green tufts, 8 in. to I ft. high, or on very rich soils perhaps more. It is a spreading evergreen, flowering sparsely on heavy and cold soil, but on light soils often blooming somewhat freely in May. The flowers are a rich yellow, about $\mathrm{I} \frac{1}{2}$ in. across, but are not ornamental. It is useful for its distinct aspect and type of leaf chiefly on the rough rock-garden or in the mixed border. Barbary. Cuttings. Perishes in severe winters, at least on clay soils.

Ourisia coccinea. - A bright dwarf Chilian creeper, producing in early summer scarlet blossoms in slender clusters, 6 to 9 in. high. ' Though perfectly hardy, it is reputed difficult to grow. It must be placed against a block of soft porous stone in a moist and partiallyshaded place, such as the foot of a wall with an east aspect. Its creeping stems will soon run over the stone and will flourish and flower freely. A dry rockgarden is fatal to it. Scrophulariaceæ.

Oxalis (Wood Sorrel).-A large genus, consisting chiefly of plants requiring protection. A few, however, are quite hardy, neat, extremely pretty, and especially suitable for the rock-garden on account of their dwarf growth. They all thrive best in a sandy soil in the warmest and driest place in a garden. The following are the most suitable :-

0. Bowieana is one of the finest. It is a robust species, forming bold masses of leaves, 6 to 9 in. high. The large umbels of flowers are produced continuously throughout the summer. O. Bowieana is suitable only for warm borders or the foot of a south wall. In cold soils it seldom or never flowers, but on very sandy, warm, and well-drained soils it flowers abundantly, and when this is the case it may be used with effect as an edging to beds of autumn - blooming plants. Division. Cape of Good Hope.

O. floribunda.-A free-flowering kind, quite hardy in all soils; for months in succession it bears numbers of darkveined rose-coloured flowers. The whiteflowered variety flowers as freely and is in every way as valuable as the rose-coloured form. Both are very useful for the rockgarden and for margins of borders, and are easily increased by division. $\mathrm{O}$. floribunda appears to be the commonest kind of Oxalis in cultivation. It is hardy enough to encourage an attempt to naturalise it in rocky places or about ruins. S. America.

0. lasiandra.--One of the most distinct and beautiful kinds, produces very large dark green leaves, and bears in early summer umbels of numerous bright rose- 
coloured flowers. Suited for a warm rock-garden. Mexico.

O. lobata.-This stemless little gem has slender leaf-stalks and three deeplylobed bright green leaflets. Considerably above the leaves are borne singly, on slender erect stalks, blossoms about $\frac{3}{4}$ in. across, of a rich yellow colour, the centre delicately pencilled with chocolate.

lobata is very free-flowering, and is a bright little plant during sunshine. It thrives in warm sandy loam on welldrained borders or rockwork. It survives mild winters unprotected. Chili.

0 . luteola is one of the most lovely of Oxalises, and, when planted out, forms a compact tuft. The buds are $\frac{1}{2} \mathrm{in}$. in becomes a troublesome weed. If a collection be grown, it should be borne in mind that it is very difficult to preserve the correctness of the names, for the minute bulblets become mixed up with the earth, and the elasticity of the seedpods permits the seeds to scatter in all directions.

\section{Ox-eye Daisy (Chrysanthemum Leu- canthemum). \\ Ox-eye, Great (Pyrethrum). \\ Oxlip (Primula). \\ Oxytropis.-A large genus of the Pea} family, nearly allied to the Astragalus. There are several species in cultivation, the best of which is $\mathrm{O}$. pyrenaica, a very dwarf species, with pinnate leaves covered

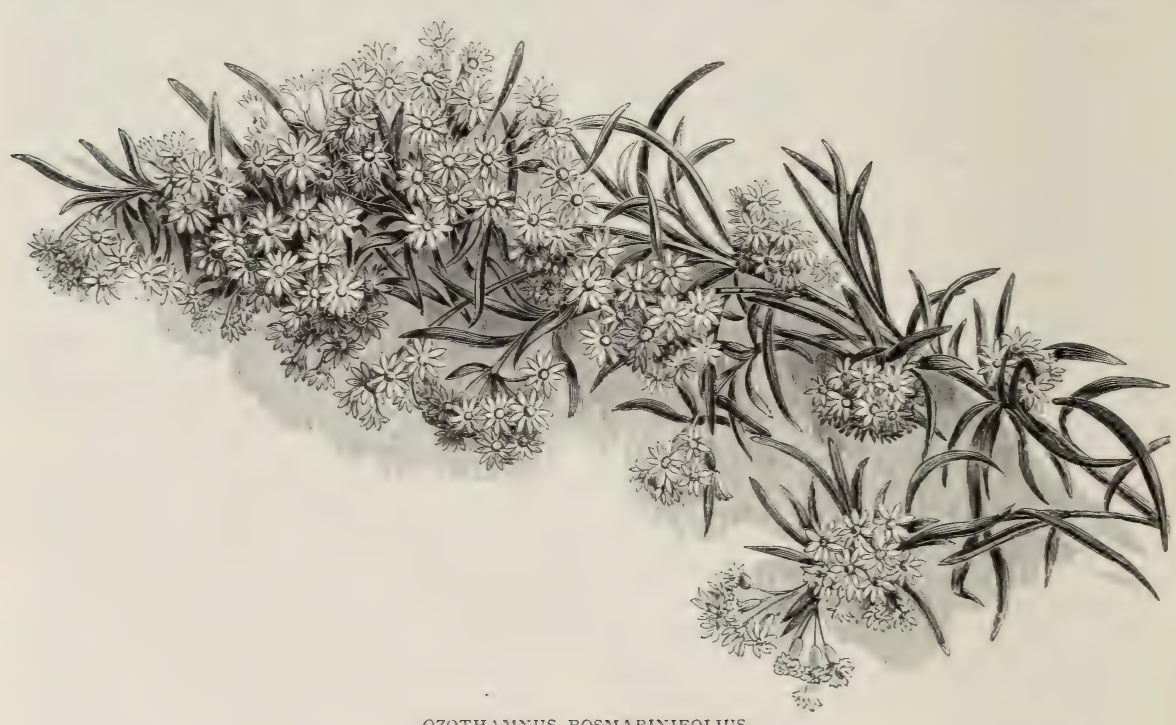

OZOTHAMXUS ROSMARINIFOLIUS.

length, and a soft creamy-yellow, but when open they are as large as a halfcrown, and pure white, shading to yellow towards the centre. O. luteola is not hardy, but in light sandy soil will survive a winter if protected.

There are other species worthy of a place, especially on very dry sandy soils, and among them are O. Smithi (a beautiful species), rosea, Deppei, speciosa, arborea, violacea, versicolor, incarnata, tetraphylla, and venusta, and the British kinds $\mathrm{O}$. Acetosella and corniculata. O. corniculata rubra is sometimes used for bedding, and should always be encouraged where there are old quarries and rough rocky places, especially in a calcareous district, for this handsome plant speedily covers the most unpromising surfaces. In gardens, however, this Wood Sorrel with silky down. These leaves barely rise above the ground, as the prostrate stems seldom exceed a few inches in height; the flowers are a purplish-lilac, barred with white, and are borne in heads of from four to fifteen. A little plant, not showy, but desirable for those parts of the rock-garden devoted to very dwarf subjects. It is a native of the Pyrenees, rare in gardens, and increased by seed or division. It should be planted on well-exposed and bare parts of rockgardens, in firm, sandy, or gravelly soil. Flowers in early summer. Another desirable plant is O. uralensis, a dwarf compact species from the Ural Mountains; its attractive rosy-blue flowers are produced in compact heads, about 4 in. high. No collection should be without it. Other kinds are-O. montana, fœetida, 
campestris and its several varieties; all of these are dwarf, similar to those described, and thrive in sandy loamy soil in open spots in the rock-garden.

Oxyura chrysanthemoides.-A neat hardy annual Composite, with showy yellow flowers. It should be sown in a broad mass in ordinary soil in autumn, and the seedlings should be well thinned out. It flowers from June to July. California.

Oyster Plant (Mertensia maritima).

Ozothamnus rosmarinifolius.-A neat little evergreen shrub from Tasmania, quite hardy in the south and coast districts. It is slender and neat, has small Rosemary-like leaves, and about the end of summer bears dense clusters of small white flowers. It flourishes in any light soil, and should be planted in an open sunny spot.

Pachyphyton bracteosum (Silverbracts).-A stout succulent plant, commonly used for placing out in geometrical beds in summer. The thick fleshy leaves form rosettes, and the whole plant has a whitened tone, giving it a distinct and ornamental character. Readily propagated by pulling off the leaves and placing them in pans in a dry warm pit or stove.

Pæderota. - Dwarf alpine herbs belonging to the Figwort family and nearly allied to the Wulfenias. There are two species in gardens, by far the more ornamental being $\mathrm{P}$. Bonarota, which is found among rocks, etc., on the Alps in various parts of Austria and Carniola. It varies in height from $2 \mathrm{in}$. to I ft. The flowers are rather small, vary from pink to bright violet, and are borne during May and June in dense erect terminal racemes, I to 3 in. long. Synonymous with P. cœrulea, the other cultivated kind, P. Ageria, is much less showy. It is $\mathrm{I}$ to $\mathrm{I} \frac{1}{2} \mathrm{ft}$. high, and bears pale yellow blossoms in May and June. Alpine districts of Carinthia, Carniola, and various parts of Italy.

Pæonia (Pcony). - The Pæonies are among the noblest and most beautiful of hardy flowers, and are indispensable for the garden. They combine stateliness of growth with beauty of colour and, frequently, delicious fragrance. Though there are several typical species in botanical collections, by far the most important are the hybrids obtained by intercrossing some half-a-dozen kinds. Pæonies are divided into two groups - the tree or shrubby kinds, comprising the varieties of P. Moutan; and the herbaceous kinds, of which the common P. officinalis is typical. The hybrid sorts have been obtained chiefly from P. officinalis and other European kinds, together with the Chinese species albiflora, sinensis, and edulis, the forms of the latter class being particularly fine. The European varieties flower early and the Chinese late, so that the flowering season is considerably prolonged.

HyBRIDS. - Among these there is an extensive variety of colours-white, pale yellow, salmon, flesh colour, and numerous intermediate shades from pale pink to brightest purple. Among the oldest varieties the most remarkable are grandiflora, double white; Louis Van Houtte, papaveriflora, rubra triumphans, sulphurea plenissima, rosea superba, Zoé, Mme. Calot, Gloria Patriæ, and Prince Troubetskoy. The most beautiful of more recent date are: Arthémise, atrosanguinea, Virgo Maria, Mme. Lemoine, L'Espérance, Triomphe de l'Exposition de Lille, Jeanne d'Arc, Eugène Verdier, and Mme. Lemoinier; and among those most worthy of notice are: Mme. Lebon, Marie Lemoine, Henri Laurent, Mme. Jules Elie, multicolor, Stanley, Charlemagne, Mme. Geissler, Bernard Palissy, and Van Dyck. There are also many commoner varieties-for example, those varieties of $P$. officinalis(such as anemonæflora, rubra, and Sabini), of P. albiflora, peregrina, paradoxa, and especially of the small P. tenuifolia, with its feathery foliage and large deep red blossoms. There is also a double variety of this species. These as well as the varieties are perfectly hardy, and need no protection against frost, however severe.

CUlture.-A good moist loam, enriched with cow manure, is the soil best suited to them. They can be planted at any time, but from October to April is the best time. Have the ground well prepared by manuring and by trenching to the depth of about $3 \mathrm{ft}$., and plant them at least $4 \mathrm{ft}$. apart in each direction. They must not be expected to flower well before the second or third year. An open position renders them robust, and they need not be shaded from the sun until they flower, when some slight shade will prolong and preserve their delicate tints, and enable them to become more thoroughly developed than they otherwise would. As soon as the buds are well formed, water the plants judiciously now and then with liquid manure. When the tufts have become very strong, and have impoverished the soil, separate and transplant them in fresh ground. 
Position.-Most gardens contain spots so shaded that few plants will thrive in them. In such places Pronies would grow luxuriantly ; and their colour would often be more intense, while they would last much longer than if fully exposed to the sun. They may therefore be made useful as well as ornamental, even in small pleasure-grounds, although their proper place is undoubtedly the fronts of shrubberies, plantations, and the sides of carriage drives. Where distant effect is required, no plants answer so well, as their size and brilliancy render them striking even at a long distance. When planted on either side of a Grass walk, their effect is admirable, especially in the morning and about sunset; and when planted in masses, they are invaluable plants which are very handsome in spring and early summer, but which do not continue in perfection very long, so that their effect when out of flower, or even their disappearance shall not mar any arrangement. This is very important, and Pæonies deserve this kind of attention.

P. Moutan (Tree Pcony).-This is another noble plant from which we have derived great wealth of beauty, for its varieties, like those of the herbaceous kinds, are very numerous. It is quite hardy, and, when properly planted, requires little care. It is invaluable for mixed borders, and is specially suited for isolation on lawns; and if, in winter, its appearance is against it, this is amply compensated for by its fine foliage and

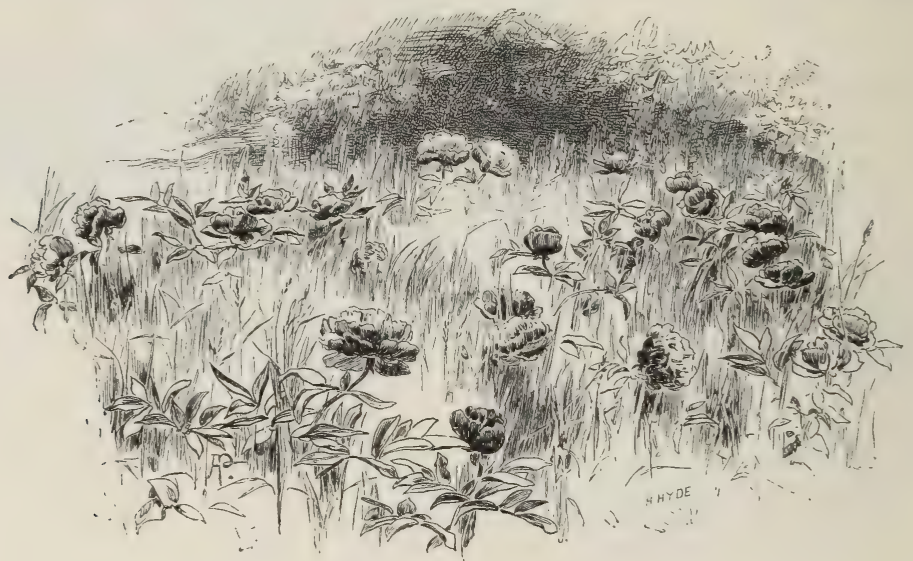

DOUBLE PEONIES IN GRASS.

for lighting up sombre nooks. If grown only for their flowers, or their buds, or for the purpose of increasing them, they may be placed in nursery lines in some rich part of the kitchen-garden.

Besides being used for the garden proper, there are few plants more fitted for the wild garden; and the most brilliant and one of the boldest things in wild gardening is a group of scarlet Pæonies in meadow Grass, in early summer. This may be managed so that they come into the garden landscape, so to say, and are seen at a considerable distance from certain points of view. So placed, they could not be an eyesore or in the way when out of flower, as they sometimes are in the mixed border. There is a good deal to be clone by the tasteful cultivator in considering the positions suited for some kinds of plants ; in deciding, for example, how to arrange gorgeous blossoms in summer. Then, too, in spring its young leaves assume every shade of colour, from violet-crimson to green. Tree Pæonies are not particular as to soil or position; they grow as well in sand, nearly pure, as in strong loam, though they prefer a good strong soil. If the soil is too sandy, decomposed manure and loam, or if too clayey, manure, sand, and similar materials should be added. Moutans are gross feeders, and amply repay occasional top-dressings of half-decomposed cow manure. Of the scarcer and better varieties nurserymen generally send out plants one or two years old, which are grafted on the roots of P. edulis. In a proper place, dig out a pit $1 \frac{1}{2} \mathrm{ft}$. deep and $2 \mathrm{ft}$. in diameter; put in a few inches of half-decomposed cow manure, and mix it well with the soil, insert the plants with the grafts buried a few inches under the ground, 
where they will, in time, throw out roots of their own. The plants do not flower well until the third year after planting, but they afterwards produce blossoms in profusion. Being of slow growth, they are not propagated by division to any great extent, but are multiplied chiefly by grafting upon the roots of the herbaceous varieties. This grafting is performed in August. The grafts are placed in frames, where they unite, and in the succeeding year are transplanted in rows in the nursery.

September and October are the best months for planting Moutans, but if varieties: Athlète, large, double, lilac; Bijou de Chusan, pure white; Carolina, bright salmon; Colonel Malcolm, violet; Comte de Flandres, very large, rose; Confucius, deep pink; Elisabeth, deep scarlet, very double ; Farezzii, large, pale lilac striped with violet; Fragrans maxima fl.-pl., pale rose; Lambertiana, blush rose petals, tipped with violet; Louise Mouchelet, large double pink; Madame de Sainte - Rome, bright lilac - rose ; Madame Stuart Low, bright salmon-red; Marie Ratier, large, rose ; Odorata Maria, pale rose ; Prince Troubetskoy, very large, double, deep lilac or violet; purpurea,

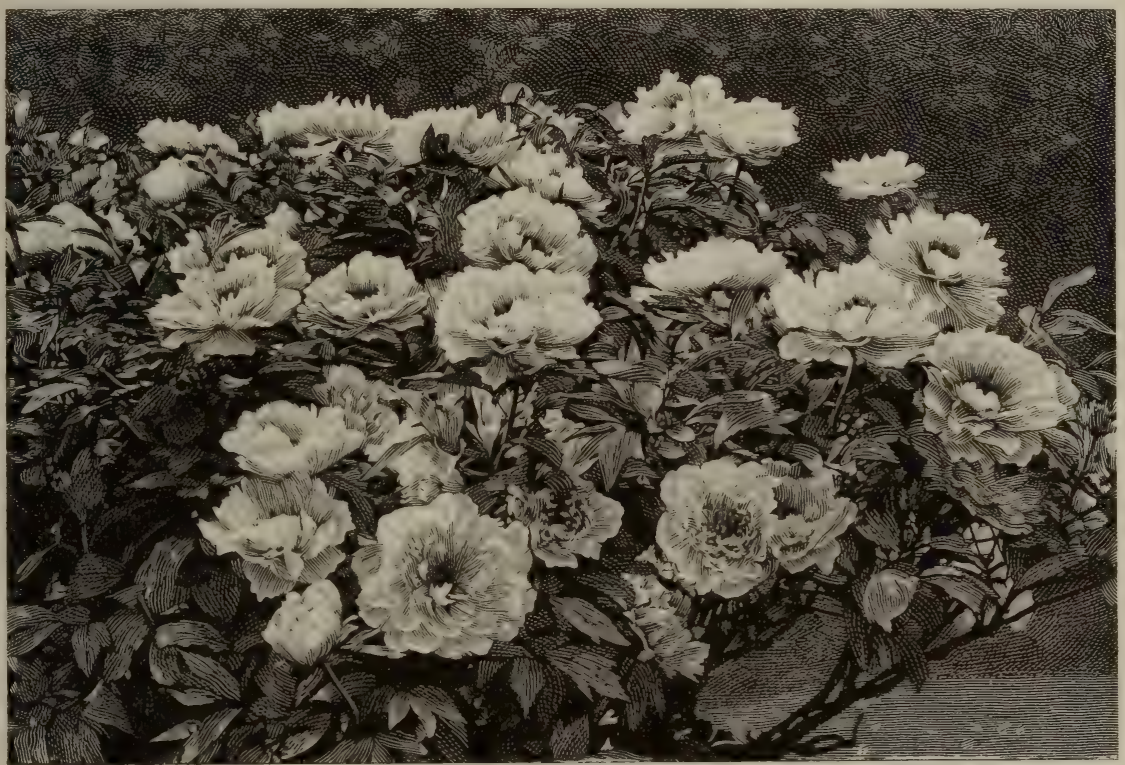

PAEONIA MOUTAN (TREE PAEONY).

planted in pots they may be put out in spring, when all danger of frost is over. Good plants set in autumn produce many flowers the second or third year after planting. Each year they increase in size and beauty, and soon become the most attractive features of the garden. They flower the first of any Pæonies, and put forth their blooms early in May. Until the second half of this century only white, rose, salmon, and lilac sorts were known; and we are indebted to $\mathrm{Mr}$. Fortune for his Chinese varieties, most of which have scarlet, violet, and magenta flowers. Von Siebold, too, introduced a number of Japanese varieties, which, however, form a different race, and are mostly single or semi-double. The following list contains some of the best a deep amaranth, semi-double kind; Ranieri, bright amaranth; Rinzii, very large, bright rose; Rosini, a semi-double, brilliant rose-coloured variety; Rubra odorata plenissima, very large, double, lilac-rose; Souvenir de Madame Knorr, large, double blush; Triomphe de Malines, large, violet, a colour which deepens at the base of the petals; Triomphe de Vandermaelen, very large, and double violet-shaded rose; Vandermaeli, blush, almost white ; Van Houttei, large, double, carmine ; and Zenobia, white. Some of the most strikingly beautiful, such as Gloria Belgarum, Elisabeth, and Souvenir de Gand, are well worthy of glass - that is, having a sash or two put over them in spring to save them from late frosts and rainy weather. Plenty of air must be 
admitted, and the flowers gain in an astonishing degree, both in size and colour.

\section{Pagoda Tree (Sophora japonica).}

Palafoxia Hookeriana. - A pretty dwarf annual Composite, forming a dense tuft about I ft. high, and producing freely loose clusters of rosy-pink flowers. It should be treated as a half-hardy annual, and grown in a warm border of sandy soil. Mexico.

Palava. - Mallow - like annuals from Peru and Chili. P. rhombifolia, about I $\mathrm{ft}$. high, is somewhat procumbent, and in July and August has rosy-purple blossoms, about $I$ in. across. P. moschata is similar, but erect. P. flexuosa, a pretty Chilian plant, about $\mathrm{I} \frac{1}{2} \mathrm{ft}$. high, also has rosy-purple blossoms. They all require sowing in heat in early spring, and, when large enough, they should be transplanted to ordinary garden soil, in a sheltered situation of the open border.

Pampas Grass (Gynerium argenteum).

Pancratium.-The only really hardy species of this bulbous genus is the South European P. illyricum, I to $2 \mathrm{ft}$. high, which bears in summer a stout flower-stem terminated by numerous umbels of attractive large white blossoms, deliciously fragrant. It thrives best in a warm exposed border of sandy loamy soil, well drained. During winter the bulbs should be protected by litter or some such material. The plants are better for transplantation about every third year; this should be effected in autumn as soon as the leaves are decayed, and the bulbs should be replanted immediately. It may be propagated by offsets from the parent bulbs. The hardiest of the other species are P. parviflorum, maritimum, littorale, and rotatum, but these require more attention, and only succeed on warm soils in exceptionally mild localities. They are best grown in a frame or a cool greenhouse.

Panicum.- - Grasses, chiefly tropical, though a few are hardy enough for outdoor cultivation.

P. altissimum is a very handsome hardy perennial Grass, very much like $\mathrm{P}$. virgatum, but more elegant. It forms dense erect tufts, 2 to $6 \frac{1}{2} \mathrm{ft}$. high, according to climate, soil, and temperature. When in flower it is very attractive, the flowers being a dark chestnut-red.

P. bulbosum.-A strong species, with a free and beautiful inflorescence. It is about $5 \mathrm{ft}$. high, and the flowers spread out very gracefully. It is elegant if grace and variety are sought, and is suited for dotting about here and there, near the margins of shrubberies, etc., and for naturalisation.

P. capillare.-A hardy annual, growing in tufts from 16 to $20 \mathrm{in}$. high, and very ornamental in full flower, the tufts being then covered with large pyramidal panicles, borne at the ends of the stems and in the axils of the stem-leaves. It grows in any soil or position, it sows itself, and is suited for border beds or for isolation, being one of the most graceful plants in cultivation.

P. virgatum. - A handsome, bold, hardy species from North America, growing, in good soil, to a height of nearly $3 \frac{1}{2} \mathrm{ft}$. It forms close compact tufts of leaves, I $\mathrm{ft}$. or more long, which are crowned from July to the first frosts with large, dense branching panicles. Its general colour is a fine lively green, and its graceful habit renders it admirable for borders or for isolation in the picturesque flower garden, the pleasure-ground, etc. The best mode of multiplying it is by division in the spring, when vegetation is just commencing.

Pansy. See Viola.

Papaver (Poppy).--Some of the most brilliant of hardy flowers, of the simplest culture. There are a few good perennials, but the majority are annual and biennial. They range from the tiny alpine Poppy to the stately $\mathrm{P}$. orientale and its varieties. The following is a selection of the best garden kinds.

P. alpinum (Alpine Poppy).-This has beautiful large white flowers, with yellow centres, and bears smooth or hairy dissected leaves, cut into fine acute lobes. A native of the higher Alps, it may sometimes be seen in good condition in our gardens, but is liable to perish, unlike a true perennial. It varies a good deal as to colour, there being white, scarlet, and yellow forms in cultivation. The variety albiflorum has white flowers, spotted at the base, while the hairy variety flaviflorum has showy orange flowers, and grows 3 or 4 in. high. Easily raised from seed. $P$. pyrenaicum is similar to $P$. alpinum, but taller. It occurs with white, yellow, and orange-red blossoms, which, however, do not always come true from seed.

P. nudicaule (Iceland Poppy).-A dwarf kind, with leaves deeply lobed and cut, and large rich yellow flowers on naked stems, 12 to 15 in. high. It is handsome for borders or the rock-garden, is easily raised from seed, and forms rich masses of cup-like flowers, but, like other dwarf Poppies, does not seem permanent, 
and should be raised annually. There are several white, yellow, and orange-red varieties, and one is very large, bold, and handsome. Siberia and the northern parts of America.

P. orientale (Oriental Poppy), the handsomest of all the poppies, is among the noblest of hardy plants. The type is a fine plant, but the variety bracteatum is flowers are pure scarlet, but a good many have a black spot. It seems as if orientale has been crossed by bracteatum, for there are a good many hybrids in gardens. The fault of this Poppy is its weak stalk, owing to which it does not hold its large flowers erect like its rival, and is sooner over. There are several varieties besides bracteatum; concolor has no spots at the

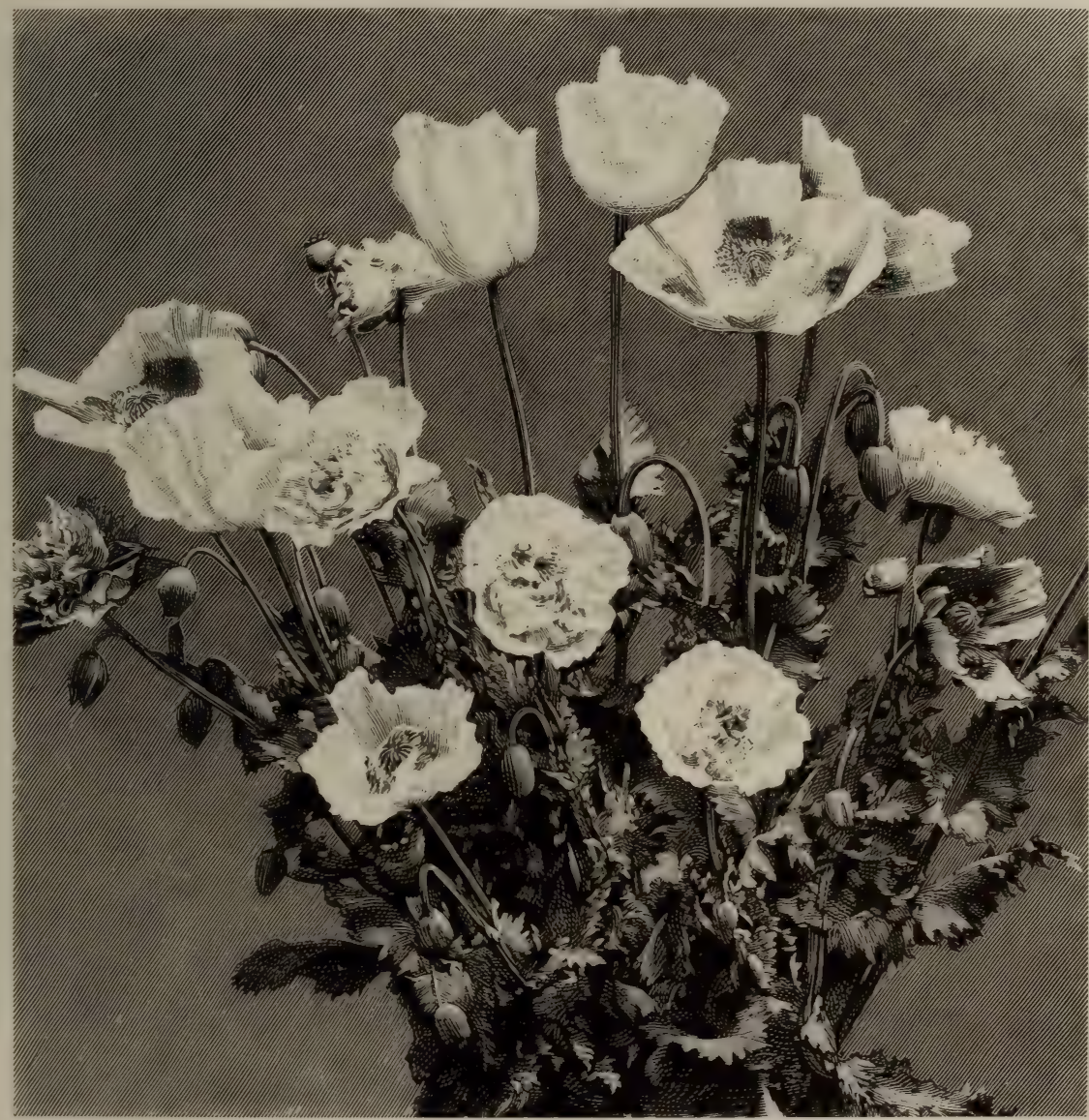

WHITE POPPIES.

much larger, and much more attractive. This variety forms huge masses of handsome foliage; the flowers are on stiff stalks, with leafy bracts at intervals, and one well-developed bract under each flower, 6 to 9 in. across, and of brilliant scarlet. Each of the four petals is marked inside at the base with a purple-black spot, the whole forming a cross which imparts to the flower a very distinct appearance. The original P. orientale has naked flower-stalks. As a rule the inner base of the petals; triumphans is dwarfer, and is very floriferous. These are all highly ornamental, valuable for borders, or for isolated masses on lawns, and also for the open parts of pleasuregrounds, as they flourish in almost any well-drained soil. They are most effective as isolated plants in the rougher parts of the pleasure-ground, and a single specimen shows to great advantage in a group of green-leaved subjects like the Ferulas. 
The Carnation, Picotee, and Ranunculus Poppies are double forms of the common red Poppy, possessing almost every colour except blue and yellow ; some being selfcoloured, while others are beautifully variegated. They are also known as French and German Poppies. Some are dwarfer than others, but all are between 2 and $3 \mathrm{ft}$. in height. Of recent years pretty single forms of the Corn Poppy have become popular under the name of "Shirley Poppies." Being hardy annuals, they can be sown where they are to bloom, but should be grown in good soil to bring out fully their size and colour. The seed, being very small, should be sown thinly, and the plants eventually thinned out to 6 or 8 in. apart, so that the lateral shoots may develop and the flowers have sufficient space. In semi-wild places, and by the sides of drives, they can be made conspicuous features; and their cultivation is recommended to lovers of hardy border flowers. Few annuals afford such a brilliant display as the different kinds of Poppy in outlying beds and borders during summer. Even at a distance their colours are strikingly effective.

P. somniferum (Opium Poppy).-This beautiful and variably-coloured Poppy is a valuable hardy annual. It generally grows about $2 \frac{1}{2} \mathrm{ft}$. in height, and varies from white to deep crimson. 'The double scarlet, the double striped, and the double white are all varieties of it, and their great flower-heads have a bold and striking effect planted in masses. By selection, a type called the Pæony-flowered Poppy has been obtained from them; it has large but very double broad-petalled flowers, which vary in colour from pure white to dark crimson. It is known in some seed lists as P. pæoniæflorum, and is distinct enough to represent a type. P. somniferum and its varieties require the same treatment as P. Rhæas.

P. umbrosum is a strikingly brilliant hardy annual, about $2 \mathrm{ft}$. high, and in habit like the common field Poppy. The flowers are a dazzling scarlet, with a jetblack blotch on the inner base of each petal, which is sometimes margined with ashy-grey. This black blotch being conspicuous also on the outer face of the petals, renders masses of the plant a grand sight. It flowers early in summer, and, as it were, perpetuates the waning glory of Anemone fulgens, which is scarcely more brilliant. It is a native of the Caucasus, and therefore perfectly hardy. Its seeds should be sown in autumn, so that strong plants may be ensured for the following summer. P. arenarium is another showy annual from the Caucasus. Other handsome Poppies, such as P. spicatum, pilosum, and lateritium, are perennial. They have orange-red blossoms, and may be grown in a full collection like the annual P. caucasicum and armeniacum. All are of the simplest culture.

Paradisia Liliastrum (=Anthericum). Paranaphelius uniflorus. - A hand-

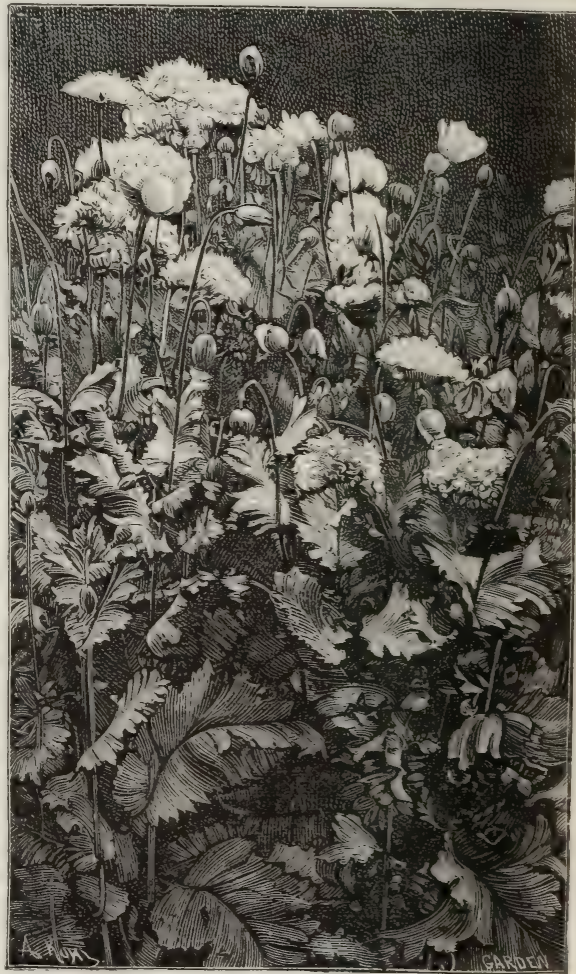

OPIUM POPPIES (PAPAVER SOMNIFERUM).

some Composite perennial, with large yellow flowers, but very rare, and little is known of its culture.

Pardanthus chinensis. - An Iris-like plant, 3 to $4 \mathrm{ft}$. high, with orange-coloured blossoms spotted with crimson. These, however, are very fugitive, and the plant not being hardy is scarcely worth growing. It should be treated like Ixia and Sparaxis.

\section{Iridaceæ. China.}

Paris quadrifolia (Herb Paris). - A native plant, about I $\mathrm{ft}$. high, and with yellowish-green flowers. Though not very handsome, it may be naturalised in places where it is not plentiful, and in shady or moist bushy spots. 
Parnassia (Grass of Parnassus).Singularly interesting and pretty plants for the artificial bog or for moist spots in the rock-garden. In our moist heaths and bogs the Marsh Parnassia (P. palustris) is frequent, and a very pretty plant it is-handsome enough to cultivate in moist spots where it could grow as in its native haunts. Three other species, natives of North America, are quite as showy, and the newest kind ( $P$. fim-

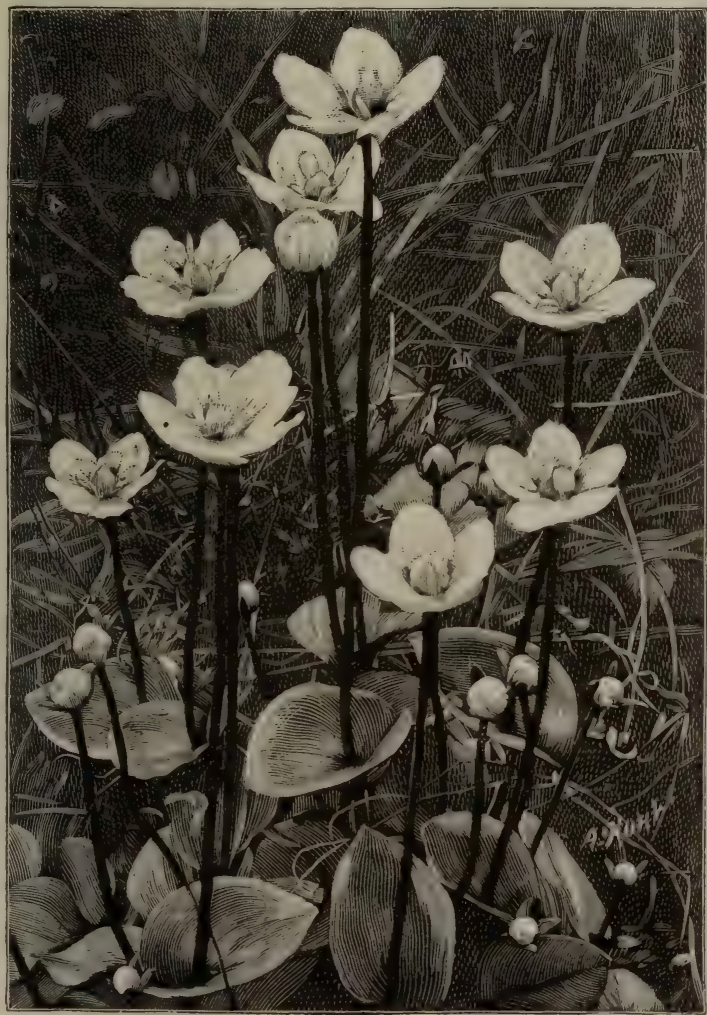

PARNASSIA PALUSTRIS (GRASS OF PARNASSUS).
Parochetus communis (Shamrock Pea).-A beautiful little creeping perennial, with Clover-like leaves. It is 2 to 3 in. high, and bears in spring Pea-shaped blossoms of a beautiful deep blue. It is of easy culture in warm positions on the rock-garden and the choice border, and where it is tender it may be grown in a cold frame. Division or seed. Nepaul. Leguminosæ.

Paronychia.--Small creepers of slight ornamental value. P. serpyllifolia, on account of its dense turfy growth, might be used for clothing a dry bank where little else thrives, or for covering a bare space in the rock-garden.

Parsley Fern (Allosorus crispus).

Parsnip, Cow (Heracleum).

Parsnip, Giant (Heracleum).

Partridge Berry (Mitchella repens).

Pascalia glauca.-A hardy Chilian plant of the Compositæ, related to Heliopsis. It is an erect perennial, with glaucous leaves and yellow flower-heads, and thrives in ordinary soil.

Paspalum.-Grasses, chiefly tropical and sub-tropical. P. elegans is a pretty hardy annual, and is about the only cultivated kind that thrives in the open air and is worth attention.

Pasque - flower (Anemone Pulsatilla).

Passerina nivalis (Sparrow-wort). - An interesting dwarf alpine plant, nearly allied to the Daphne. It is about I ft. in height, and bears Mezereum-like blossoms, and is found at very high elevations of the Pyrenees.

Passiflora cærulea (Passion-

briata) is even more attractive, as it has larger flowers, with peculiar fringe-like appendages. Its kidney-shaped root leaves resemble those of $\mathrm{P}$. asarifolia, another hardy species, about 9 in. high, which bears similar white flowers without fringes. P. caroliniana is the other species, differing from $\mathrm{P}$. asarifolia only in having oval or heart-shaped leaves; it flowers about the same time, usually from the beginning of July till the end of August. These hardy Parnassias thrive best in a moist peaty soil or a spongy bog; such as exists by the sides of streams or pools. flower). - The hardy blue Passion-flower, so common as a wall-climber in the south and in mild districts, apart from its graceful growth and its flower-beauty, is so different from other out-door plants, that it should be grown wherever the climate permits. In southern gardens, indeed, we have seen it as a trailing shrub, its long shoots being allowed to run over a sunny bank facing south ; and in such a position the plant flowered abundantly, and produced a crop of rich yellow fruits about the size of Plums. It is not so suitable for arbours or trellises as for walls, as the heat from walls 


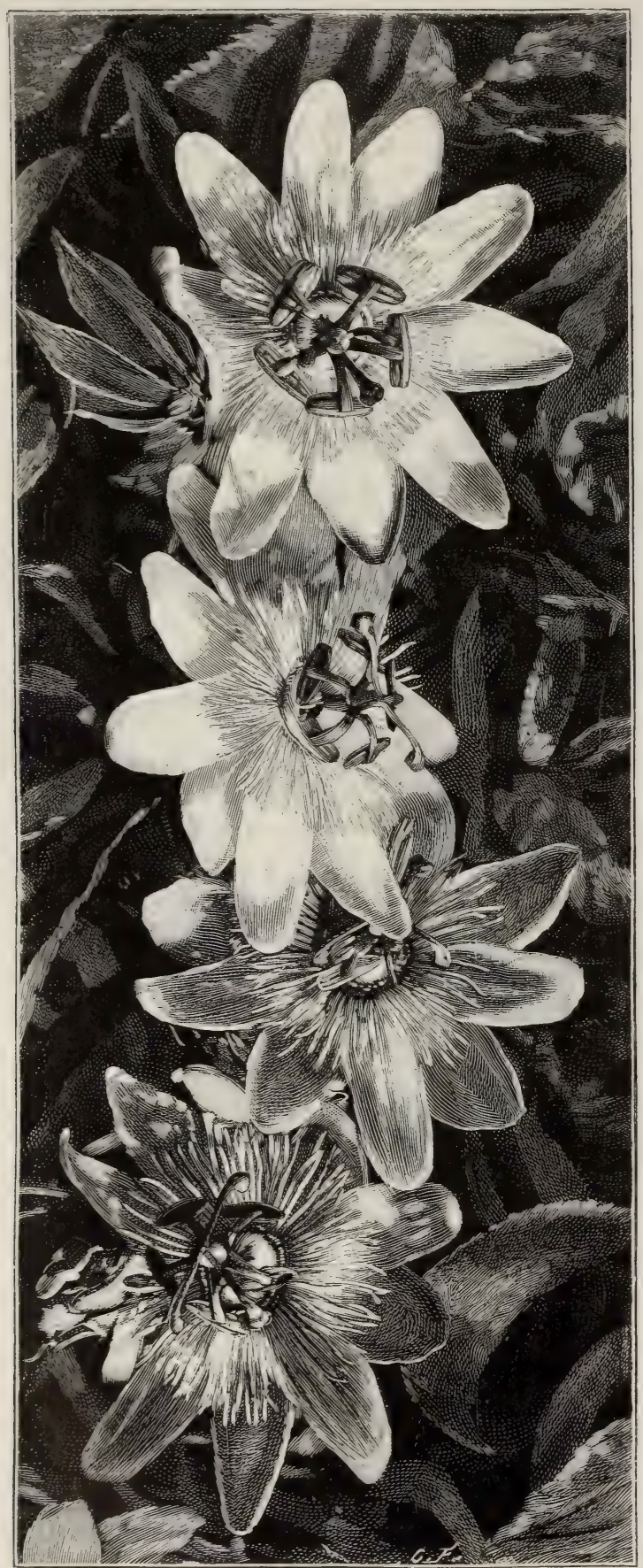

PASSIFLORA CONSTANCE ELLIOT. seems to aid in ripening, and to enable it to withstand the winter. A southern aspect is always best for it, though it flourishes against west or east walls. It only requires a good soil, the nailing of the shoots, and, perhaps, a slight protection during winter. There is now a lovely white variety, named Constance Elliot, which is quite as hardy as the type. The flowers, which are of ivory whiteness, are very freely produced. As yet rather uncommon, it is confined mainly to the greenhouse, but no one need hesitate to plant it against a sunny wall. No other variety of $\mathrm{P}$. cærulea is so distinct, and no other Passion-flower is hardy enough for out-door walls. The blue Passionflower first came from Brazil two hundred years ago.

Patrinia. - A small genus of the Valerian family, not much in cultivation. $\mathrm{P}$. rupestris is a dwarf yellow Valerian. It succeeds in light soils, but must be preserved from excessive wet in winter. Siberia.

Paulownia imperialis. - A fine flowering tree from Japan, hardly suitable for our climate, though in a few favoured places it succeeds, and numerous fine specimens have reached a considerable age. Its chief defect is that it comes into flower and leaf so early, that if the winter is mild and the spring late the buds and often the young leaves are injured by late frosts; but if otherwise, there is a glorious display of bloom. It is noble in foliage as well as in bloom, for the leaves are a foot in length, and have even exceeded 20 in. They are of a dull green and are generally lobed. The flowers are produced in erect spikes, and resemble in form those of a Bignonia ; they are of a delicate mauve-purple, blotched inside with a deeper tint. At maturity the Paulownia assumes a dense rounded head, but rarely exceeds $30 \mathrm{ft}$. in 
height, although in some south coast gardens there are specimens nearly 40 $\mathrm{ft}$. in height. If the shoots of young plants are cut back annually, as those of the Ailanthus and Catalpa often are, the Paulownia makes strong growths bearing enormous foliage, and is then of sub-tropical aspect. Paulownias are generally best on a light but deep loam, and rarely succeed in very sandy or in excessively stiff soils.

Peacock Iris (Vieusseuxia glaucopis). Pearl Bush (Exochorda grandiflora).

Pearlwort (Sagina).

Pectis angustifolia. - A pretty dwarf annual Composite from New Mexico, where it forms dense golden cushions, 6 to Io in. high. As many similar plants are much hardier, it is scarcely worth attention except in botanical collections.

Pea, Sea (Pisum maritinum).

Pelargonium. - Nearly all Pelargoniums are indigenous to the southern hemisphere, or have originated as hybrid or cross - bred varieties in European countries. They are often erroneously termed Geraniums, but although allied to the Geranium family they are totally distinct from it, Geraniums being chiefly indigenous to the northern half of the globe, some of them belonging to England, and all of them being hardy plants. The genus Pelargonium contains many species, which botanists have divided into several sections. Many kinds will grow and flower in the open during summer, although unable to withstand an ordinary winter.

Of all varieties suited for outdoor decoration, the "zonals" are the most popular and the most useful. They are supposed to be descended from two distinct species, viz. P. zonale and $P$. inquinans. First as regards the wellknown modern Zonal Pelargonium and its ever-increasing and improving varieties : As bedding-out plants they are certainly of the greatest importance ; and, indeed, without them "bedding-out" might never have become fashionable. The facility with which they yield hybrid and improved forms has led to the introduction of numerous beautiful varieties, of nearly all shades of colour, from the purest white to the most intense scarlet; while the richest purple and violet shades are also to be found, and these would almost appear to foretell the advent of even a blue Zonal Pelargonium. Great improvement has lately been effected in many families of decorative plants, but in no instance more markedly and decidedly than in the case of Zonal Pelargoniums, which, in addition to their merits as decorative plants during the summer, either under glass or out-of-doors, are also found, with proper treatment, to flower throughout the winter. The Zonal Pelargonium, on account of the profusion and brilliancy of its bloom, has sometimes been too freely used in the flower garden and elsewhere. But these matters are now, generally speaking, better understood; and by the judicious use of flowers of subdued tints in connection with bright bloom and plants with highly ornamental foliage, a glaring effect is generally avoided. The Pelargonium supplies this desideratum in an eminent degree, as among the zonal varieties there are many with variegated and exceedingly beautiful foliage. This is particularly the case in that section of the zonals known as the Tricolors, which, on account of their not succeeding so well in some localities and soils as might be desired, are possibly less grown out-ofdoors than they deserve. Where they succeed, however-which they generally do with proper attention - they form very beautiful beds, more particularly when grown for the sake of their foliage alone, the trusses of bloom being removed from time to time as they appear. The varieties known as the "bronze zonals" are also very beautiful outdoor plants, the free exposure intensifying the rich tints of the foliage.

Probably no family of decorative plants is more easily increased than the varieties of the Zonal Pelargonium. Cuttings may be.inserted whenever they can be obtained, and will root freely in any ordinary light or sandy soil. The insertions may be made in the open air during summer and autumn, but of course under glass during winter and spring. The principal stock of plants is, however, generally obtained by cuttings inserted in pots, pans, or boxes in the open air during the early autumn, such cuttings being generally considered to make the best plants. During winter the protection of a glass roof, and the exclusion of frost, are required. Zonal Pelargoniums may also be treated as annuals, and will bloom in less than ten months from the time of sowing the seed; but the seed should be sown as soon as it is ripe, say during August. Enough seed can always be had by retaining a few plants in front of a greenhouse, or in any light, airy, and warm situation. If new and improved varieties are desired, recourse must be had to artificial fertilisation; but this is unnecessary if the plants are merely required for planting out or massing in the parterre. If the plants used for seed beall of the same 
sort, the progeny may be expected to prove tolerably true, i.e. the same variety as the seed plants. The pots should be of convenient dimensions (say 6 in. in with a piece of glass, and place them in a temperature of $65^{\circ}$ more or less; the seeds will soon vegetate, and the piece of glass should then be removed; the plants

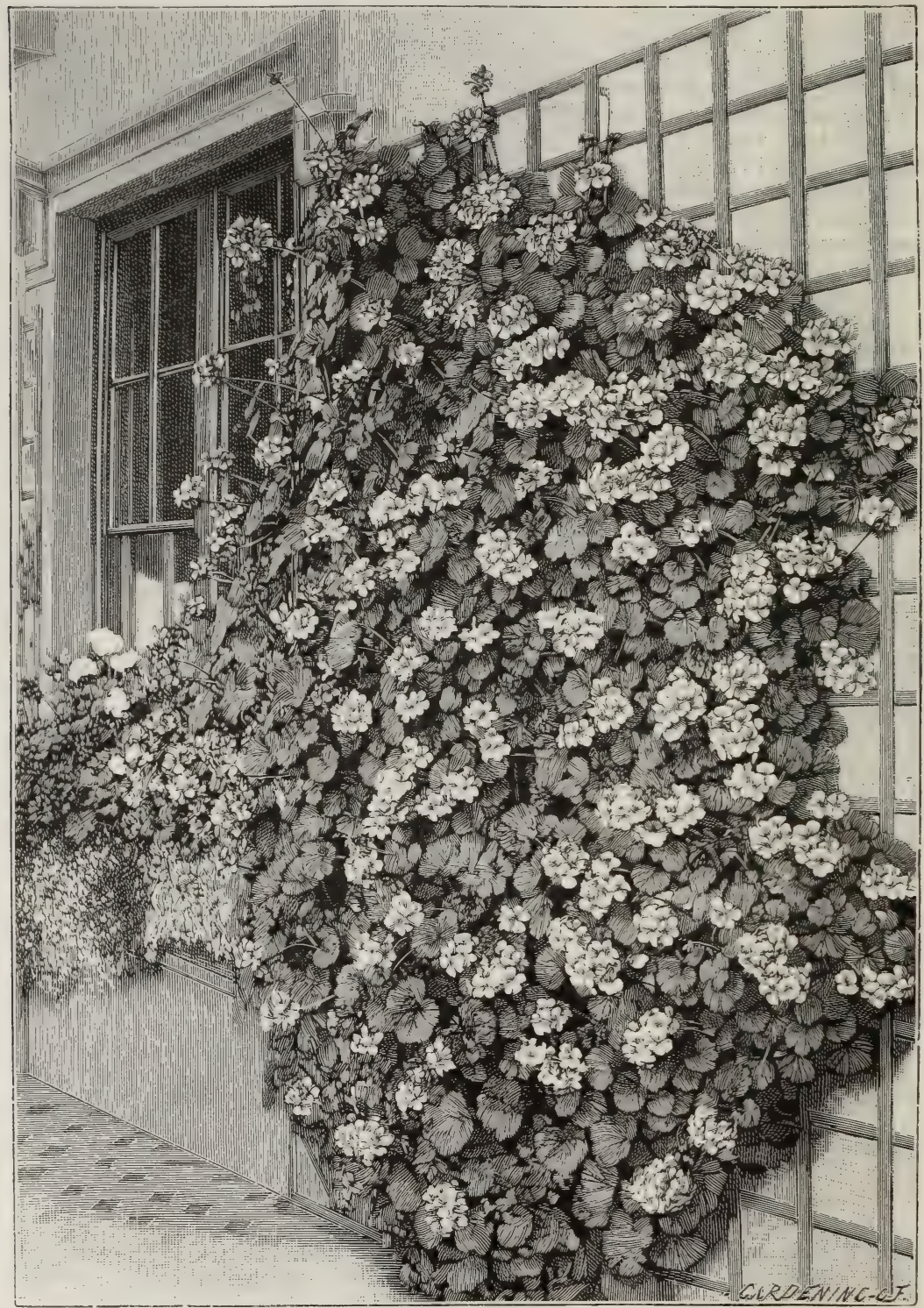

PELARGONIUM GROWN UNDER A VERANDAH.

diameter), and filled to within $\frac{1}{2}$ in. of the rims with light turfy soil ; the seed may be sown tolerably thick, gently pressed into the soil, and slightly covered with it. Water with a fine rose, cover the pots when large enough should be pricked into seed-pans and kept near the glass in a reduced temperature during the winter. Early in the following March they should be potted singly into 3 -in. pots and placed 
in a cold pit, or a similar structure where frost is excluded, until the time arrives when they may be safely planted in the flower garden or wherever they are required. During the early part of the season such plants may bloom less profusely than those propagated by cuttings, but their neat compact habit and their bright healthy foliage will amply compensate for this.

Many sorts remarkable for the beauty of their blooms, as regards form and colour, are, nevertheless, by their habit, unsuited for bedding-out; and few, if any, of the many beautiful double varieties of zonals can be recommended for outdoor culture, unless as standards, with clean stems, $2 \frac{1}{2}$ or $3 \mathrm{ft}$. in length. In this form they are sometimes very effective ; for being compelled to draw sustenance through a comparatively slender stem, this almost invariably induces a very free-flowering habit. Of course strong stakes are necessary to assist the stems to support the heavy heads, and the principal branches should be secured to strong circular wires or hoops. Single varieties may with equal facility be formed into standards, and in their case seedlings are likely to form specimens sooner than propagated plants. In the autumn or before frost, all standards should be well cut back, taken up, and repotted in pots not larger than may be required to contain the roots; they should be staked and afterwards placed in a temperature not under $60^{\circ}$ until they become fairly established. Treated thus annually, such plants are sometimes in perfect health, even when twelve or fourteen years old.

Next in importance to the zonals for outdoor culture are the Ivy-leaved species, or the varieties of $P$. lateripes. More particularly is this the case since their union with the zonal varieties, a union which has produced many highly interesting and beautiful sorts, all of which are useful for outdoor culture. As to treatment, soil, propagation, etc., they may be said to be in nearly all respects identical with those of the zonal varieties, with the possible exception of being somewhat more tender, and requiring a little more warmth during winter.

Among other Pelargoniums few are suitable for outdoor culture, or for bedding, their tendency in the open air, in even light or poor soil, being to become too luxuriant, and consequently to produce few flowers. Each section will now be considered separately, and the varieties that succeed when planted out will be mentioned. There are, however, so many varieties of the zonals, and the older varieties are so continually being superseded by others that are not always improvements, that it will only be necessary to give a short list of sorts really known to be desirable. It must, however, be borne in mind that some sorts succeed in certain soils and situations which are by no means successful in others.

The following are a few of the many zonal varieties suited for outdoor culture or for massing in the flower garden or elsewhere: Anna Pfitzer, Ball of Fire, Corsair, Culford Rose, Distinction, Dr. Orton, Fire King, Harry Hieover, Henry Jacoby, Havelock, Jenny Dodds, John Gibbons, King of the Bedders, Master Christine, Mrs. Lancaster, Mrs. Turner, Mrs. Miles, Mulberry, Newland's Mary, Vanessa, Vesuvius and its salmoncoloured variety, Violet Hill Nosegay, White Perfection, White Princess, and White Vesuvius.

The bronze zonal varieties are as well suited for bedding-out as the green-leaved kinds, being in all respects as vigorous. Their flowers vary in colour. The bright golden ground colour and rich leaf zones of some of them, however, show to greater advantage when the blooms are removed. The following are a few of those that may be considered the best bedders: Black Douglas, Bronze Beauty, Bronze Queen, Crown Prince, Gilt with Gold, Golden Harry Hieover.

There are also some useful bedding varieties with yellow zoneless leaves, such as Crystal Palace Gem, Golden Christine, and Robert Fish; while Happy Thought is a singular variety, each leaf having a large disc of a creamy-white colour, while the margins are green. This variety is inclined to grow rather too robust in rich soils.

Though the variegated zonals, or golden tricolors, do not succeed equally well as bedding plants in all kinds of soil, the following varieties will, with ordinary care, generally give satisfaction : Mrs. Pollock, Sophia Cussack, Sophia Dumaresque, Beautiful Star, Victoria Regina, Edward Richard Benyon, Macbeth, Lady Cullum, Peter Grieve, William Sandy, Prince of Wales, and Howarth Ashton.

The great drawback as regards the silver tricolor sorts, when planted out in the open air, is the circumstance of the central or green portion of the leaves expanding faster than the white or coloured margins of the same, so that the centres of the leaves become somewhat puckered. 
The following are among the best for this purpose : Italia Unita, Lass o' Gowrie, Eva Fish, Maxwell Masters, Lady Dorothy Neville, and Miss Farren.

Among silver-margined zoneless sorts, Mangle's Variegated, although a very old variety, is still useful, together with Silver Chain, Flower of Spring, Mrs. J. C. Mappin, Princess Alexandra, and Waltham Bride, the three last having pure white flowers.

Of the Iry-leaved sorts, and their hybrid

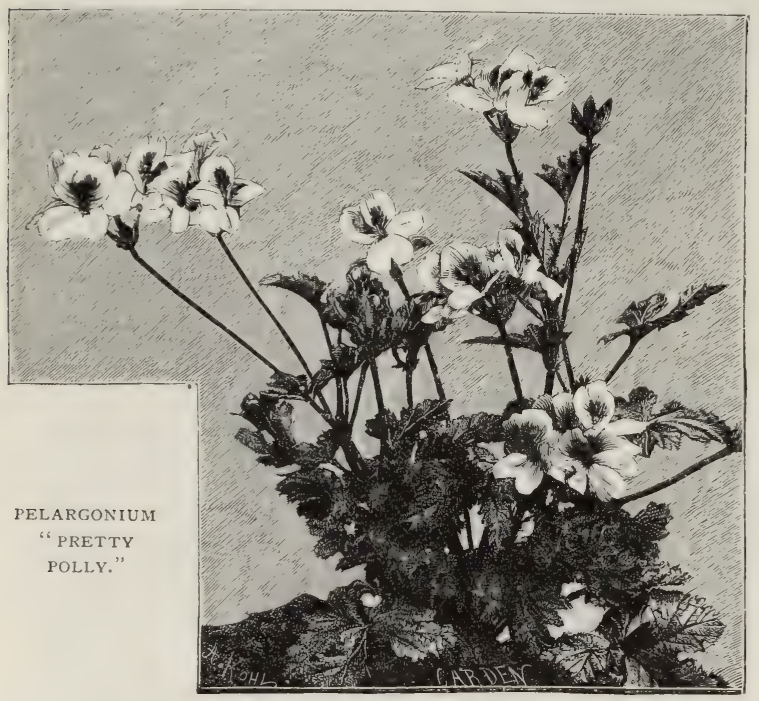

varieties, the following are useful as bedding plants: Album grandiflorum, Duke of Edinburgh, l'Elégante, Bridal Wreath, Willsi roseum, Dolly Varden, and Emperor.

Comparatively few of the Cape species or of their hybrid varieties are of much use as bedding plants; a few, however, are sometimes used with pretty good effect. Some of these are-Diadematum, Lady Mary Fox, Lady Plymouth, Pretty Polly, Prince of Orange, Rollisson's Unique, Crimson Unique, etc. Most of the sweetscented sorts, when planted out - of doors during the summer, succeed admirably, and furnish abundance of fine, healthy, fragrant flowering shoots for cutting.-P. G.

Pellæa atropurpurea. - An elegant dwarf North American Fern, quite hardy in sheltered localities if planted in a shady peat border that is well drained in winter. Some of the other North American species might also prove hardy.

Peltandra virginica. - A handsome- leaved plant of the Arum family, and a native of North America. The deep green leaves are broad, and when the plant is well grown it is effective. It is 2 to $3 \mathrm{ft}$. high, is perfectly hardy, and, like the Callas, is excellent for shallow pools or lakes. = Caladium virginicum.

\section{Peltaria alliacea.}

Pennisetum longistylum.-One of the most elegant of Grasses. It is $I$ to $I \frac{1}{2} \mathrm{ft}$. high, and the flower-spikes are borne on slender stems. They are from 4 to 6 in. long, have a singular twisted appearance, and are enveloped in a purplish feathery down. Admirably suited for cutting, as it lasts a long time. Unlike most ornamental Grasses, it is perennial and perfectly hardy. P. fimbriatum is a similar species, equally desirable.

\section{Pennyleaf (Hydroco-} tyle).

Penthorum sedoides (Virginian Stonecrop). - A Sedum-like plant from N. America, only valuable for the botanic garden.

Pentstemon. - The rocky ravines whence arise the mighty rivers of North America are the home of the Pentstemon. Varied in colour, profusely floriferous, and possessing a graceful habit, Pentstemons have a value for our flower-beds, rockgardens, and shrubberies that few other plants possess, especially as their blooming season extends over at least five months, commencing in June with the charming blue $\mathrm{P}$. procerus, and finishing off with the endless varieties of P. Hartwegi, in all shades of rose, scarlet, and crimson, whose beauty holds its own even in the dull dreary month of November, long after the more fragile denizens of the flower garden have become things of the past. Within the past few years also much has been done to improve the Pentstemon by selection of seminal varieties of $\mathrm{P}$. Hartwegi and $\mathrm{P}$. gentianoides, which, with all their wide range of colour, lack the beautiful clear blue of some of the species, and have a somewhat monotonous effect. The garden varieties, or so-called hybrids, resulting from this selection, may be ranged under two series of colours - those from P. Hartwegi belonging to the red-flowered set, and those from $\mathrm{P}$. gentianoides belonging to 
the purple-flowered class; and, strange to remark, these series of colours run parallel to other structural peculiarities. As regards culture, the species have unfortunately gained the reputation of being difficult to manage, as some, especially those of the shrubby section, show a tendency to suddenly die away when they are apparently in robust health. To ensure ordinary success, thorough drainage is a primary consideration, as they suffer more from excessive moisture at the roots than from cold. The soil best suited for all Pentstemons is good friable loam, with a mixture of well-decayed leafmould and sharp sand. It is specially advisable to have a few plants in cold frames, in order to fill any vacancies that may occur in the borders. They may be propagated either by cuttings or seeds. The former mode applies chiefly to the shrubby kinds, which strike freely in spring; and, in favourable seasons, seeds are freely produced from those from which it is not practicable to obtain cuttings. Any attempt to multiply them by dividing the tufts will generally result in the entire loss of the plants, but P. barbatus and $P$. procerus endure this mode of propagation. Seed should be sown in February or March on a gentle hot-bed under a frame, in seed-pans well drained with broken plaster and filled with a compost of peat soil and sand. In April the seedlings should be pricked out under a frame, and these, planted out in May, will usually come into flower by autumn. Another mode is to sow in May or June in the open air, in ground enriched with leaf-mould. The seed-beds should be covered with chopped Moss, to preserve a uniform coldness and humidity. In August the seedlings should be potted and removed to a greenhouse or conservatory for the winter. It is necessary to observe that the seed sown at either of these seasons frequently does not germinate until the following year.

The following are some of the best cultivated species. Many are excluded, however ; some on account of their rarity, and others, such as P. antirrhinioides, cordifolius, and Lobbianus, because they are not sufficiently hardy for border culture, though they succeed well enough against a warm wall.

P. azureus is a well-known and very effective dwarf, branching kind, with numerous erect branches, bearing many blossoms in whorls. These blossoms are rather large, and of a clear violet-blue colour. They begin to show towards the end of summer, and last a long time. Sacramento Valley, California.

P. barbatus. - A handsome and wellknown plant, commonly known as Chelone barbata. Like $P$. procerus it has the peculiarity of developing underground stems all round it, which form a tuft or patch readily divisible, whence rise, to a height of $3 \mathrm{ft}$. or more, several graceful stems, almost bare. From the axils of the bracts spring pedicels of varying length, which support numerous rosyscarlet flowers, diminishing in brightness in the lower part of the tube. Were its flower-stems capable of standing without a stake, its value would be much enhanced, but it is well worthy of a little trouble. The flowers are produced in succession, hence its beauty is retained for a considerable time. There is a white variety. The variety Torreyi is a very fine robust plant, of greater height and stronger growth, and without the beard on the lower lip of the flower, which characterises the species. Being a native of Colorado and Northern Mexico, it is hardier than the type, and is a very showy border perennial of easy culture.

P. campanulatus is an old inhabitant of our garden borders. It is a slender plant, about 18 in. high, branching freely, and in the southern counties acquiring an almost shrubby character; the rosecoloured flowers are borne in one-sided racemes. It continues blooming for a long period, as the primary branches are succeeded by secondary ones. Mexico. P. pulchellus is a variety.

P. Cobæa is one of the handsomest yet introduced. It freely produces, late in autumn, long leafy racemes of flowers, nearly 2 in. long, which are of a pale purple, pencilled with red streaks and delicately suffused with yellow, the base of the tube being a creamy-white. P. Cobæa thrives vigorously, generally without protection, but it is very difficult to propagate extensively. The name does service in trade lists for several spurious kinds, but the true plant when in flower can be readily recognised from the above description. Texas.

P. crassifolius bears in many respects a close relationship to P. Scouleri, but the flowers are of a charming light lavender colour. It is rare in cultivation, but is most desirable, and is admirably suited for a dry knoll of the rock-garden; but this knoll must be well exposed to the sun and erected on a good deep mass of bog soil or peat, so that while the situation of the plant is dry, the roots may find abundant nutriment. P. Menziesi 
resembles $\mathrm{P}$. Scouleri, but has reddishpurple flowers.

P. cyananthus. - A lovely kind, 3 to 4 ft. high, bearing in May and June dense spikes about I ft. long of bright blue flowers. Rocky Mountains. The new variety Brandegei is an improvement on the type, being more robust, and having brighter flowers.

P. diffusus is a beautiful semi-shrubby kind, 2 to $4 \mathrm{ft}$. high, freely producing violet-purple flowers in a large, loose, manybranched head. It flowers throughout the greater part of summer and autumn. Its relative $\mathrm{P}$. Richardsoni much resembles it, but is inferior in beauty, and P. Mackayanus and P. argutus are much the same. Though capable of enduring the vicissitudes of climate and the extreme cold of its native locality, it is liable to succumb to the damp of our early winters; or, if it should survive this, to keen incisive north-eastern blasts, which scorch the early spring growth as though it had been subjected to the lee-side of a blast furnace. Like all the Pentstemons, P. diffusus is readily increased by cuttings, and might come true from seed, but, in this country, seed is rarely matured. Native of the rocky ravines of the tributaries of the Columbia River.

P. Digitalis is a large-leaved freegrowing kind, of erect habit, but not very showy. The same remark applies to $\mathrm{P}$. pubescens, lævigatus, perfoliatus, and glandulosus.

P. Fendleri.-A very pretty glaucous species, with a long, erect, one-sided raceme of light purple flowers. It rarely exceeds ${ }_{5} 5$ in. in height. It is quite hardy in ordinary soils, and is one of the most distinct species in cultivation. $\mathrm{P}$. Wrighti is a similar plant with magentatinted blossoms, and its variety angustifolius is also pretty. Both are worthy of culture.

$\mathrm{P}$. Hartwegi is more generally known as P. gentianoides. Not only was the old species one of our very best autumnflowering border plants, but its progeny, called into existence by the skill of the florist, included endless variety of colour and increased size of bloom, the old narrow tubular flower acquiring almost the dimensions of a Foxglove. About the beginning of this century it was found by Humboldt and Bonpland in Mexico, at an altitude of nearly II, $000 \mathrm{ft}$., but it was not introduced into cultivation till $\mathrm{I} 828$.

P. heterophyllus. - A handsome dwarf sub-shrubby kind. Its showy flowers are produced singly or in pairs from the axils of the upper leaves. They are of a pink- lilac in the type, but seminal varieties are very liable to vary. Though hardier than many species, it succumbs to severe winters; and reserve plants should be secured. Sacramento Valley, California.

P. humilis is a very distinct alpine species, rarely exceeding 8 in. in height. It forms compact tufts, is remarkably free-flowering, and its blossoms, which are large for its size, are very attractive, being of a pleasing blue suffused with reddish-purple. $P$. humilis should be planted in the rock-garden in the most select and fully-exposed spot. A compost of gritty loam and well-decomposed leafmould should be used, and during summer the plant should be copiously watered. It blooms in early June, and is a native of the Rocky Mountains, being abundant about Pike's Peak.

P. hybridus. - In cultivation among the most precious of all flowers, are generally supposed to be descended from P. gentianoides, a species that has disappeared from the garden; but there is no doubt that the majority have come from the pretty P. Hartwegi in its simple state, a plant tolerably common in most botanical collections. P. Cobæa, too, has probably been employed in hybridising, for some varieties bear a strong resemblance to it. Whatever their parentage, they are beautiful plants, and much use should be made of them, as they are very valuable in autumn and carry their beauty into winter.

The varieties of Pentstemon generally succeed in any good soil, but are certain to do well in a good loam enriched with manure and leaf-soil. They can be planted out singly or in groups, in beds or in the mixed border, where their various colours blend charmingly. Among them we have a wonderful range of colour from pure white to glowing scarlet, with intermediate shades of pink, rose, purple, carmine, and purplish-lilac. If good plants be put out by the end of April, they will bloom about the middle of June, and yield a succession of flowers until winter. They require a deep moderately rich soil, and a position fully exposed to the sun. They are increased both by cuttings and by seeds. The former method must be resorted to in order to increase any particular variety. Cuttings should be taken in August or early in September from the young growths round the main stem, and they should be put into a prepared sandy bed, on a shady border, under a hand-glass, or into boxes or pots in a cold frame. They root readily, and those in boxes or pots might 
be wintered there, and not transplanted till spring. Those in the border should be lifted and potted, planted out in a cold frame for the winter, or transplanted to the open ground in a well-prepared bed, and protected during severe weather with a little litter or branches of evergreens ; but the young plants should not usually be planted out till March or April. To increase the stock of any given variety rapidly, the store pots of cuttings rooted in autumn should be put in a gentle bottomheat in spring, and induced to grow ; and if the young growths be taken off when they are 2 in. in length, and put into pans of sandy soil of the same temperature, they will quickly strike, and by May and June, if properly treated, will be healthy plants. The Pentstemon is a very free seeder, and there is no difficulty in obtaining seed. Seed for sowing should be taken from only the very finest varieties shawing novelty of character-for variation is always most acceptable, - and such varieties can scarcely fail to yield something worthy of cultivation. The seed should be sown in February or early in March in a gentle heat. It will quickly germinate, and when the plants are large enough to handle, they should be pricked off into shallow boxes, and, after a time, hardened off in a cold frame. Here they can remain till the end of May or later, according to size, and they should then be planted out in well-prepared beds. A generous soil will bring out the quality of the flowers as fully as possible. When they flower, which they will do by August and September, any especially good varieties should be marked to propagate from, while the inferior ones will do for the mixed border. If the bed of seedlings be allowed to stand for another season (and this is always a good plan), the seedstalks should be cut away as soon as ripe, and the bed cleaned, top-dressed with leaf-soil and short manure in spring. There will then be a plentiful harvest of flowers the following summer. Seedlings should be protected by a cold frame during winter, and planted out early in April in a deep soil and in a sunny situation. The varieties change so frequently and so many are raised from time to time that we do not give the names of the varieties supposed to have most merit, but leave the selection to taste, assisted by the catalogues of the best growers.

P. Jaffrayanus is a remarkably showy kind, and the best of the blue-flowered class. Its glaucous foliage contrasts finely with its bright clear blue blossoms. These blossoms are borne in profusion during the greater part of the summer. P. Jaffrayanus is a handsome dwarf border plant. Not being a good persistent perennial, it should be supplemented by young seedlings, which will bloom much more vigorously than old plants. Strong sunshine or wet injures the appearance of the flowers, but this is the only drawback to the cultivation of the plant. North California.

P. lætus is a close ally of P. azureus and $\mathrm{P}$. heterophyllus, and, like them, is of dwarf branching habit, with blue flowers in terminal raceme-like panicles. It grows about $\mathrm{I} \frac{1}{2} \mathrm{ft}$. high, and blooms in July and August. It is a native of California, and is as hardy as most of the species from that region.

P. Murrayanus.-A noble and distinct plant, and one of the most satisfactory to grow. When well grown, it has stems 4 to $6 \mathrm{ft}$. high, furnished with tiers of brilliant scarlet flowers, and besides its specially attractive flowers, it is very handsome in foliage, having broad glaucous lower leaves, and large stem-piercing upper ones. It should be raised from seed annually, and the seedlings should be grown well for flowering the following summer. Few plants are more worthy of care and attention. It is a native of Texas, and loves a warm sunny soil. P. centranthifolius is similar, but not so handsome, though easier to grow, and hardier.

P. ovatus, also known as P. glaucus, is a fine vigorous plant, attaining a height of 3 to $4 \mathrm{ft}$. The flowers are comparatively small, but are borne in dense masses, and exhibit shades of colour varying from intense ultramarine to deep rosy-purple; and indeed their brilliant colour, rich profusion, and the handsome contour of the plant combine to give it a special value. It should be considered a biennial, as it usually flowers so vigorously in the second year as to make little or no provision below for the following year's growth. Mountains of Columbia.

P. Palmeri.--This handsome species is of robust habit, and in good soil attains a height of 3 to $5 \mathrm{ft}$. The flowers are borne in a many-flowered naked panicle 18 to 24 in. long, they are peach-coloured and streaked with red, and the peach-coloured corolla is remarkable for a short inflated tube and a gaping mouth. The plant is quite hardy, succeeding in almost any well-drained soil. It flowers about midsummer. P. spectabilis is similar.

P. procerus is a beautiful little plant, and about the hardiest of all the species, 
as it takes care of itself in any soil. It is of a creeping habit, sending up from the tufted base numerous flowering-stems, 6 to $\mathrm{I} 2 \mathrm{in}$. high. The small flowers are in dense spikes, and, being of a lovely amethyst-blue, they make it charming for either the border or the rock-garden. It seeds abundantly. It is the earliest to blossom of all the Pentstemons. P. nitidus and $\mathrm{P}$. micranthus are synonymous with $\mathrm{P}$. procerus, and $\mathrm{P}$. confertus is somewhat similar. P. confertus has straggling stems, and is a very distinct species, though by no means showy.

P. Scouleri is a small semi-shrubby plant of twiggy growth. Its large flowers are of a slaty bluish-purple, and are arranged in short terminal racemes; they are not produced in great abundance, but, combined with the dwarf and compact growth of the plant, they have charms sufficiently distinct to render it worthy of cultivation. P. Scouleri may be readily increased in spring by cuttings of the young shoots, since such cuttings strike freely in a little bottom-heat similar to that used for ordinary bedding plants.

P. speciosus, a remarkably handsome kind, has stems 3 to $4 \mathrm{ft}$. in height, and many-flowered clusters of flowers, which are sky-blue, varying to a reddish hue. $\mathrm{P}$. glaber is nearly related to P. speciosus, but is dwarfer. The flowers are of various shades of purple, and early in summer are borne in crowded spikes about $\mathrm{I} \mathrm{ft}$. in length. On account of its dwarfness it is better suited for the rock-garden than most of the kinds. P. grandiflorus is extremely handsome, and allied to P. speciosus and P. glaber. It grows about 3 ft. high, and from July to August produces large flowers of a beautiful pink colour. Another and similar species is $\mathrm{P}$. secundiflorus, which bears in one-sided racemes blossoms of clear blue and violet. It is about $\mathrm{I} \frac{1}{2} \mathrm{ft}$. high when well grown. P. acuminatus is a beautiful similar kind. These all require to be raised from seed annually, and to be planted out the second year.

Perilla nankinensis. - A half-hardy annual, with dark vinous-purple foliage. Generally used in lines, but a few plants in a group here and there in the mixed border or the sub-tropical garden are effective. Seed should be sown about the middle of February in pans or boxes in heat : the seedlings should be transplanted into boxes in soil not over-rich, and after being gradually hardened off, they should be planted out about the end of May. For those without artificial heat in spring it is not a very suitable plant, as it requires heat to get to the requisite size for planting in proper time. It is much used in bedding-out, and often with the worst results, so far as taste is concerned.

Periploca græca.-A rapid-growing shrubby climber. It is excellent for walls, arbours, trellises, and the like, but on account of the somewhat unpleasant odour of its flowers it is not advisable to plant it against the walls of a dwellinghouse. Its long slender stems and branches form a dense mass, and at midsummer are covered with a profusion of brownish-red flowers, which have a velvety appearance. It is deciduous, and therefore unsuitable for a winter-screen. A native of Southern Europe, it is perfectly hardy, and has been grown in English gardens for nearly three centuries.

\section{Periwinkle (Vinca) \\ Pernettya mucro-} nata. - A beautiful little Evergreen of the Heath family. Though from South America, it is hardy enough for every English garden. Apart from the ever-

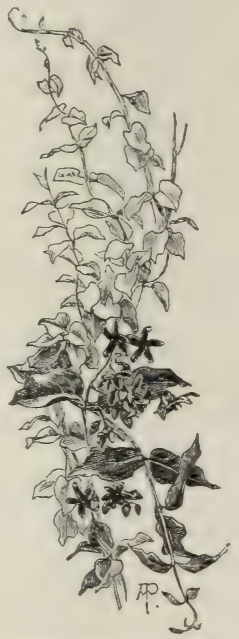

PERIPLOCA GRACA. green foliage, its principal beauty lies in the berries which it bears in autumn. After an abundant crop of small white blossoms, they are the size of small Cherries, are a dull purple in the type, but there are varieties with berries of white, rose, pink, crimson, purple-black, and every intermediate shade of tint. There are few more charming dwarf shrubs than Pernettyas. They should be planted in every garden where the soil is peaty, sandy, or of light loam. Even a heavy soil may be made suitable by a large addition of decayed leaf-mould and sand. For autumn and winter beds on a lawn near the house they are excellent, as they have a cheerful aspect throughout the winter.

\section{Persicary (Polygonum Persicaria).}

Petasites fragrans (Winter Heliotrope). - A plant 4 to $\mathrm{I} 2$ in. high. In December and January, unless the weather is very severe, it bears flowers, which are deliciously fragrant, of a pale dingy lilac, in a rather short racemose panicle. It is unfit for garden culture, as it runs very much at the root and becomes a perfect weed, but it may be 
planted in semi-wild places, lanes, and hedgerows, as it is very useful for winter bouquets, and may carpet, so to say, a small clump of shrubbery, where it can be conveniently gathered, but it should be confined to this. Another species, P. vulgaris (Common Butterbur), is a native herb, 2 to $2 \frac{1}{2} \mathrm{ft}$. high, closely allied to the common Coltsfoot, but having great Rhubarb-like foliage. The flowers appear in spring before the leaves, and are of a dull pinkish-purple. Exotic plants, with less effective leaves, have lately been much used in gardens; but it should not be allowed to come nearer to the garden than the margin of some adjacent stream, though it may be in a moist bottom among other large-leaved herbaceous plants. Division.

Petrocallis pyrenaica (Rock Beauty). -A beautiful little alpine plant, forming a dense cushion, 2 to 3 in. high, and, when not in flower, resembling a mossy Saxifrage. Its flowers are pale lilac, faintly veined, sweet-scented, and appear in April. Though perfectly hardy, it is fragile, and is suited only for careful culture in the well-made rock-garden; and there it should be planted in sandy fibry loam, in rather level warm spots, where it can root freely in moist soil, and yet be near broken rocks and stones, down the buried sides of which it could send its roots. It should always have a sunny position. It may also be grown in pots plunged in sand in the open air, and in frames in winter, but it becomes drawn and delicate under glass of any kind. Easily increased by seed or careful division. Alps and Pyrenees.

Petunias.-Petunias have lately been less used for summer bedding, doubtless owing to the great increase of bedding varieties of Pelargoniums, and the more general use of fine-foliaged plants. In certain positions, however, some Petunias produce a charming effect in masses ; and all are so well suited for large vases, for baskets of mixed plants, for low trellises, and for planting under windows and walls, that their culture is worthy of being continued and even extended. The spot chosen for Petunias should be open and sunny, and the soil deep and rich, for in low damp situations they mildew and canker as soon as the first cold nights of autumn set in. The best bedding varieties are Spitfire, dark purplish-crimson; Dr. Hogg, purple, with white throat; Miss Amy, crimson and white ; Countess of Ellesmere, rosy-crimson, with a lighter throat; and Delicata, white, striped with purple. If they are sown in heat in Febru- ary or March, good plants may be had for putting out at the end of May, but it is not safe to plant them out earlier. Seedlings, too, are now so good that they are frequently planted in mixed borders for cutting. The named kinds must be propagated from cuttings. Cuttings should be inserted in August in a bed of leaves or other fermenting material at a temperature of $70^{\circ}$ to $75^{\circ}$, and with a top-heat of $65^{\circ}$, since they strike quickly under such conditions. As soon as rooted they should be taken out of the bottom-heat and placed in cold frames till frosty nights set in; then they should be removed to an intermediate house and placed on shelves near the glass, remaining there in store-pots till spring, and then potted off singly and grown on till plantingout time as sturdily as possible. The roots are so brittle that, however well they are rooted, the soil does not adhere to them; and this is why it is necessary to pot singly, for if the plants are put in pans or boxes, and transplanted thence to the beds, they suffer greatly, and are a long time getting re-established.W. W.

Phacelia.-A small Californian genus of hardy annuals, but none of the cultivated kinds are very desirable. $P$. congesta is the best, being smaller than either P. tanacetifolia or circinalis. They have dense heads of small blue or violet flowers. Hydrophyllaceæ.

\section{Phalangium (=Anthericum).}

Phalocallis plumbea. - A Mexican bulb. Its slender stems, a yard or so high, bear flowers about 3 in. across, which are lead-coloured and tinged with yellow. These flowers, however, are very fugitive, often lasting only a few hours. P. plumbea is not very hardy, but is interesting to grow with tender bulbs such as Sparaxis and Ixia. Iridaceæ.

\section{Pharbitis ( = Ipomea).}

Phaseolus (Kidney Bean).-A very large genus of the Pea family. The common Scarlet Runner (P. multiflorus) and the French Bean (P. vulgaris) are the most familiar examples, and the other species are suitable only for botanical collections. A pretty effect is often given by the Scarlet Runner on trellises in cottage-gardens.

Pheasant's-eye (Narcissus poeticus).

Philadelphus (Mock Orange).—A valuable genus of shrubs commonly represented by the Mock Orange or Syringa (P. coronarius), which is in almost every shrubbery. To many this common kind is objectionable on account of the powerful odour of its blossoms, but such a 
vigorous grower and profuse flowerer cannot well be dispensed with; though it is well not to plant it too near to the house or to a walk. There are a great many kinds, but the great similarity among them renders it necessary to make a limited selection of the very best. The North American species are very much finer than the common Syringa, and are best represented by $\mathrm{P}$. grandiflorus, P. inodorus, P. speciosus, and P. Gordonianus. These are all large shrubs, 6 to Io $\mathrm{ft}$. high, and form rounded masses almost as broad as they are high. They all produce from midsummer till the end of July clusters of large white flowers, with little or no scent, and the largest- the names of the Mock Oranges in nurseries, that with the exception of those like $\mathrm{P}$. coronarius and $\mathrm{P}$. grandiflorus, one can never be sure of getting the species ordered. There are numerous named varieties of $P$. coronarius. The variegated-leaved form is attractive, the variegation being creamy-white and deep green. One variety called primulæflorus has semi-double flowers, but is undesirable, as the doubling of the flowers is not complete. A really ornamental variety is P. c. foliis aureis, with golden-yellow foliage, particularly bright in early summer ; it is most effective in company with contrasting foliage like that of the purple Hazel or purple Cherry Plum, but should

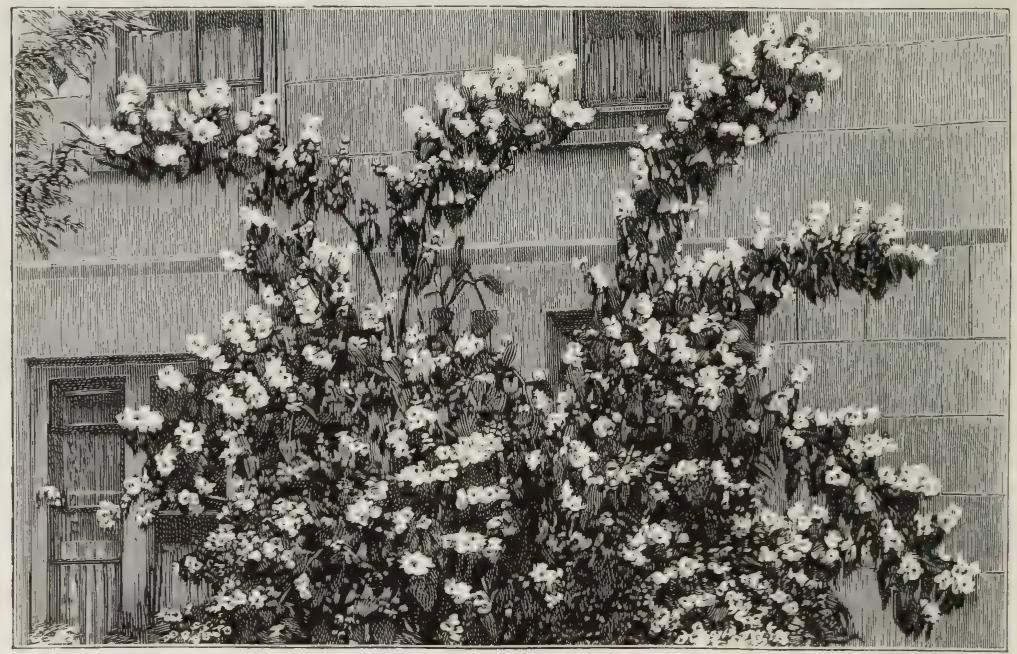

PHILADELPHUS GRANDIFLORUS.

flowered kind is P. grandiflorus, with snowy-white blossoms 2 in. across. Its scarcely less beautiful variety is called laxus, on account of its less dense habit of growth and flower-clusters; indeed, there is not a finer white-flowering shrub in our gardens than P. grandiflorus, and if there is only room for one kind, it should certainly be the one planted. The other kinds, though they resemble one another in growth and flower, are desirable because they flower in succession. P. inodorus, P. Gordonianus, and $\mathrm{P}$. hirsutus are all fine species, and if space will permit, the gardener may add to these the slender P. Satzumi from Japan, P. Lewisi from North America, and P. verrucosus, also American. Most of these are procurable from nurseries, but they are not invariably known under the names cited; indeed, so confused are be planted in partial shade, or its foliage will be damaged by the hot sun of summer. An extremely pretty little shrub is $\mathrm{P}$. microphyllus, the pigmy of the genus. Its foliage is smaller than the Myrtle, and its slender branches are whitened in summer with a profusion of small flowers. It has recently been introduced from New Mexico, and though hardy enough for the south, is perhaps too tender for northern or cold districts.

Phleum (Cat's-tail). - Grasses, some native. The variegated-leaved form of $\mathrm{P}$. pratense is pretty and constant, and is suitable for edgings in any soil. Division.

Phlomis (Jerusalem Sage). - Among the finest hardy plants of the Sage family. There are about a dozen species and varieties in cultivation, and amongst them there is a great diversity of size and habit. Some, like P. fruticosa, are shrubs, 
others are stout herbaceous plants, while others again, such as P. armeniaca, are sufficiently alpine to allow of their being grown in the rock-garden. The most desirable is P. fruticosa, a half-shrubby plant, 3 to $4 \mathrm{ft}$. high. Its hoary branches and Sage-like leaves are covered with rusty down, while its large rich yellow flowers are produced in dense whorls, for about half the length of the branches. They are very attractive during June, July, and August. It may be grown in the mixed border or may be associated with shrubs, but should be placed in an open spot. It is a native of S. Europe, but is hardy in all light soils in the southern counties. Of the few other shrubby kinds none is so fine, and though $\mathrm{P}$. ferruginea is similar, it is neither so effective nor so hardy. Of herbaceous kinds the best is P. Herbaventi, a strong plant, forming an erect spreading mass, I to $3 \mathrm{ft}$. high. Its rich purplish-violet flowers are borne in dense whorls. P. tuberosa and P. purpurea, with purple flowers, are handsome when grown well, and are excellent for naturalising with it, as they flourish in any soil or situation. The best herbaceous kinds with yellow flowers are P. Russelliana and P. Samia, both of which grow about $3 \mathrm{ft}$. high, and bear in summer a profusion of flowers in whorls. They are strong growers, and do well for naturalising. P. armeniaca, a very dwarf species with neat silvery leaves and reddish-purple flowers, is very suitable for the rock-garden. P. cashmeriana, a handsome species, has lately reappeared in cultivation. It somewhat resembles $P$. Herba-venti, but its flower-heads are denser, and its flowers, besides being larger, have a broad violetpurple lip. All the species are easily propagated--the shrubby kinds by cuttings and seed, the herbaceous sorts by division and seed.

Phlox.--One of the most popular of North American genera. It contains, for the most part, showy garden perennials; but the annual P. Drummondialone has produced distinct varieties enough to furnish a garden with almost every shade of colour. The perennials are very numerous, and present such variety in habit, that for garden purposes they may be divided into three distinct groups. One is alpine in habit ; of this the beautiful P. subulata, or Moss Pink, is the best-known, but there are many others in the Rocky Mountains and westward, some of them more truely alpine and unknown to cultivators. Next to these are several that may be grouped as running or creeping
Phloxes. These are perennial, but their principal stems are prostrate, though their flowering stems are erect. Lastly, there are the well-known tall garden Phloxes, generally called the perennial Phloxes, though all Phloxes but P. Drummondi are perennial. Perennial Phloxes have been so hybridised that the types are quite lost sight of in a vast number of garden forms. P. subulata, for instance, varies so much in the wild state that its forms have been described as species.

EARLY OR SUMMER - FLOWERING PHLOXEs have chiefly been derived from P. suffruticosa. They include many varieties, varying principally in colour, and flowering during June and July. They grow in any good border or bed. If the ground be naturally unsuitable, it can easily be adapted; if the subsoil be too wet, it must be drained, and about 9 in. of good Hazel-loam laid on the surface and enriched with good old manure and a small quantity of broken bones. In the herbaceous border a pit can be dug-say, I 2 in. square and 9 in. deep-and filled with this compost. Summer Phloxes are extremely useful in the herbaceous border in June and July, as they come between the spring and autumn sorts. The following are twenty-four of the finest: Beauty, Beauty of Edinburgh, Bridesmaid, Conqueror, Caller Ou, George Eyles, James Nicholson, Mrs. P. Guthrie, Mrs. Burton, Mrs. Gellatly, Philip Pollock, William Mitchell, Allen M'Lean, Dr. Robert Black, Duchess of Athole, Indian Chief, Mary Shaw, Mrs. Ritchie, President, Redbraes, Socrates, The Bouquet, The Deacon, and The Shah.

AUTUMN OR LATE - FLOWERING PhLOXES have been obtained by hybridising and selecting from various N. American species, principally from P. paniculata and its varieties acuminata, decussata, and pyramidalis. This class is stronger and taller than the early Phloxes, and immediately succeeds them in flower, thus prolonging the season at least two months from the end of July. They are remarkable for exceedingly bright and varied colours, including all shades from rich vermilion to pure white. Some are beautifully striped. There are endless varieties, more or less distinct, but the following will be found a good selection: Coccinea, David Syme, Gavin Greenshields, Jane Welsh, Jenny Grieve, Lothair, Matthew Miller, Mrs. Keynes, Monsieur Rafarin, Rêve d'Or, Robert Paterson, William Blackwood, Andrew Borrowman, Carnation, Henry Cannell, James Alexander, James Cocker, Madame 
Verlot, Major Molesworth, Miss Wallace, Mrs. Tennant, Thos. Chisholm, Triomphe du Parc de Neuilly, and William Veitch. For large beds, back lines of borders, or park decoration, the following are the most effective varieties, and can be used according to the shades of colour required,

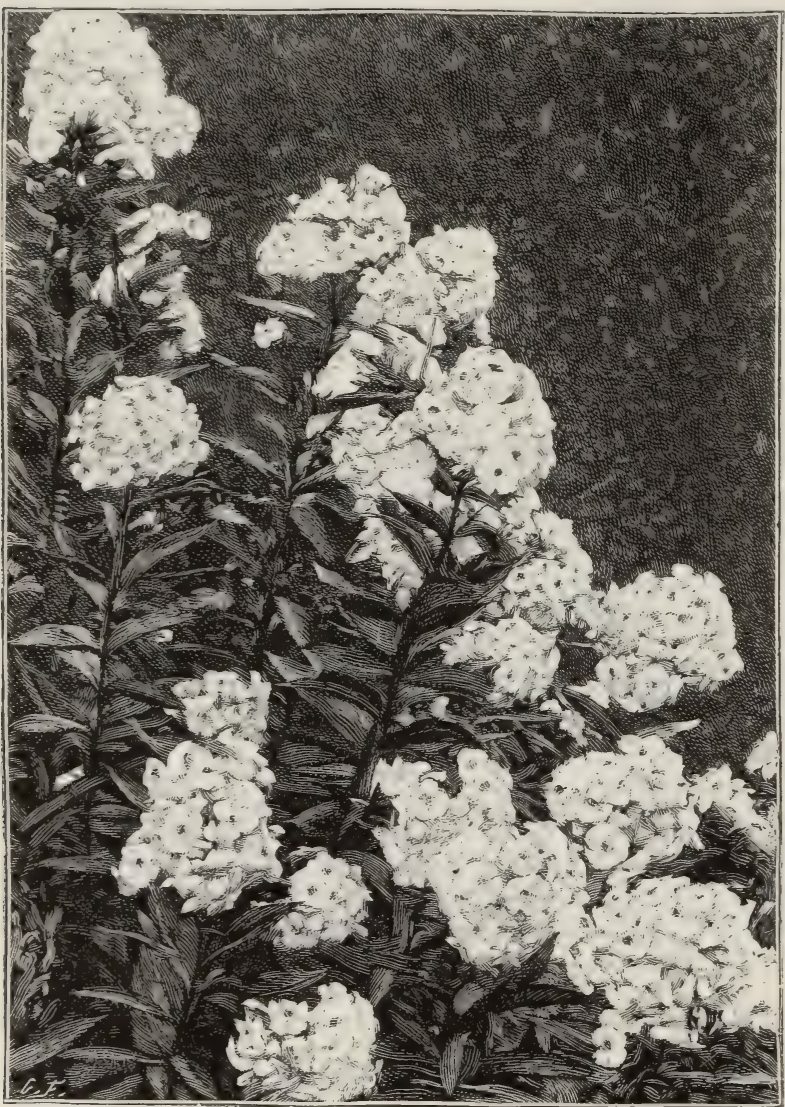

WHITE HERBACEOUS PHLOX.

viz.: Coccinea, rich vermilion; Carnation, white and spotted with purple; James Alexander, rich crimson; Lothair, bright scarlet; Mrs. Keynes, pure white; Robert Paterson, rich crimson; William Blackwood, rosy-salmon; Miss Wallace, pure white; and Major Molesworth, scarlet, with a crimson eye. When cultivated in beds or borders, the early and late sorts should be planted alternately, and arranged according to height and colour, and a mass of bloom, lasting for at least three months, would be produced. The only labour required after planting would be to give each plant a good stake, and to tie it up when necessary. In spring the number of shoots should be reduced according to the strength of the plant and nature of the variety. Phloxes of this group are also improved by a liberal top-dressing every spring of good rich soil; and in very hot and dry seasons a good watering will very much prolong the bloom.

PROPAGATION may be effected by seed, by cuttings of the stems and roots, and by division. Seed should be taken from the best sorts; it should be sown in boxes or pans in good free loam, immediately after being saved, and kept in a greenhouse or warm pit close to the glass. The young seedlings will appear in February and March; and as soon as they are fit to handle, they should be pricked into boxes of good soil, and kept close and warm for a short time ; they can then be grown with the other plants intended for the flower garden. The strongest will be fit to plant out in April and May. They will flower the first season, but will not be strong or well until the second. In the second year all the best sorts ought to be marked and then grown a third year, to test them with the best named kinds. Cuttings can be taken at all seasons. In the case of new or rare sorts, a few might be treated in a hot pit like Dahlias, the cuttings being taken off as soon as they are $3 \mathrm{in}$. in length; or the plants might be cut into single eyes, in which case they will soon root in the bed of a propagating-house. Phloxes can also be propagated by roots, the oldest of which should be cut into pieces about $\frac{1}{2}$ in. in length, sown, so to speak, in boxes, and treated like seedlings.

The leaves also strike, but they are long in making shoots, and altogether this mode of propagation is too slow to be recommended. The mode of propagating by division consists simply in 
taking the old plant and cutting it into small pieces.

Exhibition PhLOXEs, ETc.-An exhibition Phlox should be a perfect circle, quite smooth on the edge, and of good substance ; the colours should be clear and well defined, the flowers arranged close on the spike and overlapping each other; their size should be about one inch in diameter. The spike of an early Phlox ought to be quite conical, and that of a late one a corymb. The habit of the plant should be strong and erect, with plenty of broad and healthy foliage, and it should not exceed 3 or $4 \mathrm{ft}$, in height.

P. Carolina is a handsome plant, about I ft. high, with slender stems terminated by a cluster of large showy blossoms of a rich deep'rose. P. ovata is equally desirable, and has broader leaves; while P. nitida is also handsome. P. glaberrima, of more slender growth, is less attractive, and is more suitable for a botanical collection. These kinds flower in summer, and in an open position grow well in any ordinary soil.

P. divaricata. - A very distinct and handsome plant, and larger than either the Creeping Phlox ( $P$. repens) or the Moss Pink ( $P$. subulata), attaining a height of about I $\mathrm{ft}$. It bears large lilac-purple blossoms, while the leaves are rounded at the base, and are egg-shaped or lanceshaped. Rock-garden in good soil. Flowers in summer. North America. Division.

P. Drummondi.-One of the most beautiful of half-hardy annuals. Its colours are varied and brilliant, and are not injured by bad weather, like those of many other flowers. Considering its easy culture, and the fact that a few packets of seed will yield so many pleasing colours, the wonder is that it is not more extensively grown. It may be used in a variety of ways apart from border decoration. Beds of standard Roses carpeted with it are highly effective ; and as it does not interfere with the well-being of the standard Roses, but on the contrary hides and ornaments their naked stems, this should be a sufficient inducement to plant it specially for that purpose. It is also very suitable for rustic vases and boxes; but it is when grown in masses that its beauty and diversity of colour are best seen. Seed should be sown about the first week in March in shallow pans or boxes, in a light rich soil, and a warm and rather moist temperature. As soon as the seedlings can be handled without injury, they should be pricked off in boxes or a bed in a warm house in a tempera- ture of $50^{\circ}$ to $60^{\circ}$. Here they will soon grow, and as the weather gets warm the boxes should be placed out in the shade to harden the plants. Those growing in a bed should be again transplanted to a prepared bed in a cold frame, kept covered for a few days, and hardened gradually. When the plants are 3 to 4 in. high they should have the main shoot pinched out, to induce a lateral and bushy growth, and to prolong the flowering period. The soil should be rich, and an abundance of decayed leaves suits this Phlox well. The bed should be fully exposed to the sun, and as long as there is good moist soil at the roots the plants will be uninjured even in the hottest weather. Although generally treated as an annual, P. Drummondi strikes freely from cuttings in autumn; and these are useful for potculture and early spring bloom in the conservatory or the greenhouse. Varieties are endless, and some very distinct named sorts differ from the type not only in colour, but in growth. Among these are Hortensiflora, Rose Chamois, Heynholdi cardinalis, Radowitzi,'grandiflora, Victoria, and compacta. The first two are very dwarf and compact, and of all the strains there is an indescribable range of colour.

P. pilosa is a pretty plant, ro or 12 in. high. From June to August it bears in rather large flat clusters a great many purple flowers, $\frac{1}{2}$ to $\frac{3}{4}$ in. in diameter. It is one of the rarest of cultivated Phloxes, though a spurious kind is sometimes sold for it. The true plant reminds one of P. Drummondi by its leaves, its habit and size, and the colour of its flowers. Another rare species is the true P. bifida, a very elegant plant, the leaves of which are narrow and the corolla cut into very narrow segments; the colour is a bluish-purple.

P. reptans (Creeping Phlox).--This is a beautiful little plant with the large flowers : and the rich colour of the taller Phloxes. It mantles the old border or the rock-garden with a soft green, I or 2 in. thick, and sends up numbers of stems from 4 to 6 in. at the end of April or beginning of May, each producing from five to eight deep-rose flowers. It is almost indispensable for the rock-garden or for borders; and it makes pretty tufts round beds of hardy plants, and on the front edge of the mixed border : it is also useful for spring-bedding, for vases, or for the edges of raised beds; and everybody who cares about hardy spring flowers should grow it for some of the purposes mentioned. It is by no means fastidious as to soil or situation, but will 
thrive best in peat soils or in light rich soils. As it creeps along the ground giving off numbers of rootlets at the joints, it is propagated with the greatest ease. It is known as $P$. verna and $P$. stolonifera as well as $P$. reptans. $P$. procumbens is a similar plant, but taller, and not so desirable.

$P$. setacea is sometimes considered the same as P. subulata, but its leaves are longer and are farther apart on its trailing stems, while the whole plant is less hard and rigid. The flowers are of a charming soft rosy-pink, and have delicate markings at the mouths of the tubes. P. s. violacea is a handsome Scotch variety distinguished by a greater laxity of growth and by a much deeper tint of colour, almost approaching a crimson. Both the variety and the type are lovely plants and desirable for the rock-garden, where with roots deeply seated among the fissures-and enjoying coolness and moisture, the plants thrive luxuriantly in any amount of sunshine.

P. subulata (Moss Pink).-A Mosslike little Evergreen. The pointed leaves are very numerous; and the flowers, which are of pinkish-purple or rose colour, with a dark centre, are so dense as to completely hide the plant during the blooming season. The stems, though 4 in. to I $\mathrm{ft}$. high, are always prostrate, so that the dense matted tufts are seldom more than 6 in. high; but in very favourable rich and moist, sandy, and welldrained soil, when the plant is fully exposed, the tufts attain a diameter of several feet, and a height of $\mathrm{I} f \mathrm{ft}$. or more. P. frondosa is a vigorous form of P. subulata, admirably suited for the front rank of a sunny herbaceous border, and there in any ordinary light garden soil it will soon cover almost a square yard of surface. Its trailing branches are made to look more massive by the formation of a dense rosette of leaves in the axil of each of the older leaves. $\mathrm{P}$. nivalis is as trailing, but is smaller, and has shorter leaves more densely arranged. Its flowers are of snow-white purity. P. Nelsoni is no doubt a hybrid between P. subulata and its forms, as it possesses foliage of an intermediate character. It has pure white flowers with a charming pink eye. Besides this, the late Mr. Nelson, of Aldborough, raised a large number of seedlings, as varied in hue as Phlox Drummondi, the most distinct being $P$. Vivid, Model, Grandiflora, Aldboroughensis, Bride, and Perfection. All are very lovely, and are almost indispensable to every good rock-garden or border.

Culture of Alpine Phlox.-The dwarf species are so closely allied that the cultural remarks which apply to one will apply to all. Well-drained ordinary garden soil and a good sunny exposure are essential. Though perfectly hardy and unaffected by even extreme frosts, they cannot endure the damp atmosphere of mild winters. They do not seed treely, and must be increased by cuttings. Some care is necessary, but a sharp knife and a careful hand will soon remove the two or three pairs of leaves with their included buds without damaging either the slender stem or the joint. These should be taken off in July, when the branches are just commencing to harden, and should be inserted in sandy soil in a frame where they can be shaded from full sunshine, and given the benefit of the night dews by the removal of the lights. Here they will soon root and become good flowering plants the following season. With large patches, the readiest mode of increase is to sprinkle sandy soil over the entire plant and to work the same gently amongst the branches with the hand; and if this be done during the summer or the early autumn, the trailing branches will form roots the following season, and may be planted elsewhere. Few plants are more valuable than these Phloxes for the spring-garden, as they are hardy and dwarf, neat in habit and profuse in bloom, and form gay cushions on the level ground, or pendent sheets from the tops of crags or from chinks in the rock-garden. Rocky hills and sandy wastes in North America.

Phormium tenax (New Zealand Flax). - A hardy plant, with something of the habit of a large Iris, and forming tufts of broad, shining leathery leaves, 5 to $6 \frac{1}{2} \mathrm{ft}$. high, and gracefully arched at the top. The lemon-coloured flowers are borne in erect loose spikes just above the foliage. It will generally enjoy greenhouse temperature, though in genial places in south and west of England and Ireland it does very well in the open air. It thrives best in a light deep soil. Its best use is for the summer decoration of the garden ; and a few specimens well grown and plunged in the Grass or in the centre of a bed give a most distinct aspect to the scene. The large plants are best suited for this, but small ones will prove equally useful and effective in vases, to which they give a grace that vases rarely possess. In winter also, the New Zealand Flax is useful alike for the house, conservatory, and hall-decoration. When grown large in tubs it is very suitable for the large conservatory and for important positions in 
the flower garden. In the extreme south of England and Ireland it thrives in water as well as on land, and may be used with fine effect as an aquatic. The variegated variety is also a capital plant for the open air in warm situations in the south of England and Ireland, and in any case it will do out-of-doors in the summer. Division of the tufts in summer.

Phragmites communis (Great Reed).This common indigenous elegant waterside Grass should always find a place by the margins of artificial water wherever it is not plentiful. It is excellent as a cover for Duck.

Phygelius capensis. - This highly ornamental plant appears to be nearly related to the Chelone and the Pentstemon, but is very distinct in its general effect. It grows some 3 or $4 \mathrm{ft}$. high, and has numerous semishrubby stems, is terminated by a long branching raceme of brilliant scarlet flowers, and is most persistent in flower, for it begins in May and June and blooms far into autumn. It is hardy in the neighbourhood of London, though it does not flourish so well in the open border as it does under the shelter of a wall. In this latter position it attains large proportions, and thrives vigorously. It prefers a light rich soil, but in warm seashore districts is not fastidious. Readily increased by portions of the root-stock, the bases of the stems being furnished with rootlets. S. Africa. Scrophulariaceæ.

Phyllostachys bambusoides.-A noble fine-foliaged plant, resembling and allied to the Bamboos. It grows from io to $12 \mathrm{ft}$. high, with broad shining panicles, nearly $2 \mathrm{ft}$. long. It requires the same treatment as the Bamboos, and, like them, is best suited for sheltered sunny positions in deep, sandy, well-drained loam. It is quite hardy in the southern counties.

Physalis Alkekengi (Winter Cherry). - A singularly handsome plant, bearing in autumn and winter bright orange-red bladder-like calices, which enclose Cherrylike fruits. It is a hardy perennial, but requires a sunny situation in a warm border. It is a good old plant, and worth a little care as to position. It is $\mathbf{I}$ to $I^{\frac{1}{2}}$ ft. high. Easily propagated by division or seed. S. Europe. Solanaceæ.

Physostegia.-Handsome perennials of the Labiatæ, closely allied to Dracocephalum, and useful for associating with the bolder kinds of hardy plants. There are three kinds. $P$. virginiana has erect stems, I to $4 \mathrm{ft}$. high, and flesh- coloured or purple flowers crowded in terminal racemes. P. imbricata has higher and more slender stems, broader leaves, a globular, and not egg-shaped, calyx, and larger flowers of a deeper colour. Texas. P. denticulata is similar to $\mathrm{P}$. virginiana, but is rarer and less showy. All these kinds flower in summer

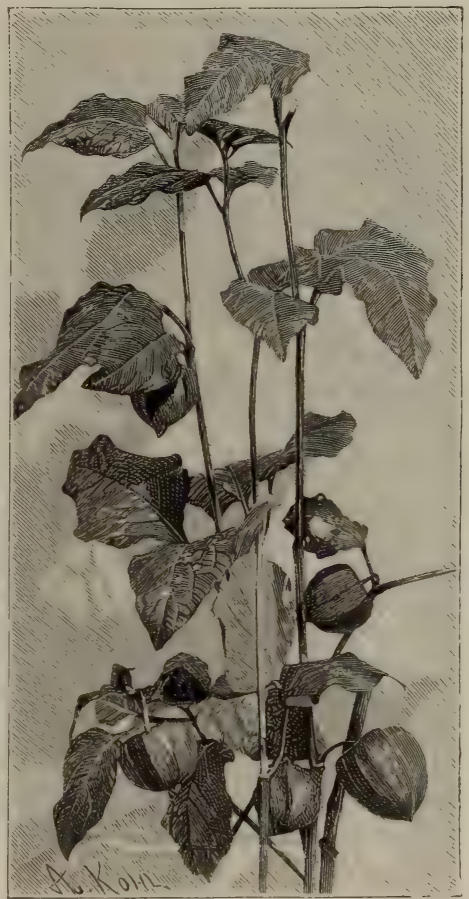

PHYSALIS ALKEKENGI (WINTER CHERRV),

and thrive in any ordinary soil. Division in spring. Excellent for naturalising in moist loam.

Phyteuma (Rampion).-Although the Rampions are not as showy as other members of the Hairbell family, they are neat, pretty, and interesting. Their flowers are produced in globose or elongated heads; they are small, but their want of size is compensated for by their numbers. Rampions enjoy a sunny position, and some of them are capital rock-plants. P. orbiculare is a rare and desirable native Rampion. Its flowerheads are $\mathrm{I}$ to $2 \mathrm{ft}$. high, and it may be classed amongst plants suitable for the front of the border; but it is better among rock-plants, where it would be free from the destructive effects of the hoe and rake. On the rock-garden it flourishes in a dry position in a mixture of limestone grit, 
peat, sand, and loam. Its flowers, which are violet-blue, are borne in July. It is extremely impatient of removal or division, and should be raised from seed sown in autumn in a cool frame. P. Sieberi is very desirable and neat for the rockgarden. It requires a moist but sunny situation, and does well in a mixture of leaf-mould, peat, and sand. It forms cushion-like tufts, and in May and June produces abundance of dark blue flower-

dwarfer. It bears pretty blue flowers, on stems from 6 to $\mathrm{I} 2$ in. in height, and is evergreen. Seed sown in autumn.

Phytolacca decandra (Virginian Poke).-A herbaceous perennial, from $5 \frac{1}{2}$ to nearly Io ft. high, and with stems, branches, leaf-stalks, veins of the leaves, and flower-stalks all of a reddish hue. The flowers, which are numerous and borne on cylindrical spikes, are at first white, but afterwards change to a delicate rose. In autumn the colour of the leaves contrasts finely with the pendent purple berries. It is very hardy, requiring scarcely any attention, and grows in almost any kind of soil. Seed or division. It forms a very free and vigorous mass of vegetation, and though perhaps scarcely refined enough in leaf for flower-garden use, it merits a place wherever rich herbaceous vegetation is desired, whether near the rougher approaches of a hardy fernery, in open glades near woodland walks, or in any like position. N. America.

P. icosandra is a bushy plant, 2 to $3 \mathrm{ft}$. high, the leaves of which are similar to those of a Hydrangea. It bears longish spikes

heads, on stems 4 to 6 in. long. Division. $P$. humile is a neat tufted plant, suitable for the rock-garden, requiring a dry sheltered position in winter, and plenty of water in summer. It is not so neat as the last, but is a little larger in all its parts. The flowers are blue, and are produced in June on stems 6 in. high. Division. P. comosum is an extremely slow-growing plant, and requires to be carefully watched, or a slug will do it considerable damage in a single night. It is a genuine rock-plant, and is suitable for a fissure vertical or sloping to the sun. It does best amongst a mixture of a little loam, peat, sand, or grit, where it can root to the depth of $2 \mathrm{ft}$. It bears almost stalkless heads of dark purple flowers, and has Holly-like leaves in June and July, and comes best from seed. P. Charmeli and P. Scheuchzeri are too nearly allied to be in the same garden, except for purposes of comparison. P. Scheuchzeri is the of rather inconspicuous creamy-white flowers, which are succeeded by fruitclusters similar in size and shape to Indian Corn, but composed of ripe Blackberries. It requires the same treatment and position as $\mathrm{P}$. decandra.

\section{Pine Barren Beauty (Pyxidanthera} barbulate).

Pinguicula (Butterwort). - These pretty and interesting dwarf bog-plants are very desirable for the artificial bog or moist spots in the rock-garden. There are about half-a-dozen kinds, all resembling each other. All except P. vallisneriæfolia are natives. P. grandiflora (Irish Butterwort) is the finest. Its flowers are large, and uniformly of a decidedly bluepurple, and the leaves, which are broad and spreading, lie flat upon the rock or soil. It prefers the shady side of a moist mossy rock, where the face is steep and the narrow chinks are filled with rich loam. If planted in earth alone, 
where the drainage is imperfect, it usually perishes in winter. The blossoms are borne four or five on each crown, the latter being usually solitary, as the result of their dense wide-spreading foliage. P. alpina differs from all the other species in having white flowers, marked more or less with lemon-yellow stains on the lip, but sometimes tinted with pale pink. It roots firmly, by means of strong woody fibres. It prefers a peaty soil mingled with shale or rough gravel, and shady humid positions, such as are afforded by a high rock-garden with a north aspect, or by the shelter of a north wall. P. vulgaris, which is too well known to require description, grows freely in any sunny position in rich moist peat or peaty loam. A small form, with leaves almost exactly resembling those of $\mathrm{P}$. alpina, both in form and colour, is found in alpine bogs in the north of England. P. lusitanica, found on the west coast of Scotland and in Ireland, is smaller than any of the preceding, and has pale yellow flowers. It grows in peaty bogs exposed to the sun.

P. vallisneriæfolia. - This beautiful species differs from others of the genus in its clustered habit of growth, having sometimes six, eight, ten, or even twelve crowns massed together in one clump. Its leaves are of a pale yellowish-green, and sometimes very thin, almost transparent. They are linear and undulated at the margins, and are borne in dense erect tufts. Towards the end of the season they lengthen, sometimes becoming 4 or 5 in. long, and occasionally even 7 in. The flowers are large, and of a soft lilac colour, with conspicuous white or pale centres. Dripping fissures and ledges of calcareous rocks (frequently in tufa) suit the plant perfectly, but it requires very free drainage, continuous moisture, and a very humid atmosphere. Mountains of Spain.

\section{Pink (Dianthus).}

Pink, Fire (Silene virginica).

Pink, Moss (Phlox subulata).

\section{Pipsissewa (Chimaphila).}

Piptanthus nepalensis (Nepaul Laburnum). - A Pea-flowered shrub, hardy enough for walls, which it covers with large deep green leaves similar in shape to those of the common Laburnum, and in southern and warm localities, withstands our winters without even this protection. But it is only to be recommended for walls, and is not the most desirable of plants even for them. It has evergreen foliage, and in early summer bears long dense clusters of large bright yellow flowers similar to those of the Laburnum, but larger. It succeeds best in light soils. Himalayan Region.
Piptatherum multiflorum.-A large perennial Grass with elegant feathery panicles, useful for arranging with cut flowers. Vigorous in any soil, and quite hardy.

Pisum maritimum (Sea Pea).-An interesting and pretty native prostrate plant, with bluish-purple flowers produced in summer. It is suited for borders and fringes of shrubberies, in deep sandy soil. In the College Botanic Gardens, at Dublin, it makes a free and handsome plant, owing perhaps to its proximity to the sea, and to being rooted in a rich marine deposit. Division and seed.

Pitcher-plant (Darlingtonia).

Plantain Lily (Funkia).

\section{Plantain, Rattlesnake (Goodyera).}

Plantain, Water (Alisma).

Platycodon. - P. grandiflorum, sometimes called Campanula grandiflora, is a handsome Campanula-like plant and a good perennial, perfectly hardy in light dry soils, but most impatient of damp and undrained situations, where its thick fleshy roots are sure to decay. Sometimes the decay commences below and spreads upward, but it generally begins above and spreads downward, and the plant rots off at the neck. The flowers are 2 to $3 \mathrm{in}$. across, and of a deep blue with a slight slaty shade. They are produced in clusters at the end of each branch. The branches are 18 in. high, and very slender at the base, so that if unsupported in their early stage of growth, they are sure to fall to the ground, and the plant, however beautiful its blossoms, will present an untidy appearance. Such a result, due to early neglect, it will be almost impossible to repair when the flowers are nearly developed, as branch after branch will break away in the process of tying. In such a case it will be better to leave them alone and allow the beauty of the bloom to compensate for the untidy appearance of the plant, merely pegging down the branches, to secure them from being broken by the wind. Perhaps the best position for the plant would be to let it overhang a ledge in some sunny corner of the rock-garden, where its negligent growth would be in keeping with the situation, and where its flowers, being on a level with the eye, would be shown to great advantage. Like most Campanulas it has a tendency to sport in colour, and to revert from blue to white through various modifications. Equally pretty and acceptable as a garden plant is the white variety, though by no means so frequent as the type. A good rich loamy soil suits it best, but it requires good drainage and an open situation. 
The best mode of propagation is that of raising seedlings, as seed can be readily procured. The young shoots, if taken off when about 3 in. long, in spring, and placed in a gentle bottom-heat, will strike, but not freely. The plant is a bad one to divide-division often resulting in failure, and, if attempted, must be carried out in May, when the growth has just commenced. Siberia. July. P. autumnale, or chinense, from China and Japan, is taller and more robust than P. grandiflorum, and under favourable circumstances attains a height of $3 \mathrm{ft}$. Its leaves are narrower, but more dense, and its flowers, though smaller, are more numerous, and pretty evenly distributed along the upper half of the stems. Being taller, and the young shoots being far more woody and vigorous than those of $P$. grandiflorum, it should be in the second or third rank of the herbaceous border. Besides a white variety, it has a tendency to become semi-double, by a sort of "hosein-hose" reduplication of the corolla, similar to what occurs in many of our Campanulas. The dwarf variety, Mariesi, from Japan, is distinct and excellent.

Platyloma.-In some mild localities the elegant New Zealand Fern, P. rotundifolium, will thrive in the open air, but it seldom does satisfactorily. P. atro-purpureum is synonymous with Pellæa.

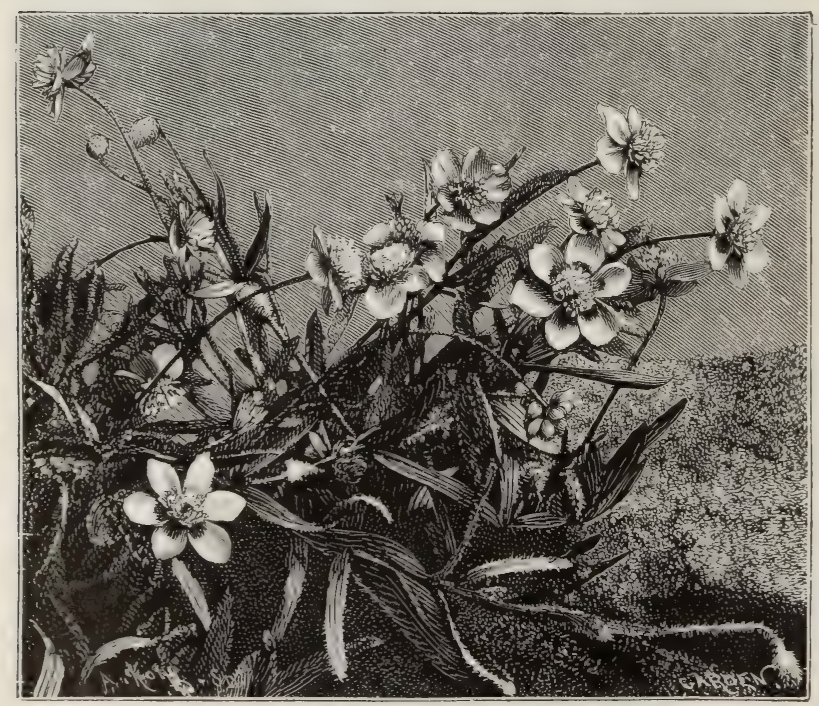

PLATYSTEMON CALIFORNICUS.

Platystemon californicus.-A pretty Californian Poppywort, and a hardy annual. It is a dwarf trailer, growing freely, and forming a dense tuft, which in summer is studded thickly with sulphuryellow blossoms. It is of the simplest culture, merely requiring to be sown in ordinary soil in the open border either in autumn or spring; but the seedlings should be well thinned out. P. leiocarpum is a similar kind.

Plectogyne variegata.-A Liliaceous plant with broad handsome leaves, like the common Aspidistra lurida. It is worthy of extended culture, but as yet it has not been introduced elsewhere than at Kew. There it is hardy in light soil though unprotected in winter. Japan.

\section{Plum (Prunus).}

Plumbago capensis, usually grown under glass, is a capital plant for planting out in summer, for it produces lovely pale blue flowers profusely and continuously throughout the summer. In view of this, the plants should be specially prepared, young ones being. always the best for edgings, though taller ones may be used in certain positions. P. capensis is used with admirable effect in German gardens.

P. Larpentæ.-A dwarf herbaceous plant, perfectly hardy. Its numerous wiry stems form neat and full tufts, varying from 6 to Io in. high, according to soil and position. In September these become nearly covered with flowers, arranged in close trusses at the ends of the shoots, and of a fine cobalt - blue, changing to violet, and usually lasting till the frosts. A warm sandy loam or other light soil and a sunny warm position greatly improve the show of bloom. In consequence of its semi - prostrate habit, the plant is well suited for planting above the upper edges of vertical stones or slopes on the rock-garden, and it may be used with good effect as a border plant, or for edgings in the flower garden, particularly in the case of slightly - raised beds. It is also suited for banks. China. Very easily increased by division of the root during winter or early spring.

Poa.-Perennial and annual Grasses, few being worth cultivating. P. fertilis is 
one of the most elegant of Grasses. Its dense tufts of long, soft, smooth, slender leaves are Io to $\mathrm{I} 8 \mathrm{in}$. high, and arch on every side in the most graceful manner. In the flowering season they are surmounted by airy, diffuse, purplish or violet-tinged panicles, rising to twice

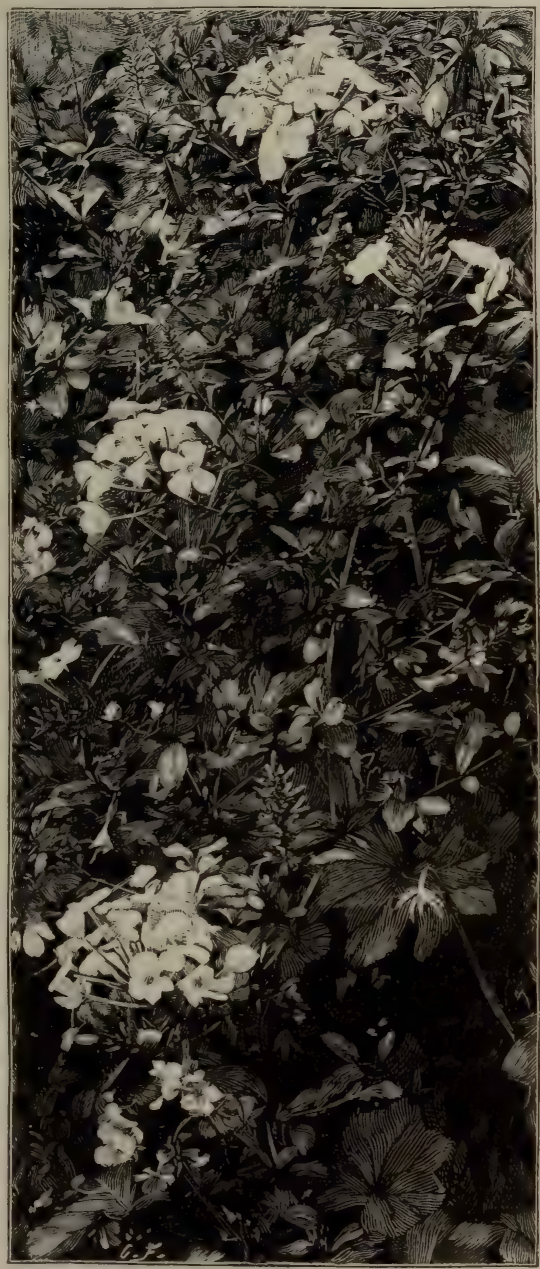

PLUMBAGO CAPENSIS.

the height of the tufts. Isolated on lawns, the plant is most effective, and if planted in good soil it gives no trouble. $P$. aquatica is a stout native Grass, 4 to $6 \mathrm{ft}$. high. It usually occurs in wet ditches, by rivers, and in marshes. It is one of the boldest and handsomest of hardy Grasses for planting by the margins of pieces of artificial water or streams, associated with such plants as the Typhas,
Acorus, Bulrush, and Water Dock. It increases rapidly.

Podolepis. - A pretty half-hardy annual from New Holland. P. gracilis is of slender growth, about $I \frac{1}{2} \mathrm{ft}$. high, and bears terminal flower-heads of rosy-purple about $I$ in. across. There is also a white variety. $P$. acuminata and $P$. chrysantha are similar, but have yellow flowers. They require to be sown in light warm soils in spring. Compositæ.

Podophyllum Emodi is similar to P. peltatum, but handsomer. The stem and leaves have a reddish tinge, which gives the plant a very distinct appearance. The fruits are 2 in. long, and are of a coral-red colour. The plant succeeds perfectly in peaty soil if planted in warm sheltered spots; and in such positions is a capital subject for the margins of beds of American plants. Seed or division. It is so distinct in habit, and so effective in spring and early summer, that it well deserves a place in all good gardens.

P. peltatum (May Apple).-An interesting plant with glossy, green, wrinkled leaves, borne aloft, umbrella-like, on slender undulating stems, about I ft. high. Its Christmas Rose-like flowers, of waxy whiteness, are produced in May, and are succeeded by green Crab-like fruit; hence the popular name. It is a capital plant for shady peat borders, or for woods, but it requires moist vegetable soil, and shady or half-shady positions. Seed or division.

Poet's Daffodil (Narcissus poeticus).

Pogonia.-Terrestrial Orchids, chiefly from North America, but few, if any, have grown well in this country. P. ophioglossoides is said to be pretty and worth cultivating, and no doubt it will thrive under the treatment given to similar plants.

Poison Elder (Rhus Toxicodendron).

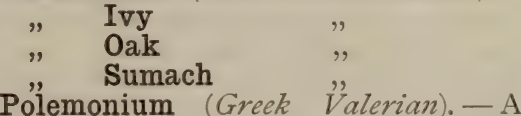
small genus of Phloxworts containing a few good garden plants. The most distinct kinds are-

P. cœruleum (Jacob's Ladder), with which most people are familiar, a useful though common border plant. Besides the original blue-flowered species, there is a variety with white blossoms, and another handsome form with variegated foliage, which is so desirable as an edging plant in the flower garden that its propagation and culture are of importance. On good garden soil the variegated form will generally be found almost as easy of culture as the common one. It 
is apt to go off on a very wet clayey soil, but flourishes finely in deep, rich, but well-drained loam. Propagation is effected by digging up well-established old plants, pulling them to pieces, and planting them immediately in a nursery bed of good soil; this is best done in early autumn, so that they may be nicely established in the nursery beds before midwinter. Where plants are merely required for borders and rock-garden, all that is necessary is to take up, divide, and replant the old stools where desired, in the old-fashioned way of dealing with herbaceous plants. As the variegated variety is grown for leaf-beauty alone, the flower-stems should be removed when they appear. In the north, where its variegation is both more constant and more decided, this is an important garden plant.

P. confertum.-This is the latest addition to the cultivated kinds, and is one of the finest of all. It is a dwarf hardy plant, quite distinct from any other kind, has slender deeply-cut leaves, and bears dense clusters of deep blue and very attractive blossoms on stoutish stems, about 6 in. high. It requires a warm spot in the rock-garden and a well-drained, deep, loamy soil, rather stiff than otherwise. Though it requires plenty of moisture in summer, it is impatient of excessive dampness about the roots in winter, and precautions should be taken in this respect. It should be allowed to remain undisturbed for years after it has become established. Rocky Mountains.

P. humile is a plant of low stature, truly alpine in character. Its pale blue flowers are borne on stems a few inches high. In a dry situation and a light sandy soil it is perfectly hardy, but on a damp subsoil it is sure to die in winter. North America. P. mexicanum is a similar but larger plant, but, being only of biennial duration, it is scarcely worth cultivating.

P. reptans is an American alpine plant, and, though far inferior in beauty to $\mathrm{P}$. confertum, is well worthy of cultivation. Its stems are creeping, and its slate-blue flowers form a loose drooping panicle, 6 or 8 in. high. As snails devour it ravenously, especially the scaly rootstocks during winter, a watchful eye is required to prevent their depredations, P. sibiricum, grandiflorum, and Richardsoni much resemble $P$. coruleum, but are larger and more vigorous, and bear larger flowers, and should therefore be preferred for borders. There are several other species in cultivation, but they are not of a sufficiently perennial or ornamental character.

Polianthes tuberosa (Tuberose). Though a native of the East Indies, strong imported bulbs of this deliciously fragrant plant, if inserted in warm soil, will flower well in the open air during August. But sufficient strength to flower well is only found in bulbs grown and matured under the sunny suns of Italy and France. Most Tuberoses grown in this country are imported. In the neighbourhood of London we have seen the Tuberose flowering freely in the open border. The plants were vigorous and healthy, the flower-spikes thickly studded with buds and blossoms. They were growing in a light, sandy, welldrained soil, in which the bulbs had remained all the winter, slightly protected during severe weather by means of ashes or other dry material. It is better, however, to plant fresh sound bulbs every spring, as the result is more satisfactory. It must be remembered that, like Hyacinths and similar bulbs, Tuberoses will not flower so well the second year as in the first.

Polyanthus (Primula).

Polygala (Milkwort). - The hardy species of Milkwort are neat dwarf plants, with flowers much resembling those of the Pea family.

P. Chamæbuxus (Box-leaved Milkwort).-A valuable little creeping shrub, a native of the Alps of Austria and Switzerland, where it often forms but very small plants. In our gardens, however, on peaty soil and some fine sandy loams, it spreads out into compact tufts covered with cream-coloured and yellow flowers. The variety purpurea is much prettier, and deserves a place in every rock-garden. The flowers are a lovely bright magentapurple, with a clear yellow centre. The plant appears to have a greater tendency than the type to expand a portion of its blossoms during autumn. It is of easy culture, succeeding in any sandy welldrained soil in almost any situation, though it seems to do best in sandy peat, if slightly shaded from the mid-day sun. It is a most desirable addition to hardy spring-flowering plants, being useful alike in the rock-garden and ordinary flower border, and even when out of flower it is interesting owing to its dwarf compact habit, bright shining evergreen leaves, and olive-purplish stems. P. paucifolia is a handsome perennial, 3 to 4 in. high. It has slender prostrate shoots, with concealed flowers, and from these shoots spring flower-stems bearing in summer 
from one to three large and handsome flowers about three-quarters of an inch long. These flowers are generally rosypurple, but sometimes white. It is suited for the rock-garden, in leaf-mould and sand, and for association in half-shady places with Linnæa borealis, Trientalis, Mitchella, etc. N. America. Some of the British Milkworts, especially P. calcarea and vulgaris, are worth cultivating. They are very interesting and easily grown, and do very well in sunny chinks of the rockgarden if planted in calcareous soil. They form neat dressy tufts of blue, purple-pink, and white flowers, and bloom profusely in early summer. Seed may be gathered from wild plants and sown in sandy soil. are worthy of the choicest border or group, but they are, perhaps, seen to greatest advantage when leaning forth from beneath shrubs or low trees on the margin of a shrubbery or grove, where their elegant growth is in marked contrast to the surrounding vegetation. They should be abundantly grown in woods. They are easily multiplied by division of the root-stocks. $P$. verticillatum and $P$. roseum are quite distinct from the foregoing, as the stems are erect and bear whorls of leaves and small blossoms which in P. roseum are of a purplish-pink hue. These two are best suited for border culture in good loamy soil.

Polygonum (Knotweed). - Now that

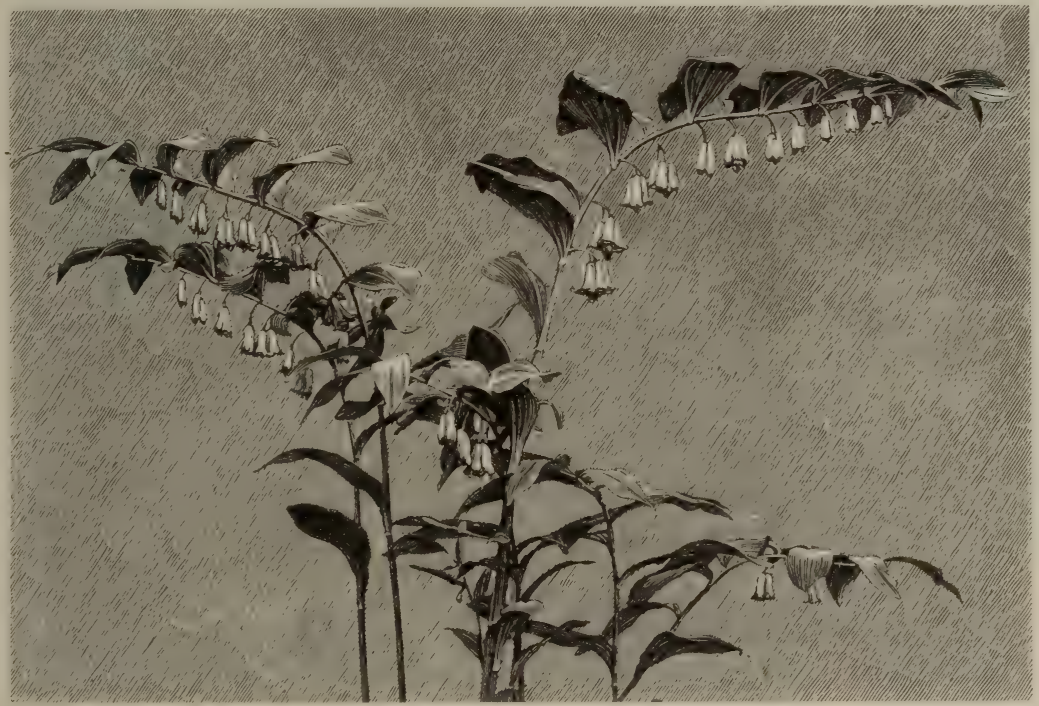

POLYGONATUM MULTIFLORUM (SOLOMON'S SEAL).

Plants carefully taken up from their native positions have also been established in gardens.

Polygonatum (Solomon's Seal). - Of this genus there are about a dozen species in cultivation, the majority of which are similar to each other. They have tall stems, elegantly arching, and thickly set with pretty pendent white blossoms. They grow from $\mathrm{I} \frac{1}{2}$ to $3 \mathrm{ft}$. high, though $\mathrm{P}$. giganteum, a kind lately introduced, attains as much as $6 \mathrm{ft}$. in height. Besides P. multiflorum (our native species), the most distinct are P. pubescens, oppositifolium, latifolium, and officinale ; and there is a double-flowered variety of $\mathrm{P}$. multiflorum, and another with handsome variegated foliage. These Polygonatums thrive in any position in sandy loam, and beauty of form is beginning to be appreciated, many graceful plants formerly discarded as worthless, either on account of their gross habit or their inconspicuous flowers, are coming into notice, and in all probability will form a prominent feature in the gardens of the future. The vast genus Polygonum, comprising I 50 species of world-wide distribution, the majority of which are insignificant weeds, nevertheless includes several noble plants, which are well worth considering. They are of the easiest culture, thrive in any ordinary garden soil, and are capable of being greatly improved by cultivation. Those of a bushy habit should be allowed plenty of space all round, so as to give air and light, and avoid the overcrowding which is frequently the cause of naked stems 
and a straggling habit,- - to remedy which tying-in has to be resorted to. This tying-in detracts much from the beauty of the plants, which consists in the innumerable flower-spikes rising above a gracefully-developed mass of foliage reaching to the ground. Plants of the P. cuspidatum type have stems of sufficient strength to support their spreading foliage, though a tendency to droop at the points is not unusual, and is by no means an objectionable feature. The dwarf perennials, most of which are evergreen, need no support, and very little attention beyond an occasional trimming, but the annuals, unless grown as single specimens, constitutes a very ornamental feature of the alpine vegetation in the Himalayas, where it inhabits the wet river banks and meadows, and hangs in rosy clumps from moist precipices. In cultivation it is 6 to 8 in. high, with a few narrow leaves and rosy-red flowers in dense spikes. In the open border it flowers freely in September and October, and is an attractive plant. P. Brunonis is a similar plant, equally desirable for the border or the rockgarden. The flowers, of a pale rose or flesh colour, are borne in dense erect spikes nearly 8 in. high. It continues to bloom more or less through the summer.

P. alpinum. - This native of the Swiss

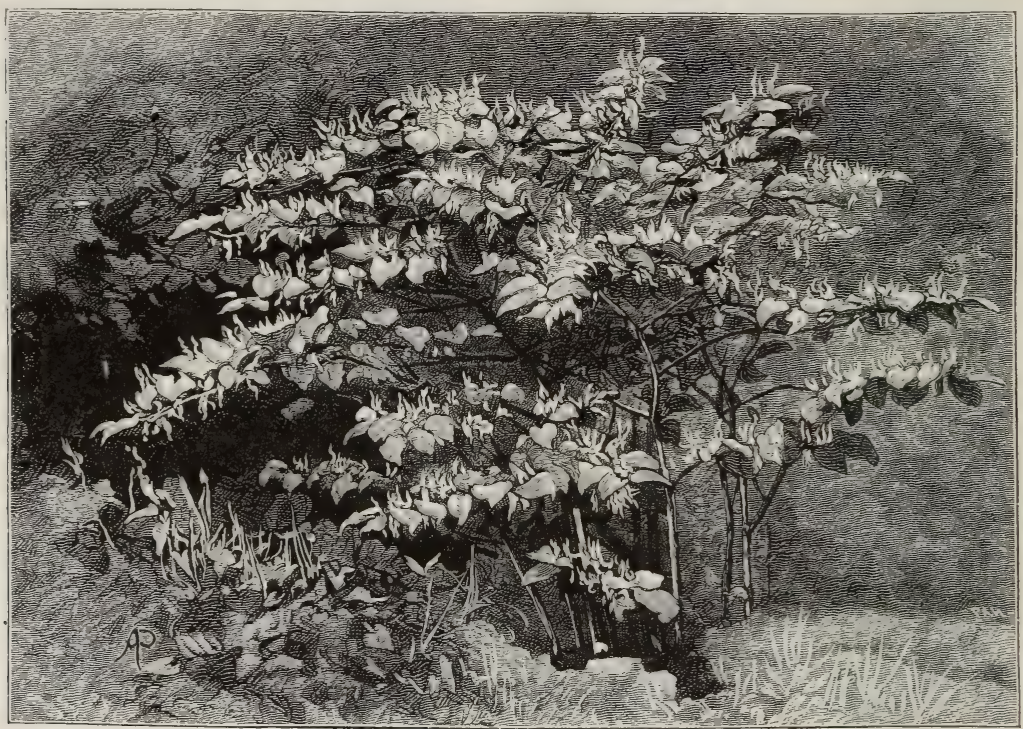

POLYGONUM CUSPIDATUM (JAPAN KNOTWEED)

and in sheltered situations, require support. The stems of all the tall hardy species perish in the autumn, and succeeding ones do not appear before April or May, and this must be taken into consideration when planting for effect. Cuttings, division, or seeds. If the seeds are taken from the $\mathrm{P}$. orientale group, they should not be sown in the open ground until the middle of April. Much has been done to popularise these plants, but they have not been kept within bounds and have fallen into disrepute. To remedy their encroaching propensity, their underground creeping rhizomes should be cut back every spring. The selection described below includes most of the best garden sorts, and illustrates the various types of the genus.

P. affine, one of the Bistorta group. It
Alps is a very old inhabitant of our gardens. Its stems are 3 to $4 \mathrm{ft}$. high, and have ovate-lanceolate deep green leaves, with ciliated margins. Its flowers, which appear early and continue in bloom for several weeks, are arranged in snow. white panicles. They prove very serviceable where quantities of cut flowers are in request, but the plant is scarcely good enough for borders.

P. capitatum.--This charming little spreading annual bears oval greyishgreen leaves, with a dark blotch in the centre of each, and has numerous globose heads of pink flowers. Once established in light warm soils it sows itself, and fresh plants appear every year. The neatness of its habit and the delicacy of its flowers never fail to attract admiration.

P. compactum is similar to P. cuspi- 
datum. Its stems, I to $2 \mathrm{ft}$. high, form a compact tuft. It bears white flowers in great profusion, and its leaves are similar to those of P. cuspidatum, though much smaller. Although not very showy, it flowers late in autumn, and this will recommend it to lovers of herbaceous plants.

P. cuspidatum, also known as P. Sieboldi, is a plant of sterling merit, and now becoming quite common. It is of fine and graceful habit, and the peculiar curve of its stems brings nearly the whole of the foliage of each stem into the same plane. It has copious shoots speckled with purple, and its broadly-ovate leaves are of a dark dull green, frequently variegated with faint silvery blotches, and its creamy-white flowers are borne in great profusion. Its stately habit of growth and the luxuriance of its foliage strike the most casual observer, especially when the plant is in full bloom. It is undoubtedly one of the finest herbaceous plants in cultivation. It should be grown as an isolated specimen on the turf or in some prominent part of the wild garden. Japan.

\section{P. orientale (Persicary).}

-A gigantic free-growing annual, 8 to Io ft. high. Its stems are very robust, and give off numerous lateral shoots. These shoots have large, oblong, acute, rich green leaves, Io to $I_{5}$ in. in length. The leaves nearest the flowers are stem-clasping, and are inclined to be sagittate. The inflorescence is both terminal and axillary, and consists of slender spikes of crimson flowers, which appear in July and continue until the frosts. To obtain good foliage the plant should be grown as a single specimen without shade. It will then bloom freely, and make a grand ornament in the sub-tropical garden or among its congeners in the wild garden. There is a variety with pure white flowers, but, like the type, it is rarely met with. Northern India.

P. sachalinense. - A native of the island of Sachalian, of a similar habit to P. cuspidatum, but larger, and sometimes attaining a height of $\mathrm{I} 2 \mathrm{ft}$. It has broadly-oblong bright green leaves upwards of a foot in length. Its flowers are rather inconspicuous, being of a greenishwhite, and disposed in slender drooping racemes. It luxuriates in a moist subsoil near water, where it is very effective

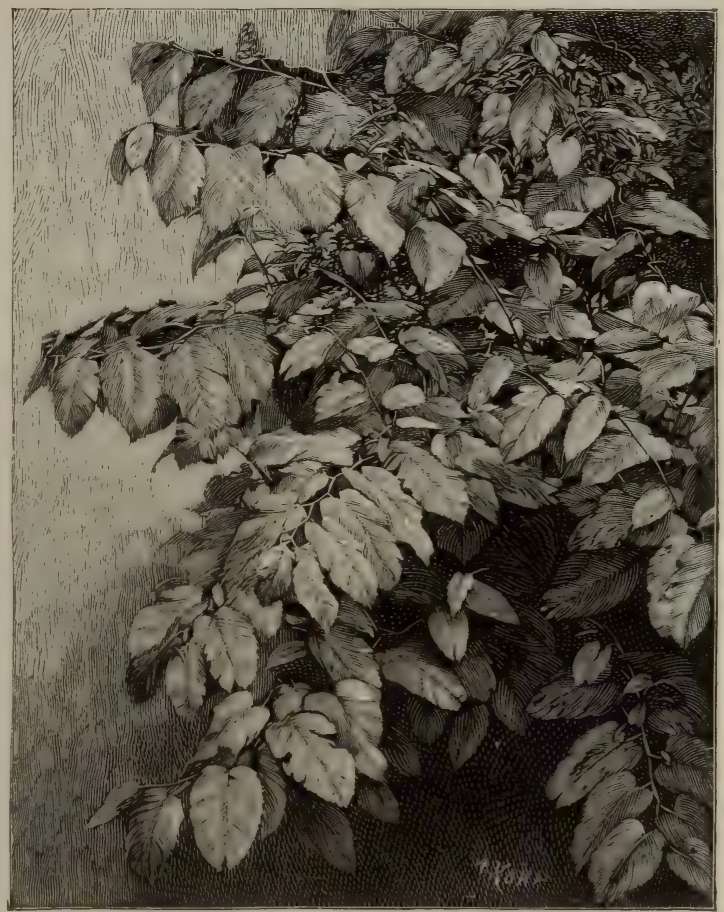

POLYGONUM SACHALINENSE.

when in company with grassy vegetation ; and it makes a bold feature on the turf or in a good position where it can develop its noble proportions. No better plant could be employed for semi-wild places, or for association with vigorous herbaceous plants on the turf in the pleasureground. For those whose gardens will not admit of such special places, a tuft on the edge of a shrubbery will well repay the planter; it should not always be in the shrubbery, but just a few feet clear of it.

P. vaccinifolium.-Few plants are better for the rock-garden. It differs widely from all its congeners in cultivation, unless $P$. crispum, once a favourite flower, and resembling it in twiggy habit, is still grown. It is quite hardy, and thrives in almost any moist soil, but is seen to best advantage where its shoots can ramble over stones or treestumps. Under favourable conditions it grows rapidly, and produces a profusion of Whortleberry-like leaves and rosy flowers. Himalayas. 
Polymnia grandis.-This is second to no plant for bold effect in the garden. It is a half-hardy shrub with large, opposite, much-divided, and elegantlylobed leaves which are often nearly $3 \mathrm{ft}$. long, presenting very striking and luxuriant masses of foliage. The stem and leaf-stalks are spotted with white, and the leaves when young are covered with soft white down. Like most large soft-growing things, it is best planted out in a young state, so as to ensure a fresh and unstinted growth. It is easily multiplied from cuttings, which freely produce plants if placed in heat in January. It is best planted out at the well-decayed woody matter, to which a thin top-dressing of similar material may be added every autumn. The evergreen Polypodiums associate well with flowering plants that do not require frequent removing, and they may be made to cover bare spaces beneath trees, or to overrun stumps; a beautiful effect, too, might be obtained by their use as a carpet or setting to some of the plants in the rock-garden. They are also very useful for cutting; and no garden, large or small, should be without some good patches of them, planted specially for furnishing at all seasons a good supply of their beautiful fronds. Besides P. vul-

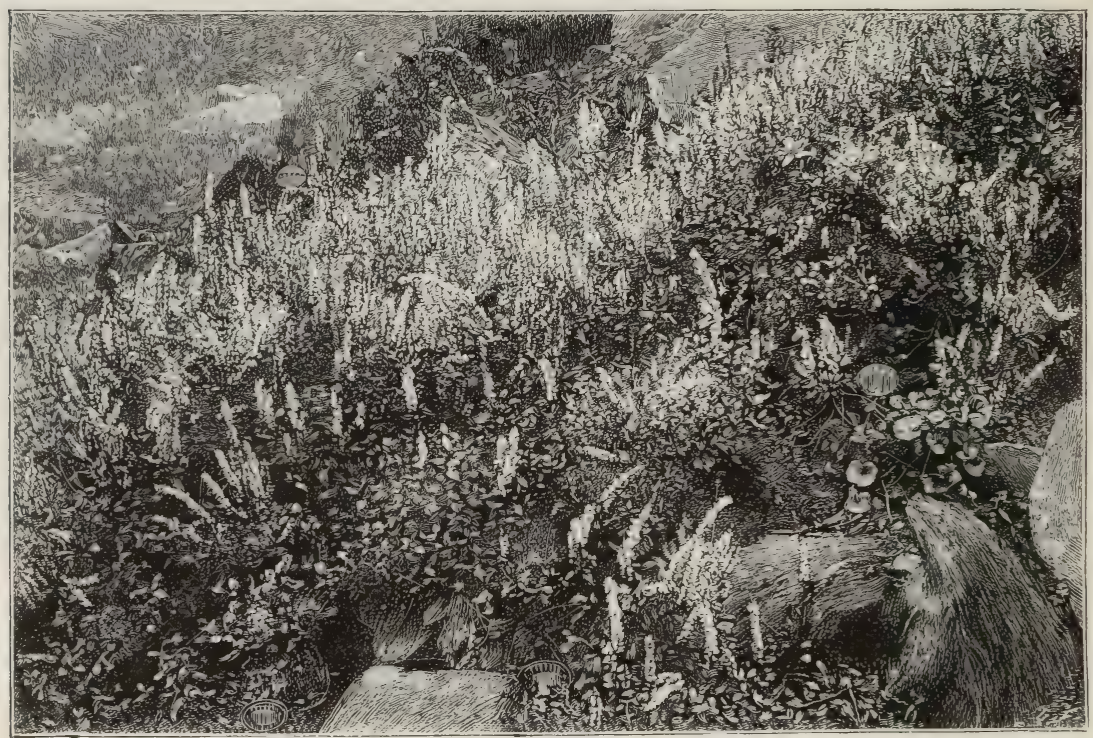

POLYGONUMI VACCINIFOLIUM.

end of May, and should be in every collection. Mexico. = Montagnea heracleifolia.

Polypodium (Polypody).-This large genus of Ferns contains several valuable hardy kinds, the principal being the common $\mathrm{P}$. vulgare, which has about a score of cultivated varieties differing more or less widely from each other. The most distinct and beautiful as well as the freest in growth are cambricum, elegantissimum, omnilacerum, and pulcherrimum. Though they prefer shade, they only need a good supply of water at the root during summer and they will thrive even exposed to the full rays of the sun. They should be planted in a compost of fibry loam and tough and fibry peat, with a liberal admixture of leaf-mould and gare and its varieties, there are several deciduous species, such as P. Dryopteris (Oak Fern) and P. Phegopteris (Beech Fern), well known to all Fern lovers. These plants thrive best in a compost of peat, loam, and sharp sand, with the addition of some broken lumps of sandstone. They prefer a dry situation, and do well in the rock-garden ; indeed they cannot be out of place in any situation which is not fully exposed to the sun. A slightly shaded spot should therefore be selected where they might be planted among flowering plants amenable to the same treatment, and affording the needed shelter. P. Robertianum (Limestone Polypody) is a beautiful deciduous species, but somewhat difficult to manage ; it will endure sunshine, but should have a dry 
sheltered position. It prefers a mixture of sandy and fibry loam, with a plentiful addition of pounded limestone. $P$. alpestre is a distinct and handsome Fern, bearing a close resemblance to the Lady Fern; the fronds are dark green, and sometimes exceed $2 \mathrm{ft}$. in length. It may with advantage be grouped with Lady Ferns, as it flourishes under similar treatment. P. hexagonopterum, a native of N. America, is quite hardy in sheltered positions, and produces elegant tapering dark green fronds about $\mathbf{I} \mathrm{ft}$. in height.

Polypogon (Beard Grass). - Pretty Grasses, chiefly annual. P. monspeliensis and littoralis are native. $P$. affinis is an elegant Chilian annual. All should be sown in the open border in spring or autumn.

\section{Polystichum (Aspidium). \\ Pomegranate (Punica). \\ Pond-flower (Aponogeton). \\ Pond Lily, Yellow (Nuphar).}

Pontederia cordata (Pickerel Weed). - One of the handsomest water-plants in cultivation, combining grace of habit and leaf with beauty of flower. It forms thick tufts of almost arrow-shaped, erect, longstalked leaves, from $I \frac{1}{2}$ to over $2 \mathrm{ft}$. high, crowned with handsome spikes of blue flowers, which issue from the long stalks just below the leaves. P. angustifolia has narrower leaves. Both should be planted in shallow pools of water. Division of tufts at any season. North America.

\section{Poppy (Paparer). \\ Poppy, Blue Himalayan (Meconopsis). " Caucasian Scarlet (Papaver umbrosum). \\ Californian (Eschscholtzia). Horned (Glaucium). Plume (Bocconia). Prickly (Argemone). \\ Welsh (Meconopsis cambrica).}

Portulaca (Purslane).-Most of these beautiful half-hardy annuals, now so much grown, are varieties of the Chilian P. grandiflora. They are very numerous and very varied in colour. The principal are alba, aurea, aurea-striata, caryophylloides (rose streaked with crimson), rosea, splendens (deep crimson-purple), striatiflora (white and crimson striped), Thellusoni (crimson-scarlet), Thorborni (yellow). These are nearly all represented by full double flowers, which are the more desirable as they are more enduring. The plants are 6 to 9 in. high, and form a dense carpet of foliage, and the effect of the brilliant flowers in full sunshine is very fine. The seeds should be sown in heat in February or March. The seedlings should be potted off singly in small pots, so that by planting-out time they may be good strong plants. In May they should be planted out in good soil in an exposed position, each plant being allowed ample space to develop itself in. They begin to flower at the end of June, and continue in bloom for several weeks. Sometimes the plants sow themselves in autumn, but they are seldom so satisfactory as when treated as above.

\section{Potato Tree (Solanum).}

Potentilla (Cinquefoil). - A large family of plants, many hardy herbs and alpine flowers among them. The most important are the fine hybrid varieties recently obtained by hybridising showy Himalayan species such as P. insignis and P. atro-sanguinea. These two species are well worth growing. The former has clear yellow and the latter deep velvety crimson flowers. The beautiful rosy-pink $P$. colorata, a plant that flowers, throughout the summer, is likewise useful ; but these three are about the only typical species of tall growth worth cultivating. The double kinds are most showy, and their blooms last in perfection both on the plants and in a cut state longer than the single sorts. There are about three dozen distinct named varieties, all of which may be obtained from any of the large hardy plant nurseries. These varieties represent every shade of size and colour that it is possible to obtain. A good selection of the most distinct kinds would embrace most of the qualities of the whole race. The culture of these plants, like that of most hardy flowers, is simple. They luxuriate in a light deep soil, and the more fully exposed the position, the better it appears to suit them. They form vigorous specimens very soon, and from the beginning of summer till the middle of autumn produce flowers in profusion.

The following is a good selection of double sorts: M. Rouillard, reddishcrimson; Belzebuth, dark crimson; Chromatella, yellow ; Dr. Andry, scarlet, margined with yellow ; Escarboucle, crimson; Belisaire, reddish-orange ; Vase d'Or, yellow; Le Dante, orange shaded with scarlet; Louis Van Houtte, crimson; Phœbus, rich yellow; Le Vesuve, crimson with yellow margin; Versicolor, yellow suffused with brownishcrimson; Vulcan, scarlet shaded with yellow ; Variabilis fl. - pl., yellow with scarlet margin ; Eldorado, scarlet-crimson with yellow margin; Perfecta plena, bright scarlet-crimson slightly tinged 
with yellow; Imbricata plena, orangescarlet; Etna, reddish-crimson; Panorama, yellow heavily stained with scarlet; Nigra plena, dark crimson; Meteor, yellow suffused and blotched with scarlet; Meirsschaerti fl.-pl., yellow veined and striped with crimson; William Rollisson, deep orange-scarlet with yellow centre; Fenelon, orange and scarlet; Purpurea lutea plena, scarlet-crimson slightly tipped with yellow.

Among the dwarf alpine species there are some very beautiful plants indispensable to the rock-garden. Of these the following are the best :-

P. alba (White Cinquefoil).-A pretty species, the leaves of which are quite silvery, and have a dense silky down on the lower sides. It is very dwarf, and is neat and not rampant in habit. Its white Strawberry-like flowers are nearly $I$ in. across, and have a dark orange ring at the base. Alps and Pyrenees. Of the easiest culture in ordinary soil, and a good ornament for borders or for the rock-garden. It flowers in early summer, and is easily increased by division.

P. alpestris (Alpine Cinquefoil).- - A plant closely allied to the spring Potentilla (P. verna). When well grown it forms tufts nearly I ft. high, with bright yellow flowers about I in. across. It is worthy of a place in the garden proper, or in the rock-garden; for it is of the easiest culture, and, while enjoying a moist deep soil, it cares little how cold the position is. Though not very common, it is found on rocks and dry banks in several parts of the country.

P. ambigua is a dwarf compact creeper, bearing in summer numerous large clear yellow blossoms on a dense carpet of foliage. It is of the simplest culture, being perfectly hardy, and requiring only a good deep well-drained soil in an open position in the rock-garden. Himalayas.

P. calabra (Calabrian Cinquefoil).-A very silvery species, particularly on the under side of its leaves, their hue constituting its principal value. It has prostrate shoots, and bears in May and June lemon-yellow flowers nearly $\mathrm{I}$ in. across. It flourishes freely in sandy soil, and is worthy of a place in the rock-garden, or wherever dwarf Potentillas are grown. Italy and Southern Europe.

P. fruticosa (Shrubby Cinquefoil).-A pretty hardy shrub, well worthy of a place in a garden. It is a neat bush, 2 to $4 \mathrm{ft}$. high, and bears in summer clusters of showy golden-yellow flowers. It is suited for the rock-garden or the dry bank.

P. nitida (Shining Cinquefoil). - A beautiful little plant a couple of inches high. Its silky silvery leaves seldom have more than three leaflets each. The flowers are of a pretty and delicate rose. It is well worthy of a choice place in the rock-garden. Of the easiest culture and propagation. Alps.

P. pyrenaica (Pyrenean Cinquefoil).This dwarf but vigorous and showy species has fine, large, deep goldenyellow flowers. It will grow in the rockgarden or in the mixed border without particular attention. High valleys in the Central and Southern Pyrenees. Division or seeds. The shrubby kind P. fruticosa and its varieties are worth naturalising and growing among small shrubs in rougher parts of the rock-garden.

\section{Prairie Sunflower (Harpalium rigi- dum).}

Pratia angulata. - There are few prettier subjects for the rock-garden than this New Zealand plant. It creeps over the soil like the Fruiting Duckweed (Nertera depressa). The flowers are of a pure white, and resemble those of the common dwarf Lobelia, and are borne very profusely, especially on an exposed part of the rock-garden, if the plant is given room to spread. In autumn the flowers give place to numerous violet-coloured berries about the size of large Peas. P. angulata is perfectly hardy, and is a desirable little plant. Syn., Lobelia littoralis.

\section{Prickly Poppy (Argemone).}

Prickly Thrift (Acantholimon).

Primrose, Evening (Enothera).

Primula (Primrose).--There is so much charm and beauty among Primroses that no garden is complete without them, and there is scarcely a species not worth cultivating. They have a great diversity of habit and growth. Some are at home on the sunny slopes of the rock-garden, others in shade, many make excellent border flowers, and a few exotic species are at home in the woodland with our common Primrose. The family contains nearly a hundred different sorts ; and we have therefore confined ourselves to the most distinct kinds and the most desirable for general cultivation. There is so much confusion among certain sections, particularly in the Alpine and the Himalayan species, that we have not attempted to deal with these exhaustively; while others, such as P. nivalis, are too little known in gardens to render it necessary for us to speak of them.

P. amœna (Caucasian Primrose).-An uncommon and beautiful species, allied to our own wild Primrose, but quite distinct. The corolla is purplish-lilac in bud or 
when recently expanded, but turns bluer after a few days. The umbel is manyflowered, and the blooms, which are larger than those of $\mathrm{P}$. denticulata, are borne about 6 or $7 \mathrm{in}$. high; the leaves are rather large, and are woolly beneath and toothed. The blooms come out before the snow has left the ground. It is so much earlier than the common Primrose, that while that species is in full flower, amœna has quite finished blooming, and has sent up a strong tuft of leaves very much like that sent up by the common Primrose after its own flowers are faded. A sheltered position slightly shaded will be best for the perfect health and development of the plant. It flourishes quite freely in common borders, and is one of the most valuable additions to the early spring garden and mixed border that have been made for many years. It is charming for the rock-garden or for well-arranged borders, and, when plentiful enough, will, no doubt, be used in various ways. There is a stemless variety, which would probably prove a great addition to our gardens. $\mathrm{P}$. sibirica is somewhat similar to $\mathrm{P}$. amœna, but is rare. Division of the root. Caucasus.

P. Auricula (Common Auricula).-In a wild state this is one of the many charming Primulas that rival Gentians, Pinks, and Forget-me-nots in making the flora of alpine fields so exquisitely beautiful and interesting. Possessing a vigorous constitution, and sporting into a goodly number of varieties when raised from seed, it attracted early attention from lovers of flowers ; its more striking variations were perpetuated and classified, and it became a "florists' flower." Its cultivated varieties may be roughly thrown into two classes: first, self-coloured varieties, or those which have the outer and larger portion of the flower of one colour or shaded, the centre or eye white or yellow, and the flowers and other parts usually smooth, and not powdery ; second, those with flowers and stems thickly covered with a white powdery matter or "paste." The handsomest of the former kinds are known by the name of "alpines," to distinguish them from the florists' varieties, and are the hardiest of all. The florists' favourites are distinguished by the dense mealy matter with which the parts of the flower are covered. They are divided by florists into four sectionsgreen-edged, grey-edged, white-edged, and selfs. In the "green-edged "varieties, the gorge or throat of the flower is usually yellow or yellowish ; this is surrounded by a ring, varying in width, of white powdery matter, which is surrounded by another ring of some dark colour, and beyond this a green edge, which is sometimes $\frac{1}{2}$ in. in width. The outer portion of the flower is really a monstrous development of the petal into a leaf-like substance, identical in texture with the leaves. The "greyedged" varieties have the margin of a green leafy texture, but this is so thickly covered with powder that the colour cannot be distinctly seen. The same occurs in the "white-edged" kinds, the difference being in the thickness and hue of the powdery matter. In fact, the terms "green-edged," "grey-edged" and "whiteedged," are simply used to indicate slight differences between flowers having an abnormal development of the petals into leafy substance. It is a curious fact that between the white and the grey the line of demarcation is imaginary, for both classes occasionally produce green-edged flowers. The "selfs" are really distinct, since the outer portion of the corolla is of the ordinary texture, though a ring of powdery matter surrounds the eye.

The classification of such slight differences merely tends to throw obstacles in the way of the general growth and enjoyment of the flower in gardens. Let the florists maintain these fine distinctions; those who merely want to embellish their gardens with the prettier varieties need not trouble themselves with named sorts at all. It should be borne in mind that the florists' kinds are the most delicate and difficult to cultivate. The curious developments of powdery matter, green margins, etc., tend to enfeeble the plant. They are, in fact, variations that in Nature would have little or no chance of surviving in the struggle for life. The general grower will do well to select the free sorts-alpines, and good varieties of the common border kinds. The special merit of these is that they may be grown in the open air on the rock-garden and in borders, while the florists' kinds must be grown in frames.

The free-growing kinds are most likely to be enjoyed in all classes of gardens. Their culture is very simple, light vegetable soil and plenty of moisture during the growing season being the essentials. In many districts the moisture of our climate suits the Auricula to perfection, and great tufts of it are grown in gardens without any attention. In others it must be protected against excessive drought by stones placed round it, and Cocoafibre and leaf-mould are also useful as a surfacing. However, as none but good varieties of the alpine section are worthy 
of even this trouble, we would prefer, wherever practicable, that they should be placed in the rock-garden on spots where they would have some shelter and could root freely into rich light soil. They would cause no trouble beyond taking up, dividing, and replanting. This should be done every second or third year, or as often as they become too crowded or lanky. The very common kinds may be planted as edgings, or in beds in the spring garden, but wherever the plant is free, naturally improved varieties should be substituted for the common old border kind.

Auriculas are easily propagated by division in spring or autumn, but best in early autumn. They are also easily raised from seed. Seed ripens in July, and is usually sown in a gentle heat in the following January. It should be sown thinly in pans. The plants need not be disturbed till they are big enough to prick into fine rich light soil on a halfshady border. It is most desirable to raise seedlings, as in this way many beautiful varieties may be obtained, and if a desirable variety is noticed, it should be marked, placed under conditions calculated to ensure its health and rapid increase, and propagated by division as fast as possible.

As to the florists' varieties, innumerable and precise descriptions of the culture considered necessary have been given, but the essential points may be summed up in a few words. They require protection in frames or pits during winter and spring, and may be placed in the open air in summer and early autumn. In winter they should be put in pits, and placed as near to the light as may be convenient, the lights being left off in mild weather, and air being given at all times, except in severe frosts. Air by night as well as by day is decidedly beneficial. The pit or frame may be the usual one for the winter months; but as soon as the plants begin to show flower, they ought to be removed to one with a northern exposure, so as to prolong the bloom. In such a place, with abundance of air, they form objects of much interest and beauty through April and the first weeks of May. After flowering they should be potted in May, and kept shaded till they have recovered. The potting usually consists of carefully shaking away all the soil and putting the plant in fresh compost; and the practice is a good one, for this plant and its wild allies put forth young roots higher up the stem every year, and the encouragement of these young roots is sure to have a good result. The pots generally used (the 4 -in. size) are quite large enough where annual disrooting is practised, one sucker of a kind being placed in the centre of each pot. The wisdom of potting every plant in this way is doubtful, and it is better to select those that have sound roots, and are set firmly and low in the earth, and while disturbing the ball but little to give them a careful shift into a 5-in. pot. In growing the alpine kinds in pots-and they are as worthy of it as the other kindsgrowers should put five or six plants in a 6 -in. pot, one in the centre and four or five round the side, so as to form a handsome specimen. The same principle may be carried out in pans, and applied to the free-growing florists' varieties as well as the alpines. In summer all the plants should be placed in the open air on boards or slates or a bed of coal-ashes, or some substance that will prevent the entrance of worms into the pots. Some careful growers guard the plants from heavy rains, but this is unnecessary if the pots are perfectly drained and everything else is as it ought to be. The florists rarely plunge the pots; but, if plunged in a bed of clean sharp sand, or in any like material on a well-drained bottom, and free from earthworm, they will be safer and less troublesome, because free from the vicissitudes that must attend all plants exposed in a fragile porous shell containing but a few inches of soil. Some pot their plants in August, but the best time is just after the flowering, as, if disrooted in the autumn, the plants have not that accumulated strength for flowering which is acquired by a long period of undisturbed growth.

The perfect development of the choicest florists' kind is secured by mixing one part of good turfy loam and one part of leaf-mould with another of well-decayed cow manure and silver or sharp river sand. Although we have given such full directions in regard to the culture of the florists' varieties, we again earnestly advise all who care for the flower, to cultivate the free and hardy forms that thrive in the open air. It is a good plan to select bright or delicate self or other colours that please one. Such kinds should be increased, so that definite effects may be worked out with each colour.

P. capitata.-One of the finest of all Primroses. It is like $\mathrm{P}$. denticulata, but is very distinct as a garden plant. It has a tuft of sharply-toothed pale green leaves, not half the size of that of a fully- 
developed $\mathrm{P}$. denticulata. In autumn it produces dense heads of flowers of the deepest Tyrian purple, which as regards depth is very variable, and is shown to advantage by the white mealy powder in which the flowers are enveloped. It is not so vigorous as $\mathrm{P}$. denticulata, though quite hardy, and it cannot be termed a good perennial, as it is apt to go off after flowering well. It is therefore advisable to raise seedlings. This is easy, as the plant seeds freely in most seasons, and the seedlings flower in the second year. An open position with a north aspect in good loamy soil well watered in dry weather suits it best. ful and easily raised of the Primulas, being readily increased from seed, and quite hardy in any well-drained and suitable position. Siberia.

P. denticulata.-A pretty Himalayan Primrose, of robust growth, 8 to 10 in. high. It has large tufts of broad foliage, and produces in spring, on stout erect stems, large dense clusters of lilac blossoms. It is a most variable plant, and some of its more distinct forms have received garden names, of which the principal are mentioned below. It is paler in colour than any of its varieties, and its foliage and flower-stalks are not mealy. P. pulcherrima is a great im-

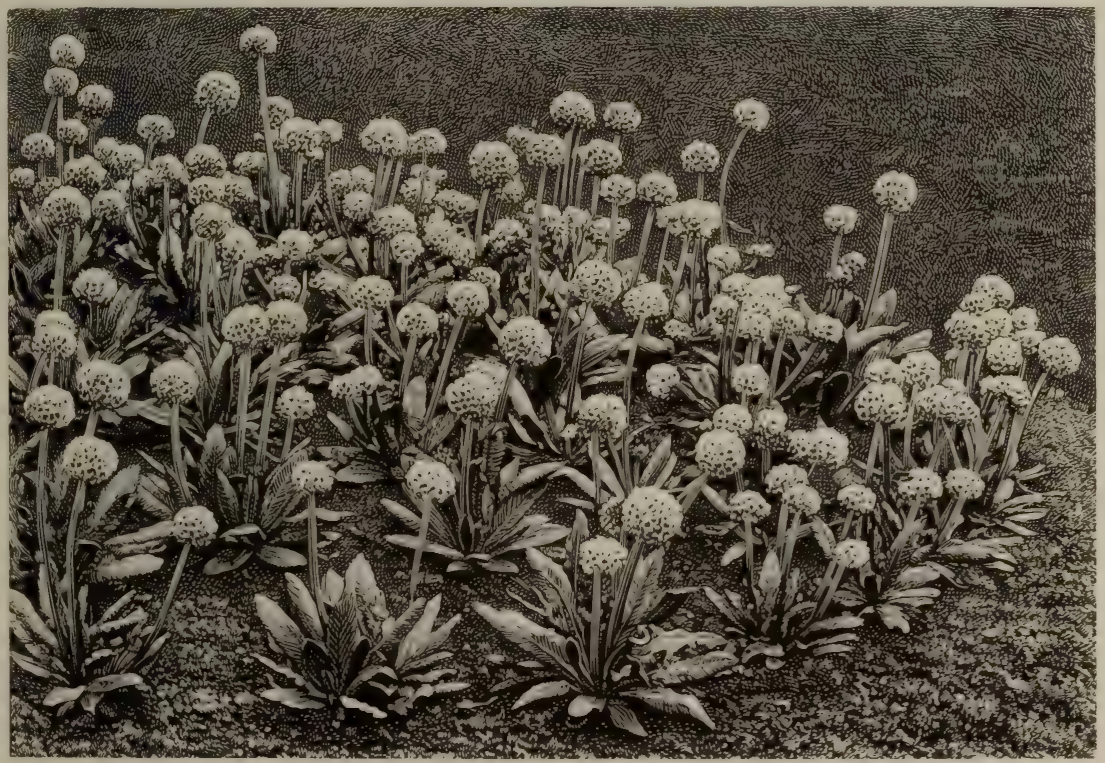

PRIMULA CAPITATA.

P. cortusoides. - A distinct species bearing clusters of deep rosy flowers on stalks 6 to to in. high. In consequence of its tall free habit it is liable to injury if placed in an exposed spot or open border; and should therefore be put in a sheltered position, such as a sunny nook in the rock-garden, where it is surrounded by low shrubs, etc., or in any place where it is not exposed to cutting winds, and at the same time not shaded to its injury. It forms a charming ornament for the rock-garden, for a sunny sheltered border near a wall or a house, or for the margin of the choice shrubbery. The soil should be light and rich, and a surfacing of Cocoa-fibre or leaf-mould is beneficial in dry positions. It is one of the most beauti- provement on the original. It grows from Io to 12 in. high, and has a more globular flower-truss, which is of a deep lilac colour. The stalks are olive-green, and, like the leaves, are slightly mealy. It is very beautiful when in flower, and P. Henryi is a very strong - growing variety, but does not otherwise differ from $P$. pulcherrima. It is a very fine plant, often $2 \mathrm{ft}$. across, and in Ireland it reaches even larger dimensions. P. cashmeriana is by far the finest variety. The flowers are of a lovely dark lilac, closely set together in almost a perfect globe on stalks over I ft. high. They last from March till May. The foliage is beautiful, and, like the stalk, is of a bright pale green, thickly powdered with meal, in 
which as in many other points the plant strongly resembles $\mathrm{P}$. farinosa.

All the varieties are perfectly hardy, though their foliage is liable to be injured by early spring frosts. They may be placed either in the rock-garden or in an ordinary border, and will grow vigorously in a deep moist loamy soil, enriched by manure. They prefer a shady situation, with a clear sky overhead, and delight in an abundance of moisture during warm summers. If grown in masses in beds, the flowers should be protected by a elevated parts of the country it flourishes in the rock-garden and in slightly elevated beds without any attention; but in most districts a little care is necessary. In the rock-garden it is perfectly at home in a moist, deep, and well-drained crevice, filled with peaty soil or fibry sandy loam. In the drier districts it would be well to cover the soil with Cocoa-fibre, leaf-mould, or broken bits of sandstone to protect the surface from being baked and from excessive evaporation. P. f. acaulis is a very diminutive variety of the preceding.

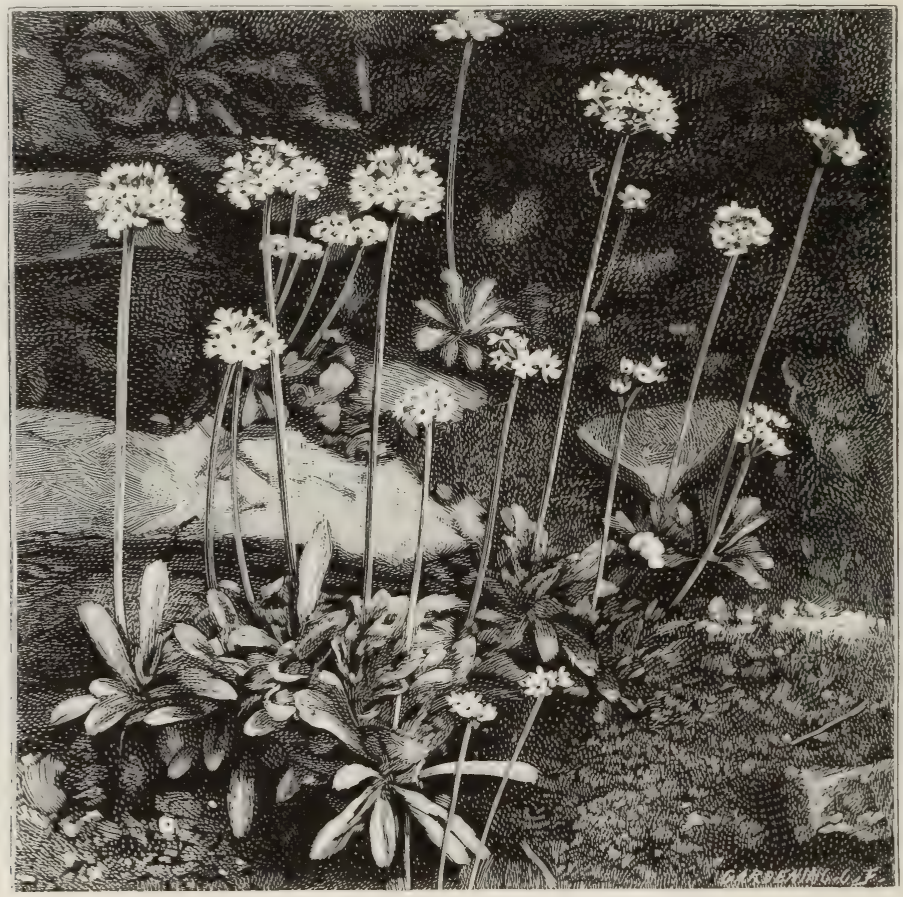

PRIMULA FARINOSA (BIRD'S-EYE IRIMROSE).

hand-light or frame placed over them to preserve them. P. erosa is similar to P. denticulata, but is smaller and less hardy, it has paler flowers, and altogether it is an inferior plant.

P. farinosa (Bird's-eye Primrose).-A charming native species with small rosettes of silvery leaves, and flowerstems generally 3 to $I 2$ in. high, though sometimes more. The flowers, which are borne in a compact umbel in early summer, are lilac-purple with a yellow eye. They vary a little in colour, there being shades of pink, rose, and deep crimson. In our gardens it loves a moist vegetable soil, and in moist and
The flowers nestle in the hearts of the leaves, and both flowers and leaves are very small. When a number of plants are grown together, they form a charming little cushion of leaves and flowers not more than $\frac{1}{2}$ in. high. Being so small, the plant should have greater care, whether it is grown in the rock-garden or in pots. P. scotica is a native plant similar to $\mathrm{P}$. farinosa, and requires similar treatment. The flowers, which are produced in April, are rich purple with a yellow eye, and are borne on stems a few inches high. Native of damp pastures in the northern counties of Scotland.

P. glutinosa.-A distinct little Prim- 
rose, rare in gardens. On mountains near Gastein and Salzburg, in the Tyrol, and in Lower Austria, it flourishes, in peaty soil, at a height of 7000 to $8000 \mathrm{ft}$. It is 3 to 5 in. high, bearing one to five blossoms of a peculiar purplish-mauve, with divisions rather deeply cleft. Suitable for the rock-garden, or for pots in moist peaty soil or very sandy soil. Similar to P. glutinosa are P. tirolensis, Flœrkiana, Allioni, and others, all natives of the Alps.

P. grandis.-A distinct species from the Caucasus, remarkable only for its large foliage and the smallness of its flowers.

P. integrifolia - A diminutive Primrose, easily recognised by its smooth shining leaves, which lie quite close to the ground, and by its handsome rose flowers, which are borne one to three on a dwarf stem, and are often large enough to obscure the plant. There is no difficulty in growing this plant on flat exposed parts of the rock-garden, if the soil be firm, but moist and free. The best way is to form a wide tuft, by dotting six to twelve plants over one spot, and, in a dry district, scatter between them a few stones or a little Cocoa-fibre mixed with sand, so as to prevent evaporation. $\mathrm{P}$. Candolleana is another name for this plant. P. glaucescens, spectabilis, Clusiana, and Wulfeniana are of a similar character. All are natives of the Alps. Division or seed.

P. intermedia. - A charming hybrid between $P$. ciliata and $P$. Auricula. In habit it closely resembles some of the dwarf alpine Auriculas, and its purplishcrimson flowers have a conspicuous yellow eye, and are borne on stout erect scapes. On sheltered portions of the rock-garden its richly-tinted blossoms are seen to advantage. It is delicately fragrant.

P. japonica.-One of the handsomest of Primroses, and now too common to need description. It is a good perennial, and is not in the least tender. It is a first-rate border plant, and in moist shady spots of deep rich loam it grows as vigorously as a Cabbage, throwing up flower-stems $2 \mathrm{ft}$. or more high, and unfolding tier after tier of its beautiful crimson blossoms for several weeks in succession. It may be grown in the rock-garden as well as in the border, and is an excellent wild-garden plant, thriving almost anywhere and sowing itself freely. It is said to be rabbit-proof. There are several for ms differing in colour ; there is a white form, a pale pink, and a rose form, but the best is the original rich crimson form. In raising $P$. japonica from seed it should be borne in mind that the seed remains some time dormant, unless it is sown as soon as it is gathered, and that it must on no account be sown in heat. A cool frame is the proper place for the seed-pan, and till the seed has germinated, care must be taken to prevent or keep down the growth of Moss and Liverwort on soil.

P. latifolia. - A handsome Primrose, with from two to twenty violet flowers in a head. It is less viscid, but larger and more robust than its Alpine congener the better-known $P$. viscosa. Its leaves sometimes attain a height of 4 in. and a breadth of nearly 2 in., and it grows to a height of 4 to 8 in. Its fragrant flowers appear in early summer, and in pure air it thrives on sunny slopes of the rockgarden, if it has sandy peat, plenty of moisture during the dry season, and perfect drainage in the winter months. Like $P$. viscosa, it will bear frequent division, and may be easily grown in cold frames or pits. Alps.

P. longiflora is related to P. farinosa, but is distinct from it, being deeper in colour, and is considerably larger than the best varieties of it, the lilac tube of the flower being more than $I$ in. long. It is not at all difficult to cultivate either on the rock-garden or in pots, and the treatment recommended for $\mathrm{P}$. farinosa will suit it perfectly. Austria.

P. luteola-One of the handsomest of the yellow Primroses, and a noble plant when well grown. The flower-stems are often $I \frac{1}{2}$ to $2 \mathrm{ft}$. high, though they are usually under I ft. in height. They sometimes become fasciated, and thus carry a huge cluster of flowers 4 to 6 in. across. These flowers are like those of a Polyanthus or an Auricula, but they are borne in more compact heads. P. luteola is perfectly hardy. It likes a moist situation in full exposure, and if put out in rich borders of rather moist soil, or on the lower banks of the rockgarden, or in a copse with a good bed of leaf-soil, it will soon repay the planter. Caucasus. It has been well figured in The Garden, from plants that flowered at Chipping Norton, in Oxfordshire.

P. marginata.-One of the most attractive of the family, and readily distinguished by the silvery margin of its greyish leaves, and by its sweet, soft, violet-rose flowers. Even when not in flower it is pleasing from the tone of the margins and surfaces of the leaves. The flowers appear in April or May. Our wet and mild winters 
are doubtless the cause of its becoming rather lanky in the stems after being more than a year or so in one spot. When the stems become long, and emit roots above the ground, it is a good plan to divide the plants, and to insert each portion firmly down to the leaves, and this will be all the more beneficial in dry districts, where the little roots issuing from the stems would be the more likely to perish. P. marginata is a charming ornament for the rock-garden, and thrives freely there. In the open ground a few bits of broken rock placed round the plants, or among them if they are grown in groups or tufts, will prevent evaporation, and protect them, as they rarely exceed a few inches in height. Alps.

P. minima (Fairy Primrose).-One of the smallest of European Primroses. Usually there is only one flower, which is generally rose-coloured, and sometimes white, and appears in summer. The plant is only an inch or so high, but its single flower is nearly $\mathbf{I}$ in. across, and almost covers the tiny rosettes of foliage. Bare spots in firm open parts of the rockgarden are the best places for the plant, but the soil should be very sandy peat and loam. It is peculiarly suited for association with the very dwarfest and choicest of alpine plants. Division or seed. Mountains of S. Europe. P. Flœrkiana is very much like it, and probably is only a variety, since the sole difference is that it bears two, three, or more flowers, instead of only one. It enjoys the same treatment in the rockgarden. Austria. Of both kinds it is desirable to establish wide-spreading patches on firm bare spots, scattering half an inch of silver sand between the plants to keep the ground cool.

P. Munroi. - This has neither the brilliancy nor the dwarfness of the Primulas of the high Alps, nor the vigour of our own kinds, but it is distinct, and is of the easiest culture in any moist boggy soil. It grows at very high elevations on the mountains of Northern India, in the vicinity of water. Its smooth green leaves have a heart-shaped base, and are 2 in. long, and nearly as much across. From them arise flower-stems 5 to 7 in. high, bearing creamy-white flowers with a yellowish eye, which are more than an inch across. These flowers appear from March to May, and are very sweet. Altogether, P. Munroi highly merits culture in a bog or in a moist spot of the select rock-garden. P. involucrata is a closely-allied kind also from the mountains of Northern India. It is, however, somewhat smaller, its leaves are not heart-shaped at the base, and it is not quite so ornamental. It thrives under the same conditions as its relative.

P. Palinuri. - This is quite different from other cultivated Primroses, inasmuch as it seems to grow all to leaf and stem ; while many of the other kinds often hide their leaves with flowers. In April its bright yellow flowers appear in a bunch at the top of a powdery stem. They are ornamental, though rarely fulfilling the promise of the vigorous-looking plant, and they emit a Cowslip-like perfume. P. Palinuri flourishes as a border plant in rich light soil in various parts of these islands, and nothing more need be said of its culture. It is well suited for some isolated nook on the rock-garden, where there is an unusually deep bed of soil. Established plants are easily increased by division. Southern Italy.

P. Parryi.-A pretty Primrose, bearing about a dozen large, bright, purple, yellow-eyed flowers nearly I in. across. These flowers are borne on stems about I ft. high. Though an undoubted alpine, and growing on the margins of streams near the snow-line, where its roots are constantly bathed in ice-cold water, it has succeeded in the open border in moist, deep, loamy soil mingled with peat ; indeed it is perfectly hardy, and requires partial shade from extreme heat rather than protection from cold. N. America.

P. purpurea.-A handsome Primrose, allied to P. denticulata, but far finer, for the exquisite purple flowers are larger. They are borne in heads about 3 in. across. The leaves are entire, and distinguish it from its near relations. Sheltered and warm but not very shady positions either in the rock-garden, or in the open parts of the hardy fernery, will best suit it if the soil is a light, deep, sandy loam, and well enriched with decomposed leaf-mould. It never thrives so well as in nooks at the base of rocks, where it enjoys more heat than it would if exposed. It must not be confused with the variety of $\mathrm{P}$. denticulata, commonly called by the same name of $P$. purpurea.

P. rosea (Rosy Himalayan Primrose) is a charming little Primrose, with flowers of the loveliest carmine-pink, produced in heads like the Polyanthus. Its pale green leaves form compact tufts, and the flowerstems, 4 to 9 in. high, are produced in early spring, often as many as half-a-dozen from one plant. It is perfectly hardy, and though only recently introduced from the Himalayas, has become quite acclimatised and grows vigorously in 
almost any soil, preferring, however, a deep rich loam in a moist shady part of the rock-garden. When plentiful it should be tried in various positions and soils, as it has not yet been thoroughly tested.

P. Sieboldi.-Though this handsome Primrose is considered a variety of $P$. cortusoides, it is very distinct in many important particulars. The size of its flowers, the breadth of its foliage, the creeping character of its root, its exclusively vernal habit, its pseudo-lobed or grooved seed-vessel, and the roundish plants are rare ; and another is, that they are remarkably free bloomers, throwing up successive flower-stems, and lasting a long time in perfection. Their cultivation also is comparatively easy. The best soil for them is light, rich, free material, consisting of fibry loam, leaf-mould, pulverised manure, and some grit to keep it open. They are impatient of excessive moisture, and when put in open ground should be planted in well-drained soil, or in raised positions in the rock-garden. The roots creep just below the surface,

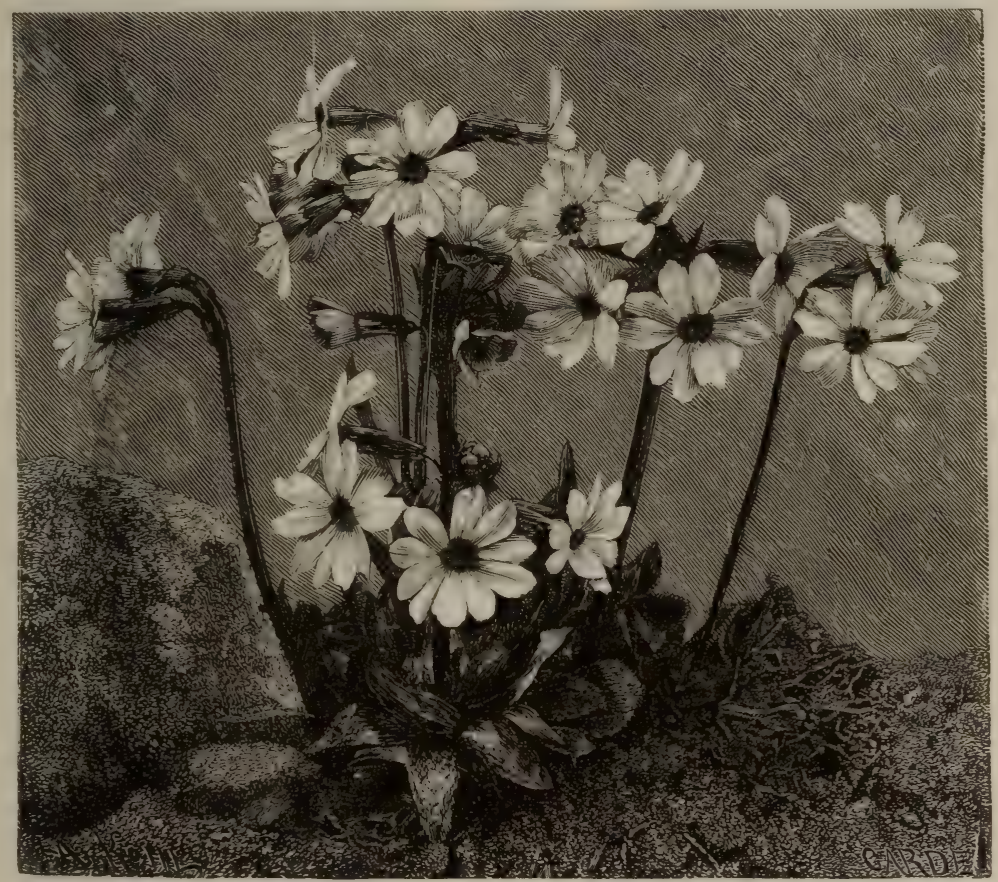

PRIMULA ROSEA.

flattened form of its seed, all warrant the belief in its distinctness from P. cortusoides as a garden plant. It is at any rate one of the showiest and most charming of all the Primulas, and is as easy to grow and as hardy as many others. Since its introduction from Japan numerous beautiful varieties have been raised, some of the most distinct being clarkiæflora, lilacina, marginata, fimbriata oculata, vincæflora, cœrulea-alba, Mauve Beauty, Lavender Queen, laciniata, and maxima. These possess a great diversity of colour, and some have the petals beautifully fringed. One of the chief merits of these Primulas is that they bloom early, flowering about the month of April when other flowering and form eyes trom which any variety can be easily propagated. P. Sieboldi is a hardy herbaceous perennial, which loses its leaves in autumn and winter, when it goes to rest, and breaks up again early in spring.

P. sikkimensis. - This is a robust species, deciduous or herbaceous in our climate, and quite distinct from all other sorts. It throws up strong flower-stems, I 5 to $24 \mathrm{in.} \mathrm{high,} \mathrm{bearing} \mathrm{numerous} \mathrm{bell-}$ shaped flowers of a pale yellow, with mealy pedicels, and having a peculiar but agreeable perfume. Some of the stems bear a head of more than five dozen buds and flowers, and each flower is nearly I in. long and more than $\frac{1}{2}$ in. across. P. sikkimensis starts into growth in April or 
early in May, and should have a shady position when in bloom, as its delicate blossoms suffer from cutting winds and bright sunshine. Blossoming in May, it remains in flower many weeks. It is perfectly hardy, and loves deep, well-drained, and moist ground; but spots
P. Stuarti (Stuart's Primrose). - A noble and vigorous yellow Primrose, about 16 in. high. It has leaves nearly I ft. long, and many-flowered umbels. A light deep soil, never allowed to get dry in summer, suits it well; but the most suitable place for it is some perfectly-

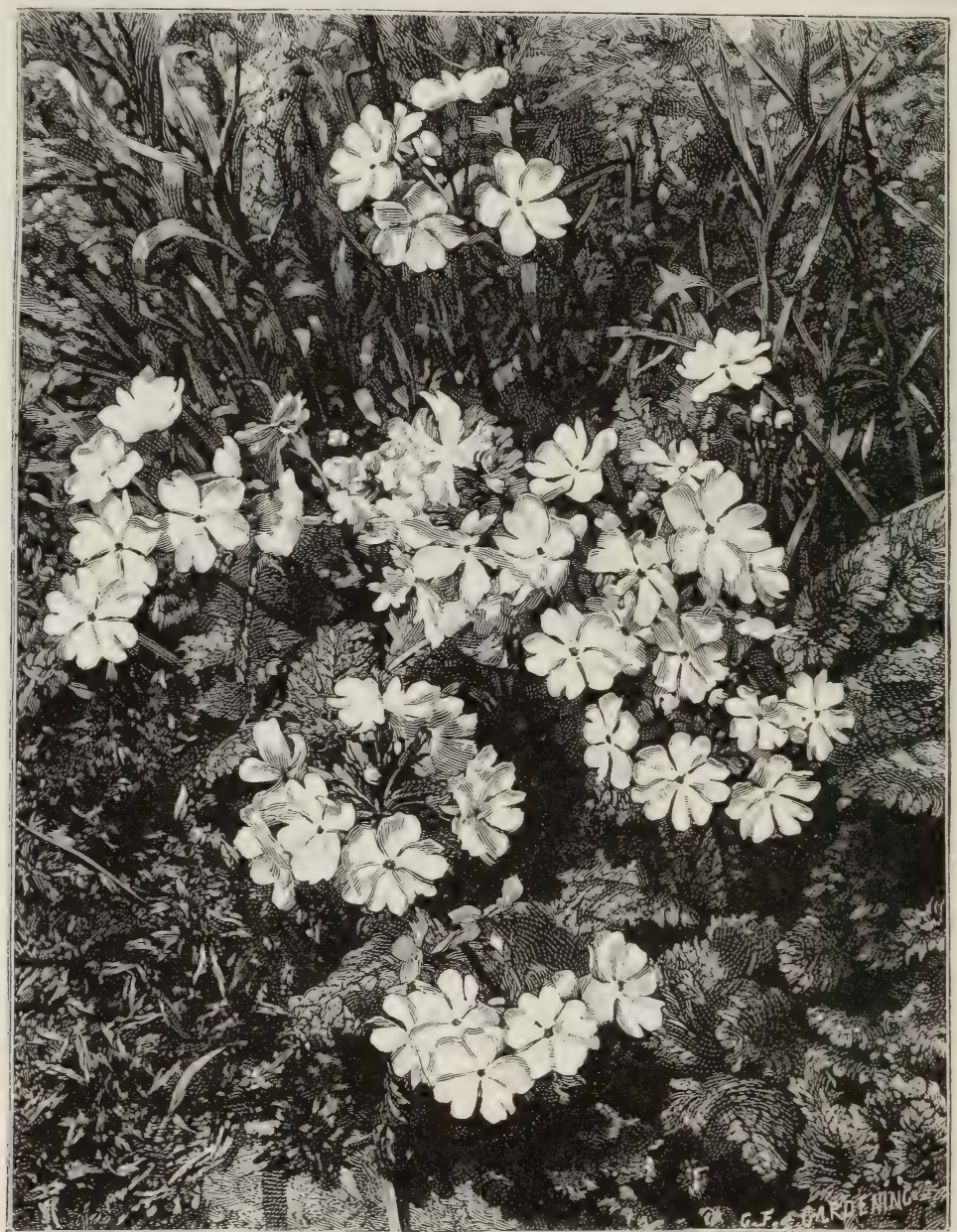

PRIIILLA SIZBOL1)I.

in the lower parts of the rock-garden near water, or situations in deep boggy places, suit it best. It is readily increased, either by seeds sown in summer as soon as they are ripe, or by careful division in spring or autumn. This Primrose is said to be the pride of all the Primroses of the mountains of India, inhabiting wet boggy localities at elevations of from 12,000 to $\mathrm{I} 7,000 \mathrm{ft}$., and covering acres of ground with its yellow flowers. drained and sheltered, slightly elevated spot in the rock-garden. It may be planted against the base of rocks, to shelter it from cutting winds, though when sufficiently plentiful, this precaution is unnecessary. Mountains of India.

P. villosa.-A lovely little Primrose, and one of the oldest cultivated. It is known by dark green obovate or suborbicular leaves. These leaves have closeset teeth, and are covered with glandular 
hairs, and are viscid on both sides. Its flower-stems, also viscid, barely elevate the sweet blooms above the foliage. It is well adapted for the rock-garden, in which it may be grown in any position, but it requires light peaty or spongy loam, about one-half being fine sand, and its roots should be kept moist during the dry season. It is easily increased by division, and may be raised from seed. Varieties are sometimes, but rarely, found with white flowers. It is sometimes grown under the name of $P$. viscosa. The variety nivea or nivalis is a beautiful plant, dwarf and neat in growth, producing trusses of lovely white flowers, which are quite distinct from any other in cultivation. It is of very easy culture, and may be grown either in pots or in the open ground. It deserves a select position in the rock-garden or in the border, a light free soil, and plenty of water during the warm season. It flowers in April and May. Alps. Similar to P. villosa are $P$. ciliata, Steini, hirsuta, pubescens, rhætica, pedemontana, œenensis, and Dinyana, charming little species from the Alps. All thrive under the same conditions as $\mathrm{P}$. villosa.

P. vulgaris (Common Primrose).-Of all the Primula family none excel our native Primroses in loveliness, and they are the earliest of all to flower. The Gentians and dwarf Primulas do no more for the Alps than these charming wild flowers do for our hedgerows, banks, groves, open woods, and the borders of our fields and streams. In some places the Common Primrose varies a good deal in colour. Some of the prettiest of the wild varieties are worthy of being introduced into shrubberies and semi-wild places; and so long as lovely colour and fragrance are esteemed in the spring flower garden, some of the more distinctly toned varieties should be sought after. Varied hues of yellow, red, rose, lilac, bluish-violet, lilac-rose, and white have already been raised, and if the good single varieties become popular, striking and desirable variations from the commoner types will be much more likely to be preserved. For shrubberies and woodland walks single varieties will always prove more useful than the old double kinds, because more vigorous and more easily increased. All the varieties are readily increased by division of the offsets, or by seeds, which are produced in abundance. In woods and shrubberies the plants will take care of themselves, a quality which adds to their charms; but in the flower garden some system of culture must be pursued. The following very simple one will secure the best results, both as to the production of vigorous free-blooming plants and an abundant stock. In autumn, after the summer occupants of the flower-beds are faded and removed, the Primroses and other spring flowers are planted in beds as the taste of the grower may direct. About the middle or the end of May it will be time to think of preparing the beds for their summer ornaments, and by that time also the Primroses will have begun to fade after yielding a long and abundant bloom. Then take them up, divide the offsets singly, doing this, if the day be sunny, in a shed or in a shady position. New or scarce varieties, or varieties of which a large stock is required, may be divided into the smallest offsets, but where much increase is not desired, the plants should be simply parted sufficiently to allow of their healthy derelopment. As soon as they are parted, plant them in the kitchen-garden or in some by-place. The more rich and moist the soil the better they will grow; especially if the position be a half-shady one. The alleys between Asparagus beds would do admirably if more convenient positions cannot be found. If the weather be very bright, it would be desirable, for a few days after planting, to shade the plants by spreading boughs or old garden mats over them, and they should at this time be thoroughly watered. If the plants are strong and regular in their development, they should be planted in lines, Io or I2 in. apart each way, but if the offsets are small they should be closer in the lines. By autumn they will make fine plants, and may then be taken up; as much of the root as will come up with ordinary care but not necessarily any soil or ball being preserved, and the plants should be transferred to beds in the flower garden or the pleasure-ground. The varieties of single coloured Primroses are so numerous, that it seems a folly to name them; but a few of the most distinct of those propagated by division have received names. Among these may be mentioned: Auriculæflora, one of the finest; Altaica, or grandiflora, also a beautiful sort; Rosy Morn, deep rosyred; Gem of Roses, rosy-pink; Queen of Violets, deep purplish-violet; Crimson Banner, deep maroon-crimson ; Violacea, pale purple; Fairy Queen, pure white with good eye ; Sulphurea, large, sulphur colour; Virginia, pure white; Brilliant, rich vermilion-red; King of Crimsons, rich massive crimson; Violetta, a very 
beautiful violet-purple; Lustrous, very deep crimson, with small perfect lemon eye ; and Scott Wilson, a singular bluishpurple. The propagation of these kinds, as well as of all the perennial Primroses, is slow, unless they can be reproduced true from seed. A seedling may produce two others the first year after blooming; and these may produce six or eight the next year, so that it takes several years to raise a hundred plants, and some to know long ago. The best-known and most distinctly marked are the double lilac, double purple, double sulphur, double white, double crimson, and double red. These and several allied forms are occasionally honoured with Latin names descriptive of their shades of colour. In catalogues will be found the following: Primula vulgaris alba plena, lilacina plena, purpurea plena, rosea plena, rubra plena, sulphurea plena; but we had

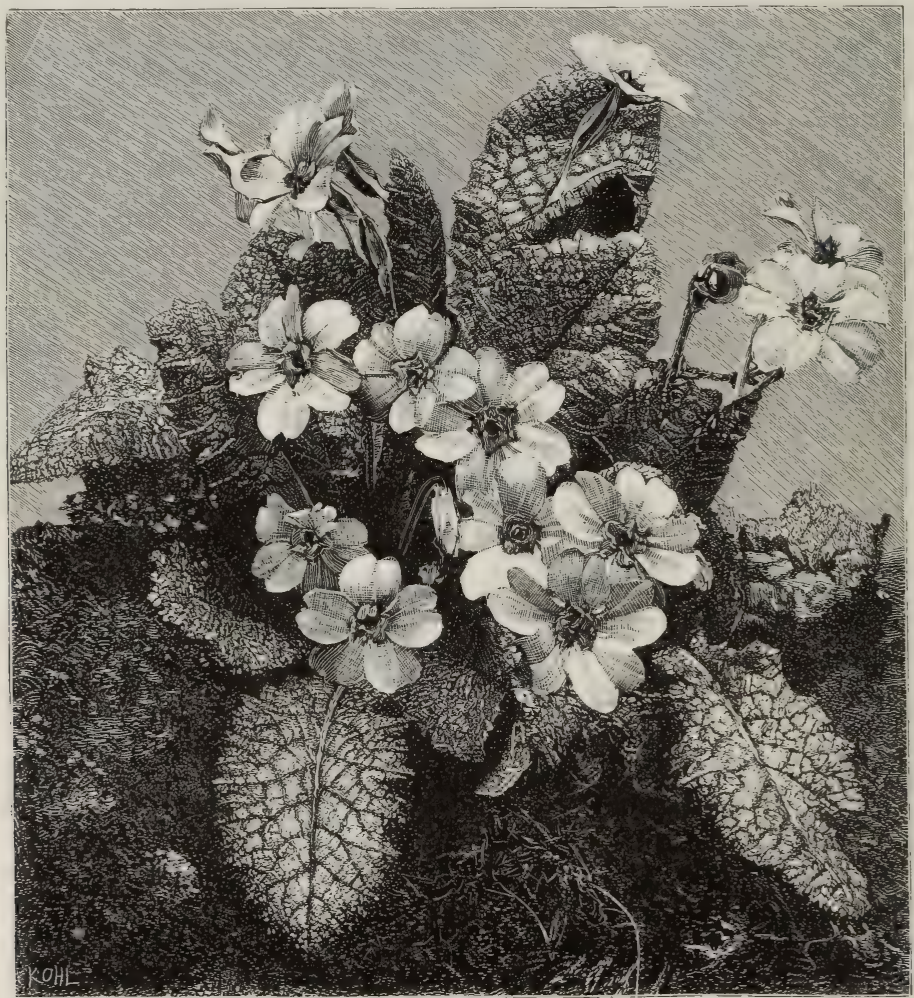

PRIMULA VULGARIS.

patience must therefore be exercised before the newest forms can be circulated largely.

DOUBLE VARIETIES.-The forms most precious for the garden are the beautiful old double kinds. No sweeter or prettier flowers ever warmed into beauty under a northern sun than their richly and delicately-tinted little rosettes. Once they were in every garden; but the day came when, like many hardy flowers, they were cast aside to make way for gaudier things; now, however, people are beginning to grow them again, and are inquiring for old and half-lost kinds which they used better speak of them in plain English and confine the Latin term to the species. The double kinds are slower-growing and more delicate than the single ones, and require more care, and the development of healthy foliage after flowering should be the object of those who wish to succeed with them. In the double kinds the deeper the hue the less robust the plant. The rich crimsons and the deep purples are usually most difficult to cultivate ; but in the extreme north, where the climate is at once moist and temperate, they grow almost with luxuriance. The climate of Ireland also favours them, but in the 
south and midland districts it is necessary to give them shade and abundant moisture during summer, and in winter the protection of glass against the continued frosts and rains. The white, lilac, and sulphur kinds, on the other hand, are very hardy, and, if established, appear to stand our climate well.

Shelter and partial shade are the conditions chiefly necessary to their successful culture. Open woods, copses, and half-shady places are the favourite haunts of the wild Primrose. In them, in addition to the shade, it enjoys the shelter, not merely of the tall objects around, but also of the long Grass and herbaceous plants growing near. never to be disturbed except for the purpose of division. They may, however, be employed as bedding plants, and treated in the manner recommended for single varieties, but they are not then so useful or so pretty as when in good colonies or large informal groups. Double Primroses well grown, and the same kinds barely existing, are such different objects, that nobody will grudge them the trifling attention necessary to their perfect development. Occasionally they may be seen flourishing by chance in some cottage-garden or some old country garden, where they find a home more congenial than the fashionable prim and bare flower garden. Division of the roots.

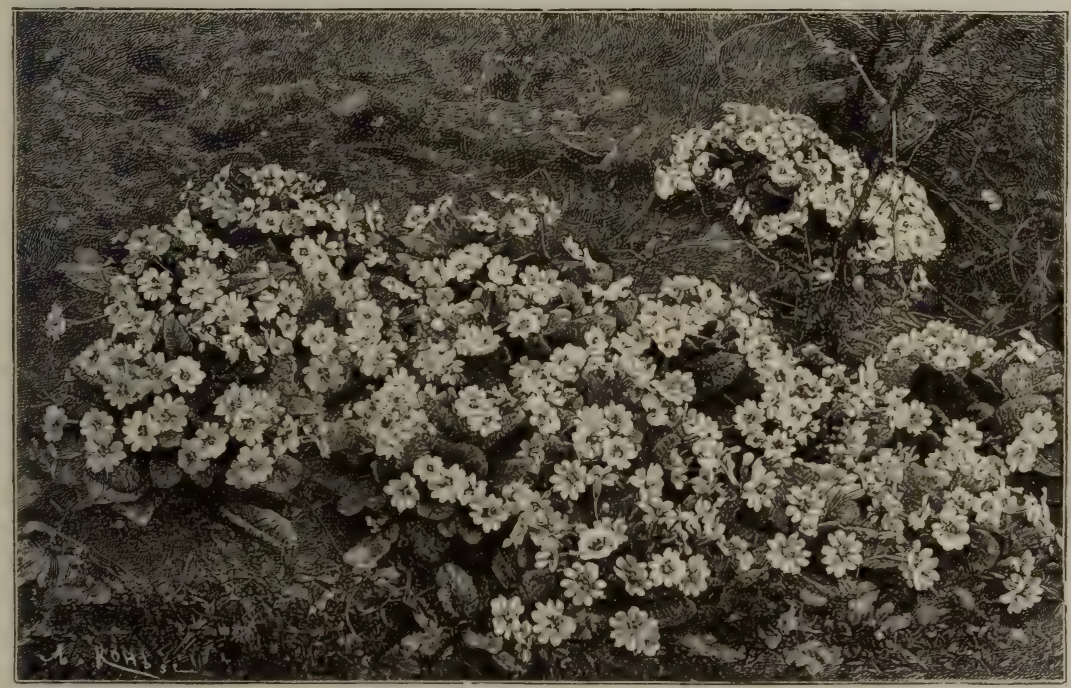

PRIMROSE MUNSTEAD EARLY WHITE

Taking into account the moisture consequent upon such companionship, let these facts guide us in the culture of the double kinds. It will readily be seen that a plant exposed to the full sun on a naked border is under conditions very different from one in a thin wood: the excessive evaporation and the searing away of the leaves by the wind would be quite sufficient to account for its failure.

It is therefore desirable to plant the beautiful double Primroses, in slightly shaded and sheltered positions, in borders of light rich vegetable soil ; and, to keep the earth from being dried up too rapidly, spreading Cocoa fibre or leaf-mould on it in summer. It would be better to plant them in some favourite spot permanently than to change them repeatedly from place to place. Indeed, they ought
The Polyanthus. - Though the origin of this beautiful old-fashioned flower is somewhat obscure, it is considered to be a form of the common $\mathrm{P}$. vulgaris with the stems developed. Polyanthuses are not at all sufficiently appreciated, considering the wonderful array of beauty they present, and that for rich and charmingly inlaid colouring they surpass all other flowers of our spring gardens. It would require pages to describe even the good varieties. At one time the Polyanthus was highly esteemed as a florists' flower, and none in existence better deserved the attention and regard of amateurs ; but nearly all the choice old kinds are now lost, and very few florists really pay any attention to the flower. In consequence, however, of the great facility with which varieties are raised 
from seed, nobody need be without handsome kinds, especially as raising them will prove interesting amusement for the amateur. The rules of the florists are in this case of a little more value than usual, and Maddock, in the following passage, describes a very beautiful variation of the flower: "The ground colour is most to be admired when shaded with dark rich crimson resembling velvet, with one mark or stripe in the centre of each division of the limb, bold and distinct from the edging down to the eye, where it should terminate in a fine point." $\mathrm{He}$ further says: "The pips should be large,
As to the capabilities of the various kinds of Polyanthus, it would be difficult to name any hardy flower which is so generally useful. The finer varieties are worthy of a place in the rock-garden amidst the choicest alpine plants; while the showier ones are suitable for spring bedding. Numbers of vigorous varieties will form the most appropriate ornaments that can be massed by shady walks in pleasure-grounds, and some may be employed as edgings. Many varieties are worthy of being naturalised abundantly in pleasure-grounds and along wood walks, though the enthusiastic florist

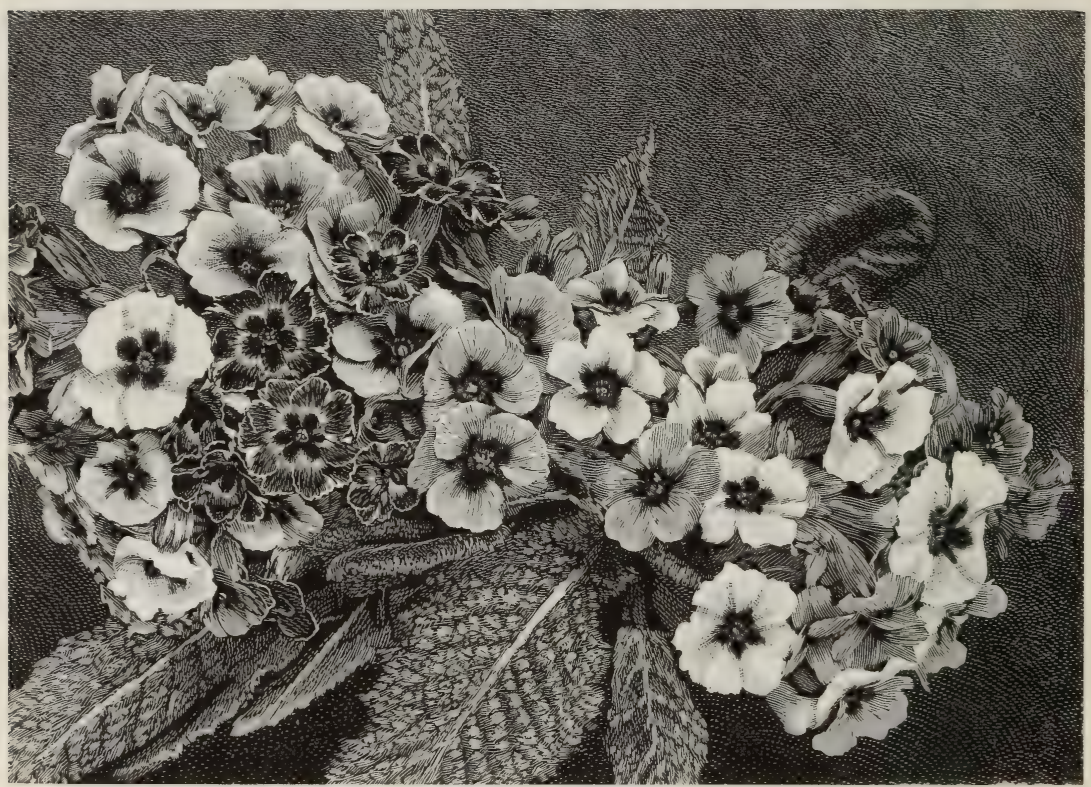

BUNCH" PRIMROSES.

quite flat, and as round as may be consistent with their peculiarly beautiful figure, which is circular, excepting those small indentures between each division of the limb, which divide it into five or six heart-like segments. The edging should resemble a bright gold lace, bold, clear, and distinct, and so nearly of the same colour as the eye and stripes as scarcely to be distinguished. In short, the Polyanthus should possess a graceful elegance of form, a richness of colouring, and symmetry of parts not to be found united in any other flower." Here, however, as in most similar cases, the grower will do well to select the most beautiful of his own raising, and not be tied by any conventional rules. grows the finer ones in pots. Polyanthuses are scarcely to be recommended for using in masse's in the spring garden as much as the finer varieties of the Primrose, since in order to be admired they require to be seen rather closely; but wherever flowers are placed for their beauty rather than their effect as colour, Polyanthuses are invaluable, and they should be seen in strong colonies in shrubberies and borders. Their cultivation is almost as simple as that of meadow Grass. They grow vigorously in almost any garden soil, but best in a soil that is somewhat rich and moist; and though they thrive in the full sun, they best enjoy a partially shaded and sheltered position, and are 
somewhat impatient of heat and drought. When grown for bedding, they are, like the Primroses, etc., removed in early summer from the flower garden to the kitchen-garden or nursery, and replaced there when the summer bedding plants have passed away.

There have been lately raised some varieties, a good deal larger in their parts than the type, and these are very easy of culture and very vigorous. There are, however, very few, if any, double varieties, but some varieties are curious and interesting from the duplication of the calyx or corolla ; these are popularly known as "hose-in-hose" Polyanthuses. They grow with the same facility as the others. The beautiful Gold-laced Polyanthuses are much prized. The best are those raised years ago, such as Cheshire Favourite, George the Fourth, Formosa, Duke of Wellington, Black Prince, Lancashire Hero, and others, and they are mentioned in most florists' catalogues of hardy plants. The common Oxlip is a hybrid more or less intermediate between the Cowslip and the Primrose. It differs from the true or Bardfield Oxlip ( $P$. elatior) in bearing much larger and brighter flowers with longer foot-stalks, and in having in the throat of the flower the five bosses characteristic of the Primrose and the Cowslip. Some of its varieties approach the Cowslip, and some the Primrose in character. The treatment that suits Polyanthuses and Primroses will suit the Oxlip. P. suaveolens is a variety of the Cowslip found in many parts of the Continent, but is not sufficiently distinct or ornamental to merit cultivation. P. elatior, the true Oxlip, is not very ornamental, the flowers being of a pale buff-yellow, and readily distinguished by their funnel-shaped corolla, which is quite destitute of the bosses present in the Primrose and Cowslip. It is found on clayey soils in woods and meadows in the eastern counties of England, particularly in Essex, Suffolk, and Cambridgeshire. It is of easy culture, and is most suitable for collections of interesting plants, but is neither distinct nor ornamental enough for limited collections of ornamental kinds. It is also known as the Bardfield Oxlip. The blue Polyanthus (P. e. cœrulea) is a singularly handsome variety of it with slaty-blue flowers. It is now rare in gardens, but is well worth growing.

CUlTURE.-Where soil is prepared for the choicer varieties, any good loam with a free addition of sand, decomposed leafmould, and decomposed cow-manure will form an admirable compost. The Polyanthus may be raised with great facility from seed, which should be sown immediately after it is gathered, say about the end of June. It will indeed grow with vigour if the seed is not sown till the following spring, but by sowing it immediately nearly a year is gained. The amateur wishing to raise choice kinds had better sow the seed in pans or rough wooden boxes, but for ordinary purposes a bed of finely-pulverised soil in the open air will answer to perfection. Sowings in early spring are better made in pans or rough shallow boxes, placed in cold frames, as time will be gained thereby. The best plan is not to lose time by allowing the seed to lie idle in the drawer all the autumn and winter, but to sow it as soon as it is ripe, and have strong plants in the following spring.

\section{Prince's Feather (Amarantus). \\ Prophet-flower (Arnebia).}

Prunella grandifiora (Large Selfheal). - This handsome and vigorous plant is readily distinguished by its large flowers from the common British Self-heal (P. vulgaris), which is unworthy of cultivation. There is a white and a purple variety, both handsome plants, thriving in almost any soil, but preferring one moist and free, and a somewhat shaded position. In winter they are apt to go off on the London clay, at least on the level ground, but are well suited for mixed borders, banks, or copses. The variety laciniata has deeply-cut leaves. Europe. Flowering in summer. P. pyrenaica (Pyrenean Self-heal) is allied to the preceding, and is considered a variety of it. It is about Io in. high, and its beautiful violet-purple flowers are larger than those of P. grandiflora. It should have the treatment recommended for P. grandiflora. Labiatæ. = Brunella.

Prunus (Plum).-Besides the edible Plums, there are numerous showy kinds grown in botanical collections; but though the best deserve to be better known, few are to be found in nurseries and private gardens. There is not a more beautiful early-flowering tree than P. divaricata. In April, and sometimes in March, before its leaves appear, it is covered with small white blossoms. On account of its gracefully-spreading growth and its early bloom, which is as welcome as that of the Peach and Almond, it is one of the choicest of trees for the lawn. Next perhaps in importance is the Chinese $\mathrm{P}$. triloba, a lovely shrub, which is happily becoming more generally cultivated. It is perfectly hardy, and of vigorous, 
yet slender and graceful growth. In spring every shoot is beautifully wreathed with clusters of double rosette-like blossoms of a delicate colour, sometimes pink, and sometimes almost pure white. It generally blossoms before the leaves are fully expanded, and lasts in bloom for quite a fortnight. It makes a capital bush for the lawn or shrubbery, and is always seen to the best advantage in isolated groups of three to six plants. It is, however, never so fine as when against

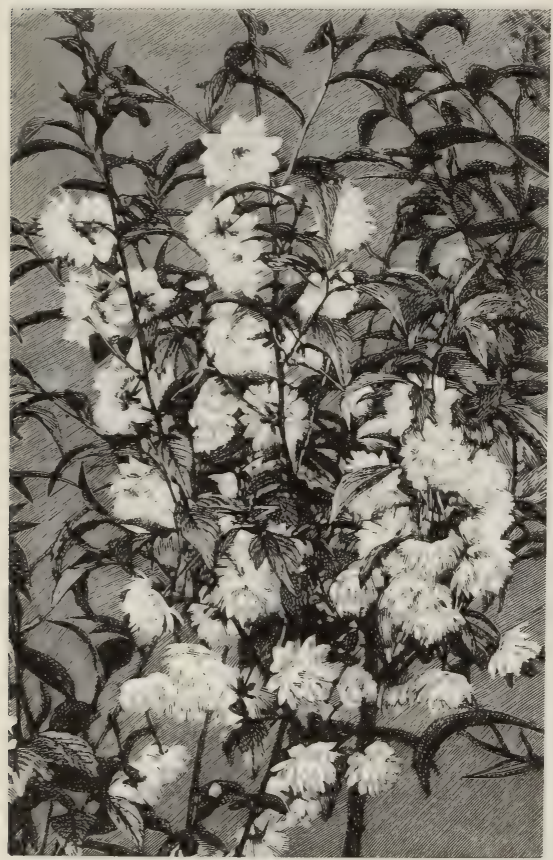

PRUNUS SINENSIS FL.-PL.

a sunny wall, for then it blossoms more abundantly, on account of its shoots being thoroughly ripened. There are few more beautiful wall shrubs, and it will quickly clothe a large surface to a height of Io ft. or more. It requires an annual pruning, and the old wood should be cut out to encourage the new shoots which bear the bloom. P. triloba is also known as Amygdalopsis Lindleyi, P. virgata, and Prunopsis Lindleyi. Another very fine Chinese Plum is the dwarf $P$. sinensis, a slender early-flowering shrub with small white flowers. It is now commonly grown as a pot-plant for greenhouses in early spring, but is perfectly hardy, and may be planted in the open shrubbery. Its double variety $(\mathrm{P}$. sinensis fl. $-\mathrm{pl}$.) is more ornamental and more gener- ally grown. Its flowers are like small rosettes wreathing every twig with white. The American wild red Cherry (P. pennsylvanica) is an extremely pretty little tree, and frequently seen in old gardens. It blooms early, and about May produces a great many tiny white blossoms on every twig. The Cherry Plum, or Myrobalan, is worthy of consideration, being very pretty when in bloom in early summer. More ornamental, however, because of its rich purple foliage, is the variety P. Pissardi, recently introduced and now becoming common. In May it is crowded with blush-tinted blossoms, which harmonise well with its foliage, and it is then one of the most beautiful of all hardy trees or shrubs. It is, in fact, indispensable to a tastefully-planted garden. Other ornamental Plums worth planting are the double variety of the Sloe or Blackthorn (P. spinosa), which in good soils and suitable spots reaches 8 or Io $\mathrm{ft}$. high, and produces in spring an abundant crop of tiny rosette-like white blossoms. Some of the varieties of the Bullace Plum (P. insititia) and of the common garden Plum ( $P$. domestica) are very ornamental whether in flower in spring or when in fruit in autumn, and, like the Pear, Apple, Medlar, and Quince, should not be confined to the orchard and kitchen-garden.

Ptarmica (=Achillea).

Pteris (Brake). - The Bracken (P. aquilina), the only thoroughly hardy species of this genus, is generally so common as not to need cultivation. If, however, any one wishes to introduce it where it is scarce, he should bear in mind that to transplant it successfully large sods containing the strong creeping roots must be dug up, and planted in light soil ; if peaty, so much the better. In very mild localities, such species as P. cretica and the elegant P. scaberula, from New Zealand, sometimes thrive in sheltered nooks.

Pterocephalus Parnassi. - A Scabiouslike plant of dwarf compact growth, forming a dense rounded mass of hoary foliage which in summer is studded with mauve-coloured flower-heads. It is a most desirable plant, thriving best in light warm soils, and is suited either for the rock-garden or the ordinary border. $=$ Scabiosa pterocephala. Greece.

Pterostyrax hispidum.-A deciduous Japanese shrub, scarcely hardy enough for culture as a bush. It makes a capital wall shrub, being rapid in growth, handsome in foliage, and very beautiful in flower. The leaves are heart-shaped, 
and are about 6 in. long and 3 in. broad. The small white flowers are borne very freely in drooping clusters about the end of July. Another Japanese species, P. corymbosum, is less common, and though inferior in flower-beauty, is desirable for walls. Its flowers, which are white or faintly tinged, are produced in crowded clusters. Both species are 8 to $12 \mathrm{ft}$.

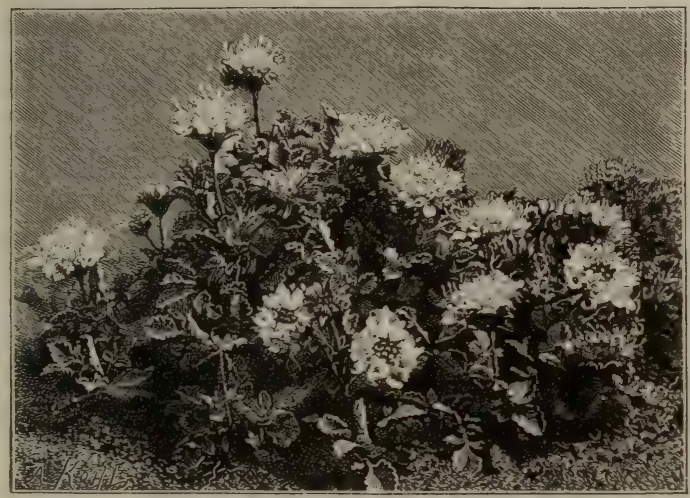

PTEROCEPHALUS PARNASSI

high in this country. Their true character is not seen when growing against walls. They are known botanically as Halesia hispida and $\mathrm{H}$. corymbosa, but ever since their introduction they have been known as Pterostyrax in gardens.

Puccoon (Sanguinaria canadensis).

Pulmonaria(Lungwort).- - These plants are very vigorous and hardy, and thrive on any soil. Most of them grow well under the shade of trees, and all succeed best in shade. They are of compact growth, and form dense tufts of foliage, which is generally handsomely blotched and speckled with white. They form pretty groups in the spring garden, and deserve to be planted in semi-wild places, but are unworthy of the select border, except where more valuable plants are very scarce. There are about half-adozen kinds, and all of them bear a strong resemblance to each other. P. officinalis and $P$. angustifolia are native plants. P. officinalis (sometimes called P. saccharata) has rose flowers turning to blue, and P. angustifolia bears blue flowers. P. mollis is intermediate between these two, and P. grandiflora is somewhat similar to $\mathrm{P}$. officinalis. P. azurea has rich blue flowers. Chiefly natives of Europe. Boraginaceæ. P. dahurica $=$ Mertenzia dahurica.

Pulsatilla (=Anemone).

Punica granatum (Pomegranate). -
Like the Myrtle, the Pomegranate is commonly grown as a wall shrub. The walls of some old houses 30 or $40 \mathrm{ft}$. high are covered with it, and it makes a very beautiful covering with its dense mass of tender green foliage. The type has single flowers of a brilliant scarlet, but the best is the double-flowered sort (florepleno), which is also scarlet, and is that most commonly seen. There is also a yellow-flowered sort and a white or almost white kind (albescens) with single and double forms, but these are rare. The flowers are produced plentifully on the young slender shoots of the previous year's growth, and in pruning, these shoots must be left untouched.

Purple Coneflower (Echinacea).

Purple Loosestrife (Lythrum Salicaria).

Purple Sweet Sultan (Centaurea moschata).

Purslane (Portulaca)

Puschkinia scilloides. - A charming bulbous plant, and one of the most beautiful of spring flowers. In its growth it resembles some of the Scillas, but its flowers are of a delicate blue, each petal being marked through the centre with a darker hue. The flower spikes are 4 or 5 in. high. There are two forms of the plant-the ordinary form and P. compacta. Compacta is so called on account of its blossoms being more numerous and more dense, and it is therefore the handsomer of the two. P. scilloides is also known as P. libanotica and P. sicula. The culture of this plant is easy. It is perfectly hardy in a dry position and a thoroughly-drained soil. It delights in a sunny border with a southern aspect near a wall, but if this is not available, an open border slightly raised above the level of the ordinary ground will suit it. The soil should be light and friable and about I $\mathrm{ft}$. in depth; and the bulbs should be planted about 4 in. deep. The Puschkinia will not thrive when mixed indiscriminately with plants of coarse growth, for their shade and their consequent dampness injure the bulbs. During winter a protective mulching is advisable, but this should be removed as soon as the severe cold is past. After the flowering season, which is late in spring, the soil should be entirely exposed, to allow it to become warm and dry, and to ripen the bulbs well - a most important point. Shady situations in sub-alpine districts of Asia Minor. 
Pyrethrum.-By far the most important of the numerous species of this genus is the Caucasian P. Roseum, which has yielded the innumerable varieties, both single and double, that have now become such popular border flowers. These varieties have much to recommend them : they are extremely showy, are very hardy and easy to grow, are little affected by sun or rain, and are invaluable as cut flowers for several months in summer and autumn. The blossoms are continually becoming more varied in colour and more refined in shape. Though Pyrethrums are in their fullest beauty in June, they are seldom altogether flowerless throughout the summer; and a succession can they grow and the more luxuriantly they flower. Mulching, especially in dry soils, is very advantageous, as it keeps the ground moist and cool. The varieties are so numerous that it is difficult to make a selection, and new sorts are continually being raised, but the following are some of the best: White and white-shadedBoule de Neige, Delicatum, Madame Billiard, Nancy, Niveum plenum, Olivia, Argentine, Prince de Metternich, and $\mathrm{Ne}$ Plus Ultra. White with yellow centre -Bonamy, Impératrice Charlotte, La Belle Blonde, Virginale, and Voie lactée. Purple and red - Mrs. Dix, Rubrum plenum, Mons. Barral, Brilliant, and Wilhelm Kramper. Crimson - Michael

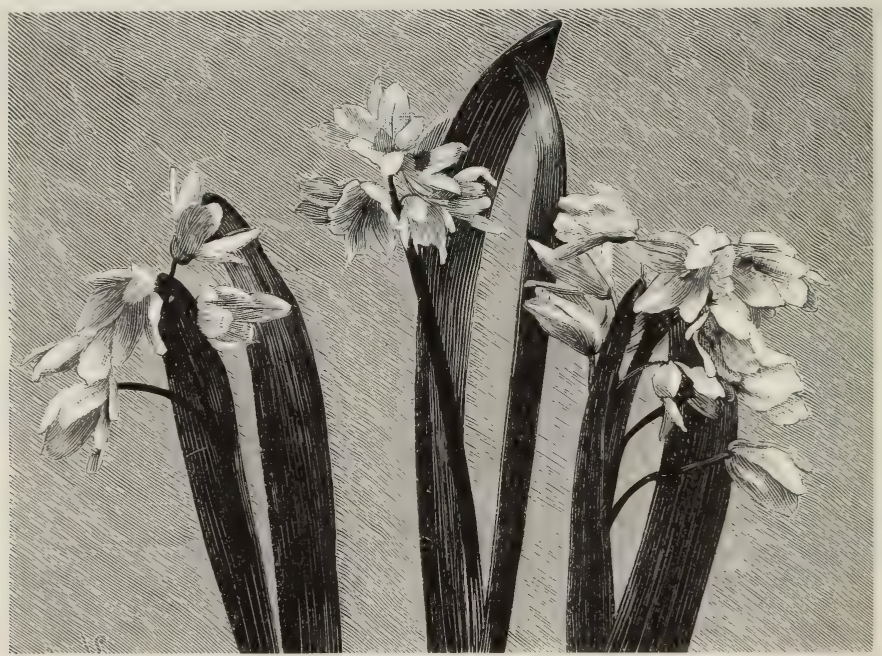

PUSCHKINIA SCILLOIDES.

easily be kept up by judicious stopping and thinning. They are also invaluable for autumn decoration, for if they are cut down after flowering in June they flower again in autumn. They are easily propagated by division or seed, but seed cannot be recommended, as only a very small number of good varieties come from the best seed. The proper time for propagation is in spring. Take the plants up, shake off all soil, pull them to pieces, put them in small pots, and place them in a cold frame for a few weeks until they become established. Do not keep them too close, as they are apt to damp. When they are established they may be planted out. A good rich loam suits them best, though they will grow and flower freely in any good garden soil, and the more we incorporate wellrotted manure with the soil the better
Buckner, Miss Plinkie, Modèle, Multiflorum, Prince Teck, Progress, Emile Lemoine, and Marquis of Bute. Carmine and pink-Carmineum plenum, Charles Baltet, Floribundum plenum, Gloire de Stalle, Imbricatum plenum, Nemesis, Fulgens plenissimum, Haage et Schmidt, Iveryanum, J. N. Twerdy, and Rev. J. Dix. Yellow-Sulphureum plenum, Solfaterre. Lilac and rose-Comte de Montbrun, Delicatissimum, Dr. Livingstone, Gaiety, Galathée, Hermann Stenger, Lady Blanche, Lischen, Minerva, Uzziel, and Roseum plenum. Most of these are double-flowered sorts; but there is also a great diversity of colour among the single kinds, and they are quite as beautiful as the heavy-headed double flowers, and are more suitable for vases. Other species of garden value are-

P. Parthenium (Feverferv). - The 
golden-leaved variety of this plant ( $P$. $\mathrm{P}$. aureum or Golden Feather) is now common in every garden. Of this there are several forms. One is called laciniatum, and is very distinct from the older kind. These have their uses in geometrical borders, where they have a bright effect. Their culture is of the simplest description. Seed is sown in heat in spring, and the seedlings are pricked off in pans and when large enough transferred to open borders, and there they withstand the winter unprotected. New plants should be raised every year, as after flowering the second year the old plants lose their neat compact growth.

P. Tchihatchewi (Turfing Daisy).-A Caucasian species, chiefly remarkable for retaining its verdure in dry weather on even banks or slopes where few perennials would flourish. Being a dwarf creeper, it quickly forms a carpet of green, which needs no alteration beyond removing the flower-stems thrown up. These, though perhaps not uninteresting, may sometimes lessen the utility of the plant. The flowers closely resemble those of the common Ox-eye(Chrysanthemum Leucanthemum), and have white rays and a yellow disc, but the stems are dwarfer, and scarcely exceed I ft. in height. P. Tchihatchewi may be used with good effect for covering dry banks.

P. uliginosum is one of the noblest of tall herbaceous plants, and forms dense tufts 5 to 7 feet in height. These are crowned by lax clusters of pure white flowers, each about twice the size of an Ox-eye Daisy. It is excellent for cutting, and its blossoms are produced late in autumn before the Chrysanthemums come in. It is a stately plant for a rich border, and thrives best in a deep, moist, loamy soil. It may be naturalised in damp places. Division. Syn., P. serotinum. Hungary.

Pyrola rotundifolia (Larger Wintergreen).-A rare native plant, 6 to $\mathrm{I} 2$ in. high, inhabiting woods, shady, bushy, and reedy places. It has leathery leaves, and its erect stems bear long, handsome, and slightly-drooping racemes of pure white flowers, half an inch across, ten to twenty of which are borne, on a stem. They have a sweet scent. P. r. arenaria is a very graceful plant, found wild on sandy sea-shores. It differs from the preceding in being smooth, deep green, and dwarfer, and in having as a rule several empty bracts below the inflorescence. Both the type and its variety are beautiful plants for the shady mossy flanks of the rockgarden in free sandy and vegetable soil.
They flourish more readily in cultivation than any other species of the family. In America there are varieties with fleshcoloured and reddish flowers, but none of

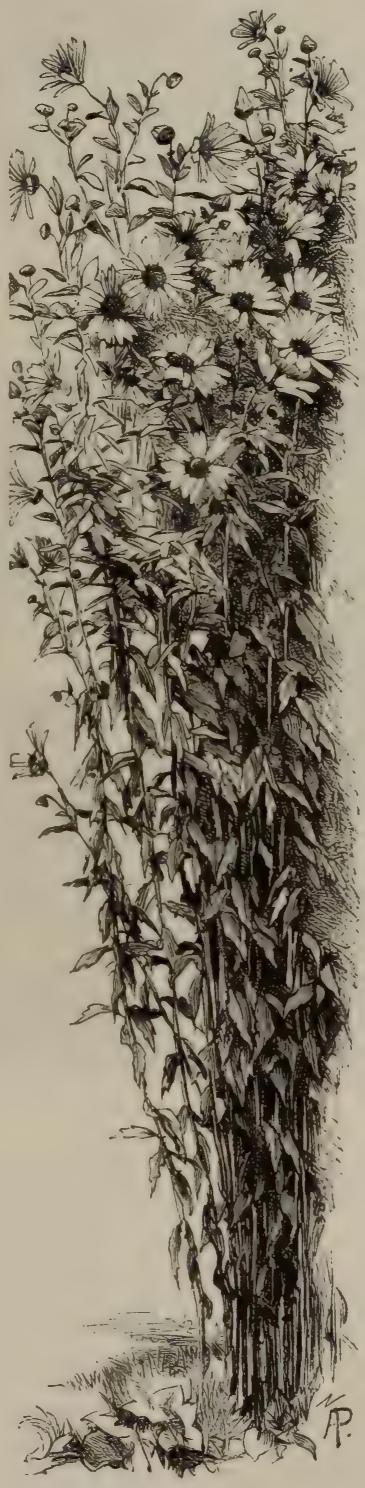

PYRETHRUM ULIGINOSUM.

these are in cultivation with us. P. uniflora, P. media, P. minor, and P. secunda are also interesting British plants, and the first-named is very ornamental, besides being very rare. P. elliptica, a native of $\mathrm{N}$. America, is also found in our gardens, 
though rarely. Any of these plants are worthy of a place in thin mossy copses on light sandy vegetable soil, or in moist and half-shady parts of the rock-garden or the fernery.

Pyrus (Pear and Apple).-Of the purely ornamental species of Pyrus there is now a bewildering number, since botanists have classed all Apples, Pears, and their allies under the one genus. Here, however, it will be convenient to adhere to the old classification, which places Pears under Pyrus, Apples under Malus, ${ }^{\circ}$ Beams under Aria, and Mountain Ashes and Service Trees under Sorbus. No one is likely to confuse one with another, and antly wreathed with large semi-double blossoms of a delicate rose-pink. It is not often met with, except in old gardens. The varieties of P. M. baccata or Berry Apple (so called from its small round fruits) are known as Siberian Crabs. They are graceful in growth, and showy in flower, and they usually produce an abundant crop of highly-coloured fruits, which add much to the interest and beauty of the garden in autumn. The Japanese Crab (P. M. Toringo) is extremely beautiful, and the flowers and fruits are plentiful. The flowers are white or pale pink, and the very small fruits are hung on long slender stalks. Ot the Toringo Crab

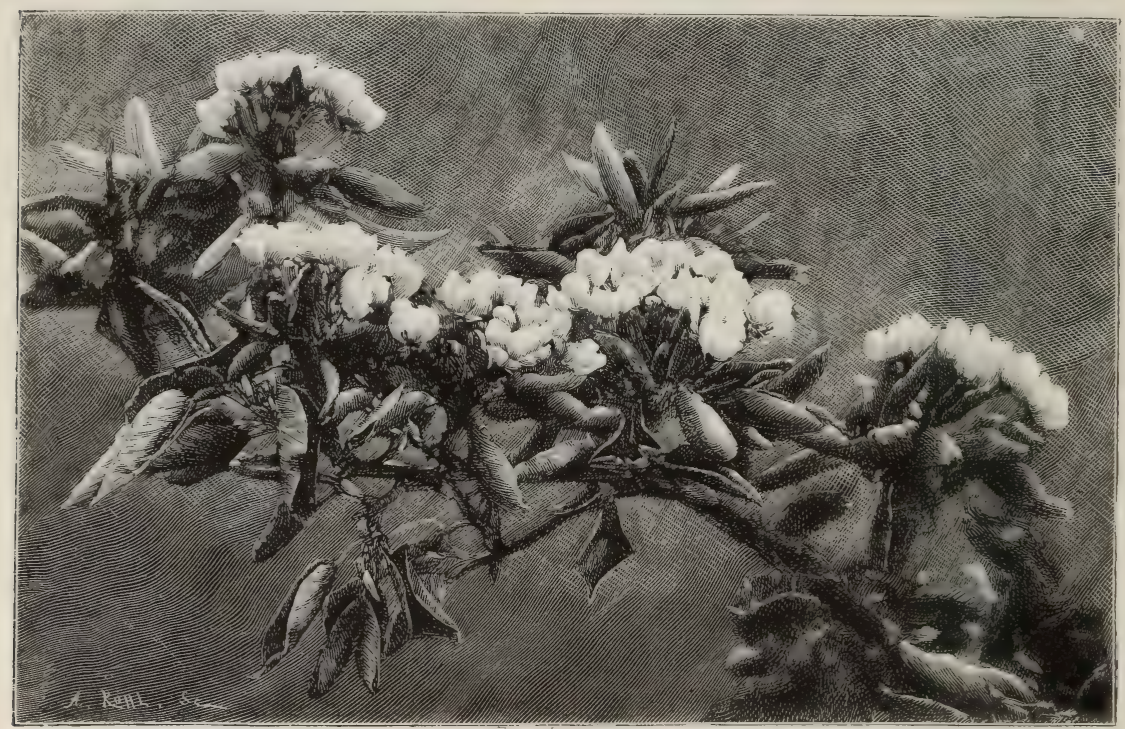

PEAR BLOSSOM.

their names are more easily remembered when so classified. These old genera are now placed as sections of the genus Pyrus. The finest flowering trees, and the most valuable for ornamental planting, are those included under the section Malus, the type of which is the common Crab Apple (M. communis). There is a beautiful flowering variety of the Crab Apple called the Paradise Apple, having large handsome flowers, but it is seldom planted for ornament, although in common use as a stock for grafting. The Chinese and Japanese Crab Apples are very beautiful, and include the finest of our small trees that flower in early summer. The Chinese double-flowered Crab (P. M. spectabilis) is a lovely tree, I 5 to $25 \mathrm{ft}$. high, and has a wide-spreading head of branches abund- there are now several forms, differing in colour of flower and of fruit. The Toringo Crab is a small tree, and is a large spreading bush if the leaders are removed. The finest of the Eastern Crab Apples is the Japanese P. M. floribunda, now becoming so common in gardens. Fully grown it makes a low tree with a dense widespreading head of slender branches. These branches are loaded every May with a profusion of flowers of a pale pink when expanded, and of a brilliant crimson in the bud stage, when they are most beautiful. No garden is well planted if this tree is wanting, as it is hardy, grows rapidly anywhere, and costs little to buy. There are a few new varieties of it, one called Halleana being remarkable for the larger and more richly-tinted blossoms. 
The North American Sweet-scented Crab Apple (P. M. coronaria) is a lovely little tree with large pale pink deliciouslyscented flowers. There are other ornamental Apples in the section Malus, but the foregoing include the finest and the most readily obtainable. The charming Cydonia Maulei is now placed under Pyrus, but in these articles it is described under Cydonia. Of the true Pears as ornamental trees little can be said. They are a good deal like orchard and garden Pears in growth and flower, and their fruits are not remarkable. One or two, however, may be planted for ornament. One is P. Bollwylleriana, from Central Europe, which produces in spring an abundance of small white blooms in clusters ; and another, P. salicifolia (the Willow-leaved Pear), which is well worthy of planting on account of its distinct and beautiful foliage, has leaves of silvery whiteness. P. olæagnifolia, or Oleasterleaved Pear is another Eastern species with hoary leaves.

Of the Sorbus section the common Mountain Ash (P. Aucuparia) is a familiar example, but it is too common to need description. There is a rare kind with yellow berries (fructu luteo), another kind with weeping branches (pendula), a third of erect growth (fastigiata), and a fourth with variegated leaves. The last, however, is not very ornamental, as the variegation is seldom distinct. Other species worthy of attention are P. S. americana, the American Mountain Ash, which is a good deal like our own Mountain Ash; and P. S. hybrida, a tree of very distinct growth, with a dense pyramidal head. The leaves of P. S. hybrida are intermediate between those of P. S. Aucuparia and P. Aria (the White Beam). The true Service Tree, P. S. domestica, used to be more frequently planted than now. It is a handsome tree with elegant foliage. Of the White Beam (P. Aria) there are some very handsome kinds. Even our native White Beam is ornamental. Like the Mountain Ash, it is also one of the best trees for planting in exposed places on poor soil, and no tree thrives so well on chalk. Its broad silvery foliage renders it a distinct object in the landscape, and it is therefore a valuable park tree. Its allies and varieties include some beautiful trees, such as latifolia, with leaves which are broader than the type and quite as silvery. It is most easily obtainable. P. A. Hosti is a very handsome tree, both in foliage and flower. Its leaves are large and silvery, and its delicate rose- pink flowers are in broad flat clusters. It is a Central European tree, perfectly hardy, and about Io ft. high. The Himalayan Beam Tree, P. vestita (called also P. lanata and nepalensis) is extremely fine, but is not hardy everywhere. Its very large leaves are like those of the Loquat, and are of silvery whiteness. Where it thrives it is 20 to $30 \mathrm{ft}$. high.

Pyxidanthera barbulata (Pine Barren Beauty).-A curious little American plant. It is an evergreen shrub, yet smaller than many Mosses. Its numerous flowers are rose-coloured in bud, and white when open, and the effect of the rosy buds and the white flowers on the dense dwarf cushions is singularly pretty. It is as yet very scarce in our gardens, but plentiful in the sandy dry "Pine barrens" between New Jersey and North Carolina. It is generally found on little mounds in low, but not wet, places. It is a gem for the rock-garden, and should be planted in pure sand and vegetable earth, and fully exposed to the sun. It flowers in early summer. Division. Polemoniaceæ.

\section{Quamash (Camassia esculenta).}

Quamoclit coccinea.-A pretty Convolvulus-like plant. Its fine scarlet flowers are borne with a profusion which compensates for their rather small size. Its slender stems are of very rapid growth, and attain a height of 6 to $8 \mathrm{ft}$. in a few weeks. It may be treated either as a half - hardy annual, and sown in February or March under glass or in a hot-bed, or as a hardy annual, and sown in April or May in the open ground. Q. hederæfolia is another pretty species. It has scarlet flowers and lobed foliage, and requires the same treatment as $Q$. coccinea. Both are excellent plants for sheltered trellises, as they produce an abundance of flowers from July to September.

Queen of the Prairie (Spircea lobata).

Quercus (Evergreen Oak).-This most interesting and wonderful family is mainly composed of stately trees; but while many are forest trees, some are very beautiful for the garden, and nothing is better for this purpose than the charming Ilex of Italy, which is, happily, hardy in our gardens. It is perhaps most beautiful and largest in sea-shore districts, and many gardens in such districts, both in England and Ireland, have fine specimens. It gives excellent shade, and is a very pretty shelter for the flower garden. Among the most beautiful things I have seen in Nature's gardens 
are the Evergreen Oaks in glades on the mountains of California, one with camellia-like leaf, the under side being a beautiful brown-gold colour, the cup precious in many positions. With such a great shore-line, the opportunities for growing them well are vastly greater than they would be in a Continental

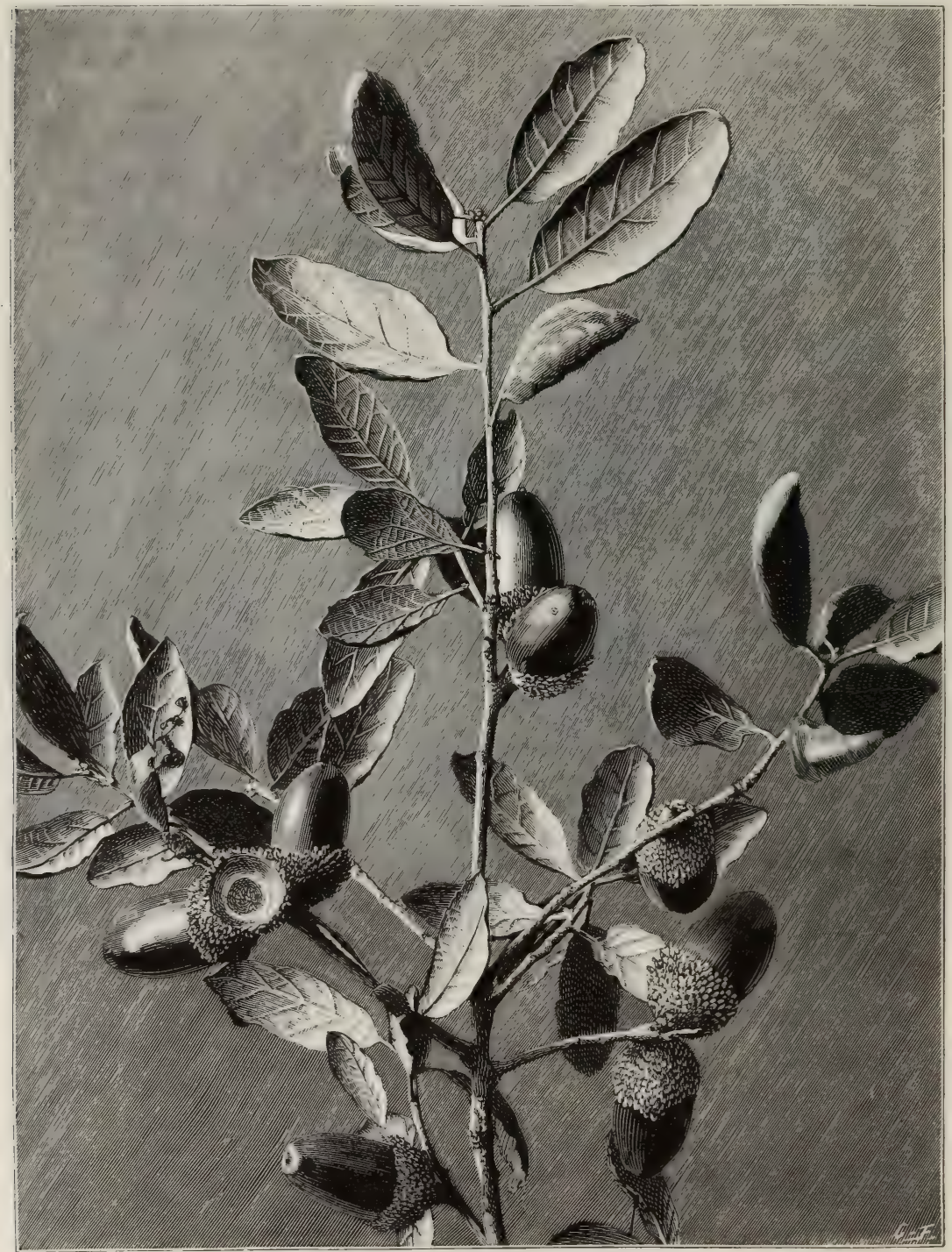

SHOOT AND ACORNS OF EVERGREEN OAK.

being covered with fur of the same colour. This, perhaps, is not hardy with us; but there are other Evergreen Oaks of sterling value for our gardens generally, and though they must not stand among the flowers, their near shelter and background of beautiful leaves will be country of like temperature to ours, and of this we should take advantage.

They are lovely shelter trees as groups or groves for gardens swept by sea winds. There are instructive examples of their use in this way in large places, as at St. Ann's, near Dublin, and Holkar, in 
Norfolk, and they would be equally useful for the protection and adornment of small places. Sometimes after very hard winters the trees look as if they were killed, but afterwards throw off the injured leaves and grow happily again. They should be transplanted with the greatest care when young, and the best way is often to raise plants from acorns, common where the tree grows well, and which may be often gathered from interesting places in Italy. They should be sown as soon as possible after ripening.

The following notes do not include all the species of Evergreen Oak which have been introduced into British gardens, but the most important kinds are referred to. For convenience of reference, these are arranged alphabetically.

Q. acuta is a native of Japan, and has dark leathery leaves about the size of those of the common Cherry Laurel. Even after such a winter as the one through which we have last passed, specimens of this species about London escaped. This has not been long enough in the country to enable one to judge the merits of an adult tree, but even as a bush it is a fine object. It is met with in books and catalogues under the names of Q. Buergeri and Q. marginata. Q. Buergeri robusta is a vigorous largeleaved form. Q. Buergeri pyramidalis only differs slightly in habit from the ordinary form.

Q. agrifolia, the Enceno of the Californian coast, is a distinct species, rarely seen in gardens. In general aspect it is not unlike some forms of $\mathrm{Q}$. Ilex, but the leaves are of a different shade of green from that of the Holm Oak. The largest specimen I have seen is at Kew; it is there more a large bush than a tree. According to Dr. Engelmann, however, it attains very much larger proportions in its native habitat. "A large tree, with a stout, low trunk, often 8 to $12 \mathrm{ft}$., sometimes $\mathrm{I} 6$ to $2 \mathrm{I} \mathrm{ft}$. in circumference, and with a spread of branches of $120 \mathrm{ft}$." It also occurs as a small shrub.

Q. alnifolia, the Golden Oak of Cyprus. -Its chief charm resides in the bright gold of the under surface of the Alder-like leaves. Snow persists for a month on the hills where this Oak is found wild, and, therefore, there seemed every probability that in the south and west of England it would thrive. Although it has withstood the past winter at Kew, it does not grow well, and, as far as the immediate neighbourhood of London is concerned, it has not turned out a success.
Q. chrysolepis (Californian Live Oak) is found along the coast ranges and along the western slopes of the Sierra Nevada, where it forms a tree 3 to $5 \mathrm{ft}$. in diameter, or, at higher elevations, is reduced to a shrub. It has not been long enough in cultivation in this country for a definite judgment to be formed respecting it, but it has pretty spiny-toothed dark green leaves, somewhat golden on the under surface.

Q. coccifera is a native of Southern Europe and the Levant. In this country it forms a dense bush with small spinyedged dark green leaves, and is a welcome denizen of the shrubbery. It has very small acorns, often hardly larger than a Pea, which now and then ripen in Southern England.

Q. cuspidata, a Japanese species, does well in some positions. In the Flora Japonica of Siebold and Zuccarini, the former of the two authors, to whose efforts European gardens are indebted for so many rare Japanese plants, gives us the following information: "In 1830 I succeeded in sending to Europe this species of Oak as well as many others. The method of the Japanese, who preserve the fruits of a large Sweet Chestnut until the middle of summer by enveloping them with clay, gave me the idea of sending acorns similarly treated to Europe."

Q. densiflora is a native of California, where it extends from the Santa Lucia Mountains, through the coast ranges, and especially among the Red Woods to the Shasta region. It is a tree 50 to $60 \mathrm{ft}$., or rarely $80 \mathrm{ft}$. high, and a foot or two in diameter ; in some positions often a mere shrub 5 to $7 \mathrm{ft}$. high. At Kew this grows freely in rather sheltered places, and produces fine leathery leaves of a dark green colour, in outline somewhat like those of a small Spanish Chestnut.

Q. glabra, another Japanese Oak, has large handsome leaves as large as those of a common Laurel; the acorns are borne in upright spikes and take two years to ripen. Several varieties are mentioned in some Continental catalogues, but they are hardly distinct enough to merit attention. At Kew the species makes a large compact bush and is thoroughly hardy.

Q. Ilex.-This is the best-known of all the Evergreen Oaks, and is perhaps the most valuable for Britain. Old trees, which have been allowed plenty of space and have not been pruned, but allowed to grow naturally, exhibit a remarkable similarity in appearance to the Olive trees of the Italian coast and of the 
Riviera about Mentone. Q. Ilex is one of the most variable of Oaks, but few of the named varieties, and there are many, are so beautiful as the type.

Q. phillyræoides is a Japanese kind with light bright green rounded leaves with few or no teeth. In England I have only seen it as a bush; and it is the Q. rotunda of Dutch nurseries.

Q. Suber (The Cork Oak) seems to me to be confined in a wild state to Western Europe. Except for the wonderful growth of its bark, this hardly differs in effect from the Holm Oak. The species thrives at Kew, and has to be protected by iron hurdles to prevent the public from cutting off and taking away the bark. The finest trees I have seen in England are in the fine gardens of the Earl of Mount Edgcumbe, near Plymouth.

Q. virens (Live Oak of Virginia) is in its native country a tree of the first economic value, and certainly deserves all the encomiums passed on it by the enthusiastic Cobbett in his Woodlands. All the trees in England I have seen under this name are, however, forms of Q. Ilex, and I doubt there being any fine trees of the true $\mathrm{Q}$. virens in cultivation in this country.

Quince (Cvdonia).

Ragged Robin (Lychnis Flox-cuculi).

Ramondia pyrenaica.-An interesting and ornamental Pyrenean plant, with

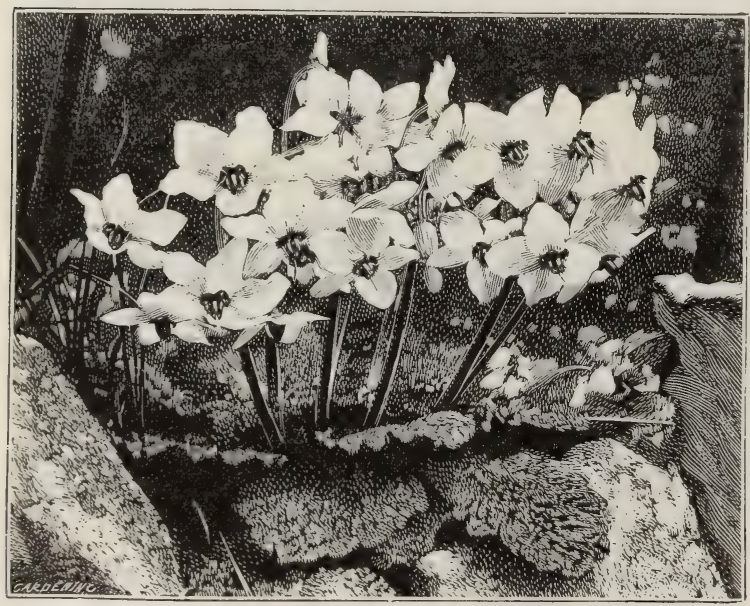

RAMONDIA PYRENAICA.

leaves in rosettes spreading very close to the ground. The flowers, which are of a purple-violet colour, and have an orangeyellow centre, are $I$ to $I \frac{1}{2}$ in. across, and are borne on stems 2 to $6 \mathrm{in.} \mathrm{long.} \mathrm{R}$. pyrenaica does very well in the rockgarden, and in mossy fissures filled with well-drained peaty earth, and is easily grown if put in cold frames in welldrained pots, plentifully watered during the warm months. It flowers in spring and early summer. Seed. It is found in the valleys of the Pyrenees, on the face of steep and rather shady rocks. There is a rare white variety which does well in borders of American shrubs in peat soil. There has been a good deal of writing about its cultivation, but it is really not difficult; growing in peat borders, on the lower ledges of the rock-garden, or in moist chinks. Cyrtandraceæ.

Rampion (Campanula Rapunculus).

Ranunculus (Crowfoot).--A very numerous family. Many species are useless weeds, while others are among the choicest of garden flowers, and are worthy ornaments of the border or the rock-garden. They are for the most part of the simplest culture, but R. asiaticus requires somewhat special treatment.

R. aconitifolius. - The double-flowered variety, known as Fair Maids of France, is a very pretty plant about I 8 in. high, forming for several weeks in early summer a dense tuft profusely laden with small rosette-like white blossoms. Thrives best in a deep moist loam. I find it a really charming plant in deep moist soils.

R. acris (Bachelors' Buttons).--The pretty double form of this plant is also a profuse flowerer. Its rich yellow blossoms are borne in button-like rosettes. It is a useful border plant, and thrives well in moist soil, fully exposed.

R. amplexicaulis is a lovely and most important garden plant, about I ft. high. It has slender stems, glaucous-grey foliage, and a few blossoms, I in. across, which are pure white with bright yellow centres. It blooms in April and May, and makes a pretty border plant, flourishing best in a deep moist loam.

$\mathbf{R}$. anemonoides is a new alpine species of very dwarf growth. Its flowers are borne on short stalks, and are I in. across; they are white and tinged with purple, but its unexpanded buds are wholly tinged with rosy-purple. Like some of the Anemones, it has a dense 
tuft of finely-divided foliage. Not much is known of its culture, but doubtless it will thrive in any well-constructed rockgarden. R. alpestris is somewhat similar but is rarely cultivated.

R. asiaticus.-It is scarcely necessary to speak of the beauties of this oldfashioned plant, with its neat dressy double flowers of every colour of the rainbow. Its innumerable varieties are divided into various sections, such as the Dutch, Scotch, Persian, and Turkish, each representing a distinct race, but all beautiful and well deserving any amount should be made with a small hoe; the claws of the roots should be placed downwards and pressed firmly into the soil, which should be raked over the roots, and a top-dressing of about 2 in. of good loam given. If the surface soil is light, it may be gently beaten with a spade in order to obtain a firm surface, and this may be repeated just before the foliage appears, say about a month or six weeks after the planting. As this Ranunculus delights in moist soil, water should be plentifully supplied if there is a scarcity of rain, and in no case should the roots be allowed to

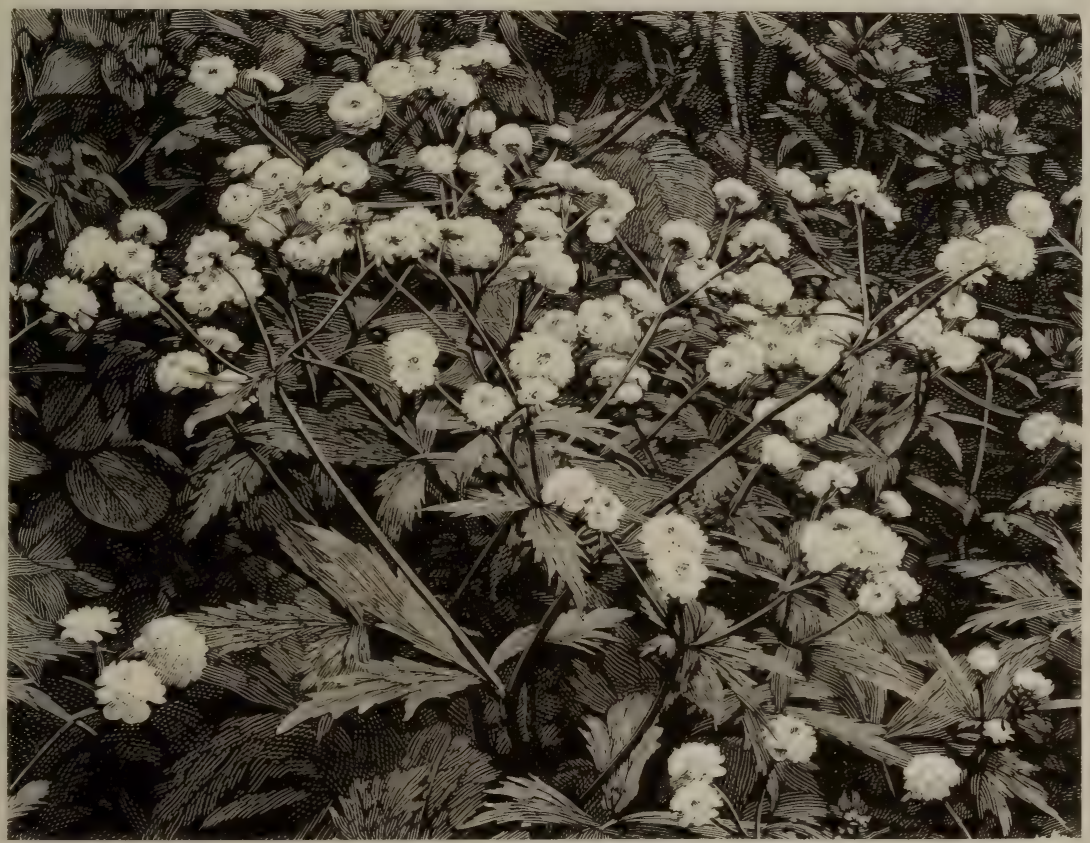

RANUNCULUS ACONITIFOLIUS FL.-PL. (FAIR MAIDS OF FRANCE).

of care and attention ; for they look well anywhere or in any position, but are best where they can be seen in bold masses. The culture of this Ranunculus, though usually considered somewhat difficult, is simple enough if a few essential particulars are observed. The situation should be open, but not exposed, and the soil a loam thoroughly mixed with good decayed stable manure equal to a third of its bulk. About a month previous to planting, the bed should be prepared to a depth of 15 in., and planting should take place about the last half of February, but in some seasons it may take place in October, though such an early date is not advisable. Drills about 5 in. apart and $1 \frac{1}{2}$ deep become very dry. A light top-dressing of artificial manure or guano just as the foliage is developed will be beneficial. When the flowers are past and the leaves have faded away, the roots must be taken up and dried and stored in a cool place in sand till the next planting season, for roots left in the ground are injured by rains and are never strong. The Persian varieties are the finest as regards colour, compactness, and symmetry of growth; but the Turban varieties are of hardier constitution and of freer growth than the edged and spotted kinds, and therefore are better suited for beds, lines, and masses. The Scotch and Dutch varieties are also fine for masses in beds, being all 
of highly effective colours. It is useless to enumerate the different varieties, as they are usually sold according to colour, and are mentioned in nearly every bulb catalogue. The large semi-double French (de Caen) and the Italian forms of this anemone are good additions.

R. bulbosus fl.-pl. is a showy plant, about $\mathbf{I}$ ft. in height, producing in early summer numerous very double yellow blossoms. It grows well in any soil. Of $\mathrm{R}$. repens there are two double varieties, one neat and the other untidy.

R. bullatus is a fine border plant, only about 6 in. high. It has large orangeyellow blossoms like those of the Marsh Marigold (Caltha palustris). It is not so hardy as the majority of the Crowfoots, and should therefore be placed in warm dry soil.

R. cortusæfolius, a handsome plant from Madeira, is scarcely hardy enough for open-air culture, though with a little attention it succeeds tolerably in favoured localities. It has large foliage, and heads of bright yellow flowers. R. platanifolius is a similar plant requiring the same treatment.

R. glacialis, an alpine species, is not more than 3 or 4 in. in height, and requires some little attention. It does best in light gritty soil kept moist during the heat of summer. The same treatment serves for $R$. montanus, another alpine species, and also for such kinds as $R$. Traunfellneri.

R. Lingua, a native species, is a noble aquatic, well deserving of cultivation where it does not occur naturally. Its large leaves rise boldly out of the water, and it has large, yellow, and attractive flowers. It requires to be immersed in water about I $\mathrm{ft}$. The other aquatic species, such as R. aquaticus and fluitans, are pretty plants for artificial water, but should be introduced cautiously, as when once established they spread rapidly and become too plentiful.

R. Lyalli. - This beautiful New Zealand species, called the Water-Lily of the Shepherds, is, unfortunately, not hardy enough for open-air culture. It succeeds in a frame, and is well worthy of attention. Recently introduced, and still rare.

R. parnassifolius has Cyclamen-like leaves, and yellow blossoms. It is a beautiful plant, but is rather difficult to cultivate. It requires the most select spot in the rock-garden, and must have a deal of attention. The same may be said of a similar kind, R. Thora, which also has yellow blossoms.

R. rutæfolius has Rue-like leaves and white flowers with dark yellow centres. As it comes from the highest parts of the Alps, it requires the same treatment as the choicest alpine plants. It should be in a fully-exposed spot in moist soil with plenty of grit in it.

R. speciosus is a very showy plant, producing in May compact rosette-like flowers of bright yellow. It succeeds in any light soil partially shaded. Where a full collection is required, $R$. gramineus, chærophyllus, illyricus, fumariæelolius, and Flammula may be included.

Raphiolepis ovata Japanese Haw thorn). - A beautiful Japanese shrub. It is perfectly hardy in southern districts, and with a little winter-protection may even be planted in cold parts. Its thick oval evergreen leaves are of a dark colour, and its flowers, which are large, white, and sweet-scented, are borne in clusters terminating the young branches. It is a low spreading bush, somewhat open and straggling, and should not be crowded with other shrubs. Some of the other species, such as R. indica and R. salicifolia, both from China, are not hardy enough for the open ground, but make good wall shrubs.

Red Campion (Lychnis diurna).
Red Hawkweed (Boerkhausia mura).
Red Valerian (Centranthus ruber).
Reed Grass (Arundo).
Rehmannia chinensis.-A handsome dwarf perennial of the Gesnera family. In summer it produces large tubular flowers of a purplish colour, striped with a darker hue. It is not thoroughly hardy, but succeeds in warm sheltered localities. The best specimens of it we have seen grew in a moist peaty border under a wall running east and west. It is generally best to winter it under glass. China.

\section{Rein Orchis (Habenaria).}

Reineckia carnea. - A dwarf Liliaceous plant of low tufted growth. There is a variegated yariety. The grassy foliage of the plant is dark shining green in the type, but in the variety is handsomely striped with creamy-yellow and green. This variegated variety is the more valuable as it makes a pretty edging plant, and being hardy and of sturdy growth succeeds in an open situation in any ordinary soil. Its flowers are not remarkable. China.

Reseda (Mignonette). - The only species worth growing is the common Mignonette, which is admired everywhere on account of its delicious fragrance. Seed sown in the open ground in March or April produces in a few weeks flowering plants, which continue 
to bloom till late in autumn, and yield an abundant supply of cut flowers. If, however, a few specially fine masses be wished for, the seed should be sown in pans about the end of March, the seedlings placed singly in 3 -in. pots, and ultimately planted out in good soil in an open position. A little attention should be given to thinning out the weak shoots and stopping the vigorous ones. Of the red sorts Victoria is the best, and of the light kinds the tall spiral variety. Plants sown in autumn will survive mild winters and will produce flowers in early summer, and these flowers are altogether finer than those of spring-sown plants. There are now a number of varieties with slight and sometimes important differences in colour.

\section{Rest Harrow (Ononis).}

\section{Rhaponticum cynaroides} (Srviss Centaury). - A hardy perennial from the Pyrenees, $3 \mathrm{ft}$. or more in height. It has a stout stem and large leaves. It is covered underneath with silvery down, and its purple flowers are borne in very large heads. It thrives in a deep, substantial, moist, but welldrained and free soil ; and is worthy of a place in full collections of hardy fine-leaved plants, and is suitable for borders, the margins of groups, and for isolation. R. pulchrum is another hardy perennial from the Caucasus. Its stenis are 2 $\mathrm{ft}$. or more in height, its leaves are ashy or sea-green in colour, and the flowers are small and purplish. It is suitable for embellishing dry, arid, rocky positions ; for which purpose R. scariosum is also useful. Division. Compositæ.

Rheum (Rhubarb). - The Rhubarbs, from their vigour and picturesqueness, are well worthy of cultivation among hardy fine-leaved plants. They are so hardy that they may be planted in any soil, and afterwards left to take care of themselves ; and their bold habit and fine leaves make them valuable ornaments for the margins of shrubberies and for semi-wild places where free and luxuriant vegetation is desired. Though not particular as to soil, they like it deep and rich, and the deeper and richer it is the better they will grow. R. Emodi is a fine-leaved plant,

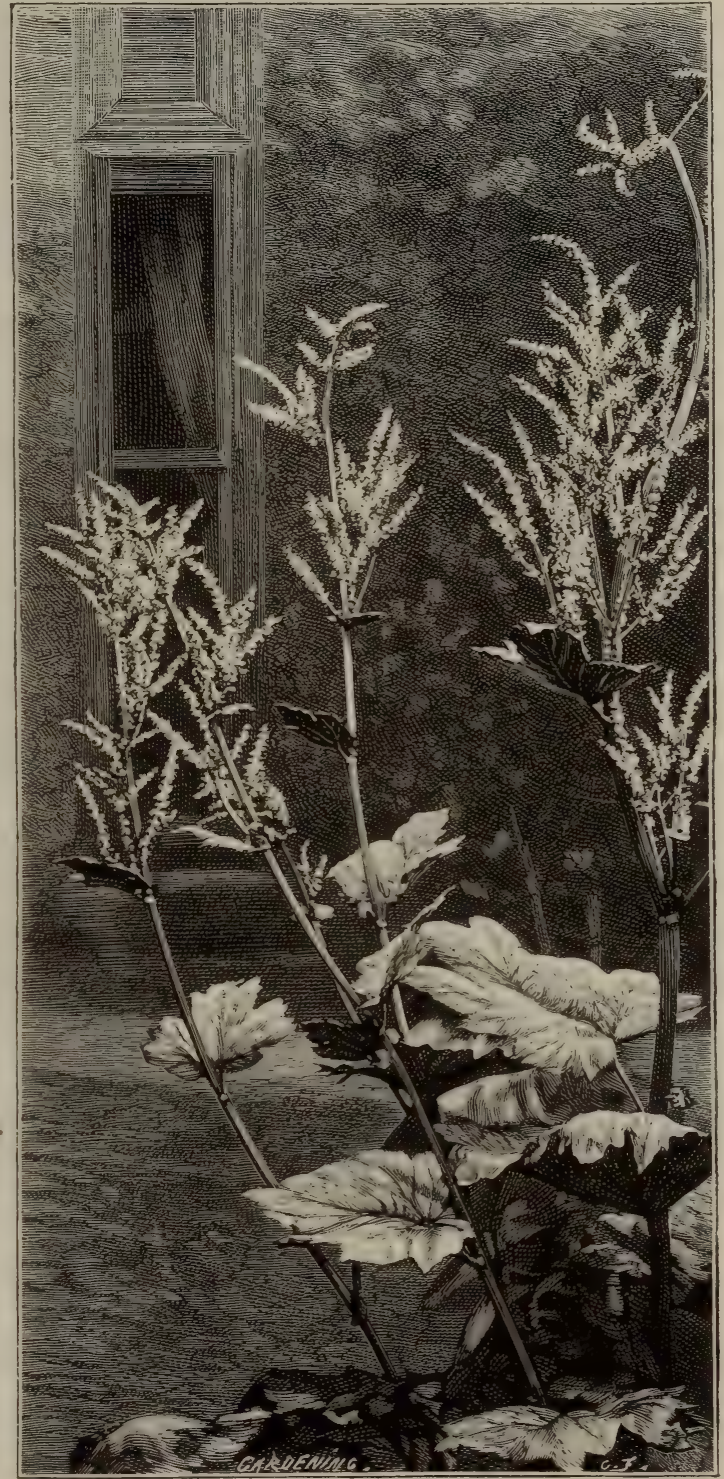

RHEUM OFFICINALE.

suitable for groups in the pleasure-ground, but requiring good soil. It grows about $5 \mathrm{ft}$. high, and is very imposing with its wrinkled leaves and large red veins. It is, however, surpassed by $\mathrm{R}$. officinale, which as regards foliage is the most 
effective hardy plant introduced for many years. All the old Rhubarbs are insignificant beside it. It produces a fine effect early in the year, and is of luxuriant growth. It is really a grand plant for placing near the shrubbery, on the turf, or in the wild garden. In certain gardens it could be grown in a colony of fine-leaved hardy plants, and in small glades with rich soil a fine effect might be produced by a good selection, embracing Ferulas, Heracleums, Rhubarbs, Acanthuses, Yuccas, the common Artichoke, Gunnera scabra, and many other vigorous hardy subjects. $R$. officinale bears our northern winters with impunity. It is easily propagated. R. palmatum is a slow-growing plant, and smaller than its variety, R. p. tanguticum, which increases rapidly. R. p. tanguticum has fine and boldly-incised foliage, and will be welcome to those who grow the other hardy species. R. nobile is a most remarkable species, and distinct from all the rest, as it forms a dense pyramid of foliage. It is, however, one of the most difficult to cultivate, and in Europe has succeeded only in the Edinburgh Botanic Garden. Sikkim Mountains. R. Ribes is too rare and delicate to recommend. The common Rhubarbs, said to have sprung chiefly from $R$. Rhaponticum and $R$. undulatum, are worth planting for ornament. They have been so planted in Hyde Park, but there they are arranged in masses, which is not the proper way to employ them. Kinds deserving of notice are $R$. australe, $R$. compactum, R. rugosum, R. hybridum, Victoria Rhubarb (a variety with very large leaves and long red stalks), Myatt's Linnæus, and Prince Albert. Scott's Monarch is the most imposing and ornamental of all the garden varieties.

Rhexia virginica (Meadow Beauty).A northern representative of a beautiful South American family. It has vivid rosy flowers, and is 6 or 8 in. high. It grows in sandy swamps in New England and the Eastern States, and is found as far west as Illinois and Wisconsin. It is rarely well cultivated; but healthy roots will thrive in a boggy or marshy place in peaty or sandy soil. The plant, however, should not be taken in hand by persons who do not possess a bit of suitable boggy ground, unshaded by trees and not overrun by coarse plants. R. Mariana is even scarcer in this country than $R$. virginica. It is hardly so brilliant, and is certainly less worthy of attention. It does not grow so far north in America, but is plentiful in the sandy fields of New Jersey, and would probably thrive in sandy heath soil. The Rhexias are impatient of too much division. Good tufts should be obtained from their native localities, and planted in a sandy peat bed on a cool clay subsoil, when the chances of success are almost as certain as are the chances of failure if the plants are broken up into small fragments. Melastomaceæ.

Rhinopetalum Karelini.-A bulbous plant of the Lily family, 4 to $5 \mathrm{in}$. high. It is allied to Fritillaria, and is sometimes classed with it. It bears two or three broad stem-clasping leaves, and a terminal raceme of slightly-drooping bellflowers. These flowers are about $\mathrm{I}$ inch across, and are of a pale purple colour, with dark veins, and spots, and a yellowish-green pit at the base of each reflexed segment. Central Asia. It flowers in late autumn or early winter, and is therefore valuable for a winter collection of outdoor plants. According to Dr. Regel's experience this bulb must be kept dry and until November, and it should not be growing or showing bloom before spring. If planted in November, growth is retarded, and the plant blooms in spring, as it ought to do. Plants flowering in autumn invariably dwindle away, and do not produce any more new bulbs. It should be planted in light soil in well-drained borders with a warm exposure.

Rhodanthe. - Charming half-hardy annuals from Australia, valuable as border flowers and for winter bouquets, as they come under the class of everlasting flowers. They are all of slender growth, I to $\mathrm{I}_{2} \mathrm{ft}$. high, and have glaucous-grey foliage and showy flowers. The original species, R. Manglesi (Austrian R.), has fine rosecoloured blossoms with yellow centres. It has a double variety. R. maculata has a deep crimson ring encircling the eye of the flower; and it has a pure white variety of this kind. R. atro-sanguinea differs considerably from R. maculata, being not only dwarfer, but more branched, and consequently it yields more blossoms, while its bluish-green foliage is longer and more pointed. The blossoms, of a bright magenta colour, are rather smaller than those of maculata, but average $I$ in. in diameter. It is rather less hardy than maculata, but is sufficiently hardy for openair cultivation. All these kinds should be sown thinly in heat in pots in February or March. In the southern counties they may also be sown in the open air in May on warm borders in good soil. In frames, freely watered, and placed in a temperature of $65^{\circ}$ to $70^{\circ}$, the seeds will speedily germinate, but if insufficiently 
watered, they will remain dormant for several weeks. The seedlings should be pricked while young, as they do not transplant well when large. They should be planted in a warm open position, and a soil which is well manured and of a light friable nature -if peaty, the better. They ought to be protected and attended to for a few days after transplanting. They flower from July till October. Compositæ. heads of small flowers, which are not, however, very attractive.

Rhodochiton volubile. - A beautiful, slender, twining plant which is usually grown in greenhouses, but which, like Lophospermum scandens, succeeds in the open air in sheltered parts. It is a beautiful plant for festooning arbours, trellises, etc., and in warm localities is well worth a trial. Strong young plants should be placed out in May in good soil.

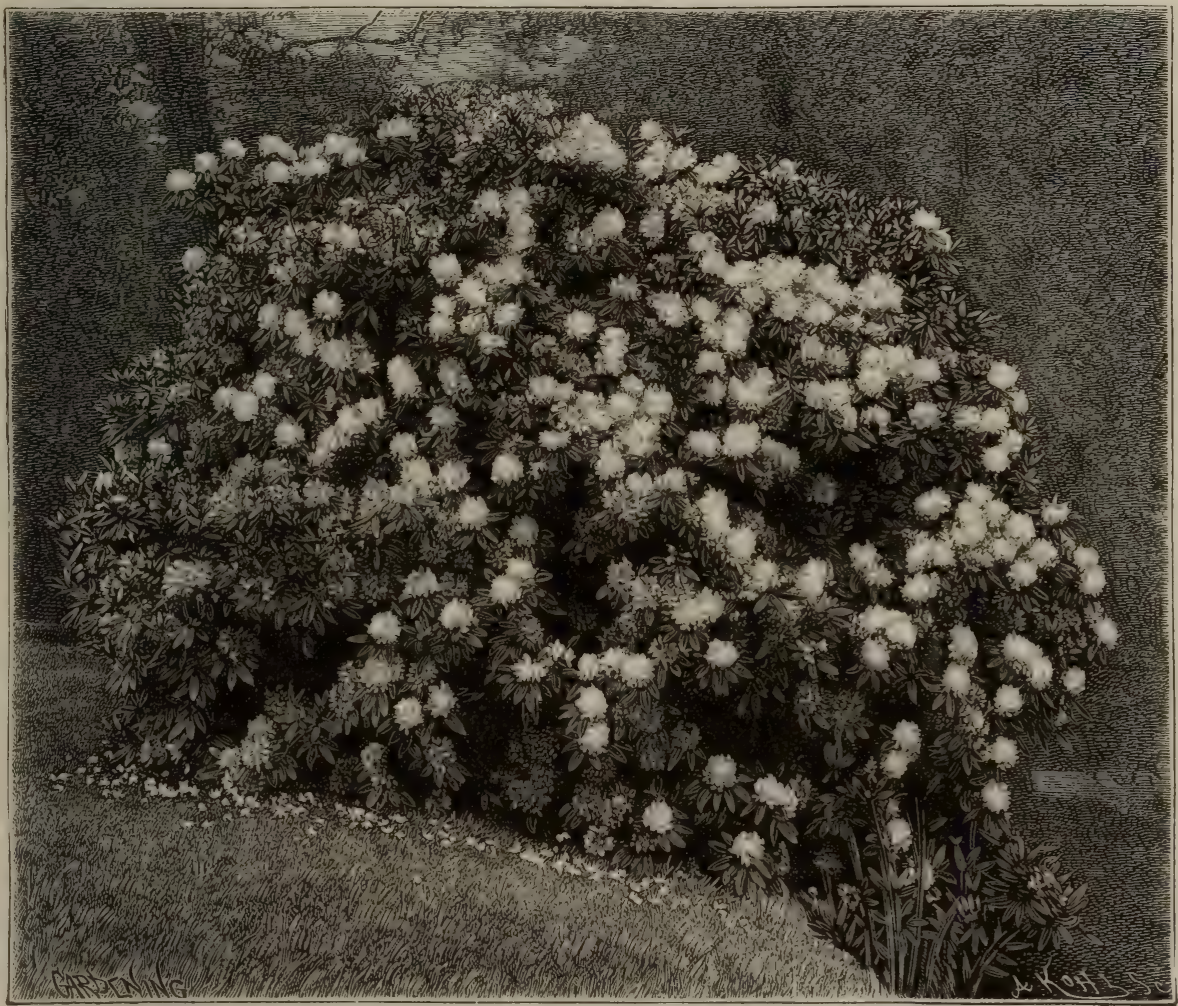

EARLY RHODODENDRON IN BLOOM.

Rhodea japonica.-A Liliaceous plant with thick broad leaves of deep green. It has a variegated form, the leaves of which are elegantly striped with white and green. It is therefore handsomer than the type, and more desirable for general culture. $R$. japonica is hardy, but is vigorous only in the most favoured districts, and seldom or never flowers in the open. An ordinary garden soil suits it, but the position should be warm and sheltered. Japan.

Rhodiola. - Plants of the Crassula family, resembling some of the larger Stonecrops. They have fleshy leaves and
Rhododendron (Rose Tree).-A noble family of shrubs, of the highest value to the garden, and so popular that they are often over-planted; that is to say, we are sure to see Rhododendrons in large and often inartistic and ugly masses in many country-places where no planting of any other kind worth speáking of is carried out. In districts where they do well, the soil and climate being perfectly suitable, very monotonous effects are produced through their over-use, against which all who care for beautiful gardens should protest. There are many other shrubs as well worthy of a place as the Rhodo- 
dendron. Even frequent misuse of a plant is, however, no reason against its artistic use ; the flower has led people to ignore many things equally good : the charm of the evergreen leaf and the large and handsome flowers taking English planters by storm. The mild climate of our country and generally our rather mild winters allow many more kinds to grow with us than grow on the Continent of Europe generally, or in N. America, though that is the home of the Rhododendron. In severe winters some kinds we mention the colours that go best together. Among the numbers of kinds that have been raised by English nurserymen, a good many poor, dull, or ugly in colour have been sent out, and therefore it is important to get good kinds in this respect and to group and arrange them better than has hitherto been done; that is to say, not so much in flat areas and lumpy beds. A far better way is to break them up into bold and simple groups, holding the colours more together and not scattering them about in

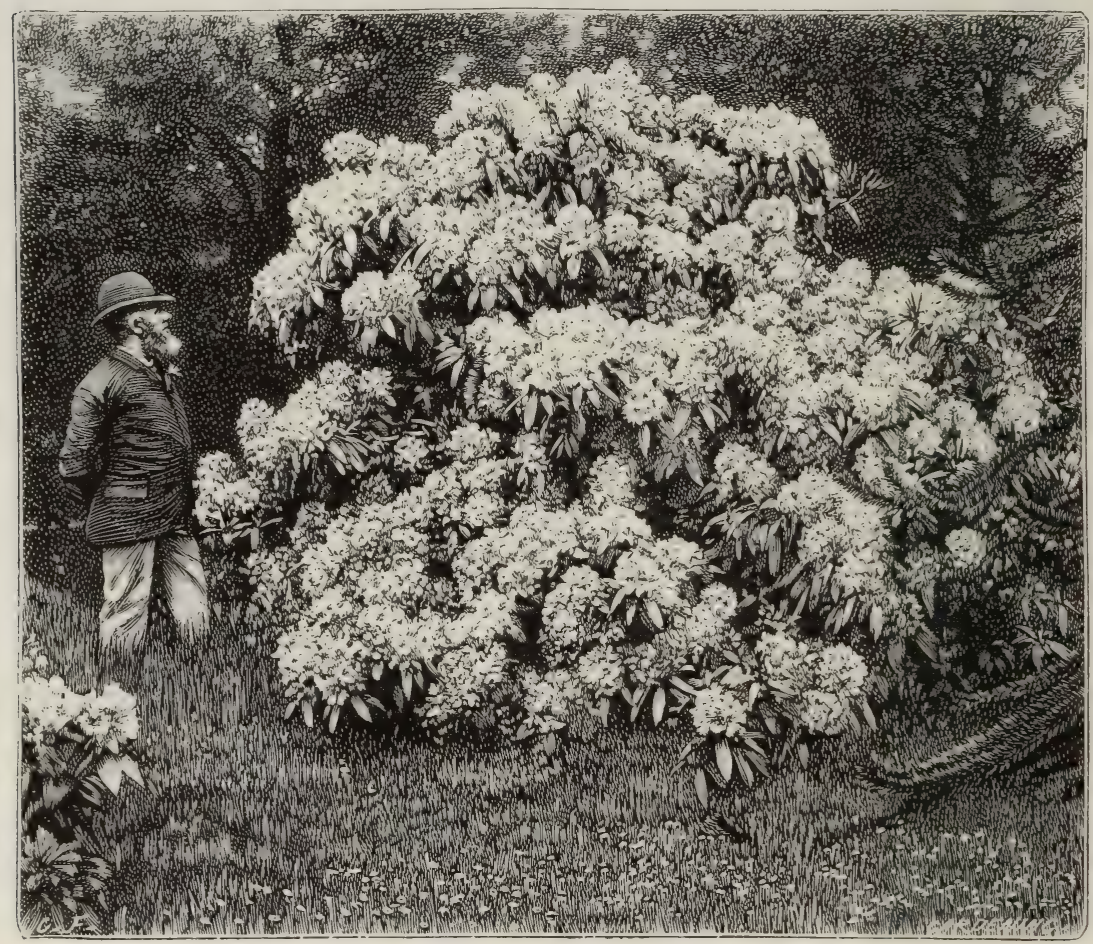

RHODODENDRON NOBLEANUM.

are touched even with us, and therefore it behoves us to be on our guard against planting other than the hardy varieties, of which a selection is given here. The hardy American species should be grown more in lowland valleys, as I find that they stand winters which kill $R$. ponticum.

The vast range in our country over which the plant will grow well, alike in Ireland, England, and Scotland, makes the possession of the finest kinds most important. The proper arrangement of the plants as to colour deserves much attention, and in a separate paragraph indefinite mixtures everywhere, but giving a distinct impression of their beauty in different parts of the grounds. This would very much enhance their value to us. A very important point is to secure plants from layers where possible, and not grafted plants, as these are apt to perish and their places be taken by the common stock, of which we have already far too much. Hitherto it has been very difficult to get layered plants; but if the public would let nurserymen know their wishes, layers would be forthcoming. It makes an immense difference in the end whether the kind has its own roots and is 
spread about into many plants, or is on some wretched stock on which it perishes.

As to culture, it is very simple, the plants being of free growth in almost any soil that is not a lime soil. On many loamy soils free from the enemy lime the plants do perfectly well, although perhaps never so much at home as on a sandy peat. Over a large area of choice kinds rather thinly. Where from previous thick planting the bushes are too close together, it would be much better to thin them promptly and severely, leaving the choicer kinds and the finestformed bushes. In this way we get light and shade among the plants instead of allowing them to form one flat level head. The excellent plan of placing lilies and

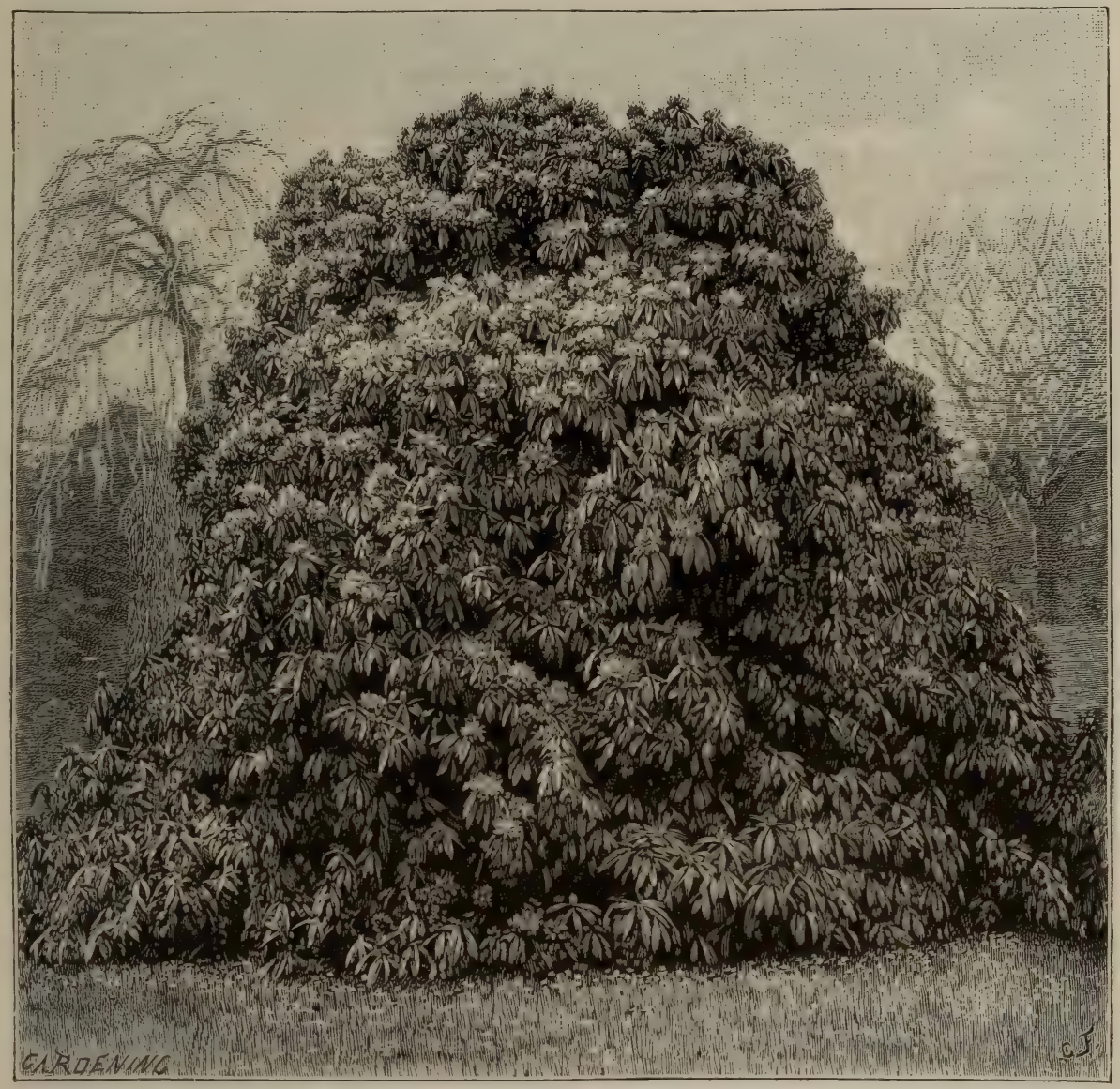

TREE RHODODENDRON AT CASTLEWELLAN, CO. DOWN.

Ireland where the limestone prevails it is extremely difficult, and I think not worth trying, to cultivate Rhododendrons. It is always better to grow things that grow best on one's own soil. Given a peaty or limeless soil, the difficulty is to prevent their growing so quickly as to smother each other. They are very often too closely planted, and after a few years of rapid growth such close plantations cannot show their beauty. It would be very much better to plant all the the other fine handsome hardy flowers among Rhododendrons and like shrubs tends to keep them more open and delightful in every way, their forms as well as flowers being better shown.

As regards transplanting, the plants being very finely rooted and forming generally, in all well-managed nurseries, close balls of earth, they are more easily transplanted than most shrubs. This indeed may be, and often is done in late spring and summer, as in the case of the 
London flower-shows, where numbers of the finest kinds are brought in spring and taken away in summer. An important point in the case of all choice and rare varieties is the removal of the seedvessels after flowering. This saves the strength of the plants for future good growth and flowers.

Hardy Rhododendrons seldom flower profusely in consecutive years, but fine displays biennially are usually made. A very little observation will show that the shoots which are to furnish flowers for the next year begin to grow simultaneously with the expanding of the flowers, or rather before that time. Therefore it is evident, that if a plant has flower-spikes on nearly every branch, it will be very thinly flowered the next season; because the growth made after the flowering season is over does not, as a rule, get sufficiently matured to bloom. In the case of small plants this is very noticeable, though less apparent in that of large ones.

In the management of established plants there is not much to be saidthey are so well able to take care of themselves. In strong loamy soil artificial waterings are not required. In very dry summers mulching the roots of a few single plants that occupy a rather dry position is often necessary, but where the beds are on level ground the plants succeed without any attention in that way. This is not so in all cases, as drought in the early autumn months often kills many of the large plants. This, however, generally occurs in shallow soils. There are some soils which in their natural state have Io or 12 in. on the surface favourable to the growth of Rhododendrons, but the subsoil is quite unsuitable; consequently, the roots only penetrate as far as the good soil goes, and therefore they suffer from want of moisture in dry seasons. Rhododendrons are, as a rule, safe from over-dryness at the root until the month of August ; then, if the weather should be dry, a good soaking of water twice a week and a mulch over the roots of half-rotten manure, 3 or 4 in. in thickness, will be necessary to maintain the plants in health.

THE Evils OF GRAFTing.-Apropos of this subject, Mr. Scrase Dickins, who is a good grower himself, writes: "We have a large number of grafted Rhododendrons, planted over thirty years ago, from the base of which every year a thick growth of suckers springs up; these require to be cleared off in the early summer, and again in the autumn, if the intended variety is to retain its claim to existence ; but the labour entailed is considerable, and many are overlooked or passed by for want of time. Occasionally one comes across a great bush of the common ponticum, with a small scraggy piece in the centre to show that once it was meant to be a hybrid variety of special beauty; but the worst of the whole business seems to be that the older the plant the larger is the base from which the suckers spring, and consequently the larger is the number of suckers. With Ghent Azaleas the trouble is nearly as bad; the common yellow form on which they are grafted, being a strong grower, soon makes short work in ejecting the less vigorous intruder. It is very unfortunate when, after a certain number of years, the labour and money spent in an endeavour to obtain some specially beautiful effect results in a commonplace arrangement of lilac and yellow. When the snow has prostrated large Rhododendrons, those that are on their own roots will often raise themselves in a thaw without help; whereas those that are grafted will most likely have broken off short at the base. If the union between the stock and the scion is so imperfect as to give way under these provocations, it follows that the flow of sap and consequent development of the plant must be seriously interfered with. In some cases this may prove beneficial in restraining a coarseness of growth and inducing fertility, but it is the reason why we do not possess in our gardens finer examples of graceful and welldeveloped natural specimens. In order to gain new and improved varieties, it is necessary to raise a large number of seedlings. If nurserymen were to give their attention more generally to raising seedlings and layered plants, it might with reason be expected that they would raise a large number of new and improved varieties. If planters, looking forward to the future, as planters as a rule must do, would insist on being supplied by the nurserymen with seedlings only, then our successors would have finer examples to thank us for, and we should be increasing our store of what is beautiful and of value among our treasures in garden and wood."

The following is a list of the best hardy varieties :-

Achievement, clear rosy-scarlet, white centre; Adrian, pale rose, dark centre; Agamemnon, rich lake, white centre; Album elegans, blush, changing to white; Album grandiflorum, blush, fine foliage; Alexander Adie, deep rose; Alma, crimson, fine habit; Amphion, pink, light centre; Annie Dixwell, clear 
rose, deep magenta blotch; Archimedes, rosy-crimson, lighter centre : Atro-sanguineum, intense blood-red Auguste van Geert, rosy-purple, early ; Bacchus, crimson; Barclayanum, deep rosy-crimson; Baron Schrœder, plum colour, yellow centre; Beauty of Surrey, scarlet: Bertram, flesh: Blandyanum, rosy-crimson Bluebell, blush, light purplish margin; Boule de Neige, white, early; Bouquet de Flore, blush, spotted, early Brayanum, rosy-scarlet, light centre; Broughtoni, rosy crimson: Bylsianum, white ground, margined deep pink: Caractacus, rich purplish-crimson; Catawbierse, true; Catawbiense album, white; Charles Bagley, cherry-red; Charles Dickens, dark scarlet; Charle Thorold, purple, greenish-yellow centre ; C. S. Sargent, rich crimson: Chionoides, yellowish-white : Ccerulescens, blush ; Concessum, clear pink, light centre; Congestum roseum, light rose, spotted ; Coriaceum, pure white; Crown Prince, bright rose, yellow centre Cruentum, rich lake; Cynthia, rosy-crimson; Delicatissimum, white, blush, faintly edged pink; Delicatum, blush, changing to white, with brown spot; Doncaster, brightest of scarlets ; Duchess of Bedford, deep rose, light centre; Duchess of Connaught, white yellow sputs; Duchess of Sutherland, rosy-lilac, deeper margin; Duke of Connaught, rosy-crimson, lighter centre; Elfrida, rose, deeply spotted; Everestianum, rosy-lilac, spotted and fringed; Fair Helen, pure white, marked with a yellow spot; Fimbriatum, bright rose, fringed; Fleur de Marie, rosy-crimson, lighter centre; Florence, pink, light centre; Francis Dickson, scarlet, late; Frederick Waterer, crimson; Garibaldi, bright salmon; George Paul, crimson, spotted; Gloire de Bellevue, rose, spotted, early; Govenianum, pale rose, the flowers scented; Guido, deep crimson; Hamlet, purple, richly spotted; Hannibal, rose, late ; Helen Waterer, centre white, edged with crimson; Hendersoni, purplish-crimson; Hermit, scarlet, finely spotted ; $H$. H. Hunnewell, dark crimson; H. W. Sargent, crimson Iago, pale rose, spotted; Ingramii, blush-white ; Jack Waterer, scarlet, light centre; James Bateman, clear rosy-scarlet; James Macintosh, rosy-scarlet: James Mason, light centre, deeper edging; James Nasmyth, rosy-lilac, intensely blotched maroon; J. Marshall Brooks, rich scarlet, with a brown spot; John Spencer, rose, margined with deep pink, late; John Walter, rich crimson; John Waterer, free-blooming dark crimson kind; Joseph Whitworth, rich dark lake, spotted; Kate Waterer, rose, yellow centre; Kate Alice Waterer, light centre, scarlet edged; Kettledrum, rich purplishcrimson, a fine hardy free-blooming sort: Lady Annette de Trafford, cream colour, distinct chocolate blotch, late; Lady Armstrong, pale rose, very much spotted Lady Clementina Mitford, peach colour, deeper mar gin; Lady Clermont, rosy-scarlet, intensely blotched Lady Dorothy Neville, blush, distinctly spotted; Lady Eleanor Cathcart, pale rose, spotted chocolate; Lady Falmouth, rose, with a dark spot; Lady Francis Crossley, rosy-pink or salmon: Lady Grey Egerton, silvery blush, splendid truss and foliage ; Lady Godiva, white, blotched with yellow; Lady Olive Guinness, white, spotted chocolate; Lady Tankerville, pink, light centre: Lalla Rookh, dark puce, finely spotted : Limbatum, white, margined crimson, early; Lord John Russell, pale rose, intensely spotted; Lord Palmerston, rosy - crimson: Lucidum, purplish-lilac, brown spots ; Madame Carvalho, blush, changing to pure white; Marchioness of Lansdowne, pale rose, with an intense black spot; Marie Stuart, blush, maroon spot; Martin Hope Sutton, scarlet, richly marked: Mason's White Seedling, white, spotted chocolate ; Maximum; Maximum album, white, very fine truss: Maximum Wellsianum, blush, changing to white; Maxwell T. Masters, rosy-crimson; Melton, rich purple, dark centre; Memoir, fine white, good foliage ; Meteor, fiery crimson; Michael Waterer, crimson, spotted; Minerva, rose, yellow eye; Minnie, blush-white, spotted with chocolate; Mirandum, light rose, spotted ; Miss Jekyll, cream, chocolate blotch, beautiful truss; Miss Owen, blush, red spots; Mont Blanc, a very nice dwarf white variety; Morion, rosy-pink, beautifully blotched; Mrs. Arthur Hunnewell, pink, primrose centre; Mrs. Charles Leaf, rose, light centre; Mrs. Charles Thorold, bright pink, yellow centre; Mrs. Fitzgerald, rosy-scarlet Mrs, Frank Phillips, deep rose, light centre; Mrs. Fredk. Hankey, salmon, richly spotted; Mrs. G. H. W. Heneage, rosy-purple, white centre, and fringed; Mrs. Harry Ingersoll, deep rosy-lilac, greenish centre Mrs. John Clutton, white ; Mrs. John Kelk, clear rose, late; Mrs. John Penn, salmony-pink; Mrs. J. P. Lade, French grey, deeper centre; Mrs. John Walter, light centre, edged pink; Mrs. John Waterer, bright rose spotted; Mrs. Mendel, pink, each petal rayed white, yellow centre: Mrs. Milner, rich crimson; Mrs. K. S. Holford, rich salmon; Mrs. Russell Sturgis, white, spotted chocolate; Mrs. Shuttleworth, scarlet, lighter centre, much spotted; Mrs. S. Simpson, white, finely spotted; Mrs. Thomas Agnew, white, yellow blotch; Mrs. Thomas Longman, rosy-crimson, large truss; Mrs. Thomas Wain, pale rose, with a rich brown blotch. Mrs. W. Agnew, pale rose, yellow centre; Mrs. William Bovill, rich rosy-scarlet; Neige et Cerise, white, edged with crimson; Nero, fine dark rosypurple, richly spotted; Nigrescens, dark plum, almost black; Norma, pink, light centre; Notabile, fine rose, large truss; Novelty, pink, edged with white; Odoratum, pale blush, nearly white; Old Port, rich plum colour: Onslowianum, delicate waxy blush, yellow eye; Othello, crimson, with a purplish or rather mauve tinge; Paradox, purple, light centre; Perfection, blush, yellow eye; Perspicuum, blush, changing to white; Pictum, white, distinctly spotted; Picturatum, cream colour, with a chocolate blotch; President van den Hecke, light rose, very much spotted, early ; Prince Camille de Rohan, blush, dark eye, early; Princess Christian, white, with black spot; Princess Mary of Cambridge, light blush, deeper edging; Punctatum Purpureum elegans, very fine purple; Purpureum grandiflorum, very fine purple; Purity, white, with a faint yellow eye ; Ralph Sanders, rich purplish-crimson Raphael, large spotted crimson; Rosabel, pale rose Roseum elegans; Roseum pictum, rose, yellow eye R. S. Field, scarlet ; Sappho, white, distinctly blotched with maroon; Scipio, rose, with a fine deep spot ; Sefton, dark maroon; Seraph, claret, bronze blotch, rather early ; Sherwoodianum, spotted rosy-lilac ; Sigismund Rucker, magenta, richly spotted; Silvio, rich purple, yellow centre; Sir Charles Napier, rose, light centre, spotted; Sir Isaac Newton, plum colour, shaded and spotted; Sir James Clark, dark crimson; Sir Robert Peel, spotted rose-carmine; Sir Thomas Sebright, rich purple, with bronze blotch; Sir William Armstrong, crimson; Snowflake, pure white, fine conical truss; Standard of Flanders, blush, distinctly spotted; St. Simon, rich purplish-crimson, spotted; St. Blaise, purplish-crimson, intensely spotted; Stella, pale rose, with an intense chocolate blotch; Sultana, white, with reddish-brown spots; Sunray, scarlet, light centre Surprise, light, chocolate blotch; Sydney Herbert, crimson, dark spotted; Sylph, bright rosy-pink, fine truss; The Cardinal, bright scarlet, spotted; The Moor, dark crimson, finely spotted; The Queen, blush, changing to white; The Warrior, rosy-scarlet, late Titian, clear rosy-scarlet: Torlonianum, a hybrid, between Azalea and Rhododendron; Towardii, rosy-lilac ; Vandyck, rosy-crimson; Vauban, mauve, with yellow blotch; Verschaffeltii, blush, much spotted, early Vestal, pale rose, much spotted; Victoria, claret, freeblooming variety; Vivian Grey, bright rosy-pink, spotted; William Austin, crimson spotted; William Downing, rich dark puce, finely blotched.

RHODODENDRONS GROUPED FOR EFFEC' OF COLOUR.-Reds, rose-colours, and pinks with a few whites, viz. Reds - James Marshall Brooks, John Waterer, Atro-sanguineum, Alexander Adie, Baron Schroder. Rose and rosy-pinks-Mrs. Penn, Ingramii, Cynthia, Bianchi, Fair Rosamund. Whites-Mrs. John Clutton, Minnie, Pictum, Fair Ellen, Madame Carvalho.

Rhododendrons of salmon-red colour are best kept separate from others; of these, good colourings are-Lady Eleanor Cathcart and Mrs. R. S. Holford.

Purples must be kept away from reds, but group well with any whites; some of the best for colour are-Everestianum, Album elegans fastuosum, Cyaneum, 
Lady Normanton, Reine Hortense, Luciferum.

DWARF KINDS.- There are some comparatively dwarf kinds which may be associated with alpine plants in the rockgarden-indeed, some are but a span high. One of the prettiest of these is R. Chamæcistus, which has tiny leaves, and which produces in early summer exquisite purple flowers, the same size as those of Kalmia latifolia. It is rarely seen in good health in gardens, and requires to be planted in limestone fissures, filled with peat, loam, and sand mixed in about equal proportions. A native of calcareous rocks in the Tyrol, and one of the most precious of dwarf rock-shrubs. The well-known $R$. ferrugineum and $\mathrm{R}$. hirsutum both bear the name of alpine Rose, and often terminate the woody vegetation on the great mountain chains of Europe. They are easily obtained from nurseries, and are well suited for the large rock-garden, where they attain, in deep peat soil, a height of about $\mathrm{I} 8$ in. R. Wilsonianum, R. myrtifolium, R. amœnum, R. hybridum, R. dauricum-atrovirens, R. Gowenianum, $\mathrm{R}$. odoratum, and R. Torlonianum are also comparatively dwarf kinds, which may be tastefully employed in the rockgarden-the last two being very sweetscented. They should not be too intimately associated with minute alpine plants.

Himalayan RHODODENDRONS IN BRITAIN.-There has been a good deal of interest taken in the Himalayan Rhododendrons, which, unfortunately, are not hardy enough for our country generally - certainly not for inland parts, though, no doubt, from time to time some of them, and also hybrids from them, will be found hardy here and there. Also there are many kinds very well worth growing in mild and favoured districts such as the south of England and Ireland. A correspondent in the south of Ireland, in Fermoy, sends to The Garden the following account of the kinds he has found to do well there-quite hardy without protection-and also of his failures :-

"As I have taken much pleasure in cultivating and hybridising Rhododendrons for about twenty-five years, especially with a view to acclimatise those of Sikkim and Bhotan, I think the results at which I have arrived may be interesting. In order to avoid occupying too much space, I shall first give the names, as furnished to me, of those varieties which I have found perfectly hardy trees without the slightest protection, although some of those which bloom early (about March) have their flowers occasionally spoiled by the spring frosts :-

"Alpinum; Æruginosum; Anthopogon; Arboreum album; Arboreum roseum, very beautiful; Arboreum nepalense; Barbatum, magnificent; Calyculatum ; Camelliæflorum ; Campanulatum Campbelli ; Campylocarpum ; Ciliatum ; Cinnamomeum ; Cinnabarinum ; Crispiflorum, not bloomed ; Eximium, fine, like Falconeri; Falconeri, grand; Fulgens ; Falconeri superbum, not bloomed; Glaucum ; Hodgsoni, grand, has not yet bloomed; Hookeri; Keysi ; Lanatum ; Lancifolium, not bloomed; Metternichi; Massangei, beautiful bloom this year; Niveum; Nobile, a grand plant, never bloomed; Ochraceum; Roylei; Virgatum; Wallichi, I think same as Niveum; Wighti, I think not true.

"The following were more or less injured last spring (those marked * I have not yet succeeded in acclimatising) :-

"Argentum, much injured, growing well, not bloomed yet; Aucklandi, much injured, growing well, bloomed well in r878-79-80; Calophyllum, apparently killed, but growing well; * Dalhousianum, do not give this up; ${ }^{*}$ Edgeworthi, I do not give this up; Formosum Gibsoni, much injured, but growing well; Jenkinsi, much injured, doing well, never injured in twenty years previous ; Kendricki, I doubt its name ; Longifolium, much injured, growing well, has never bloomed; Lindleyanum, much injured, growing well; Maddeni, much injured, growing well (I see no essential difference between this and Jenkinsi ; centre of Jenkinsi flower, rose, of Maddeni, yellow); Nilghiricum, not bloomed, much injured; * Nuttali, many plants killed, I fear hopeless; Thomsoni, much injured but growing; Windsori, very much injured, but growing well. The last two plants appear to me less hardy varieties of R. arboreum.

"I have not included any European hybrids in my list, of which, between Himalayan sorts alone, I know many and have a great number of my own rearing also, and the reason I do not give up Dalhousianum and Edgeworthi is that I have seedlings from crosses of them which promise well to be hardy, one especially, between Edgeworthi and, I think, Calophyllum, which only lost its bloom-buds last spring, I am very proud of; its fragrance is far beyond any I know - Rollisson's fragrantissimum and Lindleyanum being, so far, the best. I have named it the Empress of India in honour of our Queen.-H. H."

Rhodora canadensis (Canadian Rhodora). - A pretty déciduous shrub allied to the Rhododendron. Being a native of the swamps of Canada it is very hardy, and it needs only a moist light soil, though it prefers peat. In very early spring it produces clusters of rosy-purple flowers before the leaves unfold, and is interesting on this account. It is a thin bush, 2 to 4 ft. high.

Rhodotypos kerrioides (White Jezws Mallow). - A beautiful deciduous shrub from Japan, with a growth and foliage recalling the familiar old Jews' Mallow on cottage-walls, but with white flowers resembling single Roses. It is of slender growth, but makes a dense bush when 


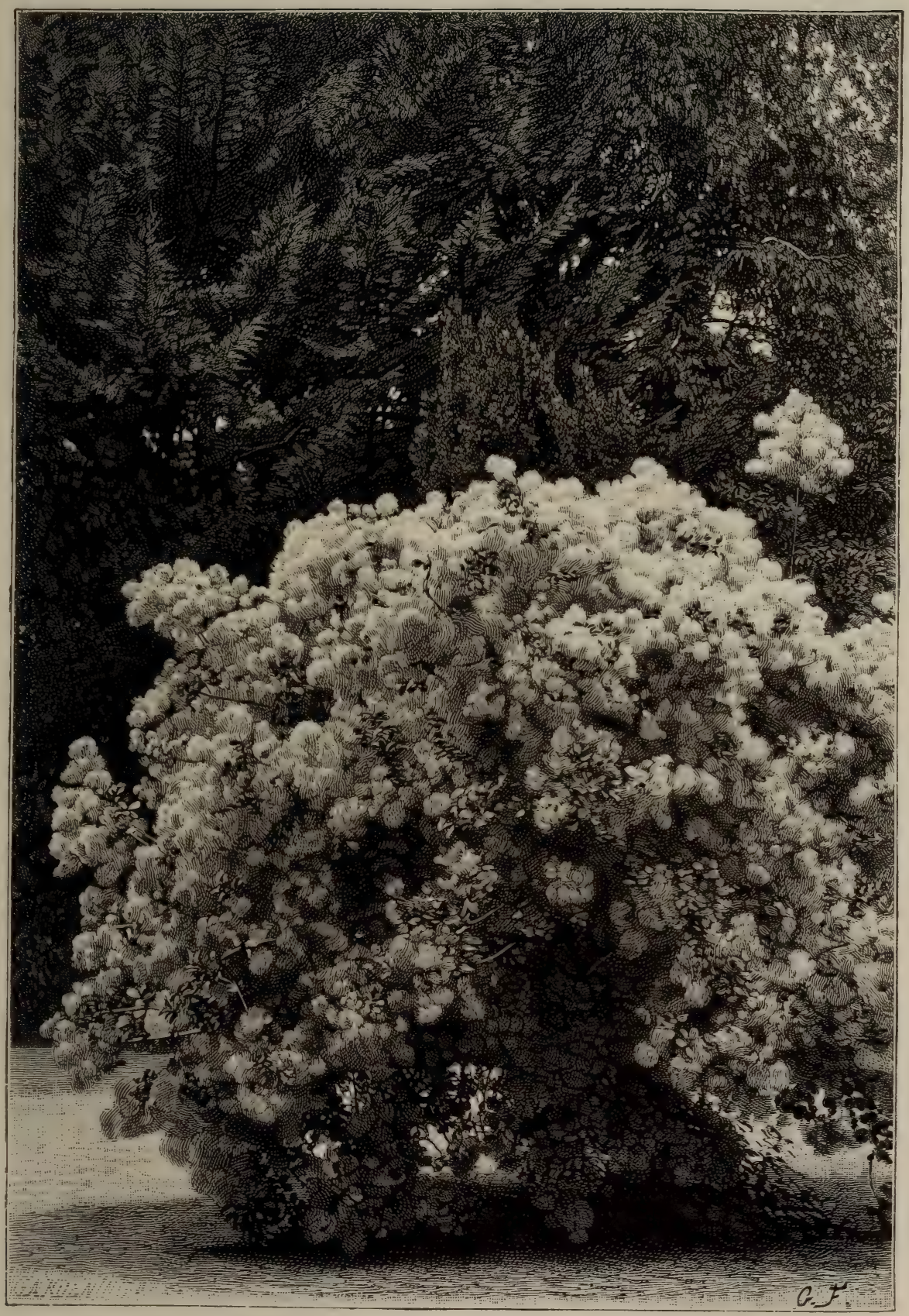

RHUS COTINUS (VENETIAN SUMACH). 
well grown, and is usually 5 or $6 \mathrm{ft}$. high, though against a wall it reaches a height of 10 or $12 \mathrm{ft}$. It flowers in May and keeps in bloom a considerable time.

\section{Rhubarb (K'he'um).}

Rhus (Sumach).-Several important ornamental shrubs are contained in this genus, and a few of them are indispensable to all gardens. They are mostly remarkable for their elegant foliage and picturesque growth, though the Venetian Sumach (R. Cotinus) and the Stag's-horn Sumach (R. typhina) are beautiful when in flower. The Venetian Sumach, Wig Tree, or Smoke Plant (R. Cotinus) is a remarkable late-flowering shrub, and, being different from all others, is of exceptional interest. Its flowers are inconspicuous, but the feather-like clusters that succeed them are of a reddish-purple and highly attractive, and they remain so for several weeks. This plant is a very old introduction from Southern Europe; it is perfectly hardy, and thrives almost anywhere, but should always be allowed ample room to develop itself. The Stag'shorn Sumach (R. typhina), also called the Vinegar 'Tree, is a most beautiful autumn shrub or small tree. Its dense massive spikes of bright crimson fruits look like velvet, and remain until destroyed by frosts; while the foliage is handsome, for the leaves are long and numerous, and the general growth, being open and irregular, is singularly picturesque when fully developed. R. typhina is, therefore, a striking tree whether as a single specimen on a lawn or when grouped with the dwarfer Sumachs. There are some distinct varieties of it, arborescens being of more tree-like growth and frutescens being dwarf. Crimson seed-clusters are characteristic of all the varieties except viridiflora, in which the seed-clusters are green. The popular name "Stag's-horn Sumach" points to the resemblance between the crooked downy branches and the young horns of a stag. N. America. The Smooth Sumach (R. glabra) has elegant foliage. In the variety coccinea the seedclusters are velvety crimson, but are not so beautiful as those of $\mathrm{R}$. typhina. The variety laciniata is one of the noblest of fine-foliaged plants, and young and vigorous specimens are most valuable for sub-tropical effect. It grows from 4 to 7 ft. high. It has finely-cut and elegant leaves, and the strongest is about I $\mathrm{ft}$. long when the plant has been established a year or two. These leaves combine the beauty of the finest Grevillea with that of a Fern-frond. When unfolding they remind one of a finely-cut umbelliferous plant in spring; when fully grown the midribs are red ; and in autumn the leaves themselves glow off into a bright colour after the fashion of American shrubs and trees. The variety in the shape, size, and aspect of the foliage makes the bush charming. Its chief merit is that, in addition to being elegant in foliage, it is hardy and very dwarf. R. vernicifera is distinct from the preceding. It has fine pinnate leaves, and is useful for grouping with laciniata or with hardy shrubs of like character. The foregoing comprise the best of the Sumachs, but there are others in cultivation that could be added, and these include R. semialata Osbecki, an elegant Japanese shrub, but not perfectly hardy, except in the south. The creeping or trailing Sumachs, such as R. Toxicodendron (which is known as Poison Ivy, Poison Oak, and Poison Sumach), R. venenata (Poison Elder), and $R$. radicans, should be excluded from a garden, as the sap of the bruised growth is highly poisonous.

Rhynchocarpa dissecta. - This plant has perennial tuberous roots and incised foliage. Its fruits are orange-red and are terminated by a kind of beak. It requires warm situations and light rich soils, but is more likely to succeed in the southern counties than in the northern. It may be grown under glass with more success than in the open. In Paris it does well. Cucurbitaceæ. S. Africa.

\section{Ribbon Grass (Digraphis).}

Ribes (Currant). - The favourite old Crimson-flowering Currant (R. sanguineum) is typical of the few species that can be called ornamental shrubs. This shrub is so common that I need only allude to the fine varieties of it that are to be obtained from the best nurseries. Deeper and richer in colour is the variety atro-rubens (called also splendens), though the flowers and racemes are smaller. The crimson-red of its blooms forms a striking contrast to the variety named albidum, whose flowers are almost white, though slightly suffused with pink. The double sort (flore-pleno) is an admirable shrub, with very double flowers, which last a long time in perfection, and as they expand later than the common kind, prolong the season. The botanical variety glutinosum is distinguished by clammy foliage and large pale rosy-pink flowers, but like other botanical varieties it is difficult to procure from nurseries.

The Yellow - flowering, or Buffalo Currant (R. aureum), deserves to be more commonly grown. It is a different shrub from R. sanguineum, having larger 
flowers of a rich yellow, which appear about the end of April or beginning of May; the leaves also are smaller, more deeply lobed, and of a paler green. The variety præcox is so named because it flowers earlier than R. aureum, and is most desirable on that account, and the variety serotinum, because it flowers late. Serotinum is even finer than the type.

R. Gordonianum, a hybrid between R. aureum and R. sanguineum, is an old and tolerably common shrub - intermediate in growth as well as in flowers, which are an orange-red; it is distinct and showy. It is also known as R. Beatoni and R. Loudoni. Of the numerous other species there is none so fine as the Californian Fuchsia Currant ( $R$. speciosum), whose flowers so much resemble miniature Fuchsia-blossoms that in some places it goes by the name of $\mathrm{R}$. fuchsioides. Its deep red blooms have protruding stamens, and hang from the leaf-axils in clusters of two or three. In growth and foliage it resembles a Gooseberry. A densely-flowered bush is extremely pretty and lasts in perfection a long time. Though quite hardy enough to be grown as a bush in the milder parts of England, it is usually seen against a wall, and there are few more elegant wall shrubs. Grown thus it is 6 to $8 \mathrm{ft}$. in height. Most of the other varieties have inconspicuous flowers, but one or two are worth growing for the sake of their autumn foliage, which dies away in various shades of crimson. The Missouri Currant ( $R$. floridum), also called $\mathrm{R}$. missourense, is one of the best of these. It is a stock plant in some of the largest nurseries. The Flowering Currants are really an important group of shrubs and deserve the best attention, and instead of being crammed in the usual shrubbery mixture, should be grouped by themselves.

Rice-paper Plant, Chinese (Aralia papyrifera).

\section{Richardia æthiopica (Calla).}

Ricinus communis (Castor-oil Plant). - There is not in the whole range of cultivated plants a more imposing subject than the Castor-oil Plant. In the London parks it has grown nearly i $2 \mathrm{ft}$. high, and has had leaves nearly a yard wide. It is a good plant for bold and noble beds near beds of the more brilliant flowers, and tends to vary the flower-garden finely. It is used for bedding-out, but it is not well to associate it closely with bedding plants, because of its strong growth and the shading capacity of its leaves. For bedding purposes it is a good plan to make a compact group of it in the centre of some wide circular bed and to surround this with a band of a dwarfer subject, say Aralia or Caladium, and to finish with whatever flowering plants may be most admired. A bold and striking centre may be thus obtained, while the effect of the flowers is much enhanced, if the planting be tastefully managed. For such groups indeed the Castor-oil Plant is not likely to be surpassed. It requires a bed of very rich deep earth to make it attain great dimensions and beauty; but with ordinary attention it grows well everywhere. To raise the plants a brisk hotbed is needed in February or March, in which to plunge the pots of rich light soil in which the seeds should be sown. The pots should be well drained, and the soil pressed down tolerably firm, with a little finely-sifted soil placed over the seeds. Afterwards a good watering should be given. When the plants are large enough, pot them singly into 4 -in. pots in soil composed of sandy loam and leaf-mould or rotted manure ; keep them in a warm moist temperature, and give them plenty of water at the roots. When the roots have reached the sides of the pots, place them in 6 or 8 -in. pots. About the end of May gradually inure them to a cool temperature, and after a few weeks place them in a sheltered position out-ofdoors. By the end of June they may be planted out permanently in the open ground ; but the more sheltered the situation the better. Dig out holes for them, placing in the bottom a few forkfuls of manure, and, if this be taken from a warm manure-bed, so much the better. Plant and water them with soft rain water, and mulch the surface with manure. During hot weather liberal supplies of manurewater will be of great benefit.

The best varieties are sanguineus, borboniensis, Gibsoni (a very fine dark variety), giganteus, Belot Desfougerès (a very tall and branching kind), viridis (of a uniform lively green), insignis, africanus, africanus albidus, minor, hybridus, microcarpus, macrophyllus, atro-purpureus, and sanguinolentus, all of which are forms of R. communis, a native of the East Indies.

Robinia (False Acacia).- Beautiful flowering trees for lawn or shrubbery. The common Acacia or Locust Tree (R. Pseudacacia) is beautiful in foliage and in flower, and is valuable for ornament, as it is of quick growth, is very hardy, and thrives almost anywhere. The ordinary form, with its profuse crop of white Peashaped blossom in full beauty about the end of July, is familiar to every one. Of 
the numerous varieties the following are the best: Decaisneana, with delicate pink flowers ; semperflorens, flowering throughout the summer, and having white blossoms and bright green foliage; and Bessoniana, the thornless branches of which form a dense globular head of deep green foliage, which is retained until very late in autumn, hence its great value as a town or a street tree. There are many other forms of the False Acacia more or less distinct, such as fastigiata, of upright
The flowers resemble those of Decaisne's variety of the common Acacia, being of a pale pink colour, but the clusters are shorter and denser. It is a very beautiful lawn tree, and is particularly valuable because it flowers while the tree is still small. Fully grown it is of a spreading and picturesque habit, from 30 to $50 \mathrm{ft}$. high. It thrives best in a deep light soil in a sheltered spot.

The Rose Acacia ( $R$. hispida) is, like the other two Robinias, a native of North

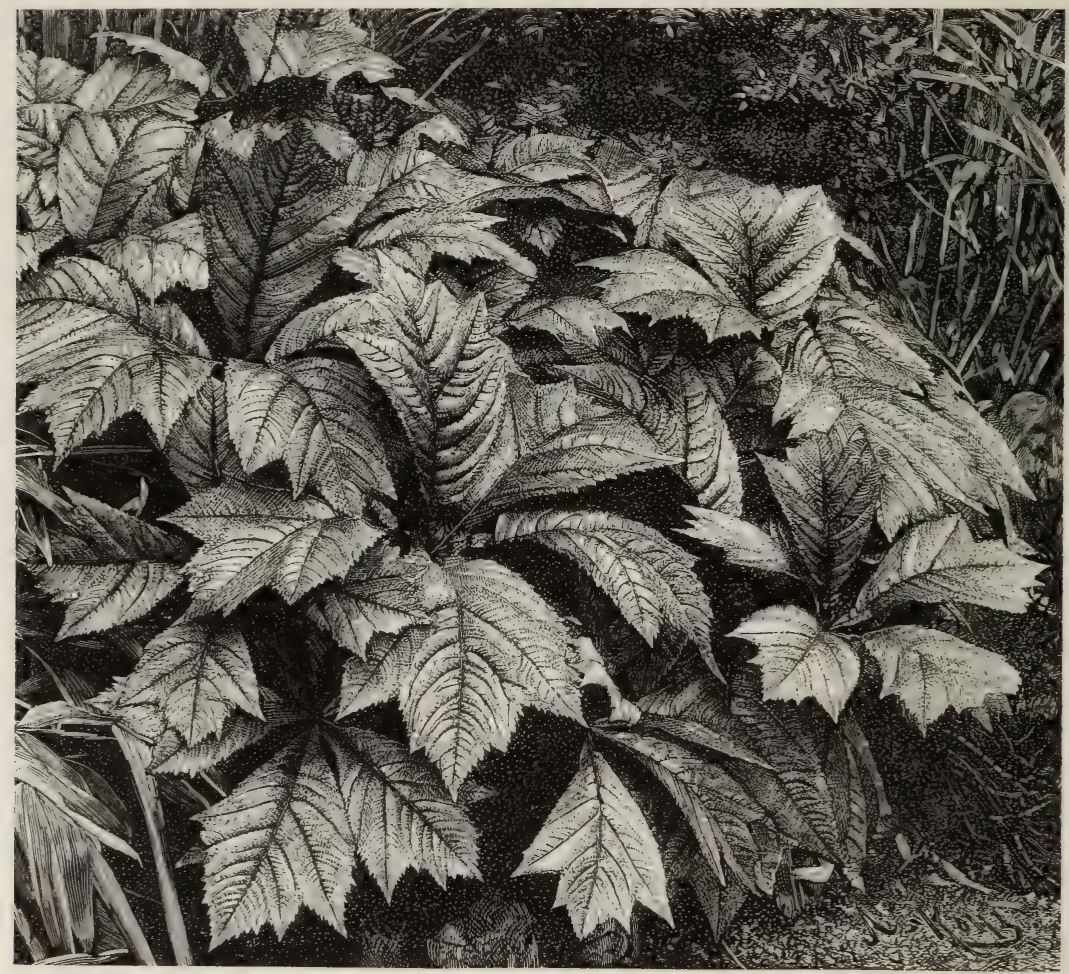

RODGERSIA PODOPHYLLA.

growth ; crispa, with curled foliage ; monophylla with leaves entire instead of pinnate; umbraculifera, with a spreading head; macrophylla, with large leaves; sophoræfolia, with leaves like the Japanese Sophora; and inermis, with a small head of spineless branches.

The Clammy Locust ( $R$. viscosa), known also as R. glutinosa, is smaller than the ordinary False Acacia, but is elegant in foliage and beautiful in flower. It so much resembles $R$. Pseudacacia that the two, when out of flower, can only be distinguished by the clamminess of the bark on the young shoots of $R$. viscosa.
America. It is, unquestionably, one of the finest of all small trees or shrubs, and should never be omitted even from small gardens. It requires little room, and is not fastidious as to soil. It is naturally straggling in growth, but a symmetrical bush or tree may be formed by pruning. It is 5 to $15 \mathrm{ft}$. high. Its foliage is much larger than that of the other Robinias, and less dense. The clear rose-pink flowers are also much larger. A profuselyflowered specimen is a glorious sight ; and the more enjoyable as the flowers appear when the first flush of spring bloom is past. It flowers most plentifully in June, 
but often continues in bloom at intervals till autumn. The dense, short, rusty hairs covering the young twigs form a characteristic by which it may be known when not in leaf. Its branches are brittle and liable to be broken by high winds, especially if it has been grafted high; and it is, therefore, advisable to choose a spot sheltered from high winds. If the
R. spectabilis, complexa, glabra, inermis, and Camuseti differ but slightly, if at all, from the type.

Rock Cress (Arabis).

Rocket (Hesperis).

Rocket Larkspur (Delphinium Ajacis).

Rockfoil (Saxifraga).

Rock Rose (Cistus).

Rockwood Lily (Ramunculus Lyalli).

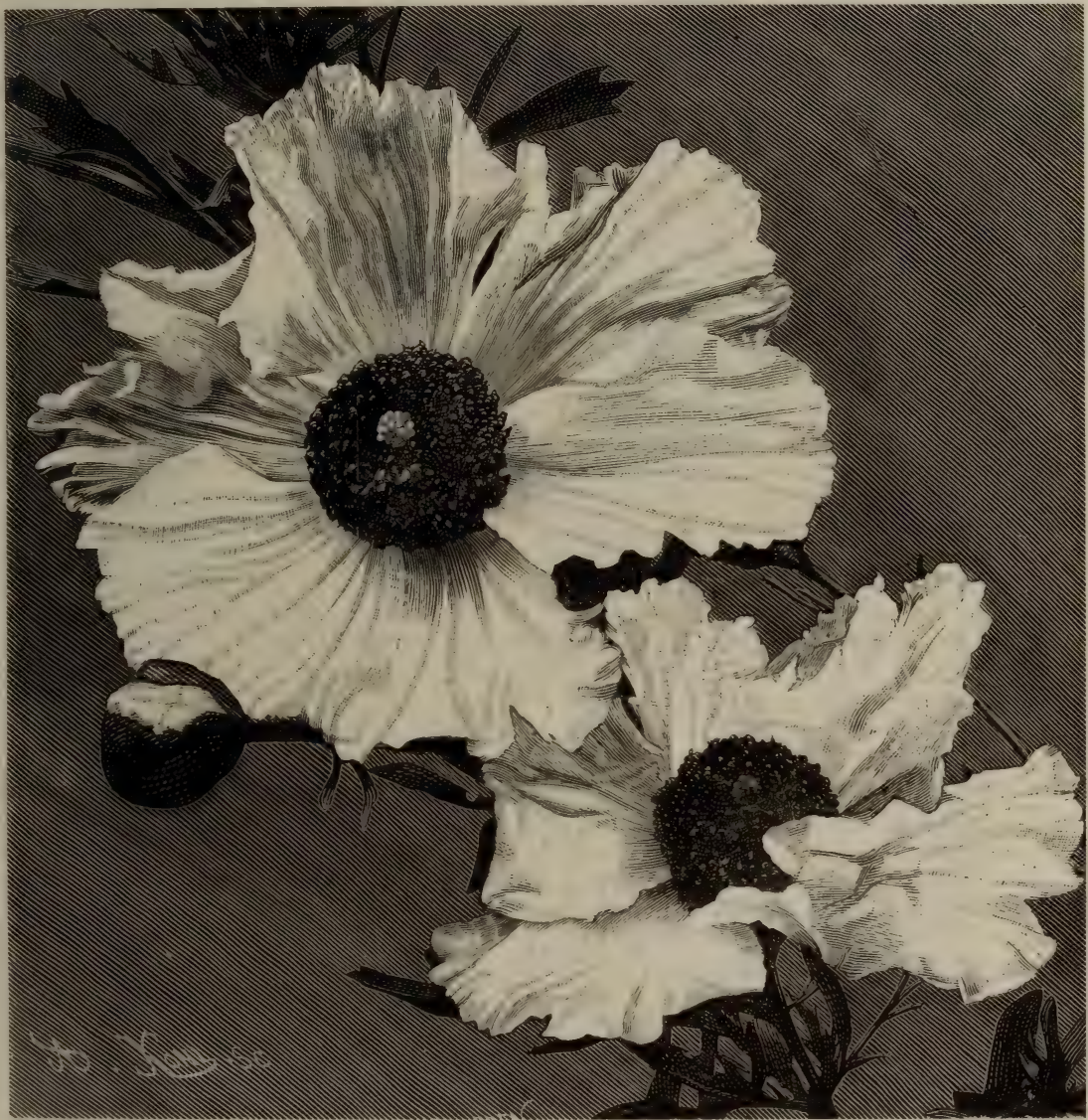

ROMNEYA COULTERI.

branches become heavy, especially in flower-time, they should be supported by stakes. It may be grown as an espalier, like a fruit tree, and this will protect it from winds, or it may be trained against a wall. Such a beautiful tree is worthy of the best attention. There are several so-called varieties of the Rose Acacia, but they are hardly worth consideration, as none is more beautiful than the type. The variety macrophylla (large-leaved) is of stronger growth and has finer foliage and flowers, but those named in nurseries
Rodgersia podophylla.-A handsomeleaved plant of the Saxifrage family. Its leaves measure I ft. or more across, and are cleft into five broad divisions; and their bronzy-green hue renders the plant very distinct from other hardy plants. They are borne in stalks 2 to $4 \mathrm{ft}$. high. The inconspicuous flowers are produced on tall branching spikes. R. podophylla is rather uncommon at present, but it certainly deserves attention from those who admire fine-foliaged plants. It is perfectly hardy and likes a peaty soil and 
a shady situation. It is easily propagated by cutting the stoloniferous root-stock, and twenty plants can be obtained from a single root-stock in one year. Japan.

Romanzowia.- $R$. sitchensis and $R$. unalaschcensis, both from Russian America, are small dwarf plants forming in summer a dense tuft of foliage studded with tiny white flowers. They are quite hardy, and will grow well in open positions in the rock-garden. They are interesting but not attractive plants. Hydrophyllacea.

\section{Romneya Coulteri (White Bush} Poppy).-Among plants of recent introduction perhaps none surpass in stately beauty this fine Californian Poppywort. In favourable localities it has flowered freely on lengths of the current year's growth, fully $7 \mathrm{ft}$. high, when, with some twelve or fifteen flowers in bloom at the same time, the plant has a charming and imposing appearance. The flowers are of a peculiarly delicate texture, the petals scarcely opaque, and yet enduring in a good state for many days; their fragrance is equally delicate, something like that of a Magnolia. It is perennial, but not herbaceous, and the deeply-cut glaucous foliage is retained throughout the winter. It does not appear to flower on the last year's growth, though that growth remains in good condition. The flowers are borne mainly on the points of the new shoots and on laterals nearest the points, but more sparingly on the lower laterals. The capabilities of this fine plant have as yet hardly been fully tested in our climate, but it is hardy in genial soils in our southern counties. It certainly enjoys a warm sandy soil. One-year-old plants in a garden on clay have grown but poorly, while others from the same batch on a warm peaty sand, in an elevated position, have grown vigorously and flowered abundantly, blooming continuously from the end of June to the end of September. Where it will not grow in the open, it would probably do well in many places against or near a wall with a southern or western aspect. I have seen it doing well on warm soils in very different parts of the country, so that no one need doubt the fitness of this noble flower for English gardens.

Romulea.-Bulbous plants of the Iris family. They are of dwarf growth, and have grassy foliage; but though their blossoms are showy, they are not perfectly hardy, and they require to be grown either in frames or in very warm sheltered borders, in light soil. The best known are R. Bulbocodium, ramiflora, and
Columnæ, natives of South Europe, and R. rosea and R. Macowani from the Cape of Good Hope. The showy Crocus-like flowers of these open fullest in sunshine.

Rosa (Rose).- The flower of flowers has been ill treated in its literature! It would be difficult to imagine anything more confusing than the writings on the Rose and catalogues of the present day! Almost useless groups, like the Boursault, are dignified as classes, while more important classes like the noble Teas often receive no due notice; the confusion arising from the misleading term "hybrid perpetual" has effectually concealed the fact that the true perpetual bloomers are the Tea Roses, so keeping the noblest of all Roses out of gardens even in the southern counties. For many years Roses far superior to the many so-called "perpetuals" in point of continuity of bloom have been raised, and yet, as a result of that ill-chosen name, one may go into some of the largest places in the country and hardly see a Rose in the Rose-garden in August. The set idea of the Rose-garden itself, as laid down in all the books, i.e. a place apart where one can only see flowers at a certain season, was unfortunate and harmful, as it led to the absence of the Rose from the flower garden itself, in which it is the most delightful of all known adornments. Instead of seeing the Rose in many different attitudes in a country place, we see a wretched mob of standards and halfstandards rising out of the ground, generally in a miserable formal arrangement called the Rosery. Instead of forming beautiful Rose-gardens, many growers have distinguished themselves by growing Roses on tall Briers and other stocks, from which they get perhaps one or two flowers bigger than their neighbours' to send to a Rose-show. The Rose exhibitor's Rose-garden is even uglier than the so-called Rosery in the large country-seat. In this way, through the stupidities of books and the curious power for evil of words, the beautiful human and artistic side of the Rose-garden has been forgotten. But there is the dawn of better things, and the following abstract of a paper, read by Mr. T. W. Girdlestone at the Rose Conference at Chiswick, gives a fairer view of the

ROSE FOR THE GARDEN.-It is curious how few people seem to consider the value or beauty of a Rose as a growing plant in the garden. Nearly every one, when supposed to be describing some particular variety of Rose, in reality describes an individual blossom. In almost 
every Rose catalogue it is the same; the individual flower is described, and only as a cut flower its beauty is dilated upon. The reason is easy to find, but hardly the justification. No doubt the Rose has always been the most popular of flowers for decorating our rooms and houses, a position from which it is never likely to be deposed, and from this it has probably come about that the Rose is generally estimated only as a cut flower. It is time that more attention should decorative display with Roses has, undoubtedly, been the frequent and perverse employment for particular purposes of varieties utterly unsuited thereto. The number of Roses suitable for standards is comparatively small, yet people persist in attempting to grow all varieties in this form ; and when an army of gawky scarecrows is the result, the Roses are blamed. Similarly, effective Rose-pillars can only be made with a limited number of sorts, amongst which few of the ordinary Hybrid

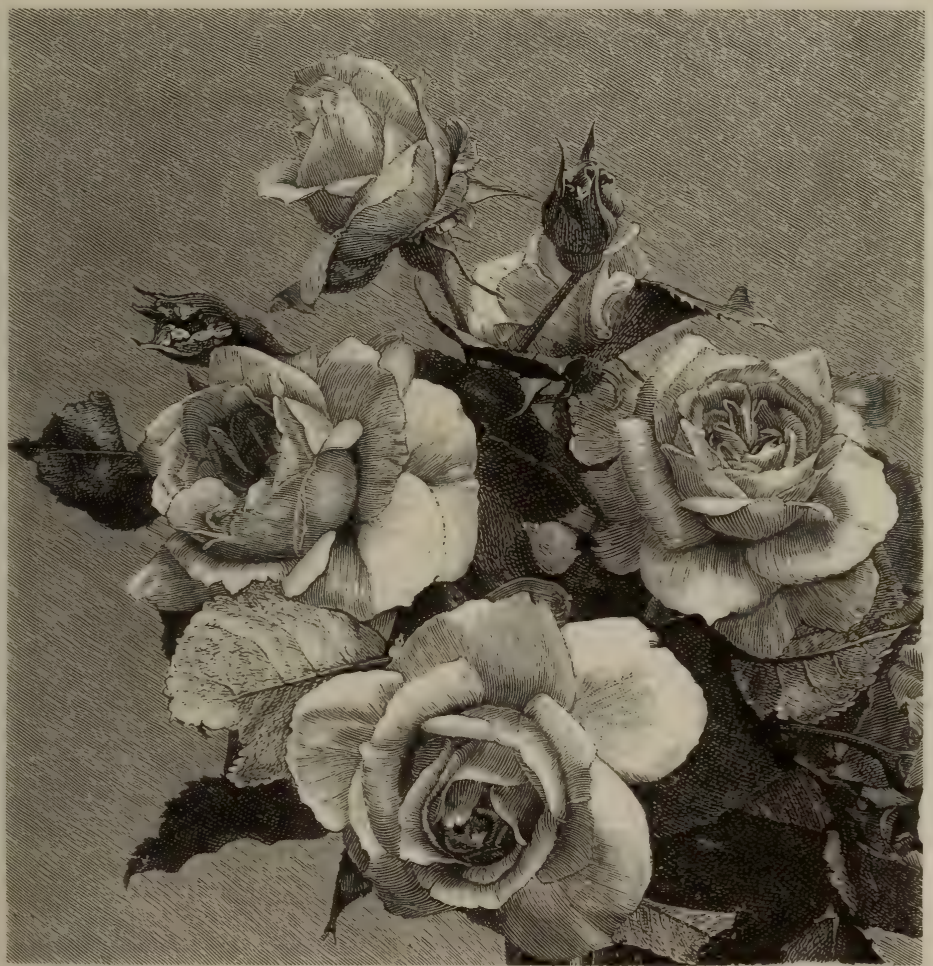

TRIOMPHE DE RENNES.

be paid to the Rose as a decorative garden plant.

One sees sometimes in catalogues collections of (say) roo Rose trees in as many varieties. Such a miscellaneous assortment planted together would certainly not make an effective Rose-bed, nor a decorative display; and one is tempted to think that those who declare Roses to be always ineffective and untidy, and deserving only of cultivation in the kitchengarden to supply cut flowers for the house, must have gathered their experience from Rose-growing of this kind.

A great source of failure in making a
Perpetuals are included ; yet who has not seen innumerable attempts made with varieties of this class, of which the outcome has been the production of a solitary shoot I or $2 \mathrm{ft}$. taller than the rest of the plant, which is carefully tied to the stake, and looks as though it were longing to hide behind the great Larch post it so vainly essays to cover?

It has often been urged that although Roses are gay enough while they are in full bloom, for the rest of the season they are dull and unsightly. Apart from this being only half true, and becoming annually less so, as more thoroughly perpetual 
Roses are raised, if the objection is to be admitted, it must apply equally to a great majority of herbaceous and bulbous plants; and our gardens, hardly emancipated from the dreary tyranny of "bedding-out," must relapse into the inane monotony of ribbon borders and carpet beds, in the latter of which especially the enforced primness of the poor little plants is as unnatural as children that never have grubby fingers or rumpled collars. Those whose sympathies are so strangely arranged as to cause them to love carpetbedding, are not likely to admit the claim of Roses to be considered as decorative plants; but it may be hoped that those who underrate the attractions of the Rose in the garden will eventually be a small and constantly-decreasing minority.

There are four ways in which Roses may make a very decorative effect as growing plants in the garden, namely, in beds of dwarf plants; as large isolated bushes or real tree standards; for the formation of Rose - pillars; and as climbers, whether on walls or over arches, etc.

In planting dwarf Roses in beds for the purpose of effective display, avoid the employment of too many varieties. If a bed of seventy-two dwarf Rose trees is to be planted, half-a-dozen varieties are ample, the twelve plants of each variety being grouped all together; and these varieties should be selected for freedom of growth, abundance and continuity of flowering, handsome foliage, and for being as little liable to mildew as may be ; and, most important of all, for their sturdy habit and ability to carry their flowers erect, pendulous blooms being necessarily ineffective. The flowers should be substantial and of good quality, capable of enduring sunshine or shower without being burnt or getting all their petals stuck together.

It is also important that the plants of a particular Rose should be planted at the distance apart best suited to the habit of that variety. In old days it was commonly recommended to plant Roses $3 \mathrm{ft}$. apart each way; and, no doubt, when the vigorous hybrid Chinas were in vogue, this amount of space was necessary. But there are now so many modern varieties, such as the races sprung from Victor Verdier and Baroness Rothschild, which, although possessing abundant vitality, make such compact sturdy growth, that to make the best display they should not be planted much more than one foot apart. Some of the modern Roses are as vigorous and strong in growth as many of the old sorts, and these will need to be planted greater distances apart; but if the distance be carefully proportioned to the habit of the variety, and a dozen or more plants of each variety be grouped together, there will be little fear of the display of bloom being ineffective, or of Rose beds not being decorative.

The cultivation for several years of almost every variety of Rose at all generally grown in this country has resulted in the selection of the following kinds as the best for planting in beds, in groups or masses, for the purpose of decorative display in the garden:-

Varieties of which the plants should stand about I ft. apart. - Baroness Rothschild, White Baroness, Merveille de Lyon, Marquise de Castellane, Earl of Pembroke, Alphonse Soupert, Marie Finger, Caroline Swailes, Mrs. Baker, Hippolyte Jamain, Captain Christy, Mme. Bois, Marguerite de Rohan.

Varieties of which the plants should stand about $\mathbf{1} \frac{1}{2} \mathrm{fl}$. apart.-Cannes la Coquette, a fleshcoloured seedling from La France, and one of the most charming and useful of Roses, whether for massing, for exhibition, or for cut flowers ; Alfred K. Williams; Comtesse de Paris (Lévêque, I882), a very pretty rose colour, immensely free and perpetual; Viscountess Folkestone; Annie Laxton; Duchesse de Vallombrosa ; Pride of Waltham; Kronprinzessin Victoria; Laurette Messimy, a China or Hybrid Tea of the most vivid and lovely rose colour; Heinrich Schultheis; Lady Helen Stewart; Suzanne-Marie Rodocanachi; Henri Ledechaux; Sophie Fropot; and of summer Roses, Rosa Mundi, the brightest and best worth growing of all the striped Roses, and commonly, though wrongly, called York and Lancaster, and the Scotch Roses in variety.

Varieties of which the plants should stand about $2 \mathrm{ft}$. apart. - Mme. Gabriel Luizet ; Charles Lefebvre ; Anna Alexieff; Prefet Limbourg, a most useful dark crimson Rose of great freedom and effect; Boule de Neige : Mme. Nachury; La France; Ulrich Brunner; Jules Margottin, and his lovely daughter Violette Bouyer, freest and most charming of white Hybrid Perpetuals; John Hopper ; Julie Touvais, a very early and most distinct and attractive Rose, far too little cultivated; and Gloire Lyonnaise, a very beautiful Rose, both in plant and flower, and making always a most striking group.

It will probably have been noticed that, with half-a-dozen exceptions, the Roses best adapted for effective display in the garden are also among the best for exhibition, and the more they are cultivated with a view to producing exhibition blooms, the more decorative they will be. Pegging down is not recommended, the only Roses with which its employment has been completely successful being some of the very vigorous Mosses, such as Lanei, Captain Ingram, etc. The plants should be fairly 
hard-pruned, liberally cultivated, and vigorously disbudded.

If the beds are large enough they may be margined or fronted with groups of the everblooming miniature Polyantha Roses, of which the best are Mignonette and Gloire des Polyanthas, pinks; Anne Marie de Montravel and Ma Pâquerette, whites; and Perle d'Or and Golden Fairy, orange-yellow.

The best Tea-scented Roses for massing - that is to say, the varieties that can most certainly be relied on to be effective in any season--are Marie Van Houtte; Mme. Lambard; Hon. Edith Gifford; Comtesse de Panisse, a very handsome varieties. Of these the best are Anna Alexieff, Mme. Alfred, Carrière, Prefet Limbourg, Marie Van Houtte, Mme. Perny, Mme. Gabriel Luizet, Glory of Cheshunt, Mme. Nachury, Jules Margottin; and of summer-flowering Roses, Persian Yellow, Harrisoni, White Provence, Chênédolle, Celestial, a Rose similar to, but of far greater beauty than, Maiden's Blush, and the double marbled Sweet Brier; of these, the first ten varieties named make especially fine largeheaded standards.

A pillar Rose, so called, and a Rosepillar worthy of the name, are not of

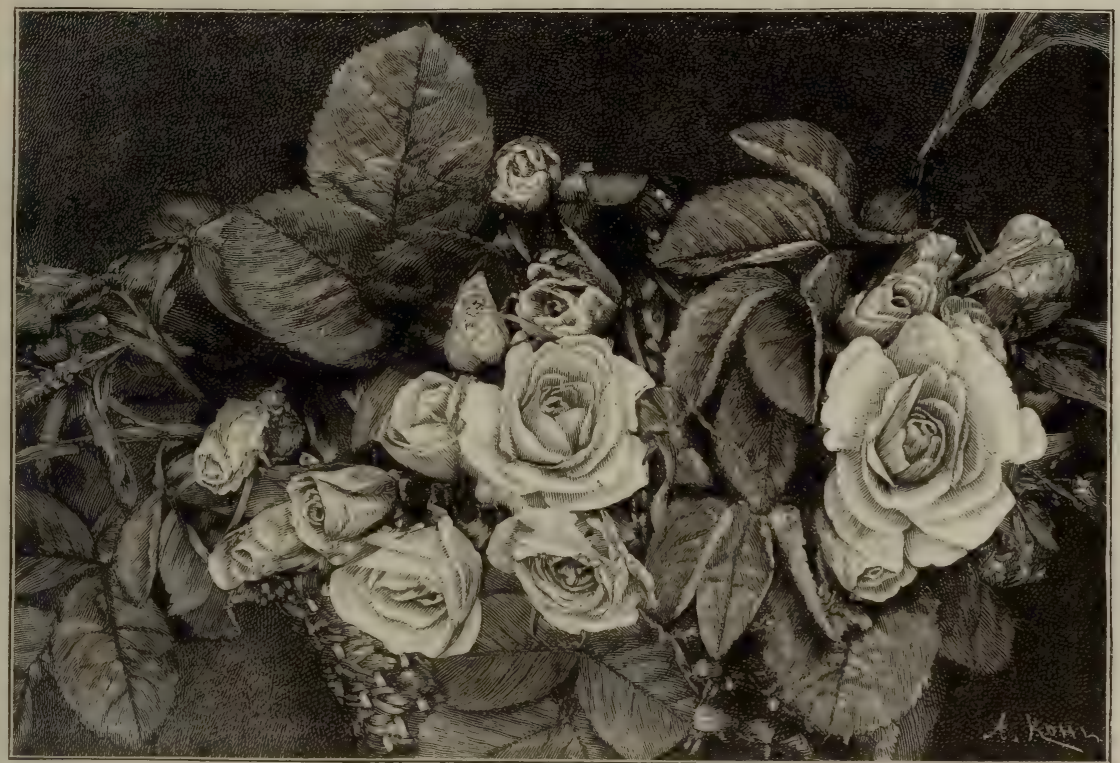

ROSE, CELESTE.

and reliable Tea that has been unaccountably overlooked by exhibitors; Anna Oliver: Mme. Charles; Mme. Chedane Guinoisseau, loveliest of yellow buds; Mme. Hoste, most free and constant, a great acquisition, which may also be said of Ethel Brownlow; Narcisse ; Souvenir de Gabrielle Drevet; Princesse de Sagan, a rich velvety maroon-crimson Tea, lacking size and fulness for exhibition, but ever-blooming and most effective in the garden; R. indica (Lowe), a lovely single red Tea, of which a group of dwarf plants is charming throughout the entire season; and Jean Ducher, when the weather is not wet and cold.

To obtain large isolated bushes and genuine tree standards, the one thing necessary is the employment of suitable necessity synonymous. The requirements to make a good Rose-pillar are, that it should be very vigorous, but not too long and rampant a climber, very free-flowering - perpetual if possible-with handsome and abundant foliage, and a hardy constitution. The Roses that make the finest pillars will generally do so from a single plant, but of some varieties it is frequently a good plan to employ two or even three plants at the base of each post for the better formation of a first-rate Rose-pillar. The best Roses for pillars are also the best for covering fences of from 4 to $8 \mathrm{ft}$. high, and for either purpose, were it only an autumnal, Mme. Plantier would be an ideal variety. Although it flowers but once a year, it makes a more beautiful pillar than almost any Rose, for its in- 
variable profusion of bloom and the pure whiteness of its flowers, its hardiness and vigorous bushy habit, present all the qualities best adapted to the formation of a perfect Rose-pillar, with the sole exception of not being perpetual. In addition to Mme. Plantier, the following varieties are also first-rate Roses for the purpose : Ophirie, a delightful coppery-orange Noisette, making a pillar of extreme beauty; Mme. Alfred Carrière, whose large creamy-white flowers have a most shades; the summer Roses, Blairi No. 2 , and Souvenir de Pierre Dupuy, and Rosa macrantha, one of the most beautiful of all the single Roses.

Of climbing Roses grown against high walls and houses, or over arches of considerable span, not much is to be said, except to urge once more the employment only of varieties suited to the purpose and to the position they are to fill. It is not wise, for the sole reason that there is a blank wall or the bare side of a house,

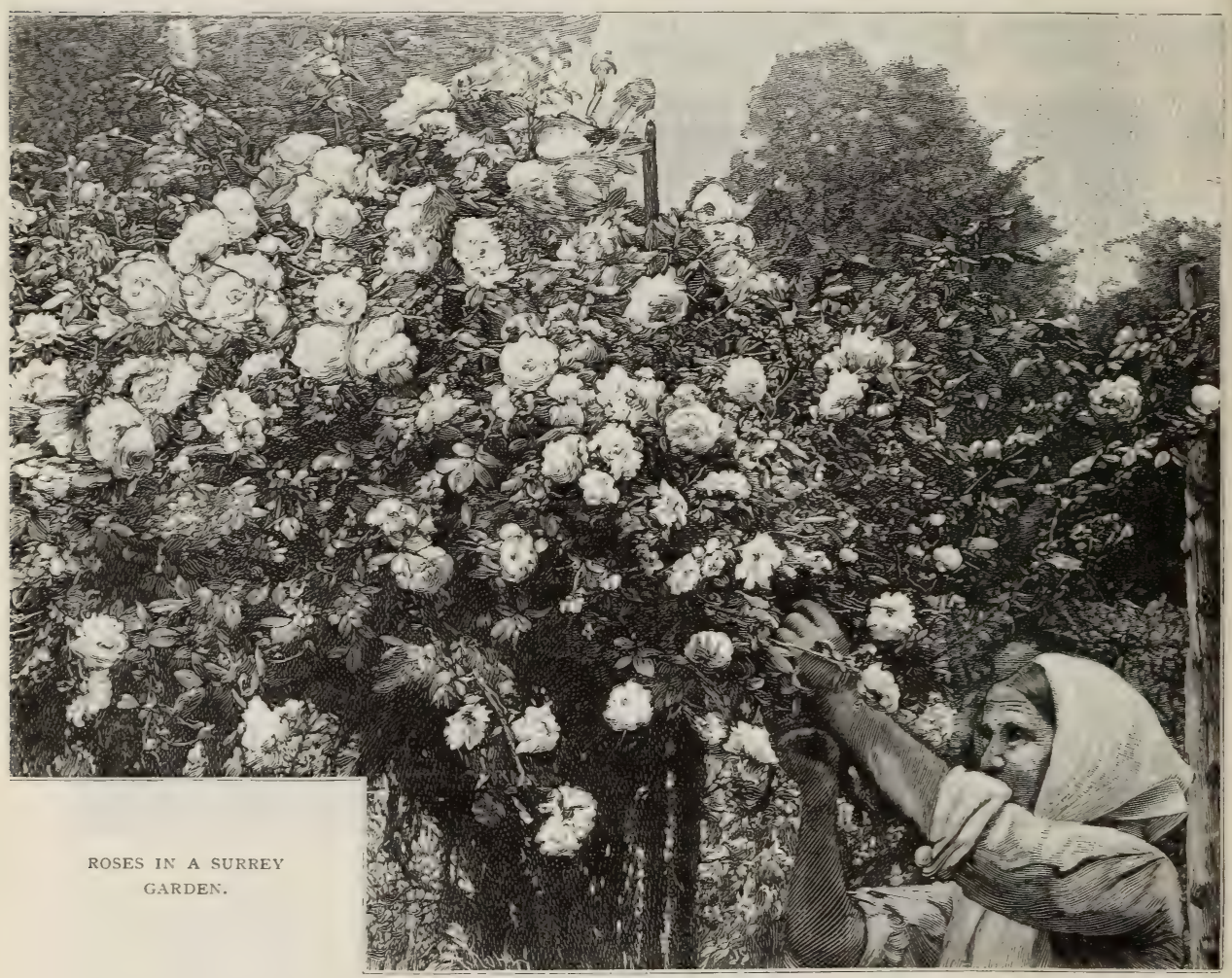

delicious fragrance; Bouquet d'Or, and Rêve d'Or, both with the additional charm of conspicuously-beautiful foliage; Climbing Captain Christy, the freest and most valuable of all these "climbing" sports; Max Singer, a useful hybrid multiflora with well-formed cherry-red flowers of good size continuously produced in trusses of from three to seven blooms, in spite of the curious fact that it was described when sent out by the raiser Lacharme as "non-perpetual, and producing solitary flowers"; Bardou Job, an improved Gloire des Rosomanes, with very large semidouble deep crimson flowers with darker to plant against it Maréchal Niel or the tender Climbing Devoniensis, without regard to aspect, soil, or climate. There are abundant situations where such Roses will flourish, but to consider it necessary to attempt to grow Maréchal Niel in circumstances under which only an ineffective apology for a plant can be produced, merely because it has the reputation of being, when at its best, the most superb yellow Rose as well as the grandest climber in the world, is absurd, and involves a waste of time and energy which, if only applied to the cultivation of Roses adapted to less favourable 
surroundings, would result in a decorative display affording the keenest pleasure. It is the case, that in spite of the unsurpassed beauty of perfect individual flowers of Maréchal Niel, it is less decorative as a climber, even fairly well grown, than many of the following: William Allen Richardson, Reine Marie Henriette, Reine Olga de Wurtemberg (a magnificent climber, very perpetual, producing bright crimson flowers, and deserving of very extended cultivation), Mme. Berard, Bouquet d'Or, Emilie Dupuy, Aimée Vibert, Celine Forestier, Lamarque, Princesse de Nassau (Musk), Mme. Trifle; and the summer Roses, Fortune's Yellow, Félicité-Perpétue, Laure Davoust, Splendens, Ruga, The Garland, Alice Gray, Flora, Claire Jacquier, the single Rosa multiflora, Rosa mult. grandiflora, and the deliciously fragrant Rosa Brunonis (syn., moschata, Crépin).

Mention has been made of some of the most decorative single Roses in the selections given of the best varieties for certain purposes; but there are a few others which ought to be included in every Rose garden. The rugosa Roses are so well known that it is only necessary to insist on the exceeding beauty of the white form; but among those far too rarely seen are the Austrian Briers, Rosa lutea, the yellowest Rose in the world, and its wonderful scarlet variety, Rosa punicea; Rosa rubrifolia, with its red leaves, red stems, red everything, including its immense clusters of hips in autumn ; Rosa lucida, also beautiful in fruit at the end of the season, as in flower and glossy leafage during the summer; Rosa bracteata, the very distinct Macartney Rose; Rosa damascena, the crimson damask; Rosa Beggenana, the starry white Rose from Afghanistan, all blooming, and producing the most brilliant little hips imaginable; and last, but not least, a garden variety classed as a hybrid Sweet Brier under the name of Hebe's Lip, beautiful exceedingly, having large substantial creamy-white petals with a Picotee edge of purple. Nearly all these single Roses only require to be put into the ground and left to themselves to thrive and produce their myriad flowers and fruits.

The subject may be briefly summed up as follows :-

Only employ for particular purposes varieties well adapted thereto.

In the case of groups or masses of dwarf Roses in beds-

(I) Plant many plants of few varieties;
(2) Cultivate as highly, prune, disbud, and keep clear from insects, etc., as if every bloom were to be required for exhibition.

Then a display of bloom will ensue, well deserving the epithet decorative, and likely to be maintained more or less throughout the season.

TEA Roses For the Flower GaRDEN.-These are in many respects so superior to all other Roses, that we might place them first and foremost, and there is yet room for a great extension of their culture in gardens, both large and small. We find even standard works on Rose-growing speaking of the Teas as tender, and needing protection. Others say that only in a few instances can they be grown in the open ground; and to have them in full beauty, to ensure a constant succession of flowers, and to produce them in all their loveliness and purity of colour, they must be grown under glass. This is not so. Tea Roses may be grown in hundreds of gardens where they cannot now be found, and I would urge all who love Roses to try them fairly, for none are more worthy, and the reward for the labour is greater from these than any others. The variety of lovely tints amongst Tea Roses, the delicate odour, the profusion of bloom, the long season over which it is produced, and their charming habit and foliage, are great merits. Let us for ever give up the stupid old notion of growing our Roses only in a rosery or rosarium, in some out-of-the-way spot. The grand Tea Roses now under notice are worthy of the best position in the garden. There are also many' Tea Roses excellent for clothing walls, fences, or any other erections about our homes, and we shall need much space if we want to grow all that are good. Here I name all the best Tea Roses, and if we would make our gardens sweet from June to November, these are what we should plant. Every kind except the last two is described from experience of it in a flower garden, where the climbing kinds wreathe the walls and the dwarfs are grouped in beds and borders solely for effect. The aim has been to show what can be done with Tea Roses. They prove to be amongst the most precious plants in existence, and beyond all others fitted to adorn our gardens, the variety of tint and freshness of leafage being a charm almost as great as their continuous blooming. None, with me, have ever been protected, but winter winds blow furiously over the garden, and on several occasions more than $20^{\circ}$ of frost have been registered 
among the plants. If we in the east can have such a feast of Tea Roses, hundreds can do likewise in the south and west. What a glorious Rose is

APRICOT or W. A. RICHARDSON. In the catalogues it is classed as a Noisette, but it is more a Tea Rose than anything. The same will apply to one or two other kinds to be mentioned. That under notice can only be called a first-rate Rose. It is hardy and vigorous, free in bloom, and unsurpassed in its deep orange-yellow shade. The flowers are borne in clusters, and are best in the bud state, being only semi-double when fully open.

GLOIRE DE DiJON is one of the earliest to bloom and one of the last to cease. This Rose will not fail us on walls facing any point, and therefore we may call it one of the great Roses. It is the type, and, in some cases, the parent of a little family called Dijon Teas, because they resemble it in vigour, freedom, and continuity of bloom.

BOUQUET D'OR is a grand Rose to cover the high walls, and flowers abundantly. The flowers are a fawn-yellow, with deeper centre, the shape very good, and the buds longer and finer than those of Gloire de Dijon.

Emilie Dupuy is a vigorous and lovely kind, at times resembling the preceding variety, but quite distinct. Produces flowers of great substance, the outer petals sometimes forming a kind of cup round the centre, like the guard petals of a Hollyhock.

MME. BERARD is most distinct in many respects. It is very vigorous, and one striking characteristic is that it is almost thornless. Its salmon colour is fringed with yellow and rose; the flower is fine and well formed.

Mme. Chauvry is a new addition with the Mme. Berard habit of growth, but distinct from any in its rich yellow colour, shaded with pink, deepening to rich buff at the base of the petals. Its merits are as yet hardly known.

Mme. B. Lever is a lovely kind ; not quite so vigorous as most of the family, but in other respects good, especially in the rich orangeyellow and delightful odour of its flowers.

Henriette de Beauveau only appeared in 1887 , but has shown qualities that include it among the best Roses of to-day. A warm wall and little pruning and it produces flowers freely. They are very fine and sweet, of a clear canary-yellow.

DUCHESSE D'AUERSTADT is very vigorous in growth, thoroughly hardy, most profuse in bloom, and has large yellow flowers, which sometimes take a very deep rich yellow shade. Many of these Dijon Teas may be grown away from walls, which for such hardy vigorous kinds only furnish support, shelter not being needed. Plant in groups of from 3 to 12 plants where they have room to develop. A stake here and there is all the support needed, and they will make huge bushes and bear flowers by the hundred. In gardens where the dwarf Teas cannot be grown, these Dijon Teas are just the kinds for the place. It would be a gain to destroy a lot of common shrubs that overrun much ground, and plant bold masses of these Roses. One other good use they have is for pegging down. So treated, they flower freely, and make fresh strong shoots to peg down another year.

RÊVE D'OR is a good wall Rose, and one that will cover a great space. It must be allowed to do so before it will flower with any freedom; but once it has expended its vigour in growth, it settles down a free-blooming Rose, and a desirable kind in many ways.

Climbing Devoniensis is not everybody's Rose, but in a sunny favoured spot it sometimes grows sufficiently to cover a cottage by itself, and flowers proportionately.

L'IDEALE.-One of the most distinct wall Roses yet raised, is akin to W. A. Richardson in all but colour, and is almost indescribable. The flowers, which must be seen to be fully appreciated, are yellow, and a peculiar shade of red, streaked with golden-yellow - a harmonious commingling of striking hues.

MARÉCHAL NIEL, though grown by thousands under glass, is a grand Rose on warm walls outside, and will furnish early flowers. Encourage vigorous growth, and lay in young strong shoots, and flowers will be abundant.

\section{The dwarf varieties are very numerous :}

ADAM is one of the oldest, having been in cultivation over fifty years. Half a century of Rose improvement has given us nothing that could fittingly take the place of this kind. It is not so vigorous in growth as most Teas, but is hardy and free in bloom, with large, globular sweet-scented, salmon-rose-coloured flowers.

Adrienne Christophle is very lovely, especially in hot years, is vigorous in growth, most abundant in bloom, and its flowers are often quite indescribable in colour, being yellow, which deepens into apricot and copperred, shaded with pink and rose.

Amazone.-One of the best dwarf yellow Teas, is most ornamental and useful for cutting. It makes a pretty, compact bush, grows well, and flowers freely. Its buds are long, and of the pretty popular shape. They are a deep lemon-yellow.

Anna Olivier is as vigorous as any Rose, hardy, strong, and free, making a great bush. In the bud state it is one of the most charming, the buds urn-shaped, flesh-coloured, deepening into buff at the base of the petals.

BOUGERE is one of the good old kinds now unfortunately neglected. It is as old as the Tea Rose Adam, or even older, and as meritorious. Its flowers, of a rich salmon shade, are fine and globular in form, with petals of great substance.

Catherine Mermet is indispensable, for it produces flowers of matchless form. Its habit is rather thin, and in grouping it should be thickly planted. It flowers very freely, even slender twigs producing magnificent fleshcoloured blooms, deepening into pink.

Comtesse DE Frigneuse, of recent 
origin, is a decided acquisition. It is a good grower and a free bloomer, with flowers of a rich canary-yellow hue, full, and very sweetscented.

Comtesse de Nadaillac. - The variety of its tints is great, and the flower simply magnificent. Unfortunately, an uncertain grower, but generally does well in a sunny aspect at the foot of a wall. It is well worthy of a select spot with special care bestowed upon its culture. Yellow, deepening into copper, shaded with pink and rich rose, are the predominating hues.

COMTESSE RIZA DU PARC is very charming, mingled that it is hardly possible to properly describe them.

ERNEST METz, a nearly new kind, has come rapidly to the front. Its flowers are borne mostly singly on a strong stalk, sturdily erect, very full and fine in shape, of the palest rosypink, but brighter towards the centre of the flower.

Francisca KRUGER is one of the freestblooming Tea Roses. It is necessary to disbud it, as the buds come in such immense clusters that they cannot all open properly. In colour it is copper-yellow, shaded with peach, the form fine, large, and double.

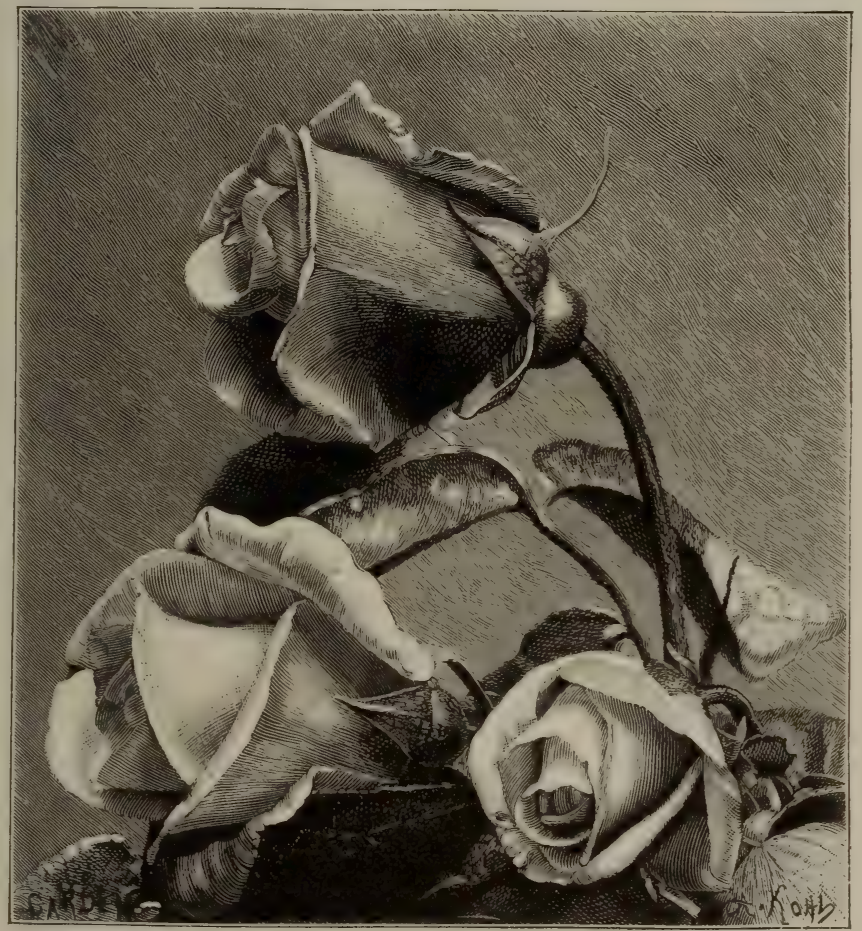

BUDS OF TEA ROSE ANNA OLIVIER.

and most distinct and showy in the garden. It is strong in growth, lovely in foliage, and very abundant in bloom. The flowers are large and open, not so good in form as those of most kinds, but unlike any in its rich bright salmon-rose colour, shaded at the base with copper. The shoots are very strong, erect, and terminated with large clusters of bloom.

DEVONIENSIS is very old, but a fine Rose still, vigorous in growth and free in bloom. The flowers are creamy-white, flesh-tinted, and of great size when fully open.

DR. GRILL. - Comparatively new, but fresh, and a grand Rose for grouping. It makes a big bush, being a vigorous grower, and its flowers and buds are extremely lovely. Their colours are so varied and so harmoniously
GouBAuLT is an old kind, with rosy-pink flowers that might be forgotten in the present day, but for one great charm-it is exceedingly sweet-scented. The buds are lovely in shape and rich in colour.

Hon. EDITH Gifford. - The best Dwarf Tea Rose for grouping effectively. The old leaves are dark green, the young ones of a purplish-crimson, and even without a flower it is the handsomest group in a garden that has all the kinds here named. Then when the flowers come they almost hide the leaves, they are so numerous, open so well, last so long, and are so good in form. In colour they are flesh-white, with salmon-pink centre.

InNocenta Pirola is a good companion to the preceding kind, and one of the best white 
Teas. It grows vigorously, Howers freely, and the blooms are of lovely form. It is creany. white, with the palest flesh shade, but is a slow grower on cool soil, at least on the Brier stock.

JEAN DUCHER is fittingly named in honour rest, strong in growth, and abundant in bloom, with flowers of lovely form. In colour it is a rich apricot-yellow, shading to pale yellow with age. It is apt to dwindle on cool soil, at least on the Brier stock.

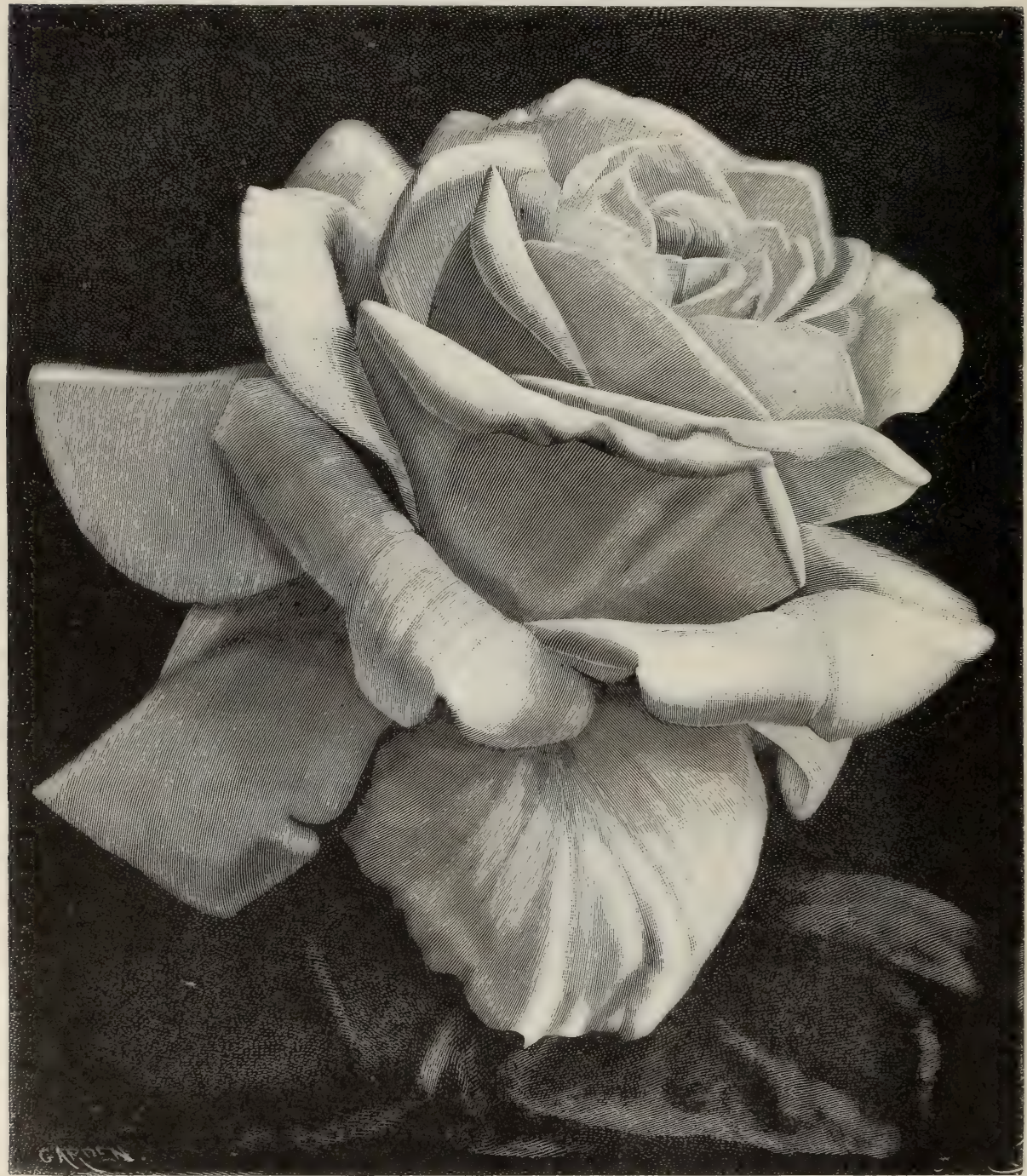

TEA ROSE, EDITH GIFFORD.

of its raiser, who, by the way, has given us a great many first-rate kinds. It is a grand Rose, especially in a hot year. The flowers are massive, very full and double, yellow, shaded with pink, deepening into buff in the centre of the flower.

JEAN PERnet bears the name of another noted raiser, and is a first-rate Rose, erroneously supposed to be tender, but as hardy as the
Jules Finger is one of the best growers, and most free in bloom. The flowers are finely formed and of a clear rose colour, deepening in tint as they expand fully.

L'ELEGANTE is valuable for the sake of its pretty buds, which open well at all times, and are so useful for button-holes. In colour they resemble that of the Pink China Rose, but they shade to pale yellow at the base. The 
bush is dwarf, but flowers with amazing freedom.

LUCIOLE, another of the newer kinds, is of great merit; dwarf in growth, profuse in bloom, with long-pointed buds that attract attention by reason of their shape and exquisite colouring. They are of the brightest rosycarmine shade, with a suffusion of yellow, which shades into copper at the base of the petals.

MA CAPUCINE, like the preceding kind,
MME. Charles is one of the very best. When growth begins this kind is conspicuous, its shoots and leaves being of a purplishcrimson hue, not uncommon among Teas, but especially bright and effective. Then it flowers well. Apricot-yellow, with a deep buff shade internally at the base.

MME. DE WATTEVILLE grows strongly, and produces such a quantity of buds that some of them must be removed. Its great erect double flowers have been aptly compared to Tulips.

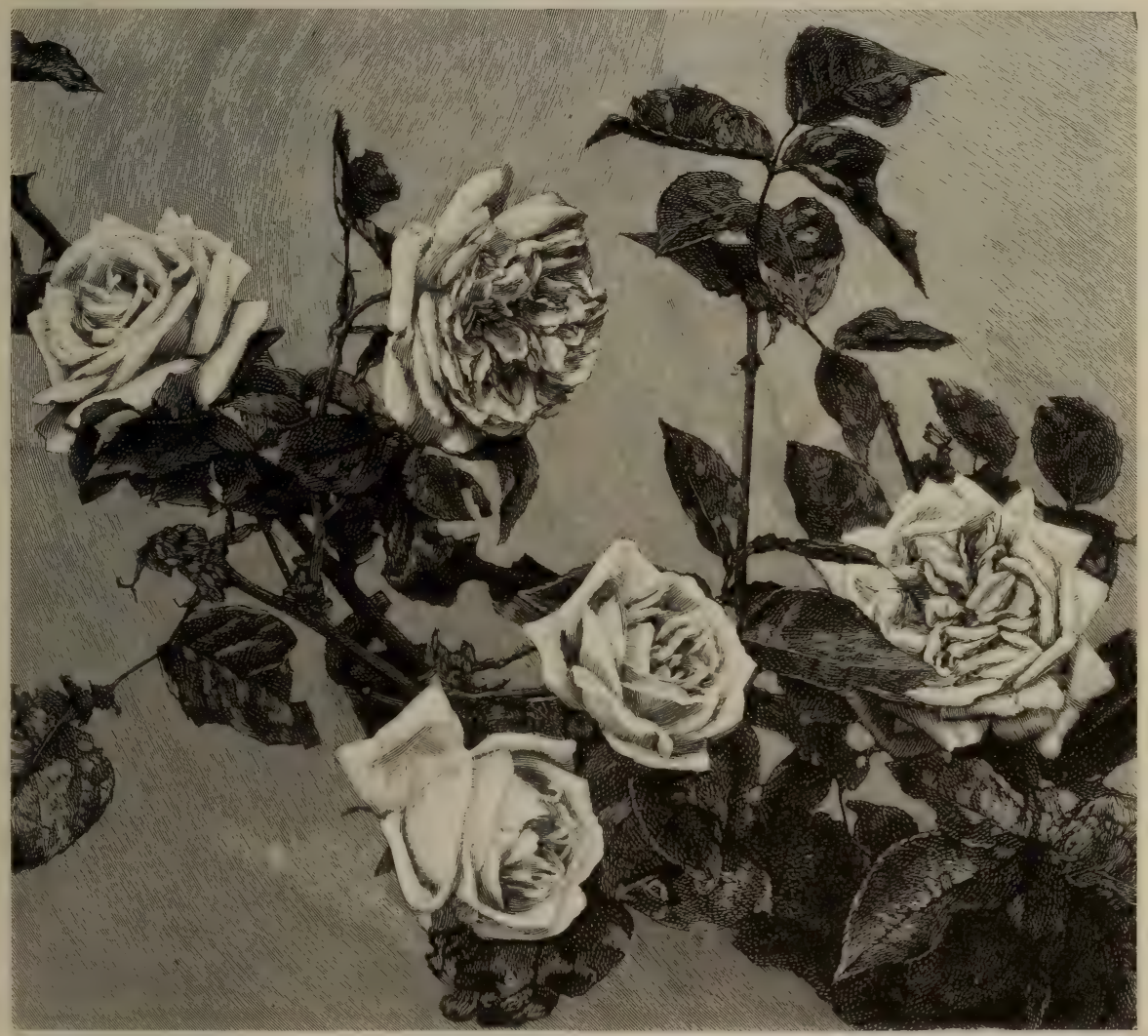

TEA KOSE, MADAME LAMBARD.

concentrates all its charms in a bud of fine form. When fully open it is little more than a single Rose, but in the early days of the Rose season, long before the double kinds have perfected their buds, it is charming in colour, deep orange-yellow, with red sufficient to make the flower bright. It is a dwarf grower, but the smallest bushes flower freely.

Mues. Chedane Guinoisseau, Caroline Kuster, and Falcot may be mentioned together as a trio of lovely kinds when in the bud state. For cutting they are most valuable. They all grow freely enough. The two first-named kinds have pale yellow flowers, whilst those of the other kind are of a deeper yellow tint.
The petals are broad, like shells, white in colour, with a faint salmon or pink shading, which deepens into clear rose at the edge of the petals, often forming a regular bordering.

MiE. Hoste. - Among the pale or strawcoloured Teas this stands out the best of them all, and is a grand Rose. It is a good strong grower and a free bloomer, and the flowers are enduring, large, and often of the most perfect form.

MME. Joseph GoDIER is one of the newer kinds that has not become popular, but for all that it is distinct and charming in colour-a bright rose suffused and shaded with copperyyellow. 
MME. Joseph Schwartz is a Rose to group for effect in the garden. At the top of its erect shoots it produces great clusters of flowers, which are white, suffused with flesh and tinged with bright rose on the edges of the petals.

MME. LAMBARD is lovely, free in growth and bloom, and variable in colour. Generally its flowers are pale rose, but they shade to yellow and apricot, and also at times become very pale pink.

MARIE VAN HoutTe. - This is one of the best Tea Roses, and is equalled by few for the out-door garden. It is vigorous, handsome in growth, and most profuse in bloom. In colour it is never more lovely than when grown in the sun outside.

MARQUISE DE VIVENS is first-rate, sturdy and bushy in growth, and profuse in bloom, with long buds of most attractive colour. They are pale pink externally, shading to straw colour at the base, but as they open they show a rich glowing shade of carmine-rose.

Niphetos is one of the great Tea Roses for growing under glass, but it should be grown outside also. It is as hardy as any of the rest, as free in bloom, and truly lovely to see with its buds crowning every shoot. I always think that the open-air flowers are more enduring and have much more substance than those grown under glass.

PERLE DES JARDINS is one of the most charming Teas we have, and usually is very fine, but it requires warm soil to open well. Its flowers are generally borne singly, open well, and vary from pale straw to canaryyellow in colour. It makes a strong bush.

Primrose DAme, though only a moderate grower, is a marvel for free-flowering. On small plants, not more than a foot in height, every shoot will produce a fine flower, which, as the name would imply, is of a primroseyellow hue, but later in the summer the flowers develop a rich apricot shade in the centre, and are then still more lovely.

PRINCESSE DE SAGAN is the darkest of Red Tea Roses, a vigorous and free-blooming kind. In the bud and half-open stages it is splendid, a rich dark maroon shade overlying the velvet-crimson colour of the body of the flower.

RuBENS is first-rate in every way, one of the earliest and most continuous bloomers, strong in growth, and lovely in form. The flowers flesh-white, shading into pink, large and full.

SAFRANO is one of the indispensable buttonhole Roses, hardy, free, and good, flowering profusely at all times. In colour it is apricot yellow, deepening into buff.

SAPPHO is nearly new, and resembles Francisca Kruger, but distinct and very charming. Externally the flower is a palefawn colour, but deep yellow in the centre, suffused throughout with pale rose.

Souvenir DE Gabrielle Drevet is charming in colour, but only a moderate grower. The flowers, borne erect on strong stalks, are rich in a variety of tints of salmon, shaded with yellow and peach.
Souvenir de PAul Neron is a grand kind, as hardy as any, and bearing magnificent flowers upon small bushes, the form matchless, the colour lovely creamy-white edged and shaded with pale rose.

SOUVENIR D'UN AMI is one of the finest, a great grower, profuse bloomer, with splendid foliage admirably setting off the great drooping rosy flowers. These are very large and double, of a fine globular form. Souvenir de S. A. Prince, or The Queen, is a white Souvenir, and has taken rank among the best.

Sunset.-This is a sport from Perle des Jardins, producing flowers of a deep apricotyellow shade. It is more vigorous than the type from which it sprang, and is fine during late summer and autumn. The Bride is a sport from Catherine Mermet, with the fine form of the parent and greater vigour, its colour being almost pure white. It is one of the very best. Waban is a sport from the same source, and is not just now being offered for sale. It has sported in an opposite direction, producing fine flowers of a deepcarmine shade.-A. H.

Hybrid Perpetual Roses.-This is the largest section of our Roses, and to many the most desirable, their colours being the brightest, and in most cases they are delightfully scented. Most Hybrid Perpetuals are quite frost-proof; they also grow well, are usually best as dwarf plants, and their growth being strong, the blooms do not suffer in wet weather so much as do those of Teas cultivated in this way owing to the weaker growth of their wood. I would not, however, wish to convey the impression that Hybrid Perpetuals are for these reasons to be grown to the exclusion of Tea Roses.

The general name "Perpetual" to all of this class I consider to be a misnomer, as many are not at all perpetual; but some varieties, more especially some of our oldest Roses, keep on blooming up to the month of November. Amongst the old H.P. kinds I may instance especially La France and Charles Lefebvre, and amongst newer varieties, Viscountess Folkestone and Victor Hugo as true perpetuals ; whereas Mrs. John Laing, Margaret Dickson, Gabriel Luizet, General Jacqueminot, and many other H.Ps. do not usually bloom after the month of August - it is quite the exception when they do. One advantage which H.P. Roses possess over the Teas is, that they appear to have no marked preference for locality or position. Give them a fair start by good planting, and they do equally well on heavy or light land, in warm or cold positions, on the side of a hill or on a dead level. Natur- 
ally, they bloom earlier when they have every advantage, and they will be heavier in petal off heavy land, but, taking them all round, H.Ps. do well in almost all usually allowed that Teas grow best on the Brier. My own experience is in favour of the Brier as the best of all stocks. Some consider that maidens on

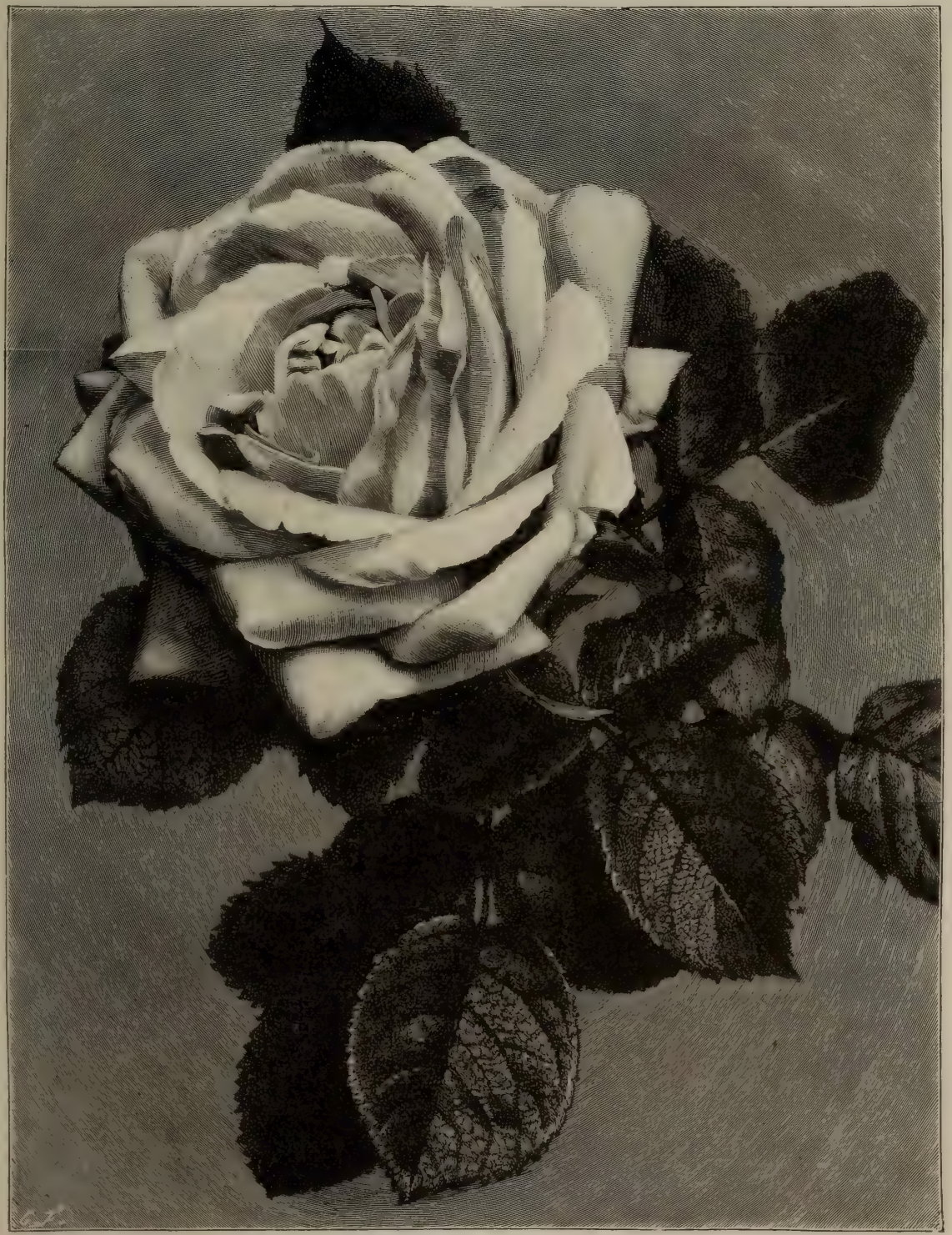

BARONESS ROTHSCHILD.

localities and situations where the air is pure and where they have been properly planted.

There is great divergence of opinion as to the best stock on which to grow Hybrid Perpetual Roses, although it is
Briers develop their first blooms too late in the season, and therefore those who use this stock are handicapped when they grow maidens extensively for exhibition.

Now which are the best Hybrid Perpetual Roses to grow? The question might 
lead to controversy, as our Rose lists alter annually. Each year a few (very few) good, apparently new, Hybrid Perpetuals are brought out. Some last in favour a year or two, some even longer, but the great majority are relegated to the dust-heap or given to friends who grow Roses in a casual sort of way. Few Hybrid Perpetual Roses have been brought out of recent years which can be said to excel our oldest favourites. No doubt many good ones have been produced, notably Mrs. John Laing, Gustave Piganeau, Jeannie Dickson, Sir Rowland Hill, Viscountess Folkestone (best of all), Her Majesty, and Margaret Dickson, most of which will permanently hold their positions, but are they better, or will they supplant as exhibition varieties A. K. Williams, Baroness Rothschild, Charles Lefebvre, La France, Marie Baumann, Comte de Raimbaud, Mme. Gabriel Luizet, Alfred Colomb, Dupuy Jamaim, and General Jacqueminot? Certainly not! But there is a marked peculiarity in the Roses newly brought out; we seldom see a really first-class dark and distinct red Rose. In the year I89o, the late Henry Bennett exhibited a new red Rose called Captain Hayward. I think it is one of the few good dark Roses brought out of recent years, the others being Gustave Piganeau, Lady Helen Stewart, Salamander, and Sir Rowland Hill; the last being the most distinct of all, and a glorious velvety Rose of the darkest class. There are too many new Hybrid Perpetuals of various shades of light and dark pink, and too much alike, such as Jeannie Dickson and Mrs. W. J. Grant; but if we want new Roses rapidly introduced, which I doubt, we do not want these uncertain lighter colours, but decided shades of red, like the brilliant scarlet of Duke of Teck or Cheshunt Scarlet, or such whites as Margaret Dickson. We already have too many pink Hybrid Perpetuals similar in shade and shape, and between which at times even experts can hardly discriminate. Another quality which of late years has not been considered a sine qua non in producing new Hybrid Perpetual Roses is scent. Surely scent is the crowning point in a good Rose, and the greatest defect in two such good Hybrid Perpetuals as Baroness Rothschild and Her Majesty. Who would prefer either even in their greatest glory to a really good La France or Mme. Gabriel Luizet, sweetest of all Hybrid Perpetuals? I think almost all the dark red Hybrid Perpetual Roses are sweet-scented, the want of scent being confined principally to some of the pink varieties, to Merveille de Lyon, Susanne Rodocanachi, and Duke of Edinburgh.

I have mentioned that Hybrid Perpetuals can be well grown as dwarf plants-in fact most rosarians who grow for exhibition have practically discarded standard Hybrid Perpetuals-but there are many varieties which do equally well on standard Briers; for instance, La France, Victor Hugo, Mme. Gabriel Luizet, A. K. Williams, Marie Baumann, Her Majesty, Charles Lefebvre, Merveille de Lyon, Le Havre, Mrs. John Laing, and several others do exceedingly well and produce blooms of exhibition standard. A short time ago it was the fashion to decry standards, but the tendency is to revert to them; and although the advantage is not so great in Hybrid Perpetuals as in Teas, there are times when, and places, such as closely fenced-in gardens, where, dwarf plants will not succeed so well as standards. One thing to avoid is planting them in single trees at long distances apart on the borders of walks, as they look stiff in that way. If, however, grown in large beds with dwarfs amongst them, the inelegant appearance of the standard stocks is hidden by the growth of the dwarfs, and when they bloom the combination is most effective. -C. J. G.

It has been a favourite practice in journals to make-strict selections of the most popular Hybrid Perpetual Roses, but we do not follow it here, as it is best not to be narrow in one's selection where there are so many beautiful and wellknown kinds. It is otherwise with the Tea Roses, which have been unaccountably neglected as roses for the open garden, even by the great Rose-growing nurserymen, and of these a careful selection has been given.

HyBRID TEAs.-The Hybrid Teas are really distinct enough to form an important separate class for convenience of nomenclature at least. Every one who has looked into the question of garden Rose-classification will not expect much from it. The race of Hybrid Teas was obtained from crossing the beautiful Tea Rose and the Hybrid Perpetuals; and so we get a group intermediate in form and in colour, and often, as in the case of $\mathrm{La}$ France and its varieties, very charming and precious. They are also in some cases very enduring in bloom, which makes them more useful than the ordinary red Roses of our gardens. The ordinary culture of the Rose-garden suits them well, and the finer kinds should, if possible, be got on 
their own roots as well as grafted. Among the kinds grown are: Annette Gamon, Antoine Mermet, Augustine Guinoisseau, Bona Weill Schott, Camoëns, Cannes la Coquette, Cheshunt hybrid, Comte Henri Rignon, Countess of Pem-

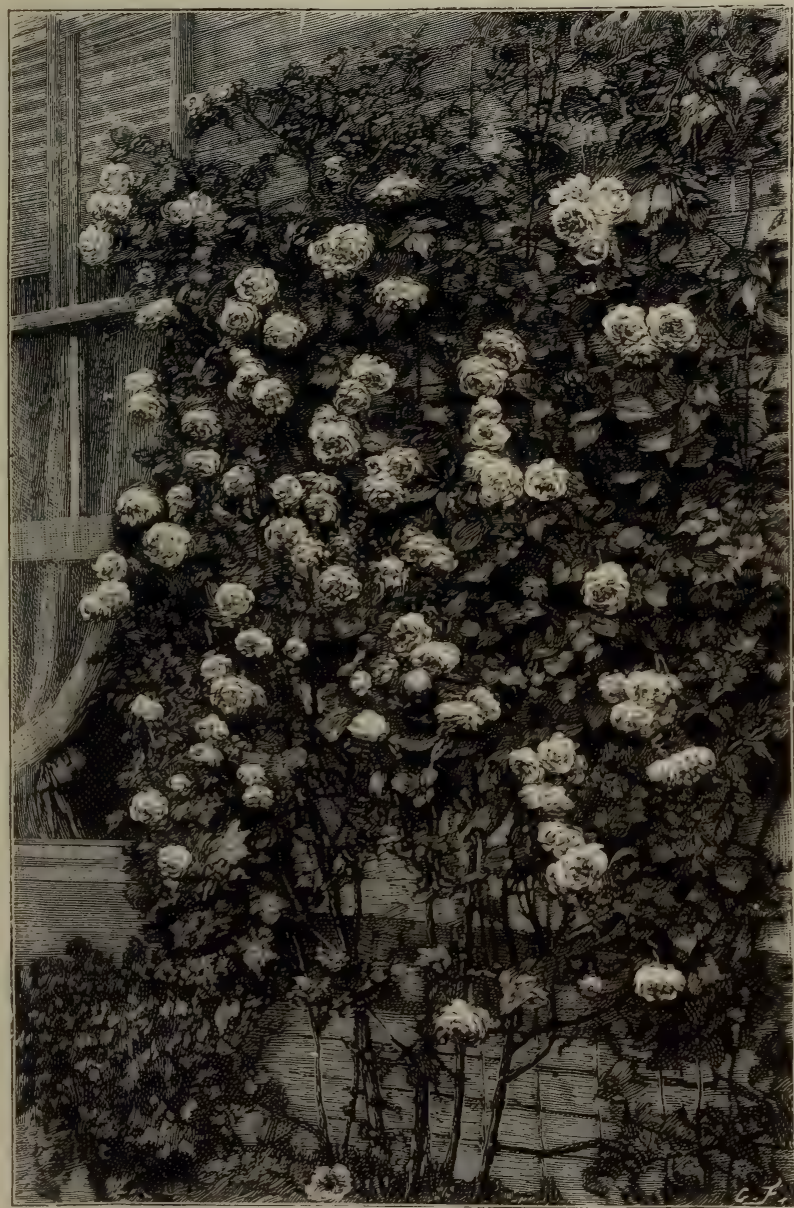

ROSE, CHESHUNT HYBRID.

broke, Duchess of Connaught, Duchess of Westminster, Esméralda, Jules Bassonville, Lady Alice, Lady Mary Fitzwilliam, La France, Madame Alexandre Bernaix, Madame André Duron, Madame Carle, Madame Etienne Levet, Madame Moser, Michaël Saunders, Pearl, Pierre Guillot, The Puritan, Waltham Climber, Viscountess Falmouth.

Climbing ROSES. - If we look at southern Continental gardens, which have never received a tithe of the labour and care lavished on English gardens, but which enjoy the advantage of warmer climate and more constant sun, we shall see such arcades, bowers, pillars, and climbing masses of beautiful Roses on all sides as will put us out of humour with our own beautiful individual blooms, and will cause us to regret the absence from our gardens of these luxuriant masses that neither receive nor indeed require or obtain any special care from one year's end to the other. If it is unfortunately the case that Roses which produce such glorious effects in foreign gardens are not hardy enough for us, why not try to raise new varieties that will endure our cold and changeable seasons? Surely in a genus that ranges from Kamtschatka to India, we may find at least one species that shall be the parent of hardy climbing varieties, as beautiful in our climate as the Noisette and indica major are in the south of France and elsewhere. We have $R$. sempervirens, and the several garden varieties, such as Felicité Perpetuée, that will climb a pillar or shade an arcade. The Ayrshire Roses, R. arvensis, and varieties of the Boursault Rose ( $R$. alpina), though very charming, bloom only in summer. They are all quite hardy and of vigorous climbing growth, but they do not satisfy those who love the Hybrid Perpetual, the Noisette, or the Banksian Rose. We have also the continuousblooming $R$. rugosa, the semi-double yellow R. Fortunei, and the beautiful R. sinica, the parent of the so-called large white Banksian Rose Fortunei. Cannot some hybrids be raised from these and the semperflorens, alpina, or arvensis species, or shall we use the R. canina, the common Dog Rose, for a parent? Let us make use of what we have at hand: let us plant in the wilder parts such hardy climbers as are already mentioned, and 
make combinations of such red climbing roses as can be found hardy - the excellent Gloire de Dijon and its progeny (none of which, unless it be Belle Lyonnaise, comes up to the parent in abundance or sweetness of bloom). The Cheshunt Hybrid, their way, but require good soil and plenty of space. When a warm wall needs clothing, the Banksian Rose or the various hybrids of the Noisette and Tea Roses may be used, though they are liable to be cut down in cold situations

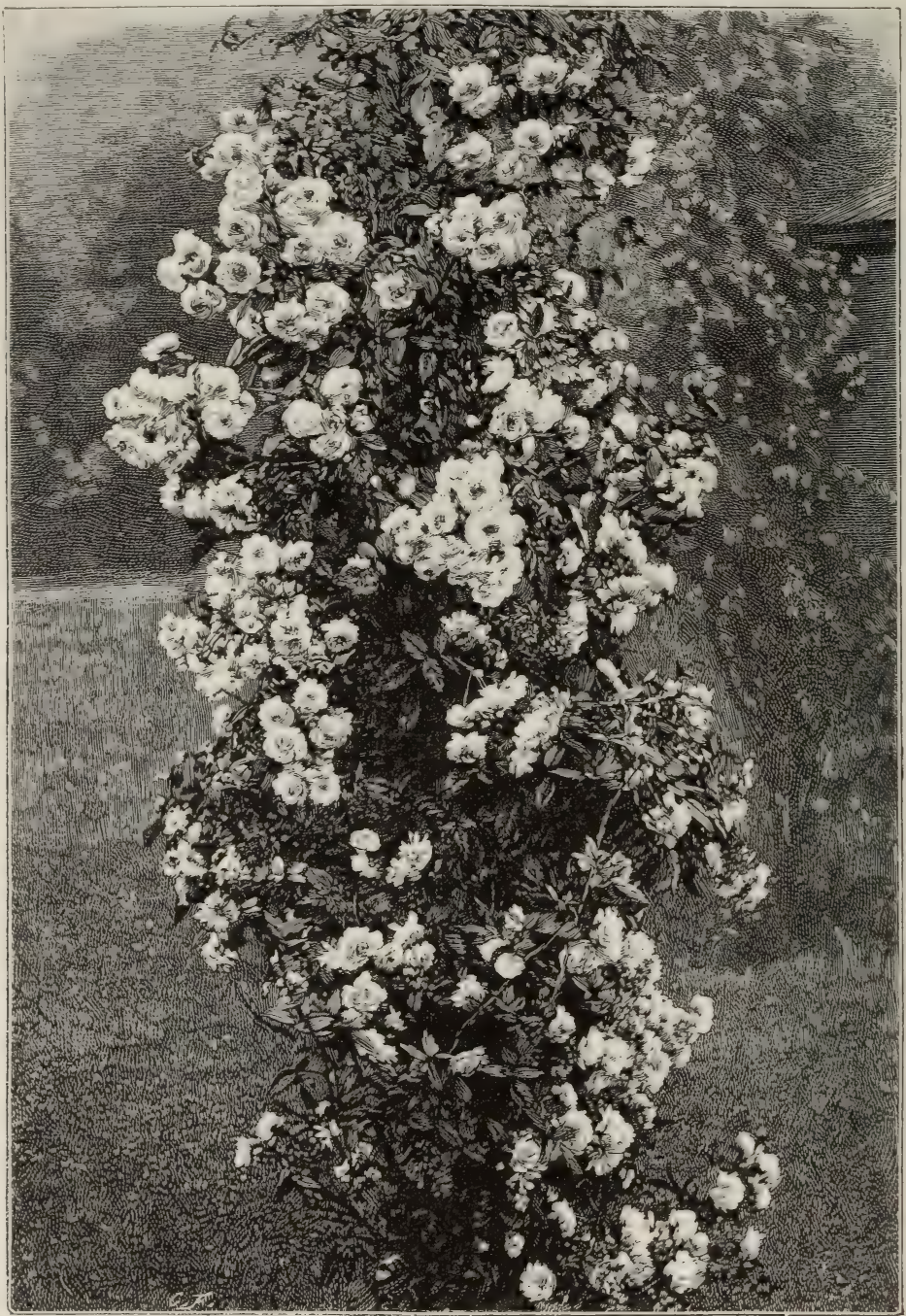

CLIMIBING ROSE, AIMÉE VIBERT.

where the temperature does not fall below zero, is perhaps the best for this purpose. The old semi-double Bourbon Rose, Gloire des Rosomanes, will succeed in warm soils, and light up an arch with its bright red blooms in autumn as well as in summer. The many climbing varieties of H.P. Roses lately raised are good in and seasons. Of these, the palm for general effect is borne away by Ophirie, whose vigour of growth is amazing, and whose glossy sub-evergreen leaves and clusters of apricot blooms contrast exquisitely with the autumn Clematis. For sweetness as well as continuity of bloom Lamarque's clusters of lemon-white flowers 
must stand first. Maréchal Niel, though unrivalled for the splendour of its golden blooms, is only a shy bloomer in autumn. Climbing Aimée Vibert, the only thoroughly hardy member of this section, should be in every garden. Its blooms are small, but its white clusters are so continuously abundant and its foliage is so persistent that it ranks very high as a garden Rose. Rêve d'Or is a delightful climber, in a warm situation, and may be called a climbing Madame Falcot, so bright are its half-expanded buds. There are many other charming Roses in this section, but, as a rule, they do not succeed unless in situations exceptionally good. If some hybrids were raised from $\mathrm{R}$. indica major, the Dog Rose, the single Banksian, and the Japanese R. rugosa, a new race of perfectly hardy climbers might result.

MON'THLY OR CHINA ROSES.-Monthly or China Roses have bright and varied colours, free growth, and hardy constitution, and are most constant bloomers. They are the first to open in the early summer, and often continue to produce their buds and blossoms almost until winter has merged into spring again, a Monthly Rose bush in a warm nook being scarcely ever without at least a bud. They are perpetual and perennial in the fullest sense. A bed I know of the old Blush has occupied its place for more than a quarter of a century, and during the last year or two it had been neglected. This spring the worn-out shoots were cut away, the bed top-dressed, the remaining shoots pegged down, and now, midOctober, they are a mass of fresh growth, buds, and open flowers. Their cultivation is of the simplest ; growing well either in light or heavy soil, preferring that which is light and warm, but not dry. Just in proportion as they are well planted at first and well fed afterwards, so will they grow vigorously and blossom abundantly. Severe pruning is good for them, though on walls, when the earliest possible flowers are wished for, a few shoots may be left their full length. There are a goodly number of varieties, all more or less distinct in colour or habit, from the lovely pumila alba, with its shell-like flowers, and the other pompon varieties which are suitable for the smallest beds or as edgings to small beds, up to the vigorous Crimson Queen or Cramoisie Grimpante, which will climb to the top of a two-storied house and bedeck it with rich crimson flowers during most of the year. The original single China Rose forms a bush $1 \frac{1}{2}$ to $2 \mathrm{ft}$. high; its crimson blossoms, like brilliant butterflies hovering about, are lovely. Then but once removed from these is the free-growing, semi-double, brilliant scarlet-crimson Gloire des Rosomanes. This for a large bed, interspersed with Fellenberg, equally free, and edged with Cramoisie supérieur or Louis Philippe, is most effective. Alfred Aubert, Eugene Beauharnais, Nemesis, Prince Eugène, Prince Charles, and St. Prix de Beuze have crimson flowers of various shades. Beau Carmin de Luxembourg, Belle de Moutza, Confucius, Hermosa, Hebe, and Sanglant are pink or rosecoloured. Lemesle is perhaps the handsomest of this colour, deep pink with crimson reverse, which gradually creeps over and suffuses the whole flower; the leaves of this variety have also great substance. Ducher and Rival de Poestum have white flowers. The latter is particularly beautiful, the flowers not very full, but of charming purity and form, and produced in the greatest abundance. Madame Laurette Messimy is perhaps the most distinct variety which has yet appeared, being unlike in colour any previously-known variety. It is not only unique in colour, but of vigorous growth, and one of the most constant bloomers.

Monthly Roses are also amongst the very best of cottage window-plants. Many are the instances of specimens, scarcely ever repotted, having grown on from year to year until they had filled up all the space and become a living curtain.-T. S.

Moss Roses.-These are far more interesting than some of the minor groups of Roses. Moss Roses are divided into two sections - namely, those which bloom only in summer-that is, during May, June, and July - and the so-called perpetual-flowering kinds. Among the early kinds, the old Common Moss Rose may be found, and beautiful it is. This charming Rose has been grown in English gardens for more than a century, and it still remains one of the best, although it is not seen nearly so much as it might be. In a few gardens I have seen this Rose grown as a standard, but the method is not to be recommended. Far better results accrue when dwarfs or bushes are grown, and these, if possible, on their own roots. It is not generally known that the Common Moss Rose will make twice as much growth and flower more profusely when grown on its own roots than when grafted or budded on a stock. On its own roots it will send out long vigorous shoots, if planted in rich soil, and these should be pegged down to the ground. Some of the other kinds may also be grown on a similar method with advantage. 
In addition to the Common Moss, there is Little Gem, a charming miniature Rose, with small double crimson and well-mossed flowers. Crimson Globe is an acquisition to the Moss Roses, the buds being nicely mossed, large, and of a deep crimson colour. Lanei, too, with large rosycrimson buds, Crested Moss (pale rosypink), Marie de Blois (rosy-lilac), Celina (rich-crimson), Reine Blanche (pure white), Luxembourg (crimson), Baron de Wassenar (bright red), and White Bath (paper-white), are all good. As regards the Perpetual or autumn - flowering Moss Roses, these require much the (bright-rose). The last-named is sweetscented, but not quite so free in blooming as other varieties. Zenobia is a new Moss of satiny-rose colour.-C.

Considering their charms, it is curious how seldom Moss Roses are well grown in private gardens. They are oftenest seen at their best in small gardens, where the owner is kind to his soil. Success with Moss Roses cannot be had except in good rich soil. The Moss Rose is a form of the Provence Rose or "Cabbage," to which the same remarks as to cultivation apply.

AUSTRIAN Roses (Rosa lutea and vars.)--The Copper Austrian Rose, and

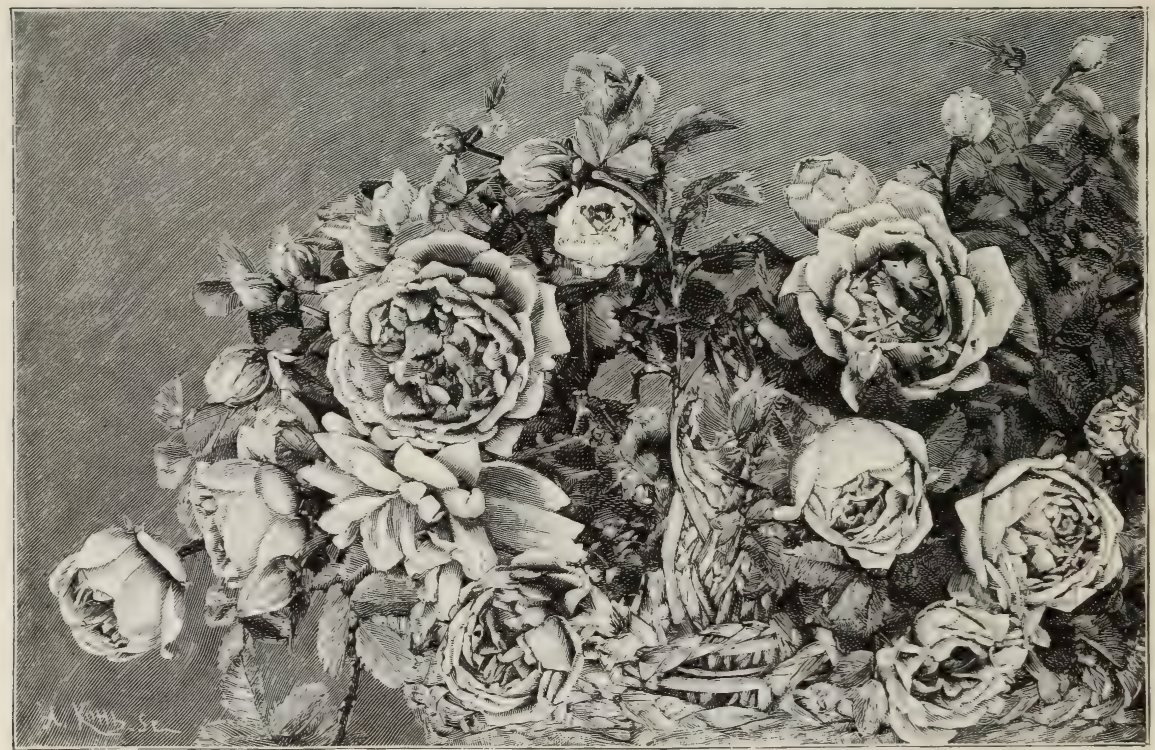

ROSE HARRISONI,

same treatment as the others, and do best in a rich soil. They should be grown for providing flowers after the others have finished blooming. There are many varieties of them, but not a few are inferior, and scarcely worth growing. Still, some kinds are deserving of notice, and one of the best is Blanche Moreau. This is a pure white, and the buds are large, of good form, and well mossed. Madame William Paul is a fine variety with bright rose-coloured flowers, and the same may be said of Madame Moreau, rose-coloured, edged with white. Madame Edouard Ory is one of the best, too, with large rosy-carmine flowers, and the Perpetual White Moss, which blooms in clusters, is also worth mentioning. Other good kinds are Salet, and Soupert and Notting its yellow type, for I have seen both yellow and copper-coloured flowers on one shoot, is one of our hardiest and most distinctive wild Roses. An inhabitant of S. Germany, Austria, and N. Italy, it was in cultivation in 1596 , and it has remained a favourite ever since.

It is best grown as a dwarf, though I have standards in my garden which flower freely, but the slender leafage and short time of flowering hardly render them nice-looking objects for the rest of the year. As dwarf bushes they succeed admirably, growing in any good light soil, either on their own roots or worked; indeed, I think the stock gives an additional root-power, and so leads to stronger and more vigorously pushed-up shoots, the flowers being produced along 
the full length of the. last year's suckers or shoots. Good suckers are very valuable and give the finest blooms. The small wood should, on pruning in March, be cut closely in to the two-year-old wood, the strong wood be left long, and these shoots be bent over in the shape of a bow, or they may be pegged down parallel with the ground their full length. So far this Rose has not given, to my knowledge, any hybrid progeny. It has been tried at Lyons, and Lacharme had it freely planted on the wall upon which he seeded his Roses, no doubt with the hope of the pollen effecting natural hybridisation, but no seedling of his which I have seen showed any signs of hybridisation. In its native home I believe it seeds freely.

As a rock or sunny bank plant it is effective, and should have a sunny southern exposure to ripen the wood. In common with other Roses, the riper the wood the better it flowers. In saying that no hybrids have been produced, I do not forget Harrisoni and Persian Yellow, which are probably double forms of this variety.-GEORGE PAUL, Garden, p. 6oo, I 890.

SCOTCH ROSES.-Varieties of our hardy native Rose, they are as callous to frost and snow, wind and storm, as the proverbial Highlander in his plaid; and, if only the ground be well broken and manured when the plants are first put in, they are better able to take care of themselves than any other Rose of garden origin. If carefully planted at first, they will need neither pruning nor protection, training nor top-dressing, they are not victims of green-fly or mildew, and they may be trusted to thrive for a considerable number of years without special attention. Scotch Roses are not particular as to soil; and, if the soil is poor, a light mulching of short manure in November will keep them in good condition. They should be planted in a place by themselves, when they will throw up their spine-covered suckers freely from the base, and will soon entirely cover the ground; and as they do not grow more than 2 , or at least $3 \mathrm{ft}$. in height, they make a very ornamental mass, flowering freely at every joint. Their very floriferousness tends to make them essentially garden Roses, as opposed to Roses for cutting, for in addition to their innumerable thorns making them uncomfortable to handle, the flowers are so freely produced at every bud that unless an entire spray be gathered they are liable to be inconveniently short - stalked. Scotch Roses are only summer-flowering, but then their delightfully - fragrant flowers come so long before the generality of Roses that they are especially welcome. One of the prettiest and most sweetscented varieties is a perpetual, blooming a second time in autumn. This variety was raised at Stanwell, and distributed by Mr. Lee under the name of the Stanwell Perpetual. In habit and appearance it differs little from the summer-flowering varieties, but its pretty globular blush flowers, of a most delicious fragrance, are freely produced both early and late, and are not uncommonly found in good condition during October.

Numerous varieties of the Scotch Rose have been distributed at various times. Max Singer catalogues about thirty named sorts, chiefly of Prévost and Vibert's raising, but probably few of these now exist, at any rate in this country. Mr. William Paul records some two dozen more named varieties, but these are now hardly ever referred to or even obtainable by name, being as a rule merely described according to colour, as white, pink, yellow, etc. There are, unfortunately, in cultivation many very dingycoloured varieties, which have got these Roses a bad reputation from a decorative point of view. This may to some extent account for the fact stated by the authority above quoted, that Scotch Roses have never really been popular among English amateurs. When only delicately-coloured varieties are grown, nothing can be more charming than a mass of these dwarf, delightfully - fragrant, and very hardy Roses, the buds of which are in miniature the perfection of form-a quality which is maintained in the globular flowers of the more double varieties; while in soils and situations where the cultivation of most other Roses would be hopeless, flourishing plants and flowers in abundance may be had of the Scotch Roses.-T. W. G.

POLYANTHA ROSES.-These are often of a dwarf bushy habit, rarely exceeding a foot in height. The flowers naturally are very small, but delightfully fragrant. Of course, being of a tender nature, these charming little Roses must be grown in pots under glass. They do well in ordinary or unheated greenhouses, and make capital window-plants, providing they have proper attention. Rather small pots are best, and a good-sized plant may be grown in one 5 in. in diameter. A mixture of sandy loam and decayed cow-manure suits them well, and it is advisable to repot in the summer, immediately after the plants have flowered. After repotting, stand the 
plants in a sunny position outdoors until the end of September, when return them to a cool airy position in a greenhouse or frame, where they may remain at rest all the winter. What PRUNING is required should be done early in the spring, just previous to starting the plants into growth, and it consists of cutting the shoots back to within two or three buds of their base. Comparatively little water will be necessary during the winter, but give more liberal supplies in summer, and when showing bloom occasional doses of weak liquid manure may be applied with advantage. Other many-flowered or Polyantha Roses are of a similar character, or, at least, some varieties of them, and deserving of being extensively grown in pots by amateurs.

They possess, however, a hardier constitution than the Fairy Roses, and are most robust in growth. Besides being grown in pots they make charming masses in beds or borders, and are useful for edging Rose-beds. Some nurserymen make a speciality of these Roses, growing them as small standards in pots, and in this manner they are very effective when laden with bloom. They require the same treatment as advised above for the Fairy Roses when grown in pots, and among the best varieties are Anne Marie de Montravel, pure white, very free; minutifolia alba, white, double Daisy-like flowers ; Little Dot, soft pink; Mignonette, pale-rose, very pretty; Perle d'Or, nankeen - yellow; Paquerette, white; Blanche Rebatel; Camille de Rochetaille; Clothilde Soupert; Dr. Reymont, Georges Pernet; Gloire de Polyantha; Golden Fairy; Jeanne Ferron; Josephine Burland; Madame Allegatiere; Marie Pave; Max Singer ; Souvenir d'E. Chatelaine.

There is some danger in taking up seriously new classes of Roses of this kind, because there are very few that are not inferior in beauty to the lovely Tea and other Roses which are now obtainable. Roses that have not the finest forms, and are unfit for cutting for the house, are likely to take a back place, and really deserve it.

THE BAnKsia Rose (Rosa Banksiæ) is a native of China, named in honour of Lady Banks by the botanist Robert Brown. It was brought to England in I807. The flowers are small, in clusters early in the season, and have a violet perfume. The wood is very smooth, slender, and of rapid growth. The leaflets are often but three in number, are long, dark, and lustrous. The best-known sorts are Alba Fortunei, white and yellow. They should be sparingly pruned.
The Banksian Roses require a warm wall and dry border, with two or three years' growth to bloom in perfection; they are then very beautiful. They should be pruned very little, merely cutting out a few of the old already-bloomed shoots, and any late-growing sappy wood about July. They are very precious for covering house walls in many parts of England, but are not so good on wet and hilly places.

The primary requirements of Banksian Roses are a south wall and warm dry borders. Given this, they will not fail to prove satisfactory; but I would warn the inexperienced against planting them in wet shady positions. Exercise some care in the selection of the site. See that the wall on which the plants are to be trained is facing south, or nearly so, and that it gets plenty of sun. If the soil is bright and dry, so much the better; but where such is not the case a remedy can easily be found. Should it be rather heavy and damp, excavate to the depth of $2 \mathrm{ft}$. or so, and the same in width; place a thick layer of broken bricks in the bottom of the hole, and on this some turf-sods, Grass-side downwards, filling up, as the planting proceeds, with some good turfy loam, and treading the whole moderately firm. Banksian Roses require very little pruning. Many people prune their Banksians as they would other Roses, with the result that they seldom bloom satisfactorily. All the pruning necessary is to cut out a few needless shoots about midsummer, or immediately after the plants have flowered. Remove any growths that have been injured by severe frosts during the winter, but beyond that no spring pruning is needful.

The PrRARIE Rose (Rosa Rubifolia) is much the most valuable of all the nonremontant climbers. It is found in Michigan and many of the W. American States. The foliage is rough, large ( 5 to 7 leaflets), generally of a dark green colour ; for rapidity of growth they equal or excel the Ayrshires, and surpass all climbers in hardiness. They bloom in large clusters late in the season, when other summer Roses are past and have gone their way, and succeed over a greater extent of territory than any other climbers. Although inferior to the Noisettes and Climbing Teas, their hardiness and vigour make them of value where the more beautiful Roses are too delicate. When, then, it is desired to cover walls, old trees, unsightly buildings with Roses, none will be found to do the work so efficiently as varieties of the 
Prairie Rose. It is very desirable that further development of this important class should be made; we should endeavour, by artificial fertilisation, to produce hybrids, blending Hybrid Perpetual, Bourbon, and Noisette with the Prairies.

The best of the class are Anna Maria, Baltimore Belle, Gem of the Prairies (the only variety that is fragrant), Queen of the Prairies, and Triumphant. Baltimore Belle is the most beautiful, and seems to contain some Noisette blood, which makes it less hardy than the others ; it is sufficiently robust, however, to withstand all ordinary winters. The Prairie Roses, like all climbers, should be sparingly pruned.-H. B. Elwanger, The Rose.

NOISETTES.-This group is a cause of much confusion, owing to some of the most important kinds in it being often classed with the Teas, even in catalogues which class them as Noisettes. We therefore omit Roses such as Bouquet d'Or, which we group among the Teas. They bloom long and well in clusters, grow freely, and are fragrant and useful for climbing or pillar Roses. The following are some:-Aimée Vibert, Celine Forestier, Cloth of Gold, Cornelia Koch, Desprez à Fleur Jaune, Fellenberg, Grandiffora, Isabella Grey, Jeanne d'Arc, Joseph Bernacchi, La Biche, Lamarque, Duchess of Mecklenburg, Madame Carnot, Madame Alfred Carriere, Madame Caroline Kuster, Madame Massot, Ophirie, Solfaterre, Triomphe de Rennes, Unique Jaune.

THE DAMASK Rose (Rosa Damascena) is a native of Syria, whence it was brought to Europe about 1270 by Thibault IV., Count of Brie, returning from a crusade in the Holy Land. In Syria this Rose is so common that there is a valley called the "Valley of Roses." It is a parent of the Hybrid Red Roses. The Damasks have pale green leaves ( 5 to 7 leaflets), green shoots, with numerous spines, are of free growth, and hardy; the flowers are pretty in form, and very fragrant. They need but little pruning.

Among the kinds, besides the common one, are La Ville de Bruxelles, Leda, Madame Hardy, Madame Stoltz, Madame Zoetmans, York and Lancaster (true).

The Provence Rose or Cabbage Rose. -Of this the origin is not known, but growing abundantly in Provence, it has received that name, though the French themselves always call it Rose à Cent-Fevilles. Their habit is straggling, the foliage massive; the flowers are generally of globular form and of fine scent. These Roses demand good culture and close pruning.
"The rosarian should devote a small bed of rich soil, well manured, to the cultivation of this charming flower, growing it on its own roots, and pruning closely. The Double Yellow Provence Rose, of a rich, glowing, buttercup-yellow as to complexion, and prettily cupped as to form, full of petal, but of medium size, has almost disappeared from our gardens, and I have only seen it at the Stamford shows, sent there from Burleigh. Although common at one time in this country, it seems never to have been happy or acclimatised."-DEAN HOLE.

BOURBON ROSES are among the most useful of garden Roses. They seem somewhat capricious, with the exception of Souvenir de la Malmaison, which, however, is often placed among other Roses. There is no hard and fast dividing line between them. Among the best kinds are-Mrs. Paul, Armosa, Gloire de Rosomanes, Madame Isaac Pereire, Queen, Sir Joseph Paxton, Souvenir de la Malmaison, Empress Eugénie, Kronprinzen Victoria, Madame Baron Veillard, Marquis Balbiano, Mrs. Bosanquet, President de la Rocheterie.

Alba Roses(R.alba).- The Alba Roses form but a small section, but are, from their: delicacy of colouring, interesting. They are distinct and surpassingly beautiful, as blush and flesh-coloured Roses almost without equal. They thrive under ordinary cultivation. The moderate growers should be pruned closely, the others moderately. Blanche Belgique, Belle de Segur, Celestial, Felicité (Parmentier), Madame Audot, Madame Legras, Maiden's Blush.

EVERGREEN ROSES (R. sempervirens). - These are Climbing Roses, blooming in large clusters of from ten to fifty blooms each, and holding their dark green shining foliage through a great part of winter; they are free growers and quite hardy. In pruning, the head should be thinned out, a few of the more pendent shoots being left their whole length. Donna Maria, Felicité Perpetue, Flora, Leopoldine d'Orleans, Rosea plena.

Gallica (R. Gallica).-This is an old group, that used to be important, but is no longer so in consequeuce of the splendid Roses of other kinds that have been raised. These Roses are of increased beauty under good cultivation. They may be distinguished by their stiff erect growth. The flowers are remarkable for their varied hues and fragrance. They require close pruning. The striped varieties of this section (Rosa Mundi, etc.) are often called York and Lancaster. 
The following are the best known :Boula de Nanteuil, Blanchefleur, Cynthie, D'Aguesseau, Duchess of Buccleuch, Kean, Eillet Parfait, Ohl, Perle des Panachées, Rosa Mundi, Village Maid.

Ayrshire Rose (Rosa Arvensis vars.) - These roses, of native origin, are of rapid growth, often running 15 or $20 \mathrm{ft}$. in one season, and are of use in covering rough buildings, unsightly banks and trees. They do not require rich soil, and should be pruned very little, or not at all. Bennett's Seedling, Queen of Ayrshire, Queen of Belgians, Ruga, Dundee Rambler, Splendens, and Virginia Rambler, are the best known sorts. it can have one. Its Japanese variety (R. Camellia) is equally attractive ; but the palm for hardiness and decorativeness in exposed situations must be given to another Japanese Rose (R. rugosa), which is exceedingly hardy even by the sea, enduring the bitterest frost, and braving the keenest winds. This rose is now well known; and its white and purplered varieties are to be found in many gardens, where its large and handsome fruit is seen in autumn. Persia has given us the Persian yellow; but it is from the Levant that we obtain that most perfect of all Roses in colour and shapeR. sulphurea. The despair of many a

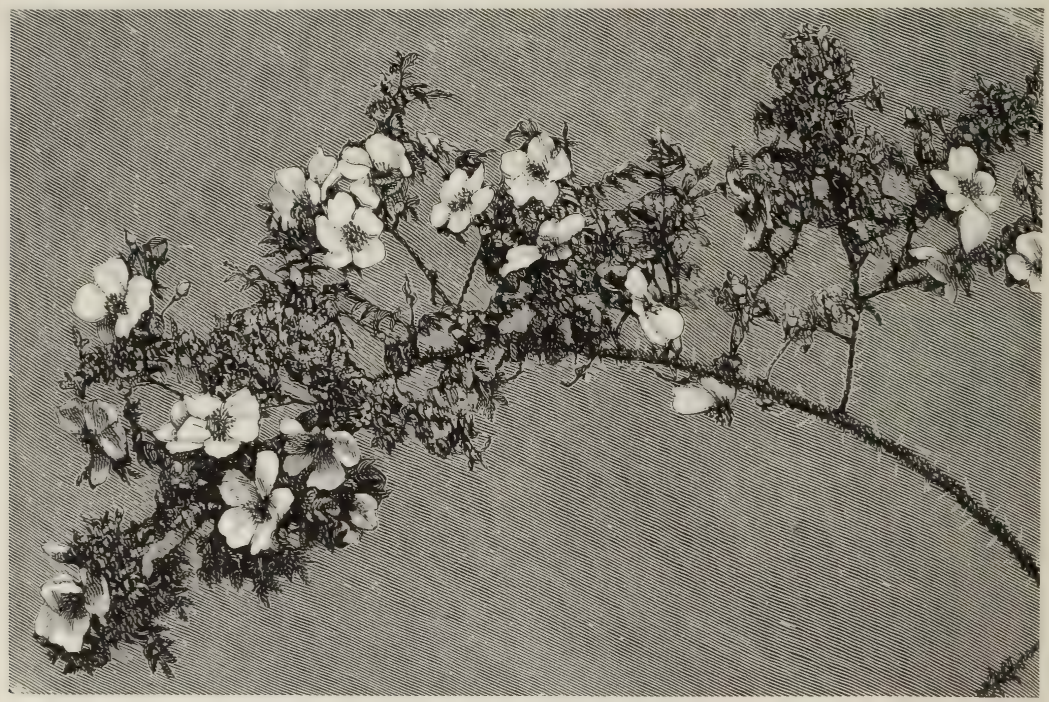

ROSA SPINOSISSIMA.

Boursault Rose (Rosa Alpina).This is a distinct species, but its varieties form a worthless group, which receives its name from M. Boursault. Most of the varieties are free from thorns and have long reddish shoots. Amadis is most grown. It is one of the groups of roses not worth keeping up.

Wild Roses. - No one who has seen the dainty Cistus-like spotted blooms, glossy leaves, and dwarf growth of the yellow Persian R. berberifolia, will neglect to give it the sunny but somewhat dry situation in the rockgarden that suits it best. The single Macartney Rose (R. bracteata), with its large white single flowers and orange stamens, though less hardy, is even more charming in foliage and more vigorous in growth, and deserves a wall whenever cultivator, its glaucous-blue leaves and pure golden globes of bloom can never be forgotten by those who have seen it in all its beauty. No doubt where heat and sunshine are reflected from rocks there is a greater chance of flowering this beautiful low-growing Rose than in the Rosegarden. R. lutea, the single yellow, and R. punicea, the brilliant Austrian Brier, are also rock-garden Roses. $R$. alpina is sometimes so richly coloured as to adorn any situation, and it has very handsome hips. R. pyrenaica, a tiny form of this species, is already a favourite in many places, and bears long handsome fruits after its short-lived flowers. The Scotch Rose (R. spinosissima), with its white flowers, is not unworthy a place in the rough rock-garden and on sandy banks, and its double varieties thrive in situations 
where no other Rose could exist. The Sweet Brier (R. rubiginosa) deserves a place beside it for the sake of delicious fragrance, bright hips, and pretty flowers. A Japanese Rose, lately introduced - the Bramble Rose ( $R$. polyantha) - may be planted for its distinct habit and its thyrsoid heads of white flowers. It is, however, much to be hoped that a greatly superior Chinese variety, with larger flowers, larger growth, and more goldenyellow stamens, may soon be introduced, as in its native country it thrives anywhere and stands severe frost. The little Fairy Rose, R. Lawrenceana, is very pretty in the rock-garden, where it gains the needful warmth and protection. R. microphylla is very quaint in flower and fruit, and its double form will give a good effect in the Wild Rose garden, if it has a fair amount of shelter.

SYNONYMS OF ROSES.-The following Roses bracketed together have been regarded as synonymous, according to the rule adopted by the National Rose Society; and the name standing first in each case, being believed to be the original one, is considered as the true name of the Rose, and the one that should stand.
(Charles Lefebrre.
$\{$ Marguerite Brassac.
( Paul Jamain.
(Monsieur Boncenne.
$\{$ Baron de Bonstettin.
f Marichal Vaillant.
$\{$ Avocat Duvivier.
fugénie Verdier.
Marie Finger.
f Amadis.
$\{$ Crimson Boursault.
f Duchesse de Caylus.
$\{$ Penelope Mayo.
I Prince C. de Rohan.
La Rosière.
f Marie Rady.
$\{$ Comtesse de Choiseul.
Maurice Bernardin.
Ferdinand de Lesseps.
Sir Garnet Wolseley.
Exposition de Brie.
f Thoresbyana.
\{ Bennett's Seedling.
Devoniensis.
\{ Climbing Devoniensis.
f Adam.
$\{$ President.
Sadame Bravy.
Madame de Sertot.
Alba Rosea.
Josephine Malton.
f Fortune's Yellow.
\{ Beauty of Glazenwood.

Planting. - Heavy soil suits Roses best. With plenty of manure, a sandy soil may produce a few good blooms in the first season, but that will be all; therefore sandy soil should be used as little as possible. Nor does very old worn-out soil grow Roses well; and, where the bed is of very old worn-out soil, a good deal of heavy loam should be added. When the plants have to be put back in the bed, they should be lifted out carefully and laid in stock until it is ready for them, for it is destructive to allow them to become dry at the root through being out of the ground. If Rose blooms of the finest "show" form are wanted, all the old soil should be taken out, and the bed filled up wholly with new loam, and in all cases the new soil should be got in, and the beds thoroughly prepared, before planting. Put new soil in first, make the bed up with it, and dig in the manure afterwards. The soil ought to be at least $2 \mathrm{ft}$. deep, but the manure should not be put down at this depth, as that would tend to draw the roots downwards - a bad result. If the manure is close to where the roots are to come, it is in its proper place. Roses like manure, but when it is put in so thickly as to lie in lumps and heaps under the surface it is injurious, and the greatest benefits are to be had from it only when it is well mixed in with the soil. The poorer the soil the more manure must be given. It should always be of the best quality. Half-rotten straw and leaves are no good ; heavy pig or cow manure is the best. Make the hole big enough to take the roots comfortably. The roots should not be inserted in a bundle, nor should one be placed without care above another, but kept spaced apart. Rose-roots ought to radiate from the centre and to spread out well, but the long thick fibreless roots of old plants should be cut carefully in to within 8 or Io in. of the base of the stem. Deep planting should be avoided. Let the roots be covered with about 3 in. soil and no more. If the roots are let down a foot or more to keep the wind from blowing them away, the plants will neither grow nor bloom well. Make the soil fine round and over the roots. As the roots should not be moved after planting, standards and dwarfs should alike be tied to firm stakes. A good coating of half-decayed manure should be placed over the beds. Individual plants well grown are more pleasing than a crowd and confusion.

PRUNING. - Even moderate-growing Roses make several feet of wood a year, 
and need restraint if more than a few are to be grown. No doubt there is a strong tendency to plant Roses too closely together, and a good many gardens would look richer and better were fewer Roses allowed to grow large; but while the present modes of growing continue, a considerable amount of pruning is needed to keep each plant in its place. On most Rose-shoots there are probably from six to a dozen blooms in embryo. Were all these allowed to remain they must necessarily be smaller than if only one or two were allowed to develop into flowers. Pruning, so far as it reduces the number of flowers, concentrates the force of the plant, and heightens the colour and enlarges the size of the Roses. This is so obvious as to need no proof. The shoots of summer Roses, such as the Cabbage Rose and the Moss Rose, are spurred back to two or three buds, or even less, and each of these buds produces one or more flowers of better quality than if left intact. The same principle is kept in view in the pruning of other Roses, though in some varieties feet or even yards of young wood may be left instead of eighths or quarters of an inch.

In shrubberies, and in woods, and in the case of Roses isolated on turf the more the trees or bushes are left to themselves to wander as they list, the more artistic and beautiful is the effect; but generally in gardens Roses must be pruned into form and kept in shape afterwards with the knife. No doubt many of them are over-pruned, and not a little of the beauty and all the grace is cut out of them. Still it need not be so. Pruning can heighten beauty as well as mar it. And then we prune for vigour as well as form. By cutting out exhausted branches we cause young and more vigorous trees to spring from their base, and thus we force the Rose to renew its youth. The removal of weak, worthless, unsightly, and dead wood improves the appearance and health of our Roses; and a branch that has failed should be pruned out before it becomes diseased.--E. W.

Rose HEDGES.- "If the soil is naturally a good Rose soil, the work will be light. In that case mark out the position of the hedge $2 \mathrm{ft}$. wide, trench up that space $2 \mathrm{ft}$. deep, and incorporate with the soil at various depths a liberal quantity of wellrotted manure. Where there is any doubt about the staple being of the right sort, the whole of it should be removed, and its place supplied with a mixture consisting of three parts loam and one of manure. There are, however, many gardens the soil of which, with the addition of one barrowful of loam to every yard length of hedge, and about half that quantity of manure, will grow Roses in a satisfactory manner. When practicable, the preparation of the ground should be done in dry weather, as there is some danger of the loam running together in heavy masses if moved about when it is wet. Plants on their own roots are indispensable for this purpose, and if they can be had from 2 to $3 \mathrm{ft}$. high so much the better, as they will form a hedge the sooner. Those that have had one season's growth in pots and another in the open ground are what we have used; these have been two years planted, and some of them have this year made shoots $2 \mathrm{ft}$. long. Thoroughly hardened and established plants in pots may be used in the absence of others. The time of planting must depend on the condition of the plants, but, if only small plants in pots are to be had, the planting should be done in April or May. In any case it should be done when the soil is moderately dry, and some finely-sifted mould should be prepared to place round the roots, about which the ground should be made moderately firm. Deep planting must be avoided. The crown should be about 2 in. under the surface, as the soil will afford it some protection during severe weather. As soon as the planting is done, some support should be given to the branches; a neat stake and a strong tie will prevent them from being blown about by the wind. Place a layer of short rotten manure over the roots; this should be 3 in. thick, and $\mathrm{I} \mathrm{ft}$. wide on each side. During the first two years very little pruning will be necessary. The second spring after planting, any strong shoots that exceed $3 \mathrm{ft}$. in length should be cut back to that point. In the ground should be placed a few neat sticks, to which some of the lower branches should be tied to form the base of the hedge and bring it into shape. After the second year the growth will gain more vigour and increase in length. The strongest shoots should be cut down to $4 \mathrm{ft}$. the third year, and from that time the height should be allowed to increase slowly, so as to give the lower branches time to fill up the base. Some supports will be necessary to keep the growth in shape. The after-management consists in giving the roots a good dressing of rotten manure every winter. I find the best plan is to rake away the soil from over the roots, lay the manure on them, and then replace the soil. It seems hardly neces- 
sary to say that the plants will be greatly benefited by copious supplies of water, especially during the first two years after planting."

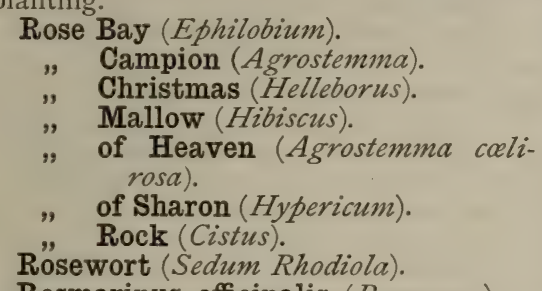

Rosmarinus officinalis (Rosemary).This well-known shrub should always have a place in gardens. It is hardy enough to grow in any ordinary soil. In the embellishment of dry, warm, rocky banks it is useful ; all like its fragrance, and the flowers are pretty and plentiful on dry soils.

\section{Rosy Rock Cress (Arabis blepharo-} phylla).

Rubia. - Plants, weedy for the most part. Our native species, R. peregrina, is as handsome as any on account of its deep vinous-purple foliage; its slender shoots are useful for arranging with flowers in winter. Rubiacer.

Rubus (Brambles).-With the exception of our native Bramble, all the important garden Brambles are from North America; the finest of the American kinds is unquestionably the Rocky Mountain Bramble, than which there are few lovelier hardy shrubs. It is quite unlike an ordinary Bramble, being without spines or prickles, and more resembling the Black Currant. It makes a rounded spreading bush about $4 \mathrm{ft}$. high, and, in June, bears flowers of snowy whiteness, about the size of Dog Roses, and resembling them in form. It is quite hardy in most gardens where the soil is light. In cold districts it may be grown against a wall, which it quickly clothes with a beautiful growth, and flowers more abundantly than when planted as a bush. It is worthy of the best attention, and should be more frequently planted.

R. odoratus is 3 to $8 \mathrm{ft}$. high. It has large-lobed leaves, and from June till August bears large clusters of rich purple flowers. It is extremely robust, but as it requires a great deal of space it should never be crowded. It may be used with good effect in the rougher parts of the rock-garden, or in the wild garden. Its relative the White-flowering Currant ( $R$. nutkanus) strongly resembles it, but is weaker, and has white flowers instead of purple. If planted near each other, the two would in time make a beautiful mass. The Salmon Berry (R. spectabilis), from North-west America, is less important than the other two, though its flowers, generally produced singly, are large and a bright red. Like the other two, it is suited for the rougher parts of the rockgarden or for the wild garden. The White-washed Bramble ( $R$. biflorus, or R. leucodermis), from the Himalayas, is a singular but not unattractive shrub. Its tall wand-like stems often reach Io $\mathrm{ft}$. or more in height, and are whitened with a mealy substance on the bark. Its white flowers are not particularly showy, and are succeeded by edible Raspberry-like fruits which are pleasantly acid. R. australis, from New Zealand, is hardy enough for wall-culture. It is devoid of true leaves, and is excessively prickly, but, being so curious, always arrests attention. In warm situations it grows several feet high. The beautiful $\mathrm{R}$. rosæfolius (Rose-leaved Bramble), from the Himalayan region, is scarcely hardy enough for open-air culture except in the most favoured spots or against sunny walls. Its double variety (coronarius) alone is worth growing. It has loose clusters of large white flowers, which are very double, and is often grown as a greenhouse shrub on account of its profusion of bloom. Almost the only native Brambles worthy of our notice are the beautiful double varieties of $R$. fruticosus, which are of particular value for the garden, as they flower late in summer when very few shrubs are in bloom. There are the double pink and the double white kinds, both of which are known under various names, such as pomponius, flore-pleno, and bellidiflorus, or Daisyflowered; but for practical purposes, the names of double pink and double white are sufficient. As they are forms of distinct species or varieties, they differ in habit, the double pink being much the stronger and flowering more freely. Under favourable conditions the double pink makes a wide-spreading mass like the common Bramble, and produces from the middle of August till autumn an abundance of bloom, every flower being a perfect rosette of delicate pink petals. The double white is a form of $R$. tomentosus, and its flowers are larger than those of the double pink, but less double. The double white and the double pink should be planted near each other, and are admirable for clothing banks or associating with bold rocks, natural or artificial. Another fine Bramble is the Cut-leaved, or Parsley-leaved Bramble. 
It bears a profusion of white bloom, succeeded by large delicious fruits, and it has elegant growth and foliage. Some of the so-called American Blackberries, such as the Lawton and Kittatinny, do not thrive or fruit in our country.

A few of the small kinds, such as $R$. arcticus (which grows a few inches high and bears numerous rosy-pink blossoms), the Cloud-berry, R. Chamæmorus (also dwarf and with white blossoms), and $R$. saxatilis, are very pretty. They are excellent for partially-shaded spots in the rock-garden in moist peaty soil.

Rudbeckia (Coneflower). - North American Composites, with showy yellow flower-heads, which usually have a dark centre cone. All are hardy perennials, except R. bicolor, but there is so much similarity between them that, except in full collections, the best only should be grown. One of these is R. speciosa, also called Obeliscaria speciosa and R. Newmani. The flowers of this are of a rich orange-yellow, with conspicuous, velvety, maroon centres; they are from 3 to 4 in. in diameter, and are borne profusely in dense masses from early in August till late in October. The height of the plant is 2 to $2 \frac{1}{2} \mathrm{ft}$., and its habit is neat and compact. It is easily cultivated, flourishing in any ordinary garden soil, but best in soil which is moderately rich, light, and well drained. It forms a very gay bed during summer and autumn. To make up for its autumn-flowering, blue branching Larkspur, planted alternately in the same bed and pegged down, has a good effect. The foliage of the Delphinium lightens up that of the Rudbeckia, and it comes early into flower. When both plants are in bloom they look well. The Rudbeckia may be easily and rapidly increased by division of the roots. When fairly established, annual top-dressing is all that it requires, but, like all herbaceous plants, it enjoys good fresh soil, and when crowded should be broken up and replanted. Among other showy kinds are R. hirta, R. subtomentosa, R. pinnata, and R. laciniata, but R. speciosa is better than any of these. The annual R. bicolor has a dwarf branching habit of growth, while its bright yellow rays and blackish-purple discs afford an effective contrast of colour. It grows about $\mathrm{I} \frac{\mathrm{I}}{2} \mathrm{ft}$. high. The flowers dre about 3 in. in diameter, and closely resemble those of $\mathrm{R}$. speciosa. It is of easy cultivation in any soil as a halfhardy annual. It blooms in July, and continues in flower till late in autumn. As a free-blooming and showy annual it can be recommended. Texas. $\mathrm{R}$. purpurea is synonymous with Echinacea purpurea.

\section{Rue (Ruta).}

Rue Anemone (Thalictrum anemonoides).

Rumex (Dock).-The only one worth growing is our great native Water Dock (R. Hydrolapathum), a very large plant, and sufficiently striking to entitle it to a place amongst ornamental subjects by the water-side. Its leaves, sometimes 2 ft. or more in length, form erect tufts of a very imposing character; while its flowering stem, frequently $6 \mathrm{ft}$. in height, bears a very large, dense, pyramidal panicle of an olive-fawn or reddish colour. Though always striking in appearance, R. Hydrolapathum is most effective in autumn, when the leaves change to a lurid red, which colour they retain for some time. A root or two deposited in the mud near the bank of a pond or a slow stream will require no further attention.

Ruscus (Butcher's Broom). - Ornamental and curious plants, well worth a place in gardens. With one exception, they are hardy, and are distributed throughout Europe, North Africa, and temperate Asia. All the hardy kinds are useful for planting under the drip and shade of trees where few other evergreens could exist. The most ready method of propagation is by division of the roots. The R. aculeatus (Common Butcher's Broom) is the best known. It is a native of our copses and woods. It has curious prickly leaves, or rather substitutes for leaves, and its small greenish flowers appear in April and are succeeded by bright red berries about the size of Peas. This dense, much-branched Evergreen rarely attains a greater height than $2 \mathrm{ft}$. Its thick, white, twining roots strike deep into the ground, and when once established, even under apparently adverse conditions, it grows freely. The Alexandrian Laurel (R. racemosus) is an elegant shrub with glossy dark green leaves. It is not nearly so dense as R. aculeatus, but it is about the same height. Its stems are very valuable for cutting from either in winter orat any other season; and it should therefore be extensively grown. It is one of the best plants for partial shade, and flourishes best in deep loamy soil, but thrives admirably on chalk. S. Europe R. Hypophyllum, a very dwarf kind, and R. Hypoglossum are fit only for botanical collections.

\section{Rush (Juncus).}

Rush, Flowering (Butomus). 
Rush Lily (Sisyrinchium).

Ruta (Rue).-The common Rue (R. graveolens) is not ornamental, but two other species deserve attention. $R$. albiflora is a graceful autumn-flowering plant about $2 \mathrm{ft}$. high. Its leaves somewhat resemble those of the common Rue, but are more glaucous and more finely divided. The small white blossoms, borne profusely in large terminal panicles, which droop very gracefully, last until sharp frosts curtail their beauty. In some localities it is quite hardy, but, unless planted against a wall, it should generally speaking have some slight protection in severe weather. It is also known as Bonninghausenia albiflora. Nepaul. Another pretty plant is the Padua Rue ( $R$. patavina), 4 to 6 in. high, with small golden-yellow flowers, which have the same odour as the common Rue. It is of about the same degree of hardiness as R. albiflora.

Sabbatia (American Centaury). - A lovely genus of $N$. American plants of the Gentian family. The species introduced are $-\mathrm{S}$. chloroides, with large pink flowers; S. campestris, with light rose flowers; and S. angularis, with purplishred flowers. The variety $\mathrm{S}$. angularis alba, also in cultivation, has white flowers. The plants are not difficult to manage, provided the habitat of each species be imitated as nearly as possible. S. chloroides, being found in bogs, requires a very moist position; $S$. campestris, an open and a drier place; S. angularis, a sheltered situation and partial shade, in imitation of that afforded by the vegetation amongst which it grows wild. The soil should consist of equal parts of good fibry loam and finely-sifted leaf-mould, with enough sand to make it open. Seed, which should be sown in summer. The seedlings should be potted off before they become in the least drawn, or they will make weak plants. They should be wintered in a cold airy frame. In spring repeatedly stopping the shoots will induce them to form bushy plants before flowering. All these kinds are biennial, and plants should be raised annually.

Saccharum ægyptiacum.-A vigorous perennial Grass. It forms ample tufts of reed-like downy stems, 6 to Io ft. high, and is clothed with graceful foliage. It is suited for the margins of pieces of water and for pleasure-grounds, and requires a warm position. In our climate it does not flower, but even without its fine feathery plumes it is still rendered a pretty plant from its foliage and habit. It is easily and quickly multiplied by division in spring. The offsets should be started in a frame or pit. In May or June they may be planted out when established. N. Africa. S. Maddeni is a quick-growing hardy perennial, about 5 ft. high. It has handsome foliage, and is well worthy of association with other large Grasses.

\section{Sacred Bean (Nelumbium).}

Safflower (Carthamus tinctorius).

Sage (Salvia).

Sagina (Pearlwort).-The only species worthy of culture is the Lawn Pearlwort (S. glabra), a plant very generally known in consequence of being much talked of a few years since as a substitute for lawn Grass, though it has not answered the expectations formed of it. It is none the less a very beautiful little alpine plant, forming on level soils carpets almost as smooth as velvet, and these in early summer are starred with pretty little white flowers. It is most readily multiplied by pulling the tufts into small pieces and then replanting them a few inches apart. They soon meet and form a carpet. It is also readily increased by seed, but this mode of propagation is rarely worth resorting to, unless a large stock for lawn-making is desired. Although S. glabra does not generally form a permanent or satisfactory turf, yet by selecting a rather deep sandy soil a turf may be made, but it must be kept perfectly clean and well rolled. This is, however, rarely worth attempting, except on a small scale. When the plant begins to perish in flakes, it should be taken up and replanted. It is very commonly grown under the name of Spergula pilifera. High mountains in Corsica.

Sagittaria (Arrowhead).-Handsome aquatic plants of the Water Plantain family (Alismaceæ). The most familiar species is our native Arrowhead, which is known by its arrow-shaped leaves and tall spikes of white blossoms. Its double variety is very handsome, and is by far the most desirable, as its blossoms last much longer. S. heterophylla and S. obtusa, two N. American species, are scarcely so handsome as the British kind. The Arrowheads should never be excluded from artificial water; they grow best in water $\mathrm{I} \mathrm{ft}$. deep, if their tubers are planted in mud.

Sainfoin (Onobrychis).

St. Bernard's Lily (Anthericum Lilago).

St. Bruno's Lily (Anthericum Liliastrum). 


\section{St. Dabeoc's Heath (Menziesia poli- folict).}

St. James' Flower (Lotus Jacobcus).

St. John's Wort (Hypericum).

Salisburia adiantifolia (The Maidenhair Tree).-Beautiful as is the Maidenhair Tree in all stages and at all seasons, it is perhaps most attractive during the autumn, just before the leaves drop, since the foliage assumes then a bright goldenyellow, without any suspicion of that red or crimson which is more or less pronounced in the autumn tints of most trees. Although to an ordinary observer it differs very much from the Conifers, it really belongs to that extensive order, and is one of the few deciduous members of it. It might with advantage be more frequently planted for ornament, for it forms a handsome specimen, very distinct from any other hardy tree. Its peculiarlyshaped leaves (from which its name is derived) form an interesting feature. Probably its scarcity is to a certain extent accounted for by its not being very readily propagated, and by its making slow progress during its earlier stages: since, on this account, it is not popular in nurseries. After a time, however, its growth is fairly rapid, though it is never a quick-growing tree. A rather deep, fairly moist soil of a loamy nature seems just to meet its requirements, but it is not very particular as to soil; for a fine specimen grows on the shallow gravelly subsoil of Kew. As a lawn tree S. adiantifolia is seen to very great advantage, the whole of its prominent characteristics being then very noticeable. Its fruits are said to be eaten in China and Japan, but they are rarely produced here. In the first place the tree must attain a good size before bearing fruit; and secondly, being diœecious, the male and female flowers are borne on separate trees, and most of the larger specimens seem to be males. There are two or three varieties of the species, and, when raised from seed, there are frequently individual differences in the progeny. The recognised varieties are macrophylla, with leaves larger than the ordinary form; variegata, seldom constant in character; and pendula, with more or less drooping branchlets. The typical kind is better than any of them. The Salisburia is also known as Ginkgo biloba, and was introduced over a century ago.

Salix (Willow).-There are no trees in the world more beautiful for our country than our own Willows, such as the white Willow, the Osier, and its scarlet-barked variety called the Cardinal Willow, and also the Weeping Willows of various kinds; all of which, though they cannot be grown with flowers, should often come into the garden picture, not only beside water, but in other situations not too near the flowers. Some minute alpine Willows are interesting for the rock-garden or the margins of beds of dwarf shrubs, but they are more suited for botanical collections. . The dwarf creeping kinds grown in gardens are-S. herbaceæ, S. lanata, S. reticulata, S. retusa, and S. serpyllifolia, all natives of the northern parts of Europe and America. They grow well among stones in ordinary garden soil.

Salpiglossis sinuata. - A beautiful member of the Solanum family, and one of the finest of half-hardy annuals. It is slender, and has an erect stem, I to $2 \mathrm{ft}$. high, bearing large funnel-shaped blossoms resembling Petunias. They are beautifully feathered, and have dark veins on a ground which varies from white to crimson, yellow, orange, or purple, and every intermediate shade. As the colour of the blossoms is so variable, the plant is known as $S$. variabilis, and its varieties have Latin names according to their tints. It is difficult to make a selection, but a packet of mixed seeds will produce a wonderful variety of colours, and will yield a fine display. This display will last from late summer till autumn. S. sinuata thrives in light, rich, sandy loam, and should be treated as a half-hardy annual. Chili.

Salvia (Sage).- Though the Sages constitute one of the most easily recognised of all genera, they are exceedingly diverse in their duration, in the size and shape of their leaves, and in the colour of their flowers. They are found in almost all sub-tropical and temperate countries, but they occur principally in the mountains of Tropical America and in the countries bordering on the Mediterranean Sea. The best hardy sorts are from the Mediterranean region, and the showiest kinds are from the mountains of Tropical America, especially those of Mexico. Few of the Mexican species are really hardy, but many of them are among the best autumn and winter ornaments of the conservatory and the greenhouse, while, during summer, others are exceedingly effective in beds and borders. Few of the Sages require special treatment. The herbaceous perennials may be rapidly propagated by division or seed, and the half-shrubby species by cuttings of the young soft shoots in heat. The hardy perennial species require only a little care 
in the selection of a suitable situation and soil, but they are few in comparison with the half-hardy kinds. One of the handsomest of the hardy sorts is $\mathrm{S}$. pratensis, a native species sporting into several varieties, which differ from each other in colour, and are called alba, rubra, bicolor, etc. S. sylvestris is even handsomer, and has long showy spikes of deep purple flowers. The well-known S. Sclarea and its variety bracteata are noble plants for a mixed border, and so is $\mathrm{S}$. Forskohlei, a species similar to them in habit and in colour. The finest of all kinds is S. hians, which is, however, rarely seen. Some of the forms of the common garden Sage (S. officinalis), especially the variegated-leaved kind, are very pretty;
Of the half-hardy species, S. patens is, undoubtedly, the most brilliant, being equalled by few flowers in cultivation and surpassed by none. Although not hardy, it is easily preserved through the winter, and it is readily propagated from cuttings. In some districts, in light warm soils, it survives an ordinary winter, but as a rule it is safer to lift the plants. S. cacaliæfolia is a beautiful plant similar to $S$. patens, but of the same hardiness as those mentioned below. S. porphyranthera is a dwarf close-growing species with an abundance of rich crimson flowers. It rarely fails in the open border. S. farinacea is a beautiful kind, bearing light lavender blossoms with a white lip, and having a flower-spike covered with white

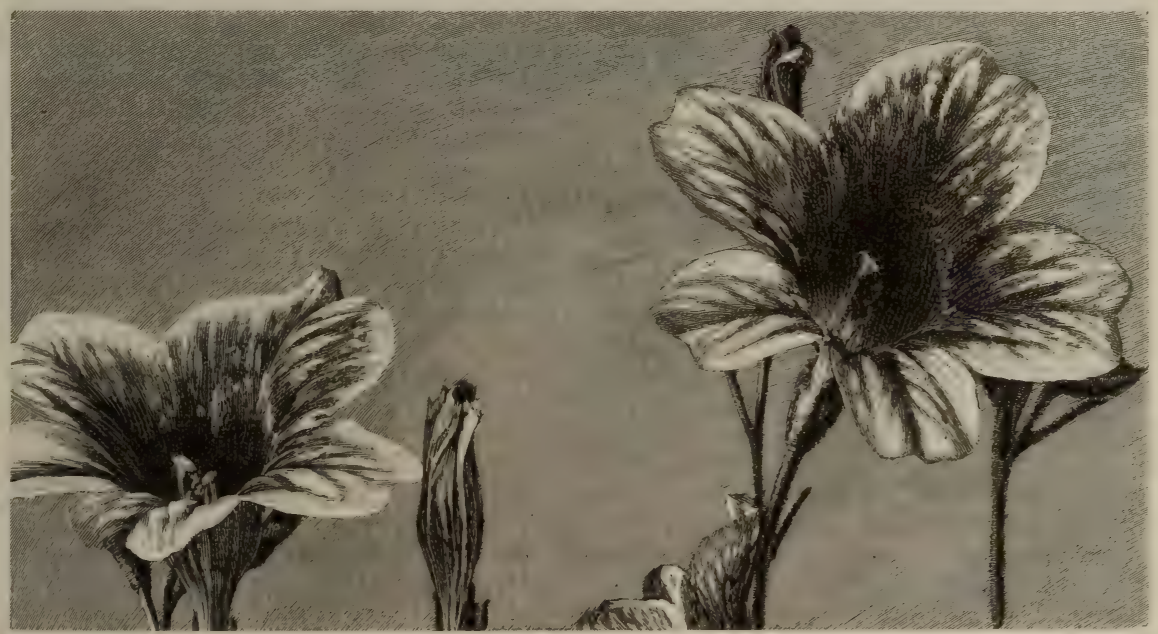

SALPIGLOSSIS SINUATA.

and so are the blue-flowered North American S. Pitcheri, and its white variety. The pretty purple red-topped Clary (S. Horminum) is a South European annual of easy culture. The tufts of coloured bracts which terminate its stems make it useful for cutting as well as for border decoration. The silvery Clary (S. argentea) is also an excellent border plant. It has silvery leaves, 6 to $\mathrm{I} 2 \mathrm{in}$. long, which are very ornamental when allowed to spread. Patches of seed may be sown every spring on banks or borders of light /sandy soil. S. candelabrum, a native of the south of Spain, is a halfshrubby species like the kitchen Sage, and has similar foliage, associated with ample panicles of rich violet and white flowers, borne 'on long stalks clear of the leaves. S. taraxacifolia is equally handsome. powder. S. interrupta, a very fine species from Morocco, has large white and light blue flowers. S. Grahami, a very old Mexican kind, has a distinct habit and bears bright carmine blossoms. S. angustifolia and S. azurea are blue kinds, worthy of open-air culture, as are also several of the sorts usually grown in greenhouses, such as S. Heeri, S. fulgens, S. gesneræfolia, S. elegans, S. tricolor, S. rutilans, S. splendens, and their varieties; for, though some of them do not flower till autumn, their use for indoor decoration is improved by their being planted out during summer.

In summer many beautiful tender kinds have a fine effect in the open border, and are all easily propagated by cuttings. In August and September they should be raised in a close cold frame, and in spring they should be treated like Heliotropes 
or Ageratums. When large plants are required, the old ones can either be potted, or put close together in deep boxes; and, if potted, they should be cut down to within 6 in. of the soil. Both old plants and potted cuttings are easily wintered in any dry place where frost is excluded. The tender Sages are not particular as to soil, and thrive in any common garden soil that is moderately enriched.

Sambucus (Elder).- The common Elder (S. nigra) is not generally looked upon as ornamental, but its cut-leaved, golden, and variegated varieties are so regarded. That the Elder when well developed is a beautiful tree is admitted by all. We do not recommend the planting of young common Elders, but it sometimes happens that, in forming a new garden, fine old Elders are among the natural growth of the place, and when such is the case a few should be preserved, and cultivated by pruning and other means into handsome specimens. The Elder likes rich moist soil and an open airy situation, conditions which are generally found where it grows wild. A large Elder with branches sweeping the turf is no mean object on a lawn at midsummer, when covered with its flowerclusters, or again in autumn when in berry. The golden Elder (foliis aureis) is becoming very common-too common, in fact,--for, like all conspicuous objects, it requires to be employed with caution, or a spotty effect will be produced. The same remark applies, but in a less degree, to the variegated golden-leaved and silverleaved Elders. The Parsley-leaved or Cut-leaved Elder (laciniata) is a most elegant shrub, and should be preferred to the common Elder, as it is ornamental even in a small state. It should be allowed to form itself into a small tree or a round symmetrical bush. A highly ornamental shrub is the Scarlet-berried Elder (S. racemosa), which resembles the common Elder in growth and foliage, save that instead of bearing black berries it has dense clusters of brilliant scarlet fruits. Unfortunately, it is capricious in English shrubberies, and is seldom seen in perfection of berry. Its natural home is in alpine valleys, where in August and September it rivals the Mountain Ash in splendour of fruit. In hill districts it may be grown and fruited, but it must have a cool moist spot. Its cut-leaved variety (serratifolia) is an elegant shrub, with pinnate leaves deeply cut. S. Ebulus is a herbaceous Elder, having handsome spreading foliage, cut into elegant leaflets.
It is an admirable plant for association with other fine-leaved plants, but is scarcely suitable for border culture. It is perfectly hardy, will grow in any soil, and may be readily increased by division. For dry banks either in the open or in the shade it is a capital plant, and it never becomes sickly through drought. The stems, being herbaceous, die down in autumn. As with most of the Elders, the flowers are inconspicuous. Europe and the Caucasus. S. adnata and S. racemosa are similar plants, also suitable for dry banks.

Samolus littoralis.-A pretty trailing plant, with long slender stems, and small evergreen foliage, and in summer, with numerous pink blossoms. It is suitable for the artificial bog, or for moist spots in the rock-garden, as it delights in plenty of moisture at the roots. A peaty soil suits it best. It is a hardy native of $\mathrm{New}$ Zealand, but rare in cultivation. S. Valerandi, a British plant, is of no garden value. Primulaceæ.

\section{Sand Verbena (Abronia).}

\section{Sandwort (Arenaria).}

Sanguinaria canadensis (Blood-root or Puccoon).-A pretty and singular plant. Its thick creeping root-stocks send up glaucous kidney-shaped leaves about 6 in. high. The flowers, produced singly on stems as high as the leaves, are $I$ in. across and white, with a tassel of yellow stamens. These appear in spring, and in a good-sized tuft produce a pretty effect. The variety grandiflora has larger blossoms than the type. It grows well in any border, but under the branches of deciduous trees on lawns it spreads about, and, without any attention, becomes a charming plant, preferring a rather moist soil. It may be increased by division in autumn, but its fleshy stems must not be kept long out of the ground. Papaveraceæ.

Santolina (Lavender Cotton).-Dwarf shrubby plants, remarkable for their neat habit generally and their pretty hoary foliage. One of the most distinct and useful of them is S. incana, a small silvery shrub, with numerous branches and narrow leaves. It is covered with dense white down. The pale greenish-yellow flowers are rather small, in no way attractive, but the plant is popular from its neat habit and silvery hue. It forms neat prostrate tufts of edgings, grows readily in ordinary soil on the level border, and may be tastefully used on slopes of the rock-garden. It is considered a variety of the better-known S. Chamæcyparissus (Lavender Cotton). 
S. Chamæcyparissus and its variety $\mathrm{S}$. squarrosa are fitted for very large banks and rock-gardens, as in suitable soils they form spreading silvery bushes $2 \mathrm{ft}$. high, but are not suited for association with very dwarf alpine plants. They are also used with good effect in bedding out to tone down the glaring colours of other plants. Other species of Santolina suited for large rock-gardens are S. pectinata and S. viridis, which form bushes something like the Lavender Cotton. S. alpina is of more alpine habit, forming dense mats quite close to the ground. From these mats arise long slender stems bearing yellow button-like flowers. S. alpina grows in any soil, and may be used in the less important parts of the rock-garden. It is easily increased by division. Cuttings of the shrubby species strike readily in spring or autumn.

Sanvitalia procumbens. - A hardy annual from Mexico, with trailing branches and bright yellow flowers. In the singleflowered kind the blossoms have a darkpurple centre, but in the double ( $\mathrm{S}$. procumbens fl.-pl.), which is by far the showier, they are wholly a bright yellow. S. procumbens flowers from July till late in September. Owing to its dwarf compact growth, it is very useful for masses in beds or for the front rows of borders, and grown in suspended baskets it is very useful, as the slender branches droop gracefully over the sides. It may be sown in any ordinary garden soil-in autumn for spring flowering, or in March and April for summer-flowering. Compositæ.

Saponaria (Soapwort).- This genus of the Pink family has a few very desirable garden plants.

S. cæspitosa is a neat little alpine perennial. In the higher regions of the Central and Eastern Pyrenees it flowers in August, but in the lowlands its beautiful rose-coloured blossoms are developed towards the end of June. It forms rosettes of linear leaves, which are somewhat thick, glabrous, and of a beautiful green colour. The flowers, which form a thick cluster, are supported by short stout stems. This graceful little plant is very valuable for the rock-garden. A sandy soil suits it best, and it will endure the winter without any particular care being bestowed on it.

S. calabrica is a pretty prostrate hardy annual, 6 to 9 in. high. From June to September, its slender stems are covered with small pink blossoms. There is a white variety called alba. S. calabrica is much used for mass beds and edgings.
Seeds may be sown in the open border in April, or earlier in heat if bloom is required early in the season. The plant thrives best in a moderately rich sandy loam. S. Vaccaria is not worth attention.

S. ocymoides is a beautiful trailing rock-plant with prostrate stems. In early summer its rosy flowers completely cover its leaves and branches. It is most valuable for clothing arid parts of the rockgarden, particularly where a drooping plant is desired. The shoots fall profusely over the face of the rocks, and become masses of rosy bloom in early summer. It is also excellent for ruins and old walls, and the seed should be sown in mossy chinks where a little soil has gathered. It is valuable for the border, as it forms roundish spreading cushions with its masses of flowers, and it is well worthy of being naturalised in bare and rocky places. It thrives in any soil, and grows freely in poor soil, but when it is planted with the view of ornamenting the face of the rock, a greater development will be secured by deep rich loam. Seeds and cuttings. Stony and rocky places in Southern and Central Europe.

S. officinalis (Soaprort).-This is a handsome native plant about $2 \mathrm{ft}$. high, and with a profusion of large blossoms, varying from white to rose-pink. The double variety is the best. It is a rambling plant, and soon spreads rapidly; therefore it should not be planted in select borders, but is a capital plant for rough places in the pleasure-ground and wild garden, as it grows in any soil. Division.

Sarana kamtschatica (=Fritillaria).

Sarcodes sanguinea (Californian Snow-plant). - A Californian parasite, which probably cannot be grown in gardens. Ericaceæ.

Sarracenia purpurea (Huntsman's Horn).-This singular plant belongs to a family of Pitcher-plants peculiar to North America. It is the hardiest of the genus, and is very handsome when well grown. Its curious leaves, hollowed like a horn, are of a deep blood-red colour, and form a compact tuft $\mathrm{I} \mathrm{ft}$. or more in height and the same in breadth. The flowers, though singular in shape, are not very attractive. It is a good plant for the artificial bog, or for damp spots in the rock-garden, but should have an open and fully-exposed position, and be associated with Cypripedium spectabile, the Parnassias, etc. The soil should consist of fibrous peat well mixed with Sphagnum 
Moss, which is common in most marshy places. A layer of living Moss should be placed round the plant to keep it moist, and the soil must be kept perpetually moist, but should not be always saturated. The plant is hardy under these conditions, but precautions should be taken to prevent birds from disturbing the soil and exposing the roots. S. purpurea is imported largely and may be obtained cheap. It is not easy to propagate, but may sometimes be raised from seed. Some of the hybrids between it and others may be hardy. S. flava, the hardiest species next to S. purpurea, is rarely satisfactory in the open air.

\section{Satin-flower, Crimson (Brevoortia} coccinea).

Satyrium.-Beautiful terrestrial Orchids, natives of the Cape of Good Hope, and therefore scarcely hardy enough for open-air culture. With attention, however, they succeed fairly well in sheltered and warm localities if protected in winter, but they thrive best under glass. The handsome S. carneum and aureum are in cultivation.

Saussurea.-These composite plants have a Thistle-like aspect, and are suitable mainly for botanical or full collections. Some, such as S. pygmæa, grow only a few inches high, and may be cultivated in the rock-garden. The leaves of S. discolor are white underneath, and contrast well with the light purple blossoms. $\mathrm{S}$. alpina is a native species. All grow well in any soil.

Saxifraga (Rockfoil). - This genus includes, perhaps, more true alpine flowers than any other. In the Arctic Circle, in the highest alpine regions, on the arid mountains of Southern and Eastern Europe and Northern Africa, and throughout the length and breadth of Europe and of Northern Asia, they are found in many interesting varieties of form and colour. One might expect them to be as difficult of cultivation as most alpine plants, but they are the easiest to grow of all. They were common in collections of alpine flowers where few other families were represented. Of late years many pretty species have been introduced, and the variety of the family is now so great that a very interesting garden might be made of Saxifrages alone. For the purposes of cultivation some rough division is convenient, as Saxifrages are very different in aspect and uses. The most ordinary form is the Mossy or Hypnoides section, of which there are many kinds in cultivation.
Their delicate Moss-like spreading tufts of foliage, so freshly green, especially in autumn and winter, when most plants decay, and their countless white flowers in spring, make them very precious. They are especially suited for the tasteful practice of carpeting the bare ground beneath taller plants. They are also admirable for the fresh green hue with which they clothe rocks and banks in winter. They are indeed the most valuable winter "greens" in the alpine flora. Next to these we may place the very extensive silvery group. These have their greyish leathery leaves margined with dots of white, so as to give to the whole a silvery character. This group is represented by such kinds as S. Aizoon and the great pyramidalflowering S. Cotyledon of the Alps. Considering the freedom with which they grow in all cool climates, even on level ground, and their beauty of flower and foliage, they are perhaps the most precious group of alpine flowers we possess. Anybody with a cottagegarden can grow them. The London Pride section is another of great beauty. The plants of this section thrive under ordinary circumstances in lowland gardens, etc., and soon naturalise themselves in lowland woods and copses. But the most brilliant, so far as flower is concerned, are found in the purple Saxifrage (S. oppositifolia) group and its near allies. Here we have tufts of splendid colour in spring with dwarfness and perfect hardiness. The large leathery-leaved group, of which the Siberian S. crassifolia is best known, is also of much importance; the constitution of its members is such that they thrive in ordinary soil and on the level ground. There are various minor groups. Such of the smaller and rarer alpine species as require any particular attention should be planted in moist sandy loam mingled with grit and broken stone, and made very firm. Very dwarf and rather slow-growing kinds, like S. cæsia and $\mathrm{S}$. aretioides, should be surrounded by half-buried pieces of stone, to prevent their being trampled on or overrun. Stone will also help to preserve the ground in a moist healthy condition in the dry season, when the plants are most likely to suffer. Very dry winds in spring sometimes have a bad effect when such precautions are not taken. Established tufts are apt to throw out stem-roots into their own cushions, so to say. These cushions are frequently moist during the autumn and winter months. When the 
tufts are suddenly dried, the plants suffer if the ground-roots be dried too.

The following are among the most important cultivated kinds, though the list excludes many species that are difficult to grow or to procure, and which are found only in very full collections.

S. aizoides. - A native plant, very abundant in Scotland, the north of England, and some parts of Ireland, and generally found in wet places and by the sides of mountain rills or streams. At the end of summer or in autumn it produces an abundance of flowers, $\frac{1}{2}$ in. across, of a bright yellow, but dotted with red towards the base. It forms dense masses of dwarf bright green leaves, and has leafy branched flower-stems, which its rather oblong and finely-dentated leaves, densely margined with encrusted pores, and stiffly ciliated at the base; and is further distinguishable by its flower-stems, which grow 6 to 15 in. high, and are furnished with glandular hairs on the upper part, the lower being usually smooth. As to the culture of S. Aizoon, nothing can be easier ; the plant is very often grown in pots, but it flourishes as freely as any native plant, and is best perhaps when exposed to the full sun. There are several named varieties. S. pectinata, S. Hosti, S. intacta, S. rosularis minor, S. australis, S. cartilaginea, and others are only slight variations from the type. Division in spring.

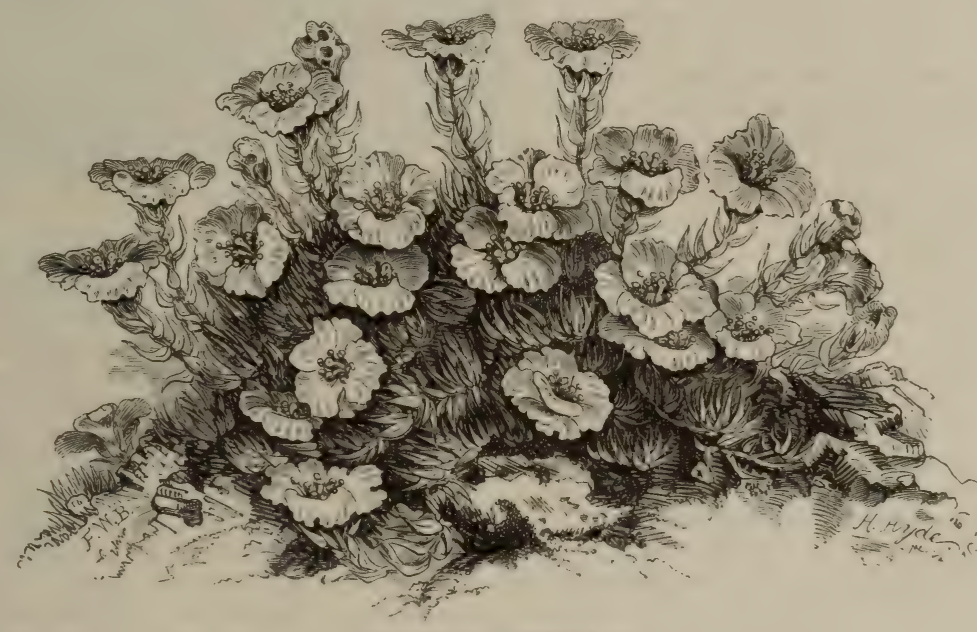

SAXIFRAGA BLRSERIANA.

distinguish it from other yellow Saxifrages. Although a mountain plant, it is quite easy to grow in lowland gardens, though it does best in moist ground. Wherever a rill or streamlet is introduced into the rock-garden or its neighbourhood, $\mathrm{S}$. aizoides may be most appropriately planted so as to form wide-spreading masses, as it does on its native mountains. Easily propagated by division or by seed. S. autumnalis is similar.

S. Aizoon deserves to be cultivated as a rock, border, and edging plant. Plants established for two or three years form grey-silvery tufts, I ft. or more in diameter, and about 6 in. high-sometimes a few inches more. These great tufts do not flower so freely as the wild plants, but this need not be regretted, as it is the silvery mass, and not the flowers, that is sought. The plant is distinguished by
S. Andrewsi.-Among the green-leaved Saxifrages there is no better kind than this. Its flowers are freely produced, are prettily spotted, and are larger than those of S. umbrosa. S. Andrewsi is more worthy of the rock-garden than is London Pride, does quite freely on any border soil, and merely requires to be replanted occasionally when it spreads into very large tufts, or to have a dressing of fine light compost sprinkled over it annually. The variety Guthrieana is distinct and handsome.

S. aretioides.-A real gem of the encrusted section, forming cushions of silvery rosettes about $\frac{1}{2}$ in. high, and almost as !small and dense as those of Androsace helvetica. It has rich goldenyellow flowers, which appear in April on stems a little more than I in. high, and remind one of the flowers of Aretia Vitalliana. S. aretoides is not difficult to 
grow ; but it requires a moist and welldrained soil, and being so tiny, must be protected from coarser neighbours. Pyrenees. Seed and careful division.

S. aspera.-A small, grey, tufted, prostrate plant. The flowers are small and a dull white, and are borne on stems about 3 in. high. S. bryoides, a variety of it, forms a dense tuft, and it has pale yellow flowers. Both are worth growing for their Moss-like character. Natives of the Pyrenees $-\mathrm{S}$. bryoides being found in the most elevated regions. They grow freely in the open air in London, but rarely flower.

\section{S. Burseriana.--None of the Saxifrages} surpass S. Burseriana in vernal beauty. It is dwarf, and indeed almost Moss-like in habit, forms broad patches, and spreads rapidly over the earthy interstices of warm moist sandstone, if planted where it will not suffer from stagnant moisture. The blossoms are borne singly on slender red stalks, which rise 2 or 3 in. above the general surface of the plant, and are pure white, the margins of the overlapping petals being elegantly frilled or crisped. They appear freely in January and February. Before they are expanded, their unopened buds, which are of a dullish crimson-brown, have a cheerful effect as they emerge from the compact silvery tufts of foliage, while, interspersed among full-blown flowers, they show to excellent advantage, and enhance the pearly whiteness of the petals. S. Burseriana soon forms goodly-sized tufts in the open border or in the rock-garden, but prefers a dry sunny situation and a calcareous soil. All lovers of hardy spring flowers should possess it. There are two or three distinct forms which differ from each other chiefly in habit, one being much more tufted than the others. There is also a form with larger flowers than those of the type. Austrian Alps.

S. cæsia resembles an Androsace in the dwarfness and neatness of its tufts. On the Alps it covers the rocks and stones like a silvery Moss ; and on level ground, where it has some depth of soil, it develops into beautiful little cushions, 2 to $6 \mathrm{in}$. across. It is easily known by its exceeding dwarfness and neatness, and its threesided keeled leaves, regularly margined with white crustaceous dots. It has pretty white flowers, about the third of an inch in diameter, borne on smooth thread-like stems, I to 3 in. high. Though a native of the high Alps and Pyrenees, it thrives in our gardens in very firm sandy soil, if fully exposed and abundantly supplied with water in summer. It may also be grown in pots or pans in cold frames near the glass; but, being very minute, it should always be kept distinct from coarse neighbours, as even the smallest weeds will injure or obscure it. Flowers in summer. Seeds or careful division. Of a similar character are $\mathrm{S}$. calyciflora, $\mathrm{S}$. luteo-viridis, S. Kotschyi, S. valdensis, S. squarrosa, and $\mathrm{S}$. diapensoides, all of dwarf growth, and, for the most part, extremely difficult of cultivation, though their beauty amply repays the trouble bestowed on them. They should be grown in the same way as $\mathrm{S}$. cæsia.

S. cæspitosa. - A dwarf kind. It forms dense carpet-like masses of foliage, arranged in neat tufts, studded in summer with white blossoms. It succeeds in almost any situation in any garden soil ; is very valuable for margins to herbaceous borders, and makes a beautiful covering for moist banks. S. cæspitosa is one of the most variable of all Saxifrages. Of its numerous varieties the most distinct are palmata and gronlandica. They are as easily grown as the type, and as suitable for the same position.

S. ceratophylla(Stag's-horn Saxifrage). -An ornamental species of the mossy section, with very dark, finely - divided leaves. Its pure white flowers are abundantly produced in loose panicles in early summer. It quickly forms strong tufts in any good garden soil ; and is admirably adapted for any kind of rock-garden, whether grown in level tufts on the flat portions, or in sheets overhanging the brows of rocks. It may also be used with good effect in borders. Spain. Seed or division. Similar to this species are S. paniculata, ladanifera, Wilkommiana, geranioides, irrigua, ajugæfolia, aquatica, Schraderi, etc., all of which are desirable for a full collection.

S. ciliata.-One of the broad-leaved or Megasea section. Its large broad leaves, covered with soft hair, are carried on creeping stems, which in well-established plants form a spreading mass. The flower-stems are 6 to 9 in. high, and bear numerous large flesh-coloured flowers in spring. A native of North India, S. ciliata is suitable for open-air culture in the south of England only, but it is so handsome and distinct that it should be tried whereever it can be grown. A sheltered nook in the rock-garden, partially shaded, suits it best.

S. cordifolia.-This differs entirely in aspect from the ordinary dwarf Saxifrages. It has very ample heart-shaped leaves on long and thick stalks. Its clear rosecoloured flowers are arranged in dense 
masses, and in early spring are half concealed among the great leaves, as if hiding from the cutting breath of March. S. cordifolia and its varieties are thoroughly hardy, and flower in any soil and position; but, to encourage their early-flowering habit, it is desirable to place them in warm sunny positions, where their fine flowers may be induced to open well. These Saxifrages are perhaps more fitted for association with the larger spring

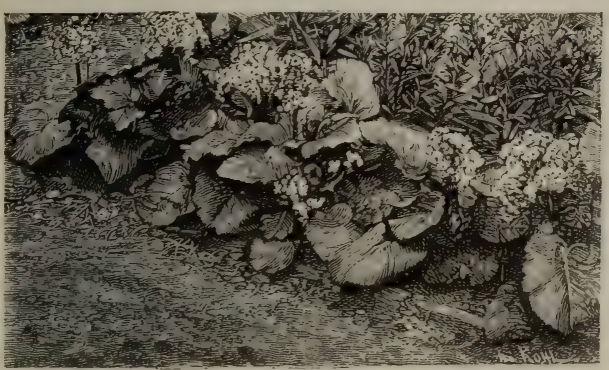

SAXIFRAGA CORDIFOLIA.

flowers and with herbaceous plants than with dwarf alpines; and are worthy of naturalisation on bare sunny banks, in wild sunny parts of the pleasure-ground, or by wood walks. They may also be used with fine effect near cascades, or on rough rock or root work, or on the rocky margins of streams or artificial water, their fine evergreen glossy foliage being quite distinct. They may, in fact, be called the fine-foliaged plants of the rocks. There are several handsome varieties of $\mathrm{S}$. cordifolia, the finest of all the group being one called purpurea. Siberia.

S. Cotyledon (Pyramidal Saxifrage).A noble Saxifrage, which embellishes with its great silvery rosettes and elegant pyramids of white flowers many parts of the great mountain ranges of Europe, from the Pyrenees to Lapland. It is easily known by its rather broad leaves, margined with encrusted pores, and its fine handsome bloom. It is the largest of the cultivated Saxifrages, and also the finest, except S. longitolia, the linear leaves of which it does not possess. There is considerable disparity in the size of the rosettes, which when grown in tufts are generally much smaller than in isolated specimens. The flower-stem varies from 6 to $30 \mathrm{in}$. high, and about London, in common soil, often reaches 20 in. In cultivation the plant usually attains a greater size than on its native rocks. A variety more pyramidal and more robust is known in gardens under the erroneous name of S. nepalensis, and sometimes by the more appropriate one of S. pyramidalis. It is of easy culture, the chief point, in order to obtain good specimens, being to denude the parent plant of the offsets as they appear. The plant may be grown in the rock-garden or the ordinary border.

S. crassifolia.-A well-known species of the Megasea section, with large broad leaves. The flowers are produced in dense panicled cymes, which rise from the terminal shoots in showy pendent masses ; they are a pale rose colour with a faint suspicion of lilac. In spite of somewhat coarse foliage, the plant is a gay and useful accessory to the spring-garden. It fulfils the same purposes as S. cordifolia. The chief varieties are ovata, which carries its deep rose-coloured flowers well above the foliage; rubra, similar to the last, but with flowers of a deeper tinge of rose; orbicularis, a free bloomer, producing an abundance of light rosy flowers, well above the foliage, and sometimes ranked as a species, but in reality only a smaller form of ovata, with rather broader leaves and a more branching habit ; and media, a distinct and ornamental variety, with large, dark, shining green leaves and clusters of bright rosy-pink flowers, borne in great profusion on strong stems. There is also a variety called aureo-marginata, with variegated foliage. Siberia.

S. Cymbalaria. - Quite distinct in aspect from others of the family, and one of the most useful. Little tufts of it form in early spring masses of bright yellow flowers set in light green, glossy, ivy-like leaves, the whole not above $3 \mathrm{in}$. high. Instead of fading, it preserves its little rounded pyramids of golden flowers until autumn, when it is about 12 in. high. It is an annual or biennial, and sows itself abundantly. It is peculiarly suitable for moist spots on or near the rock-garden, grows freely on level ground, and in large pleasure-grounds is readily naturalised on the margins of a rocky stream and elsewhere.

S. flagellaris is not only one of the most distinct, but also one of the freestgrowing of its race. Like its ally, S. Hirculus, it has large bright yellow blossoms, borne in threes on viscid stems 3 or 4 in. high. Each rosette throws off thread-like stolons, which root at the tips, and in moist, peaty, and gritty soil quickly form new rosettes. One of the most arctic of plants. 
S. Fortunei has large panicles of white blossoms which rise in profusion from rosettes of dark green rounded leaves. It is a desirable plant, for it flowers in autumn and is not particular as to treatment.

S. Geum very much resembles the London Pride in habit and flowers, fulfils the same purposes, and is cultivated with the same facility. It will grow freely in woods or borders, especially in moist districts, and is worthy of naturalisation in the former. It is suitable for the rockgarden, but does not deserve a place there so well as many plants much more difficult to grow. S. hirsuta comes near to it, and is probably only a variety of it, the chief difference being that in S. hirsuta the leaves are longer than they are broad, less heart-shaped, and more hairy than in S. Geum. It is suitable for similar positions. S. cunefolia and its numerous varieties are also allied to S. Geum, and are desirable for a full collection.

S. granulata (Meadowe Saxifrage).A lowland plant, with several small scaly bulbs in a crown at the root, and numerous white flowers three-quarters of an inch across. It is common in meadows and banks in England. Its double form is very handsome, and is useful as a border plant in the spring-garden or in the rougher parts of the rock-garden.

$\mathbf{S}$. Hirculus is a native plant sometimes found on mountains. It has weak prostrate stems and flower-stems, about 6 in. high, bearing a solitary yellow flower. It is handsome in very moist peaty soil, or even in loam when wet, but is not otherwise worthy of culture. S. Hirculus major produces flowers nearly double the size of the type, has broader foliage of much greater substance, and is more amenable to cultivation.

S. hypnoides (Mossy Saxifrage) is a very variable plant as regards stems, leaves, and flowers, but it usually forms mossy tufts of the deepest and freshest green, and no plant is more useful for forming carpets of glistening verdure in winter. For this reason it is peculiarly suited for the low rocky borders frequent in town and villa gardens. It thrives either in the rock-garden or on level ground, either in half-shady positions or when fully exposed to the sun, and when so exposed it forms the fullest and healthiest tufts, and flowers profusely in early summer. It is also suitable for forming dwarf verdant carpets in the flower garden or the rock-garden with a view to placing plants above it. Nothing can be easier to grow or to increase by division. Under this species may be grouped S. hirta, S. affinis, S. incurvifolia, S. platypetala, S. decipiens, and several others, all exhibiting differences which some think sufficient to mark them as species. They present considerable differences in appearance when grown together in a garden, and many no doubt think them worthy of a place there. They thrive as freely as S. hypnoides, and appear to suffer only from drought or drying winds. If when first planted a few largish stones are buried in the earth round each, the plants will soon lap over them; they will serve to preserve the moisture in the tufts, and the plants will be much less likely to suffer from drying winds. S. densa and S. Whitlavi are two of the very best freegrowing species, and, being compact and always green, are suitable for a margin.

S. juniperina (Juniper Saxifrage) is one of the most distinct and desirable kinds. It has spine-pointed leaves, densely set in cushioned masses, which look, so to speak, like Juniper bushes compressed into the size of small round pin-cushions, which show little but the prickly points of the leaves. The yellow flowers appear in summer, and are arranged in spikes on a leafy stem. S. juniperina thrives in moist, sandy, firm soil, and is worthy of a place in the rockgarden, and in every collection of alpine plants grown in pots. Caucasus. Seed and careful division.

S. lantoscana.-One of the finest of all the incrusted-leaved section. Though somewhat similar to the pyramidal variety of $\mathrm{S}$. Cotyledon, it is smaller, its leaves are narrower and more crowded in the rosette, and its flower-spike, which is not erect but slightly drooping, is more densely furnished with flowers. It is easily grown in a fully-exposed position in a well-formed rock-garden, in a welldrained gritty soil. It remains long in flower, and is one of the most satisfactory of rock-garden plants.

S. ligulata.-A plant with broadly obovate leaves, bearing flowers in small cymose panicles. The flowers are white, with a rosy tint towards the margin of the petals; and the anthers before expansion are of a deep crimson, which adds much to the beauty of the flowers. Nepaul. Its tendency to very early spring-growth makes it liable to suffer from frosts, a form of injury which, occurring in three or four consecutive seasons, will ultimately prove fatal to the plant, which should therefore be given a sheltered situation and a little shade also. The varieties rubra and speciosa, particu- 
larly the latter, are in every way finer than the type. S. ligulata may be associated with others of the Megasea section.

S. longifolia.-This Pyrenean plant has single rosettes often 6,7 , and 8 in. in diameter, and may well be termed the queen of silvery Saxifrages. Its greyish chink in the face of a rock-garden, where it can root deeply, it is very striking when the long outer leaves of the rosette spread away from the denselypacked centre. It may also be grown on the face of an old wall by first of all carefully packing a very small plant of it

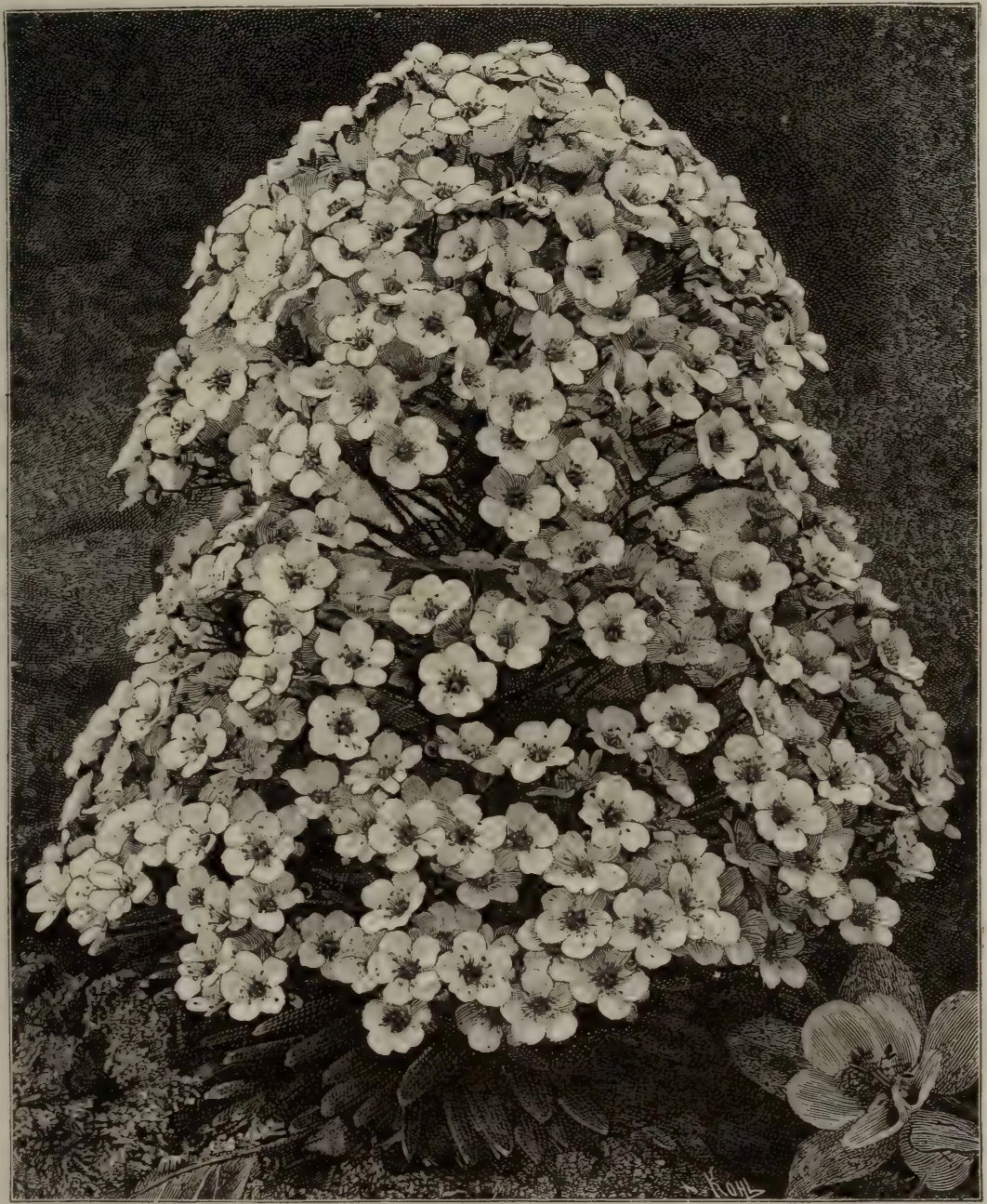

SAXIFRAGA LONGIFOLIA.

leathery leaves are beautifully dotted with white on the margins, which makes it attractive at all seasons. In early summer it pushes up fox-brushlike columns of white flowers, from I to $2 \mathrm{ft}$. long, the stems being covered with short, stiff, gland-tipped hairs. It is perfectly hardy, not difficult of culture, and may be grown in various ways. On some perpendicular into a chink with a little soil. The stift leaves will, when they roll out, adhere firmly to the wall in the form of a large silver star. S. longifolia will thrive on a raised bed or border if surrounded by a few stones to prevent evaporation and to guard it from injury. It also thrives in a greenhouse or frame, and perhaps the readiest way of developing a weak young 
nursery plant into a sturdy rosette is to put it in a 6-in. pot, well drained and filled with a mixture of sandy loam and stable manure, and to place it in a sunny pit or frame, giving it plenty of water in spring, summer, and autumn. S. longifolia is propagated by seeds, which it produces freely. The seeds ripen from the bottom of the stem upwards, so that the lower seed-vessels should be cut off first, leaving the unripe capsules to mature, and the plant should be visited on the stems, which remain dormant till the following spring. Though rare, it is of easy culture. Similar, but finer, is a new kind called S. Wallacei, which is far more robust, and far earlier, and freer as regards flowering, but which does not develop buds during summer. It is a most desirable plant for the border or the rock-garden. It is easily cultivated and easily propagated.

S. muscoides (Mossy Saxifrage).-A beautiful little plant, forming a dense bright green carpet like

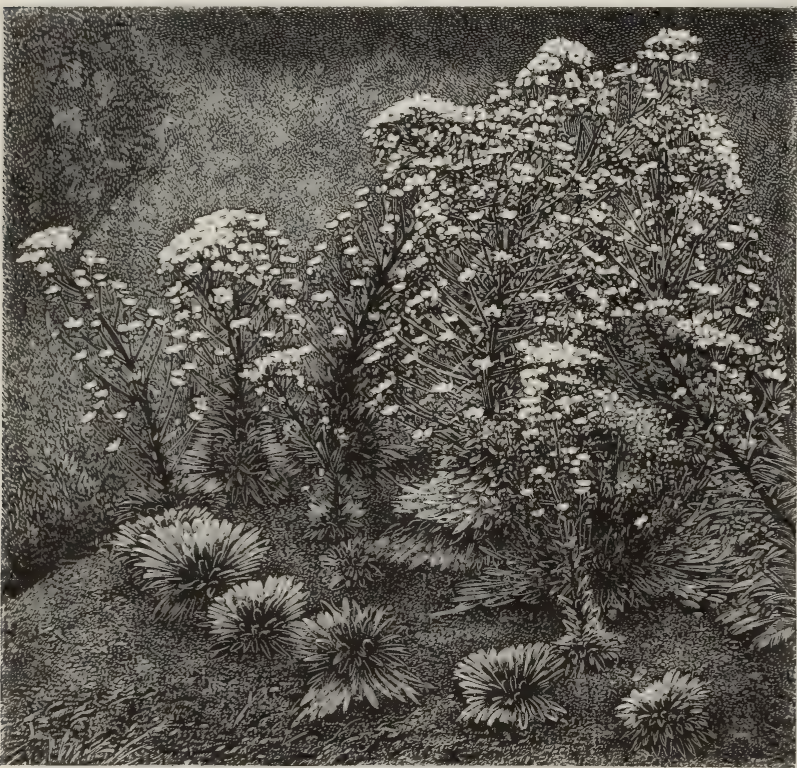
S. hypnoides and $\mathrm{S}$. crespitosa. There are several forms of it, but the best is atro-purpurea, which produces a dense mass of deep red-purple blossoms on stalks a few inches high. The varieties pygmæa and crocea are also pretty, and so are the allied kinds S. exarata, S. pedemontana, S. Rhei, S. aromatica, and a few others, all of which are excellent for the rock-garden, as they grow in almost any soil.

S. mutata. - A yellow-flowered species bearing considerable likeness to S. ligulata, and having the flowerpanicle about 18 in. high. It is rare in cultivation, owing to the fact that it not infrequently exhausts all every day or two in order to collect the seeds as they ripen. S. lingulata is by some united with the preceding, from which it chiefly differs in having smaller flowers and shorter stems ; the leaves also are smooth instead of glandular; while the leaves in the rosette are shorter and very much fewer. $\mathrm{S}$. lingulata is a charming rock-plant, and will succeed with the same treatment and in the same position as S. longifolia. S. crustata is considered a very small variety of S. longifolia; but being much smaller, requires more care in planting, and should be associated with dwarfer plants.

S. Maweana is a very handsome species of the crespitosa section. It is larger than any other as regards both foliage and flowers. The latter, about the size of a shilling, form dense white masses in early summer. After flowering, this species has the peculiarity of forming buds its vigour in producing blooms, and it rarely matures seeds in this country; and further, it does not produce offsets, like most of this section. It is a native of the Alps, but limited in its distribution. An allied species, S. florulenta, is a beautiful plant of the Maritime Alps, which no one has succeeded in cultivating in this country.

S. oppositifolia.-It is impossible to speak too highly of the beauties of this in habit so distinct from the familiar members of its family. The moment the snow melts, its tiny herbage glows into solid sheets of purplish-rose colour; the flowers are solitary, on short erect little stems, and often so thickly produced as to quite hide the leaves, which are small, opposite, and densely crowded. Of the several varieties in cultivation, that known as splendens has flowers of far greater bright little mountain-plant, in colour and 
brilliancy, though slightly smaller than those of the type ; in bud especially the colour is almost carmine and is exquisitely beautiful. In density of bloom it approaches the typical form, but rarely equals it. This variety was obtained many years ago on the mountains of Scotland. S. o. major has flowers twice the size of the type ; they are a clear rose, inclining to cherry, and have less of a purple tinge. The petals are broad and well rounded, and when fully expanded, bright rose to a deep blood-red, the petals being narrow and wide apart. $S$. Kochi is similar in habit to the last, and its rosy-purple flowers are borne in twos and fours at the extremities of the shoots. It is good in form, the petals being broad and close. The foliage of $\mathrm{S}$. retusa is very short, firm, dense, and compact. Its small flowers are borne in clusters at the extremity of erect stalks ; and their narrow petals are usually a pale rose colour, and sometimes brighter. It blooms rather

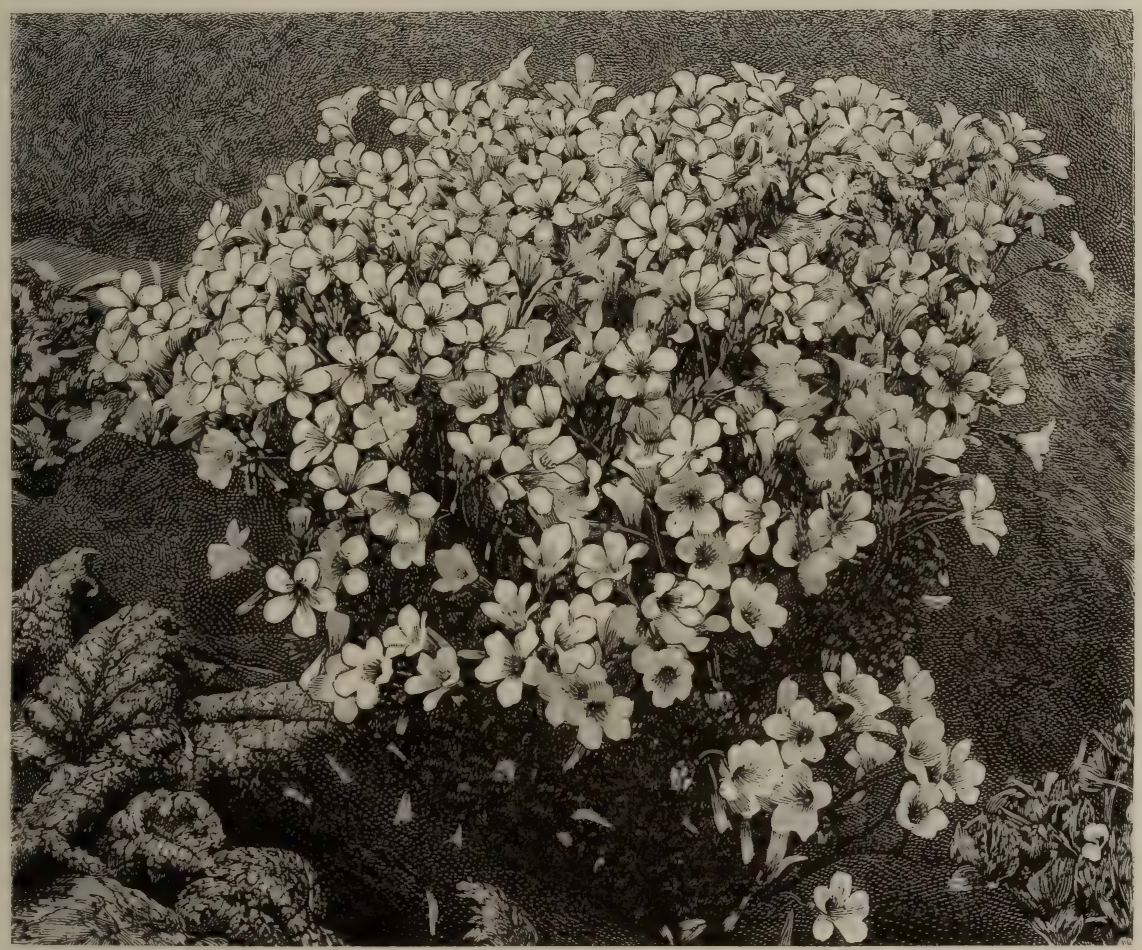

SAXIFRAGA WALLACEI.

are less compact than those of the type. In S. o. pyrenaica the shoots are ascending, and are twice as robust as those of any of the preceding kinds, and the flowers are larger and usually sparser. Its finest form is S. o. p. maxima, which has lovely light rose blossoms as large as a shilling. S. o. alba has white flowers, in pleasing contrast to the other varieties. S. Rudolphiana has a more spreading habit of growth, and its rosy-purple flowers are sometimes borne singly, and sometimes (though rarely) in pairs. It is allied with S. biflora, the beautiful dwarf species of loose habit, the flowers of which, on clusters of two to four, vary in tint from a later than the varieties of S. oppositifolia. S. Wulfeniana is closely allied to S. Kochi, and is probably the Tyrolese form of it. S. oppositifolia and its varieties flourish in open, rich, loamy soil, either in the common garden border or in fissures of the rock-garden. In either place the soil should be trenched or prepared fully $2 \mathrm{ft}$. deep, so that the roots may get below the reach of summer drought. They are perhaps finest in a fissure or on a ledge of the rock-garden, where the roots can ramble backwards or down to any depth. For the soil, a rich light loam mixed with fragments of limestone or grit, small fragments of any rock, and a little river 
sand will do. S. oppositifolia should always be placed where it can get sunshine; for though it will grow in the shade, it will not flower freely. The same treatment, with the addition of a little peat or vegetable mould, suits $\mathrm{S}$. retusa, and S. Wulfeniana. The Tyrolese species (S. biflora, S. Rudolphiana, and $\mathrm{S}$. Kochi) are less easy to please. They grow wild on the moraines of glaciers, where light vegetable soil, sand, and debris of every kind blend with massive rocks, coating the surface, and filling the interstices; where water drips or oozes around, and frequently flows in volume within 2 or $3 \mathrm{ft}$., so as to soak the bases of the rocks on which their rosy carpet is spread. They will grow in pots, but rarely with the freedom which characterises the varieties of S. oppositifolia.

S. peltata.-The shield-like leaves of S. peltata make it unique among Saxifrages; and on this account some have referred the plant to a section under the name Peltiphyllum. It is about a yard high, is even more across, and is remarkably bold and handsome. From a very thick and fleshy creeping rootstock rise stout erect leaf-stalks, at the ends of which grow the targetike leaves, I ft. or more in diameter. The flowers, which are produced in spring, a little before the leaves, are borne on stalks I to $2 \mathrm{ft}$. high, in loose clusters 3 to 6 in. in diameter, and are about $\frac{1}{2}$ in. across, and of a white or pale pink. It is found in the neighbourhood and in the beds of quick-running streamlets throughout the Sierra Nevada of California. It succeeds best in a deep moist border of peaty soil. It is easily propagated by division, or by seeds, which in some seasons are produced in abundance.

S. purpurascens is, perhaps, the finest of the Magasea section. It is neatly edged with red, which colour is conspicuous in the midrib. The stem rises to a height of Io or 12 in., and is considerably branched; and the flowers are produced in pendent masses of red and purple. Though by no means a rapid grower, S. purpurascens possesses a vigorous constitution, and is perfectly hardy. It succeeds best in a moist peaty soil in a rather sheltered spot. High elevations about Sikkim.

S. Rocheliana (Rochel's Saxifrage).A very compact and dwarf kind, forming dense silvery rosettes of tongue-shaped leaves, with white margins and distinct dots. It is distinguished among the dwarf silvery Saxifrages for producing in spring large white flowers on sturdy little stems. There is no more exquisite plant for the rock-garden, for culture in pans, and for small rocky or elevated borders. Any good, free, moist, loamy soil suits it, and in London it thrives very well on borders, but it should always be exposed to the full sun. It is fit for association with the choicest spring flowers and alpine plants. Austria. Seeds or careful division. S. coriophylla is similar but not so valuable.

S. sancta.-A beautiful species, lately come into cultivation, and not much known, yet promising to become a valuable plant for the rock-garden. It is of dwarf spreading growth, and forms a dense carpet-like mass of deep green foliage, studded in early spring with numerous bright yellow blossoms on stems an inch or so high. It seems to grow freely in any position in the rock-garden.

S. sarmentosa (Creeping Saxifrage).-

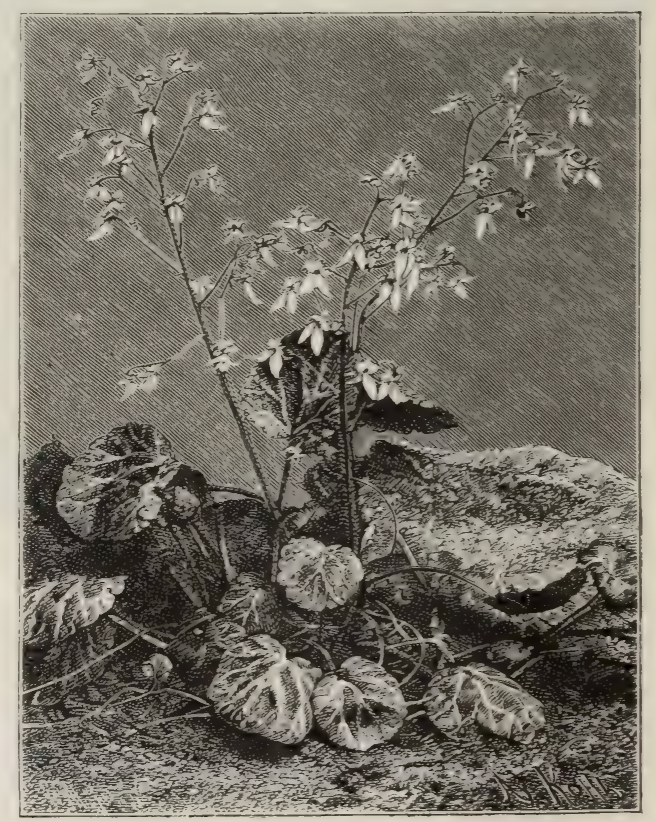

SAXIFRAGA SARMENTOSA.

A well-known old plant, with roundish leaves mottled above and red beneath, and numbers of creeping, long, slender runners, producing young plants Strawberry fashion. Striking and singular in leafage, it is ornamental in bloom. It 
grows freely in the dry air of a sittingroom, and may often be seen gracefully suspended in cottage-windows. It is, perhaps, most at home running wild on banks or rocks in the cool greenhouse or conservatory; but in mild parts of England it lives in the open air, and may be used in graceful association with Ferns and other creeping plants. China.

Flowers in summer. Closely allied to $\mathrm{S}$. sarmentosa is the delicate Dodder-like Saxifrage, S. cuscutæformis, with its thread-like runners similar to the stems of a Dodder, and distinguished from S. sarmentosa by having smaller leaves and petals more uniform in size. It serves the same purposes as S. sarmentosa, but, being much more delicate and fragile, it requires a little more care. It is a beautiful plant for growing in Moss in a cool fernery, for it is perfectly at home and the delicate markings of its leaves show to full advantage against the green of its surroundings. The plants grown in gardens, as S. japonica and S. tricolor, are considered varieties of $\mathrm{S}$. sarmentosa.

S. squarrosa.-This pigmy alpine is the smallest of the Crustaceous section of cultivated Saxifrages. When out of flower it looks like a Lichen until closely observed, but when in flower its hoary mass is studded with very pretty small white blossoms. It is somewhat difficult to grow, as it requires a fully-exposed position in deep gritty moist soil, among sandstone, in the most select part of the rock-garden.

S. Stracheyi is a strong plant with leaves nearly as broad as long. Its flowers, which are produced on broad branching panicles, are of a light pink with a shade of lilac. It is hardier than its closest ally $\mathrm{S}$. ciliata. It blooms in March; and should be sheltered against bleak winds, which would soon destroy the delicacy and beauty of its blossoms. It is suited for borders and rock-gardens.

S. tenella. - A very handsome prostrate plant, forming tufts of delicate fine-leaved branches, 4 or 5 in. high, which root as they grow. The flowers, which appear in summer, are numerous, whitish - yellow, arranged in a loose panicle. Similar in growth are $\mathrm{S}$. aspera, S. bryoides, S. sedoides, S. Seguieri, S. Stelleriana, and S. tricuspidata, all of which are suitable for clothing the bare parts of the rockgarden and slopes, but require moist soil and cool positions. Division in spring or the end of summer.

S. umbrosa (London Pride).-This al-

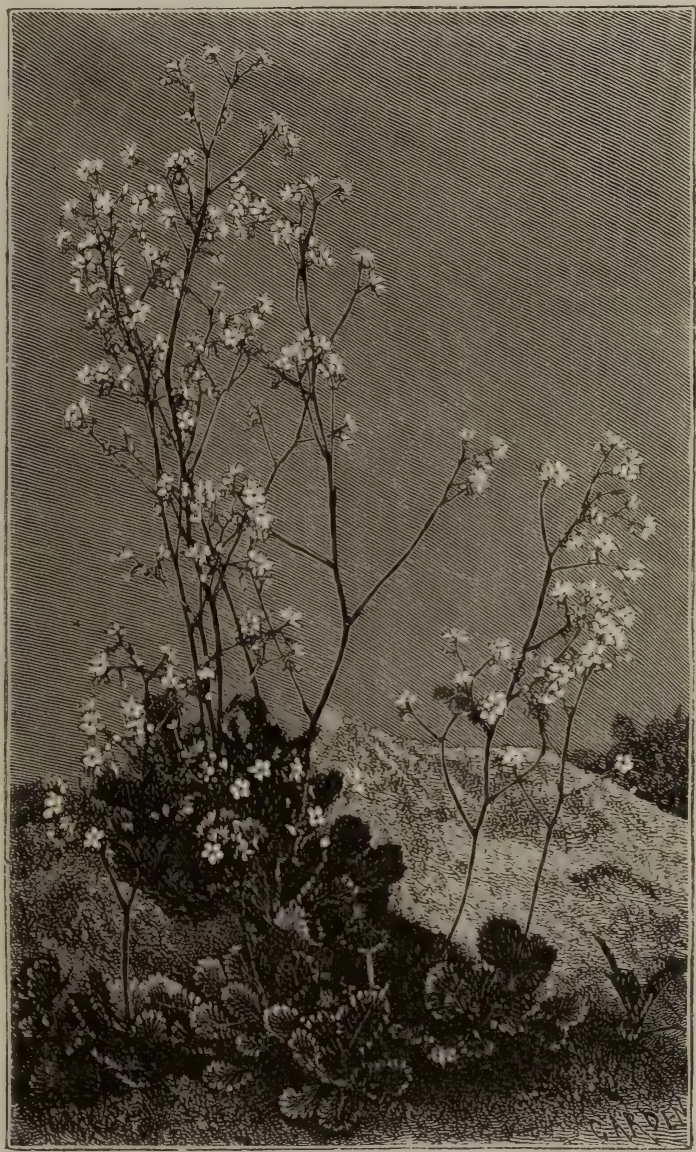

IRISH ROCKFOIL.

most universally - cultivated plant is abundant on the mountains round Killarney, though it has long been grown in our gardens. It is distinguished from $\mathrm{S}$. Geum by its oval-shaped leaves, which are narrowed and not heart-shaped at the base; and its flowers, which are a little larger and more freely dotted with red. In old gardens it is much used as an edging plant, and, being a pleasing Evergreen, should be freely used in the rough parts of rock-gardens, the fringes of 
cascades, etc. It is naturalised in several parts of England, and grows freely in dwarf herbage, or in rocky parts of woods. There are several varieties, for example, S. punctata and S. serratifolia, which are distinct enough when grown side by side, but submit to the same culture. The variety Oglevieana, a most distinct form of this species, produces pinkish blossoms in dense dwarf panicles not over $6 \mathrm{in}$. high. S. rotundifolia and similar kinds are related to $\mathrm{S}$. umbrosa, but except in botanical collections are scarcely worth culture. This plant and its forms will thrive in ordinary soil. Among the biennial species the finest is $\mathrm{S}$. atropurpurea, a very handsome plant, and for two or three centuries a favourite in English gardens. It will not fail to give satisfaction, as regards showiness or length of bloom. It will continue in bloom from June to October, and will flower through the winter if properly treated. S. atro-purpurea grows about $3 \mathrm{ft}$. high, but there is now a dwarf variety (nana) that scarcely exceeds I ft., and some consider this the more desirable, as it is neater and more compact. The

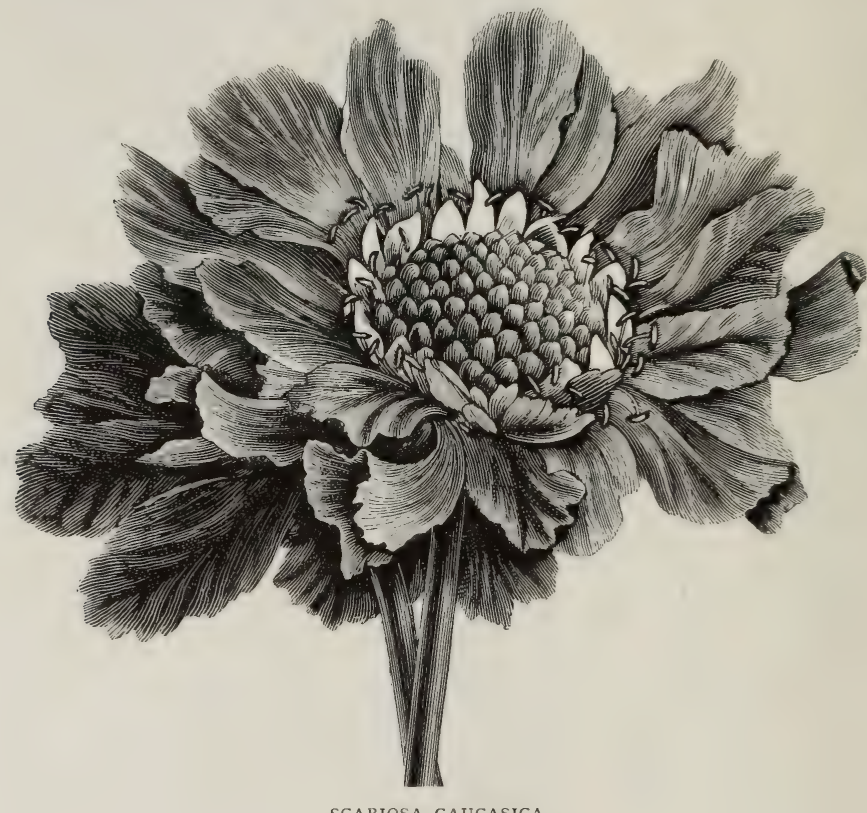

thrive in the cold shade of high walls where few other things will live.

Scabiosa (Scabious). - A small genus of the Teazel family, consisting of annual, biennial, and perennial plants, some of which are valuable garden flowers. Of the perennials in cultivation, which number about a dozen, by far the finest is S. caucasica, which grows $\mathrm{I} \frac{1}{2}$ to $3 \mathrm{ft}$. high, and bears in summer large heads of pale lilacblue flowers on long slender stalks. It is a large spreading plant, and requires plenty of room. As it grows freely in open situations on ordinary soil, it is excellent for naturalising. Less desirable though pretty plants are S. graminifolia, which is about 18 in. high, and has pale blue flowers, and S. Webbiana, a very dwarf tufted kind with white flowers. colour of S. atro-purpurea is a deep rich maroon-crimson, but there is a white kind. There is also a variety with deep purple flowers margined with white ; and another (striata) with streaked and spotted flowers. The very distinct variety foliis aureis has yellow leaves, and its flowers have a sweet musky odour and are peculiarly suited for cutting. Being biennial, S. atropurpurea requires to be raised annually from seeds, which should be sown in good soil in the reserve border in March or April, and when large enough the seedlings should be well thinned. In autumn they may be transplanted to their permanent places in the borders. Thus treated they will become strong before winter, flower early in the following summer, and produce an abundance of seed. 
If sown under glass earlier in the year the plants will flower the same year. The dwarf Scabious is now used for potculture in winter, and hence seed is sown in summer, and the plants are strongly grown for winter-flowering. It is one of the most useful plants for cut blooms.

Scabious, Giant (Knautia).

Scaly Fern (Ceterach officinarum).

Scarborough Lily (Vallota purpurea).

Scarlet Painted Cup (Castilleja coccinea).

Scarlet Twin-flower (Bravoa geminiflora).

Schistostega pennata (Iridescent Moss).-Mosses are small, but this is so very small that it would hardly be noticed by the naked eye but for the iridescent gleams of beautiful colour which it displays in positions where it flourishes. It is no exaggeration to say that some of the stones and sods on which it grows look as if sown with a mixture of gold and the material that forms the wings of green humming-birds. It is almost startling to see this little gem for the first time, no "plant" being visible to the casual observer. It was supposed to require a particular kind of rock ; but its wonderful coruscations have lately been seen to spread over sods of turf and masses of peat, as well as over chips of rock brought from its native place. Messrs. Backhouse have it in perfection in the open air, in a quiet deep gorge of rocks, where it obtains sufficient moisture without being washed by rains, and also in their underground fernery, which was constructed for the rarer filmy Ferns. This proves that there is no insurmountable difficulty in establishing it in such positions; and certainly the most graceful dwarf Fern or the biggest Tree Fern is not capable of giving a more decided charm than this diminutive Moss.

Schivereckia podolica.-This small hardy alpine of the Crucifer family is nearly allied to Alyssum. It has hoary foliage, and produces, in early summer, a profusion of small white blossoms. It is suited for the rock-garden or the margins of borders, and will grow well in any ordinary soil. It is not of the first merit. South Russia.

Schizandra.-Of this genus of climbing shrubs S. chinensis and S. coccinea are hardy enough for open-air culture, and may be used for clothing walls, arbours, and the like. S. chinensis is a native of Northern China, and S. coccinea is an old introduction from N. America. Both have tall, slender, twining stems, large leaves, and inconspicuous flowers, which in the case of $\mathrm{S}$. chinensis are succeeded by small scarlet berries. Neither kind is important, and both are difficult to obtain.

Schizanthus.-Very pretty annuals of elegant growth, which produce in summer many showy and curiously - shaped blossoms. There are in cultivation three or four species, and these have yielded numerous varieties. $S$. pinnatus is a hardy annual, $\mathrm{I} \frac{1}{2}$ to $3 \mathrm{ft}$. high, and its rosy-purple and yellow blossoms are copiously spotted. Its chief varieties are - papilionaceus (purple spotted), Priesti (white), atro-purpureus (deep purple with dark eye), and Tom Thumb (a dwarf compact variety). S. porrigens is similar to S. pinnatus, but has larger flowers. These kinds are hardy and may be sown in spring or autumn in light sandy loam in the open border. The half-hardy kinds are S. retusus (deep rose and orange flowers with crimson tips), Grahami (lilac and orange), and Hookeri (pale rose and yellow). These are also very beautiful, and worthy of being grown well. If treated as half-hardy annuals, the seed should be sown in heat in spring, but if treated as biennials, the seed should be sown in August, the plants preserved in the greenhouse till May, and then planted out. Like the hardy kinds they prefer a good, rich, sandy loam. Chili.

Schizopetalon Walkeri.-A singular Cruciferous half-hardy annual about I ft. high. It has slender stems, and its numerous white almond-scented blossoms are elegantly fringed. If sown in April or May, in light, warm, rich soil in the open border, it flowers in July and August. It may also be sown in pots, but the ball of earth should be transferred to the border without disturbance, for the plants do not well bear transplanting. Chili.

Schizophragma hydrangeoides (Climbing Hydrangea). - A climbing shrub allied to the Hydrangea. Its tall slender stems send out roots which will fix it to a wall. In favourable situations, when fully grown, it produces flat clusters of white or pinkish flowers similar to those of the Hydrangea. It is interesting but not important, and has not yet come into general cultivation. Japan.

Schizostylis coccinea.-A handsome bulbous plant with the habit of a Gladiolus. It is 2 to $3 \mathrm{ft}$. high. The flowers are produced late in autumn and appear on a one-sided spike opening from below upward. They are of a bright crimson colour, and resemble in form those of Tritonia aurea. S. coccinea is very useful, and should be extensively grown 
wherever cut flowers are in request during the winter. It is perfectly hardy, and in a mild autumn will flower out-of-doors, but it should have some protection from inclement weather. A good row planted close to a wall or fence, and having some temporary protection against severe frosts, will yield a great many spikes for cutting. $\mathrm{S}$. coccinea loves moisture both in the air and in the soil. "When residing close to the sea in Dorset," says West Dorset, "I could grow this winter Flag splendidly. I used to grow it in a shallow trench in good rich soil. In summer it was deluged with water when the weather was dry, and in autumn a splendid crop of strong spikes of bloom resulted. In North Hants, with a hot, dry, light soil, I never could grow it with any degree of satisfaction, although I always kept it well watered at the roots during summer." Caffraria.

Scilla.-The Squills comprise a numerous genus of bulbous plants, few, however, being suitable for garden cultivation; but such as are, are indispensable. These all flower in spring ; and some indeed bloom even before spring. They are of the simplest culture. In early autumn, when the plants are at rest, they should be planted a few inches deep in any good garden soil that is not too heavy. If, when established, they are not disturbed for years, except, perhaps, for a slight yearly topdressing of manure, their annual display will amply reward any trouble that has been taken. Some kinds, especially the many-coloured varieties of the Spanish Squill (S. hispanica-syn., S. campanulata) and the English Squill (S. nutans), are admirably suited for placing by the sides of woodland walks, on the margins of shrubberies, in the wild garden, etc., where they form attractive features in spring.

As regards propagation, offsets may be taken from established clumps during summer. Raising Squills from seed is very interesting, though somewhat slow. In some seasons the seeds are produced plentifully, and many varieties of real merit, both as regards size and colour, have been obtained by this mode of propagation, but there is still room for improvement in this direction.

The following is a selection of the best kinds :

S. amœna.-A distinct Squill, flowering in early spring, and opening about three weeks after S. sibirica. It is readily known by the large yellowish-green ovary which is conspicuous in the centre of the dark indigo-blue flowers. Though sufficiently attractive to merit a place in a border or in a collection of hardy bulbs, S. amœna is less ornamental than any other Squill, for its flowers are sparse and rigid, with none of the grace of $\mathrm{S}$. campanulata and the varieties of S. nutans, and none of the dwarfness and brilliancy of S. sibirica. The leaves, usually about half an inch across, attain a height of about I ft. They are very easily injured by cold or wind, so that a sheltered position is best suited to the wants of the plant. S. amœna is not exactly suited for the choice rock-garden, though it is worthy of being grown on sunny banks in semi-wild spots. Tyrol. Seeds or separation of the bulbs.

S. bifolia.-Although not nearly so well known or so popular as S. sibirica, $\mathrm{S}$. bifolia is quite as worthy of cultivation. In the very dawn of spring, and indeed often in winter, it bears rich masses of dark blue flowers, and forms very handsome tufts of vegetation. The flowers are four to six on a spike ; and the plant varies from 6 to ro in. high, according to the richness and lightness of the soil, and the warmth and shelter of the position. $\mathrm{S}$. bifolia thrives in almost any position in ordinary garden soil, the lighter the better. Although the plant blooms earlier than S. sibirica, it does not so well withstand the cold rains and the storms of winter and spring, and therefore some tufts of it should be placed in warm sunny spots of the rock-garden or of the sheltered border. Southern and Central Europe. The varieties are numerous and important. The following are most distinct and the most worthy of cultivation : alba, candida, carnea, compacta, maxima, metallica, rosea, pallida, præcox, and taurica. The name S. præcox, which so often occurs in gardens and in catalogues, does not belong to a distinct species, but refers to the variety of $\mathrm{S}$. bifolia which usually flowers somewhat earlier than the common form. The variety taurica is very handsome, and is larger and more robust than the type ; while its flowers are larger and more numerous, and it has several leaves, thus departing from the bifoliate character generally though not uniformly observed by the type.

S. campanulata (Spanish Scilla).-A vigorous species, long cultivated in England. It is one of the finest of early summer bulbs, and, though a more southern species than most of the others, it is the most robust of the family. It is I 2 to $18 \mathrm{in}$. high. S. campanulata is easily known by its strong pyramidal raceme of pendent, short-stalked, large, bell-shaped flowers, usually of a clear light blue. A 
variety major is larger in all its parts, and is a noble flower; while the white variety (alba) and the rose-coloured variety (rosea) are also excellent kinds. S. campanulata is never seen to greater advantage than when peeping here and there from the fringes of shrubberies and beds of Ever-

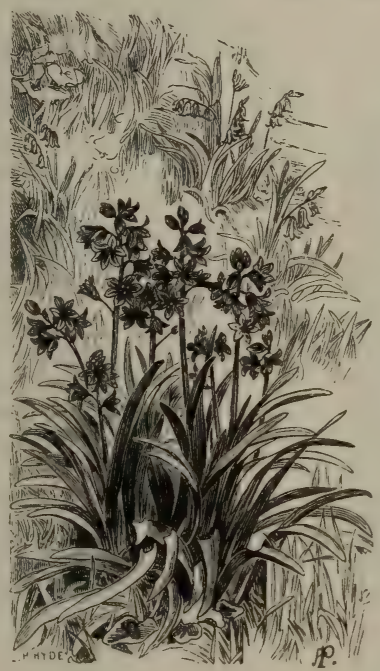

SCILLA CAMFANULATA.

greens. The shelter it receives in such positions protects its very large leaves from strong winds, but it is sturdy enough to thrive in any position. It deserves to be naturalised by wood-walks and in the grassy parts of the pleasure-ground. S. Europe. $=\mathrm{S}$. hispanica.

S. italica (Italian Squill). - This Squill, with its pale blue flowers, intensely blue stamens, and delicious odour, is one of the most interesting and distinct of cultivated kinds, if not the most brilliant of them. It grows from 5 to Io in. high, the leaves are somewhat short, slightly keeled and oblique, and the flowers are small and spreading in short conical racemes, which open in May. S. italica is perfectly hardy, living in almost any soil, but thrives best in warm and sandy ones. Division should be performed only once every three or four years, and the bulbs should then be planted in fresh positions. S. italica is worthy of a sunny but sheltered spot on the rock-garden, particularly as it does not thrive so freely as some of the other Squills. Italy and S. Europe.

\section{S. maritima.}

S. nutans (Wood Hyacinth or Bluebell).- Though the Bluebell abounds in every wood and copse, its beautiful varieties are not so well known as they deserve to be. They are fitted to be great ornaments of the early summer garden, and amongst the best are-the white variety, alba; the rose-coloured variety, rosea; the pale blue variety, cœrulea ; and a pleasing "French-white" variety. The variety bracteata is interesting on account of its long bracts, and cernua is a Portuguese form with reddish flowers. S. patula is closely allied to the Bluebell. Its flowers are of a pleasing violet-blue, but are not sweet or arranged on one side like those of the Bluebell. They are larger and more open, and have narrow. bracts. All these kinds are highly suitable for planting here and there in tufts among common Bluebells, along the margins of shrubberies or near the rock-garden, or for borders, or for the spring garden, or for woods.

S. peruviana.-A noble plant, not, however, a native of Peru. It grows from 6 to I 8 in. high, and flowers in May and June. The flowers, which are a fine blue and very numerous, are arranged in a superb, regular, umbel-like pyramid, - which lengthens during the flowering period, the white stamens contrasting charmingly with the blue of the flowers. Though it thrives in many parts of these islands, it suffers from cold soils; and therefore, in all but the warmest parts, should be given a somewhat elevated, warm, and sheltered position, and deep, light, and welldrained soil ; the bulbs, which are large and pear-shaped, being planted 6 in. below the surface. It is really a native of Southern Europe and North Africa; and deserves a sheltered sunny nook in every rock-garden, and on every warm raised bed or border devoted to choice hardy bulbs. There is a white variety (alba), which is not quite so beautiful, and there are reddish varieties, such as sub-carnea and elegans, and also whitish and yellowish varieties, such as pallidiflora, flaveola, and sub-albida. S. Hughi, a robust form of S. peruviana, has flower-stalks tinged with red. It is a native of the island of Maretina near Sicily. S. Cupani, another Sicilian Squill, is similar to the Peruvian Squill, but is less showy. Tufts of the Peruvian Squill should be taken up every three or four years, when it is at rest, the bulbs should be divided, and immediately replanted.

S. sibirica (Siberian Squill). - A minute gem among the flowers of earliest spring, and no rock-garden, or garden of any kind, is complete without the striking and peculiar shade of porcelainblue which distinguishes this plant from 
all others of the species. S. sibirica has had a great number of other names, but, unlike S. bifolia, it has sported into few varieties, $\mathrm{S}$. amœnula being the only one worth mentioning. S. amœnula, though not really distinct, is desirable, because it flowers a fortnight earlier than the type. Varieties with larger blossoms and with one blossom on a stem instead of two or five blossoms are preserved in herbariums

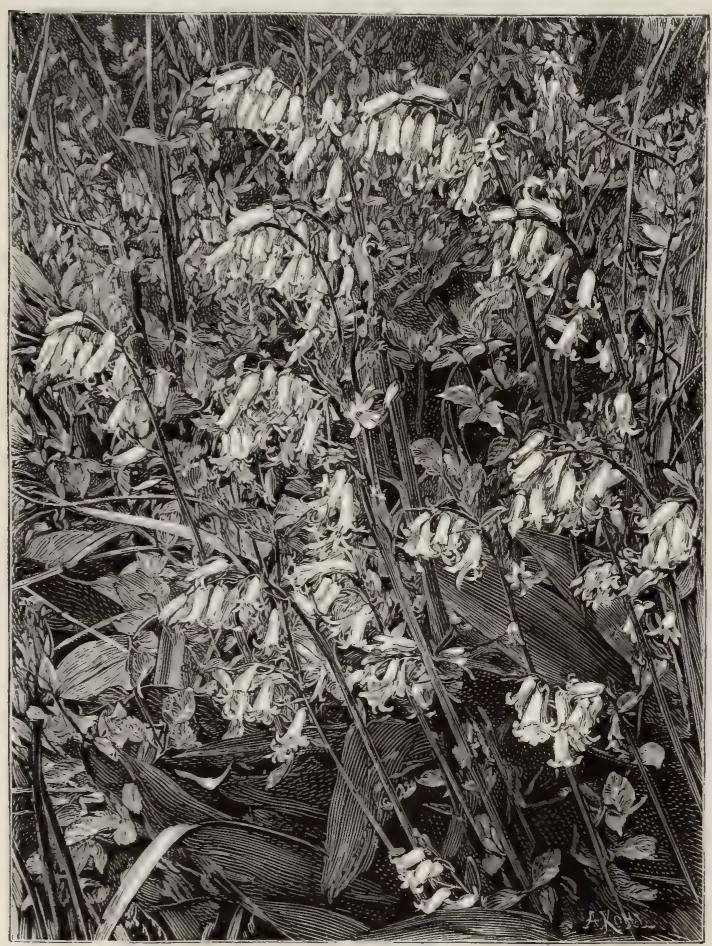

SCILLA NUTANS (BLUEBFLL).

and are occasionally cultivated, but the difference between these varieties and the type is only trifling, and often arises from the conditions in which the plants are placed. S. sibirica is perfectly hardy, and thrives best in a good sandy soil. Bulbs that have been used for forcing should never be thrown away; for they thrive well if in a pit or frame allowed to fully develop their leaves and go to rest, and are afterwards planted out in open spots in warm soil. It is unnecessary to disturb the tufts, except every two or three years for division, when they grow vigorously. S. sibirica flowers in very early spring, a little later than S. bifolia, but withstands the storms better, and remains much longer in bloom. In places where it does not thrive very freely, whether from the coldness of the soil or from other causes, it would be well to give it a sheltered position, so that its leaves may not be injured by the wind, and the plant itself thereby weakened. The Siberian Squill may be used with good effect as an edging to beds of spring flowers or choice alpine shrubs.

OTHER CUltivated KindS.-S. verna and S. autumnalis are only worthy of cultivation in botanical collections. The plant usually sold as S. hyacinthoides is occasionally S. patula and sometimes S. campanulata ; and the true S. hyacinthoides is scarcely worthy of cultivation. S. cernua is not sufficiently distinct from $\mathrm{S}$. patula. One or two southern species allied to S. peruviana are not sufficiently hardy for general cultivation.

Scirpus.-Sedge-like plants of no value, except for fringing artificial lakes and ponds, which too often present a bare appearance. There are numerous native species that might be readily transplanted, and the best are $\mathrm{S}$. triqueter, $\mathrm{S}$. atro-virens, and S. lacustris. $\mathrm{S}$. lacustris (Bulrush) is 3 to $8 \mathrm{ft}$. high, and is very effective on the margins of lakes or streams associated with other tall and imposing aquatic plants.

Scoliopus Bigelowi. - A very singular dwarf Liliaceous plant allied to Trillium. It has a pair of broad oval leaves, and bears in summer several dull inconspicuous flowers. It grows well in shady and moist peat borders, but is only to be recommended for the curious garden. California.

Scolopendrium vulgare (Hart's tongue) is one of the best known of all hardy evergreen British Ferns. It has broken into numberless interesting forms and varieties, some of which are very striking and beautiful. It is a wonderfully accommodating plant, and so various are the places in which it thrives that good use may readily be made of it. It prefers a shady situation, and though it is sometimes met with on dry stone and brick walls, its favourite position is by the side of a stream in a shady ravine. Fine specimens have been seen between the joints of brickwork at the tops of old 
wells, and in such positions the fronds have been known to attain wonderful dimensions. The first point to be considered is the provision of suitable soil, for if treated on the supposition that any soil is good enough, failure will result. A suitable compost for it is made of about equal portions of fibrous peat and loam, good sharp sand being added, together with a fair supply of broken oyster-shells or limestone. Scolopendriums should be associated with Lastreas, Polystichums, and Lady Ferns, or be placed in groups on the rock-garden in conjunction with some flowering plant that will thrive in the same soil and conditions. During hot dusty weather in summer a daily afternoon syringing will much refresh and invigorate the plants. All the Hart'stongues thrive in pots, and are useful for rooms and tables.

No fewer than 400 varieties of the Hart's-tongue'were described thirty years ago, and since then this number has considerably augmented. Most of these, however, are deformities - vegetable cripples, so to speak - and only one-fourth are really worth cultivating. A few of the characteristic forms of each group might be used with advantage where collections of hardy Ferns are being formed, being evergreen and possessed of great diversity of form. Scolopendriums supply a type of foliage uncommon among hardy Ferns. Of the following selection, commencing with simple forms and ending with muchdivided ones, S. latifolium is a fine bold variety, having ovate or oblong fronds, 8 to ro in. long, and 2 to 3 in. broad, with a wavy margin and an obtuse point. The plant is of a spreading habit, and its broad bright green foliage looks very fine when seen from above. S. reniforme has oblong, roundish, or kidney-shaped fronds, 4 to 6 in. in length, and $I$ to 2 in. in breadth. S. cornutum is an interesting form with similar fronds. The midrib terminates a short distance below the point of the frond, and is prolonged into a horn-like appendage. S. marginatum is a very distinct variety. Its fronds have linear points, distinctly crenated margins, and a prominent vein underneath close to the edge. Some of the best forms of S. pinnatifidum are very attractive and have fronds cut into blunt or acute lobes, nearly to the midrib. S. crispum is an old favourite, and is by far the prettiest of the simple forms; its fronds retain the habit of the type, but the margin is regularly undulated or frilled. A form of it called grandidens has its margin deeply incised. Stansfieldi is a form with curled and twisted incisions, and Wrigleyi is a luxuriant form with erect fronds upwards of $3 \mathrm{ft}$. in length. S. laceratum has broad flat fronds, deeply cut into lobes of variable length and breadth, some measuring 3 in. in length. S. sagittato-cristatum has three-lobed or sagittate fronds, with wavy margins and lobes surmounted with a crest. In the singular form called $\mathrm{S}$. cervi-cornu the lower part of the frond is narrow, and the upper part is divided into two, three, or more divisions of slender erect teeth. The very narrow blade of $\mathrm{S}$. contractum has a toothed margin and a terminal flat hemispherical crest of serrated lobes. S. acrocladon has a narrow frond slightly widened at the base, and divided at the upper end into several wedge-shaped divisions, which have their upper margins deeply incised. S. sagittatopolycuspis is a robust form, with the lower lobes enlarged and the upper portion deeply cleft. The separate divisions are cut into acuminate lobes, variously twisted. S. patulum is one of the ramose type. Its fronds are cut down near to the base into two or three divisions, each having a narrow wing and a broad terminal crest of flat-pointed lobes. S. digitatum is an extremely elegant plant. Its fronds, I ft. or more in length, are divided in a digitate manner, and the divisions are terminated by a multifid crest of forked and twisted lobes. S. tortuoso-cristatum is an interesting form allied to S. digitatum. Its divisions are incised to the base; its terminal crest is variously contorted; and its fronds form a cushion-like mass, I ft. in breadth. S. Elworthi is not more than 6 in. in height. It has a profusion of fanshaped fronds divided into three to five triangular divisions, and the margins of these divisions are cut into roundish lobes and crenelles. S. Gloveri has the central rib of the fronds cut into four or five divisions, which are flat, palmate, and regularly crenate. The fronds of $\mathrm{S}$. concavo-ramosum are divided into four or five distinctly-stalked divisions, with triangular blades. The lower half of these blades is laciniated at the edges, and the upper half is deeply cleft and forked. S. Kelwayi is a handsome form, the fronds of which terminate in a large crest, 6 to Io in. broad. S. ramosa-marginatum resembles S. Kelwayi in form of frond, but has a broad-winged stalk, and its crest is nearly flat and is not unlike the tasselled frond-extremity of the maximum form of Pteris serrulata cristata. The base of the frond of S. corymbiferum is like the type, but the upper half has 
innumerable contorted and twisted incisions and looks like the leaf-ends of some of the ragged Kales. S. Coolingi is very similar to S. corymbiferum, but the divisions form an intricate mass of slender segments, curled and twisted in various ways so as to form a globular head. This kind of division represents the extreme form of variation.- J. M. S.

Scolymus (Oyster Plant). - Large coarse Composites with Thistle-like leaves and bright yellow flowers. The plants are not suitable for the ordinary border, but in the rougher parts of the garden are effective in bold masses. S. hispanicus, a perennial, is the best known, and $\mathrm{S}$. grandiflorus is the handsomest. Both grow well in an open position in light sandy soil. S. maculatus is an annual with silvery blotched foliage, but is scarcely worth attention.

Scorpiurus. - Curious annuals of the Pea family.

Scrophularia (Figwort). - The only kind worth mentioning is the variegatedleaved variety of the common native S. nodosa. This is useful as an edging to tall perennials, and in summer its green and white foliage is very handsome. It requires a good soil, and should be frequently pinched to prevent its flowering. The flowers are inconspicuous. Cuttings in autumn or division in spring.

Scutellaria (Skullcap).-Hardy perennials. Several species are in cultivation, but only a few of them are good garden plants. These few are handsome flowers for the border, and on account of their dwarf neat growth may be given a place in a large rock-garden in an open sunny situation in any kind of soil. Division or seed. S. macrantha, a native of Siberia, is the finest of all the species. It is an excellent alpine perennial. It forms a hard woody root-stock, is 9 in. high, and produces an abundance of rich, velvety, dark blue flowers, much finer in colour than those of S. japonica. S. japonica is, however, a handsome plant. The alpine Skullcap (S. alpina) is a spreading plant with all the vigour of the coarsest weeds of its Natural Order, but neat in habit and ornamental in flower. The stems are prostrate, but so abundant that they rise in a full round tuft, I ft. or more high in the centre. The leaves are ovate, roundish or heart-shaped at the base, and have very notched and very short stalks, while the flowers are borne in terminal heads, short at first, but afterwards elongating. These flowers are purplish, or have the lower lip white or yellow. The variety bicolor, with the upper lip purplish and the lower white, is very pretty. S. lupulina is a very ornamental kind with yellow flowers. Pyrenees, Swiss and Tyrolese Alps, and many other parts of Europe and Asia. Division. Flowering freely in summer. These kinds are admirably suited for borders, the margins of shrubberies, and the rougher parts of the rock-garden. S. japonica, S. orientalis, S. scordiifolia, S. altaica, S. galericulata, S. peregrina, and the British S. minor, an interesting little plant for the artificial bog, are among the best of the other cultivated kinds, but it is doubtful if they are worth a place in any but a very large collection.

Scypanthus elegans (Cup-flower).A beautiful slender climber, 5 to $8 \mathrm{ft}$. high, with forked stems, and valuable for trailing over a trellis or against a wall. Its leaves are deeply cut and enhance its graceful appearance. The flowers are produced singly in the forks of the branches. They are cup-like in shape, and are of a bright golden-yellow, with fine red spots inside. They appear profusely from August till October. S. elegans is easily cultivated in rich light soil, and should be treated as a half-hardy annual. Chili. Loasaceæ.

\section{Sea Bindweed (Convolvulus Solda-} nella)

\section{Sea Cottonweed (Diotis maritima). \\ " Heath (Frankenia levis). \\ , Holly (Eryngium maritimum). \\ "Lavender (Statice). \\ "Pea (Pisum maritimum). \\ Pink (Armeria).}

Sedum (Stonecrop).-The Stonecrops, like the Houseleeks and the Saxifrages, are among the commonest of garden plants. They may be grown in the ordinary border, in the rock-garden, on walls, and on ruins, and, indeed, in any place where the roots can obtain a foothold. Like the Saxifrages, they represent a great diversity of habit, some, like S. acre, being humble and creeping; while others, like S. spectabile, are stately plants for the border. A great many are in cultivation, and we mention the most desirable of the hardy kinds, which are nearly all easily-cultivated perennials.

S. acre (Wall Pepper).-This little plant, with its small, thick, bright green leaves and its brilliant yellow flowers, grows abundantly on walls, thatch, rocks, and sandy places. The variegated variety (aureum) has shoots with tips of a yellow tone in early spring, and the tufts or flakes look quite showy. The silvery tones of the variety elegans are not so effective; nor is the plant so vigorous as 
the variety aureum. This is a beautiful plant for the winter garden; its golden tips peep out in November, and only vanish with the heat of May. S. sexangulare is similar to $\mathrm{S}$. acre.

S. Aizoon is I ft. or more in height, and has erect stems terminated by dense clusters of yellow flowers. It is hardy, and is an old garden plant suitable for the border or for the large rock-garden. It requires open positions and a light soil. Siberia and Japan. S. Maximowiczi and S. Selskyanum are similar kinds.

S. Anacampseros (Evergreen Orpine). thick leaves and inconspicuous flowers. Other Sedums are nearly allied to it ; for instance, S. dasyphyllum, S. glanduliferum, S. farinosum, and S. brevifolium ; but although these are hardy on walls and rocks, they have not the vigour of many Stonecrops, and it is desirable to establish them on old walls or on dry stony parts of the rock-garden, so as to secure a stock in case the plants perish in winter.

S. kamtschaticum (Orange Stonecrop). - A broad-leaved prostrate species, not unlike S. spurium in habit, but dis-

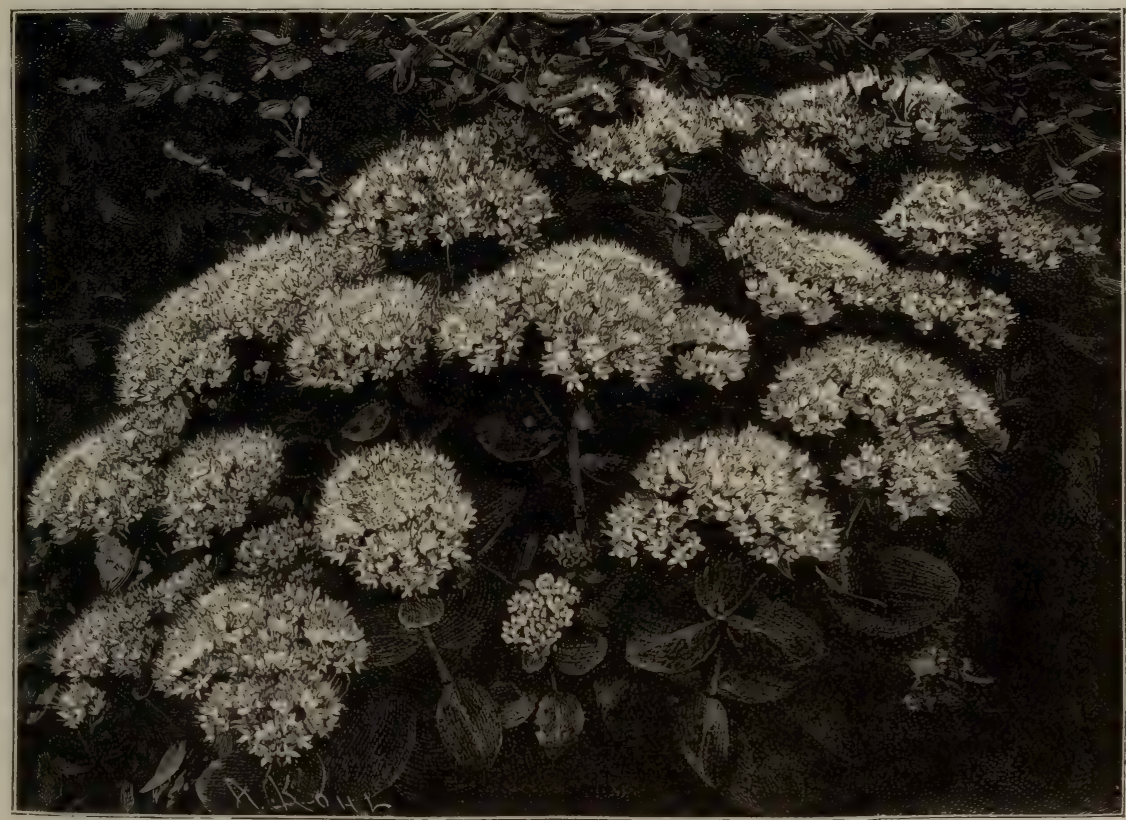

THE JAPANESE STONECROP (SEDUM SPECTABILE).

-Easily recognised by its glaucous leaves, which are entire and very obtuse. They are closely arranged in pyramidal rosettes on prostrate branches that do not flower. The rose-coloured flowers are in corymbs, and are not very ornamental, but the distinct aspect of the plant may secure it a place among dwarf border plants. Alps. Flowers in summer. Division.

S. Ewersi,-A neat little plant, rarely more than 3 in. high. It has broad glaucous leaves and corymbs of purplish flowers; is of a silvery hue, and fragile appearance, though quite hardy. N. India and Asia.

S. glaucum.-A minute species of a greyish tone, forming dense spreading tufts of short stems, densely clothed with tinguishable from it by dark orangeyellow flowers. It flowers profusely in summer, and is quite hardy in almost any soil, but succeeds best in a warm rich loam.

S. Lydium. - A pretty little plant scarcely an inch high. It is similar to S. glaucum, except that the tiny crowded leaves are greenish and tipped with red. For edgings, or for slopes bordering footpaths, it is not excelled. In the rock-garden it shows much less to advantage than when grown where it can get plenty of moisture. It roots on the surface with great rapidity, and may, therefore, be speedily propagated. Very small pieces put in the soil in spring soon form a mass of verdure, scarcely 
exceeding an inch in height, and as level as a turf. Its rich verdure is pleasant to the eye, and neat, and requires very little attention to keep it in this condition. In spots where turf will not thrive S. Lydium will do well. It is known also as S. lividum, S. pulchellum, and S. anglicum. Asia Minor.

S. maximum.-A large species. Like $\mathrm{S}$. Telephium it is extremely variable, there being no fewer than a dozen named varieties. Of these by far the most important for the garden is hæmatodes, or atro-purpureum as it is commonly called, from the vivid purple of the stems and of the large fleshy leaves. It grows from I to $2 \mathrm{ft}$. high, and though the flowers are not very showy, it is a most telling plant, being bold and stately, and admirably suited for massing. It should be planted in the poorest, stony, gravelly soil, and smoke will not injure it. On white calcareous rockwork it is all that can be desired.

S. pulchellum (Purple American Stone$(r o p)$. - A very pretty species, distinguished by purplish flowers, which are arranged in several spreading and recurved branchlets, bird's-foot fashion, with numerous spreading stems densely clothed with obtuse alternate leares. S. pulchellum is abundant in North America, and though not common in our gardens, it is far more worthy of cultivation than many plants commonly grown. In France it is a good deal used for edging, for which purpose it is well suited. It is also highly appropriate for the rock-garden or the front margin of a mixed border, growing in any soil, and flowering in summer. Division.

S. rupestre (Rock Stonecrop).-A glaucous, densely-tufted native plant, with rather loose corymbs of yellow flowers, and numerous spreading shoots generally rooting at the base, but quite erect at the top. It is frequently used as an edging or border plant, though it is less ornamental than some kinds more rarely grown. There are several similar kinds, such as S. pruinatum, a handsome glaucous-leaved kind, commonly known as S. elegans; S. Fosterianum, with light green leaves; and S. reflexum. S. reflexum has several varieties, including cristatum, a curious crested variety, sometimes known as monstrosum or fasciatum. S. album, another native kind, has brownish-green leaves and white or pinkish flowers. It is as easily cultivated as the common Stonecrop, and like that plant occurs on old roofs and rocky places in many parts of Europe. All these kinds are worthy of naturalisation on walls or old ruins, in places where they do not occur naturally, and also on the margins of the pathways and on the less important surfaces of the rockgarden.

S. sempervivoides (Scarlet Stonecrop). - This beautiful and distinct Stonecrop has rosettes of leaves like those of the common Houseleek (Sempervivum tectorum). These leaves are thick, fleshy, and a pale green blotched with reddishbrown. The small flowers are of a brilliant scarlet, and form a dense head similar to the well-known Rochea falcata. S. sempervivoides is strictly a biennial, as it flowers from seed freely in the second year and then dies. It cannot be considered hardy, but during summer it grows freely on a dry bank, and in winter it stands a large amount of frost if the weather is dry, but frost and wet combined are fatal to it. Seeds germinate freely, and the plant is very easily managed. It should be sown in January in gentle heat, great care being taken in watering, as the seed is very fine, indeed it would be better not to water at all, but to keep the pot plunged, so that the soil may not get dry. As soon as the young plants are large enough to handle, they should be pricked off and kept near the glass, but not allowed to get dry. As soon as they are large enough they should be potted singly. If liberally watered while growing, they ought, by the end of the summer, to be as large as a crown-piece. During autumn and winter water must be withheld, and the plants only just kept moist enough to prevent their leaves from shrivelling. In spring they should be re-potted and then grown freely until the flower-spike is developed. The time of flowering depends a great deal upon treatment, time of sowing, etc., but under ordinary circumstances the plant flowers in July or August. The flowers last six or seven weeks. Asia Minor and the Caucasus. Erroneously called Umbilicus Sempervivum, this being the name of a totally distinct plant.

S. Sieboldi.-A well-known and elegant species, frequently cultivated in pots. Its roundish leaves are bluntly toothed in the upper part; they are of a pleasing glaucous tone, and in late autumn frequently assume a lovely rosy-coral hue. They are borne in whorls of three on numerous stems. In autumn these stems bear soft rosy flowers of small round bouquets. At first the boldly-ascending stems form neat tufts, but as they lengthen, 
the weight of the buds and flowers at the points bends them outwards, and makes the plant a graceful object for pots, small baskets, or vases. S. Sieboldi is hardy, and merits a place in the rock-garden, especially in positions where its branches may fall without touching the earth and its graceful habit may be seen to advantage ; but, except in favoured places, it does not make such a strong and satisfactory growth as most of the other Sedums. It is, perhaps, best seen in a frame or a greenhouse. Japan. Division. There is a variegated variety, but it is not so good as the ordinary form, and is much more tender.

S. spectabile.-This is the handsomest of the tall species, and being very distinct and beautiful, is worthy of the choicest collection of hardy plants. It is erect, and its stout stems, 12 to 18 in. high, have broad glaucous leaves. Its rosy-purple flowers are produced in dense broad corymbs, appear about the middle of August, and remain in perfection for two months or more. S. spectabile may be employed to break up the uniformity of large flat surfaces, or may be planted in the centres of beds, or on patches in borders; and where the style is formal and severe, its rigid aspect will harmonise with the surroundings; but for this purpose it is best to divide it into single crowns early in the spring. In three years a single crown will produce about two hundred plants. The glaucous foliage of this Sedum, even before the flowers, is a pleasant relief to any high-coloured plant that may be near it. It withstands extreme cold, heat, or wet. Unlike most plants it will grow and flower to perfection in shaded places ; and should therefore be generally cultivated in such situations. A rich soil suits it best, but it thrives in nearly any soil. Japan. Known also as S. Fabaria. S. erythrostichum, or albo-roseum, is a similar plant, but scarcely so handsome.

S. stoloniferum (Purple Stonecrop).Several Sedums have large flat crenate leaves, and by far the best of these is the Purple Stonecrop, the rosy-purple flowers of which compare favourably with the dull white blooms of the allied kinds. It flowers late in summer, and often through the autumn, makes a bright display, and is well suited for edgings, for the margins of mixed borders, and for the rock-garden. It is not sufficiently grown, though it is of the easiest culture and propagation. It is also known as S. spurium and S. denticulatum. Caucasus. Other species are S. oppositifolium, S. trifidum, S. dentatum, and S. ibericum, the last-named kind having white flowers.

S. Telephium. - This species of the Stonecrops is the most variable. No fewer than twenty forms have received names either as sub-species or as varieties, but our native form is as showy as any of them, and is the most desirable for cultivating as a border flower. It is I to $2 \mathrm{ft}$. high, and has stout erect stems, which are furnished with roundish fleshy leaves, and in late summer and autumn terminate in dense broad clusters of blooms, usually of a bright rosy-purple, but sometimes white. S. Telephium is distributed about the country, usually in hedgerows and thickets. Like all the other varieties and allied species of about the same size, it is particularly useful for places that are too dry for other plants, such as dry borders and the rough parts of the rock-garden, but treated liberally it will grow and flower the more vigorously. Cut blooms last a long time; indeed are so tenacious of life, that they are often called Everlasting Livelongs.

The Sedums mentioned are the most distinct and ornamental. The pretty $\mathrm{S}$. cœeruleum is an annual; S. carneum variegatum is not hardy enough for our winters. There are in cultivation many kinds of the easiest culture.

Selaginella.-A few hardy kinds of this large genus of Lycopods are valuable for carpeting the fernery, or for clothing shady spots in the rock-garden. These kinds are S. denticulata, S. helvetica, and S. rupestris, small trailing plants of a delicate green, mossy growth. S. Kraussiana, generally known in plant-houses as S. denticulata, is also quite hardy in many places, and in Ireland grows and thrives better than any of the kinds mentioned. All of these plants require a well-drained peaty soil and a shaded and sheltered position.

Sempervivum (Houseleek).-Succulent plants, many of them hardy perennials, of which the common Houseleek (S. tectorum), often seen growing in patches on old roofs and walls, is the most familiar. There is such a strong family likeness throughout, that from a knowledge of one all the others can easily be recognised. They form rosette-like tufts of fleshy leaves, which chiefly differ in the colour of the foliage, some being deep red and others pale green. The flowers of most of them are of a reddish tinge, and several are yellow, but in point of beauty the latter are not of great value. All the hardy kinds are capital subjects for dry sandy parts of the rock-garden 
where few other alpines thrive; and they are excellent also for adorning old walls, ruins, and the like, merely requiring to be placed in chinks with a little soil. Most of them will thrive in any ordinary border, if the soil be not too stiff and damp; but they prefer a dry elevated position, and full exposure to the sun. Nearly all of them are easily propagated by offsets, which,

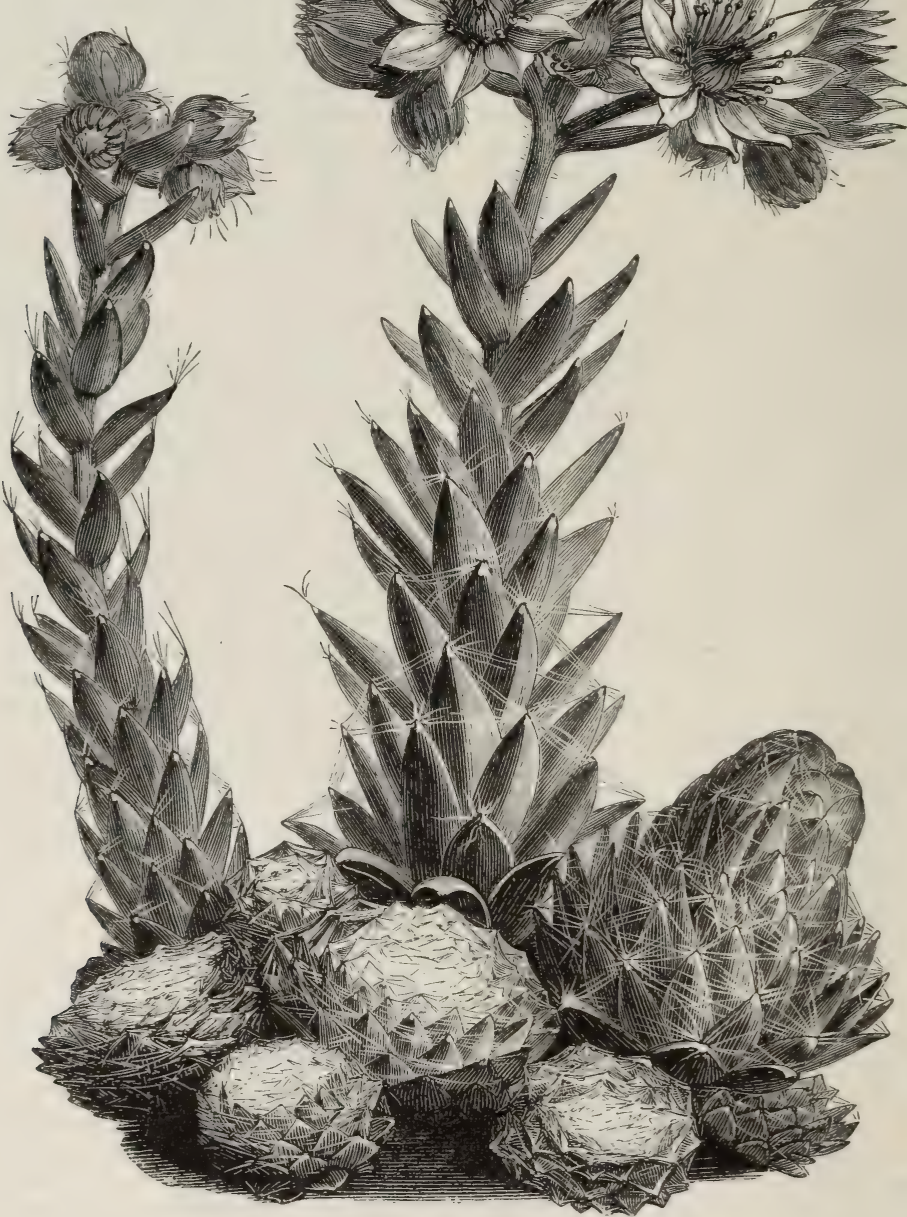

COBIVEB HOUSELEEK.

as a rule, are abundantly produced. Of late years some of the larger kinds, such as $\mathrm{S}$. calcareum, have been used for geometrical beds. Europe and W. Asia.

S. arachnoideum (Cobweb Houseleek). -One of the most singular of alpine plants. Its tiny rosettes of fleshy leaves are covered at the top with a thick white down, which intertwines itself all over the

.

\section{(1)}

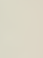


without it. Its sheets of whitish rosettes look as if a thousand spiders had been at work upon them, and in summer send up pretty rose-coloured flowers. About London it sometimes suffers from sparrows plundering the "down." Division. Similar to this species are S. tortuosum (or Webbianum of gardens), S. Fauconneti, $\mathrm{S}$. heterotrichum, and S. Laggeri, which are remarkable for having the rosettes of leaves united by a web of white threads.

S. arenarium :(Sand Houseleek).Grown in dense patches, this plant has a lovely effect. It is much smaller than S. globiferum, to which it is allied; and, unlike the latter species, the leaves of the rosettes are not incurved. The flowers are small, yellow, and pretty, and the leaves are usually a rich crimson. $\mathrm{S}$. Heufelli, a similar species, is remarkable in autumn for the rich almost chocolate-crimson tint of the foliage. The flowers of this species are yellow. Other species of similar character are S. hirtum, S. Neilreichi, and S. soboliferum, which is often confused with $\mathrm{S}$. globiferum.

S. calcareum (Glancous Houseleek).Under the name of S. californicum this species is now becoming very common in gardens, and no finer Houseleek has ever been introduced. It is as easily grown and as hardy as the common Houseleek (S. tectorum), and thrives in any soil. Planted singly, its rosettes are sometimes nearly 5 in. across, and as its leaves are of a decided glaucous tone, and are distinctly tipped at the points with chocolate, it is deservedly popular for edgings in the flower garden. It is also admirable for the rock-garden. Other cultivated kinds are S. glaucum, S. Camollei, S. Lamottei, S. Verloti, and S. juratense, and these are all desirable for a full collection. Division.

S. fimbriatum (Fringed Houseleek).One of the most profusely blooming kinds. The dark rose-coloured flowers appear in summer, and are borne on stems 6 to ro in. high. The leaves, which are in small rosettes, are smooth on both sides, and are strongly fringed, and they terminate in a long point. They are marked at the end with a large purple spot. S. Funcki, S. Powelli, S. barbatulum, S. atlanticum, and S. piliferum are similar kinds.

S. globiferum (Hen-and-chicken Houseleek.-This is one of the neatest and most distinct of the family. It grows in firm dense tufts, and its little round offsets are so abundantly thrown off that they are pushed clear above the tufts, and lie on the surface in small brownish-green balls. The rosettes of leaves are not more than $I \frac{1}{2}$ in. in diameter. The small leaves of the young rosettes all turn inward and appear of a purplish colour. In the full-grown rosettes the leaves are of a peculiar light green, and the tips of the under side are of a decided chocolate-brown for nearly one-third of their length. S. globiferum has small yellow flowers, and is admirably suited for forming wide tufts in the rock-garden, and on banks below the eye. It grows freely in any soil. It is also known as $\mathrm{S}$. soboliferum, but this is the name of another kind similar to $\mathrm{S}$. arenarium. There are several sorts in gardens which resemble this but do not possess its peculiar characteristics. Among these are S. Wulfeni, S. Brauni, S. ruthenicum, S. Pittoni, S. Zellebori, S. grandiflorum, and S. albidum. All of these have yellow blossoms, and, being distinct, are worth cultivating in a full collection.

S. montanum (Mountain Houseleek).A dark green kind, smaller than the common Houseleek, with a very pleasing, almost geometrical, arrangement of the leaves. They are ciliated, and are pubescent and glandular on both sides, and form neat rosettes, from which spring dull rosy flowers in summer. S. montanum is suitable for edgings or for the rock-garden. It grows in any soil, and is easily propagated. Alps. S. assimile and $\mathrm{S}$. flagelliforme are similar kinds.

S. Reginæ Amaliæ is one of the newest and handsomest of all Houseleeks. It forms the largest rosettes; its leaves are broad and green, tipped with reddishbrown, and its flowers are yellow, though it rarely blooms. It is not a rapid grower, and is a difficult kind to propagate, as it does not throw out offsets so freely as the others, on which account it is still comparatively rare.

S. tectorum (Common Houseleek).Though a native of rocky places in the great mountain ranges of Europe and Asia, the common Houseleek, having been cultivated from time immemorial on house-tops and on old walls, is well known to everybody. It may be used in flower-gardening for dwarf borders, etc., but it would be better to select some rarer species for this purpose. S. tectorum varies somewhat, and a glaucous form called rusticum is one of the most distinct of its varieties. Other similar varieties are Royeni, Rœgnerianum, Sequieri, calcaratum, and Greenei. Greenei is a new species, resembling the common Houseleek, but smaller. 
S. triste is distinct from other Houseleeks, as its rosettes of leaves are of a deep dull red, which makes it a handsome plant. It is about the size of $\mathrm{S}$. tectorum, and in light warm soil is quite as vigorous and rapid a grower. Its singular colour makes it a valuable contrast to other plants, but at present it is not much known.

Besides these kinds there are several tender species which are now largely used for summer gardening. The most popular of these are-S. tabulæforme, a singularly handsome kind, with broad rosettes of leaves that lie flat on the soil ; the rock-garden, and makes a beautiful dwarf edging. Similar to this, but inferior, are S. incanus, S. uniflorus, and S. carniolicus, which are good rock-garden plants. They may be increased by division.

S. artemisiæfolius is a neat little perennial, with broad clusters of showy clear yellow flowers, on stems $\mathrm{I}$ to $\mathrm{I} \frac{\mathrm{l}}{2} \mathrm{ft}$. high. The deep green leaves are finely divided, and give the plant an elegant feathery appearance. S. abrotanifolius has similar foliage, but its orange-yellow flowers are larger and are fewer in number. Both kinds are hardy European plants

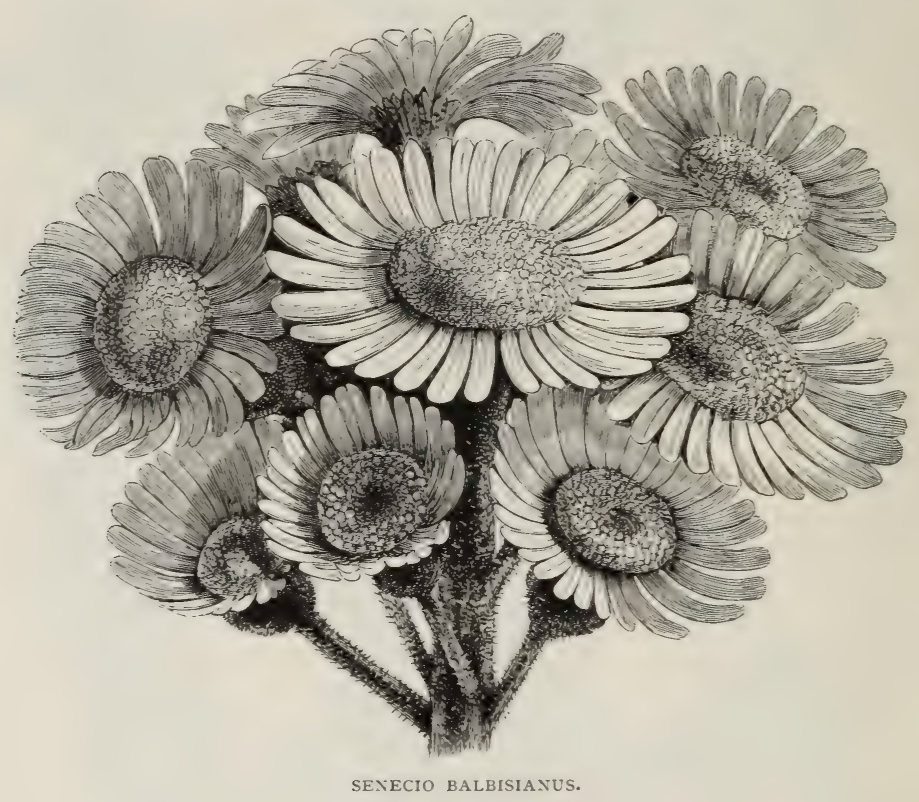

S. Bolli, with leaves that form a dense cup-like tuft from 3 to 6 in. across; and S. arboreum, a tall, straggling plant, with stout branches terminated by a rosette of foliage. Propagated by quantity in heat in spring or autumn from offsets.

Senecio (Groundsel).-Most of these Composites are troublesome weeds, but a few are worthy of cultivation. The following are among the most desirable :-

S. argenteus (Silvery Groundsel).-A minute but sturdy silvery-leaved plant, resembling on a small scale the popular Centaurea Ragusina. It is only $2 \mathrm{in}$. high when fully developed, and its leaves are from $\frac{1}{2}$ to $I \frac{1}{2}$ in. long. It will stand any weather, and live in sandy soil in any well-drained border. It is valuable for and thrive in ordinary soil either in the rock-garden or in the border.

S. Doronicum is one of the showiest and most useful of Groundsels. It is I ft. to $3 \mathrm{ft}$. high. In summer it produces stout stalks of numerous large bright yellow flowers. It is perfectly hardy and is of easy culture in any soil. Seed or division. Central Europe.

S. elegans (Purple Jacobaca).-This beautiful half-hardy annual has for generations been a favourite garden plant. It has a dwarf strain (nana), about I ft. in height, and there are varieties with single and double flowers, the latter being the showiest and most desirable. The colours of these varieties vary from white to deep crimson. S. elegans grows best in rich sandy loam. It flowers from July 
to October, according to the time of sowing; and looks best in good-sized masses. Cape of Good Hope.

S. japonicus. - This is one of the finest of the large kinds. It is about $5 \mathrm{ft}$. high, and its leaves are nearly I $\mathrm{ft}$. across, and are divided into about nine divisions. The flower-stems are slightly branched, the flower - heads are about 3 in. across, and the outer narrow florets are a rich orange colour. S. japonicus is a hardy moisture-loving plant, and should have plenty of water in summer. It should be grown in a rich and moderately stiff loamy soil, by a lake or a pond, so that its roots may have plenty of moisture. Japan. Syn., Erythrochæte palmatifida.

S. pulcher.-One of the handsomest of the Groundsels, growing 2 to $3 \mathrm{ft}$. high, and bearing in autumn large fleshy leaves, and rosy-purple flowers 2 to 3 in. across, with the stems stout and branched. S. pulcher is perfectly hardy, but its beauty is somewhat impaired by the late season of its flowering. It succeeds best in a good deep loamy soil, and should have a moist position, somewhat shaded and sheltered. It rarely ripens seed in this country, but it may be freely propagated in spring by cuttings of the roots, I in. long, and sown like seeds in a pan of light sandy earth, placed in a cool frame or put on a shelf in the greenhouse. Buenos Ayres.

S. saracenicus. - In moist situations in some parts of the west of England S. saracenicus grows wild, and attains a height of 4 to $5 \mathrm{ft}$. It is a showy plant, suitable for the margins of ponds or streams in semi-wild places, where it spreads rapidly, and if associated with the Willow Herb (Epilobium angustifolium) produces a beautiful contrast, as the habit of growth and the colour of the flowers of each are distinct and effective. Coarse species similar to this are S. Dorio and S. macrophyllus. These are suitable for the wild garden, but not for border culture.

S. spathulæfolius is a rare hardy species, and an interesting and pretty plant. The pleasing orange-yellow flowers are about the size of a shilling, and are borne in terminal clusters 6 to 12 in. high. A similar species is the Piedmont Groundsel (S. Balbisianus), from elevated districts in Northern Italy, particularly Piedmont. It is 3 to 9 in. high, and has hoary rootleaves. The golden-yellow flowers, when contrasted with the foliage, have a remarkably bright appearance. S. spathulæfolius and the Piedmont Groundsel flourish in light rubbly soil and an exposed dry situation in a well-drained rock-garden.

\section{Self-heal (Prunella).}

Senna, Scorpion (Coronilla Emerus). Sensitive Fern (Onoclea sensibilis).

Serapias.-Terrestrial Orchids from S. Europe, worthy of a collection of hardy Orchids, as the flowers are always singular and in some kinds beautiful. The most desirable are $\mathrm{S}$. cordigera, with large showy flowers, chiefly of a blood-red colour; S. lingua, with peculiar brownishpurple flowers; and S. longipetala, with large rosy-red flowers. These are all 9 to 12 in. high, and their flowers are densely arranged on broad erect stems. The plants succeed best in a soil composed of two parts of peat, one of loam, and one of sand and leaf-mould. The position should be partially shaded, and well sheltered from cold winds.

Seseli gummiferum (Gum Seseli).-A handsome plant, $I \frac{1}{2}$ to $3 \mathrm{ft}$. high, with elegantly-divided leaves of a peculiarly pleasing glaucous or almost silvery tone. Though a biennial, it is so distinct that some may like to grow it. The best position for it is on dry and sunny banks, or in raised beds or borders.

Shamrock Pea (Parochetus communis).

\section{Sheep's Scabious (Jasione)}

Sheffieldia repens.-A hardy little New Zealand creeper, with small leaves, small slender stems, and tiny white flowers which appear in summer. It is interesting for the rock-garden, and grows in any good well-drained soil. Primulaceæ.

Shortia galacifolia.-An interesting, but rare, N. American plant, about 4 in. high. It is not showy, but is a welcome garden alpine. Its leaves are Galax-like, both in form and in colour, and its white bell-flowers are borne singly on stems 3 in. high. As to its culture in this country, little or nothing is known.

Sibbaldia.-Small plants of the Rose family, resembling some of the dwarf Potentillas. S. cuneata, one of the few species in cultivation, is a dwarf alpine with small yellow flowers, and is suitable for open spots in the rock-garden.

Sibthorpia europæa (Moneywort).-A little native creeper with slender stems and small round leaves. In summer it forms a dense carpet on moist soil. It should always be grown in the boggarden, as it is a capital plant to run among taller subjects. The variegated form is far prettier; it is much more delicate than the type, and rarely succeeds in the open; but in a cool house or frame no prettier foliaged plant could be 
grown. Shady banks and ditches suit it. The flowers are inconspicuous. Scrophulariaceæ.

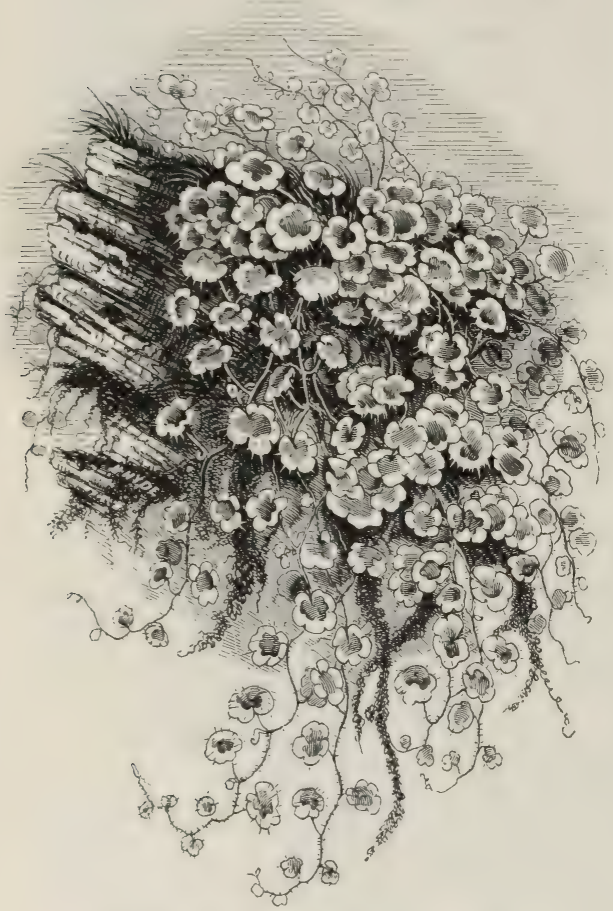

SIBTHORPIA EUROPAA VARIEGATA (MONEYWORT).

Sida.-S. dioica and S. Napæa are stout vigorous plants, suitable chiefly for the wild garden and shrubbery borders.

Silene (Catchfly).-A genus of considerable extent, containing among its numerous annual and biennial species few showy plants; but among the perennials there are species of great beauty. Southern and Central Europe is the home of the Silene, though a few species extend westward to America, a few eastward to Siberia, and a sprinkling of them will be found on the southern shores of the Mediterranean and in Asia Minor. The following dwarf kinds are suitable chiefly for the rock-garden :-

S. acaulis (Cushion Pink).-A very dwarf alpine herb tufted into light green masses like a wide-spreading Mosș, but quite firm. In summer it becomes a mass of pink, rose, or crimson flowers barely peeping above the leaves. Many places on the mountains of Scotland, Northern Ireland, North Wales, and of the Lake District of
England are sheeted over with its firm flat tufts of verdure, which are often several feet in diameter. In cultivation S. acaulis is as beautiful and as distinct as when wild. It grows freely in almost any soil in the rock-garden, not shaded, or it may be grown in pots and pans. Division. There are several varieties : alba ; exscapa, with flower stems even less developed than in the type; and muscoides, dwarfer still ; but none of them are far removed from the typical form or are of greater importance for the garden.

S. alpestris (Alpine Catchfly). - An alpine plant worthy of extended culture, possessing great beauty of bloom, perfect hardiness, a very dwarf and compact habit, and a constitution that enables it to flourish in any soil. It is 4 to $6 \mathrm{in}$. high. Its flowers appear in May, are of a polished whiteness, and have notched petals. It should be used abundantly in every rock-garden. Some forms are quite sticky with viscid matter, while others are free from it. S. quadridentata and quadrifida are similar to S. alpestris, and are worthy of a full collection. All these Alpine Silenes are propagated either by division in spring or by seed.

S. Elisabethæ.-A remarkably beautiful alpine plant, as yet very rare. It is quite distinct from its congeners, the flowers looking more like those of some handsome but diminutive Clarkia than of the Silenes commonly grown. They are very large, and of a bright rose colour, and the claws or bases of the petals are white. One to seven flowers are borne on stems 3 to 4 in. high. S. Elisabethæ is considered difficult to cultivate, but if strong plants are secured, it is as easily grown as the Cushion Pink. It is rare in a wild state, but it occurs in the Tyrol and Italy, where it grows amidst shattered fragments of rock, and sometimes in flaky rocks without any soil. It thrives freely in a warm nook in the rock-garden, in a mixture of about one-third good loam, one-third peat, and one-third broken stones. It should be planted where its roots can penetrate 18 to 24 in. back, into congenial soil. Flowers rather late in summer. Seeds.

S. maritima.-A British plant, not uncommon on sand, shingle, or rocks by the sea, or on wet rocks on mountains. It forms level carpets of smooth glaucous leaves, and from the leaves spring white flowers with purple inflated calyces. These flowers are usually solitary, and are about I in. across. The handsome double variety (S. maritima fl.-pl.) is worthy of culture, not only for its flowers, but for its dense spreading sea-green carpet of 
leaves, which makes it particularly suitable for the margins of raised borders, for the front edge of the mixed border, or for hanging over the faces of stones in the rougher parts of the rock-garden. The flowers appear in June, and those of the double variety rarely rise more than a couple of inches above the leaves. The leaves form a tuft about 2 in. deep. There is a pretty rose-coloured variety, less rambling than the type.

S. pendula. - This well-known and handsome rose-coloured biennial is now much used in the spring flower garden. There are several varieties of it, notably compacta, compacta alba, Bonnetti, ruberrima, variegata, and Zulu King, all of which are decided improvements on the original. The compacta varieties are mostly used for spring-bedding. They form compact rounded tufts, and are only about 4 in. high. The other forms are 6 to $\mathrm{I}-2 \mathrm{in}$. high. S. pendula is perfectly hardy. To obtain the finest plants for spring-flowering, seed should be sown in the reserve garden in autumn, and afterwards transplanted to permanent beds. S. pendula flowers from May to August, according to the season of sowing. Italy and Sicily.

S. pennsylvanica.-The wild pink of the Americans is a dwarf and handsome plant. It has narrow spoon-shaped rootleaves, which are nearly smooth, and the leaves on the stems are lance-shaped. It forms dense patches, and from April to June it produces clusters of six or eight purplish-rose flowers, about I in. across, on stems from 4 to 7 in. high. When strongly grown it is an attractive border plant, succeeding best in rather light sandy soil, but is not fastidious. It is a native of sandy gravelly places in many parts of $\mathrm{N}$. America. It will occasionally flower the first year from seeds, but it does not generally blossom till the second season, and may also be readily increased by cuttings.

S. Pumilio. - A beautiful species, resembling our own Cushion Pink in dwarf firm tufts of shining green leaves. The leaves of S. Pumilio, however, are a little more succulent and a little more obtuse. The rose-coloured flowers are also much larger, handsomer, and taller, though scarcely more than I in. above the flat mass of leaves, so that the whole plant seldom attains a height of more than 3 in. S. Pumilio thrives in rockgardens as well as the Cushion Pink. It should be planted in deep sandy loam on a well-drained and thoroughly-exposed spot, sufficiently moist in summer, facing the south. A few stones should be placed round the neck of the young plant to keep it firm and to prevent evaporation. Once it begins to spread, it will take care of itself. There is a white variety which is not cultivated. Tyrol.

S. Schafta.-A much-branched plant, which is not compressed into hard cushions like the alpine, stemless, or dwarf Silenes, but which nevertheless forms very neat tufts, 4 to 6 in. high. These tufts are covered with large purplish - rose flowers. It is perfectly hardy. As it flowers late (from July till September, or later), it should not be used where spring or early summer bloom is chiefly sought, but in summer it is more suitable than most alpines for edgings to permanent beds, for small circles round standard Roses, etc. It also is a fine ornament for the front margin of the mixed border, but is best suited for the rockgarden, where it grows in almost any position. Seed or division of established tufts. Caucasus.

S. virginica (Fire Pink).-A brilliant perennial, with flowers of the richest and brightest scarlet. These flowers are 2 in. across, and sometimes more. The somewhat slender stalks lie flat on the soil and the flowers are borne a few inches above it. The Fire Pink succeeds in a well-drained rock-garden ; but it requires to be looked after, particularly in winter, as at that season it is liable to "damp off " from excessive moisture. It is a native of open woods in America, from New York southwards, and flowers there from June to August. Division or seed. The strongest plants, however, are obtained from seed, and it does not bear division well. Similar in character to the Fire Pink are S. regia and S. rotundifolia, both rare, but well worthy of culture. S. Zawadski (dwarf, with white flowers), S. arborescens (a dwarf, shrubby, evergreen species, with rose-coloured flowers), the dirty-white S. Saxifraga, S. Bolanderi, S. fimbriata, S. laciniata, and many others are only worthy of a place in a very large collection, or in a botanic garden. S. rupestris, a sparkling - looking white species, little more than 3 , in. high when in bloom; reminding one of a dwarf $\mathrm{S}$. alpestris, is better worthy of a place ; and so is S. Hookeri, a beautiful dwarf Californian species, which, however, is very rarely cultivated.

Silkweed (Asclepias).

Silphium (Rosin Plant). - Coarse North American Composites, and very showy Sunflower-like plants, with a stately and large habit. No mixed border should contain them, but they are among 
those which suggested the idea of the "wild garden" to me. There they will be found at home among the most vigorous growers, as they thrive and flower freely on the worst clay soils. S. laciniatum is a vigorous perennial with a stout round stem, often $8 \mathrm{ft}$. in height. Its leaves are large and deeply divided, and its flowers, borne on large horizontal or drooping heads, which have the peculiarity of facing the east, are of a fine yellow colour with a brownish centre. S. perfoliatum (Cup Plant) is 4 to $8 \mathrm{ft}$. in height, and has broad yellow leaves 6 to 15 in. long, and flower-heads about 2 in. across. S. tere- strikingly handsome, and well deserves to be associated with other large finefoliaged plants. Its leaves, which are of great size, are variously cut and are undulated, and are tipped and margined with scattered spines; they are of a bright glistening green, are marbled, and are variegated with broad white veins. The Milk Thistle is easily raised from seed, and thrives in almost any welldrained soil. Vigour and development are added to the foliage if the flower-stems are pinched off as soon as they appear. A few plants raised in the garden and planted out in rough and somewhat bare

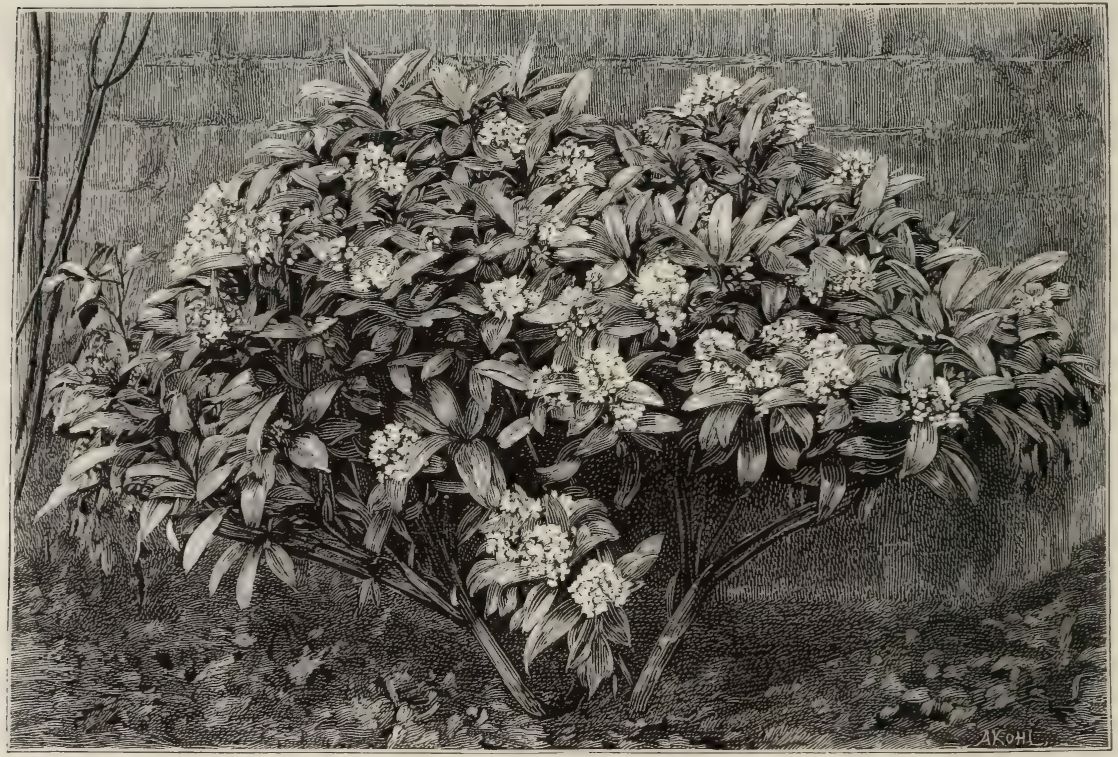

SKIMMUA FRAGRANS.

binthinaceum (Prairie Dock) has stems 4 to Io $\mathrm{ft}$. high, panicled at the summit, and bearing many small heads of light yellow flowers. The leaves, which are borne on slender stalks, are ovate, thick, and rough, and are from I to $2 \mathrm{ft}$. long. A variety (pinnatifidum) has leaves deeply cut or pinnatifid. S. terebinthinaceum is remarkable for its strong turpentine odour. Other species are S. trifoliatum, $\mathrm{S}$. integrifolium, and $\mathrm{S}$. ternatum. If planted in numbers in bold masses, these plants produce a stately effect in the wild garden, especially in autumn.

\section{Silverbracts (Pachyphitum bracteo-} sum

Silybum marianum (Milk Thistle). -A very robust and vigorous native biennial, $5 \mathrm{ft}$. or more in height. It is places or banks, etc., will soon establish themselves. S. eburneum is a more tender species, very closely resembling the above, but with spines that look as if they were made of ivory. = Carduus.

Sisymbrium.-Chiefly weeds belonging to the Cruciferæ. S. millefolium is a perennial with elegant feathery foliage of a whitish colour and small yellow flowers. It is rather tender, but is worthy of cultivation in mild districts. It grows well in any light soil.

Sisyrinchium. - Iridaceous plants, only one species of which is worthy of general culture. This is $\mathrm{S}$. grandiflorum, a beautiful perennial that flowers in early spring. The foliage of this species is narrow and Grass-like ; the flowers, borne on slender stems 6 to 12 in. high, are 
bell-shaped and drooping; a rich purple in the type and a transparent white in the variety album. Both variety and type are extremely graceful, and no garden should be without them. They are charming for the rock-garden or for borders, but like best a light peaty soil or sandy loam. Division. N.-W. America.

Skimmia.-Beautiful dwarf evergreen shrubs from Japan, very distinct and compact in habit, and charming for peat beds or large rock-gardens.

The only ones worth cultivating of the four species comprised in this genus are S. japonica and S. Fortunei. There has been very much confusion between these two species. The plant universally known in gardens as $\mathrm{S}$. japonica is really not Japanese at all, but a native of China. Mr. Fortune discovered it in I 848-in a garden at Shanghai. Originally the plant came from a high mountain in the interior called Wang Shang. Of all the plants Fortune sent home only one reached England alive, and was exhibited at the Horticultural Society's rooms, 2 I Regent Street, on 23rd Oct. I852, when the Knightian medal was awarded it. The proper name of this species is Skimmia Fortunei. The true S. japonica is a Japanese plant, and did not find its way into British gardens for some years after S. Fortunei. Like that species, it was introduced by Fortune. Unlike S. Fortunei, it is dicecious. Both sexes have received specific names, and mere forms of both have been described specifically in horticultural periodicals. S. fragrans, for instance, is simply the male of the true S. japonica. The first plant of S. japonica which flowered in this country was named $\mathrm{S}$. oblata by the late Mr. Thomas Moore in 1864. Since then Dr. M. T. Masters has clearly shown that this plant is identical with the one named S. japonica by Thunberg, and that name has been transferred to it, and the one named $\mathrm{S}$. japonica in gardens is now called $\mathrm{S}$. Fortunei.

The Skimmias thrive as well in strong clay as in poor sandy soil and peat. $S$. japonica is one of the very best town Evergreens we possess.
Other forms of $\mathrm{S}$. japonica are $\mathrm{S}$. Foremani, S. Rogersi, S. oblata ovata, S. fragrantissima, and S. oblata Veitchi. In order to produce beautiful berried species it is necessary to plant specimens of the two sexes in proximity.

Of S. Fortunei (the S. japonica of gardens) S. rubella is a seedling form. S. japonica argentea is a seedling or sport, only differing from the type in having the leaves bordered with white. $\mathrm{S}$. Fortunei is a much dwarfer grower than S. japonica, and does well as a potplant for window decoration, etc.- N.

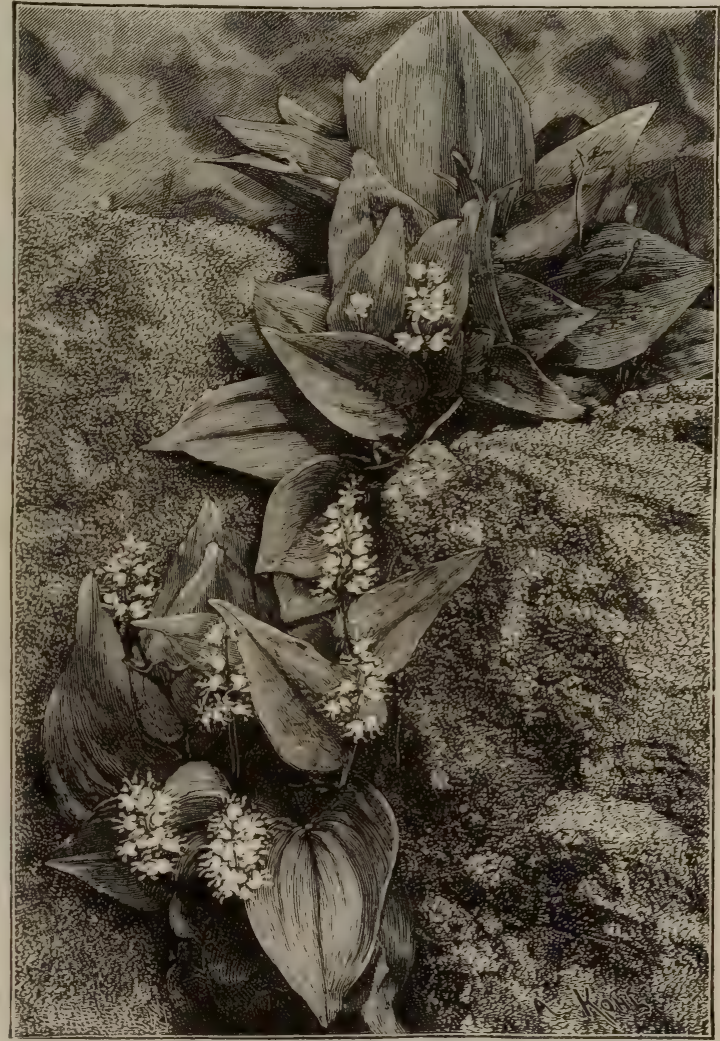

SMILACINA BIFOLIA.

Sloe (Prunus spinosa).

Smilacina.-Interesting but not showy perennials, resembling Solomon's Seal. S. racemosa and S. stellata are about $2 \mathrm{ft}$. high, and in early summer bear numerous small white flowers on slender stems. Although hardly suitable for borders, they are desirable for moist shrubberies, for open woods or copses, or for bushy banks. They thrive in ordinary soil, but best in a deep vegetable one; 
they grow well under heavy shade, and also in dry places. N. America.

Smilax (Green Brier). - Very interesting plants, some of them being handsome, and though rare in our gardens, deserving more attention than they get. A few are useful for garlanding rocks, and make valuable evergreen climbers as a relief to the motonony of Ivy and other common Evergreens. They are also useful for planting singly

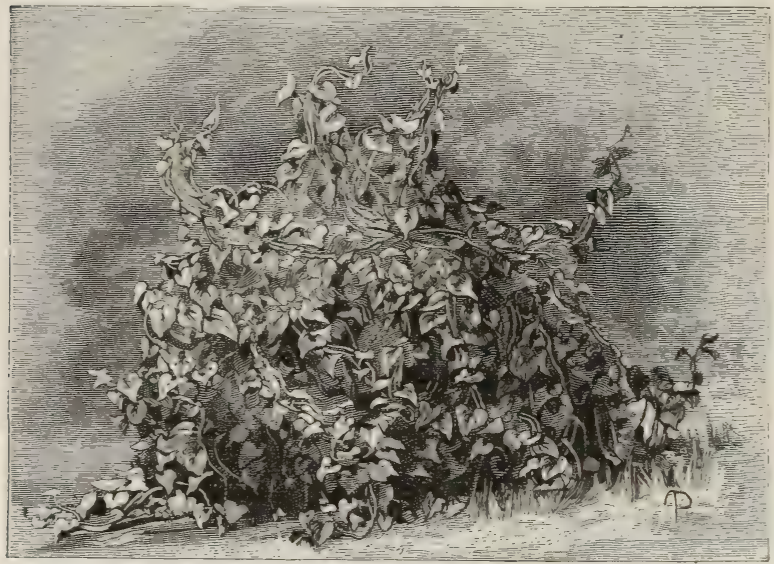

SMILAX ASPERA (PRICKLY IYI').

on lawns or banks in a dry soil. The $\mathrm{N}$. American species $\mathrm{S}$. rotundifolia, S. herbacea, and S. tamnoides, are among the best and most easily obtainable. S. aspera, from S. Europe, is good. S. mauritanica is an extremely pretty kind of rapid growth. Among the handsomest is S. latifolia. We have found them do best in dry or free soil.

Smoke Plant (Rhus Cotinus).

Smooth Lungwort (Mertensia).

Snake Plant (Arum Dracunculus).

Snakeroot (Liatris).

Snake's-beard (Ophiopogon).

Snake's-head (Fritillaria).

Snapdragon (Antirrhinum majus).

Sneezeweed (Helenium).

Sneezewort (Achillea Ptarmica).

Snowball Bush (Viburnum).

Snowberry (Symphoricarpus).

Snowdrop (Galanthus).

Snowdrop Tree (Halesia).

Snowdrop Windflower sylvestris).

Snowflake (Leucojum).

Snow Gem (Chionodoxa Lucilice).

Snow in Summer (Cerastium).

Soapwort (Saponaria).

Solanum. - A wonderfully - varied family, comprising many species that are graceful and imposing in a young and free-growing state, but too ragged to be tolerated in a tasteful garden; and others for which our climate is too cold. The most useful are described below. Most of these may be raised from seed or from cuttings. The latter, struck in February, will make good plants by May. The kinds named are suitable for association with the largerleaved plants, but do not as a rule attain the height and vigorous development of those of the first rank like Ricinus. As a rule, they require temperate-house treatment in winter, and about the middle or end of May should be planted out in a warm position, sheltered, and in rich light soil.

S. betaceum.-A small tree from S. America, which, if taken up in autumn and kept in a house through the winter, attains a height of nearly Io $\mathrm{ft}$. The stems are stout, smooth, and fleshy. The oval and pointed leaves resemble those of the Beet, and are of a deep green colour. The small rosecoloured flowers hang in cyme-like clusters, and are succeeded by fruits which are of the shape and size of a hen's egg, which become a deep scarlet during the winter. $\mathrm{S}$. betaceum is suitable for grouping in round beds with dwarfer plants or shrubs at its base, or climbing plants ascending its stems, but it is much more suitable for isolation on slopes, etc. It is a vigorous grower, and should have rich soil. In the variety purpureum the leaves are green tinged with violet. In other varieties the flowers are tinged with purple, and the fruits striped with brown.

S. crinitum.-A vigorous species, $5 \mathrm{ft}$. or more in height, with stout stems set with short strong spines and dense long hairs. It has very large roundish leaves, $2 \frac{1}{2} \mathrm{ft}$. long. It bears very large white flowers, and its berries are roundish and villose, and are twice or thrice as large as a Cherry. It attains a remarkable development in warm sheltered spots in the south of England. It is fine in medium-sized groups. Guiana.

S. crispum (Potato Tree).-This beautiful little tree is the only ornamental Solanum hardy enough for the open air. In the south and in coast districts it may 
be grown without any protection, but elsewhere it needs the shelter of a wall. When fully grown, it is 12 to $16 \mathrm{ft}$. high. In late summer it has large clusters of fine purple-blue flowers, which, in the most favoured spots, are succeeded by small whitish berries. When grown against a wall, it should be pruned vigorously in autumn, or it will be injured by frosts; but when it thrives as a standard this pruning is unnecessary. Chili.

S. jasminoides. - Perhaps the most beautiful of the family we know of in England, and a lovely hardy climber. With its delicate white and starry flowers and trusses, it is one of the most delightful things for planting against the walls of the house in borders of peat or other light soil. It is frequently grown in greenhouses, but appears hardy in Kent and Surrey and southern England generally.

S. Karsteni. - A robust and slightlybranching shrub, which is covered with long hairs interspersed with spines. It is of a variable greyish-violet hue. Its broad oval leaves are $2 \mathrm{ft}$. or more in length, and its large delicate violet flowers are borne in crowded almost one-sided clusters. $\mathrm{S}$. Karsteni is about $5 \mathrm{ft}$. high. It is best isolated, for if placed in close groups it is liable to be torn by the leaves of the subjects with which it is associated. It is sometimes called $\mathrm{S}$. callicarpum. Venezuela.

S. lanceolatum. - This is the best kind for blooming. Itș somewhat fluffy and Willow-like foliage has no marked characteristic, but its flowers have orangecoloured stamens, which have a fine effect against the mauve petals. These flowers are borne abundantly in clusters of twenty or more. There are a dozen or more species that flower freely, but which have little beauty of leaf. Among the best of them is S. Rantonnettii, a neat bush, with flowers more than $I$ in. across. These flowers, which are very pretty, are of a dark purple colour and have orange centres. S. Rantonnettii flowers freely in the southern counties if put in warm sunny spots and on light soils. Mexico.

S. macranthum. -- One of the best species in cultivation, and somewhat resembling Polymnia grandis. It grows in one year to a height of nearly $7 \mathrm{ft}$. Its stout spiny stem is of a deep shining green, spotted with grey, and is sparsely armed with short strong spines. The elegant leaves of the plant are deeply cut. They are of a light green with red veinings on the upper surface, and have a reddish hue on the under. Some of them are over $2 \frac{1}{2} \mathrm{ft}$. long, and fall gracefully downwards. The violet flowers are seldom seen in our climate. They grow in corymbs. S. macranthum will not attain its full dimensions in cold places, and should have positions as warm as possible. Cuttings. Cuttings struck in February are fit to plant out in May. Brazil.

S. robustum. - This species has a vigorous and much-branching stem, which is more than $3 \mathrm{ft}$. high, and which has very sharp strong spines, and is densely clothed with long, reddish, viscous hairs. The leaves are very large; and the flowers, which are white with orange stamens, are borne in unilateral clusters; while the brown berries are round, and are of the same size as a small Cherry. For foliage S. robustum is one of the plants most suitable for our climate. It requires a warm sunny aspect in an airy position sheltered from strong winds. Brazil.

S. Warscewiczi. - A very fine ornamental kind resembling S. macranthum, but lower and more thick-set, and branching more at the base. The small flowers are white. The stem is armed with strong spines slightly recurved, and both the stems and the petioles of the leaves are densely covered with short stiff brown hairs scarcely rising above the skin. $\mathrm{S}$. Warscewiczi is one of the handsomest and best of Solanums.

Soldanella.-These plants are all of minute growth and are very beautiful; and though they bear a strong resemblance to each other, they are all worth growing, as they do not flower together.

S. alpina is one of the most interesting of the plants growing near the snow-line on many of the great mountain-chains of Europe. It is not brilliant, but it has beautiful pendent pale bluish flowers. These flowers are bell-shaped, and are cut into narrow strips. Three or four of them are borne on a stem. This stem is 2 to 6 in. high and springs from a dwarf carpet of feathery shining leaves, which are roundish or kidney-shaped. S. alpina is comparatively rare in gardens, and is considered difficult to cultivate, but healthy young plants succeed in the rockgarden or on a raised border if placed in a little bed of deep and very sandy loam. These young plants thrive best in moist districts, and in dry ones evaporation may be prevented by covering the ground near them with Cocoa fibre which is mixed with sand to give it weight. The most suitable position for the plant is a level spot in the rock-garden near the eye. 
S. alpina is readily increased by division, though, being usually starved and delicate from confinement in small worm-defiled pots, exposed to daily vicissitudes, it is rarely strong enough to be pulled to pieces.

S. montana is very nearly allied to S. alpina, and indeed differs in no important point except that its leaves are larger, and its flowers are of a bluer purple. Like S. alpina it inhabits several of the great continental chains, and it thrives under the same treatment as $\mathrm{S}$. alpina. It is readily increased by division, but the cause that usually renders S. alpina too weak to be divided, renders S. montana weak also.

S. pusilla has kidney-shaped leaves, which are heart-shaped at the base. The corolla is not deeply cut into fringes. The very small $\mathrm{S}$. minima, with its minute round leaves and its single flower fringed for a portion of its length only, is also in cultivation, but is rare. Both of these plants thrive under the same conditions as the others; but, being much smaller, they require more care in planting. They should be planted in a mixture of peat and good loam with plenty of sharp sand, and associated with minute alpine plants. They require plenty of water in summer. S. Clusii and S. Wheeleri are similar to those mentioned above.

Solidago (Golden Rod).-Scarcely one of these N. American Composites is fit for culture. In borders they exterminate valuable plants, and give a coarse and ragged aspect to the garden. They are also such gross feeders as to impoverish any good border. They hold their own, however, in a copse, or a rough open shrubbery among the coarsest vegetation. For a full collection the best are S. altissima, S. canadensis, S. grandiflora, S. nutans, S. multiflora, S. rigida, and $\mathrm{S}$. Virgaurea.

\section{Solomon's Seal (Polygonatum).}

Sonchus (Sow Thistle). - The Marsh Sow Thistle (S. palustris) is really a noble plant, attaining a height of $6 \mathrm{ft}$. It has broad deeply-cut foliage, but unattractive yellow blossoms. In damp parts of the wild garden it takes care of itself, and soon develops into fine proportions. It is a native.

Sophora japonica (Pagoda Tree).One of the finest of ornamental flowering trees. It is elegant in foliage, and, in September, is covered with highly attractive clusters of white bloom. It is one of the largest of trees, and when old has a wide-spreading head with huge limbs. Its long pinnate leaves retain their deepgreen colour until they fall in autumn.
S. japonica has such a different growth from most trees that it is indispensable to any garden, and where space is limited it may be kept within bounds by hard pruning. There are several varieties of it, a drooping kind which is one of the best of all pendulous trees, and a variegatedleaved kind, which is not satisfactory, as the variegation is seldom conspicuous.

Sorghum halepense. - A handsome hardy Grass, with an erect stem $3 \frac{1}{2} \mathrm{ft}$. high, and broad flat leaves more than I ft. long. These leaves are chiefly collected round the base of the plant. S. halepense is most attractive at the end of summer, when it bears a dense panicle of purplish awned flowers. Suitable for isolation, for groups, or for borders. S. Europe. N. Africa and Syria.

Sowbread (Cyclamen).

Sow Thistle, Blue (Mulgedium Plumieri).

Sparaxis. - Charming bulbous plants from the Cape of Good Hope. Many varieties are in cultivation. These varieties, which are derived chiefly from $\mathrm{S}$. grandiflora and S. tricolor, are about I $\mathrm{ft}$. high, are of slender growth, and bear large showy flowers. These flowers vary from white to bright scarlet and deep crimson, and usually have dark centres. Sparaxis are valuable for early summerflower, and well repay the trouble of cultivating. They should be treated like Ixias.

S. pulcherrima, a native of the Cape, so distinct from other Sparaxis that its claim to be a member of the genus has often been made the subject of comment. It is a lovely plant. Its tall and graceful flower-stems rise to a height of 5 or $6 \mathrm{ft}$., and wave in the wind, but though slender, they are so tough and wiry that they are never broken in a storm, like the much stouter and much stronger-looking stems of the Pampas Grass. For six or seven weeks S. pulcherrima produces its lovely Foxglove-shaped bells on almost invisible wire-like lateral foot-stalks. Though the flowers of the type are usually rosy-purple, there are forms which are nearly white, and forms of almost every intermediate shade, while some forms are beautifully striped. $\mathrm{S}$. Thunbergi is an allied species, but $\mathrm{S}$. pulcherrima is by far the finer and the more elegant. S. Thunbergi is indeed very handsome, but it has none of the waving beauty of the tall arching flowerstems of S. pulcherrima, while it has a stiffer habit and is much dwarfer-its erect flower-stems being seldom more than $2 \frac{1}{2} \mathrm{ft}$. high,--and its flowers have very short stalks, and are not pendulous. 
The best position for S. pulcherrima is in clumps among sheltering shrubs, where its whip-like spikes rise gracefully, and are seen to advantage. In such a position it might be associated with Tritonia aurea, as the two plants flower together. S. pulcherrima is about as hardy as Tritonia, Montbretia Pottsi, and similar plants, and, though it is more difficult to establish, it well repays a little care given during the first year or two. It has a great objection to removal, and, if removal is necessary, this should be effected as soon as the flowers begin to fade ; for immediately after the flowers begin to fade, stout fleshy roots are emitted from the bulbs, and much injury would result if these roots were seriously broken or seriously bruised. The general appearance of S. pulcherrima would lead one to suppose that it is a water-loving plant, but it succeeds in dry positions as well as in damp ones, if it has a rich friable soil, or if when beginning to grow it is well watered. It probably requires a much stronger soil than the S. grandiflora family. Among seedlings there occur long and short flowers, some having the perianth slightly closing towards the mouth and others having the perianth reflexed.-H. C. S.

Sparganium.-British water-plants, resembling the common Flag, and suitable for fringing artificial water where they are not plentiful. Reed Mace family.

Spartium junceum (Rush, or Spanish Broom).-A flowering shrub, valuable on account of its blooming in July, August, and September, when shrubberies are usually flowerless. It is a thin-growing shrub, 8 or Io ft. high, and its Rush-like shoots have so few leaves as to appear leafless. It bears erect clusters of fragrant bright yellow flowers shaped like Peablossoms. It is perfectly hardy, and is useful for dry, poor soils, where, like the common Broom, it does well. As it grows rapidly, small plants, which can be obtained cheap, may be used. S. Europe.

Specularia (Venus's Looking-glass).These are similar to Campanulas, and are often placed with them, though distinct enough for garden purposes. S. Speculum, with numerous open bell-like flowers of a bright violet-purple, is one of the showiest of our annuals. Besides the largeflowered form called grandiflora, which is sometimes purple and sometimes white, there is a double-flowered kind which comes true from seed, and there is also a procumbent variety which is dwarf and compact, and bears violet-blue flowers. $\mathrm{S}$. pentagonia is another favourite. Its flowers are larger, but are less profuse than those of S. Speculum. They are purple, with a deep blue centre. S. Speculum and $\mathrm{S}$. pentagonia generally scatter seed, which germinates year after year, and no trouble is necessary, except indeed the trouble of preventing the plants from becoming too plentiful. Both kinds are perfectly hardy.

\section{Speedwell (Veronica).}

\section{Spergula (Sagina).}

Sphenogyne speciosa. - A beautiful half-hardy annual Composite. It is of slender, much - branched growth, and attains a height of about $\mathrm{I} \mathrm{ft}$. The flowers, produced from July to September, are yellow, with a brownish centre encircled by a conspicuous black ring. In the variety aurea the centre is orange. The flowers close at dusk. S. speciosa will succeed if sown in the open in spring, but it flowers much earlier and thrives much better if treated as a half-hardy annual and sown in early spring in heat. Any ordinary light soil suits it. Mexico.

Spider-flower (Cleome).

Spider Orchis (Ophrys aranifera).

Spider-wort (Tradescantia).

Spigelia marilandica (Worm Grass). -A beautiful native of North America, and distinct from all other hardy plants. It forms a dense tuft of slender stems about I ft. high, each stem being terminated by long tubular flowers. These flowers are deep red outside, and deep yellow inside, and their colours make a brilliant show. S. marilandica is rare in gardens, being considered difficult to cultivate. In its native country it grows in sheltered situations, the roots finding their way deep down into a body of rich vegetable mould. These natural conditions should be imitated; and, if the soil is not of the right description, it should be taken out to the extent of $2 \mathrm{ft}$. in depth, and filled up with a well-sanded mixture of loam, leaf-mould, and peat. Partial shade in summer, with abundance of moisture in hot weather, is essential to the cultivation of this beautiful plant. S. marilandica is suitable for borders, or the lower parts of the rock-garden, or for margins of beds of American plants.

\section{Spignel (Meum athamanticum).}

Spiræa (Meadow Sweet).--This extensive genus includes both shrubby and herbaceous species. They constitute a beautiful class of plants almost indispensable to every garden.

S. Aruncus (Goat's-heard) is a vigorous perennial, 3 to $5 \mathrm{ft}$. high. It flowers in summer. It is beautiful in foliage and habit as well as in flower. Its flowers are freely produced in large gracefully- 
drooping plumes. S. Aruncus is as good in midsummer as the Pampas Grass is in autumn. It is valuable for grouping with other fine-foliaged herbaceous plants. It thrives in ordinary soil, but succeeds best in a deep moist loam. Division. Various parts of Europe, Asia, and America. S. astilboides is a hardy variety from Japan, with white feathery plumes.
N. America, from New Mexico to Northern Nevada. S. cæspitosa grows wild on rocks; and when in cultivation thrives in good soil in an open position in the rockgarden.

S. Filipendula (Dropwort).-A rather common, but very pleasing, British species, I to $2 \mathrm{ft}$. high. It has loose terminal clusters of yellowish-white

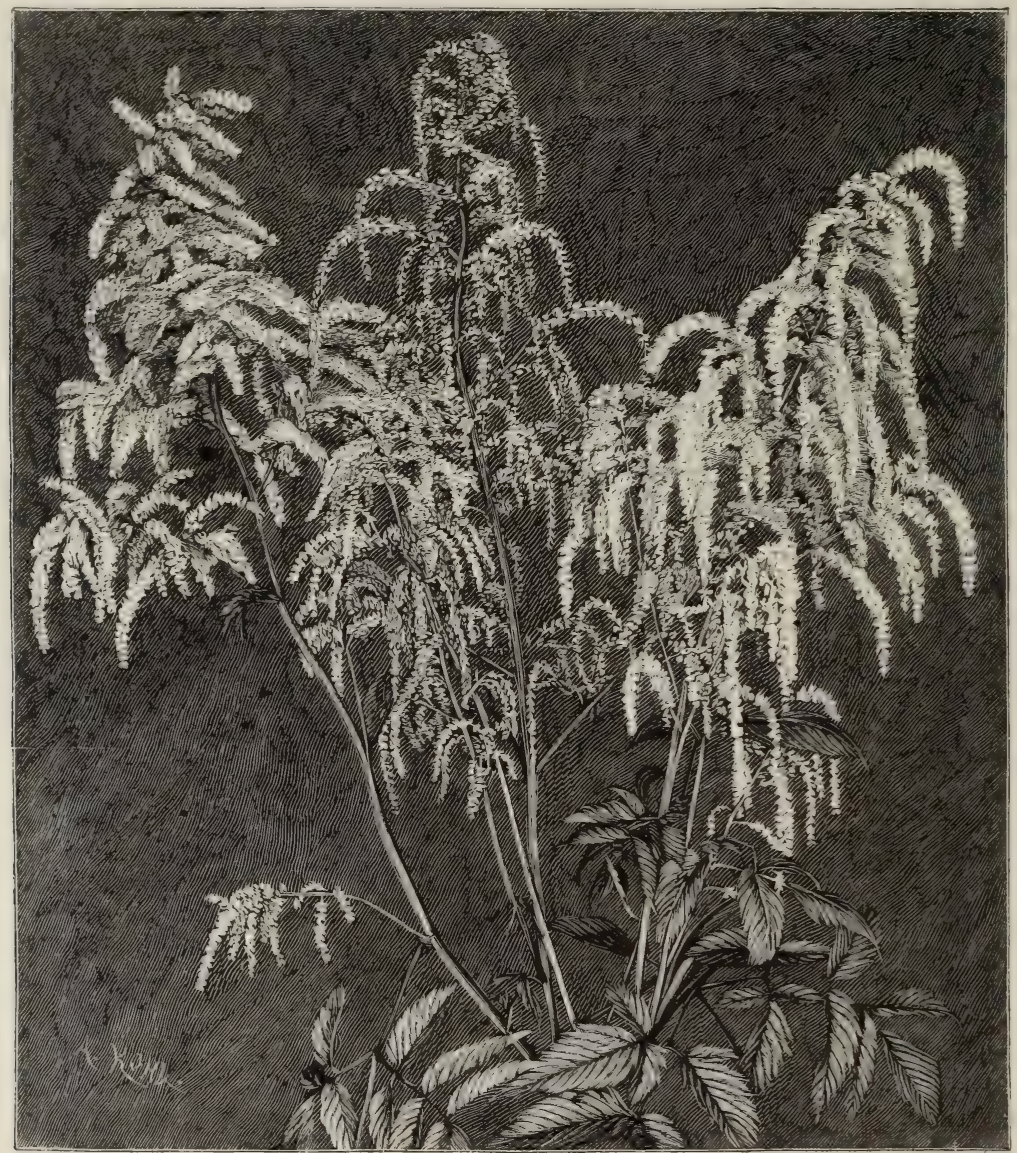

SPIRÆA ARUNCUS.

S. cæspitosa is one of the smallest, if not the very smallest, of Spiræas. The narrow leaves, which are $\frac{1}{4}$ to $I$ in. long, are silky and glaucous on both surfaces, and are arranged in dense rosette-like tufts springing from a woody root-stock. They are very numerous and form a carpet-like tuft similar to the Stemless Catchfly (Silene acaulis). The flowers are I to $3 \mathrm{in}$. high, and are terminated by a dense cone-like spike of very small white flowers. Mountains of flowers, which are often tipped with red. The leaves are mostly on the lower part of the stem. When the flower-stems are pinched off, S. Filipendula forms an effective edging plant, its Fern-like foliage rendering it very distinct from many plants used for edging. The double variety (S. Filipendula fl.-pl.) is very useful in the mixed border and for cuttings. It thrives in ordinary soil, and is multiplied by division of the tufts.

S. lobata (Queen of the Prairie) is one 
of the handsomest of the hardy Spiræas. It is 18 to $36 \mathrm{in.} \mathrm{high.} \mathrm{Its} \mathrm{deep} \mathrm{rosy-}$ carmine flowers are in large terminal compound cymes. Its leaves are pinnate, and its leaflets are pointed and irregularly toothed. S. lobata does best in sandy loam. It is valuable for planting in the mixed border, on the margins of less than half that height. Being considered tender, it is grown largely in pots, but it is perfectly hardy, thriving in moist deep loam which is well enriched by decayed manure. It is a fine plant for many positions in large rock-gardens, in borders, or on the margins of shrubberies; and it may be

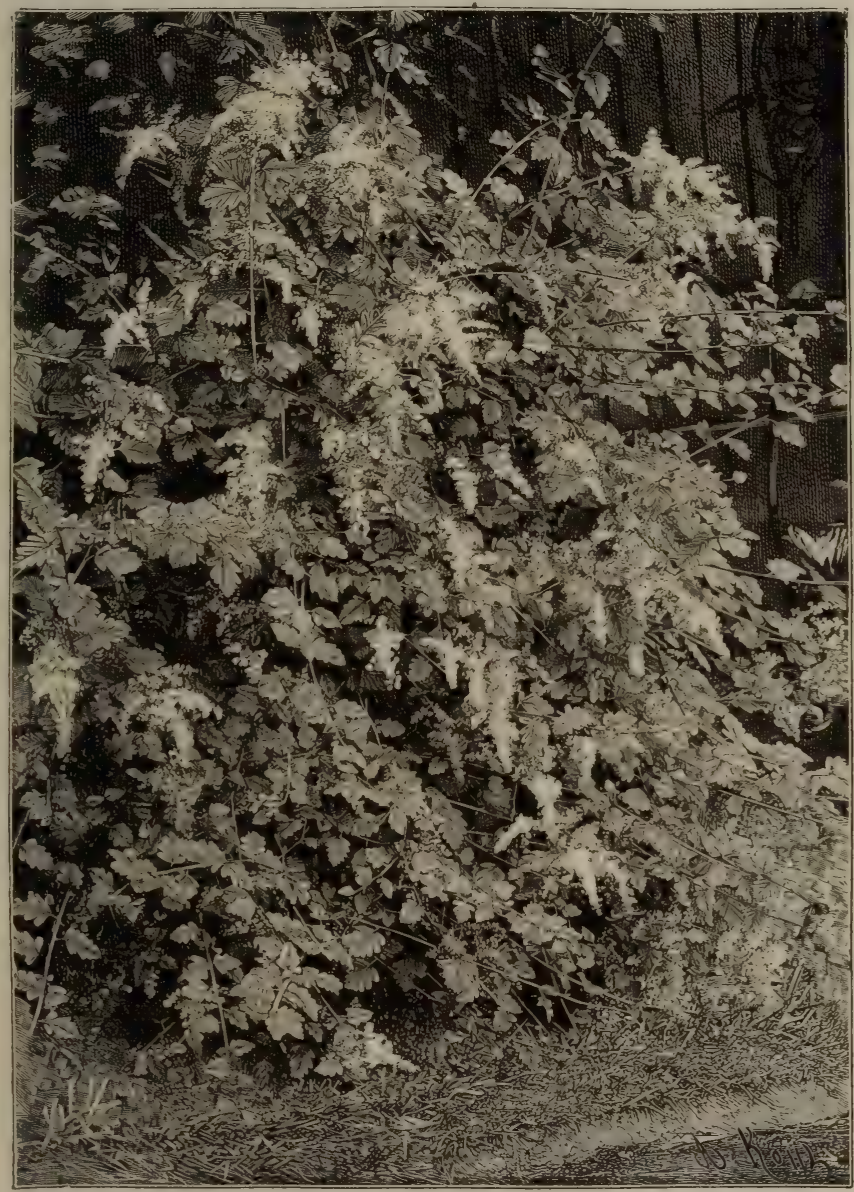

SPIREA ARIEFOLIA.

shrubberies, or in beds among groups of the finer perennials. Syn., S. venusta. Similar to S. lobata are the handsome S. Humboldti and S. digitata.

S. palmata is one of the most beautiful of the herbaceous species, and is among the finest of hardy plants. It has handsome palmate foliage, and it bears in late summer broad clusters of lovely rosy-crimson blossoms. When wellgrown it is $4 \mathrm{ft}$. high, but it is often naturalised, as it is quite vigorous enough to take care of itself. It looks best in masses. The variety elegans is said to be a hybrid. The flowers are a pale pink, and it is altogether inferior to the best forms of $\mathrm{S}$. palmata.

S. Ulmaria. - This common British Meadow Sweet would, no doubt, be considered of high merit if it were an exotic. It is seldom cultivated, but worse things are often seen in our borders. It deserves 
a place, if only for the sake of variety, in the mixed border, on the margins of shrubberies, or in the rougher parts of pleasure-grounds, where it may be planted with other subjects which do not require much looking after. Almost any soil
S. ARIÆFOLIA, from N. America, a slender shrub, 6 to $10 \mathrm{ft}$. high, which produces about the end of July a profusion of plume-like clusters of dull white flowers. The beautiful S. japonica is one of the finest of all dwarf hardy

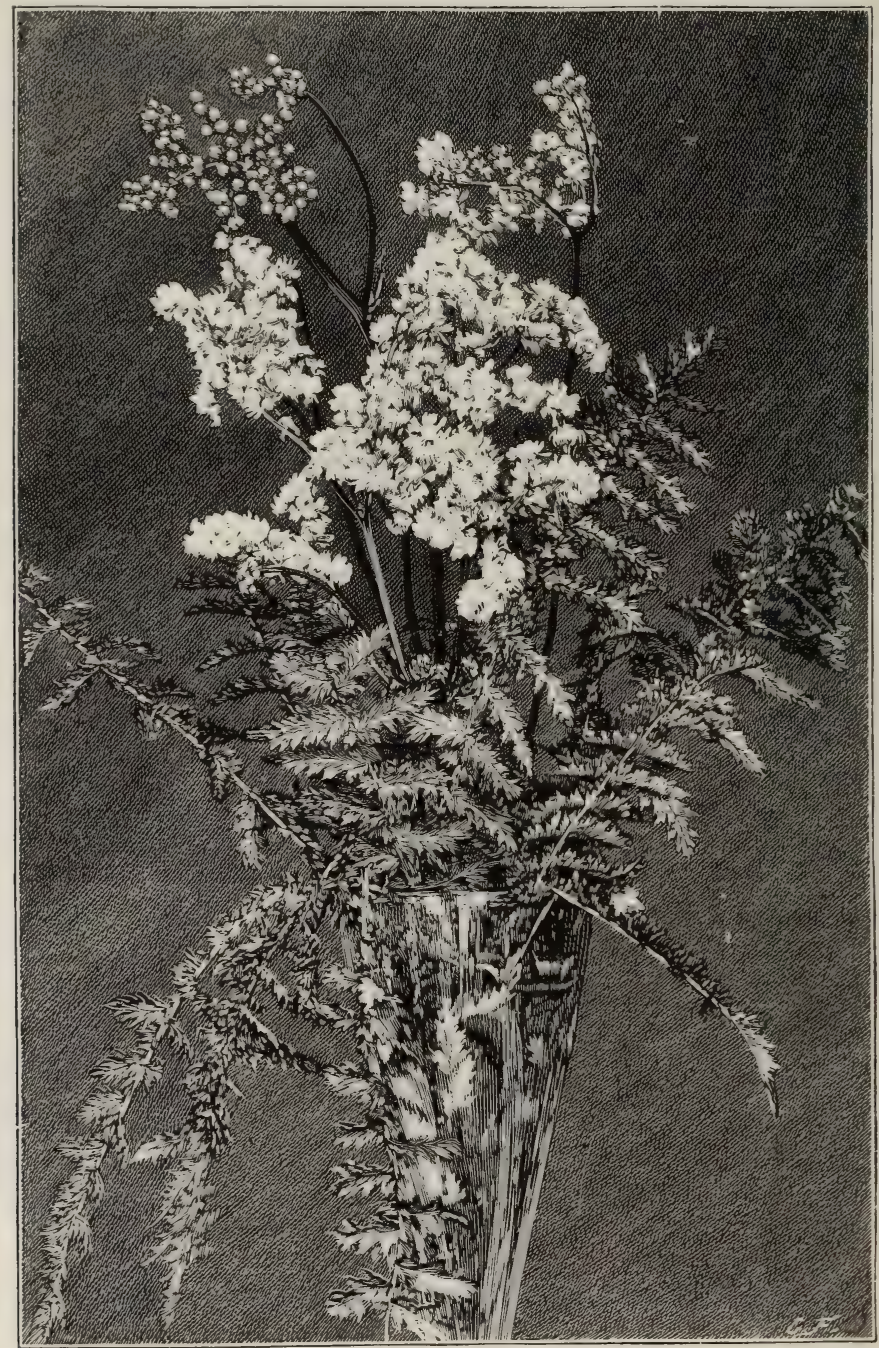

SPIREA FILIIENDULA (DROPWORT).

will suit it ; if the soil be moist, so much the better. The variegated-leaved form is ornamental, the creamy-yellow and green variegation being effective.

SHRUBBY SPIRÆAS. - The best shrubby Spiræas are well known, and are obtainable from nurseries. A selection of the best would include the following :- shrubs. It is easily recognised by slender stems 3 or $4 \mathrm{ft}$. high, which are surmounted by broad flat clusters of deep pink flowers. The varieties splendens, rubra, superba, and atro-sanguinea are much richer and deeper than the type, while the variety alba produces an abundance of white flowers in small clusters. 
$\mathrm{S}$. bella is dwarfer and denser than $\mathrm{S}$. japonica.

S. BUMALDA is a variety of S. japonica, and a valuable addition to the garden, being very dwarf and compact. It is not more than $2 \mathrm{ft}$. high, and has broad clusters of deep rose-pink flowers. It is a rapid grower, and is hardy.

S. Douglasi and S. Nobleana are so similar in growth and flower that they may be conveniently coupled, though as they flower at different times it is advisable to have them both. They are of vigorous growth and they produce dense erect clusters of deep red flowers. Both are from N. America. S. Douglasi succeeds in every part of the British Isles, but S. Nobleana, being a native of California, is less hardy.

S. HYPERICIFOLIA, from Asia Minor, is the type of a small group, all very elegant in growth and pretty in flower. The tall slender stems arch over gracefully, and in good soils and sheltered spots reach a height of $8 \mathrm{ft}$. The leaves are small and are arranged in rows. In the flowering season the branches are wreathed with small clusters of small white flowers. S. flagelliformis and S. acuta are forms of this species, and both are superior to the type.

The CANTON SPIRÆA (S. cantoniensis) is among the choicest of the shrubby Spiræas, and is valuable for forcing in early spring. It is a slender bush, about a yard high, and bears an abundance of small clusters of white flowers. There is also a beautiful double variety, which is less common. The Plum-leaved Spiræa, S. prunifolia, is most commonly represented in gardens by the double variety (flore-pleno), which is a beautiful shrub. The flowers of the double variety are like tiny snow-white rosettes, and in early summer they wreathe every twig and branch. S. media, better known in gardens as $\mathrm{S}$. confusa, resembles $\mathrm{S}$. cantoniensis, and therefore need not be included in a selection; but its variety rotundifolia is a most desirable shrub. Unfortunately, this variety is not common, as it has been only recently introduced from Japan. What is known in gardens as S. lanceolata is a very pretty shrub, of dwarf growth, with clusters of white flowers.

S. THUNBERGI has of late years become quite common, and is a favourite shrub for forcing into early flower. It is a neat and dense bush, has small bright green leaves, and bears in early spring a profusion of tiny white blossoms. It is perfectly hardy, and is especially suitable for planting in a bold rock-garden or on a raised bank among tree-stems.
S. Lindleyana is a noble shrub, sometimes Io ft. high. Its graceful foliage is divided, and is of a delicate green, the flower-clusters are large, white, and plume-like, and have a beautiful effect when at their best, which is usually about the middle of August. The other pinnateleaved Spiræas, such as S. sorbifolia, S. Pallasi, or S. grandiflora, are less desirable, as none of them is so effective either in growth or in bloom. Though a native of the Himalayas, S. Lindleyana cannot be termed absolutely hardy. It thrives best in warm deep soil, not too light or too heavy, and is always the better for shelter from cold winds, for cold winds injure its young growth in spring. When a large collection is desired, the following kinds may be added: S. vaccinifolia, S. Blumei, S. chamædrifolia, S. trilobata, S. tomentosa, and S. opulifolia. The goldenleaved variety of $\mathrm{S}$. opulifolia is a most effective shrub in early summer, when the young foliage is of a bright glowing yellow.

CULTURE.-Like most other shrubs, they like a good soil, sheltered position, and need attention as regards pruning, the aim being to encourage young flowering growths from the old wood.

\section{Spleenwort (Asplenium)}

Spotted Wintergreen

maculatcr).

(Chimaphila

Spraguea umbellata.-A singular and pretty plant, allied to Claytonia. It is 6 to 9 in. high, and has fleshy foliage, and spikes of showy pinkish blossoms. It has not been cultivated much here, but it appears to be either annual or biennial, according to the treatment it receives. If seeds are sown early in February in a warm frame, and seedlings are afterwards pricked out singly in small pots, and are planted out in May, the plants will bloom in August and September; but if sown in May, the plants will not flower till the following summer. In light soils $\mathrm{S}$. umbellata will resist an ordinary winter, but, on the whole, it should be protected by a frame. Like most tap-rooted plants, it does not bear transplantation well, except while it is small. If seeds are plentiful, they may be sown in the open ground, and stronger plants will result; but, as seeds are usually scarce, they should be sown in pots, in a moderate temperature. California.

\section{Spring Beauty (Claytonia virginica). " Bitter Vetch (Orobus vermus). " Snowflake (Leucojum vernum).} Spurge (Euphorbia).

Squirrel-tailGrass (Hordeumjubatum). 
Stachys (Woundrvort).-Few of these Labiates are worth cultivating. The common S. lanata, the woolly-leaved plant, is much used in edging. It may be naturalised, as it thrives in any soil. It may be easily propagated by division in autumn or spring. S. coccinea is a rather pretty perennial with spikes of red flowers. It grows about I ft. high, and if planted in a partially-shaded border succeeds in any soil.

Staff Vine (Celastrus scandens).

Staphylea (Bladder Nut).-There are three species in cultivation, but only $\mathrm{S}$. colchica is important. This is a beautiful shrub with pinnate leaves, and produces in early summer an abundance of large terminal clusters of snow-white flowers, and is $6 \mathrm{ft}$. high. It is hardy, and grows well in any good soil, and, indeed, seems to prefer partial shade; but it is commonly forced into flower for the greenhouse in early spring. It is worthy of a select place in a shrubbery.

Starflower (Trientalis europaa).

Star of Bethlehem (Ornithogalum).

Star Thistle (Centaurea).

Starwort (Aster).

Statice (Sea Lavender). - Plants of the Leadwort or Plumbago family. About a score of hardy or half-hardy species are in cultivation. All of these are dwarf perennials or annuals, and are chiefly natives of shore and mountain districts. Most of them bear large twiggy flowerstems covered with myriads of small flowers. These flowers are for the most part dry and membraneous, and retain their colour a long time after being cut, so that they are frequently mixed with other everlasting flowers for vase decoration in winter. The larger species thrive admirably without requiring care if they are planted in an open exposed bed of sandy soil, while many of them are admirable for the rock-garden. The best of the larger kinds are S. Limonium, of which there are several varieties; $S$. latifolia, the finest of all, which bears wide-spreading flower-stems with a profusion of small purplish-blue flowers ; and S. tatarica, a dwarfer species, with red flowers which are quite distinct from those of any other. The smaller species, such as S. minuta, S. minutiflora, S. caspia, S. eximia, are good rock-plants. Among the half-hardy annuals and biennials the best are: S. Bonduelli (yellow), a biennial if protected in winter ; S. spicata, with spikes of small rosy flowers; Thouini (violet), very free flowering; and sinuata (purple and white), very pretty and very easy to grow. There are several varieties of $\mathrm{S}$. sinuata hybrida which have varied colours, and which make pretty border flowers. All the annual and biennial Statices should be raised from seed in early spring, and planted out as soon as they are large enough. The half-hardy biennials need protection during winter, and should not be planted out until the spring after they are raised.

Stauntonia hexaphylla.-A fine evergreen twining shrub, hardy enough in the south and in the warmer parts of these islands for wall-culture. It has long trailing shoots and handsome pinnate foliage of deep green. Its small flowers are whitish. They are fragrant and are produced in early summer. It must have a sheltered sunny wall, and during severe frosts must be protected in a simple way. China.

Stellaria (Chickreed). - The goldenleaved form of the Grass-leaved Chickweek (S. graminea aurea) is now a favourite plant for bedding, and the wild kinds are pretty, but rarely cultivated.

Stenactis (=Erigeron).

Sternbergia lutea. - A beautiful bulbous plant, having narrow deep green leaves, and producing in autumn and often in winter showy bright yellow flowers. It is about 6 in. high, and forms a compact tuft. S. angustifolia has also narrow leaves, but it has rather larger flowers. $\mathrm{S}_{\mathrm{z}}$ - sicula is a miniature of S. lutea. These plants are of simple culture, and should be planted 6 in. deep in good, deep, and fairly dry soil ; while a carpet of Sedum should be given to keep the bulbs sheltered in winter, and to protect them from drought in summer. The position should be sheltered. S. Europe. = Oporanthus luteus and Amaryllis lutea.

Stevia. - Composites, for the most part of shrubby growth and somewhat tender, and therefore scarcely worth attention, except in large collections.

Stipa (Feather Grass).-These plants are all more or less ornamental, but none of them approaches the elegance of the S. European S. pennata. In bundles the beauty of this plant almost equals that of the tail of a bird of paradise. S. pennata is hardly to be distinguished from a strong stiff tuft of common Grass, except in May and June, when the tuft is surmounted by numerous gracefully-arching flower-stems, nearly $2 \mathrm{ft}$. high, and is covered with long, twisted, feathery spikes. S. pennata loves a deep sandy loam, and may be used either in an isolated position or in groups of small 
plants, but its flowers continue too short a time to make it very valuable except in borders. Division or seed. S. calamagrostis, S. capillata, and S. elegantissima are other Feather Grasses worthy of a place in a full collection.

Stobæa purpurea. - A Thistle-like plant, 2 to $3 \mathrm{ft}$. high, which bears in autumn numerous large bluish-purple flowers. It is hardy and grows in any soil, but succeeds best in a deep and rich one. It may be readily increased by detaching the running underground stems that push up in spring. Seeds are sparingly produced, except in very favourable seasons. S. Africa.

Stock (Matthiola).

Stokesia cyanea.-A handsome hardy perennial, 18 to 24 in. high, and is of stout free growth. It produces in September large showy blue flowers somewhat similar to a China Aster. It is really a fine autumn plant, and on this account is largely grown for supplying the market with blue flowers in autumn. It grows freely in good warm soils, but on account of its late flowering it does not always expand its flowers well. In damp localities, a hand-light over the plants at the flowering season will be beneficial, but this should be so arranged as to allow the free admission of air. S. cyanea is very useful for conservatory decoration in autumn and winter. Division in spring. The slips should be inserted a few inches apart in a warm border or a frame, in sharp sandy soil. As soon as they get well rooted and begin to grow they should be transplanted. A little river sand and leafmould should be mixed with the soil.

\section{S. United States.}

\section{Stonecrop (Sedum).}

\section{Stork's-bill (Erodium)}

Stratiotes aloides (Water Soldier).An interesting native water-plant with a compact vasiform tuft of leaves. From the centre of this tuft arises in summer a spike of unattractive blossoms. In artificial lakes or ponds S. aloides will take care of itself. Hydrocharidaceæ.

\section{Strawberry Blite (Blitum).}

Strawberry, Indian (Fragaria Indica). Strawberry Tree (Arbutus).

Strumaria gemmata. - A pretty bulbous plant of the Amaryllis family, sometimes erroneously catalogued as hardy; but it is a native of the Cape, and, if grown at all, it should have frame-protection, or should be treated as the Ixias.

Struthiopteris (Ostrich Fern). - The fronds of these fine hardy exotic Ferns have somewhat the appearance of ostrich feathers. They are of two kinds, fertile and sterile. The fertile fronds are always grouped in the centre of the plant, and the sterile fronds form a cordon round the fertile ones. Struthiopteris can be easily increased by division of the creeping underground stems, which run for some distance round well-established plants. Good well-drained peat and loam is necessary, and the plants should be grouped in bold slightly-sheltered spots, where their noble appearance would not fail to be admired. As they are deciduous, it would be advisable to plant among and around them, for winter effect, some Polystichums or other robust evergreen Ferns, while, for effect at other seasons, some of our finer Lilies would form a useful mixture. The kinds suited for gardens are $\mathrm{S}$ germanica and S. pennsylvanica. S. germanica is a native of Germany, and is one of the most elegant of hardy Ferns, having fronds nearly $3 \mathrm{ft}$. long. It is particularly suited for the slopes of pleasure-grounds, for cascades, for grottoes, for the rough rock-garden, and for the margins of streams and pieces of water, and it will thrive either in the full sun or in the shade. S. pennsylvanica closely resembles it, but has narrow fertile fronds. Both kinds add much beauty of form to a garden, and should not be confined to a fernery.

Stuartia.-Deciduous shrubs allied to the Camellia, and among the rarest and choicest of hardy flowering shrubs. S. virginica and $\mathrm{S}$. pentagyna are both natives of $\mathrm{N}$. America, and were introduced during the last century. S. virginica is the commonest and best known, and fine specimens may be found in several old English gardens. It is a handsomely-shaped bush of rounded and spreading growth, and is 6 to Io ft. high. In early summer, usually about May, it produces lovely blossoms, about 3 in. across, and in shape like those of a single Rose. The stamens are a deep crimsonred, and the flowers, which are of a soft creamy-white, afford a charming contrast to the pale green foliage. In the neighbourhood of London and in gardens of Sussex and of other coast counties S. virginica is perfectly hardy. The finest specimens we have seen were growing in a rather moist light soil in situations well exposed to the sun, but sheltered on the north and east by trees and shrubs. S. virginica is of slow growth. S. pentagyna (labelled in somegardens Malachodendron ovatum) is rather larger and taller than $\mathrm{S}$. virginica, but its white flowers are very similar. The tuft of stamens is longer 
and the flowers have five distinct styles. Its native habitat is said to be more north than that of S. virginica, and it is therefore considered the hardier. Like S. virginica it is of slow growth. S. pseudo-Camellia is a recently-introduced Japanese species, and was lately exhibited in flower for the first time. It resembles the other two in growth, foliage, and habit, but its flowers are larger and whiter, and have yellow stamens instead of red. It appears to be as hardy as the others, since it has withstood full exposure for some years in the Coombe Wood Nursery in Surrey. These Stuartias are so beautiful when in bloom that they deserve the attention of all lovers of hardy flowering shrubs, and though they are sometimes thought capricious, there must be numerous gardens where the exact conditions suited to them could be found.

Stud-flower (Helonias bullata).

Stylidium.-Interesting plants, sometimes cultivated in the open air and frames, but too tender for open-air culture generally. New Holland.

Stylophorum diphyllum.-A handsome Poppywort, which somewhat resembles Celandine (Chelidonium majus), but which is a much finer plant. Its foliage is greyish, and its large attractive flowers of bright yellow are plentifully produced in early summer. S. diphyllum is I to $2 \mathrm{ft}$. high, and is quite hardy in any ordinary garden soil. N. America. Syns., S. ohioense and S. japonicum.

Styrax (Storax). - The Styraxes are deciduous shrubs. The Japanese kinds are pretty when in flower, and though they are as yet rare in gardens, they are likely to become generally cultivated. S. serrulata (also called S. japonica) is the best, and is very beautiful. It is now becoming common, in some of the best nurseries, and is readily obtainable, but it has not been long enough in cultivation to show what size it will grow to in this country, and though in Japan it is said to be a tall tree, here it is known only as a dense shrub of neat habit. Its white flowers have a tuft of yellow stamens about threequarters of an inch across. They are shaped like a shallow bell, and are profusely borne singly on thin stalks, on the under sides of the flattish branches, and, in combination with the foliage, have a pretty appearance about midsummer. The variety $\mathrm{S}$. virgata is also in cultivation. Both the type and the variety grow freely in the open border, in a light position in good soil, and seem thoroughly suitable for the southern parts of England and for warm districts. The N. American kinds, S. americana and S. pulverulenta, are not so desirable, since they flower less freely, and are rarer. They are fitted only for botanical collections. S. officinalis, which yields the Storax of commerce, is grown in botanical gardens, but is not so pretty as S. serrulata.

Sumach (Rhus).

Summer Snowflake (Leucojum cesti vum).
Sundew (Drosera).
Sundrops (Enothera fruticosa).
Sunflower (Helianthus).
Sun Rose (Helianthemum).
Swamp Honeysuckle (Azalea).
Swan River Daisy (Brachycome).
Sweet Alyssum (Koniga maritima).
" Brier (Rosa rubiginosa).
" Cicely (Myrrhis odorata).
" Fern (Comptonia asplenifolia).
" Fern Bush
"Flag (Acorus" Calanus).
" Gale (Myrica).
" Pea (Lathyrus odoratus).
" Pepper Bush (Clethra).
"Sultan (Centaurea moschata).
", Verbena (Aloysia).
" William (Dianthus barbatus).

Swertia perennis (Marsh Swertia). A singular perennial, with slender erect stems, I to $3 \mathrm{ft}$. high, which are terminated by erect spikes of flowers. These flowers are of greyish-purple spotted with black, and are produced in summer. S. perennis is not showy, but it is interesting for the bog-garden, or for moist spots near the rock-garden, and it may be naturalised in damp places in peaty soil. Seed or division.

Symphoricarpus (Snowberry). - The common Snowberry, S. racemosus, is a familiar shrub, but we would exclude it from a choice collection. We would also exclude from choice collections the Wolf Berry (S. occidentalis); and S. vulgaris, the Coral Berry, or Indian Currant. S. vulgaris has small purplish berries in clusters. The flowers of these kinds are not showy, their growth is not neat, and they smother choicer things. Their chief value is for pleasure-grounds, for undergrowth in woods, or for ornamental covert (as birds eat the berries), and they are all able to take care of themselves under almost any circumstances. S. vulgaris has a pretty variety with foliage variegated with green and yellow. This variety is now common, and being hardy and vigorous, is one of the best of variegated shrubs.

Symphyandra. - Campanula - like plants, two kinds of which are in cultivation. S. pendula is a showy perennial. 
It has branched pendulous stems and large cream-coloured bell-like flowers, which are almost hidden in the leaves. It is very hardy and very dwarf, rarely reaching $\mathrm{I} \mathrm{ft}$. in height. It likes to be borne copiously on branching racemes, and they are of a deep mauve colour. It differs from S. pendula in having a very slightly lobed corolla as well as in the colour of the blossoms. Like S. pendula,

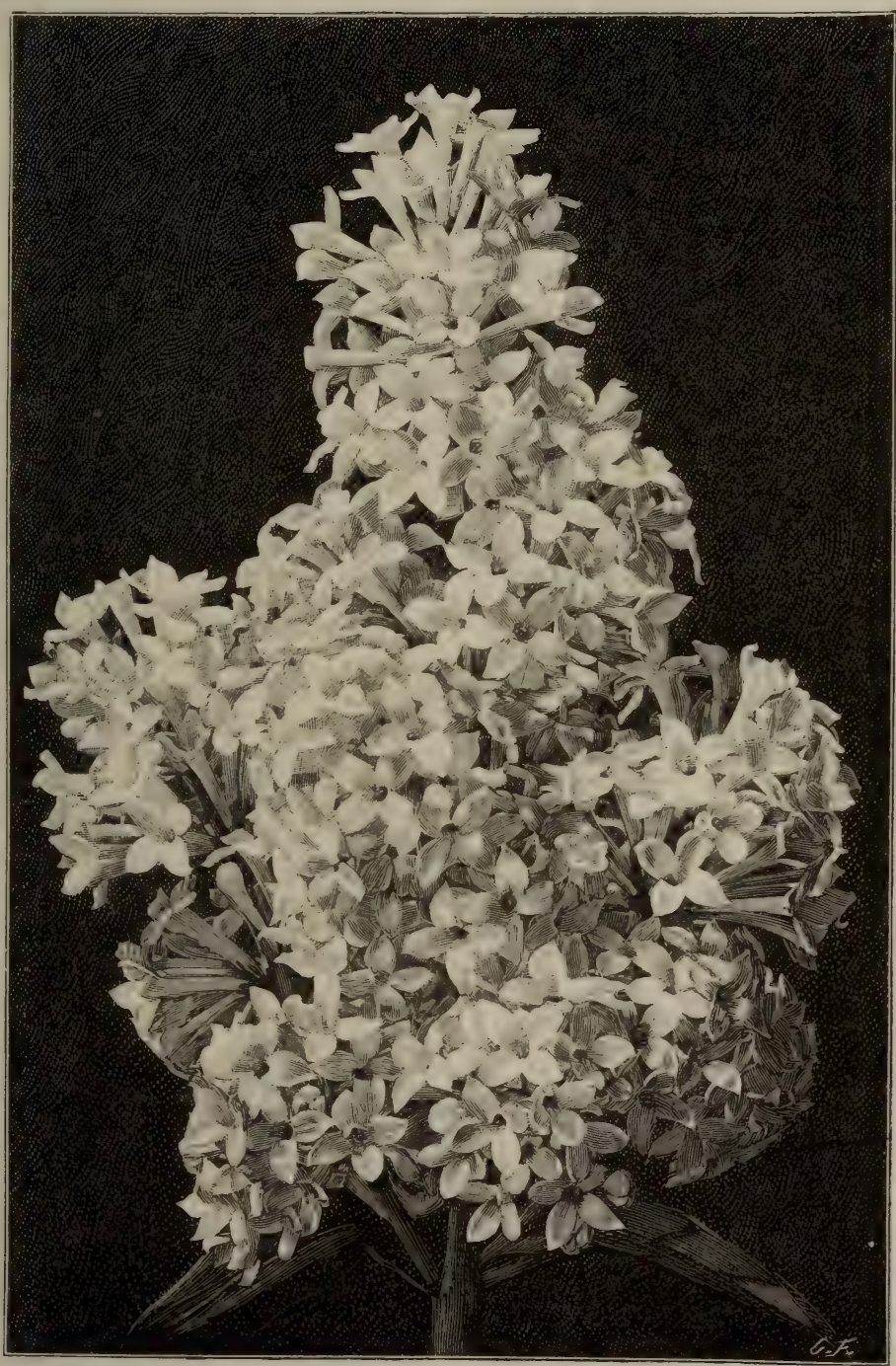

SYRINGA BRETSCHNEIDERI.

associated with most Bell-flowers, but in consequence of its pendulous habit it is best seen at the level of the eye in the rock-garden; it is also a first-rate border plant, and thrives in ordinary garden soil. Rocky parts of Caucasus. Seed. S. Wanneri is also a dwarf plant, and rarely exceeds I ft. in height. Its flowers are it succeeds in company with the majority of the Bell-flowers, but it prefers a light, warm, rich soil and a partially-shady situation. Both plants are short-lived, and duplicates should be kept at hand. Austria.

Symphytum (Comfrey).- These Borage-worts are chiefly bold, but somewhat 
coarse plants, which, though scarcely desirable for the border, are admirably suited for naturalising in rather open sunny places, since, when well developed, their bold foliage has a fine effect in masses. The largest kinds, and the kinds best suited for the wild garden, are $\mathrm{S}$. asperrimum and $\mathrm{S}$. caucasicum. The Bohemian Comfrey ( $\mathrm{S}$. bohemicum) is suitable for the border. It is a very handsome and brilliant perennial, about I ft. high. In early summer it bears erect twin racemes of brilliant reddish-purple flowers. The variegated-leaved form of the common Comfrey (S. officinale) is very handsome, on account of its bold and striking variegation. In spring the leaves form rosettes close to the ground, and, later in the year, the stems and leaves rise and form a larger plant with numerous drooping blue flowers over all. S. officinale may be used with excellent effect in a garden of hardy flowers, although it is generally seen only in mixed collections of hardy variegated plants. Like S. bohemicum it thrives in any ordinary garden soil in open sunny borders.

Symplocarpus fotidus (Skunk Cabbage).-A curious plant, whose bronzypurple cowls marbled with green are not without beauty when closely examined. Its leaves are very large, and it is worthy of a corner in moist deep soil. N. America. Arum family.

Syringa (Lilac).--Most of the common kinds of Lilac may be classed in three species, viz. the common Lilac (S. vulgaris), the Chinese Lilac (S. chinensis), and the Persian Lilac (S. persica) There are several sorts of the first two. Of the white varieties the best are Marie Legrange, Alba grandiflora, Alba magna, and Alba virginalis. If only one white kind is selected, it should be Marie Legrange. The finest of the coloured sorts is Souvenir de L. Spath, which has massive clusters of large flowers, richly coloured. Charles the Tenth is a first-rate sort. It is usually forced into early bloom, and then its flowers are white. Other kinds good in colour are Alphonse Lavallée, Louis Van Houtte, Rubra de Marley, Le Gaulois, and Aline Mocquery. Some double sorts have recently come into cultivation, and the chief of these are Lemoinei, Ranunculiflora, Renoncule, Hyacinthiflora plena, and Rubella plena. These double forms have denser flowerclusters, and usually last longer than the single varieties. An indispensable Lilac is the small Persian (S. persica). It is distinct from the others, and, being dwarf and erect, is well suited for the outskirts of a group of Lilacs or a shrubbery. Its small flower-clusters are of a pale lilac, or are nearly white. The pretty variety, with deeply-cut leaves (laciniata), must not be overlooked. The Rouen or Chinese Lilac (S. chinensis), also known as S. dubia and $\mathrm{S}$. rothomagensis, is an intermediate between the common Lilac and the Persian Lilac, and, like the Persian Lilac, is a most desirable shrub. The large S. Emodi, from the Himalayas, is only suitable for large shrubberies. It is coarse in growth, and is not remarkable for its flowers, which are pale purple. They are produced after those of the common Lilac are past. There is, however, a variegated form. The Hungarian Lilac (S. Josikæa) is a pretty shrub, and worth consideration, as it is different from other Lilacs. It reaches a height of nearly $6 \mathrm{ft}$., and bears erect spikes of small flowers, which are of a pale mauve. The new S. japonica, known also as $\mathrm{S}$. amurensis and Ligustrina amurensis, is likely to prove a valuable hardy-flowering shrub. It bears in summer large dense clusters of creamywhite flowers, which somewhat resemble those of the Japanese Privet. Though a native of Japan, it appears to be hardy, and to be suitable for English gardens. Though deep loamy soil best suits Lilacs, there is scarcely any soil in which they will not grow. Attention should be given to pruning, especially to removing rootsuckers as they appear. They are often grafted on the Privet, but die on it, and all who care for Lilacs should get plants from layers of all the finer sorts.

Tagetes.-The well-known French and African Marigolds, beautiful half-hardy annuals which have been for centuries favourite objects of culture. There are annual and perennial Tagetes. The perennial kinds are not hardy enough to make satisfactory garden plants, though one or two, such as T. lucida and $T$. Parryi, are desirable for a full collection. The annuals in cultivation are all natives of Mexico. The following are the most desirable :-

T. erecta (African Marigold) is easily distinguished by its stiff erect habit, its pale green stalks and foliage, and its huge massive double orange and yellow blooms. It is one of the peculiarities of the African Marigold that one-third of the seeds saved from the finest double flowers always produce single flowers, while the rest are invariably double. Though occasionally African Marigolds are grown for exhibition, the points required are not 
so difficult to obtain as is the case with the striped French kinds; large, round, massive centre, well filled up, being the chief requirement. In garden borders, where a clump of three or four plants will produce telling masses of bloom from June till November, and though size is of less importance, single flowers are best eradicated. It is best to sow seed under glass in April, for then, even without bottom-heat, they will germinate freely. When the young plants are 3 in. in height they should be dibbled out again either into a frame or under hand-lights till they are very stout in the stems, as slugs are very partial to the young plants. Where very large blooms are desired, the soil can hardly be too rich, and the buds on the branches should be thinned out. A good strain thus treated will give flowers nearly as large as Dahlias. Though African Marigolds are generally known as tender annuals, they are as hardy as most summer flowers. They need little special attention, and give a grand show of bloom.

T. patula (French Marigold) is a very charming summer annual. It is highly favoured in exhibitions, but the hard-andfast rules of the florists favour only the striped flowers, which though very beautiful are very monotonous. The colours, however, are not so limited as in the case of the African Marigold. In addition to the striped varieties there are mottled varieties, and varieties of yellow, orange, and chestnut, and of various other hues. The older and coarser forms are spreading, yet tall, and in good soil make huge plants, carrying scores of flowers. These flowers are of medium size, and if good, are double, rounded, sometimes partly reflexed, and invariably very pretty. The striped forms can be kept true only by growing them free from other sorts, but even in the best strains the flowers will vary. Sometimes one plant produces perfect blooms, and at other times selfyellow or maroon flowers. The unpleasant odour of annual Marigolds unfits them for cutting. Of more recent introduction are the compact forms of the French Marigold. These are bushy and robust, usually grow to a height of I2 to 15 in., and carry dense heads of perfect flowers. When these have fully developed the beautiful striped qualities found in the older forms, these latter will cease, probably, to be cultivated. These dwarf forms make effective masses, and answer admirably as edgings for beds of tall African Marigolds. There is little to add to the directions for cultivation given above. It is absolutely necessary that the plants should be well hardened before being planted out, and the planting should be singly and not in clumps.

T. tenuifolia is allied to the French Marigold, but has much smaller flowers, which are sometimes double and sometimes single. It was formerly largely grown for summer bedding. Its elegantly-cut leafage is perhaps its most pleasing feature. As it needs a little starving to induce it to bloom freely in beds and masses, the soil must be rather poor. T. tenuifolia, like all other Marigolds, stands drought well. It is difficult to get any tender flowers which will produce a good mass of yellow during summer, and perhaps this dwarf yellow Marigold, particularly its variety pumila, is among the best for that purpose. Syn., T. signata.

Tamarix. - The common Tamarisk (T. gallica) is a very graceful shrub, with its feather-like growth, and with its clouds of pinkish bloom in late summer. It grows on the shore, but, like the Sea Buckthorn, it also thrives well in inland places. It is a capital shrub for planting on a dry sandy bank where few other tall shrubs would grow; and, in fact, it thrives anywhere and under almost any conditions. It should be planted when small, as in poor soil plants have a better chance of getting a strong root-hold. In very windy places the young plants should have a little artificial shelter at the outset. T. gallica grows fast, 6 to $10 \mathrm{ft}$. in height. T. parviflora, T. Pallasi, T. indica, and T. tetrandra have the Heath-like aspect of the common Tamarisk, but are not so desirable. Britain.

Tamus communis (Black Bryony).-A common and handsome climber in hedges and copses.

Tanacetum vulgare var. crispum (Crisped Tansy).-A very elegant variety of the common Tansy, but much dwarfer in stature than the type. Its emeraldgreen leaves are smaller, and are very elegantly cut, and have a crisped or frizzled appearance. T. v. crispum forms an effective ornament to the margins of shrubberies. It is quite hardy, and does best when fully exposed in deep but rather moist soil, but it will grow anywhere. If the shoots are thinned in spring so as to give them room to suspend their graceful leaves, the plant looks much better than if the stems are crowded. The flowers should be pinched off before they open. $\mathrm{T}$. v. crispum is increased by division in autumn, and at that time every crown will make a plant. Britain. 
Tansy (Tanicetum viulgare).

Tarweed (Chamcebatia foliosa).

Taxus (Common Yew). - This, one of the most beautiful of evergreen trees, has been much used in our flower-gardens for many years, clipped and distorted in what is called "topiary" work. Evelyn is said to have introduced the practice with the gardens is frequent and often good, but its misuse is very evident in many of the great gardens of the world, such as Versailles, where nothing is more ugly than the Yews cut hard against the sky-line, many of them distorted and diseased and ugly from constant clipping for years. Their effect at Versailles is in

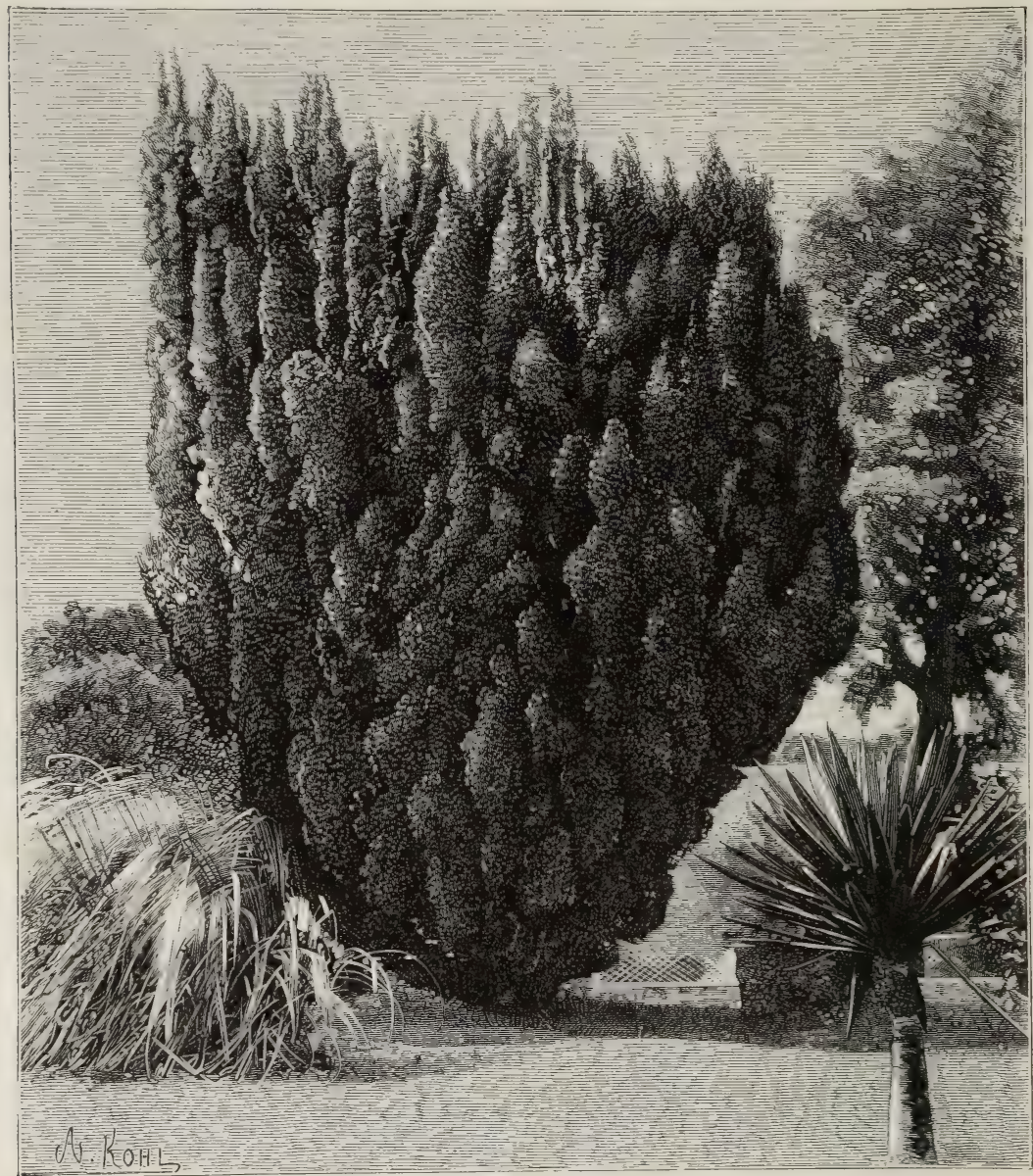

THE IRISH YEW. ONE OF THE FORMS OF THE COMMON YEW.

Yew, and we should be glad if it had no earlier authority, but probably it originated with very old gardens, in which the Yew tree stood by the door or gate and had to be clipped if it was not to overshadow the house or garden. In such a case clipping was necessary, but in modern gardens much clipping of a less profitable kind is often resorted to, so that the Yew is seldom seen in all its stately grace. As a hedge its use in every way bad, either against the palace, the landscape, or the trees around. Although intimately connected with the flower garden, it need hardly be said that the Yew, being a gross feeder, should be kept as far as possible from the flowers of the garden. Indeed, in many cases hedges are used where walls would be better, as the walls have not the defect of eating up all the good soil near. It is more as shelter, and as fine evergreen 
trees for groups seen from the flower garden that the Yew is precious. As a shelter-belt there is perhaps no tree known to us quite so good in all stages of its life. Unlike many other fine evergreen trees, it is not at the mercy of heavy snowfalls and winds, and we have rarely seen it injured by them. A precious shelter from the north and east may be created round the flower garden, or any choice garden, by its means, if allowed to grow naturally and the plants are not too thick. Delightful shaded bowers may be formed under old Yew trees ; and alcoves and arches for seats under clipped Yews occasionally. Lines of hedging Yews should never be formed without good reason.

The Golden Yews and variegated kinds may be used to form striking groups of colour; but are better grouped held together than dotted about at regular intervals, which is fatal to all artistic effect. The Golden Yew, and every Yew worth having of variegated sorts, is most striking in colour in bold picturesque groups. The Irish Yew, a plant of striking form, has been very much over-used by those who do not consider the effect of things in the landscape. I have seen houses with rows of Irish Yews on every side, destroying all possibility of good effect from other and far more beautiful trees, and all the variety and life that should be in an English garden. Variegated and other interesting forms often come from seed.

Of the recognised forms sold in nurseries the following is an abstract of a classification by Mr. William Paul :-

VARIETIES OF SPREADING HABIT.T. baccata, common Yew. T. b. fructuluteo (yellow-berried Yew). This is one of the most elegant; the fruit is yellow instead of red; growth vigorous; the leaves are of a green medium tint. $T$. $b$. nigra. This is a striking plant of bold upright growth; leaves bluish-green. It is effective in the landscape, forming a somewhat sombre, but massive tree. $T$. b. procumbens forms a spreading bush with bright green leaves, the plant having a reddish tint.

VARIETIES OF ERECT HABIT.-T. b. fastigiata (Irish Yew) is a plant of rigid growth, columnar in form; leaves dark green. Seeds of this variety produce for the most part the common Yew, but some vary in form and tint. $T$. $b$. cheshuntensis is a very graceful variety, of pyramidal growth, the leaves closely set; the colour is of a glossy green. It is midway between the common and Irish
Yew, but less formal than the latter and grows twice as fast. T. b. pyramidalis. This variety resembles cheshuntensis in form; the leaves are, however, broader and shorter, and the bark of the young shoots is reddish. T. b. nidpathensis (Nidpath Yew) resembles cheshuntensis in the leaf, branch, and colour of foliage, but is of stiffer growth, being columnar rather than pyramidal, with a disposition to spread at the top. T. b. stricta is similar, but has smaller and paler green leaves, is almost as erect as the Irish Yew, and forms a compact dense tree. A seedling from the Irish Yew, from the same batch as cheshuntensis. T. b. nana is a neat dwarf plant of compact upright growth, with leaves of a dark and more glossy green than the common Yew. It is equally suitable for a single tree on the lawn, for planting in masses, for the shrubbery, or for a dwarf hedge in a geometrical garden. This also was raised from the Irish Yew. T. b. erecta is similar, but of larger growth, though smaller leaves. T. b. erecta Crowderii was first brought under notice by $\mathrm{Mr}$. Crowder, of Horncastle. It is of compact pyramidal growth, and approaches more nearly to erecta than to any other, but has smaller branches, and will probably not grow to so larye a size. It is of more regular growth than erecta, and may perhaps be considered an improved variety of it. T. b. ericoides (empetrifolia) is an interesting and neat little plant of dwarf growth, closely set with branches; the leaves are small and the bark reddish.

VARIETIES OF WEEPING HABIT.T. b. Dovastonii is a weeping variety, somewhat picturesque, the branches shooting horizontally to some distance from the main stem, and drooping at their points. The foliage is ample and of a dull dark green. T. b. Jacksonii is a distinct and elegant weeping variety, with small light green leaves somewhat curled. T. b. recurvata is a handsome variety, with leaves of a pale dull green. The habit is diffuse and rather drooping, the leaves curled in the way of Picea nobilis.

VARIETIES WITH VARIEGATED FOLIAGE.-T. b. variegata (Golden Yew) is a well-known plant of great beauty, suited for planting in masses, and relieving the monotony of large surfaces of green. It is said, on good authority, that the Golden Yew is a male plant, but there are two or more varieties of too close an external resemblance to be distinguished ; moreover, the offspring from seed retain the variegation of the parent, though 
differing slightly among themselves. $\mathrm{T}$. b. elegantissima is paler and more erect and uniform in growth than the lastmentioned. Both varieties, if grown entirely in the shade, quickly become green, but regain their golden appearance on re-exposure to the sun. T. b. fastigiata variegata (variegated Irish Yew) is a sport from the Irish Yew, with occasional silver leaves; of slow growth, and scarce, but hardly striking enough to become a general favourite. T. b. fastigiata variegata (Handsworth variety). This is one of the best variegated Yews, and most useful, growing freely and standing the sun well.

Teasel (Dipsacus Fullonum).

Tecoma. - The hardy Tecomas are described under the name of Bignonia.

Tecophylæa cyanocrocus.-A beautiful spring-flowering bulbous plant, of dwarf growth, bearing large open flowers, of a deep blue. Chili. The variety Leichtlini has a white centre and a sweet perfume. This variety is not thoroughly hardy, except in very mild localities, but it succeeds well under frameculture. About August, bulbs of the flowering size should be planted $3 \mathrm{in}$. deep, in rich soil in a frame. If the bulbs are potted, a depth of $2 \mathrm{in}$. is sufficient. The pots should be plunged and the plants treated like those outside. They should be kept cool, and have as much air as possible. The lights must be taken off in February and March, when the weather becomes warm, and the pots should remain exposed until the flowers begin to expand. The plants may then be transferred to the greenhouse. The bright colours and the delicious scent of the large flowers will always secure a firstrate position for this desirable plant from "the Valley of Paradise."-M. L.

Tellima.-Plants of the order Saxifrage resembling Heucheras. T. grandiflora has leaves prettily coloured and veined like Heuchera Richardsoni, and spikes of small yellowish bell-like flowers. T. parviflora is not so desirable. Both grow in tufts, and both thrive well with Heucheras in moist peaty soil. Division in autumn. N. America.

Teucrium (Germander).-A few of these Labiates are commendable for their neat dwarf growth. T. Chamædrys (Wall Germander) is a compact perennial, 6 to ro in. high, and has shining leaves and reddish-purple flowers borne profusely in summer. It is found throughout Europe on walls, rocks, etc., and is suitable for borders and for naturalisation on ruins, stony banks, etc., in any light soil, and it is also useful as an edging plant. T. Marum (Cat-Thyme) is a small, grey, wiry shrub with somewhat the habit of the common Thyme. Its flowers, which are bright red, are produced in summer. Being a Spanish plant, it is likely to prove hardy only in the southern parts of these islands, and then only on ruins, old walls, or in dry chinks in chalk or gravel pits. If planted out, the soil should be of the driest and poorest description - brick rubbish, etc., with sand and a little poor dry loam. The Cat Thyme should be placed where cats cannot get to destroy it. Cuttings. T. Polium (Poly Germander), a curious dwarf whitish herb, 3 to 5 in. high. The small pale yellow flowers are densely covered with short yellow down, and appear in summer. T. Polium is suited for sunny spots in the rock-garden, and for light free soil. It is not hardy except in the milder southern districts and in favourable spots in the rock-garden, but there it grows freely. Seed, cuttings, and division. South Europe. T. pyrenaicum (Pyrenean Germander) is a dwarf hardy perennial, 3 to $7 \mathrm{in}$. high. The flowers are purplish and white and borne in dense terminal clusters." The leaves are thickly covered with soft down, and so are the short branches and the stem. T. pyrenaicum is very desirable for the rock-garden and for borders. Seed, cuttings, or division. T. hyrcanicum, T. lusitanicum, T. orientale, and T. multiflorum might also be included in a full collection.

Thalia dealbata is one of the most stately of all hardy aquatics, and quite different from the Cannas, to which, however, it is closely related. Its glaucous foliage and its elegant panicles of purple flowers make it most desirable for cool aquaria or for planting along the margins of shallow ponds or streams, as it is hardy in sheltered positions in this country. It is best grown in pots or tubs pierced with holes, in a mixture of stiff peat and clayey soil, and river mud and sand. In winter the pots or tubs may be submerged, and the plants are thus effectually protected. T. dealbata does not attain its greatest size except in warm places in the southern counties, and in such places alone it may be planted out. S. Carolina. Division.

Thalictrum (Meadow Rue). - These perennials have elegant foliage, but not showy flowers. A few of the smaller species have foliage of a most graceful kind-foliage rivalling in delicacy of form and colour some of the charming Maidenhair Ferns. These smaller kinds there- 
fore are valuable for many ornamental purposes in association with flowering plants, or with plants of fine or characteristic foliage.

T. anemonoides (Rue Anemone). - This delicate and interesting species is usually only a few inches high. Its white flowers

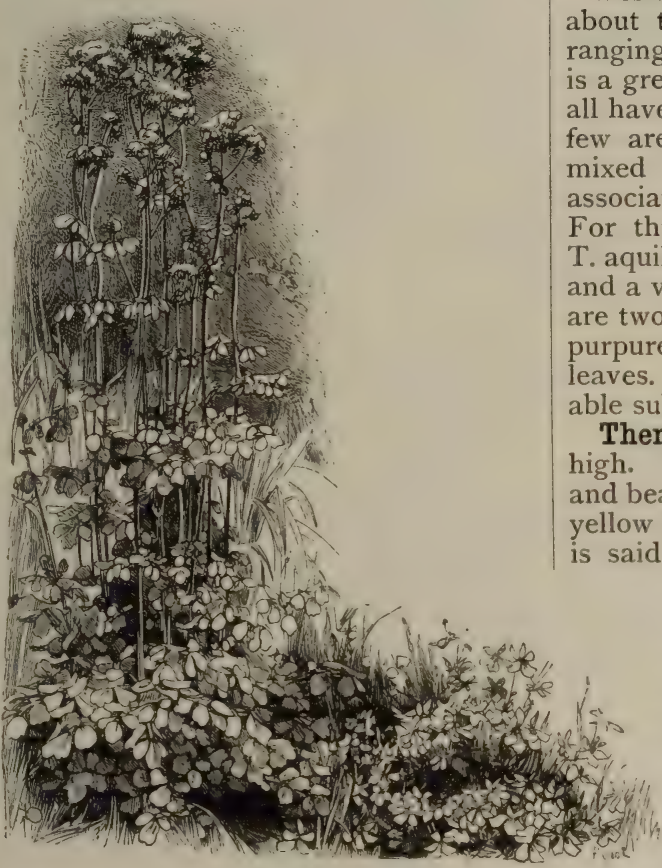

THALICTRUM AQUILEGIFOLIUM.

are nearly $\mathbf{I}$ in. in diameter, and open in April and May. It is best suited for cultivating in the rock-garden in deep moist soil and partial shade. The double variety may be preferred to the type. N. America.

T. minus, one of the most desirable of all the Thalictrums, forms compact symmetrical tufts, 12 to $18 \mathrm{in}$. high, which are of a slightly glaucous hue. T. minus may be grown in any soil, and only requires that the slender flower-stems, which appear in May and June, should be pinched off. Not only in aspect does this bushy little tuft resemble the Maidenhair Fern, but its leaves when mingled with flowers are almost pretty enough to pass for those of the Fern; they are, however, stiffer and more lasting than Fern fronds, and are well suited for mingling with flowers in vases, etc. T. minus would look pretty isolated in large tufts as an edging, or in borders, or in groups of dwarf subjects. Division. $\mathrm{T}$. adiantifolium is a similar plant.
T. tuberosum grows about 9 in. high. In addition to the graceful foliage which we find in all the dwarf Thalictrums, we have here an abundant mass of yellowish cream-coloured flowers. T. tuberosum is perfectly hardy, and thrives in a deep peat soil. S. Europe.

Besides these dwarf kinds there are about two dozen species in cultivation, ranging from 3 to $6 \mathrm{ft}$. in height. There is a great sameness among them, as they all have elegant and finely-cut foliage. A ew are well worthy of cultivating in a ed border, for their elegant growth ssociates admirably with gay flowers. For this purpose we would recommend $T$. aquilegifolium, which is about $4 \mathrm{ft}$. high, and a vigorous grower in any soil. There are two or three varieties of it, one (atropurpureum) with dark purplish stems and leaves. All the Thalictrums are admirble subjects for naturalising.

Thermopsis.-Showy plants, 2 to $3 \mathrm{ft}$. high. They are of slender erect growth, and bear long terminal spikes of attractive yellow Lupine-like blossoms. T. montana is said to be a variety of the older $T$. fabacea or rhombifolia, but it is quite distinct enough for garden purposes. It is of graceful growth, and as it flowers at the same time as the perennial Lupine, it will be found useful for association with that plant and with other border plants of the season. It grows best in good soil in an open situation. It is a native of California and of other parts of Western North America. T. fabacea occurs farther north. Divides badly, and should be propagated by seeds. T. barbata, a beautiful Himalayan species with purple flowers, has apparently gone out of cultivation.

Theropogon pallidus. - A pretty Liliaceous plant, 6 to 12 in. high. It has grassy foliage similar to that of an Ophiopogon, and its flowers resemble the Lily of the Valley, but are rather larger, pink in colour, and appear later. It is presumably hardy, as it inhabits high elevations in the Himalayas. Found on mossy rocks at the bases of old trees, etc., where its roots spread superficially in loose soil.

Thistle, Blessed (Carduus benedictus). " Fishbone (Chamcpeuce). " Globe (Echinops ruthenicus).

" Stemless (Carlina acaulis).

" Woolly - headed (Carduus eriophorus).

Thladiantha dubia. - A handsome creeping perennial of the Gourd family. 
The long climbing stems bear a profusion of bright yellow flowers, and have heartshaped leaves of a lively green. As the plant is very hardy, it may be effectively employed in covering trellises, arbours, etc. In the neighbourhood of Paris it survives the winter in the open air. N. China and India.

Thlaspi latifolium. - A dwarf but vigorous perennial, 6 to $\mathrm{I} 2$ in. high. It has large root-leaves, and its flowers are something like those of Arabis albida, but larger. Suitable for borders, for the spring garden, for beds, and for naturalisation with the dwarfer flowers of spring and early summer. It thrives in ordinary garden soil. Caucasia. Division and seed. T. rotundifolium is the same as Iberidella.

\section{Thorn (Crategus).}

\section{"Apple (Datura). Box (Lycium).}

Thrift (Armeria vulgaris).

\section{" Prickly (Acantholimon).}

Thunbergia alata. - These beautiful half-hardy annuals, so common in greenhouses, are elegant dwarf climbers of the easiest culture, and in summer thrive well in the open air, and are valuable for draping dwarf trellises or for similar uses. The flowers of the type are showy and are a yellowish-buff colour, but there are varieties of colour. Alba is pure white; aurantiaca is bright orange; Fryeri is orange, but has a white eye ; Doddsi has variegated foliage; and there are varieties with yellow and with sulphur-coloured flowers. T. alata and its varieties are 4 to $5 \mathrm{ft}$. high, and from July till October their slender stems are covered with bloom. Seeds should be sown in heat in early spring, and the seedlings should be potted separately as soon as they are large enough. In May the seedlings should be planted out in good light soil. East Indies. Acanthaceæ.

Thymophylla aurea. - A neat little Composite plant, very dwarf, forming a branching tuft about 4 in. high and from 6 to 9 in. in diameter. The flowers are in terminal heads, about $\frac{1}{2}$ in. across, resembling a miniature single Marigold, with a bright yellow ray and disc; and the resemblance is still more marked by the cup-like involucrum and the tiny akenes, which yield a strong aromatic odour. T. aurea is of the easiest culture as a hardy annual, and prefers a rather dry soil. Colorado. = Lowellia aurea.

Thymus (Thyme).-Of the numerous Thymes in cultivation only a small number are ornamental enough for general cultivation, although few plants are more suited for arid parts of the rock-garden and for places where many other plants will not thrive. So quickly do they spread, however, into wide dense cushions, that they ought not to be placed near delicate or minute alpine plants. T. Serpyllum albus, the white variety of our common wild Thyme, is a lovely plant for a sunny bank; and nothing can be more charming than such a bank covered with the common wild Thyme and the white variety. T. lanuginosus, though usually considered a very woolly variety of our common wild Thyme, is far more ornamental. It is pleasing at all seasons, and forms wide cushions in any soil, provided it be thoroughly exposed to the sun. Another very desirable plant is the variegated form of the Lemon-scented Thyme ( $T$. citriodorus aureus). It is more robust than the green-leaved kind and, apart from the beautiful character of its leaves, it retains its foliage through the winter, and consequently is much more useful for the garden than the common variety. Indeed, considering the beauty of the foliage, and the perennial character of the leaves of the Golden Thyme, it seems difficult to understand why the common kind should be grown at all. The Golden Thyme is 9 in. high, and, being of dense and compact growth, is much used as an edging plant. It may be increased by cuttings. Cuttings strike readily in September, either in handglasses or in cold frames, and should be planted out in spring. Those cuttings which are the best variegated should be chosen, as othercuttings have a tendency to revert to the normal green type. Various other Thymes are worthy of the dry arid slopes of a large rock-garden, and of old ruins. The minute, creeping, and Peppermint-scented $T$. corsicus, with flowers so small as to be almost invisible, should be planted in every rock-garden, where it will soon become one of the welcome weeds. Other kinds in cultivation are T. azoricus, $T$. azureus, $T$. bracteosus, $T$. Zygis, T. thuriferus, T. Chamæedrys, and T. Mastichina.

\section{Tickseed (Coreopsis).}

\section{Tick Trefoil (Desmodium).}

Tigridia Pavonia (Tiger Flower), one of the most gorgeous of all flowers, is an Iridaceous plant, about $2 \mathrm{ft}$. high, with erect rigid foliage and triangular flowers. These flowers are about 6 in. across, are of a brilliant scarlet, copiously spotted with crimson. A single flower, indeed, lasts only one day, but for at least six or eight weeks flowers are produced in quick succession from the same stem. Many seminal 
varieties have sprung from $\mathrm{T}$. Pavonia. The most noteworthy is T. Wheeleri, with flowers larger and deeper in colour than those of the type, while $T$. splendens and $\mathrm{T}$. speciosa are also larger and brighter than T. Pavonia ; but description fails to convey an idea of the distinctive points of these varieties. The form grandiflora is superior to the type, as this variety has larger and richer-coloured blossoms, and

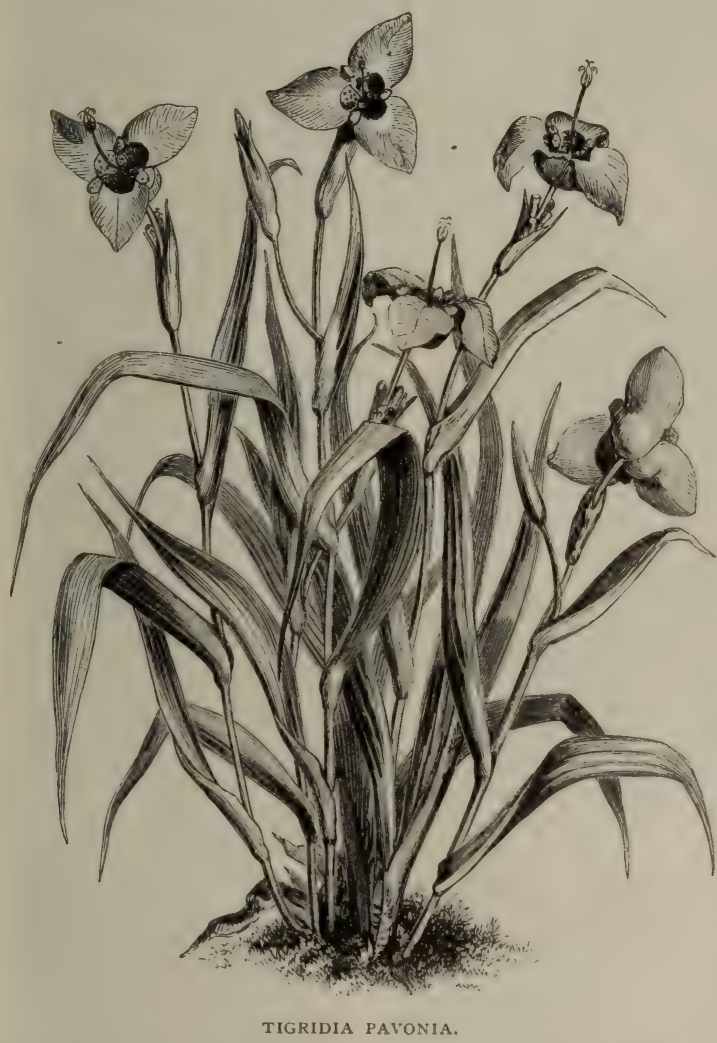

prepare a bed-if partially shaded so much the better; thoroughly drain this bed with rubble, etc., placed at a depth of 18 or 24 in., and fill it in with a well-mixed compost of rich loam and well-decayed leaf-mould in equal quantities, together with a sprinkling of sand. Early in April plant the bulbs 5 to 6 in. apart, and 3 in. deep, placing a little sand under and round each. The bulbs will require no further care, except slight waterings in dry weather, until the blossoms begin to expand. When the foliage becomes decayed in autumn, the bulbs should be carefully lifted, tied in bunches of about twelve, according to their size, and hung in a cool airy place until the next planting season. Some cultivators allow them to remain undisturbed during the winter, and in warm localities and in light soils this is perhaps advisable for a year or two ; but, as a general rule, lifting is preferable, as it entails little trouble, and the bulbs are at hand for propagation. Propagation is effected by offsets, which are freely produced. If carefully removed and treated as above, offsets will flower in the second year. Seeds also afford a wholesale means of propagation. Seeds should be sown in shallow pans, either as soon as ripe or in the following spring, and placed in a heated frame or greenhouse. When the seedlings are of sufficient size they should be pricked off into other pans, and afterwards treated as matured bulbs. If thus treated, they will produce blossoms in the third and fourth seasons.

Toadflax (Linaria).

its small fiddle-shaped petals are more copiously spotted; while the deep green of its plaited sword-like foliage much enhances the effect. T. Pavonia conchiflora is less robust than the type, and its blossoms are of bright yellow and are spotted with scarlet. That it is but a variety of $T$. Pavonia is evident from the fact that, in the early part of the season, its bulbs have produced blossoms in which yellow predominated and later on the bulbs have borne scarlet flowers. Groups of this charming variety are highly effective if associated with Lilies, Gladioli, and other noble subjects. As regards culture of T. Pavonia, about the end of March
Tofieldia.-A genus of Liliaceous plants suitable for botanical collections. $T$. palustris is a native perennial, found in marshy places.

Tolmiæa Menziesi is a curious rather than handsome Saxifrageous plant from Oregon, related to Tiarella. It propagates naturally and freely by adventitious buds, produced at the junction of the leaf-stalk with the blade in the manner of Begonia.

Toothwort (Dentaria).

Tovaria oleracea.-A handsome Liliaceous perennial, nearly related to Smilacina and to $\mathrm{S}$. racemosa. The stems are about $\mathrm{I} \frac{1}{2} \mathrm{ft}$. high, and are gracefully arched. 
The flowers are borne at the end of the stems in broad racemes about 4 in. across. Their pure white colour contrasts well with the purplish hue of the stems and the flower-stalks. Native of Sikkim, but quite hardy.

Tournefortia heliotropioides. - A modest half-hardy plant with pale lilac flowers, which are borne in clusters in much the same way as those of the common Heliotrope. It should be treated as a half-hardy annual, being sown in heat in early spring, and the seedlings should be planted out in May. It likes a good deep loamy soil, and should have an open position in order to develop itself freely. As it is of spreading growth, the seedlings should not be placed very near to each other. Buenos Ayres.

Trachelium cœruleum (Blue Throatwort). - An attractive plant from the Mediterranean region. It is a sub-shrubby much-branched perennial, I to $2 \mathrm{ft}$. high, and produces in summer broad clusters of small blossoms, which are blue in the type and white and lilac in the varieties. It is not thoroughly hardy, and can be grown only in the warmest situations in dry borders, rocky banks, and old ruins or walls. It is an elegant plant for vases, etc., and should be protected during severe cold. Seed or cuttings. Campanulacaæ.

Tradescantia virginica (Virginian Spiderwort).- -Some of the hardy Tradescantias are pretty plants, but $T$. virginica is by far the best, and with its varieties it represents all the beauty of the genus. It is a distinct and valuable perennial, I 2 to $30 \mathrm{in.} \mathrm{high.} \mathrm{It} \mathrm{flowers} \mathrm{abundantly}$ during summer, and has showy purpleblue flowers. There are several varieties, one with double violet, one with single rose-coloured, one with single lilac, and one with single white blossoms. These grow in any soil, from ordinary garden soil to the wettest clays. They are suitable for the mixed border, for margins of shrubberies, for the rougher parts of extensive rock-gardens, and for the wild garden. Division in spring. T. Barclayana, T. iridescens, and T. subaspera, are desirable for a full collection.

Trapa natans (Water Chestnut).-An interesting aquatic plant of doubtful hardiness with us. S. Europe.

Treefoil, Bird's-foot (Lotus)

Treefoil, Tick (Desmodium).

Tree Mallow (Lavatera arborea).

Tree of Heaven (Ailantus).

Trichomanes.--Beautiful filmy Ferns, but not suited for open-air culture. They require a special place under glass, so that they can at all times be kept growing in an atmosphere heavily charged with moisture, and be kept shaded. In the mildest parts, perhaps, the Killarney Fern (T. radicans) and similar kinds would succeed, but only in shady caves under waterfalls and in like positions.

Trichonema (= Romulea).

Trichosanthes (Snake Gourd). Cucurbitaceous plants, producing singularly-shaped fruits, but better suited for hothouses than for the open air.

Tricyrtis hirta.-An interesting perennial, about $3 \mathrm{ft}$. high, with slender erect stems which are terminated by a few curiously - shaped pinkish blossoms, spotted with purplish-black. It is perfectly hardy, but it flowers so late that it is invariably damaged by frosts. The variety nigra flowers three weeks earlier, and is consequently more desirable, and the flowers, moreover, are more attractive. $\mathrm{T}$. pilosa is dwarfer, but is otherwise a similar plant, though rarer. These Tricyrtes thrive in a moist peat border, partially shaded, and if somewhat protected, so much the better. Japan.

Trientalis europæus (Star-flower).A delicate and graceful plant, which inhabits shady, woody, and mossy places. It has erect slender stems, rarely more than 6 in. high. These stems bear from one to four slender flower-stems, and each supporting a white or pink-tipped flower shaped like a star. Healthy well-rooted plants are not difficult to establish among bog-shrubs in some half-shady part of the rock-garden, or in the shade of Rhododendrons, etc., in peat soil. T. europæus is very suitable for association with Linnæa, Pyrolas, and Pinguiculas, among mossy rocks. Flowers in early summer. Division of the creeping rootstocks. Europe, Asia, and America.

Trifolium (Trefoil).-There are very few garden Trefoils, and these few are not generally known. Among them are a few dwarf creeping alpines that are desirable for the rock-garden. Of these the best is $T$. uniflorum, a neat trailing plant with pink and white flowers, which are larger than those of any other Trefoil. These flowers are borne singly, and are studded profusely over the plant, rendering it a very striking object. $T$. uniflorum is of the easiest culture, and delights in an exposed position on the rock-garden, and in an open space on which to creep. T. alpinum is a stout spreading kind, 3 to 6 in. high. The flowers appear in summer, are large, but not brilliant, and the upper petal is flesh-coloured and streaked with 
purple. T. alpinum is suitable for the rock-garden and for margins of borders. $T$. rubens is a stout perennial, about $\mathrm{I} f \mathrm{ft}$. high, and produces large dense heads of carmine flowers in early summer. It grows almost anywhere, but as it seems to prefer dry, calcareous, marly or species in cultivation the finest by far is T. grandiflorum (White Wood Lily), one of the most beautiful of all hardy plants. It is 6 to 12 in. high, and bears on each stem a lovely white three-petalled flower, fairer than the white Lily, and almost as large. The size of the flower, however,

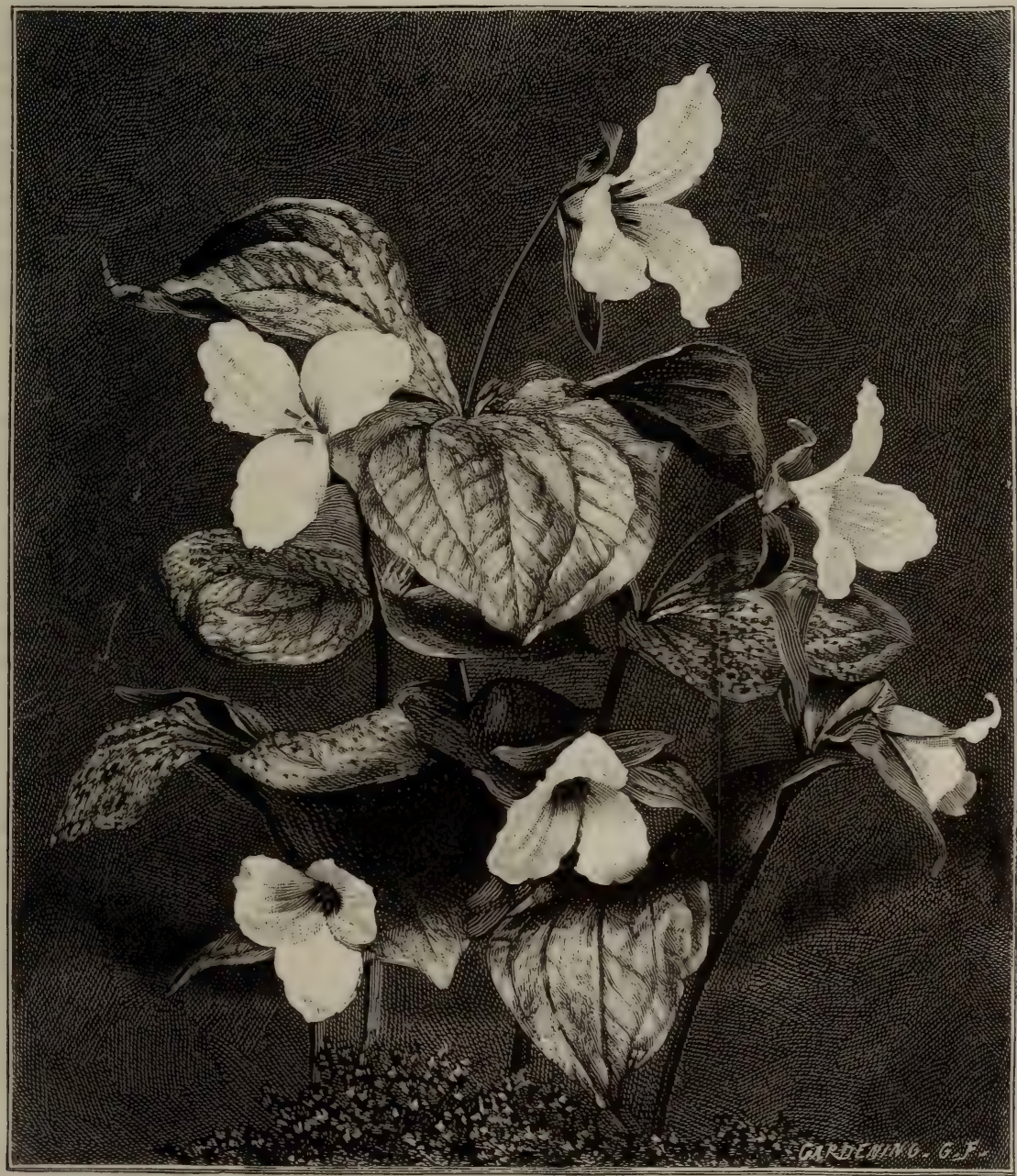

TRILLIUM GRANDIFLORUM (WOOD LILY).

gravelly soil, it is specially suited for naturalisation on arid declivities with a southern aspect. T. pannonicum, with creamy-white flowers, is another ornamental plant. All these Trefoils may be readily propagated by division or seed.

Trillium (Wood Lily).-Perennials of low growth, which inhabit the shady woods of N. America. Of the several depends on the vigour of the plant. $T$. grandiflorum thrives under almost any treatment. It becomes a free-growing herb of goodly size in a shady peaty border in open air; but in a sunny or exposed position its large soft green leaves do not develop. Depressed shady nooks in the rock-garden or the hardy fernery suit it admirably. T. atro-pur- 
pureum, T. erythrocarpum, T. sessile, and $T$. pendulum are not equal to $T$. grandiflorum, but some of them are pretty, and all of them are interesting.

Triteleia uniflora (Spring Star-flower). -A delicately-coloured, free-flowering, hardy, bulbous plant, 4 to 6 in. high, the flowers of which are of an iridescent white with bluish reflections, and are marked on the outside through the middle of the divisions with a violet streak, which is continued down the tube. They open at sunrise, and are conspicuously beautiful on bright days, but they close in dull and sunless weather. The plant comes into flower with or before the Siberian Squill (Scilla sibirica), and, during the last days of April, remains in effective bloom, when the vivid blue of the Squill has been long replaced by green leaves. T. uniflora flowers profusely in pots, and even flowers boldly in an unfavourable position in clay. There are several forms, which differ in the shade of their flowers. Associated with the best Scillas, Leucojum vernum, Iris reticulata, dwarf Daffodils, and the like, T. uniflora forms a charming addition to the select spring garden, and is equally useful for the rock-garden, borders, or edgings. Native of Mendoza in S. America. T. (Leucocoryne) alliacea is scarcely so ornamental. It is nearly allied, and thrives under similar circumstances. For other species see Brodiæa.

\section{Tritoma (Kniphofia).}

Tritonia aurea.-This beautiful bulb is so common as to need no description. Though usually grown as a greenhouse plant, it is valuable for the open air. The bulbs should be bought as soon as they can be got, and should be out of the ground as short a time as possible. As a border plant T. aurea succeeds in any soil except clay, but it seems to prefer moist beds of peat soil, and it may be planted out in late spring. The shoots are sometimes killed to the ground by frost in May, and that without injury to the bulb, but the growth is weakened and retarded. Treated as cold-frame bulbs, and planted out, they will flower in August in the south, and a month later in the north. In cold places it is better to bring them on for a longer time under glass, and plant them out later, or to treat them altogether as greenhouse bulbs. Though tolerably hardy, the lateness of their flowering is an objection to leaving them out all the winter, and besides this, they are liable to be killed in severe winters unless they are well protected with litter; while, owing to their habit of straying, in which they much resemble Lilies of the Valley, they are apt to leave the place in which they were planted, and to come up where they are not wanted. It is better, therefore, to lift them about the middle of November. If necessary, many of them may be potted together, and separated when planting-out time comes, so that the lifting takes little trouble and little room. This lifting must be carefully managed, for in September, although the tops are not dead, the shoots that form the new bulbs next year are already several inches long, and sometimes they are even more than I ft. long. The old bulbs can be distinguished by having no stalks or shoots, and may be pulled off and thrown away. It will be understood after what has been said that anything like drying off or storing the roots in a dry place is fatal. The roots should not be uncovered for a single day. T. aurea is also known as Crocosma aurea. Cape.

Trollius (Globe-flower).-Few garden plants are more desirable than Globeflowers. They vary considerably in height, but are of compact habit, and never require stakes or other supports. They may be grown in beds, or in borders, on lawns, or by ponds or streams, and any one not possessing a garden may grow them in deep pots. They are of a dense habit of growth, and the foliage and the flowers rise from an underground crown, which does not possess the rambling proclivities that mar the value of many a good herbaceous plant. The roots are numerous and deep-searching, especially in a border where drainage removes the water-level to a considerable depth. The flowers vary from a pale yellow to a deep gold, almost bordering on vermilion. The Globe-flowers bloom in spring or in summer, and are at their best in April, May, and June. Occasionally old-established plants develop a few flowers in September and October; these flowers depend alike on the season and the strength of the plant itself. Globeflowers may be most readily increased by division of the root, which operation should be performed either in September or in March ; the former is to be preferred, as it gives the plants an opportunity of making fresh roots during the rest of autumn, and of thoroughly repairing, before the dry early summer sets in, the damages inseparable from root-division. If the plants are divided in March, a few bright dry days will cause the foliage to be prostrate on the ground, and the blossoms are certain to be puny and short-lived. Globe-flowers may be propa- 
gated by seeds, as well as by division. Vigorous well-established plants produce seeds freely, and these seeds generally retain with persistency the specific characters. It is to be noted, however, that Globe-flowers rarely vegetate in the year they are sown, but come up vigorously in the following spring, and, if for the mountain meadows where they grow are almost invariably supplied with cool springs below, which enable them to withstand the burning heat of a day's uninterrupted sunshine, without showing, by flaccid leaves, any indication of exhaustion.

T. asiaticus (Asiatic Globe-flower).The leaves of $T$. asiaticus are much more

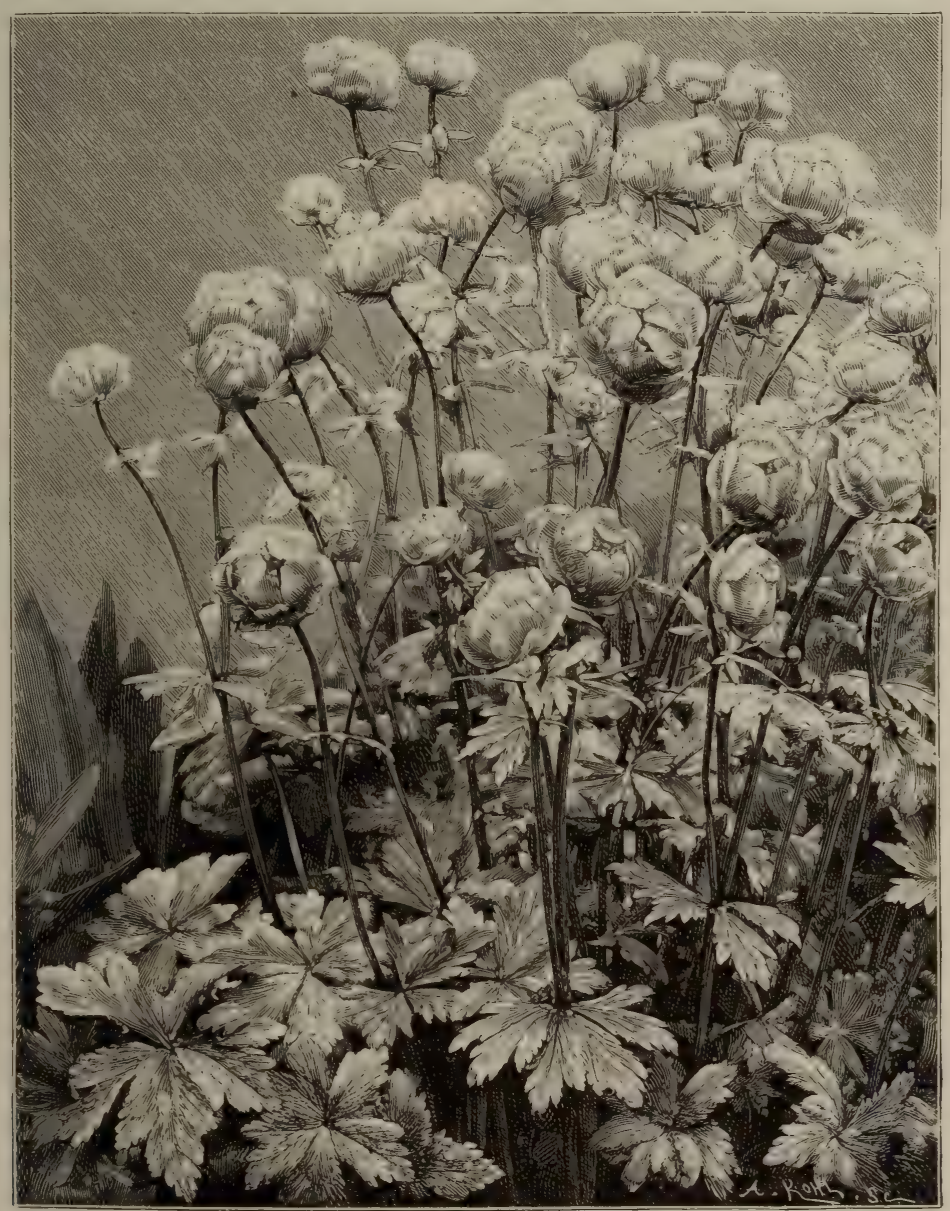

TROLLIUS EUROPÆUS (MOUNTAIN GLOBE-FLOWER).

carefully attended to, make fine flowering plants in the second season after vegetating. They will not, however, attain their full development until the fourth year or even later. They grow freely in any soil, and are partial to a good stiff loam overlying a cool moist sub-soil, but, if cultivated in a dry situation, they should have a good supply of manure, not only as a stimulant, but as a mechanical and moisture-retaining element in the soil; divided than those of $\mathrm{T}$. dauricus, and are distinguished by their bronzy-green colour; and its flowers, though similar in size to those of $T$. dauricus, are of a golden-yellow and are not globular, while the sepals expand as they reach maturity. $T$. asiaticus flowers in the early part of May. When growing vigorously it attains a height of 18 in. It rarely perfects its seeds, but is readily increased by rootdivision. Siberia. 
T. dauricus is distinguished from $\mathrm{T}$. europæus by its gigantic development and bloom. Its leaves are large and much divided, and are a deep olive-green. They have long foot-stalks. The lemoncoloured flowers are large, and the sepals overlap one another in a globose form. Dahuria. T. dauricus seeds freely, and may be readily increased, true to type. Heavy soil appears to be admirably suited to the requirements of the Globeflowers, and T. dauricus attains the height of $3 \mathrm{ft}$. or more. $\mathrm{T}$. dauricus is identical with the species known as $T$. giganteus and T. Demayanus.

T. europæus (Mountain Globe-flower) is the familiar native Globe-flower. Its height is about 15 in. Its lemon-yellow flowers are perfectly globular, and are I to 2 in. in diameter. It is common throughout the upland meadows of Europe, and is by no means a native of Britain alone. T. albus, sometimes considered a mere variation of $\mathrm{T}$. europæus, has been occasionally met with under the title of T. pumilus. The flowers are of a pale lemon colour, and not white, as the specific name would indicate. $T$. albus is dwarf in stature as well as small in development. It is particularly fond of peat soil-more so, perhaps, than any other Globe-flower. It is exceedingly compact, and distinct in the arrangement of its leaves, which, like its blossoms, are scarcely half the size of the common European species.

T. napellifolius is a strong handsome species. Its flower is globose, deep yellow, bordering upon orange, and is more than 2 in. in diameter. T. napellifolius is a native of Central Europe, and on the slopes of the Carpathians it forms a very conspicuous object. In our herbaceous borders it carries off the palm as unquestionably the most showy of the Globe-flowers.

T. sinensis is a very distinct plant. Its flower-stems attain a height of 2 or $3 \mathrm{ft}$. Its flowers are of a deep yellow, and the sepals are partially expanded. It blooms in July, and in this respect bears a resemblance to the American variety of the Asiatic Globe-flower, to which it is in some degree related. Japan and China.

$\mathrm{T}$. altaicus, $\mathrm{T}$. caucasicus, $\mathrm{T}$. intermedius, T. tauricus, and T. medius bear a very close relationship to either the European or the Asiatic forms. So slight, indeed, is the difference, that the species enumerated will supply the ordinary cultivator with all that the genus can afford towards the decoration of early summer borders.
Tropæolum (Nasturtium):- The Tropæolums are almost confined to the mountainous region extending from New Granada to Chili. They seldom descend into the tropics, and, therefore, do not require great heat, which indeed is rather unfavourable to them, but, on the other hand, the first frost cuts most of them down to the ground. They love a halfshaded situation, and succeed in the open air in the summer. It is quite unnecessary to dwell on their merits as ornamental plants, becaúse three or four species and their hybrid varieties are familiar and fully appreciated, but we would call attention to the fact that many other species are even more attractive. There are annual and perennial species, and the perennials may be divided into two groups, one with fibrous roots, and the other with tuberous roots. The rapid growth of the annuals, T. majus, T. minus, etc., is proverbial, and their hardiness in a temperature above freezing-point, as well as their indifference to the quality of the soil, should recommend them where anything unsightly is to be hidden. Tropæolums are not always so easy of culture as the annual species. The following are the most fitted for the open air :-

T. aduncum (Canary Creeper).-Undoubtediy the favourite among Tropæolums; it is almost unrivalled for lightness and elegance among yellow flowers. Its yellow is of the most pleasing shade, having more of the green than the red element in it. The precise home of the Canary Creeper is uncertain, as the plant occurs all over the west of S. America, from Mexico to Chili ; but it has doubtless spread from the Andes. It is a valuable plant, accommodating itself to any conditions, and thriving in sun or shade, but doing best in a position with a north aspect. For festooning trellises, arbours, shrubs, etc., it is unsurpassed, as it rarely fails to produce a profusion of pretty yellow blossoms. It is a free annual. Seeds should be sown in April in the open ground in sandy loam. The Canary Creeper is also known as T. peregrinum and T. canariense.

T. Lobbianum.-This most beautiful annual is of vigorous climbing growth, and is easily distinguished from the old T. majus by being more or less hairy. The varieties of it differ chiefly in the colour of the blossoms, which are mostly yellow, scarlet, and crimson. There are no finer forms than those known in seedshops as Coronet, a large yellow sort; Perfection, a rich crimson-scarlet sort; and Octoroon, a deep mulberry sort. 
These sorts are all great improvements on the old Nasturtiums, and persons who have greenhouses will find Perfection useful for winter decoration in pots. $T$. Lobbianum is an excellent plant for clothing unsightly spots, or for providing temporary shelter during the summer time. Seeds should be sown about the middle of April. All the after-culture needed is the guiding of the leading shoots in the direction in which they are to grow. T. Lobbianum has a pleasing effect when sown here and there amongst shrubs in the back of a border. As the plants grow, they attach themselves to the bushes, and climbing over or through in catalogues are atro-sanguineum (dark orange-crimson), citrinum, or Shillingi (pale yellow), and Scheuermannianum (pale yellow with dark spots). There is also a very handsome double variety. These climbing sorts are useful for the same purposes as T. Lobbianum, and require the same treatment. The most important varieties of $T$. majus are the dwarf or Tom Thumb strain, which includes a large number of sorts, the most valuable being the compactum strain. Few annuals come into flower more quickly than these dwarf Nasturtiums, and few bloom longer or more constantly. In poor soil the compactum forms bloom

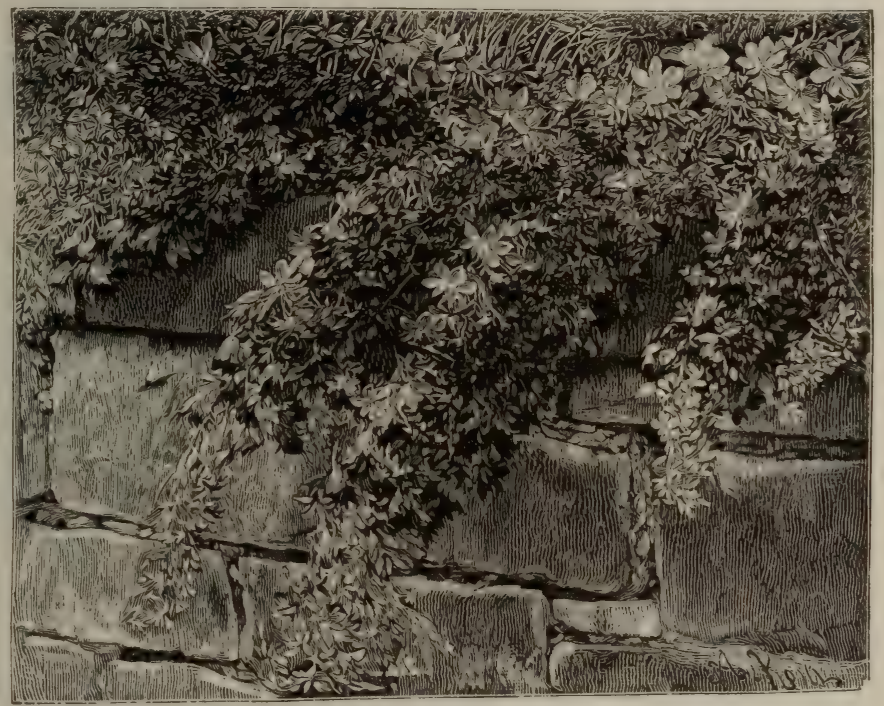

TROPFOLUM POLYPHYLLUM.

them, throw out wreaths of lovely blossoms which retain their beauty until cut down by frost. When that takes place, the haulm should be removed to obviate any unsightliness. Temporary floral fences may also be made with this plant. All that is required is a row of Pea stakes for the shoots. T. Lobbianum may also be made to assume a pyramidal form by being allowed to overrun the dead tops of young Fir trees. In short, there is no end to the uses to which the climbing Tropæolum may be put.

T. majus (Large Indian Cress or Nasturtium) is too well known to need description. It differs from $\mathrm{T}$. minus in being larger, and from T. Lobbianum in the absence of hairiness. There are many beautiful varieties of it, most of them hybrids. The principal sorts named best. Their rich, bold colours are marvellously effective in masses, and they are never without flowers from first to last. In this respect they outshine the other Tom Thumb kinds, which have a short season of flower and then collapse. The compactum forms can be had good from seed, and seedlings usually come true; but actual truthfulness can only be ensured by propagation from cuttings. Fortunately, cuttings are furnished by the plants in great abundance, and will strike freely anywhere under glass if put in about the middle of September. A few dozen plants put into store pots will yield a large number of cuttings in spring, and spring-struck cuttings make the best plants for summer bedding; while plants from cuttings make less leafage, and furnish more bloom, though curiously 
enough they produce little seed. The seed they produce, however, may be relied upon to fairly reproduce the parents if no other Nasturtiums are growing near. The other Tom Thumb kinds may be sown in the open ground in spring, but the compactum race grows so freely, if raised in this manner, that it is best sown under glass and then planted out. If sown under glass, compactums bloom earlier, and are more compact, and they can be planted out to succeed spring-bedding plants. All who love rich masses of colour will find these dwarf Nasturtiums worth cultivating. The varieties are so numerous and at the same time so uniformly beautiful, that it is difficult to make a selection; and the catalogues of the seedsmen abound with names of favourite sorts. Of T. minus there are several varieties, including a double one, but these are less desirable than T. majus.

T. pentaphyllum.--A rapid climber, 6 to ro $\mathrm{ft}$. high. Its flowers are yellowish-red, and are abundant in summer. It is an admirable plant for covering pillars, walls, chains, bowers, and it revels in sunshine, and does splendidly on the south wall of a greenhouse or in any warm aspect. It does best in light and warm loams or calcareous soils. Division or seed. Chili.

T. polyphyllum. - This is one of the most valuable hardy plants ever introduced, not only for its freedom of growth and its freedom of flower, and for the readiness with which it may be grown, but also for its picturesqueness. While its foliage may form a dense carpet on a bank, its wreaths of flowers usually throw themselves into irregular windings and groupings. It is very distinct whether in or out of flower. Its leaves are glaucous and almost Rue-like in tone, and are cut into fine divisions or leaflets. In a warm rock-garden the stems creep about, snake-like, through the neighbouring vegetation, sometimes extending to a length of 3 or $4 \mathrm{ft}$. The flowers are of a deep yellow, and are produced as freely as the leaves. T. polyphyllum is a tuberous-rooted kind, and is quite hardy in dry situations in the rock-garden and on sunny banks, but it should not often be disturbed.

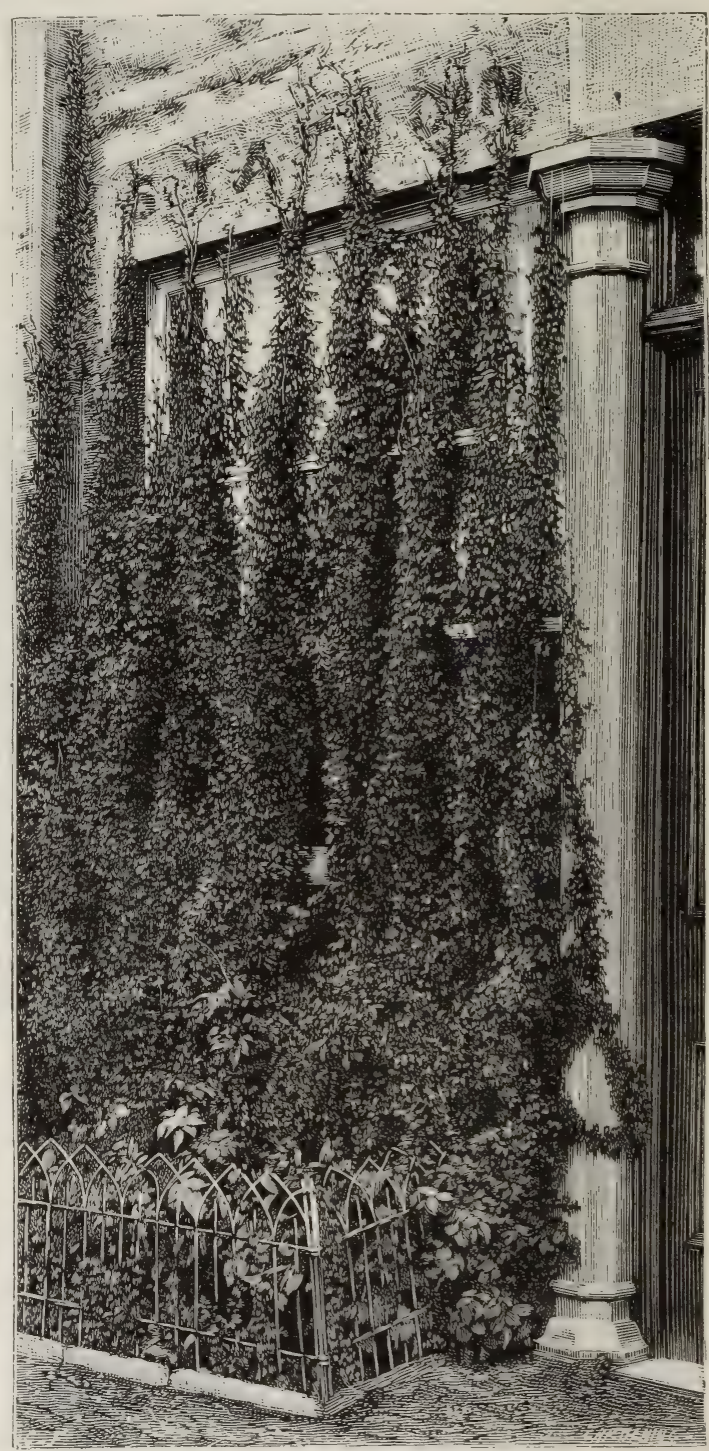

TROPAOLUMI SPECIOSUM (FLAME NASTURTIUM).

It springs up early, and dies down at the end of summer. Chilian Cordilleras.

T. speciosum (Flame Nasturtium).A splendid creeper, with long and elegant annual shoots, which are gracefully clothed with six-lobed leaves. From the 
axils of these leaves spring such brilliant vermilion flowers, that a long shoot is startingly effective, especially if seen wandering among Ivy leaves or in verdure of any kind. T. speciosum has been introduced a considerable time from $\mathrm{S}$. America, but, notwithstanding its graceful beauty and its perfect hardiness, it is little known, especially in the south of England. It is impossible to find anything more worthy of a position where its shoots may fall over or climb up the face of some high rock or high bank in the rock-garden ; while it is suited for an open spot in the hardy fernery, or for any other position where its peculiar beauty may be seen to full advantage. It is very beautiful when clambering through evergreen shrubs which are nailed against terrace walls. It enjoys a deep, rich, and rather moist soil, and appears to flourish best in cool moist places, or near the sea. No pains should be spared to establish it in a vigorous condition.

A correspondent writes to The Garden: _."In warmer districts of England success does not frequently attend the attempt to cultivate this beautiful climber. It evidently dislikes hot sun and a dry atmosphere, and I am of opinion that the great portion of the failures in growing it are due to a want of realising how indispensable a cool and comparatively moist atmosphere is to its welfare. Several years ago a friend who knew nothing of the nature of this plant received some roots from the fine old specimens that grow on Lismore Castle. The great beauty of this Tropæolum had been described to him, and he naturally wished to see it thrive in his garden. By my advice some of the roots were planted against a west wall, in front of which grow some good-sized Nut-bushes and a few tolerably large Apple trees, so that in the hot summer weather the sun could only reach the plants for a couple of hours daily. The remaining roots were planted against a north wall, where scarcely any sun came, and at the west end of the dwelling-house, where the full force of the afternoon sun was felt. In all these cases the soil was alike. The plants behind the Nut-bushes and Apple trees grew remarkably well and bloomed as freely as could be expected in the first year of planting. On the north wall the growth was good, but the flowers were not so numerous; but in the sunny position, although the roots made a growth of a foot or so, this growth gradually withered away as soon as the power of the sun made itself felt. There could be no better proof that the successful growth of the Flame-flower is simply a matter of position, and that, even in the southern counties, there are probably few gardens where the requirements of the plant may not be met."

When a position is selected, the soil should be made light, deep, and free by the addition of leaf-mould, peat, fibry loam, and sand, according to the nature of the ground. The soil should be mulched in summer with an inch or two of leaf-mould or manure to prevent excessive evaporation ; and whatever manure is used, it must be well decayed. The young plants should be planted in spring, the roots being inserted 6 or 8 in. in the soil and the plants should be well watered. These plants themselves also enjoy a deep bed of manure beneath the roots. The Flame Nasturtium is best planted where the shoots may ramble among the spray of shrubs, Ferns, or trailers, but as it must be placed on a cleared spot, it is well to put a few branchlets over the roots for the young shoots to crawl over. When the shoots are established they may be allowed to take care of themselves, and it is much better to let them have their own wild way than to resort to any staking or support, except that of other subjects growing near. Division or seed. Seeds should be sown as soon as they are ripe, in a pan or box, in light loam, leaf-mould, and sand; the pan or box must be placed in a pit or a frame, and the soil must be kept moist, but not wet, until the plants make their appearance in spring. The careful division of the old roots is, however, much the best and much the easiest method of propagation.

T. tuberosum.-A distinct and beautiful climber with tuberous roots. The slender stems are 2 to $4 \mathrm{ft}$. high, and bear, in summer, a profusion of showy scarlet and yellow flowers on slender stalks. T. tuberosum should be grown in open spots in the poorest of soils. Its branches may be supported, or allowed to trail along the ground. As it is not hardy in all soils, the tubers should be lifted in autumn, stored in a dry place through the winter, and planted in spring. Peru.

Truffle Sunrose (Helianthemum Tuberaria).

\section{Trumpet-flower (Bignonia).}

Trumpet - weed (Eupatorium purpureum).

\section{Tuberose (Polianthes tuberosa).}

Tulipa (Tulip). - There are many wild Tulips, but comparatively few are in general cultivation. This, no doubt, is owing to the fact that most of them are 
inferior in beauty to the numerous varieties that have so long been such favourite garden plants, and which have been derived principally from T. Gesneriana, $T$. suaveolens, and $T$. præcox. These varieties are so valuable that no garden should be without them, especially as their culture is very simple. With regard to the early-flowering kinds, the and moist sandy soil is the home best fitted for Tulips during the summer. The blooming season is not nearly so short as is generally supposed, for between the earliest and the latest kinds a considerable time intervenes. Beds of Tulips should be carpeted with small tufted or creeping plants, and there are many hardy flowering and foliage plants suited

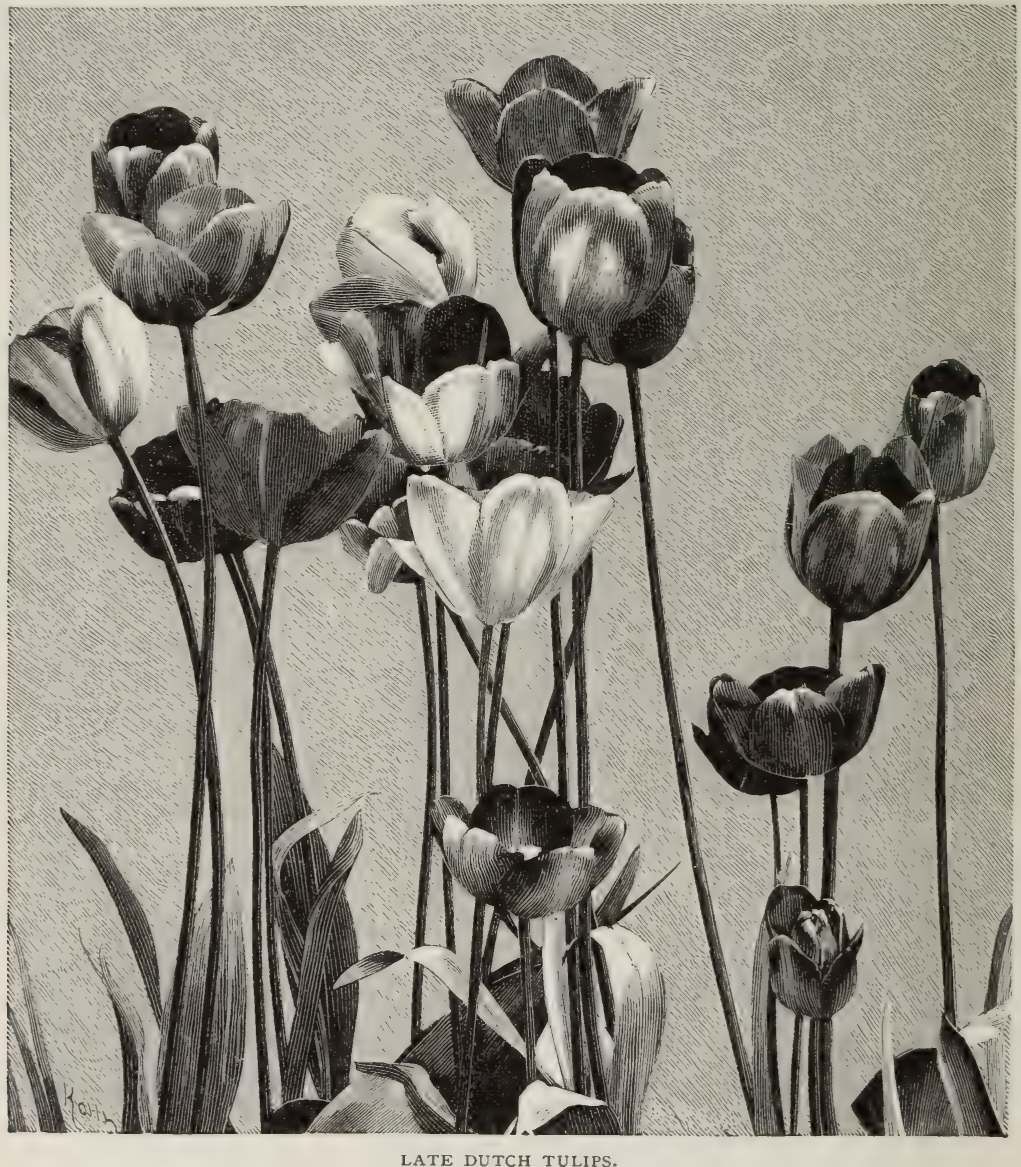

bulbs are usually taken up and stored away in summer, but if left undisturbed in a warm sunny border they will increase rapidly and produce plenty of fine flowers. They cannot, however, always be left undisturbed, and, therefore, the best way is to have a reserve garden to which they can be removed when summer planting commences. Here they will not only mature themselves, but will throw off offsets which in two or three years will make fine flowering bulbs. A good light for the purpose. The White Rock Cress (Arabis albida), togetherwith its variegated form, the Aubrietias, Hepaticas, Primroses, Cowslips, the drooping Catchfly (Silene pendula), the Pansies, earlyflowering Violas, Saxifrages, the white Iberis corifolia, Sedum acre aureum, the pretty creeping Ajuga reptans rubra, and many others make excellent carpets for beds or bulbs. When a collection of Tulips is sufficiently large, it is a good plan to rest the bulbs every third year 
by preventing them from blooming. They occupy but a small space in a reserve garden, and can be planted quite thick. A light, rich, well-drained soil is required for Tulips, but as their roots rarely extend more than 9 or 10 in. from the bulb, room is easily made for them. They should have 3 or 4 in. of soil above the crown of the bulb; for if they are planted nearer the surface they are liable to injury during a severe winter.

Tulips require a rich soil and the careful hand of the gardener. The bulbs should be planted early in November, and, although the plants withstand our most severe winters, they must be protected either by glass frames or canvas as soon as the flowers and bulbs are observed, otherwise wet will lodge in the axils of the leaves and be frozen by subsequent frosts. The succulent leaves also are easily broken by high winds. Some persons cover the beds with glass; and others have stout canvas fixed to rollers to run up and down. The object should be to expose the plants to light and air on every favourable opportunity, and to shelter them from high winds, heavy rains, and hailstorms, and to cover the beds on frosty nights. In planting the bulbs, it is usual to put a little clean sand round them. Although many varieties are tall and their flowers are heavy, the stems are usually strong enough to support the flowers without the aid of sticks. Some of the Asiatic species and many of the European species succeed perfectly in the open border, but it is best to lift and replant the bulbs every year or two. The time for lifting the bulbs depends upon the condition of the flower-stems; when these bend without breaking, the bulbs may be taken up, dried, and stored away until planting time. The only mode by which many of the species can be propagated is by seed, as offsets are produced very sparingly, and in some cases hardly ever. The seed, if sown when ripe, germinates in spring, and produces full-sized bulbs in six or seven years.

The late-flowering Tulips are chiefly descendants of $T$. Gesneriana, a very handsome plant when wild. Its variety fulgens is particularly handsome. This variety has very large cup-shaded flowers of a glossy deep crimson. For centuries late-flowering Tulips have been cultivated, and they are still classed among florists' flowers. They are divided into four sections, viz. breeders or self-flowers, bizarres, bybloemens, and roses. When a seedling flowers for the first time, it is usually a self, and in a few years (but occasionally not until thirty years) it will break into the flamed or feathered state. A feathered Tulip has the colour finely pencilled round the margin of the petals, the base of the flower being pure, and in a flamed flower stripes of colour descend from the top of the petals towards the base. In the bizarres the colours are red, brownish-red, chestnut, and maroon, the base being clear yellow; in the bybloemens the colours are black and various shades of purple, the base being white; and in the roses, rose of various shades and also deep red or scarlet, the base being white again.

Among the wild Tulips there are some really beautiful plants which are quite distinct from the garden varieties, but only a few are worthy of mention, though many might be included in a full collection.

The finest natural species of Tulips for general culture are those mentioned below.

T. Celsiana.-A species whose bright yellow flowers are much smaller than those of common bedding Tulips, and sometimes remind one, when in clumps, of yellow Crocuses. The outside of the petals is tinted with reddish-brown and green. T. Celsiana begins to flower about the Ist of May, and usually attains a height of 6 to 8 in., and sometimes 12 in. The bulbs emit stolons after flowering. S. Europe and shores of the Mediterranean. Well suited for the rock-garden or for well-drained sandy soil in choice borders.

T. Clusiana is delicate in tone, and modestly pretty in appearance. The bulbs are very small, the stem being seldom more than 6 to 9 in. high, and it sometimes flowers when it is scarcely 3 in. high. The flower is small, and has a purplish spot at the base of the petals; the three outer divisions of the petals are stained with a pleasing rose, and the three inner ones are a transparent white. T. Clusiana is a little more delicate than most of its family. It requires to be planted in good light vegetable soil, well drained, and in a warm sheltered position. Although so small, it should be planted rather deep, say from 6 to 9 in., and placed in some snug spot where it need not be disturbed too often. It is well suited for the rock-garden or for a collection of hardy bulbs, and is readily distinguished by its peculiar colouring. S. Europe. T. stellata, a North Indian species, is a somewhat similar plant, and 
very beautiful. Its large white blossoms appear in early summer. It is somewhat tender, and needs protection.

T. Greigi. - Of all the Tulips this is perhaps the most showy, and the most desirable as a garden plant.

Its bulbs are so hardy that they withstand freezing and thawing with impunity, and its half-grown leaves endure, unprotected, a temperature as low as zero. T. Greigi is a vigorous grower, and attains a height of 9 to 15 in. It blooms freely in April or May, and its large gobletshaped flowers are generally of a vivid orange-scarlet colour, and they are 4 to 6 in. in diameter. T. Greigi also bears three or four lanceshaped glaucous leaves having undulated margins, and having the upper surfaces boldly blotched with purple or with chocolate-brown. Varieties occur without spots on the leaves, and other varieties with spotless yellow flowers, while others have purple flowers. T. Greigi grows freely in any light rich soil in an open sunny position, and rarely requires transplanting. Turkestan.

T. Oculus-solis is a handsome plant, having brilliant scarlet blossoms with black spots at the base of the interior. The varieties maleolens, præcox, and Strangwaysi are very showy. Of a similar character are $T$. altaica, $T$. Fransoniana, T. undulatifolia, T. elegans, and $T$. bœtica.

T. pulchella is typical of a numerous race of beautiful dwarf Tulips, which, though rare at present, must eventually find their way into all good gardens, for they are extremely beautiful when seen in full blossom in a warm sunny border. T. pulchella has pretty purplish-pink blossoms, on stems 2 or 3 in. high; T. saxatilis has pale magenta flowers, with bright yellow centres; and T. biflora has white flowers with a yellow eye. T. sylvestris, our only indigenous Tulip, is a beautiful species, producing in early summer showy blossoms of a clear yellow. Biebersteiniana has yellow flowers, Orphanidea has flowers of salmon colour, shaded with purple, and the flowers of tricolor are white on the inside and yellow at the base.

Tulip Tree (Liriodendron tulipifera).

Tunica Saxifraga.-A small plant with narrow leaves, and with a profusion of wiry stems that bear elegant little rosy flowers which are very numerous. It forms tufts a few inches high. It does best on poor soils, but thrives without

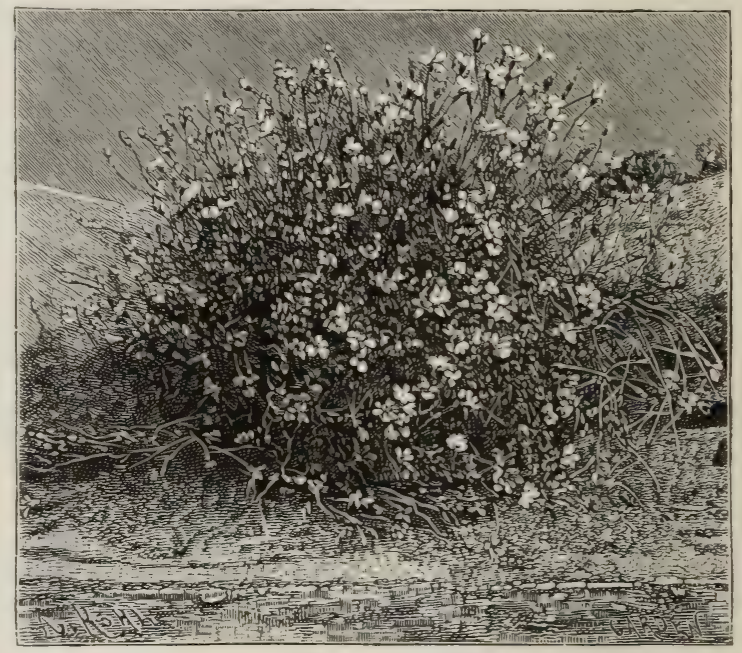

TUNICA SAXIFRAGA.

particular care on most soils. It is a native of arid stony places on the Pyrenees and the Alps; but it often descends into the lowlands, where it is found on the tops of walls; and there can be no doubt that it will grow in such positions and on ruins in this country. It is a neat plant for the rock-garden and for the margin of the mixed border. It is not unlike a Gypsophila in appearance. Seed.

Tupa. - Perennials resembling Lobelias; so much indeed, that some place them in the same genus. There are two kinds of Tupa in gardens, but neither kind is perfectly hardy, and, in fact, both kinds must be treated as halfhardy subjects. T. Feuillei, the best known kind, is 2 to $4 \mathrm{ft}$. high, and the brilliant scarlet flowers which terminate each stem are borne in rather dense erect spikes or racemes; they appear in September and October. T. Feuillei is also known as Lobelia Tupa. T. Bridgesi is about $4 \mathrm{ft}$. high, and its dense racemes of pink flowers appear late in summer. Both of these Tupas must have a warm and sheltered position in the open air, and a light and warm soil. In autumn they should be lifted and potted, and through the winter protected in a greenhouse. Division. Chili.

Turkey's-beard (Xerophyllum asphodeloides). 


\section{Turtle-head (Chelone).}

Tussilago (Coltsfoot). - The variegated form of the common Coltsfoot ( $T$. Farfara) is an ornamental plant and perfectly hardy. It increases itself by running underground, like the Nettle or the Couch Grass, and, being of a spreading habit, it is not easily eradicated if once it gets a footing. It may be used with good effect in shady positions where other plants will not thrive. It does well as an edging to a clump of Ferns, or as a groundwork to plants with grace-

\section{Twining Fumitory (Adlumia cir-} rhosa).

Twin-leaf (Jeffersonia diphylla).

Typha latifolia (Reed Mace). - A native aquatic plant, growing in tufts of two-rowed flat leaves, I 8 to 24 in. long and $I$ or $I \frac{1}{2}$ in. wide. From the centre of each tuft springs a stem 6 or $7 \mathrm{ft}$. high, which in the flowering season is terminated by a close cylindrical spike 9 in. long. This spike is of a dark olive colour, but changes to brownish-black as it ripens. T. latifolia is one of the most

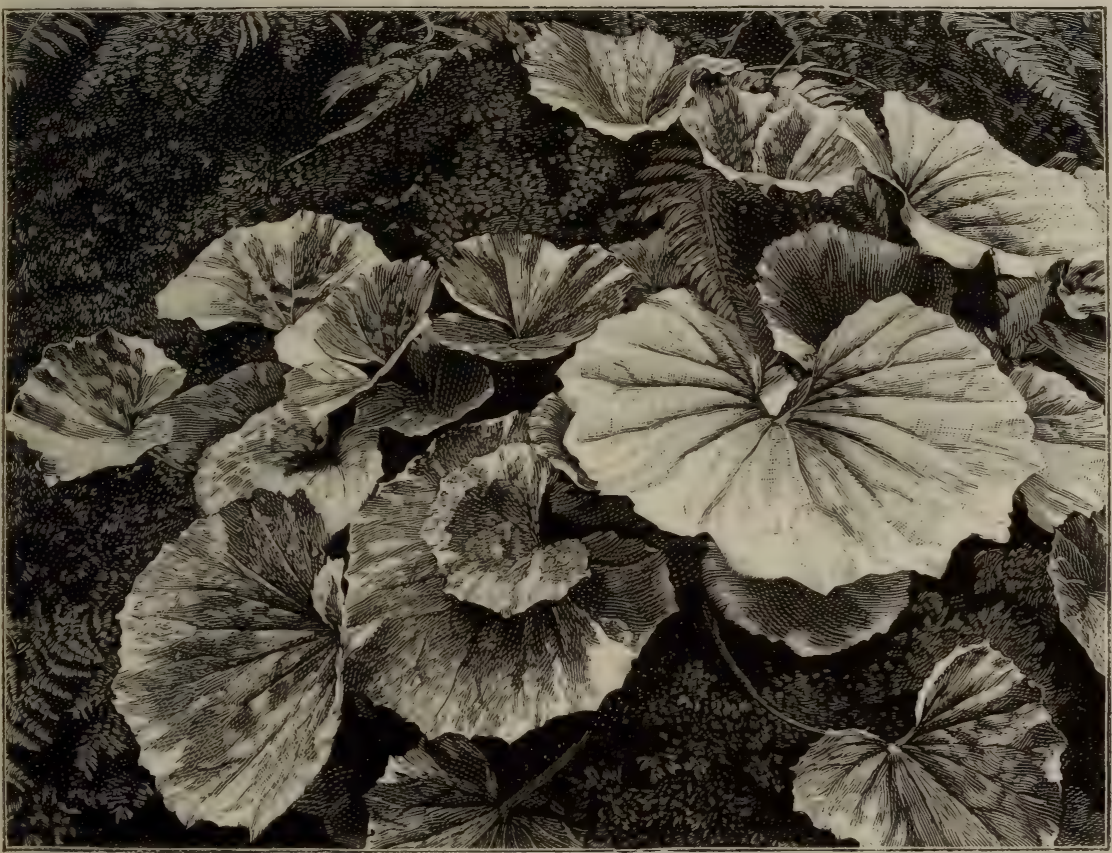

TUSSILAGO FARFARA VARIEGATA (VARIEGATED COLTSFOOT).

ful foliage. T. fragrans (Winter Heliotrope) is desirable on account of the fragrance of its spikes of purplish flowers. It spreads almost as freely as the irrepressible Coltsfoot, and is quite hardy. A waste corner cannot be better occupied than by this delicious flower. It grows well in the shade, but it flowers best in rather sunny places. Its best place is the home wood or the wild shrubbery, but it rarely blooms freely if overhung by evergreen trees, or by shrubs. In mid-winter its flowers are useful for the house.

Tway-blade (Smilacina bifolia).

Twig Rush (Cladium Mariscus).

Twin-flower (Linncea borealis). striking and ornamental of our British water-plants, and it has an excellent effect if grouped with such subjects as the Great Water Dock. T. angustifolia resembles it in all respects except in the size of the leaves and spike, and of the two it is perhaps the more graceful in aspect.

Uhdea bipinnatifida.-A sub-tropical plant of good habit, with very handsome leaves of a slightly glaucous or silvery character. U. bipinnatifida is suited for forming rich masses of foliage, and may be seen in the London parks planted in large beds with the Polymnia, Ricinus, Cannas, etc. It has a fine effect when 
isolated on turf. It is easily propagated by cuttings taken from old plants. These cuttings should be kept in a cool stove, greenhouse, or pit during winter, and in early spring placed in heat so that the plants may afford cuttings freely. Under the ordinary treatment of cuttings on hotbeds, or cuttings in a moist warm propagating house, it grows as freely as could be desired, and may be planted out at the end of May or the beginning of June. U. pyramidata has been less cultivated in England than U. bipinnatifida. It is of a lighter and fresher green, and is inclined to grow larger, having more of the aspect of a Malva in foliage. It is useful for the same purposes as $U$. bipinnatifida, but is not so valuable.

Ulex (Furze).-The native Furze is so beautiful and is so well suited for clothing dry banks and the like, that it should be included in every selection of fine flowering shrubs. Where the common Furze grows wild, the double variety is well worth planting, as it is more effective in bloom than the single kind, and lasts much longer. There is also a neat dwarf sort named $U$. nanus, which deserves a place, as it flowers at midsummer when its commoner relative is past flowering. This is also a native, and in places where it flourishes it makes a dense prickly bush $2 \mathrm{ft}$. high. The Irish Furze (U. strictus) is an uncommon variety of $U$. europæus, sometimes met with in botanical collections. As all the kinds of Furze are difficult to transplant when large, the best plan is to get small plants of the double and of the dwarf kinds, and to sow seed of the common single kind. In most nurseries the stock of double Furze is in pots, so that at any time the plants may be had and planted. There are few finer sights than a bank of double Furze in full bloom, and it fortunately may be grown in every garden. Vigorous pruning when its bushes become straggling is all the attention it needs.

Umbilicus.-Succulent plants similar to Houseleeks. U. spinosus is a very singular-looking plant, somewhat resembling a small Apicra or Haworthia. Its leaves form a rosette something like that of a Sempervivum, each leaf bearing a spine at the apex. The yellow flowers appear early in summer, and form a cylindrical spike on the top of the flower-stem. It is a good plant for dry sunny spots in the rockgarden, and is tolerably hardy, but slugs destroy it whenever they have a chance. Siberia, China, and Japan. $\mathrm{U}$. chrysanthus is about 4 in. high, and resembles a small Houseleek; it has short panicles of yellowish flowers. Suitable for the same positions as U. spinosus. U. Sempervivum strongly resembles some species of Sempervivum. It forms a rosette-like tuft of succulent leaves, and produces in the second year of its growth a large cluster of pink flowers on a stem about 6 in. in height. It is useful for carpet-bedding, and when used for this purpose the flowerstems must be pinched out. Kurdistan. Hardy in the rock-garden or in welldrained soils.

\section{Umbrella-leaf (Diphylleia). \\ Unicorn-plant (Martynia).}

Uniola latifolia. - A handsome perennial Grass from N. America. It is 2 or $3 \mathrm{ft}$. high, and has a large loose panicle, bearing large flattened spikelets. A clump, placed in rich garden soil, gathers strength from year to year, and when well established is a beautiful object. The loose drooping panicles have a wonderfully graceful expression when living, and an equally graceful appearance in a winter bouquet.

Urospermum Dalechampi.-A rather handsome composite from S. Europe. It is of dwarf tufted growth, and produces large heads of lemon-yellow blossoms. It thrives in an open position in any light soil, and is quite hardy.

Uvularia.-A pretty genus of dwarf slender plants, allied to Solomon's Seal, but bearing yellow blossoms. There are four cultivated species, U. chinensis, U. grandiflora, U. puberula, and U. sessilifolia. Of these U. grandiflora is by far the finest; and indeed is the only one worth growing generally. It attains a height of $\mathrm{I}$ to $2 \mathrm{ft}$., and its numerous slender stems form a dense compact tuft. Its flowers are long and are of a clear yellow; they droop gracefully, and are very attractive in early summer. It is a capital peat border plant, and thrives best in a moist peaty soil, if in a partially shaded place. It is a native of North America, like all the other kinds except U. chinensis.

Vaccinium (Whortleberry). - A few of the best Vacciniums may be planted for ornament in peat soil, though no Vaccinium stands in the first rank of flowering shrubs. One of the most desirable is V. corymbosum, the Blue Berry of the North American swamps. It is a rather large shrub, bearing a profusion of small pinkish flowers in dense 
clusters. The Pennsylvanian Blue Berry ( $\mathrm{V}$ : pennsylvanicum) is specially desirable. About October its bushes are usually glowing masses of scarlet and crimson. Though not remarkable for flower or berry, it is invaluable for the sake of the brilliant tints which its decaying foliage assumes in autumn. Though not common followed by berries about the size of Red Currants, which very much resemble those of the Cranberry. They are borne on wiry stems 3 to 9 in. high. V. Vitisidæa forms a neat little bush in the rockgarden or in beds of peat soil. The Marsh Cranberry (V. Oxycoccos) is a native of wet bogs in Britain. It has

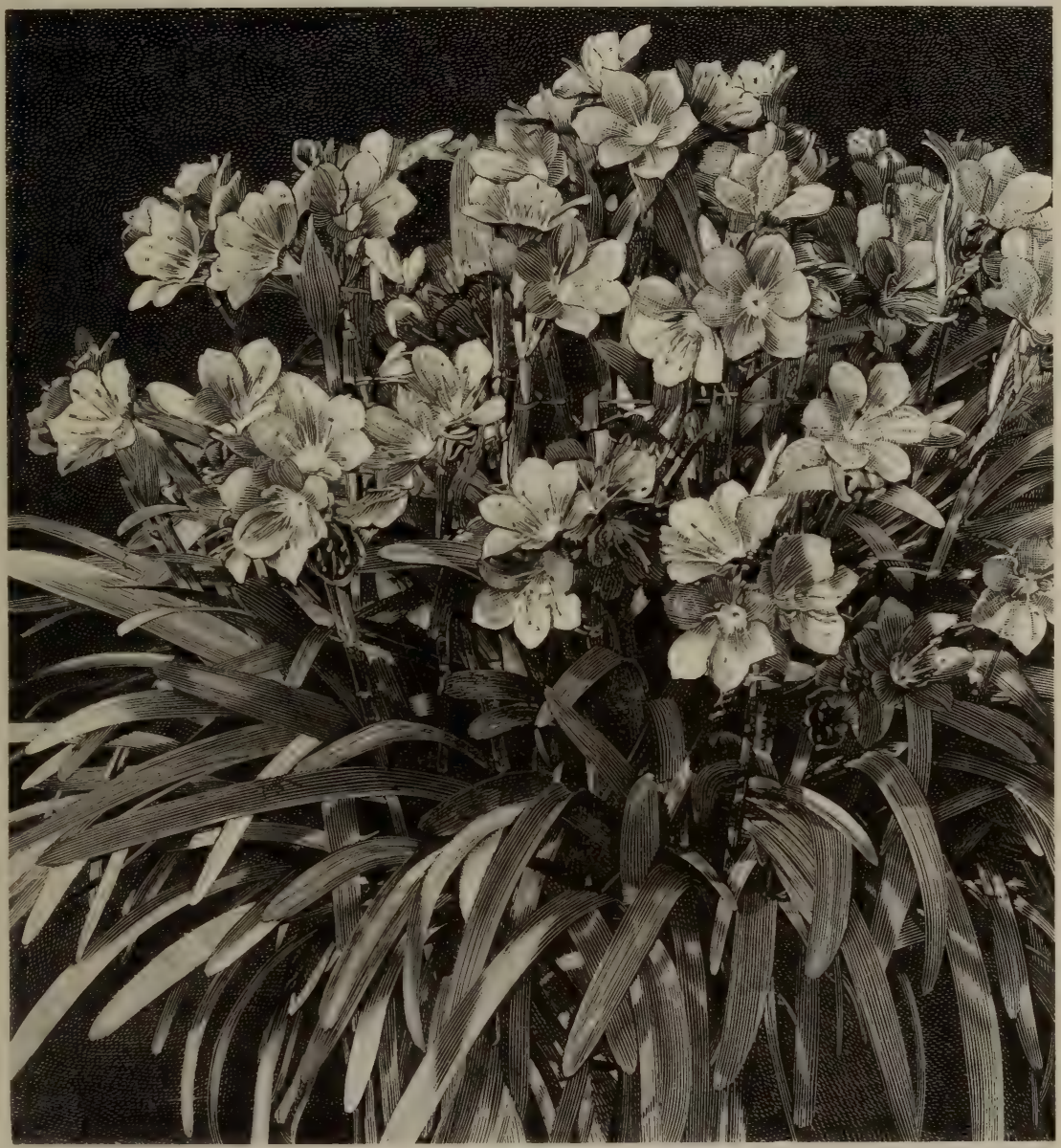

VALLOTA PURPUREA (SCARBOROUGH LILY).

it may be bought at the best tree nurseries, V. canadense, V. erythrinum, V. nitidum, and V. ovatum, with our native V. Vitis-idæa, V. Myrtillus, and V. uliginosum may be grown where a suitable soil exists, as they give variety and interest to a plantation of peat-loving shrubs.

V. Vitis-idæa (Red Whortleberry).-A dwarf British Evergreen, with Box-like foliage and clusters of small pale flowers. These flowers appear in summer, and are very slender creeping shoots, and drooping dark rose flowers. It requires wetter soil than V. Vitis-idæa, and is worthy of a place where bog plants are admired. The American Cranberry (V. macrocarpum), a much larger plant, has oblongobtuse leaves, and large fruit. It deserves a place in association with bog shrubs. It fruits profusely in beds of peat soil.

Valerian, Greek (Polemonium).

Valerian, Red (Cetranthus ruber). 


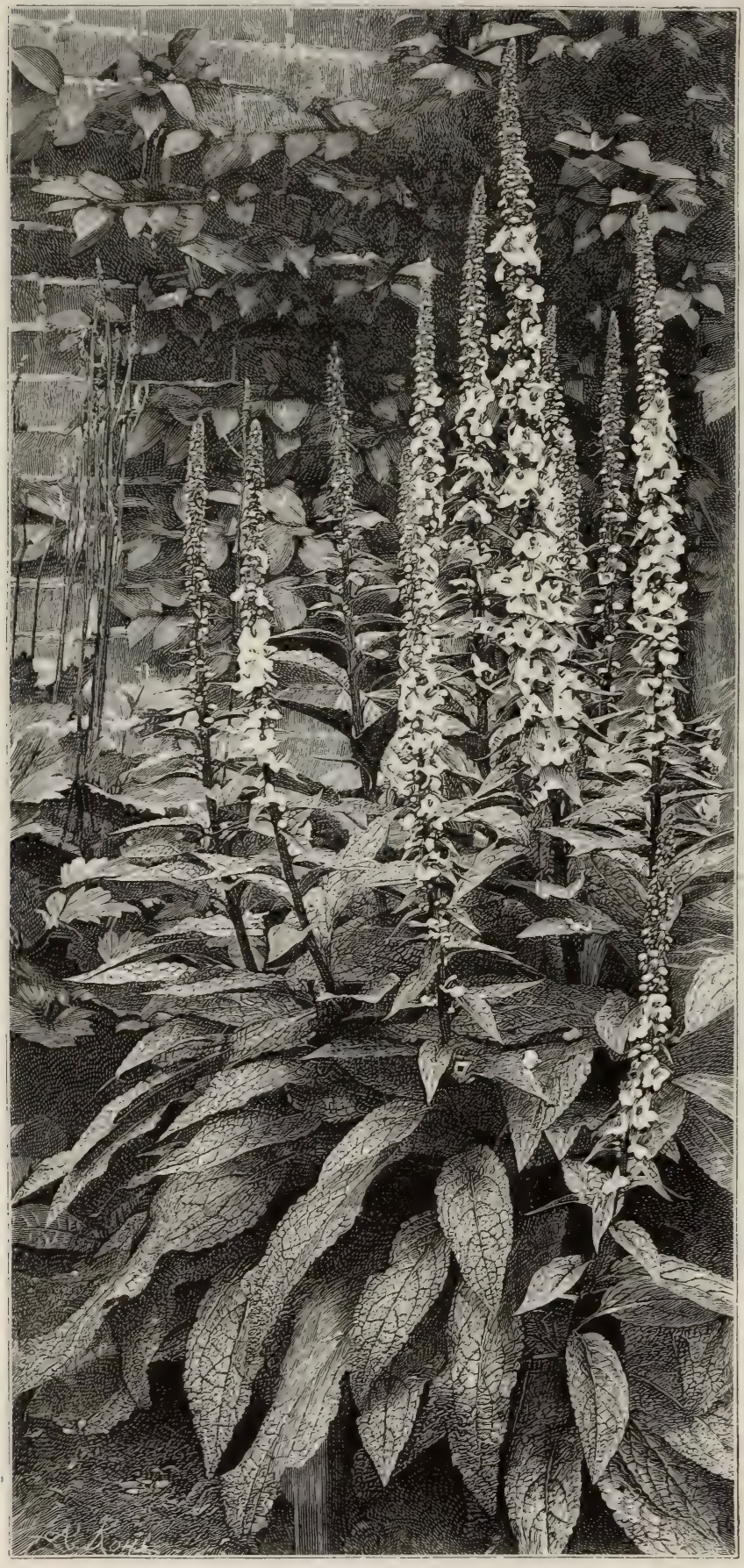

VERBASCUM NIGRUM VAR. ALBUM
Valeriana (Valerian). - The only Valerian worth cultivating in a general way is the goldenleaved variety of $\mathrm{V}$. $\mathrm{Phu}$ - a highly effective plant, especially in spring, when its foliage is young. This golden - leaved variety is of neat tufted habit. It grows freely in any soil, and is perfectly hardy. A few dwarf alpine Valerians are sometimes grown in full collections, but they are not attractive, and the unpleasant odour of the flowers of most of them renders them undesirable. Some of the larger species are pretty in rough places.

Valloradia plumbaginoides (Plumbago Larpenta).

Vallota purpurea (Scarborough Lily). - This brilliant flower, so well known in gardens, is hardy in mild climates. It requires a warm situation in light soil, for instance, at the foot of a south wall, and in such positions it often thrives better than in pots under glass, but the bulbs must be protected during severe frosts. The outdoor culture of this plant deserves more attention than it has hitherto had. Some flowers sent us by Mr. Kingsmill, grown in his garden, were superb. Offsets detached from the parent bulbs. Cape of Good Hope.

Venidium calendulaceum.-A beautiful half - hardy perennial composite. It is of dwarf spread- 
ing growth, bearing in summer a profusion of showy yellow Marigold-like blossoms. If several plants are put out together on a warm sunny border, the effect is very good. Cuttings inserted in August root freely, and may be potted and kept in the greenhouse through the winter. In winter they must not have much water, or they will damp off, and they should be planted out in May. V. calendulaceum may be readily raised from seeds sown in a hot-bed in early spring; the seedlings should be planted out in May, in friable soil, in a warm exposure. Cape.

Venus's Looking-glass (Specularia Speculum).

Veratrum album (White Hellebore).-A handsome erect perennial of pyramidal habit, $3 \frac{1}{2}$ to $5 \mathrm{ft}$. high, with large plaited leaves. Its yellowish-white flowers are borne in numerous dense spikes on the top of the stem, and form a large panicle. As the leaves are handsome, this plant is worthy of a place in full collections of fine-foliaged hardy herbaceous plants; but it looks best in small groups, either in the rougher parts of the pleasure ground or by wood walks. V. album thrives best in peaty soil. It is best multiplied by division, as the seed is very slow and capricious in germinating, sometimes not starting until the second year, and some years elapse before the seedlings are strong enough to flower. The root is exceedingly poisonous. V. nigrum differs from V. album in having more slender stems and narrower leaves, and also in having blackish-purple flowers. $V$. viride resembles $V$. album, except that its flowers are green. France.

Verbascum (Mullein). - Most of the Mulleins in cultivation are only of biennial duration. They are unsatisfactory plants to cultivate, though some of them are stately and handsome when well grown. The cultivated kinds number about a dozen. One of the finest,

V. Chaixi, or V. vernale, is a true perennial-at least on warm soilsand in this respect it is quite unlike some Mulleins occasionally seen in our gardens. It also has the advantage of great height, sometimes attaining more than Io $\mathrm{ft}$. Its large green leaves come up rather early, and are extremely effective. The colour is good, and the panicle of flowers enormous. The number of yellow flowers with purplish filaments borne on one of these great branching panicles is marvellous. The uses of a plant so good in form and so distinct in habit cannot be

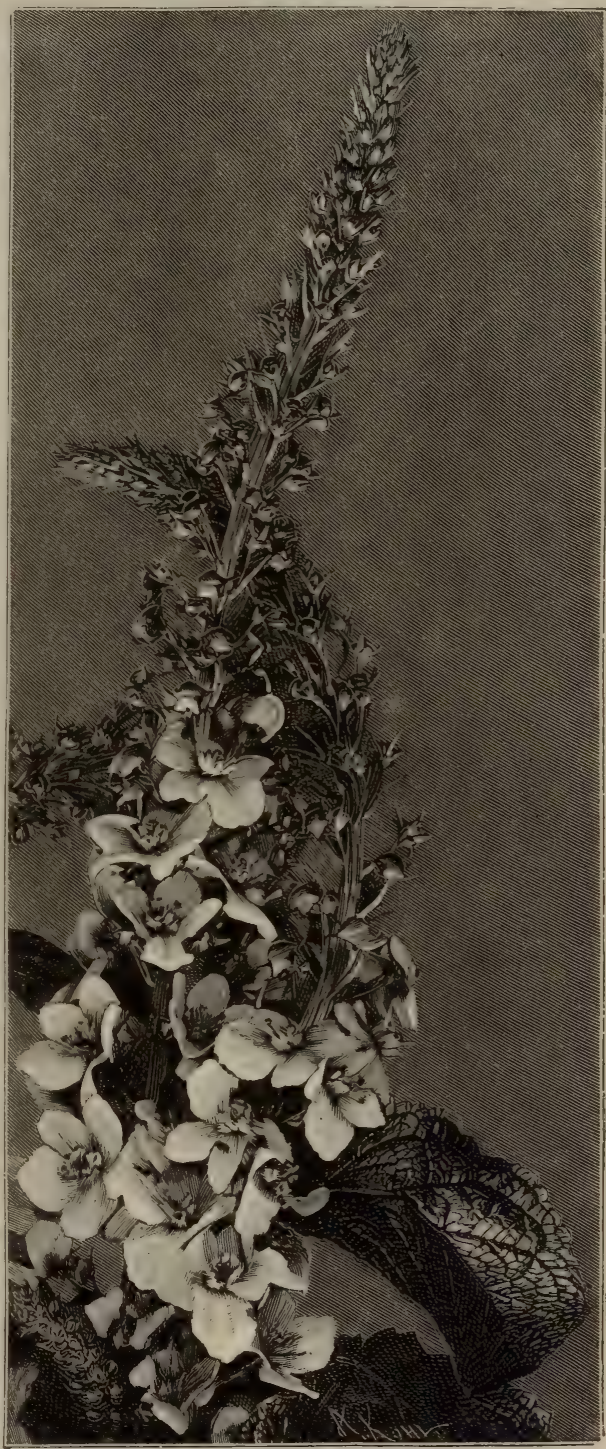

VERBASCUM PHENICEUM.

difficult to define. For the back of a mixed border, for grouping with plants of remarkable size or form of foliage, or for placing here and there in open spaces among shrubs, V. Chaixi is well suited. A bold group of it isolated on the Grass in deep, light, and well-dressed soil would 
be effective in a picturesque garden. Other tall kinds with yellow flowers are V. phlomoides, V. nigrum, V. gnaphalodes, V. Thapsus, V. pulverulentum, V. Blattaria, and $V$. pyramidatum, which may be added to a full collection.

V. phœniceum is a very handsome border plant. Its flowers are of various hues, but usually of a violet-blue on a yellow ground striped with violet. $\mathrm{V}$. phœniceum is of slender growth, 2 to $4 \mathrm{ft}$. high ; its large and showy blossoms are borne numerously on long spikes. The varieties are known as album, atroviolaceum, lilacinum, roseum, and violaceum. On warm dry soil V. phœniceum is a hardy perennial, but in cold and wet localities only biennial. It likes a good light soil and an open warm situation. It may be easily raised from seed, and it frequently sows itself. S. Europe.

Verbena. - The beautiful garden varieties of the Verbena have long been favourite plants for the garden. Of late years, however, the flowers have not been so popular, probably on account of the disease that attacks them. Verbenas are very beautiful plants, and are cultivated with comparative ease ; they bloom profusely out-of-doors, and stand well till quite late in the autumn; and if the lustre of the flowers happens to become dimmed by a storm, a burst of sunshine quickly restores their beauty. From the Continent have come many fine varieties, and some excellent kinds are the produce of English-saved seed. The majority of Verbenas are unsuitable for open-air culture, and some of the older kinds are still the best : for instance, Celestial Blue, Crimson King, Edwin Day, Firefly, James, Birkbeck, La Grande, Boule de Neige, Mrs. Mole, Oxonian, Purple King, Wonderful. Among the newer sorts are Gruss an Erfurt and Mdlle. Emilie Hulter. A pretty and effective bed may be secured by mixing a few good varieties together. The Verbena should have liberal treatment. A dry open border should be selected, and the ground should be trenched, and should be well dressed with spent hot-bed manure and leaf-soil. The plants can be put out in this soil about the end of May, and as they grow the shoots should be pegged securely over the bed and should be kept well thinned. The plants of the named sorts are propagated either in autumn or spring, but spring is the better season. Good plants cannot be had unless good cuttings are procurable. The best means of ensuring good cuttings for spring propagation is to keep a few store plants in pots all the summer, and in the autumn cut them pretty close, and to give them a shift into larger pots of rich soil. Soon afterwards these store plants should be set in a cool house, or a pit from which frost is excluded. In this way cuttings will be ensured in spring, and these cuttings will be better than cuttings taken from autumn-struck plants. Of late years Verbenas have been most successfully raised from seed like other half-hardy annuals. The seeds should be sown about the middle of January, in light soil in a warm frame or pit. The seedlings should be pricked out, when a few weeks old, in $2 \frac{1}{2}$-in. pots, and when the plants are fully established, they should be placed near the glass in a pit which is well ventilated, in order to induce stout hardy growth. About the end of March the seedlings should be potted singly in $2 \frac{1}{2}$-in. pots, and a month later they should be transferred to 3 -in. pots. About the middle of May the plants should be planted out about $2 \mathrm{ft}$. apart in a sunny border, and in a short time they will be aglow with flower. Verbenas raised from seed are valuable for garden adornment in summer, and need not be cut for propagation, while they run little risk of disease or of insects. Keeping the plants free from insects and disease in winter is a troublesome matter; but with seedlings under fair conditions insects would be avoided, and the seedlings would certainly have a vigour that would get over the so-called disease. In any case it is an interesting fact that Verbenas in any number and of the greatest vigour may be raised from seed in the same year that they adorn the garden, or, in other words, may be treated as annual plants. The wonderful diversity and brilliancy of colour and the profusion of the flowers combine to place Verbenas grown from seed among the most valuable plants we possess. Verbena seed is sold in colours - scarlet, blue, white, carnation, flaked and other forms, and all kinds come remarkably true. The scarlet kind is a fine reproduction of the old scarlet Defiance-that prince of scarlet bedding plants of some years since-and its growth and the quantity of its bloom is marvellous. The compact purplish-red kermesina is very pleasing and effective.

V. venosa is a perennial kind, $\mathrm{I} 2$ to $\mathrm{I} 8$ in. high, and produces heads of purpleviolet blossoms. It is much hardier than ordinary Verbenas, and is not so liable to be injured by mildew, or by bad weather. It looks all the brighter for drenching rains, and it lasts very late in the season. 
When all the ordinary varieties of Verbena fail, $V$. venosa is sure to give satisfaction. $\mathrm{V}$. venosa is easily kept through the winter, and if its fleshy roots are stored thickly in boxes any number of plants may be propagated in spring from the young shoots thrown out. $\mathrm{V}$. venosa should be planted rather thickly, and pegged down until the ground is covered; and it will then continue to flower until the last of the summer flowers is removed or is destroyed by the frost. V. venosa is easily raised from seed. Seed frequently takes long to germinate, and it should be sown four months before the plants are wanted. When the roots have to be lifted in autumn, they may be placed at once in the boxes where they are to start, and should be kept in a cool place until the time for putting them in heat. In herbaceous borders they may be allowed to remain for years, but they should be protected through the winter, lest they should be injured by severe frost. Being of a branching and widespreading habit, $V$. venosa has a grand effect in large patches, bound round with some contrasting colour. It associates beautifully with Mangles' variegated Pelargonium.

\section{Verbena, Sand (Abronia).}

Verbesina encelioides.-A half-hardy annual Composite, I to $2 \mathrm{ft}$. high, with broad clusters of golden-yellow blossoms. It is an interesting plant for a full collection. California, Texas, and Mexico. V. gigantea is an ornamental shrub from Jamaica, about $6 \frac{1}{2} \mathrm{ft}$. high. When young it is a very pleasing subject, its round green stems being covered with large, winged, pinnate leaves of a glistening delicate green, and very elegant outline. It is suitable for rich beds or groups. It should be planted out at the end of May or early in June. V. pinnatifida is a rough half-shrubby species, having a winged stem and woolly oval leaves with lobed or tooth margins. These leaves are larger than those of $\mathrm{V}$. gigantea, and grow $36 \mathrm{in.} \mathrm{long} \mathrm{by} \mathbf{I} 4 \mathrm{in}$. broad in the first year. Both $\mathrm{V}$. gigantea and $\mathrm{V}$. pinnatifida require hothouse treatment in winter. Cuttings in early spring. Young plants are to be preferred for effect, and will be all the better for the warmest and most sheltered position and the richest and lightest soil that can be given them.

Vernonia (Ironweed). - Coarse North American Composites, of which some half-a-dozen species are in cultivation. They bloom so late, and suffer from cold autumnal rains so often, that they are scarcely worth a place in the border; but
V. præalta is a fine plant for the wild garden, and is so stately in habit that even if its flowers are injured or escape us, it may still be considered worth room in a copse, or a ditch, or an open spot in a wood. All may be easily propagated by division.

Veronica (Speedrell).-The genus is a very large one, and comprises some very ornamental evergreen shrubs. These are mostly natives of New Zealand, and none of them are quite hardy in all parts of

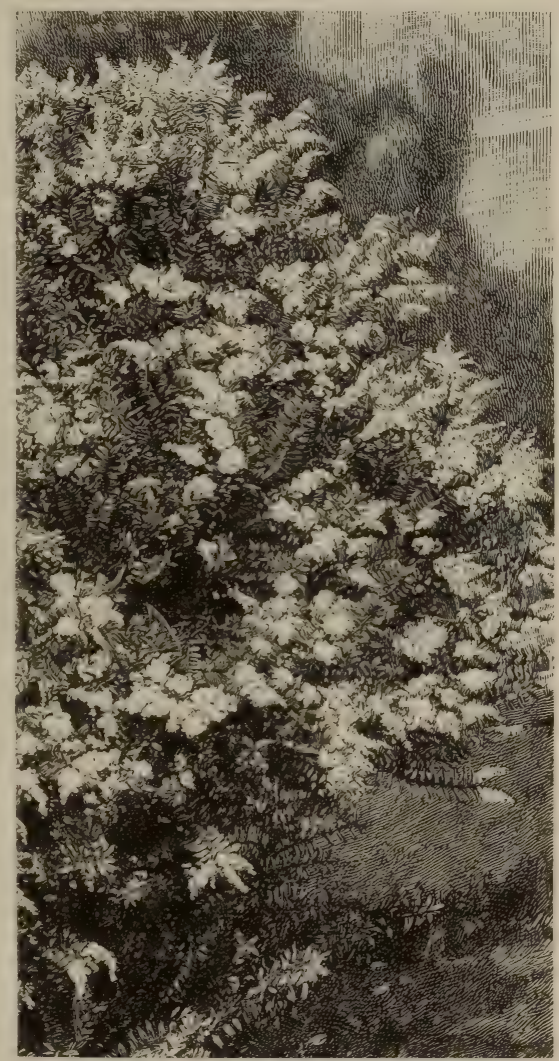

SHRUBBY SPEEDWELL.

England. They have become important in mild districts, where they are not liable to be injured during ordinary winters. For seaside gardens they are especially valuable, as they withstand wind and spray better than most shrubs. $\mathrm{V}$. speciosa is the commonest in seaside places. It is of dense growth, and has broad leaves and erect feathery spikes of deep purplish-blue flowers. The variety imperialis has flowers of a rich red-purple, and in the variety rubra they are inclined 
to red or to rose-pink. Though invaluable for the seaside or for mild districts, V. speciosa is but half hardy, and in cold localities requires protection in winter. It is a first-rate shrub for a light, airy, and cool greenhouse. V. salicifolia (the Willow-leaved Veronica), called also V. Lindleyana, is about $2 \mathrm{ft}$. high, and has long narrow leaves, together with spikes of white or purplish flowers. V. ligustrifolia is similar, but its leaves are narrower, and it has white flowers in feathery spikes. $\mathrm{V}$. elliptica, known also as V. decussata, is a common species something like $\mathrm{V}$. speciosa, but is smaller both in foliage and growth; and V. Andersoni, said to be a hybrid, also resembles $V$. speciosa, and has spikes of bluish-violet flowers. The variegated form of Andersoni is a first-rate shrub, largely used as a halfhardy bedding plant. All the foregoing are half-hardy, but suitable only for walls and warm spots in the mildest districts and at the seaside. Of the larger kinds only one can be termed thoroughly hardy in all parts of England. This is V. Traversi, a neat shrub, forming a roundheaded bush about $4 \mathrm{ft}$. high. In late summer it is very beautiful when crowded with spikes of pale mauve flowers. Among dwarfer kinds, V. verbenacea, V. fruticulosa, V. alpina, V. aphylla, V. Nummularia, V. Guthrieana, V. austriaca, $\mathrm{V}$. incisa, V. bellidioides, and V. Dabneyi, are all well worth cultivating. They are of good dwarf habit, and are admirably suited for a rock-garden. Nor should the pink variety of $\mathrm{V}$. officinalis be omitted, forming as it does when established dense patches of pink-coloured blossoms, sometimes elevated 3 in. above the ground. At least fifty species and more than twice as many varieties of hardy perennial Speedwells, herbaceous, trailing, or carpeting in their habit, are suitable for cultivation. The flowers are generally of a blue shade, but, like many blue flowers, they are often imperfect in colour, and they vary to rose or to dull white. Plants of the same species vary much in form. Some of them differ from each other more than they do from plants of different species, and therefore it is not surprising to find that the naming of the different Speedwells is difficult and perplexing. We cannot do more than mention a few of the more distinct and ornamental forms. Propagation by division of the roots is usually so easy that little need be said about it. The herbaceous kinds root from every shoot, and the creeping kinds root as they creep. Those mentioned are so hardy that they may be divided or transplanted at all seasons. Such kinds as V. longifolia require frequent division to prevent the shoots from becoming too crowded. Most of the kinds ripen abundance of seed, and round them come up seedlings which vary in colour and form. All the kinds mentioned are hardy and will grow in any soil.

V. amethystina is 12 to $18 \mathrm{in.} \mathrm{high.}$ It is of good colour, but is rather too diffuse. It should be cut down in autumn, as otherwise it trails in an untidy way. In June it produces many terminal racemes of blossoms.

V. Chamædrys (Germander Speedwell) has been recommended for covering beds where late-flowering bulbs are grown. A curious variety, named pedunculata, is quite different in appearance, and is a neat plant.

V. gentianoides is one of the earliest of the Speedwells. It flowers in May. Three forms are common-the type with grey flowers, a variety with white flowers and bright glossy leaves like the Gentianella, and another variety with handsome variegated leaves. All are worth growing.

V. incana, also called $\mathrm{V}$. candida, is a dwarf plant with silvery leaves and dark rich purple flowers. It is 6 in. high, and it seems to flourish anywhere. It is used with good effect in geometrical bedding, its grey leaves being a contrast to most other foliage. It is easily propagated by division in autumn or in spring. $V$. neglecta is a similar but an inferior plant.

V. longifolia is the commonest garden species. It is generally sold as V. spicata, and in four varieties-blue, white, rosecoloured, and purple. It has variegated leaves. The variegation of the leaves is uncertain and irregular, but the habit of the plant is very good. The rich colour of the flower, the length of the flowerspike, and the sturdy and compact growth of the plant make it handsome for the border. V. longifolia grows well in any ordinary soil.

V. pectinata is a pretty trailing kind, with elegant serrated downy leaves and blue or rose-coloured flowers. It is admirably suited for clothing dry spots in the rock-garden, for the margins of borders, and for other places. It grows in almost any soil or position.

V. prostrata.-A very dwarf species, which forms spreading tufts and bears deep blue flowers. There are varieties with rose-coloured flowers, and varieties with white flowers which appear in early summer. V. prostrata is a hardy and 
pretty plant, and flowers so freely that when in full perfection the leaves are often quite obscured by the flowers. France, Central and Southern Europe. It occurs on stony hills and in dry grassy places. In cultivation it succeeds perfectly in sandy soil. It is an admirable plant for the rock-garden, its prostrate habit fitting it best for sloping positions or for fissures on vertical faces of rocks.

V. repens is a dense compact creeper, clothing the soil with a soft carpet of bright green foliage. It is covered, in spring, with pale bluish flowers. It thrives well on moderately dry soil, but delights in moist corners of the rockgarden, and is an admirable little rock plant.

V. rupestris trails neatly and closely, and flowers abundantly in June. To those who have seen large masses of it in rock-gardens it will want no further recommendation. There are several alpine species nearly allied to it.

V. satureiæfolia is one of the best of the Speedwells. Its flowers are about the size of those of $\mathrm{V}$. saxatilis, of the same intense blue, and are produced in abundant upright racemes. V. satureiæfolia is somewhat rare, but when it is once seen in perfection it is not to be forgotten.

V. saxatilis.-A native of alpine rocks in various parts of Europe, and also of a few places in the highlands of Scotland. It forms neat tufts 6 or 8 in. high. Its flowers are little more than $\frac{1}{2}$ in. across. They are of a pretty blue, striped with violet, and have a narrow but decided ring of crimson near the bottom of the cup. The base of the cup is pure white. V. saxatilis is also an excellent rockgarden plant.

V. spicata is a dwarf native plant, not more than 5 or 6 in. high. It is useful for bare corners of rock-gardens, but it seldom flowers before the end of July. $\mathrm{V}$. corymbosa is a name given to varieties of two or three species, but the best seems to be a form of V. spicata. This form is a profuse and continuous flowerer, and is one of the best plants for rockgardens. V. hybrida is generally classed as a variety of $V$. spicata, but it seems quite distinct, since it is far more robust, and its flowers vary in colour from dark purple to lavender and light rose. It grows wild in profusion on mountain limestone hills near Llandudno and in other parts of the north-western counties. $\mathrm{V}$. spicata and $\mathrm{V}$. hybrida increase in size under cultivation, especially when they are raised from seed.
V. subsessilis is botanically considered to be a variety of $\mathrm{V}$. longifolia, with stalkless leaves, but for garden purposes it is very distinct. It is without doubt the handsomest of the hardy Veronicas, and one of the choicest plants recently added to the mixed flower border. It comes from Japan, but in constitution it is certainly superior to most Japanese plants, as these require a warm spring and a hot summer for their successful development, whilst V. subsessilis grows on and flourishes in spite of spring frosts and cold summers. Its large dense spikes of deep purple-blue blossoms render it most effective, and it should always have a position among the choicest hardy flowers. It succeeds best in a good deep loamy soil and in an open situation. Division or seed.

V. taurica.-A very dwarf, wiry, and almost woody species. It forms neat dark green tufts, under 3 in. high; its leaves are crowded, and the upper ones are distinctly toothed; while its flowers, which are borne abundantly, are of a fine Gentian-blue. It is, perhaps, the neatest of all Veronicas for forming spreading tufts in level spots of the rockgarden, or tufts drooping from chinks. It is also admirable for the margin of the mixed border, being thoroughly hardy, growing in ordinary well-drained soil, and flowering in early summer. It is a tiny, compact, prostrate shrub, and is suitable for association with the dwarfest alpine plants and mountain shrubs. Tauria. Division or cuttings.

V. Teucrium. - A Continental plant, the stems of which form spreading masses, from 8 to $\mathrm{I} 2 \mathrm{in}$. high, covered in early summer with flowers of an intense blue. These flowers are at first in dense racemes, but the racemes afterwards become much longer. The fine blue corolla has oval segments, and the three lower ones have pointed segments. V. Teucrium is an excellent plant for the rock-garden, or for borders, and grows freely in ordinary garden soil. Seeds or division.

V. virginica and other tall species are 3 to $4 \mathrm{ft}$. high, and flower in July, but are deficient in colour.

\section{Vervain, Creeping (Zapania).}

Vesicaria. - Of the twenty species comprised in this genus six at most are showy enough for cultivation. V. græca is the handsomest of these, and for several weeks of early summer, when in flower, it is really a showy plant. It bears a strong resemblance to the better-known $\mathrm{V}$. utriculata, long cultivated in gardens, but is 
more showy, and begins to flower about a fortnight earlier. It flowers profusely, and the flowers open in continuous succession for several inches on each stem. It is a hardy evergreen perennial. Rocky districts in Dalmatia and other places in South Europe. V. græca may be propagated, like V. utriculata, by cuttings placed in soil under a hand-glass, but the best mode of propagation is by seeds, which, in favourable seasons, are produced plentifully. Both $\mathrm{V}$. græca and $V$. utriculata flourish in dryish soil, on dry sunny parts of the rock-garden.

\section{Vetch (Vicia).}

\section{, Bitter (Orobus). Milk (Astragalus).}

Viburnum (Gueldre Rose, or Snowball Bush).- The most familiar of the genus is V. Opulus, a native shrub. Its sterileflowered variety, sterilis (the Snowball Bush), may be found in every shrubbery, and though so common, it is among the best of all shrubs. In early summer on a lawn a fine specimen of the Snowball Tree when covered with bloom is one of the finest sights to be seen in an English garden. Next in importance is V. plicatum, a very beautiful hardy shrub from N. China. It is a dwarf spreading bush with deeply-wrinkled foliage. In summer every branch is wreathed with clusters of snow-white flowers, larger and whiter than those of the common Snowball Tree, but equally sterile. V. plicatum grows freely in most places, but it likes a good soil, and in cold localities a warm sheltered spot. It is a shrub of the highest merit, and should be included in the choicest selections. V. macrocephalum, another Chinese species, is less hardy than 'V. plicatum, but its flowerclusters are enormous. In some places it thrives against a wall, but it is rarely seen in a flourishing condition. The N. American species $V$. prunifolium and $V$. Lentago are handsome when in flower, but they are worth the attention of those only who wish to extend their lists of flowering shrubs. V. prunifolium has foliage like some of the Plums, and bears in May abundance of bloom. V. Lentago resembles our native Wayfaring Tree (V. Lantana). Both $\mathrm{V}$. prunifolium and $\mathrm{V}$. Lentago have dense clusters of white blossoms, which are succeeded by small black fruits, but neither variety is in the front rank of ornamental shrubs. V. nudum and $\mathrm{V}$. dentatum are $\mathrm{N}$. American shrubs, interesting for a botanical collection, and so is $\mathrm{V}$. pubescens, a relative of $\mathrm{V}$. dentatum. V. pubescens has large heads of white flowers. It is an uncommon and little-known shrub. The favourite Laurustinus (V. Tinus) is known to every one, and no description of it is necessary. It has several varieties, more or less distinct. One of the best known - certainly the finest - is lucidum, so called on account of its shining leaves, which are larger than those of the common kind. The flower-clusters of lucidum are larger and its blossoms are whiter than those of the common form, and it is therefore more suitable for forcing. The roundleaved variety (rotundifolium) is beautiful and distinct. It has a variegated form, but, like the variegated form of the common Laurustinus, it is not remarkable as an ornamental shrub. The varieties variabile, Frobeli, etc., are more or less distinct from the type. They are worth growing, and, in fact, every form of so beautiful an Evergreen as the Laurustinus is valuable. It need hardly be said that the Laurustinus is not perfectly hardy in every part of these islands, and small specimens are very liable to be killed during the winter. In mild localities and in the south the Laurustinus rises to tree-like dimensions, and has few rivals among Evergreens. It flowers and lives best on soils with a sandy warm subsoil.

Vicia (Vetch).-Perennial and annual plants, several of which are natives. For a full collection, V. Cracca, V. Orobus, V. sylvatica, V. Sepium, and V. argentea would be the most desirable. $\mathrm{V}$. argentea has elegant silvery leaves, but is rare in cultivation. Vicias grow freely in almost any soil. Seeds.

Vieusseuxia glaucopis (Blue-eyed Peacock Iris). - A beautiful bulbous plant 9 to 15 in. high. The flowers appear in early summer, are about 2 in. across, and pure white, with a beautiful porcelainblue stain nearly $\frac{1}{3}$ in. broad at the base of each of the three larger divisons. This stain is deep-violet at the base, and is margined with dark purple teeth. V. glaucopis should be grown on warm sheltered borders in sandy peat or sandy loam and leaf-mould. The bulbs should be planted rather deep, having, say, 4 in. of firm soil above the crest. Increased by separation of the bulbs in autumn. Cape of Good Hope. = Iris Pavonia.

Villarisa nymphæoides (Common Villarsia).--A very interesting and attractive British aquatic. Its leaves are like those of a Water-Lily, but smaller, and they float on the water. Its yellow flowers are borne singly on stalks as long as those of the leaf. They are produced in summer. Where not plentiful it should 
be encouraged in lakes, in ponds, and in quiet bays of streams. Division.

Vinca (Periwinkle).-Perennial trailers, which, being hardy and vigorous in almost any soil or position, are useful for a variety of purposes. The well-known $\mathrm{V}$. major (common Periwinkle) is very useful for a large rock-garden, for masses of rootwork, for positions near cascades, etc., and also for rocky places or banks either in the wilder parts of pleasuregrounds or by wood walks. A variety called elegantissima is finely blotched and variegated with creamy white, while there are several other variegated varieties, including a golden-leaved kind, and these varieties are exceedingly useful for the same positions as the type. The lesser Periwinkle (V. minor) is much smaller than V. major, and is also useful for the same positions. It has several varieties well worthy of cultivation; a white-flowered one (V. m. alba), a reddish one, and one or two double ones, and there are also several variegated forms. $\mathrm{V}$. herbacea is much less frequently seen than our common Periwinkles, but it is more worthy of culture on rocks, as it is not rampant in habit. It is a native of Hungary. It flowers in spring and in early summer, and its stems, unlike the stems of its more familar relatives, die down every year. It thrives best in an open position. V. acutiloba is a distinct and elegant Periwinkle, and is valuable on account of flowering late in autumn and in winter, and also on account of the delicate mauve of its blossoms. It is not a variety of any of the old and long. cultivated Vincas, but is a species from the south of Europe. It is suitable for sunny banks and sunny slopes and for warm borders.

\section{Vine (Vitis).}

Vine, Staff (Celastrus).

Viola (Violet). - A beautiful and wellknown family, many kinds of which are alpine flowers. Some Violets are among the most beautiful ornaments which bedeck the alpine turf; and even the common Violet itself may almost be claimed as an alpine plant, for it wanders along hedgerow and hillside, along copses and thin woods, all the way to Sweden. Every spring bitterly cold winds sweep over the woods and plains of Europe and N. Asia ; and it is only a mountaineer in constitution that, in spite of these bitterly cold winds, can stain with purple the carpet of dead leaves in the copse, and fill the air with perfume, before a green bud has opened. It is impossible to separate true alpine Violets from those that haunt plains, heaths, woods, copses and hedges, and bogs, hills, meadows, and sandy shores. From all kinds of Violets the world of wild flowers derives a precious treasure of beauty and delicate fragrance; and no family has given our gardens anything more precious than the numerous races of Pansies and the various kinds of large, showy, sweetscented Violets. Far above the faint blue carpets of the various scentless wild Violets in our woods and heaths, our thickets and bogs, and above the miniature Pansies that find their home among our lowland field-weeds; far above the larger Pansy-like Violas (varieties of V. lutea) which flower so richly in the mountain pastures of northern England and even on the tops of stone walls; above the large, free-growing Violets of the American heaths and thickets, we have true alpine Violets, such as the yellow two-flowered Violet (V. biflora), and large blue Violets such as the V. calcarata and V. cornuta. It would be difficult to exaggerate the beauty of these alpine Violets. They grow in a turf of high alpine plants not more than an inch or so in height. The leaves do not show above this densely-matted turf, but the flowers start up, waving everywhere thousands of little banners. Violets are of the easiest culture; even the highest alpine kinds thrive with little care, and $V$. cornuta and V. calcarata of the Alps and Pyrenees thrive even more freely than in their native uplands, the foliage and the stems being much stronger. Some of the many stronger varieties of the Sweet Violet recently raised might be naturalised with advantage. Like the stronger American kinds they are likely to prove useful in the wild garden. Slow-growing compact kinds, like the American Bird'sfoot Violet, enjoy, from their stature and their comparative slowness of growth, a position in the rock-garden or in the choice border, and in such a position they are of easy culture in moist sandy soil. Violets of all kinds are easily increased by cuttings from stout short runners. All runners that are wiry and hard should be rejected, and none should be taken from plants that have grown in pots or under glass. The cuttings should be taken off the first week in April if they are to bloom next year. They should be put under hand-lights on a shady border, and kept close until they begin to grow, when the lights may be tilted a little, and the space may be gradually increased until at last the lights may be wholly dispensed with. By 
September the plants will be ready for transplanting, and may be placed in beds $4 \mathrm{ft}$. wide, three rows $\mathrm{I} \mathrm{ft}$. apart being in one bed. This space will afford room to hoe between the rows while they are growing. They will soon spread and fill the beds, but they must not remain more than two, or, at the most, three years in the same place, or the flowers will become small and shortstemmed. If they are more than two years in the same place, they must receive liberal top-dressings of rotten manure, or copious applications of manure water. Another mode of propagation, which is perhaps attended with less trouble, is to get a few large plants as soon as they have done blooming, and to tear them into as many pieces as possible, each piece having a little bit of root attached to it. Little pieces without roots may be placed under hand-lights and treated like cuttings.

The following are among the most distinct and among the most desirable for general cultivation :-

V. biflora (Two-flowered Yellow Violet).- This bright little Violet is a lovely ornament on the Alps, and in many parts it densely clothes every chink between the moist rocks. It even crawls under great boulders and rocks, and lines shallow caves with its fresh verdure and its little golden stars. It is readily known by its kidney-shaped or heart-shaped leaves, and its very small bright-yellow flowers, the lips of which are streaked with black. These flowers are borne in pairs. $\mathrm{V}$. biflora is especially useful in large rock-gardens where rude flights of stone are constructed to give winding pathways over the mass. It will run through every chink between the steps, and tend to make the stair replete with life and interest. If obtained in a small or weak condition, it may seem difficult to establish, but this is by no means the case; for, once fairly started in a moist and half-shady spot, it soon begins to creep about rapidly, and may then be readily increased by division. When well established in a suitable rockgarden, it is able to take care of itself. Europe, Asia, and America.

V. calcarata (Spurred Violet).-This plant very much resembles the well-known $\mathrm{V}$. cornuta in flower and spur, but, instead of forming leafy tufts, it increases itself by runners under the earth, somewhat after the manner of Campanula pulla. $\mathrm{V}$. calcarata is a very pretty plant on the Alps. It is usually found in high situations, amidst dwarf flowers, and is so plentiful that its large purple flowers sometimes form sheets of colour, the leaves being scarcely seen amidst the other dwarf plants that form the turf. $\mathrm{V}$. calcarata is as charming in the rockgarden as in its native wilds. Its yellow variety (flava) is the same as V. Zoysi.

V. cornuta (Horned Pansy). - This Pyrenean and Alpine Violet has been cultivated for ages in rock-gardens and borders, but its value as a continuous bloomer, and its consequent employment for bedding, came into prominent notice only a few years ago. It is now to be seen in every garden, its sweet-scented flowers of pale blue or mauve are abundantly produced, and make it very valuable in lines and mixtures, and it is largely used for all kinds of borders. Generally speaking, it does poorly on dry soils and in warm districts, but it succeeds remarkably well on wet places. In many cold and stormy districts the blue Lobelia grows quite to grass instead of to flower; but what spoils the Lobelia will highly improve $\mathrm{V}$. cornuta. The numerous varieties of it now existing afford a wide range of colour. Division, cuttings, or seeds.

V. cucullata (Large American Violet) is unusually floriferous, and bears some resemblance to the common Violet, though without its delicious scent. It flowers, however, much more freely than the sweet-scented Violet, and its bold and sometimes văriegated foliage makes it a valuable acquisition. It came originally from N. America. It belongs to a section which contains some fine varieties, such as V. primulæfolia, semperflorens, blanda, obliqua, sagittata, palmata delphinifolia, canadensis, pubescens, striata, and others. All these varieties are worthy of culture in a full collection.

V. gracilis is a remarkably pretty dwarf species. It never fails to produce in spring an abundance of deep purple blossoms in dense tufts. It is quite hardy in light soil. Mount Olympus.

V. lutea (Mountain Violet). - The yellow form of this Violet is very neat and compact. It is 2 to 6 in. high. From April onwards it flowers abundantly, and its flowers are of a peculiarly rich and handsome yellow, the three lower petals being striped with thin lines of rich black. It possesses first-class qualities as a bedding plant; it is dwarf and neat, and its colour is much to be desired for the flower garden; while it is less uncertain in its growth on most soils than $\mathrm{V}$. cornuta. It may be tastefully used for margining choice beds, for combining in low and rich mixtures with bright-leaved 
plants like Amarantus or Coleus, kept very dwarf, and for other purposes.

V. Munbyana.-One of the prettiest of Violets, abundant in flower, free and robust in growth, and quite hardy. Generally it begins to flower about the end of February, but it attains its greatest beauty in May. The deep purple-blue flowers resemble those of $\mathrm{V}$. cornuta; and there is also a yellow variety. Algeria.

V. odorata (Sweet Violet).-This wellknown plant is in a wild state widely spread over Europe and Russian Asia, and is common in various parts of Britain, while it is grown in almost every garden, and enormous quantities of it are sold in London, Paris, and many other cities. Its delicious odour distinguishes it from other Violets. It is seldom used in the best way. It may be grown where almost everything else but weeds would fail. It will form carpets for open groves or the fringes of woods, of hedges, the open parts of copses, or for banks. Instead of being confined to a bed for cutting from, it should fringe shrubberies, rockgardens, or ferneries. In such positions it requires no care, and rewards the planter by filling the cold March air with unrivalled sweetness. It will grow in almost any soil, best on free sandy loam, and should be put in such for choice. It is well to naturalise the plant on sunny banks, fringes of woods, and on the warmer sides of bushy places to encourage a very early bloom.

The cultivation of the Sweet Violet is of great importance, not only for private gardens, but also to supply the vast demand for it in large cities.

About Paris, the cultivation of Sweet Violets for the markets is largely carried on, and in some places three or four acres may be seen covered with these flowers. The ground is well exposed to the midday sun, and is of a rich, free, and warm nature. The plantations are made in spring, those required for the winter markets being grown in frames. It is almost needless to say that Sweet Violets may be propagated to any extent by division, but strong, healthy, free-flowering plants are easily raised from seed, which should be sown as soon as possible after it is gathered. In cold dry parts, and in gardens where Violets do not succeed well, and also where they are required in mid-winter, it is better to raise a number of healthy plants every year, and to put them in a light frame in a sunny position in autumn. With very little trouble we may have Violets from
January until May, when they bloom in the open ground. Plants which are obtained by setting out runners in spring in rich soil, and receive in dry weather all the water they need, may be set in a common cold frame early in autumn. They should be allowed to grow until the approach of winter, when the frames should be filled with leaves, the sashes put on, and a shutter should be put over the sashes. The plants must have abundance of air on mild days, and water as they need it. A frame of three sashes, separated into three parts by boards, may be uncovered, one sash at a time, at intervals of two or three weeks, and thus a succession of flowers will be kept up. Violets do not like forcing, neither do they need it if their crowns are ripened early, and they are tempted by the protection of glass to open out genially and exhibit their fragrant blossoms.

In the open border Sweet Violets thrive on a moderately heavy rich soil; if the suil happens to be light and gravelly, some stiff material and plenty of manure must be added to it; and if poor and hard clay, it will be benefited by the addition of some sharp gritty matter and abundance of rotten manure. Violets require shelter, but not that of a wall; and in town gardens or gardens surrounded by high walls they are seldom healthy. Their natural shelter is a hedgerow, in which they get currents of pure air, which are essential for keeping down redspider, and for maintaining the foliage in a healthy condition. Violets grow well on the north or north-east side of a Hornbeam hedge, if the hedge is somewhat naked at bottom, so as to allow the sun to shine on their leaves early in spring, and so as to afford a partial shade in summer. When the soil is deep and rich, however, Violets will bear a considerable amount of sunshine. It is well to have a few plants in different positions, so as to ensure a succession of bloom. On south borders Violets dwindle and die; but a few roots on sunny banks will produce some early pickings.

The insects that trouble the Violet most are green-fly and red-spider. The first is generally the result of a close unhealthy atmosphere, and is most easily got rid of by gentle smokings. Redspider is helped by strong sun and by dryness at the roots; hand-dusting with sulphur is the best remedy, but it is easy to prevent its occurrence by syringing the plants and their surroundings.

The varieties of the Violet are very numerous. We have the single white and 
the single rose, the double white and the double rose, the small Russian, the Czar, (a very large and sweet variety), the Queen of Violets (with flowers almost as large as those of the double white Cherry), and the perpetual blooming Violet-well known in France as La Violette des Quatre Saisons. La Violette des Quatre Saisons differs slightly from the Sweet Violet, but frame in severe weather. Marie Louise is a fine kind, and is a great advance upon the Neapolitan kind; its flowers are larger and rather deeper, and are more freely produced. The old double blue kind has, perhaps, the fullest and neatest flowers of all, but its stems are short. It is, however, very beautiful when grown in frames, or in beds in the open, where the

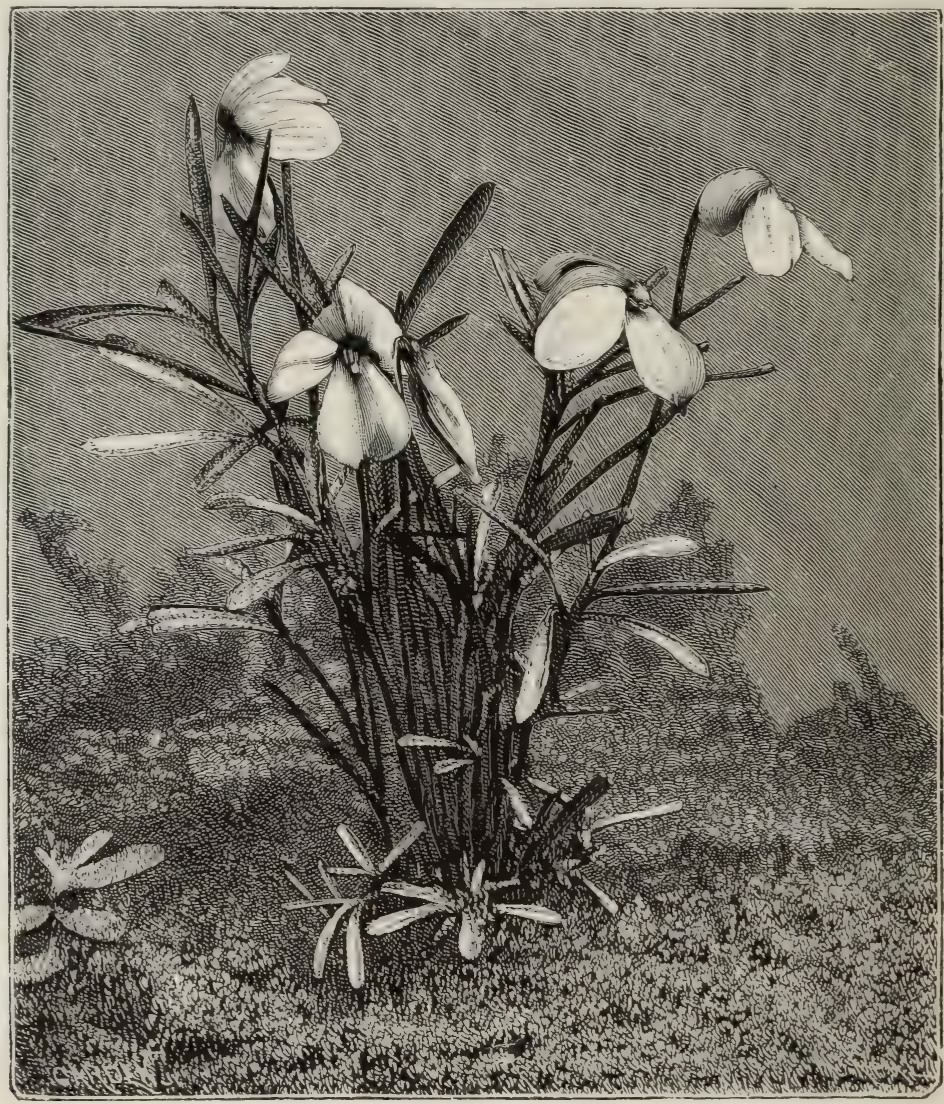

VIOLA PEDATA (BIRD'S-FOOT VIOLET).

is valuable for flowering long and continuously in autumn, winter, and spring. It is the variety used by the cultivators round Paris. The double white, or, as it becomes in the open air, the rosy-white Belle de Chatenay has a robust habit, and is a favourite for open beds or frames. Though not so pure as the old double white kind, it blooms more freely, and is not so loose in its growth. The Neapolitan kind, V. o. pallida plena will doubtless ever be a favourite, in spite of other and newer kinds, but it needs a thick growth keeps the flowers well up from the soil. Blandyana, another double kind, is of a better habit, and is a somewhat freer bloomer; its flowers are rather larger, but are not quite so dark or so neatly formed.

V. pedata (Bird's - foot Violet). - The most beautiful of the American Violets, and very dwarf and compact. Its handsome flowers are $I$ in. across, pale or deep lilac, purple or blue, the two upper petals being sometimes velvety and deep violet like the petals of a Pansy. The 
leaves are deeply divided, like a bird's foot. The variety bicolor is much prettier than the type; its flowers are larger, and the petals are arranged flat like those of a Pansy. The two upper petals are a rich velvety purple, and the three lower ones are a delicate blush tint. $\mathrm{V}$. pedata is free in growth in a light rich soil in partial shade, but the variety bicolor succeeds only in certain localities, and even then needs special attention; but any extra care is well bestowed. The variety bicolor is rare even in its native soil, but V. pedata is plentiful in sandy or gravelly soil in the Northern States of America. Flowers in summer. Seeds or division. It is best adapted for the choice rock-garden, but may also be grown in borders where the soil is peaty, sandy, and moist. V. pedata does freely in pots in places where alpine plants are grown in cold frames, and it should be so grown.

V. rothomagensis (Rouen Violet).-A distinct and handsome plant belonging to the tricolor group. It is of dwarf growth, and has low creeping stems. From these stems arise, in spring, numerous blossoms of purple and white. V. rothomagensis is a free grower, but, being a native of Sicily, it is not so hardy as some Violets, and should be grown in a light soil and a warm border.

V. tricolor (Heart's-ease).- The Pansy is usually classed under the head of $\mathrm{V}$. tricolor, though it is probably descended from $V$. altaica - a species to which a good many Pansies seem nearly allied. But the Pansies are so numerous, so varied, and, withal, so distinct from any wild species of Violet, that little can be traced of their origin. Of one thing we may be certain : the parents of this precious race were true mountaineers. Only alpines could give birth to such rich and brilliant colour and such noble amplitude of bloom. Its season never ends; it often blooms cheerfully enough at Christmas, and is sheeted with gold and purple when the Hawthorn is white with blossoms. Such a flower must not be ignored on our rock-gardens, even though it thrives in almost any soil and position. It may be treated as an annual, a biennial, or a perennial, according to climate, position, and soil. One of the commonest of weeds in Scotland, the wild V. lutea may be grown in the south of England, if sheltered from the mid-day sun. It thrives capitally with a north or, better still, a north-east exposure, if sheltered by tall trees or buildings, so that it may get the cool sun of the early morning only.
For border decoration the best way is to grow the plants from seed; and the best sorts to begin with are the Belgian or fancy Pansies, which are remarkable for the strange and almost gorgeous variety of their colours and the unusual size of many of the blooms. They are more hardy as seedlings, and more robust as plants, than the other kinds, and yield a greater variety of colours. The seed should be sown in July or August, in pans of light leafy soil, such as sand, leafmould, and mould from rotted turf, and placed in a cool shady place. When mixed seeds are sown, it is important to sow each separately at a distance of $I \frac{1}{2}$ in. or so. As soon as the first seeds have germinated and have produced three pairs of leaves, they should be removed without disturbing the weaker and more backward ones, for amongst the seedlings which are the last to appear will be found the greatest proportion of finely-coloured flowers. Thus it is important to sow the seed when fresh.

It is rarely convenient to plant the seedlings at once in their blooming places; and they therefore should be placed in pots plunged in a cool place in the open ground, and should be shifted to their final places in time to get well established before winter sets in. They stand the winter well, and the only danger lies in heavy rain or sleet succeeded by sharp frosts. A pot inverted over each plant to protect the soil from too much wet would be sufficient protection. It is not advisable to move Pansies in spring unless they have been kept in pots during winter, in which case they may be planted, though with as little root-disturbance as possible.

Pansies are divided into two sections - the show or English kinds, and the fancy or Belgian kinds. The first comprises five divisions: white and yellow ground belted Pansies, white, yellow, and purple Pansies. The selfs must be clear decided colours, and should have a black well-defined blotch under the eye. The belted kinds should have a white or yellow ground, together with centre blotch, and a broad margin of bronzy-red, chestnut, purple, or crimson, or other hue; and the colours must be dense, and the margins very distinctly defined. The flowers of the show section should be rounded, in good form, and stout of petal. They should also be of good size, but size is of less importance than the quality of the markings. Regarding the second section, a fancy Pansy should have a very large deep-coloured blotch, 
covering nearly the whole of the bottom petal and portions of the side petals. The rest of the flower may be white, yellow, buff, red, maroon, purple, crimson, and various other shades, but not so dense as the centre blotch. Some fancy Pansies are flaked or parti-coloured, but all good ones are showy and beautiful beyond the imagination of those who have only seen common strains. Some of the bedding Pansies are very free-flowering; while Cliveden Yellow, Cliveden Blue, King of Blacks, and a host of other sorts mentioned in catalogues are very effective, though less robust and less quick in growth than the Belgians. In using seedlings from mixed seed, the arrangement of colours must be left to chance, as the colour of the foliage is no guide. Named Pansies come fairly true from seed, but the only way to secure a stock of any particular variety is to take cuttings. When any plant or plants show flowers which it is desirable to perpetuate, the best way is to sacrifice the bloom for the year, pinch the bloom-buds off as fast as they show, feed the plant well with dressings of leaf-mould pricked in about the roots, and peg the first shoots down so as to leave the crown of the plant exposed, for fresh healthy shoots to rise from. A few shoots should be taken off when they have made three or four pairs of leaves, and be planted in light soil, sand, and leaf-mould, under a handglass, and kept moist and shaded. The pegged-down stems will produce shoots which may be taken off in the same way ; and when well rooted they may be treated as seedlings.

A good plant combines a profusion of fine flowers with a dwarf, short-stemmed, stocky habit, and the plant when in flower is a round green bush, with the flowers about $\frac{1}{2}$ in. clear of the leaves. It is useless to save seed before a stock of first-class plants is obtained. July is early enough to sow the seed in the south of England, but farther north it may be sown earlier, until in Scotland it should be sown in the spring.

Tufted PANsies. - These are hybrids of Pansies and alpine Violets. The term "tufted" has been very properly used to distinguish plants of a spreading habit, like Pinks, Aubrietia, and Alpine Violets, from plants with simple erect stems, like, say, the Stock, Lupine, and Aster. Sometimes the two forms of habit occur in the same family; for instance, there are Violas that are tufted and Violas that are not-- the German, French, and other Pansies in our gardens do not spread at the root as the tufted Pansies do. Plants of this "tufted" habit are often a mass of delicate rootlets even above the ground, so that they are easily increased. Hence when older Pansies die after flowering, those crossed with the alpine species remain, like true perennials, and are easily increased. The term Pansies is a good one in all ways. Without an English name, we shall always have confusion with the Latin name for the name of wild species. To all of these belongs the old Latin name of the genus Viola. It is now agreed by botanists that all crossbred garden plants - including tufted Pansies, of course-should have popular English, and not Latin, names. "Bedding Violas" is a vulgar compound of bad English and Latin; whereas "tufted Pansies" is a good English name with a clear meaning.--The Garden, I6th Jan. I 892 .

These are the flowers hitherto generally known as Violas and bedding Pansies, and Dr. Stuart, who has raised some of the best and truest of them, says:"Botanically, Violets, Pansies, and Heart's-ease are all the same. Tufted Pansies are crosses from the garden Pansy and Viola cornuta, the latter being the seed-bearer. Pollen from V. cornuta applied to the Panisy produces a common enough form of bedding Pansy-never the tufty root-growth obtained when the cross is the other way. I have proved this by actual hand-crossing. Most strains of tufted Pansies are bred the wrong way, and in consequence lack the fibrous tufty root which makes the Violetta strain perennial."

Having settled the name, the next thing we have to do is select some of the most beautiful of these charming flowers, which are certainly more valuable for our flower gardens than the ordinary Pansy, fine and rich in colour as these are. They are so because the colours are simple and generally pure and true, and because they are most effective when used in groups, and then they are perennial, and may be easily increased and kept true.

Among white tufted Pansies are surely some of the most beautiful flowers ever seen in our gardens. The best are Mrs. Kinnear, Countess of Hopetoun, Violetta, Mrs. Gray, and Marchioness of Tweeddale (with a delicate bluish shade). Near these creamy-whites come a group of creamy or pale yellow coloured kinds, such as Sylvia, Abercorn Gem, Bridesmaid (Dean), and Gravetye Primrose. Among yellows there is nothing better than (if as good as) Ardwell Gem ; another good 
one is Bullion. Perhaps the most precious of all are the lavenders and delicate blues, such as Ariel, Quaker Maid, Elegans, Azurea, Duchess of Sutherland, Mrs. Turner, Wm. Neil, and Bessie Clarke. Of the blues and rich dark purples we have Archie Grant, Blue King, Holyrood, Cliveden Purple, Lottie.

Although we generally like the colours simple and pure, there are other pretty ones of a different kind, such as Columbine, Blue Cloud, Duchess of Fife, Countess of Kintore, Skylark. Some kinds, like Violetta, are white, running off to delicate that is, such as are liable to crack with drought, use abundance of leaf-soil, burnt ashes from the rubbish fires, and the like, to bring them into better working. I also select a dry time for digging, working in the above with plenty of short manure from an old Mushroom bed, and scattering an inch or so on the surface to work in with the roots at planting time. Whereever practicable, I plant in little trenches 2 or 3 in. deep. Especially do I follow this system on light over-drained soils, with the object of earthing the young plants up as they grow. In this manner,

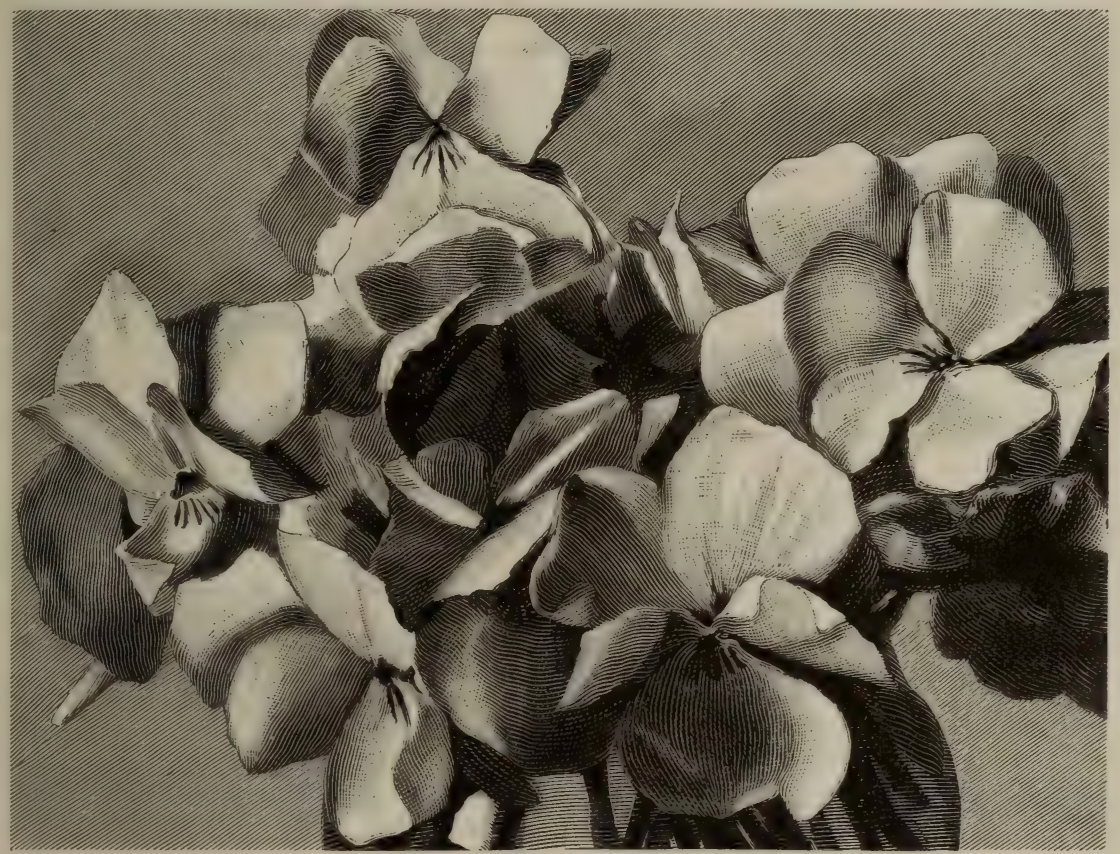

TUFTED PANSY, MRS. GRAY.

bluish or lilac hues. These delightful things are so easily raised and crossed, that it might almost be well if each garden had its own colours, by the raising of a few kinds for itself, so as to have as much variety as possible.

These plants love a cool moist soil of fair depth and rich. In northern districts they are naturally more at home under ordinary conditions than in the south, and to bring them to perfection in the south, special treatment is necessary.

For early spring-flowering the cuttings should be rooted in July or August, and planted out in their places the first or second week in October. They commence blooming early in April. In heavy soils, from October plantings I have had fine tufts before the end of the year crowded with young shoots at the base. To the free use of cow manure I attribute my success on our light soil. Cuttings, it should always be borne in mind, are better than divisions; particularly if they are made of the young shoots stripped from the old stool with a heel attached. To annually obtain a supply of these cuttings it will be necessary to plant out a reserve batch of plants for the purpose. About the second week in June, cut them back to within 2 in. of the soil. A month afterwards they will be bristling with young shoots. As soon as 3 in. long, scatter some fine soil and leaf-mould 
among the young growths, and keep well watered for a fortnight, by which time the majority will be making roots freely. A fortnight later they will be ready for planting in nursery-beds in a shady spot and in good soil, and as growth is renewed, pinch out the top of each to encourage the quicker formation of breaks at the base. By October some grand plants for putting into their permanent quarters, plants full of youth and vigour that will produce masses of their flowers by and by, will be obtained.-I.

Violet, Bog (Pinguicula).

Violet Cress (Ionopsidium acaule).

Violet, Dog's-tooth (Erythronium). Water (Hottonia).

\section{Viper's Bugloss (Echium vulgare).}

Virgilia lutea, the Yellow-wood of N. America, cannot be called a satisfactory flowering tree. Its beauty is rather that of early autumn, when its leaves, always elegant during summer, turn to a rich golden-yellow, and remain bright for days and weeks - even until cut off by frosts. The white pea-shaped flowers are borne in loose clusters, and V. lutea is an excellent lawn tree, of medium size and symmetrical growth.

Virginian Cowslip (Mertensia virginica).

Creeper (Ampelopsis).

Papaw (Asimina).

Poke (Phytolacca).

Spiderwort (Tradescantia virginica).

\section{"Stock (Malcomia)}

\section{Virgin's Bower (Clematis).}

Viscaria oculata.--This showy and beautiful hardy annual is well suited for a border. Seed should be sown in spring or autumn, and the seedlings thinned out when large enough. V. oculata is 6 or 8 in. high, and bears a profusion of rosecoloured blossoms with a dark centre. The varieties cardinalis (bright crimsonpurple), cœrulea (bluish), alba (white), Dunnetti (rose), splendens (scarlet), picta elegans (crimson - purple, edged with white), and a dwarf variety, nana, about 9 in. high, are very desirable. Algeria. V. cœli rosea is also a beautiful hardy annual, and is sometimes called Agrostemma. If sown in autumn in warm sandy soil, and the plants duly thinned out, it will produce compact cushions of rosy-blue blossoms. It may be sown in spring, but the results are not so good as those of autumn sowing. S. Europe. Pink Family.

Vitex Agnus-castus (Chaste Tree).A very old S. European shrub, but not of much importance. It has divided leaves, and in late summer bears clusters of small pale lilac flowers. It grows 6 to Io $\mathrm{ft}$. high against a wall, but even thus protected is liable to be killed during a severe winter.

Vitis (Vine).-As ornamental climbing shrubs some of the Vines are useful in the garden, especially for trailing over trellises, arbours, pergolas, and pillars. There is a similarity in the foliage of most of them, and therefore it is unnecessary to describe them in detail. The Isabella Grape (V. Labrusca), known also in gardens as V. Thunbergi, has large bold leaves, rusty-coloured beneath and turning to brilliant shades of crimson in autumn. V. cordifolia (also called V. riparia) is a North American Vine, of rapid growth and very hardy. Other $\mathrm{N}$. American kinds are V. æestivalis (the Summer Grape), and V. vulpina (the Fox Grape); while from the Himalayas we have V. lanata, whose foliage dies off in autumn with brilliant shades of red and crimson; and from China and Japan comes the beautiful little $\mathrm{V}$. heterophylla humulifolia (the Hop-leaved Vine), with small Hop-like leaves, and berries about the size of peas, and of a lovely turquoiseblue. V. h. humulifolia is one of the most valuable of hardy ornamental Vines, and is easily procurable. The common Grape, V. vinifera, is, of course, ornamental, but being less vigorous and less rapid in growth than those above mentioned, is not so desirable. Some of the more robust kinds, as the Fox Grape and the Isabella Grape, will climb and ramble over trees to a great height, and, in autumn, will light them up with the fiery hues of their decaying foliage. In planting Vines under trees, they should be placed a few feet away from the stem, where the soil is less dry and poor.

Vittadenia triloba and australis =Erigeron mucronatum $)$.

Wachendorfia.-Bulbous plants from the Cape of Good Hope. They are not hardy, but require the same treatment as Cape Ixias and Sparaxis. W. paniculata, W. hirsuta, and W. thyrsiflora are the best known. These are similar to each other. They have tall, slender, branching flower-stems, which bear, in early spring, numerous large yellow blossoms which are very showy and attractive.

Wahlenbergia hederacea (Ivy-leaved Hairbell).-An elegant little native plant, closely allied to Campanula, and often included in that class of plants. It is a weak creeping thing, its almost thread- 
like branches bear small delicate leaves, and faint bluish-purple flowers less than $\frac{1}{2}$ in. long and drooping in the bud. There is about it, however, an interest and a grace which we do not find in more robust members of the family. It creeps over bare spots by rills and on moist banks, and wherever there is a moist boggy spot near the rock-garden, or by the side of a streamlet, or in an artificial bog, W. hederacea will be worthy of a place. It occurs chiefly in Ireland and in Western England, and sometimes, but less abundantly, in the east. Division. Edraianthus are known also as Wahlenbergias.

Waitzia.-Half-hardy annual Composites from Australia. Of the four kinds of Waitzias in cultivation all are valuable for their pretty flowers, which, like those of Helichrysum, are termed Everlastings, and are very useful for winter bouquets. W. acuminata has a variety with purple flowers, and another with yellow flowers. $\mathrm{W}$. aurea has bright yellow flowers. W. corymbosa has white and purple flowers, and the flowers of W. grandiflora are like those of W. aurea, but finer. All grow about I ft. high, and require to be treated like other tender annuals, such as Rhodanthe. They succeed best in an open position in sandy peat. Seeds. The seedlings should be shifted into differentsized pots before planting out in May. Waitzias flower in August and September.

Waldsteinia.-Dwarf Rosaceous plants, three of which, W. geoides, W. fragarioides, and W. trifolia, are in cultivation. The last is the most attractive, but not one of the Waldsteinias is ornamental enough for border culture. Waldsteinias are only suitable for dry banks and such places. They grow in any soil. Their yellow flowers are produced in spring.

Wallflower (Cheiranthus Cheiri).

Wall Pennywort (Cotyledon Umbilicus).

Wall Rue (Asplenium Ruta-muraria).

Water-Avens (Geum rivale).

" Chestnut (Trapa natans).

" Dock (Rumex Hydrolapathum).

" Flag (Iris Pseud-acorus).

"Leaf (Hydrophyllum).

" Lily (Nymphcea).

" Lily, Shepherd's (lianunculus Lyalli).

Pennywort (Hydrocotyle).

Plantain (Alisma Plantago).

Soldier (Stratiotes aloides).

Violet (Hottonia palustris).

Watsonia.-Bulbous plants representing some of the most beautiful of the large Iridaceous family. Several of the finest were, long ago, favourites in gardens. Watsonias cannot be called hardy, but in the southern counties some of them succeed perfectly in open borders. There are only a dozen species and about as many varieties, half of which are variations from W. Meriana. All the species are natives of S. Africa, but their headquarters are at the Cape. What with hybrids and seminal varieties, there is a great diversity of colours, and some of the trade lists even advertise a "mixed" selection representing "all colours." The commonest species seem to be W. Meriana, W. coccinea, W. iridifolia, W. rosea alba, W. humilis, W. angusta (also known as W. fulgida), and W. aletroides. All these kinds are true Watsonias, and have much more showy flowers than the other sections of the genus. The white Watsonia (W. alba) is a lovely plant, flowering in early summer. With regard to the culture of these plants, treatment similar to that recommended for the early Gladioli will suit them. Where they are grown in frames, a good deal of trouble is saved, and they produce finer flowers than when otherwise grown, since the young growths are protected when they most need it. As a general rule, however, it will be found best to grow the plants in warm situations in open borders of light rich soil. Of the varieties offered in trade lists, the following may be taken as representative: W. coccinea, fulgens, Meriana, alba, humilis, marginata, rosea, speciosa, fulgida, brevifolia, angustifolia, Grootvorst, Louis XVI., Wreede, Duchess, George IV., Chilea, Duc de Berri, and Blucher.

Wayfaring Tree (Viburnum Lantana). Weigela (Bush Honeysuckle). - The Weigelas have long been in the front rank of flowering shrubs, and are deservedly popular, being elegant, rapid in growth, and beautiful in bloom. A multitude of varieties have sprung from $\mathrm{W}$. floribunda, W. grandiflora (known also as W. amabilis), W. rosea, and W. hortensis. These are natives of China and Japan, and have been introduced within the last forty years. They have been so much hybridised that they are rarely found pure. The most valuable sorts have come from W. grandiflora, which has the largest flowers, while the smaller, but more numerously-flowered kinds, have originated from $\mathrm{W}$. rosea and $\mathrm{W}$. floribunda. The varieties have been raised chiefly on the Continent, as may be inferred from their names. A selection of the best kinds should include the 
following : Abel Carrière, very numerous small flowers of deep red; Isolinæ, large flowers of white or pale rose with yellow markings; Van Houttei, large and showy white and red flowers; Lemoinei, numerous small deep crimson-red flowers; Groënowegenei, one of the best, the flowers being large, of pink or pale rose, with a yellow blotch; striata, a very pretty sort, having flowers striped with

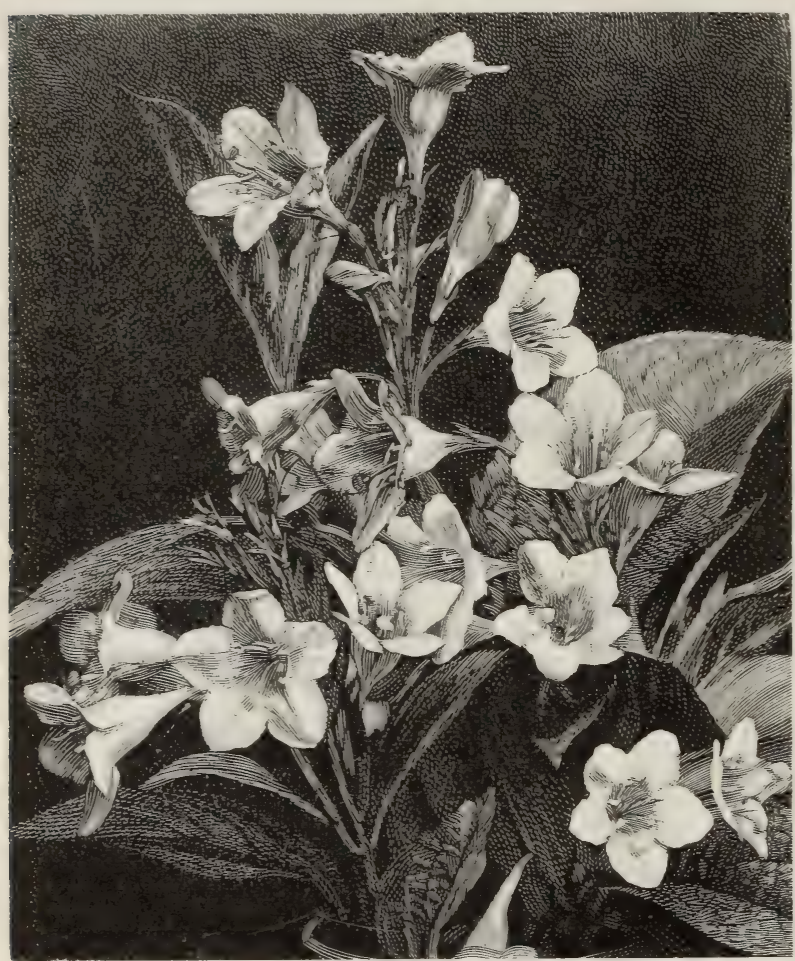

WEIGELA GRANDIFLORA.

red and white; Stelzneri, with numerous deep red flowers; Lavalléi, with numerous crimson-red flowers; hortensis nivea, more spreading than that of others, with larger and paler foliage, and large pure white flowers ; candida, resembling Lavalléi, and hortensis nivea, superior to either. Candida and hortensis nivea should always be selected. If a large collection is needed, the following may be added to those already enumerated: Carminea, Emile Gallé, Docteur Baillon, Edouard André, Aug. Wilhelm, Diderot, Montesquieu, and Desboisi. The golden-leaved W. Looymansi aurea is a very fine ornamental shrub, usually retaining its bright golden foliage through the season. Its variegated-leaved form is also excellent. All sorts are of good free habit if planted in good soil in an open position. They should never be crowded, but should be grown as isolated groups on lawns, or placed on the margins of shrubberies. Weigelas make large bushes, 6 to $10 \mathrm{ft}$. high and as much in diameter, and their graceful drooping branches are ornamental, even when leafless in winter.

Weigelas should be topdressed annually with good rich soil, and pruned of all but the vigorous stems and the branches that yield the finest bloom. Weigelas are now classed botanically in the genus Diervilla, which also includes other species, such as D. sessiliflora and D. trifida, from N. America. Neither of these is to be recommended for general cultivation, though both are worth planting for the bright tints of their autumn foliage.

Welsh Poppy (Meconopsis cambrica).

White Cup (Nierembergia rivularis).

White Hellebore Veratrum album).

White Thorn ( $\mathrm{Cra}$ tagus).

White Wood Lily (Trillium grandiflor(um).

Whitlavia grandiflora.-A beautiful plant allied to the Nemophila, and attaining a height of about I ft. It is of branched growth, and produces an abundance of showy bell-shaped blossoms of a rich deep blue. There is a white variety, and there is also a handsome variety called gloxinioides with white and blue flowers. W. grandiflora is a hardy annual, and may be sown either in autumn or in spring in the open border, in good friable soil. It is best used as a carpet-plant, or as a groundwork plant. California. Hydrophyllaceæ.

\section{Whorl-flower (Morina longifolia).}

Whortleberry (Vaccinium).

Wigandia.-These noble-leaved plants are natives of the Tropics, but they succeed in the open air in summer. The best is W. caracasana, from the mountainous 
regions of New Granada ; and the nobility of its port, and the size and form of its leaves, entitle it to a place among the finest plants of our gardens. In London it has borne leaves remarkable for size, strong veining, and texture. It will succeed in the midland and southern counties, though too much care cannot be taken to secure for it a warm sheltered position and good free soil. W. caracasana may be used with superb effect either in a mass or as a single plant. It is frequently propagated by cuttings of the roots, grown in a moist and genial temperature through the spring months, and kept near the light, so as to preserve the plant in a dwarf and well - clothed condition. Like all the other plants in this class, W. caracasana should be very carefully hardened off previous to being planted out at the end of May. This Wigandia is, however, much better to raise from cuttings of the shoots; and it may also be raised from seed. The stems of W. macrophylla, from Mexico, are covered with short stinging hairs, bearing brownish viscid drops, which adhere to the hand like oil. W. imperialis, a new variety, is said to excel the others in its growth. W. Vigieri is another fine kind, of quick and vigorous growth, and of remarkable habit. Its leaves are $3 \mathrm{ft} .9 \mathrm{in}$. long (including the leaf-stalk), and are 22 in. across, and its stem, nearly $7 \mathrm{ft}$. high and $3 \mathrm{in}$. in diameter, bears a column of leaves. This plant is distinguished from W. caracasana and W. macrophylla by its leaves and stem being covered in a greater degree with glossy, slender, stinging bodies. These bodies are so thick as to give the stems a glistening appearance. W. urens is often planted, but is decidedly inferior to the foregoing, except in its power of stinging, in which it is not likely to be surpassed. All Wigandias have clusters of blue or violet blossoms, which are not often borne in the open air with us. In their native habitats they range from 3 to I $2 \mathrm{ft}$. high, W. caracasana being the tallest.

Wilbrandia drastica.--An interesting Cucurbit of graceful growth, with dense clusters of small fruits. It should be treated as a half-hardy annual Gourd. Brazil.

Wild Bergamot (Monarda fistulosa).

"Indigo (Baptisia tinctoria).

" Liquorice (Ononis arvensis).

" Senna (Cassia marilandica).

\section{Willow (Salix).}

" Herb (Epilobium).

" Water (Dianthera americana).

Windflower (Anemone).
Winter Aconite (Eranthis hyemalis).

" Cherry (Physalis Alkekengi).

" Cress (Barbarea).

" Green, Creeping (Gaultheria).

" " Large (Pyrola rotundifolia).

" " Spotted (Chimaphila maculata).

" Heliotrope (Tussilago fragrans).

Wistaria.-The common Wistaria, W. sinensis, is the finest of the few Wistarias to be found in gardens. The type has pale purple flowers, but there is a pure white variety, and another with very long racemes, which is named macrobotrys, and is of great beauty. The double variety (fl.-pl.) is worthless, and little can be said in favour of the variegated-leaved variety recently introduced. Other eastern species in cultivation are W. multijuga, from Japan, which resembles its Chinese relative W. sinensis in its pale purple flowers, borne in racemes often $2 \mathrm{ft}$. or more in length. It is also known as W. grandiflora, and though it has been in cultivation for some years, it is still rare. Another Japanese species is W. japonica, described as a twining shrub. It has racemes of white flowers. I have no personal knowledge of this kind, beyond the specimens in the Kew arboretum, which are labelled W. japonica. These show little tendency to climb or to twine, but they make most graceful standard bushes. The N. American species, the only Wistaria of the West, is W. frutescens, a very old garden favourite, sometimes called the American Kidney Bean Tree. It is smaller than W. sinensis, has smaller foliage, and its flower-racemes are shorter and denser. Its flowers are a deep purple, varying to white. W. frutescens is a very hardy shrub, and may be grown as a standard in most parts of England; it flowers some time after W. sinensis. For arbours, trellises, pergolas, $\mathrm{W}$. sinensis and W. frutescens are equally suitable, and in southern or mild localities they may be grown as standards on a lawn, since an open trellis or framework is all that is required to support the branches. All good soils suit Wistarias, but they prefer soils that are light and warm. A sunny spot should always be selected.

\section{Witch Hazel (Hamamelis). \\ Woodbine (Lonicera). \\ Wood Lily (Trillium). \\ Woodruff (Asperula).}

Woodsia. - These pretty deciduous hardy Ferns are admirably suited for a northern position in the alpine or rockgarden. As they are impatient of sun- 


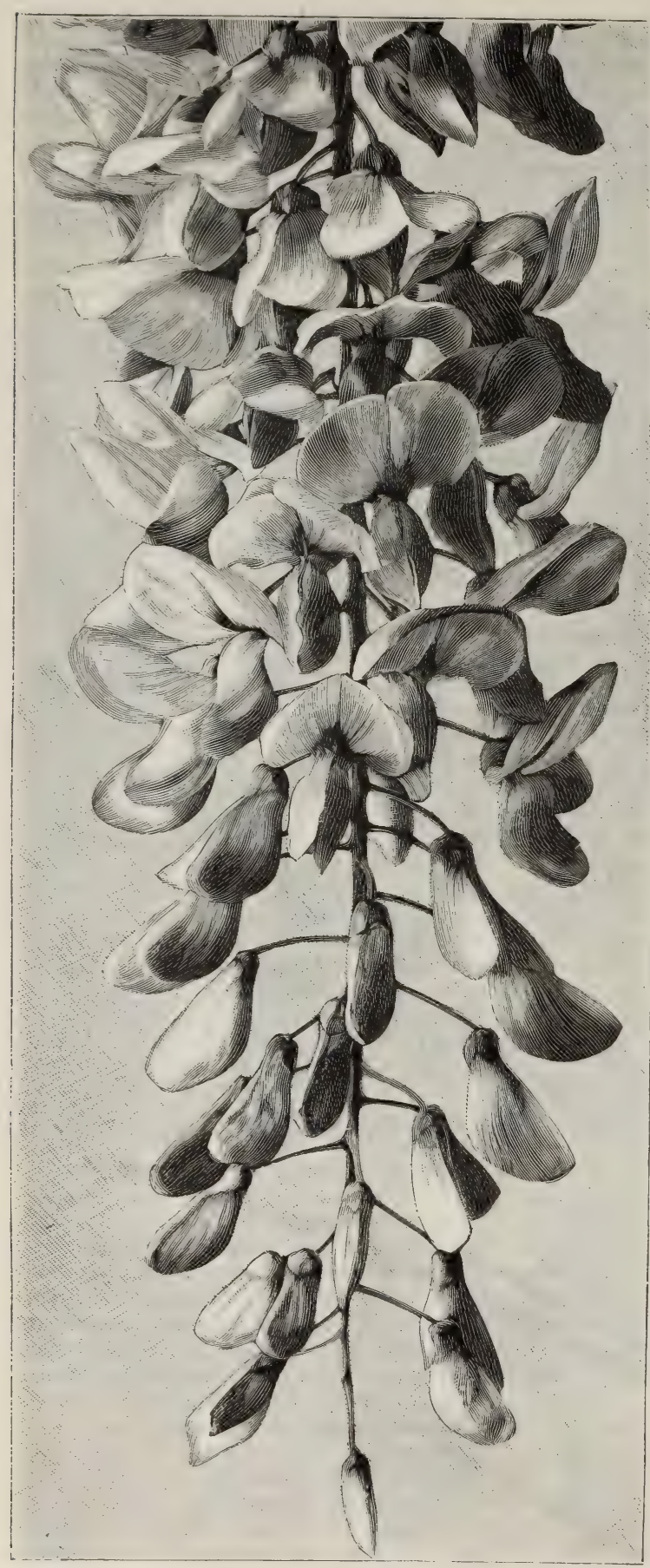

WISTARIA (GLYCINE) SINENSIS. shine, drainage should receive special attention, and they should be placed in a mixture of fibry peat and loam, which has some broken-up sandstone mixed with it. It is a good plan to place Woodsias between little blocks of sandstone which just peep out of the soil. These blocks of stone could be covered with Sedums and other flowering rock plants. W. ilvensis makes a very pretty pot plant, if the earth be well drained. The best hardy species are W. ilvensis and W. alpina ; there is also a very beautiful North American kind named W. obtusa.

Wood Sorrel (Oxalis).

Wood wardia. - There are a few hardy species of these noble Ferns. All are handsome plants, and have broad and beautifully arching fronds, which are very ornamental, especially if seen a little above the level of the eye. Woodwardias thrive under the ordinary conditions of the hardy fernery, and succeed in any place in a shady position if they have a light peaty soil that is moist in summer. The principal hardy kinds are W. areolata (angustifolia) and W. virginica, both from N. America; W. japonica and W. orientalis, from Japan ; and W. radicans, from Madeira. W. radicans is the tenderest, and requires a sheltered position, and perhaps protection in severe cold.

Woolly Thistle (Carduns eriophorus).

Worm Grass (Spigelia marilandica).

Wormwood (Artemisia).

Woundwort (Anthyllis

Vulneraria).

Wulfenia carinthiaca.A remarkably dwarf, almost stemless evergreen herb, 12 to 18 in. high, bearing in summer showy spikes of drooping purplish-blue flowers. Found only on one or two mountains in 
Carinthia. W. carinthiaca is a very ornamental plant for rock-gardens or borders, but should have a light, moist, sandy loam. W. Amherstiana is a species from the Himalayas. It is similar to the Carinthian species, but is showier. It is rare, and we have seen it only

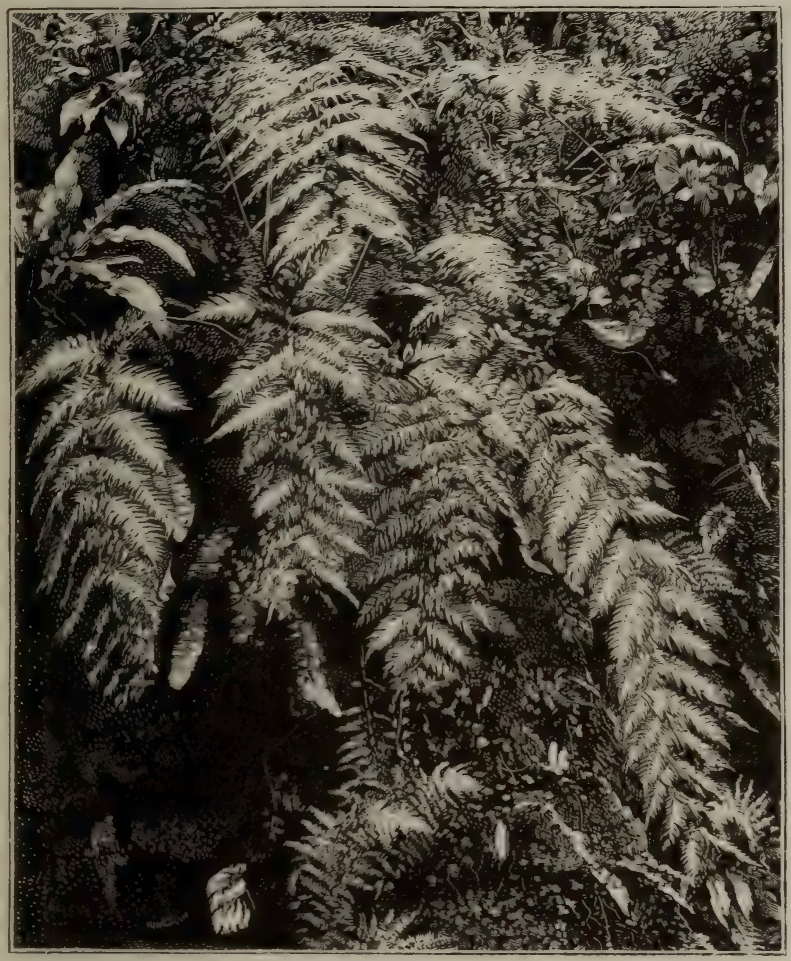

WOODWARDIA RADICANS.

and should not be placed in the open air till June.

Xanthoceras sorbifolia.-A beautiful dwarf tree. It seems to be perfectly hardy, but not a rapid grower. Its leaves are elegant, and its flowers, which are white and marked with red, are borne in erect clusters. $\mathrm{X}$. sorbifolia may prove to be valuable in the future. It is said to grow 5 to I $5 \mathrm{ft}$. high. China.

Xeranthemum annuum.-This hardy annual is one of the prettiest of Everlasting flowers. It grows about $2 \mathrm{ft}$. high, and, if sown in patches, yields abundant masses of white, purple, and yellow double, single, and semidouble blossoms. A packet of mixed seed sown in any ordinary garden soil in March will give a variety of colours, but if it is desired to keep the colours distinct, seeds of the different kinds must be sown separately. The principal kinds are-Album, white ; imperiale, dark violet - purple ; plenissimum, dark purple, double ; superbissimum, double, globe-flowered; and Tom Thumb, a compact dwarf variety. The flowers are excellent for cutting, and, if dried in autumn, are

in Kew Gardens. It grows freely in any position in the rock-garden, but it prefers a shady spot and light rich soil. It is perfectly hardy. Scrophulariaceæ.

Xanthosoma sagittifolium.-A West Indian plant of the Arum family, with very much the habit and appearance of Caladium esculentum, but less valuable. Its arrow-shaped dark green leaves are supported on rather slender stalks. Another equally large and handsome species is $X$. violaceum, the leaves and leafstalks of which are suffused with delicate violet, and slightly incline to hoariness. The position and treatment should be those recommended for Caladium esculentum. Xanthosomas should be tried only in the warmer parts of the country, useful for winter decoration. S. Europe. Compositæ.

Xerophyllum asphodeloides.-A tuberous-rooted plant with the aspect of an Asphodel, very beautiful and interesting. It forms a spreading tuft of grassy leaves. Its flower-stem is $\mathrm{I}$ to $4 \mathrm{ft}$. high, and is terminated by a compact raceme of numerous white blossoms. X. asphodeloides grows well in a moist, sandy, peaty border, and in the drier parts of boggy ground or in a moist peat bed. Common in the Pine barrens in $\mathrm{N}$. America.

\section{Yarrow (Achillea). \\ Yellow Hawkweed (Tolpis barbata). Pond Lily (Nuphar). " Sweet Sultan (Amberboa odo- rata).}

Yew (Taxus). 
Yucca (Adam's Needle).-In its own peculiar habit and peculiar style of growth the Yucca has no rival among hardy plants. Though the stiffest of all our hardy plants, it has grace and elegance; and this grace and elegance are seen under all conditions, if the plant is not cramped for room. Yuccas seem fitted for various uses. A single Yucca may stand alone on a lawn, or in the centre of a bed, or numbers may be grouped with other plants, or form a bed by themselves. Yuccas look especially well on rock-garden banks, either at the bottom, at the sides, or at the top. They are not very particular about soil, and grow in good rich mould, in stiff clay, or in any well-drained soil ; but they do not flourish so well in sand, chalk, or peat. They are hardy save in very severe winters and on cool soils. All of the kinds mentioned below are so vigorous that it is almost impossible to kill them. Suckers, unless carefully taken, are apt to die down to the ground when first planted; but if they are left alone they will renew their growth in a few months. There are several hardy species well suited for flower-garden purposes, and-what is even more advantageous-distinct from each other. The effect afforded by welldeveloped Yuccas is equal to that of any hothouse plant that we can venture to place in the open air for the summer, while they are green and ornamental at all seasons. The free-flowering kinds, Y. filamentosa and Y. flaccida, may be associated with any of our nobler autumnflowering plants, from Gladiolus to the great Statice latifolia. Even species that do not flower so often, like Y. pendula and Y. gloriosa, are magnificent if grown in the full sun and planted in good soil. Division of the stem and the rhizome. Yuccas should be planted singly, beginning with healthy young plants, so as to secure perfect specimens.

Y.aloifolia. - A fine and distinct species, with a stem which, fully developed, is as thick as a man's arm, and is 6 to $18 \mathrm{ft}$. high. The numerous leaves of the plant are dark green, but have a slight glaucous bloom; they ascend rigidly; they are 18 to $2 \mathrm{I}$ in. long and are broad at the middle, while their horny margin is rolled in for 2 or 3 in. below the point, and is finely toothed in the remaining portion. The flowers are almost white, and are borne in a vast pyramidal panicle. Y. aloifolia is hardy, but is not generally known to be so. It should be tried on well-drained slopes in good sandy loam. The finest varieties are quadricolor and versicolor. Their leaves are variously edged with green, yellow, and red. They are very hardy, but as they are yet far from common, it will be best to use them in the greenhouse or the conservatory, or to place them in the open air during summer. They look very pretty when isolated on the Grass, the pots being plunged to the rim. S. America and W. Indies.

$\mathbf{Y}$. angustifolia.-This is the smallest of all the Yuccas. When in flower it is not more than $3 \mathrm{ft}$. high. Its long strips of leaves are nearly $1 \frac{1}{2} \mathrm{ft}$. in length, but are not more than $\frac{1}{4}$ in. in width. They are thick and rigid, are of a pale sea-green colour, and are fringed with white filaments. Y. angustifolia bears a simple raceme of white flowers slightly tinged with yellow. Till it is more plentiful, it should be grown in warm borders, in well-drained sandy loam. It is excellent for rock-gardens. N. America.

Y. canaliculata.-The leaves of this Yucca are entire, i.e. neither toothed nor filamentose at the margin. They form a dense rosette on a stem. This stem is I or $2 \mathrm{ft}$. high. Each leaf is 20 to $24 \mathrm{in.}$ long, and is 2 to $2 \frac{1}{4}$ in. broad at the middle. It is very strong and rigid, and deeply concave. The flowers are of a creamy-white, and are borne in a large panicle 4 or $5 \mathrm{ft}$. high: Y. canaliculata is well suited for isolation or groups. Till it is more plentiful, it should be encouraged in favourable positions and on warm soils. Mexico.

Y. filamentosa.-A very well-known species, with apple-green leaves and a much-branched panicle, 4 to $6 \mathrm{ft}$. high. It varies very much when raised from seed. One variety (concava) has short, strong, broad leaves, which are more concave than those of the type; another variety (maxima) has narrow leaves which, though nearly $2 \mathrm{ft}$. long, are only $2 \frac{1}{2}$ in. broad. It has a panicle 7 to $8 \mathrm{ft}$. high. $Y$. filamentosa flowers with much vigour and beauty, and is well worth cultivating, not only in the flower garden or the pleasure-ground, but in the rough rockgarden, or in any spot requiring a distinct type of hardy vegetation. Its fine though delicate variegated variety is suitable for similar places. All the varieties of Y. filamentosa thrive best in peaty or fine sandy soil. N. America.

Y. flaccida.-A stemless species, somewhat resembling Y. filamentosa, but smaller. It has a downy branching panicle, 3 or $4 \mathrm{ft}$. high, and bears close rosettes of leaves. These leaves are 18 


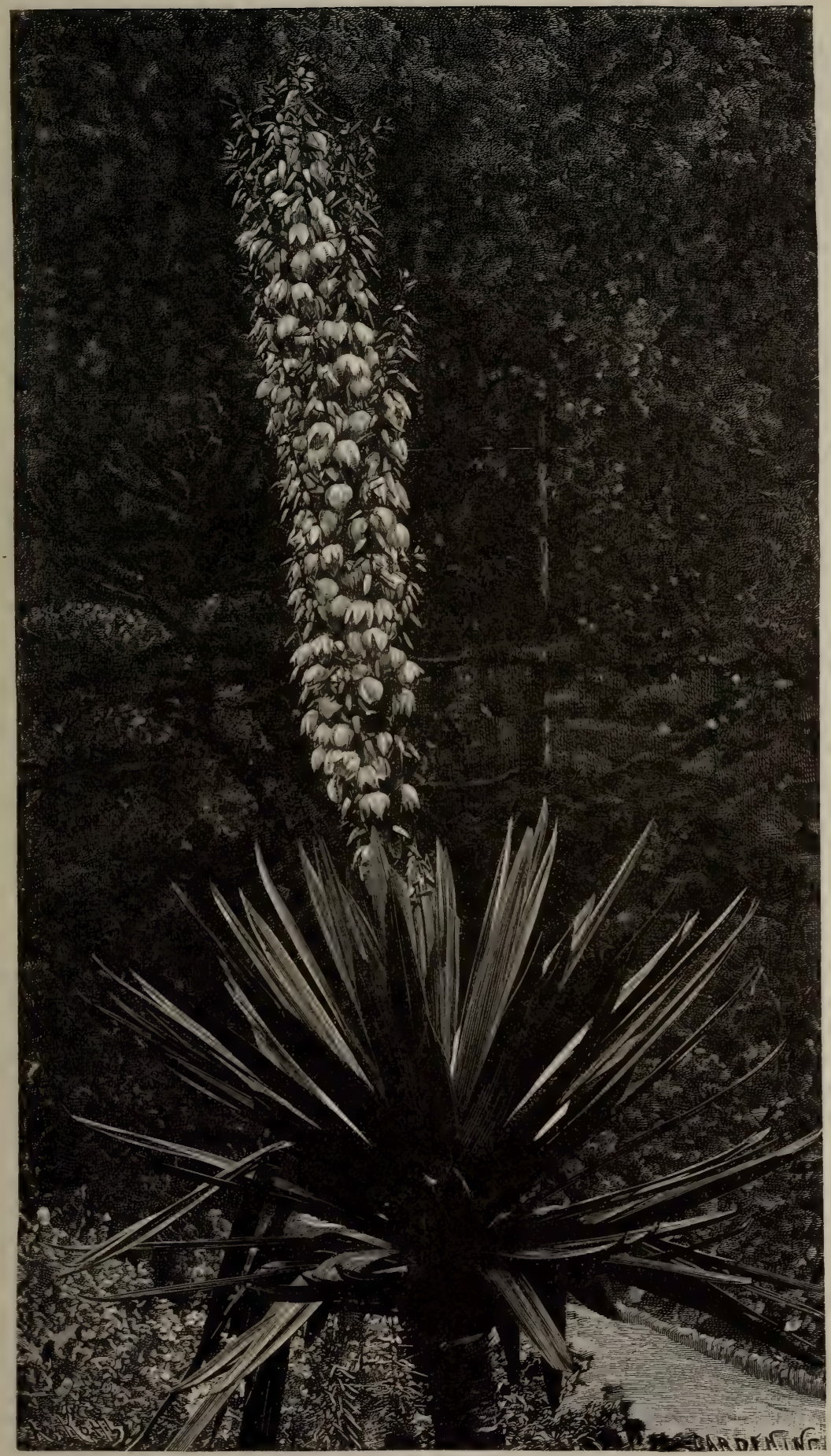

YUCCA GLORIOSA (ADAM'S NEEDLE). 
to 24 in. long, and about $1 \frac{1}{2}$ in. broad at the middle. They are often fringed with filaments, the young ones nearly erect, and the old ones abruptly reflexed in the middle, and appearing almost broken. This gives such an irregular aspect to the tufts, that Y. flaccida is easily distinguished from any of the varieties of $Y$. filamentosa. Y. flaccida also flowers more regularly and abundantly than Y. filamentosa. It is well suited for groups of the finer hardy plants, and for borders, or for being planted in large isolated tufts. N. America.

Y. glaucescens.-A very free-flowering Yucca, with a panicle 3 or $4 \mathrm{ft}$. high, and short downy branches. It bears sea-green leaves, about 18 in. long, with a few filaments on the margins. The flowers are of a greenish-yellow, and when in bud are tinged with pink, and this tends to give the whole inflorescence a peculiarly pleasing tone. Y. glaucescens is a very useful and ornamental sort. It is fine for groups or borders, for isolation, or for placing among low shrubs. N. America.

Y. gloriosa.-A large and imposing Yucca of distinct habit and somewhat rigid aspect. Its flower-stem is over 7 $\mathrm{ft}$. high, and much branched, and it bears an immense pyramidal panicle of large flowers, almost white. Its numerous leaves are stiff and pointed. It is one of the noblest plants in our gardens, and is suitable for almost any position. It varies very much when grown from seed, and this is a good recommendation, as the greater variety of fine form we have the better. Its chief varieties are Y. g. longifolia, plicata, maculata, glaucescens, and minor. The soil should be a rich deep loam. N. America.

Y. pendula.-Perhaps the best species, considering its graceful habit, which is invaluable. It is about $6 \mathrm{ft}$. high; its leaves, at first erect and of a sea-green colour, afterwards become reflexed and change to a deep green. Old and wellestablished plants standing alone on the Grass are pictures of grace and symmetry, from the lower leaves which sweep the ground to the central ones that point up as straight as a needle. It is amusing to think of people putting tender plants in the open air, and running with sheets to protect them from the cold and rain of autumn and early summer, while perhaps not a good specimen of this fine plant is to be seen in the place. There is no plant more suited for planting near flower-beds or for associating with them. N. America. =Y. recurva.
Y. Treculeana. - This species is one of the most remarkable of the Yuccas, both from its habit and from the dimensions of its foliage. Like many Yuccas of its family, young specimens of $Y$. Treculeana differ considerably from those which have reached maturity. Thus, while the leaves of young specimens are bent, and generally inflected, the leaves of mature specimens are erect, rigid, very long, and very straight. The stem of the plant is about Io in. in diameter, and is furnished on all sides with leaves about $4 \mathrm{ft}$. long. These leaves are straight, thick, and deeply channelled, acuminate for a considerable length, are very finely toothed on the edges (which are scarious and of a brownish-red), and end in a stiff sharp point. The stout flower-stalk is about $4 \mathrm{ft}$. long, and is much branched - the branches are erect, and are $\mathrm{I} 2$ to 20 in. long. They bear throughout their entire length flowers with long narrow petals of a yellowish-white, which are shining, and, as it were, glazed. Y. Treculeana is hardy and vigorous. On the Continent it is frequently more than $6 \frac{1}{2} \mathrm{ft}$. through. If placed singly it is fine for banks and knolls. It is also suitable for the boldest groups. Texas.

Any person wishing to have a distinct collection of Yuccas would find the kinds mentioned suit his purpose, but there are several other species more or less desirable. The dead flower-stems of Yuccas make capital supports for delicate creepers.

\section{Yulan (Magnolia conspicua).}

Zapania nodiflora (Creeping Vervain). -A pretty, modest, compactly-spreading trailer, with prostrate stems 2 or $3 \mathrm{ft}$. in length. Late in summer it produces small roundish heads of little purplish flowers. Suitable for the rougher parts of the rock-garden, or for borders or edgings in free warm soil. Asia and America. = Lippia nodiflora. Verbenaceæ.

Zauschneria californica.-A distinct and bright perennial from California, quite hardy in warm soils in sheltered places, but in cold localities requiring a little winter protection, such as a covering of coal ashes. It is 12 to 18 in. high, and yields an abundance of gracefully drooping bright vermilion flowers. It flourishes in sandy loam in the rock-garden, and grows capitally on an old wall. On heavy soils and moist soils we have never observed it to thrive. It can be easily propagated in spring by division of the roots, or from seeds sown on a gentle 
hot-bed. One of the best of wall plants, the good drainage and conditions of a rough wall suiting it perfectly. It flowers during summer and autumn. Onagraceæ.

Zea Mays (Indian Corn).-This is one of the noblest of the Grasses that thrive in our climate, and it is almost indispensable to our gardens. It has a fine appearance either isolated or associated with other fine-foliage plants. Cuzko and Caragua are the largest and finest of the green varieties, and gracillima the smallest and most graceful. The variegated be sown in a gentle hot-bed in April, although seeds will occasionally succeed out-of-doors. Gradually harden off the plants before they have made more than three or four little leaves, keeping them in a cool frame very near the glass, so as to keep them sturdy, and finally exposing them by taking off the lights. This method is perhaps the more desirable in the case of the variegated Maize, which does not grow so vigorously as the green kinds. In no case should the plants be drawn up long in heat, for if they are

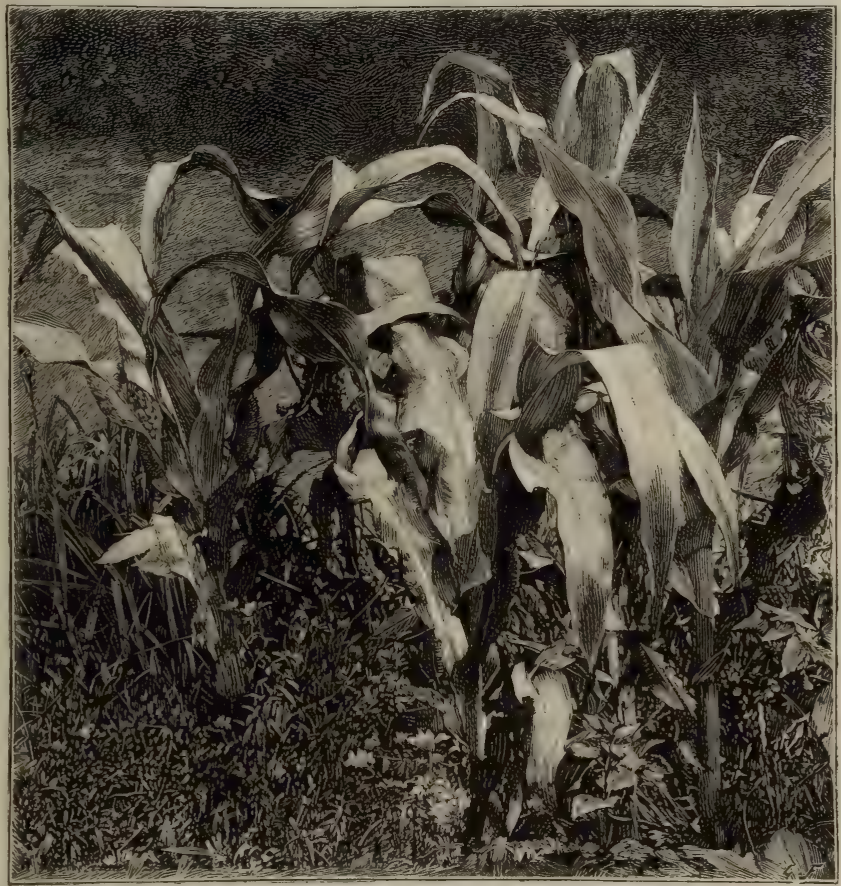

ZEA CARAGUA.

or Japanese Maize is a very handsome variety, and its beautiful variegation comes true from seed. It is particularly useful for intermingling with arrangements of ordinary bedding plants for vases; and may be grown in the margins of beds of sub-tropical plants, or in any position where its variegation may be well seen, and where its graceful leaves are effective among dumpy subjects. It should have light, rich, warm soil. It has a habit of breaking into shoots rather freely near the base of the central stem, and, where it grows very freely, this habit should recommend it for planting on the turf in an solated manner, or in groups of three or five. The seeds of the Maize should they will not thrive so well. The first few leaves of the variegated kind are green, but soon begin to manifest the striping. The plants should be planted out about the middle of May.

Zenobia speciosa.-One of the most beautiful shrubs in the Heath family. It is a dense shrub about a yard high, and has small roundish leaves of a pale green. In the variety pulverulenta, which is preferable to the type, the leaves are almost white, being covered with a mealy glaucescence. The flowers of $Z$. speciosa are white and wax-like in form, and resemble those of Lily of the Valley. In summer they are produced abundantly in loose drooping clusters. A well- 
flowered specimen is most charming, and lasts for some weeks in beauty. The shrub thrives in a peaty soil or a sandy loam. It comes from the Southern United States; and is therefore not among the hardiest shrubs. In nurseries it is known as Andromeda cassiniæfolia and $A$. speciosa, and its variety $Z$. pulverulenta as A. dealbata and A. pulverulenta.

Zephyranthes (Zephyr-flower).- This beautiful flower has been termed the Crocus of America. There are about fourteen species,--low-growing bulbous plants, with grassy leaves, which appear in spring with or before the Crocus-like flowers. These flowers are white or rosypink, and, for the most part, are large and handsome. Zephyranthes require rest during winter, and at that season are best kept dry. In spring they should be planted out in the full sun in very sandy soil. They do well in the greenhouse, four or six being planted in a pot. Offsets. The valuable species are :-

Z. Atamasco (Atamasco Lily).-This handsome plant is a native of $N$. America, where it is a conspicuous ornament of damp places in woods and fields. Its glossy leaves appear at the same time as the blossoms, and slightly exceed them in height. The white blossoms are striped with rose, are about 3 in. long, and borne singly upon a scape 6 in. high. $Z$. Atamasco flowers from May to July, and usually flowers during the last-named month. It grows well in the open border. It increases rapidly by offsets, which should be removed and divided in the spring of every third or fourth year. $Z$. candida is similar, but less hardy.

Z. carinata. - This lovely plant has narrow leaves, and its flower-stem, which is about 6 in. high, bears a delicate rosy flower, 2 or 3 in. long. It blossoms freely in the open border if kept dry in winter, and should be grown in light sandy loam. Z. carinata is widely distributed in S. America. Z. rosea, a beautiful species, with flowers of a bright rose, is a native of the mountains of Cuba.

Z. tubispatha. - A handsome plant, bearing a white, slightly fragrant flower, 2 or $3 \mathrm{in.} \mathrm{long.} \mathrm{It} \mathrm{is} \mathrm{a} \mathrm{native} \mathrm{of} \mathrm{Antigua,}$ and of the Blue Mountains of Jamaica. Though properly a stove plant, it will thrive and flower well in very mild localities, if well protected in winter. A pretty pink hybrid between this species and Z. carinata is sometimes met with under the name of Z. Spofforthiana. Z . Treatiæ, a new species resembling $Z$. Atamasco, is too rare for us yet to speak of its culture.
Zietenia lavandulæfolia.-A dwarf, creeping, half-shrubby perennial of a greyish hue, 6 to 12 in. high. Its purple flowers appear in summer, and are borne in whorls, forming a spike about 6 in. long, with a very slender downy stalk. Suitable for the margins of borders and the rougher parts of the rock-garden, or for naturalisation in ordinary soil. Division. Caucasus. Labiatæ.

Zinnia.-Few half-hardy annuals are more satisfactory than well-tended Zinnias. The flowers exhibit great brilliancy of colour, and, whether planted in beds, or rows, or singly, they are among the most effective of summer-blooming plants. Besides this, they flower well until autumn. Their blooms are not easily injured by inclement weather, but retain all their freshness and gay colouring at a time when many bright flowers present but a sorry appearance. In mixed borders, and in beds among sub-tropical plants, well-grown Zinnias are always attractive. Zinnias require a deep loamy soil and a warm open situation. Seed should be sown in gentle warmth. Nothing is gained by sowing before the middle or end of March, as, if the young plants have to stand for a considerable time before being planted, they are apt to become root-bound and stinted for nutriment, and to lose something of that fresh free growth which should be maintained until they come into flower. If the tissues once harden so much as to bring the young plants to a standstill, there will be little chance of rapid progress when they are set out in the open ground. Indeed, it is not advisable to plant them out much before the second week in June, as they are very sensitive to atmospheric changes, and are completely ruined by a few degrees of frost. Plant them in well-stirred, fairly-enriched soil and in full exposure, for they love to bask in the sun's fiercest rays, and demand merely a surface-covering, to protect the roots, and a constant supply of moisture. In a bed by themselves, they would be greatly improved if the soil were thrown out, and a good depth of fermenting manure were well trodden in, and the soil replaced. Both the single and double Zinnias are fine garden plants, and display a diversity and brilliancy of colour equalled by few plants. The double forms have of late been most in request, although both the double and single varieties have been greatly improved. There is one good characteristic about double Zinnias-they are not all so rank and unwieldy as the single types, dwarfing having gone hand-in- 
hand with multiplying petals in the flowers. Selection has also done something to induce a better habit; and it will be observed that particular types of flower often improve in habit and bloom at the same time. Some of the single Zinnias are very beautiful, for instance, the yellow, carmine, rosy-purple, scarlet, crimson, and orange kinds. $Z$. elegans is the species from which the numerous varieties mentioned in catalogues have been derived. $\mathrm{Z}$. Darwini is a beautiful hybrid with very double flowers of various colours. $Z$. Haageana, known also as Z. mexicana, has a very neat habit, and rich orange-yellow blossoms; it also occurs with double flowers.
Zygadenus.-Plants of the Lily family, of no great value as ornamental plants, for their flowers are all greenish-yellow, but their distinct growth makes them worth cultivating in a botanical or a full collection. There are three species in cultivation, all from California. These are slender bulbous plants, with narrow grassy leaves, and tall branching flowerstems, I to $4 \mathrm{ft}$. high. Z. Fremonti (also known as Z. glaberrimus, $Z$. chloranthus, and Z. Douglasi) is the largest flowered species. The other kinds are $Z$. venenosus ( $Z$. Nuttalli) and Z, paniculatus. Zygadeni thrive best in a moist peaty border in a shady position protected from cold winds. = Anticlea 
व 


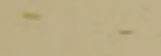




\title{
Boston Public Library \\ Central Library, Copley Square
}

\author{
Division of \\ Reference and Research Services
}

The Date Due Card in the pocket indicates the date on or before which this book should be returned to the Library. Please do not remove cards from this pocket. 
BOSTON PUBLIC LIBRARY

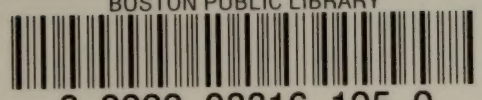

3 9999033161959 
